\title{
Archeological Testing and Data Recovery at the Flatrock Road Site, 41KM69, Kimble County, Texas
}

Jennifer L. Thompson

Raymond P. Mauldin

Center for Archeological Research, University of Texas at San Antonio

Steve A. Tomka

Raba Kistner

Eric Oksanen

Follow this and additional works at: https://scholarworks.sfasu.edu/ita

Part of the American Material Culture Commons, Archaeological Anthropology Commons, Environmental Studies Commons, Other American Studies Commons, Other Arts and Humanities Commons, Other History of Art, Architecture, and Archaeology Commons, and the United States History Commons

Tell us how this article helped you.

This Article is brought to you for free and open access by the Center for Regional Heritage Research at SFA ScholarWorks. It has been accepted for inclusion in Index of Texas Archaeology: Open Access Gray Literature from the Lone Star State by an authorized editor of SFA ScholarWorks. For more information, please contact cdsscholarworks@sfasu.edu. 


\section{Archeological Testing and Data Recovery at the Flatrock Road Site, 41KM69, Kimble County, Texas}

\section{Licensing Statement}

This is a work for hire produced for the Texas Department of Transportation (TxDOT), which owns all rights, title, and interest in and to all data and other information developed for this project under its contract with the report producer. The report may be cited and brief passages from this publication may be reproduced without permission provided that credit is given to TxDOT and the firm that produced it. Permission to reprint an entire chapter, section, figures or tables must be obtained in advance from the Supervisor of the Archeological Studies Branch, Environmental Affairs Division, Texas Department of Transportation, 125 East 11th Street, Austin, Texas, 78701. 


\section{Archeological Testing and Data Recovery at the Flatrock Road Site, 41KM 69 , Kimble County, Texas}

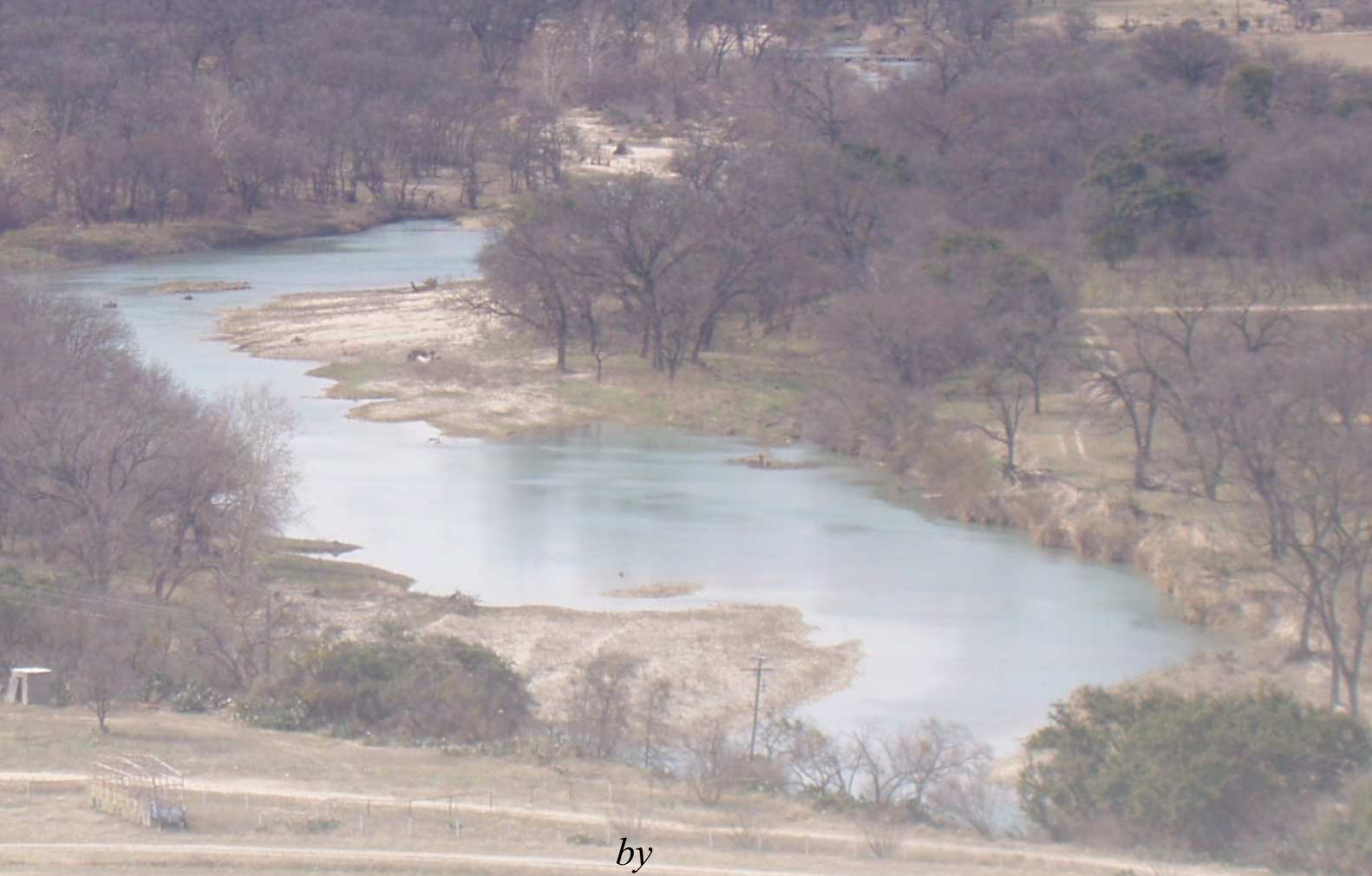

Jennifer L. Thompson, Raymond P. Mauldin, Steve A. Tomka, and Eric Oksanen

with contributions by

Lori Barkwill-Love, Vaughn M. Bryant, J. Philip Dering, James K. Feathers, Jeffery R. Ferguson, Michael D. Glascock, Russell D. Greaves, Leonard Kemp, M.E. Malainey, Barbara A. Meissner, Debajyoti Paul, and Grzegorz D. Skrzypek

Principal Investigator

Raymond P. Mauldin

Texas Antiquities Permit Nos. 3350 and 3584

Work Authorization Nos. 57315 SA002 and 57902 SA001

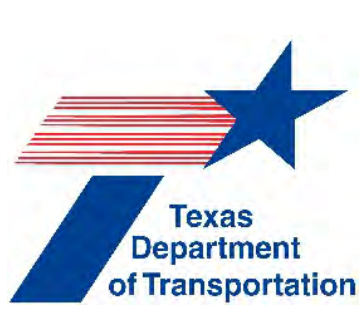

Environmental Affairs Division

Texas Department of Transportation Archeological Studies Program, Report No. 133
CSJ No. 2469-01-007

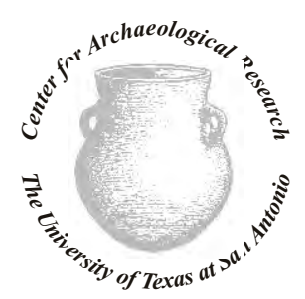

Center for Archaeological Research The University of Texas at San Antonio Archaeological Report, No. 419 


\title{
Archeological Testing and Data Recovery \\ at the Flatrock Road Site, 41KM69, \\ Kimble County, Texas
}

\author{
by \\ Jennifer L. Thompson, Raymond P. Mauldin, Steve A. Tomka, and Eric Oksanen \\ with contributions by \\ Lori Barkwill-Love, Vaughn Bryant, J. Philip Dering, James Feathers, Michael D. Glascock, \\ Russell Greaves, Leonard Kemp, M. E. Malainey, Barbara C. Meissner, \\ Debajyoti Paul, and Grzegorz Skrzypek
}

Texas Antiquities Committee Permit Nos. 3350 and 3584

Principal Investigator

Raymond P. Mauldin

Work Authorization Nos. 57315 SA002 and 57902 SA001

CSJ No. 2469-01-007

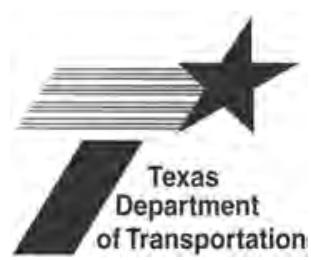

Texas Department of Transportation

Environmental Affairs Division

Archeological Studies Program, Report No. 133

Austin

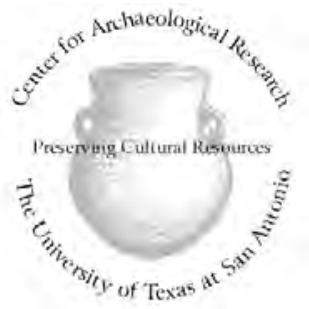

Center for Archaeological Research The University of Texas at San Antonio Archaeological Report, No. 419 


\title{
Copyright $\mathbb{C} 2012$ \\ Texas Department of Transportation All rights reserved
}

This is a work for hire produced for the Texas Department of Transportation (TxDOT), which owns all rights, title, and interest in and to all data and other information developed for the project under Contracts 57315 SA002 and 57902 SA001. Brief passages from this publication may be reproduced without permission provided that credit is given to TxDOT. Permission to reprint an entire chapter, section, figure or tables must be obtained in advance from the Supervisor of the Archeological Studies Program, Environmental Affairs Division, Texas Department of Transportation, 125 East 11th Street, Austin, 78701. Copies of this publication have been deposited with the Texas State Library in compliance with the State Depository requirements.

\author{
printed by: \\ Blue Tape \\ San Antonio, Texas
}

published by:

Texas Department of Transportation

Environmental Affairs Division

Archeological Studies Program

Scott Pletka, Ph.D., Supervisor

Archeological Studies Program Report No.133

A. McGraw, Series Editor

ISBN:978-1-935545-01-09 


\begin{abstract}
:
The Center for Archaeological Research (CAR) of The University of Texas at San Antonio (UTSA) conducted archeological significance testing and data recovery excavations at 41KM69, the Flatrock Road Site, at the request of the Texas Department of Transportation, Environmental Affairs Division (TxDOT-ENV). The significance testing was begun in 2004 under Texas Antiquities Permit No. 3350 to determine National Register of Historic Places eligibility status of the site and continued to the data recovery phase in 2005 under Texas Antiquities Permit No. 3584 with Raymond Mauldin serving as Principal Investigator on both permits. Work was begun in anticipation of alterations to Flatrock Road/FM 2169 that intersects the site because TxDOT and the Texas Historical Commission concurred with CAR's assessment that the site was eligible for listing on the NRHP and because TxDOT could not avoid impacts to intact deposits.
\end{abstract}

During testing 120 auger tests, six backhoe trenches, eight 50-x-50-cm units, and five 1-x-1-m units were excavated across the western portion of the site within the planned TxDOT right-of-way (ROW). This effort confirmed intact Late Archaic and Late Prehistoric Austin and Toyah interval components as well as a disturbed twentieth century component. The prehistoric deposits included four burned rock features including a large burned rock midden, 3,000 chipped stone artifacts, 10 temporally diagnostic projectile points, unifacial tools typical of Toyah end-scrapers, and native ceramics, also commonly found on Toyah occupations. A small quantity of bone was collected including tibia fragments from one bison. The historic component was confined to the upper level of the site from the surface to approximately $20 \mathrm{cmbs}$. The Kimble Courts resort camp once stood in the area.

Data recovery excavations targeted the prehistoric components after the historic levels were removed by backhoe. Four large blocks were excavated in areas of high artifact density. Approximately $130 \mathrm{~m}^{3}$ and 40,000 artifacts were recovered from these blocks including 350 stone tools and 114 earthenware sherds. Projectile point types found were Castroville, Pedernales, Montell, Ellis, Frio, Ensor, Fairland, Edwards, and Perdiz. Seventy-three prehistoric thermal rock features and soil stains were also recorded. We also collected bone, shell, feature burned rock, and soil samples.

Following hand excavations, the project area was monitored during Gradall stripping of the remaining deposits. Fifty-seven auger tests were also excavated after a shift in the project ROW. Artifact density was sparse in the shifted ROW, and most artifacts came from disturbed upper level deposits.

CAR developed a research design in consultation with TxDOT after all excavations were completed. This research focused on the interpretation of the deposits discovered during significance testing and data recovery from 41KM69 and a number of comparative sites around Texas. The theoretical framework draws from principles of cultural and evolutionary ecology to examine shifts in subsistence, technology, and mobility in hunter-gatherers from the Late Archaic and Late Prehistoric periods of South and Central Texas.

All artifacts and samples collected during this project, along with project related documentation are to be permanently curated at CAR according to THC guidelines. 



\section{Table of Contents:}

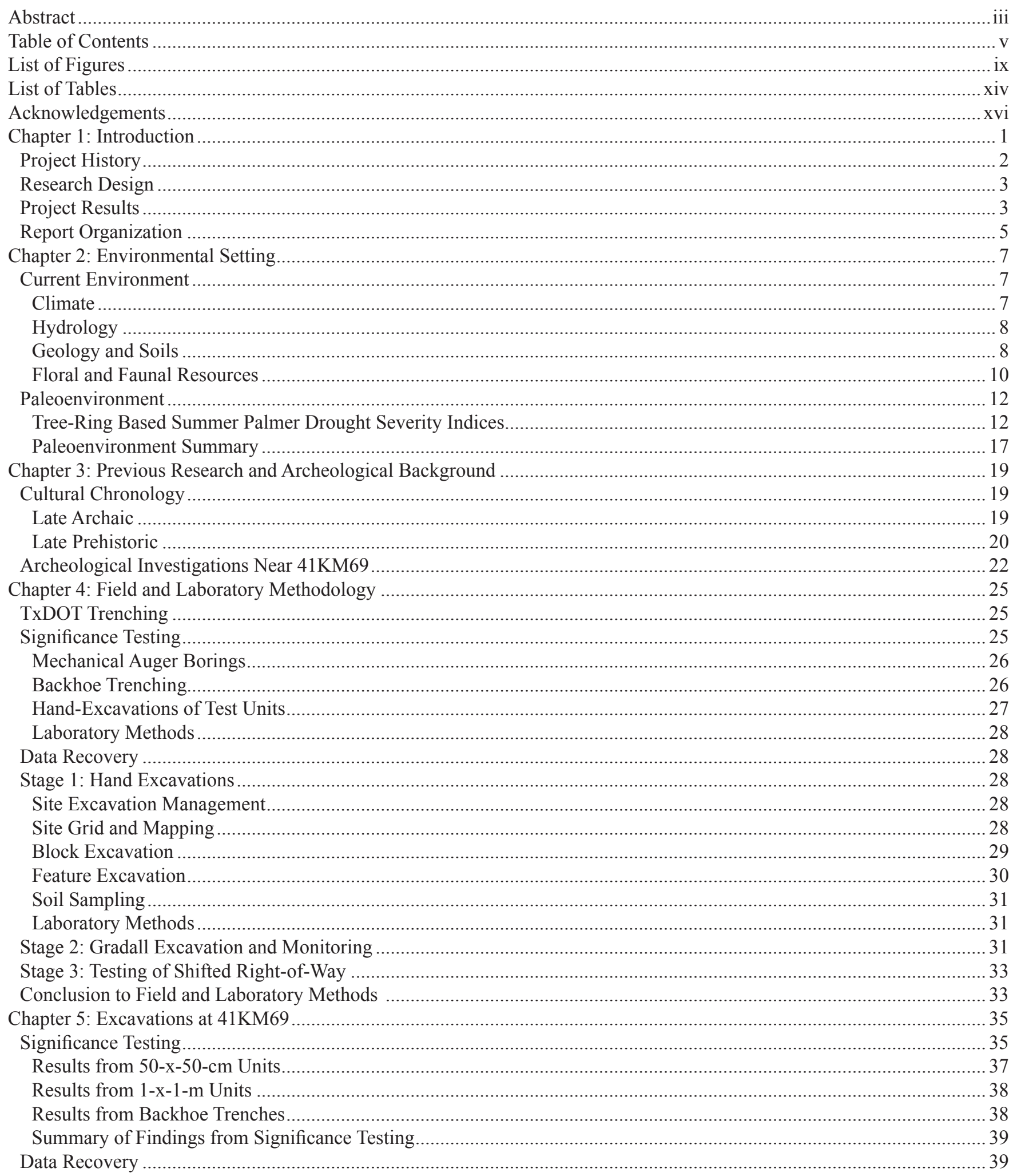




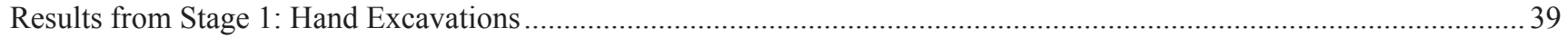

Results from Stage 2: Gradall Excavation and Monitoring ....................................................................................... 44

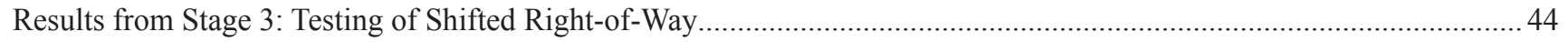

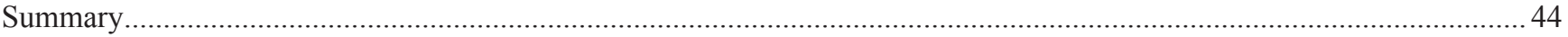

Chapter 6: Site Stratigraphy, Artifact Distribution, and Analytical Units........................................................................... 47

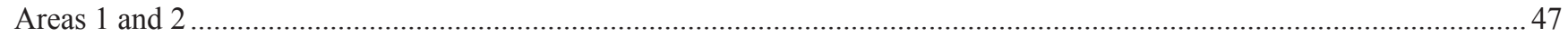

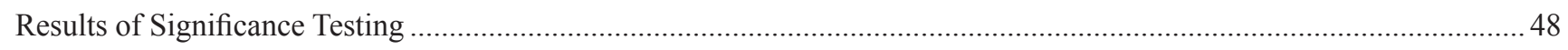

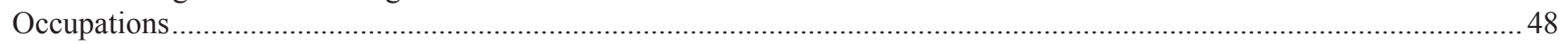

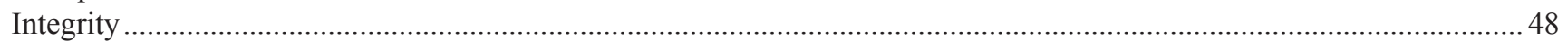

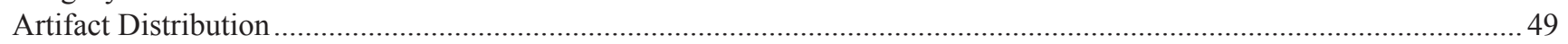

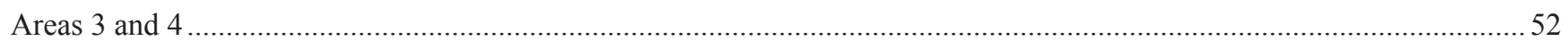

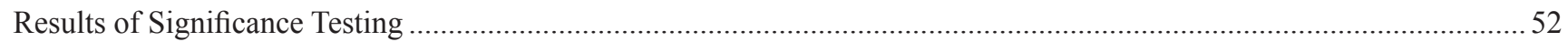

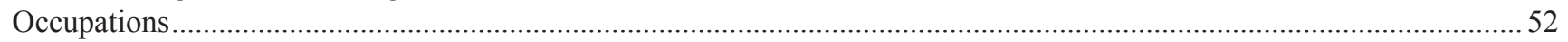

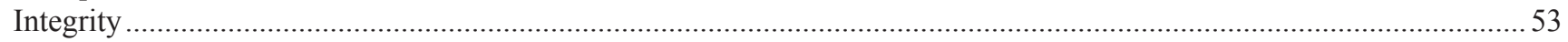

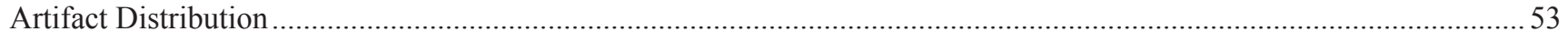

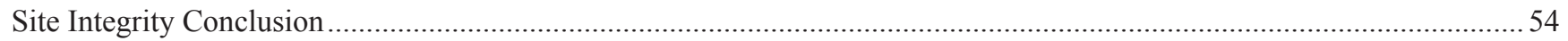

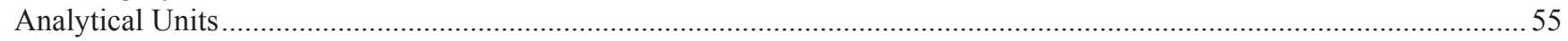

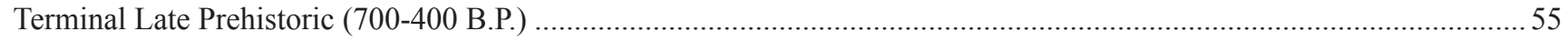

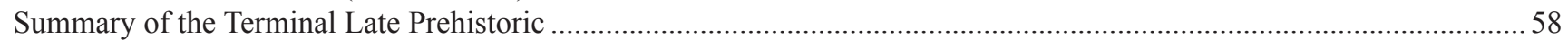

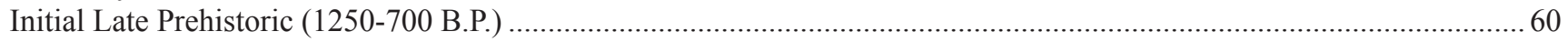

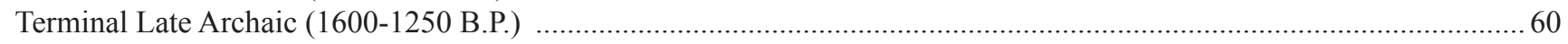

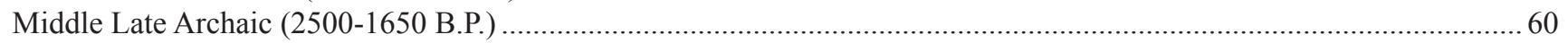

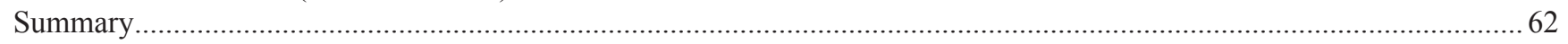

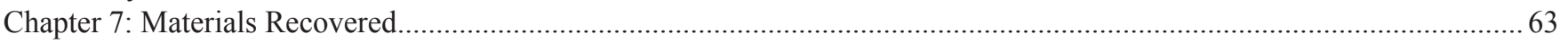

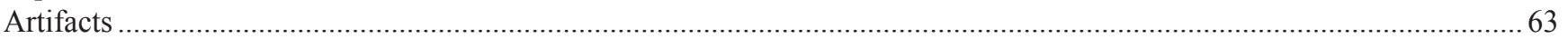

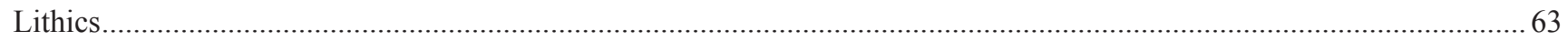

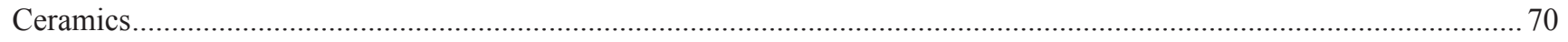

Bone and Shell ……

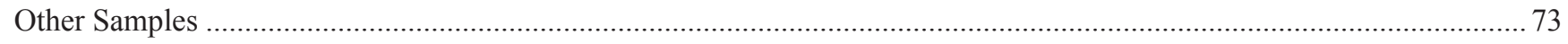

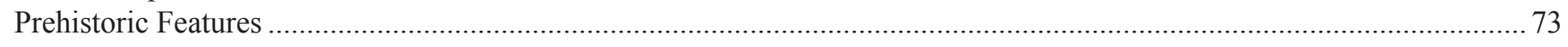

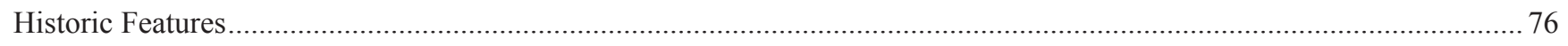

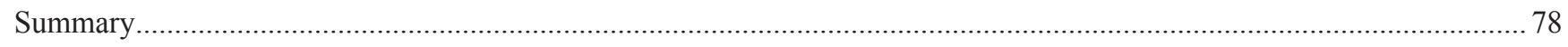

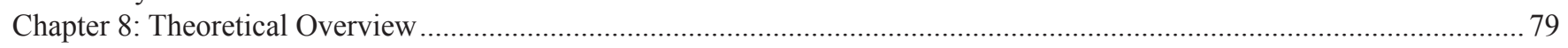

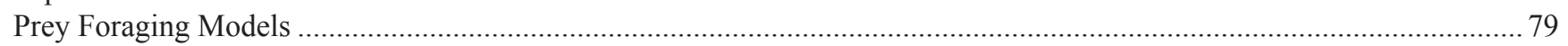

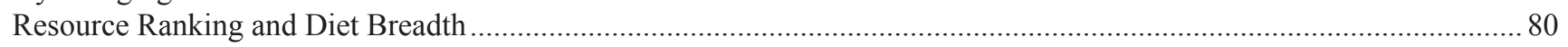

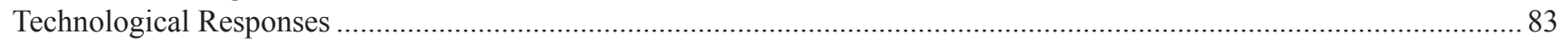

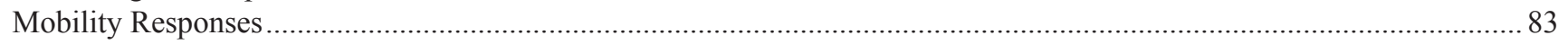

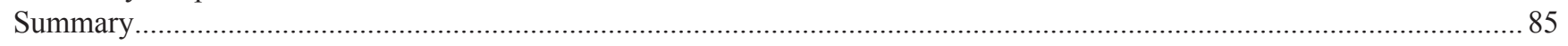

Chapter 9: Modeling Adaptations in the Late Archaic and Late Prehistoric Periods ..............................................................8 87

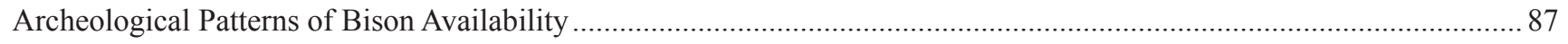

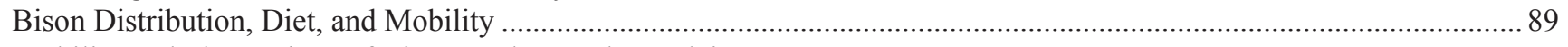

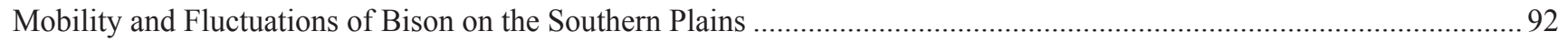

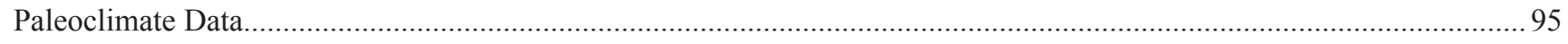

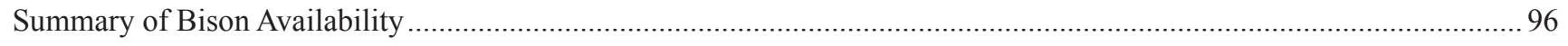

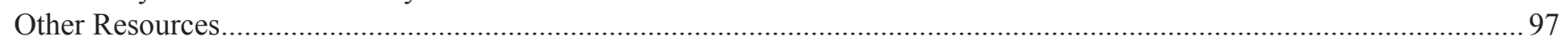

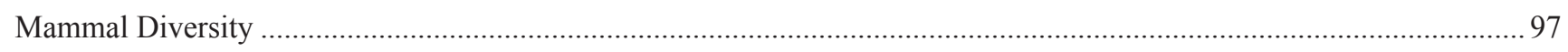

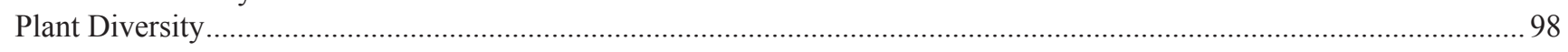

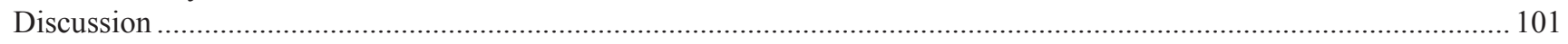

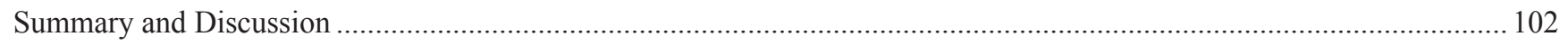

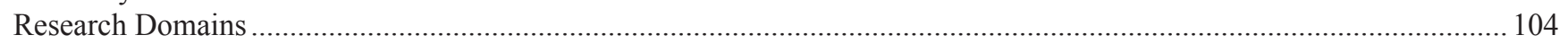

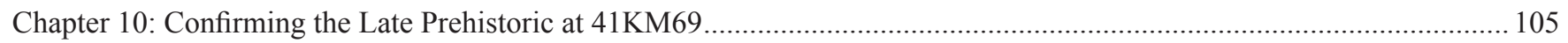

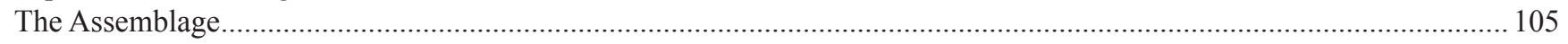

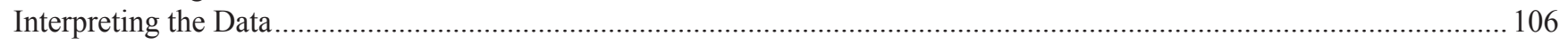

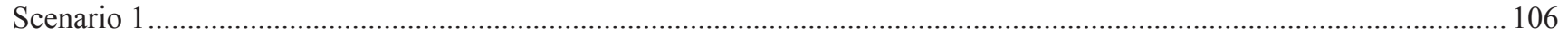




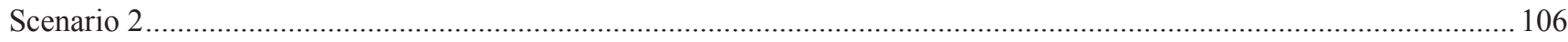

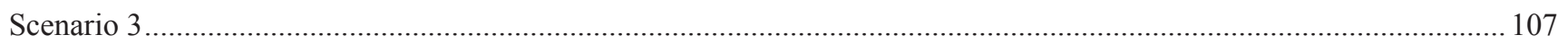

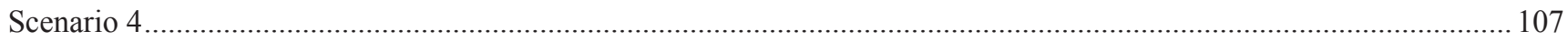

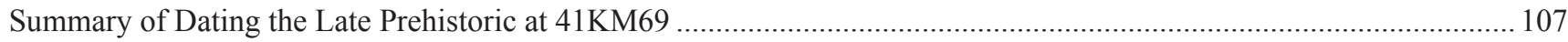

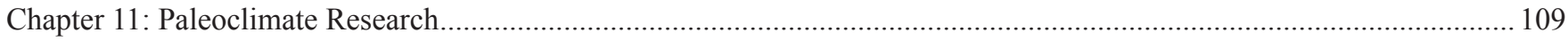

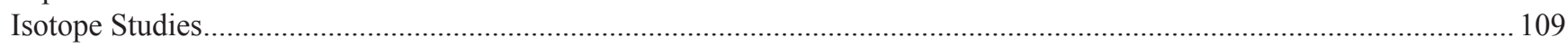

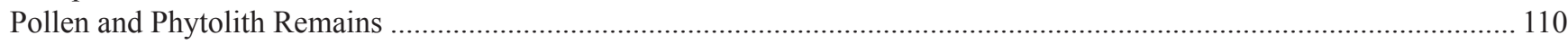

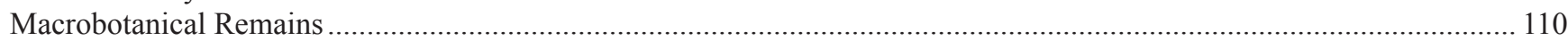

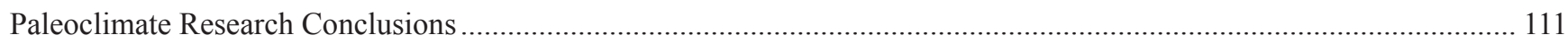

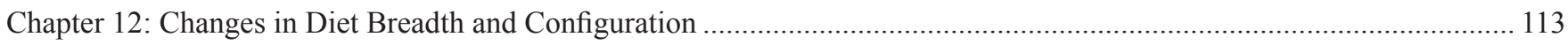

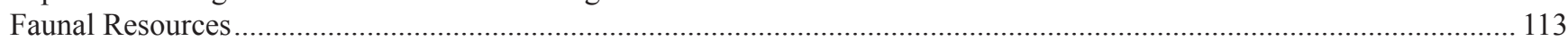

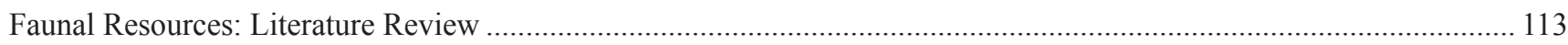

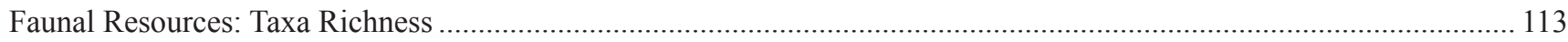

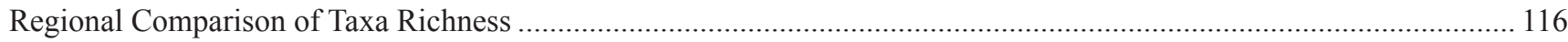

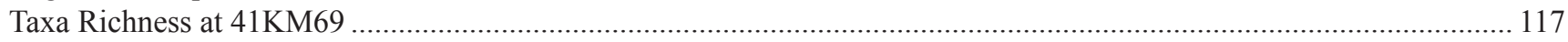

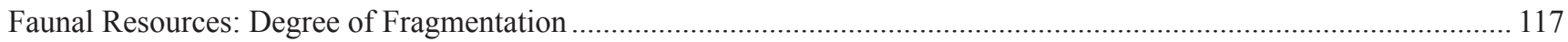

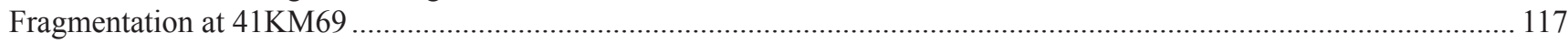

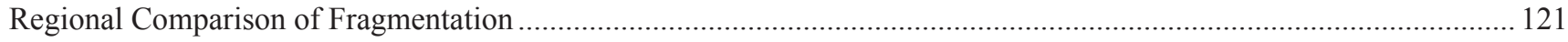

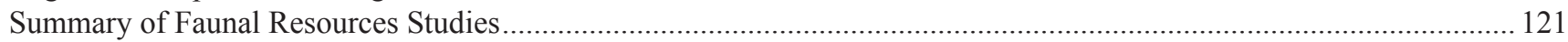

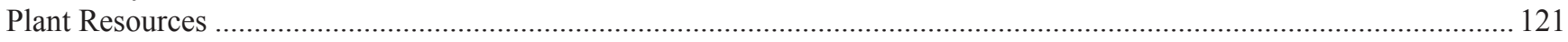

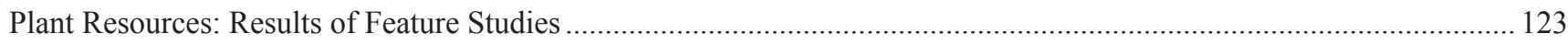

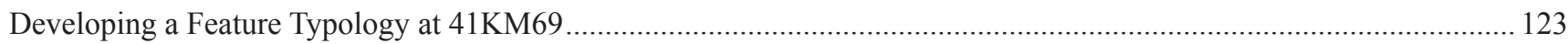

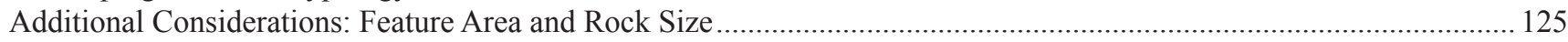

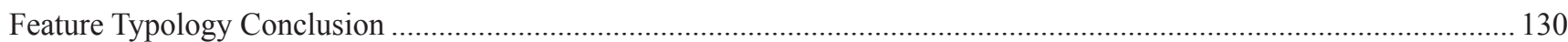

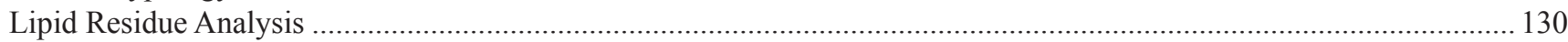

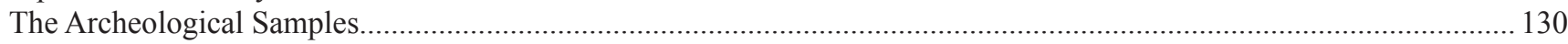

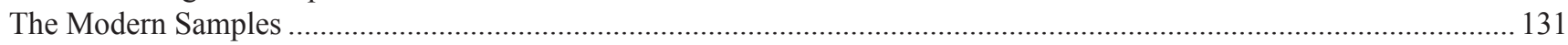

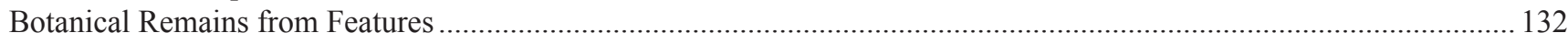

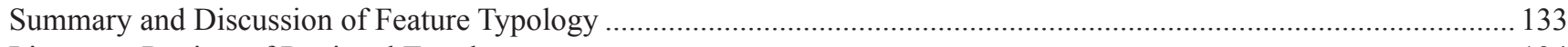

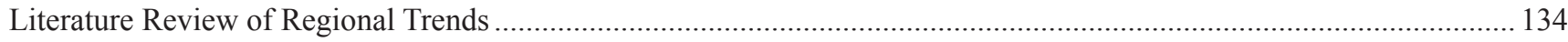

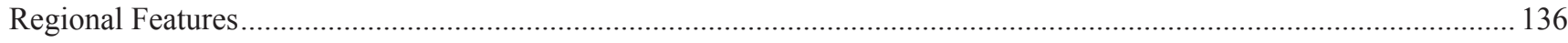

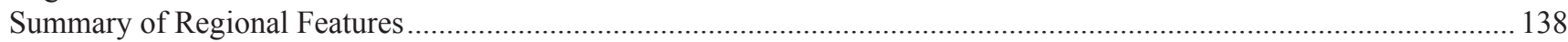

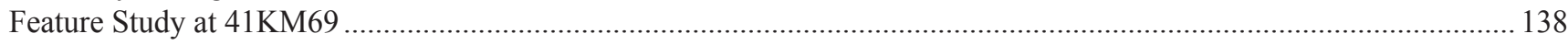

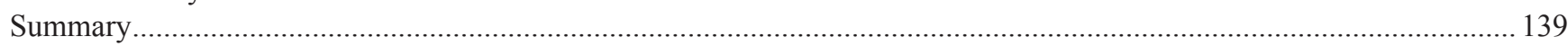

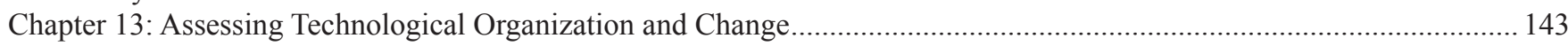

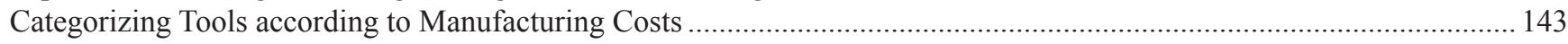

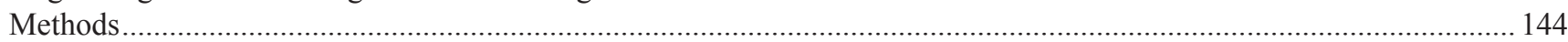

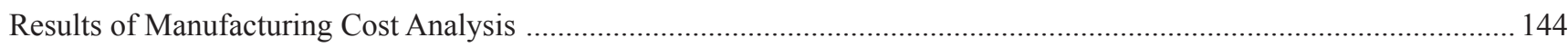

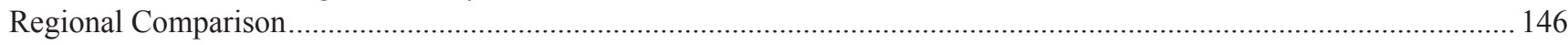

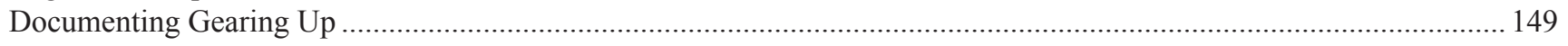

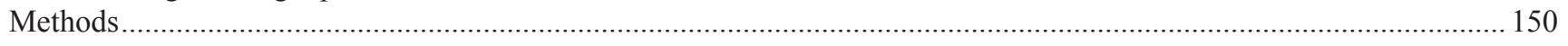

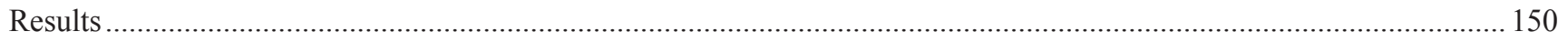

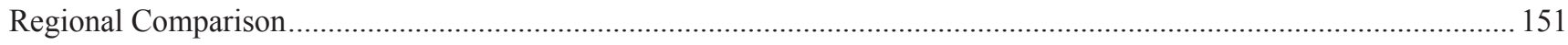

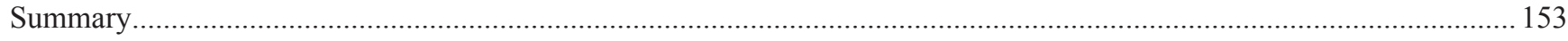

Chapter 14: Investigating Changes in Projectile Weapons Technology .......................................................................... 155

The Characteristics of Principal Prey Species: Bison, Antelope, and Deer ................................................................ 155

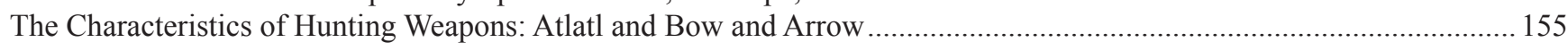

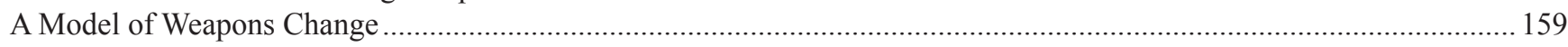

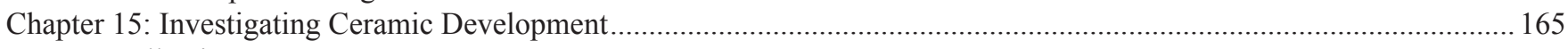

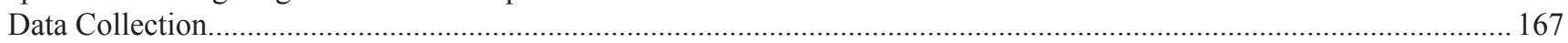

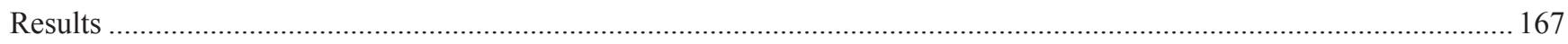

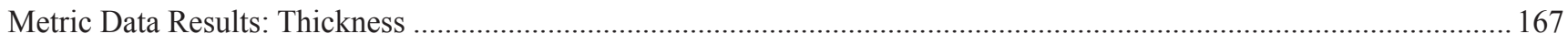

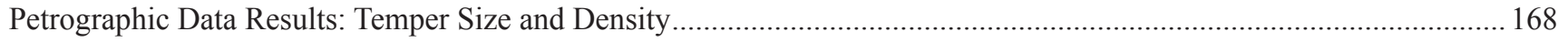

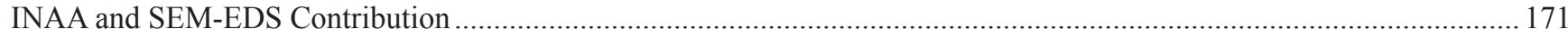


Conclusion 173

Chapter 16: Investigating Changes in Mobility 175

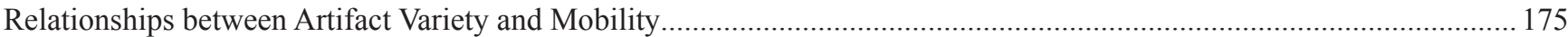

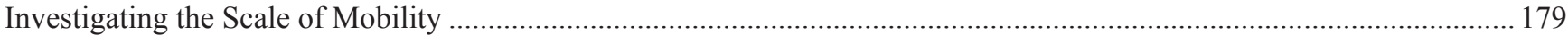

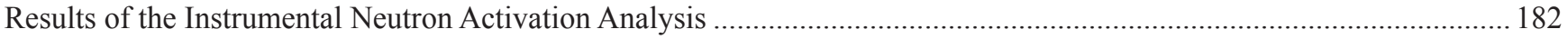

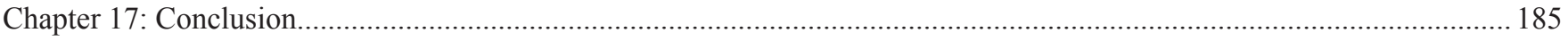

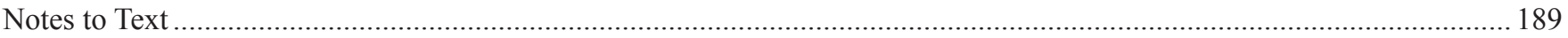

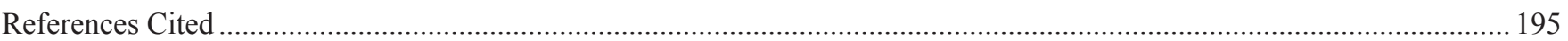

Appendix A: Geomorphological Descriptions of Backhoe Trenches at 41KM69 and Soil Susceptibility Graphs and Raw Data... 211

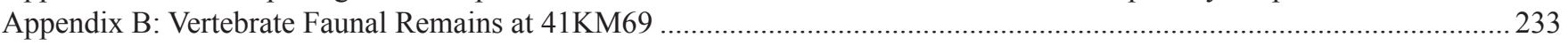

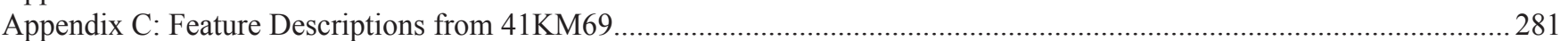

Appendix D: Analysis of the Fatty Acid Composition of Archeological Burned Rock from Site 41KM69 and

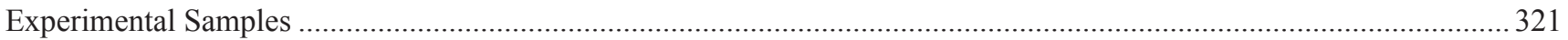

Appendix E: Analysis of Plant Remains at 41KM69 and 41KM69 Flotation Inventory ................................................331

Appendix F: Petrographic Analysis of Leon Plain and Caddoan Ceramics ................................................................. 345

Appendix G: Absolute Dating of 41KM69 Ceramics, Luminescence Dating of Ceramics from West-Central Texas,

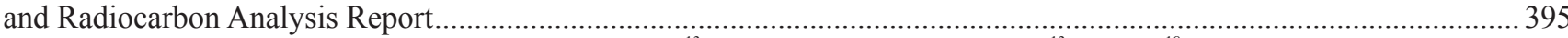

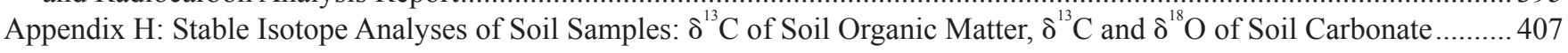

Appendix I: Pollen and Phytolith Extraction from Archeological Sediments in Area 1 of Site 41KM69,

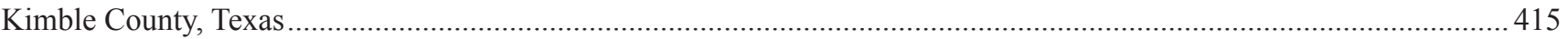

Appendix J: Bison Presence/Absence Data from Central and South Texas and Supporting Documentation ........................ 429

Appendix K: Species and Body Size Data for Texas Mammals * ............................................................................... 449

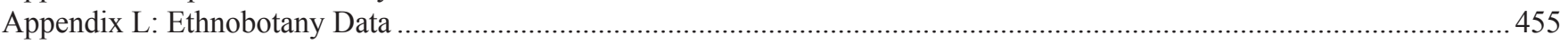

Appendix M: Instrumental Neutron Activation Analysis of Toyah Phase Ceramics from 41KM69, Kimble County,

Texas, and Results of Scanning Electron Microscopy of Sherds from 41KM69, Kimble County, Texas........................ 467

Appendix N: Analysis of Edwards Formation Chert from the Llano River Gravels and 41KM69...................................485

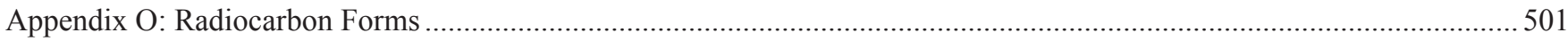




\section{List of Figures:}

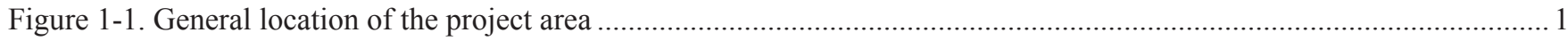

Figure 2-1. Site 41KM69 sits on the south bank of the South Llano River in Junction, Texas .......................................... 7

Figure 2-2. Mean monthly temperatures and mean monthly rainfall totals at Junction (1971-2000). Based on data from

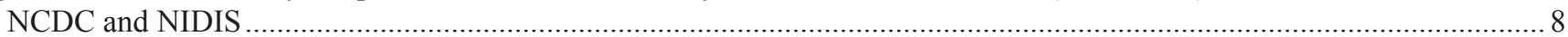

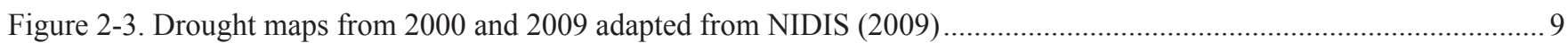

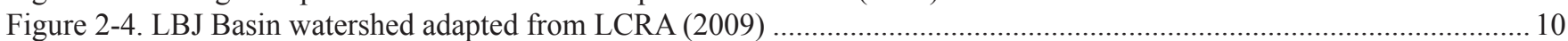

Figure 2-5. Geology of the area surrounding 41KM69 adapted from Barnes (1983) ............................................................ 11

Figure 2-6. Soil map adapted from USDA (2009) showing two soil types within the project area site boundary.................... 13

Figure 2-7. Location of long term data points (red), short term PDSI points (blue), and modern weather stations (yellow) .... 13

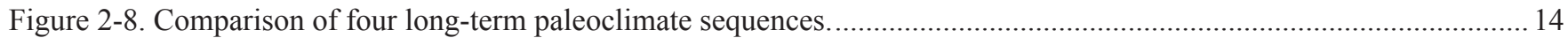

Figure 2-9. Mean PDSI values from grid points 165, 166, 180, and 181 grouped at 25 years A.D. 1000-2000

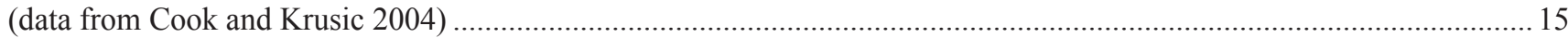

Figure 2-10. Summary at 25-year intervals of year to year variation in PDSI values A.D. 1000-2000 for grid points

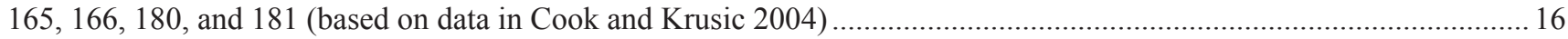

Figure 3-1. Sites discussed in the chapter and used for comparative studies in this report................................................20

Figure 3-2. Archeological sites in Kimble County discussed in the text .......................................................................2.

Figure 4-1. The location of previously excavated TxDOT backhoe trenches (from Weston et al. 2004) ...............................25

Figure 4-2. The location of auger tests excavated during Phase II testing (from Weston et al. 2004) ....................................26

Figure 4-3. Bobcat mounted auger reached depths up to $120 \mathrm{cmbs}$ during Phase II testing ..................................................22

Figure 4-4. Locations of Phase II trenches and test units (Weston et al. 2004) .....................................................................2 27

Figure 4-5. The location of the excavation blocks in each of the four areas investigated during Phase III excavations

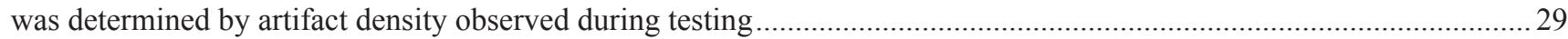

Figure 4-6. Units within the blocks were excavated on a rotating basis to expose the same level across all

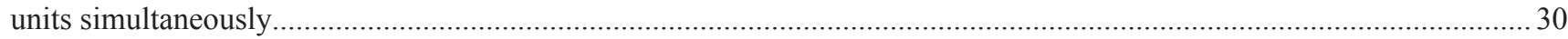

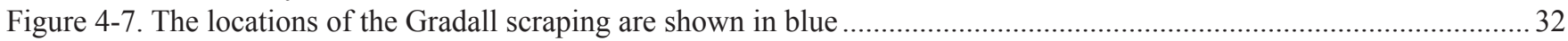

Figure 4-8. The Gradall bucket was floated in order to grade in 10-cm intervals ................................................................3.

Figure 4-9. During grading, features were bisected and only half were hand excavated ...................................................3 32

Figure 4-10. Auger tests were placed on previously untested portion of 41KM69 after the change in ROW location ..............33

Figure 5-1. Excavation units and cultural features identified during testing (from Weston et al. 2004) ..................................35

Figure 5-2. Burned rock density produced by auger testing (from Weston et al. 2004) ...................................................... 36

Figure 5-3. Chipped stone density produced by auger testing (from Weston et al. 2004) ......................................................37

Figure 5-4. Density and pattern of debitage and burned rock from Test Unit 1 against profile of BHT $4 \ldots \ldots \ldots \ldots \ldots \ldots \ldots \ldots \ldots \ldots . . . . . . . . . . . .38$

Figure 5-5. Area 1 was expanded vertically and horizontally to explore the distribution of artifacts and features .................. 40

Figure 5-6. Area 2 was excavated into the heavy gravel soils of the Ck soil horizon ........................................................ 42

Figure 5-7. The early Late Prehistoric component of 41KM69 was explored in Area 3 where excavation levels

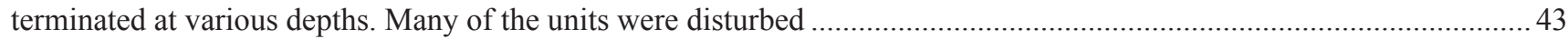

Figure 5-8. Map of Area 4 showing unit designations and terminal depth of the excavations............................................ 45

Figure 6-1. The western profile in Area 1 illustrates an AB-Bk-Ck sequence................................................................... 47

Figure 6-2. The southern profile of Area 2 shows an absence of the AB horizon ............................................................. 48

Figure 6-3. The distribution of Late Prehistoric artifacts in Area 1 shows Perdiz projectile points beneath ceramics and unifaces when they are often clustered together in the Toyah interval ............................................................................ 49

Figure 6-4. This graph illustrates the distribution of unifaces in proximity to possible Late Prehistoric features in Area 2 .....50

Figure 6-5. The Ck horizon contained a Late Archaic component with features …….......................................................51

Figure 6-6. Debitage peaks in Areas 1 and 2 correspond with soil changes....................................................................51

Figure 6-7. West wall profile of Backhoe Trench 4. Note Feature 1 and Test Units 1 and 2............................................52

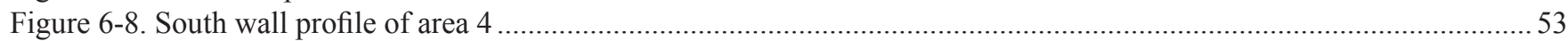

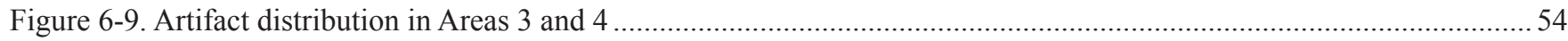

Figure 6-10. Lithic debitage counts peak at two soil horizons at 41KM69 that could indicate possible surfaces of

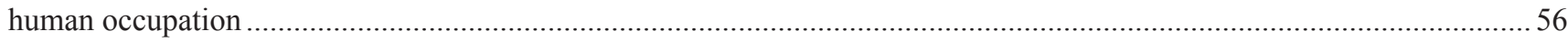




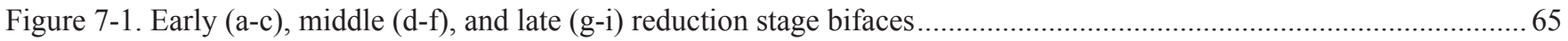

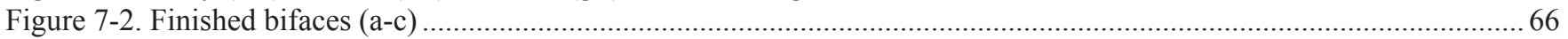

Figure 7-3. Projectile points recovered from 41KM69 include Late Prehistoric forms Edwards (a-c) and Perdiz (d-g).......... 66

Figure 7-4. The most common point type found was Frio (a-k); a Darl (1) is also pictured.................................................6 67

Figure 7-5. Late Archaic projectile points forms from 41KM69 include Castroville (a-d); Fairland (e-g); and Ensor (h-i) ..... 67

Figure 7-6. Late Archaic projectile point forms from 41KM69 include Pedernales (a-b); Ellis (c); and Montell (d-i)............ 67

Figure 7-7. Unifaces clustered in Areas 1 and 2 in the Late Prehistoric Zone of 41KM69 are teardrop shaped, indicative

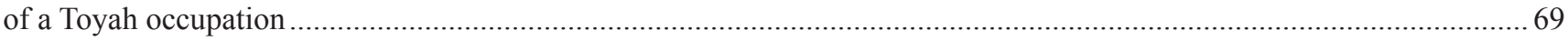

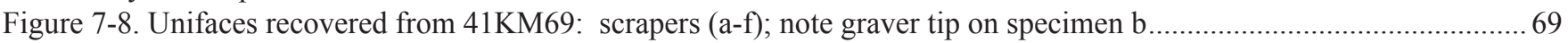

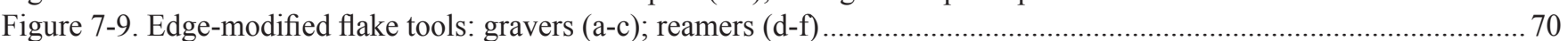

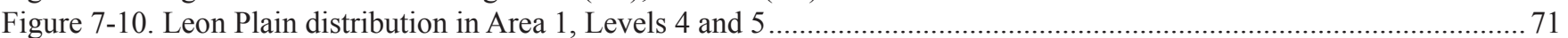

Figure 7-11. The sole ceramic type recorded at 41KM69 is undecorated and bone-tempered. We recovered rim and body

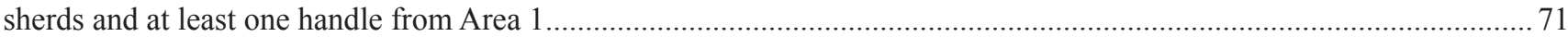

Figure 7-12. The features in Area 1 are illustrated in this map at various depth ............................................................. 76

Figure 7-13. The distribution of features in Area 2 is clustered at the $\mathrm{Ck}$ horizon along the perimeter of the block ............... 77

Figure 7-14. Only a few features besides the burned rock midden were documented in Area 3. These were located at

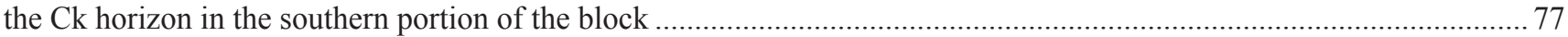

Figure 7-15. The features in Area 4 cluster at two elevations........................................................................................ 78

Figure 8-1. Handling costs by resource class (from Cane 1987; Kelly 1995; Simms 1987)...............................................8 80

Figure 8-2. Optimal diet sets as defined in Prey Model (after McArthur and Pianka 1966) ............................................... 81

Figure 8-3. Seasonal changes in the nutritional quality of mule deer (from Anderson et al. 1972) ....................................... 82

Figure 8-4. Yearly fluctuation in mesquite seeds and Prickly pear fruit (from Windberg 1997)...........................................83

Figure 8-5. An example of diet expansion from 4 (A) to 5 (B) resources under conditions of closely ranked prey

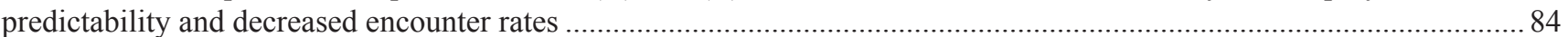

Figure 8-6. An example of the potential impacts of radical differences in prey predictability (resources 4 and 5). Diet

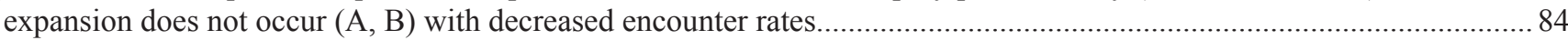

Figure 9-1. Area and sites (dots) investigated by Mauldin and Kemp (2005). Numbers associated with sites are tied to

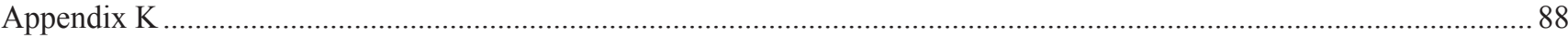

Figure 9-2. Percentage of components with bison present from the Late Archaic through the Late Prehistoric

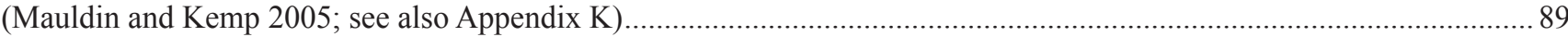

Figure 9-3. Primary range of Bison bison (after McDonald 1981:104) ........................................................................... 90

Figure 9-4. Grassland production and summer precipitation for a tallgrass prairie (1984-1999) ......................................... 91

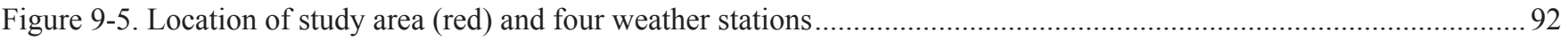

Figure 9-6. Range (top) and coefficient of variation (bottom) for June rainfall from Figure 9-5 weather stations (1914-2003) ... 93

Figure 9-7. Percentage of camps on which bison were observed from 1675 through 1767 (data from Wade 1998). Insert

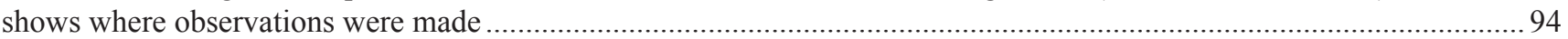

Figure 9-8. Season of bison encounters by Spanish expeditions into Central Texas from 1675 through 1767 (data from Wade 1998). Insert shows where observations were made .......................................................................95

Figure 9-9. Body size grouping for Texas mammals. See Appendix L for details ............................................................. 98

Figure 9-10. Relationship between the number of large mammal species and primary production within Texas ....................99

Figure 9-11. Relationship between the number of medium mammal species and primary production within Texas ...............99

Figure 9-12. Relationship between the number of small and very small mammal species and primary production in Texas .... 100

Figure 9-13. Number and type of plant elements (e.g., nuts, fruits) by vegetation area within Texas. See

Appendix M for details .............................................................................................................................................. 101

Figure 9-14. Number of selected potential plant food items and primary productivity for Texas vegetation areas................ 102

Figure 9-15. Location of 41KM69 with $150 \mathrm{~km}$ radius identifying limits of comparative samples ................................... 104

Figure 11-1. Location of soil columns collected from 41KM69 ……......................................................................... 109

Figure 11-2. The stable isotope composition of $\delta^{13} \mathrm{C}$ and $\delta^{18} \mathrm{O}$ and concentration of $\mathrm{CaCO}_{3}(\% \mathrm{wt})$ and carbon isotope

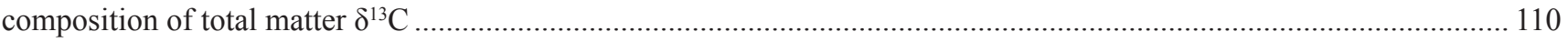

Figure 12-1. 41KM69 and comparative sites used in the diet breadth studies ................................................................. 114

Figure 12-2. Proposed sample size-variety plots for fauna from residential foraging systems (top) and logistical

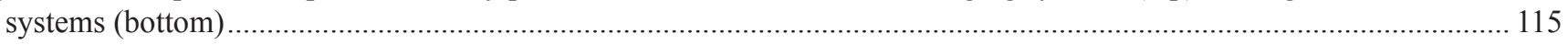

Figure 12-3. Plot of the number of faunal groups against sample size per component ........................................................118

Figure 12-4. Log transformation of faunal groups by NISP with 95 percent confidence intervals (compare to Figure 12-3) ..... 118 
Figure 12-5. Plot of faunal groups against sample size among Late Archaic components in the study area ........................ 119

Figure 12-6. Plot of faunal groups against sample size among Late Prehistoric components in the study area ..................... 119

Figure 12-7. Plot of the ratio of the weights of identified (class or order) to unidentified bone by component at 41KM69 ... 120

Figure 12-8. Plot of the ratio of weight of identified (class or order) to unidentified bone by component within the

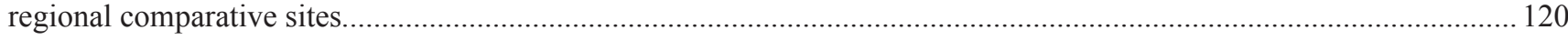

Figure 12-9. Ethnographically reported cooking time for plants (top) and meat (bottom). Bars show the interquartile

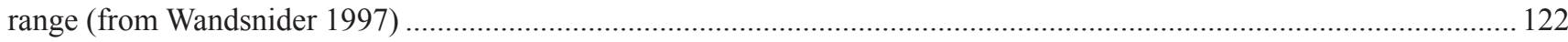

Figure 12-10. Frequency of features by feature weight for 41KM69 dataset................................................................ 124

Figure 12-11. Box plots of feature area for the Group 1 (1.00) and Group 2/3 (2.00) features types ................................. 125

Figure 12-12. Maximum size $(\mathrm{cm})$ of rock in Feature 3 (Group 3) .......................................................................... 126

Figure 12-13. Maximum size (cm) of rock in Feature 45 (Group 2) .......................................................................... 127

Figure 12-14. Rock size percentages for Group 2 (dashed) and Group 3 (solid) features at 41KM69 ................................ 127

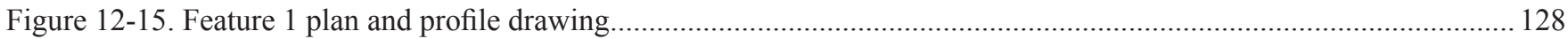

Figure 12-16. Burned rock distributional data from Feature 1, 41KM69.................................................................... 129

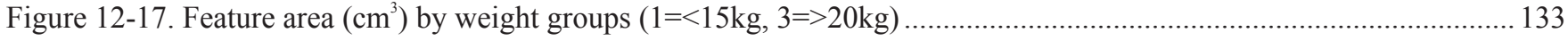

Figure 12-18. 41KM69 and comparative sites used in the regional thermal feature database …......................................... 134

Figure 12-19. Number of burned rock features per year for $100 \mathrm{~m}^{2}$ of excavated area at the component level .................... 137

Figure 12-20. Area of burned rock features per year for $100 \mathrm{~m}^{2}$ of excavated area at the component level .........................137

Figure 12-21. Number of thermal features lacking rock per year for $100 \mathrm{~m}^{2}$ of excavated area at the component level......... 138

Figure 12-22. Number of burned rock features per year for $100 \mathrm{~m}^{2}$ of excavated area at the component level at $41 \mathrm{KM} 69 \ldots 140$

Figure 12-23. Area of burned rock features per year for $100 \mathrm{~m}^{2}$ of excavated area at the component level at 41KM69........ 140

Figure 13-1. The percent of expensive tools vs. inexpensive tools per component at 41KM69 ….................................... 145

Figure 13-2. The percent of tool cost categories per component at 41KM69 ……...................................................... 146

Figure 13-3. Percentage of expensive tools per component across the comparative sites and 41KM69 ............................ 149

Figure 13-4. Proposed relationship between breakage patterns and tool production (on-demand vs. gearing-up) strategies...... 150

Figure 13-5. Middle Late Archaic tool breakage patterns across the comparative study area and 41KM69 ......................... 152

Figure 13-6. Terminal Late Archaic tool breakage patterns across the comparative study area and 41KM69 ...................... 152

Figure 13-7. Initial Late Prehistoric tool breakage patterns across the comparative study area and 41KM69 ..................... 152

Figure 13-8. Terminal Late Prehistoric tool breakage patterns across the comparative study area and 41KM69.................. 152

Figure 14-1. Relationship between prey body weight, hunting technique, and weapon type ............................................ 157

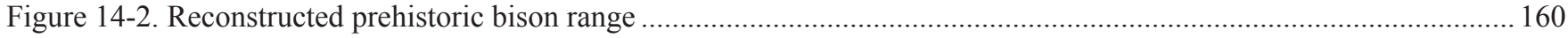

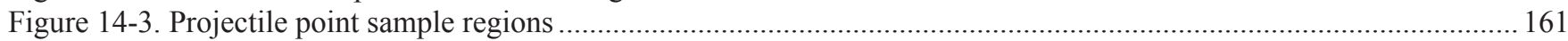

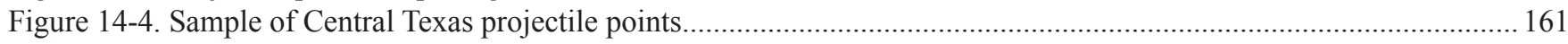

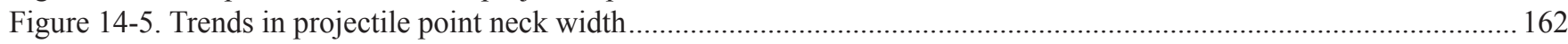

Figure 14-6. Distribution of Central Texas projectile point neck width .......................................................................... 162

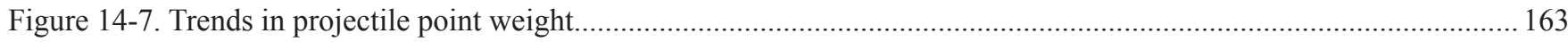

Figure 15-1. For a given area, the Caddo sherds weigh more than Toyah sherds, which is due in part to their greater thickness.. 168

Figure 15-2. Box plot showing the mean thickness of Caddo and Toyah sherds ……..................................................... 169

Figure 15-3. Box plot of mean Caddo and Toyah sherd thickness by site assemblage ........................................................ 169

Figure 15-4. Mean thickness of sherds for Toyah interval sites located on and off the Edwards Plateau.............................. 170

Figure 15-5. The mean thickness of Toyah interval sherds from sites located off the Edwards Plateau............................... 170

Figure 15-6. Percentages of bone and grog temper within Caddoan and Toyah interval sherds......................................... 171

Figure 15-7. Percentages of quartz (sand) and bone temper within Caddoan and Toyah interval sherds

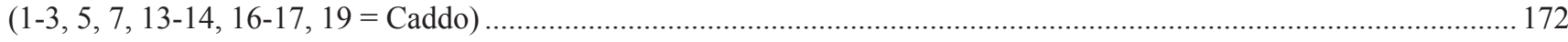

Figure 16-1. Expected relationship between the number of artifact types and sample size for different

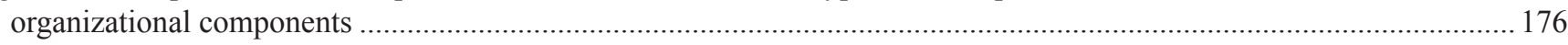

Figure 16-2. Plot of tool types against sample size among the comparative site components in the study area.................... 179

Figure 16-3. Anticipated relationship between scale and number of raw material types .................................................. 180

Figure 16-4. Plot of color types against sample size among the comparative site components in the study area.................. 181

Figure 16-5. Adjusted standardized residuals showing over- and under-represented total color counts by time period.......... 182

Figure 16-6. Plot of the number of chert color categories against the number of categories represented entirely by decorticate debitage, regional comparative database.

Figure A-1. Site map showing locations of CAR backhoe trenches and test units relative to terraces .................................213

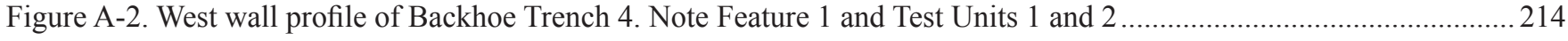


Figure A-3. South wall profile of Backhoe Trench 5. Note Feature 1 and Test Units 3 and 4 ..........................................216

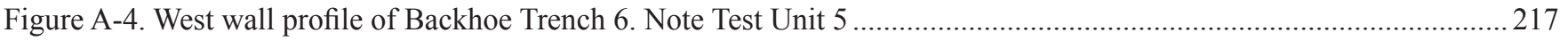

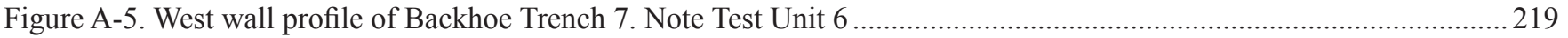

Figure A-6. West wall profile of Backhoe Trench 8. Note Features 2 and 3 and Test Units 8 and 12................................221

Figure A-7. South wall profile of Backhoe Trench 9. Note Feature 3 ...........................................................................222

Figure A-8. Soil susceptibility graph showing possible surfaces in BHT 4, west wall profile...........................................222

Figure A-9. Soil susceptibility graph showing possible surfaces in BHT 5, south wall profile, $4.27 \mathrm{~m}$ west of east end........225

Figure A-10. Soil susceptibility graph showing possible surfaces in BHT 5, south wall profile, $14.78 \mathrm{~m}$ west of east end.... 225

Figure A-11. Soil susceptibility graph showing three possible surfaces in BHT 6, $7 \mathrm{~m}$ from south end ...........................226

Figure A-12. Soil susceptibility graph showing possible surfaces in BHT 7, west wall profile, $10 \mathrm{~m}$ from south end ...........226

Figure A-13. Soil susceptibility graph showing possible surfaces in BHT 8, $4.7 \mathrm{~m}$ from BHT 9/8 intersection.................... 227

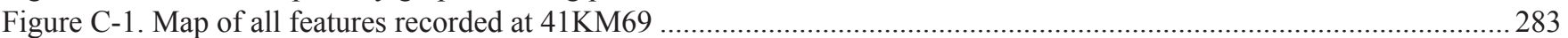

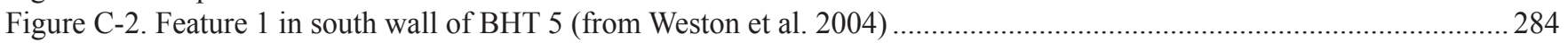

Figure C-3. Dimensions of Feature 1 as documented during data recovery excavations....................................................28

Figure C-4. The northern profile photograph of Feature 1 shows a sharp contrast between the midden fill and burned

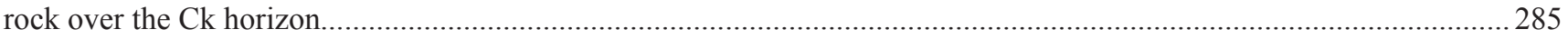

Figure C-5. Feature 2, hearth feature in Test Unit 8 (from Weston et al. 2004) ................................................................286

Figure C-6. Plan view of Feature 2 in Test Unit 8 (from Weston et al. 2004) ....................................................................28

Figure C-7. Bone fragments recovered from Feature 2 (from Weston et al. 2004) ...........................................................2 287

Figure C-8. Feature 3, burned rock cluster in Test Unit 12 (from Weston et al. 2004) .......................................................28

Figure C-9. Plan view of Feature in TU12, 30-35 cmbs (from Weston et al. 2004) ...........................................................289

Figure C-10. Feature 5, burned rock cluster in TU 9 (from Weston et al. 2004) .................................................................289

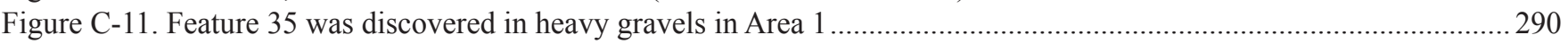

Figure C-12. Plan view of Feature 35 shows the locations of the ${ }^{14} \mathrm{C}$ samples submitted for dating. The cross section

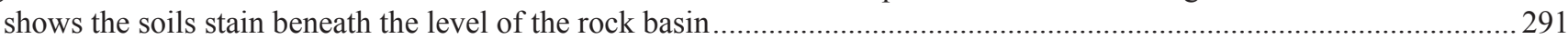

Figure C-13. Feature 42 is a large, Late Archaic hearth feature in Area 2. a) photo; b) plan view drawing ..........................292

Figure C-14. Feature 45 is a large basin-shaped hearth excavated in Area 4 .................................................................2.29

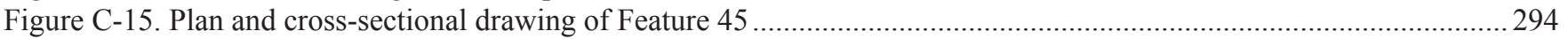

Figure C-16. Feature 47 is a small hearth with vertically set stones .............................................................................29

Figure C-17. Feature 47 illustrated in plan view and cross section showing the basin shape .............................................295

Figure C-18. Feature 48 is a large burned rock cluster in Area 4. a) photo; b) plan view drawing .......................................296

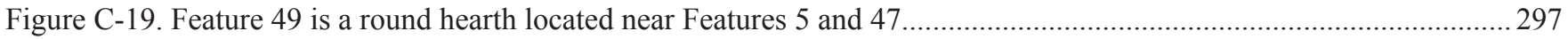

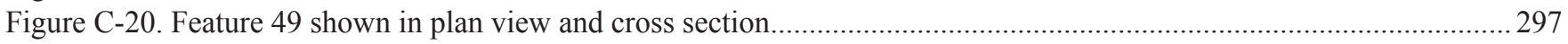

Figure C-21. Feature 52 lay at the base of Feature 1 on the Ck horizon. a) photo; b) plan view drawing............................ 299

Figure C-22. Feature 21 represents one of the many root molds excavated at 41KM69 _.....................................................300

Figure C-23. Feature 19 represents a typical post mold in Area 1 at 41KM69 ................................................................ 300

Figure C-24. Feature 4, gravel driveway in south wall of BHT 5 (from Weston et al. 2004) ............................................... 304

Figure C-25. Feature 6, historic slab foundation (from Weston et al. 2004) ....................................................................... 304

Figure C-26. The two-story main office of the historic Kimble Courts is now a private residence in Junction, Texas ............305

Figure C-27. The single story guest houses of the historic Kimble Courts have been demolished but are illustrated here in Spring 2005 in Junction, Texas, after they were moved in 1935 from the banks of the South Llano River ...................305

Figure $\mathrm{H}-1$. The stable isotope composition $\delta^{13} \mathrm{C}$ and $\delta^{18} \mathrm{O}$ and concentration of $\mathrm{CaCO}_{3}(\% \mathrm{wt})$ and carbon isotope

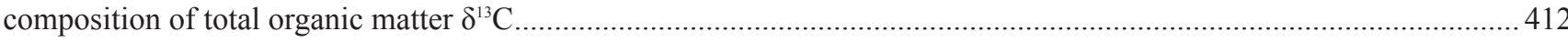

Figure I-1. Pollen and Phytoliths a) Artemisia, b) Dandelion type, c) Asteraceae HS, d) Cheno-Am, e) Asteraceae LS, f) Unknown, g) Unknown, h) Phytolith, i) Phytolith, and j) Phytolith ........................................................................ 420

Figure I-2. Phytoliths: a) Phytolith, b) Phytolith, c) Phytolith, and d) Phytolith................................................................. 421

Figure M-1. Bivariate plot of chromium and rubidium (log base-10ppm) showing the three pairs.....................................473

Figure M-2. Bivariate plot of chromium and scandium (log base-10 ppm) showing the samples relative to the CT1 and CT2 reference groups. The new samples are individually plotted. Ellipses represent $90 \%$ confidence

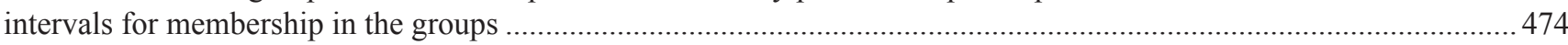

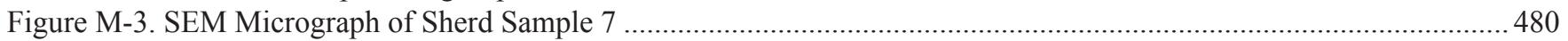

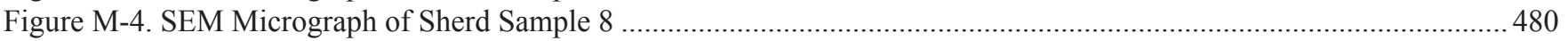

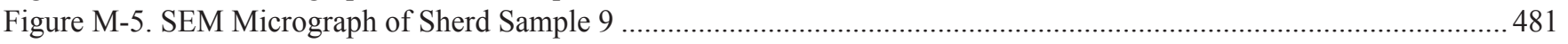

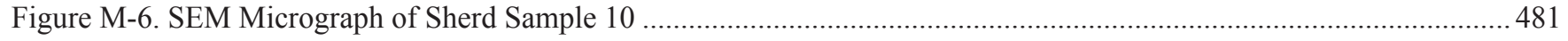




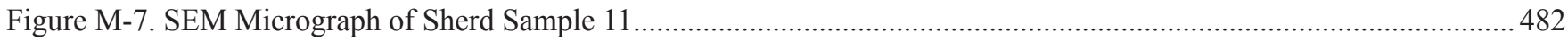

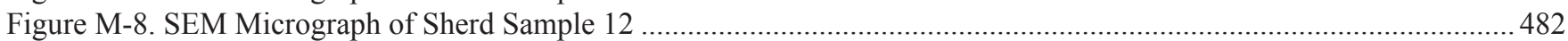

Figure N-1. General Location (red circle) of 41KM69 and the Collection Site of Gravel Samples from the Llano River in Kimble County, Texas.

Figure N-2. Biplot of PC scores and elemental vectors for the Texas chert database. Previously defined compositional groups are shown with $90 \%$ confidence ellipses

Figure N-3. Biplot of PC scores and elemental vectors for the Texas chert database. Previously defined compositional groups are shown as 90\% confidence ellipses. Newly analyzed specimens from 41KM69 and the Llano River are shown. Note that the newly analyzed samples cluster within the two compositional groups associated with the Edwards Group cherts.

Figure N-4. Bivariate plot of canonical discriminant scores for the Texas chert database. Extant compositional groups are shown with $90 \%$ confidence ellipses. Note clear separation between Fort Hood cherts and Edwards Group cherts .. 494 Figure N-5. Bivariate plot of canonical discriminant scores for the Texas chert database showing extant compositional groups as 90\% confidence ellipses. Newly analyzed specimens from 41KM69 and the Llano River are plotted and labeled with analytical IDs

Figure N-6. Bivariate plot of canonical discriminant scores for the Edwards Group chert compositional groups and the Llano River gravels. Compositional groups are shown with $90 \%$ confidence ellipses. Artifacts from 41 KM69 are plotted... 495 


\section{List of Tables:}

Table 2-1. Correlation Coefficient for PDSI Values and Yearly Rainfall, 1900-2003 …..................................................... 14

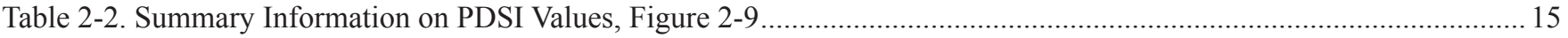

Table 2-3. Summary Information on PDSI Variability at 25-Year Segments, Figure 2-10 ................................................ 17

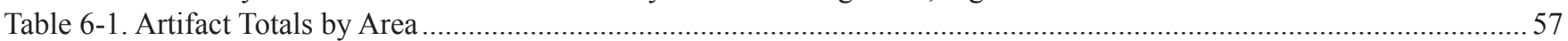

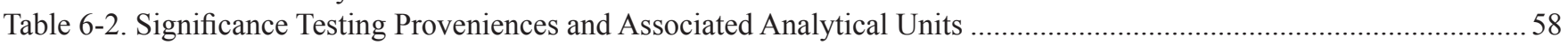

Table 6-3. Data Recovery and Significance Proveniences and Associated Analytical Units ..................................................59

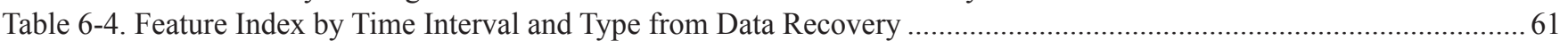

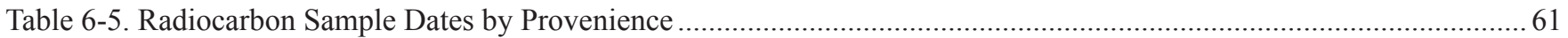

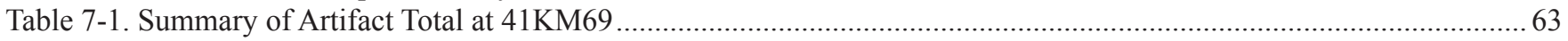

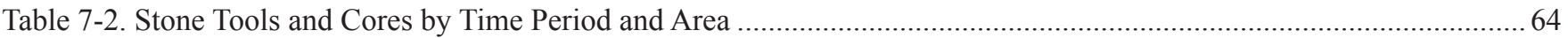

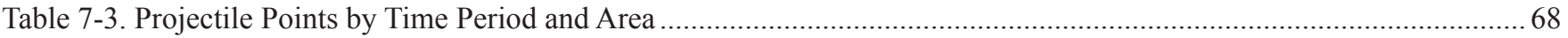

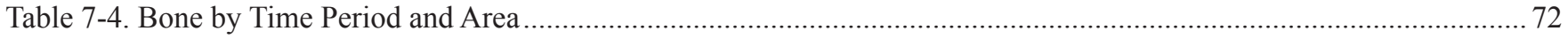

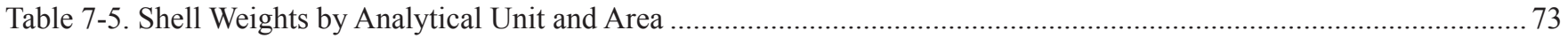

Table 7-6. Counts of Burned Rock and Macrobotanical Samples ................................................................................. 74

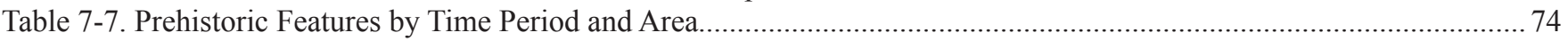

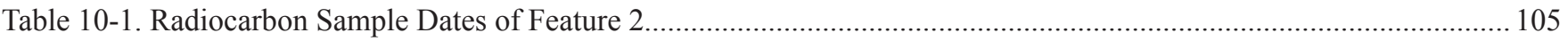

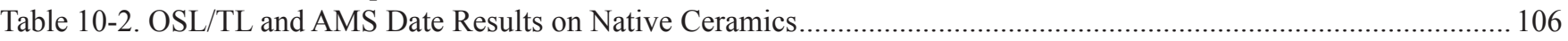

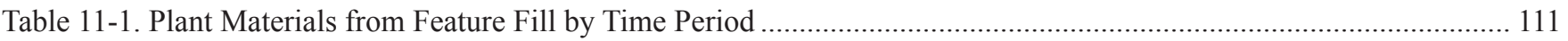

Table 12-1. NISP per Component at Sites with Published Vertebrate Faunal Data........................................................... 115

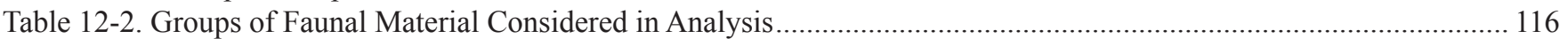

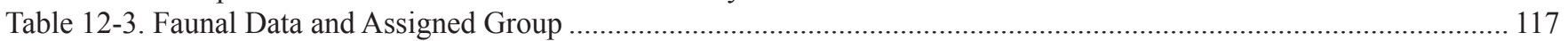

Table 12-4. Feature Weight Groups by Temporal Period (significant Adjusted Residual values in BOLD).......................... 125

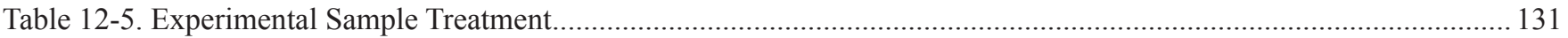

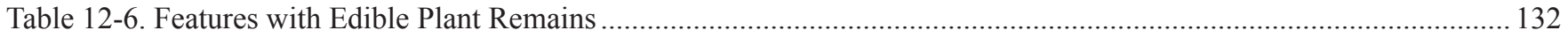

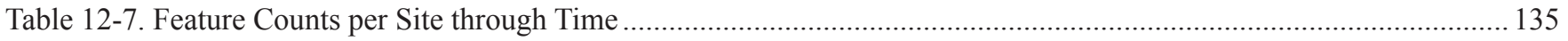

Table 12-8. Summary Data from Literature Review................................................................................................... 136

Table 12-9. Summary Data from Burned Rock Features in Literature Review................................................................ 138

Table 12-10. Area and Number of Recorded Burned Rock Features within each Component at 41KM69 ........................... 139

Table 12-11. Number of Features per Excavated Space in each Component at 41KM69 ................................................ 139

Table 12-12. Summary Data from Burned Rock Features at 41KM69 ....................................................................... 141

Table 13-1. Manufacturing Cost Categories of Chipped Stone Tools ......................................................................... 145

Table 13-2. Sites and Components for Manufacturing Cost Tool Study …..................................................................... 147

Table 13-3. Manufacturing Cost Categories of Comparative Chipped Stone Tools ............................................................... 148

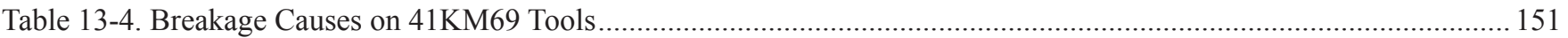

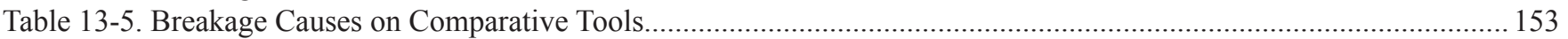

Table 14-1. Recommended Arrow Performance by Game Animal Size........................................................................ 158

Table 14-2. Momentum Values for Bow/Arrow and Atlatl/Dart Weaponry ...................................................................... 158

Table 15-1. Sample Size and Sites Used for Metric Analysis of Sherds ........................................................................ 167

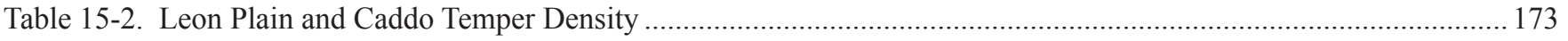

Table 16-1. Artifact Types Proposed for Use in Sample Size and Type Comparisons ...................................................... 177

Table 16-2. Tool Types within the Components of the Regional Comparative Database ................................................... 178

Table 16-3. Number of Stone Tool Color Categories by Component, Regional Database................................................. 180

Table 16-4. Number of Tool Stone Color Categories and Decorticate Colors by Component, Regional Database................. 183

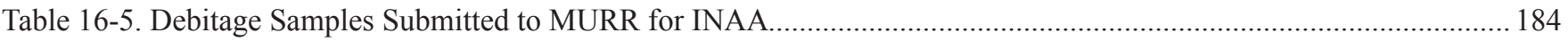

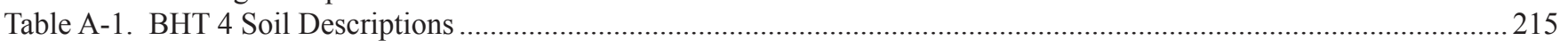

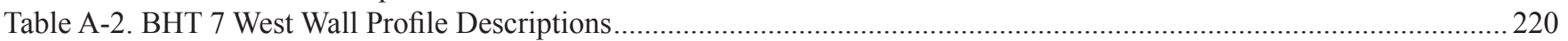

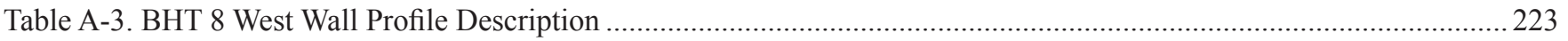

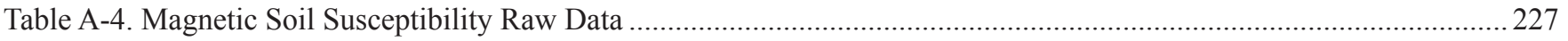

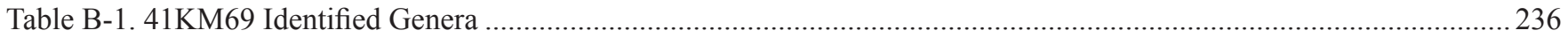


Table B-2. Category Descriptions of Vertebrate Faunal Analysis Used in TablesB-3 and B-4 ….....................................2237

Table B-3. Vertebrate Faunal Remains Recovered from Significance Testing …….........................................................2239

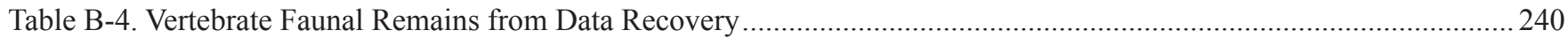

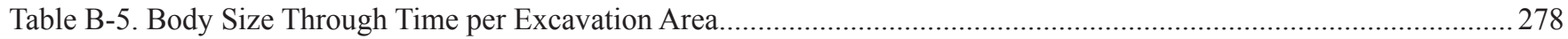

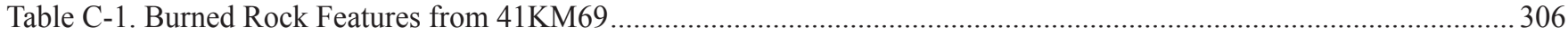

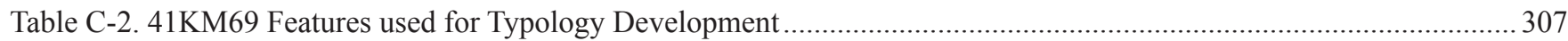

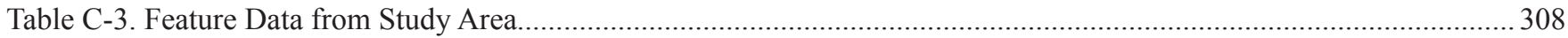

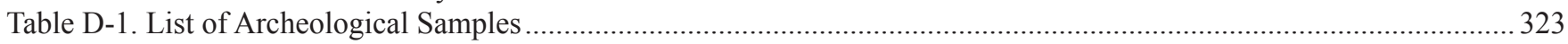

Table D-2. Summary of Average Fatty Acids Compositions of Modern Food Groups Generated by Hierarchical Cluster Analysis

Table D-3. Criteria for the Identification of Archaeological Residues Based on the Decomposition Patterns of

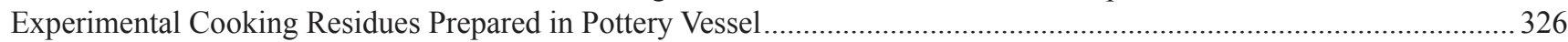

Table D-4. Fatty Acid Composition and Identification of Archaeological Residues* ...........................................................327

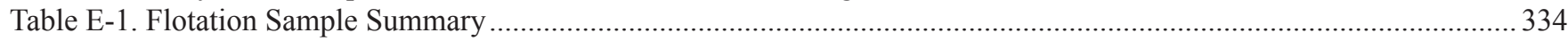

Table E-2. Plant Materials Identified in Flotation Samples from 41KM69 …….............................................................336

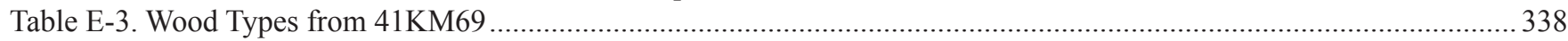

Table E-4. Inventory from Heavy Fraction of Feature Soils from 41KM69 ……............................................................343

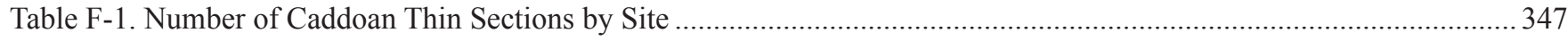

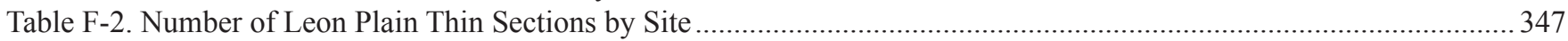

Table F-3. Results of Point Counting of Leon Plain Wares ............................................................................................ 349

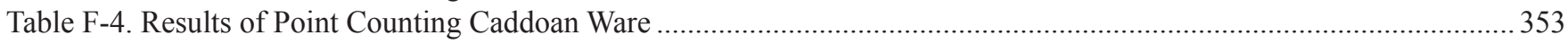

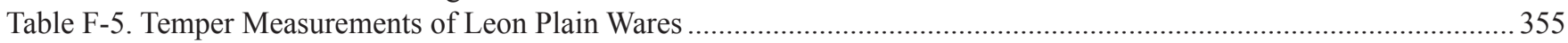

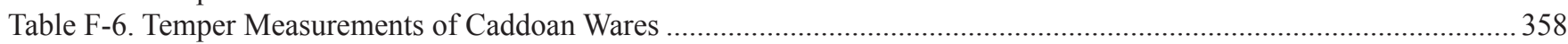

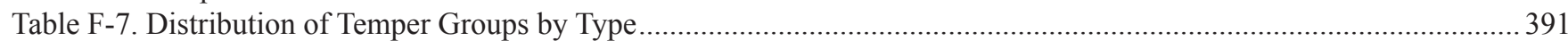

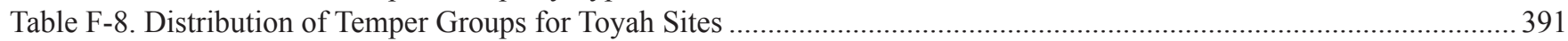

Table F-9. Distribution of Temper Groups for Caddoan Sites .......................................................................................... 392

Table F-10. Mean of Temper (in mm) by Temper Group for Leon Plain Ceramics ............................................................393

Table F-11. Mean of Temper (in mm) by Temper Groups for Caddoan Ceramics ...............................................................393

Table G-1. Uncalibrated ${ }^{14} \mathrm{C}$ Ages (with one sigma error) for Those Sherds on Which a Date Could Be Obtained .....................................397

Table G-2. Dose Rate Data for Samples on Which Date Could Be Obtained .......................................................................397

Table G-3. Equivalent Dose Data for Samples on Which Date Could Be Obtained ............................................................398

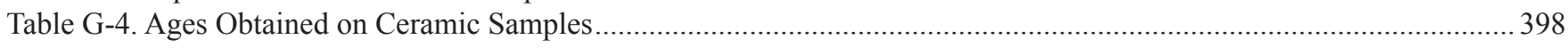

Table H-1. The Carbon and Oxygen Stable Isotopic Composition of Total Soil Carbonates and the Carbon Stable

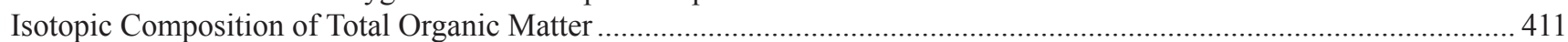

Table I-1. Soil Samples Collected from Site 41KM69 for Pollen and Phytolith Studies .................................................... 417

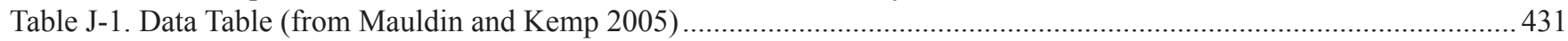

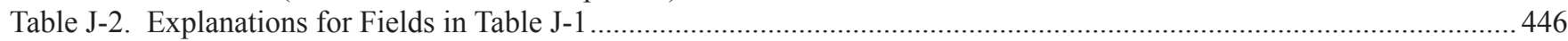

Table J-3. Association of Bison and Diagnostics or Radiocarbon Dates ..........................................................................44

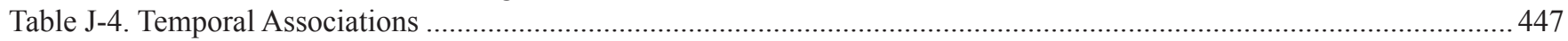

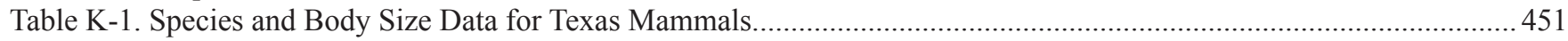

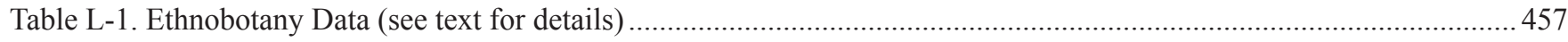

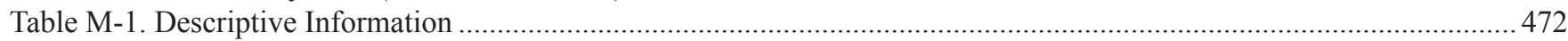

Table M-2. Probabilities of Membership in the CT1 and CT2 Groups Using a Mahalanobis Distance Calculation

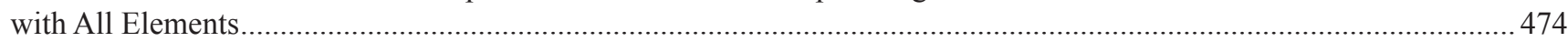

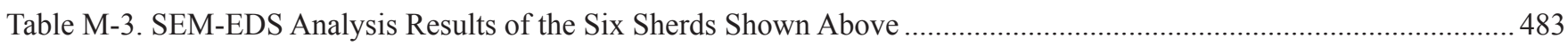

Table N-1. Summary Table of Chert Specimens Submitted for Analysis by Neutron Activation from West-Central Texas ... 488

Table N-2. Prior Studies of Texas Cherts Conducted by NAA at MURR. Note that Published Reports for Projects by Turnbow (1994) and Hudler (1998) Could Not Be Located at the Time of This Writing

Table N-3. Principal Component Analysis of the Texas Chert Database. The First 8 Principal Components are Shown, Accounting for Greater than $90 \%$ of the Cumulative Variation in the Dataset. Values in Bold Indicate Strong Elemental Loading

Table N-4. Comparison of Determinations of Local Versus Nonlocal Provenance for Artifacts from 41KM69, Kimble County, Texas. 


\section{Acknowledgements:}

The authors would like to acknowledge those individuals whose help was instrumental in the successful completion of this project, including staff from TxDOT, Texas Tech University at Junction, The University of Texas at San Antonio, and the town of Junction. First, we thank Lewis Nolin and the staff of the Kimble County/Junction TxDOT office for scheduling their equipment and operators to open and backfill trenches and excavate auger tests. Thanks also to the environmental staff at TxDOT who were involved at various points over the years, particularly Barbara Hickman, Jim Abbott, John Arnn, Owen Lindauer, Lain Ellis, Nancy Kenmatsu, and Scott Pletka, for their comments on the excavation and research design associated with this project.

We also express our appreciation to Dr. Grant Hall and the staff of Texas Tech at Junction for allowing us to access the campus' computer labs, which in turn permitted us to maintain email contact with the San Antonio office.

The CAR field crew, lab, and office staff all contributed to the project. The CAR field personnel involved in significance testing included Jon Dowling, Owen Ford, Greg Garber, Leonard Kemp, Jeff Mayrone, Cindy Munoz, Jason Perez, Beth Sain, and Carl Welsh. Jason Weston oversaw the testing efforts at the site. Russell Greaves conducted the geomorphological investigations. Cindy Munoz served as laboratory coordinator for artifact analysis and processing during significance testing.

The data recovery crew included Wilbur Barrick, Mark Darrow, Brian Davis-Brothers, Jon Dowling, Lindsay Flood, Jim Gillentine, Maggie Moore, and Juliana Vivona for the entire four months we were in Junction. Additional field crew included Roman Clem, Lynn Eschenbaum, David Kalinowski, Leonard Kemp, James Reagan, Jeff Roberson, Steve Smith, and Jeff Williams. We completed the monitoring phase of this work with Gradall operator Phil Bowden and field techs Jon Dowling, Leonard Kemp, Bryant Saner, Andy Speer, and Daniel Teague.

Bruce Moses collected survey data during both phases of excavation and drafted many of the figures used in this report with the assistance of Rick Young and Barbara Meissner. He also produced the layout of the final report in preparation for printing.

Laboratory staff included Claudia Branton, Nate DiVito, Cyndi Dickey, Antonia Figueroa, Lindy Martinez, Cody Miller, Cathy Stacy, Laura Schiotis, Steve Smith, and Joseph Thompson who washed, sorted, and pulled comparative collections under the direction of Marybeth Tomka, lab director, and Larissa Galenes, who served as lab coordinator for the data recovery phase.

The residents of Junction were very hospitable during our extended stay in their town. Many visitors to the site shared their memories of the town and their knowledge of the site. Frederica Wyatt, the town historian, deserves special recognition for freely sharing with us information about the history of the Kimble Courts.

The specialized analyses referred to in the body of the text have been carried out by scientists and researchers from many universities including in alphabetical order: Lori Barkwill-Love, Vaughan Bryant, J. Philip Dering, James Feathers, Michael D. Glascock, Russell Greaves, M.E. Malainey, Barbara C. Meissner, Debajyoti Paul, and Grzegorz Skrzypek. Many thanks to each of them for completing the analyses and providing drafts in a timely fashion. 


\section{Chapter 1: Introduction}

\section{Jennifer L. Thompson}

Site 41KM69 is a multi-component site in Kimble County, Texas, with significant Late Archaic, Late Prehistoric Austin interval, and Late Prehistoric Toyah interval components. The excavated portion of the site contained 47 burned rock features including one large burned rock midden. The site also yielded over 40,000 chipped stone artifacts from all components and a discrete group of plain, bone-tempered earthenware ceramics similar to those typically found in Toyah components. Several radiocarbon samples were submitted, with the oldest from a hearth feature dating to the middle of the Late Archaic period $(2550 \pm 50$ B.P.). The most recent sample dated the upper level ceramic assemblage, targeted during data recovery excavations, to the very Late Prehistoric or Protohistoric Period. The site contains a twentieth-century historic component as well, but it was not targeted during excavation. This report describes the history of the significance testing and data recovery efforts and reports on the inventory of artifacts collected and analysis conducted.
The Center for Archaeological Research (CAR) of The University of Texas at San Antonio (UTSA) was contracted by the Texas Department of Transportation (TxDOT) to conduct significance testing and data recovery excavations at 41KM69. The work was begun under Work Authorization No. 57315SA002 and Contract No. 573XX5A002 and completed under Work Authorization No. 7902SA001 Contract No. 579XXSA001. The investigations were conducted under Texas Antiquities Permit No. 3350 for significance testing and No. 3584 for data recovery with Dr. Raymond Mauldin serving as Principal Investigator on both permits. The excavations were to mitigate the effects of proposed improvements to Flatrock Road/FM 2169 that intersects the site. The general location of the project area is shown on Figure 1-1.

While cultural deposits exist on both the east and west sides of Flatrock Road/FM 2169, the portion of 41KM69 that was excavated is limited to the right-of-way (ROW) of the road

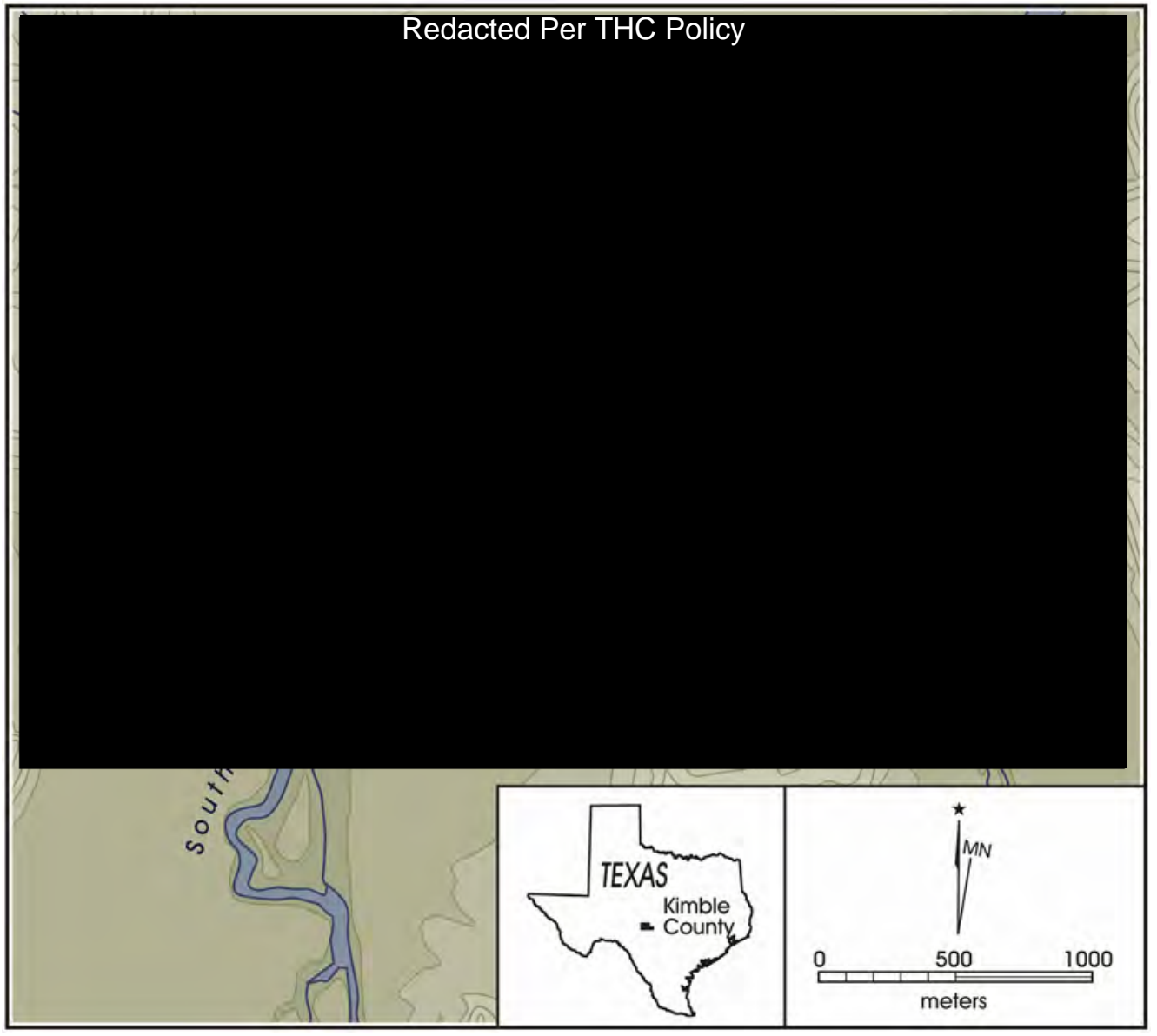

Figure 1-1. General location of the project area. 
realignment on the west side of the road. The initial ROW encompassed roughly $2,440 \mathrm{~m}^{2}(80-\mathrm{x}-30.5 \mathrm{~m})$ of the site. However, the ROW was shifted to the west some time after data recovery began. The block excavations and Gradall monitoring of the original ROW occurred January 10 through April 29, 2005. CAR returned August 15-26, 2005, and September 26-28, 2005, to investigate the expanded ROW with auger tests.

\section{Project History}

According to the Texas Archeological Sites Atlas, R.W. Ralph, of the Texas Parks and Wildlife Department, first recorded 41KM69 in 1980. The site description included a lithic scatter and a limestone burned rock midden exposed in the road cut on the east/northeast side of the road. No subsurface investigation of the site occurred at the time of the recording. Site boundaries were based on the surface scatter of artifacts and were estimated at 80 meters north-south by 200 meters east-west. The depth of the deposits, estimated at 1.5 meters, may have been determined based on the road cut exposure. On the west side of the road, the site map noted a historic concrete foundation. No temporally diagnostic artifacts were identified during this preliminary investigation. The site was designated a State Archeological Landmark (SAL) in 1990, and the site was described as consisting of several components dating from the Late Archaic through the Historic Period. The resources listed under the SAL included multiple camps, a ranch, a quarry, and a historic house site. No other records show any formal excavations at the site until TxDOT returned in 2003.

TxDOT archeologists visited the site on December 11-12, 2003, to excavate three backhoe trenches along the centerline of the planned road realignment ROW. Each backhoe trench (BHT) was five to seven meters long and approximately 1.4 meters deep. A small rock concentration was photographed in the north end of BHT 1 at approximately $76 \mathrm{~cm}$ below the ground surface. The six rocks visible in the images provided to CAR appear to range in size from approximately $5 \mathrm{~cm}$ to $<10 \mathrm{~cm}$ in maximum dimension, but it is unclear whether these rocks represent a prehistoric feature. TxDOT personnel informed CAR staff that lithics and burned rock were encountered at approximately $50-76 \mathrm{~cm}$ below surface $(\mathrm{cmbs})$ in some portions of the site (Barbara Hickman, personal communication January 23, 2004). CAR archeologists, first visiting the site in early February of 2004, noted lithic debitage and burned rock in the backfill of all three backhoe trenches (Weston et al. 2004).

Based on the findings from the backhoe trenches, TxDOT determined that the site warranted significance testing and contracted CAR to conduct the work. CAR performed the Phase II significance testing in 2004 to determine if the site was eligible for listing on the National Register of Historic Places (NRHP). The anticipated realignment of Flatrock Road/FM 2169 prompted the Phase II study, led by Project Archeologist Jason Weston (Weston et al. 2004).

The Phase II testing project involved the systematic boring of 120 mechanical auger tests to $120 \mathrm{~cm}$ below the surface, excavation of six additional backhoe trenches totaling over $114 \mathrm{~m}$ in length and reaching $150 \mathrm{cmbs}$, and test unit excavation. Eight $50-x-50-\mathrm{cm}$ units were initially dug to better define the vertical distribution of cultural materials across the site. These units were excavated to a depth of 140-170 cmbs. Five 1-x-1-m test units were placed over artifact concentrations discovered during auger testing and over features identified by the backhoe trenches (one of the $1-x-1-m$ units was expanded from a $50-x-50-\mathrm{cm}$ unit). The depth of these excavations ranged from $80-150 \mathrm{cmbs}$. The excavation of the $50-x-50-\mathrm{cm}$ and $1-\mathrm{x}-1-\mathrm{m}$ units identified intact, stratified cultural deposits containing temporally diagnostic artifacts and charcoal. The trenches confirmed the location of several features identified by augers, located additional features, and identified a buried A horizon paleosol.

These prehistoric cultural deposits included one large Initial Late Prehistoric large burned rock midden (Feature 1), one hearth feature (Feature 2), two burned rock clusters (Features 3 and 5), over three thousand chipped stone artifacts, 10 temporally diagnostic projectile points including Darl and Frio point types, several unifacial tools, and 48 native ceramics. Three charcoal samples submitted for radiocarbon dating returned dates that place the base of the burned rock midden (Feature 1) in the early Late Prehistoric (1190-970 B.P.), the buried paleosol in the Late Archaic (2349-2120 B.P.), and Feature 2 within the Terminal Late Prehistoric/ Protohistoric. The dates and artifacts demonstrated the presence of a Late Archaic component, an Initial Late Prehistoric (Austin interval) component, and a Terminal Late Prehistoric (Toyah interval) component. Feature 3 was found near Feature 2 in the same component. Neither Feature 3 nor Feature 5 had associated datable material.

Historic material and features, with the exception of a few isolated disturbances, were confined to upper levels of the site from the surface down to $20 \mathrm{cmbs}$. Weston et al. (2004) recorded most historic material on the southern and western portions of the original ROW. Feature 4 was a gravel deposit thought to be a driveway, and Feature 6 is a concrete slab first thought to be a foundation related to the Kimble Courts resort camp. The survey and site mapping identified other surviving foundations to the west of the project area. Informants provided some details about the historic hotel, 
which eventually moved into Junction (see Appendix J). Weston et al. (2004) did not consider the historic component of the site significant, as there were no intact historic deposits seen during significance testing.

Based on these results, CAR recommended that the site was eligible for inclusion to the NRHP under Criterion D of 36 CFR, Section 60.4 , because it was likely to yield information important to prehistory. Given these recommendations and the scale of the impacts associated with the anticipated work within the ROW, Weston et al. (2004) further recommended that if construction impacts to the site were unavoidable, TxDOT should initiate Phase III data recovery efforts directed at adequately sampling the significant deposits associated with the Late Archaic and Late Prehistoric components at 41KM69. The Texas Historical Commission (THC) and TxDOT concurred with those recommendations. Because TxDOT could not avoid construction impacts to the site along Flatrock Road/FM 2169, CAR initiated data recovery investigations in January 2005.

Data recovery excavations targeting the prehistoric components of the site proceeded in three stages based on the findings of the significance testing. The first stage included hand-excavation of large blocks in four areas of high artifact density. The second stage included grading of the site between the blocks to record and sample any features prior to road construction. During this stage, 39 rock features were recorded. The final stage of the data recovery effort occurred after the shifting of the ROW. TxDOT shifted the ROW adding a wedge-shaped area to the west of the Area of Potential Effect (APE) after the data recovery excavations were in progress. CAR examined this wedge-shaped section using mechanical auger borings spaced at close intervals. Additionally, archival work was conducted in Junction to provide more details on the historic Kimble Courts resort hotel that once stood within the project area.

Approximately 40,000 artifacts were recovered from handexcavations of roughly $130 \mathrm{~m}^{3}$ of the site during the first stage of excavation. Approximately half of this total consists of debitage collected from the Austin interval. The highest density of artifacts came from the Austin interval of Area 3 and the Middle Late Archaic levels, also in Area 3. Almost 350 tool forms and preforms of tools were recovered from all components, and 114 earthenware sherds were recovered from the top of the Late Prehistoric component in Area 1. The Late Prehistoric Toyah interval also contained a collection of "Classic Toyah" tear dropped shaped unifaces. The projectile point types recovered across the site include Castroville, Pedernales, Montell, Ellis, Frio, Ensor, Fairland, Edwards, and Perdiz. Sixty-eight thermal rock features and soil stains were also recorded.

\section{Research Design}

CAR developed a research design following the completion of the data recovery excavations. The research design focused on the interpretation of data from the testing and data recovery excavations at 41KM69 while also using comparative data from site reports and other archeological collections housed at CAR and the Texas Archeological Research Lab (TARL). The theoretical framework used in the research design is grounded in principles derived from cultural and evolutionary ecology. Using environmental data, Thompson et al. (2007) devised a set of models of huntergatherer subsistence, mobility, and technology, and then combined datasets from archeological sites across Central and South Texas with the data from 41KM69 for comparison with these models. Chapters 10-16 describe the analyses of this data.

\section{Project Results}

Within the broad theoretical framework of cultural and evolutionary ecology, we have identified several topics of interest that could be addressed using data types recovered from 41KM69 during testing and data recovery. These topics included aspects of paleoclimatic reconstruction to identify the factors that would have conditioned huntergatherer adaptations. Even in the absence of site-specific paleoclimatic conditions, the general regional paleoclimatic background for Central Texas suggests some broad changes over the Late Archaic and Late Prehistoric periods. Therefore, determining whether the material recovered from 41KM69 reflected any responses in diet breadth and configuration by hunter-gatherers that inhabited the site and deciphering whether these prehistoric groups changed their technological organization in response to these changes in resource type and structure became a significant theme of the analyses. We also projected that changes in resources would bring about adaptations in weapons and ceramic technology both in response to differences in prey species and changes in food processing over time. Finally, changes in resource structure would engender not only shifts in technological organization but also changes in mobility strategies. Therefore, the investigation of mobility practices as evidenced by the archaeological data sets also became of focus of the project.

One of the basic questions to address even prior to the investigation of paleoclimate and aspects of hunter-gatherer adaptations was the age of the components and in particular the age of the materials found in the lower terrace of the site. The assessment of the Terminal Late Prehistoric component present in the lower terrace at 41KM69 identified some 
disagreements in the "absolute" dating of the age of the materials and features present on the lower terrace of the site. It is our assessment that the artifact and feature data points to the presence of two groups of materials affiliated with the Toyah interval. The deeper one in $\mathrm{Bk}$ horizon contains lithic artifacts that are commonly assigned to the Toyah interval but lacks ceramics. The upper one is a very late Terminal Late Prehistoric assemblage of ceramics and unifacial scrapers. It is likely that these materials represent two distinct occupations of the site by people pursuing different activities or having different technological organizations at the time of site occupation.

The analysis of pollen and phytolith samples proved of little value due to the degradation of assemblages. The analysis of the ratios of stable carbon isotopes showed that local climatic conditions appeared to follow regional trends identified in other parts of the state. While $\mathrm{C}_{3}$ plants (e.g., trees) were always present within the site-proximate vegetation community, they became more dominant over time. Given the terrace setting of the site, this pattern suggests that the floodplain of the river became more stable over time (at least from the Late Archaic Period on) facilitating the growth of woodlands in this high water-table setting. The taxa richness analysis of the materials obtained from 41KM69 suggests that during the Austin interval the site inhabitants were practicing a rather broad diet under a residential foraging organization. In contrast, during the Toyah interval (Terminal Late Prehistoric), groups narrowed their diet breadth apparently in response to a greater focus on bison exploitation under a logistically organized land-use strategy. This site-specific pattern is in general agreement with the regional pattern of narrowing diet breadth exhibited during the Terminal Late Prehistoric compared to the Initial Late Prehistoric. The analysis of bone fragmentation indicates that at the site level, the greatest degree of fragmentation occurs in the Terminal Late Archaic bone assemblages, but unlike expectations, the least amount occurs in the Terminal Late Archaic not the Middle Late Archaic, as predicted in our research design. Using the number and types of thermal features as proxy measures for plant use, the data from 41KM69 indicates that both the number of burned-rock and non-rock features increases through time. Interestingly, feature surface area is substantially larger during the Terminal Late Archaic than any other period. This trend was not duplicated in the feature data from 41KM69. The data suggest that plant resources were under-utilized during the Initial Late Prehistoric Period. The analysis of technological organization as reflected by the manufacture costs of lithic assemblages showed that the Terminal Late prehistoric has the highest percentage of expensive tools, while the greatest use of expedient tools happens during the Middle Late Archaic Period. The regional database also shows that specialized tools are more common during the Terminal Late Prehistoric than any other time period in our sample. This time period is also the only one in which the lithic artifact assemblage appears to be the result of gearing up as suggested by the predominance of use-broken specimens over manufacture-failed pieces. The regional database shows no patterning in gearing-up.

The investigation of changes in weapons technology focused on the analysis of projectile point samples from Central, South and East Texas, areas of assumed bison availability (Central) and scarcity, respectively. One attribute examined was projectile point neck width. It was used as a measure or proxy for foreshaft/shaft thickness and the overall weight of the projectile. The data showed that projectile point neck widths were consistently greater in regions commonly populated by bison. On the other hand, projectile neck widths were consistently narrower in regions where bison was not common. A similar trend was documented in projectile point weight. Projectile point weights were consistently higher in primary bison habitats compared to regions with secondary or inferior bison habitats. The patterns suggest that the general characteristics of the hunting weaponry, particularly, the weight of the darts, were manipulated to allow increased hunting success when procuring large-bodied prey species such as bison compared to the smaller and speedier antelope and deer. That is, projectile point characteristics such as neck width and weight may be conditioned by weaponry requirements dictated by the prey species hunted. The investigation of changes in ceramic technology in response to distinct mobility strategies focused on two attributes: the proportion of temper present in the vessel fabric and the thickness of the vessel walls. While we anticipated that the wall thickness of ceramics produced by semi-sedentary populations would be less than those produced by mobile groups, the data did not bear out this expectation. Quite to the contrary, Caddo sherds tended to the thicker than Toyah sherds. The later also tend to have more size variability than Caddo sherds. In terms of temper densities, Toyah sherds tended to have higher densities of temper compared to Caddo samples, however, there was no difference in mean temper size between the two groups. The INAA analysis identified three sub-groups of sherds within the assemblage although the samples were relatively homogenous internally. The samples most resembled other sherds from southeast Central Texas. The variability in the small sherd sample from the site also was supported by the SEM-EDS analysis results which showed differences in the mineralogy of the fabric of the six samples studied. The investigation of the 41KM69 debitage assemblage revealed that the bulk of the debitage derives from locally reduced nodules and tools manufactured on site. However, the tedious sort of samples of unmodified lithic debitage samples into color and texture categories identified a number of groups that appeared not to represent 
local-origin materials. These groups consisted primarily of decorticate specimens and tended to be smaller than $30 \mathrm{~mm}$ in maximum dimension. They contrasted with other debitage groups that were composed of a range of debitage sizes and moderate to large proportions of corticated specimens. The latter groups were assumed to represent locally obtained raw materials. The comparison of raw material collections made in the vicinity of the site with the various chert color/texture groupings appeared to support in part the assignments of origin. However, the samples of chert submitted from some of these color/texture groups for INAA analysis combined with locally collected raw materials showed that, in general, the samples are adequate to define a circum-Junction subgroup within the Edward Plateau cherts. However, while most of the cherts matched the general Central Texas/ Edwards Plateau chert group, some samples had no matches anywhere within the existing INAA comparative database. This finding suggests that the range of mobility of some of the groups inhabiting the site may have taken them entirely outside of the sampling universe of the Edwards cherts or that previously un-sampled varieties of chert still remain within the Edward plateau region.

\section{Report Organization}

This report contains 17 chapters and 15 appendices. Following this introduction, Chapter 2 describes the modern environmental setting of the site and proxy paleoclimate data. The cultural history and a description of nearby sites is the subject of Chapter 3. Chapter 4 discusses the field and laboratory methods used during significance testing and data recovery. Chapter 5 describes the results of each excavation phase. Chapter 6 includes a general description of the kinds of artifacts recovered. Chapter 7 defines four analytical units and describes the number, type, and location of artifacts at 41KM69. Chapters 8 and 9 present the theoretical perspective used for developing a model for hunter-gatherer adaptations and the resultant archeological expectations. Chapter 10 outlines the problems and possible scenarios concerning both relative and absolute dating of the Late Prehistoric Toyah interval at 41KM69. Chapter 11 presents the results of site level paleoclimate studies using isotope data and compares it to regional trends described in Chapter 2. Chapter 12 focuses on changes in hunter-gatherer diet from the Middle Late Archaic through the Terminal Late Prehistoric and reports the results of feature and faunal studies at 41KM69 and at the regional level. Chapter 13 concerns changes in technological organization at 41KM69 and several comparative sites by examining the cost of tool manufacturing and tool breakage patterns. Chapter 14 discusses changes in projectile weapons technology from the Late Archaic to the Late Prehistoric across Texas and includes regions beyond the scope of the other research domains. Chapter 15 reports the results of petrographic analysis of Caddo and Toyah-affiliated Leon Plain ceramics in an effort to contrast ceramic technology under different mobility practices. Chapter 16 discussed changes in mobility based on artifact variety and chert availability. Chapter 17 provides the report conclusions and also offers more in depth discussions of the results and implications of the analyses reported in the individual chapters.

The raw data used in the analytical chapters comes from literature reviews and special analyses submitted by various researchers outside CAR. Appendix A, by Dr. Russell Greaves presents the geoarcheological study first presented in the Phase II interim report. Appendix B presents the 41KM69 faunal analysis conducted by Barbara Meissner of CAR, and the comparative database compiled by Jennifer Thompson, Project Archeologist. Appendix C provides descriptions of features from 41KM69 and the feature database compiled from the literature search by Jennifer Thompson. Appendix D, by Dr. Mary Malainey of the University of Calgary, presents a discussion of lipid residues on selected samples from archeological and experimental contexts. Appendix E, by Dr. J. Philip Dering of Shumla Archeobotanical Services, presents a discussion of the macrobotanical assemblage found in feature fill at 41KM69. Appendix F provides the petrographic descriptions written by Lori Barkwill-Love of CAR. Appendix G presents the Radiometric results from the University of Georgia and a luminescence dating report from Dr. James Feathers of the University of Washington. Isotopic analysis of a soil column taken from 41KM69 is presented in Appendix H. Dr. Debajyoti Paul and Dr. Grzegorz Skrzypek conducted this work at the Department of Earth and Environmental Sciences, UTSA. Appendix I includes the pollen phytolith report submitted by Vaughan Bryant at Texas A\&M. Additional appendixes for the bison study, also reported in Mauldin et al. (2010), are reproduced in Appendix J. Animal body size data is listed in Appendix $\mathrm{K}$ and ethnographic plant data is provided in Appendix L. The INAA report on 41KM69 ceramic samples, by Jeffrey R. Ferguson and Michael D. Glascock of the University of Missouri, is in Appendix M. The INAA analysis on chert samples from 41KM69 and the Llano River gravel bar located immediately in front of the site is presented in Appendix N. Finally, Appendix O provides the radiocarbon forms. 



\section{Chapter 2: Environmental Setting}

\author{
Jennifer L. Thompson and Raymond P. Mauldin
}

This chapter presents an overview of the environment of the project area with brief discussions of the physiographic setting, climate, soils, flora, and fauna. The chapter closes with a summary of paleoenvironmental conditions during the Late Holocene.

\section{Current Environment}

Site 41KM69 borders the Texas Tech University campus in a semi-rural setting along the southern bank of the South Llano River. A native grove of pecan trees interspersed with oak trees dominates the immediate landscape with steep hills of the Edwards Plateau in distant view (Figure 2-1). The site extends across two wide terraces above the river at elevations of 1,700-1,720 ft. amsl as found on the Junction USGS 7.5 ' quadrangle.

Site 41KM69 and the larger study area both lie within Blair's (1950) biotic Balconian Province, which covers most of the Edwards Plateau. Many rivers and small streams dissect the eastern and southern portions of the Plateau, which has greater relief than the level uplands of the northwest and central Plateau. The province is dominated by oak, juniper, and mesquite underlain by a variety of grasses (Blair 1950).

\section{Climate}

The NOAA Southern Regional Climate Center (SRCC 2009) reports annual precipitation for Junction, TX is 23.24 in. with the most rain falling in May (3.23 in.) and the least in January (.77 in.) between 1971 and 2000 (Figure 2-2).

For the same years, they also report temperature ranges from an average low of $45^{\circ} \mathrm{F}$ in January to $82^{\circ} \mathrm{F}$ in July with minimum and maximum temperatures spanning from the 20 s to the mid 90s. In 2009, the region experienced broader oscillations with temperatures dropping into the teens in January, February, and March and exceeding $100^{\circ} \mathrm{F}$ in June, July, and August. The National Integrated Drought Information System (NIDIS 2009) reports that during the last ten years,

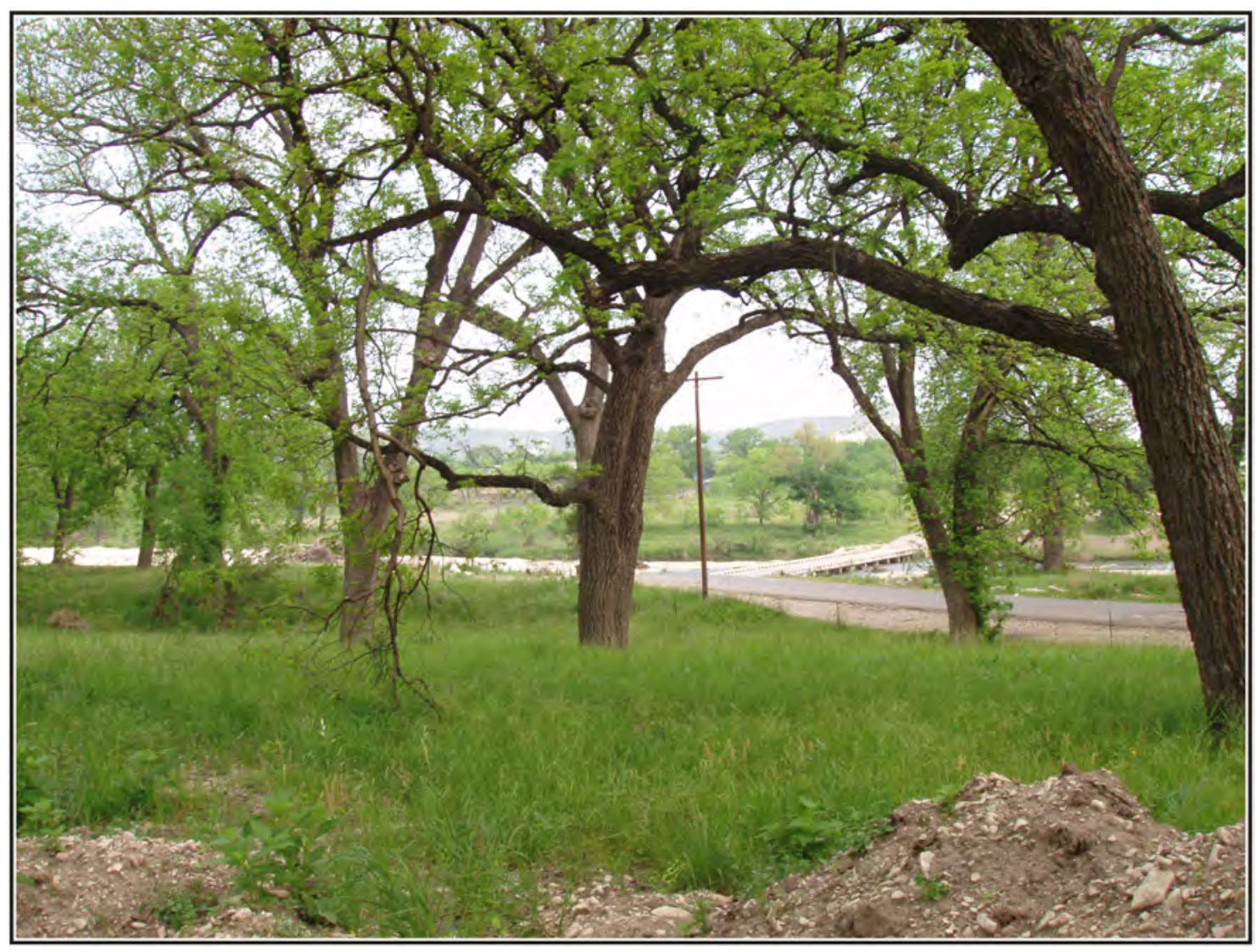

Figure 2-1. Site 41KM69 sits on the south bank of the South Llano River in Junction, Texas. 


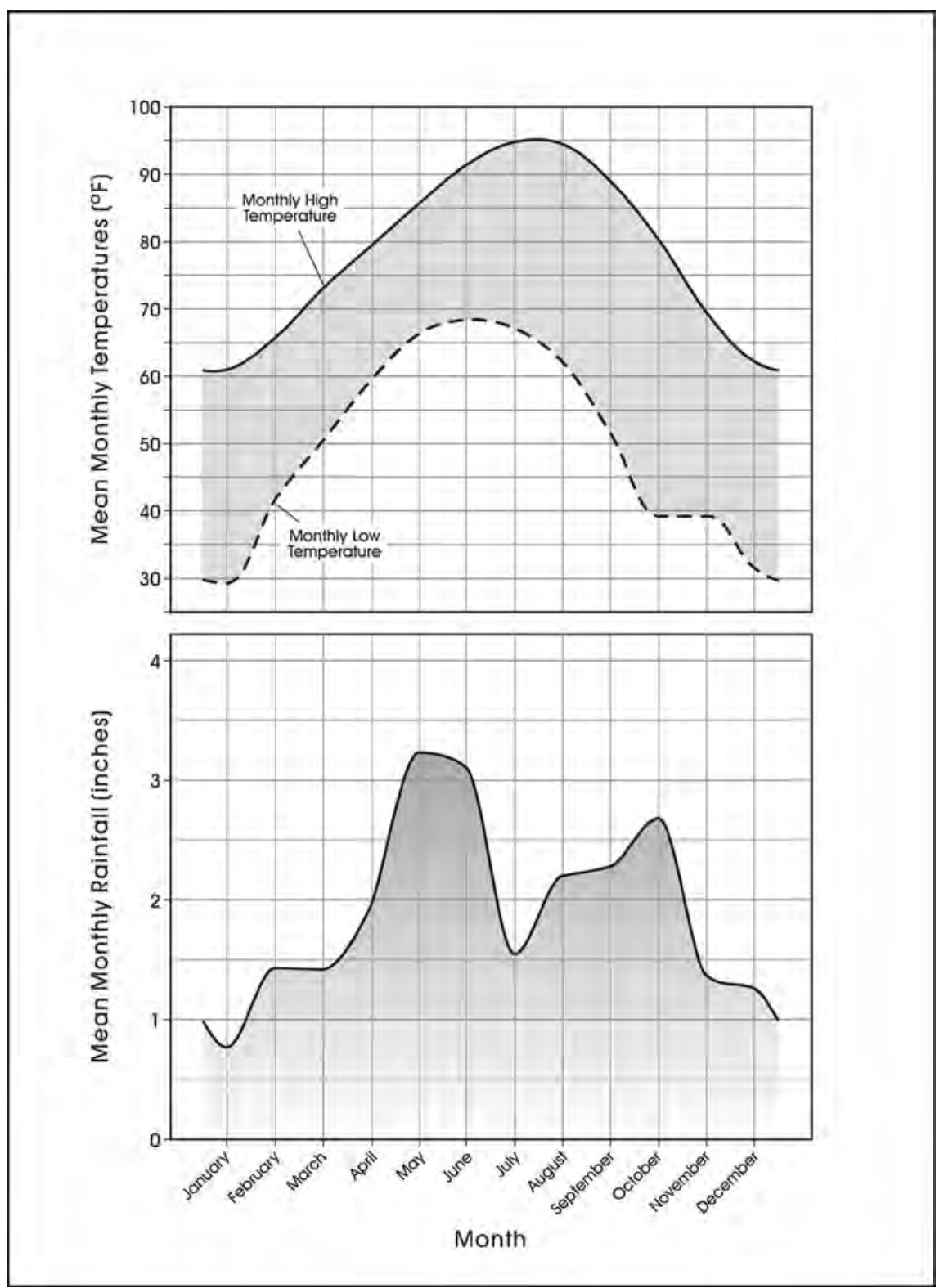

Figure 2-2. Mean monthly temperatures and mean monthly rainfall totals at Junction (1971-2000). Based on data from NCDC and NIDIS.

South-Central Texas has experienced moderate to exceptional drought conditions. Kimble County lies on the edge of the drought-stricken area of Texas (Figure 2-3). Blair (1950) reports decreased rainfall from east to west across the Balconian Province, which has a dry, subhumid eastern half and a semiarid western half.

\section{Hydrology}

The South Llano River runs north of 41KM69. Its headwaters begin about 2,300 feet above sea level in Edwards County. The river is fed by multiple springs, characteristic of the karst topography of the Edwards Plateau. In Junction, the South Llano joins the North Llano River and becomes the Llano River, which flows into Lake LBJ 100 miles to the east in Llano County. The Llano River is part of the Lake LBJ watershed, which is part of the larger Colorado River Watershed. (Figure 2-4).

\section{Geology and Soils}

The geology of the area around site 41KM69 was summarized from an examination of the Llano sheet of the Geological Atlas of Texas (Barnes 1983) on the Edwards Plateau (Figure 2-5). Most deposits are Pleistocene or Recent Holocene aged fluviatile terrace (Qt) and alluvium deposits (Qal) that con- 
tinue along the South Llano River. These deposits along with other low terrace deposits (Qf and Qc) contain chert gravels carried from upstream and from nearby chert-bearing Edwards Limestone formations. Primary sources of chert bearing deposits are locally available from the Edwards Limestone formations that sit above the stream channel. Within a day's walk $(15 \mathrm{~km})$, the local geology changes little. Edwards Limestone formations of the Lower Cretaceous (Kft and Ks) continue for miles in all directions. These deposits are more widespread and closer to the South Llano River channel upstream from 41KM69 but also continue downstream. In this direction however, the Edwards Limestone formations are separated from the streambed by expanses of Hensell Sand (Kh). Prehistoric populations in the area would have had easy access to quality Edwards Limestone cherts for tool production from both primary sources and from gravels transported downstream. Additional research on the geology of the area and the stone tool assemblage are discussed in Chapter 16.

The United States Department of Agriculture Web Soil Survey (USDA 2009) shows two soil series falling within the project boundary (Figure 2-6). The southern extent of the site falls within the Frio soil series. These are limy, grayish brown, alluvial soils that occur along floodplains. The surface layer texture is loamy to clay loam or silty clay loam and can be 25 in. thick. The deeper deposits have a finer texture and darker color. Most acreage is in pecan orchards or native pasture but can also be cultivated with corn, hay, or other grains. Site 41KM69 contains Frio clay loam 0 to 1 percent slopes (Fr).

The northern extent of the site along the river falls within the Dev, very gravelly loam, frequently flooded soils (De). The Dev unit is present on the site in the form of gravel deposits exposed in several trenches. This soil is found in bottom lands along streams. Some mapped units show gravel bars and stream channels. The soil is widely used for rangeland and not suited for crops, though it can support pecan orchards. The soil supports good wildlife habitat for deer, turkey, squirrel, quail, and dove that thrive on the woody plants, forbs, and grasses in these habitats.

The Dev and Frio are recent floodplain soils distinct from older alluvium of the Nuvalde series on the slightly higher terraces south of $41 \mathrm{KM} 69$. The site is located at the margin of older terrace sediments consisting primarily of Nuvalde clay (Blum et al. 1982).

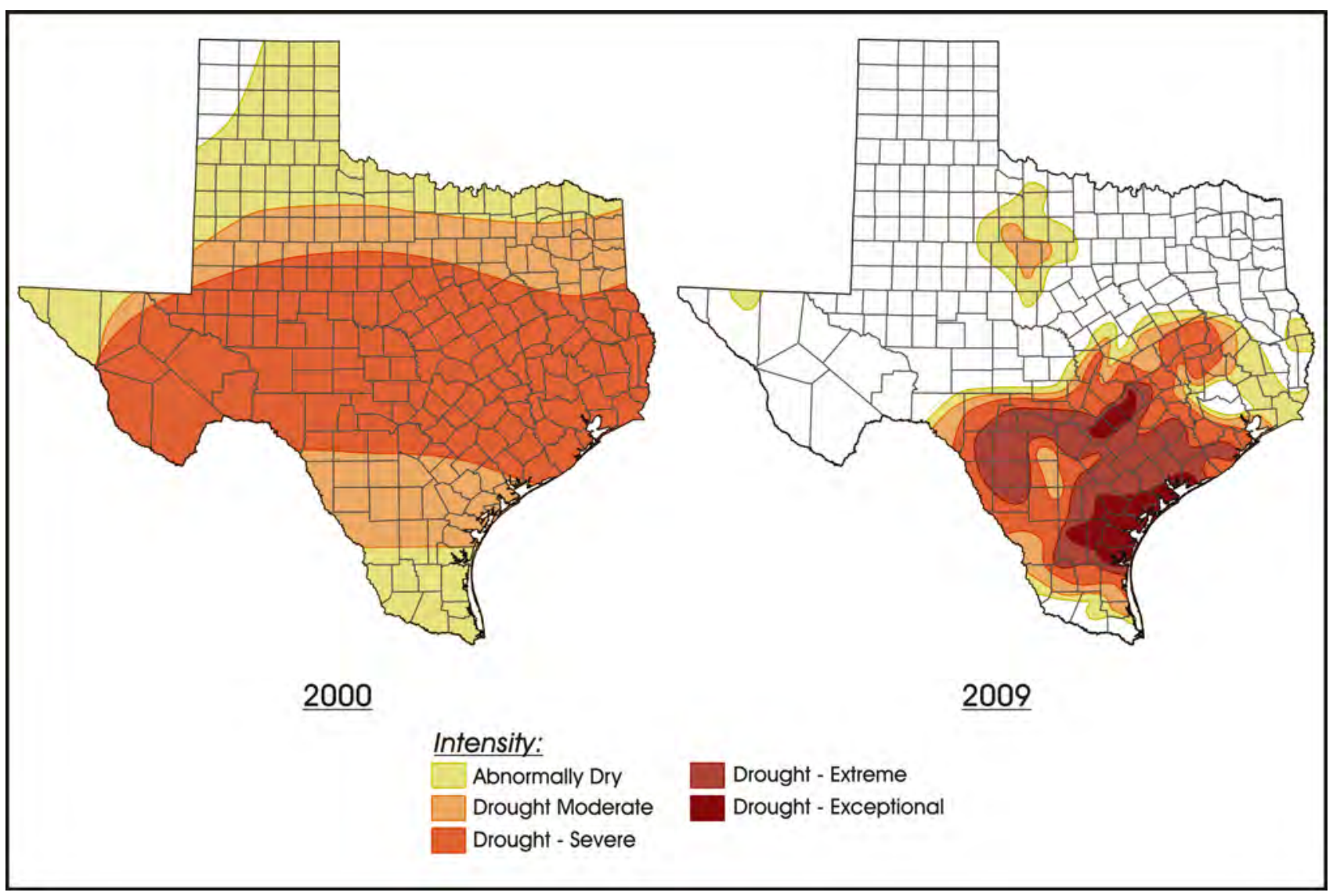

Figure 2-3. Drought maps from 2000 and 2009 adapted from NIDIS (2009). 


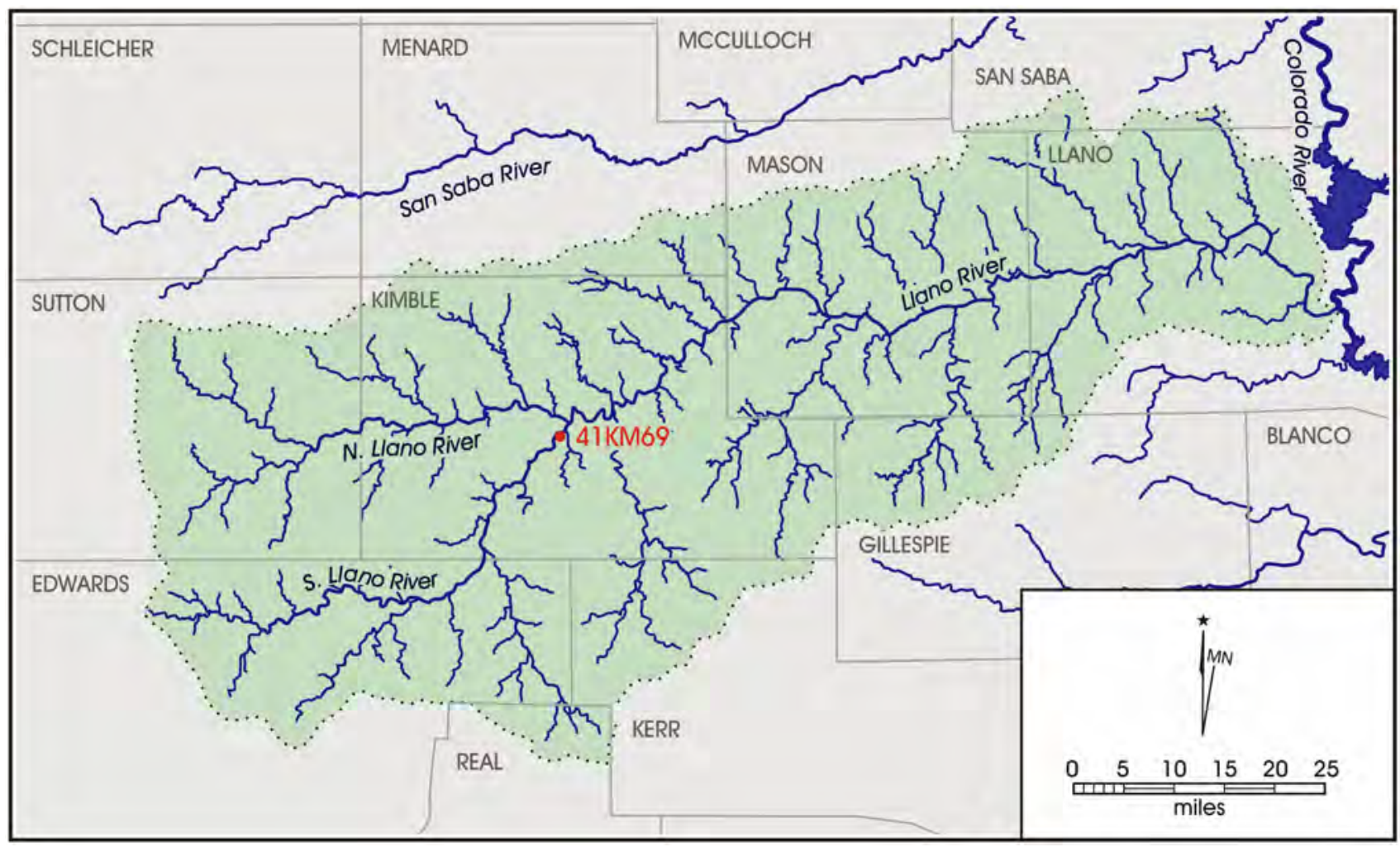

Figure 2-4. LBJ Basin watershed adapted from LCRA (2009).

\section{Floral and Faunal Resources}

The USDA Web Soil Survey also describes the plant communities found within ecosystems of the project area. The loamy bottomland plant community that corresponds to the Frio soils includes a mix of grasses, forbs, shrubs, and trees. Pecan (Carya illinioensis), live oak (Quercus virginiana), Chinkapin oak (Quercus muehlenbergii), elm (Ulmus spp.), hackberry (Celtis spp.), American sycamore (Platanus occidentalis) and baldcypress (Taxodium distichum) are common in stream bottomlands in the area. Typical shrubs found in this ecosystem are bumelia (Sideroxylon spp.), elbowbush (Forestiera pubescens), Brickellbush (Brickellia spp.), and Mexican buckeye (Ungnadia speciosa).

Supported grasses include little bluestem (Schizachyrium scoparium), Indiangrass (Sorgastrum nutans), switchgrass (Panicum virgatum), eastern gamagrass (Tripsacum dactyloides), and wildryes (Elymus spp.). Switchgrass and eastern gamagrass, along with numerous sedges (Carex spp.), spikerushes (Eleocharis spp.), flatsedges (Cyperus spp.), and brush species are common adjacent to streams. Forbs include maximilian sunflower (Helianthus maximiliani), bundleflower (Desmanthus spp.), and Engelmann's daisy (Engelmannia peristenia).

Blair (1950) reports 57 mammal species, 16 lizard species, 36 snake species, 7 newt and salamander species, 15 species of frogs and toads, and one land turtle species in the Balconian Province. The nearby South Llano River State Park and the Walter Buck Wildlife Management Area list over 150 bird species throughout the year including black-chinned hummingbirds (Archilochus alexandri) and wild turkeys (Meleagris gallopavo) that roost in the state park in winter. The riparian woodlands provide habitat for wood duck (Aix sponsa), orchard oriole (Icterus spurious), painted and indigo buntings (Passerina ciris, Passerina cyanea), blue grosbeak (Passerina caerulea), and yellow-throated vireo (Vireo flavifrons) (Texas Parks and Wildlife Department 2007). A few of the other wildlife species observed in these parks are white-tailed deer (Odocoileus virginianus), various squirrel species, jackrabbit (Lepus californicus), javelina (Tayassu tajacu), beaver (Castor canadensis), bobcat (Lynx rufus), cottontail (Sylvilagus floridanus), and armadillo (Dasypus novemcinctus). Reptiles include eastern yellowbelly racer (Coluber constric- 


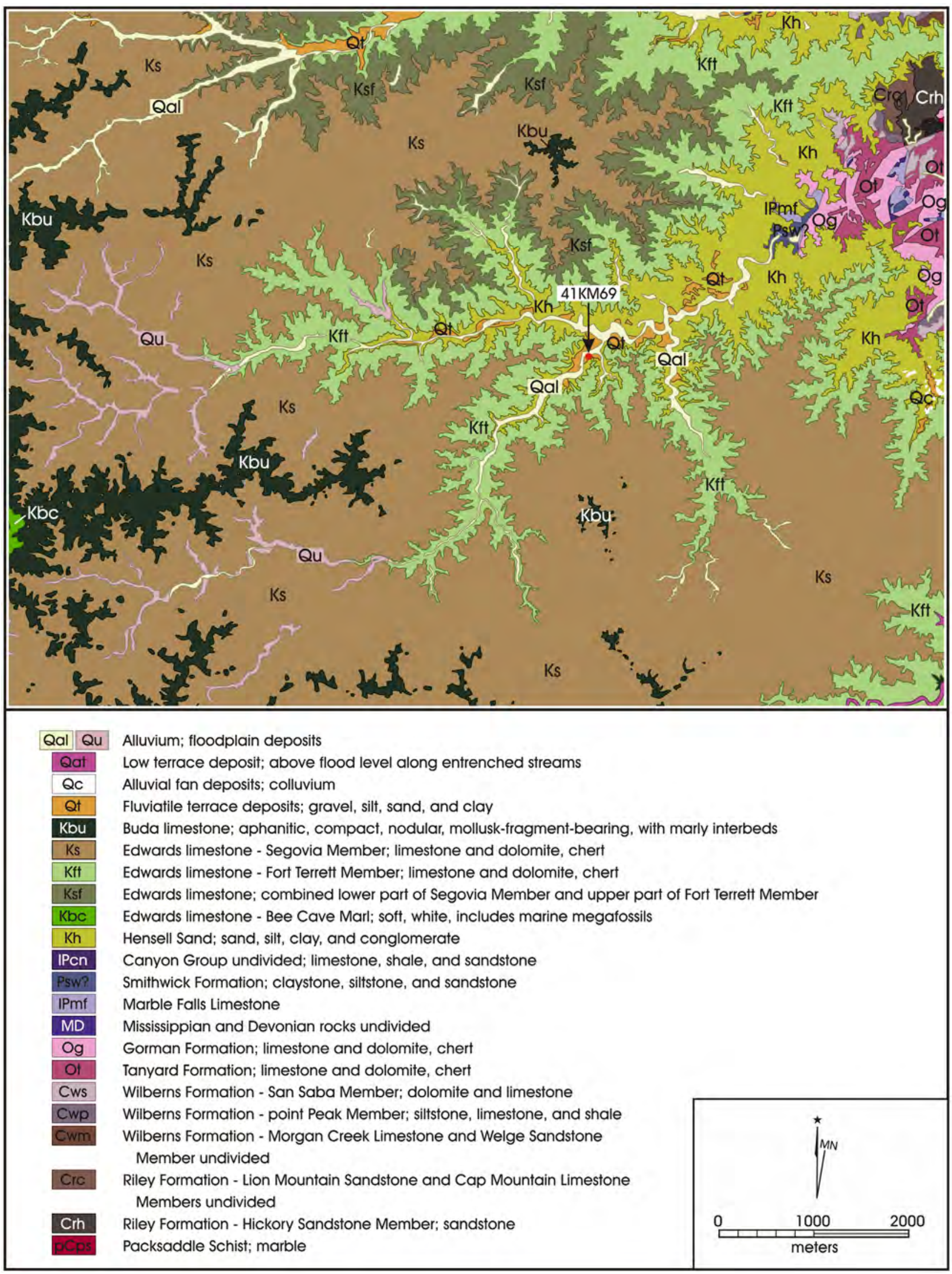

Figure 2-5. Geology of the area surrounding 41 KM69 adapted from Barnes (1983). 
tor flaviventris), western coachwhip (Masticophis flagellum testacous), and bullsnake (Pituophis catinefer sayi). Lizards such as prairie-lined racerunner (Cnemidophorus sexlineatus viridis), Texas spotted whiptail (Cnemidophorus gularis), and Texas spiny lizard (Sceloporus olivaceus) are common as well (Texas Parks and Wildlife Department 2009). Freshwater fish include channel catfish (Ictalurus punctatus), yellow catfish (Ameiurus natalis), Guadalupe bass (Micropterus treculii), spotted bass (Micropterus punctulatus), largemouth bass (Micropterus salmoides), longear sunfish (Lepomis megalotis), green sunfish (Lepomis cyanellus), redbreast sunfish (Lepomis auritus), and Rio Grande perch (Cichlasoma cyanoguttatum), and spotted gar (Lepisosteus oculatus) among many others.

\section{Paleoenvironment}

Paleoenvironment is important to this study in that the research domains in subsequent chapters are supported by a theoretical framework focused on the availability of bison as an important dietary resource and, by extension, the grasslands on which they grazed from the Late Archaic to the Late Prehistoric. This section discusses climate and drought studies across Central Texas that serve as a proxy indicator of the availability of grasslands to bison herds and bison herds to hunter-gatherers. The distribution of bison as affected by environmental factors and the implication to hunter-gatherer diet is the topic of Chapter 9 .

The first data sets come from proxy measures in climate studies using carbon isotope data from the Medina River and Hall's Cave and pollen collected from Boriack and Patschke bogs (see Bousman 1998; Camper 1991; Cooke 2005; Nickels and Mauldin 2001; Nordt et al. 2002). As outlined in the research design, these four long-term data sets may highlight large-scale patterns of vegetation shifts also affecting areas on a smaller spatial scale. Figure 2-7 presents the location of these data sets. The Medina River carbon isotopic data come from a series of buried, dated soils in southern Bexar County (Nordt et al. 2002). The Hall's Cave carbon isotope data are also on buried sediments, but from an extremely well-dated deposit in Kerr County (Cooke 2005). Boriack and Patschke bogs are located in Lee County. The Boriack arboreal pollen sequence, taken from Bousman's (1998) reanalysis of the original data, is poorly dated. The Patschke grass pollen sequence (Camper 1991), taken from a reanalysis of the original data by Nickels and Mauldin (2001), is supported by four radiocarbon dates. All the pollen sequences are quite long and were used to track changes in vegetation communities.

Figure 2-8 compares the results of the two carbon isotope data sets (Median River; Hall's Cave), Bousman's (1998) estimates of shifts in canopy cover based on Boriack and Weak- ly bog pollen, and grass pollen from Patschke bog (Camper 1991; Nickels and Mauldin 2001) over the last 10,000 years. Comparisons of the patterns suggest some regional variability encompassed by similar overall trends. The two carbon isotope data sets differ slightly, with the Medina River sequence showing an increase in $\mathrm{C}_{4}$ grass at the start of the Late Archaic and a decline in $\mathrm{C}_{4}$ grass at the close of the Late Archaic. That decline accelerates near the end of the Late Prehistoric Period. The well-dated Hall's Cave sequence shows a slight decrease in $\mathrm{C}_{4}$ in the early portion of the Late Archaic, with an increase of $\mathrm{C}_{4}$ at around 3000 B.P. A sharp decline is then present into the Late Prehistoric period. Interestingly, both sequences show a decline in $\mathrm{C}_{4}$ late in time with the decline initiated at about 1200 B.P. in the Medina River area,and at about 2000 B.P. in the Hall's Cave sequence.

Data from the two pollen based sequences suggest slightly more variability than the carbon isotope data sets (see Figure 2-8). The poorly dated Boriak/Weakley bog sequences suggest a decline in grassland after about 5000 B.P., a decline that is accelerated in the Late Prehistoric. Conversely, the Patschke pollen data suggest an increase in grass pollen and, by extension, grasslands, which reach a peak at around 3,400 years ago. Grass pollen percentages then begin a slow, though variable, decline. That decline accelerates after 1000 B.P. Overall, the long-term data sets in Figure 2-8 suggest extensive $\mathrm{C}_{4}$ grasslands were present during most of the Late Archaic within much of Central and South Texas. Grasslands seemed to be at their peak in the early portion of the Late Archaic in most sequences, and then began a slow, gradual decline until the close of that period. The data sets in Figure 2-8 suggest that a different pattern, one of rapidly declining grasslands, is characteristic of at least the last 1,000 years, including much of the historic period.

\section{Tree-Ring Based Summer Palmer Drought Severity Indices}

The data sets discussed above reflect shifts in vegetation communities that probably occur because of regional changes in climate with a temporal scale of several hundred years. The large temporal scales at which these vegetation changes operate do not document the small-scale climate fluctuations in rainfall that would produce variable forage production and potentially influence short-term responses in bison populations. Recently Cook and Krusic (2004) have compiled treering based summer Palmer Drought Severity Indices (PDSI) for much of North America. We use these data to provide a high-resolution look at climate variability in the Central and South Texas region.

The Palmer Index, developed in the early 1960s as a way to quantify drought (Palmer 1965), is a relative measure of soil moisture. Several factors, including temperature, rain- 


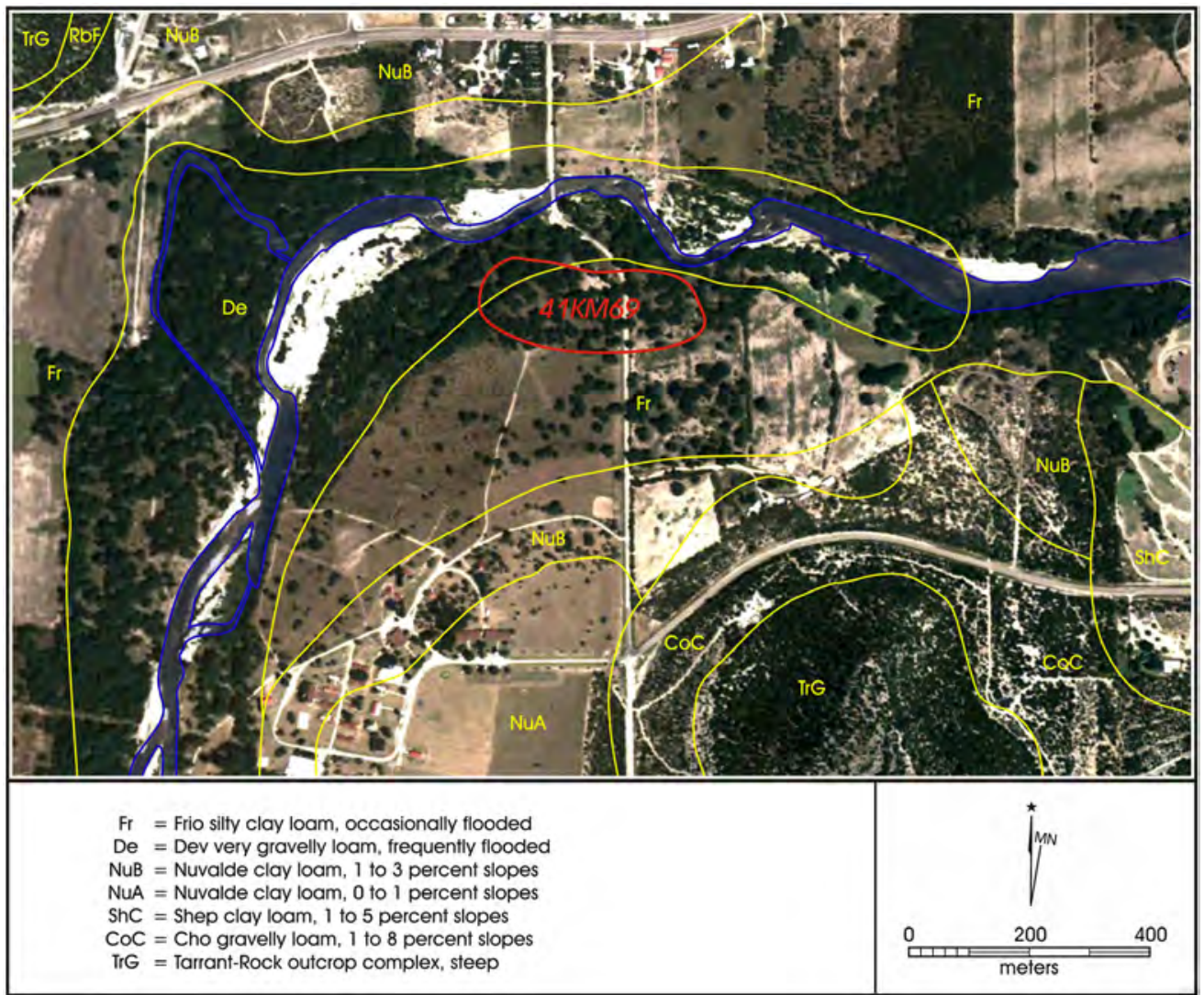

Figure 2-6. Soil map adapted from USDA (2009) showing two soil types within the project area site boundary.

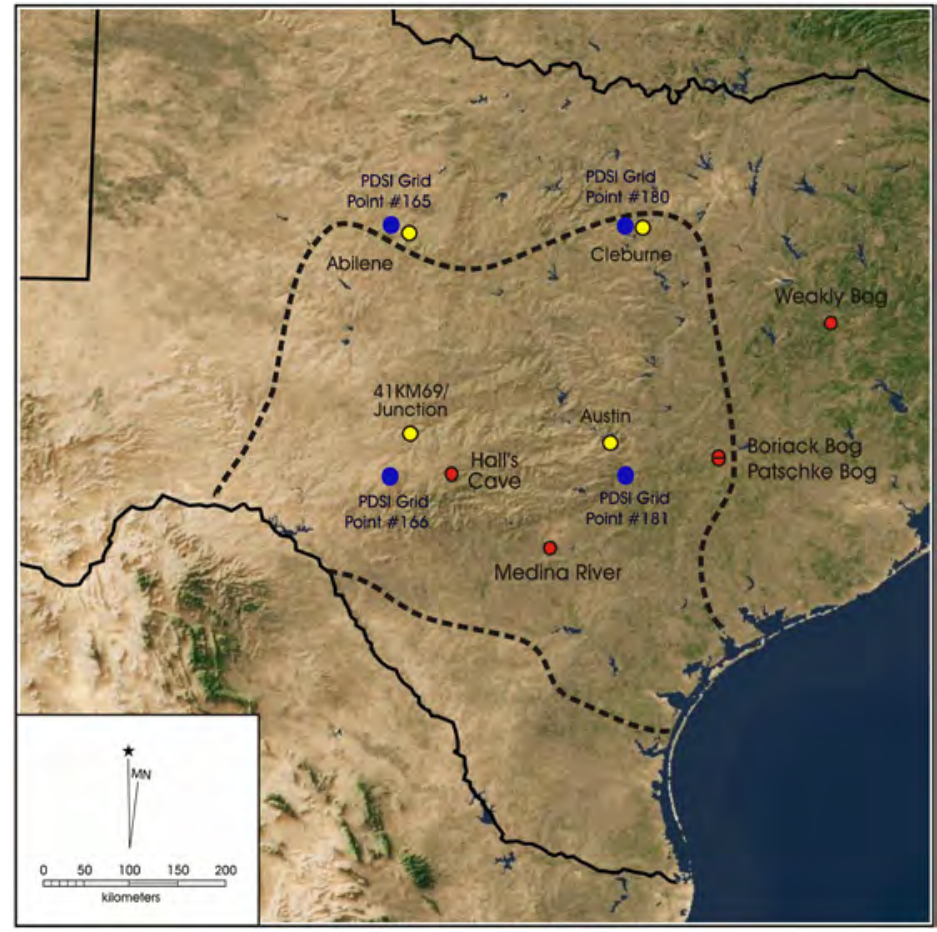

Figure 2-7. Location of long term data points (red), short term PDSI points (blue), and modern weather stations (yellow). 
fall, potential evaporation, transpiration, soil, and runoff are used in calculating the index (see Alley 1984; Karl 1986). While higher and lower values are possible, the index generally ranges from four (extreme wet spell) to a negative four (extreme drought), with a normal period designated as zero. Cook and Krusic (2004; see also Cook et al. 1999) developed the summer PDSI database used here from tree-rings using a point-by-point regression method. The PDSI datasets provide high-resolution information on drought at short temporal scales. These data are of less use in monitoring longterm shifts in climate such as those that probably produced the vegetation shifts shown previously in Figure 2-8. This is because directional variability in the underlying tree-ring sequences are standardized. The process of standardization of tree-ring widths involves adjustments for directional changes in widths in order to correct for possible compression of inner rings during normal tree growth (see Dean 1988:133-135; Fritz 1991:12, 1976:267-268). It is these directional changes, changes that the standardization technique minimizes. Nevertheless, when used in combination with the long-term vegetation shifts suggested previously, the summer PDSI values can provide a detailed picture of variability in forage production and, by extension, bison availability.

The investigation of PDSI values focuses on grid points 180, 181, 165, and 166 (see Cook and Krusic 2004). These grid points provide PDSI values for the last 2,000 years. Figure 2-7 shows the locations of these data points, along with the locations of four modern weather stations that are within close proximity. In order to assess the relationships between PDSI values and precipitation, we constructed bivariate plots of annual rainfall and PDSI values from 1900 through 2003. All scatter plots were positive in slope, with no significant outliers. Table 2-1 presents Pearson's correlation coefficients for these four comparisons. All relation-

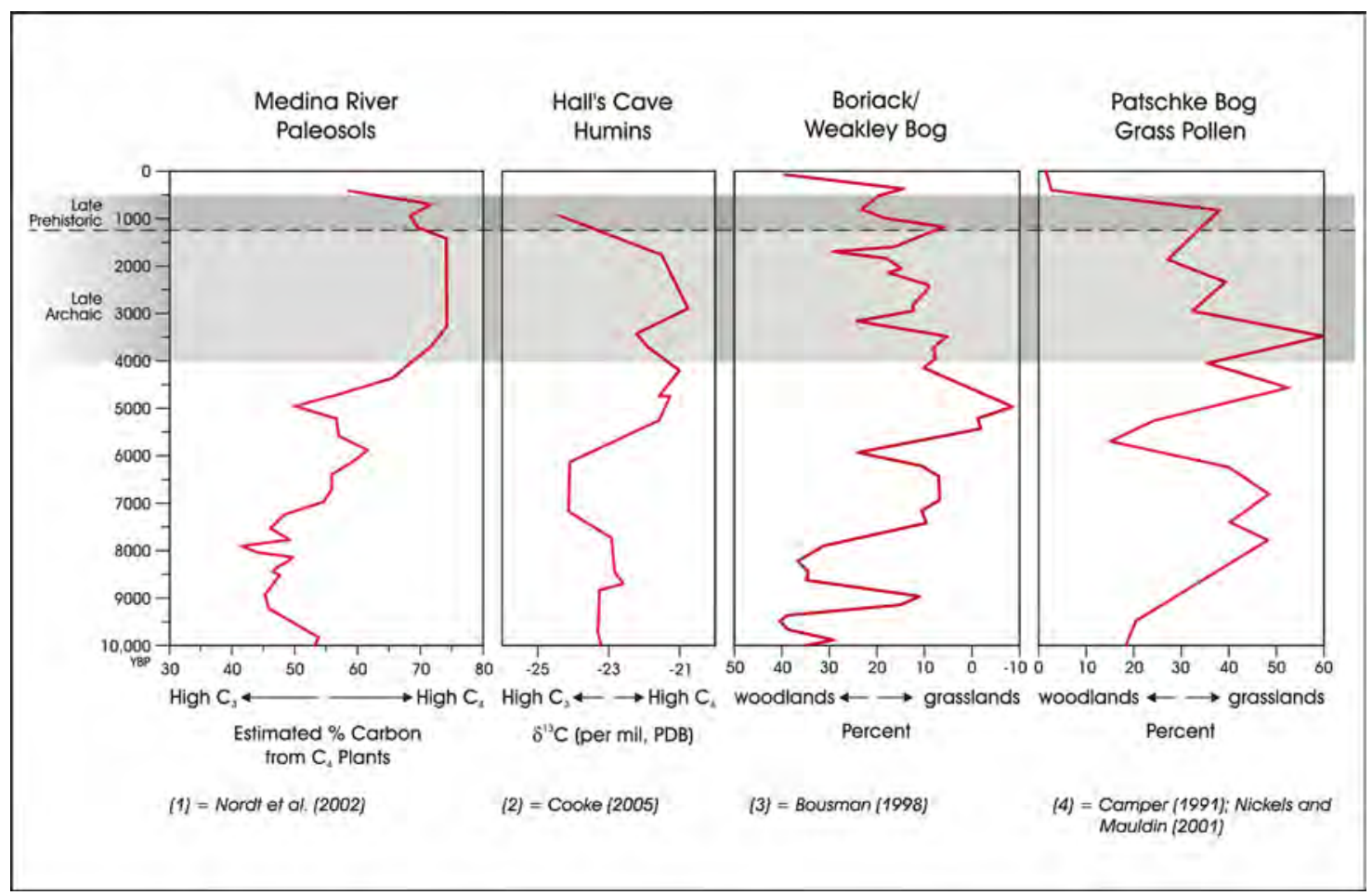

Figure 2-8. Comparison of four long-term paleoclimate sequences.

Table 2-1. Correlation Coefficient for PDSI Values and Yearly Rainfall, 1900-2003

\begin{tabular}{|c|c|c|c|c|}
\hline Station & PDSI Grid & Pearson's R & \# of Years & Significance \\
\hline Austin & 181 & 0.57 & 104 & $\mathrm{P}<0.01$ \\
\hline Cleburne & 180 & 0.5 & 88 & $\mathrm{P}<0.01$ \\
\hline Abilene & 165 & 0.42 & 104 & $\mathrm{P}<0.01$ \\
\hline Junction & 166 & 0.45 & 81 & $\mathrm{P}<0.01$ \\
\hline
\end{tabular}


ships are positive and significant beyond the .01 level. At least for the last century, a moderately strong relationship exists between annual precipitation and PDSI values within the Central and South Texas regions.

Figure 2-9 presents the mean PDSI values for 25-year groups from A.D. 1000 to 2000 for each of the four data sets. Also provided is an insert showing the locations of the four treering cores. Values that fall below the zero line are associated with relatively low soil moisture and, by extension, low rainfall, while positive PDSI values are associated with 25-year periods that had higher soil moisture. Examination of the line graph (Figure 2-9) shows that when grouped at 25-year segments, all four sequences show good correspondence. Table 2-2 provides summary information for each of the four sequences. Between the beginning of the sequences at A.D. 1000 and the end of the Initial Late Prehistoric (A.D. 1250), all four sequences are below average (Figure 2-9; Table 2-2). This period of below average rainfall is exaggerated in the two eastern sequences $(180,181)$.

During the Terminal Late Prehistoric (A.D. 1250- 1550), all four sequences improve, though the PDSI values in three of the four sequences are still negative, suggesting below aver-

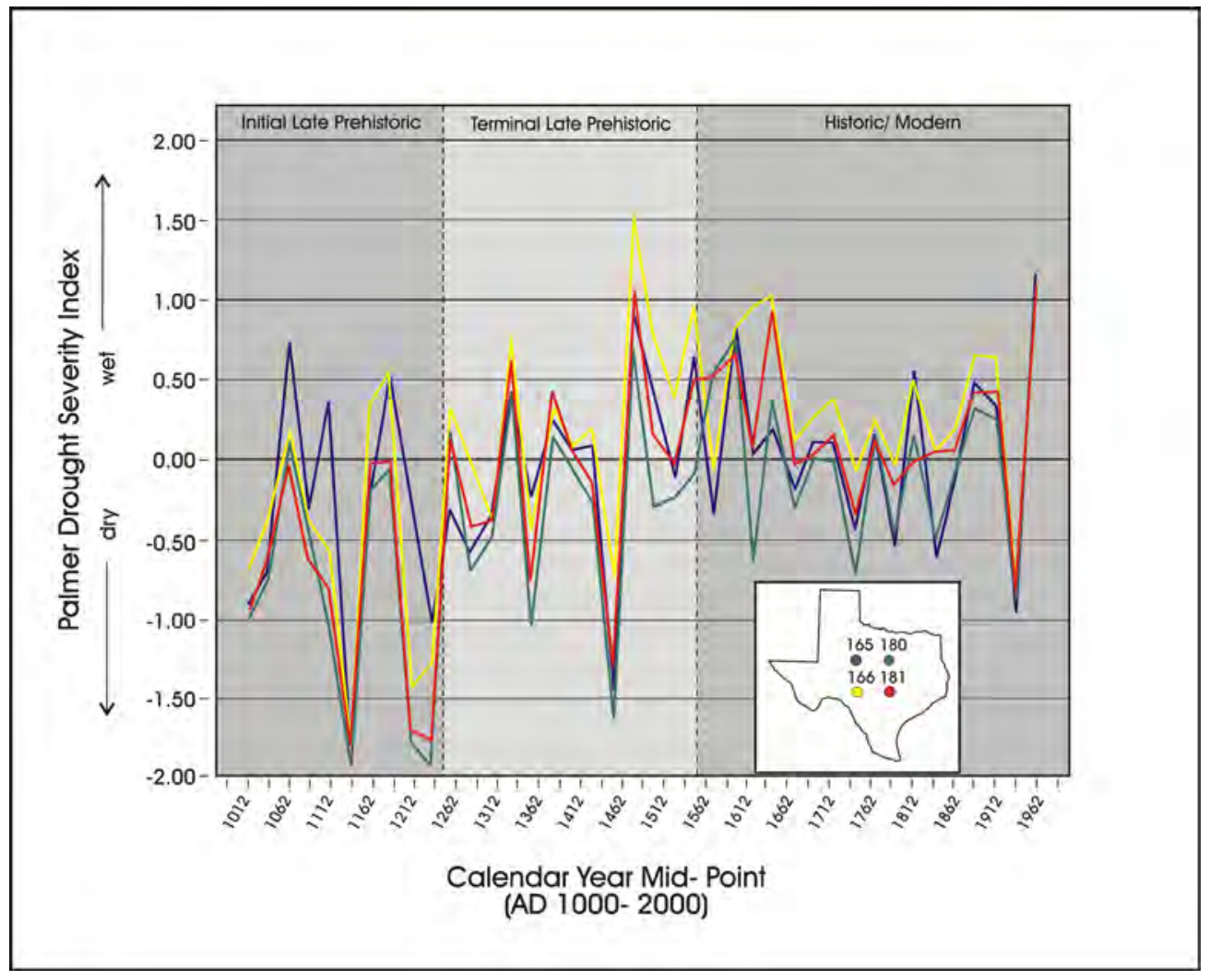

Figure 2-9. Mean PDSI values from grid points 165, 166, 180, and 181 grouped at 25 years A.D. 1000-2000 (data from Cook and Krusic 2004).

Table 2-2. Summary Information on PDSI Values, Figure 2-9

\begin{tabular}{|c|c|c|c|c|c|c|}
\hline PDSI Grid & \multicolumn{2}{|c|}{ Initial Late Prehistoric } & \multicolumn{2}{|c|}{ Terminal Late Prehistoric } & \multicolumn{2}{|c|}{ Historic/Modern Era } \\
\hline Point & PDSI Average & $\begin{array}{c}\text { 25 Year } \\
\text { Groupings } \\
\text { Below Average }\end{array}$ & PDSI Average & $\begin{array}{c}\text { 25 Year } \\
\text { Groupings } \\
\text { Below } \\
\text { Average }\end{array}$ & $\begin{array}{c}\text { PDSI } \\
\text { Average }\end{array}$ & $\begin{array}{c}\text { 25 Year } \\
\text { Groupings } \\
\text { Below Average }\end{array}$ \\
\hline 180 & -0.92 & $90 \%$ & -0.28 & $66 \%$ & -0.04 & $55 \%$ \\
\hline 181 & -0.84 & $100 \%$ & -0.05 & $55 \%$ & 0.19 & $28 \%$ \\
\hline 165 & -0.37 & $70 \%$ & -0.07 & $50 \%$ & 0.07 & $39 \%$ \\
\hline 166 & -0.53 & $70 \%$ & 0.22 & $33 \%$ & 0.37 & $22 \%$ \\
\hline
\end{tabular}


age rainfall (Figure 2-9; Table 2-2). Finally, there is a dramatic increase in PDSI values for all four stations between A.D. 1550 and 2000. Three of the four sequences average positive PDSI values during this period.

Increased PDSI values at each grid point are, over the last 100 years, associated with increased rainfall at that grid point (Table 2-1). While we lack data on grassland productivity associated with each location, it is the case that at a general level, grassland production increases as rainfall increases (e.g., see Chapter 9). The Figure 2-9 data probably reflect relatively localized productivity in grasslands. If this is the case, during the Initial Late Prehistoric, grassland production across the region was relatively low. Productivity increased slightly in the Terminal Late Prehistoric, and during the Historic/Modern era, production was significantly higher. This picture of production is at odds, at least to some degree, with that developed from the long-term data sets in Figure 2-8. Those data suggest a gradual, though fluctuating, decline in the overall extent of grasslands during the Late Prehistoric and into the Historic/Modern era. Recall, however, that the short-term, tree-ring based data sets that are represented in
Figure 2-9 are not designed to monitor long-term shifts in climate as the standardization removes much of the longterm climate signals in those data. Conversely, the data sets used to construct Figure 2-9 operate at long temporal scales, and in several cases, these data sets are not well dated. While additional research on these issues is certainly necessary, it is clear that both data sets suggest that during the Late Prehistoric, grassland production throughout the region was below the long-term average. While we lack short-term data for the Late Archaic Period, this low production during the Late Prehistoric should have resulted in reduced forage for bison populations.

Figure 2-10 uses the PDSI data for each of the four grid points in a way that is designed to measure variability in rainfall and, by extension, grass production. During a given 25-year period, we computed the absolute difference between PDSI scores for consecutive years. For example, in A.D. 1000, a PDSI of -2.283 was present in PDSI sequence at grid point 181 (see Figure 2-7). The following year, the PDSI value was 1.542 , producing an absolute difference of 3.825 between

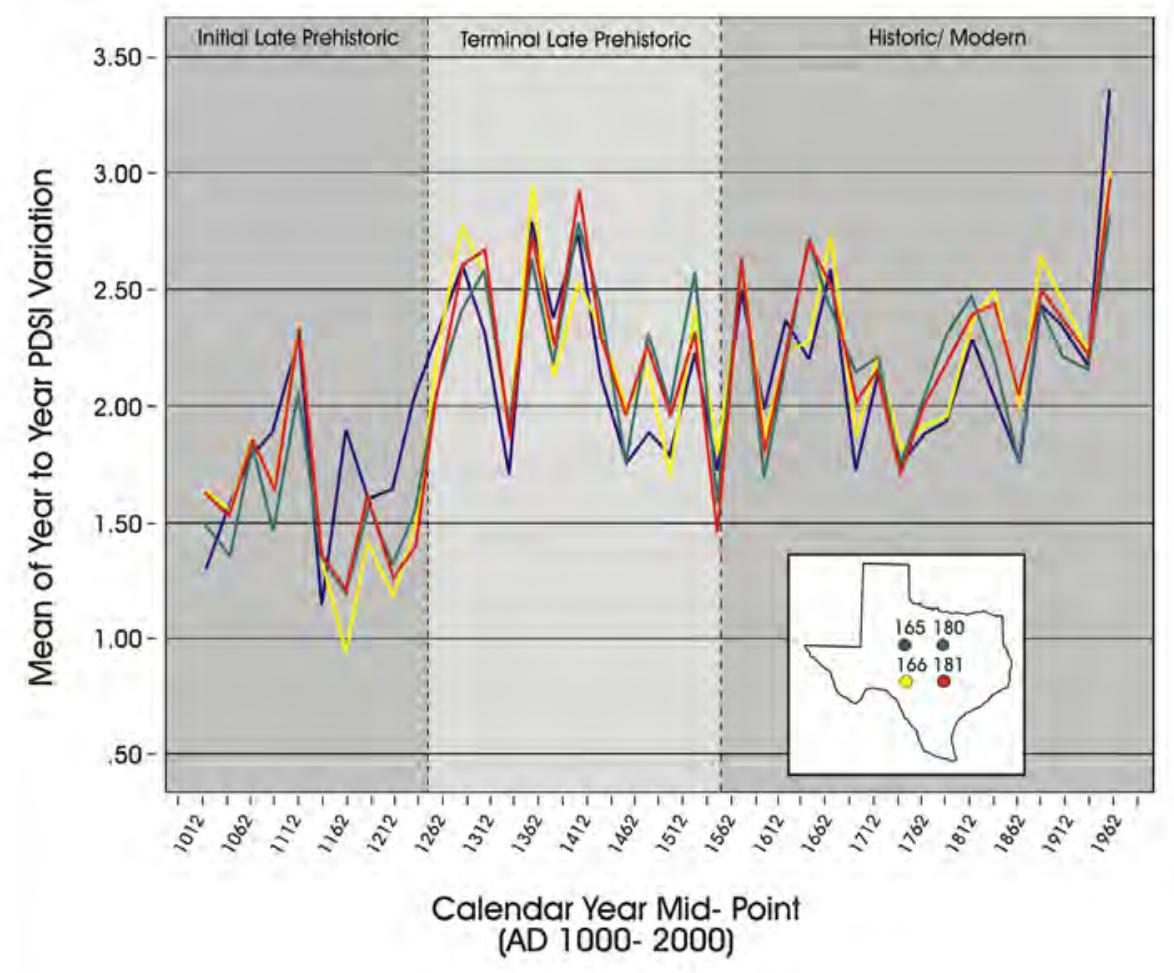

Figure 2-10. Summary at 25-year intervals of year to year variation in PDSI values A.D. 1000-2000 for grid points 165, 166, 180, and 181 (based on data in Cook and Krusic 2004). 
Table 2-3. Summary Information on PDSI Variability at 25-Year Segments, Figure 2-10

\begin{tabular}{|c|c|c|c|}
\hline PDSI Grid & Initial Late Prehistoric & Terminal Late Prehistoric & Historic/Modern Era \\
\hline \multirow{2}{*}{ Point } & Absolute Difference & Absolute Difference & Absolute Difference \\
\hline 180 & 1.52 & 2.3 & 2.19 \\
\hline 181 & 1.59 & 2.33 & 2.24 \\
\hline 165 & 1.72 & 2.21 & 2.17 \\
\hline 166 & 1.55 & 2.3 & 2.25 \\
\hline
\end{tabular}

these two years. We performed similar calculations for all years for each sequence, and summarized absolute differences at 25-year intervals. Figure 2-10 plots these 25-year segment averages for the 2,000-year period. Higher mean values are associated with periods of high variability in PDSI values and, by extension, high variability in rainfall. As with Figure 2-9, all four sequences show good agreement. Overall, the average difference in PDSI values from one year to the next for all four sequences is 2.08 (see Figure 2-10). Table 2-3 provides summary statistics for the Figure 2-10 sequences.

During the latter portion of the Initial Late Prehistoric (A.D. 1000-1250), variability in PDSI was extremely low in all four sequences (Figure 2-10; Table 2-3). For this 250-year period, the average between-year difference was between 1.52 (grid point 180), and 1.72 (grid point 165), well below the mean value of 2.08 for all sequences. In the subsequent 300 years that correspond to the Terminal Late Archaic (A.D. 12501550 ), between year differences in PDSI values increase substantially (Figure 2-10; Table 2-3), with all being in excess of 2.21. These increases during the Terminal Late Prehistoric represent a substantial jump in variability over the preceding period. The higher than average year-to-year fluctuations in climate variables continues throughout the subsequent 450 years, though for any one sequence, at no time was the variation as great as during the Terminal Late Prehistoric. The Figure 2-10 data, then, suggest that there was substantial variation in yearly PDSI values, rainfall, and resulting grass production during the Terminal Late Prehistoric. That variability should have resulted in higher levels of bison mobil- ity during some years, and possibly smaller herd sizes, while during other periods, bison would be clustered and their mobility reduced.

\section{Paleoenvironment Summary}

Using several long-term data sets from different regions of Central and South Texas, we suggest that during the Late Archaic grasslands declined slightly, with an accelerated decline at the close of the Late Archaic and through the Late Prehistoric and Historic Periods. These declines should have resulted in restricted areas of forage for bison. Tree-ring based PDSI values provide a short-term perspective on variability in forage production. These data suggest that grassland productivity was consistently low for several hundred years corresponding to the close of the Initial Late Prehistoric Period. While productivity increases slightly during the subsequent Terminal Late Prehistoric, it was still below average at three of the four locations considered, and the data suggest a dramatic increase in short term fluctuations accompanying the increased productivity. The increased fluctuations in productivity, which were at their highest during the Terminal Late Prehistoric, would have produced dramatic differences in forage quantity and quality over a given 25 -year period. Those differences should have resulted in significant fluctuations in levels of mobility in bison, and possibly variation in herd size. Such effects on bison herds should have influenced hunter-gatherer mobility and diet, which is discussed in the theoretical and analytical chapters of this volume. 



\title{
Chapter 3: Previous Research and Archeological Background
}

\author{
Jennifer L. Thompson
}

This chapter describes the known archeological record at 41KM69 and the surrounding area. A summary of the cultural history of Central Texas is presented followed by a short description of nearby sites.

\section{Cultural Chronology}

Subsistence practices in prehistoric Central Texas differed from surrounding areas in that hunting and gathering never gave way to agriculture as it did in the Southwest and Southeastern US culture areas. Not surprising, the most common artifacts found on sites in Central Texas are stone tools and debitage from stone tool production. Most sites lack ceramics, which are often used as indicators of discrete cultures, geographic locales, and time periods for more sedentary cultures. Ceramics that are found on Texas sites appear relatively late in time, at the end of the Late Prehistoric Period. Therefore, the usual cultural chronology framework of Texas archeology rests on these stone tools, their changing form, and their geographic distribution, which is tenuous and often clouded by overlapping "temporally diagnostic" forms of different time periods. While cultural chronologies can differ regionally, they all typically use projectile point forms to mark cultural shifts across the same broad expanses of time: the Paleoindian Period, the Archaic Period, and the Late Prehistoric Period. This chapter briefly describes the portion of the Central Texas cultural sequence that relates to 41KM69, specifically the Late Archaic through the Late Prehistoric Periods.

41KM69 sits on the Edwards Plateau in Central Texas. Much has been written about Central Texas archeology, although a discrete geographical archeological area defining Central Texas has not been consistently used in the literature. We use Prewitt's (1981) map of a Central Texas archeological area as others have and draw from chronologies by Collins (1995) and Johnson and Goode (1994).

\section{Late Archaic}

The Late Archaic in Central Texas spans roughly from 4000 to 1300 B.P. This extremely long period of prehistory has been divided differently by several authors. Those often cited include Prewitt (1981) whose chronology included the Uvalde Phase, identified by
Castroville, Marcos and Montell projectile points, the Twin Sisters Phase, which included Ensor point forms, and the Driftwood Phase marked by Darl point forms. Collins (1995) divided the period into six intervals by projectile point form.

Johnson and Goode (1994) divided the period at 2500 B.P. into Late Archaic I and Late Archaic II subperiods. Projectile point types found at Late Archaic I components include dart point styles such as Pedernales, Marshall, Montell, Castroville, while Marcos, Frio, Ensor, and Darl belong to the Late Archaic II. Other Late Archaic-aged material types include corner-tanged knives and stone pipes (Collins 1995).

Some believe population growth, increased territoriality, and warfare occurred during the Late Archaic as evidenced by the increase in number of cemeteries and number and size of sites. Large cemetery sites have been discovered along the escarpment forming the eastern edge of the Edwards Plateau. Cemeteries on the Plateau to the west are in sinkholes and rock shelters (Weir 1976; Prewitt 1981). Arnn (2007) uses the same evidence to suggest Late Archaic groups in Texas were settling down into smaller territories because stable ecological conditions allowed for a more stable array of dietary resources at the local level. If dietary resources were widely available such that long-range hunting and foraging forays were not necessary, groups could decrease the size of their hunting ranges from those in previous periods. Site size, in general (cemeteries, residential, logistical, etc.) then, grew not because of greater populations but because of longer or more frequent occupation by the same groups.

Though hunting remains an important source of food throughout the entire prehistoric sequence of Texas, the increased abundance of burned rock middens from the Middle Archaic Period on seems to indicate an increased reliance on plants in the Late Archaic because some believe that the middens are large earth ovens used for bulk processing of geophytes which require long-term cooking for human consumption (Mauldin et al. 2003). This may have been a response to decreasing grasslands and less reliable bison availability during the close of the Late Archaic.

Late Archaic sites used in this study include components that correspond to Johnson and Goode's (1994) Late 
Archaic II period, reported here as the Middle Late Archaic (2500-1650 B.P.) and the Terminal Late Archaic (2500-1600 B.P.). Examples of site with Late Archaic occupations used in this research are, from the middle of the Late Archaic (2500-1650 B.P.), 41KR537, 41ME29, 41TG91, 41BX1032, 41CM211, 41RN3, and 41UV60. Sites 41BN33, 41CN19, 41CN95, 41BT6, 41KM16, 41MK27, and 41UV60 date to the Terminal Late Archaic (1600-1250 B.P.) (Figure 3-1).

\section{Late Prehistoric}

The Late Prehistoric Period follows the Late Archaic with the adoption of the bow and arrow around 1300 B.P. and continues until approximately $300-400$ B.P. The period is further divided into two smaller units, the Austin and the Toyah intervals.

The Austin interval describes a material culture first recorded in the archeological record approximately 1,300 years ago and is marked by the use of the bow and arrow with the Scallorn arrow point predominating and a decline in the use of the atlatl. The lithic assemblage differs from the later Toyah interval in that it is characterized by bifacial reduction technology rather that blade technology. The artifact assemblages in this interval generally do not contain ceramics (but see Arnn 2007) and generally do not contain bison remains. The subsistence strategy was likely broad-based hunting and gathering of a variety of resources. Austin components often underlay or are mixed with Toyah components. Many Austin interval sites are cemetery sites, a pattern that has been used to argue for increased territoriality and warfare during the interval. There is continued reuse of Late Archaic sites including burned rock middens. Noncemetery sites that have been excavated are 41HY209-T, 41MM341, 41BT105, 41LL419, 41 WM130, 41WM1010, and $41 \mathrm{UV} 86$.

At Mustang Branch (41HY209-T), Ricklis reported one discrete Austin interval component dating to the end of the period at 700 B.P. (Ricklis 1994a:191). The majority of the recovered artifacts were stone tools and debitage with one engraved bone artifact although the assemblage is not large. The dearth of artifacts suggests the site was not occupied for a long period.

The Heard Schoolhouse site (41UV86) is a multicomponent site with an Austin interval burned rock midden. Both animal and plant remains typical of earth oven cooking, such as sotol bulbs, were found in the midden fill. The most numerous projectile point forms recovered were Sabinal arrow points, which outnumbered Scallorn

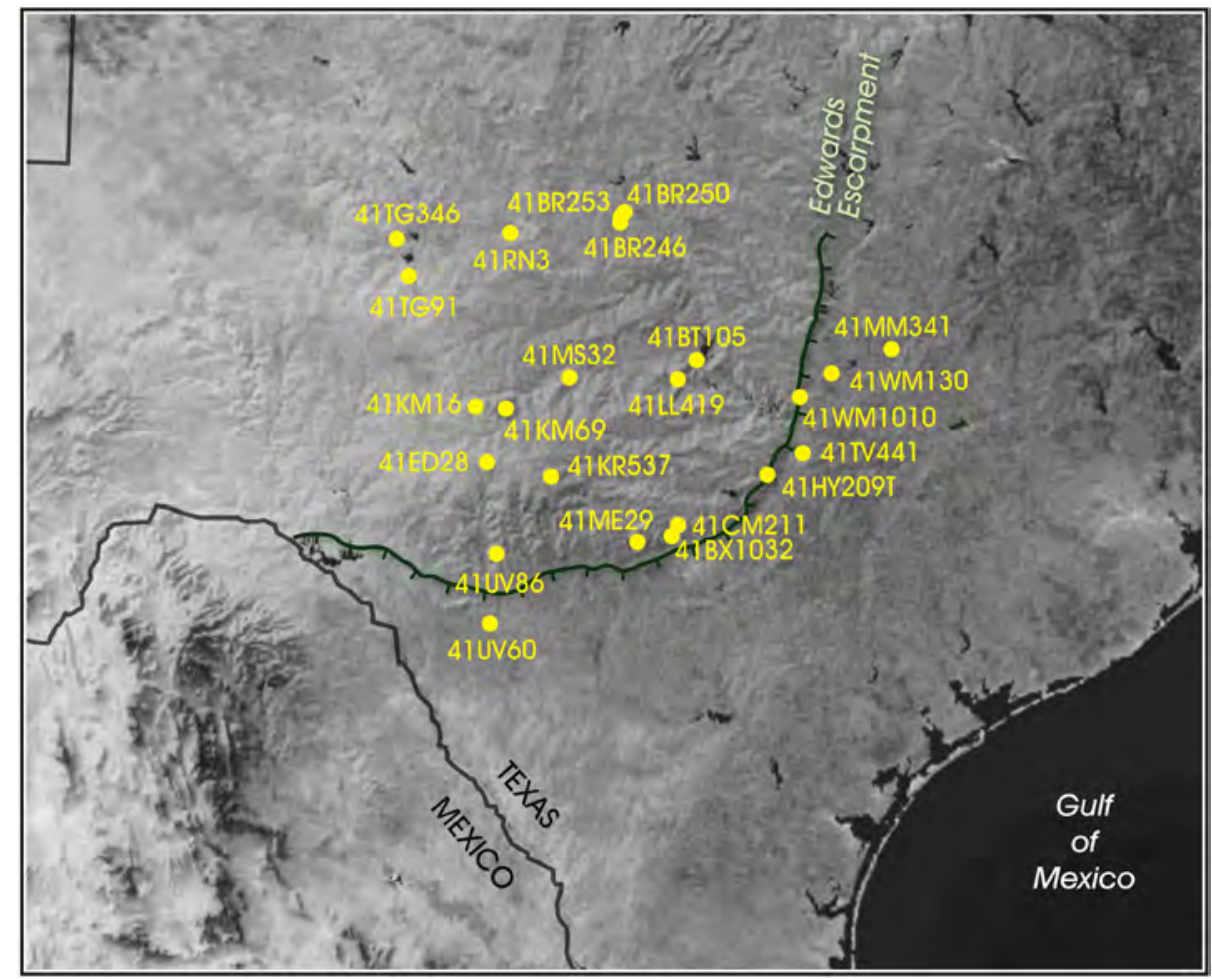

Figure 3-1. Sites discussed in the chapter and used for comparative studies in this report. 
points and the Edwards arrow points and suggested to the authors that the site saw greater use during the end of the Austin interval (Creel and Goode 1997:233). The lithic assemblage found outside the burned rock midden indicates activities other than cooking were carried out there. The high densities of debitage, bifaces, recycled dart points, and projectile points may indicate the site was used for arrow point production activities (Black and Creel 1997:291).

The Toyah interval is a distinct material culture identified in Central and South Texas often thought to represent a people focused on bison procurement. Sites have been excavated on, off and bordering the Edwards Plateau and all share similar artifact assemblages. This includes plain, bone tempered earthenware ceramics, Perdiz arrow points, and lithic tools such as large scrapers and the widespread use of blade technology (Ricklis 1994b). This tool assemblage along with dense bone deposits of bison, antelope and deer sometimes found at Toyah sites have been used to suggest that subsistence changed from broad-spectrum hunting and gathering to a focus on big game hunting of bison (Ricklis and Collins 1994b). Others find that while these groups were likely highly mobile and targeted bison when available, they likely also incorporated other resources (Dering 2008; Johnson 1994; Mauldin et al. 2003). Whether these "bison processing tools" were created as a response to an influx of bison herds or as a response to intensification of smaller bison herds, there is little debate on the importance of bison to any prehistoric diet, but other food sources had important contributions as well.

Though bison were no doubt an important part of the diet during the Toyah interval, hunting and gathering of other species continued. Dering (2008:61-62) summarizes a long list of plant resources from Toyah-aged components including fruits (Texas persimmon, grape), nuts (walnut, hickory, pecan, acorn), woody legumes (mesquite), seeds (cheno-ams, sunflower), geophytes (onions, camus bulbs), cacti (prickly pear) and arid-adapted evergreen rosettes (agaves and sotol). Remains of animals besides bison that have been found on Toyah-aged components include fish, waterfowl, pronghorn, deer, birds, amphibians, mollusks, turtles and rabbits. Burned rock features are common at Toyah sites, though large burned rock middens are not as common as they were in previous centuries. However, three Toyah sites at Camp Bowie (41BR246, 41BR250, and 41BR253) contained large burned rock middens with high numbers of geophyte plant remains and low numbers of faunal remains that include a range of species from bison to rodent-sized mammals (Mauldin et al. 2003).
The Honey Creek site (41MS32) also contained a large burned rock midden with Toyah interval materials along with other feature types (Black et al. 1997) though the site lacks a discrete Toyah component. This site also lacked a large ceramic collection (one sherd was recovered) but contained Perdiz arrow points, end scrapers, and beveled knives. The botanical remains analyzed from Toyah thermal rock features indicate that the inhabitants were cooking sotol, prickly pear, lily bulbs as well as meat (Black 1997:166-167).

Other notable sites with excavated Toyah components include the Rush Site (Quigg and Peck 1995), Kyle Rockshelter (Jelks 1962), Mustang Branch (Ricklis and Collins 1994a), 41TG91 (Creel 1990), Buckhollow Site (Johnson 1994), the Varga Site (Quigg et al. 2008) and the Rainey Site (Henderson 2001).

The Kyle site (41HI1) lies to the northeast of the Edwards Plateau and is notable for its preservation of highly perishable artifacts that include basketry, cordage, and matting from the Toyah component. A wide range of animal and plant remains, including maize, suggests a broad diet (Jelks 1962).

Near the eastern edge of the Edwards Plateau in Hays County, the Mustang Branch site (41HY209-T) contains Late Archaic, Austin, and Toyah interval components (Ricklis and Collins 1994a). The Toyah component of the site was interpreted as a short-term occupation processing locale because of the large collection of faunal remains and stone tools recovered. Numerous end-scrapers and drills were recovered along with bison, deer, antelope, and small game. The deer and antelope remains showed evidence of cut marks and marrow extraction.

The Rush site (41TG346) is on the Edward Plateau northeast of 41KM69. Excavations documented hearth and ash features, a variety of artifacts including arrow points, knives, hide scrapers, bone tools, and earthenware pottery. Most remarkable is the faunal assemblage recovered from Occupation Zone 4 thought to represent a bison processing level because of the large number of bison bones (approximately 11,000 bones representing seven individuals) recovered and the evidence of butchering and bone grease extraction. This level was dated to the end of the Toyah interval with a sample of radiocarbon dates between 330 and 410 B.P. (Quigg 1997a). The bison bone, evidence of butchering and bone grease extraction along with remains of mesquite and stone tools suggests the area was used to make pemmican (Quigg 1997a). 
The Varga site (41ED28) is on the southern edge of the Edwards Plateau (Quigg et al. 2008) southeast of 41KM69. The Toyah component here includes an artifact assemblage of 65,000 specimens. The bulk of this is consists of debitage, burned rock, and bone fragments but also includes over 1,500 stone tools and 100 ceramics.

The Buckhollow site (41KM16) is approximately 12 miles from 41KM69. The usual collection of artifacts were recovered (arrow points, hide scrapers, bison bones, earthenware pottery, and hearths) but of note here is the distribution of these artifacts. Johnson (1994) found a circular pattern described by the artifacts and concluded that a structure such as a windbreak may have served to enclose a domestic area around a hearth feature. Johnson also makes one of the leading arguments for Toyah people coming into Texas from the north following bison herds onto the Plateau.

The Toyah interval also saw the adoption of ceramics on the Edwards Plateau. This pottery is generally plain, bone-tempered earthenware, fired at low temperatures. Some examples are incised while others appear to be red slipped. Typically, sherds recovered from excavations are small and weathered so few vessels have been reconstructed. Recovered in prehistoric contexts this bone-tempered ceramic is identified as Leon Plain. Spanish Colonial site assemblages, such as those derived from the missions of Bexar County, also contain large numbers of earthenware ceramics. While there is a great degree of variability in these earthenware ceramics, they are typically referred to as Goliad wares, although at least in general technological terms Leon Plain and Goliad wares appear to be rather similar. This inconsistency points out the fact that the relationship between the two earthenwares is not well understood. Toyah interval sites with notable ceramics assemblages include the Rush Site, 41TG346, 41HY209, 41ED28, and 41KM16.

Many other Late Prehistoric components are used for comparative studies in this report, though site descriptions are not present here (Figure 3-1). References to site reports can be found in the literature review tables in the related appendixes for each study.

\section{Archeological Investigations Near 41 KM69}

No excavated and reported sites are near the boundaries of $41 \mathrm{KM} 69$ that would contribute to a comparative database. $41 \mathrm{KM} 16$ is the closest at 20 miles from Junction (Figure 3-2). Fourteen sites lie within 1.8 miles of $41 \mathrm{KM} 69$, though little information is available on

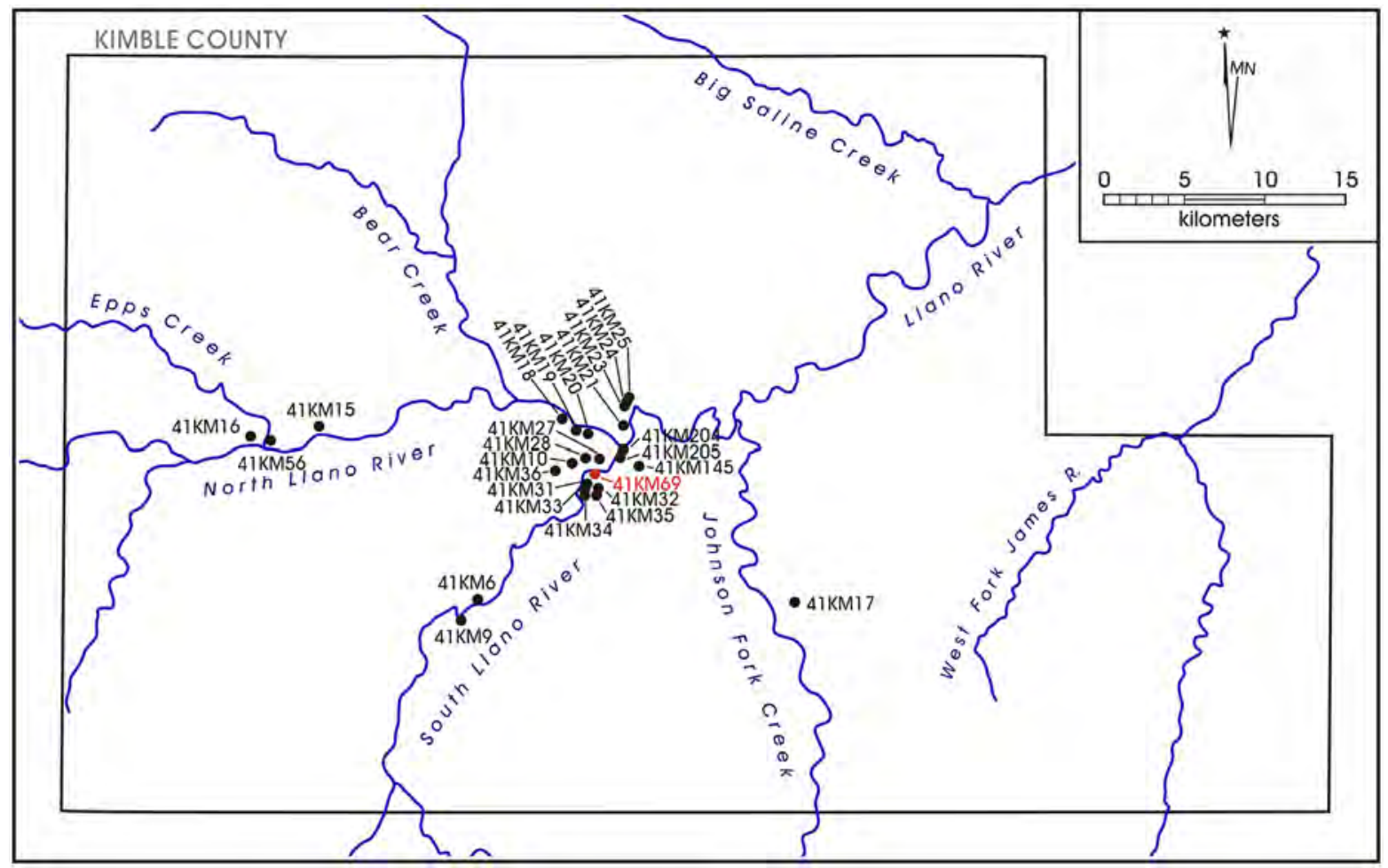

Figure 3-2. Archeological sites in Kimble County discussed in the text. 
most of these occurrences in the Texas Archeological Sites Atlas. In six cases, corrupted fields are present in the site forms. These include most of the sites located to the south and west of 41KM69 (i.e., 41KM31 through 41KM36). In addition, no site form exists for 41KM204. Of the remaining seven sites, one is historic (41KM205). Of the six prehistoric sites, temporal information is available on only $41 \mathrm{KM} 28$, where a Perdiz point was noted. This site, along with $41 \mathrm{KM} 27$, is located just to the north of 41KM69 and is in a similar terrace setting. Both of these sites are described as having lithic debris and hearths are noted on 41KM27. The four remaining sites are prehistoric, though no temporal assignment is available. Site $41 \mathrm{KM} 145$ is identified as a lithic procurement location, with high quality cherts, while site 41KM19 appears to have a burned rock midden and associated chipped stone debitage. For sites 41KM20 and $41 \mathrm{KM} 10$ the only information available is that they are prehistoric in age.

Excavated sites within the county are lacking as well. Many of the recorded sites are on river terraces and contain burned rock middens. Those recorded along rivers and creeks near the project area include 41KM15, 41KM25, and 41KM56. Site 41KM19 lies at the confluence of the North and South Llano River and site 41KM28 sits on the west bank of the South Llano River. Sites with relatively large burned rock middens include 41KM6, 41KM9, 41KM17, 41KM18, 41KM21, 41KM23, and 41KM24. Other sites in the county with ceramics include $41 \mathrm{KM} 18$ and $41 \mathrm{KM} 21$. 



\section{Chapter 4: Field and Laboratory Methodology}

\section{Jennifer L. Thompson}

CAR employed standard archeological field and laboratory methods during both phases of the excavations at 41KM69. Methods used during significance testing are described as reported by Weston et al. (2004), followed by the presentation of the data recovery methods conducted by Jennifer L. Thompson.

\section{TxDOT Trenching}

Prior to the work contracted by CAR, TxDOT archeologists excavated three backhoe trenches at the site December 11-12, 2003. Each trench was approximately 5-7 meters long and 1.4 meters deep along the centerline of the proposed ROW (Figure 4-1).

\section{Significance Testing}

The significance testing conducted by Weston (Weston et al. 2004) was the first excavation conducted at the site subsequent to the TxDOT trenching, which consisted of three backhoe trenches excavated in 2003. Bruce $\mathrm{K}$. Moses created a site map and 5-m grid across the project area prior to excavations. He returned to add the excavated areas and changes to the project area boundaries to the base map throughout the course of the entire project. After the initial topographic map was created for the testing work, CAR proceeded to excavate 121 auger tests that reached depths of $120 \mathrm{cmbs}$. The distribution of burned rock and debitage found in these auger tests guided placement of the backhoe trenches, the

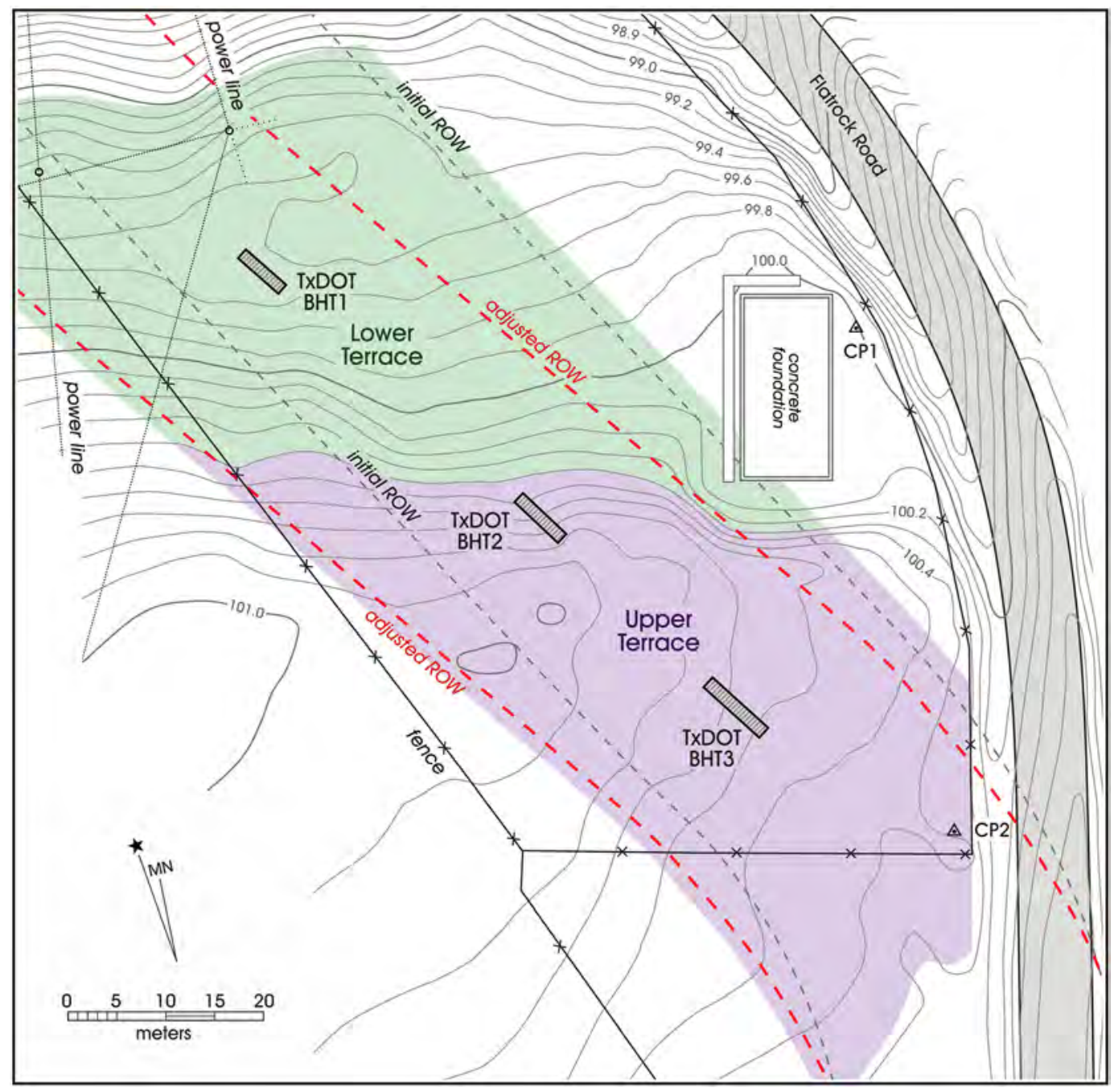

Figure 4-1. The location of previously excavated TxDOT backhoe trenches (from Weston et al. 2004). 
50-x-50-cm units and the 1-x-1-m units, which recovered Late Archaic, Austin interval, Toyah interval and Historic Period artifacts.

\section{Mechanical Auger Borings}

To allow for sampling of deep deposits, mechanical augering was used in place of shovel tests. These were placed on the 5-m grid (Figure 4-2) across the ROW using a Bobcat mounted screw auger, capable of reaching depths of $120 \mathrm{cmbs}$ (Figure 4-3). Excavations proceeded in three levels with a 9-in. bit.

The first level was bored from the surface to roughly 35 cmbs. The second level continued from 35-80 cmbs.
The third level in each auger test sampled $80-120 \mathrm{cmbs}$. Collected matrix was screened though 1/4-in. hardware mesh and all cultural material were retained for analysis.

\section{Backhoe Trenching}

CAR excavated six backhoe trenches (BHTs 4-9) during the testing phase. Backhoe trenches were placed to examine artifact concentrations found during auger testing (BHTs 4 and 5), to search for new features and, to expose long profiles for the investigation of the geomorphic context of the cultural materials (Figure 4-4; BHTs 6-9).

The trench walls were troweled and examined for artifacts, features, charcoal, and significant indicators of

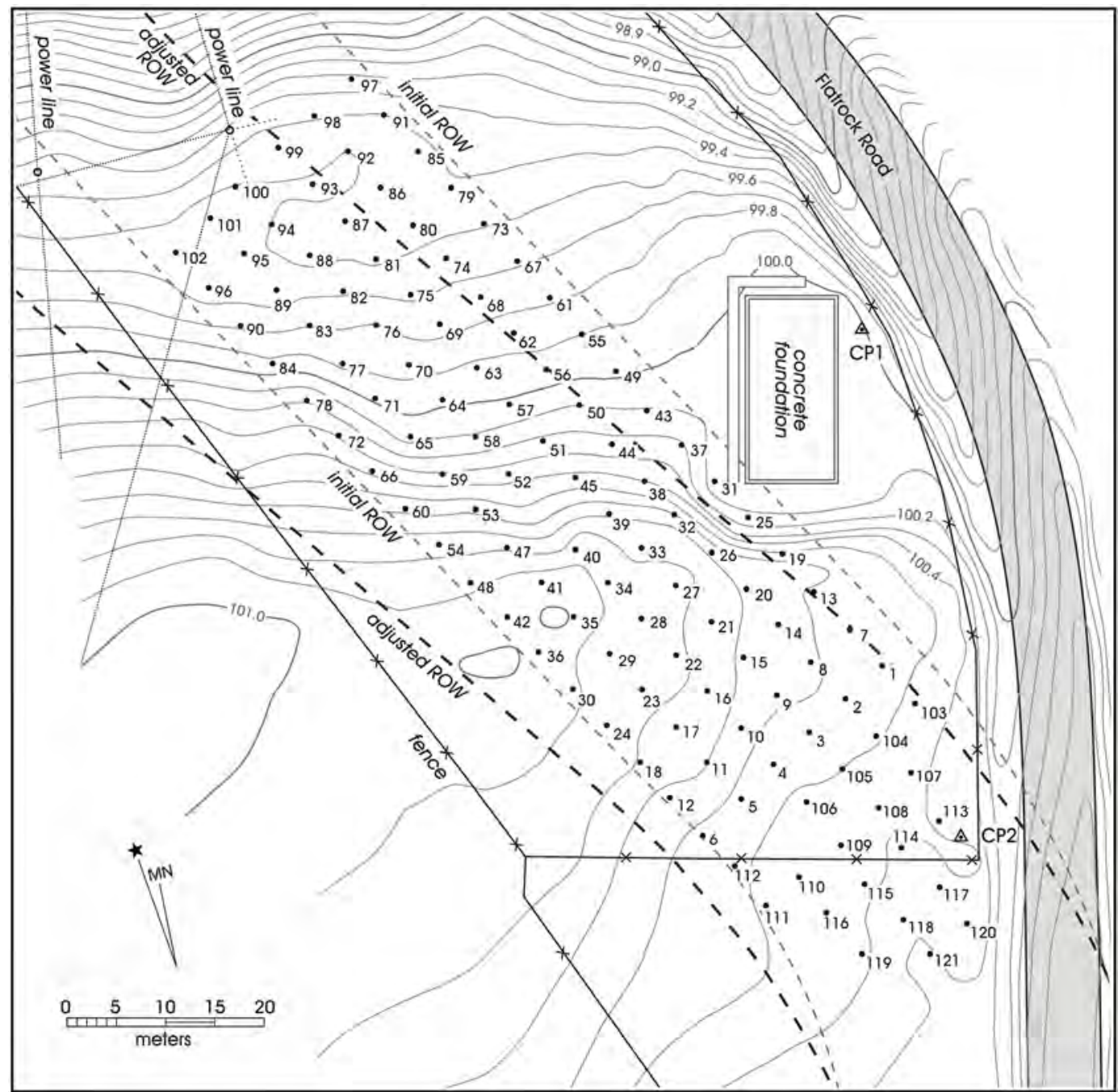

Figure 4-2. The location of auger tests excavated during Phase II testing (from Weston et al. 2004). 


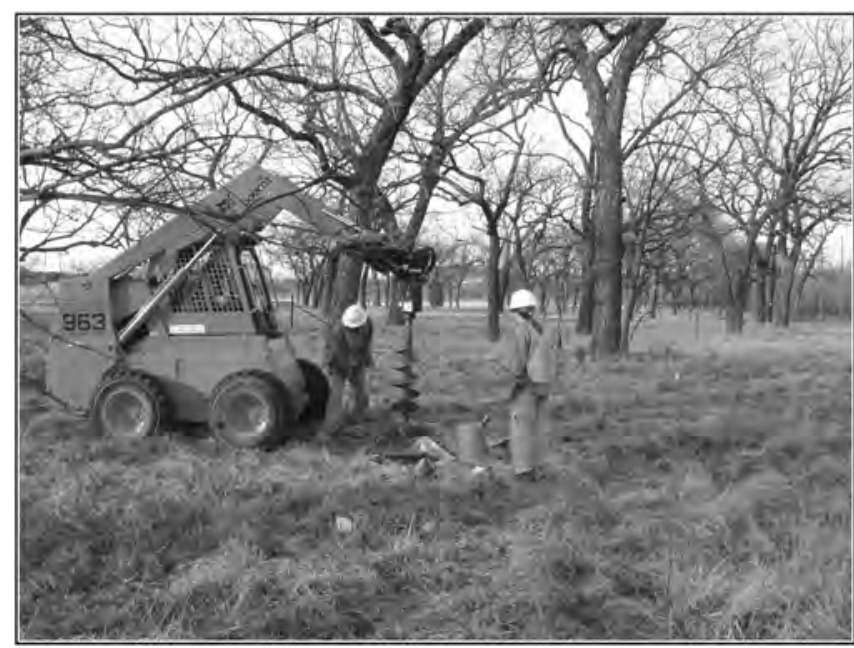

Figure 4-3. Bobcat mounted auger reached depths up to 120 cmbs during Phase II testing. formation events. One wall of each profile was drawn. Artifacts and charcoal samples were mapped from both walls. Full soils descriptions were compiled on three trenches (BHTs 4, 7, and 8).

Magnetic susceptibility samples (MSS) were collected from five of the backhoe trench profiles, including the burned rock midden exposed in BHT 5. The results of this analysis are provided following the geomorphology description in Appendix A (Figures A-8 through A-13; Table A-4).

\section{Hand-Excavations of Test Units}

Data obtained from the mechanical auger borings were at a coarse-grained vertical scale (30-40 cm thick levels). To more precisely define the vertical distribution of

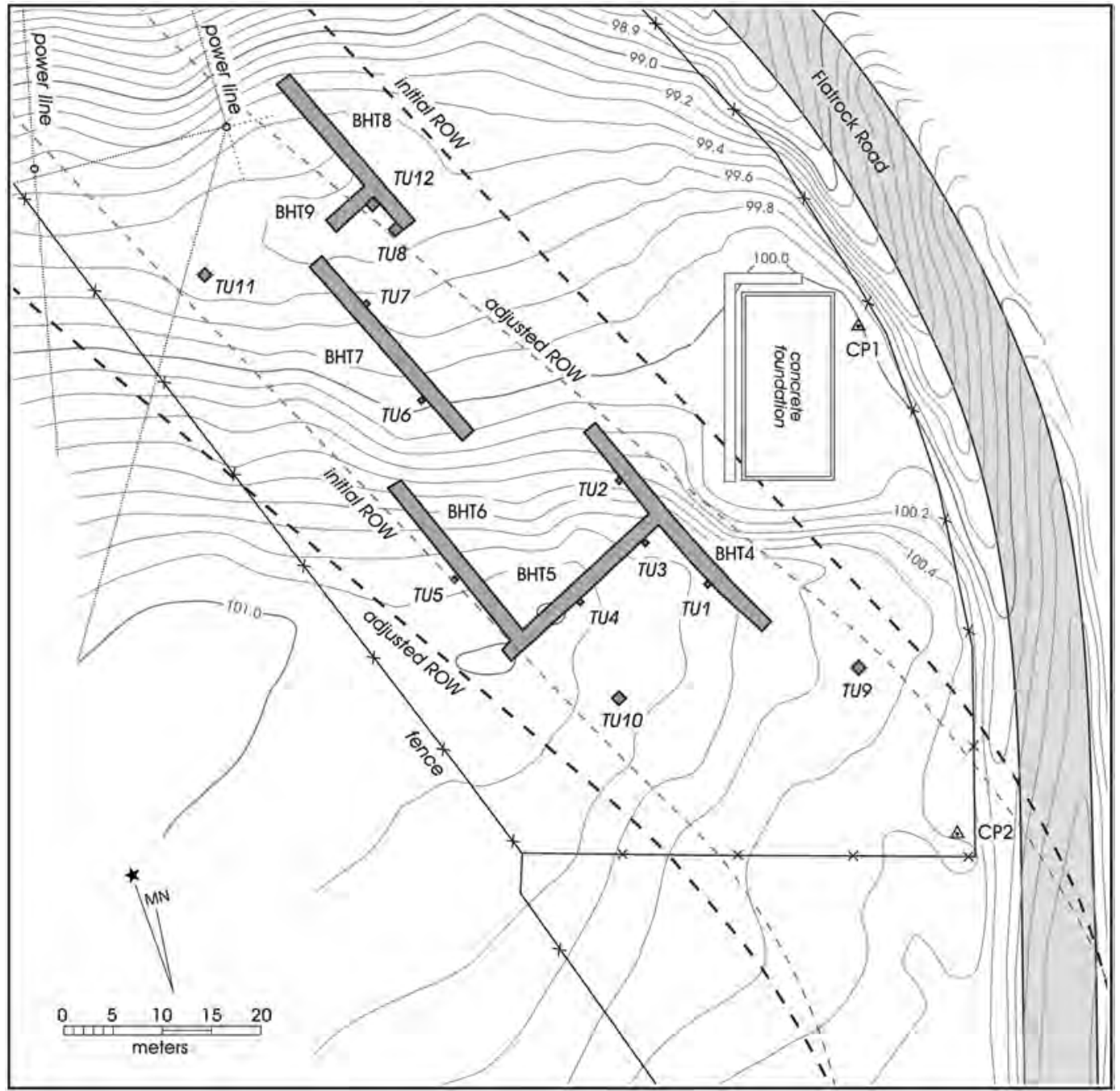

Figure 4-4. Locations of Phase II trenches and test units (Weston et al. 2004). 
cultural materials and more closely examine several archeological features identified by the backhoe trenches, a series of eight $50-\mathrm{x}-50-\mathrm{cm}$ units and five $1-\mathrm{x}-1-\mathrm{m}$ units were dug (Figure 4-4). Each test unit was excavated in $10-\mathrm{cm}$ levels using a combination of shovel skimming and troweling. All soils from these units were screened through $1 / 4$-in. mesh and all materials were collected and bagged by provenience. All units were placed at the discretion of the project archeologist in consultation with the principle investigator and the geoarcheologist. Appropriate notes, photographs, and drawings were maintained for all excavations. All discrete, intact prehistoric features encountered in the manually excavated units were exposed to the extent necessary for sampling and characterization.

All artifacts encountered in the auger borings and test units and all diagnostic artifacts encountered in backhoe trenches were collected. Charred or unburned organic materials critical in radiocarbon dating were recovered when found in good context. Charcoal samples collected were ranked by the CAR geoarcheologist in accordance with a quality assessment based on sample context and size. These were ranked $1=$ best, $2=$ very good, $3=$ good, $4=$ moderate, and $5=$ poor. Only samples of the first rank were sent for radiocarbon dating. Two sets of select radiocarbon samples were submitted for analysis shortly after the fieldwork was completed. Soil samples, consisting of 200-300 grams of matrix, were collected from undisturbed contexts.

\section{Laboratory Methods}

Following the completion of the field work, preliminary laboratory cataloging and tabulation of artifacts was done. As a comprehensive analysis of artifacts was not part of the work authorization for the production of the interim report, the project archeologist conducted a quality check of the field and laboratory data using field notes, unit/level forms, and geomorphological profiles. Laboratory processing consisted of cleaning the artifacts, and separating them into gross categories (e.g., debitage, burned rock, projectile points, tools). Counts were made of each class of artifacts, with the exception of burned rock, which was quantified by weight.

\section{Data Recovery}

CAR proceeded with the data recovery phase of excavations at 41KM69 in three stages. The first stage included hand excavation of large blocks in four areas of high artifact density (Areas 1 through 4, Figure 4-5). The second stage included grading of the site between the hand-excavated blocks to ensure that all features present in this area were documented and sampled prior to road construction. The final stage of the data recovery effort occurred after a ROW shift. The shift created a wedgeshaped area of the site west of the block excavations that had not been tested during Phase II. We employed mechanical auger borings spaced at close intervals to test this wedge-shaped area.

\section{Stage 1: Hand Excavations}

CAR used standard field methods at 41KM69 during data recovery and made every effort to tie the Phase II testing work to the Phase III data recovery excavations. CAR employed data from test units and auger tests to guide the placement of the blocks and then added them to the site map. Prior to block excavation, CAR reopened previously excavated units to facilitate consistent profiling between the testing and data recovery phases of excavations.

\section{Site Excavation Management}

During the week of January 10, 2005, a small crew from CAR began setup for the data recovery excavations of 41KM69. This involved relocating previously excavated test units and backhoe trenches and reopening them. CAR reopened portions of Backhoe Trenches 4, 5, 7, 8, and 9 mechanically, and then reopened Test Units 9, 10, and 11 by hand. TxDOT supplied a backhoe and operator who scraped $10 \mathrm{~cm}$ off Area 1 before a crew leveled the area by hand with shovels. In general, only one area at a time was excavated. This strategy limited the amount of time archeological components were exposure and also reduced the potential for their disturbance.

\section{Site Grid and Mapping}

Phase III excavation data was added to the Phase II map using established control points. The topographic map was oriented on magnetic north and tied to engineering control points in Flatrock Road/FM 2169. All excavation units in both phases of fieldwork were shot in with this grid. However, the Phase II test units and Phase III blocks were not set up to align with magnetic north. Instead, they were aligned to run parallel to the portion of the ROW under investigation with grid north in the direction of the river. The centerline was north, $23^{\circ}-46^{\prime}-37^{\prime \prime}$ west of true north, or an azimuth of $336^{\circ}-13^{\prime}-23^{\prime \prime}$. Blocks in each area fit over the previously excavated test unit within each block so the test unit aligned with all the other 1-x-1-m units in the block. 


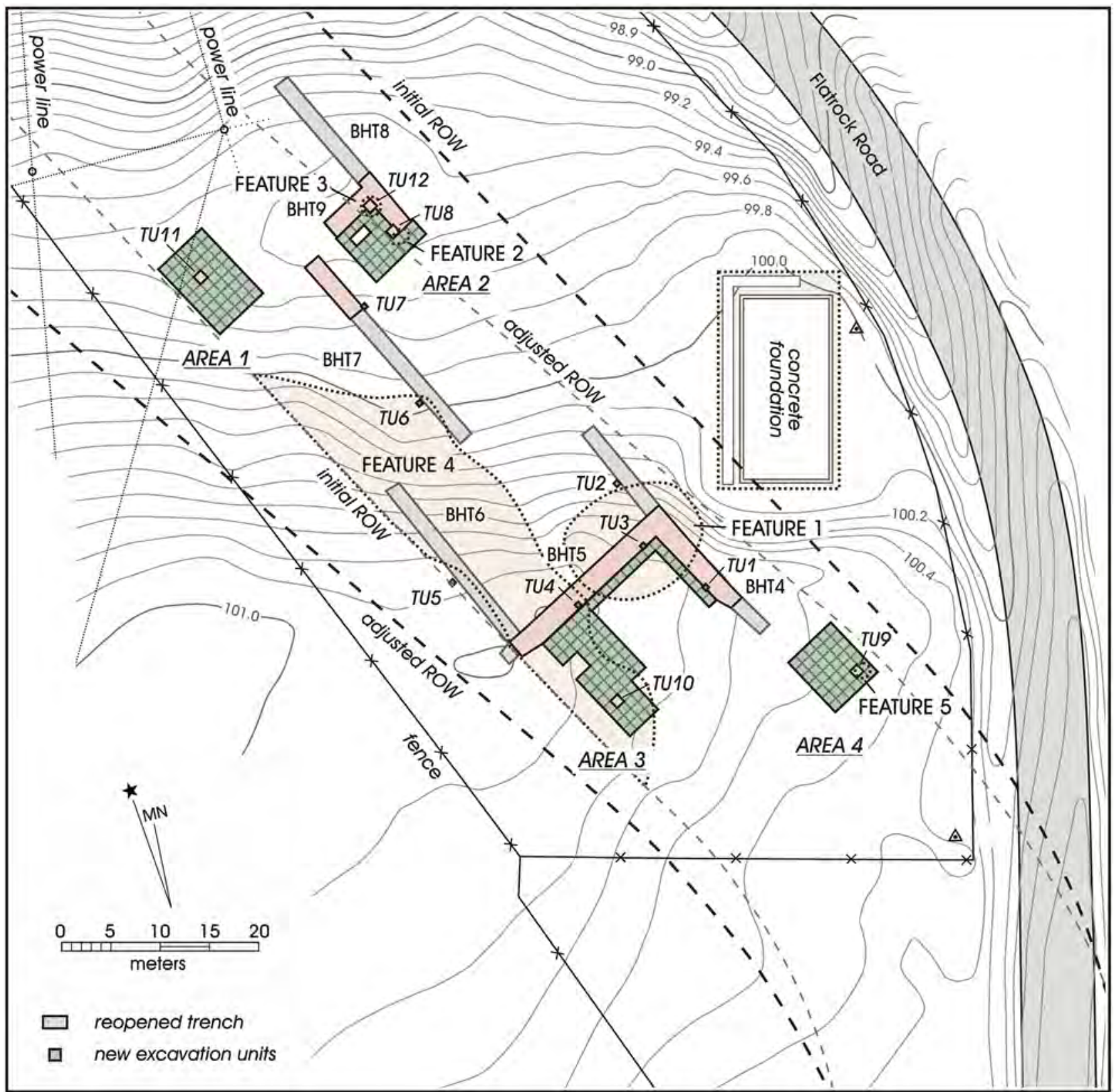

Figure 4-5. The location of the excavation blocks in each of the four areas investigated during Phase III excavations was determined by artifact density observed during testing.

The unit designations for the Phase III work are labeled by rounded northing and easting coordinates to the closest meter. These increase to the north and east across the site so a relative idea of distance between features and units at the site is possible by referring to the unit number within a margin of error of $40 \mathrm{~cm}$.

Elevation data was collected for the topographic map at $5.0-\mathrm{m}$ intervals. Prior to excavation, CAR collected original ground surface and initial excavation elevation data at each corner of 1-x-1-m units within the blocks in each area.

\section{Block Excavation}

CAR consistently followed the field methods outlined in the SOW (see Thompson et al. 2004). Blocks in Areas 1-4 were divided into 1-x-1-m units and excavation occurred on a rotating basis so the entire block was exposed at the same level at the same time (see Figure 4-5 and Figure 4-6). Therefore, excavators could observe any features encountered across multiple units immediately without waiting for the excavation of the adjacent unit(s) to reach the depth of the feature. Excavations proceeded by hand in arbitrary $10-\mathrm{cm}$ levels that were divided by natural soil 


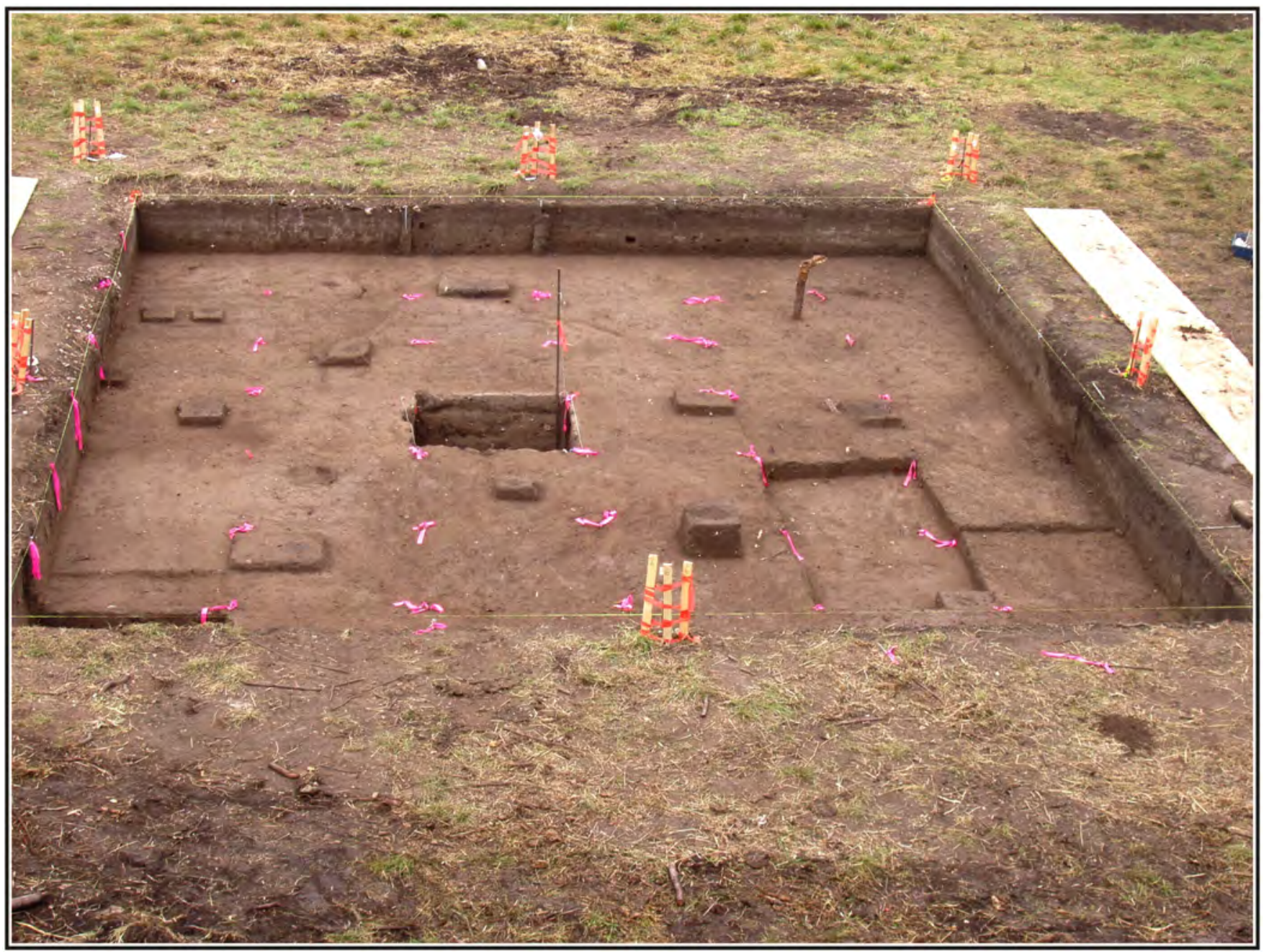

Figure 4-6. Units within the blocks were excavated on a rotating basis to expose the same level across all units simultaneously.

horizons. The crew screened all excavated soils through $1 / 4$-in. hardware cloth with the exception of soil samples, mechanically removed soils, and soils removed by hand during the leveling of an area after backhoe scraping.

\section{Feature Excavation}

Feature excavation proceeded as proposed in the SOW for all features with the exception of Feature 1, the burned rock midden. CAR treated Feature 1 differently because of its size. CAR documented all the other features by photograph, plan view and cross-section drawings, before sampling and excavating them in their entirety. The project archeologist kept a record of features as they appeared, assigned each a feature number, and recorded the center point, upper and lower elevations, and dimensions in the feature log. Excavators also recorded this information along with other observations on feature forms. The center point of the feature became the permanent provenience for a feature instead of the unit number. A minimum 2.0-liter soil (feature fill) sample was collected from features when possible and all burned or fire-cracked rock was collected from features for residue analysis, though not from the site in general and not from Feature 1.

Due to the size of Feature 1, CAR sampled the burned rock midden in 1-x-1-m units forming two trenches, one running north to south, the other running east to west (see Figure 4-5). These unit excavations proceeded in the same manner as those in each block, where units were excavated on a rotating basis exposing one level at a time across the block. In Feature 1 however, excavators collected all gravels and burned rock left in the screen and delivered them to a size-grader who processed the rock through a series of nested screens and recorded the information in a data book. After recording the rock. size, material type, and counts, the size-grader then discarded the burned rock and gravels on site. Counts 
were recorded for size categories $>4$ in., $>3-4$ in., $>2-3$ in., and $>1-2$ in. Volume was recorded for all gravel measuring $<1$ in.

\section{Soil Sampling}

To recover the floral data types necessary to address the research issues described in the SOW, CAR's field crew conducted soil sampling of excavated blocks in each area of the site to extract macrobotanical remains including seeds, shells and microbotanical remains such as phytolith and pollen samples. This is in line with the proposed research design concerning environmental changes, diet, and processing activities.

We collected column samples from two freshly cut profile walls in each of the blocks. We chose one column from which to sample in arbitrary $20-\mathrm{cm}$ levels from bottom to top while a second column targeted specific soil horizons. This entailed removing each natural stratum separately after block excavation profile drawing concluded. These methods facilitated accurate note taking, bagging, and labeling of all strata at the same time and allowed for accurate sampling of various soils. Only in Feature 1 in Area 3 were soils collected at three locations within its boundaries. Here, we collected soil samples for both general flotation and pollen and phytolith analysis extracted from the center and each end of Feature 1 in the L-shaped block.

CAR followed Pearsall's (2000) and Bryant and Holloway's (1983) guidelines for acquiring field samples. The collection of soils came from well-defined, tightly controlled contexts such as hearths and stratified soils. Samples from stratified soils came from individual, contiguous strata from the lowest/deepest to the highest/ shallowest strata to ensure that the upper soils did not contaminate the lower ones.

As proposed, the soils went into non-porous re-closable plastic bags. Each control column sample had a volume of $20-50 \mathrm{~cm}^{3}$ when possible. The sample collector noted specific volumes in the sample log. We attempted to collect the samples on calm days. The collector also noted all possibilities of contamination in the field notes and sample log. Rubbing alcohol was added to each sample bag to prevent mold growth and all tools were cleaned between sample extractions. The collector numbered each sample and assigned a letter to each column from which samples were extracted. The columns and the samples within the columns were plotted on the profile drawings for each block. CAR recorded all information concerning provenience, volume, date, and stratum in a sample logbook.

\section{Laboratory Methods}

All samples, artifacts, photographs, and related documentation of site 41KM69 were taken to the laboratory facilities at CAR. Here, preliminary processing of artifacts including washing, rough sorting and counting of artifact types, and bagging prior to analysis were completed. Following the arrival of the soil samples designated for pollen and phytolith analysis, additional rubbing alcohol was added to the samples. Samples that were targeted for a preliminary pollen/phytolith presence/absence study were separated and placed in a freezer to arrest mold development until they could be sub-sampled. The samples were submitted to Texas A\&M University's Department of Anthropology Palynology Laboratory.

\section{Stage 2: Gradall Excavation and Monitoring}

Between the hand-excavated blocks, a Gradall scraped portions of $41 \mathrm{KM} 69$ in $10-\mathrm{cm}$ increments (Figures 4-7 and 4-8). CAR staff monitored machine excavations to document features and recover stone tool artifacts. Mechanical excavation ceased and the feature or tool shot in the with total data station when tools and features were observed. When features were uncovered, the immediate area was leveled by hand in order to determine the boundaries of the feature. The feature was then drawn and photographed in plan view and bisected. Once bisected, the cross-section of the feature was examined, drawn, and photographed. A small unit was setup around the remaining half of the feature and hand-excavated in 10-cm levels (Figure 4-9). A 2.0-liter soil sample or the maximum possible volume was collected along with artifacts from the 1/4-in. screen. All features and tools encountered during the grading operations were mapped from information collected with a total data station.

The remains of Feature 1, the burned rock midden, were also graded during this stage. Because we had already sampled the midden by hand and examined it in two cross-sections, we did not examine the midden further with hand excavations. However, the horizontal extent 


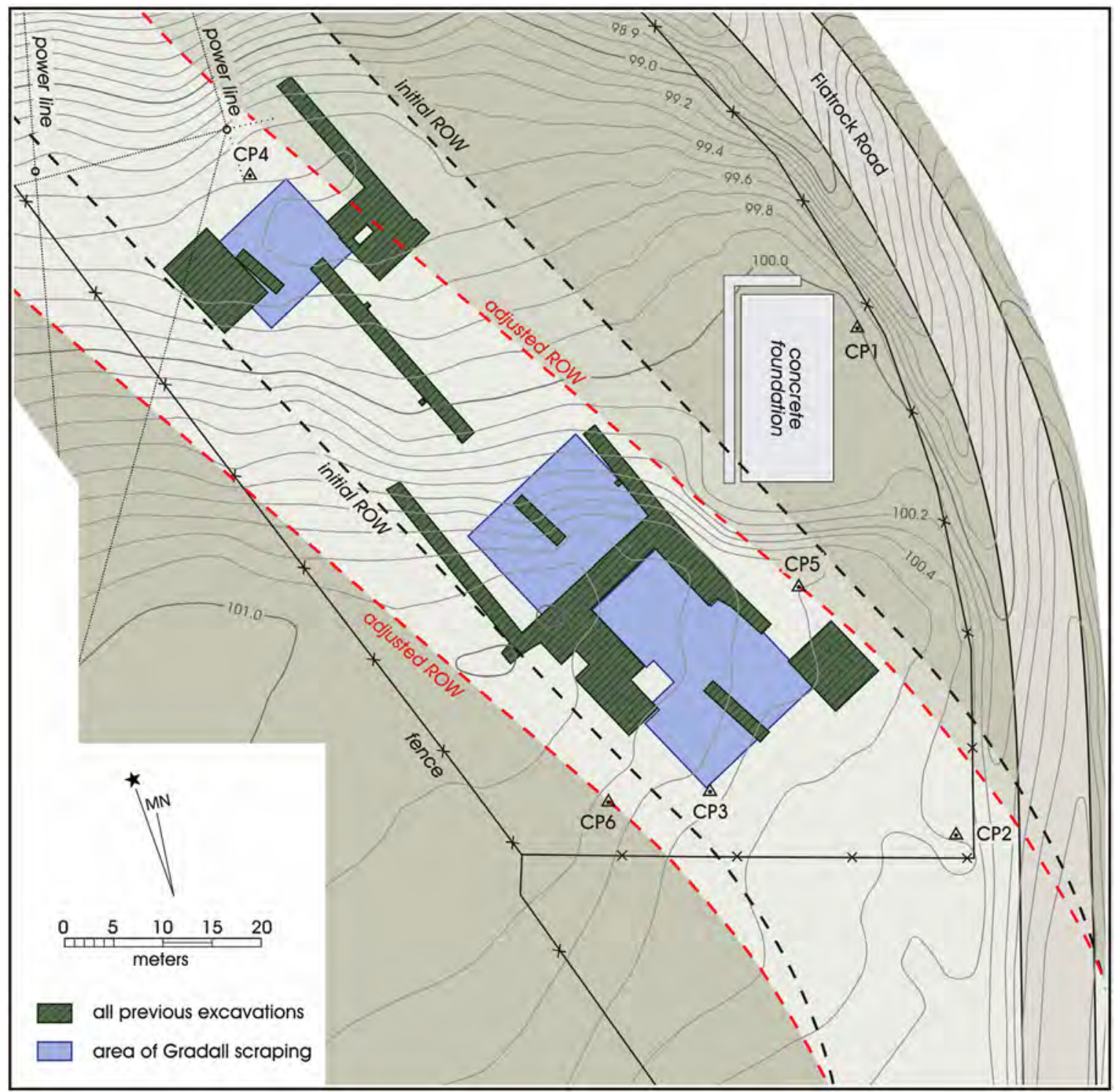

Figure 4-7. The locations of the Gradall scraping are shown in blue.

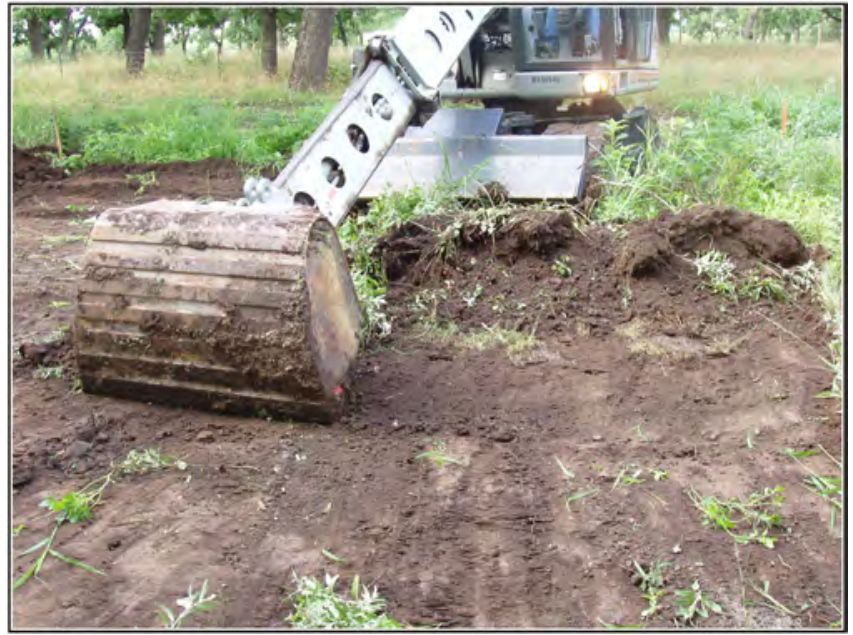

Figure 4-8. The Gradall bucket was floated in order to grade in 10-cm intervals.

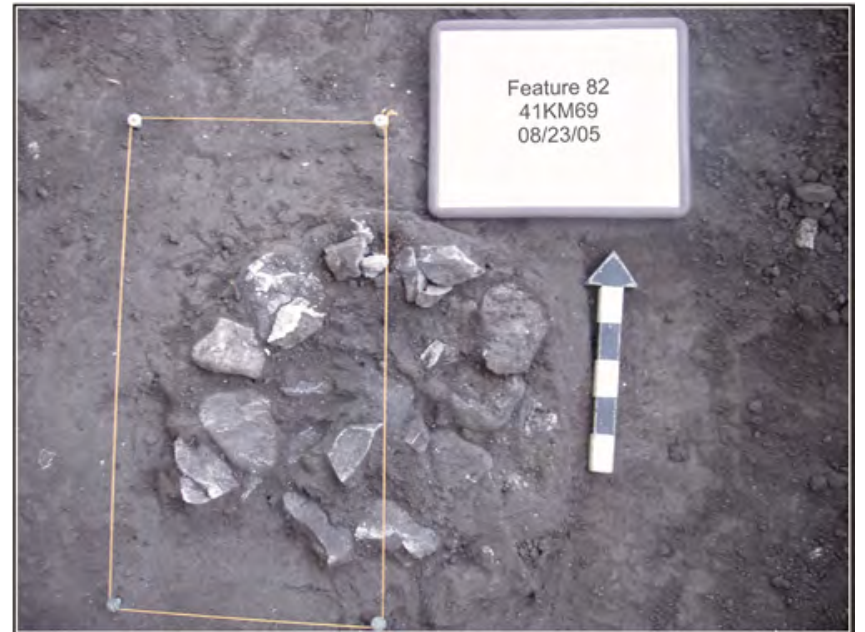

Figure 4-9. During grading, features were bisected and only half were hand excavated. 
of Feature 1 was mapped following every $10 \mathrm{~cm}$ of scraping in order to get an idea of its changing shape at various depths. TxDOT agreed to backfill the Gradall excavations after our work was completed.

\section{Stage 3: Testing of Shifted Right-of-Way}

During the course of the data recovery examinations, CAR discovered that a ROW shift had occurred and was going to impact portions of the site that were not discussed during the mitigation planning of 41KM69 (Figure 4-10). Therefore, portions of the site within the new ROW required testing. During September 26-28, 2005, crew from CAR conducted Phase II-level work on the previously untested area of the site in the ROW. This included mechanical auger testing on a $5-\mathrm{m}$ grid with additional tests offset from the $5-\mathrm{m}$ grid by $3.5 \mathrm{~m}$. The field crew screened soils from the auger tests and collected artifacts. The 57 auger tests were excavated with a 12 -in. mechanical auger in three $40-\mathrm{cm}$ levels. A form was completed for each test and the artifacts were collected from the screened soil and bagged by level. All auger tests were backfilled after each was excavated. The artifacts were collected and returned to the CAR lab for processing as with the other artifacts from the block excavations. The additional artifacts were added to the existing database.

\section{Conclusion to Field and Laboratory Methods}

This chapter outlined the field and lab methods of the Phase II significance testing and the three stages of field excavations conducted during the data recovery phase of the project. The hand excavations covered four blocks. The grading excavations included monitoring of areas between the blocks. The mechanical auger testing examined portion of the shifted ROW that had previously gone untested.

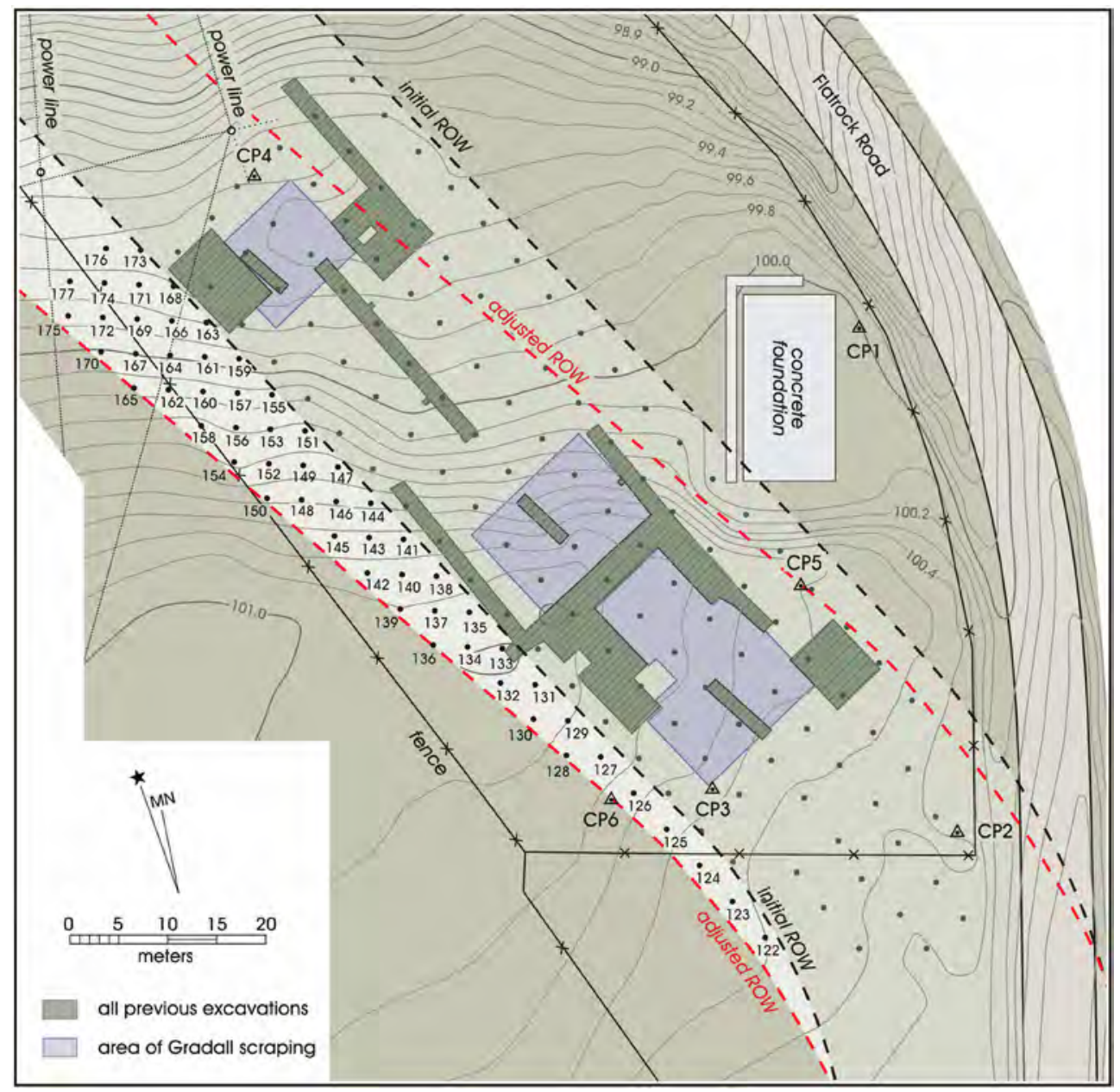

Figure 4-10. Auger tests were placed on previously untested portion of 41 KM69 after the change in ROW location. 



\section{Chapter 5: Excavations at 41KM69}

\section{Jennifer L. Thompson}

The first recorded investigations at 41KM69 consisted of three backhoe trenches excavated by TxDOT in 2003 (Figure 5-1). The trenches reached a depth of $1.4 \mathrm{~m}$ below the surface where an underlying gravel deposit was exposed. Cultural material was encountered from ground surface to at least $0.76 \mathrm{~m}$ below ground surface, where a small concentration of burned limestone, designated a feature, was observed in BHT 1. Burned rock and chipped lithics were observed in the backfill of all three trenches by CAR archeologists who visited the site in early February 2004. The findings from these trenches prompted the additional significance testing and subsequent data recovery that occurred in the following years. This chapter summarizes the extent of CAR's excavations and the deposits found. Further details on the material recovered and their contexts are discussed in Chapters 6 and 7.

\section{Significance Testing}

During significance testing, CAR created a detailed topographic map of the site and used mechanical augering, backhoe trenching, and hand excavations to assess the significance of the archeological deposits at 41KM69. This phase of work uncovered one early twentieth century component that included a gravel driveway (Feature 4) and concrete foundation (Feature 6), and four prehistoric component including temporally diagnostic projectile points, numerous stone tools, debitage, and native ceramics in good stratigraphic context. Additionally, three prehistoric feature were documented: one large burned rock midden (Feature 1), one hearth feature (Feature 2) and two burned rock clusters (Features 3 and 5). Figure 5-1 shows the location of the Phase II backhoe trench-

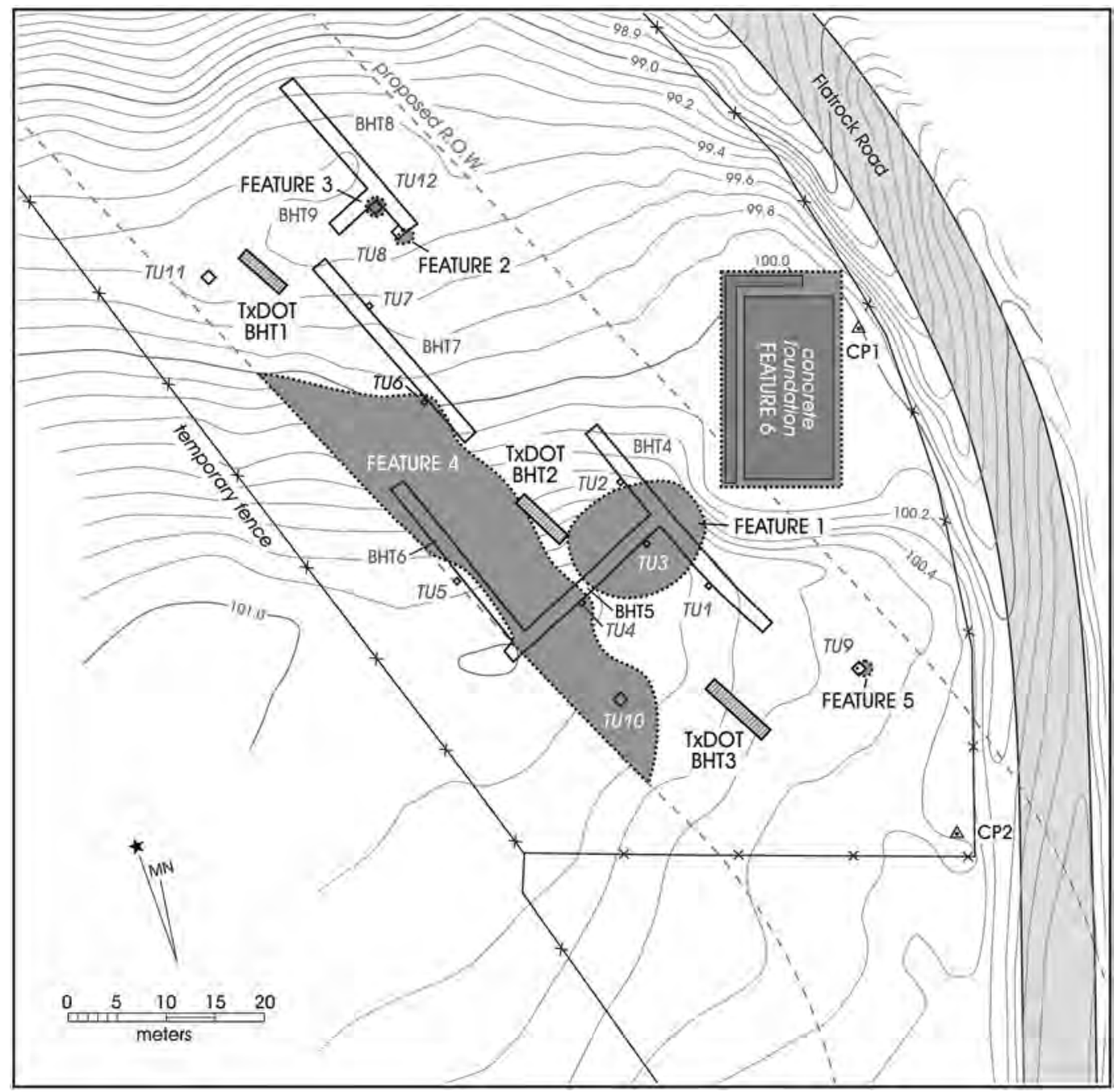

Figure 5-1. Excavation units and cultural features identified during testing (from Weston et al. 2004). 
es, test units, and features along with the TxDOT trenches. The following summary of results from significance testing is from Weston et al. (2004).

\section{Results from Auger Tests}

Auger tests were set on the 5-m grid that was originally designed to end adjacent the fence at the presumed southern end of the site. This resulted in 108 auger borings. However, auger testing showed no drop in artifact counts adjacent the fence. Therefore, in consultation with TxDOT, the grid was extended roughly 15 meters south of the fence but still within the proposed ROW. This increased the number of auger borings to 121 (see Figure 4-2).

Auger testing results indicated that the artifacts at 41KM69 were in good stratigraphic context with the majority of the historic material recovered from the top 0-35 cmbs. Nine historic artifacts were recovered from between $35-80 \mathrm{cmbs}$ and one from below $80 \mathrm{cmbs}$, but this could have been due to the level of control lost in auger boring. The historic material was concentrated in the central and south-central portion of the site in the ROW.

The prehistoric artifact distribution largely fell below the historic component. The majority of the burned rock (measured by weight) concentrated in Level 2 but was also present in Level 1 and Level 3. Figure 5-2 shows the distribution of burned rock from auger tests across the project area. One large concentrated area in the south-central portion of the site, at the location of Feature 1, was dated to the Austin interval of the Late Prehistoric Period.

Other concentrations fell to the southeast and southwest. Burned rock was less common on the lower terrace in the northern portion of the project area (Figure 5-2). Chipped stone artifact concentrations (Figure 5-3) show a different distribution than the burned rock and seemed to be separated from the burned rock horizontally.

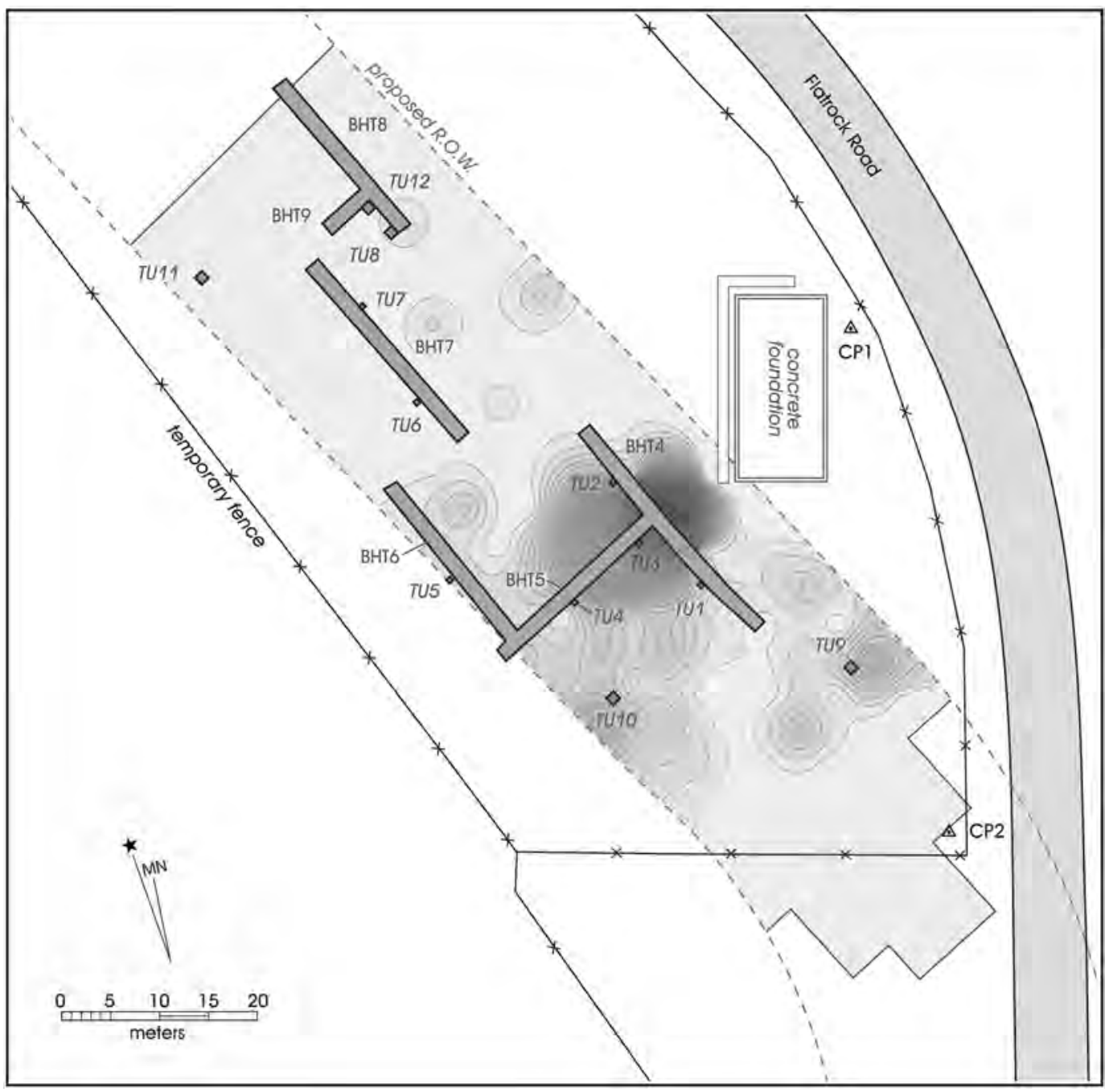

Figure 5-2. Burned rock density produced by auger testing (from Weston et al. 2004). 


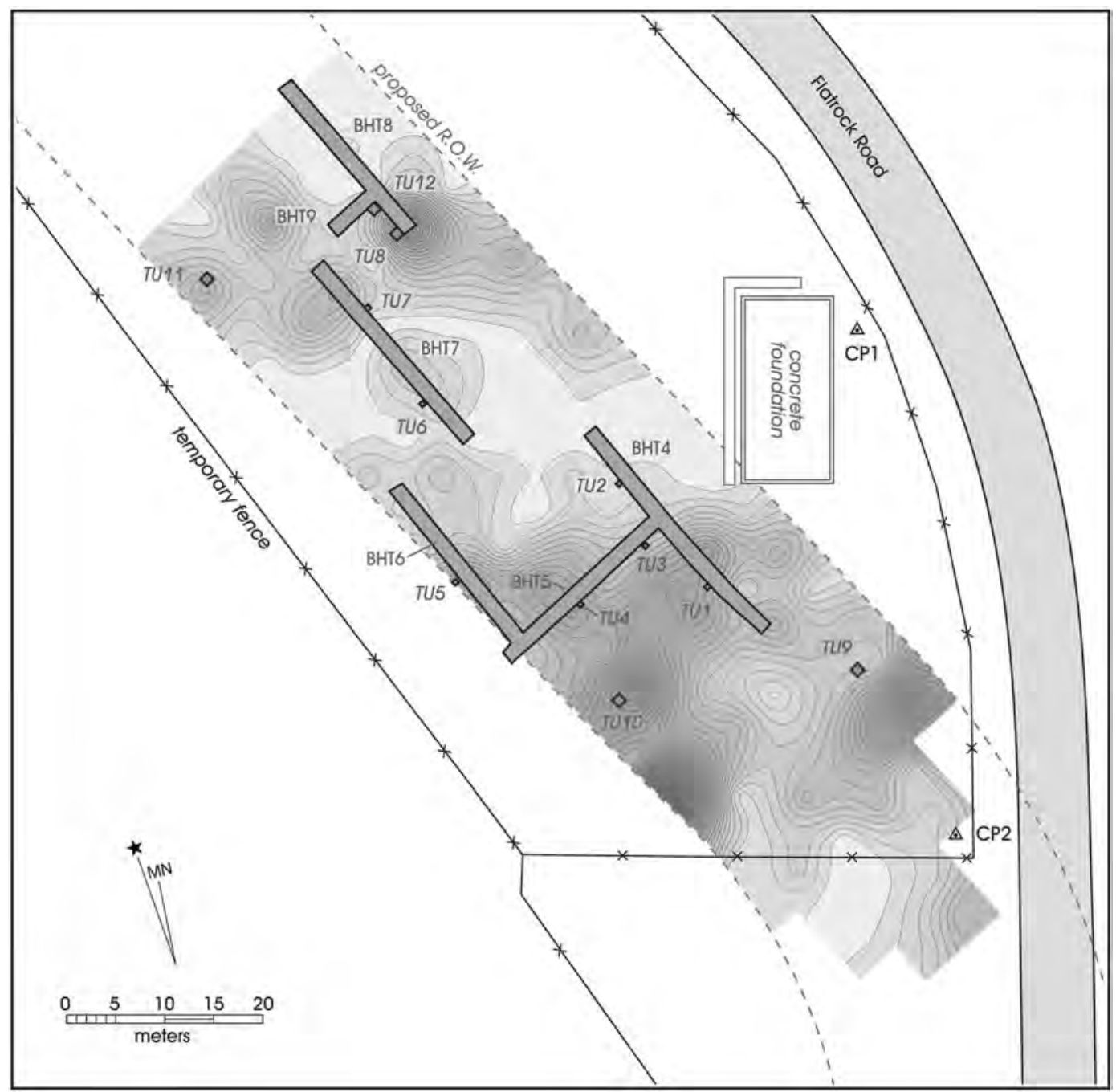

Figure 5-3. Chipped stone density produced by auger testing (from Weston et al. 2004).

Three temporally diagnostic projectile points were recovered from auger tests: an ear fragment similar to a Late Prehistoric Edwards point, a Darl point dating to A.D. 200 (Turner and Hester 1999) and a Late Archaic Frio point which is 2,150 to 1,350 years old (Turner and Hester 1999:122). The level of vertical control in auger testing makes interpretation of these projectile points difficult in this context.

The data from the borings provided information on the horizontal extent and coarse-grained vertical patterning of the archeological deposits, as well as the nature of the deposits. The distribution of burned rock and debitage guided where the mechanical backhoe trenches and hand-excavated units were placed.

\section{Results from 50-x-50-cm Units}

Eight 50-x-50-cm units (TUs 1-8) were excavated during the testing phase to examine deposits, including cultural features exposed in backhoe trenches (see Figure 5-1). These were excavated to depths between 140 and $170 \mathrm{cmbs}$. Seven of these units produced lithics, burned rock, and historic artifacts in good stratigraphic position. The greatest numbers of lithic artifacts were from units excavated in the central and north-central areas of the site (TUs 1, 5, 6, and 7). The greatest densities of burned rock were found in the center of the project area near BHTs 4 and 5, which cut through the burned rock midden (Feature 1; see Figure 5-1). TUs 1, 2, 3, and 4 were placed in or near Feature 1, but only TUs 2 and 3 were within the boundaries. TU 8 was placed in BHT 8 to explore Feature 2. This unit was later expanded to a 1-x-1-m unit.

The distribution of debitage and burned rock was patterned, peaking in upper and lower deposits in several units. In general, the upper deposits are from Late Prehistoric components and the lower deposits are from Late Archaic components. This is illustrated in burned rock and debitage densities plotted by levels in Test Unit 1 against a profile segment of BHT 4 (Figure 5-4). 


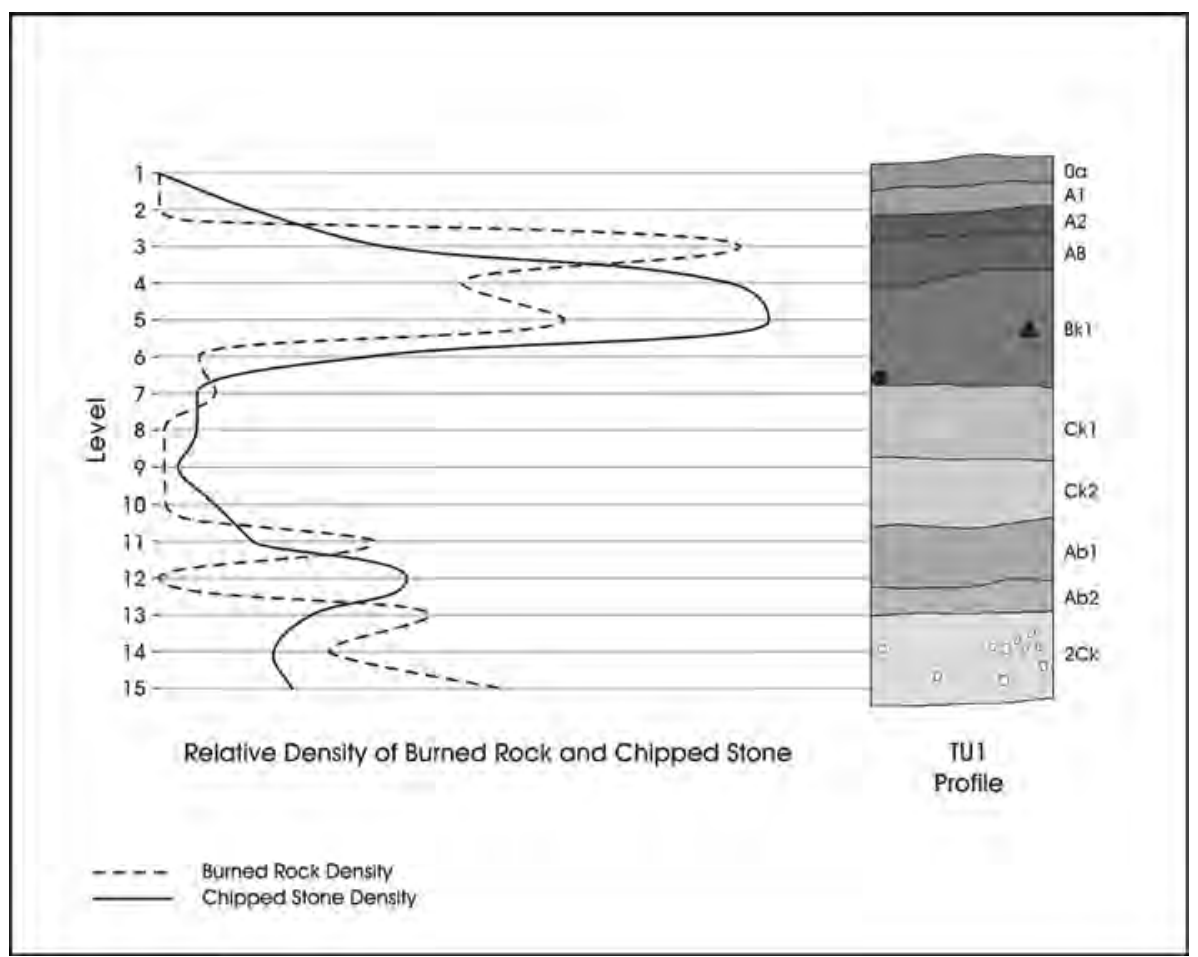

Figure 5-4. Density and pattern of debitage and burned rock from Test Unit 1 against profile of BHT 4.

\section{Results from 1-x-1-m Units}

Five 1-x-1-m test units (Figure 5-1) were excavated to investigate in more detail artifact concentrations identified from auger tests (TUs 10 and 11) and thermal features identified in both the augers and backhoe trenches (TUs 8, 9, and 12). The depth of these units ranged from 80 to $150 \mathrm{cmbs}$. TU 9 was positioned to investigate Feature 5, a small, burned rock concentration identified by auger tests that was located $10 \mathrm{~m}$ south of BHT 4 . TU 10 was placed in the highest debitage concentration identified by auger testing. TU 11 was placed near TxDOT BHT 1. TU 12 was placed at the southern juncture of BHT 8 and BHT 9 to examine a burned rock concentration, Feature 3, exposed by those trenches. Finally, $50-\mathrm{x}-50-\mathrm{cm}$ TU 8 was expanded into a 1-x-1-m unit to complete the examination of the hearth partially exposed in the southern end of BHT 8.

Because of their placement over known artifact concentrations, the five $1-\mathrm{x}-1-\mathrm{m}$ units produced a large quantity of chipped stone and burned rock artifacts. Prehistoric ceramics were also recovered from TU 11. All units produced charcoal samples, four produced faunal material, and TU 11 produced prehistoric ceramics.

As in the other excavated areas, the stratigraphic position of the artifacts indicated that the prehistoric components seemed to be intact. The 1-x-1-m test units combined showed historic artifacts confined to the upper $20 \mathrm{~cm}$ of the deposit and debitage and burned rock peaks in both upper and lower level deposits as seen in the smaller units. The prehistoric ceramics were concentrated in Level 3 of Test Unit 11.

Initially, $5.6 \mathrm{~m}^{3}$ were allocated for the excavation of 1-x$1-\mathrm{m}$ test units. With TxDOT concurrence, the excavation of an additional three levels $\left(0.3 \mathrm{~m}^{3}\right)$ was needed to pursue the feature in TU 8.

\section{Results from Backhoe Trenches}

CAR exposed over $114 \mathrm{~m}$ of deposits in six backhoe trenches (BHTs 4-9) at the site (see Figure 5-1). These exposed long profiles, provided an opportunity to define the geomorphic context for the cultural materials and located some burned rock features. BHTs 4 and 5 were intentionally cut through Feature 1, a burned rock midden identified during augering, to expose the feature morphology and provide perpendicular views of the deposit. Three trenches (BHTs 4, 5, and 6) form a contiguous excavation that provides an adjoining set of profiles. Four trenches (BHTs 4, 6, 7, and 8) were excavated as parallel samples from the highest part of the site towards the lower northern margin. Based on the presence of significant gravel deposits in the bottom of BHT 8, BHT 9 was excavated westward toward BHT 7 to determine the relationship of the high energy deposits in BHT 8 to the minimal gravel sediments in BHT 7. Two burned rock features 
(Features 2 and 3) exposed in the western wall of BHT 8 were not recognized during monitoring. They were identified during trench profiling.

Each trench was excavated to a target depth of $1.5 \mathrm{~m}$ below modern ground surface, though some exceeded this depth due to the unconsolidated nature of the gravel. Each trench was about $135 \mathrm{~cm}$ wide and centered on a row of previously excavated auger tests.

A detailed geomorphological discussion is in Appendix A. Several artifacts and charcoal samples were collected from various backhoe trench profiles. Some tools, including end scrapers possibly associated with Features 2 and 3 in BHTs 8 and 9 , are among the collected artifacts, but no temporally diagnostic projectile points were recovered. Three charcoal samples collected from trench profiles were submitted to the Center for Applied Isotope Studies at the University of Georgia for AMS dating. These analysis reports are in Appendix G. These suggest Late Archaic, Late Prehistoric, and possibly Protohistoric deposits were present.

\section{Summary of Findings from Significance Testing}

Significance testing identified three prehistoric components, a Late Prehistoric Toyah interval component, an early Late Prehistoric Austin interval component, and a Late Archaic Frio component within the ROW crossing through site 41KM69. Prehistoric materials recovered span roughly 3,500 years as evidenced by the recovery of a Pedernales projectile point, several Frio points, a Darl point, two Edwards points, a possible Perdiz preform, and 48 bone-tempered ceramics. Testing excavations also documented four prehistoric features. The prehistoric features include an early Late Prehistoric burned rock midden (Feature 1), one hearth (Feature 2) and one burned rock cluster (Feature 3) that probably reflect a very Late Prehistoric Toyah interval occupation, and a burned rock cluster (Feature 5) that may date to the Initial Late Prehistoric Austin interval. In addition, occupations associated with Late Archaic Frio projectile points were found in different areas of 41KM69. Significance testing also identified evidence of an early twentieth century component confined to the surface and upper $20 \mathrm{~cm}$ of the site. Two historic features, Feature 4, a gravel driveway, and Feature 6 a concrete foundation, are thought to be remnants of a resort hotel. Based on the stratigraphic integrity of the prehistoric components, the available data types, and the potential of the site to contribute to a number of research themes, CAR recommended that 41KM69 met minimum eligibility criteria for listing on the NRHP.

\section{Data Recovery}

During the data recovery excavations, CAR concentrated excavations at four high-density areas identified during the significance testing. Each excavation block targeted a specific time period or feature to address research questions about the paleoenvironment of Central Texas and the behavioral, subsistence and technological changes exhibited by the prehistoric groups who lived there (see Thompson 2006). These excavation blocks were labeled "areas" and numbered one through four. The location of these Areas are illustrated in Figure 4-5 with the testing excavation units, trenches, and the features recorded during Phase II work.

The specific cultural periods targeted were the Frio component of the Late Archaic, the Initial Late Prehistoric Austin interval, and the Terminal Late Prehistoric Toyah interval as revealed in the artifacts and radiocarbon dates recovered from Phase II auger testing, backhoe trenching, and test unit excavation (Weston et al. 2004). Auger test data helped determine the horizontal limits of debitage and fire-cracked rock, while test units and backhoe trenches revealed good site integrity through the vertical distribution of artifact. The Phase II hand excavations also allowed CAR to associate the Late Prehistoric components with the Bk1 horizon and the Late Archaic component with the Ck horizon (Thompson 2006).

Based on the results of the Phase II testing at 41KM69, CAR proposed the excavation of $133.5 \mathrm{~m}^{3}$ of archeological deposits. However, the vertical and horizontal extent of the artifacts and features were somewhat different from the predicted Phase II results. In Areas 1, 2, and 3 the proposed terminal depths ended up short, so CAR requested additional time to excavate more levels in order to completely capture the lower components of the site. CAR also requested approval to expand the dimensions of Area 1 southward to examine the distribution of possible post molds and pottery in the upper levels. TxDOT Environmental Affairs division staff approved both requests.

\section{Results from Stage 1: Hand Excavations}

The following paragraphs explain the excavation details at four areas across site 41KM69 focusing on the physical location and volume of matrix removed. CAR completed all the excavations outlined in the original SOW and in the additional work request made after excavation began. TxDOT granted CAR permission to excavate $5.0 \mathrm{~m}^{3}$ beyond the scope of work to explore unexpected discoveries such as features uncovered at the proposed terminal depths. 


\section{Area 1}

Area 1 occupied the lower terrace and contained a buried Late Prehistoric (Toyah interval) component and a Late Archaic component. Weston et al. (2004) documented Leon Plain ceramics and teardrop-shaped unifacial "scrapers" occurring in conjunction with a peak in debitage quantities here, so the area was targeted for data recovery. In order to recover a rep- resentative sample of this Late Prehistoric component, CAR proposed to excavate a 6-x-7-m block consisting of $421-\mathrm{x}-$ 1-m units centered on Test Unit 11 (Figure 5-5). Area 1 excavations were guided by the soil horizons seen in Test Unit 11. This test unit was reopened and profiled prior to the excavation of the block. It provided a witness-profile that helped us recognize the subtle soil changes in the units and tie level descriptions to natural strata already described on site.

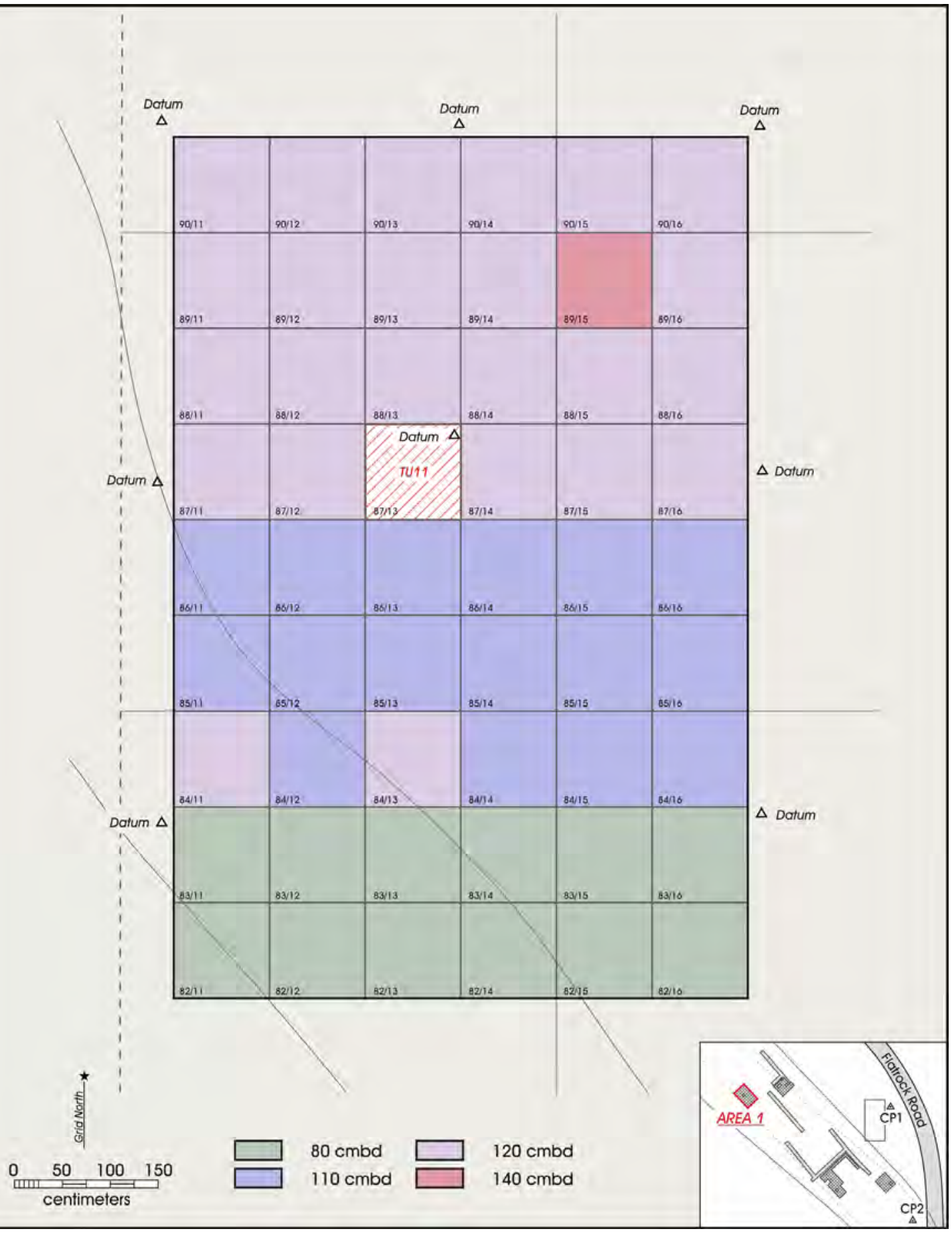

Figure 5-5. Area 1 was expanded vertically and horizontally to explore the distribution of artifacts and features. 
Accounting for the previously excavated Test Unit 11, CAR proposed to hand excavate five levels in each of 41 units (10$60 \mathrm{~cm}$ below average ground surface or $30 \mathrm{~cm}$ below datum) totaling 205 levels of the Late Prehistoric Toyah component. A peak in debitage from $60-110 \mathrm{cmbs}$ identified the lower Late Archaic component. Excavation of another five levels in each of the 41 units was necessary, resulting in excavation of 205 levels of the Late Archaic component as well.

The proposed excavation of 410 levels in 41 units of Area 1 occurred during the first sessions of the Phase III excavations. However, at the proposed terminal level of excavation $(110 \mathrm{cmbs})$, crewmembers unearthed a hearth feature (Feature 35) and noted relatively high artifact counts. This was an unexpected discovery because soils at this depth contain a high percentage of gravel (see Appendix A, Ck2 horizon) and do not appear to serve as a likely surface for human occupation. In order to explore the depth of in situ artifacts and intact thermal features, additional excavations continued down another $10 \mathrm{~cm}$ in four units (N84 E11, N84 E13, N87 E11 and N88 E16) and $30 \mathrm{~cm}$ in one unit (N89 E15; Figure 5-5).

The results of the extra effort into the Ck horizon served to prompt the excavation of one additional $10-\mathrm{cm}$ level across the northern half of the area (N87-N90 and E11-E16) totaling 25 additional levels across 25 units. CAR requested and received approval for the extra levels in order to explore what could be the earliest evidence of human occupation recorded at the site.

The discovery of possible post molds at approximately 60 $70 \mathrm{cmbd}$ and interesting artifact trends in the upper levels of Area 1 prompted the expansion of Area 1 southward by two meters across the entire block. The excavation of the additional 2-x-6 m divided into 12 units began at $30 \mathrm{cmbd}$ (the upper $30 \mathrm{~cm}$ were removed by hand but not screened) and terminated at $80 \mathrm{cmbd}$ totaling 60 additional levels. Because the level of origin of the possible posts required additional documentation, from 36-63 cmbd, excavation techniques changed based on recommendation from TxDOT to a vertical cutting back of the profile in ten-centimeter levels rather than the usual horizontal skimming and troweling technique. The benefit of this technique is that it exposes the upper boundary of the stains in profile instead of plan view. The stain boundaries are much easier to see from the side than from above. Understanding the true origin of these stains would allow us to assign them to relative occupations.

Altogether, CAR excavated 448, 10 -cm levels $\left(44.8 \mathrm{~m}^{3}\right)$ in Area 1. The final block measured 9-x-6 $\mathrm{m}$ with terminal depths varying from 80 to $140 \mathrm{cmbd}$. All beginning depths were the same at $30 \mathrm{cmbd}$.

\section{Area 2}

Area 2 is located on the lower terrace in the northeastern part of the site within the ROW (see Figure 4-5). Two test units (TUs 8 and 12) placed here during testing revealed two features ( 2 and 3 ) thought to date to the Terminal Late Prehistoric Toyah occupation as recognized in Area 1. The northern and eastern sides of Area 2 border Backhoe Trenches 8 and 9 , respectively. Reopening both of these trenches and the test units exposed soil horizons that helped guide the excavation of Area 2. Pecan trees stand in the block and along the southern edge. CAR originally proposed to excavate $17.4 \mathrm{~m}^{3}$ in 29 units in this area, but due to complications with laying a grid around previously excavated units and the pecan trees, the area ended up as an oddly configured block of 30 units (Figure 5-6). CAR also excavated small portions around the perimeter of Test Units 8 and 12 and an intact balk between Area 2 and the backhoe trenches as partial units. The upper $10 \mathrm{~cm}$ were removed mechanically, leaving hand excavations to start at $10 \mathrm{cmbs}$ and to terminate at $70 \mathrm{cmbs}$.

As in Area 1, lithic artifacts (such as Montell and Pedernales projectiles) and thermal features (such as fire-cracked rock clusters) lay at the $\mathrm{Ck}$ horizon near the terminal excavation depth of $70 \mathrm{cmbs}$. Due to these encounters and the continued moderate artifact densities, CAR took exploratory measures in unit N77 E29 to test the depths of artifacts within the Ck horizon and inform decisions concerning deeper excavations. This unit was excavated an additional $50 \mathrm{~cm}$ beyond the original scope of work. Ultimately, CAR proposed, and TxDOT agreed to, an additional single $10-\mathrm{cm}$ level across the block to capture this apparent Late Archaic component. Including the additional work beyond the original SOW, CAR excavated $21510-\mathrm{cm}$ levels within the 30 full 1-x-1-m units. This comes to $21.4 \mathrm{~m}^{3}$ excavated from Area 2, not including partial units around the test units and in the balk (Figure 5-6).

\section{Area 3}

CAR completed the excavation of two adjoining blocks in Area 3 on the slightly higher terrace to examine the burned rock midden (Feature 1) and possible activity areas associated with the Initial Late Prehistoric feature (see Figure 4-5). Backhoe Trenches 4 and 5 border Area 3 to the east and north, respectively. Portions of both of these trenches were reopened. Test Unit 10 was also reopened and profiled. Excavation of a large block of 65 units to explore areas away from the midden as well as an L-shaped block of 18 units to explore the midden proper then proceeded (Figure 5-7). Unexpected discovery of a vast system of rodent burrows, pecan tree roots, and high artifact recovery within the larger block led to a slight variation of the original proposal. Unit N36 E19 remained unexcavated due to the rodent disturbance seen in the larger block (Figure 5-7). 


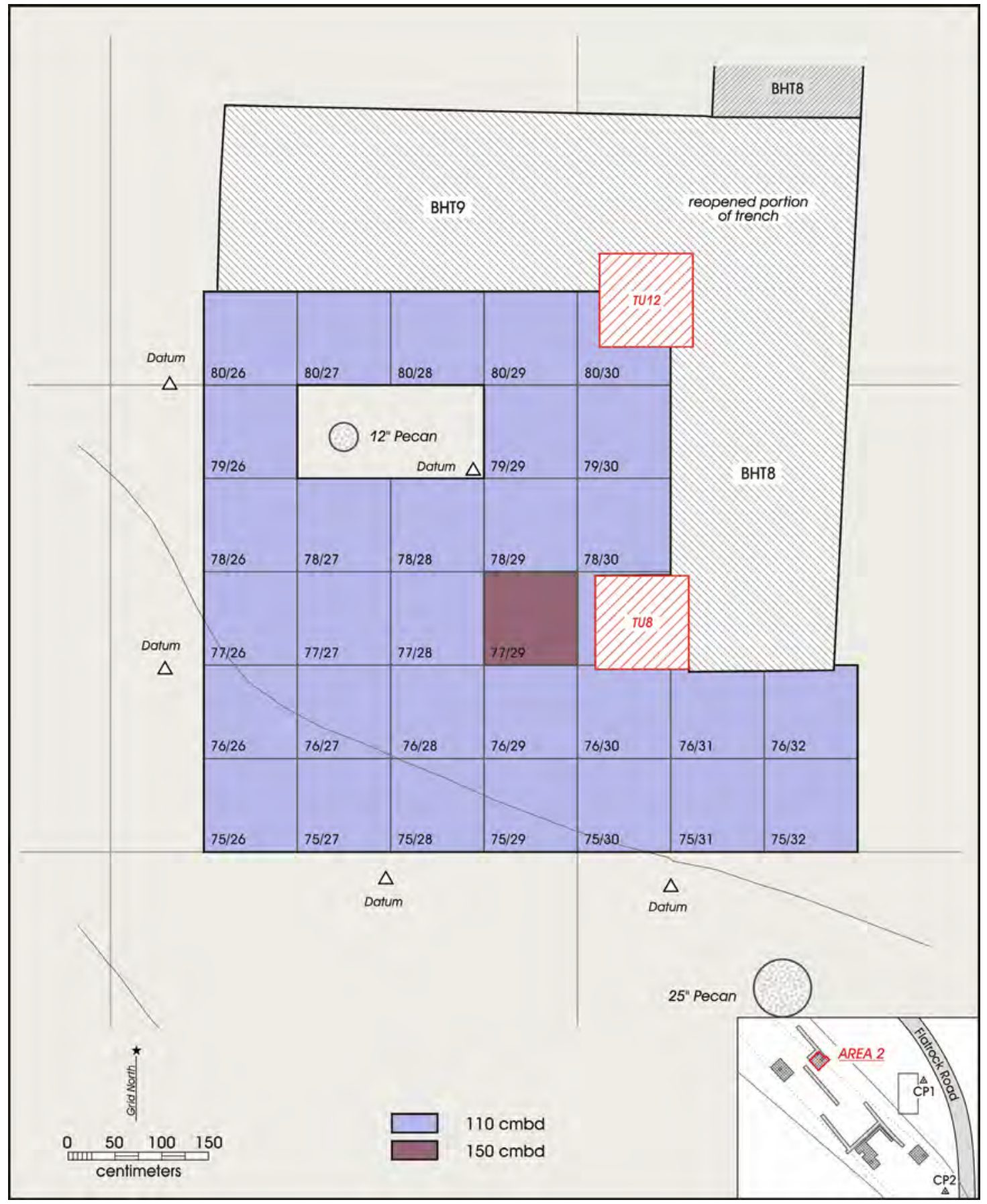

Figure 5-6. Area 2 was excavated into the heavy gravel soils of the Ck soil horizon.

The L-shaped block crossed through the expected center of the midden and across its western and southern boundaries. A 9-x-1-m section bordering Backhoe Trench 5 and an 8-x1-m adjoining section along Backhoe Trench 4 were handexcavated. The orientation of the L-shaped excavation block allowed sampling of both the central and peripheral deposits within the midden. All fire-cracked rock from this block was size-graded in the field. This provided the opportunity to collect data on midden development and to explore the possible relationship between fire-cracked rock size and pro- venience in the midden. TxDOT removed the upper $10 \mathrm{~cm}$ of the midden overburden prior to hand-excavations. The original SOW defined a terminal depth of $90 \mathrm{cmbs}$, which would have resulted in the excavation of eight levels within 18 units $\left(14.4 \mathrm{~m}^{3}\right)$. Since the purpose of these units was to explore the burned rock midden, instead of following this strict regimen of initial and terminal depths, individual units stepped down to follow the depth of the midden soils and fire-cracked rock resulting in varying terminal depths across the block. In some units, the terminal depth of fire-cracked rock was much lower 
than anticipated and resulted in the excavation of levels below the proposed terminal depth in order to fulfill the goals of the fieldwork. Excavation continued within the midden two levels beneath the fire-cracked rock zone and into the lower $\mathrm{Ck}$ horizon. This effort resulted in 173 excavated $10-\mathrm{cm}$ levels within $171-\mathrm{x}-1-\mathrm{m}$ units $\left(17.3 \mathrm{~m}^{3}\right)$. This estimate is high, as it includes fill from portions of Test Unit 1 in N29 E28 and Test Unit 3 in N36 E27.

The adjacent block was much larger with 65 1-x-1-m units (Figure 5-7). This block was oriented around standing pecan trees and over Test Unit 10. Its location was chosen to explore potential activities associated with the midden and a lithic concentration seen in auger test data from the Phase II testing (see Figures 5-3 and 5-4). Excavations in Test Unit 10 recovered an Edwards arrow point in Level 5 (40-50 cmbs) and a charcoal sample (Appendix G: UGA 14032) from 108 cmbs. The charcoal sample returned a calibrated date of A.D. 550-780 (95.4 percent probability) indicating that the materials between Levels 5 and 11 are probably contemporaneous with the early formation of the midden during the Initial Late Prehistoric.

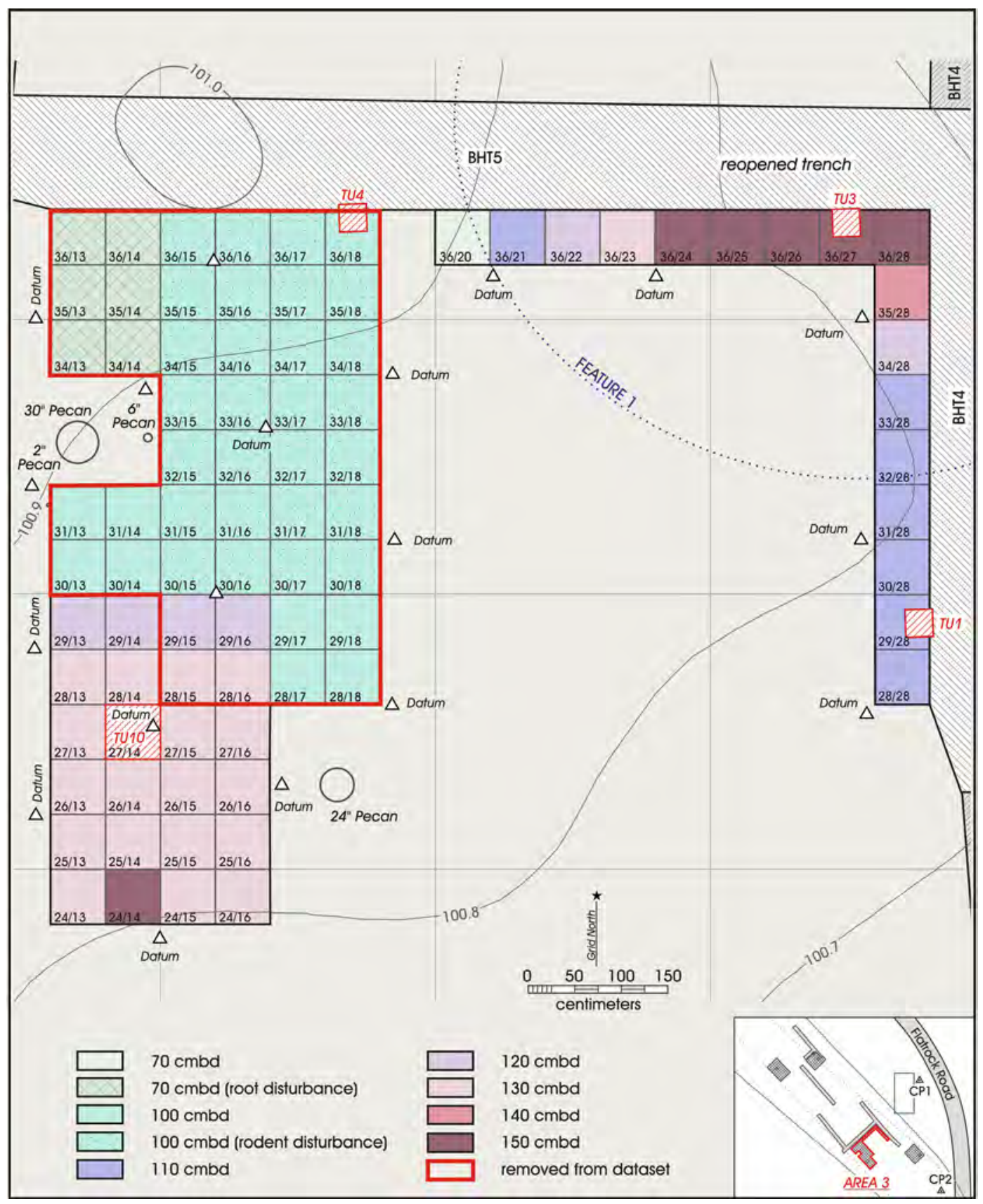

Figure 5-7. The early Late Prehistoric component of 41KM69 was explored in Area 3 where excavation levels terminated at various depths. Many of the units were disturbed. 
The original proposal for data recovery excavations was to begin at $40 \mathrm{cmbs}$ and terminate at $90 \mathrm{cmbs}$ resulting in five levels removed across the 65 units $\left(32.5 \mathrm{~m}^{3}\right)$. CAR completed this work as proposed with the exception of units N34-36 and E13-14, which terminated after two levels due to the density of large pecan tree roots. Much of this block was highly disturbed down to the proposed terminal excavation level. From N30-N36 and E15-E18, rodent burrows, nests, and historic and modern trash were uncovered. Units N28-29 and E17-18 also had major root disturbance and minor rodent disturbance. The remaining units in the south of the block contained intact deposits. These intact deposits extended increasingly deeper the farther south excavation progressed. In other words, the cultural deposit sloped down to the south. Because over 50 percent of the block was in a disturbed context, it became important to investigate the high density of artifacts in the intact southern portion of the block. CAR took exploratory measures to determine the depth at which artifact densities began to decline. Excavation continued in units N24-29 E13-16 another $20 \mathrm{~cm}$ deeper with the same high artifact counts. Unit N24 E14 was then excavated an additional $30 \mathrm{~cm}$ to reach a zone of decreased artifact recovery or a sterile level. CAR ultimately proposed, and TxDOT agreed to, an additional $10 \mathrm{~cm}$ of excavation in units N24-28 E13-16 to recover Late Prehistoric artifacts from this part of Area 3. The final artifact sample came from the excavation of $15510-\mathrm{cm}$ levels in 31 units $\left(15.5 \mathrm{~m}^{3}\right.$; see Figure 5-7).

\section{Area 4}

Excavations of Area 4 took place on the upper terrace as well (see Figure 4-5). Excavation of Test Unit 9 during the testing phase uncovered a Late Archaic Frio component from 50-120 cmbs including a burned rock feature (Feature 5). The Area 4 block overlay Test Unit 9 in order to record the rest of Feature 5 and to recover a larger sample of the Frio component. In the SOW, CAR proposed to excavate seven levels in each of 41 units $\left(28.7 \mathrm{~m}^{3}\right)$. These excavations were to begin at $50 \mathrm{cmbs}$ and terminate at $120 \mathrm{cmbs}$ with the upper $50 \mathrm{cmbs}$ removed with a smooth bucket machine.

The Area 4 block measured 6-x-7-m containing 42 1-x-1-m units including Test Unit 9. Test Unit 9 was reopened for profiling during the excavation of the 41 units for the Phase III work. TxDOT removed the upper $40 \mathrm{~cm}$ of Area 4 with a backhoe. Crewmembers leveled an additional $5 \mathrm{~cm}$ by hand. This reached $45 \mathrm{cmbs}$, approximately $5 \mathrm{~cm}$ above the proposed initial level. Excavation stopped slightly higher due to encounters with possible burned rock features thereby adding an additional $5 \mathrm{~cm}$ of hand-excavated matrix across the block.
Large pecan trees bordered the block to the east and south and proved problematic in unit N12 E35. Here, excavation stopped due to the density of large roots at $120 \mathrm{cmbd}, 30 \mathrm{~cm}$ short of the proposed terminal excavation depth. The crew completed the excavation of seven levels in the remaining units as proposed, as well as an additional 5-cm level added due to the unexpected shallow nature of the thermal features (Figure 5-8). This totals $28410-\mathrm{cm}$ levels from 41 units and 415 -cm levels from 41 units $\left(30.45 \mathrm{~m}^{3}\right)$.

\section{Results from Stage 2: Gradall Excavation and Monitoring}

CAR staff returned to 41KM69 August 15-26, 2005 to complete the grading portion of the fieldwork. Portions of the site between Areas 1 and 2, Areas 3 and 4 and the area surrounding the burned rock midden were scraped in $10-\mathrm{cm}$ increments with a Gradall (see Figure 4-7).

In the northernmost section, between Areas 1 and 2, approximately $100 \mathrm{~m}^{2}$ were excavated to $70 \mathrm{cmbs}$ in order to capture the levels of the site that contained the possible post molds. The central section targeted the burned rock midden, which was mapped at each $10-\mathrm{cm}$ level to record the changes in shape. The central section was approximately $250 \mathrm{~m}^{2}$ and was excavated to a depth of $120 \mathrm{cmbs}$. The final, southern-most section between Areas 3 and 4 measured approximately 250 $\mathrm{m}^{2}$ and reached a depth of $130 \mathrm{cmbs}$.

\section{Results from Stage 3: Testing of Shifted Right-of-Way}

Results from testing the shifted right-of-way showed a sparse layer of lithic debitage across the western line at 40 to 120 below the upper disturbed surface of the site (see Figure 4-10). The fifty-seven auger tests produced no more than five artifacts per level and no formal stone tools. In most cases the upper $40 \mathrm{~cm}$ of the site were in a highly disturbed context with gravels resembling road fill and historic and modern trash such as wire nails, glass and plastic. The lower levels, 40-120 cmbs, contained faunal material (mussel shell, entified bone, and snail shell). Root disturbance was common across the study area. Burned rock was also ubiquitous across the expanded section of ROW but no features were identified in the walls of the auger tests.

\section{Summary}

This chapter described the vertical and horizontal scope of CAR's excavations at 41KM69, a brief description of the sig- 


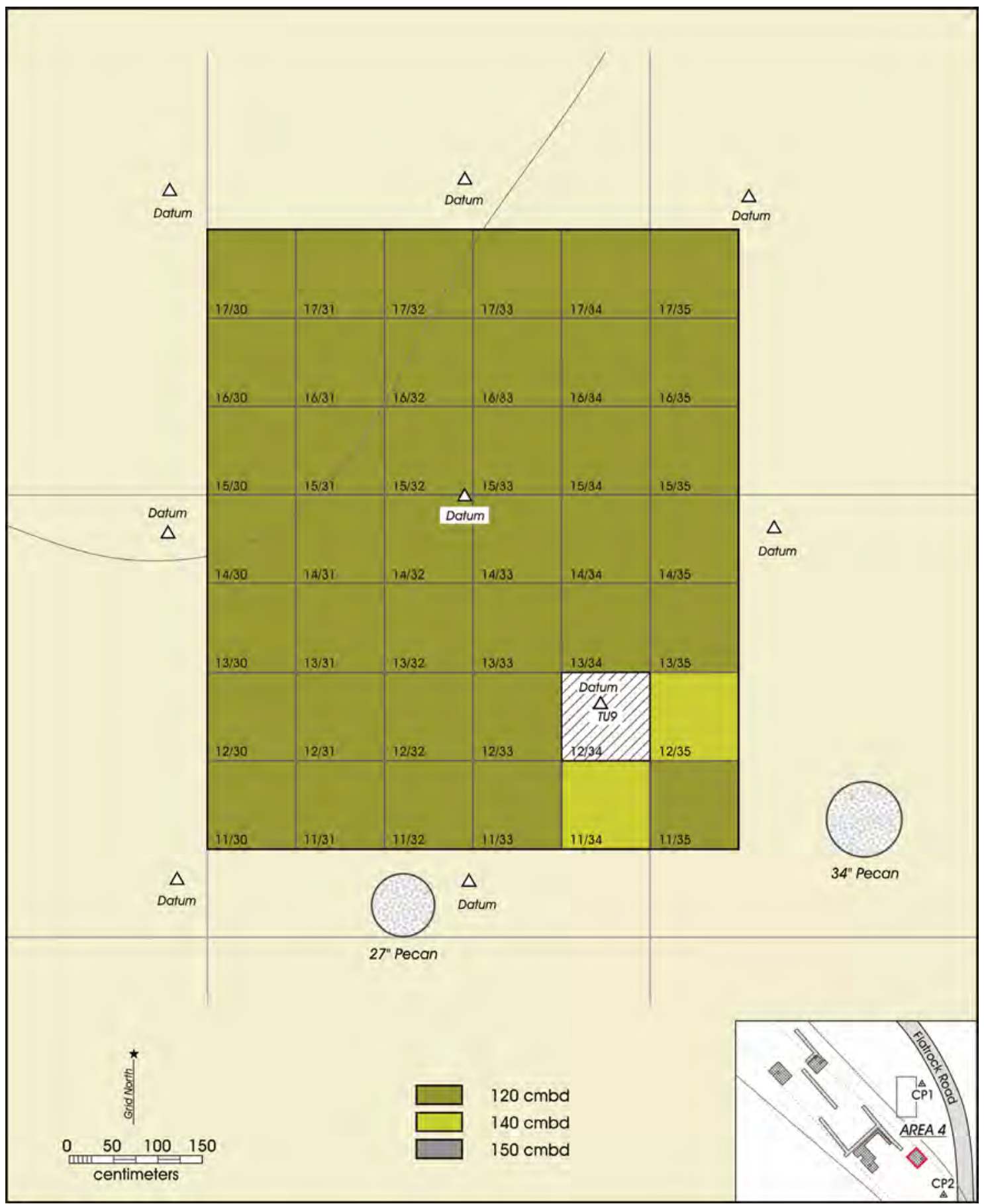

Figure 5-8. Map of Area 4 showing unit designations and terminal depth of the excavations.

nificance testing, and why excavation occurred in the four areas during data recovery. CAR hand excavated $156.65 \mathrm{~m}^{3}$ of site 41KM69. This work targeted three periods of Texas prehistory: the Late Archaic, Initial Late Prehistoric, and Terminal Late Prehistoric as identified during the testing phase. In general, the excavation went as planned though the deposits at the site lay deeper than originally thought. In these instances, alteration to the original SOW included deeper terminal excavation depths. This occurred in Areas 1, 2, and 3. In one instance in Area 1, the excavation expanded horizontally to explore the origin of possible post molds and the distribution of ceramics and other Late Prehistoric artifacts. After the completion of the hand-excavations in all areas, monitoring of Gradall scraping of the site between the excavation blocks occurred. Finally, 57 auger tests were excavated within a portion of the ROW that previously had not been tested. 



\title{
Chapter 6: Site Stratigraphy, Artifact Distribution, and Analytical Units
}

\author{
Jennifer L. Thompson
}

Information on the geomorphological formation of 41KM69 came from the examination of six backhoe trenches and four excavation blocks dug during both phases of the project. Site 41KM69 occupies two landforms within the project boundaries. These two terraces rise south of the South Llano River and have approximately $1.0 \mathrm{~m}$ difference in elevation. Excavation Areas 1 and 2 occupy the lower terrace and Areas 3 and 4 occupy the upper terrace. The field crew troweled, examined, and compared the walls of the data recovery excavation blocks to the soil data from the testing phase (see Appendix A). CAR mapped soils, features, artifacts and other anomalies from two perpendicular walls of each excavation block except in Area 2, where detailed soil profiles of adjacent BHT 8 already exist. Areas occupying the same terrace have common, but not identical, profiles though soils are similar across the entire project area on both terraces. This chapter describes the site stratigraphy as it relates to the artifacts present in each excavation area and time period. Findings of both phases of excavation are discussed with descriptions of the integrity of the blocks. The final section outlines the findings by Analytical Units used in the analysis: Middle Late Archaic, Terminal Late Archaic, Initial Late Prehistoric, and Terminal Late Prehistoric.

\section{Areas 1 and 2}

Areas 1 and 2 sit on the lower terrace of 41KM69 approximately $10 \mathrm{~m}$ from each other (see Figure 4-5). This lower terrace is the younger of the two terraces we excavated. Both areas shared a common soil profile containing similar artifact assemblages at corresponding depths, though artifacts of similar age on the upper terrace are at shallower depths than those on the lower terrace. The surface soils overlie an AB-Bk-Ck sequence in Area 1, whereas in Area 2 the A3 horizon directly overlies the Bk1 (Figures 6-1 and 6-2). The most dramatic differences in the two areas are the lack of ceramics and an AB soil horizon in Area 2.

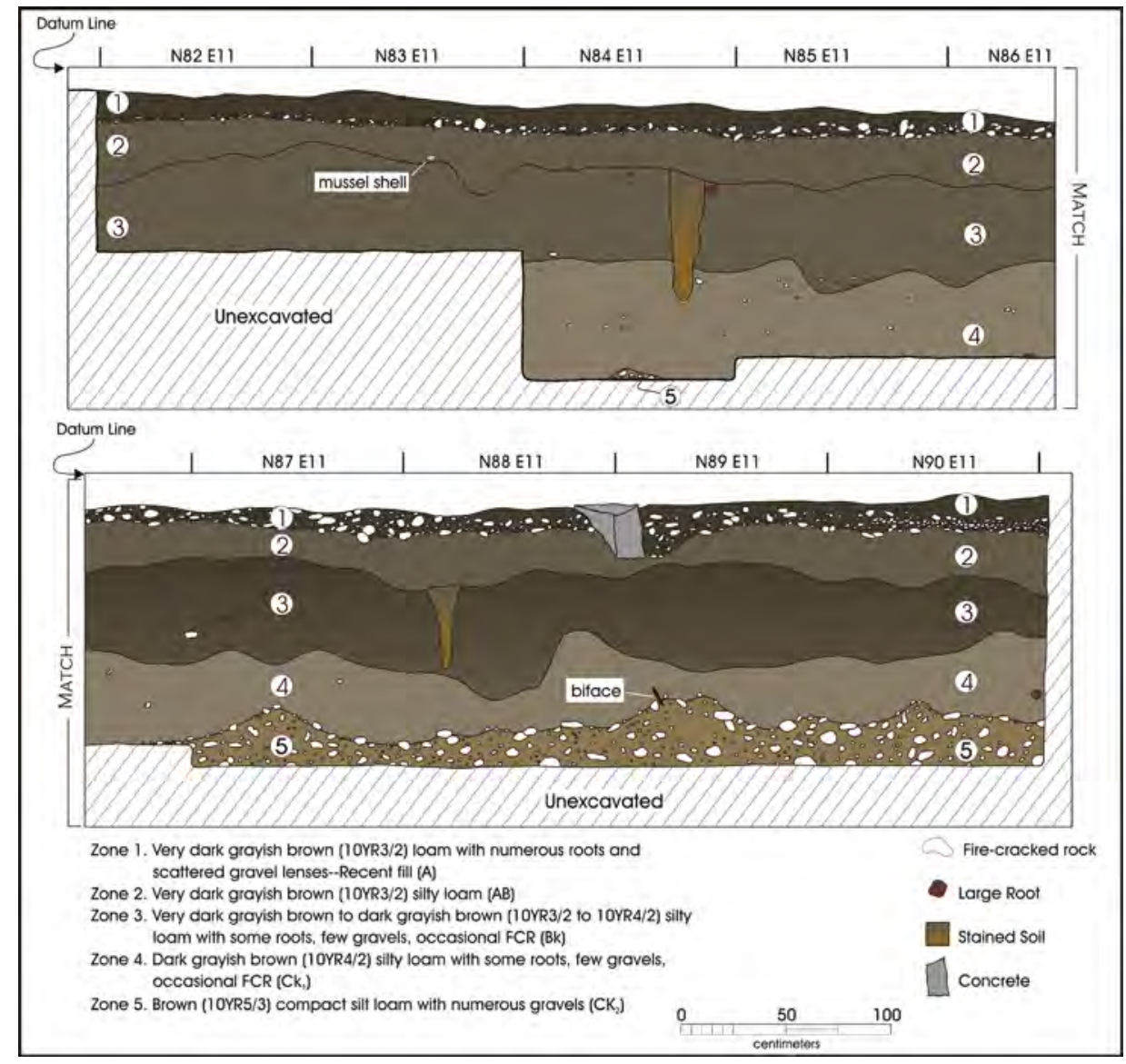

Figure 6-1. The western profile in Area 1 illustrates an $A B-B k$-Ck sequence. 


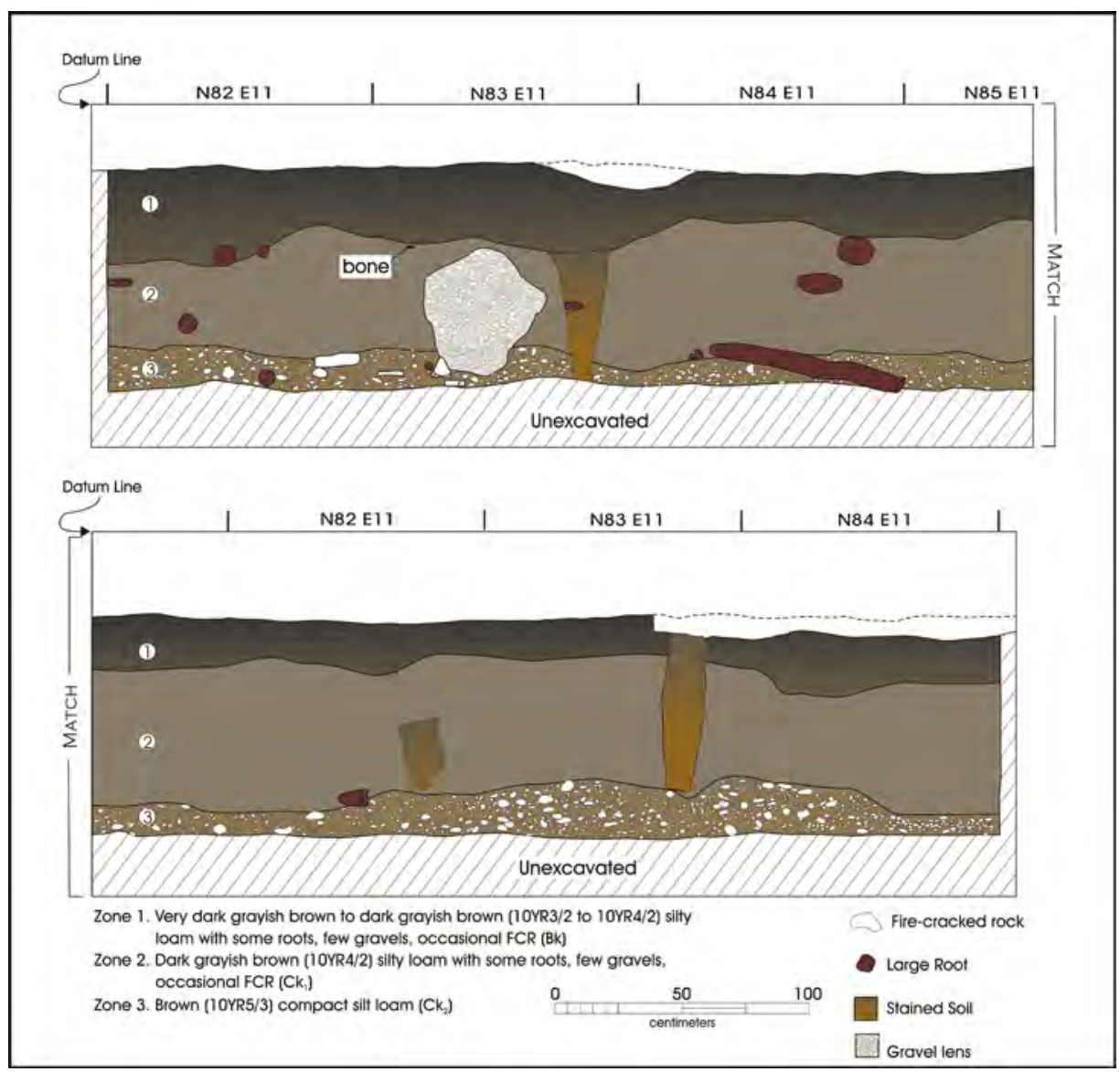

Figure 6-2. The southern profile of Area 2 shows an absence of the AB horizon.

We chose Areas 1 and 2 for excavation because testing indicated that the Late Prehistoric and Late Archaic components were well preserved. Test Unit 11 in Area 1 produced Late Prehistoric ceramics and stone tools in Levels 3-4 and 8-9. The upper peak was associated with Perdiz arrow points and unifacial end scrapers. The lower peak returned Frio projectile point forms that indicate a Late Archaic occupation.

\section{Results of Significance Testing}

Area 2 had been excavated along its northern and eastern walls by Backhoe Trenches 9 and 8, respectively. Test Units 8 and 12 were then excavated into the wall of Backhoe Trench 8 .

These excavations produced no diagnostic artifacts, but did uncover thermal rock features (Features 2 and 3 ) associated end scrapers and bison bone. The source of artifacts within these units was difficult to discern, but upper Level 5 peaks in debitage appear to be associated with the Bk1 deposit and a lower Level 7 increase crosses the $\mathrm{Bk} 2 / \mathrm{Ck}$ interface in Test Unit 8.

\section{Occupations}

Block excavations revealed the same soil profiles and artifact distribution observed in testing. The historic element of the site is largely within the A horizon, though we recovered some historic artifacts from lower horizons. There may be two Terminal Late Prehistoric occupations of the site on the surface of the $\mathrm{Bk} 2$ horizon, within the $\mathrm{Bk} 1$ and in the AB horizons. These include a possible Toyah interval component, though the Toyah artifact assemblages from Areas 1 and 2 differ. The Bk2 horizon contains the Late Archaic component, which extends through the Ck1 and Ck2 horizons. The vertical pattern of artifacts in these two areas may indicate two Late Archaic occupations: one at the top of $\mathrm{Ck} 1$ extending up through the Bk2 horizon and a second at the top of the $\mathrm{Ck} 2$ extending up through the Ck1.

\section{Integrity}

Though we retrieved some historic artifacts from the $\mathrm{Bk}$ horizon in both Areas 1 and 2, the amounts were negligible compared to the numbers recovered from the A horizon and we believe the data recovered from this portion of 41KM69 comes from an undisturbed context. 
The highest level of historic and prehistoric artifacts cooccurring is in the A horizon of Area 1. Most of the A horizon was removed by mechanical means because the investigation targeted the prehistoric component of the site, not the historic. However, our hand-excavations did recover some historic artifacts. Most of those found were in the levels above the AB horizon in Area 1. These levels with historic intrusion also contained two un-typed dart points and several other stone tools types. These were all unifacial lithic tools, many reminiscent of Toyah scrapers.

\section{Artifact Distribution}

In Area 1, a soil change was noted at the bottom of the A horizon in Level 5, marking the upper boundary of the $\mathrm{AB}$ at approximately $42 \mathrm{cmbd}$. In the $\mathrm{AB}$, debitage counts increased and reached their first peak at the transition between the $\mathrm{AB}$ and $\mathrm{Bk} 1$ at approximately $55 \mathrm{cmbd}$. In the $\mathrm{AB}$, we noted minor historic intrusions along with the first collection of native ceramics and Perdiz projectile points. The typical Toyah-shaped unifaces also were associated with the ceramics and Perdiz points, though the Perdiz points lay at lower elevations than the unifaces and ceramics, which co-occurred in Levels 4 and 5 (Figure 6-3). Minor historic disturbance reached the $\mathrm{AB}$ horizon in Level 5 , where we documented a few historic artifacts. If the A horizon dipped down somewhat, these artifacts could have been associated with the other historic artifacts recorded in Level 4 of the A horizon.

In Area 2, no ceramics or Perdiz projectile points were found, but artifact counts did peak in Level 5 at the A horizon interface with the Bk1 horizon (an AB horizon was absent; see Figure 6-2). Several unifacial tools typical of the Toyah interval were recovered near to but slightly higher than Features 2, 3, and 3B (Figure 6-4). Both areas contain a Late Prehistoric component associated with the upper boundary of the Bk1 horizon.

The surface of the Bk2 marks the approximate depth (ca. 60-75 cmbd across both Areas 1 and 2) where we noticed the possible post mold features of Area 1, Features 2 and 3 uncovered during testing, and Feature $3 \mathrm{~B}$ recorded in the data recovery excavations of Area 2. Several more stone tools lay in proximity to these rock features along with a bison tibia. Here too, artifact counts nearly double from Level 7 to Level 8 in Area 2 at this same interface. This peak is the same discussed from the Test Unit 8 testing results. The artifact assemblage most likely dates to the Late Prehistoric based on radiocarbon assays returned from Feature 2 (Table 1-1). These dates returned both Late Prehistoric and Protohistoric possibilities, but the associated bison bone fragments and unifaces suggest a Late Prehistoric Toyah occupation. The

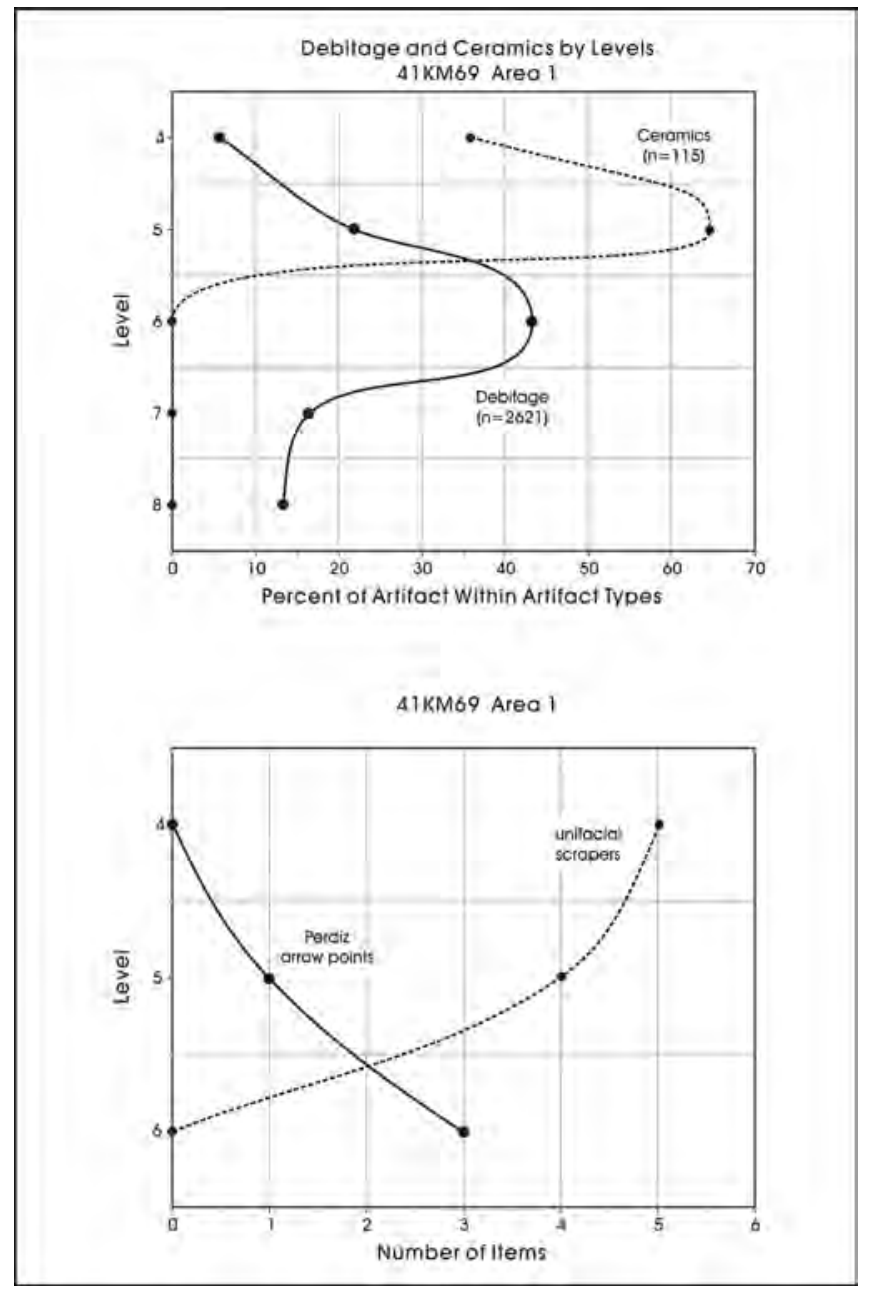

Figure 6-3. The distribution of Late Prehistoric artifacts in Area 1 shows Perdiz projectile points beneath ceramics and unifaces when they are often clustered together in the Toyah interval.

post mold features were recognized at a soil change and therefore could have originated at higher levels within the Terminal Late Prehistoric.

Within the Bk2, below the surface of Features 2 and 3 and the high density of debitage, we recovered Frio and Castroville projectile point forms, which are typical of the Late Archaic. Also, below this interface and within the Bk2 another rock feature was uncovered (Feature 40) in Area 2, but artifact counts remained low in the $\mathrm{Bk} 2$ levels in both areas. We continued to recover a few historic artifacts in the Bk horizon in Area 1. The historic artifacts likely slipped down through the root molds. Regardless of the handful of historic artifacts, we feel the deposits in the Bk2 horizons are intact and indicate a Late Archaic Frio occupation based on projectile point forms.

An increase in artifacts at the transition from the Bk2 to the $\mathrm{Ck} 1(\sim 95 \mathrm{cmbd})$ horizon is more prevalent in Area 1 


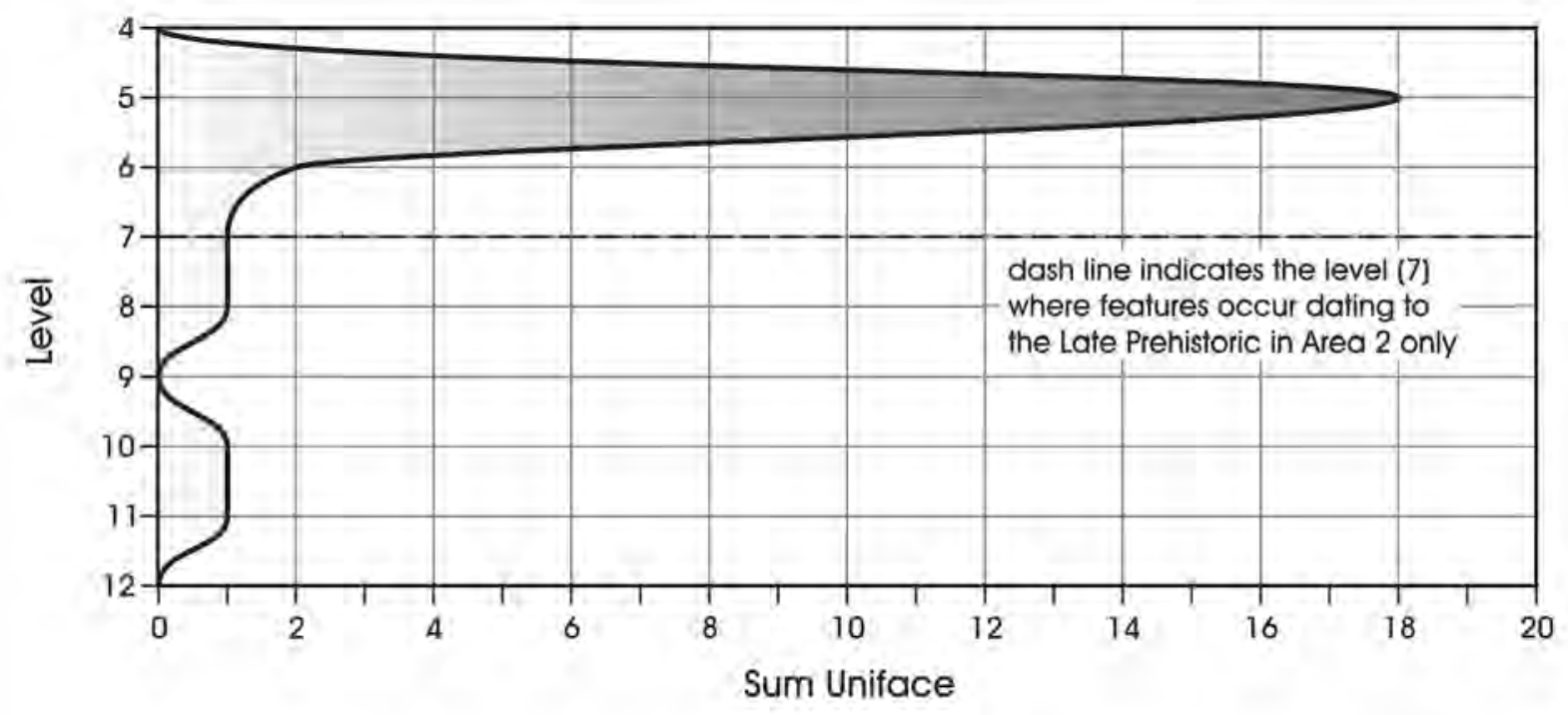

Figure 6-4. This graph illustrates the distribution of unifaces in proximity to possible Late Prehistoric features in Area 2.

than in Area 2 as reflected in the testing data as well. While Area 2 shows a slight rise in debitage and tool counts, Area 1 artifacts more than double. The Ck1 in Area 1 produced the most artifacts per 10-cm level than any other horizon at the site.

Frio projectile point forms remain the most frequent point type but occupy the same levels as Pedernales and Montell projectile forms in the $\mathrm{Ck} 1$ in both areas. Both areas also demonstrate a dramatic drop in artifacts and tools from the $\mathrm{Ck} 1$ to the $\mathrm{Ck} 2$. Near this interface $(\sim 128 \mathrm{cmbd})$, however, we recorded Features 35 and 36 in Area 1, and Features 42, 43, 55, and 56 in Area 2 marking a lower Late Archaic occupation. Feature 80 was uncovered at this level during grading. This was unexpected since the horizon contained such a high percentage of gravels and did not seem a likely zone for human occupation. Though we witnessed artifacts at this level during testing, their presence within a zone produced by such high energy, called into question their primary location. However, the presence of features, which were not rolled in by water, and sharp-edged tools suggest that there was sufficient time for camping on the heavy gravels before the next horizon was deposited. We recorded no anomalous artifacts at this depth, so we believe this early deposit at the site is intact. AMS dating of a charcoal sample from Feature 35 in Area 1 returned at date of $2550 \pm 50$ B.P. (Delta 13 corrected).
The Ck2 horizon in Area 1 does not appear at uniform levels across the block. Soil changes occur higher in the eastern units than the western units. In some places, the $\mathrm{Ck}$ did not appear until $110 \mathrm{cmbd}$. The same trend is apparent north to south. In the northern units, the heavy gravels of the Ck2 occur at a shallower depth than those of the southern units. In fact, in the southwestern units, we never reached the same high percentage of gravels as that found in the northern units (Figure 6-5).

The vertical distribution of artifacts in Area 1 shows trends similar to those found in Test Unit 11 in that there are two peaks in the number of artifacts (Figure 6-6). In the test unit, there was a peak in debitage from $46-66 \mathrm{cmbd}$ and another at 96 cmbs.

This corresponds to the artifact increases at the upper boundaries of the Bk1 horizon (the Terminal Late Prehistoric component) and the Ck1 horizon (containing a Late Archaic Frio Component), respectively. Across the entire block in Area 1, debitage counts peak in Levels 6 and 11. The lowest return for debitage between these peaks was in Level 8. Tool and core counts peak in Levels 5 and 10 with a low point in Level 7 between these. A third jump occurs below in Level 13 at Feature 35 and drops off again in Level 14. In Area 2, these same patterns occur in Levels 5, 8, and 14, but on a smaller scale (Figure 6-6). 


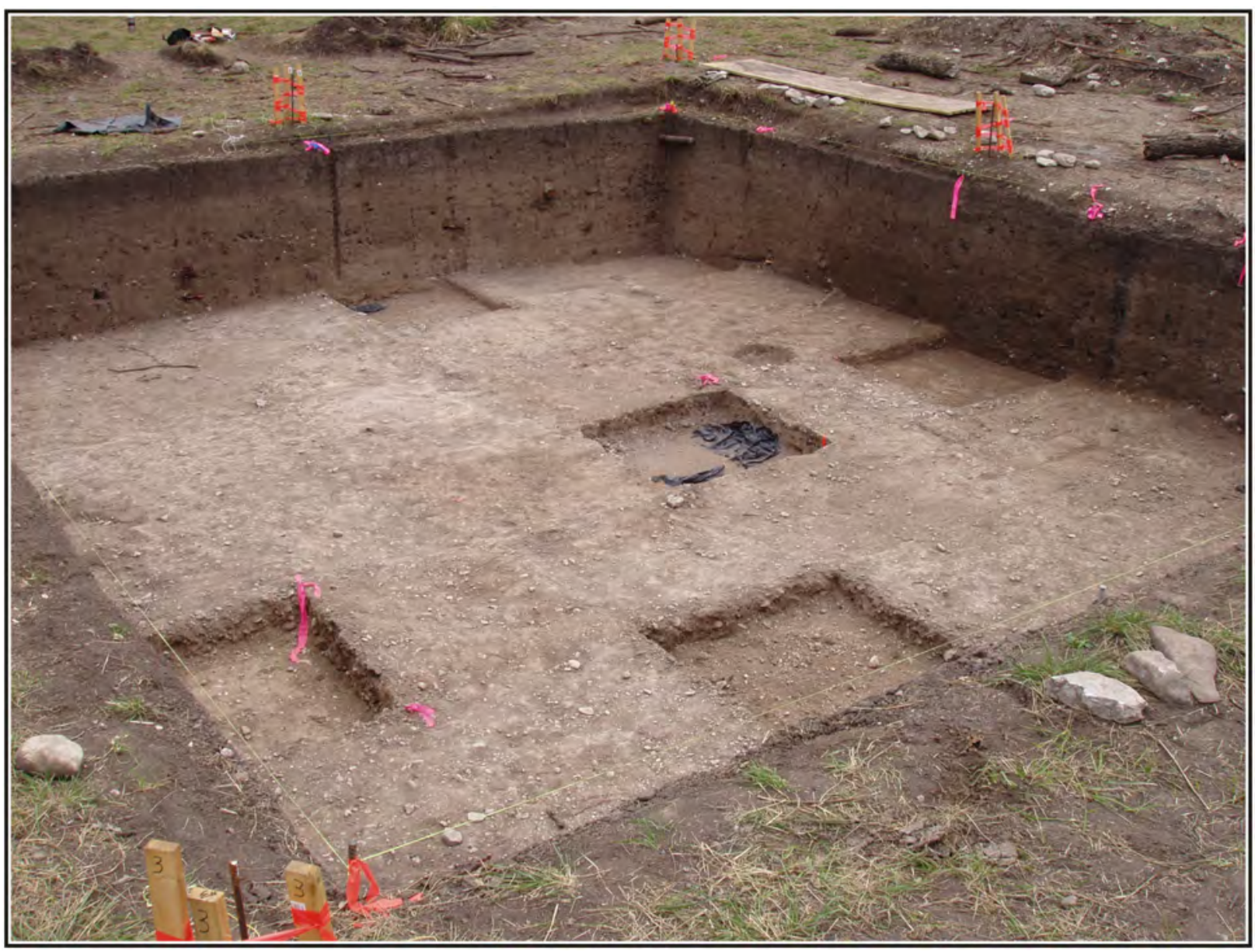

Figure 6-5. The Ck horizon contained a Late Archaic component with features.

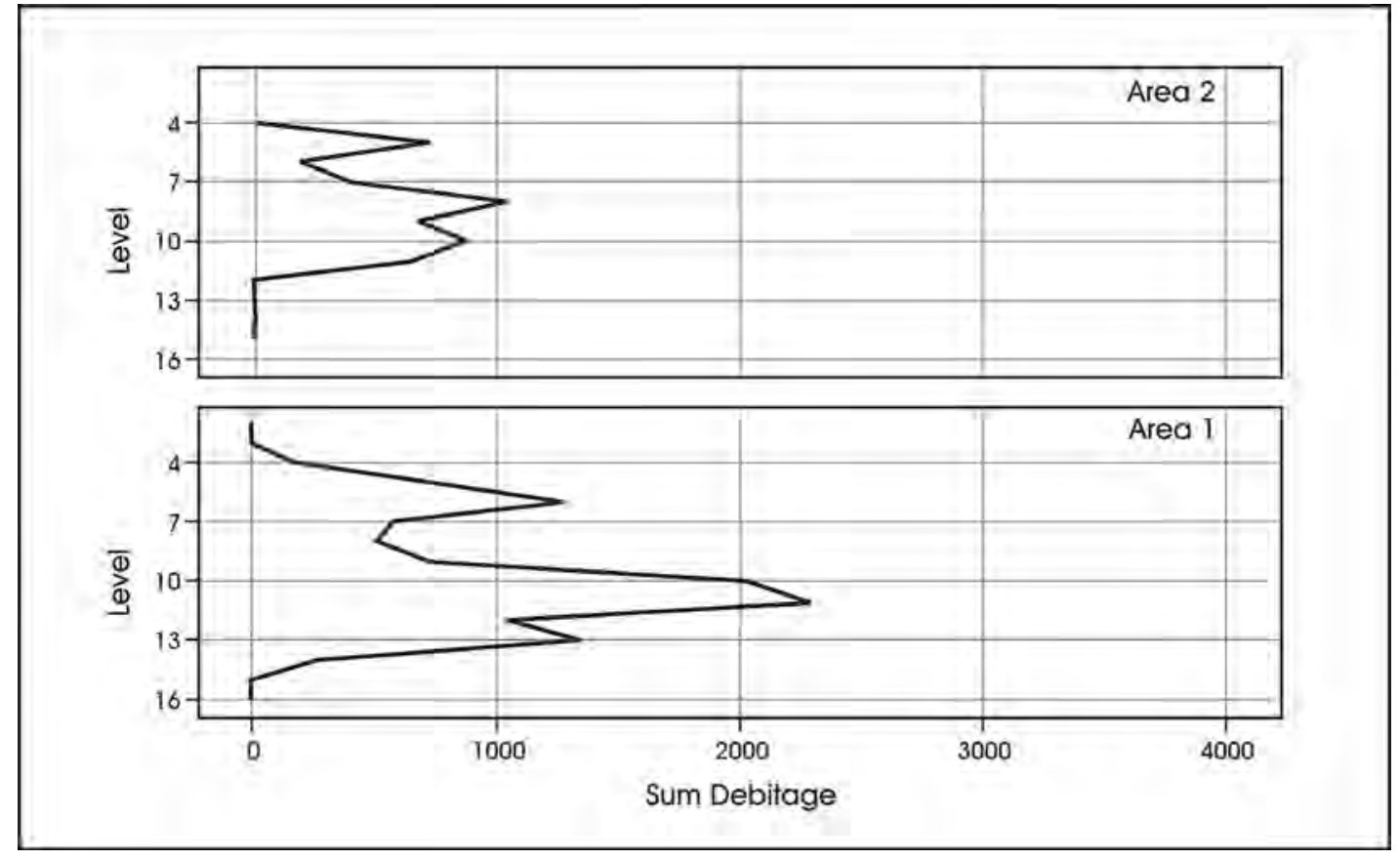

Figure 6-6. Debitage peaks in Areas 1 and 2 correspond with soil changes. 


\section{Areas 3 and 4}

Areas 3 and 4 and Feature 1 sit on the upper terrace, an older landform that still exhibits the same soil profiles as Areas 1 and 2 on the lower terrace (Figure 6-7 and 6-8). This terrace sits approximately $1.0 \mathrm{~m}$ above and to the south of the lower terrace. Soils here represent recent epipedons overlying an $\mathrm{AB}-\mathrm{Bk}-\mathrm{Ck}-\mathrm{Ab}-2 \mathrm{Ck}$ sequence witnessed in Backhoe Trenches 4, 5, and 6 (See Appendix A). Recent historic disturbance, in the form of a gravel lens (Feature 4), sits at the base of the A2 horizon. However, the main feature of interest on this terrace is the Late Prehistoric burned rock midden (Feature 1) that lies between the excavation blocks of Areas 3 and 4. Feature 1 is associated with the Bk soils dated to the early Late Prehistoric (1180-970 B.P.) Austin interval and rests on the $\mathrm{Ck}$ horizon. Our excavations in Area 3 focused on the midden and nearby units that potentially demonstrate activities associated with the midden during the Initial Late Prehistoric. Excavations in Area 3 began at the $\mathrm{Bk}$ horizon, terminated at the $\mathrm{Ck}$, and therefore did not reach the depth of the buried paleosol, which is the lower Ab horizon.

\section{Results of Significance Testing}

Three trenches (Backhoe Trenches 4, 5, and 6) were excavated in Areas 3 and 4 along with six test units (Test
Units 1-4, 9, and 10). These excavations explored the burned rock midden and provided an estimate of the size and depth of Feature 1. Test Units 9 and 10 both showed three artifact peaks in Levels 4, 6-8, and 12. Testing results suggested that the upper peak is likely Late Prehistoric while the lower two peaks date to the Late Archaic; however, this was not confirmed with artifacts or ${ }^{14} \mathrm{C}$ dates. The other test units were equally problematic in terms of dating and artifact recovery. The best results came from Test Unit 1, which showed an artifact density peaking around the Bk unit, which was dated to 1180-970 B.P. in Backhoe Trench 5.

\section{Occupations}

Block excavation results differed from the results of Phase II work. The data recovery efforts began at lower elevations than the testing, which began at the surface. Despite the mechanical removal of upper components, we still encountered numerous historic artifacts in Area 3. Disregarding those units that lack integrity, we began in the Late Prehistoric, Austin interval in Areas 3 and 4.

This occupation was limited to the Bk horizon. Few Late Prehistoric diagnostic artifacts help to date the Bk so we rely on the radiocarbon date mentioned above taken from Backhoe Trench 5. The Late Archaic component of the site

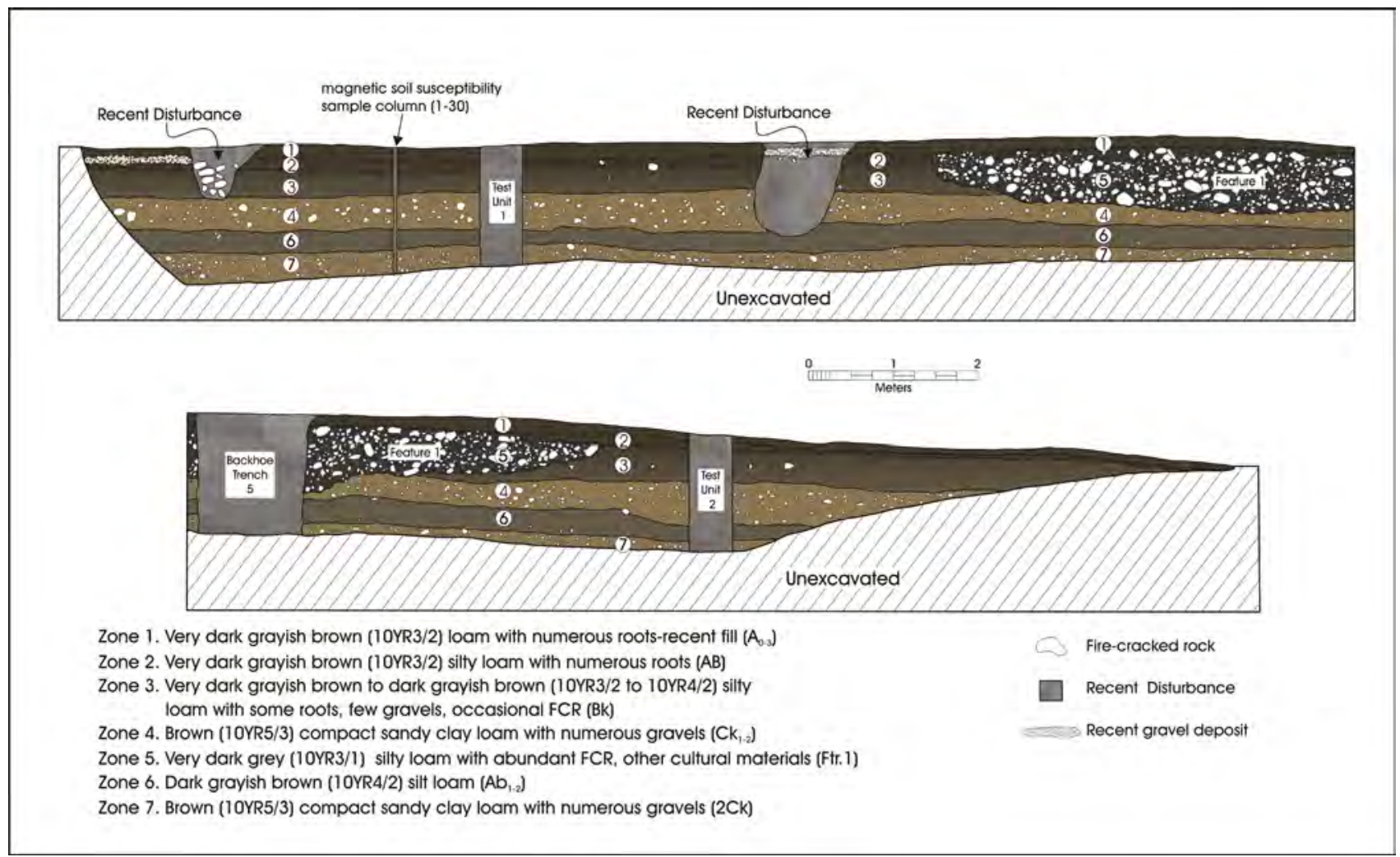

Figure 6-7. West wall profile of Backhoe Trench 4. Note Feature 1 and Test Units 1 and 2. 


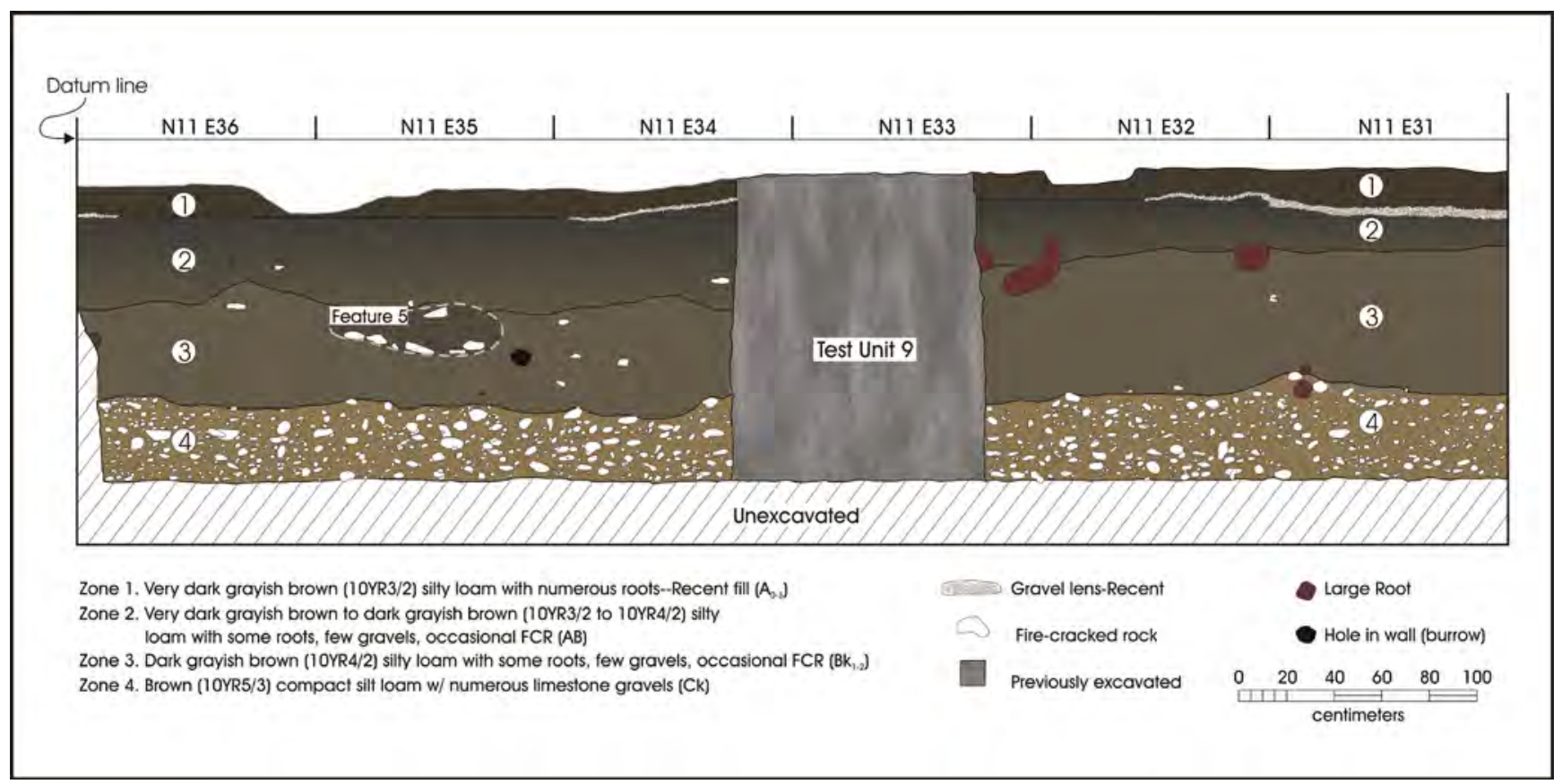

Figure 6-8. South wall profile of area 4.

on this terrace is limited to the lower $\mathrm{Bk}$ horizons, $\mathrm{Bk} 2$ and $\mathrm{Bk} 3$, and to the $\mathrm{Ck}$ soils. Patterns in soil changes and feature elevations suggest that there may have been multiple Late Archaic visits to the site in Area 4.

\section{Integrity}

Minor krotovina disturbance was witnessed near the lower boundary of the midden $(\sim 80-100 \mathrm{cmbs})$ during testing. Weston et al. (2004) reported further disturbance east of Backhoe Trench 4 associated with the possible demolition or construction of the Kimble Courts, but not such extreme disturbance as to compromise the integrity of the burned rock midden. Our hand-excavation of the large block in Area 3 showed severe disturbance from krotovina and pecan trees away from the location of the midden but in suspected activity areas above the paleosol. Though great efforts were made to separate the intact from the disturbed sediments in Area 3, several units were removed from the dataset. These include all the units in the northeastern portion of the large block in Area 3: N28-36 E15-18 and N30-36 E13-14 (see Figure 5-7).

Disturbances in Area 4 were minor compared to Area 3. Area 4 targeted the Late Archaic and possessed good integrity with the exception of some tree roots. Excavation was terminated at Level $12(120 \mathrm{cmbd})$ in the unit that contained the densest roots (N12 E35); therefore, we collected no artifacts for processing or analysis beyond this depth.

\section{Artifact Distribution}

Artifact patterns on the upper terrace in Areas 3 and 4 are unlike those on the lower terrace. Here, each area only exhibits two peaks in artifact quantities (Figure 6-9). Data from the disturbed units listed above are not included in this discussion or taken into account in Figure 6-9. Though units comprising the "L" are part of Area 3, they are not included in the following discussion with units from the large block of units comprising the rest of Area 3. Because these are associated with a midden, their vertical distribution was disturbed prehistorically during the development of the burned rock midden.

In Area 3, excavations began in the $\mathrm{AB}$ horizon with limited artifact recovery until the interface with the Bk1 horizon. Within the Bk, Late Archaic projectile point forms, including one Ensor and one Montel, were recovered from Level 6 associated with a dramatic artifact increase. In Level 8, at the Bk1/Bk2 interface, we recovered other Archaic Darl, Ensor, Fairland, and Pedernales projectile points. However, radiocarbon dates from Backhoe Trench 5 date the Bk to the Initial Late Prehistoric. Across the block of undisturbed units, artifact counts continue to climb until they peak at Level 9, the interface of the Bk2 and Ck1 soil horizons. There is not a sudden jump in artifact numbers here, but a gradual increase and then decrease around the Bk2/Ck1 interface at approximately $95 \mathrm{cmbd}$. At this interface, we recorded two more burned rock features (Features 39 and 


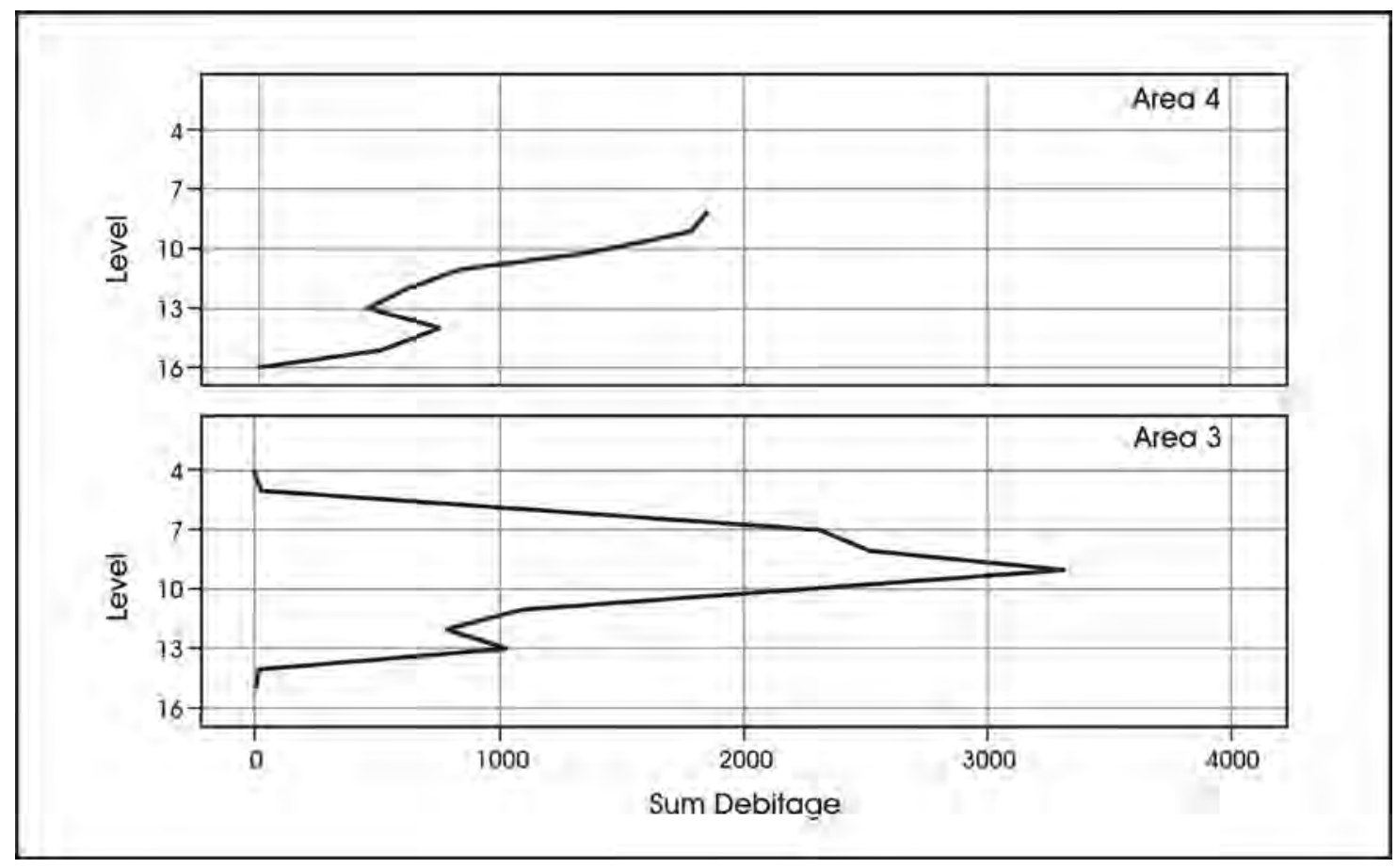

Figure 6-9. Artifact distribution in Areas 3 and 4.

53). Within the Ck, we documented two Edwards points, which are later than would be expected at this depth. Artifact counts continue to taper through the $\mathrm{Ck}$ until directly above the $\mathrm{Ab}$ where counts drop quickly from the thousands to less than 25 .

Debitage trends mimic the peak in artifacts at $\sim 95 \mathrm{cmbd}$ in Test Unit 10, but do not demonstrate three peaks as anticipated based on the testing. However, mitigation began lower than testing and therefore we did not handexcavate material represented in the upper peak of Test Unit 10. A lower peak may be present in Level 13 but due to the lack of diagnostic artifacts the age of this deposit cannot be defined.

Excavation in Area 4 began at Level 8 in the Bk1 horizon above the interface with the Bk2 soils on which Feature 5 was previously located. Work in this unit targeted the Late Archaic Frio deposit, particularly Feature 5 that was uncovered during testing in Test Unit 9. Testing found three peaks in artifacts, the first of which was in Level 5 above the depth where we began data recovery excavations. The opening level for Phase III work began at the second peak identified during in the testing and contained the highest amount of artifacts, which then tapered through Level 15 at the $\mathrm{Ck} 2$ horizon (Figure 6-9). Within the Bk1 horizon, we recovered a few projectile point forms identified as Late Archaic (Fairland, Frio, and Castroville). This horizon had many kilograms of burned rock and seems to be a surface on which many hearths were constructed. Features 44-47 and Feature 5 all lay at or near the interface of the $\mathrm{Bk} 1$ and $\mathrm{Bk} 2$ horizons. We have no radiocarbon dates to report on these features, but the $\mathrm{Bk}$ soils elsewhere on site (Test Unit 1/Backhoe Trench 5, Area 3 ) date to the Late Prehistoric so these features may as well. Additional rock Features 48 and 49 sat in the Bk2 horizon. Artifact counts continued to decrease gradually through the $\mathrm{Bk} 3$ and $\mathrm{Ck} 1$ with no anomalies occurring at soil transitions. Near the junction of $\mathrm{Ck} 1$ and $\mathrm{Ck} 2$, we recorded a slight increase in debitage counts, Ellis, Castroville, and Montel projectile points, and additional features (Features 50 and 51). This component could correspond to the lower peak seen in Test Unit 9, which is likely a Frio-aged deposit like those found in Test Units 1 and 5. Units were terminated in the Ck2 horizon (Level 15, $150 \mathrm{cmbd}$ ). The only dramatic artifact trend occurs in the Ck2 where we observed a drop in artifacts from over 500 in Level 15 of the $\mathrm{Ck} 2$ to less than 10 in Level 16 (Figure 6-9).

\section{Site Integrity Conclusion}

Geoarcheological examination of the site indicates that the archeological deposits at $41 \mathrm{KM} 69$ represent multiple occupations, but with good separation between the deposits within the floodplain setting. We were able to distinguish some trends in the vertical artifact distribution that correspond to soil horizon interfaces and match up with the Phase II excavations in general. 
On the lower terrace in Areas 1 and 2, we discerned two peaks in lithic artifacts: an upper Terminal Late Prehistoric occupation and two Late Archaic occupations -- Middle and Terminal Late Archaic (Figure 6-6). The upper peak occurs at the surface of the Bk1 horizon and the lower at the surface of the $\mathrm{Ck} 1$ horizon with a marked drop at the Ck2 surface.

Area 1 may show evidence of two Late Prehistoric occupations and three Terminal Late Archaic site visits. The upper $\mathrm{AB}$ horizon contains a possible Toyah ceramic assemblage in Levels 4 and 5. In Level 6 the Late Prehistoric Perdiz projectile points lie within the Terminal occupation of the Late Prehistoric. The Terminal Late Archaic in Area 1 falls between the top of the Bk2 horizon and the top of the $\mathrm{Ck} 2$ horizon (so within the Bk2 in Levels 7-9 and Ck1 horizons in Levels 10-12). The Middle Late Archaic occupation in Area 1 is in the Ck2 horizon in Levels 13-16.

Area 2 produced cloudier cultural horizons. However, there is a definite Terminal Late Prehistoric occupation associated with the Bk1 soil horizon sitting on the Bk2 interface. Though this horizon produced no ceramics and no projectile points, it did contain several unifacial scrapers typical of the Toyah interval and three thermal rock features (Features 2, 3 and 3B). A loosely defined Terminal Late Archaic Frio component matches a peak in artifact count at the $\mathrm{Bk} 2$ surface in Level 8 and the surface of the Ck2 in Level 11. The component contained Frio projectile point forms, flake tools bifaces, scattered mussel and snail shell, and some thermal rock features (Features 42, 43, 55, and 56).

We excavated some of the older terrace surface in Areas 3 and 4. Artifacts and features here are associated with the $\mathrm{Bk}$ and $\mathrm{Ck}$ horizons in both areas. The burned rock midden (Feature 1) is associated with the Bk 1 horizon and dates to the early part of the Terminal Late Prehistoric, the Austin interval. A lower Middle Late Archaic component is present in the $\mathrm{Ck}$ soils along with several rock features and Late Archaic projectile points. No carbon samples have been submitted for dating the occupations in these areas.

We observed common soil profiles with different cultural horizons across two terraces at 41KM69. Areas 1 and 2 were excavated on the lower terrace surface closer to the river. Here we witnessed similar soil horizons at a slightly lower elevation to those on the upper terrace where Areas 2 and 3 were excavated. Though the lower landform is younger than the upper landform, artifacts of similar age are more deeply buried in the lower terrace.
Soils containing archeological deposits at 41KM69 are fine, well-sorted silty loams with high integrity. Bioturbation in a large portion of Area 3 marks the only significant disturbance to the archeological deposits that we excavated. Other disturbances such as those in Area 4, where tree roots prevented complete excavation, have not affected the data set. Fine sediments and absence of erosion markers indicate alluvial movement of artifacts is unlikely so the only impact to the artifact assemblage is in Area 3, where we removed artifacts from 34 units of the analytical dataset.

\section{Analytical Units}

The previous section described site integrity and artifact distribution in each excavation area and outlined some probable periods of occupation. This section describes these analytical units and the numbers and types of artifacts found in each. The prehistoric occupations fall within two periods (Middle and Terminal) of the Late Archaic and two periods (Initial and Terminal) of the Late Prehistoric. These analytical units were defined from radiocarbon assays, artifact distributions, and geomorphology. The peaks in artifact distribution and the elevations of the features suggest that there were multiple visits to the site during the four periods of occupation outlined in this chapter. Figure 6-10 shows the distribution of the largest dataset, debitage, across soil horizons. Time intervals are shaded to illustrate trends. Table 6-1 shows the major artifact categories by area and time period. Area $3 \mathrm{~L}$ shows units excavated through Feature 1, the burned rock midden. In the descriptions of components in Area 3, the artifacts of Area 3 and 3L are combined. Tables 6-2 and 6-3 show the provenience information of each excavation phase and their assigned analytical units.

\section{Terminal Late Prehistoric (700-400 B.P.)}

The Terminal Late Prehistoric component was present in Areas 1 and 2 in approximately $25 \mathrm{~m}^{3}$ of the excavations. A Terminal Late Prehistoric Toyah occupation with ceramics is evident only within Area 1 on the lower terrace. This assemblage in the $\mathrm{AB}$ soil horizon contained Leon Plain sherds $(n=159)$ and hafted unifaces $(n=16)$ in Levels 4 and 5 but lacked Perdiz projectile points. The five Perdiz points in Area 1 occurred in Levels 5-6 below the sherds and scrapers (Figure 6-3). The Perdiz projectile points occur within the Bk1 soil horizon, identified as a separate Terminal Late Prehistoric occupation. A peak in debitage at the Bk1/ Bk2 level (Level 6) further supports an occupation separate from the levels containing ceramics (Figure 6-1). The Area 1 levels containing Perdiz points could represent a separate 


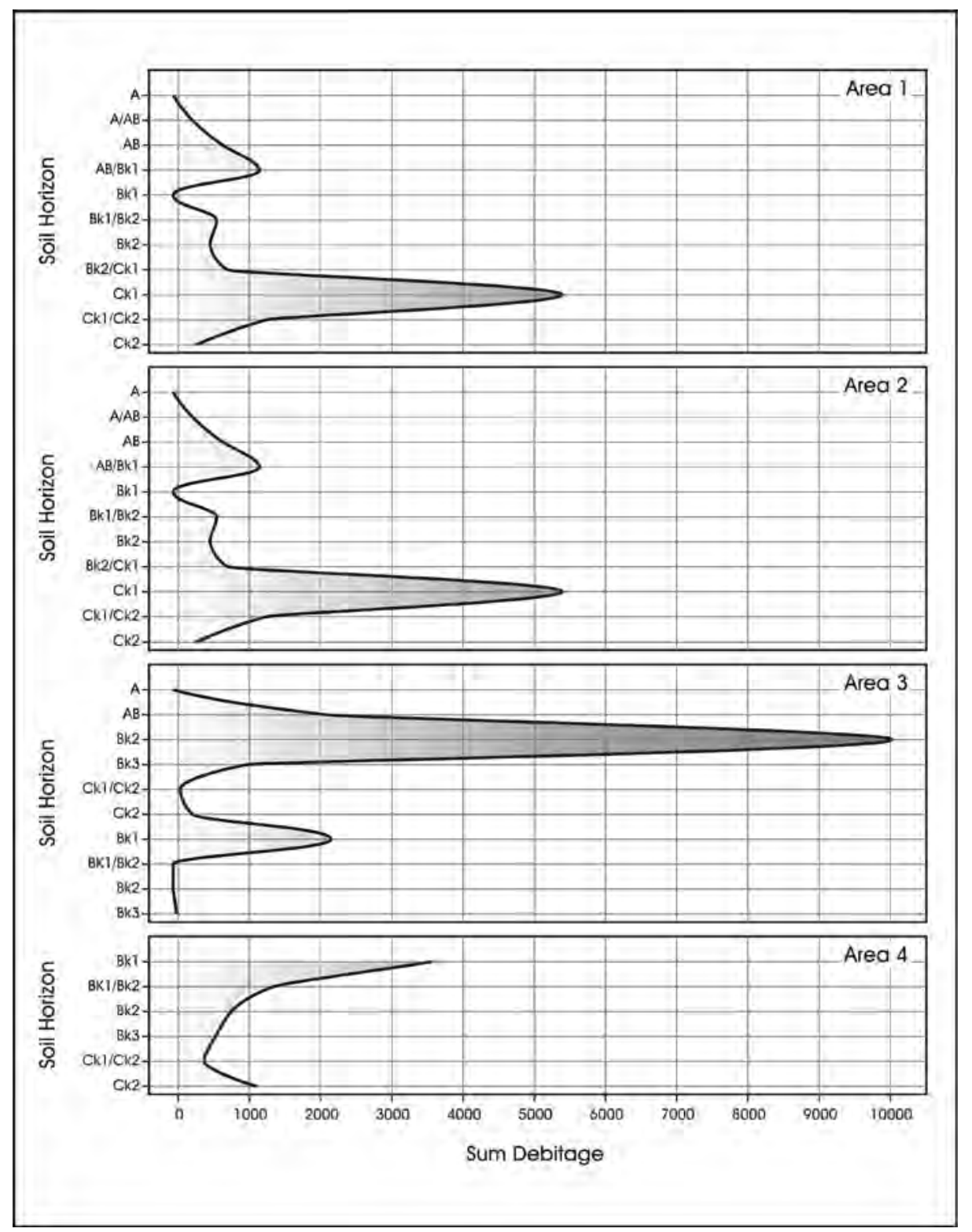

Figure 6-10. Lithic debitage counts peak at two soil horizons at 41 KM69 that could indicate possible surfaces of human occupation.

Terminal Late Prehistoric occupation also encountered in Area 2. Here, typical "Toyah-like" scrapers $(n=21)$ were collected in association with bison bone and features but they were not associated with ceramics or Perdiz projectile points (Figure 6-4). The age of this collection of artifacts from Area 1 and 2 is discussed in Chapter 10.

Combining all Terminal Late Prehistoric artifacts from multiple occupations in good context results in over 3900 pieces of debitage, 5 Perdiz projectile points, 37 unifaces, 16 bifaces, and over 30 other stone tools and cores (Table 6-1). Few fragmented faunal remains $(n=114)$ were encountered during testing and data recovery excavations at 41KM69. Bone fragment counts showed bone clustering in the Terminal Late Prehistoric on the lower terrace. In Area 1, the majority of bone fragments are in the same levels as the ceramics (Levels 4 and 5); in Area 2 virtually all the bone is in the same level (Level 5) as 18 of the unifaces.

Ten thermal features were recorded that likely date to the Terminal Late Prehistoric Period (Table 6-4). Five of these were hand-excavated and their context better understood than those found during Gradall monitoring. These include Features 2, 3, 3B, 10, and 57. Feature 10 is a conglomerate 
Table 6-1. Artifact Totals by Area

\begin{tabular}{|c|c|c|c|c|c|c|c|}
\hline \multirow[b]{2}{*}{ Time Period } & \multirow[b]{2}{*}{ Artifact Categories } & \multicolumn{5}{|c|}{ Area } & \multirow[b]{2}{*}{ Grand Total } \\
\hline & & 1 & 2 & 3 & 4 & 3L (midden) & \\
\hline \multirow{6}{*}{ MLA } & Core & 1 & 3 & 1 & 2 & & 7 \\
\hline & Debitage & 1,668 & 672 & 2,347 & 1,707 & 24 & 6,418 \\
\hline & Projectile pt & 3 & 2 & 1 & 6 & & 12 \\
\hline & Uniface & & 1 & & & & 1 \\
\hline & Edge-modified & 1 & 4 & 3 & 3 & & 11 \\
\hline & Biface & 8 & 5 & 13 & 8 & & 34 \\
\hline MLA Total & & 1,681 & 687 & 2,365 & 1726 & 24 & 6,483 \\
\hline \multirow{8}{*}{ TLA } & Core & 7 & 1 & & 2 & & 10 \\
\hline & Debitage & 7,392 & 2,675 & & 1454 & & 11,521 \\
\hline & Lithic tools and cores & & 1 & & & & 1 \\
\hline & Native ceramic & 3 & & & & & 3 \\
\hline & Projectile pt & 9 & 6 & & 3 & & 18 \\
\hline & Uniface & 5 & 2 & & 1 & & 8 \\
\hline & Edge-modified & 3 & 6 & & 2 & & 11 \\
\hline & Biface & 31 & 15 & & 5 & & 51 \\
\hline TLA Total & & 7,450 & 2,706 & & 1,467 & & 11,623 \\
\hline \multirow{7}{*}{ ILP } & Core & & & 14 & 11 & 9 & 34 \\
\hline & Debitage & & & 11,268 & 5129 & 2515 & 18,912 \\
\hline & Lithic tools and cores & & & 3 & & & 3 \\
\hline & Projectile pt & & & 9 & 6 & 7 & 22 \\
\hline & Uniface & & & 6 & 5 & 1 & 12 \\
\hline & Edge-modified & & & 15 & 5 & 2 & 22 \\
\hline & Biface & & & 45 & 24 & 16 & 85 \\
\hline ILP Total & & & & 11,360 & 5,180 & 2,550 & 19,090 \\
\hline \multirow{8}{*}{ TLP } & Core & 12 & 3 & & & & 15 \\
\hline & Debitage & 2,190 & 1,747 & & & & 3,937 \\
\hline & Lithic tools and cores & 1 & & & & & 1 \\
\hline & Native ceramic & 159 & & & & & 159 \\
\hline & Projectile pt & 5 & & & & & 5 \\
\hline & Uniface & 16 & 21 & & & & 37 \\
\hline & Edge-modified & 13 & 2 & & & & 15 \\
\hline & Biface & 11 & 5 & & & & 16 \\
\hline TLP Total & & 2,407 & 1,778 & & & & 4,185 \\
\hline Grand Total & & 11,538 & 5,171 & 13,725 & 8,373 & 2,574 & 41,381 \\
\hline
\end{tabular}


Table 6-2. Significance Testing Proveniences and Associated Analytical Units

\begin{tabular}{|c|c|c|c|}
\hline Time Period & Test Unit & Level & $\begin{array}{c}\text { Associated Data } \\
\text { Recovery Area }\end{array}$ \\
\hline MLA & 1 & $11-15$ & 3 \\
\hline MLA & 8 & $7-9$ & 2 \\
\hline MLA & 9 & $10-12$ & 4 \\
\hline MLA & 10 & $9-15$ & 3 \\
\hline MLA & 11 & $11-14$ & 1 \\
\hline MLA & 12 & 8 & 2 \\
\hline TLA & 8 & $5-6$ & 2 \\
\hline TLA & 9 & $8-9$ & 4 \\
\hline TLA & 11 & $5-10$ & 2 \\
\hline TLA & 12 & $5-7$ & 3 \\
\hline ILP & 1 & $2-10$ & $3 \mathrm{~L}$ \\
\hline ILP & 3 & $2-15$ & 4 \\
\hline ILP & 9 & $5-7$ & 3 \\
\hline ILP & 10 & $5-8$ & 2 \\
\hline TLP & 8 & $3-4$ & 1 \\
\hline TLP & 11 & $2-4$ & 2 \\
\hline TLP & 12 & $2-4$ & \\
\hline & & & 2 \\
\hline
\end{tabular}

of burned rock, concrete, debitage, and historic artifacts. It was recorded within the $\mathrm{AB} / \mathrm{Bk} 1$ transition in Area 1 where much historic intrusion was observed during data recovery. The other features were excavated in units within the Bk soil horizon, a horizon that also contained scrapers and Perdiz points on the lower terrace. Feature 57 is an isolated rock cluster recorded in the Bk1 horizon of Area 2, around $20 \mathrm{~cm}$ higher than the level of possible post molds in Area 1. Feature $3 \mathrm{~B}$ was slightly lower than Feature 57 but still above the level of the $\mathrm{Bk} 2$ horizon and was thought at first to be related to Feature 3. However, Features 2 and 3 were also associated with the surface of the Bk2 in Area 2 (Test Units 8 and 12) during the testing phase. Feature 2 produced a Terminal Late Prehistoric date $(480 \pm 40 \mathrm{cal}$ B.P.; UGA Sample 13590), along with two historic/recent dates (180 \pm 40 B.P., UGA Sample 13591; $120 \pm 40$ B.P., UGA Sample 13508) (see Table 6-5).

Though previous radiocarbon dates from Feature 2 indicated that the $\mathrm{Bk}$ unit artifacts are probably Terminal Late Prehistoric (Weston et al. 2004), additional datable materials were sought to confirm the designation of this early ceramicdeficient "Toyah "expression in Area 2, but no materials were available. Area 1 ceramics were submitted for TL and AMS dating to obtain a date for the AB horizon in Area 1. The results of these dates are reported in Chapter 10. The Terminal Late Prehistoric thermal features recorded during Gradall scraping included Features 58, 79, 82, and 91-92 (Table 6-4 and Table 7-7).
On the lower terrace, eight possible post molds were recorded in Area 1 within the same soil horizon (Bk) between 60 and $73 \mathrm{cmbd}$. Initially, twenty-four stains were recorded, but because many of them continued below the level of excavation at approximately $150 \mathrm{cmbd}$, they are likely root molds. These are labeled soil stains in Table 6-2. For some others, however, a termination level was reached within the parameters of the excavation. Features 13, 16-19, 22,31 , and 34 all meet size and shape requirements typical of a feature left by a post. Together, they do not form any obvious patterns. Excavators bisected all these features, usually on a north-south axis with the western profile drawn and photographed. All were symmetrical, straight-sided and tapered to a rounded base. They were all at least $8-10 \mathrm{~cm}$ in diameter and no greater than 60-75 cm long.

Fill for each of these soil stain/post features usually lacked artifacts and charcoal, though it was very organic and loosely compacted. Fill was difficult to remove from the crosssection because of its tendency to crumble. Also common were small voids where no fill was present. Fifteen additional soils stains were recorded during Gradall monitoring on the lower terrace that may relate to the others found in Area 1.

\section{Summary of the Terminal Late Prehistoric}

Artifacts recovered from excavations on the lower terrace include Leon Plain ceramics, Perdiz projectile points, and 
Table 6-3. Data Recovery and Significance Proveniences and Associated Analytical Units

\begin{tabular}{|c|c|c|c|c|}
\hline Excavation Phase & Time Period & Area & Level & Test Unit \\
\hline Data Recovery & MLA & 1 & $13-16$ & \\
\hline Data Recovery & MLA & 2 & $11-15$ & \\
\hline Data Recovery & MLA & 3 & $12-15$ & \\
\hline Data Recovery & MLA & 4 & $13-16$ & \\
\hline Data Recovery & MLA & $3 \mathrm{~L}$ & 15 & \\
\hline Data Recovery & TLA & 1 & $7-12$ & \\
\hline Data Recovery & TLA & 2 & $8-10$ & \\
\hline Data Recovery & TLA & 3 & $\mathrm{n} / \mathrm{a}$ & \\
\hline Data Recovery & TLA & 4 & $11-12$ & \\
\hline Data Recovery & TLA & $3 \mathrm{~L}$ & $\mathrm{n} / \mathrm{a}$ & \\
\hline Data Recovery & ILP & 1 & $\mathrm{n} / \mathrm{a}$ & \\
\hline Data Recovery & ILP & 2 & $\mathrm{n} / \mathrm{a}$ & \\
\hline Data Recovery & ILP & 3 & $6-11$ & \\
\hline Data Recovery & ILP & 4 & $8-10$ & \\
\hline Data Recovery & ILP & $3 \mathrm{~L}$ & $3-11$ & \\
\hline Data Recovery & TLP & 1 & $3-6$ & \\
\hline Data Recovery & TLP & 2 & $5-7$ & \\
\hline Data Recovery & TLP & 3 & $\mathrm{n} / \mathrm{a}$ & \\
\hline Data Recovery & TLP & 4 & $\mathrm{n} / \mathrm{a}$ & \\
\hline Data Recovery & TLP & $3 \mathrm{~L}$ & $\mathrm{n} / \mathrm{a}$ & \\
\hline Significance Testing & MLA & 3 & $11-15$ & 1 \\
\hline Significance Testing & MLA & 2 & $7-9$ & 8 \\
\hline Significance Testing & MLA & 4 & $10-12$ & 9 \\
\hline Significance Testing & MLA & 3 & $9-15$ & 10 \\
\hline Significance Testing & MLA & 1 & $11-14$ & 11 \\
\hline Significance Testing & MLA & 2 & 8 & 12 \\
\hline Significance Testing & TLA & 2 & $5-6$ & 8 \\
\hline Significance Testing & TLA & 4 & $8-9$ & 9 \\
\hline Significance Testing & TLA & 1 & $5-10$ & 11 \\
\hline Significance Testing & TLA & 2 & $5-7$ & 12 \\
\hline Significance Testing & ILP & 3 & $2-10$ & 1 \\
\hline Significance Testing & ILP & $3 \mathrm{~L}$ & $2-15$ & 3 \\
\hline Significance Testing & ILP & 4 & $5-7$ & 9 \\
\hline Significance Testing & ILP & 3 & $5-8$ & 10 \\
\hline Significance Testing & TLP & 2 & $3-4$ & 8 \\
\hline Significance Testing & TLP & 1 & $2-4$ & 11 \\
\hline Significance Testing & TLP & 2 & $2-4$ & 12 \\
\hline
\end{tabular}


unifaces that others have used to define a Toyah interval in South and Central Texas. However, all three artifact types did not co-occur and it is the vertical distribution of these Late Prehistoric artifacts that is interesting. The ceramics in Area 1 units are of particular interest because they co-occur with unifaces in Levels 4 and 5 but not with arrow points typical of a Toyah occupation (Figure 6-3). The few Perdiz projectile points that are present in Area 1 were found at elevations lower than the Leon Plain sherds and the Area 1 unifaces. Area 2, contained unifaces typically associated with bison processing in the Toyah interval, but not arrow points or ceramics (Figure 6-3). The possibility that the ceramics in Area 1 are associated with other time periods is discussed in Chapter 10. A nearby hearth in Area 2 was dated with three separate samples to the Terminal Late Prehistoric, the Protohistoric, and a recent date. The dates are suspect but provide a second reason to believe the ceramics could post-date the arrow points in Area 1 and the unifaces in Area 2 given the relative placement of this "typical Toyah" assemblage at $41 \mathrm{KM} 69$.

\section{Initial Late Prehistoric (1250-700 B.P.)}

The Initial Late Prehistoric (Austin interval) deposits were on the upper terrace in Areas 3 and 4 in approximately $40 \mathrm{~m}^{3}$ of the intact soils. Radiocarbon dates from the upper terrace testing phase excavations in Backhoe Trench 5 and Test Unit 10 correspond to these occupations (Table 6-5). The Initial Late Prehistoric seems confined to the Bk horizon, which produced approximately 19,000 pieces of debitage, and 144 stone tools including Late Archaic Castroville, Darl, Ensor, Fairland, Frio, and Pedernales projectile points and Initial Late Prehistoric Edwards projectile points at the Bk/Ck interface (Table 6-1). The artifacts peak at this same interface in Areas 3 and 4.

The majority of the lithic tools excavated from 41KM69 came from Area 3 (Table 6-1). This block produced the highest density of lithic tools. The majority of the tools was from within the Initial Late Prehistoric levels and included approximately 61 bifaces, 7 unifaces, and 17 edge-modified flakes. In Area 4, only 24 bifaces, 6 projectile points, 5 unifaces, and 5 edge-modified flakes were excavated from the Initial Late Prehistoric levels.

Feature 1, Feature 5, and Features 44-47 all lay within the $\mathrm{Bk}$ and likely date to the same period. Based on the elevation data, other features $(39,52-54,59,81,83-86$, and 93) also could date to the Initial Late Prehistoric on the upper terrace, making it the time of greatest feature activity with seventeen thermal rock features (Table 6-4). The only radiometric dates relating to this area are from the Bk horizon in Backhoe
Trench 5 (1180-970 B.P.) and from Test Unit 10 (1400-1170

B.P.) and not from within features (see Table 6-5).

\section{Terminal Late Archaic (1600-1250 B.P.)}

A Terminal Late Archaic occupation was present in three excavated areas of the site in $28 \mathrm{~m}^{3}$. This period was the most problematic as an analytical unit. The Terminal Late Archaic lies within the Bk1, Bk2 and Bk3 soil horizons in Areas 1, 2, and 4, and in the $\mathrm{Ck} 1$ horizon of Area 1. These soil horizons contain over 11,000 pieces of debitage, 18 projectile points, 51 bifaces, 8 unifaces, and 11 edge-modified flakes (Table 6-1). Of the 18 projectile points, 13 were Frios.

The majority of the debitage and Frio projectile points are from the Ck soil horizons in Area 1 on the lower terrace, which may indicate a separate occupation from the upper terrace assemblages. Twelve of the thirteen Frio points also were excavated from units on the lower terrace; eight came from the $\mathrm{Ck}$ soil horizon in Area 1. Thirty-one of the bifaces collected from the Terminal Late Archaic also came from Area 1, with 24 from the $\mathrm{Ck}$ horizon.

Radiocarbon dating of features within this period would help us relate the soils in Area 4 to other areas that have the same soil horizons. However, no samples were available for submission. The only submitted sample for dating that is relevant to this period was collected from Test Unit 10 (on the upper terrace during test excavations), $108 \mathrm{cmbs}$. It dated to 1400-1170 B.P. (Table 6-5), which places the sample at the end of the Terminal Late Archaic and the beginning of the Initial Late Prehistoric. Seven thermal rock features were excavated from this occupation (see Table 6-2: Features 40, 48, 49, 87, 94, 95, and 96).

\section{Middle Late Archaic (2500-1650 B.P.)}

The Middle Late Archaic was identified in all excavation areas in the $\mathrm{Ck} 1-\mathrm{Ck} 2$ horizons and represents the earliest period excavated and recognized at the site. Approximately $36 \mathrm{~m}^{3}$ of this component was excavated. Below the upper level of the $\mathrm{Ck} 2$, artifact densities drop quickly and do not increase again before the termination of our excavation. The artifact inventory includes over 6,400 pieces of debitage, 12 projectile points including Castroville, Ellis, Frio, and Montell projectile points and over 40 other stone tools and cores (Table 6-1). Fourteen features were excavated, 12 thermal rock features, 1 lithic debitage concentration, and 1 soil stain (Table 6-4). Features 35, 36, 42, 43, 50, 55, 56, 80, and 89 were all excavated from Areas 1, 2 and 4 from similar elevations and slightly lower than burned rock features 88 , 97 , and 98 . 
Table 6-4. Feature Index by Time Interval and Type from Data Recovery

\begin{tabular}{|c|c|c|c|c|c|c|c|c|c|c|}
\hline & \multicolumn{2}{|c|}{ Hearth } & \multicolumn{2}{|c|}{$\begin{array}{l}\text { Burned Rock } \\
\text { Cluster }\end{array}$} & \multirow{2}{*}{$\begin{array}{c}\begin{array}{c}\text { Possible Post } \\
\text { Mold }\end{array} \\
\text { Lower }\end{array}$} & \multirow{2}{*}{$\begin{array}{c}\begin{array}{c}\text { Burned Rock } \\
\text { Midden }\end{array} \\
\text { Upper }\end{array}$} & \multirow{2}{*}{$\begin{array}{c}\begin{array}{c}\text { Lithic } \\
\text { Concentration }\end{array} \\
\text { Upper } \\
\end{array}$} & \multirow{2}{*}{$\begin{array}{c}\begin{array}{c}\text { Burned } \\
\text { Rock } \\
\text { Scatter }\end{array} \\
\text { Upper } \\
\end{array}$} & \multicolumn{2}{|c|}{ Soil Stain } \\
\hline Terrace & Lower & Upper & Lower & Upper & & & & & Lower & Upper \\
\hline MLA & $\begin{array}{c}35,42 \\
56\end{array}$ & $\begin{array}{l}88,89 \\
97,99\end{array}$ & $\mid \begin{array}{c}36,43,55 \\
80\end{array}$ & 50,98 & & & 51 & & & 90 \\
\hline TLA & & $\begin{array}{l}49,94 \\
95\end{array}$ & 40 & $48,87,96$ & & & & & 41 & \\
\hline ILP & & $\begin{array}{l}45,47 \\
53,83 \\
86,93\end{array}$ & & $\begin{array}{c}5,39,44 \\
46,52,54 \\
84,85\end{array}$ & & 1 & & 59,81 & & \\
\hline TLP & 2 & $\begin{array}{c}58,82 \\
92\end{array}$ & $\begin{array}{c}3,3 \mathrm{~B}, 57 \\
10\end{array}$ & 79,91 & $\begin{array}{l}13,16,17,18 \\
19,22,31,34\end{array}$ & & & & $\begin{array}{c}63,64, \\
65,66, \\
67,68, \\
69,70, \\
71,72, \\
73,74, \\
75,76,78\end{array}$ & \\
\hline
\end{tabular}

Table 6-5. Radiocarbon Sample Dates by Provenience

\begin{tabular}{|c|c|c|c|c|c|c|c|}
\hline Area & Unit & Level/Soil & Depth (cmbs) & Date B.P. & Date BC/AD & Cultural Description & UGA Sample \# \\
\hline 3 & BHT 5 & BK & & $1180-970$ & A.D. 770-980 & Initial Late Prehistoric & 13507 \\
\hline 3 & BHT 5 & Ab & 119 & $2340-2120$ & $390-170$ B.C. & Middle Late Archaic & 13506 \\
\hline 3 & TU 10 & - & 108 & $1400-1170$ & A.D. 550-780 & $\begin{array}{c}\text { Terminal Late Archaic/Initial } \\
\text { Late Prehistoric }\end{array}$ & 14032 \\
\hline 2 & TU 8 & Feature 2 & 39 & $120 \pm 40$ & N/A & Recent & 13508 \\
\hline 2 & TU 8 & Feature 2 & 34 & $480 \pm 40$ & A.D. 1390-1490 & Terminal Late Prehistoric & 13590 \\
\hline 2 & TU 8 & Feature 2 & 32 & $180 \pm 40$ & A.D. 1640-1960 & Proto/Historic & 13591 \\
\hline 1 & N88 E16 & Feature 35 & & $2550 \pm 50$ & 650-550 B.C. & Middle Late Archaic & 15179 \\
\hline 3 & BHT6 & Ab1 & 93 & $2380 \pm 80$ & 510-350 B.C. & Middle Late Archaic & 14029 \\
\hline 3 & BHT6 & Ck1/Ab1 & 73 & $120 \pm 80$ & A.D. 40-200 & Recent & 14030 \\
\hline 3 & BHT6 & Bk & 32 & $1020 \pm 70$ & A.D. 950-1090 & Initial Late Prehistoric & 14031 \\
\hline 3 & TU 10 & - & 108 & $1370 \pm 60$ & A.D. 520-640 & Initial Late Prehistoric & 14032 \\
\hline 3 & BHT 4 & Feature 1 & 49 & $1190 \pm 40$ & 470-390 B.C. & Terminal Late Archaic & 13505 \\
\hline
\end{tabular}


Two thermal rock features (Features 35 and 36) date the earliest Middle Late Archaic occupation in Area 1. These are both at the surface of the $\mathrm{Ck} 2$ horizon with an elevation difference measuring approximately $10 \mathrm{~cm}$. Feature 36 is a FCR scatter while Feature 35 is a formal rock lined hearth which dates to the Middle Late Archaic (2550 \pm 50 B.P.). These could represent cooking and dumping areas where discarded cracked rocks formed Feature 36 after cooking at Feature 35 .

Four other thermal rock features represent a Middle Late Archaic occupation of the site that may be contemporaneous to Features 35 and 36. These were recorded in Area 2 as Features $42,43,55$, and 56. These are all associated with the $\mathrm{Ck} 1 / \mathrm{Ck} 2$ interface. Their upper elevations all lay within $6 \mathrm{~cm}$ of each other. Features 43, 55, and 56 all sit within one meter horizontally of each other. Feature 42 lies $6.5 \mathrm{~m}$ to the southeast of these and runs into the southern wall of the block. Feature 42 is a large, circular, and intact hearth with a scattering of FCR around it. The others are smaller features representing one hearth (Feature 56) and two groups of burned rock clusters (Features 43 and 55) that could have been abandoned hearths robbed of their rocks to build the larger Feature 56 hearth. There are no radiocarbon dates for these features, but one sample is available for submittal from Feature 56. During grading, Feature 80 was excavated near Feature 56 in Area 2 and seems related based on elevation data. The contemporaneous relationship of all these features is only supported by their relative positions.

The Middle Late Archaic features on the upper terrace in Areas 3 and 4 include three hearths and two rock clusters. Features 50 and 51 are a basin shaped rock feature and a lithic concentration, respectively, likely deposited at the same time during the Late Archaic. Feature 89 is a rock hearth feature excavated during the grading of Area 3 and is at approximately the same depth as Features 50 and 51. None of these has been dated. Based on the relationship to these hand excavated features, Feature 90 was assigned to the Middle Late Archaic occupation of the site. Features 88,97 , and 98 were recorded slightly higher than these on the upper terrace and may represent a separate Middle Late Archaic occupation.

\section{Summary}

The recovered artifact assemblage includes artifact types typical of the targeted time periods and is patterned in some interesting ways. Of particular interest is the Terminal Late Prehistoric collection of ceramics, Perdiz projectile points, and scrapers recorded on the lower terrace. Uniface and ceramic sherd totals peak during the Terminal Late Prehistoric, while bifaces and projectile points peak during the Initial Late Prehistoric. The origin of several soil stains found in Area 1 may be in the Terminal Late Prehistoric, though many of these are likely non-cultural, some could be post molds based on their size and shape.

This Initial Late Prehistoric period is represented only on the upper terrace in excavation Areas 3 and 4 with the majority of tools, particularly edge-modified flakes and bifaces, coming from Area 3 and from the burned rock midden. Though most of the projectile points pre-date the Initial Late Prehistoric, a radiocarbon date from a backhoe trench dated the $\mathrm{Bk}$ horizon to this interval. Therefore, all artifacts and features within this soil horizon were placed in the Initial Late Prehistoric time frame. There is also a dramatic increase in debitage from the Terminal Late Prehistoric component.

The Terminal Late Archaic is present in all Areas except Area 3, though artifact density is much higher on the lower terrace in Areas 1 and 2. Counts of unifaces and projectile points stay consistent while debitage, bifaces, and edgemodified flakes drop off from the Initial Late Prehistoric. The density of Frio projectile points in Area 1 is of particular interest.

Finally, the Middle Late Archaic artifacts counts peak at the interface of the Ck1-Ck2 horizons. Counts in all tool categories drop from the Terminal Late Archaic. This component also contains the oldest dated feature excavated on site.

The recovered artifact assemblage from excavations at 41KM69 includes a sample of lithic tools, debitage, cores, ceramics, and botanical and faunal remains. The collection includes hundreds of lithic tools and cores, including both formal and informal tools, and thousands of pieces of debitage. Formal tools include projectile point types Castroville, Darl, Edwards, Ellis, Ensor, Fairland, Frio, Montell, Perdiz, Pedernales, and other dart and arrow forms. There are many other stone tools in various stages of reduction and preservation including several Toyah-like unifaces. The ceramic collection included over 100 bonetempered sherds from the site. The faunal remains are in poor condition with few specimens identifiable to species. Seventy-three features were documented. Over half of these are thermal rock features (either hearths or clusters of burned and fire-cracked rock). The remaining features are possible post molds or non-cultural soils stains of undetermined origin. 


\title{
Chapter 7: Materials Recovered
}

\author{
Jennifer L. Thompson
}

This chapter provides an overview of the material types available for research. The counts and percentages described refer to those artifacts that could be placed in one of four analytical units from both phases of excavation. Chapters 1016 discuss artifact analyses as they pertain to the research design. Material types include debitage, stone tools, ceramics, faunal remains, features, burned rock and other charcoal and macrobotanical samples available for study from 41KM69. Though generally, the artifact inventory only includes the prehistoric components, both the historic and prehistoric features are included here.

\section{Artifacts}

Generally, the artifacts collected and recorded were typical of the targeted time periods. These include debitage, formal and informal tools, ceramics, and faunal remains. A summary table of the broad industries used for curation is provided in Table $7-1$, with the counts divided by investigation phase and component.

\section{Lithics}

Chipped stone artifacts comprise by far the largest dataset available for study (Table 7-1). Over 98 percent of the prehistoric artifact assemblage (including debitage, stone tools, cores, and native ceramics) recovered from Phase III excavations is lithic debitage, which comes to just under 40,000 pieces. Phase II recovery adds another 1,519 pieces of debitage making the total debitage within the analytical units approximately 40,788. This is our best indicator of occupation periods as compared to the stratigraphy, which is discussed in Chapter 9.

The initial laboratory sorting of the artifacts divided modified lithic artifacts into five groups that cross-cut functional categories and reduction techniques. They are cores, bifaces, unifaces, edge-modified specimens, and projectile points. Cores represent lithic raw materials that were flaked in order to produce debitage for utilization as expedient tools and/ or use as blanks for the manufacture of tools. Bifaces and unifaces are items that were flaked on either both or a single face, respectively. The two categories are defined purely on the location (one face or both faces) of the flaking and may include a number of functional tool categories such as bifacial knives, bifacially-made perforators and unifacial knives and unifacial scrapers. They may also include items that never reached the finished tool form and were discarded during manufacture. Bifacially made items with sharp tips, and well-defined hafting elements that result in shoulders and/or barbs on the blades, are categorized into the projectile point functional category. Finally, edge modified artifacts consist of

Table 7-1. Summary of Artifact Total at 41KM69

\begin{tabular}{|c|c|c|c|c|c|c|}
\hline & Phase & MLA & TLA & ILP & TLP & Grand Total \\
\hline \multirow{2}{*}{ Core } & Data Recovery & 4 & 9 & 31 & 15 & 59 \\
\hline & Testing & 3 & 1 & 3 & & 7 \\
\hline \multirow{2}{*}{ Debitage } & Data Recovery & 6,049 & 11,138 & 18,329 & 3,685 & 39,201 \\
\hline & Testing & 369 & 383 & 583 & 252 & 1,587 \\
\hline Unidentified tools & Data Recovery & & 1 & 3 & 1 & 5 \\
\hline \multirow{2}{*}{ Native ceramic } & Data Recovery & & 3 & & 111 & 114 \\
\hline & Testing & & & & 48 & 48 \\
\hline \multirow{2}{*}{ Projectile pt. } & Data Recovery & 11 & 17 & 21 & 4 & 53 \\
\hline & Testing & 1 & 1 & 1 & 1 & 4 \\
\hline \multirow{2}{*}{ Uniface } & Data Recovery & 1 & 8 & 11 & 32 & 52 \\
\hline & Testing & & & 1 & 5 & 6 \\
\hline \multirow{2}{*}{ Edge-modified } & Data Recovery & 9 & 11 & 22 & 15 & 57 \\
\hline & Testing & 2 & & & & 2 \\
\hline \multirow{2}{*}{ Biface } & Data Recovery & 31 & 47 & 79 & 15 & 172 \\
\hline & Testing & 3 & 4 & 6 & 1 & 14 \\
\hline \multicolumn{2}{|l|}{ Grand Total } & 6,483 & 11,623 & 19,090 & 4,185 & 41,381 \\
\hline
\end{tabular}


lithic debitage that exhibits modification either from minimal retouch (e.g., unifacial or bifacial flaking) or utilization. The extent of the retouch is limited to a short segment of the flake's edge (10-20 mm) and is often less patterned than would result during the manufacture of bifacial or unifacial tools such as knives and scrapers. Tools on which the edge modification is the result of use alone also are included in the edge-modified category. This edge modification typically results in more patterned scarring with flake scars being much smaller and uniform in size compared to retouch. Five artifacts could not be categorized in these groups.

In a later chapter (Chapter 13), we have classified the lithic artifact collection into tool manufacture cost categories. These categories are designed to gauge the relative amount of effort that has been expended in the manufacture of specific artifacts. The cost categories consist of: utilized flake, marginally retouched item, unifacially retouched item, bifacially retouched item, and hafted specimen. It is our assumption that utilized flakes represent the least amount of energy expenditure in manufacture while hafted tools are the most energy expensive to produce. Utilized flakes consist of pieces of debitage that are either removed from cores or selected from discarded flaking debris and subsequently used in the performance of given tasks without any modification prior to use. Marginally retouched items retain retouch that extends less than $1 / 3$ of the distance over a given face. Both bifacially modified and unifacially modified specimens can be distinguished. Unifacially and bifacially retouched items are distinguished from the marginally retouched specimens based on the extent of the retouch (exceeds $1 / 3$ of the length of margin). Hafted specimens are artifacts that have clearly identifiable modifications along the basal/stem portion of the artifact to allow its hafting. Such modifications may range from well-crafted stems (e.g., on projectile points) to minimal retouch to shape the proximal margins of a tool to allow hafting (e.g., certain Toyah interval end scrapers).

Combined, the stone tools found at 41KM69 form the next largest dataset, at less than one percent of the total (Table 7-2).

Table 7-2. Stone Tools and Cores by Time Period and Area

\begin{tabular}{|c|c|c|c|c|c|c|c|}
\hline Time Period & Tool Type & 1 & 2 & 3 & 4 & 3L & Grand Total \\
\hline \multirow{5}{*}{ TLP } & Biface & 11 & 5 & & & & 16 \\
\hline & Core & 12 & 3 & & & & 15 \\
\hline & Edge-modified flake & 13 & 2 & & & & 15 \\
\hline & Projectile pt & 5 & & & & & 5 \\
\hline & Uniface & 16 & 21 & & & & 37 \\
\hline TLP Total & & 57 & 31 & & & & 88 \\
\hline \multirow{5}{*}{ ILP } & Biface & & & 45 & 24 & 16 & 85 \\
\hline & Core & & & 14 & 11 & 9 & 34 \\
\hline & Edge-modified flake & & & 15 & 5 & 2 & 22 \\
\hline & Projectile pt & & & 9 & 6 & 7 & 22 \\
\hline & Uniface & & & 6 & 5 & 1 & 12 \\
\hline ILP Total & & & & 89 & 51 & 35 & 175 \\
\hline \multirow{5}{*}{ TLA } & Biface & 31 & 15 & & 5 & & 51 \\
\hline & Ccore & 7 & 1 & & 2 & & 10 \\
\hline & Edge-modified flake & 3 & 6 & & 2 & & 11 \\
\hline & Projectile pt & 9 & 6 & & 3 & & 18 \\
\hline & Uniface & 5 & 2 & & 1 & & 8 \\
\hline TLA Total & & 55 & 30 & & 13 & & 98 \\
\hline \multirow{5}{*}{ MLA } & Biface & 8 & 5 & 13 & 8 & & 34 \\
\hline & Core & 1 & 3 & 1 & 2 & & 7 \\
\hline & Edge-modified flake & 1 & 4 & 3 & 3 & & 11 \\
\hline & Projectile pt & 3 & 2 & 1 & 6 & & 12 \\
\hline & Uniface & & 1 & & & & 1 \\
\hline MLA Total & & 13 & 15 & 18 & 19 & & 65 \\
\hline Grand Total & & 103 & 76 & 107 & 83 & 35 & 426 \\
\hline
\end{tabular}


Over 400 stone tools and cores were recovered from testing and data recovery (Table 7-2). The majority of these are from Area 3, which is also the area of highest tool density per excavated matrix volume (4.2 tools per $\left.\mathrm{m}^{3}\right)$. Tool types (excluding cores) within this artifact category include unifaces, bifaces, edge-modified flake tools, and projectile points. The largest tool category was bifaces $(n=186)$ making up just over 45 percent of the tool count. The sample includes specimens representative of all stages of reduction (Figure 7-1) including finished bifacial tools (Figure 7-2).
Projectile points $(\mathrm{n}=57)$ comprise approximately 16 percent of the tool total. Projectile point forms recovered from the site include Castroville, Darl, Edwards, Ellis, Ensor, Fairland, Frio, Montell, Perdiz, Pedernales, and other unknown dart and arrow forms (Figures 7-3 through 7-6; Table 7-3).

The sample contains both manufacture broken (e.g., Figure 7-5d, 7-6a, 7-6d) and use-failed specimens (Figure 7-4a, 7-4f, 7-5h, and 7-6h). The Frio form was the most common, recovered from all areas of the site.

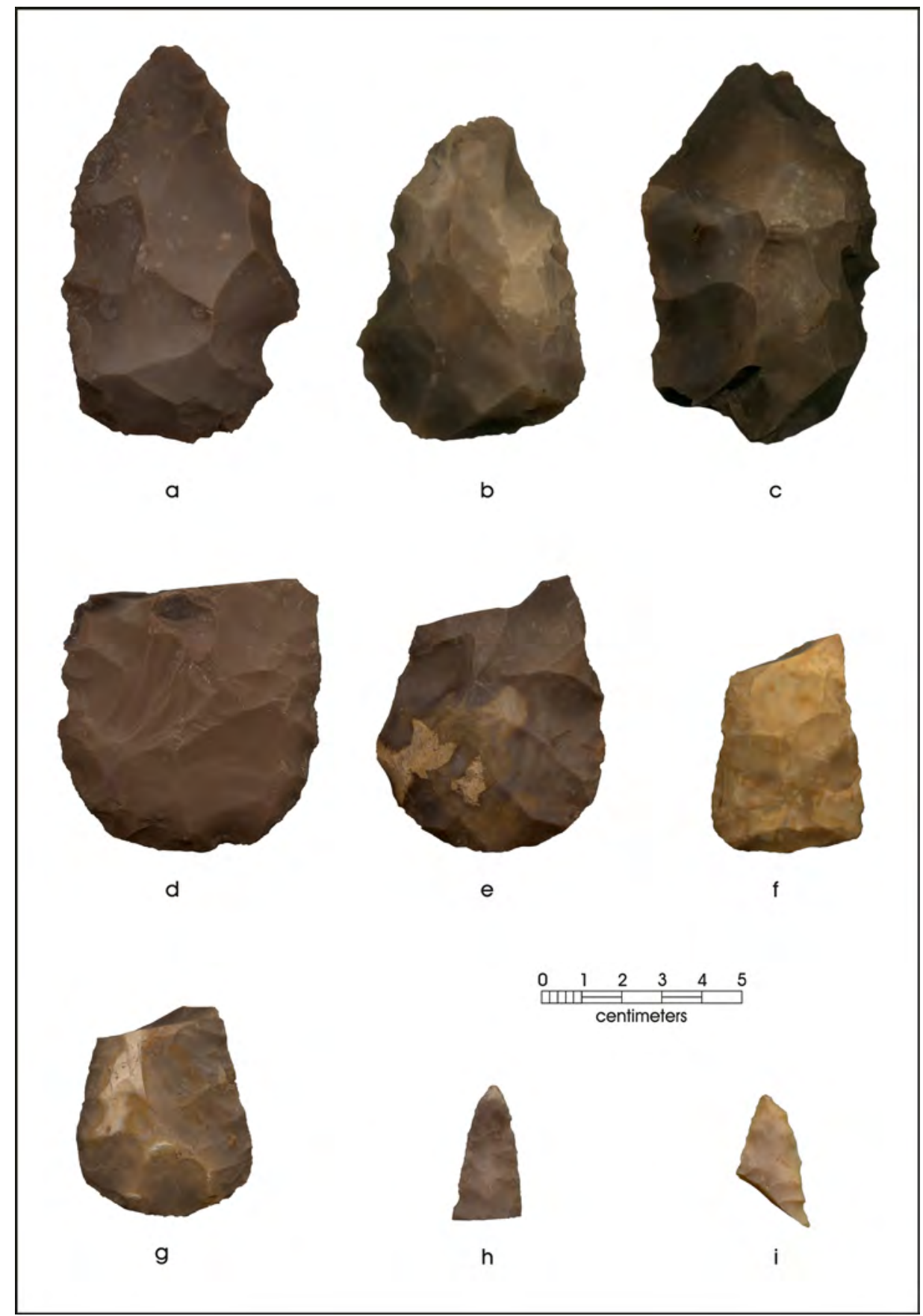

Figure 7-1. Early (a-c), middle (d-f), and late (g-i) reduction stage bifaces. 


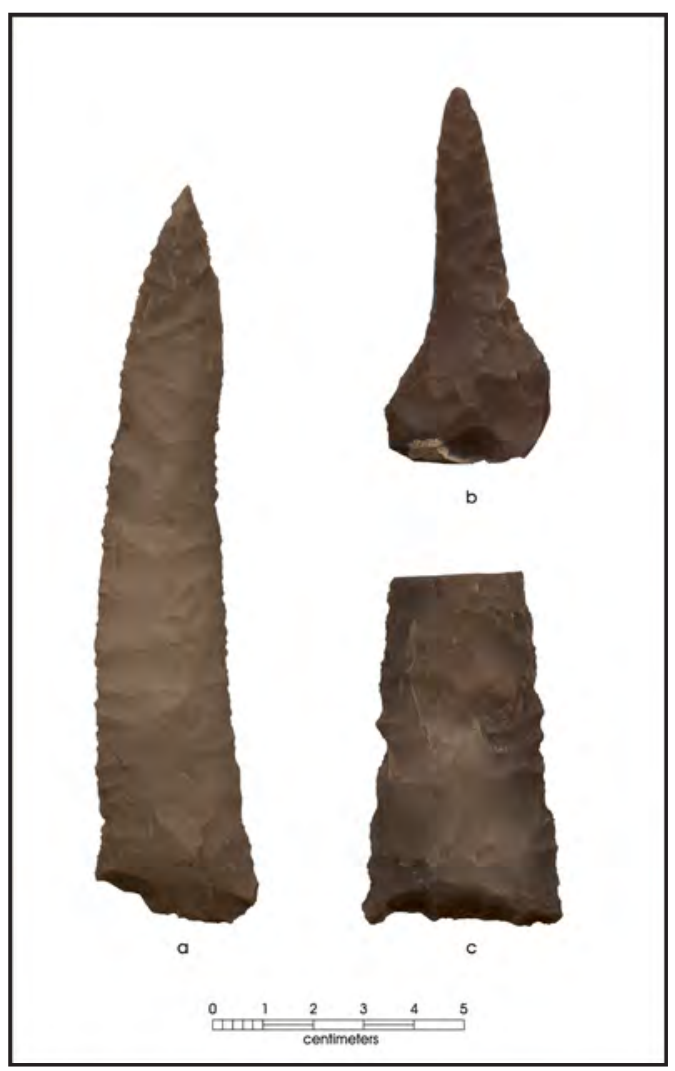

Figure 7-2. Finished bifaces $(a-c)$.

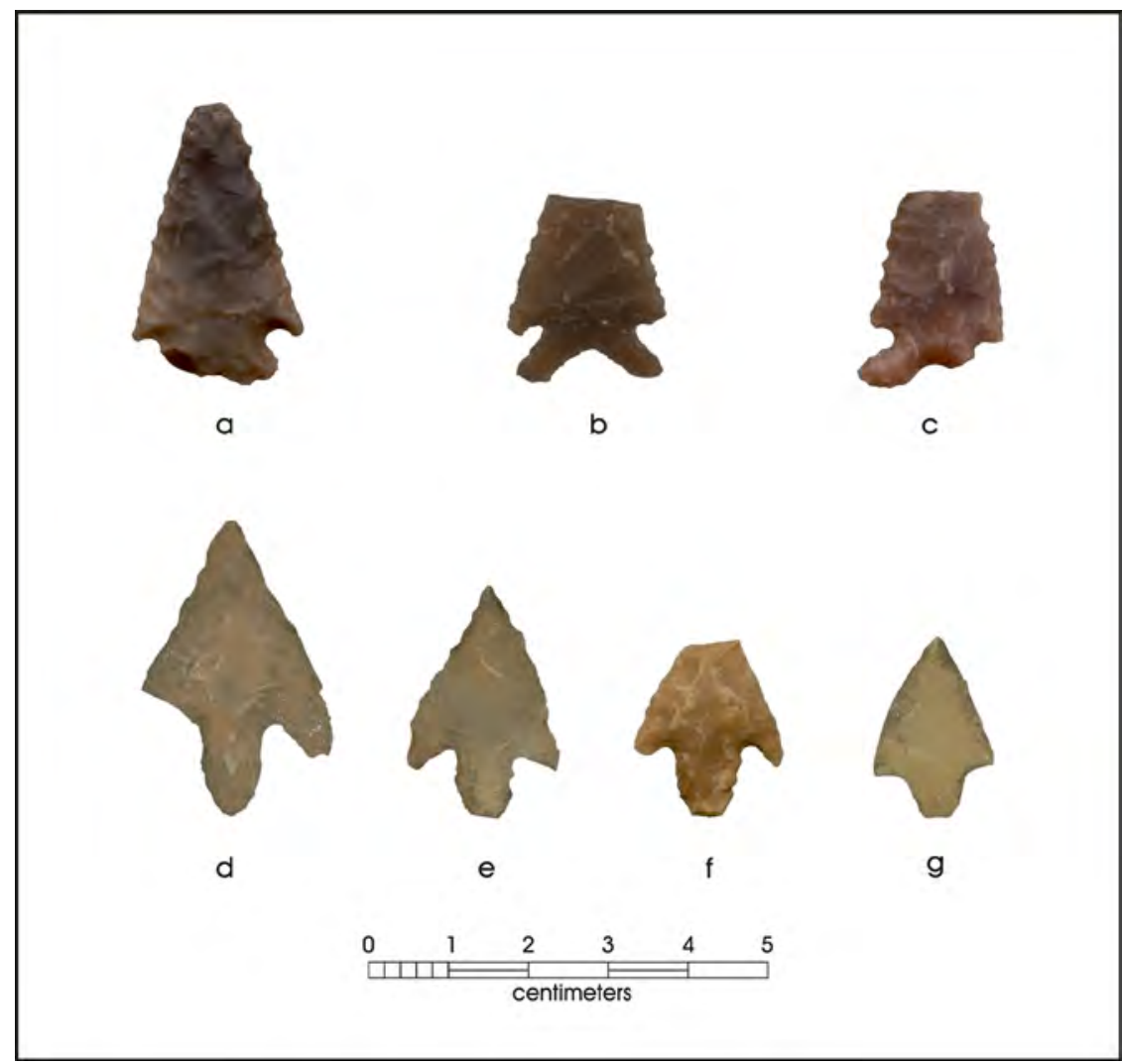

Figure 7-3. Projectile points recovered from 41 KM69 include Late Prehistoric forms Edwards (a-c) and Perdiz (d-g). 


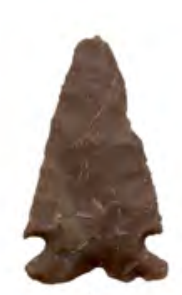

a

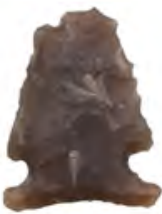

e

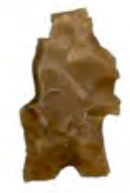

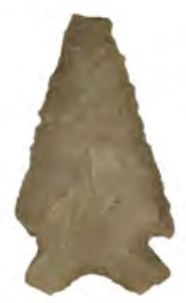

b

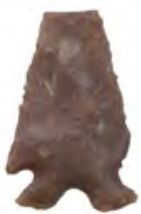

t

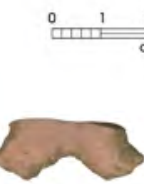

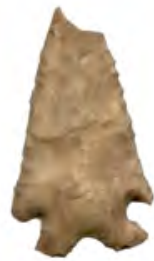

c

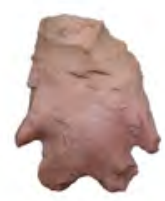

g

h

।
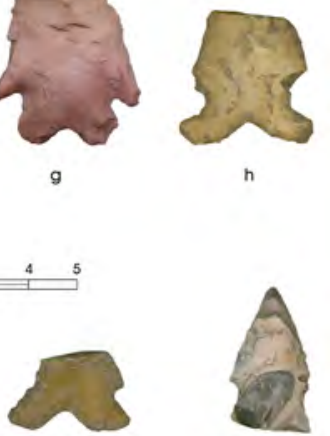

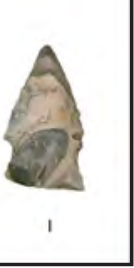

Figure 7-4. The most common point type found was Frio (a-k); a Darl (l) is also pictured.

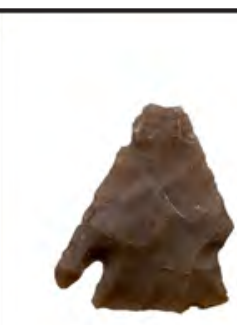

a

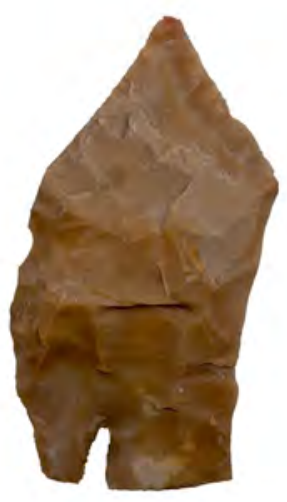

d

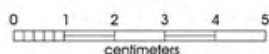

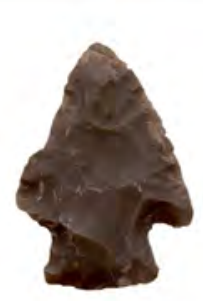

b

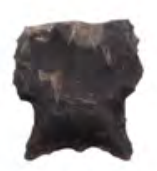

e

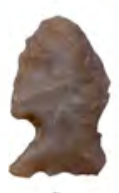

g

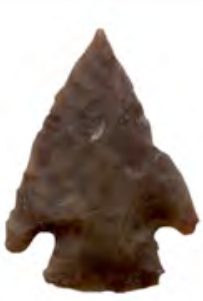

c

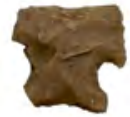

f

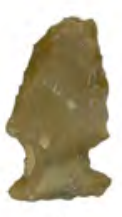

h

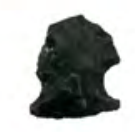

i

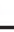

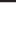

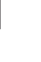


Table 7-3. Projectile Points by Time Period and Area

\begin{tabular}{|c|c|c|c|c|c|c|c|}
\hline Time Period & Point Type & 1 & 2 & 3 & 4 & $3 \mathrm{~L}$ & Grand Total \\
\hline \multirow{6}{*}{ MLA } & Castroville & 1 & & & 1 & & 2 \\
\hline & Early Frio/Montell & & & & 1 & & 1 \\
\hline & Ellis & & & & 1 & & 1 \\
\hline & Frio & & 1 & 1 & & & 2 \\
\hline & Montell & 2 & & & 2 & & 4 \\
\hline & untyped & & 1 & & 1 & & 2 \\
\hline MLA Total & & 3 & 2 & 1 & 6 & & 12 \\
\hline \multirow{4}{*}{ TLA } & Castroville & & 1 & & & & 1 \\
\hline & Frio & 9 & 3 & & 1 & & 13 \\
\hline & Pedernales & & 1 & & & & 1 \\
\hline & Untypable & & 1 & & 2 & & 3 \\
\hline \multicolumn{2}{|l|}{ TLA Total } & 9 & 6 & & 3 & & 18 \\
\hline \multirow{9}{*}{ ILP } & Castroville & & & & 1 & & 1 \\
\hline & Edwards & & & 2 & & 1 & 3 \\
\hline & Ensor & & & 1 & & & 1 \\
\hline & Fairland & & & & 1 & 1 & 2 \\
\hline & Frio & & & & 2 & 2 & 4 \\
\hline & Montell & & & 1 & & & 1 \\
\hline & Pedernales & & & 1 & & & 1 \\
\hline & Untypable & & & 4 & 1 & 3 & 8 \\
\hline & untyped & & & & 1 & & 1 \\
\hline ILP Total & & & & 9 & 6 & 7 & 22 \\
\hline \multirow{2}{*}{ TLP } & Perdiz & 4 & & & & & 4 \\
\hline & pos. Perdiz & 1 & & & & & 1 \\
\hline TLP Total & & 5 & & & & & 5 \\
\hline Grand Total & & 17 & 8 & 10 & 15 & 7 & 57 \\
\hline
\end{tabular}

Fifty-eight unifaces are in the tool collection, most of which are clustered within the Late Prehistoric components of Areas 1 and 2. Twenty-one of the Terminal Late Prehistoric uniface dataset come from Area 2; while fifteen were recovered in Area 1. In these locales, all of the unifaces in the upper levels resemble Toyah interval tools of the Late Prehistoric.

They are worked on the lateral and distal edges, shaped to the striking platform of the parent flake (Figure 7-7). Their proximity to other artifacts of the Late Prehistoric, the bonetempered ceramic assemblage and the Perdiz projectile points is interesting and explored in detail in Chapters 7 and 10. Generally, Perdiz arrow points are expected in the same levels as these unifaces and ceramics. However, in Area 1 the Perdiz points cluster slightly lower than the unifaces within the Bk1 horizon.

Figure 7-8 illustrated other unifaces that do not resemble the large hafted Toyah scrapers. These are edge modified artifacts with unifacial flaking. Some have served as cutting tools (e.g., Figure 7-8d), others as gravers (Figure 7-8b), and yet others as scraping tools (Figure 7-8f).

Fifty-nine edge-modified flakes were recovered in good context (Figure 7-9). These are flakes exhibit minor modification from use or manufacture. Though recovered from all areas, they were most common in Area 3 and in the Initial Late Prehistoric. Area 3 holds the highest percentages for all tool types except unifaces even though Area 1 contained the largest volume of excavated soils (Table 7-2). Some of the most distinctive edge-modified tools were gravers (Figure 7-9a-c, f) and the perforators (Figure 7-9d, e).

The last lithic artifact category of note includes sixty-six cores. Thirty-four of these were recovered in Initial Late Prehistoric components, with 23 in Area 3. 


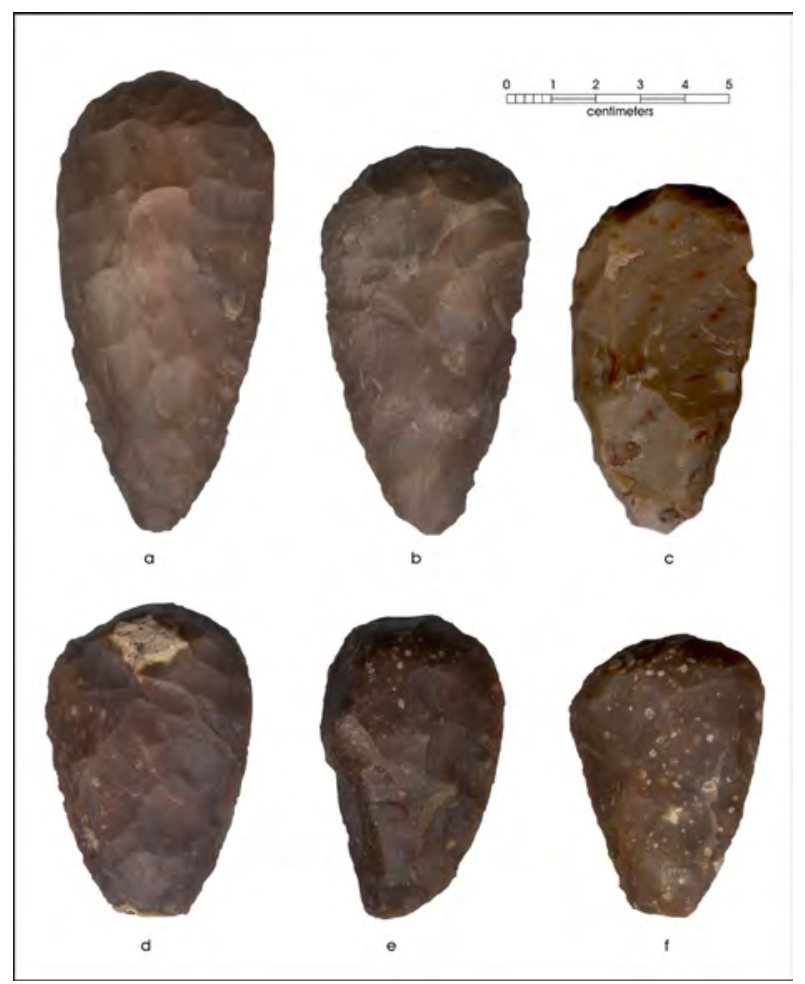

Figure 7-7. Unifaces clustered in Areas 1 and 2 in the Late Prehistoric Zone of 41 KM69 are teardrop shaped, indicative of a Toyah occupation.

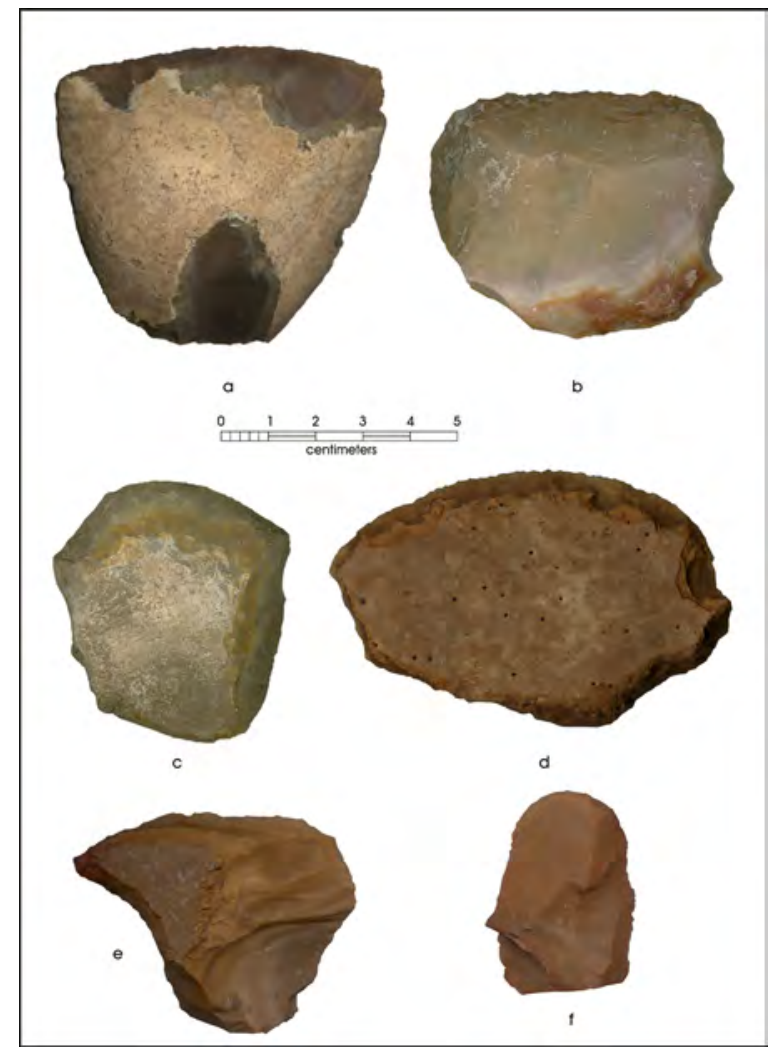

Figure 7-8. Unifaces recovered from 41KM69: scrapers (a-f); note graver tip on specimen $b$. 


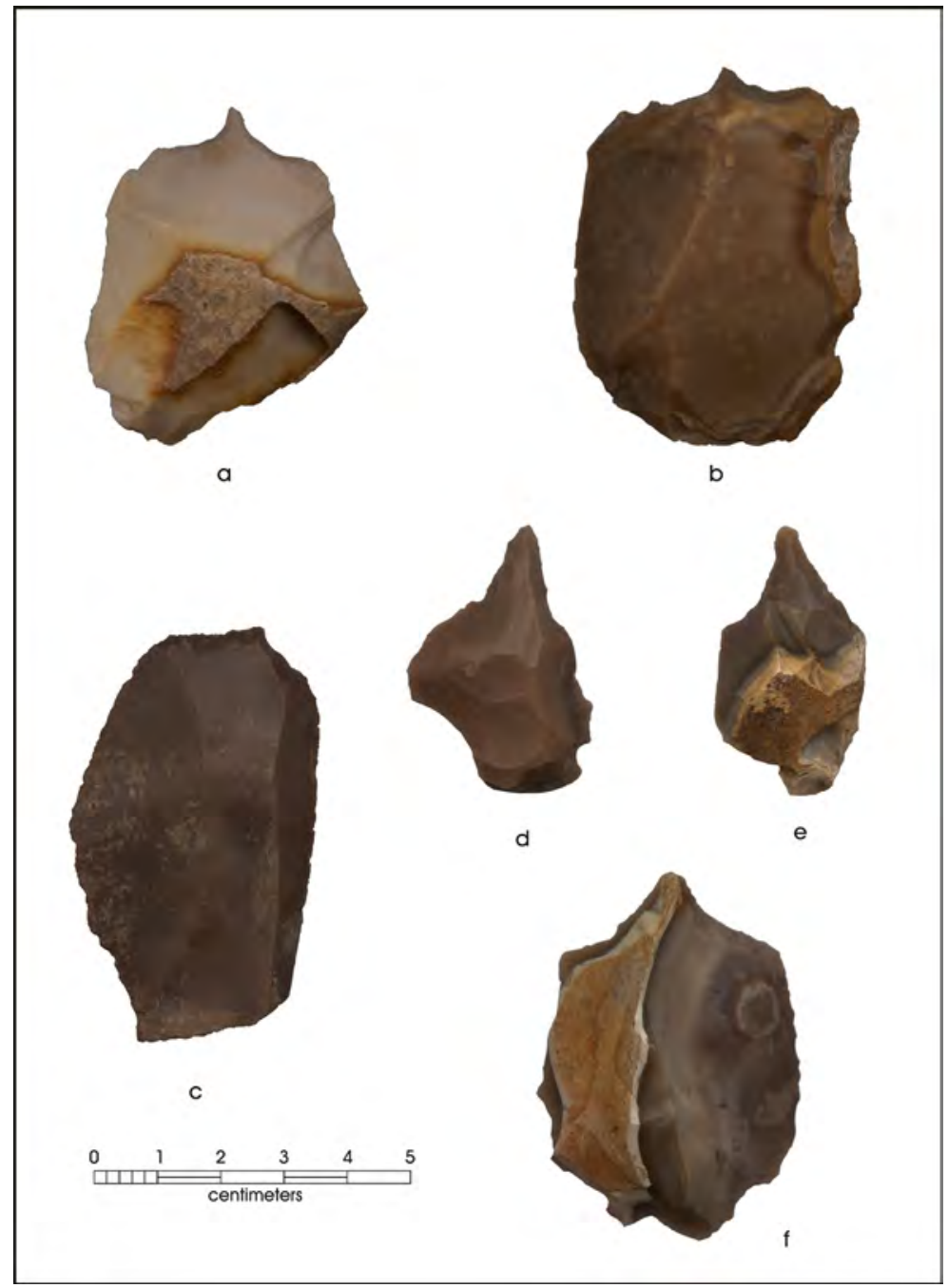

Figure 7-9. Edge-modified flake tools: gravers (a-c); reamers (d-f).

\section{Ceramics}

As mentioned above, the ceramic assemblage is of interest because of the surprising spatial patterns within Area 1. All 164 sherds collected from intact deposits came from Area 1 , and all but three of those were contained within Levels 4 and 5. The horizontal distribution is also patterned. In both levels, the concentration centers on units N87 E14 and N88 E14. In Level 4, the distribution trends to the northwest, and in Level 5, the distribution shifts more to the center of the block. Because the peripheral units contained very few or no ceramics, excavations likely captured the majority of the sherds present in Area 1 (Figure 7-10).

The collection sat above the Late Prehistoric features in Area 2, which occupied the surface of the Bk1 horizon. Level 4 sits within the A horizon of the site while Level 5 lies entirely within the AB horizon. The ceramic collection appears to come from an intact context, though the highest historic artifact count is in Level 4 , which was $\sim 10$ cmbs. These sherds, often referred to as Leon Plain in prehistoric contexts, are bone tempered and undecorated. Body sherds, rims sherds, and one handle were collected (Figure 7-11).

Their shallow depth, proximity to Perdiz points and Toyah end scrapers, and the seemingly late date obtained from a Feature 2 radiocarbon sample in Area 2 may suggest that the ceramics are Protohistoric in origin. Because radiocarbon dating is problematic when dealing with the relatively recent past, luminescent dating of selected sherds was performed by Dr. James Features of the University of Washington since previous radiocarbon dating returned mixed results. TxDOT also requested AMS dating of residues found on the same sherds submitted for luminescence dating. These residue samples were submitted to the University of Georgia. Results from the two dating methods are presented in Chapter 10 and Appendix G. 


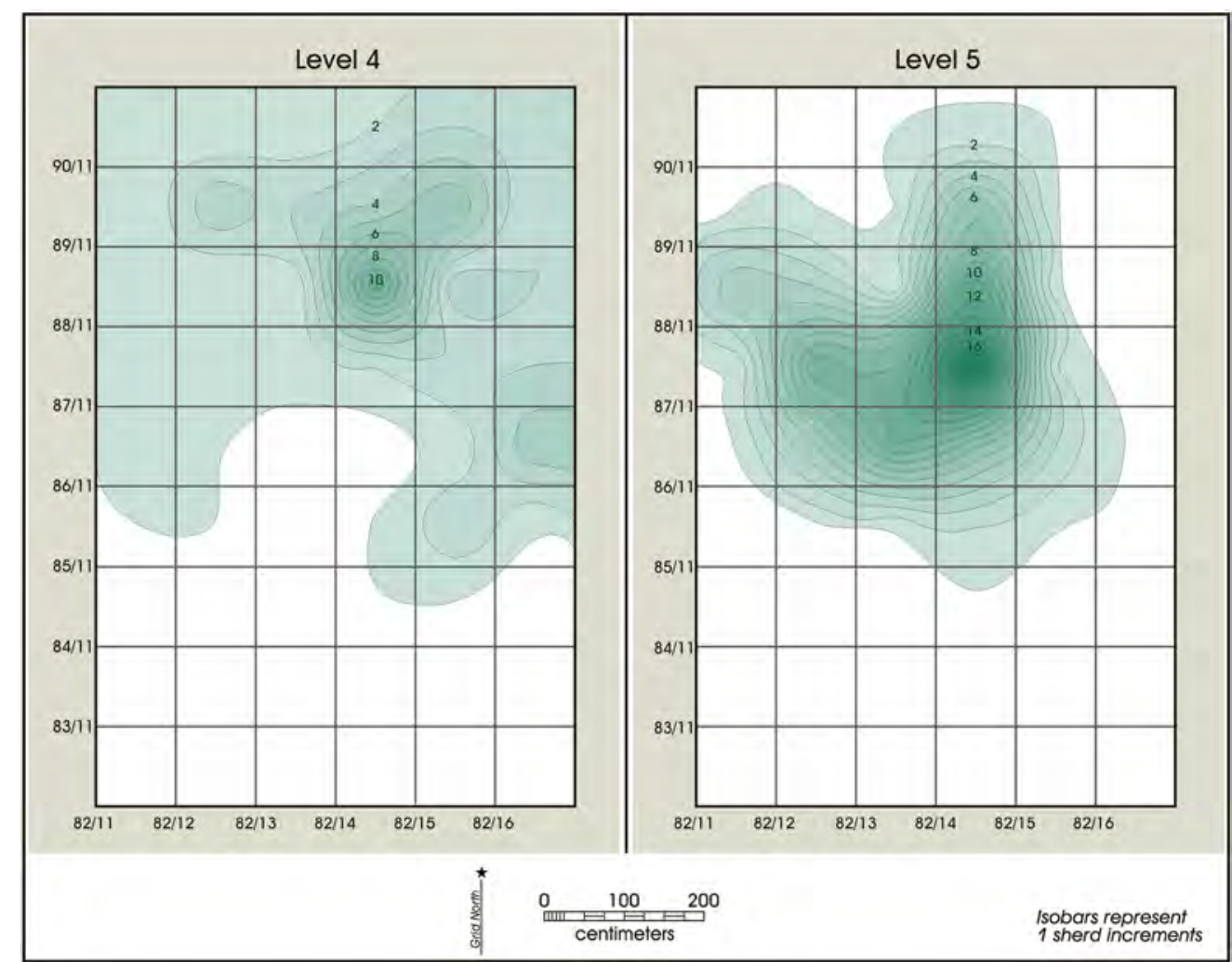

Figure 7-10. Leon Plain distribution in Area 1, Levels 4 and 5.

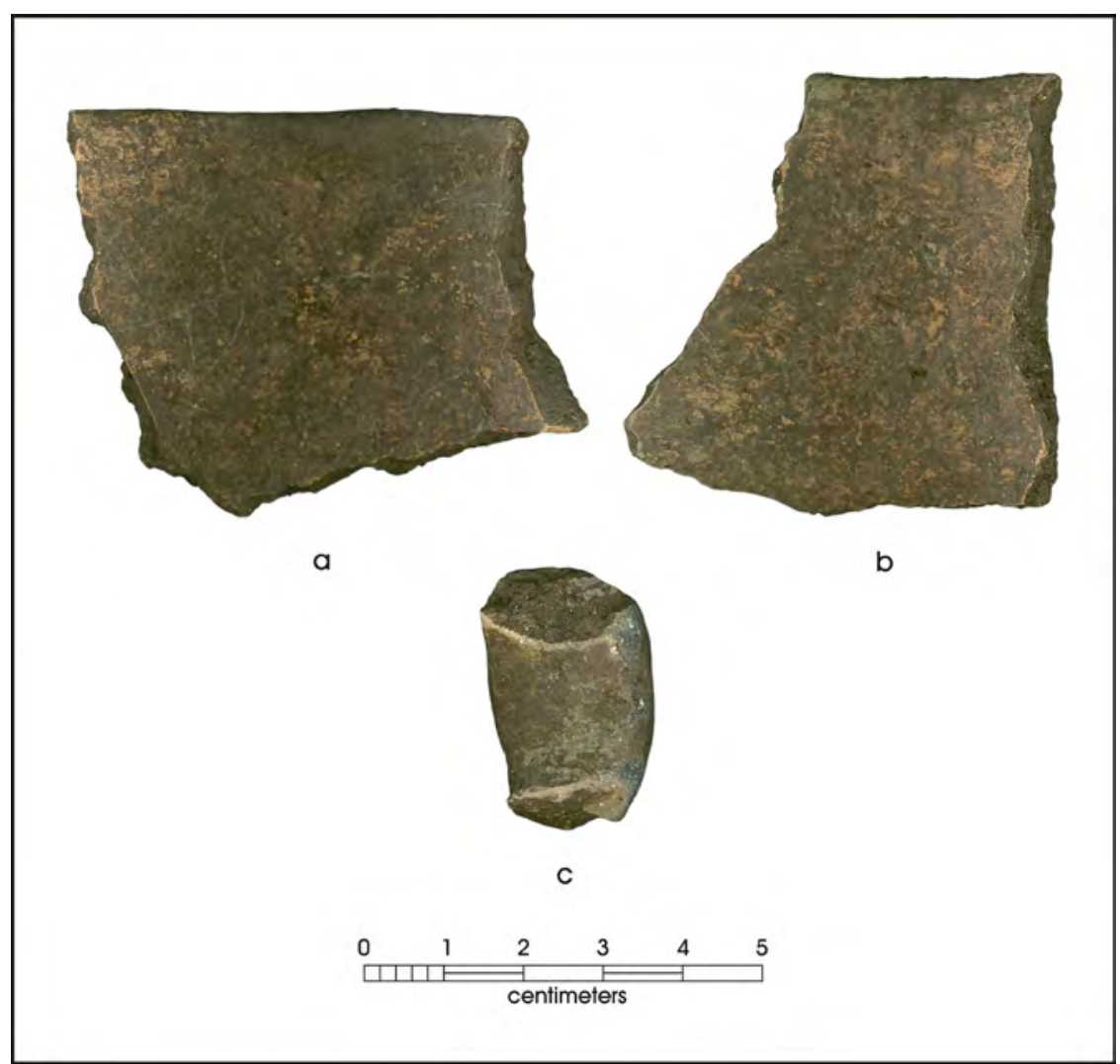

Figure 7-11. The sole ceramic type recorded at 41KM69 is undecorated and bonetempered. We recovered rim and body sherds and at least one handle from Area 1. 


\section{Bone and Shell}

Few faunal remains $(\mathrm{n}=1327,2257.7 \mathrm{~g})$ were encountered in intact units during testing and data recovery excavations at 41KM69. Bone fragments cluster in the Terminal Late Prehistoric (Levels 4 and 5) on the lower terrace (Table 7-4).

On the upper terrace in Area 3, bone counts were consistently low between Levels 6 and 13 and nearly non-existent in Area 4. Other than the ground squirrel/prairie dog bones and a few deer elements, few bones are identifiable to species. Much of the deer and bison-sized bone has numerous impact scars with some carnivore chewing and rodent gnawing present as well. Most of the recovered bone in Area 3 was found in disturbed contexts and omitted from this study, though it is included in the faunal data tables and discussions (see Appendix B).

Bivalve and gastropod shells were both present on site. Field crews identified Rabdotus sp., Polygyra sp. and Helicina sp. from excavations (Table 7-5). No mussel shell species were identified but general patterns from the entire site show bivalves peaking in Level 6. The gastropod inventory includes over 1200 whole specimens and over 200 bivalve umbos.

Table 7-4. Bone by Time Period and Area

\begin{tabular}{|c|c|c|c|c|c|c|c|c|c|c|c|}
\hline \multirow[b]{2}{*}{ Time Period } & \multirow[b]{2}{*}{ Level } & \multicolumn{4}{|c|}{ Count } & \multicolumn{4}{|c|}{ Weight (g) } & \multirow[t]{2}{*}{$\begin{array}{c}\text { Total } \\
\text { Count }\end{array}$} & \multirow[t]{2}{*}{$\begin{array}{c}\text { Total } \\
\text { Wgt. (g) }\end{array}$} \\
\hline & & 1 & 2 & 3 & 4 & 1 & 2 & 3 & 4 & & \\
\hline \multirow{6}{*}{ TLP } & 3 & 2 & & & & 2.72 & & & & 2 & 2.72 \\
\hline & 4 & 321 & 2 & & & $1,048.74$ & 0.3 & & & 323 & $1,049.04$ \\
\hline & 5 & 338 & 154 & & & 589.12 & 275.68 & & & 492 & 864.8 \\
\hline & 6 & 18 & 30 & & & 2.42 & 15.81 & & & 48 & 18.23 \\
\hline & 7 & & 1 & & & & 0.1 & & & 1 & 0.1 \\
\hline & 8 & & 1 & & & & 0.28 & & & 1 & 0.28 \\
\hline \multicolumn{2}{|l|}{ TLP Total } & 679 & 188 & & & 1643 & 292.17 & & & 867 & $1,935.17$ \\
\hline \multirow{8}{*}{ ILP } & 0 & & & 1 & & & & 19.68 & & 1 & 19.68 \\
\hline & 6 & & & 19 & & & & 21.2 & & 19 & 21.2 \\
\hline & 7 & & & 19 & & & & 7.95 & & 19 & 7.95 \\
\hline & 8 & & & 30 & 10 & & & 8.1 & 5.28 & 40 & 13.38 \\
\hline & 9 & & & 31 & 5 & & & 18.68 & 1.66 & 36 & 20.34 \\
\hline & 10 & & & 31 & 8 & & & 14.72 & 1.67 & 39 & 16.39 \\
\hline & 11 & & & 33 & & & & 18.71 & & 33 & 18.71 \\
\hline & 13 & & & 1 & & & & 0.42 & & 1 & 0.42 \\
\hline \multicolumn{2}{|l|}{ ILP Total } & & & 165 & 23 & & & 109.46 & 8.61 & 188 & 118.07 \\
\hline \multirow{6}{*}{ TLA } & 7 & 9 & & & & 1.52 & & & & 9 & 1.52 \\
\hline & 8 & 9 & & & & 1.47 & & & & 9 & 1.47 \\
\hline & 9 & 8 & & & & 1.75 & & & & 8 & 1.75 \\
\hline & 10 & 2 & & & & 0.26 & & & & 2 & 0.26 \\
\hline & 11 & 14 & & & 6 & 1.72 & & & 1.32 & 20 & 3.04 \\
\hline & 12 & 3 & & & 1 & 0.56 & & & 0.57 & 4 & 1.13 \\
\hline \multicolumn{2}{|l|}{ TLA Total } & 45 & & & 7 & 7.28 & & & 1.89 & 52 & 9.17 \\
\hline \multirow{5}{*}{ MLA } & 11 & & 2 & & & & 0.51 & & & 2 & 0.51 \\
\hline & 12 & & & 38 & & & & 16.21 & & 38 & 16.21 \\
\hline & 13 & 2 & & 104 & 11 & 0.36 & & 44.97 & 2.38 & 117 & 47.71 \\
\hline & 14 & & 1 & 2 & & & 0.19 & 25.47 & & 3 & 25.66 \\
\hline & 15 & & & & 9 & & & & 1.7 & 9 & 1.7 \\
\hline \multicolumn{2}{|l|}{ MLA Total } & 2 & 3 & 144 & 20 & 0.36 & 0.7 & 86.65 & 4.08 & 169 & 91.79 \\
\hline \multicolumn{2}{|c|}{ Grand Total } & 726 & 191 & 309 & 50 & $1,650.64$ & 292.87 & 196.11 & 14.58 & 1,276 & $2,154.20$ \\
\hline
\end{tabular}


Table 7-5. Shell Weights by Analytical Unit and Area

\begin{tabular}{|l|c|c|c|c|c|}
\hline & $\mathbf{1}$ & $\mathbf{2}$ & $\mathbf{3}$ & $\mathbf{4}$ & Grand Total \\
\hline Mussel shell & $\mathbf{3 9 2 . 2 5 4}$ & $\mathbf{2 8 . 1}$ & $\mathbf{1 6 2 . 7 8}$ & $\mathbf{8 6 . 4}$ & $\mathbf{6 6 9 . 5 3 4}$ \\
\hline MLA & 18.5 & 1.4 & 1.75 & 12.75 & 34.4 \\
\hline TLA & 112.174 & 2.1 & & 22.43 & 136.704 \\
\hline ILP & & & 161.03 & 51.22 & 212.25 \\
\hline TLP & 261.58 & 24.6 & & & 286.18 \\
\hline Snail shell & $\mathbf{1 , 5 2 1 . 3 2}$ & $\mathbf{5 9 2 . 6 8}$ & $\mathbf{2 , 8 9 7 . 1 4}$ & $\mathbf{2 , 2 9 8 . 5 8}$ & $\mathbf{7 , 3 0 9 . 7 2}$ \\
\hline MLA & 128.48 & 103.4 & 426.5 & $1,236.30$ & $1,894.68$ \\
\hline TLA & 382.35 & 90.9 & & 366.5 & 839.75 \\
\hline ILP & & & $2,470.64$ & 695.78 & $3,166.42$ \\
\hline TLP & $1,010.49$ & 398.38 & & & $1,408.87$ \\
\hline Grand Total & $\mathbf{1 , 9 1 3 . 5 7}$ & $\mathbf{6 2 0 . 7 8}$ & $\mathbf{3 , 0 5 9 . 9 2}$ & $\mathbf{2 , 3 8 4 . 9 8}$ & $\mathbf{7 , 9 7 9 . 2 5}$ \\
\hline
\end{tabular}

\section{Other Samples}

Charcoal, soil, and burned rock samples were all collected from the site because of their potential to provide information about the age and environmental setting of the site (Table 7-6). Over 60 charcoal samples were piece-plotted, collected in aluminum foil packets, and reserved for potential dating and/ or paleobotanical analyses. Seven of the features produced charcoal samples from within the feature boundaries (Features 1, 28, 34, 35, 46, 52, and 53). Soil samples each consist of approximately $20 \mathrm{~cm}^{3}$ of control soil samples. The majority of these $(n=84)$ are derived from stratigraphic units in block walls, though some are associated with features.

Burned rock also was collected from features at 41KM69. Samples were collected from most burned rock features for potential residue analysis and for the feature study described in Chapter 12. All burned rock excavated from the units in Feature 1, the burned rock midden, was counted and measured. This data was collected in order to ascertain any patterns in stone size that may correlate to construction or maintenance of the burned rock midden.

\section{Prehistoric Features}

The majority of cultural features recorded during the data recovery effort consisted of some arrangement of burned rock. These fell into two categories: hearths and burned rock clusters. Some features exhibited deliberate placement of rock (as for a hearth) while others seemed comprised of randomly scattered burned rock in a concentrated area (burned rock clusters). The term hearth describes a careful grouping of rock that may or may not show evidence of a pit, used to contain a fire. Without the presence of an identifiable pit or soil stain, we relied on the shape of the feature to determine whether it functioned as a hearth. Burned rock clusters represent close grouping of burned rock without a formal shape. We assumed that when people discarded burned rocks they did not arrange them in any formal way. Burned rock clusters may represent disturbed hearths that no longer hold their form or may represent the discard pile for rocks no longer useful in the functioning of the hearth. The burned rock scatter label applied to only two areas of burned rock identified during grading. These were large areas with fewer rocks per square meter than the other feature types and were not excavated. Detailed descriptions of the features are described in Appendix C. Prehistoric features are also outlined by time period and excavation area in Table 7-7.

During the data recovery hand excavation in Stage 1, the crew revisited the three burned rock features uncovered during testing and recorded 21 more (Table 7-7) for a total of 24 recorded burned rock features. Nine of these were hearths, 13 were burned rock clusters, one was at the base of the burned rock midden, and one was the burned rock midden itself. Stage 2 Gradall work uncovered 22 more thermal rock features. Eleven of these were hearth features, nine were burned rock clusters, and two were labeled burned rock scatters, which were relatively large areas with a sparse scattering of burned rock. No features were identified during the Stage 3 testing of the expanded ROW.

Forty-five soil stains were also recorded during the hand excavations $(n=25)$ and grading $(n=20)$. In Area 1 , the crew excavated a number of circular soil stains resembling post molds ( $\mathrm{n}=24)$, many were determined to be root molds $(n=16)$ based on their physical dimensions (Figure 7-12). 
Table 7-6. Counts of Burned Rock and Macrobotanical Samples

\begin{tabular}{|l|c|c|c|c|c|}
\hline & $\mathbf{1}$ & $\mathbf{2}$ & $\mathbf{3}$ & $\mathbf{4}$ & Grand Total \\
\hline ILP & & & $\mathbf{1 , 5 8 1}$ & $\mathbf{5 2 8}$ & $\mathbf{2 , 1 0 9}$ \\
\hline Burned rock & & & 1,483 & 493 & 1,976 \\
\hline Charcoal and macrobotanical & & & 98 & 35 & 133 \\
\hline MLA & $\mathbf{8 2 4}$ & $\mathbf{1 8}$ & $\mathbf{6 7}$ & $\mathbf{1 1 2}$ & $\mathbf{1 , 0 2 1}$ \\
\hline Burned rock & 816 & 17 & 51 & 98 & 982 \\
\hline Charcoal and macrobotanical & 8 & 1 & 16 & 14 & 39 \\
\hline TLA & $\mathbf{3 , 1 8 4}$ & $\mathbf{2 0 4}$ & & $\mathbf{1 0 0}$ & $\mathbf{3 , 4 8 8}$ \\
\hline Burned rock & 3,165 & 200 & & 89 & 3,454 \\
\hline Charcoal and macrobotanical & 19 & 4 & & 11 & 34 \\
\hline TLP & $\mathbf{2 7 7}$ & $\mathbf{1 0 2}$ & & & $\mathbf{3 7 9}$ \\
\hline Burned rock & 256 & 82 & & & 338 \\
\hline Charcoal and macrobotanical & 21 & 20 & & & 41 \\
\hline Grand Total & $\mathbf{4 , 2 8 5}$ & $\mathbf{3 2 4}$ & $\mathbf{1 , 6 4 8}$ & $\mathbf{7 4 0}$ & $\mathbf{6 , 9 9 7}$ \\
\hline
\end{tabular}

Table 7-7. Prehistoric Features by Time Period and Area

\begin{tabular}{|c|c|c|c|c|c|c|c|}
\hline Time Period & Area & Feature \# & North & East & upper el. (cmbd) & lower el. (cmbd) & Type \\
\hline TLP & Area 1 & 10 & 87.5 & 15.8 & 28 & 28 & burned rock cluster \\
\hline MLA & Area 1 & 36 & 85.4 & 13 & 105 & 105 & burned rock cluster \\
\hline MLA & Area 1 & 35 & 88.8 & 16.4 & 129 & 140 & hearth \\
\hline MLA & Area 1 & 99 & 85.5 & 12.9 & 110 & 130 & hearth \\
\hline TLP & Area 1 & 13 & 84.05 & 14.84 & 60 & 75 & soil stain \\
\hline TLP & Area 1 & 16 & 89.54 & 11.24 & 65 & 110 & soil stain \\
\hline TLP & Area 1 & 17 & 89.51 & 11.61 & 65 & 109 & soil stain \\
\hline TLP & Area 1 & 18 & 86.35 & 13.6 & 65 & 99 & soil stain \\
\hline TLP & Area 1 & 19 & 85.65 & 12.33 & 70 & 95 & soil stain \\
\hline TLP & Area 1 & 22 & 88 & 12 & 72 & 105 & soil stain \\
\hline TLP & Area 1 & 31 & 84.71 & 14.38 & 73 & 111 & soil stain \\
\hline TLP & Area 1 & 34 & 90.18 & 16.28 & 70 & 103 & soil stain \\
\hline TLP & Area 2 & 3 & 80.33 & 30.2 & 58 & 71 & burned rock cluster \\
\hline TLP & Area 2 & 3B & 80.33 & 30.2 & 58 & 71 & burned rock cluster \\
\hline TLA & Area 2 & 40 & 75.16 & 23.53 & 75 & 82 & burned rock cluster \\
\hline MLA & Area 2 & 43 & 79.75 & 26.75 & 98 & 101 & burned rock cluster \\
\hline MLA & Area 2 & 55 & 79.92 & 26.29 & 110 & & burned rock cluster \\
\hline TLP & Area 2 & 2 & 77 & 30 & 48 & 70 & hearth \\
\hline MLA & Area 2 & 42 & 75 & 32 & 96 & 110 & hearth \\
\hline MLA & Area 2 & 56 & 80.53 & 26.18 & 101 & 110 & hearth \\
\hline TLA & Area 2 & 41 & 77.52 & 27.18 & 80 & 98 & soil stain \\
\hline ILP & Area 3 & 39 & 26.4 & 14.9 & 84 & 90 & burned rock cluster \\
\hline ILP & Area 3 & 54 & 23.37 & 16.72 & 88 & 105 & burned rock cluster \\
\hline ILP & Area 3 & 1 & & & & & burned rock midden \\
\hline ILP & Area 3 & 53 & 26.75 & 15.16 & 90 & 111 & hearth \\
\hline ILP & Area 3 & 52 & 36.5 & 22.5 & 85 & 90 & Internal Hearth \\
\hline ILP & Area 4 & 5 & 12 & 34 & 85 & 85 & burned rock cluster \\
\hline ILP & Area 4 & 44 & 17.75 & 30.75 & unknown & 80 & burned rock cluster \\
\hline ILP & Area 4 & 46 & 16.1 & 33.35 & 71 & 80 & burned rock cluster \\
\hline
\end{tabular}




\begin{tabular}{|c|c|c|c|c|c|c|c|}
\hline Time Period & Area & Feature \# & North & South & upper el. (cmbd) & lower el. (cmbd) & Type \\
\hline TLA & Area 4 & 48 & 17.63 & 32.36 & 92 & 110 & burned rock cluster \\
\hline MLA & Area 4 & 50 & 14.16 & 35.8 & 139 & 147 & burned rock cluster \\
\hline ILP & Area 4 & 45 & 11.3 & 30.5 & 90 & 98 & hearth \\
\hline ILP & Area 4 & 47 & 13.9 & 34.5 & 84 & 94 & hearth \\
\hline TLA & Area 4 & 49 & 12.15 & 33.6 & 99 & 111 & hearth \\
\hline ILP & Area 4 & 51 & 14.46 & 30.99 & 140 & 143 & lithic concentration \\
\hline \multicolumn{8}{|c|}{ Features Recorded during Grading: Elevation from TDS } \\
\hline TLP & Lower Terrace & 57 & 84.8 & 20 & 99.38 & & burned rock cluster \\
\hline TLP & Upper Terrace & 58 & 46.5 & 16.6 & 100.471 & & Hearth \\
\hline TLP & Upper Terrace & 59 & 42.5 & 19 & & & burned rock scatter \\
\hline TLP & Lower Terrace & 63 & 86.6 & 23.55 & 99.07 & & soil stain \\
\hline TLP & Lower Terrace & 64 & 86.1 & 24.05 & 99.08 & & soil stain \\
\hline TLP & Lower Terrace & 65 & 87.54 & 24.8 & 99.087 & & soil stain \\
\hline TLP & Lower Terrace & 66 & 88 & 25.85 & 99.107 & & soil stain \\
\hline TLP & Lower Terrace & 67 & 86.55 & 25.55 & & & soil stain \\
\hline TLP & Lower Terrace & 68 & 85.8 & 26.1 & 99.095 & & soil stain \\
\hline TLP & Lower Terrace & 69 & 85.5 & 25.8 & 99.073 & & soil stain \\
\hline TLP & Lower Terrace & 70 & 84.75 & 25.4 & 99.041 & & soil stain \\
\hline TLP & Lower Terrace & 71 & 85 & 25.1 & 99.039 & & soil stain \\
\hline TLP & Lower Terrace & 72 & 83.5 & 22.5 & 99.104 & & soil stain \\
\hline TLP & Lower Terrace & 73 & 80.75 & 21 & 99.212 & & soil stain \\
\hline TLP & Lower Terrace & 74 & 80.8 & 19.25 & 99.218 & & soil stain \\
\hline TLP & Lower Terrace & 75 & 88.5 & 23.25 & 99.07 & & soil stain \\
\hline TLP & Lower Terrace & 76 & 87.65 & 22.75 & 99.055 & & soil stain \\
\hline TLP & Lower Terrace & 78 & & & 99.126 & & soil stain \\
\hline TLP & Upper Terrace & 79 & 24.8 & 30 & 100.627 & & burned rock cluster \\
\hline MLA & Lower Terrace & 80 & 80.05 & 26.4 & 98.847 & & burned rock cluster \\
\hline ILP & Upper Terrace & 81 & & & & & burned rock scatter \\
\hline TLP & Upper Terrace & 82 & 24.2 & 23.15 & 100 & 99.88 & hearth \\
\hline ILP & Upper Terrace & 83 & 25 & 29.95 & 100.201 & 100.15 & hearth \\
\hline ILP & Upper Terrace & 84 & 21.5 & 21.65 & 100.101 & 100.03 & burned rock cluster \\
\hline ILP & Upper Terrace & 85 & 28 & 24.5 & 100.268 & 100.14 & burned rock cluster \\
\hline ILP & Upper Terrace & 86 & 31.3 & 27.8 & 100.312 & 100.11 & hearth \\
\hline TLA & Upper Terrace & 87 & 18 & 22.2 & 100.014 & 99.98 & burned rock cluster \\
\hline MLA & Upper Terrace & 88 & 15.5 & 21.95 & 99.78 & 99.69 & hearth \\
\hline MLA & Upper Terrace & 89 & 21.99 & 22.95 & 99.393 & 99.393 & hearth \\
\hline TLA & Lower Terrace & 90 & 27.75 & 28 & 99.22 & & soil stain \\
\hline TLP & Upper Terrace & 91 & 20.6 & 18 & 100.549 & 100.379 & burned rock cluster \\
\hline ILP & Upper Terrace & 92 & 21.8 & 19.3 & 100.138 & 80.138 & hearth \\
\hline ILP & Upper Terrace & 93 & 18.75 & 18.9 & 100.186 & 100.086 & hearth \\
\hline TLA & Upper Terrace & 94 & 17.98 & 18.95 & 100.05 & 99.9 & hearth \\
\hline TLA & Upper Terrace & 95 & 14.75 & 17.25 & 100.024 & 99.884 & hearth \\
\hline TLA & Upper Terrace & 96 & 23.05 & 18 & 99.993 & 99.793 & burned rock cluster \\
\hline MLA & Upper Terrace & 97 & 21.4 & 17.65 & 99.838 & 99.688 & hearth \\
\hline MLA & Upper Terrace & 98 & 23.3 & 16.2 & 99.735 & 99.535 & burned rock cluster \\
\hline
\end{tabular}


Eight, however have uniform shape and good proportions to length and width (Table 7-7). One possible post was recorded in Area 2. The origins of some stains remain ambiguous and could be prehistoric post molds or historic fence posts.

Sixteen of the circular soil stains uncovered during grading are possible post molds. These are also of unknown origin and purpose, but are likely the product of the same occurrence(s) as the others recorded during the block excavation.

Seventy-two prehistoric features were recorded during these investigations. Features in Area 1 included eight soils stains, 2 burned rock clusters and 2 hearths. In Area 2, we excavated sever rock features and one soil stain. Two thermal features (Features 2 and 3) were found during significance testing within this block. We recorded the Phase III features from 60 to $100 \mathrm{cmbd}$ (Figure 7-13). Area 3 contained only five thermal rock features. Two of these include the burned rock midden and a hearth recorded at the bottom of the western end of the midden (Figure 7-14). Area 4 contained eight thermal rock features and one lithic concentration (Figure 7-15). During grading of the site, eighteen features were recorded on the lower terrace. All but two of these were soil stains. All twenty features recorded during grading of the upper terrace were burned rock features.

\section{Historic Features}

The historic component was not targeted during the data recovery efforts so no additional historic features were recorded after the significance testing phase was complete. Weston et al. (2004) recorded two historic features (see Figure 5-1).

Feature 4 was recognized in all excavation blocks at the site and recorded in the field profile drawings. Earlier interpretations suggested that it is a gravel driveway associated with the Kimble Courts resort (Weston et al. 2004). This interpretation remains valid though unproven. Subsequent archival research indicated that the Kimble Courts housing units did not sit within the current ROW but to the northwest.

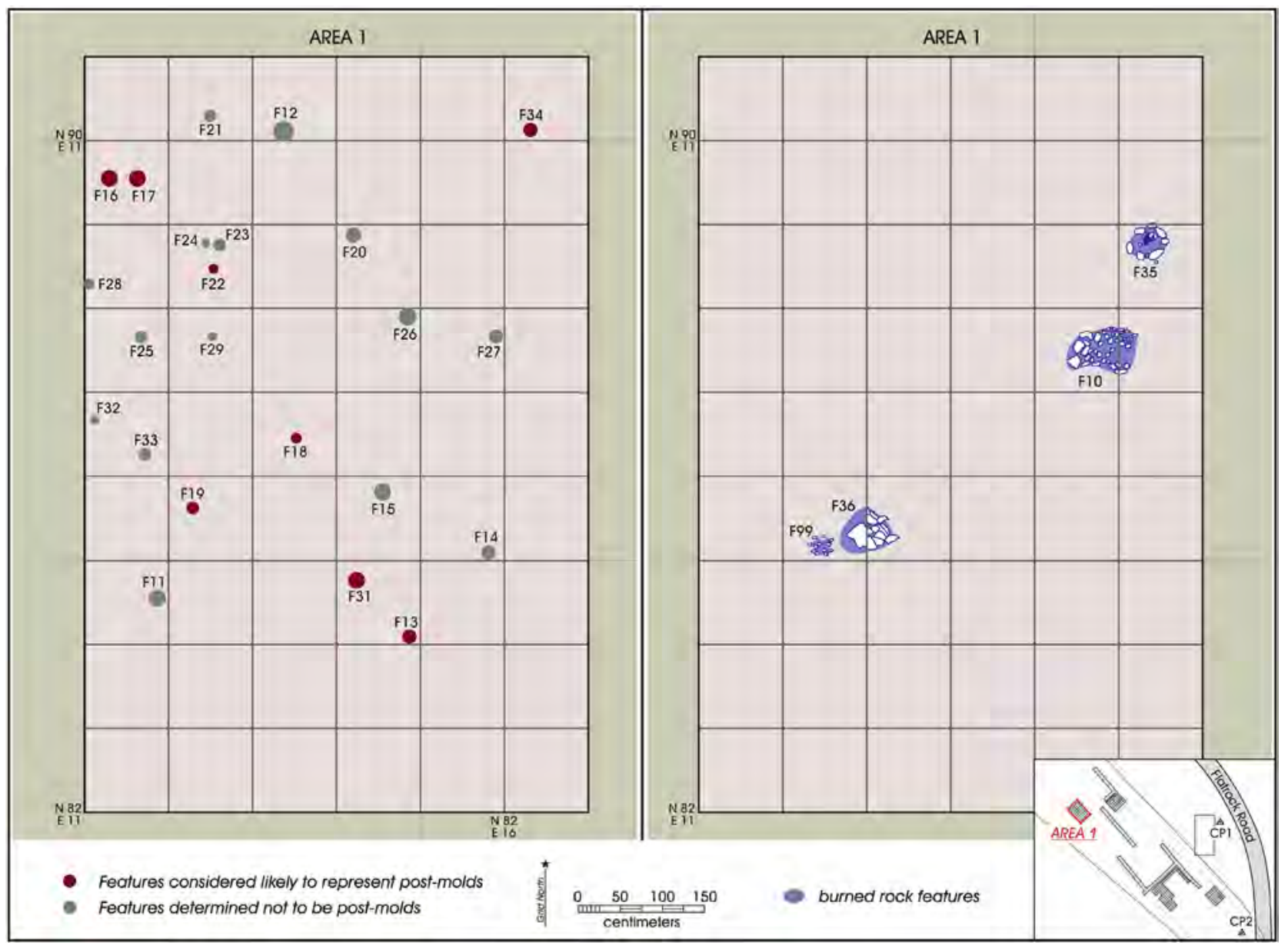

Figure 7-12. The features in Area 1 are illustrated in this map at various depth. 


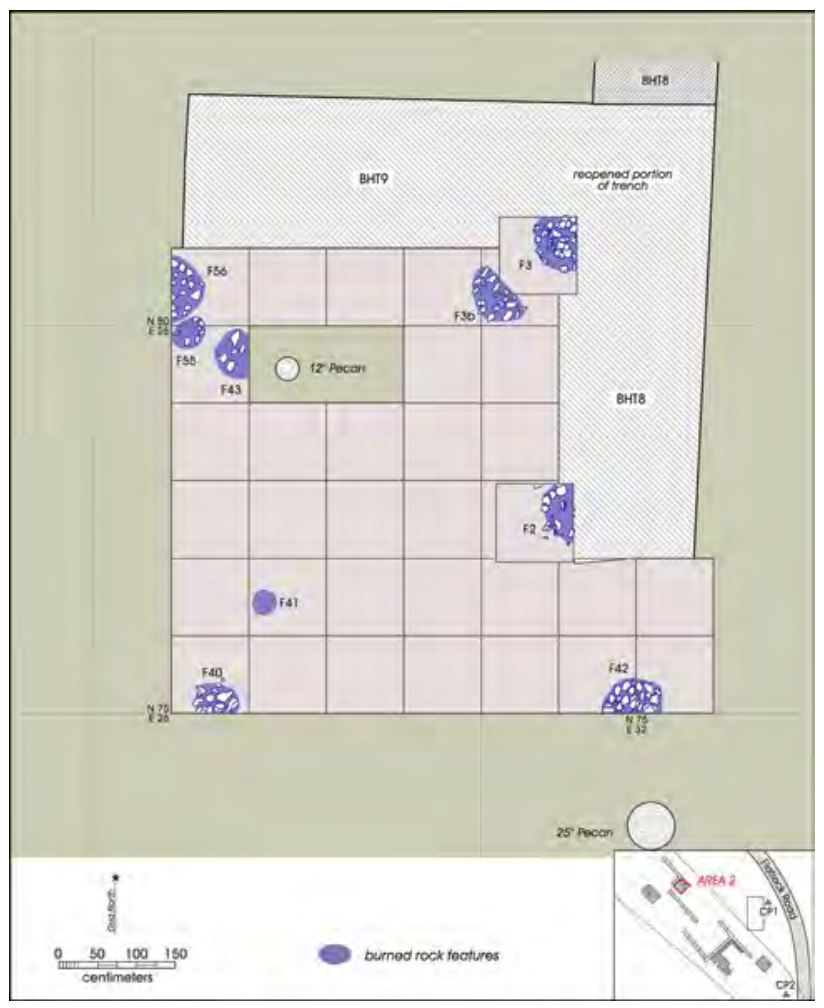

Figure 7-13. The distribution of features in Area 2 is clustered at the Ck horizon along the perimeter of the block.

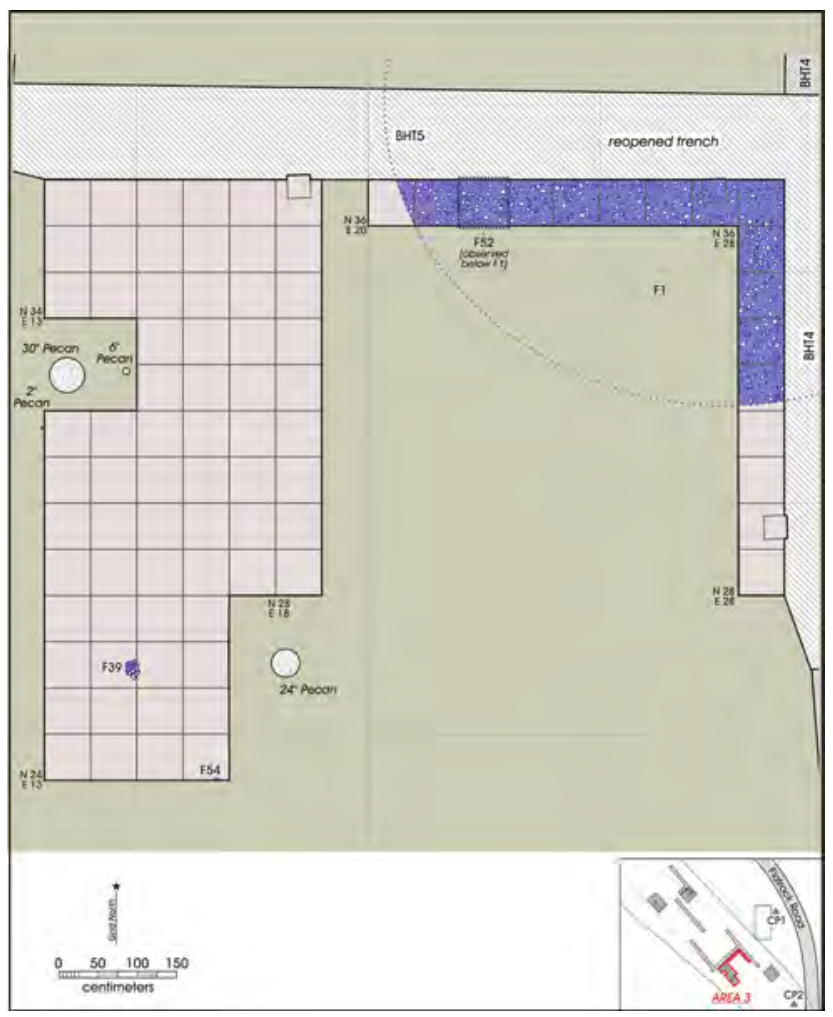

Figure 7-14. Only a few features besides the burned rock midden were documented in Area 3. These were located at the Ck horizon in the southern portion of the block. 


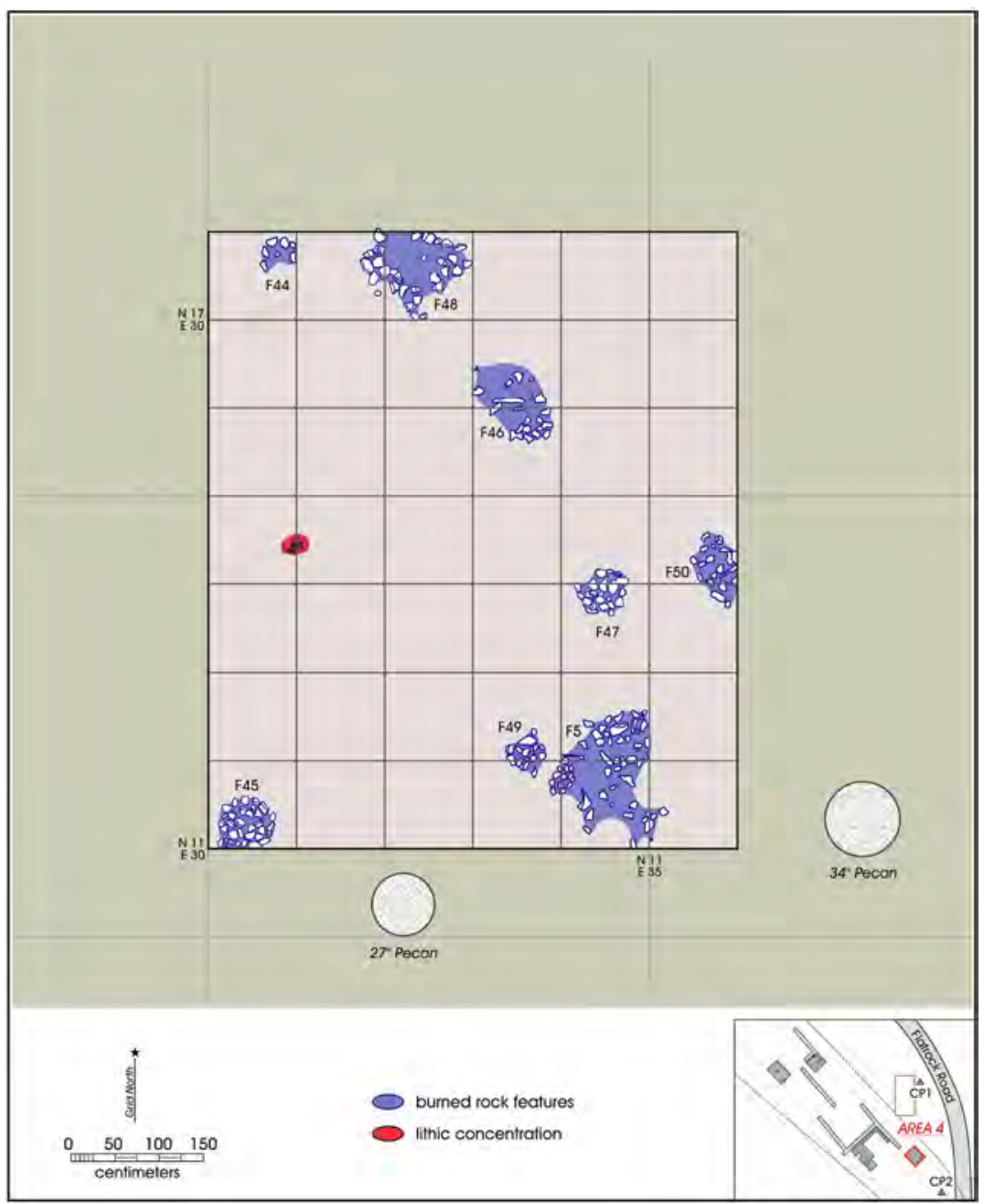

Figure 7-15. The features in Area 4 cluster at two elevations.

Local informants remember dirt roads crosscutting the hill in the 1940s, before the construction of Texas Tech University and Flat Rock Road, after the removal of the Kimble Courts. At that time, those dirt roads were popular hangouts for teenagers. Historic artifacts found in association with the gravel deposit could derive from a mixture of early resort activities and from loitering Junction youth.

Feature 6 is a concrete slab pad described as the original foundation of the main Kimble Courts structure (Weston et al. 2004; Figure 1-3). However, informant interviews now lead us to believe this was not related to the resort. Neither the Kimble Courts housing units nor the main office sat within the current ROW where the slab is located. They were located closer to the river to the northwest of the project area. During data recovery work, we were able to photograph some of the original Kimble Court buildings within the Junction City limits. These are reprinted in Appendix $\mathrm{C}$ and include the main office and guesthouses. The main office building is now a private residence (Figure C-26). The guesthouses were single story apartments which were in dilapidated condition but still standing behind an abandoned motel complex of the same name in the Spring of 2005 (Figure C-27). All the guesthouses have since been torn down.

\section{Summary}

This chapter summarized the artifact and feature inventory that resulted from significance testing and data recovery excavations at 41KM69. The numbers only included artifacts from units that were intact and could be assigned to an analytical unit. Final counts include over 41,000 pieces of debitage, over 400 stone tools and cores in various stages of reduction, and over 160 bone-tempered ceramic sherds. Other excavated samples include $2200 \mathrm{~g}$ of faunal bone, burned rock from excavated features, 60 plotted charcoal samples, and over 80 soil samples. Finally, excavation resulted in documenting 72 prehistoric and 2 historic features. 


\section{Chapter 8: Theoretical Overview}

\author{
Raymond P. Mauldin and Jennifer L. Thompson
}

At a general level, our interpretive scheme comes from cultural ecology (see Kirch 1982; Netting 1986; Sutton and Anderson 2004). We view cultural systems as both adaptive and differentiated. By adaptive, we mean that cultural systems are continually responding to changes in their physical and social environment (see Bettinger 1982). Of particular concern for us are the responses, including technology, that are involved with procurement and processing of food, fuel, and raw materials from their environment. By differentiated, we mean that people conducted different activities at different times and locations depending on specific circumstances. As activities conducted by a group vary in space and through time, the material remains generated by conducting those activities will also vary. Consequently, individuals and groups operating within a cultural system potentially will generate radically different sets of material at various points on the landscape. Variations in material culture, both at the level of individual artifact forms (e.g., projectile points), and at an assemblage level, primarily reflect adaptive responses (see Binford 1978, 1983; Gamble 1986).

In CAR's perspective, changes in cultural systems, including changes in material culture, are principally the result of changing parameters in the physical and social environment in which systems operate and to which they must adapt. Under this framework, they do not reflect movement of groups with a shared culture or influences diffused from other groups. Diffusion or migration may occur, but we are interested in why groups adopted traits or changed territories. This report is not concerned with tracing their historical connections through similarities in artifact form and our theoretical framework is not applicable to such study. We realize that our understanding of the mechanisms of change and the way we monitor those mechanisms in the social realm, is not well developed. Clearly, social factors, such as territorial disputes and shifting alliances, can alter adaptive strategies, especially through altering access to resource areas. However, in CAR's view, archeology currently lacks methods to monitor these social factors. In addition, even the best archeological data probably has a temporal resolution of decades, while most social alliances, especially in hunters and gatherers, commonly operated on a much shorter temporal scale and are archeologically invisible (note 1). This is why we focus on interactions between aspects of cultural adaptation and the ecological realm with the understanding that social factors are at play. At this level, we have better developed methods. Especially critical in the human/environment interaction are strategies and tactics, including the organization of technology and mobility, which groups used to acquire resources. It is in this realm, where cultural systems interact with the natural environment, that humans modify extant adaptive strategies. In addition, at least some of these interactions operate at long temporal scales that have the potential to manifest themselves in the archeological record.

Resources, including food, water, and raw materials, are not uniformly distributed in space, nor are they of uniform quality or density through time. Hunter-gatherers commonly solve problems created by spatial variation in resources by mobility strategies that involve positioning and changes in the composition of the group. Mobility strategies have several components that can vary, including the frequency of moves, the distance moved, and the degree to which different types of organization (e.g., logistically organized task groups, higher residential mobility) are used. Hunters and gatherers commonly solve temporal fluctuations in resources, including daily, seasonal, and year-to-year changes in resource availability and quality, as well as longer-term changes in resource structure, by shifts in mobility strategies, technological alterations, shifts in group size or composition, and through storage strategies.

\section{Prey Foraging Models}

We can investigate the responses initiated by hunters and gatherers to various scales of spatial and temporal fluctuations or change in resources using a cost/benefit framework developed in evolutionary ecology. Here, we focus on "prey models" which were developed for a single predator, searching in a random pattern, sequentially encountering potential prey in a homogenous environment (Charnov et al. 1976; Emlen 1966; MacArthur and Pianka 1966; Winterhalder 1981). Prey models (see Stephens and Krebs 1986) frequently quantify returns (benefits) as energy (kilocalories [Kcal]) obtained from food (but see Jochim 1975; Sih and Milton 1985; Speth and Spielmann 1983), and quantify costs as time expended on searching for, pursuing, capturing, and processing that food. They assume that foragers will attempt to maximize average return rates in the context of different cost/benefit ratios for different prey. Costs are usually broadly framed as search costs, the amount of time spent looking for resources, and handling costs, the amount of time required to pursue, capture, and process foods. Models assume that searching and handling are mutually exclusive, and that foragers have perfect knowledge of cost and benefits of all resources under consideration. The models focus on the question "should I pursue that resource, or should I continue to forage?" 
Human foragers violate, to some degree, many of the assumptions of prey models. They often hunt in groups, seldom search in a random fashion, often focus on a specific prey identified prior to initiating a search, lack perfect knowledge, and frequently "maximize" non-energy related elements. Furthermore, significant methodological problems plague archeological applications of such models. Nevertheless, we find the explicit cost/benefit framework appealing, and we will use elements of prey models to guide our analysis ${ }^{\text {(note } 2) .}$

\section{Resource Ranking and Diet Breadth}

One such element is ranking of prey alternatives in terms of handling costs and benefits. For human foragers, this ranking often reflects body size with larger-bodied animals (e.g., mammoths, bison) being more profitable (higher returns relative to handling costs) than smaller-sized animals (e.g., rabbit, deer) and plants. Figure 8-1 presents box plots for a series of return rates gathered from experimental and ethnographic sources in the Great Basin of North America and in Australia (see Cane 1987; Kelly 1995; Simms 1987). In the figure, we have grouped animals by overall body size and plants by approximate seed size. Clearly, the return rates on large mammals in this example are extremely high, while those on collecting and processing small seeds are extremely low ${ }^{\text {(note } 3)}$. While plants generally rank below animals, once hunters and gatherers encounter and decide to "pursue" plants they probably have a high success rate. Not all pursuits of animals result in a positive outcome for the pursuer. In fact, ethnographic accounts of hunting suggest that many pursuits of animals do not result in a successful kill. For example, Marks (1976:205-209) reports the number of kills per stalking event for various types of large mammals by Valley Bisa hunters in Zambia. Using muskets, Bisa hunter kill rates per stalking event vary from a low of 2.9 percent for impala to a high of 26 percent for buffalo. Success rates using more traditional technologies, such as bow and arrow, are probably much lower (see Hill and Hawkes 1983:164), though we lack precise figures. Consequently, Figure 8-1 probably overestimated the return rates on animals because unsuccessful stalking events would result in no return. A more realistic ranking strategy would involve the ratio of energy captured per attack to the handling time per attack. This "prey profitability" ranking of plants and animals (Stephens and Krebs 1986:17-23) would result in a reduction of rankings of animals. Nevertheless, given the return rate disparity shown in Figure 8-1 it is likely that profitability of large-body sized animals would exceed returns on smaller animals and plants.

Search costs, though not taken into account in potential prey profitability rankings, play a critical role in determining the

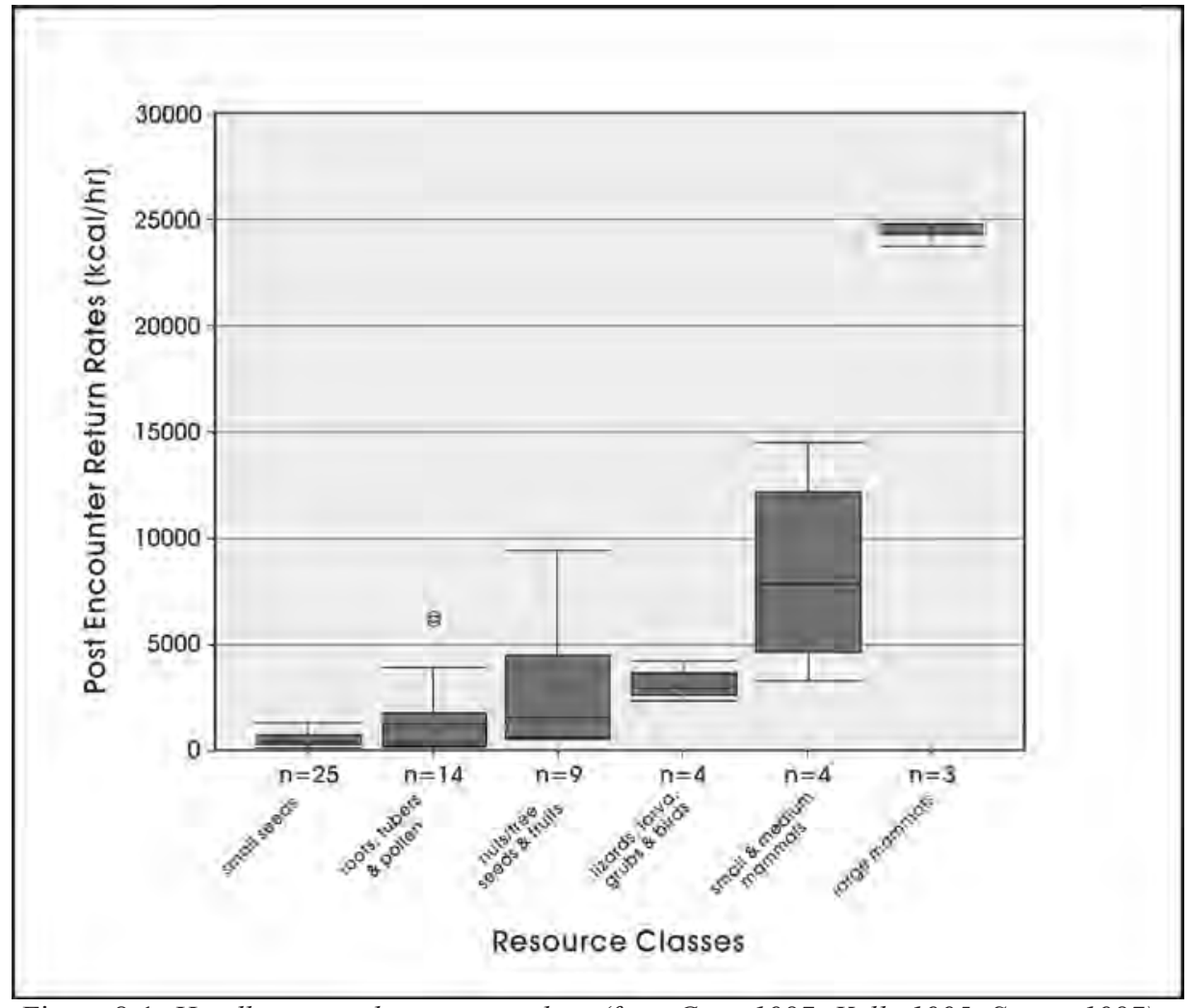

Figure 8-1. Handling costs by resource class (from Cane 1987; Kelly 1995; Simms 1987). 
actual diet. In a classic prey foraging model, as foragers add more resource types to their diet, search costs decline because foragers encounter dietary items more frequently. There is a cost to incorporating less profitable resources into a diet. Time saved in search is offset by the higher handling cost and/or lower caloric benefits of lower ranking resources. The inclusion of a resource must serve the overall profitability of the diet and will not be included until the value of higher ranked resources drops below a certain threshold. Therefore, the inclusion of a low ranked resource is dependent on its profitability relative to that of higher ranked, more profitable resources.

Foraging models predict a trade-off, then, between handling cost, benefits (energy return), and search costs that will maximize the average return and produce an optimal diet. These models predict that foragers will continue to add lower-ranked resources to the diet, increasing the diet breadth, so long as the overall profitability of the diet, seen in terms of total costs to benefits, is increased. Furthermore, foragers should drop resources from the diet, reducing their diet breadth, when doing so would increase overall profitability (Figure 8-2). Many factors, however, influence the profitability of a food item including, but not limited to, relative scarcity, climate, rainfall, and food procurement and processing technologies.
Changes in types, quality, and abundance of resources result from variations in climate, combined with differences in elevation, soils, geology, and natural history. Such environmental factors can produce dramatic differences in profitability of resources at various temporal scales and shift which animals and plants are included in the diet (see Winterhalder 1981). For example, animals in the size range of mule deer should be highly ranked, and therefore included in the optimal diet set, in most settings given their overall body weight. However, as suggested in Figure 8-3, that ranking may shift seasonally because of shifts in deer nutritional quality. The post-encounter return rates on deer in the Figure 8-3 case differ by season, with higher returns during the fall and summer months, and lower returns during winter and spring. Therefore, the optimal diet shifts seasonally in this example as it would for other plants and mammals (see Speth 1983:120-131) in other seasonal environments like Central and South Texas (note 4$)$.

The scarcity and value of the highest ranked resource also effects the inclusion of all other diet options for a forager. Though the value and abundance of lower ranked food items may fluctuate, their incorporation into a diet will only occur if the profitability of the highest-level food item drops significantly. Figure 8-4 shows two examples of yearly changes in productivity of the plants in South Texas (Winberg 1997).

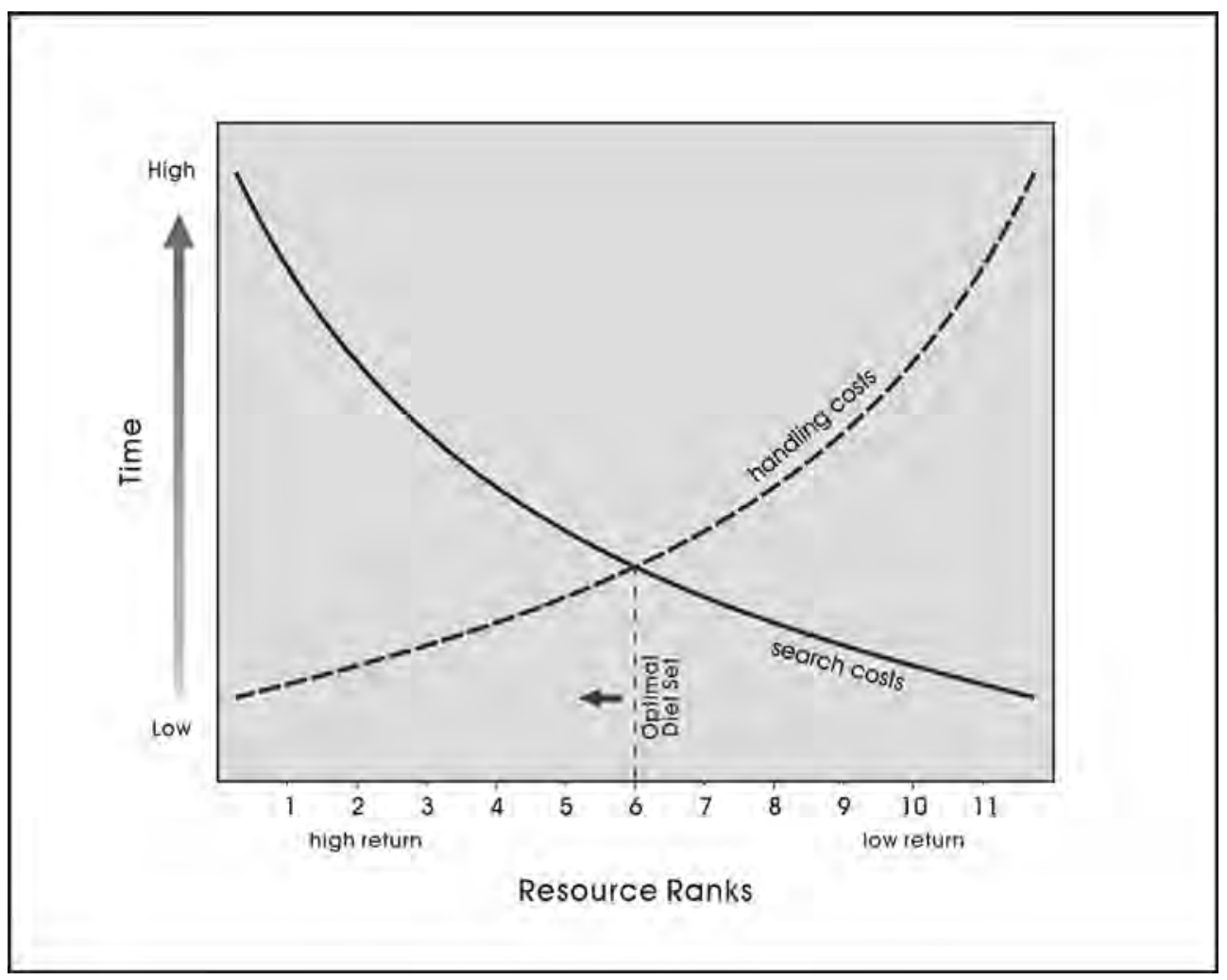

Figure 8-2. Optimal diet sets as defined in Prey Model (after McArthur and Pianka 1966). 
These data demonstrate fluctuations not in the nutritional quality of the plants, but in their yearly productivity by considering the percentage of prickly pear and mesquite that produce fruits or seeds over a 10-year period. These changes in density, which are probably responding to variability in climate, will translate into different search cost. For example, costs associated with finding mesquite in 1979, 1980, and 1981 when productivity was low would be considerably greater than the 1982 through 1984 years, when productivity was high. However, the decision to include or exclude mesquite is not related to shifts in density of mesquite as such, but rather to shifts in the density of higher ranked prey items ${ }^{(\text {note } 5)}$. In situations where the frequency of higher ranked items increase, foragers should drop lower ranked resources from the diet, thus increasing the average return. However, especially in the case of human foragers, other responses may also occur that could result in maximizing the average return rate. For example, technological changes, such as the abandonment of complex, expensive technologies in favor of those that are simpler and less costly to produce and maintain, or abandonment of specialized search methods, may be a viable option under some conditions of increasing frequency of higher ranked resources. Conversely, when higher ranked items become less common, human foragers could switch to technologies that, although more expensive to produce and maintain, might increase the kill ratio, and thereby the profitability, of the less frequently encountered high ranked prey. Foragers could also shift to search strategies that increase encounter rates for the high ranked prey.

The mix of possible responses, beyond simply increasing or decreasing diet breadth, probably depends on a variety of elements, including the relative profitability of alternative resources, as well as the costs and benefits associated with extant and alternative technologies and search strategies. For example, Figure 8-5 depicts a simple expansion of the diet under falling encounter rates for a high return resource. The top portion of the Figure 8-5A shows encounter rates (search costs), prey profitability (energy return per attack/handling costs per attack), and an optimal diet in a hypothetical environment. The difference between the profitability of Resource 4, which is included in the diet, and Resource 5, which is excluded, is minimal. If a decline in the encounter rates for the highest ranked resource (Resource 1) occurs in this setting, it is likely that diet expansion will occur. Such an expansion is shown in Figure 8-5B (bottom) with the inclusion of Resource 5 into the diet. Under these conditions, we would expect foragers to broaden their diet to include Resource 5 because its value is not much lower than Resource 4 and doing so would maximize the average return rates.

Figure 8-6A (top) presents roughly the same initial conditions, but in this scenario, the profitability of Resource 5 is much

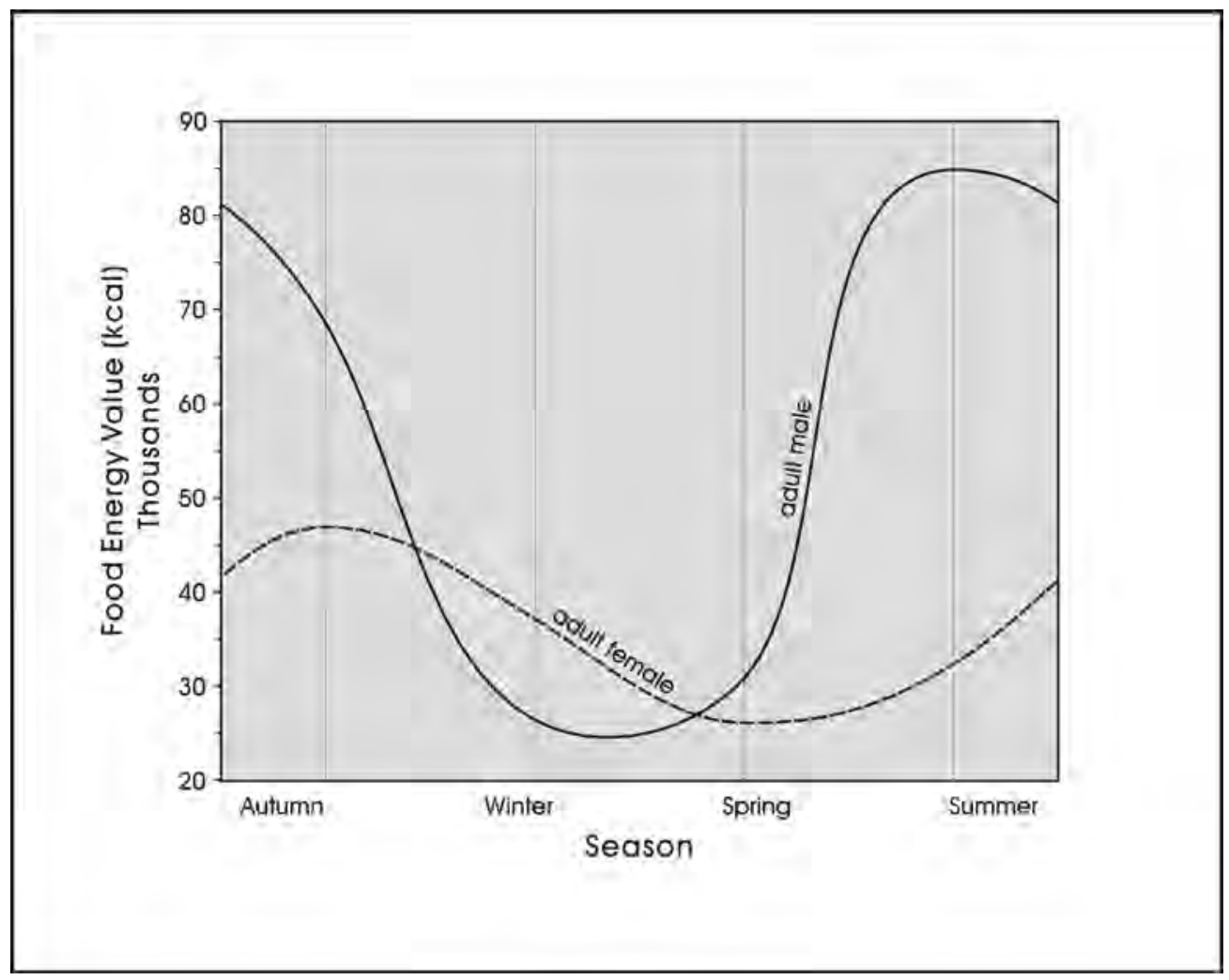

Figure 8-3. Seasonal changes in the nutritional quality of mule deer (from Anderson et al. 1972). 


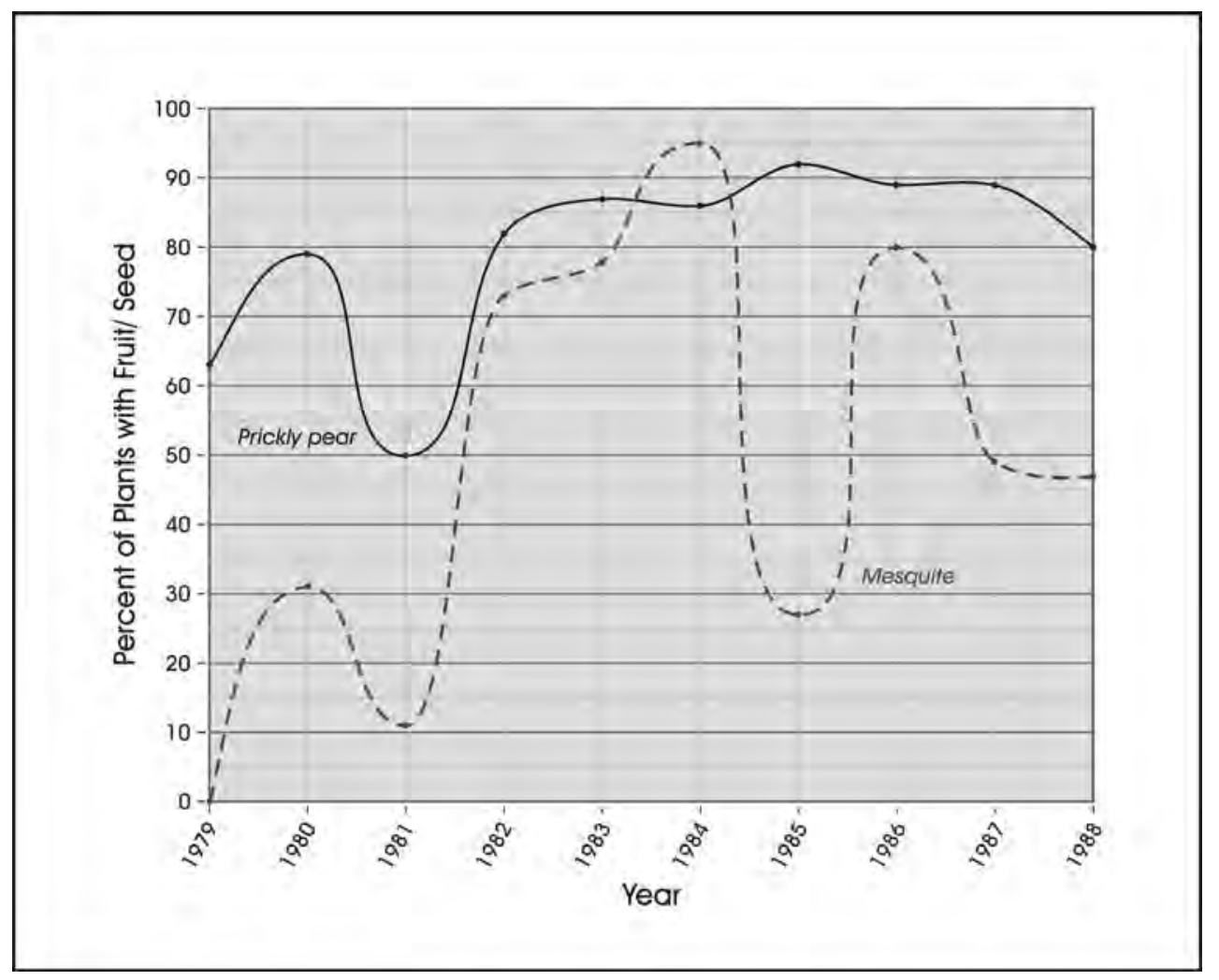

Figure 8-4. Yearly fluctuation in mesquite seeds and Prickly pear fruit (from Windberg 1997).

lower than Resource 4. So low, in fact that if it were included it would not maximize overall return rates of foraging efforts. Therefore, the same drop in Resource 1 shown in Figure 8-5B would not necessarily produce the same outcome (see Figure 8-6B). Under the Figure 8-6B scenario, the overall return rate of the diet might well be maximized by shifts to more costly processing methods, killing technologies, or search strategies that would increase the caloric returns, increase the success rate of kills, or increase the encounter rates with Resource 1.

\section{Technological Responses}

Shifts in the types of tools (e.g., use of ceramics) or processing facilities (e.g., features) will primarily influence handling costs associated with the acquisition of a given resource, although in some cases, they may also influence kill or capture rates and nutritional returns. We envision facilities and tools as ranging from generalized to specialized in form. Specialized tools (e.g., ceramics; hafted lithic tools, bows and arrows) and features (e.g., burned rock middens) tend to be more expensive to produce. Formal tools require more time, are usually more complex, and in some cases may require specific raw materials that have limited distributions. As a group, hunters and gatherers frequently maintain specialized tools and facilities, also increasing their overall costs (see Binford 1977, 1979). However, because of their specialized nature, these tools and facilities tend to be more efficient at accomplishing their designed task. Generalized tools or facilities, conversely, are less expensive to produce. They are often expediently made (e.g., utilized flakes), they tend to have few components, and they may have more flexible raw material requirements. In addition, they often have short uselives and minimum associated maintenance costs. While less costly and potentially useful in the performance of a variety of tasks, generalized tools and facilities will be less efficient at any given task.

When seen from this perspective, the decision to employ a more specialized or a more generalized technological solution can be considered in the context of the overall costs associated with tool/feature production and maintenance relative to the benefits derived from that tool or features. The adoption of more specialized processing and killing methods clearly involves increased costs in terms of time and energy. For our Figure 8-6 Scenario B example, the increased investment in technology may be offset by the increased profitability of the overall diet relative to the profitability of the diet that would be present if, because of declines in Resource 1, Resource 5 was included without any other changes.

\section{Mobility Responses}

Another set of responses concerns shifts in mobility. As noted above, mobility, in terms of search costs (travel 


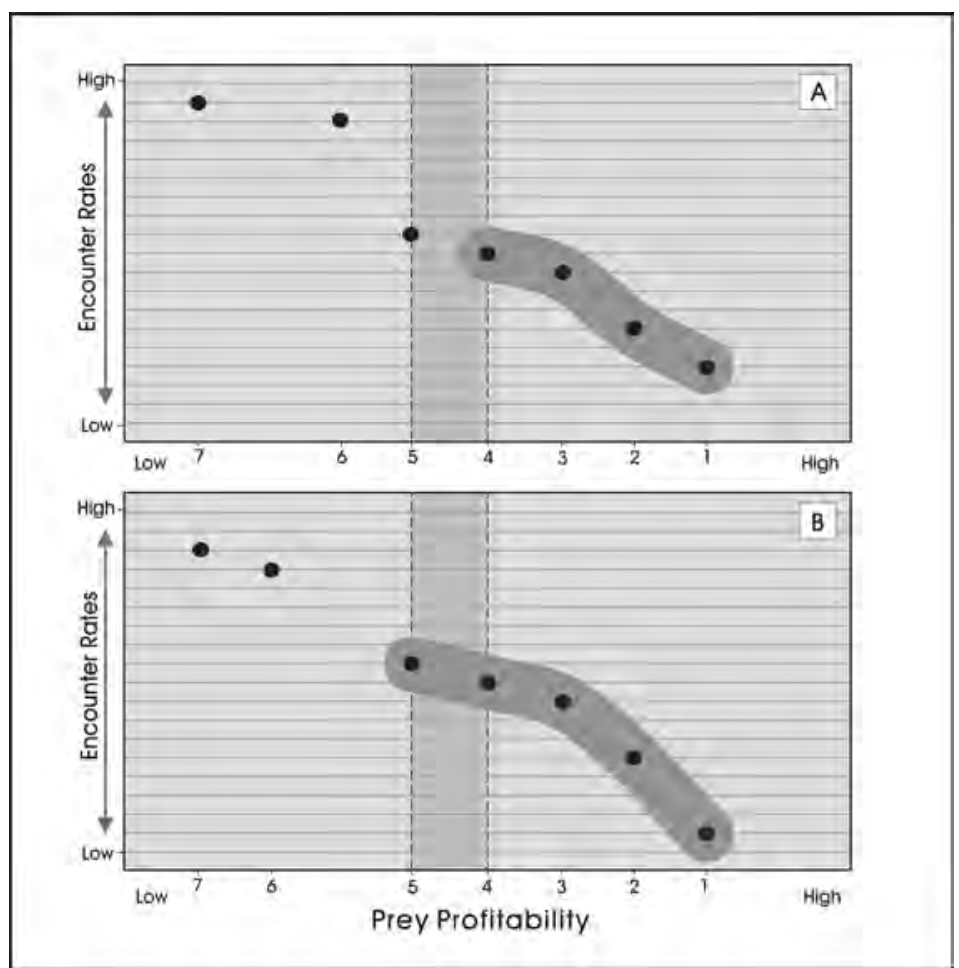

Figure 8-5. An example of diet expansion from 4 (A) to 5 (B) resources under conditions of closely ranked prey predictability and decreased encounter rates.
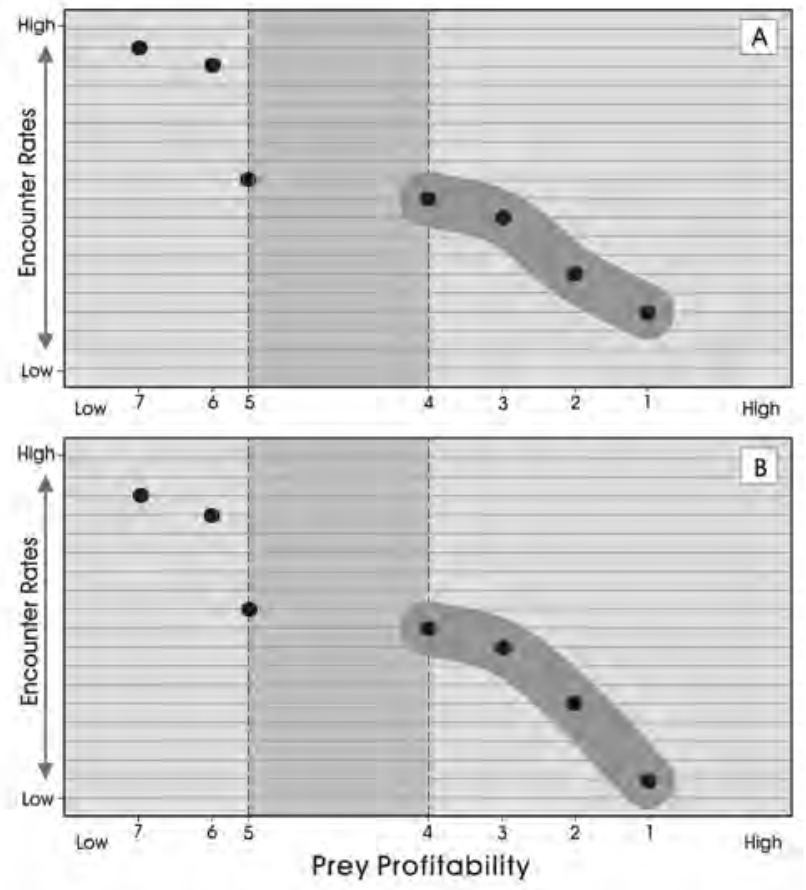

Figure 8-6. An example of the potential impacts of radical differences in prey predictability (resources 4 and 5). Diet expansion does not occur (A, B) with decreased encounter rates. 
time), plays a critical role in modeling diet breadth in prey models. Researchers increasingly discuss hunter-gatherer mobility systems in terms of "forager" and "collector" strategies (Binford 1980). Collector strategies have low residential mobility, relying extensively on task-specific groups to acquire resources and move those resources back to residential locations. Binford's foragers, in contrast, make frequent, shorter moves of residential camps and acquire food on a daily basis. Binford (1980; see also Kelly $1995)$ broadly framed these two strategies as responses to different environmental conditions, with foragers present in environments characterized by ubiquitous, low-density resources, and collectors present in settings with high temporal and/or spatial disparity in resources. In practice, these two strategies are frequently present within the same cultural system, with seasonal or resource-specific shifts in search strategies possible.

Logistical systems of resource procurement are a more specialized strategy relative to foraging-based systems. They are more costly in terms of distances covered, as well as requiring more planning, preparation, and coordination. Task groups of hunters and gatherers use logistical strategies to gather resources in excess of immediate needs, with that excess returned to residential locations. It is likely, then, that when logistical strategies are used, their target will tend to be higher-ranked resources. This is because the distance at which hunters and gatherers can effectively acquire resources in bulk is tied to the resources overall return rates, loadbearing abilities of the participants, and distance (e.g. Jones and Madsen 1989; Metcalfe and Barlow 1992) ${ }^{(\text {note } 6)}$. It is likely that the use of a logistical strategy would increase encounter rates for the targeted resource. In the Figure 8-6B scenario, if hunters and gatherers used a more costly logistical strategy but targeted Resource 1, the increased encounter rates for Resource 1 might offset that increased cost. Hunters and gatherers should use this strategy if doing so would increase the overall profitability of the diet relative to the profitability of the diet that would be present if they continued to pursue Resource 1 on an encounter basis, and they included Resource 5 without any other changes.

\section{Summary}

Using the cost/benefit framework provided by foraging theory, we have presented a number of general relationships that should be applicable to investigating aspects of diet, technology, and mobility in hunters and gathers. We have suggested that human foragers can respond to short and long-term shifts in resource availability in complex ways. Those responses may involve various mixes or shifts in what resources are included and excluded from the diet, technological changes that alter handling costs and capture rates of dietary items, and shifts in mobility strategies that alter encounter rates. The specific response hunters and gatherers initiate will depend on extant adaptations, available alternatives, and the structure of resources. Changes in the quality and quantity of resources, such as those noted above (see Figures 8-3, 8-4), further complicate the development of any detailed response model. The fluctuations mean that prey profitability and encounter rates are probably constantly changing. We can suggest that a hierarchy of responses may occur, with foragers potentially ignoring short-term fluctuations, or making minor alterations in diets such as the incorporation of alternative resources that have roughly similar ranks. Seasonal fluctuations in profitability, like those shown for deer, are likely to result in seasonal changes in what resources are included in the diet, along with shortterm shifts in technology and mobility strategies to exploit these different sets of resources (see Winterhalder 1981). Multiyear, directional changes in climate (e.g., overall increase in moisture, decrease in temperatures over several decades, increase in variability in rainfall) that may result in shifts in resource quality, type, and density, however, are increasingly likely to result in significant shifts in what resources are included in the diet, as well as in the technology and mobility strategies used to acquire those resources.

In an archaeological setting, we are unlikely to be able to monitor short term, or even yearly shifts in resources, tactics, or strategies. Even under exceptional conditions, the temporal scale at which we can define associated activities in archeological assemblages is on the order of several decades, and frequently centuries. Events that happen on a daily, seasonal, or yearly scale are temporally invisible in most archeological contexts ${ }^{\text {(note } 7)}$. In an archeological context, these short-term responses will simply add to the variability seen in adaptive responses at a location. Conversely, multiyear directional changes in resource structure, such as those that result from climate shifts, or shifts in population density, operate at a temporal scale that is well suited for archeological investigations. Documenting and exploring these multi-year, directional changes in resource structure and human response at a variety of spatial scales is the overall focus of our research. 



\section{Chapter 9: Modeling Adaptations in the Late Archaic and Late Prehistoric Periods}

\section{Raymond P. Mauldin and Jennifer L. Thompson}

This section presents a general model of adaptation for the Late Archaic and Late Prehistoric periods in Central and South Texas. Additional details of this general model can be found in Tomka et al. (2004a, 2004b). The model is grounded in foraging theory, and developed in the context of longterm shifts in the availability of bison, a high-return animal that Dillehay (1974; see also Collins 1995; Collins 2004; Huebner 1991) argued had a variable presence in Texas. Because of their large body size, bison would have been the highest ranked resource available within Central and South Texas. With an average weight of about $600 \mathrm{~kg}$, these animals were almost 12 times heavier than white-tailed deer, the next largest animal present in this section of the state (see Davis and Schmidly 1997). Given their large size and high return rates, the presence or absence of bison within Texas should profoundly influence hunter-gatherer adaptations. Hunters and gatherers should always take bison when they encounter the animal, as they would any plant or animal within their optimal diet set. As bison increase in frequency, hunters and gatherers should encounter them more often, and this should result in a change in their optimal diet set. Specifically, hunters and gatherers should eliminate the lowest ranked plants and animals from the diet as these actions would increase their overall return rate. When bison were absent, hunters and gatherers should expand their diet by adding low ranked plants and animals ${ }^{\text {(note } 1)}$. Some prey items (e.g., deer, antelope, rabbits, high return plant resources) will always remain in the optimal diet set regardless of the presence or absence of bison. As such, hunters and gatherers will always take these resources when encountered. That is, the expansion or contraction of the optimal diet set as bison availability fluctuates will differentially affect those resources that have low returns (e.g., reptiles, lizards, snails, grass seeds).

The temporal focus of this model is the Historic, Late Prehistoric, and Late Archaic periods within Texas (see Collins 1995). Several diverse data sets are used to explore aspects of this roughly 4,500 year time frame, and the spatial scales considered vary, in part, based on the data sets used and the specific elements monitored. The largest spatial scale encompasses the entire state while the smallest scale is a roughly $150,000 \mathrm{~km}^{2}$ area that covers most of what is commonly considered Central Texas (see Ellis et al. 1995) as well as a portion of South Texas stretching down to the Middle Coast (see Hester 1995). We offer a series of specific expectations concerning diet, technology, and mobility for each of the prehistoric time periods considered, expectations that we will subsequently develop in the context of our recent work at 41KM69. The focus of much of this section is on deriving estimates of the availability of bison as well as developing information on other plants and animals that were available to hunters and gatherers within Texas during the Late Archaic and Late Prehistoric periods.

Deriving expectations for changes in subsistence, technology, and mobility in periods of changing densities of bison within the study area are complex. Building such expectations minimally requires data on the relative density of bison, as well as information on other, alternative resources in the context of extant technological and mobility strategies. While we are a long way from achieving an understanding of most of these data sets, we can begin to gather data on bison availability by using two different types of information. The first type involves the occurrence of bison on archeological sites. These data are essentially presence/ absence and the format follows earlier work by (Dillehay 1974). We further present the percentage of components during a given period that have bison present. These data seem to provide a quantitative measure of bison availability, though the frequencies are still based on presence/absence data. The second data type we use focuses on estimating grassland productivity in Central and South Texas during the period of interest. Here, we use a variety of different climate data sets to assess both long-term and short-term differences in grassland productivity. As bison are primarily grazers, increases or decreases in grasslands should produce different concentrations of bison at various spatial and temporal scales. While these data sets are quantitative, they are essentially proxy data sets for bison densities.

\section{Archeological Patterns of Bison Availability}

As noted above, we designed our original model (see Tomka et al. 2004a, 2004b) in the context of the presence/absence of bison using Dillehay's (1974) earlier work. Though the distribution has been modified slightly by subsequent research (Collins 1995, 2004; Huebner 1991), Dillehay argued that bison were absent from the state in the Middle Archaic, present throughout the Late Archaic, absent in the Late Prehistoric Austin interval, and present again in the Late Prehistoric Toyah interval. As an initial attempt to verify these patterns for the Late Archaic and Late Prehistoric periods, we conducted a review of bison presence/absence on selected archeological sites (Mauldin and Kemp 2005). That review centered on a sample of 182 components from 117 sites that dated to the Late Archaic and Late Prehistoric periods within a roughly $150,000 \mathrm{~km}^{2}$ area in Central and South 
Texas. In their study, Mauldin and Kemp (2005) reviewed 182 Late Archaic and Late Prehistoric components on 115 archeological sites. They evaluated each of the components for temporal quality, as well as for the association between bison and the assigned temporal component. Ultimately, they identified 137 components on 73 archeological sites that formed the basis of their investigation.

Figure 9-1 presents the area considered by Mauldin and Kemp (2005), along with the location of the 73 archeological sites used. The numbers assigned to each site in Figure 9-1 are tied to data in Appendix K. Also listed in Appendix K are data on those sites that Mauldin and Kemp (2005) reviewed but eliminated, along with the criteria used for assessing each site and assigning the material to a temporal period. Eventually, they identified 71 components that had bison present and good temporal association, and 66 components that lacked bison but that we could assign to a temporal period (see Appendix K for details). Based on the presence of temporally diagnostic projectile points, Mauldin and Kemp (2005) defined three shorter temporal intervals, the Initial Late Archaic (4450-2500 B.P.), the Middle Late Archaic (25001600 B.P.), and the Terminal Late Archaic (1600-1250 B.P.), within the relatively long Late Archaic Period (see Appendix A). Their Late Prehistoric divisions (Initial Late Prehistoric; Terminal Late Prehistoric) are essentially equivalent to the Austin interval (1250-700 B.P.) and the Toyah interval (700400 B.P.). Sample sizes for several of these divisions are small. Only 17 components are present for the Initial Late Prehistoric and the Initial Late Archaic interval has only 18 components (Mauldin and Kemp 2005).

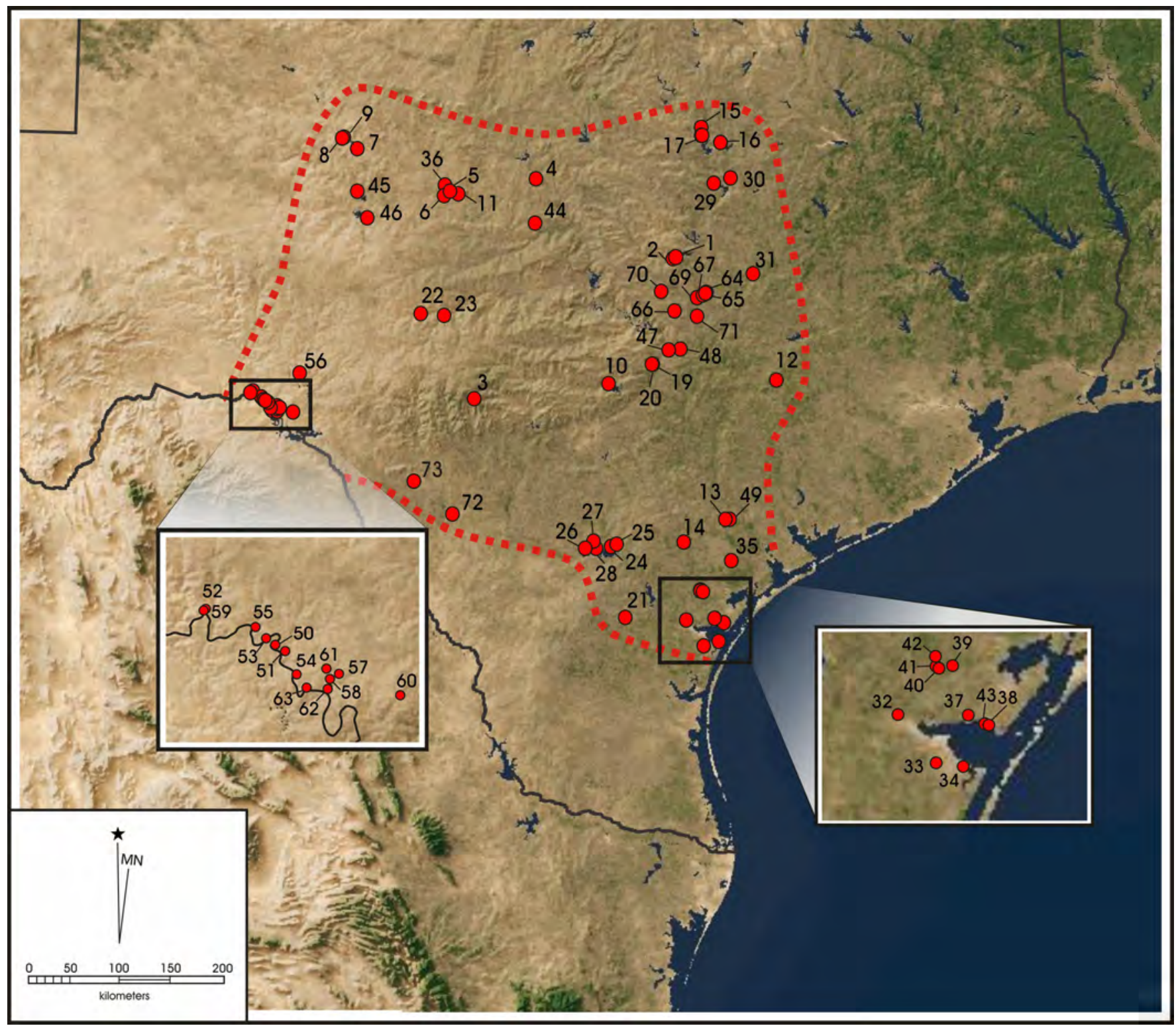

Figure 9-1. Area and sites (dots) investigated by Mauldin and Kemp (2005). Numbers associated with sites are tied to Appendix K. 
Figure 9-2 considers the relative frequency of components with bison present for each of the five intervals. Perhaps the most interesting aspect of the figure is that the Initial Late Prehistoric (Austin interval) absence period proposed by Dillehay (1974), and supported by Huebner (1991), is not supported by our review (note ${ }^{2)}$. Bison are present throughout the Late Archaic and the Late Prehistoric periods. The Figure 9-2 pattern also shows that bison are most frequently encountered on components dating to the Terminal Late Prehistoric, with over 80 percent of all components in this period having bison present. The lowest frequency of bison present, the Terminal Late Archaic (ca. 20 percent), culminates a gradual declining trend from just under 40 percent in the Initial Late Archaic (Mauldin and Kemp 2005).

These archeological data demonstrate that bison were present in much of Central and South Texas early in the Late Archaic and had a continued presence throughout the Late Prehistoric. As we will summarize subsequently, early historic accounts note that bison were present, at some level, well into the 1800s. To the degree that we can use the relative frequencies of bison present on components as a measure of the availability of bison, the archeological data further suggest that bison had a declining availability throughout the Late Archaic, and were increasingly available in the Late Prehistoric Period.

\section{Bison Distribution, Diet, and Mobility}

The species that was recovered from Late Archaic and Late Prehistoric archeological components in Texas was the Plains bison (Bison bison). The species first appeared in the north sometime after 6000 B.P. and spread rapidly south as grasslands replaced woodlands and forests during the latter portion of the Middle Holocene. They appear to have arrived in latitudes comparable to Texas sometime around 4500 B.P. (McDonald 1981). In this section, we discuss the diet and distribution of this new species. We focus on climate factors influencing forage availability and explore the potential impacts of those factors on bison mobility. We also review historic accounts of bison in Texas, some of which clearly suggest a variable, perhaps seasonal presence, of these animals. Finally, we review a variety of paleoenvironmental data, with a focus on the impact of environmental change in grasslands during the Late Archaic and Late Prehistoric periods, as introduced in Chapter 2. While the archeological data demonstrate that bison were present throughout the period of interest, and that they were present on a higher percentage of Terminal Late Prehistoric (Toyah) components, our goal in this section is to gather information on bison density, and understand factors that may have influenced shifts in availability of this high return resource in Texas. We conclude that although bison were present throughout much of Central and South Texas for all periods of concern here, there do appear to be fluctuations in their densities, at least as can be inferred from historic accounts and indirectly through fluctuations in grasslands.

Though certainly present at times in woodland settings, Figure 9-3, adapted from McDonald (1981:104), shows that the primary range of bison extended from central Texas in the south to Alberta, Canada, in the north. While bison clearly exceeded that range at various points, this core area is consistent with the approximate limits of the Great Plains grasslands and should be the region where bison densities are highest ${ }^{\text {(note } 3)}$. Plains bison are primarily grazers. Studies show that various grasses and sedges consistently comprise over 90 percent of their diet across all seasons (Coppedge et al. 1998; Peden 1976; Peden et al. 1974). Several different variables interact to produce grass of varying density and 


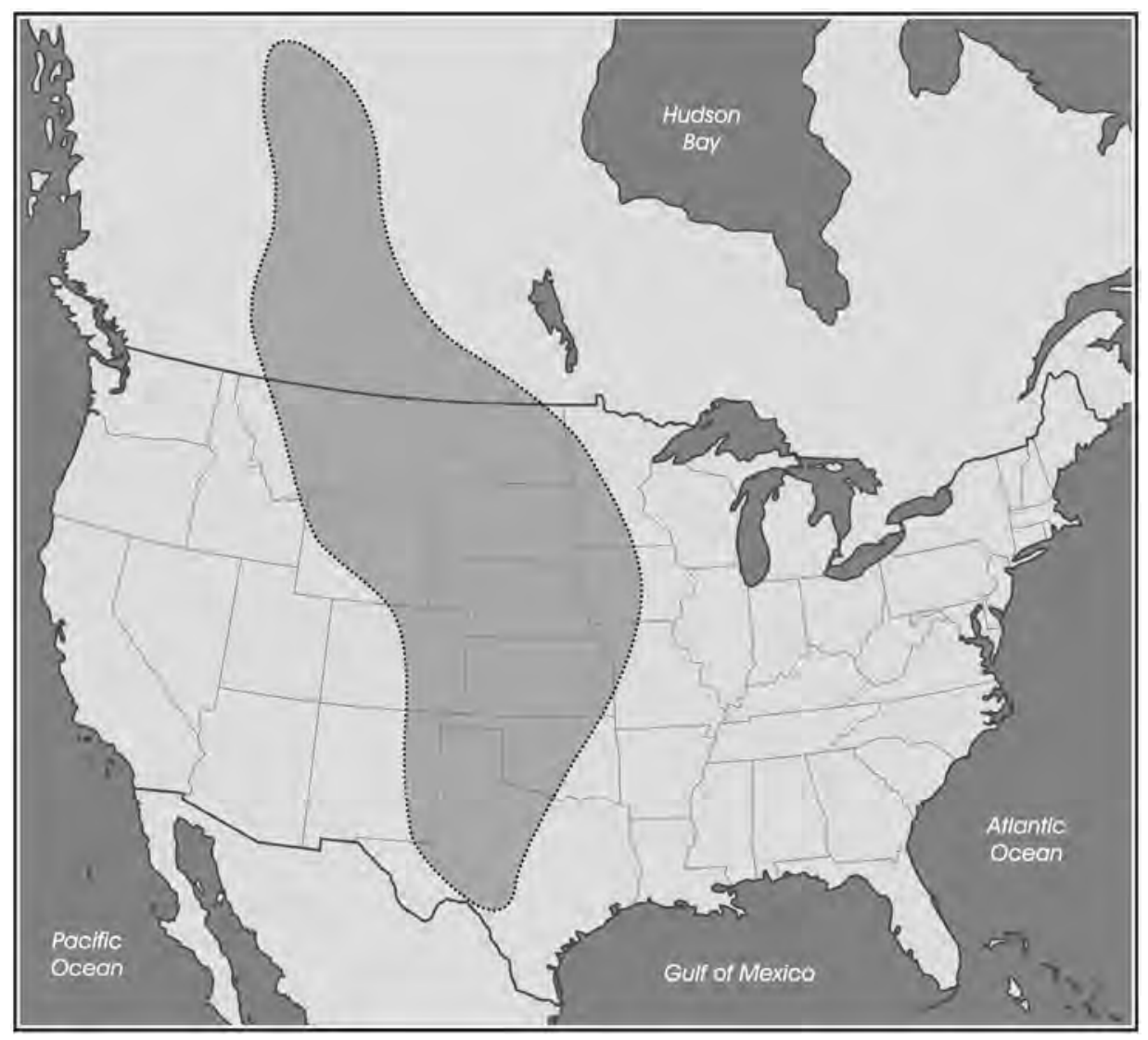

Figure 9-3. Primary range of Bison bison (after McDonald 1981:104).

quality for bison consumption at any given time and place. These include climate factors such as shifts in rainfall and temperatures, as well as factors such as soils (e.g. Epstein et al. 1997), fire frequency, and levels of grazing pressure (see Knapp et al. 1999). Here, we focus on climate variables in the context of grass production. Spatially, both the relative frequency and overall productivity of cool season $\left(\mathrm{C}_{3}\right)$ and warm season $\left(\mathrm{C}_{4}\right)$ grass are determined, to a large degree, by different mixes of precipitation and temperature in different soil regimes (see Bamforth 1988; Brown 1993; Epstein et al. 1997; Paruelo and Lauenroth 1996; Teeri and Stowe 1976). Spatial differences in the productivity in cool season grasses has a significant, negative correlation with mean annual temperature and percentage of sand in soils, and has a moderate positive correlation with mean annual precipitation (Epstein et al. 1997; Paruelo and Lauenroth 1996). Conversely, productivity in warm season $\left(C_{4}\right)$ grass show a strong, positive correlation with high mean annual precipitation $(\mathrm{R}=.85)$, and weak positive relationships with sandy soils and high mean annual temperatures (Epstein et al. 1997).

Warm season grasses dominate the southern plains, both in terms of frequencies of species and in terms of overall forage production. In contrast, $\mathrm{C}_{3}$ grasses dominate in the north. $\mathrm{C}_{4}$ grasses are more productive in terms of overall weight of forage produced per unit of area per year (Epstein et al. 1997), but there are data to suggest that $C_{3}$ grasses are both higher in protein and more easily digestible by herbivores than their warm season counterparts (see Caswell et al. 1973; Coppock et al. 1983a; Coppock et al. 1983b). For bison, the most consistently productive areas on a yearly basis are likely to be in the central portion of the Great Plains, where both cool season and warm season grasses are present. These central areas should produce consistent forage throughout much of the year, with grass production occurring from spring through the summer and into the fall. In contrast, both the northern and southern extremes of the distribution (see Figure 9-3) will have seasonally restricted production.

Several authors (e.g., Bamforth 1988; Speth 1983) have suggested that the amount of forage production for bison, the nutritional quality of that forage, and the location of that production in warm season grasses, such as those that dominate Texas, may be highly variable from year to year and across space during a given year. Growth in warm season $\left(\mathrm{C}_{4}\right)$ species frequently occurs in direct response to localized, unpredictable precipitation events during the late spring and 
summer months. Summer precipitation produces pulses of grass growth, shifts in the nutritional value of forage, and changes in the digestibility of grass for herbivores (see Hart et al. 1983; Rauzi and Dobrenz 1970; Sala and Lauenroth 1982). In the southern Great Plains, precipitation varies significantly in time and space, and several measures of precipitation (e.g., annual rainfall, summer rainfall) are strongly correlated with grassland productivity (see, Cable 1975; Knapp et al. 1998; Knapp et al. 2001; Lauenroth et al. 1999; Nippert et al. 2006; Pieper and Herbel 1982; Sims and Singh 1978a, 1978b).

The impact of year-to-year variation in grassland productivity as a function of rainfall can be seen in Figure 9-4. Here, we plot spring and summer (April-September) rainfall amounts (X-axis) against grass above ground net primary productivity (Y-axis) for 16 years using data from the Konza Prairie ecological research station in Kansas (Nippert et al. 2006). Differences in year-to-year production are significantly related to differences in growing season. Variation in rainfall will produce varying levels of grass production and by extension, variations in bison forage availability ${ }^{\text {(note } 4)}$.

Pieper and Herbel (1982), working in a desert grassland in New Mexico, demonstrate that biomass production responds rapidly to new rainfall, with measurable differences in biomass evident within days of a rainfall event. To the degree that rainfall events are spatially restricted on the southern plains, then, grassland productivity will vary from place to place. In order to consider the degree to which rainfall, and by extension productivity, is variable from place to place within Central and South Texas, we acquired precipitation data for the month of June from 1914 through 2003 ( $\mathrm{n}=90)$ for four areas located throughout the region. Figure 9-5 presents these four locations. The Austin, Cleburne, and Abilene data were derived from the National Weather Service (National Weather Service 2007a, 2007b, 2007c), while the Junction data were acquired from Weather Source (2007b, 2007a). We selected these four locations for three reasons.

First, we wanted to maximize spatial coverage of the area outlined previously in Figure 9-1. Second, these four modern stations are in proximity to the four tree-ring sequences used in Chapter 2. Finally, the Junction data come from stations adjacent to 41KM69. Unfortunately, no single station within the Junction area contained complete June rainfall data for the period considered. We used two different stations, located within 5 kilometers of each other and of 41KM69, to compile the June rainfall totals for Junction (Weather Source 2007b, 2007a). Nevertheless, we are still missing June totals from Junction for five of the 90 years between 1914 and 2003. The three other stations also are missing selected years, so that comparative June rainfall data are available from all four locations for 82 of the 90 years in the sequence.

Figure 9-6 presents histograms of two measures of year-toyear variability in June rainfall totals for the four Figure 9-5

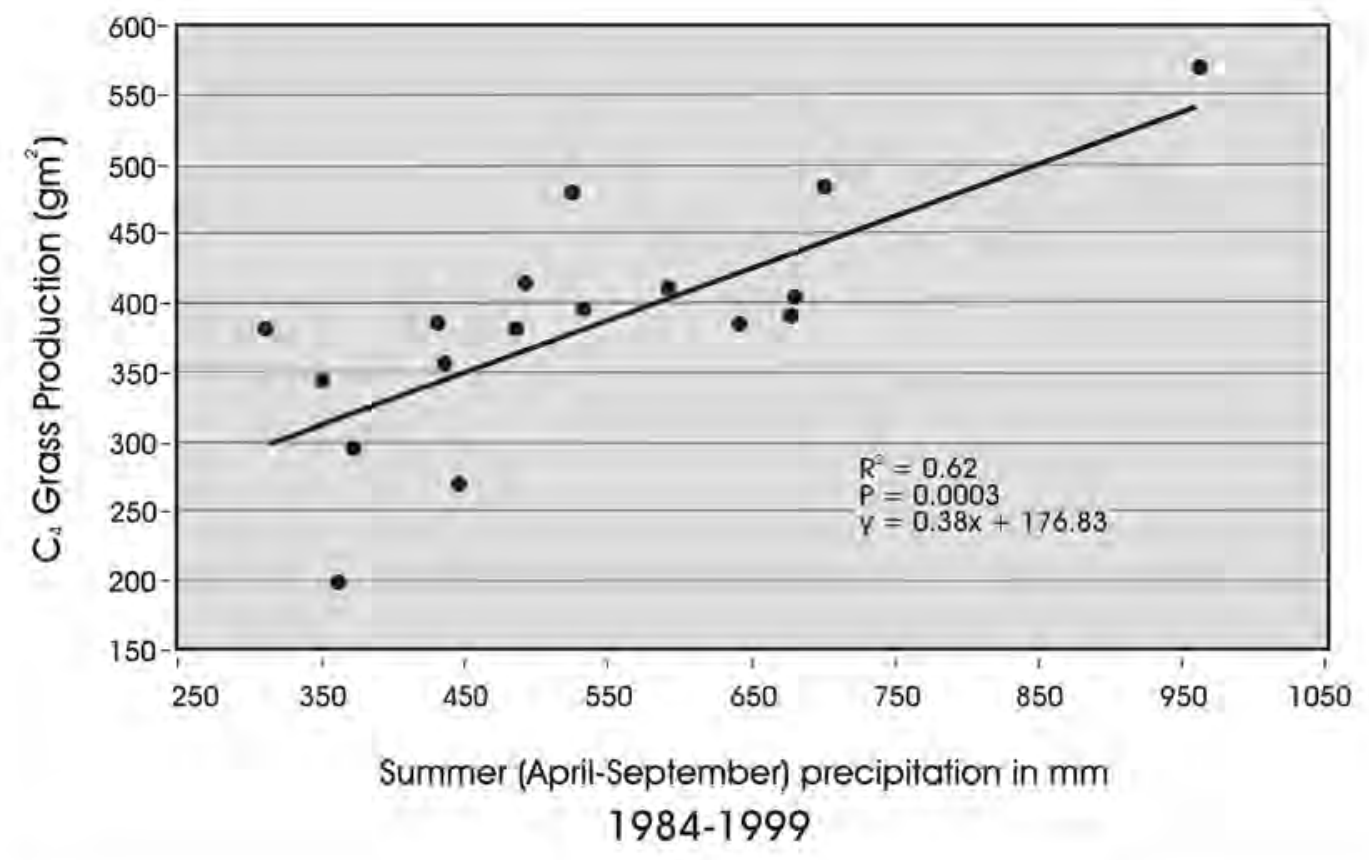

Figure 9-4. Grassland production and summer precipitation for a tallgrass prairie (1984-1999). 


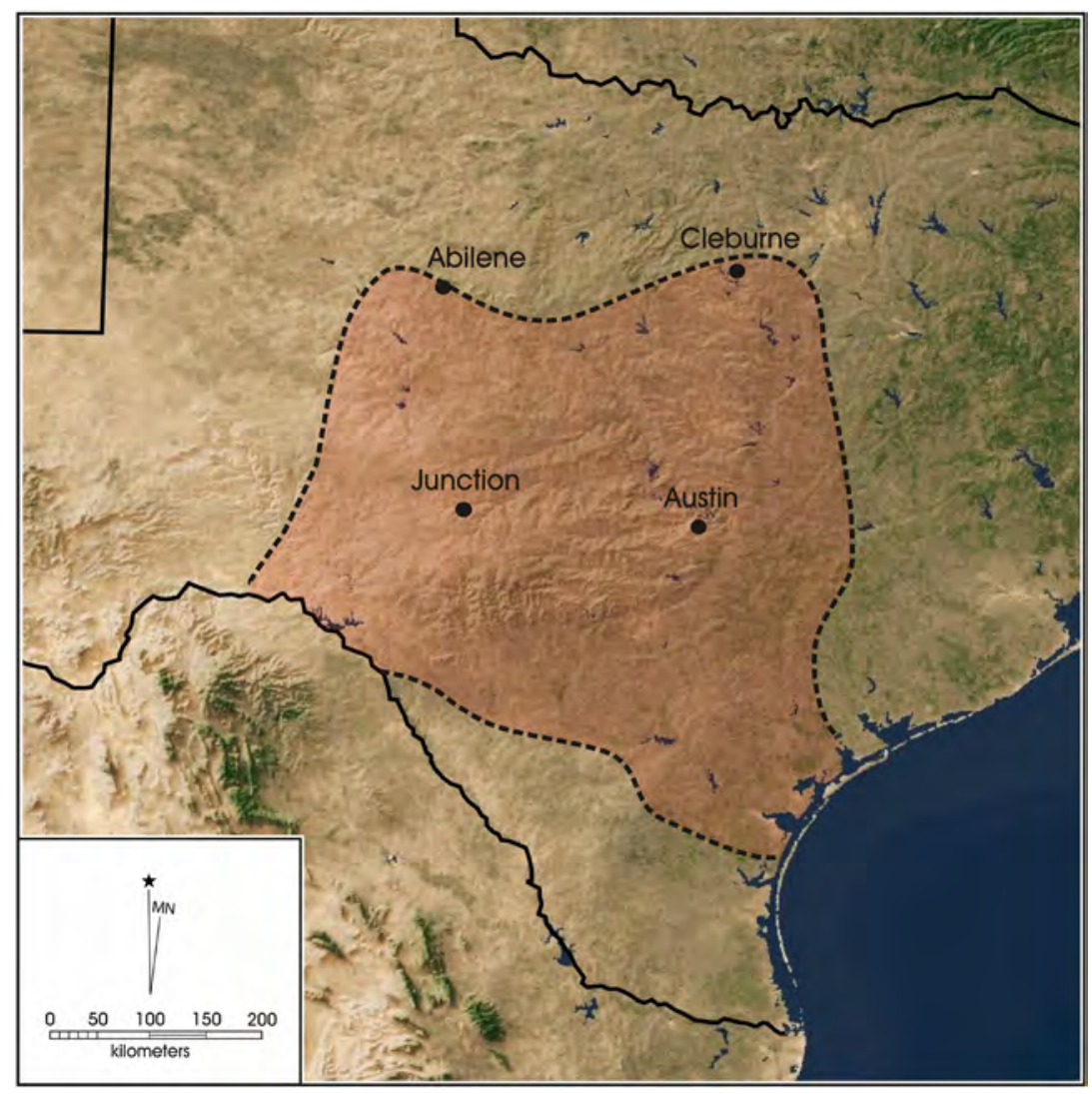

Figure 9-5. Location of study area (red) and four weather stations.

locations. The top histogram tallies the range (i.e., highest rainfall total - lowest rainfall total) of June rainfall for a given year among the four stations. The average difference between June rainfall totals in Figure 9-6 is $94.4 \mathrm{~mm}$ (3.71 in.). The maximum range occurred in June of 1981, when Austin received ca. $380 \mathrm{~mm}$ of rain and Abilene received only 69.3 $\mathrm{mm}$, a difference of just over $310 \mathrm{~mm}$ (12.23 in) in a single month. The bottom portion of Figure 9-6 plots the coefficient of variation (standard deviation/ mean) in June rainfall among the four stations for each of the 82 years. Overall, the coefficient of variation (CV) on June precipitation averaged 62 percent for these four stations over the 82 years, and in several cases $(\mathrm{n}=7)$ the $\mathrm{CV}$ exceeded 100 percent. For example, in 1974, the June CV was 120.7 percent (four station average $=37.21 \mathrm{~mm}$; $\mathrm{sd}=44.93 \mathrm{~mm}$ ), with Cleburne having a high of $103.4 \mathrm{~mm}$ and Austin receiving only $5.3 \mathrm{~mm}$ of rainfall. While there are clearly years with low CVs, only in five years are CV values below 20 percent, and in only one of those five (1984) is it below 10 percent. The dramatic differences shown in both absolute rainfall amounts (Figure 9-6, Top) and variation in amounts (Figure 9-6, bottom) at a short temporal scale should produce dramatic differences in grass production across the Central and South Texas regions.

The summer production highs and lows of $\mathrm{C}_{4}$ grasses suggested by the rainfall data in Figure 9-6, little or no cool season $\left(C_{3}\right)$ grass production (see Black 1973; Ehleringer 1978), and year-to-year variability in the amount of forage produced is characteristic of Texas grasslands. These production patterns, and lack of cool season grass production, should produce seasonal shortages in forage for bison. Speth (1983:119131), looking at warm season grasses in southeastern New Mexico, suggests that bison in this region may have operated below their maintenance threshold for crude protein and phosphorus levels from the late fall through the early spring in an average year. During years of below average rainfall, especially during the summer months, $\mathrm{C}_{4}$ forage production and the nutritional quality of the available grass would have been further reduced, resulting in potentially high levels of nutritional stress. As Emerson (1990:115-169) has demonstrated for bison on the Central Plains, nutritional stress as a consequence of low forage production can result in declines in bison weight, declines that probably have significant, multiyear consequences for reproductive rates and survivability.

\section{Mobility and Fluctuations of Bison on the Southern Plains}

Probably in response to shifts in the quality and quantity of forage, along with availability of water and climate extremes, 


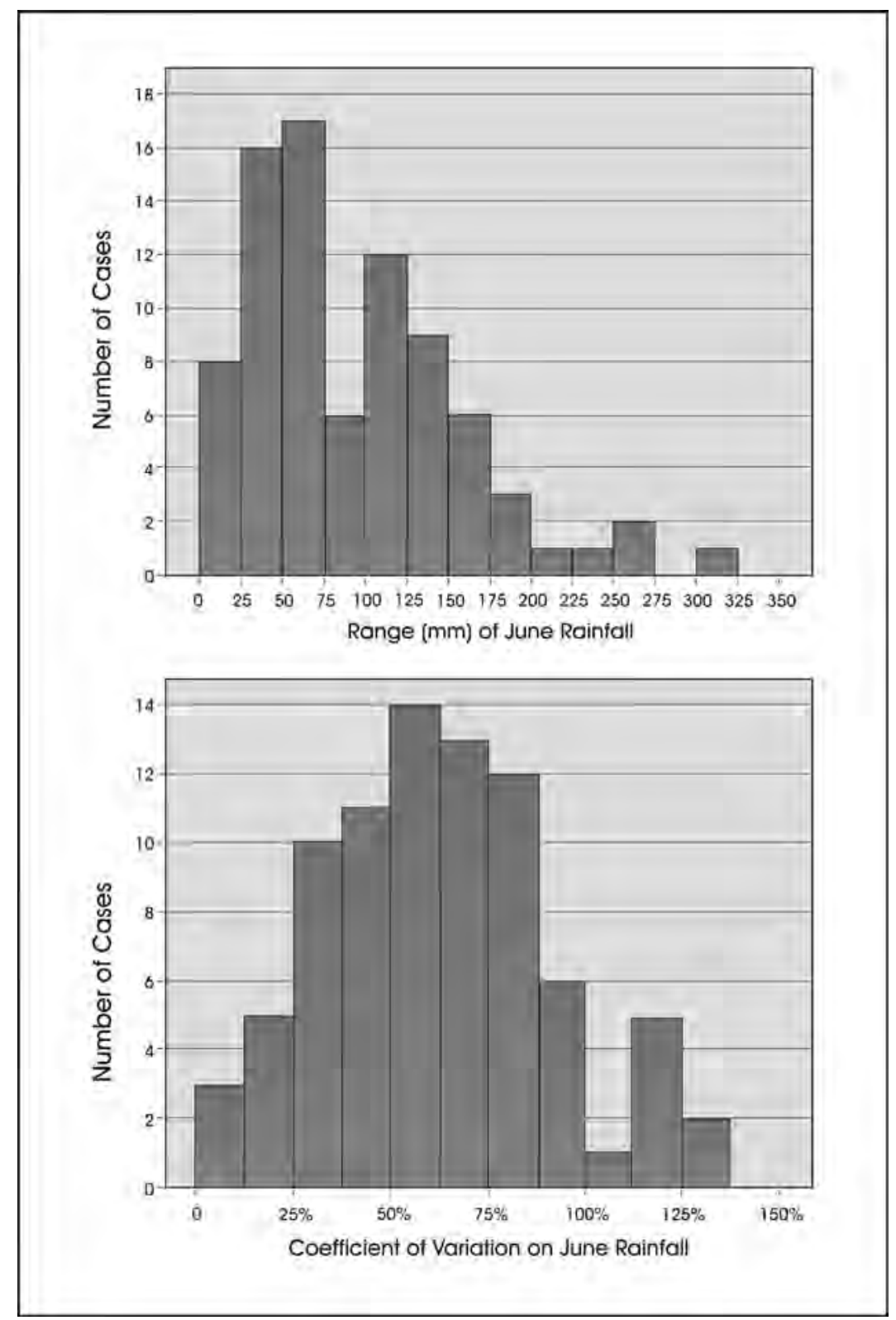

Figure 9-6. Range (top) and coefficient of variation (bottom) for June rainfall from Figure 9-5 weather stations (1914-2003).

bison populations certainly changed locations throughout the year. However, both the scale and regularity of such movements are not clear (see Bamforth 1988; Chisholm et al. 1986:195; Epp 1988; Gordon 1979; Morgan 1980), especially on the Southern Plains (see Doughty 1983:45-48; Newcomb 1961:112-116; Roe 1951). Delta $(\delta){ }^{13} \mathrm{C}$ values on bison collagen collected from archeological deposits in the northern panhandle of Texas (Quigg 1997b) demonstrate strong $\mathrm{C}_{4}$ signatures (carbon isotopic values between -7.8 and $-8.6 \%$ ), and Huebner (1991) reports the analysis of collagen from 38 bison from throughout the state that have $\delta^{13} \mathrm{C}$ values ranging from -13.6 to $-7.8 \%$. These isotopic signatures are not consistent with extensive feeding in northerly $\mathrm{C}_{3}$ grasslands. Conversely, Chisholm et al. (1986) report a variety of bison collagen $\delta^{13} \mathrm{C}$ values from the northern end of the primary range (see Figure 9-3) that fall between -17.3 and $-20.6 \%$, suggesting a diet with low $\mathrm{C}_{4}$ grass consumption. Long distance migrations of bison herds, such as shifts from Central Texas to Northern Colorado, for example, as least on a short-term basis seem unlikely given these isotopic data.

There are data from historic accounts that suggest that bison populations fluctuated in Texas, at least during the sixteenth, seventeenth, and eighteenth centuries. Cabeza de Vaca provides the earliest historic account of bison in 
Texas. De Vaca and several comrades spent from late 1528 until sometime in 1535 with indigenous groups. De Vaca spent much of this period with groups located in coastal and southern Texas (Cabeza de Vaca 1555). Surprisingly de Vaca (1555) notes only "three or four" sightings of bison. If accurate, this account suggests that bison were not frequent during this seven-year period in the southern portion of the state. Shortly after this account, Spanish forces associated with de Soto's expedition entered Texas, probably late in 1541, after wandering through much of the Southeast (see Duncan 1997; Young and Hoffman 1999). While the length of time spent within Texas is probably minimal, there is no mention of bison in the de Soto chronicles. In that same year (1541), Spanish forces associated with Franciso Vasquez de Coronado noted bison after several days travel to the east and north of the Pecos River, in what is probably the panhandle region of Texas. Numbers of animals noted seem to increase the longer the journey continued, with high densities of bison noted to the north of the state (Hammond and Rey 1940; Winship 1904).

Most detailed accounts of bison availability in Texas during the late 1600s come from recent summaries of Spanish expeditions onto the Edward's Plateau (see Wade 1998, 2003). One of the data sets compiled by Wade (1998: Appendix E; 2003:152-157) includes both probable camp locations and observations on fauna, including bison, made by the Spanish. The appendix provides detailed route and camp information on 10 different expeditions to the Plateau conducted between 1675 and 1767, and information on 246 camps used by these expeditions (Wade 1998: Appendix E). Figure 9-7 groups Wade's camp data (Wade 1998: Appendix E) at a yearly scale, with the locations of these observations provided as an insert in far left corner. Overall, these early expeditions noted bison on only 39 of the 246 camps. That is, roughly 85 percent of all camps lacked any mention of bison. As shown in the Figure, there is extreme year-to-year variability in bison observations. In two out of the 10 years shown $(1683,1691)$, bison were observed on roughly 40 percent of camps. Four of the remaining eight years also note bison as present in the area, though the frequency is considerably lower, and in four of the 10 years, members of these expeditions did not note any bison.

At roughly the same time frame as some of these Spanish observations (1685-1687), French forces at Fort
Saint Louis near the Texas coast frequently mention bison, including herds that numbered in the thousands (see Parkman 1883:216-233; Wade 2003:156). In addition, in 1691 "great numbers" of bison were reported for Bexar, Medina, Wilson, Guadalupe, and Gonzales counties in southern Texas (see Weniger 1984:178). In the 1700s and into the early 1800s, a number of accounts of bison in Texas are available which suggest that the animals were common, especially in the west-central portion of the state (see Doughty 1983; Folmer 1940; Newcomb 1961:85-99, 112-117). Bison numbers may have reached their peak in the State during the early $1800 \mathrm{~s}$ (note 5), and were reduced to near extinction by the end of that century (Doughty 1983; Weniger 1984).

These various historic accounts suggest that bison availability within the state was highly variable through time and across space. It is probable that at least during some periods, bison were completely absent from much of Central and South Texas, and there is data to suggest significant seasonal shifts in availability when they were present. Figure 9-8, constructed from Wade's camp summaries (1998:Appendix E), provides information on the possible seasonal availability of bison in Central and West Texas. Of 36 camp locations occupied during the winter months of December and January, the Spanish observed bison on only three camps ( 8.3 percent). For the months of February, March, and April there are 87 observations, 10 of which note bison (11.5 percent). Finally, there are 133 observations during the months of May, June,

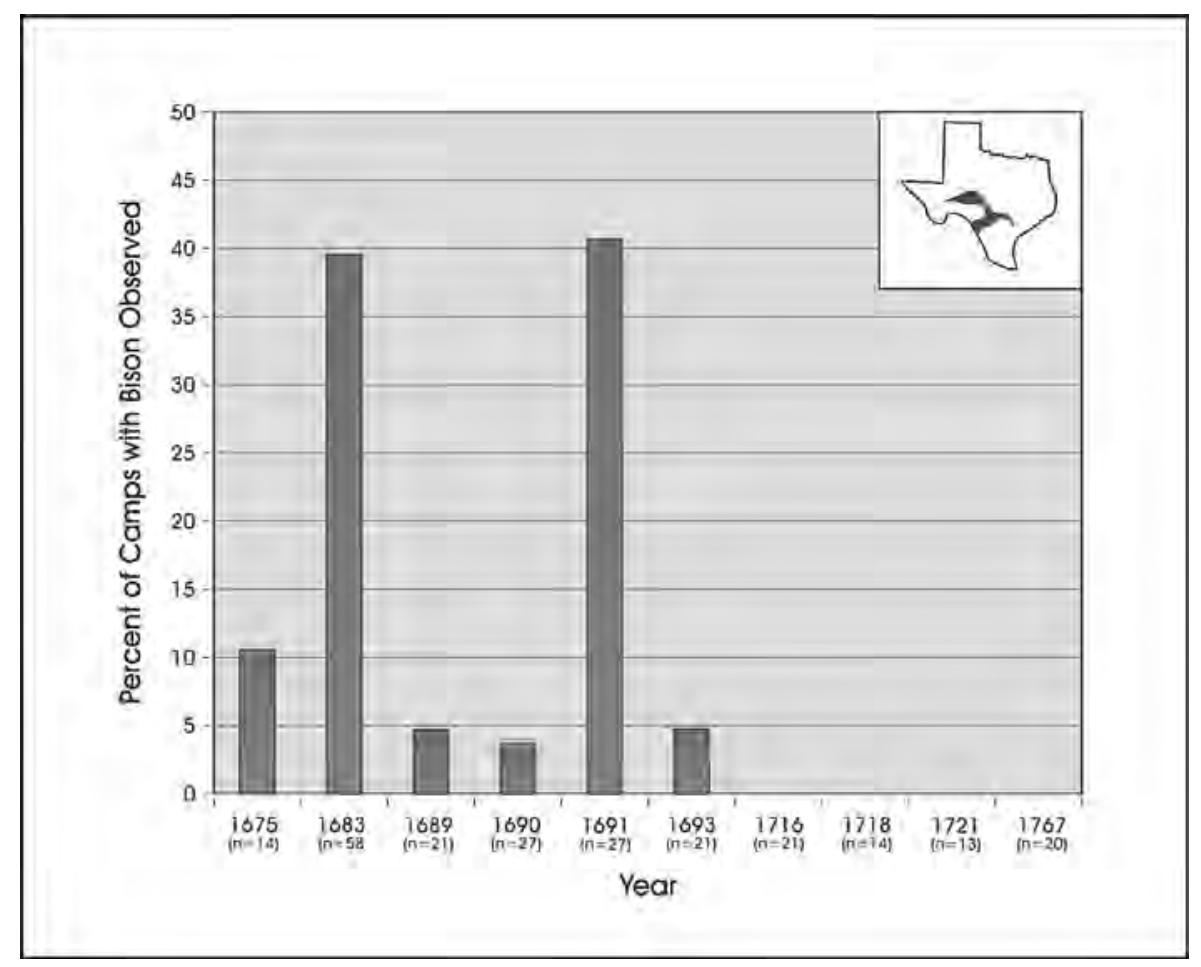

Figure 9-7. Percentage of camps on which bison were observed from 1675 through 1767 (data from Wade 1998). Insert shows where observations were made. 


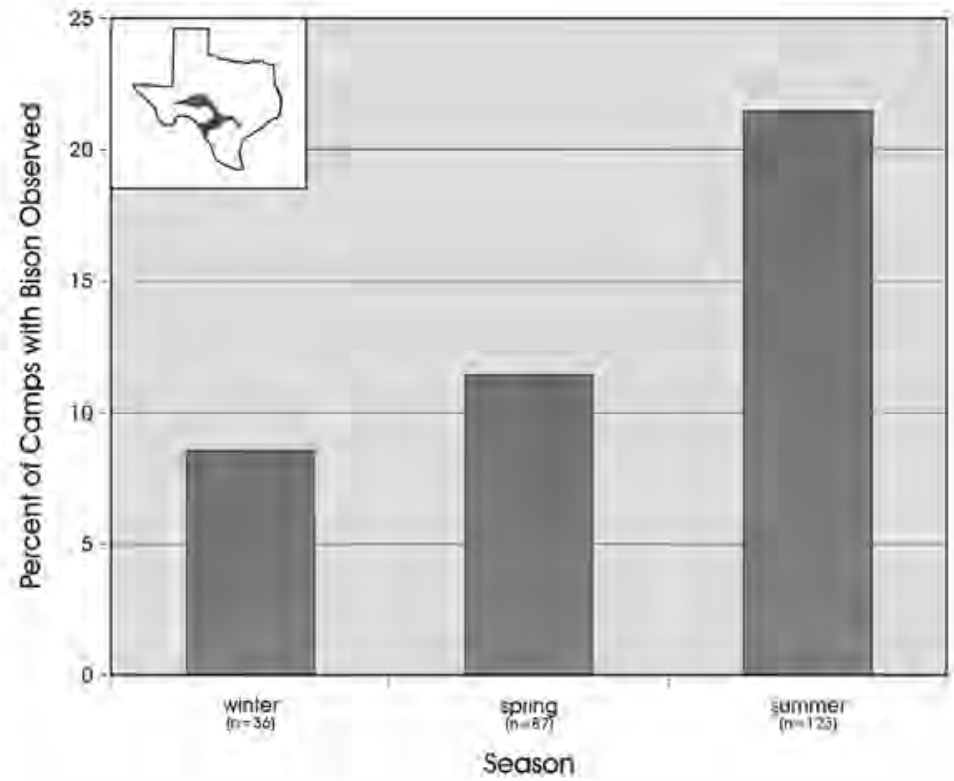

Figure 9-8. Season of bison encounters by Spanish expeditions into Central Texas from 1675 through 1767 (data from Wade 1998). Insert shows where observations were made.

July, and August. The Spanish noted bison in 26 instances (21 percent). Interestingly, while the number of observations are small $(\mathrm{n}=28)$, the late summer months of July and August do not have recordings of bison. This may suggest that bison herd size, at least in this portion of South and Central Texas and in the late $1600 \mathrm{~s}$ and into the $1700 \mathrm{~s}$, probably declined in the late summer and early fall, with a gradual increase in herds throughout the spring, with peak sizes present in the early summer months. This seasonal pattern of bison availability derived from Wade's (1998:Appendix E) data are consistent with seasonal patterns in $\mathrm{C}_{4}$ grassland production in Texas discussed previously.

A variety of factors, including seasonality and camp location, could account for these apparent fluctuations in bison sightings in the historic literature. Yet, the fluctuations are consistent with our characterization of this portion of the Southern Plains having variable forage production, with higher production occurring in the summer months. These fluctuations, in turn, should have resulted in varying periods of availability of bison in time and across space. To the degree that the carbon isotope results on bison from within Texas presented previously are reflective of bison mobility, it is clear that bison found in Texas did not spend a significant amount of their life feeding in $\mathrm{C}_{3}$ settings. That is, when grassland productivity declined, it is unlikely that bison migrated out of $\mathrm{C}_{4}$ dominated settings. Rather, we anticipate three responses. We suggest that during years of low production, or in regions of low production, it is probable that bison consumed increased quantities of low-quality forage, increased their overall mobility, and were positioned on the landscape in smaller sized herds. Conversely, during years of high production, or in areas of high production, it is likely that herd size increased, bison diet focused on higher quality forage, and mobility was reduced (Bamforth 1988:4452; Bruuggeman 2006; Emerson 1990; Van Vuren and Bray 1986) ${ }^{\text {(note } 6)}$.

We based the above ecological characterization, in part, on modern patterns of variable precipitation, characteristics of warm season grasses, and bison ethology. If these same patterns and characteristics were present in the Late Archaic and Late Prehistoric periods, producing seasonal and yearly fluctuations in grass productivity and quality, then bison densities in Texas would have experienced similar fluctuations that would have implications for hunters and gatherers. During seasons or years when grass production was low in a given region, we anticipate that bison herd sizes were smaller, that bison mobility levels were higher, and that animals were in poorer physical condition. This would have resulted in lower encounter rates, and animals that, because of their poorer physical condition, had reduced profitability. Depending, in part, on the severity, length, and spatial scale of these productivity shortfalls ${ }^{\text {(note }}$ ${ }^{7)}$, hunters and gatherers could respond by expanding their diet, changing their technologies, or altering their search strategies. Conversely, during periods or at locations where grass production was high, we anticipate that bison would form larger herds, that overall these animals would be in better physical condition, and that mobility levels would be low. For hunters and gatherers, these conditions would have potentially resulted in a reduction of the number of items in the optimal diet set, as well as other shifts in technology or mobility. Are these historic patterns of productivity and bison fluctuations reflected in the Late Prehistoric and Late Archaic periods? In order to explore this question, we return to paleoclimate data discussed in Chapter 2 and reviewed here.

\section{Paleoclimate Data}

As described in detail in Chapter 2, the paleoclimate studies using pollen from bogs and carbon isotope data from Hall's Cave and the Medina River show that grasslands slightly during the Late Archaic grasslands declined then accelerated their decline at the close of the Late Archaic and through 
the Late Prehistoric and Historic periods. The resulting effect on bison would have likely been smaller, patchier herds rather than fewer herds with large populations. Treering based PDSI values provide a short-term perspective on variability in forage production. The shorter term, PDSI grassland variability data indicates consistently low grassland productivity at the close of the Initial Late Prehistoric period. While productivity increases slightly during the subsequent Terminal Late Prehistoric, it was still below average at three of the four locations considered. Furthermore, the data suggest a dramatic increase in short term fluctuations in production accompanying that increased productivity. The increased fluctuations in productivity, which were at their highest during the Terminal Late Prehistoric, would have produced dramatic differences in forage quantity and quality over a given 25-year period. Again such variability would have affected bison mobility, as they searched for quality forage, and possibly influenced herd size. Any changes to bison availability likely have altered hunter-gatherer mobility and diet, which is discussed in the theoretical and analytical chapters of this volume.

\section{Summary of Bison Availability}

The archeological data (see Figure 9-2), as well as the historic accounts, demonstrate that bison were present in Central and South Texas throughout the Late Archaic, the Late Prehistoric, and into the Historic period. To the degree that the presence/absence component data presented in Figure 9-2 is measuring bison availability in the general environment, the patterns show that bison were slowly declining throughout the Late Archaic, and then began to increase in the Initial Late Prehistoric. That increase accelerated into the Terminal Late Prehistoric, where over 80 percent of all components had bison present ${ }^{\text {(note } 8)}$. The archeological patterns are, to some degree, at odds with the conclusions drawn from bison ethology and the paleovegetation reconstructions. While the archeological pattern of a gradual decline in bison throughout the Late Archaic is consistent with the declining grasslands suggested by the long-term paleovegetation data, the rapid increase of bison presence on Late Prehistoric components is at odds with both the long-term paleoclimate data, as well as short-term PDSI data. The long-term data sets suggest an accelerated decline in grasslands in the Late Prehistoric period. Patterning in the short-term PDSI data sets suggests that throughout the period from AD 1000 through AD 1550, $\mathrm{C}_{4}$ grass production was below average at most locations considered, especially in the Initial Late Prehistoric. While conditions improved slightly during the Terminal Late Prehistoric, a dramatic increase in year-to-year variability in production accompanied that improvement. That increased variability which continued into the Historic period, should have resulted in significant fluctuations in bison availability.
Historic observations of bison, summarized previously (see Figures 9-7, 9-8), do suggest major changes in the frequency with which this high ranked animal was encountered from one year to the next, as well as seasonally, in a portion of Central and South Texas.

If both archeological and paleovegetation data sets suggest that bison were declining slowly throughout the Late Archaic, what accounts for the apparent divergence in these two estimates in the Late Prehistoric? Were bison increasingly available in the Late Prehistoric as the archaeological data seem to suggest, or were their numbers declining, with significant year-toyear fluctuations, as the paleovegetation data suggest? We can begin to explore these questions by initially focusing on the archeological database and considering another questionWhat are the conditions required for the relative frequency of bison present on components to reflect bison availability in the general environment? Putting aside issues related to sampling and recovery, for the archeological data to reflect bison availability hunters and gatherers must pursue bison when they encounter them, they must encounter bison at a consistent rate relative to their true density in the environment, and they must have a consistent success rate in their pursuit of these animals. Once hunters and gatherers acquire bison, they must use roughly similar butchering, transport, and discard tactics, and occupation lengths must be roughly equivalent between periods. Given these requirements, and as the prehistoric time frame under discussion is over 3500 years, it seems unlikely that measures of the relative frequency of components with bison present during a given period will consistently produce reliable measures of the abundance of bison in the natural environment.

The vegetation and rainfall shifts suggested in the pollen, isotope, and tree-ring data sets appear to have been widespread. They should have produced differences in grassland productivity and distribution, and those differences should have translated into differences in bison availability at various temporal and spatial scales. The fluctuations in the observation of bison in the historic accounts are consistent with the pattern anticipated from the climate/vegetation reconstructions for the historic/modern era in that temporal and spatial variability in production should result in dramatic year-to-year changes in bison location and herd size. While we lack data to verify these relationships in the prehistoric periods, we assume that throughout much of the Late Archaic, grasslands were slowly receding. We further suggest that this decline accelerated through the Late Prehistoric, and that after $\mathrm{AD} 1250$, increased year-to-year fluctuations in grassland production occurred. While conditions improved after AD 1550, the high year-to-year fluctuations in grasslands continued throughout the historic period. The shrinking grasslands, especially during the Late Prehistoric, 
should have resulted in declining overall numbers of bison, and at the same time produced a more clustered spatial distribution as grasslands shrank. In addition, the increased fluctuations of production characteristic of the Terminal Late Prehistoric should have resulted in variable windows of temporal availability of bison ${ }^{\text {(note } 9)}$. We will subsequently suggest that these changes in where, when, and how many bison were available produced shifts in the way that mobility was organized, as well as shifts in what resources were in the optimal diets of hunters and gatherers. However, before discussing these adaptive changes, we briefly consider other potential food resources.

\section{Other Resources}

While bison are the highest ranked resource during the period under investigation, and as such shifts in their numbers play a critical element in diet, mobility, and technology, we have suggested (see Chapter 8) that the structure and profitability of other, lower-ranked resources, should also have an impact on the mix of strategies used when availability of higher-ranked resources change. The wide environmental differences across Texas should produce dramatic differences in what other resources are available, when they are available, their overall quality, and their profitability. Furthermore, environmental changes, such as those suggested by the paleoenvironmental data sets in Chapter 2, would differentially affect these environmental settings and the resources they contain. Clearly, any attempt to approximate availability of lowerranked food resources would be a massive undertaking, involving numerous estimates. However, we can make some general observations regarding aspects of alternative food resources using modern data.

\section{Mammal Diversity}

While kill rates for animals will certainly influence their profitability and therefore ranking, larger animals have higher return rates (see Figure 8-1). This is why bison, with an average weight of about $600 \mathrm{~kg}$ (Davis and Schmidly 1997), is a highly ranked resource. In this section, we consider aspects of other animals that prehistoric hunters and gatherers may have used for food. We focus our attention on animal weights as a way to place species into groups with roughly similar return rates. While all individual species probably have slightly different return rates, for analytical purposes in the current chapter we divide the sample into four groups. We lack data on most non-mammalian species. However, with the exception of some larger birds (e.g., turkey), most non-mammalian taxa (e.g., reptiles, mussels, fish, other aquatic resources, snails) will fall into the smaller weight classes, and likely have low return rates (e.g., Malof
2001), though there are exceptions (see Ricklis 1996). Focusing primarily on four weight classes of mammals using data from Davis and Schmidly (1997), we consider broad patterns of animal diversity. While we lack information on the critical variable of density for the modern data set, let alone the prehistoric mammal data, we demonstrate that modern mammal diversity can be related to measures of net above-ground primary productivity (see Rosenzweig 1968), and explore the potential impacts of changes in productivity on diversity. In situations where there exist a number of alternative species with roughly similar return rates (e.g., medium-sized mammals), these alternatives will be exploited before incorporating lower ranked resources (e.g., small and very small mammals).

Davis and Schmidly (1997) list information on over 180 mammals that are, or historically were, in Texas. We have eliminated some of these mammals, including various bat species, marine mammals, several large carnivores, and extremely small mammals from consideration. Figure 9-9 presents box plots of weights for 100 mammals that prehistoric hunters and gatherers probably ate. Table K-1 lists these animals, along with data on their specific weights. We divided these mammalian species into four different size classes by weight. There are 71 species in the "small and very small" mammal group. The species in the small and very small group range in weight from $.007 \mathrm{~kg}$ (Silky Pocket Mouse) to $.95 \mathrm{~kg}$ (Eastern Fox Squirrel, Desert Cottontail), with an average weight of .171 kg for the group. We assigned 21 species to a "medium" mammal group. This group ranges in size from $1.25 \mathrm{~kg}$ (Ringtail) to $19.0 \mathrm{~kg}$ (Collared Peccary), with an average weight of $6.44 \mathrm{~kg}$. Seven species are in the "large" mammal group that has a mean size of $124.6 \mathrm{~kg}$, with a range of $46.7 \mathrm{~kg}$ (Pronghorn) to $275 \mathrm{~kg}$ (Elk). Finally, bison, with an average weight of $600 \mathrm{Kg}$, forms the "very large" group.

To map the distribution of the large, medium, and small/very small mammal groups defined in Figure 9-9, we overlaid individual species distributional maps, presented primarily in Davis and Schmidly (1997), with 189 quadrates identified by Owen and Schmidly (1986; Owen 1988, 1990). Each quadrate is roughly $63.9 \mathrm{~km}^{2}$, and Owen and Schmidly (1986) present a variety of environmental variables derived primarily from weather stations in each quadrate, including an estimate of net above ground primary productivity $\left(\mathrm{g} / \mathrm{m}^{2} / \mathrm{year}\right)$. Net above ground productivity is simply a measure of the amount of new above ground growth on an annual basis. It is primarily a function of rainfall and solar radiation (Odum 1971; Rosenzweig 1968). At a global scale, primary productivity is highest near the equator, and decreases towards the poles. Within Texas, primary productivity is highly correlated with annual rainfall (Owen and Schmidly 1986). 


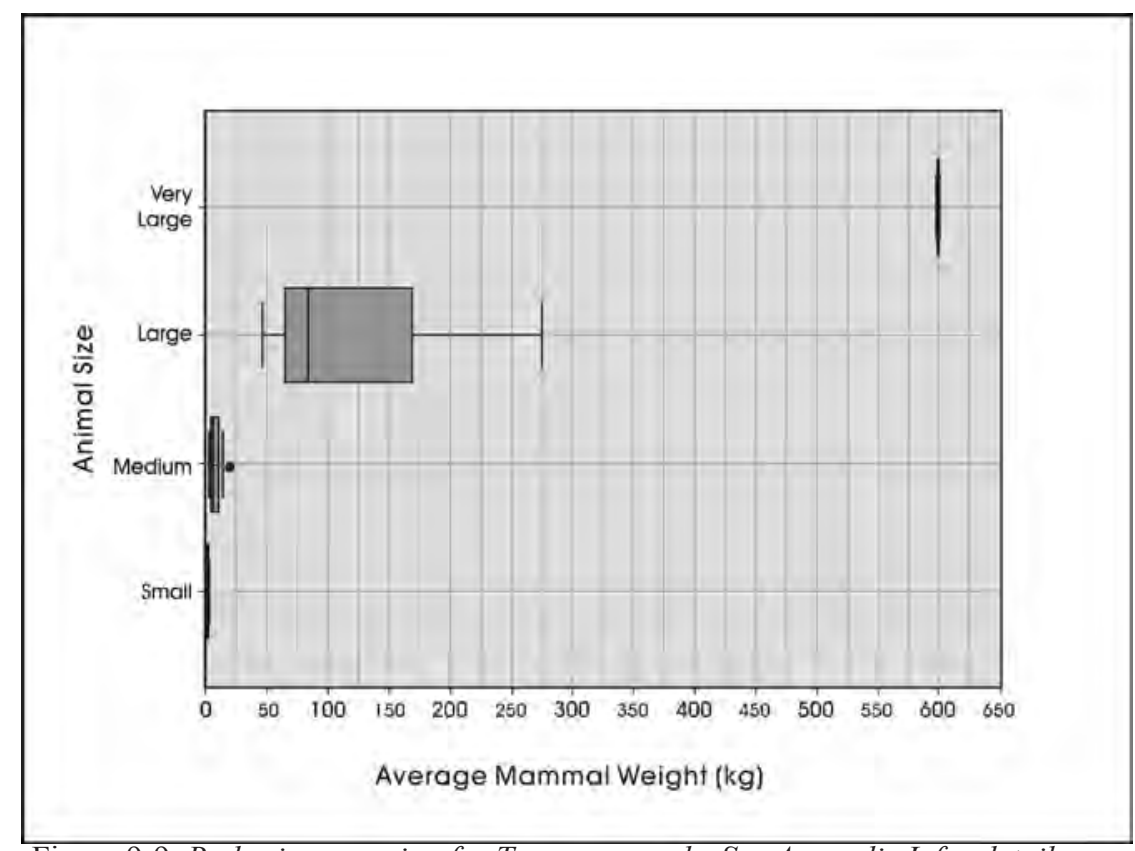

Figure 9-9. Body size grouping for Texas mammals. See Appendix L for details.

A distribution map showing the number of large mammal species that were in each quadrate is provided as an inset (upper right) in Figure 9-10. Note that the highest diversity of large mammals is in the far western portion of the state, while the lowest diversity is in East Texas, as well as the southern tip of the state. The primary portion of Figure 9-10 presents the relationship between the number of large mammal species represented within a given quadrate (X-axis) and the primary productivity of that quadrate (Owen and Schmidly 1986). While there are a handful of exceptions, there is a strong, inverse relationship between primary productivity and the number of large mammal species. Areas of the state with high primary productivity have low diversity, while areas with low primary productivity have a number of different large mammals represented.

Figures 9-11 and 9-12 provide similar distributional data as insets, as well as presenting the relationships between primary productivity and the two smaller mammal size groups (medium and small/very small). The highest diversity of medium sized mammals is in the Big Bend area, along with the southern portion of the Edwards Plateau, and western south Texas. Once again, the lowest diversity is concentrated in the eastern portion of the state. The bivariate plot in Figure 9-11 demonstrates that while an inverse relationship between primary productivity and medium sized mammal diversity is present, the pattern is not as strong as in the case of large mammals. The highest diversity of small and very small mammals is again in far west Texas, with the lowest diversity present in the upper coastal area (Figure 9-12, inset). As with the previous data sets discussed in this section, there is an inverse relationship between the diversity of small and very small mammals and primary productivity.

\section{Plant Diversity}

We lack sufficient distributional information on plant resources to conduct a similar type of analysis. Data are, however, available at the level of the 10 natural regions as defined by several researchers (see Gould et al. 1960; Hatch et al. 1990). (1990) provide a summary of over 4,000 plants within Texas. Included in that summary is the distribution of plant species relative to the natural regions. However, it is unlikely that hunters and gatherers used the vast majority of these plants as food sources. In order to identify those plants that were potentially used as food, we compared each of the 4,287 unique native species listed for Texas to the Native American Ethnobotony database (Moerman 2005), a list of 4,029 different plant species used for a variety of purposes by 291 Native American groups from across North America. We identified all matches used for food or beverage at the species level. This comparison resulted in the identification of 394 different plant species in Texas that humans have used for food.

For each species identified, we classified the part of the plant used into one of six groups: roots and tubers, seeds, nuts, greens, fruits, and other (e.g., sap, bark, stalks). We based these groupings, in part, on the return rate data presented previously in Figure 8-1. There is also a seasonal component 


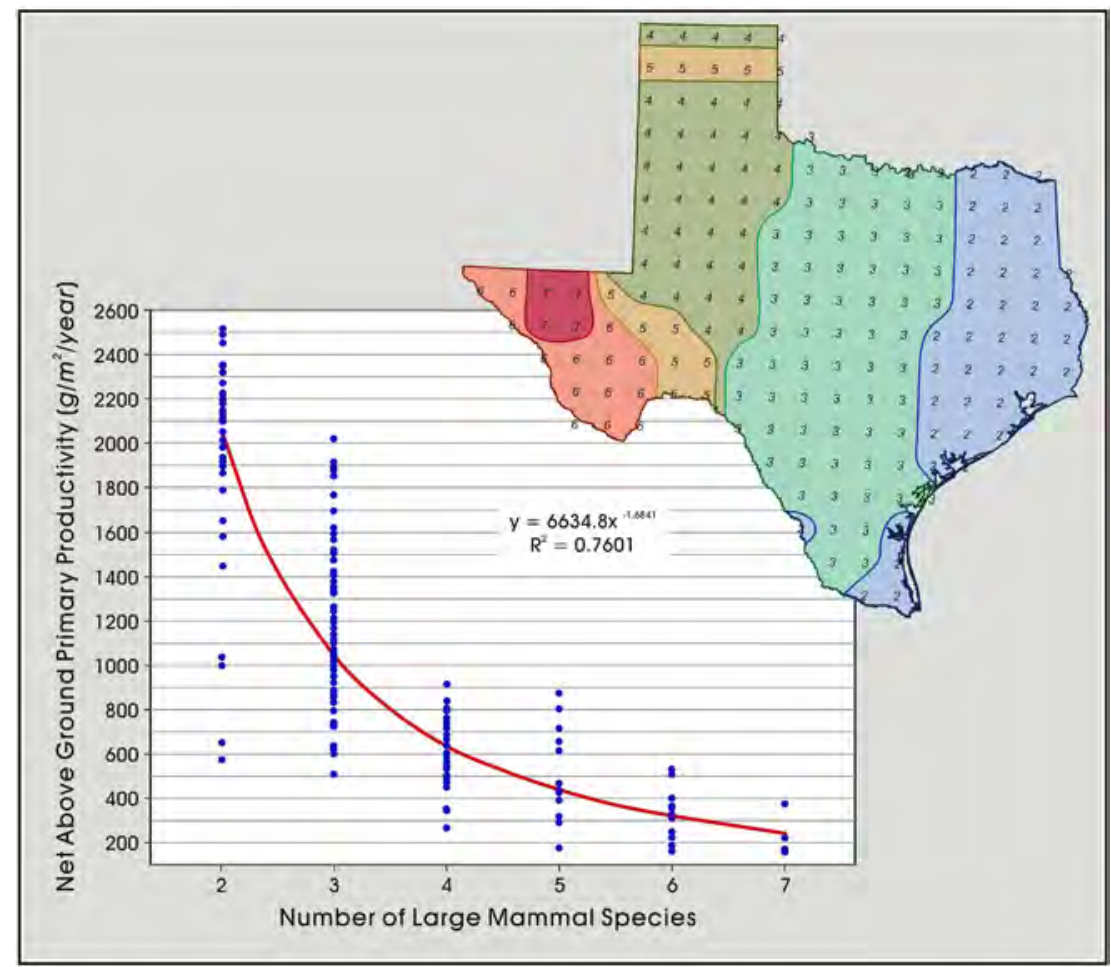

Figure 9-10. Relationship between the number of large mammal species and primary production within Texas.

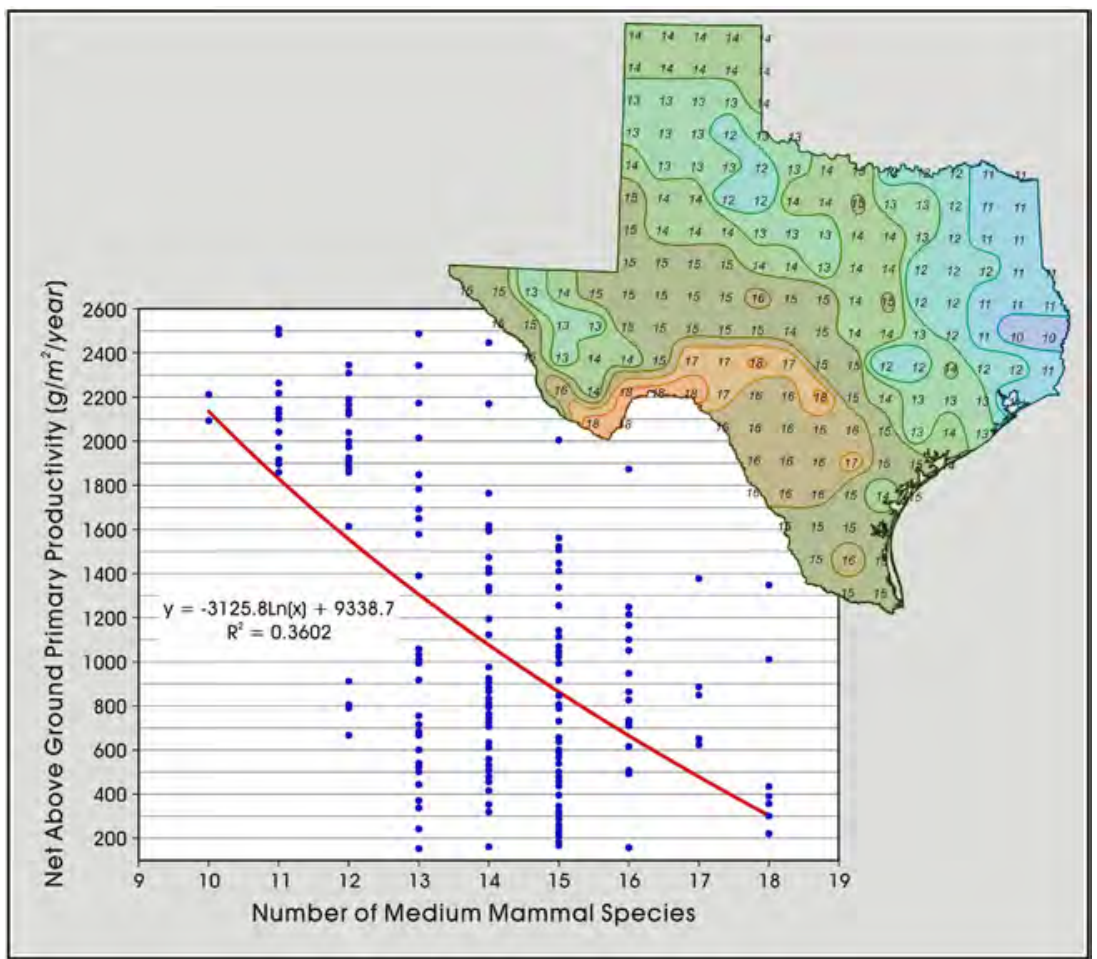

Figure 9-11. Relationship between the number of medium mammal species and primary production within Texas. 


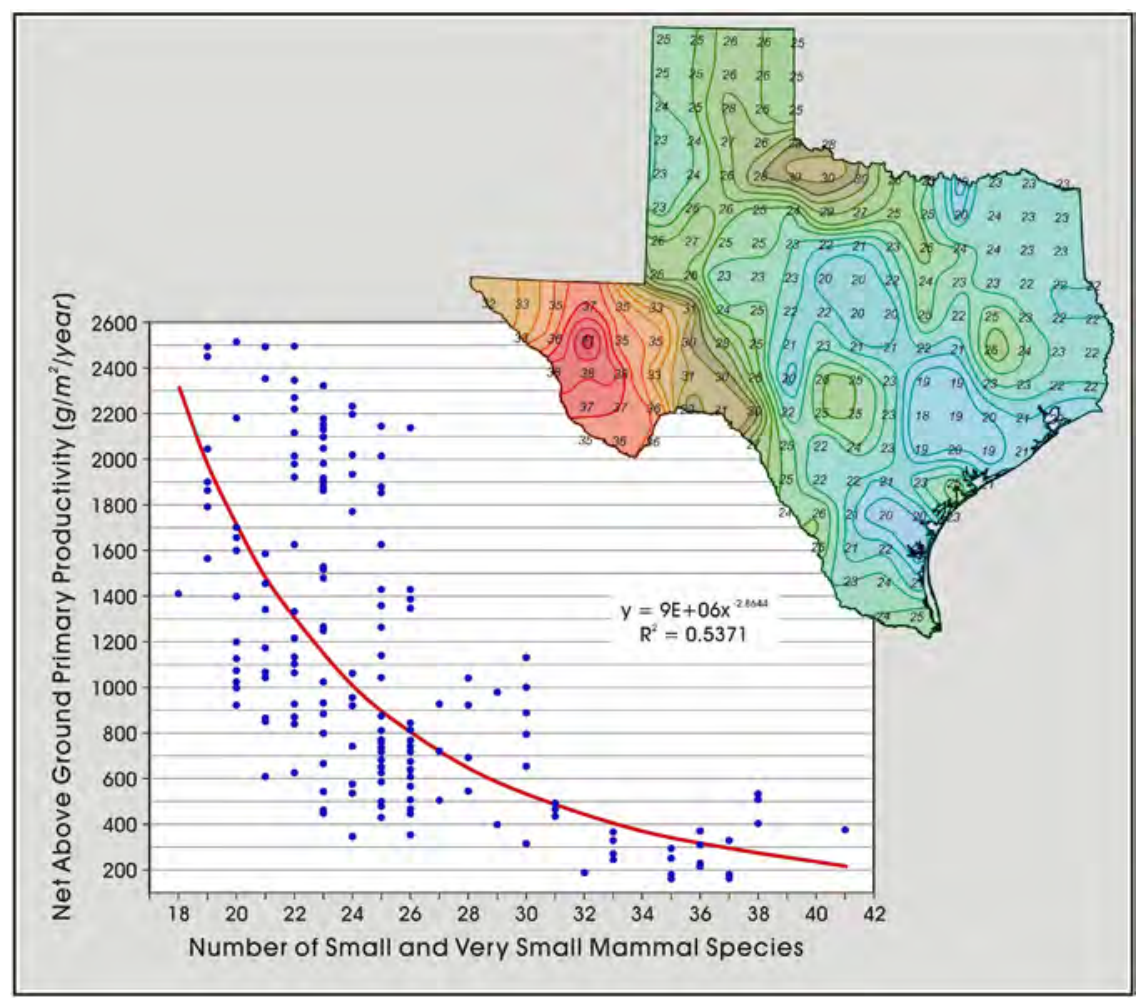

Figure 9-12. Relationship between the number of small and very small mammal species and primary production in Texas.

to these food groups. Root foods, including tubers, are generally at their peak in the winter and early spring; leaves and other foods classified as greens are available throughout the spring and into the summer. Seeds and fruits are increasingly available in late summer and into the fall, and nuts are primarily available in the late fall into the early winter. In several cases, the Ethnobotony database listed multiple components of the same plant (e.g., seeds, greens). Consequently, we reviewed 480 different food components of 394 different species that were used as food or beverage for the 10 natural regions of Texas. Table M-1 provides specific information on each of these 394 species, as well as the 480 different plant elements. As with the mammal data presented previously, we monitored net above ground primary productivity using the Owen and Schmidly (1986) quadrate data. We averaged the productivity data for each of the 10 vegetation regions.

Figure 9-13 presents a bar graph for the number of plant elements broken down by food type for each of the 10 regions. Overall, the highest diversity of food types is in the TransPecos region $(\mathrm{n}=318)$, followed by the Edward's Plateau $(n=264)$. The Trans-Pecos region has the highest diversity of five of the six different food types, and the second highest diversity in roots foods following the Edwards Plateau. The lowest overall diversity $(\mathrm{n}=124)$ is in South Texas, followed by the Pineywoods region $(n=172)$. South Texas has the lowest diversity in four of the six food types, with the Pineywoods having the lowest diversity of seeds and the High Plains having the lowest diversity of nuts. As these are modern data, it is unclear if extensive modification of South Texas vegetation by historic land use practices (see Hall 1985; Hester 1980) accounts for the extremely low values in this portion of the state.

As with the mammalian diversity presented previously, there is an inverse relationship between the average net aboveground primary productivity and the total number of food plants within a vegetation area, though the overall fit is only moderately strong (Pearson's $\mathrm{R}=-.510$ ) and not statistically significant $(\mathrm{p}=0.132)$. Examination of correlation coefficients between individual food types (e.g., nuts) and vegetation area shows that four of the six food types have negative relationships with primary productivity. Only roots and nuts have weak positive relationships. Focusing just on those food types that have a negative relationship with primary productivity (i.e., seeds, greens, fruits, other), the overall correlation is -.628 , with a probability of .052 .

Figure 9-14 presents this relationship. While the relationship is not significant at the .05 level, this is primarily a function of the low diversity value for South Texas. Eliminating that outlying value produces a Pearson's correlation coefficient of 
-.791 and a significant probability value of .011. Increasing primary productivity, then, tends to result in a decrease in the number of available food types for seeds, greens, fruits, and the class of "other" food resources, at least within the range of productivity values in Texas.

\section{Discussion}

The above consideration of lower-ranked animals and plants relies primarily on modern data and reflects presence/absence of species, rather than shifts in density. While information on shifts in prehistoric densities of these and other resources would be ideal, it is unlikely that such information will be available in any detail in the near future. The presence/ absence data, as well as relationships between net aboveground productivity and species diversity, can minimally provide insights both into the general resource structure of various areas within the state and possible alterations in that structure. At one end of the spectrum of food diversity are the Trans-Pecos and Edwards Plateau regions. The Trans-Pecos area probably never had bison present in any substantial numbers. Yet, a high diversity of mammals falling within the large size class is present, along with a moderate diversity of medium sized mammals and a high diversity of small and very small mammals. This section of the state also has the highest overall diversity of types of food plants, with 318 different seeds, fruits, nuts and other items identified for this region. The Edwards Plateau region, where 41KM69 is located, is second in total number of plant food items $(\mathrm{n}=264)$, has the highest diversity of medium sized mammals, and while the number of large mammals is limited to whitetailed deer, antelope, and black bear, the area would have, at various points, had bison present. In these high-diversity areas, hunters and gatherers could offset fluctuations in any single food type by shifts to other, alternative foods that had broadly similar prey profitability. All else being equal, the potential to ameliorate fluctuations in food resources by shifting to alternative resources of a similar rank should result in a stable, resilient hunter-gather adaptation.

At the other extreme of diversity in Texas are the Pineywoods, South Texas, and the Gulf Coast area, though the low-diversity pattern for South Texas may be a result of extensive historic modification of the environment, and the pattern in the Gulf Coast does not take into account access to marine resources (see Ricklis 1996). Like the Trans-Pecos region, bison were probably absent or in low frequency in the Pineywoods during much of the prehistoric period. However, unlike the TransPecos area, only two large mammal species, white tailed deer and black bear, are present. Hunters and gatherers cannot offset fluctuations in these species by moving to other species of similar body size because those species do not exist within the region. There are also low numbers of mammal species

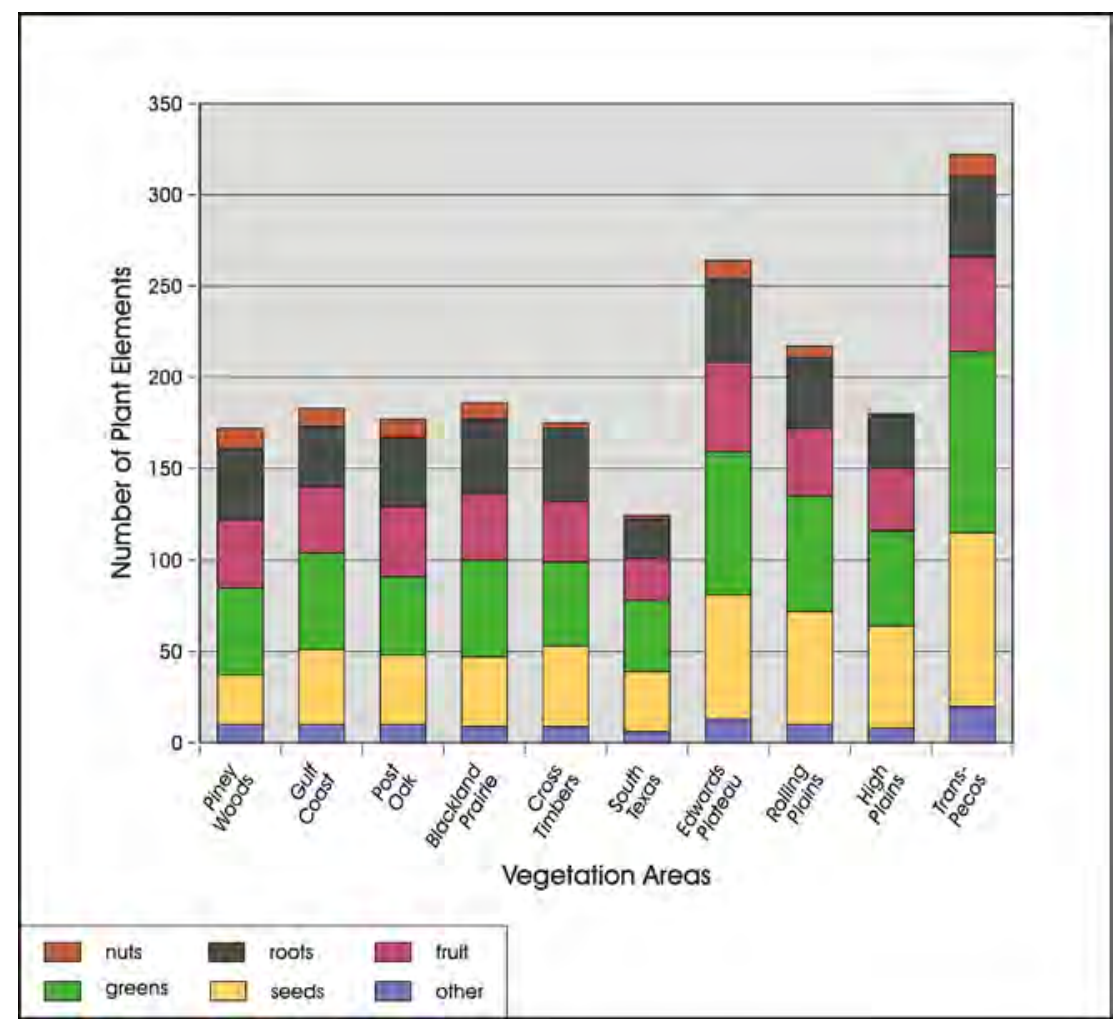

Figure 9-13. Number and type of plant elements (e.g., nuts, fruits) by vegetation area within Texas. See Appendix M for details. 


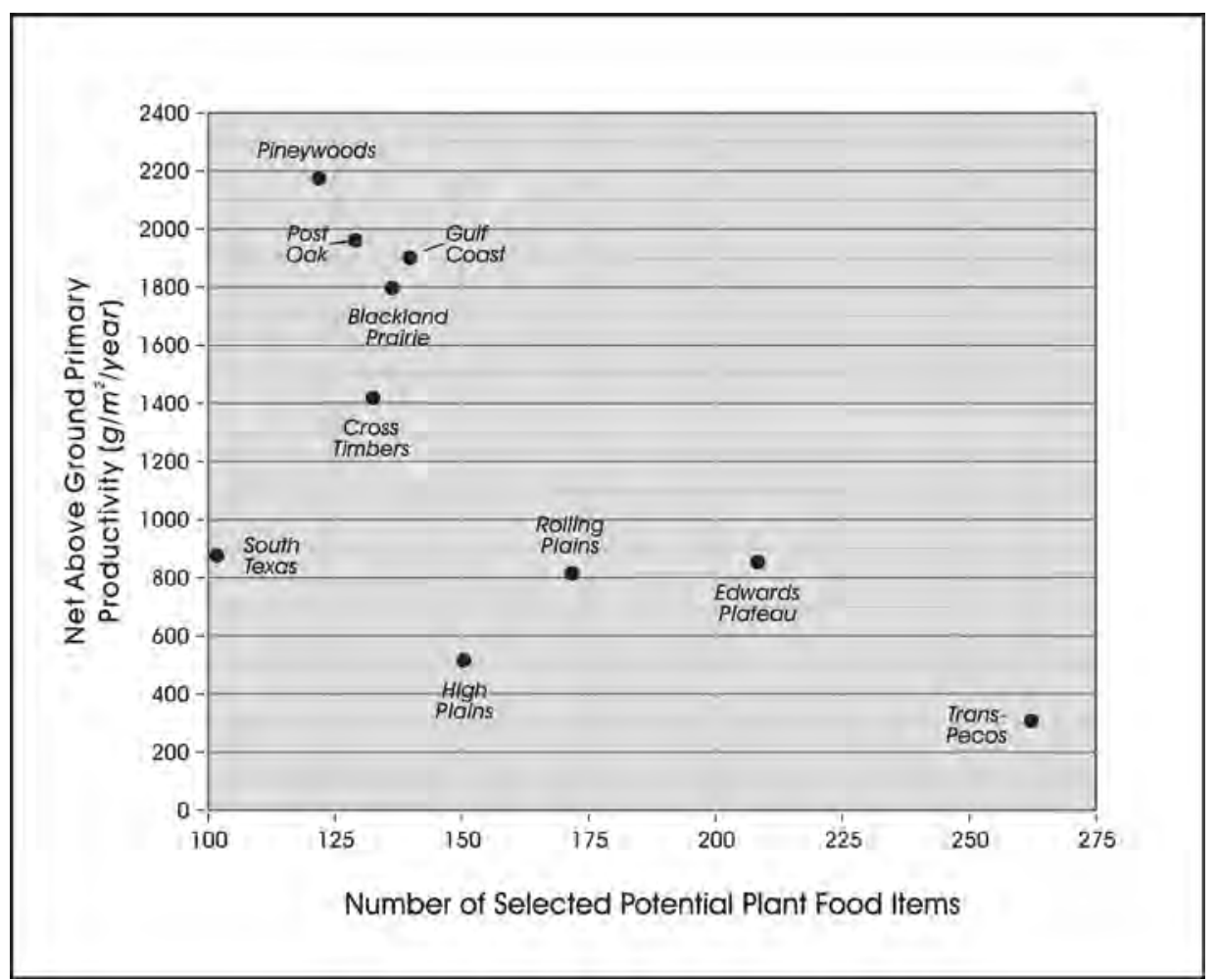

Figure 9-14. Number of selected potential plant food items and primary productivity for Texas vegetation areas.

that are classified as medium or small, and this area has one of the lowest diversities of food plant species in Texas. All else being equal, a low diversity of alternatives should result in a less stable adaptation for hunters and gatherers ${ }^{\text {(note 10) }}$.

\section{Summary and Discussion}

Models derived from foraging theory provide a coherent set of concepts and an analytical framework for investigating many aspects of hunter-gatherer adaptations. While there are certainly problems obtaining the detailed quantitative data necessary to rigorously apply foraging theory in most archeological settings, models constructed using an explicit cost-benefit framework can prove to be valuable tools in directing research. We have used aspects of prey models to suggest that when hunters and gatherers face changes in high ranked resources, they have a number of possible responses. What response they initiate should depend, in part, on the extant resource structure in the environment, as well as their existing subsistence, mobility, and technology mix. Unfortunately, we do not yet have sufficient data on plant and animal densities, return rates given various processing technologies, and technological costs to allow for specific, detailed modeling of responses. While the PDSI data sets discussed previously hint at regional differences in shortterm production, detailed models of grassland productivity will require additional paleoclimate research. However, we can make some general statements regarding responses that hunters and gatherers might initiate as grasslands decline and became patchier through time, and as bison populations probably followed suit. For example, under conditions of declining high ranked resources, hunters and gatherers may broaden their diet to include lower-ranked resources with lower search costs but higher processing costs (e.g., mussels, nuts, small seeds). They may develop or implement new technologies that are more expensive to produce and maintain (e.g., ceramics) in an attempt to reduce the processing time or improve the nutritional quality of lower-ranked resources in the diet. They may shift or reorganize their mobility or search strategies, with specialized task groups targeting shrinking grasslands in an attempt to increase encounter rates. They may shift to technologies that are more expensive to produce and maintain (e.g., bow and arrow), but which may increase the kill rates of more profitable animals given shifts in animal density or prey type. They may initiate all of these changes, as well as several others, in the context of maximizing the average return rate of their overall diet ${ }^{\text {(note } 11)}$.

We cannot predict, at present, which of these various responses would occur in a given situation. However, note that all of these suggested responses have a common element. They all involve increased costs. It is in the context of reduced access to high-ranked resources that increasing 
investment in these areas makes sense. For example, Binford $(1977 ; 1978 ; 1979)$ reports that among the Nunamiut, over 70 percent of the yearly supply of meat is gathered during two brief periods that correspond to the spring and fall migrations of highly ranked caribou through known passes. In preparation for those hunts, hunters invest significant time and effort in acquiring materials, stocking and caching gear, and in producing highly reliable tools that have a low potential for failure during the hunt. Upfront preparation, positioning of backup gear, and the over designing of tools are all costly practices, but practices that make sense in terms of the risk of food loss if, for example, a tool failed at a critical point (see discussions in Bleed 1986; Torrence 1983, 1989). Suppose, however, that caribou were suddenly available for six months of the year, or that they were suddenly available year round. What impacts would that have on this costly design strategy? We suggest that it is unlikely that Nunamiut hunters would continue to make a significant investment in producing expensive, reliable tools if caribou were ubiquitous. However, if caribou were suddenly available only once a year during their spring migration, or available every other year, then increased investment in more costly hunting strategies and tactics may be expected, along with other changes. We find these observations interesting because of the pattern that we have outlined previously for bison fluctuations in Texas ${ }^{\text {(note } 12)}$.

Using several long-term data sets from different regions of Central and South Texas, we suggested that during the Late Archaic grasslands declined slightly, with an accelerated decline at the close of the Late Archaic and throughout the Late Prehistoric periods. These declines may have resulted in a gradual reduction in overall bison populations. In addition, the reduction of grasslands would have increasingly resulted in a fragmented, patchy distribution. It is likely, then, that bison populations would be concentrated in smaller, more isolated areas. Spatially, the number of potential locations that bison had a reasonable probability of occupying should have been reduced through time. In some sense, bison locations were becoming more predictable. Overlain on these patterns of shrinking, fragmented grasslands were short-term changes in production. During the end of the Initial Late Prehistoric, tree-ring-based PDSI data suggest that variability at this short-term scale was low when seen at 25-year segments. Under these conditions, we suggest that bison populations spent little time in any one patch, and that average herd size was reduced. During the Terminal Late Prehistoric period, the PDSI data suggest a dramatic increase in year-to-year variability when seen at 25 -year segments. Relative to the pattern noted in the Initial Late Prehistoric, this should have resulted in some locations with high production. Where these productive patches were located varied from year-to-year. To the degree that bison clustered in productive areas, this would have produced at least some locations on the landscape with larger herds and with longer residence time for those herds in a patch.

How might hunters and gathers respond to these various situations? While a variety of local responses are anticipated and are dependent, in part, on the overall structure of other plants and animals, extant technologies, and a host of other elements, we can suggest some general responses. For this discussion, we assume that Late Archaic populations were, relative to subsequent periods, primarily organized in a foraging pattern, with hunters taking bison on an encounter bases. As bison populations began to slowly decline throughout the Late Archaic, we expect that small expansions of diet breadth, and possibly shifts in technology, would occur. Sometime near the end of the Late Archaic, or at the start of the Late Prehistoric, bison populations began to decline significantly. In the Initial Late Prehistoric, this should have produced an expansion of the diet in most settings, and shifts to technology that is "more expensive" to produce and maintain. As short-term production in grasslands appears to have been consistently low, we suggest that this initial period was characterized by a low degree of temporal and spatial predictability in bison. In the Terminal Late Prehistoric, the significant year-to-year variation in production when seen at a 25-year level should have produced some periods where bison distributions were similar to the Initial Late Prehistoric, and some periods where bison were spatially clustered to take advantage of high production. We suggest that under these conditions, one of the major changes in the adaptation may have been a shift in mobility strategies with an increasing portion of the system involving logistical hunting of bison. While other shifts, including diet expansion and technological shifts are likely, an increasing use of logistically organized task groups designed to increase encounters with bison would make sense under conditions of spatial clustering. Interestingly, shifts such as those suggested above are consistent with the increasing frequency of bison present on archaeological components in the Terminal Late Prehistoric. All else being equal, a shift from a foraging based system to one in which task specific groups target bison, process bison at kill sites, and return bison to residential sites, would significantly increase the number of components with bison present, regardless of the availability of bison in the natural environment. The rapid increase in bison presence seen on Terminal Late Prehistoric components (Figure 9-2) is consistent with that proposed shift.

To explore thoroughly these scenarios, we must overcome substantial problems. This is especially the case given our current lack of specific information on critical elements in the overall matrix, such as local information on production variability, fluctuations in density of other plants and animals, 
costs and benefits associated with alternative technological and mobility options, and detailed paleoenvironmental information. While it is unlikely that researchers will solve these problems in the near future, the following section uses aspects of the foraging theory-based arguments presented above to outline research directions, methods, and associated expectations that will guide the analysis of the archeological material collected from 41KM69.

\section{Research Domains}

The analytical units and artifact distribution described in Chapter 8 along with additional data from other sites are linked to the theoretical discussion and overall models presented in the previous chapters. Some of the research domains, such as those concerning issues of chronological clarification of Late Prehistoric remains and paleoenvironmental reconstruction, rely only on data gathered from 41KM69. For others, such as investigations of shifts in diet, changes in aspects of and technological organization, comparative data from other components beyond the data available at 41KM69 was used. Figure 9-15 outlines the region from which the comparative data was drawn. The area, centered on $41 \mathrm{KM} 69$, encompasses roughly $71,000 \mathrm{~km}^{2}$. Comparative data came from literature reviews of excavated and tested sites in this region from time periods present at 41KM69 (Middle Late Archaic, Terminal Late Archaic, Initial Late Prehistoric, and Terminal Late Prehistoric).

In some instances, the investigation of the research domains required broader scale data from areas outside of that identified in Figure 9-15. These included investigating domains associated with the use of ceramics, shifts in weapons technology, and shifts in mobility. The investigation of changes in weapons technology involved the comparison of attributes at the individual artifact level, and involved broad scale comparisons across wide regions. Similarly, the investigation of the ceramic research domain requires comparisons of hunter-gatherer ceramics in Central Texas with other hunter-gatherer and agricultural ceramic using groups. The scales of comparisons are identified in each of the individual domains discussed. Finally, our investigation of mobility required comparison with assemblages from outside the Figure 9-15 boundary. Whenever possible, the comparative data relied on extant literature for comparative data. However, in some cases, reviews of the collections were necessary to ascertain the appropriateness of the comparative component data, and to collect those data.

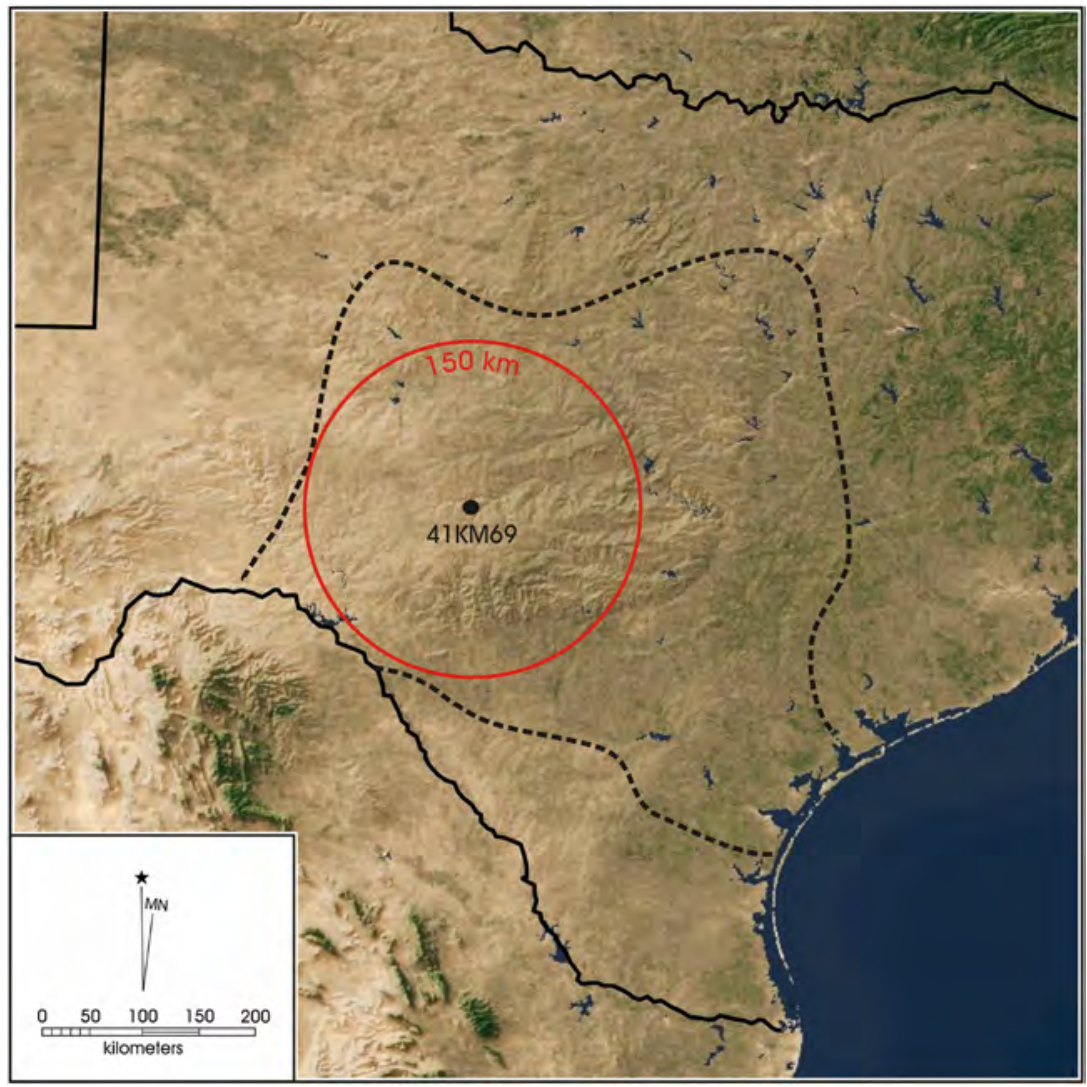

Figure 9-15. Location of 41KM69 with $150 \mathrm{~km}$ radius identifying limits of comparative samples. 


\title{
Chapter 10: Confirming the Late Prehistoric at 41KM69
}

\author{
Jennifer L. Thompson
}

As described in Chapter 7, 41KM69 produced Leon Plain ceramics, Perdiz projectile points, and formal unifaces on the lower terrace of the site in Areas 1 and 2. Researchers have used that data set to define the Terminal Late Prehistoric Period Toyah interval in Central and South Texas. However, several researchers have questioned aspects of this chronology, especially in South Texas (see Hester 1995), and as discussed above and illustrated in Figure 7-2, these three artifact types were not consistently associated with and found at the same depth at 41KM69. One issue absolute dating sought to resolve was whether the ceramics in Area 1 are associated with a Protohistoric or Historic component rather than with the Terminal Late Prehistoric because of the shallow depth of the ceramics relative to the arrow points in Area 1 and unifaces in Area 2. However, the issue was further complicated by dates obtained on samples from Feature 2, which was found in the same excavation block and at the same elevation as several of the "typical" Toyah end scrapers in Area 2. Between the upper level ceramics and the lower level scrapers across the lower terrace, a handful of Perdiz projectile points and other end scrapers were found in Area 1. Initially, this assemblage was relatively dated based on artifact type and soil horizons. CAR sought to confirm the date of the ceramics and possibly clarify up the Feature 2 dates that ranged from AD 1390 to recent times (Table 10-1).

The best possible option left for confirming a Terminal Late Prehistoric component on the lower terrace was through thermoluminescence (TL) dating of ceramic sherds. The processes for TL dating re not outlined here (Aitken 1985, 1989; Barnett 1999; Feathers 1997; Dykeman et al. 2002) but, the method dates the sample to the last high firing $\left(>450^{\circ} \mathrm{C}\right)$ and provides more accurate estimates for recent events than radiocarbon dating (Feathers 1997; Feathers and D.Rhode 1998; Roberts 1997). Results from TL dating have been tested against samples where independent dating was available (Barnett 1999; Kojo 1991). It works well for confirming the age of artifacts that are relatively dated, such as ceramics within certain seriations, for samples that do not have adequate organic material to date through radiocarbon or tree- ring methods, for samples that have been dated but returned suspect results, and for young or surface-level samples. TL dating appears to be the most appropriate method for the sherds from 41KM69 since none of the sherds were directly associated with charred material appropriate for radiocarbon dating and they are not associated with any other established chronological indicator. TxDOT also requested AMS dating of the same sherds submitted for TL dating so selected sherds were halved and submitted to both labs.

The TL dating was conducted at the University of Washington Luminescence Laboratory and the AMS radiocarbon dating was done at the University of Georgia at the Center for Applied Isotope Studies. The luminescence dating indicates the last exposure to light (OSL) or heat (TL) while the AMS method should date a sample of C-14 present on the surface of the sherd presumably transferred when the pot was on a fire. This chapter describes all the results of the radiocarbon dating and the TL/ OSL dating that occurred during both phases of excavation and provides the various scenarios that may be possible in interpreting this seemingly typical collection of artifacts.

\section{The Assemblage}

The artifact assemblage in question is described in Chapter 7 and revisited here. Levels 4 and 5 of Area 1 contained 116 plain, bone-tempered sherds, often referred to as Leon Plain when found in prehistoric contexts. These sherds were confined to the $\mathrm{AB}$ soil horizon in Area 1 along with 8 unifacial end scrapers and 1 Perdiz projectile point. Beneath the AB deposits at the surface of the Bk1 horizon of Area 1, 3 additional Perdiz points were recovered. Within the Bk1 horizon in Area 2, 21 unifacial end scrapers were found, 15 in the same level at the surface of the Bk1 horizon and at the same depth as hearth Feature 2. Therefore, there seems to be two groups of Toyah artifacts. The first (earliest) crosses both Areas 1 and 2 at the surface of the Bk1 and contains 3 Perdiz points, 15 end scrapers, and 1 hearth. The second is found only in Area 1 and includes 164 bone tempered ceramics and 8 end scrapers within the AB horizon in Levels 5 and 6.

Table 10-1. Radiocarbon Sample Dates of Feature 2

\begin{tabular}{|c|c|c|c|c|c|c|}
\hline Area & Unit & Depth (cmbs) & Date BP & Date BC/AD & Time Period & UGA Sample \# \\
\hline 2 & TU 8 & 39 & $120 \pm 40$ & N/A & Recent & 13508 \\
\hline 2 & TU 8 & 34 & $480 \pm 40$ & A.D. 1390-1490 & $\begin{array}{c}\text { Terminal Late } \\
\text { Prehistoric }\end{array}$ & 13590 \\
\hline 2 & TU 8 & 32 & $180 \pm 40$ & A.D. 1640-1960 & Proto/Historic & 13591 \\
\hline
\end{tabular}


Problems with dating this assemblage arose when trying to acquire an absolute date for Feature 2, in an attempt to also date the Bk1 horizon in which it was mapped. Initial radiocarbon samples from Feature 2, the hearth associated with end-scrapers in Area 2, returned dates from the Historic/ Protohistoric Period (180 \pm 40 B.P., UGA Sample 13591), the Terminal Late Prehistoric Period (480 \pm 40 cal B.P.; UGA Sample 13590), and a recent date (120 \pm 40 B.P., UGA Sample 13508) (see Table 10-1). The dates of Feature 2 in Area 2 had implications for the age of the rest of the excavations in the upper levels of both Areas 1 and 2 because of its relative association with typical Toyah interval artifacts on the lower terrace. Therefore, the ambiguous results were not helpful in determining a date for the hearth and by association, a date for the Toyah artifacts. The second round of dates to confirm the age of the Leon Plain ceramics was not straightforward either. Labs at University of Washington and at the University of Georgia reported problems with sample size and condition. However, the UW dates seem internally consistent and more interesting. Only four of the six sherds submitted to UGA contained carbonate amounts large enough to date.

Table 10-2 shows the results of each method on the same sherd with the first five columns applying to the luminescence dating and the last five columns showing the radiocarbon results. The UGA results do not align with the UW results. Neither do they align with any of the dates of Feature 2 (Table 10-1). In the four datable cases, the AMS results indicate the sherds predate the earliest Feature 2 date as well as the TL/OSL dates of the same sherd sample. Two of the TL/ OSL dates align with the Historic and Terminal Late Prehistoric dates returned from Feature 2.

\section{Interpreting the Data}

Without the "absolute" dating results from radiometric and luminescence labs, all the artifacts and the features in Bk1 levels and above would have likely been described as representing the Toyah interval as was done in the Phase II report and the interim Phase III reports. However, in light of the available technology, other possible scenarios seem plausible. Here we present some possibilities with the information at hand.

\section{Scenario 1}

One interpretation is to trust the AMS ceramic residue dates that place the $\mathrm{AB}$ deposits in Area 1 in the Austin interval and to disregard both the OSL results directly dating the ceramics and the Feature 2 dates. These assumptions place an Austin interval in the $\mathrm{AB}$ horizon on the lower terrace above a Toyah interval in the Bk1. The ceramics and other artifacts from the $\mathrm{AB}$ levels are removed from the Toyah assemblage and all else-(scrapers, Perdiz points, and features) within the Bk1 remain dated based on form and style to the Toyah interval in its discrete soil horizon and are part of the Terminal Late Prehistoric analytical unit. This would suggest the AB materials are out of context since the $\mathrm{AB}$ soils overlie the Bk soils.

\section{Scenario 2}

Another interpretation is to trust the OSL/TL dates which directly date the ceramics in the $\mathrm{AB}$ deposits and then disregard both the AMS dates on ceramic residues and the Feature 2 dates. The luminescence dates suggest that there are two groups of ceramics in the AB horizon, one manufactured during the Toyah interval, the other manufactured during the Historic Period. This scenario seems more likely than the first because it supports the law of superposition. As previous work at the site saw no evidence of an inverted stratigraphy, this seems reasonable. Because all dated sherds came from the same level (Level 5), there is no way to tease out artifacts in the AB into Historic and Terminal Late Prehistoric analytical units. Future analysts interested in these specific time periods may wish to disregard artifacts in Area 1 in Levels 4 and 5 or those confined to the AB soil horizon. With this interpretation, artifacts within the Bk1 deposit in Areas 1 and 2 remain in the Terminal Late Prehistoric based on form and style.

Table 10-2. OSL/TL and AMS Date Results on Native Ceramics

\begin{tabular}{|c|c|c|c|c|c|c|c|c|c|}
\hline UW Sample & $\begin{array}{c}\text { CAR } \\
\text { Sample }\end{array}$ & Date & Method & Occupation & $\begin{array}{c}\text { UGA } \\
\text { Sample }\end{array}$ & $\begin{array}{c}\text { CAR } \\
\text { Sample }\end{array}$ & 1 Sigma & Method & Occupation \\
\hline UW2006 & $66-0-2 B$ & AD1331 \pm 47 & OSL & TLP & 4357 & $66-0-2 A$ & AD 1045-1094 & AMS & ILP \\
\hline UW2007 & $86-0-2 B$ & AD $1651 \pm 97$ & OSL/TL & Historic & 4355 & $86-0-2 A$ & AD 1186-1200 & AMS & ILP \\
\hline UW2008 & $86-0-3 B$ & AD1526 \pm 38 & OSL & Historic & 4356 & $86-0-3 A$ & n/a & & \\
\hline UW2009 & $52-1-3 B$ & AD $1686 \pm 57$ & OSL & Historic & 4353 & $52-1-3 A$ & AD 1224-1263 & AMS & TLP \\
\hline UW2010 & $51-1-2 B$ & AD $1749 \pm 43$ & OSL/TL & Historic & 4352 & $52-1-2 A$ & AD 994-1023 & AMS & ILP \\
\hline UW2011 & $66-0-11 B$ & AD $1401 \pm 43$ & OSL & TLP & 4354 & $66-0-11$ A & n/a & & \\
\hline
\end{tabular}




\section{Scenario 3}

The third scenario is to trust both AMS and OSL/TL dates on ceramics and disregard Feature 2 dates. Because the two methods do not date the same event, it is possible that they are both correct. In this case, the ceramics retain their dual manufacturing groups, one in the Historic Period, the other in the Toyah interval, but were reused on an Austin interval aged fire or otherwise came into contact with Austin aged residues on the vessel surfaces before being deposited in the $\mathrm{AB}$ soil of Area 1. As in the second scenario, all artifacts in the Bk1 horizon would remain in the Terminal Late Prehistoric based on form and style.

\section{Scenario 4}

Our final interpretation is to trust that Feature 2 dates to the Historic/Protohistoric Period or the Late Prehistoric dates and trust OSL/TL dates on ceramics, but disregard the AMS dates of ceramic residues. If the historic dates of Feature 2 are correct, then the entire Late Prehistoric Toyah interval artifacts in the Bk1 in Areas 1 and 2 should also be placed in this time period. Late Toyah expressions are not unheard of (Abbott and Trierweiler 1995:435-436) and would still fit with OSL/ TL historic dates of the manufacturing of the ceramics. The assemblage of artifacts stays intact as an analytical unit likely deposited in the same general time frame. The analytical unit would then change to the Historic period and the Terminal Late Prehistoric analytical unit would be eliminated.

The same outcome may be suggested if the Feature 2 dates are believed to date to the Late Prehistoric. The associated artifacts are then left to their usual temporal placement, remain an intact expression of the Toyah interval and stay within the Terminal Late Prehistoric analytical unit.

In all scenarios, the ceramics and end scrapers in the $\mathrm{AB}$ soil likely ended up in the upper levels of Area 1 later than the artifacts beneath them. In all scenarios but the first, they represent the latest known occupation of the site prior to the twentieth century.

\section{Summary of Dating the Late Prehistoric at 41KM69}

Despite the disagreement of the "absolute" dating methods employed on artifacts and features in the upper levels of the lower terrace, the artifacts in question are no doubt similar to those described in Toyah components elsewhere. Regardless of whether we call the collection of artifacts Toyah and adjust the time frame to a wider range, or keep the time frame for the Toyah interval and suggest the ceramics were made in the Historic Period, the technology is the same.

In the judgment of the authors, the evidence points to the very Late Terminal Late Prehistoric aged collection of typical Toyah artifacts that include ceramics and unifaces that is confined to the $\mathrm{AB}$ horizon and is mixed with some historic materials. Then a second Toyah expression is found in the Bk soils that lacks ceramics but contains other artifacts common on Toyah interval sites. This interpretation relies less on absolute dates than relative dating because the absolute dates are conflicting. However, we find the TL/OSL dates of the ceramics more reliable because they date the actual firing, not residue. The UGA lab dates have returned consistently mixed results from both phases of excavation with the dating of Feature 2 as well as the ceramics, therefore we do not find the dates of Feature 2 or the AMS dates of the ceramics reliable. 



\section{Chapter 11: Paleoclimate Research}

\section{Jennifer L. Thompson and Raymond L. Mauldin}

The argument that bison availability declined during the latter part of the Late Archaic and into the Late Prehistoric periods relies on several long-term data sets that indicate a shift in vegetation composition (see Chapter 2). While these longterm data sets should reflect regional vegetation changes, and while these data sets are relatively consistent at broad scales, the actual scale of these changes remains unknown. The second research domain investigated with the 41KM69 data focuses, then, on paleoclimate. What were the paleoenvironmental conditions during the Middle and Terminal Late Archaic occupations of 41KM69? Is there evidence of climate change at 41KM69 that is consistent, or inconsistent, with the proposed decrease in grasslands suggested by the regional data sets in the Initial Late Prehistoric and Terminal Late Prehistoric time periods? While pollen and phytolith recovery from sediment at the site are not sufficient to answer these questions (see Appendix I), information on paleoclimate can be gleaned from the analysis of stable carbon isotopes extracted from soil organic matter preserved in the soil column samples recovered from the site (Appendix H). The results of isotope studies, pollen identification, and macrobotanical studies as they relate to paleoclimate research are discussed in this chapter.

\section{Isotope Studies}

Numerous researchers (Boutton 1996; Boutton et al., 1998; Jessup 2001; McPherson et al. 1993; Steuter et al. 1990) have successfully used the analysis of the ratios of stable carbon isotopes (i.e., ${ }^{13} \mathrm{C}$ to ${ }^{12} \mathrm{C}$; usually expressed as $\delta^{13} \mathrm{C}$ values). Plants use one of three photosynthetic pathways: $\mathrm{C}_{3}, \mathrm{C}_{4}$, or CAM, each of which has distinctive $\delta 13 \mathrm{C}$ ranges. $\mathrm{C}_{3}$ plants have carbon isotope ratios between -32 to $-22 \%$ (mean of $-27 \%$ ), $\mathrm{C}_{4}$ plants range from -17 to $-9 \%$ (mean of $-13 \%$ ), and plants with CAM photosynthetic pathways tend to have isotopic values similar to those of $\mathrm{C}_{4}$ plants, at least within Texas. Because soil organic matter is the product of the decomposition of plant tissue, the analysis of the $\delta^{13} \mathrm{C}$ values of soils provides a close approximation of the $\delta^{13} \mathrm{C}$ values of the vegetation communities that contributed organic matter to the soil. It is therefore possible to use the $\delta^{13} \mathrm{C}$ values of soil organic matter recovered from a soil column to investigate changes in $\mathrm{C}_{3} / \mathrm{C}_{4}$ vegetation communities over time.
A buried paleosol $(120-125 \mathrm{cmbs})$ at $41 \mathrm{KM} 69$ has been radiocarbon dated to 2340-2120 B.P. The soil formed soon after the earliest occupation of the site since it drapes over the gravel bar that contains the oldest documented hearth. We know little of the paleoclimatic conditions at the site as such, and the buried paleosol offers an opportunity to gather data on the character of the vegetation community on the banks of the South Llano as it was some 2,200-2,300 years ago. The nature of the vegetation community may in turn inform us about the paleoclimatic conditions in the immediate proximity of the site.

CAR submitted a complete soil column (from surface to 120130 cmbs; Figure 11-1) from the site to investigate changes in vegetation communities present at the locality between the present and the earliest occupations. Eleven samples were collected from between 60 and $115 \mathrm{cmbs}$, at $5 \mathrm{~cm}$ intervals between Area 3 and BHT 5. The upper seven samples came from above the buried paleosol, Sample 8 was collected at the top of paleosol, and the bottom three samples were within the paleosol. The two surface samples came from south of Area 4. We expected that if local trends followed regional trends,

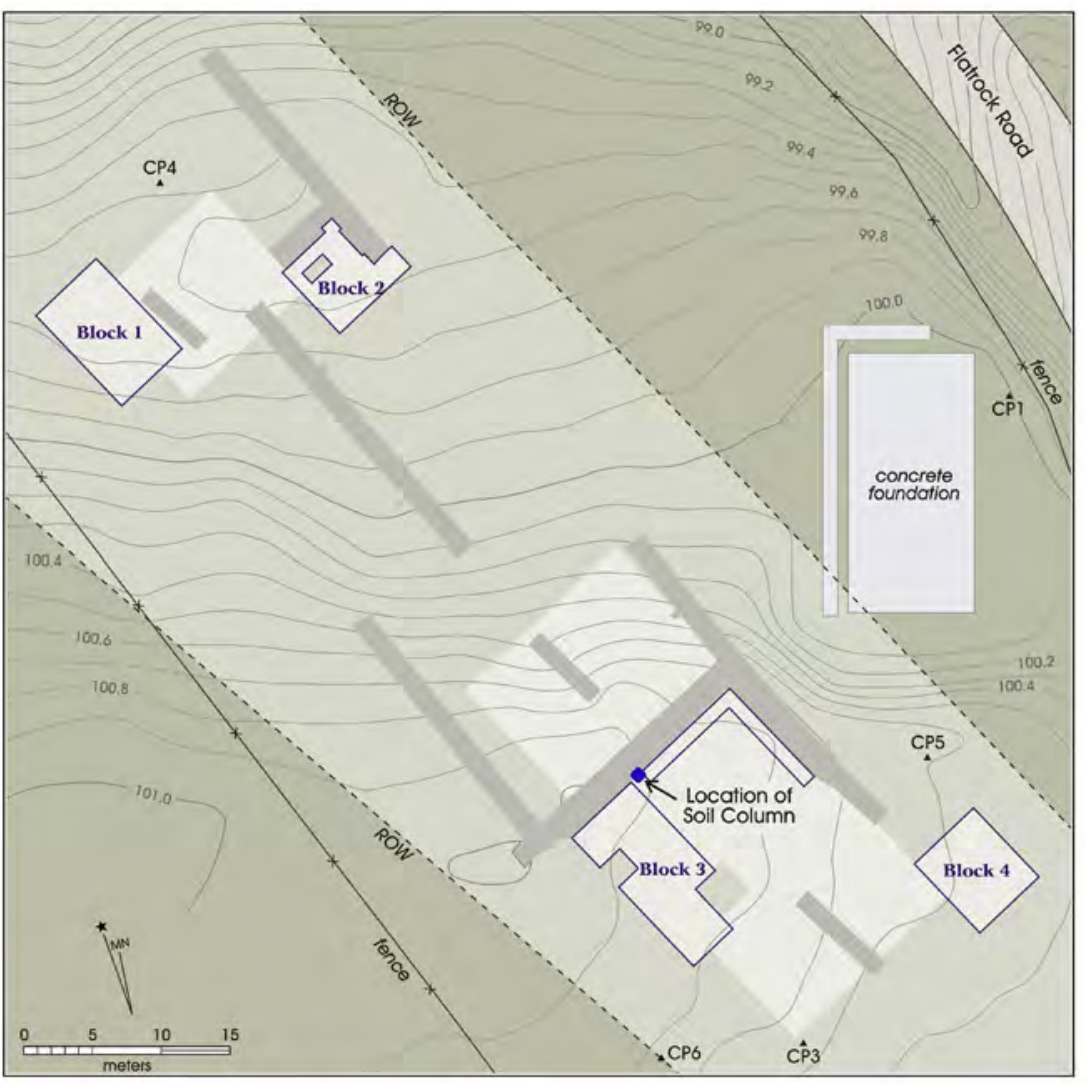

Figure 11-1. Location of soil columns collected from 41KM69. 
such as those from the bog and pollen studies outlined in Chapter 2, then an increase in $\mathrm{C}_{3}$ plants should occur over the time span of the soil column, approximately 2,000 years. To review, the pollen and bog data show widespread $\mathrm{C}_{4}$ grasslands across the region with a peak early in the Late Archaic. Then, grasslands begin to decline throughout the Late Archaic. By the Late Prehistoric, grasslands across the region show a rapid decline, particularly during the Toyah interval and Historic Period.

The results from the stable isotope analysis of the soil column show that indeed local trends follow regional trends. While $\mathrm{C}_{3}$ plants are always present and always dominate the plant community at $41 \mathrm{KM} 69$, they increase through time (from the paleosol to the surface) (Figure 11-2). This is indicated by an overall negative $\delta^{13} \mathrm{C}$ result and a sharp decrease in the modern samples. Nowhere in the column do the carbon isotope signatures indicate that the plant community was dominated by $\mathrm{C}_{4}$ or CAM plants.

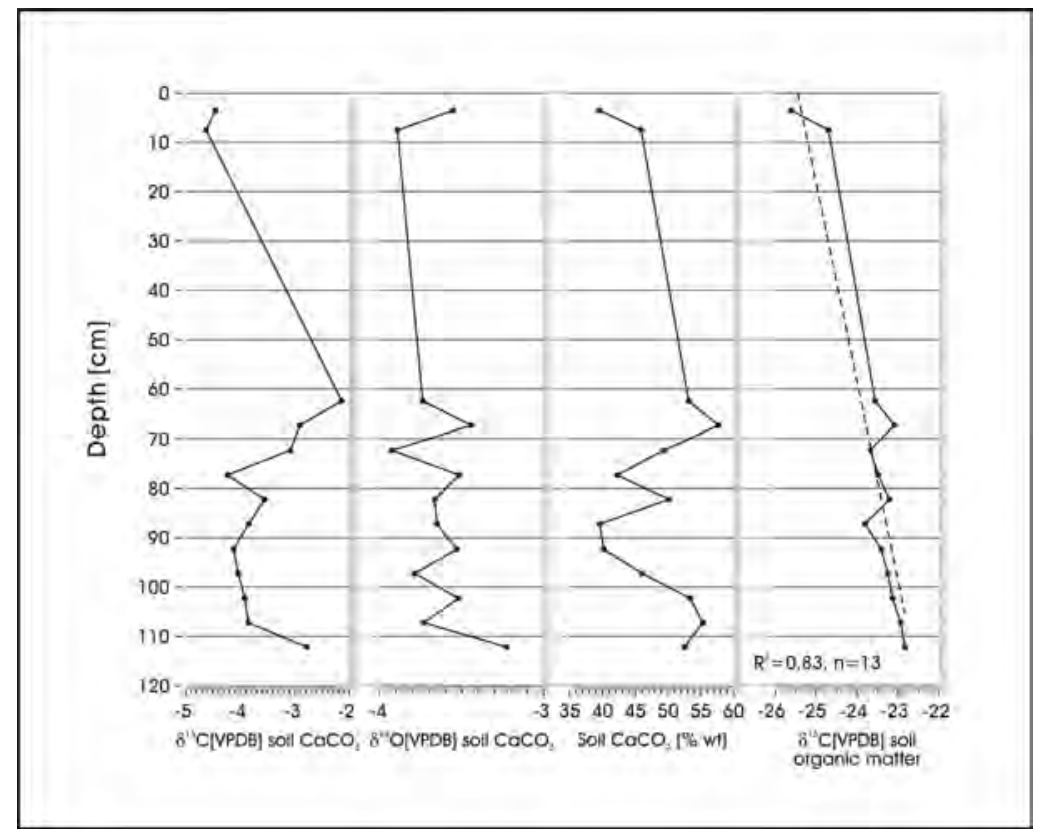

Figure 11-2. The stable isotope composition of $\delta^{13} \mathrm{C}$ and $\delta^{18} \mathrm{O}$ and concentration of $\mathrm{CaCO}_{3}(\% \mathrm{wt})$ and carbon isotope composition of total matter $\delta^{13} C$.
The same general pattern was shown in the stable carbon isotope analysis at the Varga Site (41ED28). Here, the average $\delta^{13} \mathrm{C}$ was -27.3 , which is more negative than at $41 \mathrm{KM} 69$ where the average was -23.59 . However, while the signatures became less negative at 41ED28 into the modern era, they became more negative at 41KM69. At both sites, we might expect a dominance of $\mathrm{C}_{3}$ plants over $\mathrm{C}_{4}$ species due to the proximity of the site to water.

\section{Pollen and Phytolith Remains}

Four samples were submitted for pollen and phytolith identification, all from a single column in Area 1 as a preliminary attempt to determine pollen and phytolith preservation at the site. The four samples were taken from each of the four soil horizons in the area. From bottom (145 cmbd) to top (31 cmbd) Sample 1833 was taken from the CK2 horizon, Sample 1835 came from the CK horizon, Sample 1837 came from the Bk horizon, and Sample 1845 came from the AB horizon. As is common in Central Texas open sites, the pollen and phytoliths were poorly preserved though some identifications were made (see Appendix I). Unfortunately, the surviving pollen grains are those that are typically found in highly degraded archaeological deposits. That is, pollen and phytolith grains from more fragile plant species are under-represented or entirely absent from the samples examined. Therefore, it is not possible to reconstruct an unbiased picture of the vegetation of the locality at the time of site occupation. Once it was established that pollen/phytolith presentation was not adequate, no additional sediment samples were submitted for further analysis.

\section{Macrobotanical Remains}

Macrobotanical remains extracted from soil samples collected from the site provided the most interesting results (Appendix E and see also Chapter 12). The soil samples all came from feature fill that was later floated at CAR. Like the pollen, the plant remains also showed signs of degradation and had been exposed to repeated flooding events. Furthermore, less than half the samples contained carbonized plant remains. However, taxa that were present are notable. Briefly, Dering's findings include pecan nut fragments, acorn, wintergrass/needlegrass, wild cherry species, and yucca or sotol. Among the wood assemblage, the pecan, hackberry, cherry and oak reflect a riverine environment, especially in the absence of juniper that was likely present in uplands.

The oak, pecan, and rose/cherry taxa were found in features from all time periods. The yucca and woody legume (likely mesquite) were only present in Terminal Late Prehistoric and Initial Late Prehistoric features. The wintergrass/needlegrass seeds were present in Terminal Late Archaic and the Terminal Late Prehistoric occupations (Table 11-1). The presence of the oak, pecan, and cherry suggests a riverine environment throughout all the study periods. 
Table 11-1. Plant Materials from Feature Fill by Time Period

\begin{tabular}{|c|c|c|c|c|c|c|}
\hline Common & MLA & TLA & ILP & TLP & (blank) & Grand Total \\
\hline cf. Yucca sp. & & 2 & 1 & & & 3 \\
\hline Elm & & & 1 & & & 1 \\
\hline Hackberry & 2 & 2 & 2 & & & 6 \\
\hline NA & 1 & 6 & 2 & 1 & 1 & 11 \\
\hline Oak & 2 & 9 & 9 & 6 & 2 & 28 \\
\hline Pecan & 1 & 4 & 3 & 2 & & 10 \\
\hline Rose/Cherry Family & 1 & 2 & 1 & 2 & & 6 \\
\hline Walnut Family/ pecan & & 1 & 2 & 2 & & 5 \\
\hline Wintergrass, speargrass & & 2 & & 1 & & 3 \\
\hline Woody legume & & 1 & 2 & & & 3 \\
\hline Grand Total & 7 & 29 & 23 & 14 & 3 & 76 \\
\hline
\end{tabular}

\section{Paleoclimate Research Conclusions}

Numerous soil samples were collected from 41KM69 to submit for various forms of analysis to help decipher elements of the prehistoric local environment. Some of these soils came from column samples taken from the walls of data recovery block excavation units and others came from soils associated with features. Four column samples were submitted for pollen and phytolith analysis to assess the quality of data before submitting multiple samples. Unfortunately, the samples revealed very degraded pollen considered unsuitable for paleoclimate analysis and therefore additional samples were not submitted. The light fraction from flotation samples of feature fill did provide some evidence of vegetation on the site during its occupation. Though botanical data recovery was relatively low, some unexpected species were identified in the samples. The macrobotanical results were in line with the riverine setting of the site in that most identifiable samples were $\mathrm{C}_{3}$ plants. Finally, a soil column was submitted for isotopic analysis. These analyses were most helpful in comparison with other data from Central and South Texas. Results show an overall negative $\delta^{13} \mathrm{C}$ signature becoming more negative through time from the deepest levels of the site to the modern surface. Plants using all three photosynthetic pathways were likely present at $41 \mathrm{KM} 69$, though $\mathrm{C}_{3}$ plants were always in the majority, becoming more prevalent in the Late Prehistoric. 



\title{
Chapter 12: Changes in Diet Breadth and Configuration
}

\author{
Jennifer L. Thompson and Raymond L. Mauldin
}

This chapter discusses diet breadth in Central and South Texas by examining both plant and animal remains from archeological sites reported in the literature and recovered from 41KM69. The first part of the chapter discusses the faunal analysis and the second part of the chapter includes the plant remains in the context of thermal features. Data relevant to these studies include feature and faunal data from the literature, lipid residue analysis of 41KM69 feature rock, ethnobotanical analysis of 41KM69 feature fill, a feature typology, and faunal report of the $41 \mathrm{KM} 69$ assemblage.

\section{Faunal Resources}

One set of responses to changes in the availability of higher ranked resources might involve changes in the species that are included in the diet, as well as modification in the way that extant dietary items are used. As bison re-enter the state sometime in the Initial Late Archaic, hunter-gatherers likely narrowed their diets by dropping lower ranked plants and animals that they pursued during the Middle Archaic. If bison densities fell gradually throughout the Late Archaic, then a gradual widening of the diet, with the addition of lower ranked animals, in the Middle and Terminal Late Archaic likely occurred. That dietary expansion, coupled with intensification on existing resources, should accelerate in the Late Prehistoric Period. Partly in response to the available data and analysis constraints, two measures were used to track diet breadth in fauna. The first of these measures is species or taxa richness, the second is the ratio of unidentifiable faunal fragments to identified taxa.

\section{Faunal Resources: Literature Review}

A literature search was conducted for faunal data tables of excavated sites within the $150 \mathrm{~km}$ study area (Figure 121) surrounding site 41KM69. Over 60 published sources were referenced with data incorporated from 17 sites. While many other sites contained faunal tables, only those reports that included provenience and temporal associations were included in this database (Appendix B-6). Often, published faunal data tables were compiled at the site level without more specific provenience or temporal information. Sometimes faunal discussion chapters aided assignment of the faunal data to specific components, but by far the most useful tables to this study were those that included temporal associations or proveniences that were tied to specific analytical units or occupations.
Within the comparative study area, seven sites contain Initial Late Prehistoric components with faunal remains, three sites had data from the Terminal Late Archaic, and three sites from the Middle Late Archaic contained faunal data. Almost 56,000 identifiable fragments were recorded with all but approximately 1,200 coming from components dating to the Terminal Late Prehistoric at twelve sites (Table 12-1). Data from 41KM69 was added to the dataset for the analysis on taxa richness and degree of fragmentation discussed below.

\section{Faunal Resources: Taxa Richness}

The simplest measure of diet breadth is taxa richness. An increase in species richness signals an increase in diet breadth while a decrease in number of species present at a systems level signals a narrowing of the diet breadth. Recently, Tomka et al. (2004c) used taxa richness to identify some intriguing trends in fauna through time in a number of selected Central Texas assemblages dating from the Late Archaic through the Terminal Late Prehistoric. While these results are encouraging and suggest that it is possible to track broad shifts in hunter-gatherer subsistence through this simple measure, a number of complications are present. The first of these, which is also applicable to our measures of plant dependence discussed below, is related to potential changes in mobility systems.

If hunters and gatherers organize their overall mobility system in a logistical manner as bison availability becomes restricted in time and space, it is critical that comparisons of taxa richness focus on similar types of sites. That is, if logistical sites are more common late in time, and if those sites are focused on bison procurement, comparisons of taxa richness between time periods without reference to whether a component is a logistical or residential occupation will produce ambiguous results. Therefore, comparing residential components from one period with residential components in another period, is crucial. To identify logistical and residential components this study compares sample size and diversity. The argument here is that residential components should have a greater number of animal types for a given sample size than logistical components as the latter is, by definition, focused on a smaller number of activities (Binford 1980; Kelly 1995). Here, the sample size and variety relationship to investigate changes in faunal assemblages is explored ${ }^{\text {(note } 1)}$.

Figure 12-2 presents expectations for changing assemblage size and taxa variety relationships for a system dominated by residential foraging (top) and for a system with a significant 


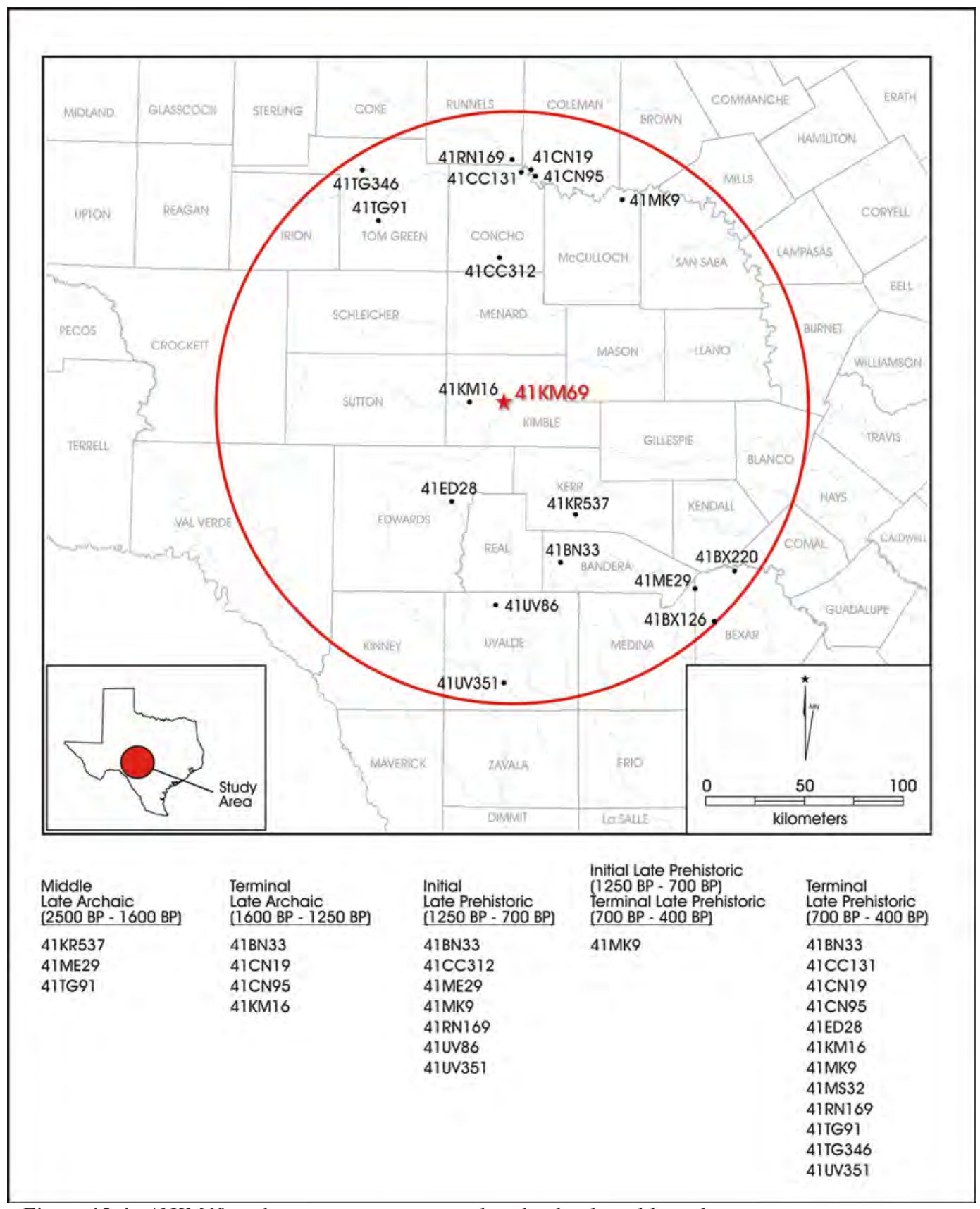

Figure 12-1. 41 KM69 and comparative sites used in the diet breadth studies.

logistical component (bottom). Similar plots were constructed for the Middle Late Archaic, the Terminal Late Archaic, the Initial Late Prehistoric, and the Terminal Late Prehistoric using a sample of components from throughout the region dating to the Late Archaic and Late Prehistoric periods (see Figure 12-1). Archeological reports reflecting these time periods were reviewed for any examples of a list of 23 different animal groups (see Table 12-2) that serve as a baseline for comparison. Sample sizes were noted for each group present, and in conjunction with an analysis of the 41KM69 data, plots similar to the Figure 12-2 examples were produced. Those fragments that could be placed in a faunal group are listed in Table 12-3 with their sample size. During periods of bison abundance, these plots should closely resemble Figure 12-2 (top), while during periods of declining bison, they should mimic the bottom plot in Figure 12-2. When residential components are considered, a wider variety of taxa should be present during periods of declining bison availability reflecting a wider diet. During the Middle Late Archaic, we would expect to see more sites with a low ratio of animal types per NISP as groups follow the same subsistence strategy throughout the time period. As bison numbers decrease we expect to 
Table 12-1. NISP per Component at Sites with Published Vertebrate Faunal Data

\begin{tabular}{|c|c|c|c|c|c|c|}
\hline Site & MLA & TLA & ILP & ILP-TLP & TLP & Grand Total \\
\hline $41 \mathrm{BN} 33$ & & 7 & 41 & & 209 & 257 \\
\hline $41 \mathrm{CC} 131$ & & & & & 9,611 & 9,611 \\
\hline $41 \mathrm{CC} 312$ & & & 48 & & & 48 \\
\hline 41CN19 & & 88 & & & 13 & 101 \\
\hline $41 \mathrm{CN} 95$ & & 6 & & & 1,598 & 1,604 \\
\hline 41KM16 & & & & & 14,359 & 14,359 \\
\hline 41KM17 & & & & & 0 & 0 \\
\hline 41KR537 & 25 & & & & & 25 \\
\hline 41ME29 & 205 & & 121 & & & 326 \\
\hline $41 \mathrm{MK} 9$ & & & 1 & 22 & 1,922 & 1,945 \\
\hline $41 \mathrm{MS} 32$ & & & & & 200 & 200 \\
\hline 41RN169 & & & 53 & & 11,838 & 11,891 \\
\hline $41 \mathrm{TG} 346$ & & & & & 1,285 & 1,285 \\
\hline 41TG91 & 531 & & & & 11,698 & 12,229 \\
\hline 41UV351 & & & 5 & & 14 & 19 \\
\hline 41UV86 & & & 62 & & & 62 \\
\hline 41ED28 & & & & & 2,043 & 2,043 \\
\hline Grand Total & 761 & 101 & 331 & 22 & 54,790 & 56,005 \\
\hline
\end{tabular}

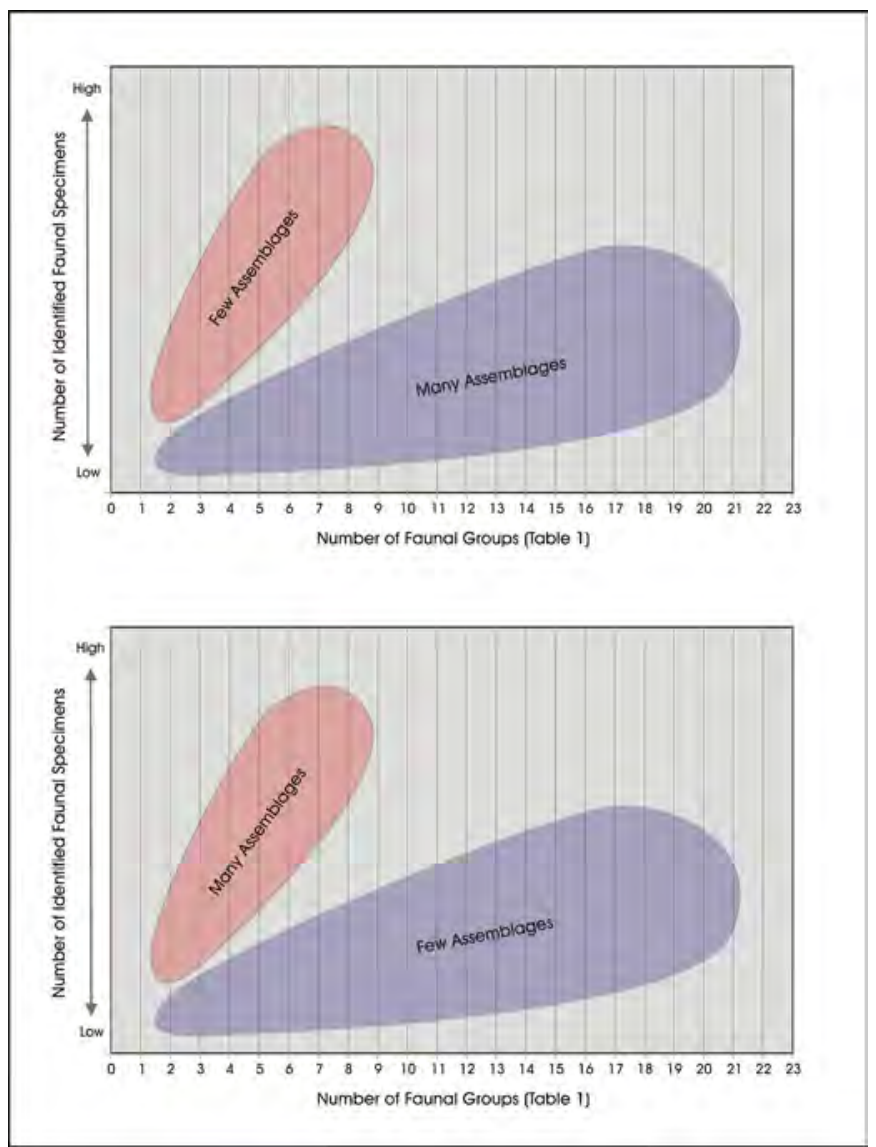

Figure 12-2. Proposed sample size-variety plots for fauna from residential foraging systems (top) and logistical systems (bottom). 
Table 12-2. Groups of Faunal Material Considered in Analysis

\begin{tabular}{|c|c|l|}
\hline Group & Class or Order & \multicolumn{1}{|c|}{ Members/ Analytical Groups Selected } \\
\hline 1 & Artiodactyla & Bison, Bovidae, Bison-Sized, Very Large Mammal \\
\hline 2 & Artiodactyla & Deer, Antelope, Sheep/Goat, Deer-Sized \\
\hline 3 & Artiodactyla & Pecary \\
\hline 4 & Carnivora & Canis, Dog-sized \\
\hline 5 & Carnivora & Felidae \\
\hline 6 & Carnivora & Mustelidae (Skunks, Badgers) and Procyonidae (Racoon) \\
\hline 7 & Insectivora & Shrews \\
\hline 8 & Lagomorphia & Jackrabbit, Rabbit-Sized \\
\hline 9 & Lagomorphia & Cottontail \\
\hline 10 & Marsupialia & Opossum \\
\hline 11 & Rodentia & Beavers \\
\hline 12 & Rodentia & Gophers, Medium-sized Rodents \\
\hline 13 & Rodentia & Mice, Rats, Voles, Small Rodents \\
\hline 14 & Rodentia & Squirrel \\
\hline 15 & Aves & Turkey, Hawks, Eagles, Large birds \\
\hline 16 & Aves & Other Birds (Ducks, Quail, Medium and Small Birds) \\
\hline 17 & Reptilia & Snakes, Lizards \\
\hline 18 & Testudines & Turtles, Sliders, Tortoise \\
\hline 19 & Anura & Frogs, Toads \\
\hline 20 & Osteichtyes & Fish \\
\hline 21 & Various & Mussels, Oysters \\
\hline 22 & Various & Snails \\
\hline 23 & Various & Other \\
\hline
\end{tabular}

see the number of such sites decrease and find more logistical sites with fewer faunal groups per NISP in the context of a broadening diet. Terminal Late Prehistoric residential sites then should show more items per NISP as an indicator of this broadening diet. At the same time, more logistical sites (as indicated by fewer faunal groups per NISP) should come into use as bison are targeted as a scarce resource through time at these locales. The regional trends incorporated from data gathered during the literature review are discussed followed by the trends discerned at 41KM69.

\section{Regional Comparison of Taxa Richness}

Figure 12-3 plots the number of faunal groups (x-axis) against the number of identifiable specimen per component (y-axis) to account for any trends simply explained by the nature of the sample. There is little to no relationship shown here so the $\log$ of each axis was taken and shown in Figure 12-4. In this transformation, many of the components fall within the 95 percent confidence interval which suggests that the number of animal types in each sample size is predictable or as expected in such a sample size. All of the Late Archaic components (both the Terminal and Middle Late Archaic) fall within the
95 percent interval except site $41 \mathrm{KR} 537$, which falls slightly below this line. The other six components that fall below this line are 41CC312, 41RN169, 41KM69, and 41BN33 from the Initial Late Prehistoric and 41MS32 and 41BN33 from the Terminal Late Prehistoric. All these components show a higher number of types than expected given their sample sizes. We interpret this as an indicator of a broadening diet at residential foraging sites. All of the components falling above the confidence interval date to the Terminal Late Prehistoric, though 41KM16 falls along the trend line and 41TG91 falls within the confidence interval. The remaining Terminal Late Prehistoric components (41CN95, 41KM69, 41ED28, 41RN169, 41TG346, and 41CC131) have fewer faunal group categories than expected for the sample size. This pattern suggests that these represent logistical components used for specific activities ${ }^{\text {(note } 2)}$.

We also broke down the analysis between the Late Archaic and the Late Prehistoric. Figure 12-5 shows Middle and Terminal Late Archaic sites with all components falling at or very near the 95 percent confidence interval. Figure 12-6 teases out the Initial and Terminal Late Prehistoric components, which are less predictable. The same trends are seen 
Table 12-3. Faunal Data and Assigned Group

\begin{tabular}{|c|c|c|c|c|}
\hline Site & Component & $\begin{array}{c}\text { \# of } \\
\text { Groups }\end{array}$ & $\begin{array}{l}\text { Groups } \\
\text { Present }\end{array}$ & NISP \\
\hline 41BN33 & ILP & 13 & $\begin{array}{c}1,2,4,5,6,9,10 \\
12,13,15,17 \\
18,20\end{array}$ & 41 \\
\hline $41 \mathrm{BN} 33$ & TLA & 1 & 2 & 2 \\
\hline 41BN33 & TLP & 13 & $\begin{array}{c}1,2,4,6,8,9,10 \\
12,13,14,17 \\
18,20\end{array}$ & 209 \\
\hline $41 \mathrm{CC} 131$ & TLP & 13 & $\begin{array}{c}1,2,4,6,8,11 \\
12,13,15,16,18 \\
20,21\end{array}$ & 3,994 \\
\hline $41 \mathrm{CC} 131$ & ILP & 6 & $31,5,7,1,3,1$ & 48 \\
\hline $41 \mathrm{CN} 19$ & TLA & 9 & $\begin{array}{c}1,2,4,8,9,11 \\
13,18,20\end{array}$ & 86 \\
\hline $41 \mathrm{CN} 19$ & TLP & 1 & 18 & 13 \\
\hline $41 \mathrm{CN} 95$ & TLA & 2 & 2,21 & 1 \\
\hline $41 \mathrm{CN} 95$ & TLP & 3 & $1,2,21$ & 942 \\
\hline 41ED28 & TLP & 7 & $\begin{array}{c}1,2,8,9,17,18 \\
20\end{array}$ & 2,010 \\
\hline 41KM16 & TLP & 9 & $\begin{array}{c}1,2,9,12,13,15 \\
18,20,23\end{array}$ & 412 \\
\hline 41KM69 & ILP & 8 & $\begin{array}{c}1,2,6,13,15,16 \\
18,20\end{array}$ & 89 \\
\hline 41KM69 & MLA & 5 & $1,2,15,16,20$ & 86 \\
\hline 41KM69 & TLA & 2 & 2,15 & 22 \\
\hline 41KM69 & TLP & 6 & $1,2,9,15,18,20$ & 729 \\
\hline 41KR537 & MLA & 3 & $2,16,18$ & 10 \\
\hline 41ME29 & ILP & 2 & 9,5 & 4 \\
\hline 41ME29 & MLA & 2 & 6,7 & 8 \\
\hline $41 \mathrm{MK} 9$ & TLP & 1 & 21 & 1,922 \\
\hline $41 \mathrm{MS} 32$ & TLP & 7 & $\begin{array}{c}1,2,4,8,17,18 \\
20\end{array}$ & 27 \\
\hline 41RN169 & ILP & 8 & $\begin{array}{c}1,2,4,8,9,13 \\
17,18\end{array}$ & 53 \\
\hline 41RN169 & TLP & 7 & $\begin{array}{c}1,2,4,8,13,18 \\
21\end{array}$ & 11,349 \\
\hline 41TG346 & TLP & 9 & $\begin{array}{c}1,2,8,13,16,17 \\
18,20,21\end{array}$ & 1,269 \\
\hline 41TG91 & MLA & 15 & $\begin{array}{c}2,4,6,8,9,11 \\
12,13,14,16,17 \\
18,19,20,7\end{array}$ & 347 \\
\hline 41TG91 & TLP & 20 & $\begin{array}{c}1,2,4,6,7,8,9 \\
10,11,12,13,14 \\
15,16,17,18,19 \\
20,21,23\end{array}$ & 4,431 \\
\hline 41UV351 & ILP & 1 & 21 & 5 \\
\hline 41UV351 & TLP & 1 & 21 & 14 \\
\hline 41UV86 & ILP & 1 & 2 & 9 \\
\hline
\end{tabular}

here as in Figure 12-3. Most of the Toyah interval components outside the explained range are above the confidence interval and can be interpreted as logistical sites or sites with a narrow range of animal groups represented in the diet. Only one Toyah interval site, 41MS32, is similar to the Austin components at the bottom of the chart reflecting a wider diet.

\section{Taxa Richness at $41 \mathrm{KM} 69$}

The pattern of changes in diet breadth at 41KM69 is similar to trends in the regional data (Figure 12-3). The nature of the faunal assemblages at both Late Archaic components at 41KM69 could simply be a function of sample size and not explained by other factors such as changes in diet breadth. However, the Late Prehistoric components at 41KM69 cannot be explained by the relationship in Figure 12-3. The Initial Late Prehistoric component falls just under the confidence interval and the Terminal Late Prehistoric component falls just above it. At the site level then, we suggest that during the Austin interval, 41KM69 was not used as a logistical site since a greater variety of animal types than expected are present. In the Toyah interval, the faunal types decrease suggesting that the occupants may have shifted their use of the site to a logistical or task specific organization.

\section{Faunal Resources: Degree of Fragmentation}

Unfortunately, the majority of the faunal remains from many sites in Texas consist of unidentified, broken specimens. To the degree that these fragments reflect increased processing of skeletal elements, either for marrow or bone grease, the fragmentation should be common during periods of dietary stress, and less common under conditions of abundance. The ratio of unidentified to identified fragments was used as a measure of the degree of fragmentation within a faunal assemblage. The expectation is that during periods of bison abundance, fragmentation should be less common, while during periods of decreasing bison, components should have more evidence of processing. Depending on the nature of the component (i.e., logistical vs. residential), fragmentation should increase throughout the Late Archaic and into the Initial Late Prehistoric, and the Terminal Late Prehistoric components should have the highest ratios. This trend should run counter to taphonomic processes, which would create more fragmentation on older components than young ones ${ }^{\text {(note 3) }}$.

\section{Fragmentation at 41KM69}

The ratios of weights for faunal groups 1-14 (the mammals) to unknown mammals were plotted through time at 41KM69 (Figure 12-7). The highest degree of fragmentation occurs in the Terminal Late Prehistoric as expected. However, the least amount of fragmentation occurs in the Terminal Late Archa- 


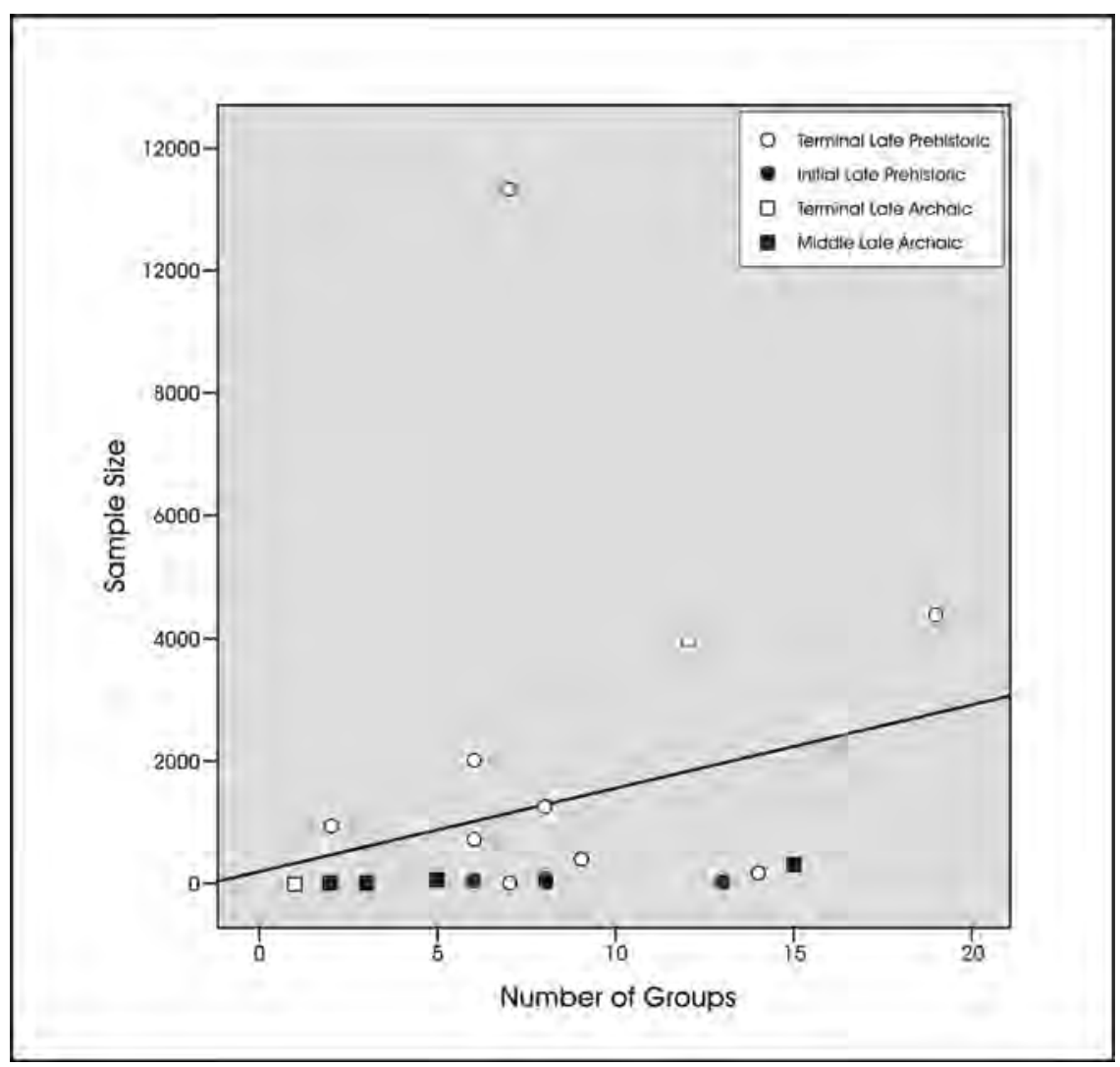

Figure 12-3. Plot of the number of faunal groups against sample size per component.

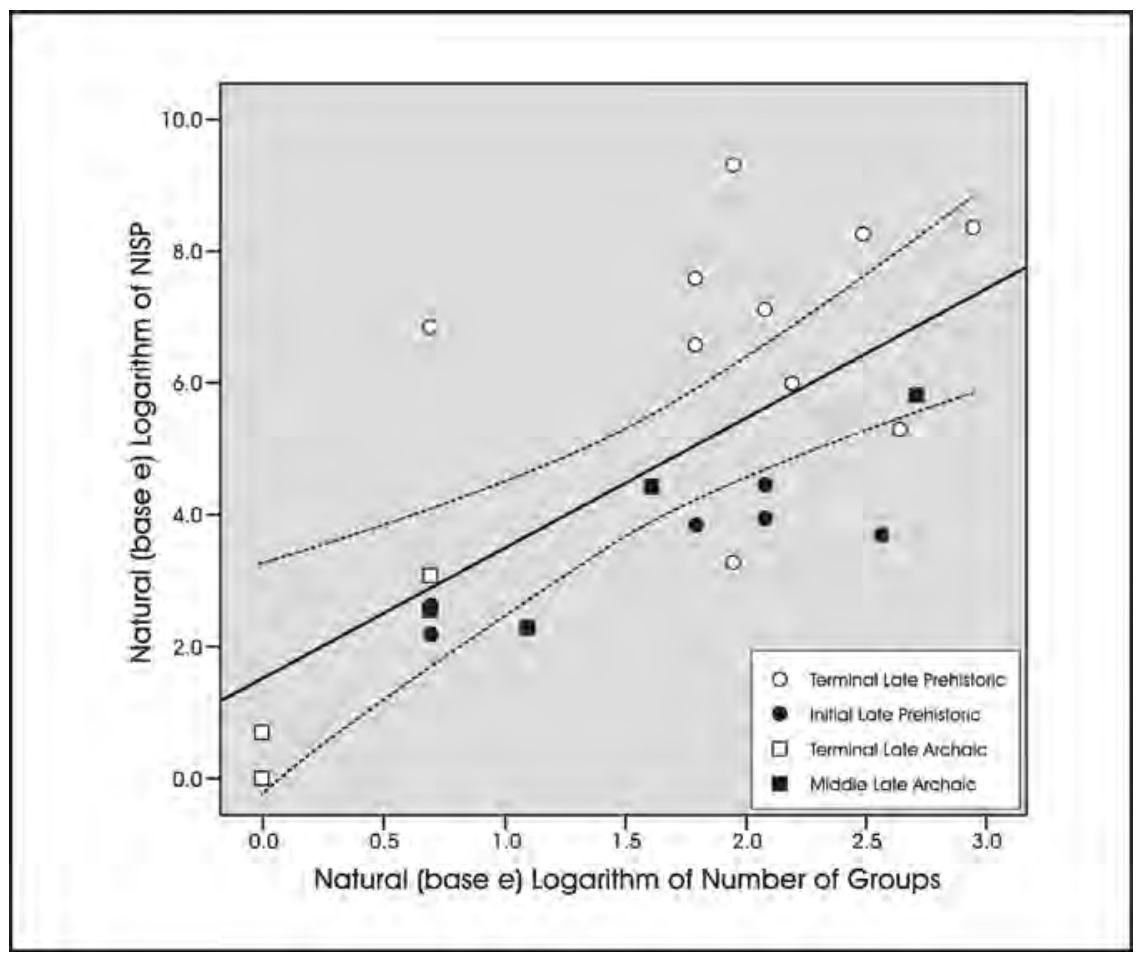

Figure 12-4. Log transformation of faunal groups by NISP with 95 percent confidence intervals (compare to Figure 12-3). 


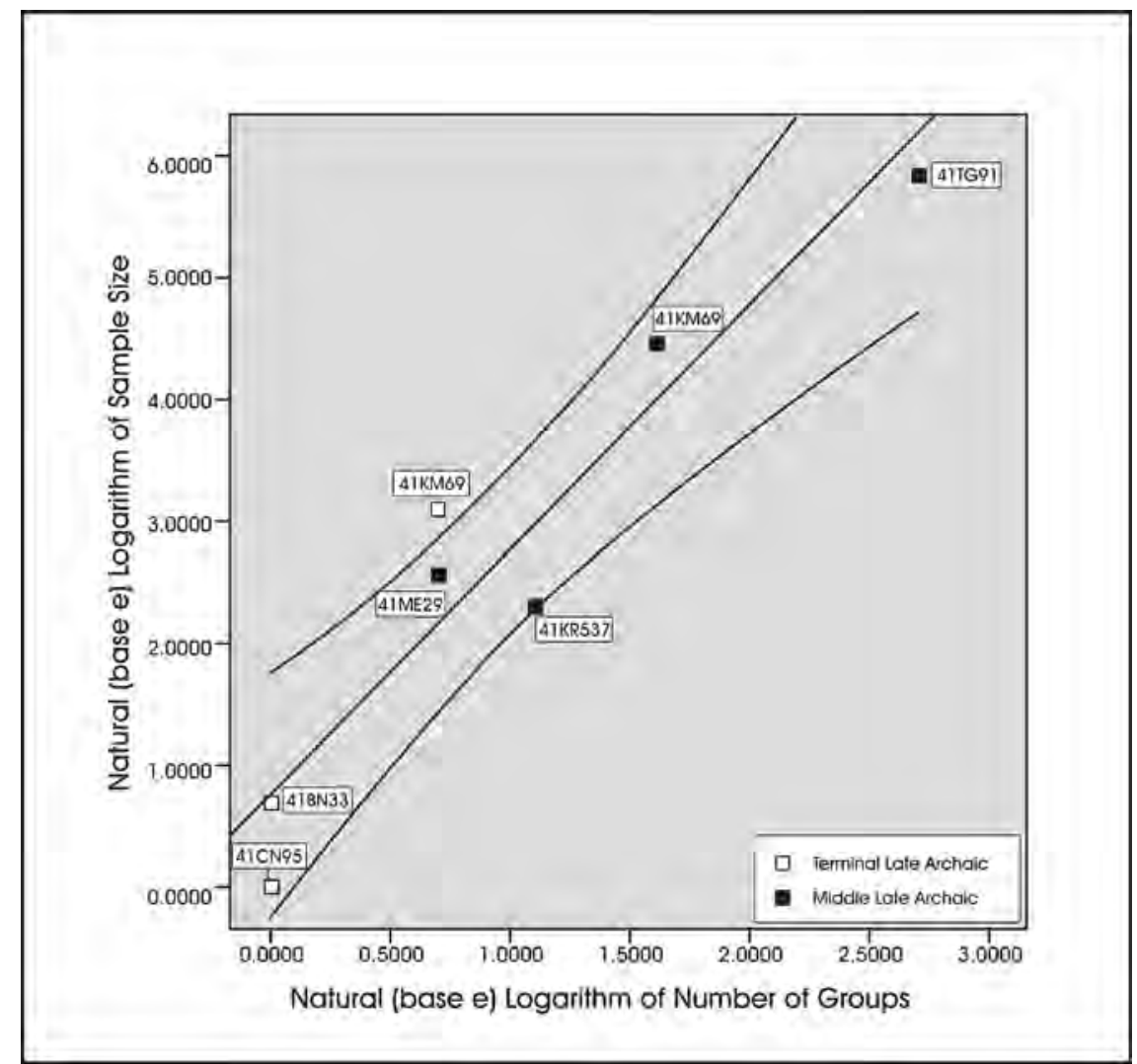

Figure 12-5. Plot of faunal groups against sample size among Late Archaic components in the study area.

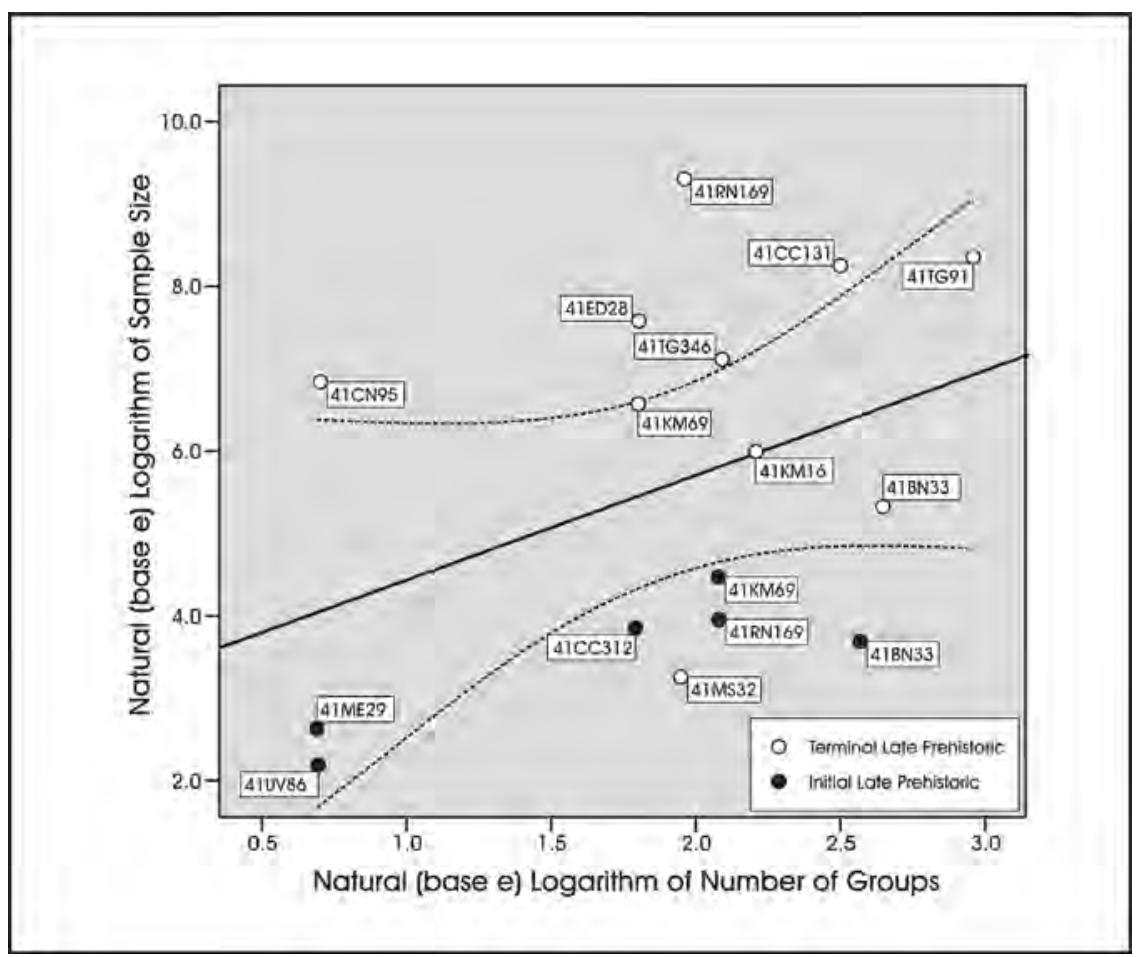

Figure 12-6. Plot of faunal groups against sample size among Late Prehistoric components in the study area. 


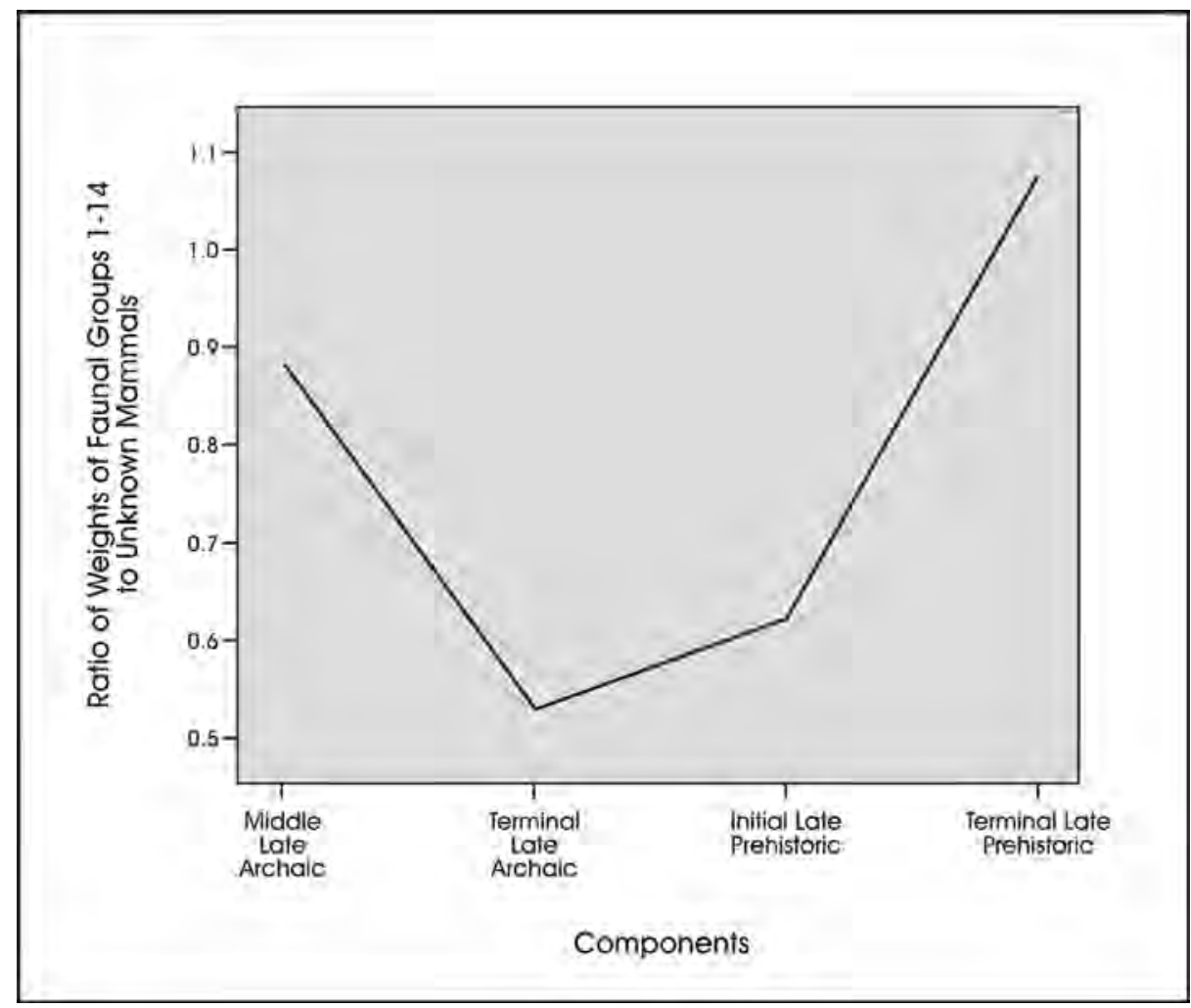

Figure 12-7. Plot of the ratio of the weights of identified (class or order) to unidentified bone by component at 41 KM69.

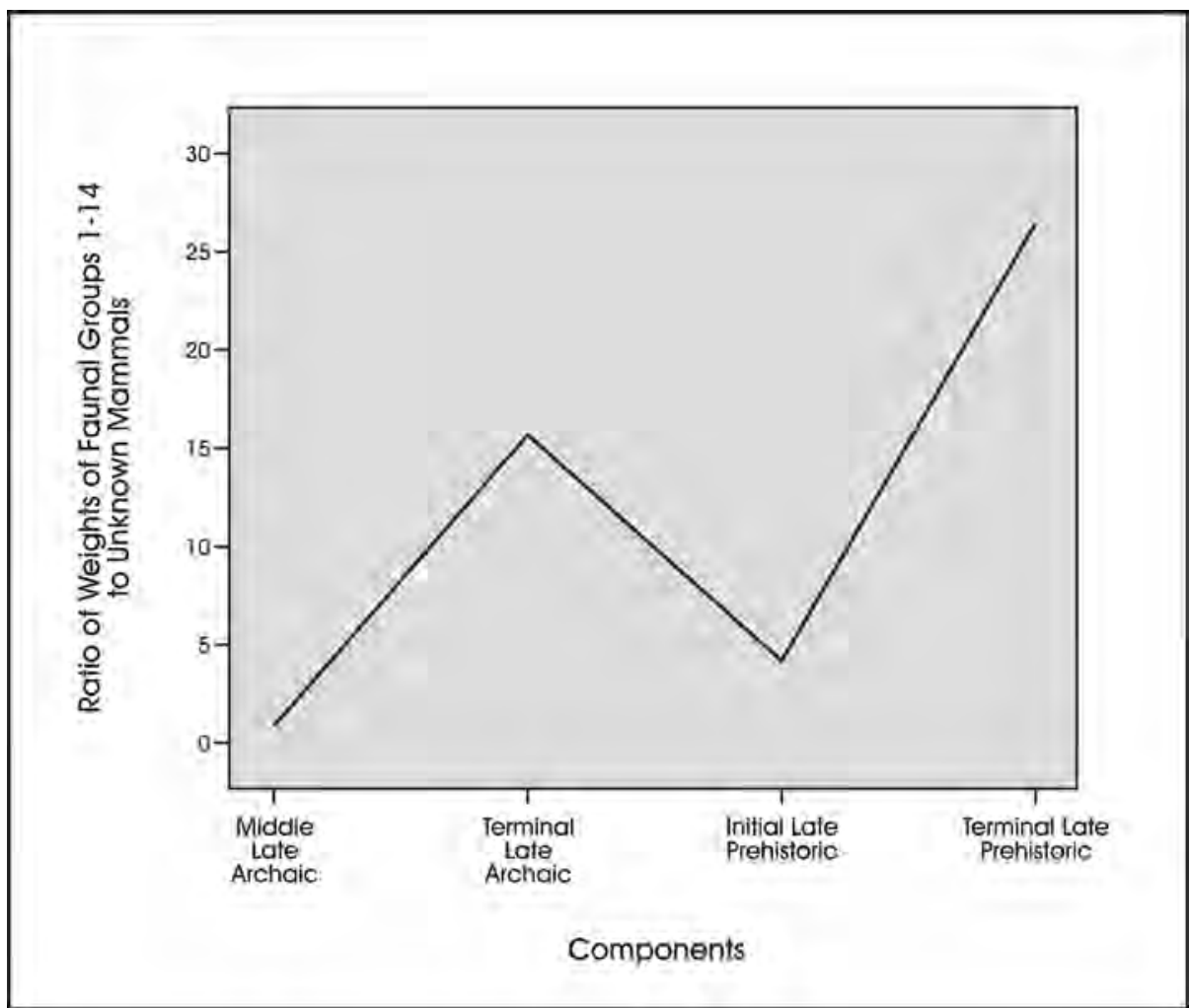

Figure 12-8. Plot of the ratio of weight of identified (class or order) to unidentified bone by component within the regional comparative sites. 
ic, not the Middle Late Archaic as predicted. While we would expect to see an increase in fragmentation from the end of the Late Archaic to the start of the Late Prehistoric, we would also expect the Initial Late Prehistoric fragmentation proportions to be higher than the Middle Late Archaic proportions.

\section{Regional Comparison of Fragmentation}

For the regional study, the same ratio weights for faunal groups were plotted through time as with the site-specific data from 41KM69. Figure 12-8 suggests that fragmentation rates through time are not explained entirely by dietary stress. While the highest ratios of both counts and weights are in the Terminal Late Prehistoric as expected and the lowest ratios of both counts and weights are in the Middle Late Archaic and increase through the Terminal Late Archaic as expected, the Initial Late Prehistoric does not fit the model. Fragmentation ratios for this time period decrease before a dramatic increase in the Terminal Late Prehistoric.

\section{Summary of Faunal Resources Studies}

The analysis of the 41KM69 faunal material, along with a literature review of well-reported faunal assemblages from sites throughout the region, provided adequate data for sample size and variety comparisons, comparisons of the number of taxa reflected in residential components, and comparisons of the ratios of fragmentation within assemblages. While potentially complicated by myriad cultural factors, environmental factors, nutritional needs of the population, preservation problems and other variables that are impossible to control, as well as differences in the diversity of animals available, these measures proved adequate for this specific consideration of diet breadth and intensification associated with animal use from the Middle Late Archaic through the Terminal Late Prehistoric periods (see Shaffer 2006).

The faunal studies conducted at the site and regional scale partially support our expectations that diet breadth widened through time from the Late Archaic to the Late Prehistoric. Overall, the number of faunal groups increased through time, though the median value decreases during the Terminal Late Archaic. Accounting for sample size, the trend is difficult to explain during the Middle and Terminal Late Archaic periods as the number of taxa represented can all be explained by the size of faunal sample. However, a dichotomy appears during the Terminal Late Prehistoric when the number of logistical sites increases from the previous Austin interval, where the faunal diversity appears to be coming from residential sites. An increase in logistical sites could be an indicator of a widening of the diet. The fragmentation study did not rule out taphonomic effects on the bone assemblages, as fragmentation rates were highest at the beginning and end of the period under study.

\section{Plant Resources}

Gauging the contribution of plants to the diet is much more complicated. In part, this complication is related to the poor preservation of plant remains from open-air sites. There are likely fewer plant taxa in the earlier periods simply as a function of preservation. In addition, certain plants (e.g., nuts) will be over represented in any assemblage. Consequently, direct measures, such as the number of different plant species present in a component are unreliable. As discussed with changes in faunal remains, there are mobility considerations that must be acknowledged. While the exploitation of lower ranked plant resources through a logistical strategy should not be common given the lower return rates on plant resources ${ }^{\text {(note 4) }}$, recent work on burned rock middens (see Mauldin et al. 2003) suggests that components associated with at least some of these large features may be logistically organized.

While estimating the contributions of plants to the diet using archeological data is complicated by problems of preservation and sampling, ethnographic data suggests a strong relationship between the use of rock in thermal features and plant processing (see Wandsnider 1997). The research design proposed that different types of rock thermal features are likely to be used to process different types of plants and suggests that the frequency of thermal features with rock may serve as gross proxy indicator of the intensity of plant processing, while the variety of feature types, defined by feature size and rock weight, may provide an indirect measure of the variety of plants represented in the diet of Texas hunter-gatherers.

Many plant resources such as bulbs, roots, and nuts often contain compounds that are not immediately digestible by humans. As a result, these classes of plants require extended cooking times to convert the indigestible starch compounds to digestible resources. Figure 12-9 (top) shows ethnographically reported minimum cooking times for plant tissue (Wandsnider 1997). Only millet and acorns require cooking times shorter than 10 hours. Most roots require between 15 and 20 hours of cooking, and cooking times for sotol, agave, yucca, and camas bulbs range from a minimum of 17 hours to nearly 60 hours. In contrast, cooking times for meat tissue derived from a majority of species require a maximum of five hours or less (Figure 12-9, bottom). Only medium body size mammals, such as deer and antelope, may require 7-10 hours of preparation and only the preparation of bison may take as much as from 4-20 hours depending on the size of the meat package cooked. In general, however, small meat packages 


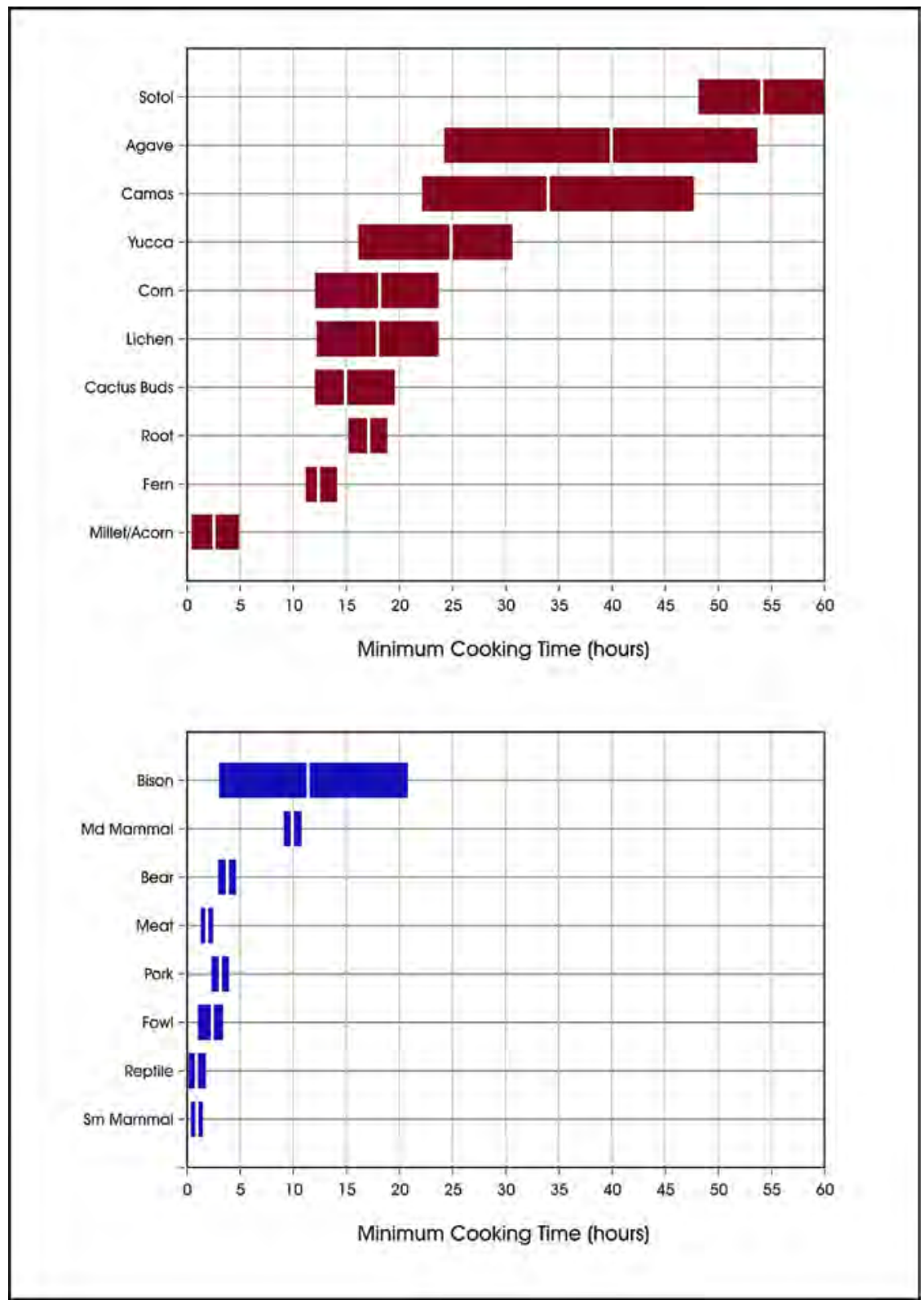

Figure 12-9. Ethnographically reported cooking time for plants (top) and meat (bottom). Bars show the interquartile range (from Wandsnider 1997).

such as a rack of ribs, meat fillets, and intestines, regardless of the animal, can be prepared in 1-2 hours or less.

Thermal features without rock are adequate in preparing foods that require short cooking times and/or are cooked in containers such as pots (e.g., stews). However, when lengthier cooking times are necessary, the use of rocks to increase heat storage and lengthen heat dissipation is commonly employed (Ellis 1997; Wandsnider 1997). If the interpretation of the relationship between plant and meat tissue cooking requirements and the length of cooking time required by each is correct, then many plant resources would be cooked in rock facilities, especially in the absence of ceramics vessels. Conversely, the majority of meats would be prepared in hearths with little or no rock. Wandsnider's (1997) search of the ethnographic literature revealed a series of case studies that seem to support aspects of this general relationship. Seventy six percent (55 of 72) of the facilities used to cook plants contain heated rocks, while in the majority of cases ( 75 percent) facilities used to prepare animal tissue do not contain rocks. Given the ethnographic support for the relationship between cooking facilities and the cooking of plant or animal tissue, the number of hearths with rock in a component could serve as a proxy indicator of the relative importance of plant resources in prehistoric hunter-gatherer diets. 
Clearly, several complications are associated with this proxy. Obviously, hunters and gatherers can use thermal features in general, and thermal features with rock in particular, for a variety of activities, some of which may have little or nothing to do with cooking. Furthermore, cooking may frequently involve both plant and animal remains. In addition, the development of ceramics, which allow direct fire cooking, may make the interpretation of patterns in the Terminal Late Prehistoric difficult. Finally, the number and size of thermal features within a given component may be responding to a variety of other factors. These minimally may include (1) the size of the area excavated, (2) the size of the inhabiting population at a location, (3) the level of reoccupation, and (4) the way that cooking activities are organized (e.g., communal cooking versus individual household). Despite efforts to lessen these impacts on the proxy measures, the association of burned rock features with plant processing is still tenuous. Furthermore, some features with burned rock, especially those with small quantities of rock, could easily represent general-purpose activities where a variety of plants and animals were prepared. Nevertheless, features with significant quantities of rock are probably associated with long-term cooking, and, as the ethnographic data demonstrate, longterm cooking is a requirement for many different types of plant resources.

In order to correct for differences in the nature of the cooking activities (communal versus individual food preparation), the feature size and shape were recorded for each component at sites in the study region. Calculating feature area from length, width, and shape data also ameliorated the impact of differences in the number of inhabitants. This is important, as larger populations would likely generate either more hearths, or larger hearths, relative to smaller groups of hunters-gatherers. Furthermore, in most cases, data on the size of the excavation area associated with a given component was available which allowed a calculation of the number of rock features per square meter of excavated space, as well as a measure of the relative amount of that space devoted to burned rock features. Both of these values should increase as plants become increasingly common in the diet due to falling bison densities.

Greater dependency on plants would likely include a greater variety of plants in the diet. Such expansion may have led to increased variety in feature types if the plants used required increased variety of processing techniques. For example, prehistoric hunters and gatherers might use variable quantities of rock to generate different quantities of heat in order to process specific types of plants (e.g., sotol vs. acorns) or different quantities of plants (see Black 2003; Ellis 1997). Feature variety may then be suitable as a measure of plant variety. To track this relationship and identify feature types, a feature typology of thermal features beyond the presence or absence of rock was developed from the feature data collected at 41KM69 using area and total rock weight independently, as well as in a bivariat plot. Flotation analysis and lipid residue analysis of burned rock (Malainey 2000; Marchbanks 1989; Quigg et al. 2002) served as independent assessments of the features types.

The feature typology was based on data recorded from 41KM69 excavations. Additional data was then compiled from a literature review of sites in the study area (see Figure 9-15) for the two Late Archaic and two Late Prehistoric periods to search for data on feature size and rock weight. The published data allowed examination of trends in feature types and provided a way to test whether an increased variety of feature types was present during conditions of diet expansion. In combination with measures of the number of rock features per square meter of excavated space, and the relative amount of that space devoted to burned rock features, the variety of feature types provided an adequate measure of plant dependence both at $41 \mathrm{KM} 69$, as well as throughout the study area, during these time periods.

\section{Plant Resources: Results of Feature Studies}

Forty-six burned rock features were recorded during excavations at site 41 KM69 (see Table C-1, Appendix C). Generally, during field excavations, measurements of feature elevation, length and width were taken, the shape of the plan view was noted, and a profile was drawn at the line of bisection. This field data was compiled with provenience information and temporal association. Additional burned rock analysis of the thermal features included measurements of individual rock weight, count, and size. This data was then used to develop a typology with which to examine other features from sites across the region (Table C-2). Published site reports from the study area were reviewed for similar data to create another spreadsheet listing all the feature data compiled from all the sites that fit the geographical and temporal parameters of the study (Table C-3). A description of the typology and the relationship between features and diet across the study area are discussed below.

\section{Developing a Feature Typology at 41KM69}

The development of a feature typology with the 41KM69 data set was guided by previous work conducted by Ellis (1997) and Wandsnider (1997). Relying on ethnographic patterns, as well as characteristics of certain groups of plants, these researchers suggest that plant resources such as bulbs, roots, and tubers often contain compounds (e.g., inulin) that are not easily digestible by humans without extended cooking. As a 
result, these classes of plants require extended cooking times to convert the indigestible starch compounds to digestible resources. Ethnographically, cooking times for plants commonly exceed those for animals, and while rock features are used to process both plants and animals, rock is disproportionately more common in plant processing (Wandsnider 1997). The addition of rock to thermal features will increase heat storage and increase the length of time over which heat dissipates from a hearth. Thermal features without rock are adequate for the preparation of foods that require short cooking times or foods that are cooked in containers such as ceramics. However, when lengthier cooking times are necessary, a condition that correlates with high starch plants, the use of rocks to increase heat storage and lengthen heat dissipation is common (Ellis 1997; Wandsnider 1997).

The initial distinction suggested by these earlier studies is between features with rock, and those represented only by stains. Experimental data measuring temperatures over time in a series of features with and without rock clearly demonstrate that the addition of rock does significantly increase heat storage, and lengthen the time over which high temperatures are present, when contrasted to features that lack rock (see Mauldin et al. 1998). Beyond this initial distinction between features with and without rock, the feature typology further divides the features with rock into classes of features that may implicate the types of plants processed. The rock feature database from the data recovery and testing efforts at 41KM69 contains 38 features with complete data on number of rock, weight of rock, feature size, and temporal assignment (see Table C-1, Appendix C). While several of these cases lack data on feature cross-section, these 38 cases form the core data set for this discussion.

Initially, the focus was on the total weight of rock within a given feature using the 41KM69 data set. Given the argument that the addition of rock is related to increasing heat storage and dissipation times, features with small quantities of rock will have different storage and dissipation patterns than those with larger rock weights. Figure 12-10 presents a histogram of the rock weights at a feature level for the 41KM69 rock feature data. There are three groups within this distribution. The first consists of 31 features with overall weights falling below $15 \mathrm{~kg}$. Four features with weights between 15 and 20 $\mathrm{kg}$ represent the second group, and the third group is represented by three hearths, all of which have weights in excess of $20 \mathrm{~kg}$.

Not surprisingly, the tri-partied distinction based on feature weight is closely related to the number of rocks present in a given feature. For the initial weight group, those with weights below $15 \mathrm{~kg}$, the average number of rock present is 26.1 $(\min =6 ; \max =105)$. The second group has, on average, 53.5 rocks $(\min =39$; $\max =78)$, while the heaviest feature group averages 115.7 rocks $(\min =91 ; \max =130)$.

Figure 12-11 presents a box plot of the areas, in $\mathrm{cm}^{2}$, for these three feature weight groups. There is a clear distinction between the smallest weight group (designated " 1.00 " in the figure) and the two larger weight groups. However, there is no difference in feature size between the two largest weight groups. Coupled with the patterns in numbers of rock per feature group

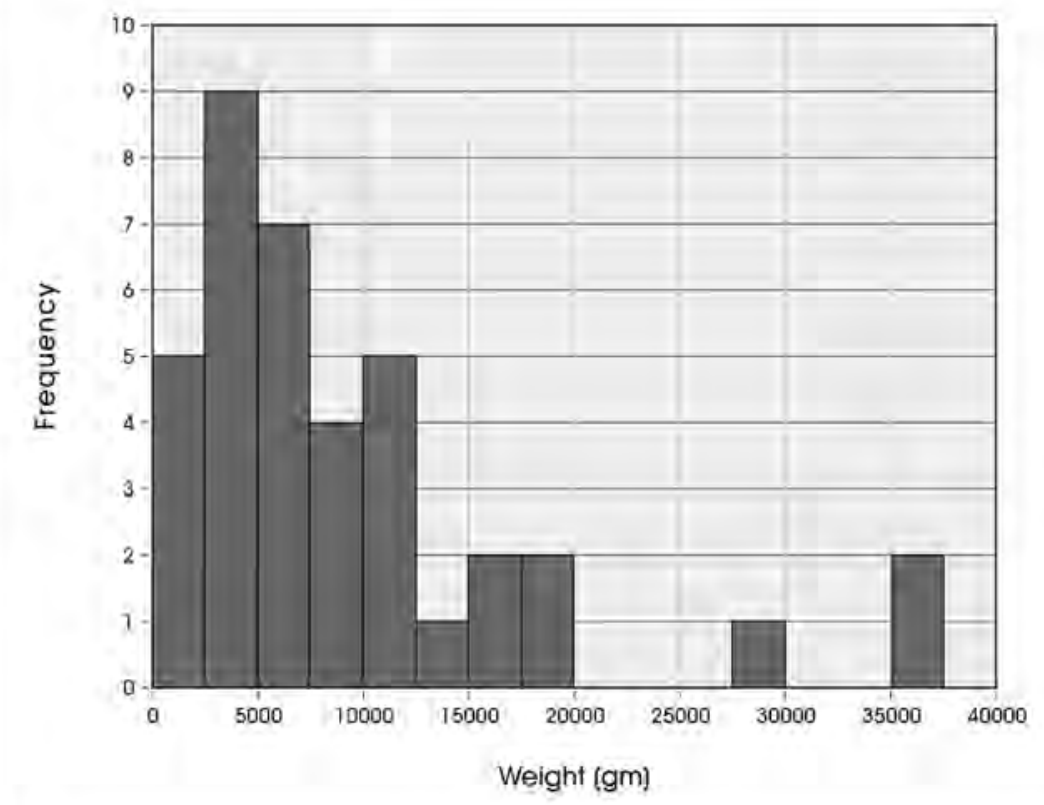

Figure 12-10. Frequency of features by feature weight for 41 KM69 dataset. 


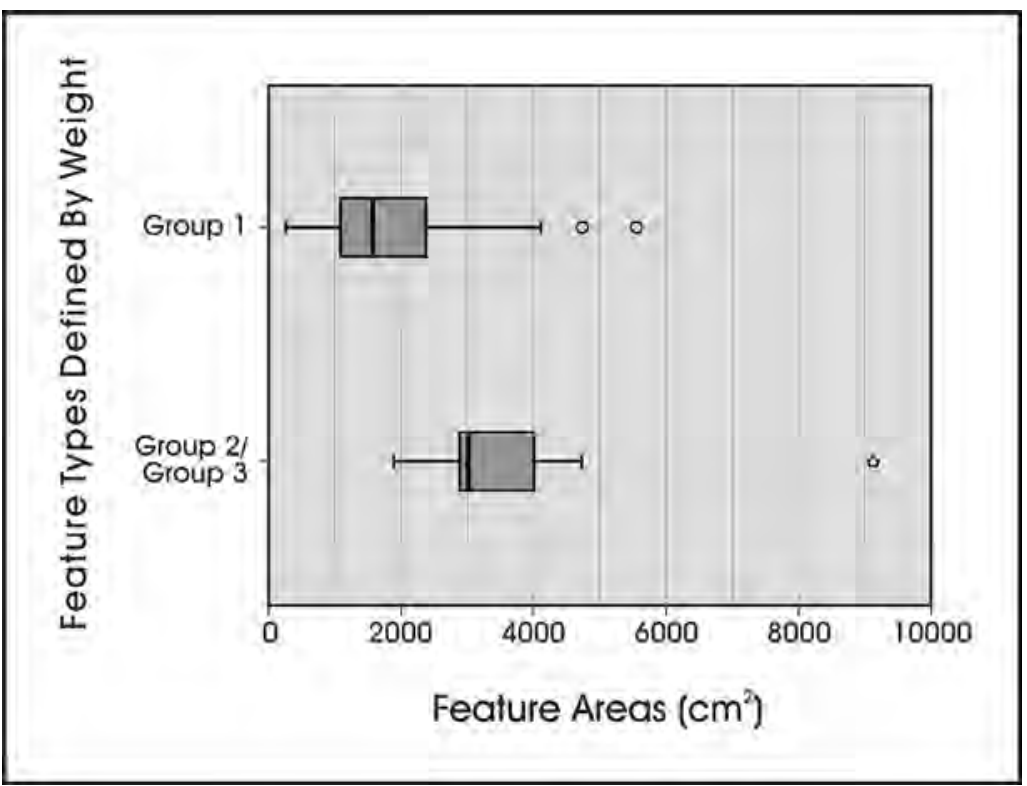

Figure 12-11. Box plots of feature area for the Group 1 (1.00) and Group 2/3 (2.00) features types.

outlined above, the lack of distinction in area between Groups 2 and 3 suggests that Group 3 features have more rock and more weight present in roughly the same space as the Group 2 features. For rock weight, this concentration can be seen by dividing the rock weight of a feature by the area of that same feature. Features in Group 3 have, on average, 9.9 grams of rock for every square $\mathrm{cm}$ of surface space, almost twice that of the Group 2 features $\left(5.5 \mathrm{gr} / \mathrm{cm}^{2}\right)$. This higher rock density in the Group 3 features, both in terms of numbers and weight, should produce a significant heating advantage beyond that gained by the addition of rock weights as such. That is, significantly more and heavier rock in roughly the same space should produce an added thermal advantage for this third group. However, this pattern may also reflect differing frequencies of reuse, with
Group 3 features having a higher frequency of reuse relative to group 2 features. Data that does, in fact, support this suggestion is presented subsequently.

Finally, a consideration of temporal patterns within the weight groups at $41 \mathrm{KM} 69$ is presented. Table 12-4 presents a contingency table contrasting the occurrence of rock features by feature group for these four time periods. The table includes standardized adjusted residuals for each cell. Adjusted residuals are analogous to $\mathrm{Z}$ scores in a normal distribution such that an absolute value of 1.95 is statistically significant at the .05 level of probability (see Haberman 1973; Everitt 1977). While the number of expected cases in many cells is small, examination of the adjusted residual values in Table 12-4 shows one significant value $(\mathrm{AR}=2.0)$ for the feature Group 3 and Terminal Late Prehistoric period cell. There are significantly more Group 3 features in the Terminal Late Prehistoric than would be expected given row and column totals.

\section{Additional Considerations: Feature Area and Rock Size}

Group definition by weight and size is problematic because it does not account for rock size. Therefore, because this feature study is directly related to food processing, a consideration of each Group in terms of rock density and size is important as those aspects point to feature reuse and help refine the typology.

The lightest group (Group 1) consists of 31 features that are small in size, with an average area of $1,885 \mathrm{~cm}^{2}$. If circular,

Table 12-4. Feature Weight Groups by Temporal Period (significant Adjusted Residual values in BOLD)

\begin{tabular}{|c|c|c|c|c|c|c|c|}
\hline & & & \multicolumn{4}{|c|}{ Period } & \multirow{2}{*}{ Total } \\
\hline & & & MLA & TLA & ILP & TLP & \\
\hline \multirow{6}{*}{$\begin{array}{l}\text { Weight } \\
\text { Groups }\end{array}$} & \multirow[b]{2}{*}{1} & Count & 9 & 6 & 10 & 6 & 31 \\
\hline & & $\begin{array}{l}\text { Adjusted } \\
\text { Residual }\end{array}$ & 0 & 0.3 & 0.2 & -0.5 & \\
\hline & \multirow[b]{2}{*}{2} & Count & 2 & 1 & 1 & 0 & 4 \\
\hline & & $\begin{array}{l}\text { Adjusted } \\
\text { Residual }\end{array}$ & 1 & 0.4 & -0.3 & -1.1 & \\
\hline & \multirow[b]{2}{*}{3} & Count & 0 & 0 & 1 & 2 & 3 \\
\hline & & $\begin{array}{l}\text { Adjusted } \\
\text { Residual }\end{array}$ & -1.2 & -0.9 & 0.1 & 2 & \\
\hline \multicolumn{2}{|c|}{ Total } & Count & 11 & 7 & 12 & 8 & 38 \\
\hline
\end{tabular}


this would represent a feature roughly $49 \mathrm{~cm}$ in diameter. On average, about 26 rocks are present, with a weight of $6.19 \mathrm{~kg}$. These small features could have been used for the preparation of a variety of different low starch plants, as well as small packages of meat. The second group of features is over twice as large (average area $=4,300 \mathrm{~cm}^{2}$ ) as the first, with roughly twice the number of rock and almost three times the average weight $($ mean $=17.6 \mathrm{~kg})$. The features in this type, along with features in Group 3, appear to be likely candidates for the processing of plant foods with moderate or high amounts of starch (e.g., geophytes). The third group is smaller than Group 2 (average area $=3,500 \mathrm{~cm}^{2}$ ), but contains both higher weights (mean $=3.36 \mathrm{~kg}$ ) and numbers of rock (ca. 116 rocks). The distinction between Group 2 and 3 may reflect differing levels of reuse, rather than different feature types.

Rock size may help support the idea that Groups 2 and 3 differ primarily as a function of reuse frequencies. As features are reused, an increasing number of smaller rocks should be generated as a function of rock breakage and replacement. While cleaning of features may obscure this pattern, and while this dataset only includes sizes for rocks greater than $2.54 \mathrm{~cm}$, hearths with few uses should be dominated by larger rock, while those with multiple uses should have distributions increasingly dominated by small rocks. To investigate this, individual histograms of rock distribution with similar scales and bin sizes for each of the features in Groups 2 and
3 were constructed. An example of a Group 3 feature is provided in Figure 12-12, while Figure 12-13 provides a Group 2 example.

Comparisons of the two figures clearly suggest that for these particular features, the Group 2 example is dominated by rocks in the larger size range $(+9 \mathrm{~cm})$, while for Feature 3 (Group 3), most of the rock is substantially smaller. The dominance of rock in the smaller ranges, a pattern consistent with high frequencies of reuse, is present in both of the remaining Group 3 features. Conversely, three of the four features in Group 2 have rock distributions similar to the Figure 12-13 example. The lone exception is Feature 36, which has a distribution pattern between those shown in Figures 12-12 and 12-13.

Figure 12-14 presents a line graph of the percentage of rock in $1 \mathrm{~cm}$ size classes for all Group 2 and Group 3 features. The Group 2 curve represents 212 individual rocks from all four Group 2 features (\# 36, 42, 45, 48). The Group 3 pattern is derived from 342 rock measurements for the three features (3, $5,10)$ that make up this group. The pattern clearly suggests that Groups 2 and 3 are unlikely to represent different types, at least with regard to food processing. The patterns seen in both overall weight differences, as well as differences in the number of rock, appear to be a function of differing levels of reuse. For subsequent analysis, these groups are considered identical, at least with respect to the typology developed here.

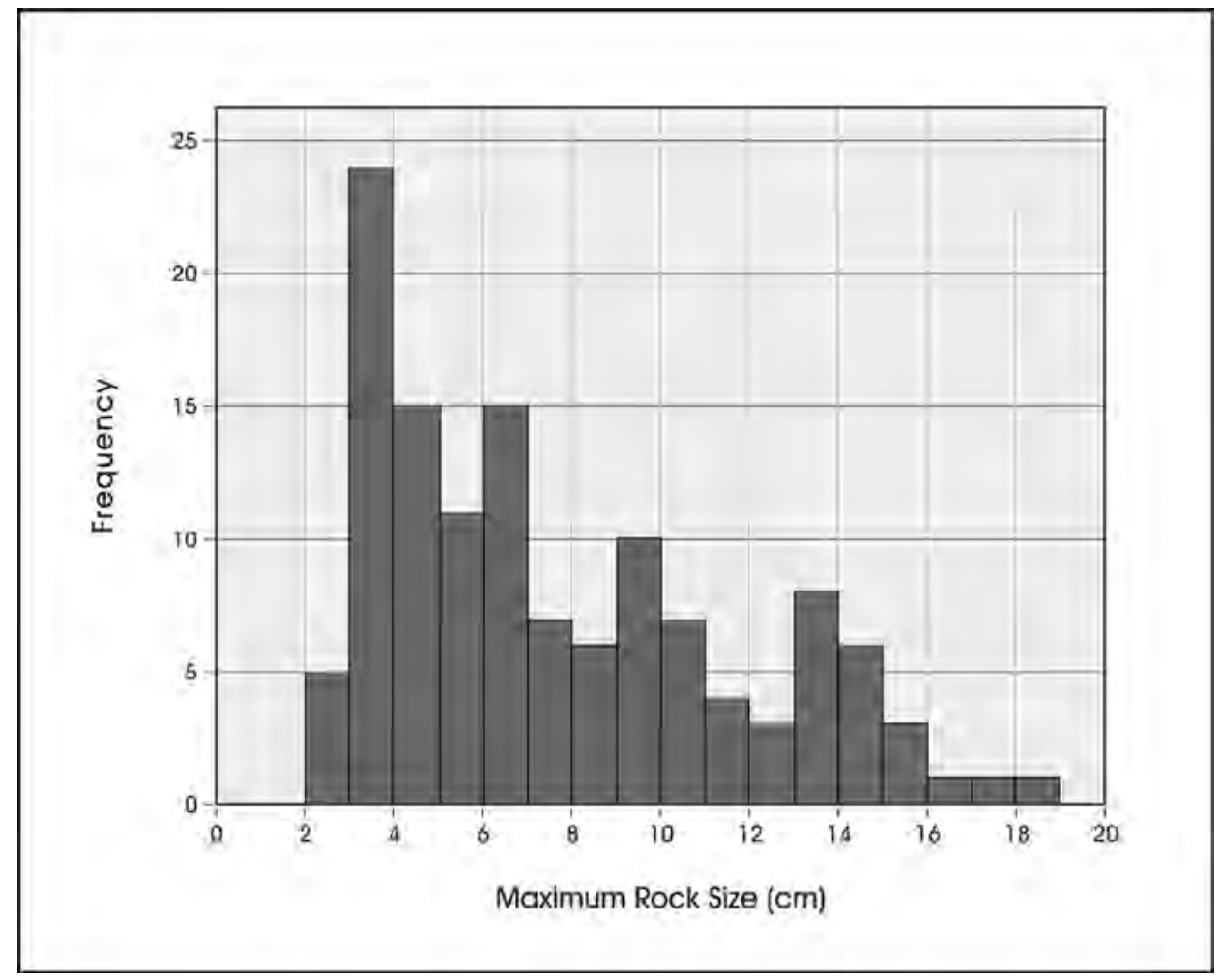

Figure 12-12. Maximum size (cm) of rock in Feature 3 (Group 3). 


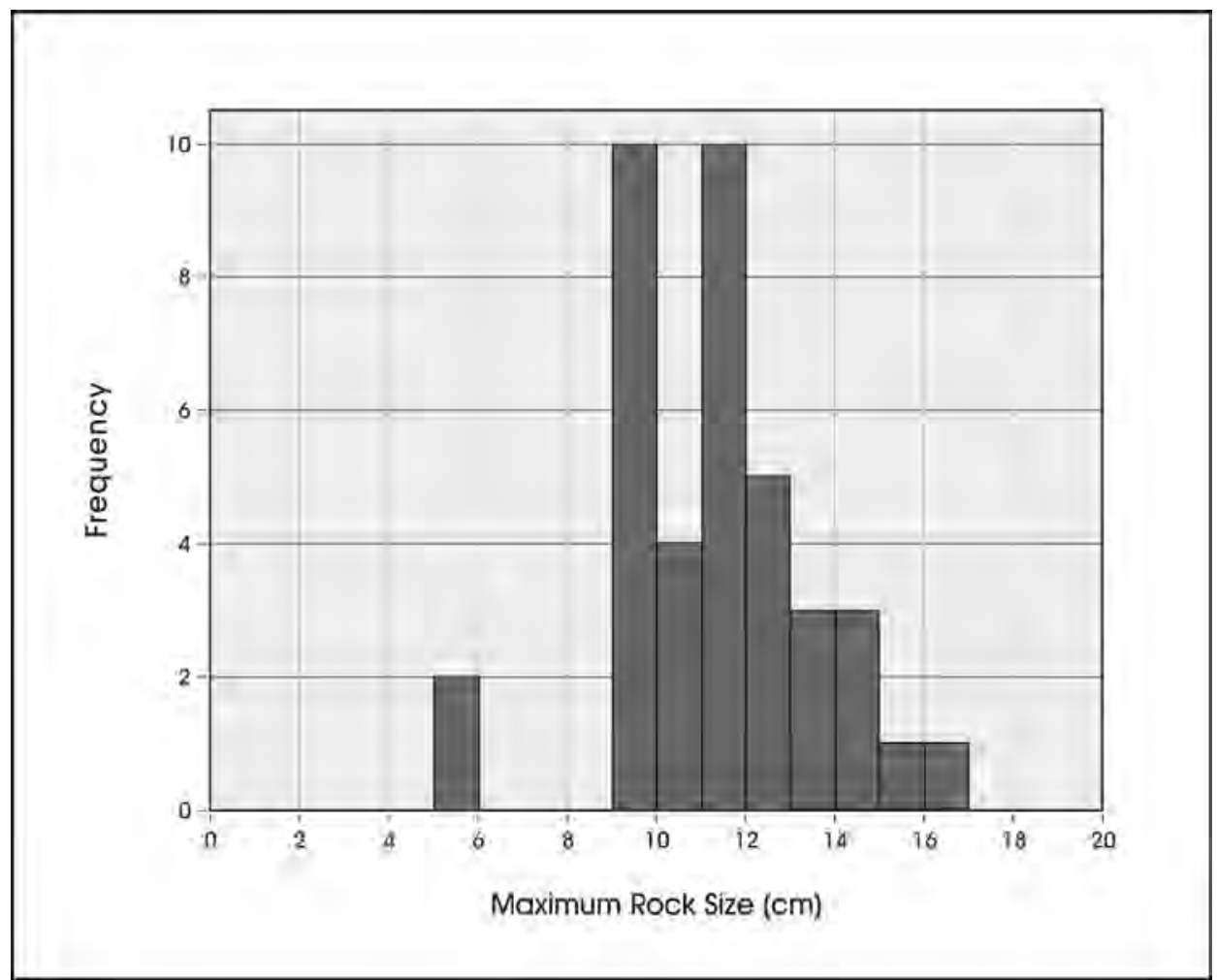

Figure 12-13. Maximum size (cm) of rock in Feature 45 (Group 2).

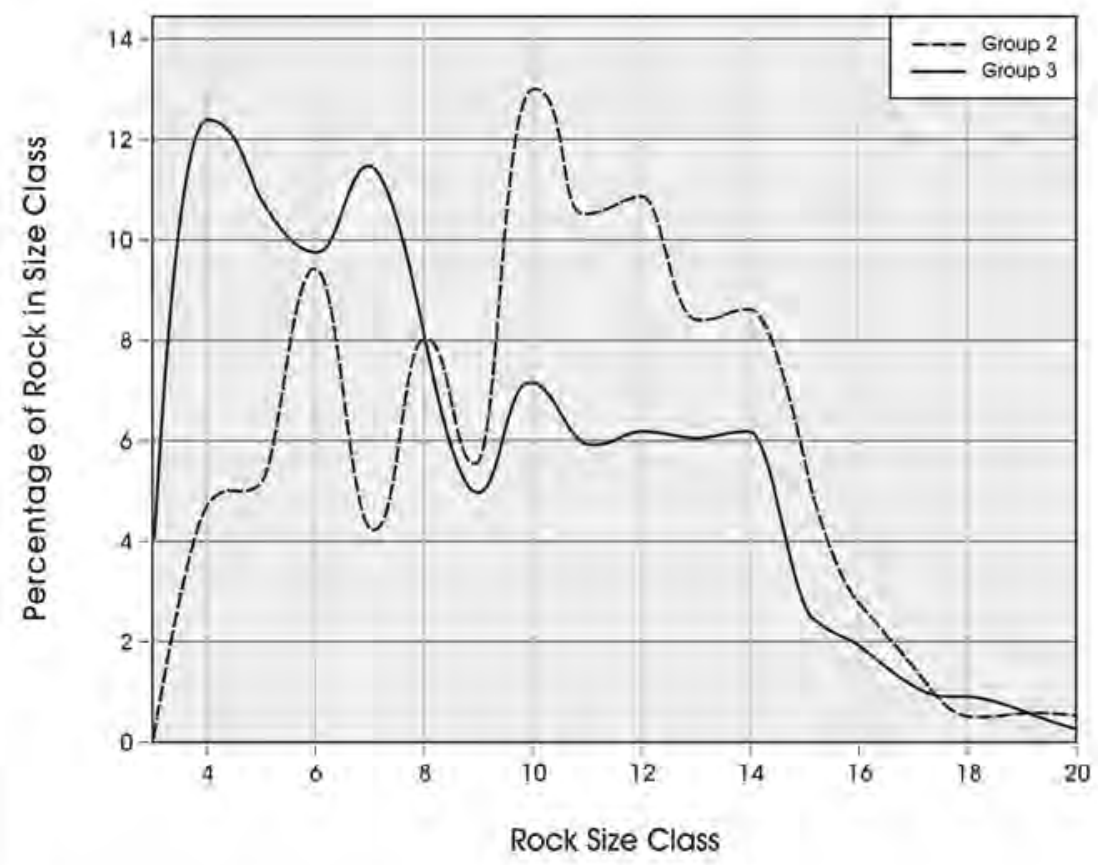

Figure 12-14. Rock size percentages for Group 2 (dashed) and Group 3 (solid) features at 41 KM69. 


\section{Burned Rock Midden Group, Feature 1}

Three different types of features that may reflect, at a broad level, different types of food processing activities have been identified. These are features without rock, small features with low rock weights (Group 1) and moderate sized features with rock weights greater than $15 \mathrm{~kg}$, and less than $40 \mathrm{~kg}$. At $41 \mathrm{KM} 69$, however, there is a final thermal feature type represented by Feature 1, a burned rock midden. This feature was not fully excavated, and so was not included in our discussion up to this point. However, there is some rock size data from this feature that can be used to explore this final type.

Controlled excavations in Feature 1 at 41KM69 were limited to a single, L-shaped trench consisting of $121-\mathrm{x}-1 \mathrm{~m}$ units within the feature. For each unit, field workers recorded the number of burned rock greater than 1 inch in size, size graded those rocks in 1 inch increments, and recorded the volume of FCR less than 1 inch. Unfortunately, the excavation of Backhoe Trench 5 during testing may have removed any central feature. Figure 12-15 shows a plan view and profile drawing of the excavation, and provides a probable outline of the southwestern quadrant of this large feature. Also identified in the figure is a probable location of a central feature, the repeated use of which may have resulted in the overall distribution of burned limestone and dark sediment that defined the larger feature. The proposed location of this central feature relies both on the depth of the staining and rock, as well as on the break in the underlying $\mathrm{Ab} 1$ and $\mathrm{Ab} 2$ soils as seen in the profile (Figure 12-15). Previous work on burned rock middens (see Black et al. 1997; Mauldin et al. 2003) suggest

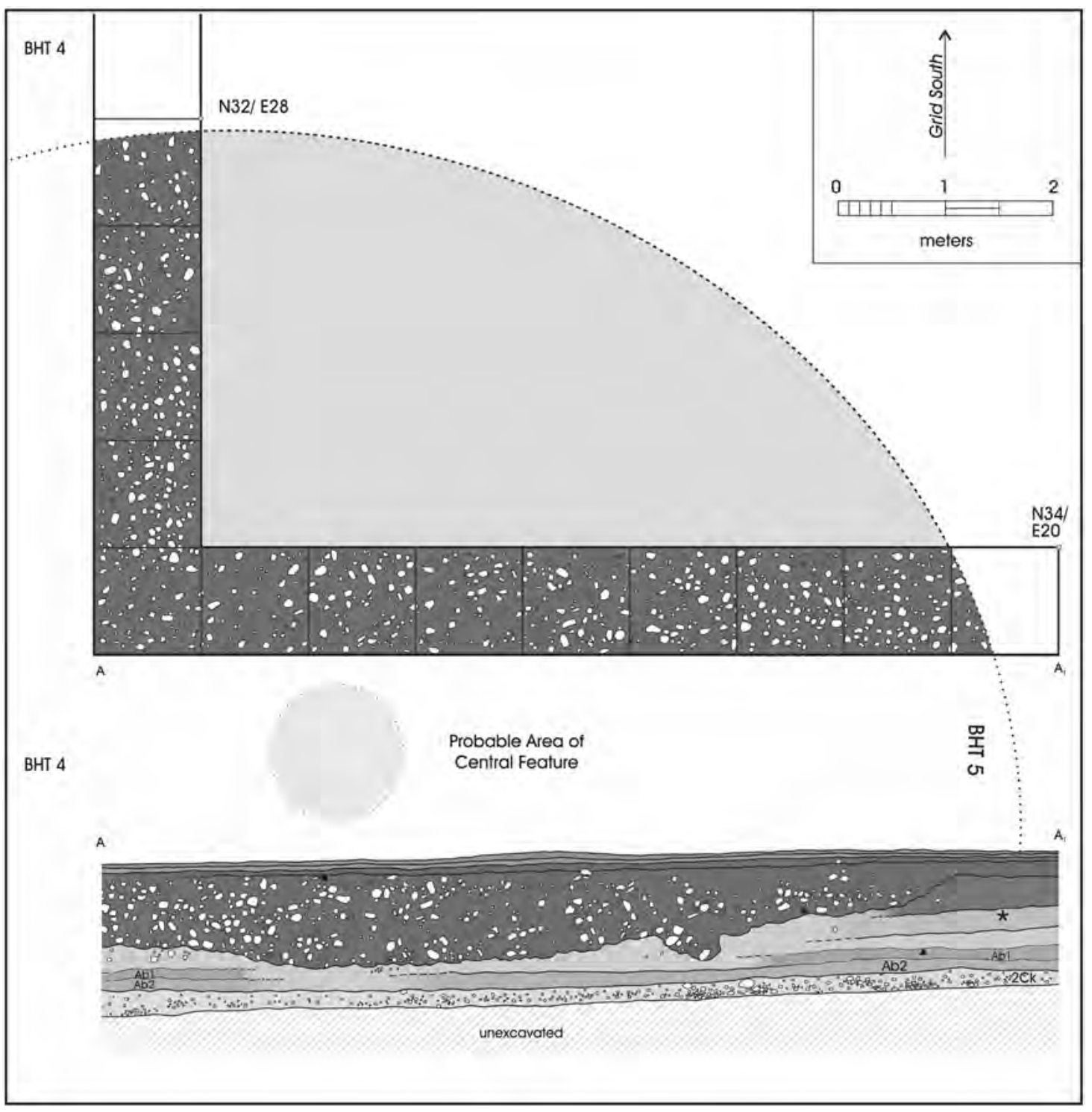

Figure 12-15. Feature 1 plan and profile drawing. 

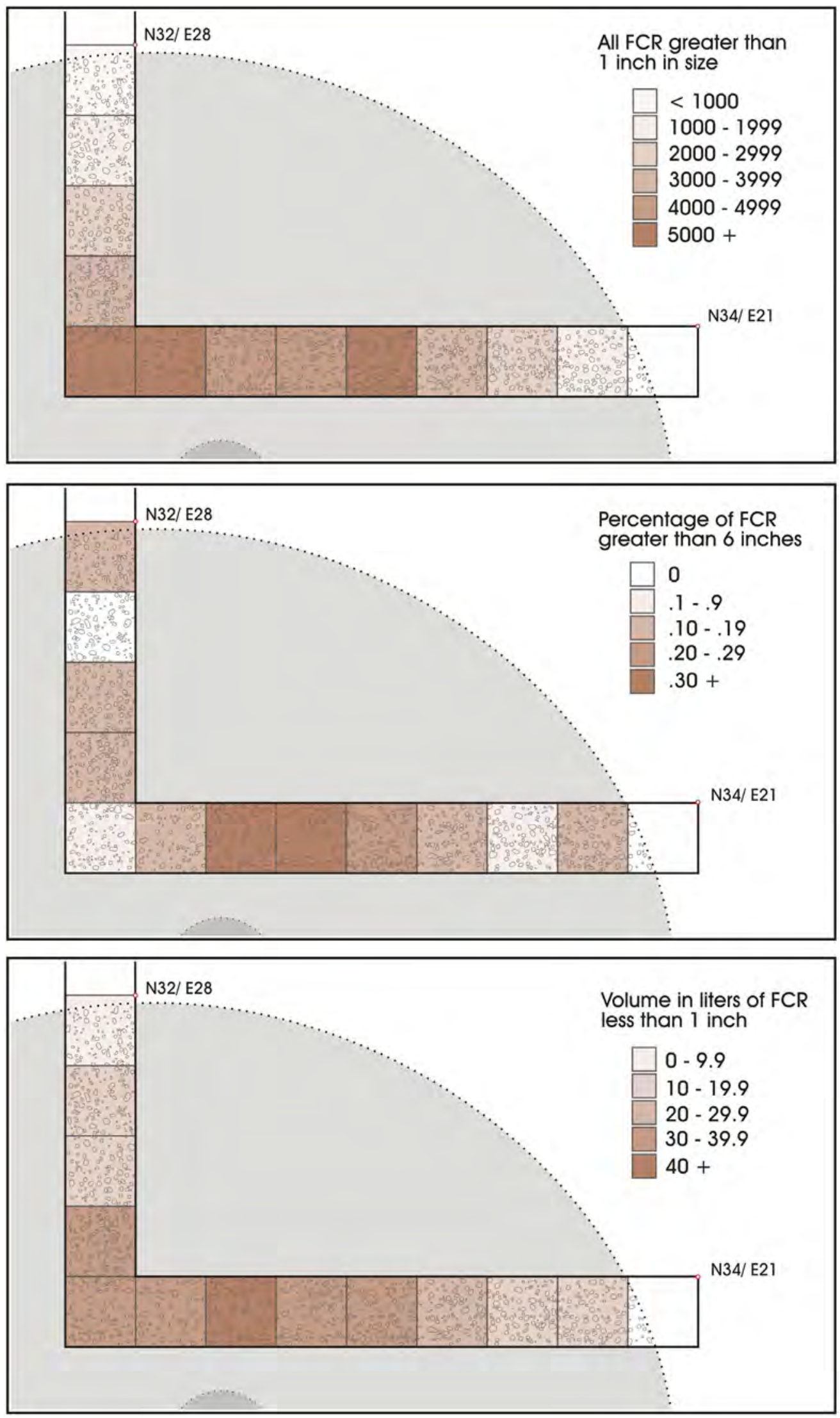

Figure 12-16. Burned rock distributional data from Feature 1, 41 KM69. 
that the repeated use of a central baking feature over a significant time frame results in the large accumulations of fire cracked rock.

Patterning in rock size in these features can be anticipated as a result of repeated use, cleaning, and rock replacement (Mauldin et al. 2003). Figure 12-16 provides a series of plan views that show distributional data on all rock greater than 1 inch in size (top), the percentage of large ( +6 inches) rock (middle), and the total volume of rock less than 1 inch in size (bottom), in order to consider such patterning relative to the proposed central feature location.

The top plan view in Figure 12-16 clearly suggest that burned rock densities near the center of the large feature are significantly higher, with the highest densities occurring to the southwest and southeast of the proposed central feature location. The central plan view shows that with regard to larger rocks, the highest densities are in N34/E25 and N34/E26, and the distribution of rock less than 1 inch in size shows the highest volumes in N34/E26. These patterns are consistent with differential removal of rocks in the range of 1 to 6 inches from a central feature and replacement of that shattered rock with larger stone. Such activity would result in a high density of rock, dominated by 1 to 6 inch stone, forming a ring around the central feature, as well as an accumulation of both small $(<1$ inch) and large ( $>6$ inch) sized stones near the central pit (Mauldin et al. 2003). Given the profile evidence (Figure 12-15), the rock distributional patters are consistent with the presence of a small central feature that is repeatedly used. Flotation results from Feature 1 found several wood species including oak, walnut or pecan, elm, and woody legumes. The only edible plant remains found were pecan, though work elsewhere strongly suggest that these features are designed to process high starch plants foods (e.g., onion and camus bulbs, sotol and agave hearts) requiring long term baking for effective human digestion (Black et al. 1997; Mauldin et al. 2003; Dering 2003).

\section{Feature Typology Conclusion}

A feature typology was developed using feature data from excavations at 41KM69 to explore the relationship between feature type and food processing. The typology could be used to identify increased use of plants throughout the Late Archaic and Late Prehistoric as diet expanded to include additional lower ranked foods like plants. Recognizing the use of an increasing number of plant species in the prehistoric diet is plagued by poor preservation in open air sites on the Edwards Plateau. The authors suggested that more varied use of features in terms of size, rock density, and rock size might be used as a proxy indicator of a diet expanding to include plant foods requiring a range of cooking requirements. These cooking requirements would require different cooking facilities (thermal features) that would be recognizable in the archeological record. The previous section outlined the feature typology that originally identified three groups. Group 1 included small features likely used for small meat packages and low starch plants that would require relatively short cooking times. Groups 2 and 3 included large features likely used for cooking very large quantities of meat or starchy plants like geophytes that need long cooking times. A refinement of the typology examining rock size found that Groups 2 and 3 were essentially used for the same purposes and the differences in rock weight merely reflected degree of reuse. These were combined into one Group referred to as Group 2/3.

The next sections discuss the findings of the lipid residues found on a sample of feature rock and the identification of botanical remains in the light fraction of features excavated from $41 \mathrm{KM} 69$ and how they support or counter the feature typology.

\section{Lipid Residue Analysis}

Three rocks from each of six archeological rock features and eight experimental samples were submitted to Dr. Mary Malainey for lipid residue analysis. Lipids are abundant in plants and animals, and different groups of plants and animals have fatty acids with different molecular structures. These varying molecular signatures of fatty acids seem to be identified in archeological situations (e.g., Quigg et al. 2002). Researchers have developed several broad groups of plant and animal signatures based on fatty acid composition of modern plants and animals, and while some overlaps exist, lipid analysis can sometimes provide an additional clue to determining the range of plants or animals processed in rock features at the site.

The experimental data, in combination with the residue results from features at $41 \mathrm{KM} 69$, and the flotation analysis, were conducted to provide an independent assessment of the feature typology based on rock weight and size attributes. Discussion of the modern sample results follows the results of the archeological sample results. Dr. Malainey's report is reproduced in Appendix D.

\section{The Archeological Samples}

Burned rock was submitted from six features excavated during data recovery at 41KM69: two from the Middle Late Archaic component (Features 35 and 42), one from the Terminal Late Archaic component (Feature 49), two from the Initial 
Late Prehistoric component (Features 45 and 47), and one from the Terminal Late Prehistoric component (Feature 82). Features 42 and 47 had insufficient lipid residue for analysis, which left one feature from each component available for analysis, though Feature 49 had "low residue." All rock features analyzed were from the Group 1 Feature Typology except Feature 45, which was from Group 2/3.

All rock samples returned lipid residue analysis consistent with plants except Feature 82, from the Terminal Late Prehistoric. This residue produced results found in large herbivore products like bison, deer, moose, fatty elk meat, bovines or cervids, as well as javelina. Feature 45 returned lipid residue results similar to that found in medium fat level foods and low fat plants like freshwater fish, terrapin, Rabdotus, mesquite beans, corn, and cholla.

These results, though limited in the number of features examined, support the ethnographic data that most facilities used to cook plants contain rock because of their extended cook times. Likewise, large meat packages, such as some of those described in the Feature 82 lipid analysis would also require long cooking times (see Figure 12-9). The mixed nature of the results from Feature 45 having both plant and animal residue is in line with the idea that Group 2/3 features have seen more reuse than Group 1.

The lipid residue results do not apply to the idea that plant use intensified during the Terminal Late Prehistoric because only one feature from each component was tested. There is no trend in increased use of plants as all samples returned lipid residues with plant processing, except the one sample from the Terminal Late Prehistoric.

\section{The Modern Samples}

The analysis of lipids from archeological specimens, first used by Condamin et al. (1976) and recently expanded through the work of Marchbanks (1989), Skibo (1992), Loy (1994), and Malainey (2000), is becoming increasingly common in Texas. However, CAR knows of no blind tests of the method conducted within the state and therefore developed samples for such a blind test over the years preceding this study in order to test samples of a known history. Eight sandstone samples were submitted from the same parent slab (Table 12-5). All samples were from the same parent rock

Table 12-5. Experimental Sample Treatment

\begin{tabular}{|c|c|c|c|c|c|}
\hline Lab No. & Sample \# & Description & $\begin{array}{l}\text { Residue } \\
\text { Exposure }\end{array}$ & $\begin{array}{c}\text { Oven } \\
\text { Storage }\end{array}$ & Sample Size (g.) \\
\hline DUT 1 & 1 & $\begin{array}{l}\text { Heated and } \\
\text { buried }\end{array}$ & & $\begin{array}{c}\mathrm{BU}-45 \\
\text { days at } 75^{\circ} \mathrm{C}\end{array}$ & 18.847 \\
\hline DUT 2 & 2 & $\begin{array}{l}\text { Heated and } \\
\text { buried }\end{array}$ & & $\begin{array}{c}\mathrm{BU}-45 \\
\text { days at } 75^{\circ} \mathrm{C}\end{array}$ & 21.804 \\
\hline DUT 3 & 3 & $\begin{array}{l}\text { Heated and } \\
\text { buried }\end{array}$ & & $\begin{array}{c}\mathrm{BU}-45 \\
\text { days at } 75^{\circ} \mathrm{C}\end{array}$ & 29.092 \\
\hline DUT 4 & 4 & $\begin{array}{c}\text { Not heated/ not } \\
\text { buried }\end{array}$ & & $\begin{array}{c}\mathrm{BU}-45 \\
\text { days at } 75^{\circ} \mathrm{C}\end{array}$ & 29.593 \\
\hline DUT 5 & 5 & $\begin{array}{c}\text { Heated } 1 \text { hour } \\
\text { @ } 500^{\circ} \mathrm{C} \text {, not } \\
\text { buried }\end{array}$ & & $\begin{array}{c}\mathrm{BU}-45 \\
\text { days at } 75^{\circ} \mathrm{C}\end{array}$ & 31.484 \\
\hline DUT 6 & 12 & $\begin{array}{c}\text { Boiled in water } \\
1 \text { hour }\end{array}$ & Mesquite & $\begin{array}{c}\text { UTSA }-1 \\
\text { year at } 75^{\circ} \mathrm{C}\end{array}$ & 41.075 \\
\hline DUT 7 & 13 & $\begin{array}{c}\text { Boiled in water } \\
1 \text { hour }\end{array}$ & $\begin{array}{c}\text { Prickly Pear/ } \\
\text { Mesquite }\end{array}$ & $\begin{array}{c}\text { UTSA }-1 \\
\text { year at } 75^{\circ} \mathrm{C}\end{array}$ & 20.498 \\
\hline DUT 8 & 14 & $\begin{array}{c}\text { Boiled in water } \\
1 \text { hour }\end{array}$ & Prickly Pear & $\begin{array}{c}\text { UTSA }-1 \\
\text { year at } 75^{\circ} \mathrm{C}\end{array}$ & 33.348 \\
\hline
\end{tabular}


and all were heated to $500^{\circ} \mathrm{C}$ for one hour prior to other exposures. This is to effectively destroy any naturally occurring residues. Three sandstone samples (\#s 12-14) were boiled in water containing three different plants for two hours then buried for five years. Sample 12 was cooked with mesquite, Sample 13 with prickly pear and mesquite, and Sample 14 with prickly pear. To "age" the samples they were then placed in an oven for one-year exposure to constant $\left(75^{\circ} \mathrm{C}\right)$ temperature and two years exposure to open-air conditions $(\mathrm{n}=3)$, and finally sealed in plastic bags for three years $(n=3)$. In addition, Sample 4 of the "raw" sandstone was submitted. This item was not exposed to any residues. Sample 5 was heated to $500^{\circ} \mathrm{C}$ for one hour, was not exposed to any plant residues and not buried. CAR submitted these eight samples as an independent, blind-test of the utility of lipid residue analysis.

The results from the experimental samples did not identify residues to a degree relevant to diet breadth research at 41KM69. The study found low fat content fat residue on Samples 1 and 2, though no residue was introduced to them. Sample 3 was found to be blank, consistent with the experimental treatment. Sample 4 was not exposed to any meat or plant residue and not heated or buried, but results returned high fat content food like nuts. Low fat content plant residues were found on Samples 5, 7, and 8. Only Samples 7 and 8 were exposed to plants. The extreme heating of Sample 5 did not serve the purpose of destroying any previous residues left on the rock prior to the experiment. Therefore, any residues identified could not with certainty be explained by cultural behavior. Sample 6 was exposed to mesquite and results suggested it was exposed to unknown plant residues. While this is true, the level of residue identification is not specific enough for use in the 41KM69 research domains.

\section{Botanical Remains from Features}

Sixty-five flotation samples (143.9 liters) from features excavated during data recovery were floated at CAR. The light fractions were submitted to Phil Dering of Shumla Archeobotanical Services in order to identify carbonized seeds or other plant parts that may reflect what items were cooked in the features.

Dering reports sparse but interesting plant remains in the samples (Appendix E). Carbonized plant remains were in 31 of the 63 samples, including wood, fiber fragments, seeds, and nut fragments. Fifteen of the samples Dering finds remarkable for an open air site on the Edwards Plateau. For the purposes of the feature study, the edible plant remains are more useful, though wood types are also discussed in the archeobotanical report in Appendix E. The surprising finds include pecan, acorn, yucca fibers, and wintergrass seeds.

Of the submitted light fractions, 15 contained edible plant remains. Six of these were from typed features. The feature number, the plant remains, the feature group and the component are summarized in Table 12-6. The four Group 1 features here contain pecan and wintergrass. These are all from

Table 12-6. Features with Edible Plant Remains

\begin{tabular}{|c|c|c|c|}
\hline Feature & Edible Items & Feature Group & Component \\
\hline 1 & nut & & ILP \\
\hline 2 & Acorn, pecan & & TLP \\
\hline 16 & Acorn, pecan & & TLA \\
\hline 17 & Pecan, yucca & & TLA \\
\hline 18 & Wintergrass & & TLA \\
\hline 36 & Pecan & 1 & MLA \\
\hline 41 & Pecan & & TLA \\
\hline 47 & Acorn & $2 / 3$ & ILP \\
\hline 52 & Yucca & & ILP \\
\hline 53 & Pecan & $2 / 3$ & ILP \\
\hline 57 & Wintergrass & 1 & ILP \\
\hline 78 & Wintergrass, pecan, yucca & & TLA \\
\hline 82 & Pecan & 1 & TLA \\
\hline 83 & Pecan & 1 & ILP \\
\hline $12,1.3$ & Acorn & & \\
\hline
\end{tabular}


the Middle Late Archaic, the Terminal Late Archaic, and the Initial Late Prehistoric. The two Group 2/3 features contain acorn and pecan and were both from the Initial Late Prehistoric. None of the Terminal Late Prehistoric features returned edible plant remains from the light fractions which make it difficult to say that Terminal Late Prehistoric hunter-gatherers were intensifying their use of plants during the waning availability of bison base on this data alone. The identification of botanical remains in the light fraction of the 41KM69 features does little to support or counter the typology, though it does provide other valuable information rarely found in open air sites.

\section{Summary and Discussion of Feature Typology}

Following early cross-cultural ethnographic work conducted by Wandsnider (1997; see also Ellis 1997), this study proposed that features with rock are more likely to be used in plant processing as some plants, especially those with high starch contents, require significant cooking times to make them digestible by humans. Furthermore, the study suggested that the overall weight of rock should provide a proxy for the thermal characteristics of that feature. Using data from 38 features with rock excavated at 41KM69, along with information on the burned rock midden (Feature 1) at the site, three different rock feature types were identified. These are rock features with overall rock weight below $15 \mathrm{~kg}$ (Group 1), rock features with rock weights between 15 and $40 \mathrm{~kg}$ (Groups 2 and 3), and burned rock middens (Feature 1). Cou- pled with the initial distinction between thermal features with and without rock, these four different feature types are probably used to process different ranges of plants and animals. The study included lipid residue analysis and identification of botanical remains from the 41KM69 features to refine the typology. However, neither provided enough data to definitively assign feature Group Types to plant or animal types.

Note that in our previous discussions of the use of burned rock weights at a feature level as one of several proxy measures to monitor plant dependence, we did not address the potential complication of feature reuse. As seen above (Figures 12-12, 12-13, 12-14, and 12-15), the repeated use of a feature can result in a significant accumulation of rock that is not related to a specific processing event. In fact, it is possible that our Group 2/3 type is simply an under used burned rock midden. This complicates any simplistic association of feature types defined by weight with specific plant types.

An additional complication is that details such as rock weight at a feature level are seldom reported in the literature. As such, the application of this specific typology in our literature review is problematic. While the number of rocks within a feature is sometimes mentioned, size data is generally not provided. Figure 12-17 attempts a solution to this underreporting by focusing on the overall area of the Group 1 and Group 2/3 feature classes. Area is frequently reported in the literature or can be estimated from plan view drawings.

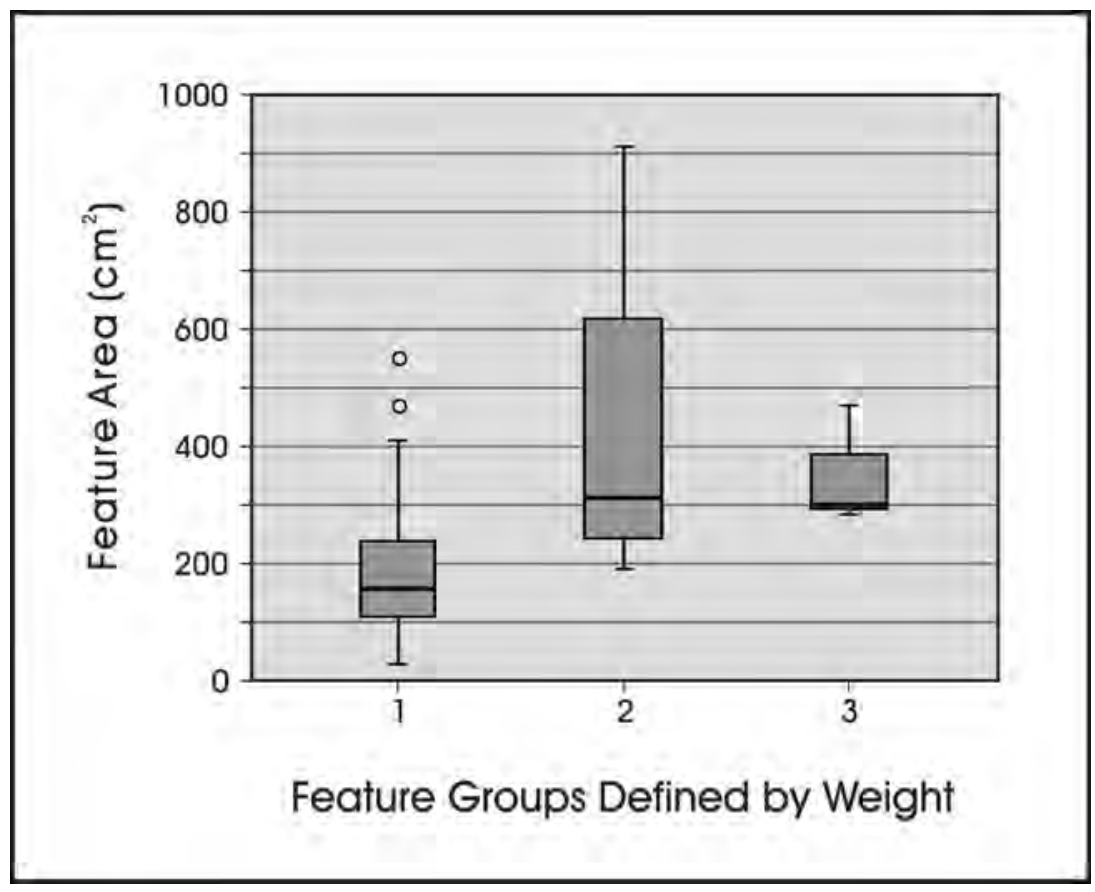

Figure 12-17. Feature area $\left(\mathrm{cm}^{3}\right)$ by weight groups $(1=<15 \mathrm{~kg}, 3=>20 \mathrm{~kg})$. 


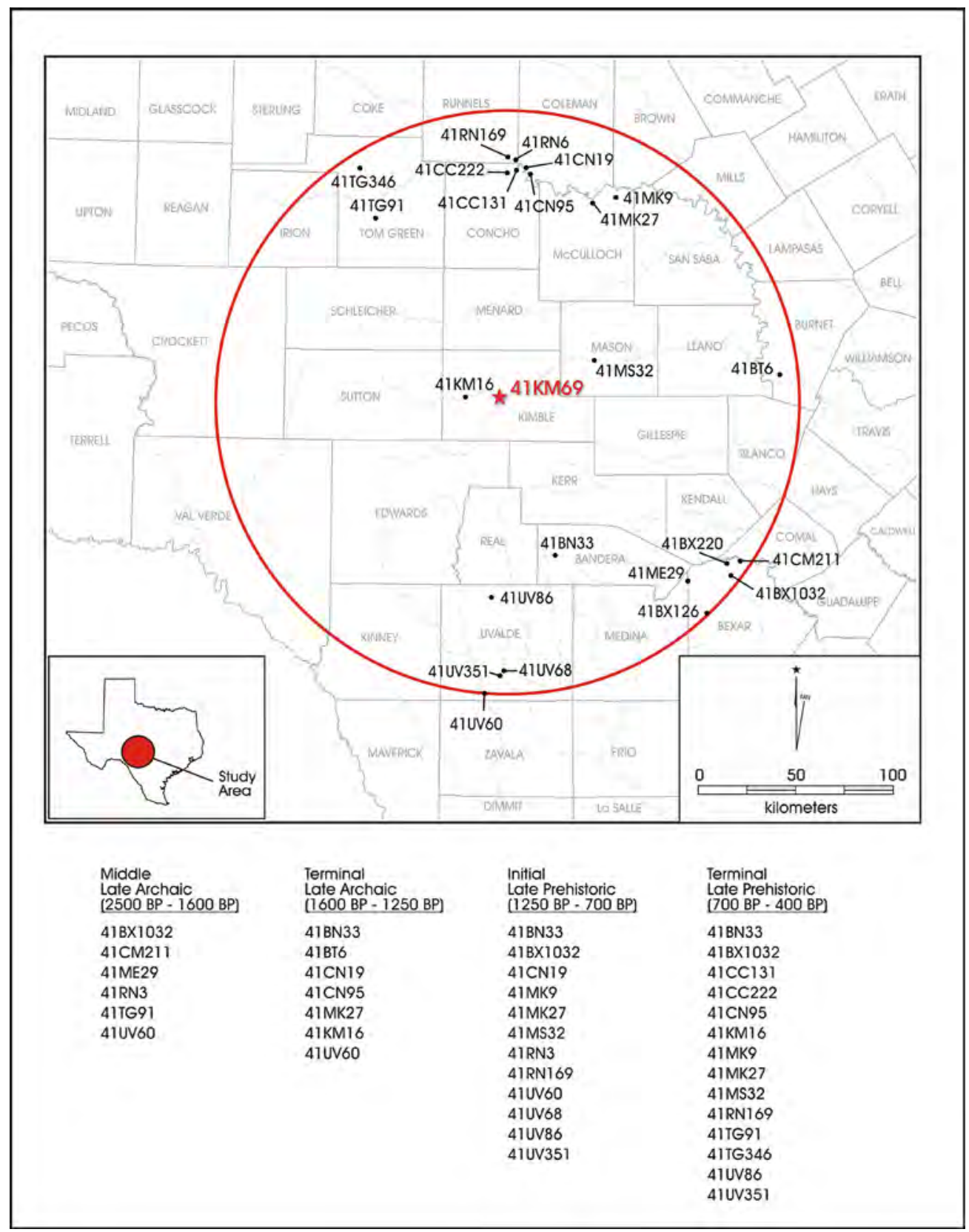

Figure 12-18. 41KM69 and comparative sites used in the regional thermal feature database.

Using the area estimates (Figure 12-17), identification of weight Group 1 membership by focusing on an area break point of $2,250 \mathrm{~cm}^{2}$ is likely to be correct. Of the 31 Group 1 features, 23 (74.2 percent) are correctly placed by reference to this area cutoff. Only a single case of a Group 2/3 feature being incorrectly classified as belonging to Group 1 is present. However, the characterization of a feature as belonging to Group 2/3 based on area is more problematic. While correctly placing six of the seven Group $2 / 3$ cases identified at $41 \mathrm{KM} 69$, the area distinction incorrectly assigns eight Group 1 cases as belonging to Group 2/3. In spite of this high rate of miss assignment, the focus on area, at least for the literature comparison below, is necessitated by the under reporting of critical feature data, such as rock weight, number, and rock size, in the study area.

\section{Literature Review of Regional Trends}

The literature search was conducted of published excavation reports within a $150 \mathrm{~km}$ radius from 41KM69. This included over sixty reports from parts of over twenty counties (Figure 12-18). A list of the reviewed reports is listed in Appendix C. The review began with Kimble County and progressed out- 
ward, to bordering counties and so forth until reaching 150 $\mathrm{km}$. The site inventory and the abstracts of reports for each county in the study area were reviewed as listed on the Texas Archeological Sites Atlas as of June 2007 to find sites that had seen at least a testing level of investigation and had been reported within the specific time periods in question. TxDOTENV also provided copies of all the reports of archeological investigations they had contracted or published within the study area. These TxDOT reports were reviewed along with all relevant reports housed at UTSA and CAR libraries. The reports were read for information on thermal features that had a known temporal association.

Published data on well-dated sites in central Texas is scarce. Limitations were increased by the nature of the data under consideration here. Specifically for the typology development, data recorded included thermal feature size, nature of fill, volume, rock type, rock counts, rock weights, and a solid temporal association. For feature density, reports were reviewed for the volume excavated from the site in each component. Therefore, some sites within the space and time constraints may have been excluded because of poorly recorded or under-reported feature and excavation data. Some of the most extensive excavations were written years after the team left the field by authors who were not involved in the excavations. Though such reports have obvious value, we found they often lack information important to this study. The feature spreadsheet presented in Table C-2 includes only those thermal features that could be assigned to one of the four components defined in the 41KM69 excavations, not all features recorded at the site.

Four components identified at 41KM69 were targeted during the literature review: the Middle Late Archaic, the Terminal Late Archaic, the Initial Late Prehistoric, and the Terminal Late Prehistoric. Twenty-one sites contained thermal feature data in one or more of these time periods (Figure 12-18). Only one site, $41 \mathrm{KM} 16$, was used in Kimble County. Furthermore, only one site with well-published data on features was found in any of the counties bordering Kimble County.

Table 12-7. Feature Counts per Site through Time

\begin{tabular}{|c|c|c|c|c|c|}
\hline Site & MLA & TLA & ILP & TLP & Grand Total \\
\hline $41 \mathrm{BN} 33$ & & 8 & 34 & 35 & 77 \\
\hline 41BT6 & & 11 & & & 11 \\
\hline 41BX1032 & 1 & & 2 & 1 & 3 \\
\hline $41 C C 131$ & & & & 31 & 31 \\
\hline $41 C C 222$ & & & & 3 & 3 \\
\hline 41CM211 & 1 & & & & 1 \\
\hline $41 \mathrm{CN} 19$ & & 1 & 3 & & 4 \\
\hline $41 \mathrm{CN} 95$ & & 1 & & 15 & 16 \\
\hline $41 \mathrm{KM} 16$ & & 1 & & 11 & 12 \\
\hline 41ME29 & 6 & & & & 6 \\
\hline 41MK27 & & 8 & 2 & 1 & 11 \\
\hline 41MK9 & & & 2 & 3 & 4 \\
\hline 41MS32 & & & 4 & 11 & 14 \\
\hline 41RN169 & & & 1 & 32 & 33 \\
\hline 41RN3 & 5 & & 1 & & 6 \\
\hline $41 \mathrm{TG} 346$ & & & & 12 & 12 \\
\hline 41TG91 & 3 & & & 10 & 13 \\
\hline 41UV351 & & & 2 & 1 & 3 \\
\hline 41UV60 & 3 & 6 & 8 & & 17 \\
\hline 41UV68 & & & 1 & & 1 \\
\hline 41UV86 & & & 7 & 4 & 9 \\
\hline Grand Total & 19 & 36 & 62 & 165 & 287 \\
\hline
\end{tabular}


Most information came from data recovery excavations at $\mathrm{O}$. H. Ivie Reservoir in Runnels, Concho, and Coleman counties (Treece et al. 1993a; Treece et al. 1993b).

The results of the literature search are listed in the Table 12-7 below and in the Table C-2. Six sites with 19 features were included in the Middle Late Archaic dataset. Thirty-six features from seven sites were recorded from the Terminal Late Archaic component. Twelve sites with 62 measured features fell in the Initial Late Prehistoric component. Fourteen sites including 165 measured features were recorded for the Terminal Late Prehistoric component. The sites are shown in Figure 12-18, which also illustrates the sites by component. Some sites had recorded features from multiple components; therefore, the same site may be used more than once. For comparative purposes, feature data from 41KM69 (see Table 12-10) includes 46 features, with 13 in the Middle Late Archaic, 7 in the Terminal Late Archaic, 16 in the Initial Late Prehistoric, and ten assigned to the Terminal Late Prehistoric.

An Excel spreadsheet was compiled from the feature data described in the reports that includes the site number, feature number, group code from the feature typology, feature dimensions (length, width, thickness, area), plan view and cross-section shape, and time period (Table C-2). Other data included in the spreadsheet when available were radiocarbon dates, raw material type, rock counts and weights, the feature type as reported (e.g., hearth, ash lens, burned rock concentration), the reported time period, the 41KM69 component to which it corresponds, and source information. In the following sections, this data along with the 41KM69 data are used to examine the number of hearths with rock per component to evaluate the relative importance of plant resources in prehistoric hunter-gatherer diets at the regional and site level at 41KM69.

\section{Regional Features}

Table 12-8 provides a preliminary summary of several broader patterns seen in the literature review. For each of the four temporal periods, the spreadsheet provides the total excavated area, the number of burned rock features not including burned rock middens, the area of those features, the length of the time period, the number of burned rock middens, and the number of thermal features reflected by stains. Note that the exclusion of burned rock middens is a function of the fact that seldom is the entire midden excavated. Consequently, using the total midden area, a figure often estimated based on a few test units, the amount of space devoted to a feature will significantly exceed the total excavated area. While the midden area from Feature 1 was included in the discussion of
Table 12-8. Summary Data from Literature Review

\begin{tabular}{|c|c|c|c|c|}
\hline & MLA & TLA & ILP & TLP \\
\hline Excavated Area $\left(\mathrm{m}^{2}\right)$ & 697.5 & $1,297.01$ & 723.41 & $1,492.62$ \\
\hline $\begin{array}{c}\text { Number of Rock } \\
\text { Features }\end{array}$ & 17 & 29 & 43 & 69 \\
\hline Area of Rock Features & 5.07 & 60.23 & 38.54 & 49.19 \\
\hline Period Length (Years) & 900 & 350 & 550 & 300 \\
\hline Burned Rock Middens & 1 & 0 & 8 & 3 \\
\hline Number of Stains & 1 & 7 & 16 & 98 \\
\hline
\end{tabular}

the 41KM69 data sets in other chapters, the type of statistical analysis conducted here necessitates that only features completely excavated are included in the comparisons.

The initial use of the data in Table 12-8, then, is a consideration of the number of non-midden burned rock features for each of the four components. Figure 12-19 summarizes these data. The figure was constructed by standardizing both the amount of excavated space and the time frame. For example, reference to Table 12-8 will show that for the Terminal Late Archaic (AD 350-700), 29 rock features are present within an excavated area of $1297.01 \mathrm{~m}^{2}$. There is, then, one feature for every 44.72 excavated meters. Within a $100 \mathrm{~m}^{2}$ area, there would be 2.24 features. As the time period is 350 years in length, this yields .0064 features within the standardized area per year. Similar calculations were made for each period. Reference to Figure 12-19 clearly suggests that the number of burned rock features increases throughout the sequence.

Figure 12-20 presents a similar histogram, but focused on the area covered by burned rock features. The consistent increase through time seen in Figure 12-19 is interrupted by the Terminal Late Archaic period. Though few in numbers, Terminal Late Archaic features average over $2.0 \mathrm{~m}^{2}$ in area.

Table 12-9 provides summary data on the literature features using the burned rock portion of the typology developed previously with the 41KM69 data. Note that in the Terminal Late Archaic, 19 of 29 total features (ca. 66 percent) fall in our large burned rock feature group, and there are no burned rock middens recorded for this period. It may well be the case that the pattern seen in Figure 12-20 is related to the Table 12-9 distribution. That is, the higher frequency of large Group 2/3 features in the Terminal Late Archaic may be serving the same role as burned rock middens during other periods. An examination of ethnobotanical remains from the features in this regional study may help confirm this. 


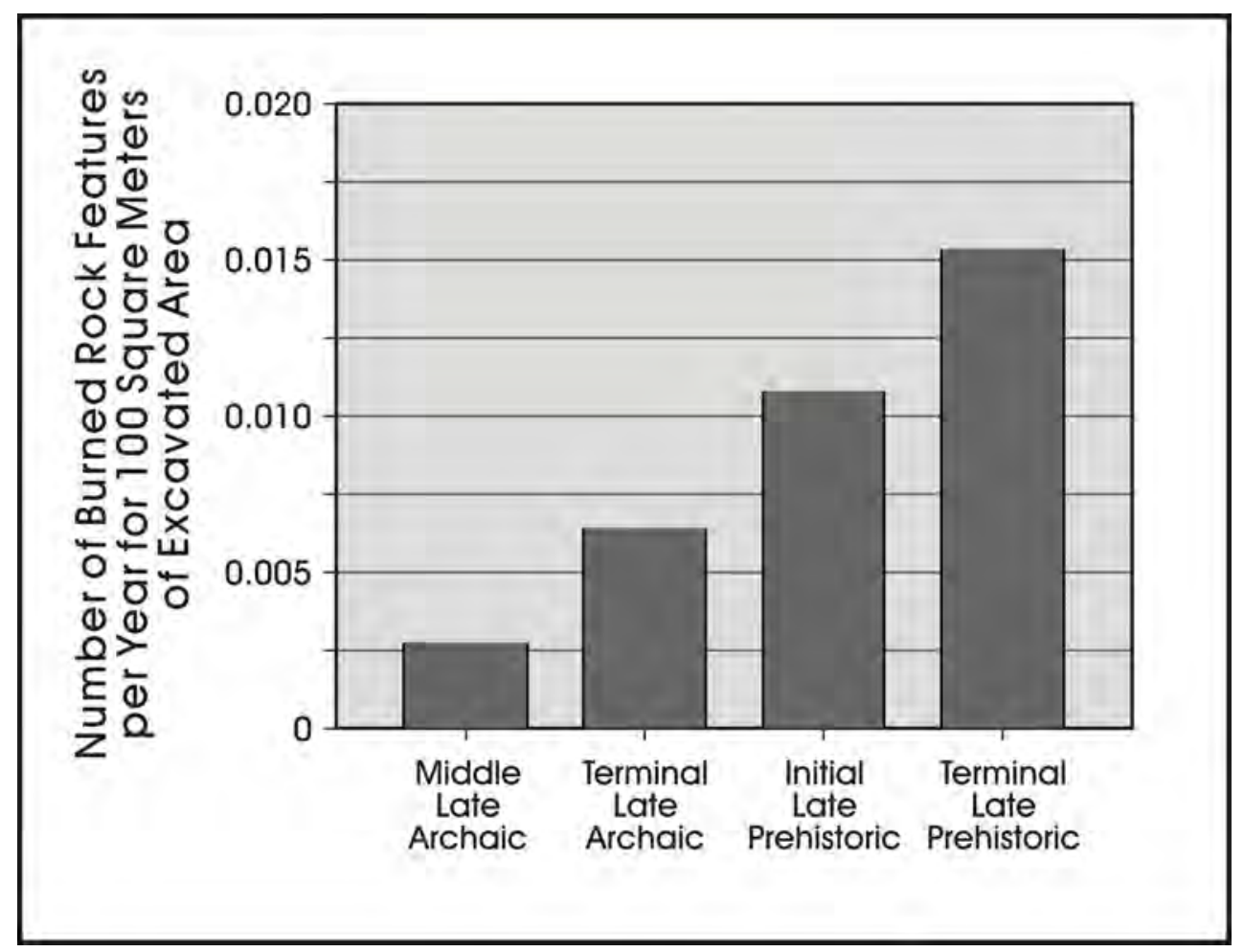

Figure 12-19. Number of burned rock features per year for $100 \mathrm{~m}^{2}$ of excavated area at the component level.

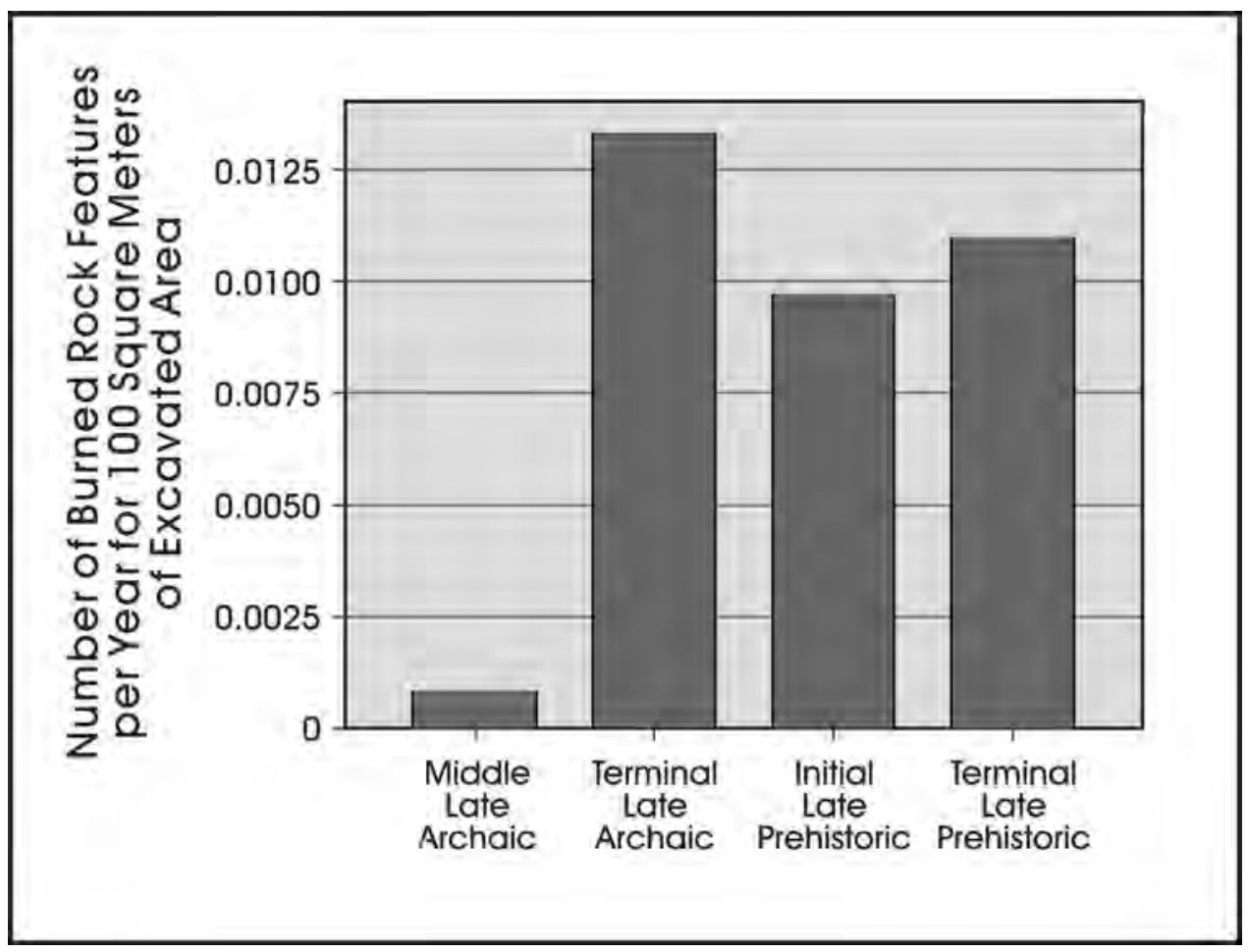

Figure 12-20. Area of burned rock features per year for $100 \mathrm{~m}^{2}$ of excavated area at the component level. 
Table 12-9. Summary Data from Burned Rock Features in Literature Review

\begin{tabular}{|c|c|c|c|c|}
\hline & MLA & TLA & ILP & TLP \\
\hline $\begin{array}{c}\text { Group 1 - small } \\
\text { FCR features }\end{array}$ & 10 & 10 & 18 & 25 \\
\hline $\begin{array}{c}\text { Group 2/3 - large } \\
\text { FCR features }\end{array}$ & 7 & 19 & 25 & 44 \\
\hline $\begin{array}{c}\text { Burned Rock } \\
\text { Middens }\end{array}$ & 1 & 0 & 8 & 3 \\
\hline
\end{tabular}

Finally, Figure 12-21 considers patterning in non-rock thermal features through time using the procedures outlined previously for Figures $12-12$ and 12-13. There is a gradual increase through time, with a dramatic jump in the number of such features late in time. This pattern may well be related to the introduction of ceramics allowing direct fire cooking of a variety of foods.

\section{Summary of Regional Features}

Data compiled from a literature review of excavated sites in Central and South Texas suggest increased importance on burned rock features from the Middle Late Archaic through the Terminal Late Prehistoric and could indicate increased use of plants in the diet. While the number of recorded features rises with each subsequent time period, the area covered by burned rock features shows a different trend. The Terminal Late Archaic features were larger than those from any other component though there were fewer of them. This jump may be explained by the absence of burned rock midden in this component in the literature and the use of Group 2/3 features for similar purposes.

\section{Feature Study at 41 KM69}

Forty-six thermal features, all burned rock features, were identified during two phases of excavations conducted by CAR. These were identified during hand excavations of test units and larger blocks and during monitoring of Gradall stripping of the upper and lower terraces between the excavation blocks. Table 12-10 shows the number and total area of features recorded per excavation area and component. Areas 1-4 were blocks excavated by hand. Upper and Lower Terraces refer only to the location of those features that were identified during Gradall monitoring, though the block excavations also occurred on these terraces.

Individual analysis of the 41KM69 burned rock from fortytwo features was conducted. Some of the larger burned rock

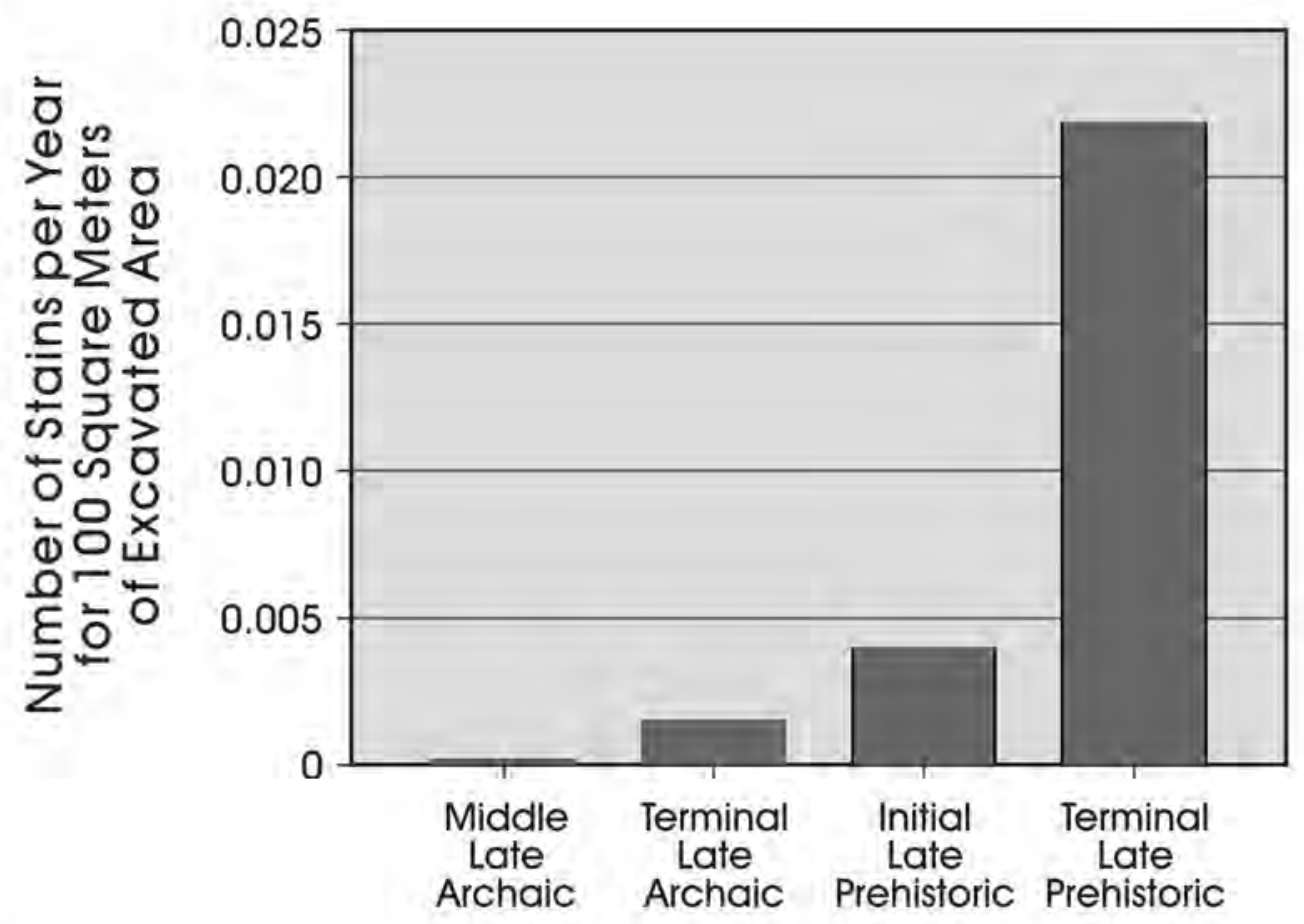

Figure 12-21. Number of thermal features lacking rock per year for $100 \mathrm{~m}^{2}$ of excavated area at the component level. 
Table 12-10. Area and Number of Recorded Burned Rock Features within each Component at 41KM69

\begin{tabular}{|c|c|c|c|c|c|c|}
\hline Areas Excavated & Feature Data & MLA & TLA & ILP & TLP & Grand Total \\
\hline \multirow{2}{*}{ Area $1\left(42 \mathrm{~m}^{2}\right)$} & Feature area $\mathrm{m}^{2}$ & 0.475 & & & 0.471 & 0.946 \\
\hline & \# of Features & 3 & & & 1 & 4 \\
\hline \multirow{2}{*}{ Area $2\left(31 \mathrm{~m}^{2}\right)$} & Feature area $\mathrm{m}^{2}$ & 0.529 & 0.173 & & 0.3 & 1.001 \\
\hline & \# of Features & 4 & 1 & & 2 & 7 \\
\hline \multirow{2}{*}{ Area $3\left(66 \mathrm{~m}^{2}\right)$} & Feature area $\mathrm{m}^{2}$ & & & 0.449 & & 0.449 \\
\hline & \# of Features & & & 5 & & 5 \\
\hline \multirow{2}{*}{ Area $4\left(42 \mathrm{~m}^{2}\right)$} & Feature area $\mathrm{m}^{2}$ & 0.198 & 1.048 & 1.28 & & 2.525 \\
\hline & \# of Features & 1 & 2 & 5 & & 8 \\
\hline \multirow{2}{*}{ Lower Terrace $\left(105 \mathrm{~m}^{2}\right)$} & Feature area $\mathrm{m}^{2}$ & 0.136 & & & 0.294 & 0.43 \\
\hline & \# of Features & 1 & & & 2 & 3 \\
\hline \multirow{2}{*}{ Upper Terrace $\left(525 \mathrm{~m}^{2}\right)$} & Feature area $\mathrm{m}^{2}$ & 0.899 & 0.561 & 10.225 & 5.021 & 16.706 \\
\hline & \# of Features & 4 & 4 & 6 & 5 & 19 \\
\hline Total sum of feature area & & 2.236 & 1.782 & 11.953 & 6.087 & 22.058 \\
\hline Total number of features & & 13 & 7 & 16 & 10 & 46 \\
\hline
\end{tabular}

Table 12-11. Number of Features per Excavated Space in each Component at 41KM69

\begin{tabular}{|c|c|c|c|c|}
\hline Excavation Block & MLA & TLA & ILP & TLP \\
\hline Excavated Area & 745 & 661 & 738 & 714 \\
\hline Number of Rock Features & 13 & 7 & 16 & 10 \\
\hline Area of Rock Features & 2.236 & 1.782 & 11.953 & 6.087 \\
\hline Period Length (Years) & 900 & 350 & 550 & 300 \\
\hline
\end{tabular}

scatter features were not excavated during Gradall scraping. This explains the discrepancy between the burned rock measurements of 42 features and the 46 features recorded in the field. The individual rock analysis includes counts, weights, and measurements of each rock greater than one inch at the axis of greatest length for 42 features. After these measurements were made, some of these rocks were sent for residue analysis as discussed previously.

Table 12-11 provides a synthesis of feature data comparable to that compiled for other sites in the study area. It is important to note that all of thermal features at 41KM69 were also burned rock features. The same trend is apparent at $41 \mathrm{KM} 69$ as for the general region. The number of burned rock features increase through time (Figure 12-22). However, at 41KM69 there were no large Terminal Late Archaic burned rock features recorded, so at this site, feature size increases through time rather than peaking during the Terminal Late Archaic. Instead, the Initial and Terminal Late Prehistoric feature areas are nearly identical, despite excluding the burned rock middens from this dataset (Figure 12-23). Features used during the Initial Late Prehis- toric were slightly larger than those used during the Terminal Late Prehistoric at 41KM69 (Table 12-12).

\section{Summary}

Feature data are surprisingly under reported in the literature, a fact that clearly hampered the comparative efforts. In addition, interpretations, as well as the development of the typology as such, are complicated by feature reuse. Reuse of burned rock features, whether at the level of burned rock middens or smaller features such as Feature 3 on 41KM69, will generate both increased rock weight as well as features with larger areas. While it is possible to recognize reuse by focusing on rock size data, the pattern complicates any facile interpretation.

The feature typology generated with the 41KM69 data set focused on weight. The initial idea was that different rock weights would generate different thermal ranges, and that these ranges may be designed for processing different types 


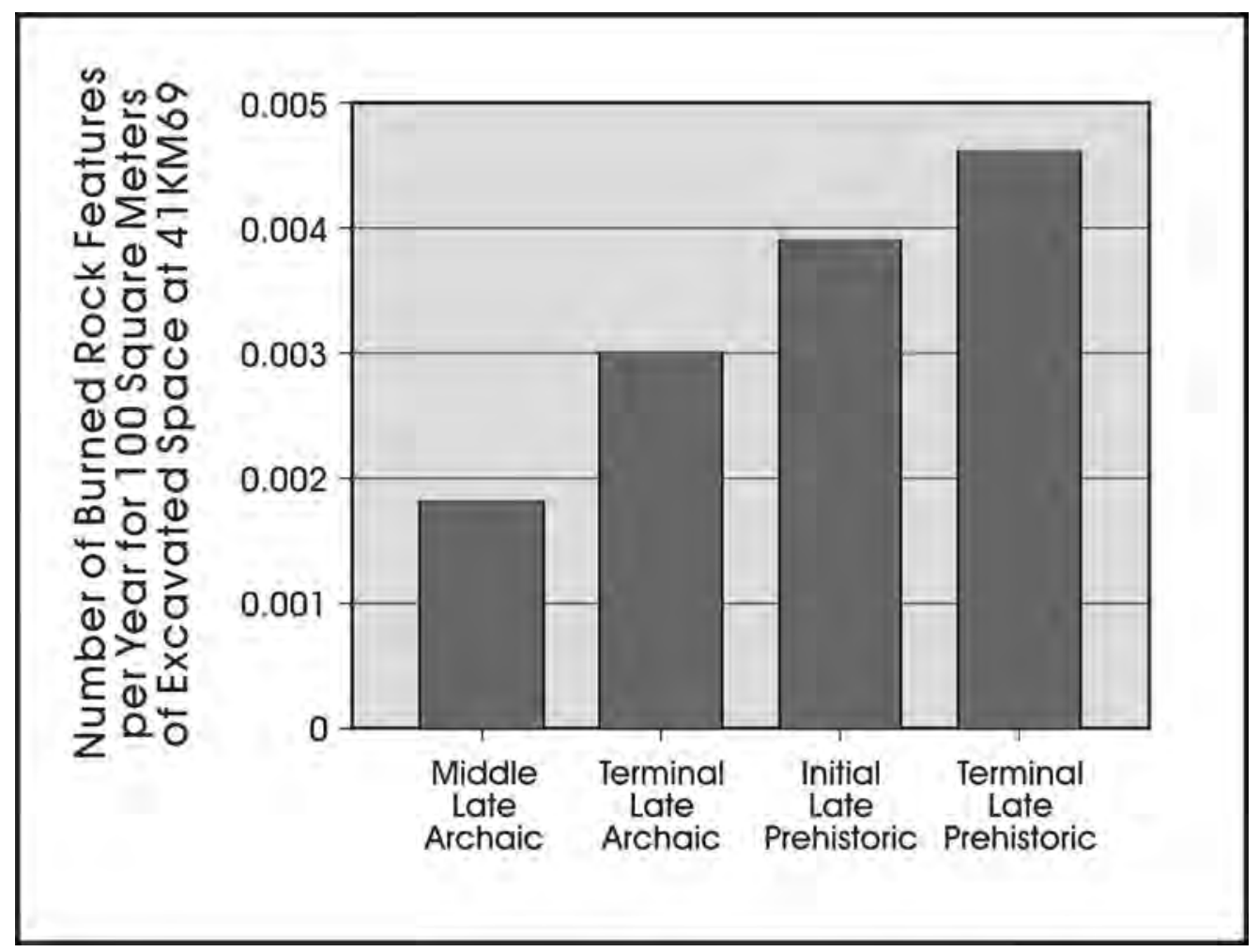

Figure 12-22. Number of burned rock features per year for $100 \mathrm{~m}^{2}$ of excavated area at the component level at 41KM69.

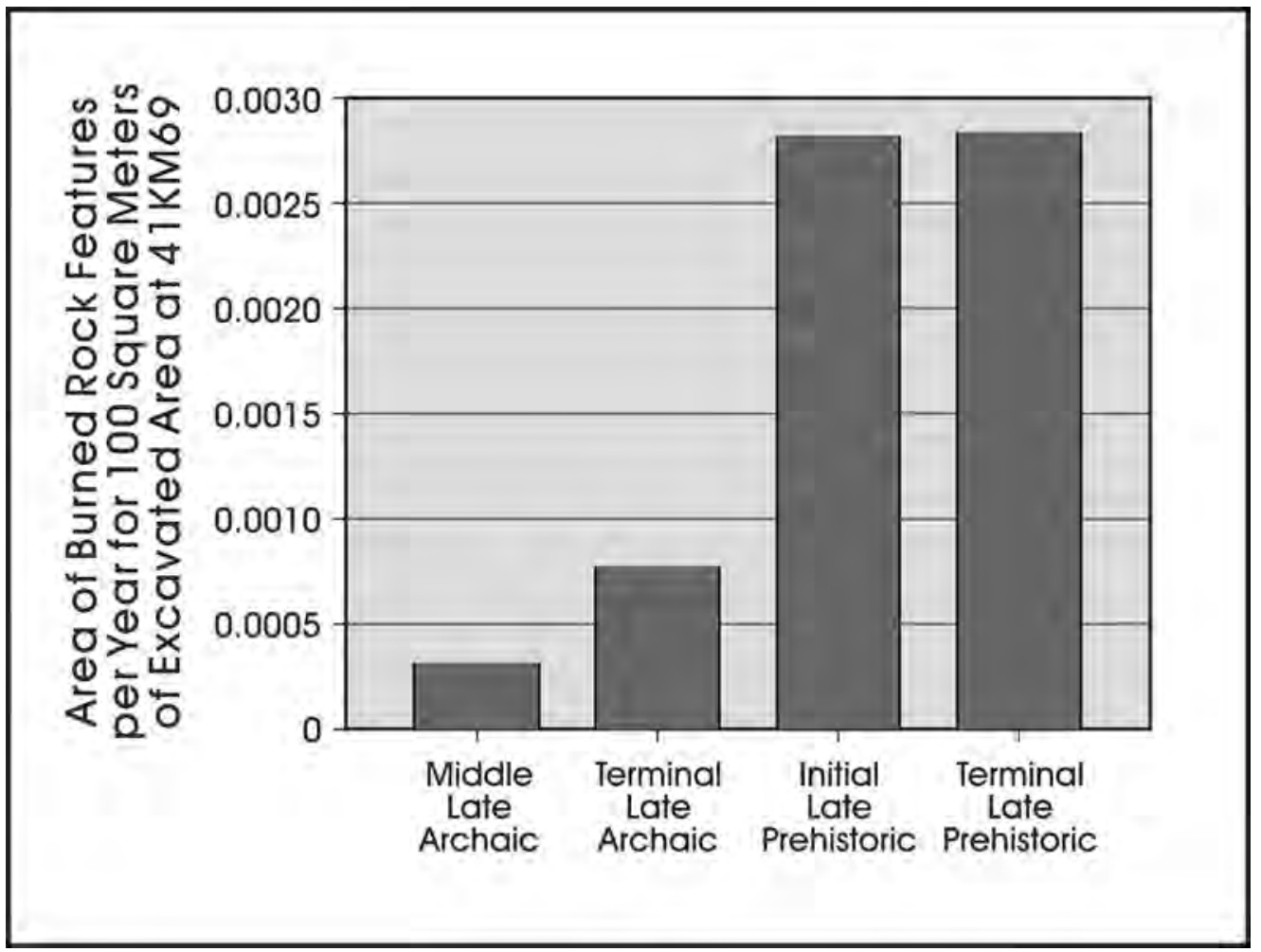

Figure 12-23. Area of burned rock features per year for $100 \mathrm{~m}^{2}$ of excavated area at the component level at 41 KM69. 
Table 12-12. Summary Data from Burned Rock Features at 41KM69

\begin{tabular}{|c|c|c|c|c|}
\hline & MLA & TLA & ILP & TLP \\
\hline Group 1 - small FCR Features & 8 & 6 & 6 & 4 \\
\hline Group 2/3 - large FCR features & 3 & 1 & 6 & 4 \\
\hline
\end{tabular}

of plants. Small features (our Group 1 type) seem well suited for a variety of low starch plants, as well as animals if meat packages were small, and heavier, larger features (Group 2/3), as well as the burned rock midden at the site (Feature 1), were probably associated with longer-term processing necessitated by higher starch plants. These suggested uses were further investigated through comparison of flotation results for these feature groups, as well as lipid residue analysis though neither were overly supportive due to the small samples.

Rock from four burned rock features, one from each component, underwent lipid residue analysis. Each sample returned plant residues except the Terminal Late Prehistoric Feature 82, which is a Group 1 feature. This feature was found to have residues consistent with large herbivores.

The botanical remains identified at 41KM69 were interesting in their rarity at open-air sites in Central Texas but did not serve to support the feature typology. Only six of the typed features had identifiable, edible remains. The four Group 1 features from the Middle Late Archaic, the Terminal Late Archaic, and the Initial Late Prehistoric contained pecan and wintergrass seeds. The two Group 2/3 features were both from the Initial Late Prehistoric and contained acorn and pecan. None of the Terminal Late Prehistoric features contained edible plant remains.

The literature review of features produced several interesting trends, including a consistent increase through time in both the number of burned rock features and the number of non-burned rock thermal features. The trend in the number of non-rock thermal features was especially pronounced in the
Terminal Late Prehistoric. The trend seen in these data sets was also present in the feature area data with the exception of the Terminal Late Archaic period. Though few in number, burned rock features during this period are significantly larger than other periods. Interestingly, no burned rock middens were noted for the Terminal Late Archaic in the comparative data set, suggesting the possibility that these larger features may be playing the same role as burned rock middens in other time periods.

Examined with the same analysis, features at 41KM69 showed similar trends in the number of burned rock features across time as the comparative data. However, the data do not show an increase in burned rock feature area during the Terminal Late Archaic. The trend seems to occur during the Initial Late Prehistoric instead, when fewer features have a total area equal to greater numbers of Terminal Late Prehistoric features. Additionally, all the thermal features at 41KM69 contained burned rock. At 41KM69 as across the region, the size and number of burned rock features suggest increasing use of plants in the diet of hunter-gatherers from the Middle Late Archaic through the Terminal Late Prehistoric.

Note that burned rock middens were not successfully integrated into the discussion. As a group, these features have a high frequency of reuse, and are not completely excavated making area comparisons impossible. Nevertheless, this feature type is common in the Initial Late Prehistoric Period. To the degree that the general trends in thermal features outlined here will ultimately serve as a proxy for plant dependence, the importance of plants in the Initial Late Prehistoric is underestimated by these trends. 



\title{
Chapter 13: Assessing Technological Organization and Change
}

\author{
Jennifer L. Thompson, Raymond P. Mauldin, Steve A. Tomka, and Eric Oksanen
}

In our general hunter-gatherer model presented in Chapter 8 , we argued that changes in the relative density of bison within the area exploited by hunter-gatherers could significantly affect not only diet breadth but also tool design and the organization of tool manufacture and repair strategies. Specifically, we suggest that possible decreases in bison availability, a restricted spatial distribution, and increasing fluctuations in bison availability, especially during the Terminal Late Prehistoric, may have resulted in the intensification of bison procurement. A shift to a tool kit that was more specialized, and consequently more expensive to produce and maintain, may have been part of this intensification process. In contrast, we expect that more generalized tools that are less energy intensive to manufacture (i.e., flakes with suitable working edges) would have been favored by hunter-gatherers during the Middle and Terminal Late Archaic as processing requirements were not temporally restricted, did not occur in bulk, and were dictated more by day-to-day needs. While it is likely that both specialized and generalized tools would have been present in any given system, it is our expectation that the increased costs associated with the production of specialized tools would tend to favor their use in situations where the intensified exploitation of high-ranked resources was the primary focus of activities. This would especially be the case if an important component of annual subsistence relied on resources that were declining in number, were becoming restricted spatially, and had high year-to-year fluctuations. Under these conditions, there is a pressure on hunters and gatherers to acquire large quantities of that resource during the period of availability (see Bamforth and Bleed 1997). In contrast, the day-to-day acquisition of resources within a forager system does not lead to intensive energy expenditures since some resources are procured each day and a failed hunting or collecting trip can easily turn into a successful one the next day.

As outcomes of these suggestions, we would expect to find fewer tools with high manufacture costs and little evidence of what some have termed gearing up (see Binford 1977, 1979; Bleed 1986) in assemblages dating to the Middle and Late Archaic. This should shift slightly during the Initial Late Prehistoric as bison numbers decline and bison are restricted spatially. A significant portion of the tool kits associated with Terminal Late Prehistoric hunter-gatherers should consist of forms that have high manufacture costs as fluctuations in bison populations become common. In addition, signs of gearing up should be more prevalent in Terminal Late Prehistoric assemblages compared to preceding components.

\section{Categorizing Tools according to Manufacturing Costs}

To investigate the assumed relationship between tool design (i.e., energy expended in the manufacture of a tool) and the changes in bison population densities, the Senior Lithic Analyst scanned selected lithic assemblages and categorized each identified tool according to the level of energy that has been expended for its manufacture and added them to an existing database. The making of lithic tools is a reductive activity that leaves evidence of the amount of effort that a knapper invested in the manufacture process. Specifically, the area covered by retouch (i.e., flake removals) present on a tool can serve as a proxy for the level of effort expended in the manufacture of tools. Here, manufacturing costs are only those aspects of tool making that include the percussion and/ or pressure flaking of a piece of raw material into a finished product. That is, the costs of raw material procurement are not part of the consideration. In addition, we recognize that the stone portion of the tool often represents only one element of a compound tool. Ethnographic studies indicated that the perishable portion of a compound tool is often the most expensive portion. Nonetheless, we assume that under circumstances when tools are manufactured anew rather than reworked from recycled specimens, there is a correlation between the level of effort expended in overall tool manufacture and the level of effort that is used in the manufacture of the stone portion of the tool.

Accepting this assumption, and given the relationship between the manufacture costs (i.e., generalized versus specialized tools) and resource procurement strategies (i.e., residential versus logistical foragers), we feel assemblages in terms of stone tool manufacture costs can be a productive research avenue to identify and differentiate technological organization and resource procurement strategies. Specifically, we expected that during the Late Archaic, when resource procurement occurs on a day-to-day basis, tool manufacture costs on average would be low given a heavy reliance on generalized tools and decreased likelihood of curated specimens. During the Initial Late Archaic, this pattern should shift to one where tools that are more specialized are increasingly common. By the Terminal Late Prehistoric, when we have argued that hunters and gatherers may have procured bison through logistical mobility, and bison populations were increasingly variable from year to year, the primary emphasis would have been on the manufacture of specialized tools. 
We assume here that within any tool kit employed by huntergatherers, there may be functionally specific forms (i.e., projectile points) that may not fit these general expectations since manufacture costs are conditioned by the degree of dependence of the tool user upon the specific tool (Tomka 2001). That is, even within residentially mobile foragers, some of the tools employed will be costly to manufacture because of the high degree of dependence on this tool to carry out tasks in an efficient and effective manner. However, at the level of the entire assemblage, when we compare Late Archaic, Initial Late Prehistoric, and Terminal Late Prehistoric assemblages, we expected to find the patterns in tool manufacture costs outlined above.

\section{Methods}

Relying on these assumptions and expectations, the analyst categorized stone tools from selected assemblages into one of five manufacture cost categories. From the least energy expensive to the most expensive these categories are: 1) utilized flakes; 2) marginally retouched items; 3) unifacially retouched specimens; 4) bifacially retouched forms; and 5) unifacially and bifacially retouched items with haft elements. This classification scheme assumes that as the number of faces being retouched increases, the energy expended during tool manufacture also increases. As mentioned above, costs associated with the construction of the haft element add to the overall manufacture costs of a compound tool ${ }^{\text {(note } 1)}$.

The quantification of manufacture costs depends on comparing the proportions of tools found within each of the five categories mentioned above. One of these categories, utilized flakes, is often under-reported in archeological collections. To address this potential effect on the sample, we selected a random sample of 500 flakes from each target assemblage and scanned these specimens for macroscopic or low-power microscopic evidence of use wear. We used macroscopic patterns of use wear defined by Tringham et al. (1974) to classify the tools into the task-specific categories (i.e., cutting, scraping, graving, and perforating). The task-specific data was used to quantify the relative contribution of specialized versus generalized tools to individual assemblages (see Chapter 16: Investigating Changes in Mobility).

Items that we could not classify into functional categories based on macroscopic use wear were subjected to low powered micro-wear analysis at 50-80-times magnification to discern the utilized edge and the manner of use or the task performed with the tool. Items that were still not classified into a functional category were excluded. Once we quantified the total number of use-modified tools and their associated tasks, we estimated the total number of specimens within the collection by dividing the total number of debitage from the component/site by the count in each class.
All other specimens categorized as miscellaneous bifaces, unifaces, and formal tools in previous analyses of the selected assemblages were classified into functional categories when possible using the criteria outlined above. Next, each tool was assigned to one of the five manufacture cost groups dependent on the degree of retouch that went into their manufacture. The data was entered into contingency tables and inter-assemblage comparisons made using standard statistical techniques (i.e., residual analysis).

\section{Results of Manufacturing Cost Analysis}

We expected that as bison densities decrease, hunter-gatherers might have chosen to intensify their procurement by using specialized tools. If this were the case, then such behavior would have left a pattern in the archaeological record. Fewer specialized tools should have been made during the Late Archaic and greater numbers of specialized tools during the Terminal Late Prehistoric Toyah interval.

Table 13-1 lists the 41KM69 tool assemblage by manufacturing cost. The utilized flakes are combined with the marginal retouched flakes in this discussion to form an inexpensive tool group but are left separate in the table. In each analytical unit but the Terminal Late Prehistoric, bifaces were the most common cost category. Bifaces make up the highest percentage of the MLA tool collection with 49 percent. Combined, the inexpensive tools (marginally retouched flakes and the utilized flakes) are next at 28 percent followed by hafted tools at 23 percent. There are no unifacially flaked tools in the MLA analytical unit. Bifaces are also the most common tool type of the Terminal Late Archaic at 45 percent, followed by hafted tools ( 25.5 percent), retouched/utilized flakes (18 percent) and unifacially retouched tools (11.3 percent). The Initial Late Prehistoric analytical unit has the same trend at the MLA with bifacially retouched tools most common at 54 percent followed by marginally retouched/utilized flakes (21.5 percent), hafted tools (15.8 percent) and unifacially flaked tools (8.86 percent). Finally, in the Terminal Late Prehistoric, we see a different trend. Hafted tools were most common in the TLP likely because of the hafting elements associated with the large scrapers that contributed to this group. Bifacially flaked tools and unifacially flaked tools each comprised 19 percent of the TLP analytical unit and marginally retouched/utilized flakes made up 14 percent.

Percentages of expensive tools (unifaces, bifaces, and hafted tools) from each component are charted in Figure 13-1. We expected the greatest use of specialized, expensive tools during the TLP and the greatest use of expedient, inexpensive tools during the Middle Late Archaic. While the TLP and the MLA percentages are as expected, the TLA and the ILP per- 
Table 13-1. Manufacturing Cost Categories of Chipped Stone Tools

\begin{tabular}{|c|c|c|c|c|c|c|c|c|c|c|}
\hline 䒕 & 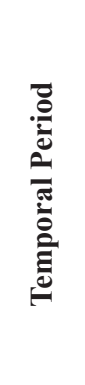 & 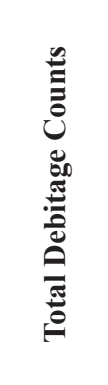 & 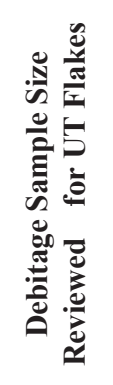 & 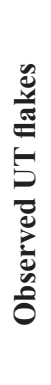 & 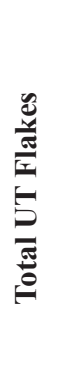 & 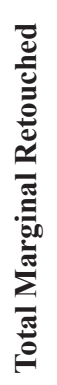 & 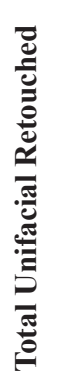 & 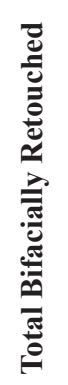 & 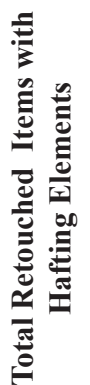 & 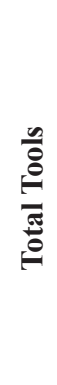 \\
\hline 41KM69 & ILP & 17,684 & 17,684 & 1 & 1 & 33 & 14 & 85 & 25 & 158 \\
\hline 41KM69 & MLA & 5,511 & 5,511 & 3 & 3 & 13 & 0 & 28 & 13 & 57 \\
\hline 41KM69 & TLA & 9,981 & 9,981 & 3 & 3 & 16 & 12 & 48 & 27 & 106 \\
\hline 41KM69 & TLP & 3,298 & 3,298 & 1 & 1 & 7 & 11 & 11 & 28 & 58 \\
\hline Totals & & 36,474 & 36,474 & 8 & 8 & 69 & 37 & 172 & 93 & 379 \\
\hline
\end{tabular}

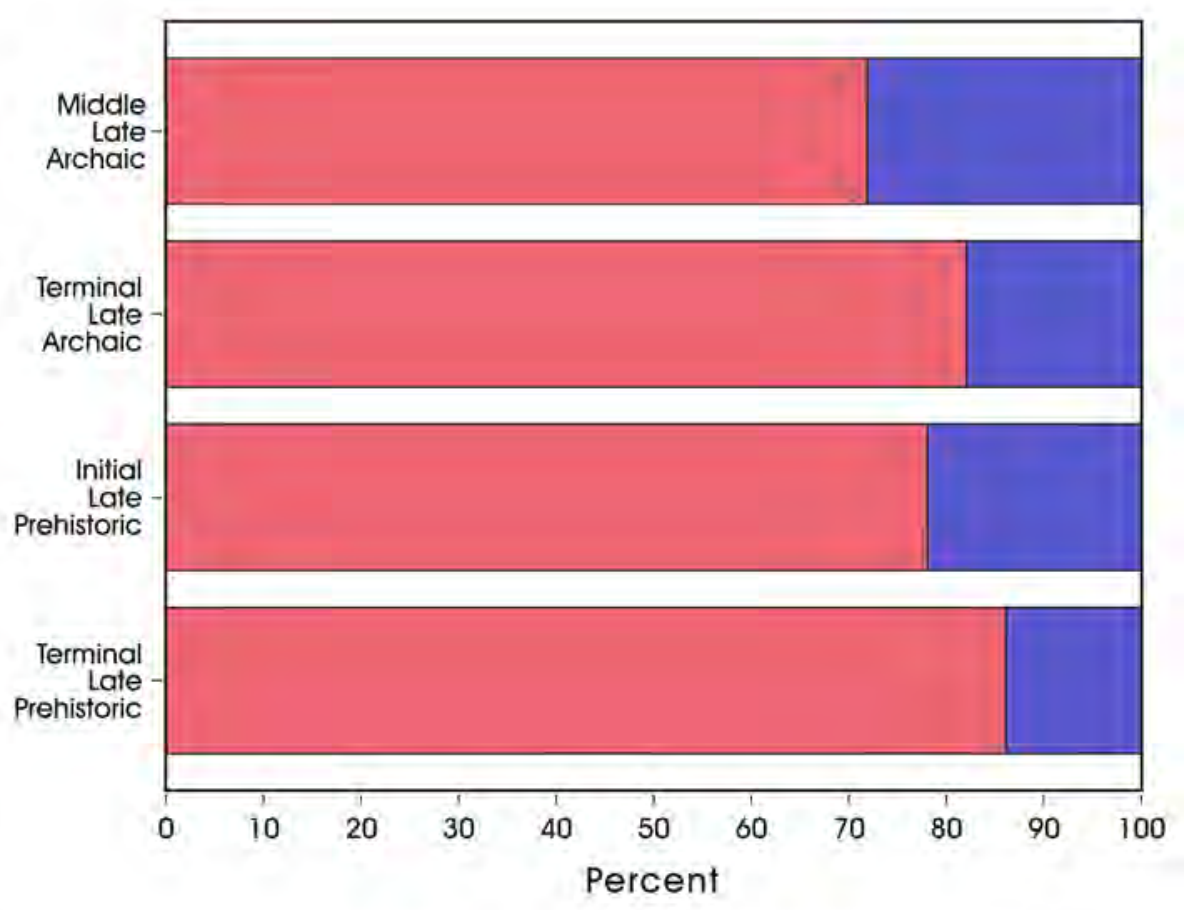

Percent Expensive Tools

Percent Inexpensive Tools

Figure 13-1. The percent of expensive tools vs. inexpensive tools per component at 41 KM69. 
centages are not. These time periods show a reversed trend where a higher percentage of expensive tools are present in the TLA than in the ILP.

Figure 13-2 shows a breakdown of the percentages of tool cost categories for each component at 41KM69. When ranking the percentages of each of the five cost groups, our expectations hold for the TLP. This period has the highest percentage of hafted tools and the lowest percentage of flake tools. In the Initial Late Prehistoric, we would expect larger numbers of specialized tools than in the Late Archaic periods but less than in the Terminal Late Prehistoric. Though the Initial Late Prehistoric has the lowest percentage of hafted tools of all the analytical units, it has the highest percentage of bifaces from any time period. Overall, we clearly see a trend from general to specialized tools across the analytical units at 41KM69 with the greatest use of flake tools in the MLA and greatest use of hafted tools in the TLP, though the trend wavers during the middle of the time span under consideration.

\section{Regional Comparison}

The trends identified at the site level above were compared to the same data for the larger study area. The regional analysis included tools classified according to manufacturing cost from a sample of fifteen components on 10 comparative sites and 41KM69 (Table 13-2). Six components were added to the database, which already included thirteen components from other studies.

Comparative sites were chosen based on the descriptions of components found in literature reviews. Only collections housed at CAR were selected due to logistical ease and to keep down costs of the analyses. Nine components from sites included in the research design were dropped after closer examination of the available data. For example, 41UV68 ( 2 components) was originally included but, the collection housed at CAR was from an earlier excavation that produced a limited number of artifacts. Artifacts from subsequent work at the site, which were meant for incorporation in this study, are housed at TARL. The TLP component from 41BX228 was dropped because the reported proveniences are not specific enough to locate the analytical units needed for this study among the curated boxes. The same is true for the MLA and TLP components of 41BX300. Two components from 41ED28 (MLA and TLA) and one component from 41MV120 (TLA) were dropped due to the poor integrity of these assemblages. We were unable to differentiate the Late Archaic analytical units as first thought.

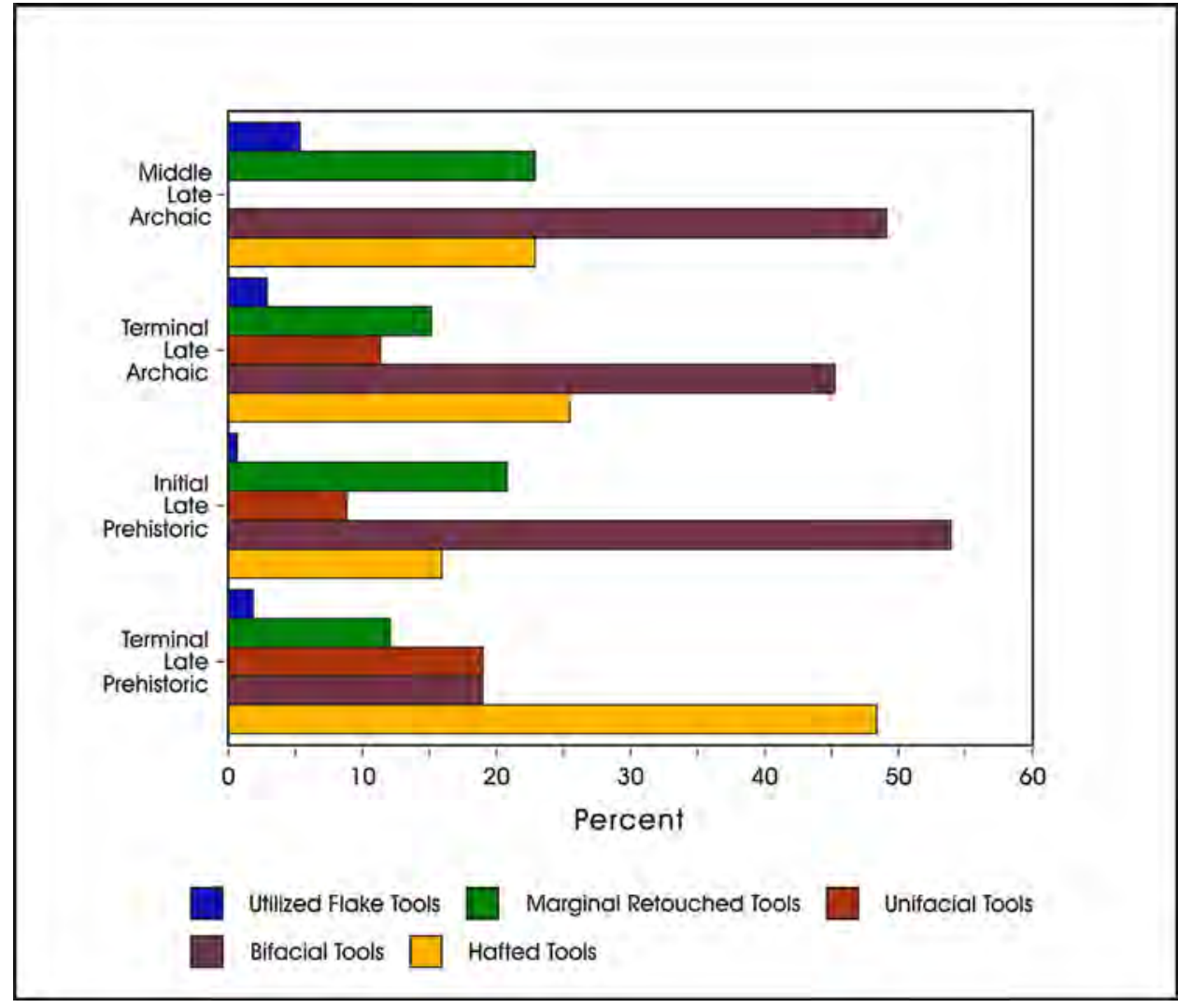

Figure 13-2. The percent of tool cost categories per component at 41 KM69. 
Table 13-2. Sites and Components for Manufacturing Cost Tool Study

\begin{tabular}{|c|c|c|c|c|}
\hline \multicolumn{5}{|c|}{ Components Examined during Current Study } \\
\hline 41BN33 & & TLA & ILP & TLP \\
\hline 41BX300 & & TLA & & \\
\hline 41ED28 & & & & TLP \\
\hline 41MV120 & MLA & & & \\
\hline \multicolumn{5}{|c|}{ Components Used from Previous Studies } \\
\hline 41MM341 (AU1) & & & ILP & \\
\hline 41MM341 (AU2) & & & ILP & \\
\hline 41JW8 & & & & TLP \\
\hline 41LK67 & & & ILP & TLP \\
\hline 41MC296 & MLA & & & \\
\hline 41MM340 (AU2) & MLA & & TLP & TLP \\
\hline 41LK201 & & & TLA \\
\hline 41KM69 & MLA & & ILP & TLP \\
\hline
\end{tabular}

Table 13-3 lists all 19 components reviewed and has 14 columns. Specifically, the columns are 1) component 2) temporal period (i.e. Middle Late Archaic- MLA; Terminal Late Archaic- TLA; Initial Late Prehistoric-ILP; Terminal Late Prehistoric-TLP), 3) the debitage count for the component, 4) the number of debitage reviewed, 5) the percent of the total debitage reviewed, 6) the number of utilized flakes seen in that review, 7) the estimated number of new utilized flakes present in the assemblage (based on the percent sampled, the number of new utilized flakes, and the total debitage counts), 8) the number of utilized flakes observed in the tools, 9) the total number of utilized flakes (estimated new flakes and observed flakes), 10) the number of marginally retouched flakes, 11) the number of unifaces, 12) the number of bifaces, 13) the number of expensive and hafted items, and 14) the total number of tools.

Table 13-3 shows that on 19 components, a sample of debitage ranging between a low of 437 and a high of 837 items was scanned for the presence of utilized flakes. The average sample size reviewed for the 15 components (excluding 41KM69) was 534, which exceeds the target of 500 per component. The debitage sample in this spreadsheet represents a random sample of between 73.38 and 2.44 percent that was drawn using functions in Excel. The sample operated at the bag level using lot numbers rather than the level of the individual artifact. Consequently, depending on the number of items in a given bag and on which bag was randomly selected, some variability in numbers were produced, In addition, note that in a small number of cases, items assigned as debitage were, in fact, burned rock or other items. While this was not frequent, most components had at least a few items that were not debitage.

We assumed that utilized flakes would be the tool type most likely overlooked during analysis. We were able to estimate the number of utilized flakes overlooked (Column 7) by using the debitage sample size reviewed (Column 4), the number of utilized flakes discovered in the sample (Column 6), and the total number of debitage in a component (Column 3 ). These estimates were added to the utilized items identified in the tool assemblages (Column 9). Utilized flakes were not commonly overlooked in most assemblages. Only a single utilized flake was found in four components. However, given the small percentages of debitage reviewed in most cases, the discovery of a single flake resulted in an estimated increase of between 3 and 26 utilized flakes at an assemblage level (Column 7).

Columns 10-14 contain data on five tool categories defined by level of investment. From the least expensive to the most expensive, these are utilized flakes, marginally retouched flakes, unifacially retouched items, bifacially retouched items, and hafted/highly specialized items. In practice, the distinction between the two least "expensive" tool categories (utilized flakes and retouched flakes) proved difficult to make in many cases. That is, while the classification on a given tool as not belonging to either a facially retouched or hafted area was relatively easy, deciding how much damage (e.g., depth 
Table 13-3. Manufacturing Cost Categories of Comparative Chipped Stone Tools

\begin{tabular}{|c|c|c|c|c|c|c|c|c|c|c|c|c|c|}
\hline 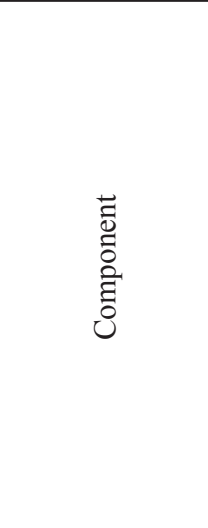 & 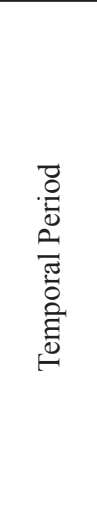 & 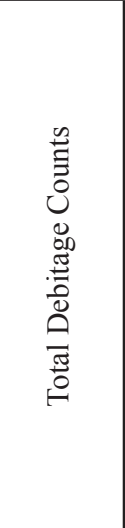 & 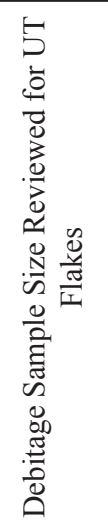 & 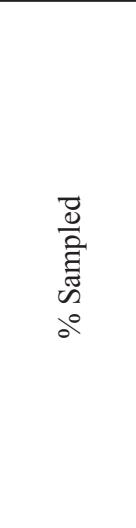 & 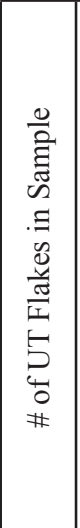 & 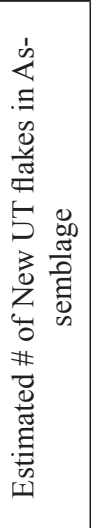 & 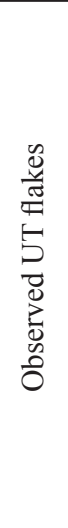 & 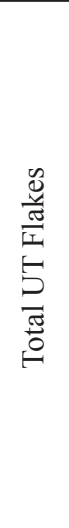 & 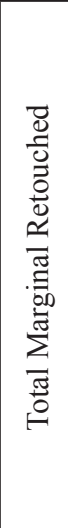 & 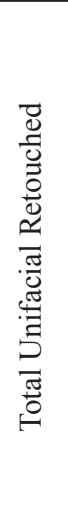 & 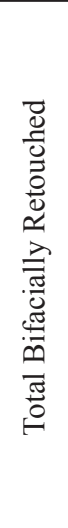 & 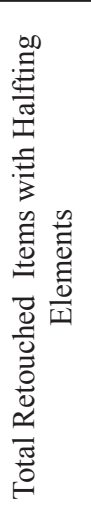 & 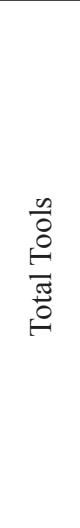 \\
\hline $41 \mathrm{BN} 33$ & ILP & 3,710 & 585 & $15.8 \%$ & 0 & 0 & 12 & 12 & 9 & 1 & 13 & 24 & 59 \\
\hline $41 \mathrm{BN} 33$ & TLA & 680 & 499 & $73.40 \%$ & 0 & 0 & 5 & 5 & 3 & 0 & 2 & 3 & 13 \\
\hline $41 \mathrm{BN} 33$ & TLP & 2,044 & 503 & $24.60 \%$ & 1 & 4 & 20 & 24 & 19 & 1 & 13 & 24 & 81 \\
\hline 41BX300 & TLA & 2,225 & 837 & $37.60 \%$ & 0 & 0 & 1 & 1 & 2 & 0 & 7 & 1 & 11 \\
\hline 41ED28 & TLP & 2,483 & 559 & $22.50 \%$ & 0 & 0 & 39 & 39 & 61 & 1 & 63 & 36 & 200 \\
\hline 41JW8 & TLP & 12,665 & 494 & $3.90 \%$ & 1 & 26 & 47 & 73 & 115 & 64 & 196 & 142 & 590 \\
\hline 41KM69 & ILP & 17,684 & 17,684 & $100.00 \%$ & N/A & $\mathrm{N} / \mathrm{A}$ & 1 & 1 & 33 & 14 & 85 & 25 & 158 \\
\hline 41KM69 & MLA & 5,511 & 5,511 & $100.00 \%$ & $\mathrm{~N} / \mathrm{A}$ & $\mathrm{N} / \mathrm{A}$ & 3 & 3 & 13 & 0 & 28 & 13 & 57 \\
\hline 41KM69 & TLA & 9,981 & 9,981 & $100.00 \%$ & N/A & N/A & 3 & 3 & 16 & 12 & 48 & 27 & 106 \\
\hline 41KM69 & TLP & 3,298 & 3,298 & $100.00 \%$ & N/A & N/A & 1 & 1 & 7 & 11 & 11 & 28 & 58 \\
\hline 41LK201 & TLP & 15,972 & 530 & $3.30 \%$ & 0 & 0 & 9 & 9 & 33 & 11 & 85 & 72 & 210 \\
\hline 41LK67 & TLP & 1,907 & 463 & $24.30 \%$ & 0 & 0 & 11 & 11 & 9 & 3 & 7 & 5 & 35 \\
\hline 41MC296 & ILP & 1,103 & 437 & $39.60 \%$ & 0 & 0 & 7 & 7 & 3 & 0 & 13 & 1 & 24 \\
\hline $41 \mathrm{MC} 296$ & MLA & 1,454 & 506 & $34.80 \%$ & 1 & 3 & 5 & 8 & 5 & 1 & 6 & 1 & 21 \\
\hline $41 \mathrm{MC} 296$ & TLP & 3,142 & 489 & $15.60 \%$ & 0 & 0 & 4 & 4 & 19 & 11 & 27 & 36 & 97 \\
\hline 41MM340 & MLA & 20,282 & 506 & $2.50 \%$ & 0 & 0 & 94 & 94 & 29 & 8 & 52 & 34 & 217 \\
\hline 41MM341-au1 & ILP & 21,769 & 531 & $2.40 \%$ & 0 & 0 & 148 & 148 & 73 & 16 & 98 & 44 & 379 \\
\hline 41MM341-au2 & ILP & 13,712 & 520 & $3.80 \%$ & 1 & 26 & 81 & 107 & 43 & 4 & 64 & 24 & 242 \\
\hline 41MV120 & MLA & 1,884 & 521 & $27.70 \%$ & 0 & 0 & 1 & 1 & 3 & 1 & 4 & 1 & 10 \\
\hline Totals & & 141,506 & 44,454 & & 4 & 59 & 492 & 551 & 495 & 159 & 822 & 541 & 2568 \\
\hline
\end{tabular}

of flake scars) to an edge was necessary to qualify as "retouched" proved difficult. Note also that in a significant number of cases, earlier analysts identified items as being used or retouched that we felt were not tools. While we did not change those earlier designations, we did not include these items in our tool summaries presented in the table.

In a small number of cases, projectile points (placed in the "hafted tool/specialized" class), found in a component, dated either earlier or later than that component. In cases where points dated earlier or later and when that earlier or later component was present in our sample, the points were simply counted in the time period where it was thought to have been produced. When earlier or later components at a site were not among the components in our initial sample, we simply did not count the item.

We would expect regional trends in the cost analysis of tool production to vary with bison densities. Therefore, we expect greater numbers of specialized tools when bison are scarce in the Terminal Late Prehistoric than in the Middle Late Archaic when bison are more abundant. Taken as a percentage 
of total tools per analytical unit, the most common tools during the MLA were utilized flakes (35 percent) followed by bifacial tools (30 percent), marginally retouched flakes (16 percent), hafted tools (16 percent), and unifacial tools (3 percent). Bifacial tools are most common in the combined TLP assemblages (44 percent), followed by hafted tools ( 24 percent), marginally retouched tools (16 percent), unifacial tools (9 percent) and, utilized flakes ( 7 percent). The ILP trends are similar to the MLA and the TLP is closest to the predicted outcome. Here, the greatest percentage of tools is bifaces (32 percent) followed by hafted tools ( 27 percent), marginal retouch tools ( 21 percent), utilized flakes (13 percent) and unifacial tools ( 8 percent).

Grouping the tools by specialized and expedient groups the trend shows a near 50/50 split during the MLA, becoming more specialized during the TLA before falling back to an even split in the ILP (Figure 13-3). The TLP shows the most specialized toolkit of all the analytical units. As with $41 \mathrm{KM} 69$, the overall trend is as expected as the toolkit becomes more specialized through time, with the exception of the ILP.

\section{Documenting Gearing Up}

Gearing up represents the manufacture of large numbers of artifacts in anticipation of future need. Because the artifacts manufactured are used in bulk procurement activities and they are made to reduce in-field manufacture needs, usually gearing up involves the making of large numbers of tools. Most importantly, the number of tools made is in response to anticipated needs and failure rates rather than ongoing needs for tool replacement. Tools manufactured for gearing up (i.e., future need) contrast with tools manufactured for ondemand replacement of failed tools. On-demand replacement involves the manufacture of replacement specimens at the location where the tool failed and immediately reintroduces a needed implement into the systemic context. As a result, the manufacture of on-demand replacement tools results in the production of one replacement tool for each use-failed tool. A successful tool manufacture process will terminate in the production of a complete functional specimen that will replace the use-failed component of the compound tool.

Figure 13-4 presents an example of these anticipated patterns. The gearing-up locations are in red, while the on-demand replacement locations are in blue. Locations at which hunters and gatherers manufactured tools for anticipated needs (gearing-up locations in Figure 13-4- upper left) will have a higher percentage of manufacture-failed items than use failed items. At the location where the activities are conducted (activity locations in Figure 13-4- lower right), conversely, few manufacturing failures will be present, and use-failed items should dominate the assemblages. The on-demand replacement strategy, conversely, should produce roughly similar percentages of use-failed items relative to tools that had manufacturing failures and fall in the center of the graph. The location of the dividing lines between the various sections of the graph will

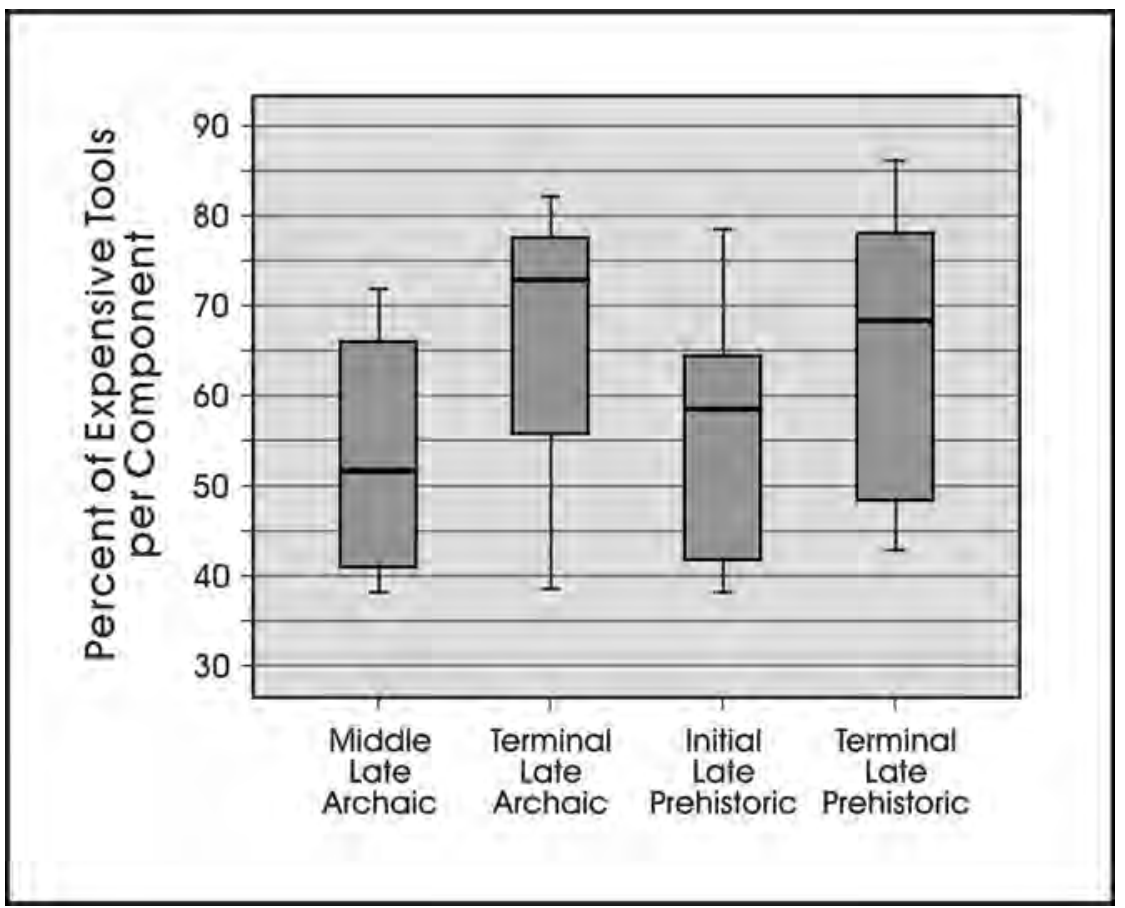

Figure 13-3. Percentage of expensive tools per component across the comparative sites and 41KM69. 


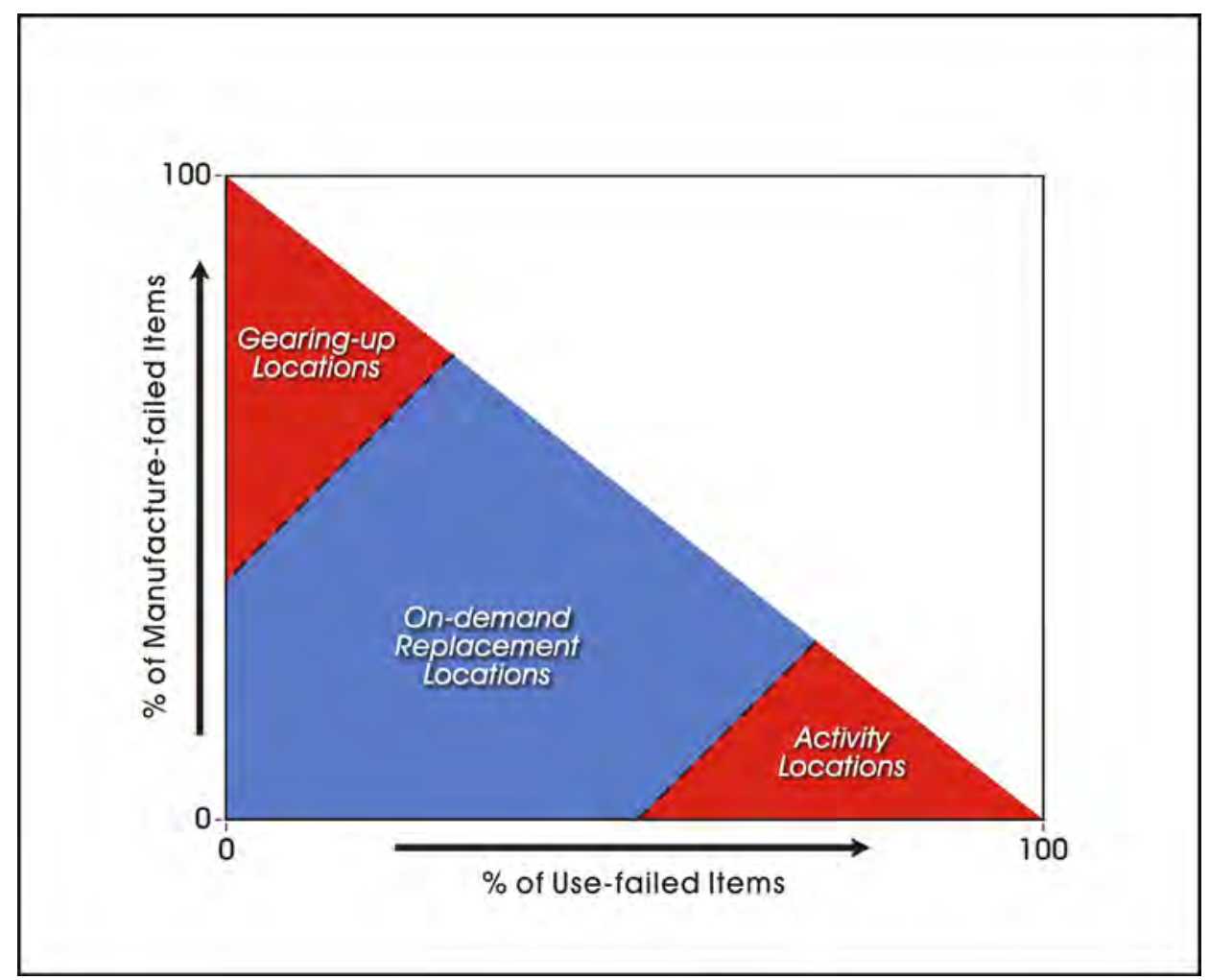

Figure 13-4. Proposed relationship between breakage patterns and tool production (on-

demand vs. gearing-up) strategies.

depend on a variety of factors (e.g., failure rates, production trajectories, activity levels). Though we cannot account for all these factors and we realize that gearing up and replacement activities occurred throughout all the periods, the model may still be useful for identifying broad trends.

Given the differences in manufacture rates between gearingup and on-demand tool replacement, we suggest that comparisons of failure rates (i.e., manufacture versus use) within functionally specific tool classes can be used to identify gearing up. We expect that during the Middle and Terminal Late Archaic, when resource procurement was more consistently organized on a day-to-day basis, tool failure and tool manufacture for on-demand replacement will result in roughly similar ratios of manufacture-failed to use-failed specimens within functionally specific groups (i.e., use and manufacture broken unifaces, knives, etc). That is, they should fall in the blue region of Figure 13-4. We expect that during the Initial Late Prehistoric, this pattern would begin to shift as bison availability declined. During the Terminal Late Prehistoric period, the emphasis will be on tool manufacture for future use resulting in higher ratios of manufacture-failed to use-failed specimens within functionally specific groups (i.e., use- and manufacture-broken unifaces, knives, etc.) at some locations, and high ratios of use-failed items at other locations. Terminal Late Prehistoric assemblages should fall in the red portions of the graph.

\section{Methods}

To search for the presence of gearing up in the prehistoric assemblages, we identified use-broken from manufacture-failed specimens in each functional category. Our identifications of the causes of failure were based on comparative specimens and descriptions of the break morphologies of experimentally broken items (Callahan 1979; Crabtree 1972; Johnson 1979, 1981; Muto 1971; Tomka 1986). Failure cause is defined within functionally specific formal tool categories (i.e., expensive to manufacture) to allow the identification of what aspect of the tool kits is responding to gearing up requirements. Because only specific resources would be targeted for bulk procurement during limited periods of availability, it is possible that only the tools associated with the procurement and processing of these resources will be manufactured in advance of actual need. We use contingency tables and bivariate plots to analyze these data. This data is from the same comparative study area outlined in Figure 9-15 and the four time periods that are well represented at 41KM69.

\section{Results}

Table 13-4 lists time periods (Column 2) at 41KM69, and the total number of tools reviewed for each component (Column 3). Non-hafted bifaces, projectile points, and hafted 
Table 13-4. Breakage Causes on 41KM69 Tools

\begin{tabular}{|c|c|c|c|c|c|c|c|c|c|c|c|c|c|c|}
\hline $\begin{array}{l}\vec{\Xi} \\
\overline{0} \\
\text { : } \\
00\end{array}$ & 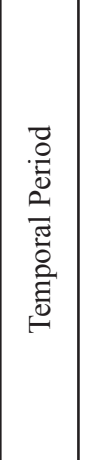 & $\begin{array}{l}\overrightarrow{0} \\
0 \\
0 \\
0 \\
0 \\
0 \\
0 \\
0 \\
0 \\
0 \\
0\end{array}$ & 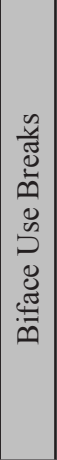 & 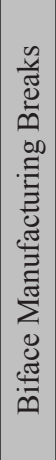 & 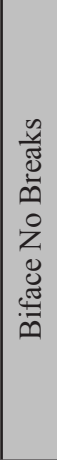 & 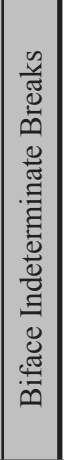 & 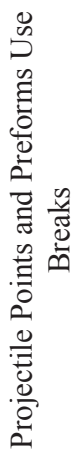 & 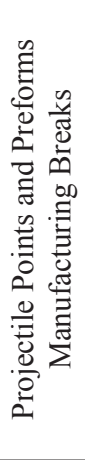 & 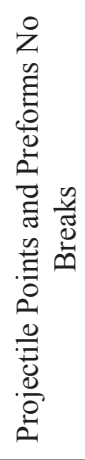 & 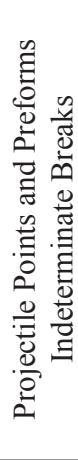 & 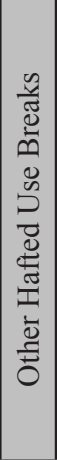 & 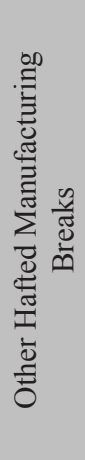 & 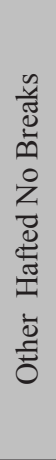 & 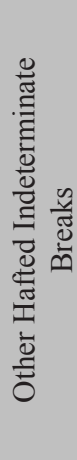 \\
\hline 41KM69 & \begin{tabular}{|l|} 
ILP \\
\end{tabular} & 107 & 17 & 46 & 12 & 9 & 7 & 0 & 0 & 3 & 4 & 5 & 3 & 1 \\
\hline 41KM69 & MLA & 39 & 6 & 13 & 2 & 5 & 5 & 2 & 2 & 2 & 0 & 1 & 1 & 0 \\
\hline 41KM69 & TLA & 73 & 5 & 31 & 2 & 8 & 20 & 0 & 2 & 3 & 0 & 0 & 2 & 0 \\
\hline 41KM69 & TLP & 38 & 2 & 7 & \begin{tabular}{|l|}
1 \\
\end{tabular} & 1 & 0 & 1 & 0 & 2 & 0 & 0 & 21 & 3 \\
\hline Totals & & 257 & 30 & 97 & \begin{tabular}{|l|l|}
17 \\
\end{tabular} & \begin{tabular}{|l|l|}
23 & \\
\end{tabular} & 32 & 3 & 4 & 10 & 4 & 6 & 27 & 4 \\
\hline
\end{tabular}

tools were each assessed for typed of break (manufacturing or use). For each of these three groups, the first column presents the number of tools broken through use, the second column lists the number broken during manufacturing, the third lists those items that did not have breaks, and the fourth column lists those tools where the cause of the break could not be determined.

Of the 90 hafted tools examined at 41KM69, half $(n=45)$ are complete or have indeterminate breakage patterns. The majority of the complete tools are unifaces from the TLP. Excluding these from the discussion, most tools across all analytical units at the site are broken from use and not from manufacture, though these are extremely small samples. Adding the complete hafted tools to the use category and the indeterminate breakage numbers to the manufacturing column also results in more breakage from use than by manufacturing. Use breaks hover around 60 percent in the MLA and ILP, 78 percent in the TLP and 89 percent in the TLA. However, most of the miscellaneous bifaces which are not hafted have manufacturing breaks. If this group is added to the hafted sample, the outcome reverses to 60 percent of the tools in each analytical unit from MLA through the ILP possessing manufacturing breaks, which suggests the components from this time period were used more commonly for tool production or gearing up than for tool use. During the TLP we see a shift when approximately 60 percent of the tools were broken during use, which suggests these tools came from sites where tool use was more common than tool manufacture. Never do breakage patterns from 41KM69 fall in the extreme upper left or bottom right of the distribution; rather, they hover around the center of the graph in the on-demand replacement area until the TLP when breakage shifts toward the gearing up portion of the graph with a 60 percent use failure rate. This can be seen in Figures 13-5 through 13-8 with the comparative sites discussed in the next section.

\section{Regional Comparison}

Using the same components assessed during the tool manufacturing cost study, we reviewed 446 tools from 10 Late Archaic and Late Prehistoric components and added them to the dataset of 906 tools from 9 other components already examined from other projects. Table 13-5 lists all 19 components (Column 1) with the same layout as Table 13-4 above. As with the 41KM69 tools collection, tools types were grouped by breakage (from either manufacture or use). Items with no breaks were grouped as use breaks and, items with indeterminate breaks were grouped as manufacturing breaks.

Once grouped, items were plotted by time period as a percentage of the total tools reviewed. Three of the four MLA components cluster in the center of the graph near the 50 percent manufacture-failure, 50 percent use-related point. One component (41MV120) falls in the 80 percent manufacture failure portion of the graph. The three components in the TLA distribution all cluster in the center of the graph with 41BX300 falling in the exact middle at the $50 / 50$ break point. The five ILP components all cluster around the 50-60 percent manufacture-failed area except $41 \mathrm{MC} 296$, which is at 70 percent manufacture-failed. The seven TLP components form three groups. Three between 56-58 percent manufacture fail rates, three between 42 and 49 percent manufacture fail rates, and one (41KM69) at a 63 percent use-fail rate, which is the highest use-fail component in the comparative collection. 


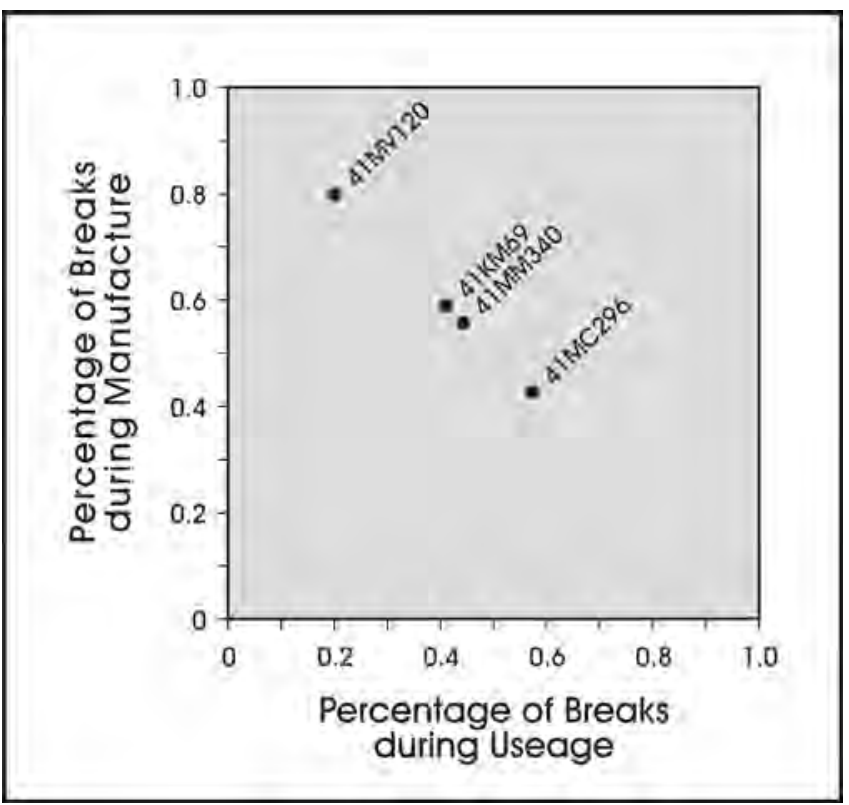

Figure 13-5. Middle Late Archaic tool breakage patterns across the comparative study area and 41KM69.

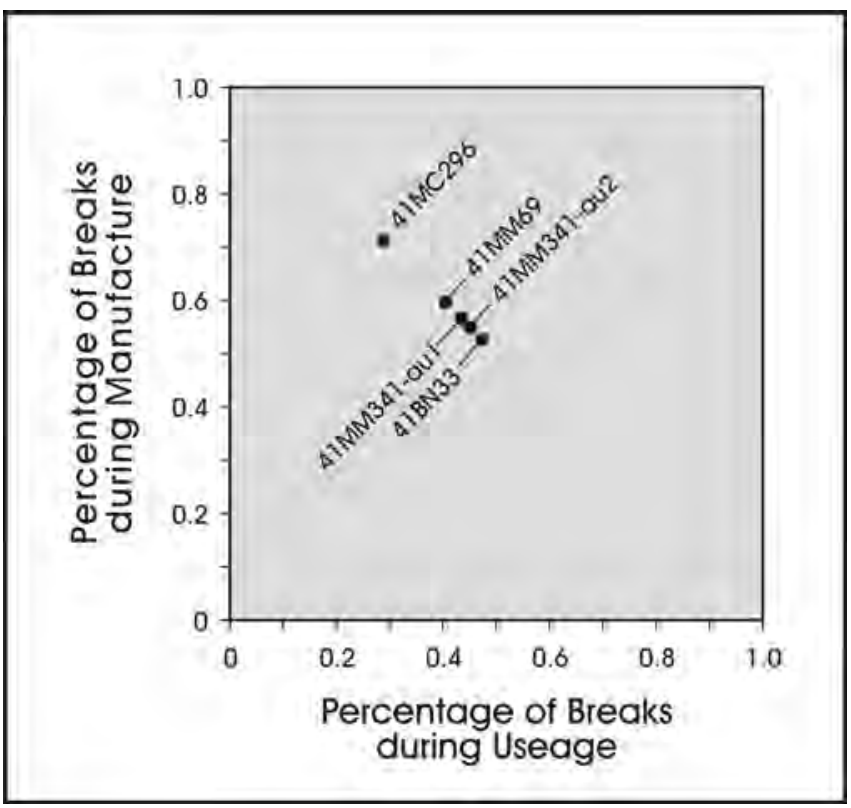

Figure 13-7. Initial Late Prehistoric tool breakage patterns across the comparative study area and 41KM69.

In the "Gearing Up" section of the Technological Organization study, we predicted on demand replacement of tools with close to a 50/50 between manufacture and use breakage patterns during periods when bison were relatively abundant during the earliest period of study, the MLA, and an increasing pattern of gearing up indicated by higher ratios of the breakage groups through time, the highest being in the TLP when bison were relatively scarce. We also recognized that

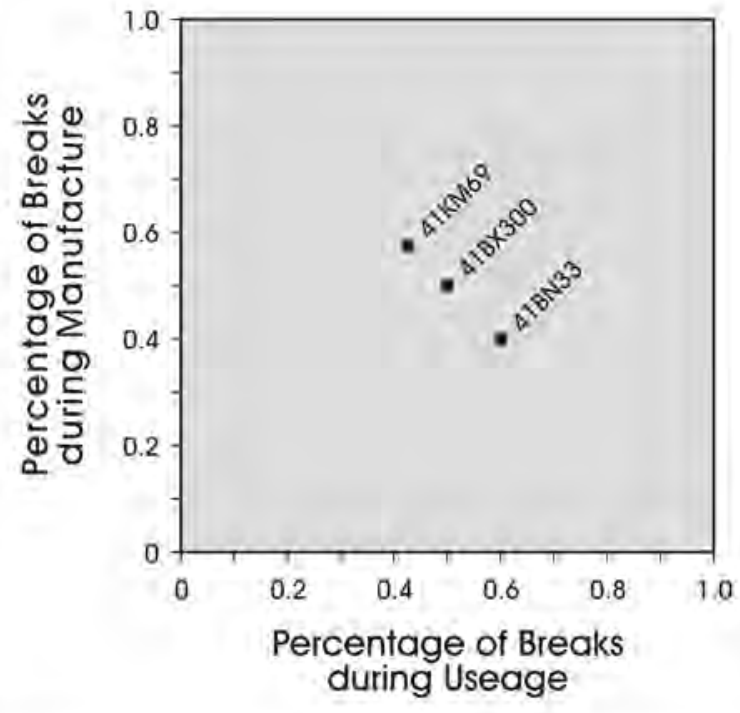

Figure 13-6. Terminal Late Archaic tool breakage patterns across the comparative study area and 41KM69.

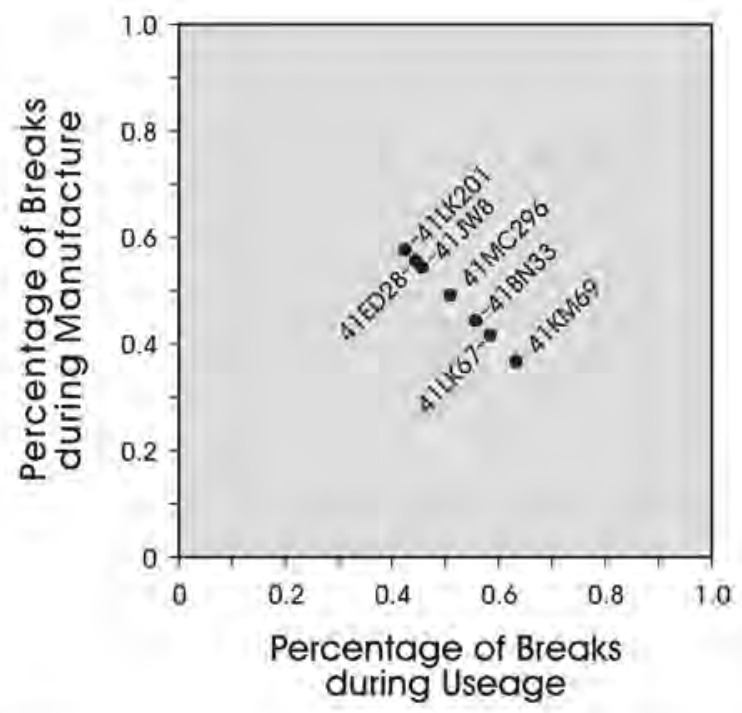

Figure 13-8. Terminal Late Prehistoric tool breakage patterns across the comparative study area and 41KM69.

all patterns should be present to some degree throughout the study period. The graphs in Figures 13-5 through 13-8 show most components clustering in the center of the graph at the 50 percent break indicating an on-demand replacement strategy. Few components reach percentages above 60 percent manufacture failure rates (41MC296-ILP, 41MV120-MLA) or use failure rates (41BN33-TLA and 41KM69-TLP) which indicate a trend toward gearing up. In these cases, samples 
Table 13-5. Breakage Causes on Comparative Tools

\begin{tabular}{|c|c|c|c|c|c|c|c|c|c|c|c|c|c|c|}
\hline 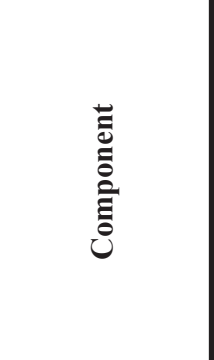 & 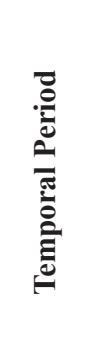 & 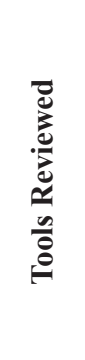 & 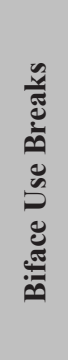 & 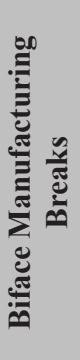 & 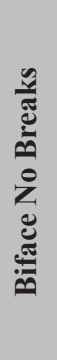 & 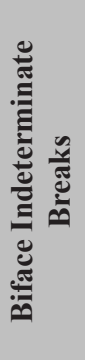 & 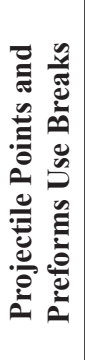 & 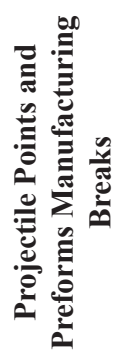 & 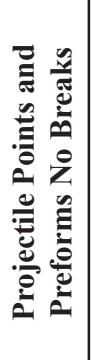 & 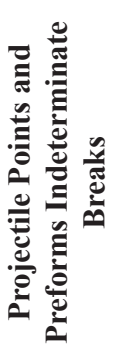 & 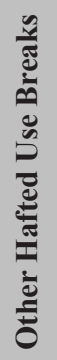 & 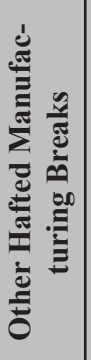 & 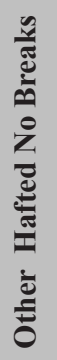 & 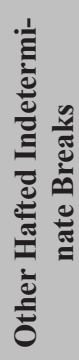 \\
\hline 41BN33 & ILP & 36 & 0 & 10 & 1 & 2 & 13 & 6 & 1 & 0 & 2 & 1 & 0 & 0 \\
\hline 41BN33 & TLA & 5 & 0 & 2 & 0 & 0 & 3 & 0 & 0 & 0 & 0 & 0 & 0 & 0 \\
\hline 41BN33 & TLP & 36 & 1 & 7 & 1 & 3 & 13 & 5 & 3 & 1 & 0 & 0 & 2 & 0 \\
\hline 41BX300 & TLA & 8 & 0 & 3 & 1 & 0 & 3 & 1 & 0 & 0 & 0 & 0 & 0 & 0 \\
\hline 41ED28 & TLP & 99 & 13 & 34 & 5 & 11 & 17 & 5 & 2 & 3 & 7 & 0 & 1 & 1 \\
\hline 41JW8 & TLP & 338 & 42 & 101 & 12 & 41 & 56 & 18 & 31 & 21 & 6 & 2 & 3 & 5 \\
\hline 41KM69 & ILP & 107 & 17 & 46 & 12 & 9 & 7 & 0 & 0 & 3 & 4 & 5 & 3 & 1 \\
\hline 41KM69 & MLA & 39 & 6 & 13 & 2 & 5 & 5 & 2 & 2 & 2 & 0 & 1 & 1 & 0 \\
\hline 41KM69 & TLA & 73 & 5 & 31 & 2 & 8 & 20 & 0 & 2 & 3 & 0 & 0 & 2 & 0 \\
\hline 41KM69 & TLP & 38 & 2 & 7 & 1 & 1 & 0 & 1 & 0 & 2 & 0 & 0 & 21 & 3 \\
\hline 41LK201 & TLP & 156 & 10 & 60 & 8 & 6 & 12 & 16 & 20 & 3 & 2 & 4 & 14 & 1 \\
\hline 41LK67 & TLP & 12 & 4 & 2 & 1 & 0 & 1 & 2 & 1 & 1 & 0 & 0 & 0 & 0 \\
\hline $41 \mathrm{MC} 296$ & ILP & 14 & 3 & 4 & 1 & 5 & 0 & 1 & 0 & 0 & 0 & 0 & 0 & 0 \\
\hline $41 \mathrm{MC} 296$ & MLA & 7 & 3 & 2 & 0 & 1 & 1 & 0 & 0 & 0 & 0 & 0 & 0 & 0 \\
\hline $41 \mathrm{MC} 296$ & TLP & 63 & 8 & 7 & 2 & 10 & 10 & 9 & 10 & 5 & 1 & 0 & 1 & 0 \\
\hline 41MM340 & MLA & 86 & 12 & 29 & 3 & 8 & 11 & 7 & 12 & 4 & 0 & 0 & 0 & 0 \\
\hline 41MM341-au1 & ILP & 141 & 7 & 53 & 26 & 12 & 14 & 6 & 9 & 4 & 2 & 4 & 3 & 1 \\
\hline 41MM341-au2 & ILP & 89 & 8 & 34 & 14 & 9 & 9 & 2 & 6 & 2 & 1 & 1 & 2 & 1 \\
\hline 41MV120 & MLA & 5 & 0 & 4 & 0 & 0 & 1 & 0 & 0 & 0 & 0 & 0 & 0 & 0 \\
\hline Totals & & 1352 & 141 & 449 & 92 & 131 & 196 & 81 & 99 & 54 & 25 & 18 & 53 & 13 \\
\hline
\end{tabular}

sizes are all under 10 except at 41KM69, where the sample size is 38 . Despite sample size issues, there is not a pattern of increased gearing up evident on the comparative sites through time as predicted.

\section{Summary}

This chapter presented the data used to investigate technological organization from the Middle Late Archaic through the Terminal Late Prehistoric and the effects of changing bison availability at both the site level at 41KM69 and across the comparative region. The first section of the chapter focused on the cost of manufacturing tools. The second section examined tool breakage patterns for evidence of gearing up for future need versus on demand replacement. As bison numbers gradually declined from the Middle Late Archaic through the Terminal Late Prehistoric, we anticipated an increase in tools that were expensive to produce and increased evidence of gearing up for bison hunts ${ }^{\text {(note } 2)}$.
Overall, we see a trend from general to specialized tools across the analytical units at 41KM69 and across the study area with the greatest use of flake tools in the Middle Late Archaic and greatest use of hafted tools in the Terminal Late Prehistoric, though the trend wavers during the middle of the time span under consideration, specifically during the Initial Late Prehistoric. The tool kits from Initial Late Prehistoric resemble the Middle Late Archaic toolkit.

No clear evidence of gearing up was present in the site specific or the region breakage data either. Assuming a gradual decrease in bison from the Middle Late Archaic on, we expected a trend in breakage patterns from low to high ratios of use and manufacture-failed tools that would indicate increased gearing up. The site-specific data shows a stable relationship until the Terminal Late Prehistoric, when an increase in use-failures occurs. At the regional level, this trend is not supported. Most components keep a low ratio throughout the selected time periods. 



\title{
Chapter 14: Investigating Changes in Projectile Weapons Technology
}

\author{
Steve A. Tomka and Raymond P. Mauldin
}

In Chapter 9 we argued that bison populations were slowly decreasing during the Late Archaic and that even once their densities began to increase again during the Initial Late Prehistoric bison populations tended to have a relatively restricted spatial distribution and increased fluctuation in year-toyear availability. It is our opinion that these changes in bison availability set in motion significantly changes in weapons technology during the Late Archaic and that these changes culminated in the adoption of bow and arrow technology during the Initial Late Prehistoric Period. Below we outline this argument in greater detail and present the result of projectile point analyses conducted to investigate trends in weapons technology as manifested in the archaeological record.

\section{The Characteristics of Principal Prey Species: Bison, Antelope, and Deer}

Bison are large animals. They are reasonably slow to frighten, are unlikely to react by rapid flight, and have a slow initial speed. Bulls range from 1,600 to 2,200 lbs (727-1,000 kg), while cows weigh 700-900 lbs (318-409 kg). These animals have well-developed senses of smell and hearing that they use to detect approaching threats (McHugh 1972:148-149). While they can detect objects in motion from a distance, bison have poor eyesight, and camouflaged objects may remain visually undetected (McHugh 1972:149). Bison are frequently in herds, with herd size influenced by habitat and weather. On open plains and during inclement weather buffalo often form closely bunched groups of several hundred individuals (McHugh 1972:153-154).

Thick hides protect the bodies of bison, and a massive rib cage offers added protection to vital organs. Measurements of a sample of five sub-adult bison ribs from the CAR comparative faunal collection show that near the proximal articular end, at the middle, and near their distal ends, they have a mean thickness of $13.1,13.9$, and $13.5 \mathrm{~mm}$, respectively. In addition to being quite thick, these ribs are also relatively wide measuring 20.4, 24.8, and $24.52 \mathrm{~mm}$ at the 3 respective locations along the rib.

Antelope and deer are medium-sized mammals with rapid flight response and great initial speed. Antelope bucks weigh between 90-125 lbs (41-57 kg), while females seldom exceed $90 \mathrm{lbs}(41 \mathrm{~kg})$. Deer bucks range between 70-200 lbs (32$91 \mathrm{~kg})$, while does are between $60-90 \mathrm{lbs}(27-41 \mathrm{~kg})$. While deer depend on hearing and smell to detect danger (Hiller
1996:32-39), antelope have excellent eyesight that can detect approaching threats from long distances on the open prairie (O'Connor 1961:69-70). Both species have the ability to react to danger instantaneously, with a frightened deer or antelope able to pick up speeds of 30-35 miles an hour in a matter of seconds (Hiller 1996:32; O’Connor 1961:70). Neither deer nor antelope have a strong grouping tendency.

Most of the time, deer and antelope are present in small groups along the forest edge or on the open prairie. Their bodies are lighter overall and thin skin and more gracile rib cages protect their vital organs. Measurements of a sample of eight sub-adult deer ribs from the CAR comparative faunal collection showed that near the proximal articular end, at the middle and near their distal ends, they have a mean thickness of 5.25, 3.99, and $3.03 \mathrm{~mm}$, respectively. A sample of nine sub-adult antelope ribs had the following thickness at the same loci: 5.07, 4.23, and $2.51 \mathrm{~mm}$. In addition to being quite thin, the ribs of these animals are narrow. For deer, we recorded means of $8.2,10.6$, and $14.1 \mathrm{~mm}$ at the 3 respective locations. For antelope, the means were 7.87, 10.02, and $15.5 \mathrm{~mm}$.

\section{The Characteristics of Hunting Weapons: Atlatl and Bow and Arrow}

Atlatl darts generally range in length from 142 (Raymond 1986: Table 2) to $276 \mathrm{~cm}$ (Cotterell and Kamminga 1990) and weigh from 52 to 600 grams (Raymond 1986: Table 2 and Cotterell and Kamminga 1990:168). Replicated darts propelled by atlatl generally reach initial speeds of 19.4 to 23 meters per second (Bergman et al. 1988: Table 1; Raymond 1986: Table 3). The effective range of the atlatl dart appears to be between 30-50 yards (Churchill 1993: Table 1.4; Cotterell and Kamminga 1990:161-175). The kinetic energy of darts at impact tends to be relatively high ( 15.43 joules for a 70 gram dart), due primarily to the weight of the dart.

The dimensions of arrows tend to conform to draw-length of the individual hunter but tend to range from 53 ( 21 inches) to $96 \mathrm{~cm}$ (38 inches; Van Buren 1975: Table 1) and weigh between $.46(14 \mathrm{~g})$ to 4 ounces (435 g; Van Buren 1975:84 Table 1). Arrows shot with reproductions of traditional bows reach flight speeds between 30 to $40 \mathrm{mps}$ (Raymond 1986:Table 5) and even up to $60 \mathrm{mps}$ (Hamm 1989:107; 60\# Osage Orange bow). The effective range of the bow and arrow appears to be around 20-30 yards (Churchill 1993: Table 1.4; Pope 
1918:126), although in some instances, it may reach as much as 50 yards (Ray 1976; Schambach 1995). The kinetic energy of arrows at impact tends to be less than that of darts due primarily to the smaller mass of arrows versus darts. However, the higher speed of arrows fired from powerful bows can compensate for lower mass. For instance, a 28 -gram arrow shot from a $40 \mathrm{lbs}$ bow has a kinetic energy of 12.6 joules while the same arrow shot from a $50 \mathrm{lbs}$ English longbow has a kinetic energy that exceeds that of the 70-gram dart (22.4 joules; Raymond 1986).

While strategy is a critical element in a successful hunt, the two weapons systems also have some inherent characteristics that provide some advantages and disadvantages to their users. Christensen (1986:122) identifies several advantages of bows and arrows. First, the projectile has a higher initial velocity than the dart. The bow and arrow combination has a greater accuracy than the atlatl dart due to its higher velocity and because it is back-sighted. The arrow has a longer effective range than the dart. The bow and arrow can be easily employed in wooded areas and cramped situations. A bow hunter can carry a larger supply of projectiles and arrows and can fire more rapidly than hunters armed with an atlatl. The construction of arrows requires less material than the construction of darts. Finally, shooting an arrow affords a greater degree of concealment that may allow more than one shot at the prey because it requires less violent movement and arrows can be delivered from a variety of positions.

In contrast, Christensen (1986:122) identifies only three advantages that may derive from atlatl use. First, it requires only one hand to operate. Second, it is easier to manufacture and maintain than the bow/arrow. Finally, the darts have higher impact force than arrows. Two additional factors are worth mentioning. First, during use, the atlatl experiences lower levels of mechanical stress and therefore, it is less likely to fail. Second, once failure occurs, the manufacture of a replacement atlatl requires less time than the manufacture of a bow and several arrows using aboriginal tools (Spencer 1974; Mickey Miller, Personal Communication 2006).

Larralde (1990) provides an additional perspective on weapons technology. She divides weapons and projectiles into three groups based on the manner in which they help immobilize prey: high impact, surgical and low impact weapons. High impact weapons immobilize prey species through the impact of heavy and/or multiple projectiles that cause systemic shock and/or the breakage of limbs or joints. Shock value is derived from projectiles that strike the prey without opening a wound through the hide or by a combination of numerous high velocity impact wounds that initiate a systemic shock in the animal. Hunters use surgical weapons to im- mobilize game by penetrating their vital organs and arteries. The projectiles involved are light but are effective when they injure vital organs. Finally, low-impact weapons immobilize game by introducing poisons into their bloodstream.

Both arrows and darts can serve as high impact weapons, since the definition is dependent on prey size. That is, hunters may use an arrow tipped with a wooden blunt to bring down effectively a rabbit or squirrel. They may also use a dart tipped with a blunt to bringing down waterfowl. Blunts have been consistently found with both dart and arrow mainshafts (see Guernsey and Kidder 1921: plate 34; Sharrockand Keane 1962: Figure 12n). This suggests that hunters have used both weapons to hunt a variety of small prey.

A final consideration related to weapons technology is the hunting strategies under which the weapons are used. Five distinct hunting tactics can be identified among hunter-gatherers: disadvantage, ambush, approach, pursuit, and encounter. Disadvantage hunting involves the use of landscape features (i.e., lakes, ravines, etc) to prevent or slow the flight of animals as they are harvested. Ambush hunting involves the concealment of the hunter and the dispatching of prey as it passes nearby. Approach hunting involves the stalking of animals to within weapons range.

Pursuit hunting entails the chasing of a prey until the hunter is sufficiently near it to discharge the weapon. Encounter hunting represents the taking of prey as the hunter is on the move. A review of the hunting conditions under which the two weapons systems are used among historic and extant hunter-gatherers from throughout the world conducted by Churchill and Curran (1991) and Churchill (1993) indicates that at least within the number of available cases, atlatl propelled darts are used on small targets within the context of encounter hunting (Figure 14-1). However, this pattern may simply be the result of the absence of large-bodied prey species within regions where atlatls are used today (see also Churchill and Curran 1991). In the sample examined, atlatls were used exclusively in ambush and approach hunting. Interestingly, hunters used hand-thrown spears in four hunting strategies and they were commonly used in disadvantage and pursuit hunting. In these instances, the spear was used to immobilize medium to large prey $(200-350 \mathrm{~kg})$. Hunters use the bow and arrow in a variety of context and for a broader range of prey species and body-sizes. However, the mean weight of the prey against which the bow and arrow was employed was around $225 \mathrm{~kg}$ (Churchill and Curran 1991: Figure 2), indicating that the weapon tended to be used against medium to large prey. However, it was the hand-thrown spear and thrusting spear that hunters consistently used for the largest and heaviest of prey. 


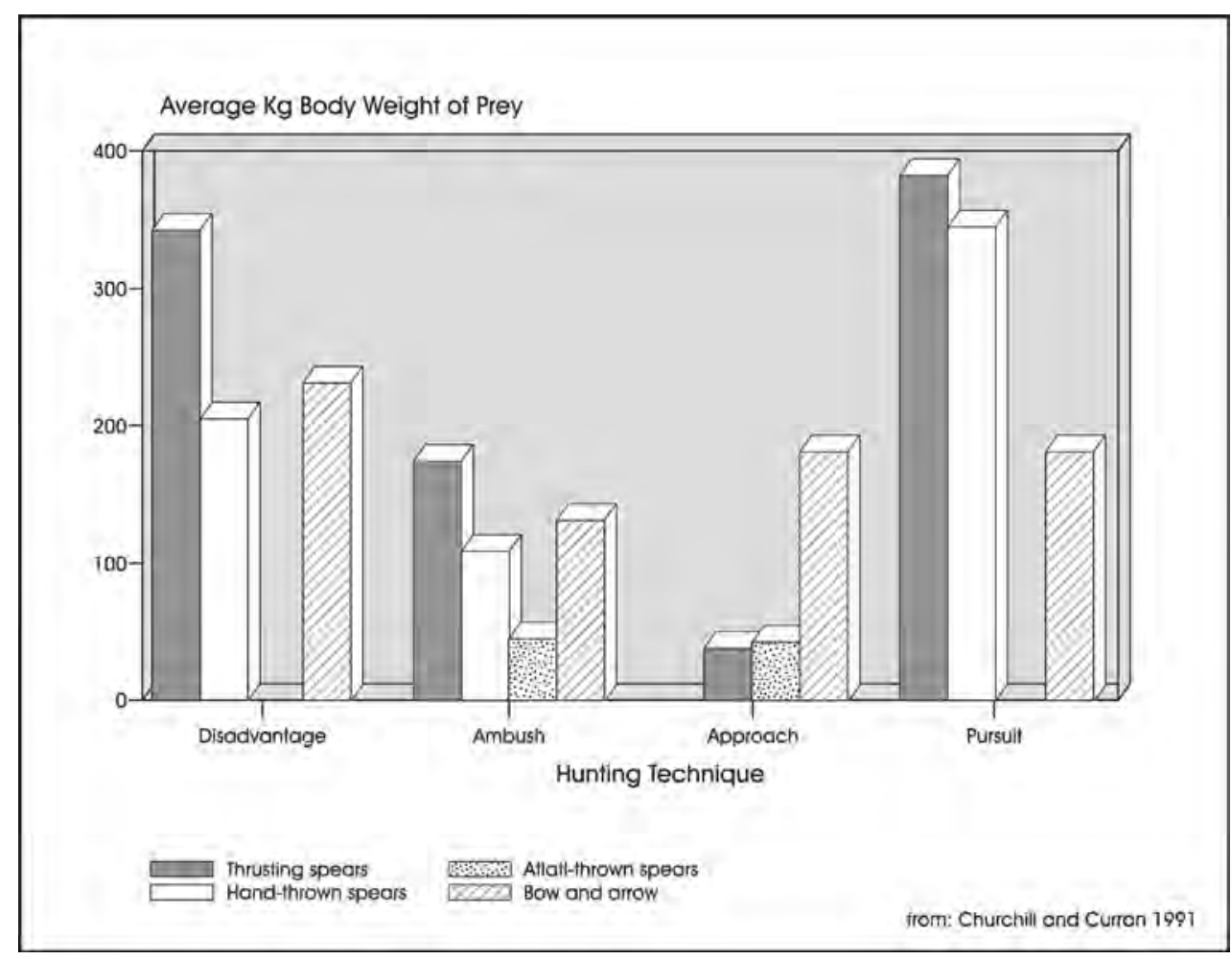

Figure 14-1. Relationship between prey body weight, hunting technique, and weapon type.

Based on the characteristics of the weapon systems and prey species reviewed above, we assume that a correlation exists between prey size and projectile weight. Other things being equal, the heavier the prey, the more likely it is that hunters will use heavy projectiles in an attempt to bring it down. Other things are not, however, equal. The hunting record (see Churchill and Curran 1991) and the archaeological evidence indicates that there are exceptions to this general principle in that heavy projectiles may, on occasion, be used in hunting small prey (i.e., blunts on darts and arrows used to immobilize small prey). In addition, hunters may use light projectiles to bring down heavy prey such as the use of arrows in buffalo hunting (McHugh 1972). While the former exception requires little explanation, the latter is worth considering in more detail.

Historic hunters have used light arrows fired from bow in buffalo hunting. During the historic period, the bow and arrow was often employed to dispatch animals that were disadvantaged and could not flee, and multiple arrows were used to bring down the target. Other times, while the hunter was in pursuit of the prey (i.e., mounted hunters), arrows were fired from close range and with relative precision to damage vital organs and quickly incapacitate the animal. Again, multiple arrows were necessary to bring down the animal if the initial shot missed its target. Approach hunting with camouflage also was used to insure a closer shot. Better aim and greater arrow penetration were the advantages of the reduced range.
Based on the above review of weapon system characteristics, hunting strategies and ethnographic examination of hunting practices, it appears that as the body-weight of the prey decreases, there is a lessening for the need for close range and multiple arrows to dispatch the animal. Close range increases precision in the placement of the projectile but is less necessary as the prey size decreases. It appears that in the small to medium weight prey classes, it is no longer necessary to disadvantage the prey or to place the arrow with surgical precision because the power of the weapon system and the kinetic power of the arrow are sufficient to bring down the prey. In contrast to the speedy and light arrow, the slower but heavier atlatl dart may be more effective than the arrow. Its increased effectiveness may derive from its weight. Although a dart may hit a target slower than an arrow, it will outperform all but the fastest arrows in terms of kinetic energy when it gets to the target. Kinetic energy relates to penetration. It determines how far a projectile will penetrate into the target. Even more importantly, because the penetration of a solid object depends on the momentum of the projectile rather than its kinetic energy, the heavier dart will be superior in terms of momentum when compared to the arrow.

Having provided these generalizations, how can we assess whether the arguments put forth have any support in real-life conditions? To answer this question the author turned to the bow hunting literature since the hunting of deer and smaller bodied prey species has a long tradition in modern American. 
As the power of bows increased through the use of modern technology, bow hunting has been extended to the hunting of large and very large game animals such as grizzly bear and elk in North American and cape buffalo and other large game in parts of Africa. The hunting of these very large prey species has brought into focus the weaponry requirements necessary to effectively harvest very large game versus the medium prey species traditionally hunted with bows and arrows. Specifically, based on the effectiveness of bow hunting prey of different sizes with modern compounds bows, recommended limits have been defined in terms of arrow momentum for small to very large game species. While a number of factors affect weapon lethality (including kinetic energy, and projectile sectional density), the momentum of the projectile is one of the principal factors that affects projectile penetration into the body cavity and therefore the likelihood that the animal will be mortally wounded.

Table 14-1 shows the ranges of arrow momentum by game animal size category recommended to effectively bring down a target. It is evident that very large prey species are mortally wounded with arrows that deliver 65 foot pounds or more of momentum while medium sized prey can be effectively brought down by arrows that deliver significantly less momentum. Momentum is the product of arrow speed and mass with mass being calculated by dividing the projectile's weight by a gravitational constant (32.2). While these ranges in projectile momentum have been defined for bow hunting, they should be equally valid for other weapon systems, such as the atlatl propelled dart. More importantly, they may be used as yardstick of the effectiveness of traditional weapon systems in harvesting distinct prey species.

Surveys of Native American bows and arrows by Mason (1894), Pope (1923), Hamilton (1982) and others, coupled with experiments using reproductions of prehistoric bows, and experimentation with atlatl and dart replicas (Hill 1948; Hutchings and Büchert 1997) allow us to define the general characteristics of traditional bows and arrow weapons and the atlatls and darts. These characteristics are summarized by several authors including Raymond (1986), Miller et al. (1986), Bergman et al. (1988), Cotterell and Kamminga (1990), Van Buren (1975), Hill (1948), and Hutchings and Büchert (1997). Even more importantly, in a few instances,

Table 14-1. Recommended Arrow Performance by Game Animal Size

\begin{tabular}{|c|c|}
\hline Size of Game & Momentum (slug feet/sec)* \\
\hline Small & $<.24$ \\
\hline Medium & $.25-.45$ \\
\hline Large & $.46-.56$ \\
\hline
\end{tabular}

*http://www.eastonarchery.com/store/kinetic_calculator these surveys and experiments provide key data allowing us to calculate the momentum of arrows compared to dart replicas. Even more importantly, in a few instances, these surveys and experiments provide key data to allow us calculate the momentum of arrows versus replicas of atlatl darts. Table 14-2 contrasts the momentum of selected arrows and darts. The three arrows shown in the table are fired by traditional Apache and Sioux bows and a replica of the Mounds Plantation bow recovered in Louisiana (Webb and McKinney 1975:104-105; Schambach 1995:16-17). The replica long bow pulls $70 \mathrm{lbs}$ at full draw and represent one of the most powerful prehistoric bows on record. Data for the faster of the two darts derives from experiments conducted by Hutchings (Hutchings and Büchert 1997) while the momentum of the slower dart is calculated based on dart velocities reported in the literature (Raymond 1986:Table 3; Miller et al., 1986:Figure 1). The calculations show that significant differences exist in the momentum of arrows and darts 30-meters down range, the generally reported effective range of these weapons.

Table 14-2. Momentum Values for Bow/Arrow and Atlatl/Dart Weaponry

\begin{tabular}{|c|c|}
\hline Weapon & Momentum \\
\hline Sioux Bow/Arrow & 0.1830 \\
\hline Apache Bow/Arrow & 0.2448 \\
\hline Mound Plantation Bow/Arrow & 0.5000 \\
\hline Slowest Experimental Atlat1/Dart & 1.4044 \\
\hline Fastest Atlatl/Dart & 2.2521 \\
\hline
\end{tabular}

*Momentum figures calculated from data presented in Hutchings and Buchert 1999

Comparing these momentum values with the recommended ranges in momentum for prey species of distinct size, it is notable that the 28-30 gram arrows fired from traditional bows do not have the minimum momentum to serve as effective projectiles against very large prey. Only a 50-gram arrow shot from the very powerful Mound Plantation bow replica, has the momentum to be effective against large game. The 50 -gram arrow is nearly twice the weight of traditional arrows recorded by Pope (i.e., Apache, Osage, Cree, Cheyenne, Blackfoot, Sioux, and Tomawata), and the bow replica is significantly more powerful than the typical traditional bows described by Pope and others. It is unlikely therefore, that traditional bows shooting traditional arrows would generate momentum figures near or just above those of the Apache and Sioux arrows. In contrast, the atlatl-propelled dart retains sufficient momentum to effectively penetrate the body cavity of very large prey even when launched at a relatively slow speed of $21 \mathrm{~m} / \mathrm{sec}$.

Based on these observations, we suggest that the Atlatl/Dart system with its slower flying but heavier projectile is well suited to the hunting of large and very large game species. 
In contrast, the bow and arrow with it lighter but faster projectile is best suited for hunting medium and small game. In addition to adequate penetration of medium prey species, the higher speed of arrows compensates for the increased reaction speeds of species such as pronghorn antelope and deer. These species react instantaneously to the sound of the bowstring that travels at about 1100 feet per second, much faster than the speed of the arrow (approx., 120-150 ft/sec). Projectile speed is less critical with the slower moving large bodied, and slower to react prey such as bison.

\section{A Model of Weapons Change}

In constructing a model of change in projectile point technology throughout the Late Archaic and Late Prehistoric periods, based on the previous characterizations, we begin with the assumption that the atlatl/dart weapons system was well adapted to the hunting of the larger bodied bison present during the Late Archaic. As bison densities decrease over time, we expect a more frequent reliance on the next lower ranked prey species, deer and antelope. However, given the characteristics of the atlatl/dart, this weapons system would not have been ideal for the medium sized prey. The smaller and faster deer and antelope required a faster projectile to compensate for their rapid reactions.

One technological change that could improve flight speed would be decreased weight. While decreasing projectile point weight decreases the weight of the overall projectile, the gains may be relatively small. The weight of a projectile point typically constitutes a small part of the overall weight of the projectile. A greater decrease in the overall weight of the projectile would be achieved by decreasing the weight of the shaft. The most effective strategy, of course, would be to decrease the weight of both the shaft and of the projectile point. Hunters can achieve decreased shaft weight through at least two design strategies or combinations thereof: 1) employing lighter materials (i.e., replacing a hard wood shaft with a cane shaft), and 2) decreasing the diameter of the shaft. While decreasing the length of the main shaft and complimenting it with a foreshaft (i.e., mainshaft and foreshaft combinations) may appear to result in a lighter shaft, measurements carried out by Tomka do not support this. Replicas of foreshafts made of Roosevelt willow (Baccharis neglecta), a species that was available prehistorically and that grows straight shoots, consistently weighed more than an equal length and diameter giant cane (Arundo donax) shaft piece. The solid wood foreshaft weighed anywhere from 6.5-2.7 grams more than the cane equivalent dependent on the length and diameter of the foreshaft. The weight difference would have been even greater if prehistoric hunters used native common reed (Phragmatis communis) because it has thinner walls than the giant cane.
A decrease in shaft weight is difficult to gauge in an archaeological context given the poor preservation of organic components of weapon systems. However, since a decrease in foreshaft diameter will prompt a narrowing of the projectile point neck width, it is possible to use projectile point neck width as a proxy measure of changes in shaft weight as reflected by a reduction in shaft diameter. In addition, design strategy that reduces projectile point weight by reducing both the weight of the shaft and the projectile point, would be reflected in a decrease in projectile point weight over time.

We mentioned earlier that bison populations would have varied across space and time between the Late Archaic and Late Prehistoric periods. Furthermore, even when present in large densities, it is likely that bison were not ubiquitous across the state. As shown in Figure 14-2, McDonald (1981) indicates that the primary range of bison in Texas was limited to the northwestern part of the state. Reviews of CRM reports published over the past 35 years suggest that archaeological sites and/or components with bison remains tend to distribute across the central part of the state (see Appendix J) perhaps representing the secondary range of bison in the state. East, South, and West Texas may not have had large/dense populations at any time during the 4,000-year sequence.

We anticipate that bison, deer and pronghorn would likely have been part of most prehistoric optimal foraging diets. Due to its higher post-encounter return rates, bison would have been the principal target while encounter rates remained high. However, we would expect that as bison encounter rates decreased over time, hunter-gatherer populations would have regularly targeted medium prey species such as deer and pronghorn. In addition, because East, South and West Texas appear to have been outside of the prehistoric range of bison, we would expect that hunter-gatherers in these regions would have primarily targeted deer and/or pronghorn antelope, where available.

We further expect weapons systems to be designed to be effective in the procurement of the prey species that constitute the bulk of the animal protein consumed during the annual cycle. Also we expect that throughout their primary and secondary range, when bison were present in high densities over long periods of time, the weapon system employed by hunter-gatherers would have been tailored to facilitate their effective procurement. Specifically, the weapon system would be geared for maximum penetration derived from projectile weight. However, as the density of bison decreases over time, and medium species become the predominant prey, we expect that there would be a modification in the weapon to make it better suited to the hunting of medium prey species. The modification we expect under these conditions should result in an increase in projectile velocity in response to the 


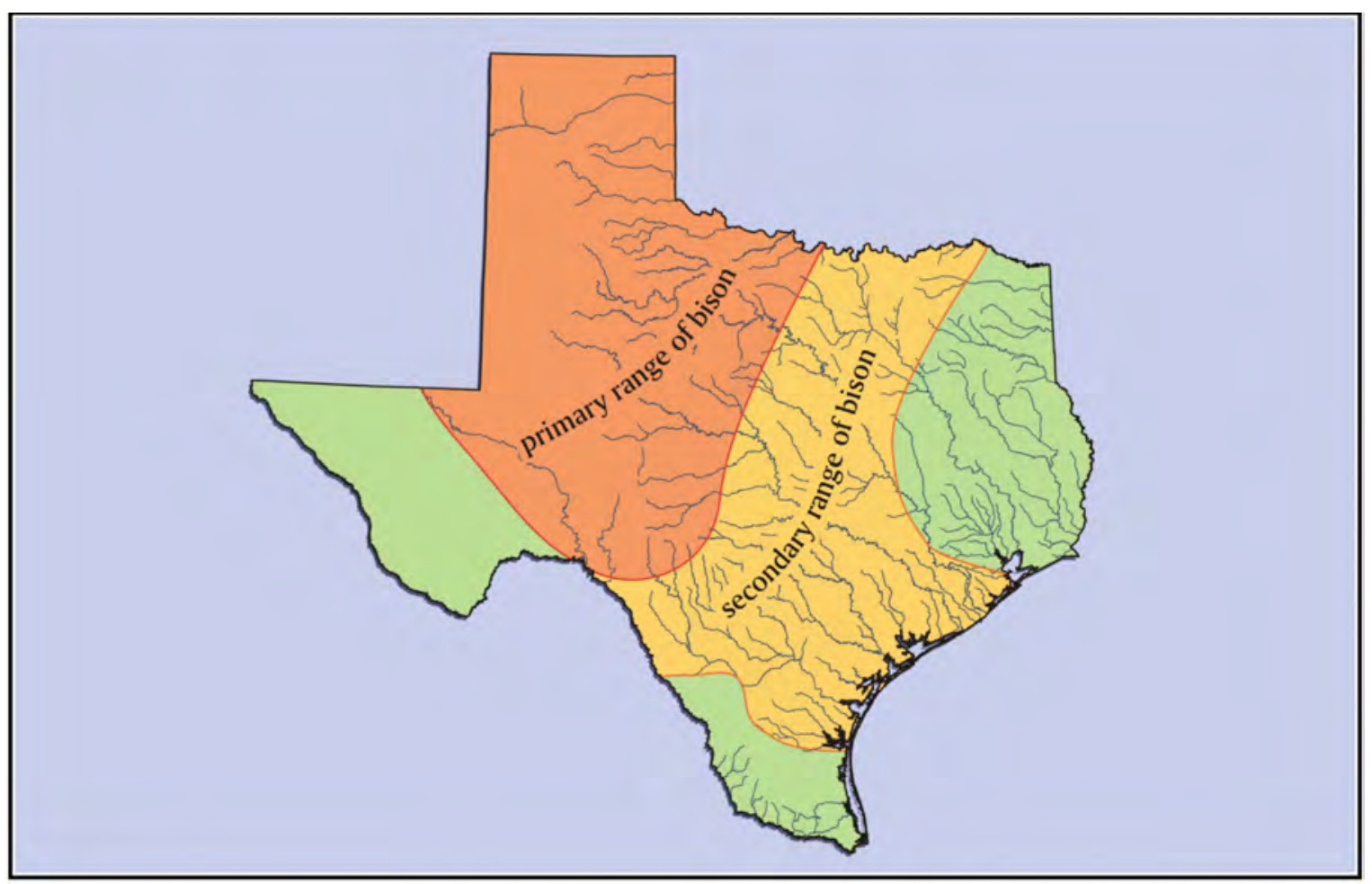

Figure 14-2. Reconstructed prehistoric bison range.

higher reaction speed of medium prey species such as deer and antelope. Finally, we propose that in regions of the state where deer or other medium game species were the dominant prey and bison was infrequently encountered, projectile velocity would have been at a premium at all times.

To investigate how these proposed temporal and regional trends in weaponry compare to archaeological assemblages of projectile points, we collected or assembled data on projectile point neck width and weight from four parts of the state including central, east, west and south Texas, as shown in Figure 14-3). There are 93 named dart and arrow points in these four regions spanning the period between the late Middle Archaic and the Late Prehistoric.

A sample of points from Central Texas for which data was collected is shown in Figure 14-4. Because there can be significant variability within the same type and between types falling within a time period, rather than looking at individual projectile point types, we calculated the mean neck widths and weights of samples of projectile points spanning the late Middle Archaic, the first and second halves (early and terminal, respectively) of the Late Archaic and the Late Prehistoric. Also, rather than looking at trends in each region individually, we combined the point samples into those derived from regions where bison would have been present (i.e., Central Texas) and regions that would have been outside of the range of bison (i.e., such as East, South, and West Texas).
Figure 14-5 compares the trends in projectile point neck width documented in the Central Texas samples with those documented for the other three non-bison regions of the state combined. No neck width can be measured on the stemless points of South Texas so they are not included in this figure. As a result, however, the non-bison regions sample consists of specimens from sites found in East and West Texas. The figure shows that in Central Texas, neck width increases through the early Late Archaic, the period when bison return to the region. Thereafter, projectile point neck widths decrease dramatically through the terminal Late Archaic as medium-sized prey species become a greater proportion of faunal assemblages. The dramatic decline in neck widths during the Late Prehistoric period is a direct reflection of the adoption of the bow and arrow.

In the combined projectile point samples from the East and West Texas non-bison regions, neck widths decrease from the late Middle Archaic through the early Late Archaic, at the same time as bison return to the State. Neck widths remain relatively steady during the Late Archaic followed by the significant drop caused by the adoption of the bow and arrow during the Late Prehistoric. In other words, in the combined non-bison regional sample, projectile point neck widths, and therefore, overall projectile weights, do not appear to respond to the return of bison into the State.

A closer look at the trends in neck width among Central Texas projectile points shown in this box plot, Figure 14-6, 


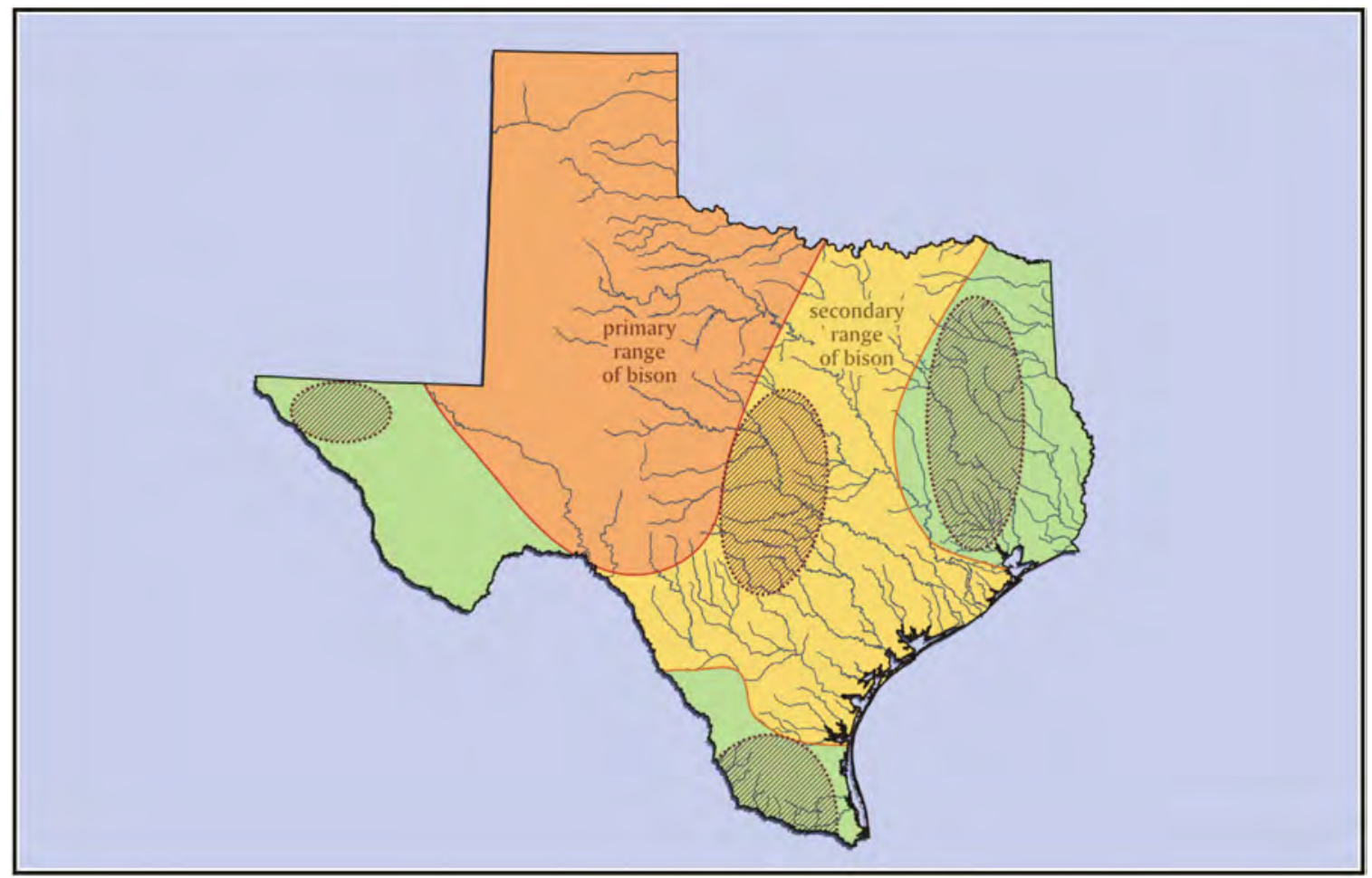

Figure 14-3. Projectile point sample regions.

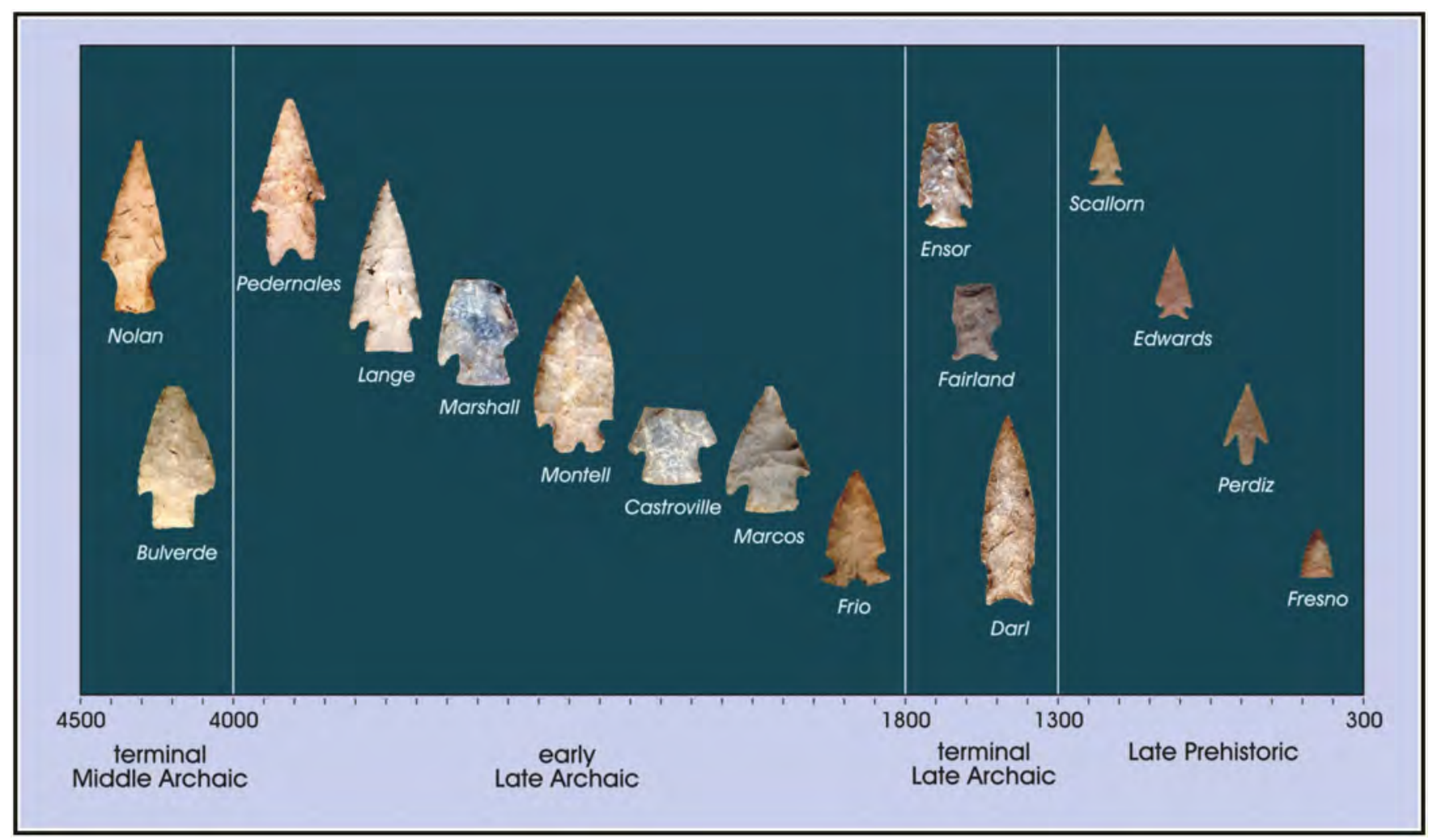

Figure 14-4. Sample of Central Texas projectile points. 


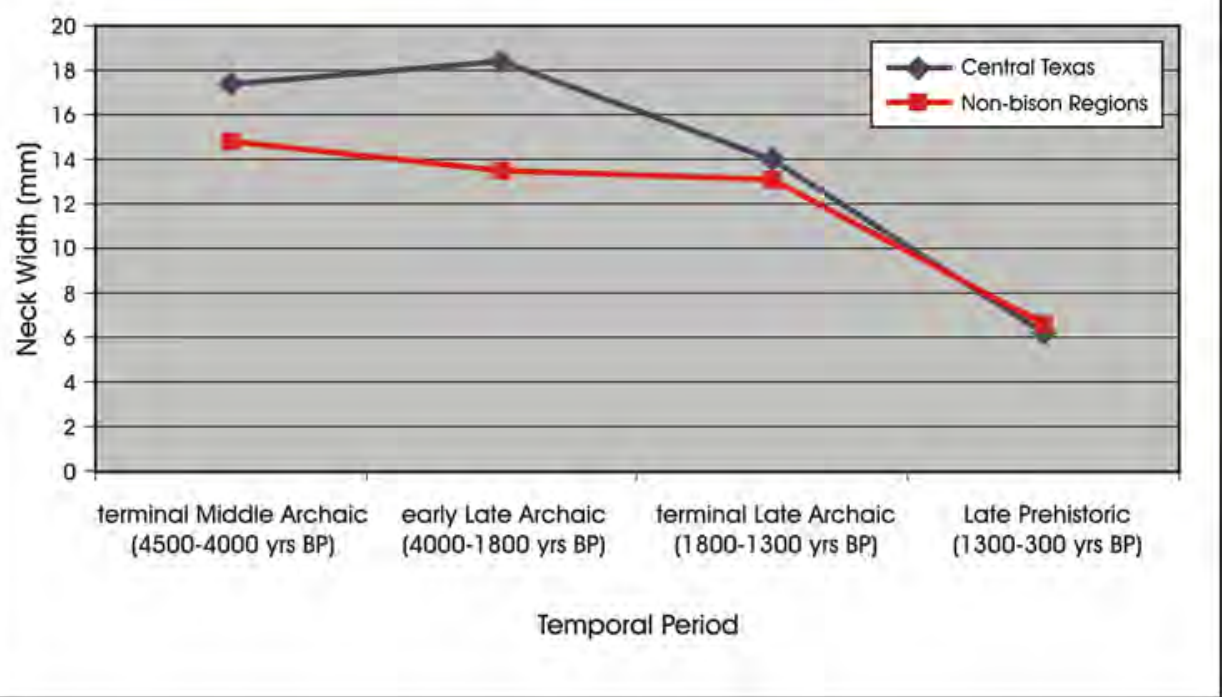

Figure 14-5. Trends in projectile point neck width.

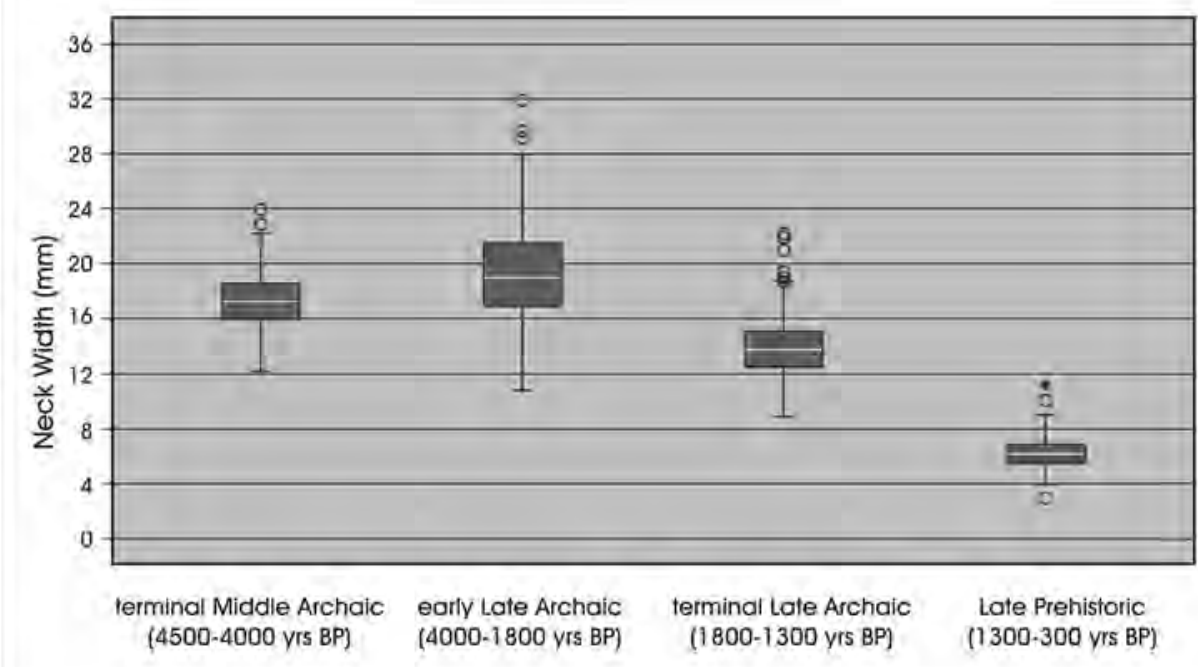

Figure 14-6. Distribution of Central Texas projectile point neck width.

demonstrates that there is considerable range in neck widths within Middle and Late Archaic projectile points and there is overlap in the distribution of neck widths over time. However, a paired T-Test comparison of the means of the four distributions indicates that they are significantly different at the .0001 level of significance. Similar ranges and overlaps in neck widths by sub-period and through time are present in the individual east and west Texas samples as well.

Figure 14-7 compares the trends in projectile point weight in Central Texas with the combined non-bison regions. Projec- tile point weight data for the non-bison region comes from collections recovered from East and South Texas. The bisonpresent sample consists entirely of points from Central Texas sites. The figure shows that in Central Texas, projectile point weights remain virtually identical between the late Middle Archaic and early Late Archaic as bison return to the State. However, a dramatic decrease in projectile point weight is noted between the early and terminal Late Archaic as bison population densities decrease. A nearly equal drop in projectile point weight is seen between the terminal Late Archaic and the Late Prehistoric related to the adoption of the bow and arrow. 


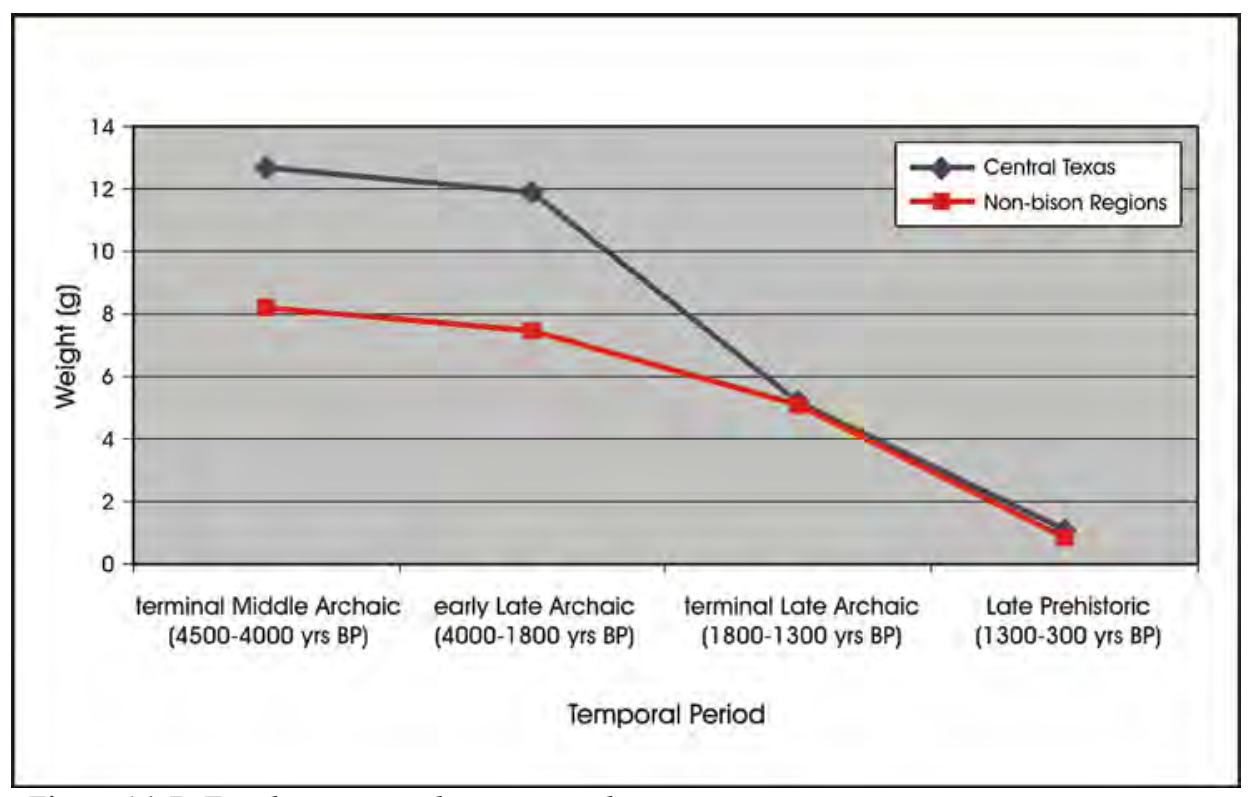

Figure 14-7. Trends in projectile point weight.

In the combined non-bison regions, there is a dramatic drop in projectile point weight between the late Middle Archaic and the early Late Archaic, just as bison appear to return to the state. Projectile point weight decreases only slightly throughout the terminal Late Archaic followed by a significant drop with the adoption of the bow and arrow.

In summary, there are significant changes in projectile point neck width and weight through time across all four regions. In Central Texas, where we expect that hunter-gatherer populations focused on the systematic procurement of bison, projectile point neck widths and weights, suggestive of heavy darts, tend to be at their highest during the early Late Archaic when bison populations are thought to be at their peak. There is substantial range in neck widths during the early Late Archaic suggesting perhaps that not all forms were designed for the effective harvesting of very large prey. Also, we do not intend to imply that forms that may have been well suited for bison hunting would not have been used in the procurement of medium prey species. However, we do suggest that the design characteristics of the darts, specifically their weight, would have affected hunting success rates and that over time hunter-gatherers would have made design adjustments to increase hunting success. One such change would have been the reduction of dart weights to attain increased velocity faced with the hunting of deer and pronghorn antelope as bison densities decreased during the terminal Late Archaic. In East, South and West Texas, where bison densities were likely low and bison hunting was not a significant adaptation, trends in projectile point neck widths and weights suggest the reliance on lighter darts throughout much of the 4,000 year prehistoric sequence. This pattern does fit our expectations that the weaponry would be most specifically adapted to the procurement of medium prey species.

The data investigated in this chapter suggests some intriguing temporal and regional trends in projectile point and weaponry characteristics during the 4,000 year Archaic and Late Prehistoric sequence. These trends are consistent with the interpretation that projectile weaponry was undergoing slow but gradual changes in design in response to the principal prey species hunted across the state. 



\title{
Chapter 15: Investigating Ceramic Development
}

\author{
Jennifer L. Thompson
}

As stated throughout this document, there are many explanations for the variability seen in the archeological record. Our proposed research only attempts to explore certain possible explanations for this variability and does not necessarily discount other explanations. This is also true of our ceramic study. Scholars have posited that the rise of ceramics is linked to sedentism (Smith 1986), increased reliance on cultigens (Crown and Wills 1995), increased food processing efficiency (Sassaman 1993), and countless other explanations. Some have suggested that ceramics did not grow out of either increased sedentism or reliance on agriculture (Barnett and Hoopes 1995). It should be sufficient to say that pottery has multiple origins and its first uses differed across geography and culture. This chapter discusses one of many possible explanations for why hunter-gatherers decided to use certain ceramic technologies and how those would be archeologically patterned, not how they acquired the technical knowledge.

Situations where groups have limited availability to resources or process resources in bulk should favor a specialized tool kit. Increased return rates from the successful procurement of food should offset the greater cost investment associated with the production of specialized tools and their maintenance. Conversely, a group should have generalized tool kits when resources are not restricted and not processed in bulk. Though both specialized and generalized tool kits are likely present in any given adaptive system, and because each could potentially process a range of resources of different ranks, the increased costs associated with the production of specialized tools suggests that these would be used more frequently on higher-ranked resources.

In this context, ceramics are a technological issue rather than a cultural-historical item. This chapter examines ceramics as tools in hunter-gathering societies. Examining ceramic vessels as tools in the context of foraging theory provides the opportunity to explore the conditions under which huntergatherer groups would decide to produce ceramics in the same manner as exploring the technological shift from darts to arrows. Using this perspective, we address ceramic development in mobile hunter gathering groups in Texas. Specifically, under what subsistence constraints would ceramic technology arise in the material culture?

Some have argued that ceramic production is absent from mobile societies (see Arnold 1985). High breakage rates during transport across long distances would increase costs associated with maintaining ceramic vessels. Frequent moves may not allow sufficient time to complete a vessel because manufacture requires a time commitment that cannot be halted and resumed when convenient. Although there are correlations between sedentary groups, food-producing groups, and ceramic development, this does not preclude ceramics from highly mobile hunting and gathering groups. The Ethnographic Atlas lists seven of 33 hunter-gatherer groups (those who are not agriculturalists and who do not domesticate animals for food) who use ceramics (the Tehuelche, Kutenai, Aweikoma, Gros Ventre, Ingalik, Andamanese, and Vedda). Evidence from the Numa (Eerkin et al. 2002) and at various archaeological sites in the Great Basin suggests that residential mobility could even encourage the production of pots under the right economic conditions (Eerkin 2003; Simms et al. 1997).

Data from several sites in the Great Basin show the production of ceramics contributed to the overall fitness of hunters and gatherers in spite of the constraints of a mobile lifestyle. For example, Eerkin (2003) theorizes that these groups placed caches in locations where certain resources were available in high densities to allow for prolonged settlement. During the time spent at these locations, they would be assured food and have the time to produce more pots. Simms et al. (1997) refer to this as occupational redundancy, where the degree of occupational residency in areas with resources suited to mass collecting and boiling (such as with small seeds) are best correlated with pottery use. This caching strategy is dependent on predictability of resources for which the tools (e.g. groundstone, pots, and burned rock middens) are needed and the ability to leave the tools without fear of theft or breakage (Eerkin 2003).

With a group producing pots for use with a specific resource available in a specific location, we would expect to see similarities in pot production. In the case of the Eerkin study, pots were small-mouthed and thin-walled. They possessed a small surface area and roughened exterior, contained a finer temper, and conformed to a standard shape and size. These production attributes all address issues likely important to mobile hunter-gathering societies. The finer temper would increase tensile strength in thin walls (Braun 1983; Eerkin 2003). Thin walls with roughened surface area are more conductive and therefore should be more heat efficient. The roughened, thinned pots would also take less time to dry during production, weigh less, and present fewer problems during firing (Rice 1987; Eerkin 2003).

In food foraging societies, then we can begin to see how diet breadth would relate to the production of ceramics. Incorporating ceramics into the subsistence strategy could increase 
processing efficiency and therefore increase return rates when diet breadth expands to incorporate resources suited to processing food with ceramics. This may occur when search time for higher ranked resources increases and new elements best accessed with ceramics are added or increased in the diet. Ceramic vessels should decrease aspects of handling time relative to extant processing methods (e.g. stone boiling) and increase benefits relative to other processing methods. It may also allow access to nutritional elements that would be difficult to extract with stone boiling in the case of food items requiring prolonged simmering or boiling (e.g. bone grease). Prolonged cooking in ceramic vessels would also affect processing time by freeing-up the cook for other activities when food preparation does not require constant attention. Another particularly valuable benefit in areas of scarce firewood is that ceramic pots are more efficient, and use less wood, relative to stone boiling. Of course, we would only expect the incorporation of ceramics into food processing strategies when the energetic return rates from the processed food outweigh the energy put into hunting and processing, including ceramic manufacturing costs.

Therefore, mobility may not limit ceramic production since ceramics are neither differentially associated with low mobility in the ethnographic record among hunters and gatherers nor absent from the archeological record at hunter-gatherer residential sites. This does not mean that mobile groups were not concerned with the detriments of using ceramics. Issues such as breakage likely influenced the adoption of particular ceramic technologies and the use of certain manufacturing methods.

Two ceramic properties are of interest in examining degree of mobility and the ceramic record: mechanical strength and thermal strength. Mechanical strength for the purposes of this study is a vessel's ability to withstand various impact stresses without fracturing and becoming obsolete. Thermal strength is a vessel's ability to withstand repeated heating and cooling as happens during cooking. The strength of a ceramic vessel is determined by its composition, construction method, firing and drying conditions, and conditions of use and can therefore be manipulated by altering any step in the construction (Rice 1987).

These two properties are not mutually exclusive as many elements contribute to a vessel's durability and heating efficiency. However, this study simplifies the decisions made by early potters to examine some predicted patterns and assumes that sedentary groups will adopt technologies promoting thermal strength and conductivity and mobile groups will adopt technologies that promote mechanical strength. It correlates mechanical and thermal strength to vessel wall thickness, temper type, and temper size. Under the assumption that mobile groups would find mechanical strength more important than sedentary groups would, ceramics from high mobility, hunter-gatherer archeological assemblages were expected to be thicker than those from low mobility residential sites, since thicker walls add mechanical strength and thinner walls increase thermal strength, conductivity, and cooking times.

Of course, walls do not need to be as thick to be resistant to mechanical failure if you adjust paste composition. A common method of manipulating paste to produce desired performance results is the addition of temper in various sizes and concentrations or the use of clays with natural inclusions that serve as tempering agents. Pastes can give high-fired strength to thinner walls through their natural inclusions or through the addition of temper. Generally, the finer the temper is, the stronger the vessel will be (Bronitsky and Hamer 1986; Eerkin 2003; Kirchner 1979). Specifically, a vessel's resistance to crack initiation, thermal, and mechanical stress all increase by the addition of a low concentration of finer temper particles (Simms et al. 1997; Tite et al. 2001). A heterogeneous paste with large temper particles will decrease the occurrence of crack propagation but increase the occurrence of crack initiation. This relates to differences between the thermal-expansion rates of the clay and the temper. Adding temper with expansion rates lower than or equal to the expansion rate of the clay will help increase thermal stress resistance, as will increased porosity, which allows room for the vessel to expand (Rice 1987:227-230).

By focusing on two elements of ceramic production, wallthickness, and temper, we expect that highly mobile groups will have thick-walled vessels with low concentration of finegrained temper. As any group, regardless of their level of mobility, should want the strongest vessel possible, they likely made trade-offs when determining factors most important to their situation. Ceramic vessel failure happens either due to impact (mechanical failure) or through repeated heating and cooling (thermal shock). Potters can enhance mechanical and thermal strength in a variety of ways, some of which are observable in the archeological record. By examining sherds from sites across Texas, to test the expectations related to ceramic sherd characteristics and the level of mobility of ceramic manufacturers this study examined sherds from groups with known sedentary lifestyles, the Caddo, and sherds from presumed mobile groups, those with Toyah interval components.

This study assumes that with a greater degree of sedentism comes a greater reliance on the thermal properties of ceramics. Sedentary groups should be more reliant on cooking and should prefer thermal strength to mechanical strength, good heat conductors to poor ones, and lighter, easier to lift vessels, to heavy ones. Archeologically, this would produce small vessels (and sherds) with relatively thin walls, fine-grained temper, and a porous paste. Those properties that increase thermal strength also increase conductivity, both important to sedentary groups. 
With higher mobility, this study assumes some increased reliance on a vessel's mechanical strength. Chiefly, this should result in relatively thicker walls with somewhat coarser grade temper. Though increasing vessel weight, these characteristics will decrease heat conductivity and thermal shock resistance, but will increase resistance to mechanical shock and prevent cracks from spreading, once initiated.

By examining sherds from archeological sites known to have been occupied by mobile hunter-gatherers like the Toyah and by more sedentary groups like the Caddo, this research tests the prediction that sherds will be thicker on Toyah sites than on Caddoan sites.

\section{Data Collection}

We sampled sherds from known Caddoan sites and known hunter-gatherer sites across Texas, for coarse-grained macroscopic analysis and for thin section microscopic analysis. For small collections, we measured all sherds in the collection. For large ceramic collections, we targeted metric data on 200 plain or brushed sherds. For microscopic analysis, six of the sherds from each site were selected for thin sectioning for a total of six sherds per site unless slides were already created. Thin sections already made were incorporated into this study without further destruction of additional sherds. When possible, sherds previously used for INAA analysis were chosen for petrographic analysis.

First, the size of each sherd was measured for length, width, and thickness. Then area was calculated in $\mathrm{cm}^{2}$. Each sherd measured in the study was at least $2.0 \mathrm{~cm}$ in one dimension, either length or width. Because thickness is variable across most archaeological vessels, the mean of several measurements taken from sherds were calculated. Thickness due to the position of the sherd on the vessel is insignificant since here coarse-grained analysis is used to compare "sedentary" assemblages with "nomadic" ones. Each assemblage will have a range of thicknesses that include relatively thinner and thicker sherds from all vessel positions. The weight that any outliers (i.e. thin neck or thick basal sherds) would place on the overall mean thickness in one assemblage will also be true of all other assemblages and only account for a small number of sherds since most ceramic sherds are body sherds. Using calipers, a maximum of four measurements taken within $5.0 \mathrm{~mm}$ of the edge of a sherd in the center of each axis of a rectangular piece should produce a good average thickness measurement. For triangular sherds, a maximum of three measurements, in the center of each axis was taken. To reduce error between the mean thickness of large sherds and small sherds, thickness was divided by the area.
The ceramic samples chosen from Toyah components are 41KM69, 41BX228, 41ED28, 41JW8, 41LK201, 41LK67, 41WN88, 41RN169, 41KM16, and 41TG346. Most of the collections from these sites are house at CAR. Sites 41RN169, $41 \mathrm{KM} 16$, and $41 \mathrm{TG} 346$ are houses at TARL, as are all the Caddo components we included. The Caddo ceramics were taken from 41CE19, 41NA27, 41MX5, 41HP106, 41RR9, 41AN1, 41AN8, 41AN19, 41SM9, and 41WD13 (Table 15-1).

Table 15-1. Sample Size and Sites Used for Metric Analysis of Sherds

\begin{tabular}{|c|c|c|}
\hline Site & Count & Mobility \\
\hline 41AN1 & 84 & Caddo \\
\hline 41AN19 & 199 & Caddo \\
\hline 41AN8 & 48 & Caddo \\
\hline 41CE19 & 200 & Caddo \\
\hline 41ED28 & 40 & Caddo \\
\hline 41HP106 & 199 & Caddo \\
\hline 41MX5 & 200 & Caddo \\
\hline 41NA27 & 199 & Caddo \\
\hline 41RR9 & 200 & Caddo \\
\hline 41SM9 & 192 & Caddo \\
\hline 41WD13 & 149 & Caddo \\
\hline 41BX228 & 38 & Toyah \\
\hline 41JW8 & 154 & Toyah \\
\hline 41KM16 & 91 & Toyah \\
\hline 41KM69 & 91 & Toyah \\
\hline 41LK201 & 216 & Toyah \\
\hline 41LK67 & 37 & Toyah \\
\hline $41 \mathrm{MC} 296$ & 9 & Toyah \\
\hline 41RN169 & 25 & Toyah \\
\hline 41TG346 & 56 & Toyah \\
\hline $41 \mathrm{WN} 88$ & 266 & Toyah \\
\hline Grand Total & 2693 & \\
\hline
\end{tabular}

Petrographic slides were prepared by National Petrographic Services for all sites except 41WN8, 41ED28, 41KM16, 41TG346, and 41RN169 because thin sections already existed for these. Additional thin sections were created from blocks of impregnated sherds from 41HP106. The blocks from this site were available but thin sections were not.

\section{Results}

\section{Metric Data Results: Thickness}

During metric data collection, the size disparity between sherds from Caddo sites and sherds from Toyah interval sites became apparent. Grouped by settlement pattern 
(Toyah=mobile; $C$ addo=sedentary), the data confirms the initial impression from examining collections and does not conform to the expectations of the research design. Overall, the Toyah sherds were smaller in all dimensions including thickness, more weathered and therefore weighed less. The sherds from Caddo sites were larger and in a far better state of preservation. For a given area, Caddo sherds weighed more, which is likely due to greater thickness (Figure 15-1).

Figure 15-2 further shows the mean thickness by settlement pattern is statistically greater from the Caddo collections. The Caddo sherds also have more size consistency from site to site than the Toyah sherds.

Figure 15-3 shows the metric data (area/weight) on a scale from thick to thin at the site level to illustrate that while the Toyah sites have thinner sherds, they also tend to have more size variability within one assemblage than the Caddo sherds.

We also looked for regional trends among the Toyah sites used in the study by examining sites on and off the Edwards Plateau. The sites on the plateau are relatively thinner than those off the plateau, with the thickest sherds coming from sites 41BX228, 41JW8, 41LK201, and 41WN88 (Figure 15-4). The thickness data for Toyah interval sites off the Edwards Plateau are shown in Figure 15-5).

Our level of knowledge about vessel size is greater for Caddo pots than Toyah pots. Tough Toyah pots are likely more similar to other Toyah pots than they are to Caddo pots, some knowledge of original vessel size for all those used in this study would help with sample selection. With a lack of this knowledge across the Toyah samples, all sherds were compared as if they fulfilled the same function and were the same size, which is likely not the case, but difficult to tease out archeologically.

\section{Petrographic Data Results: Temper Size and Density}

Petrographic work proved more timely and problematic than hoped. The methods employed in data collection were not consistent with research questions. While the results of these methods are not as statistically sound as we had wished, there are some useful trends in the data. During data collection,

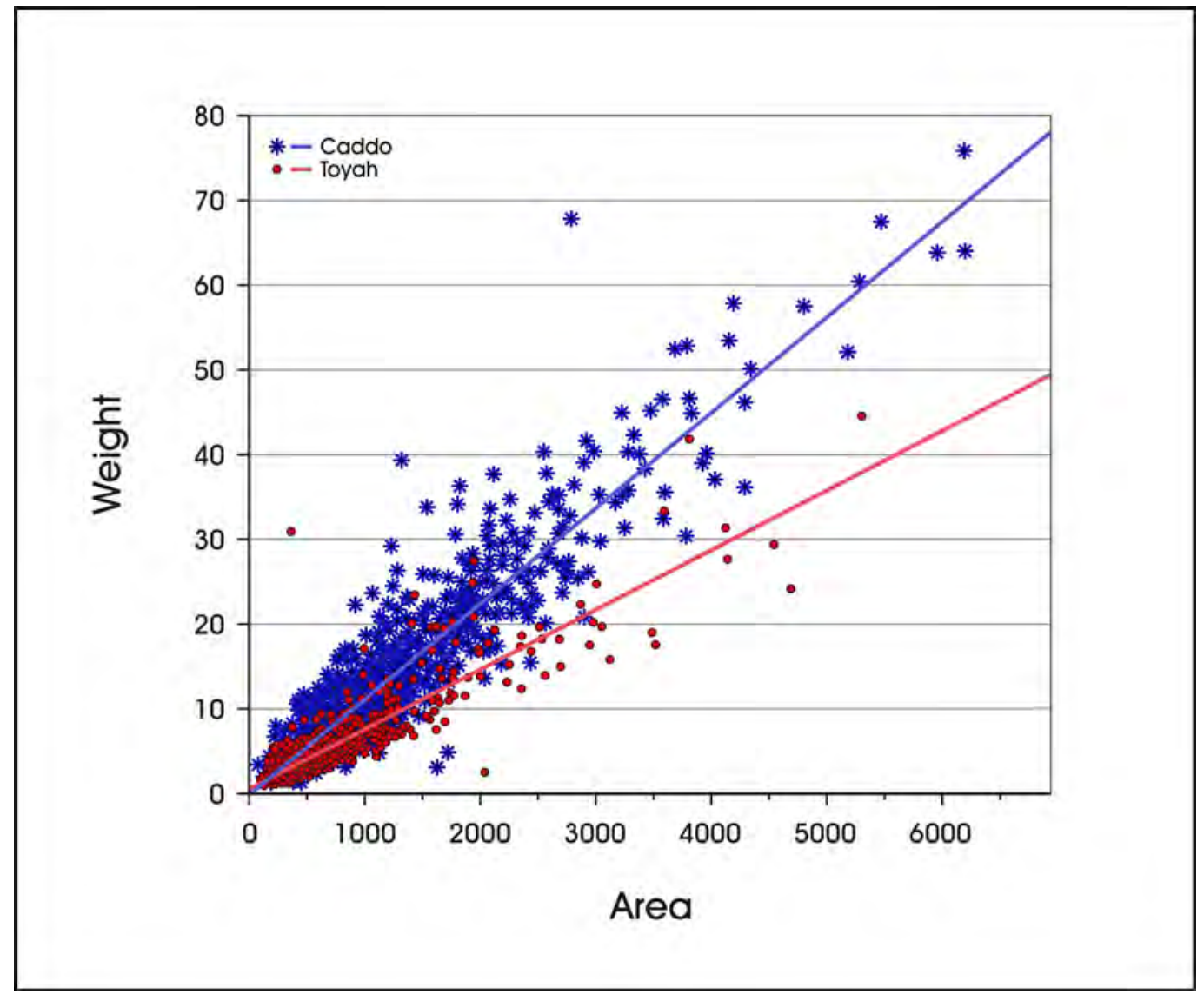

Figure 15-1. For a given area, the Caddo sherds weigh more than Toyah sherds, which is due in part to their greater thickness. 


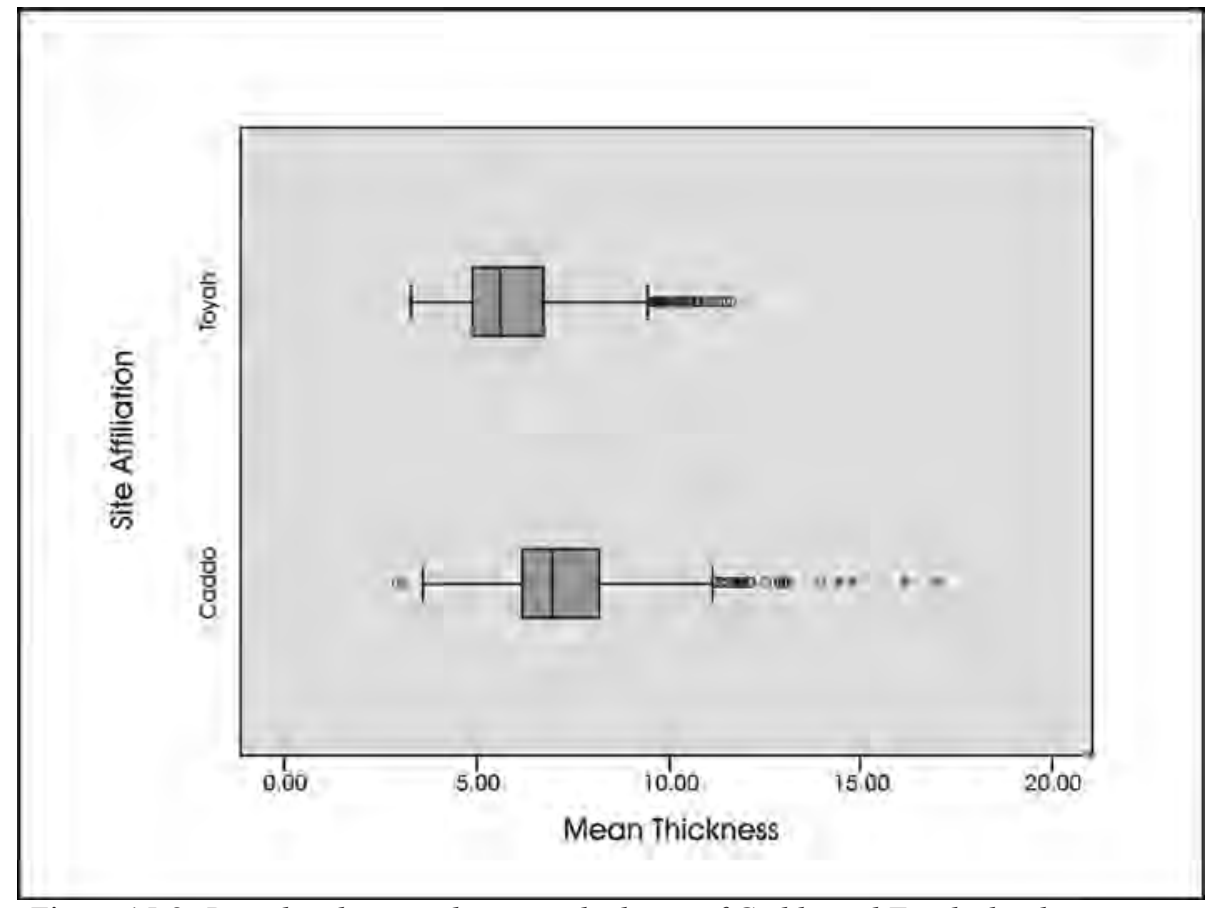

Figure 15-2. Box plot showing the mean thickness of Caddo and Toyah sherds.

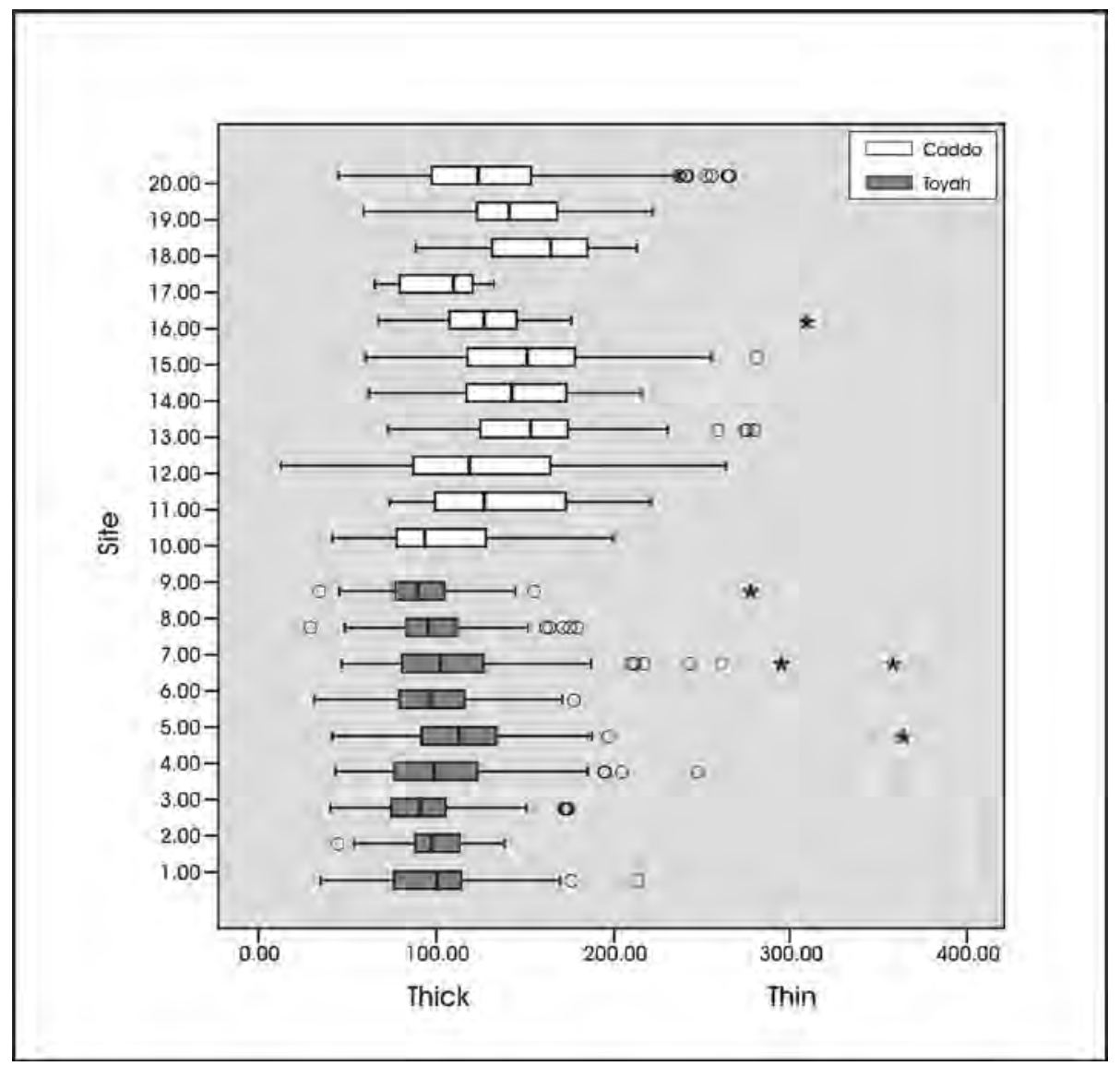

Figure 15-3. Box plot of mean Caddo and Toyah sherd thickness by site assemblage. 


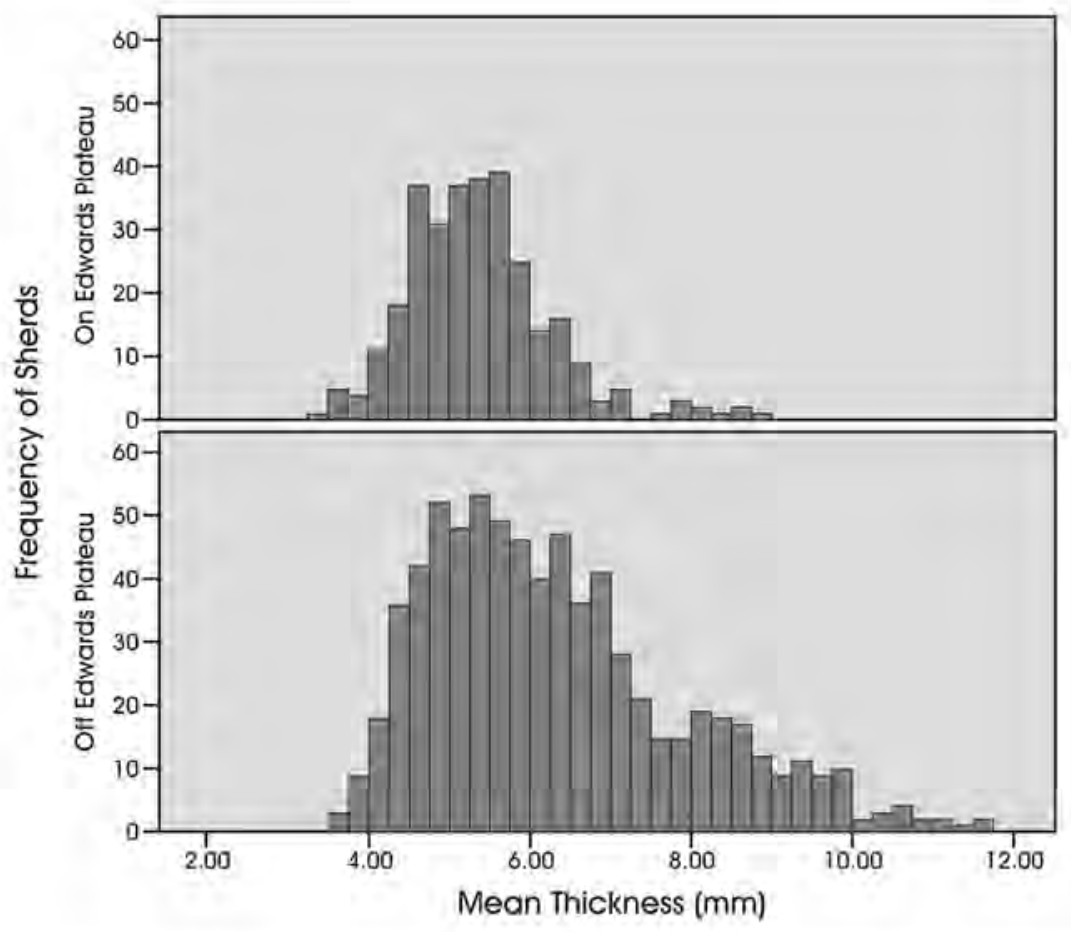

Figure 15-4. Mean thickness of sherds for Toyah interval sites located on and off the Edwards Plateau.

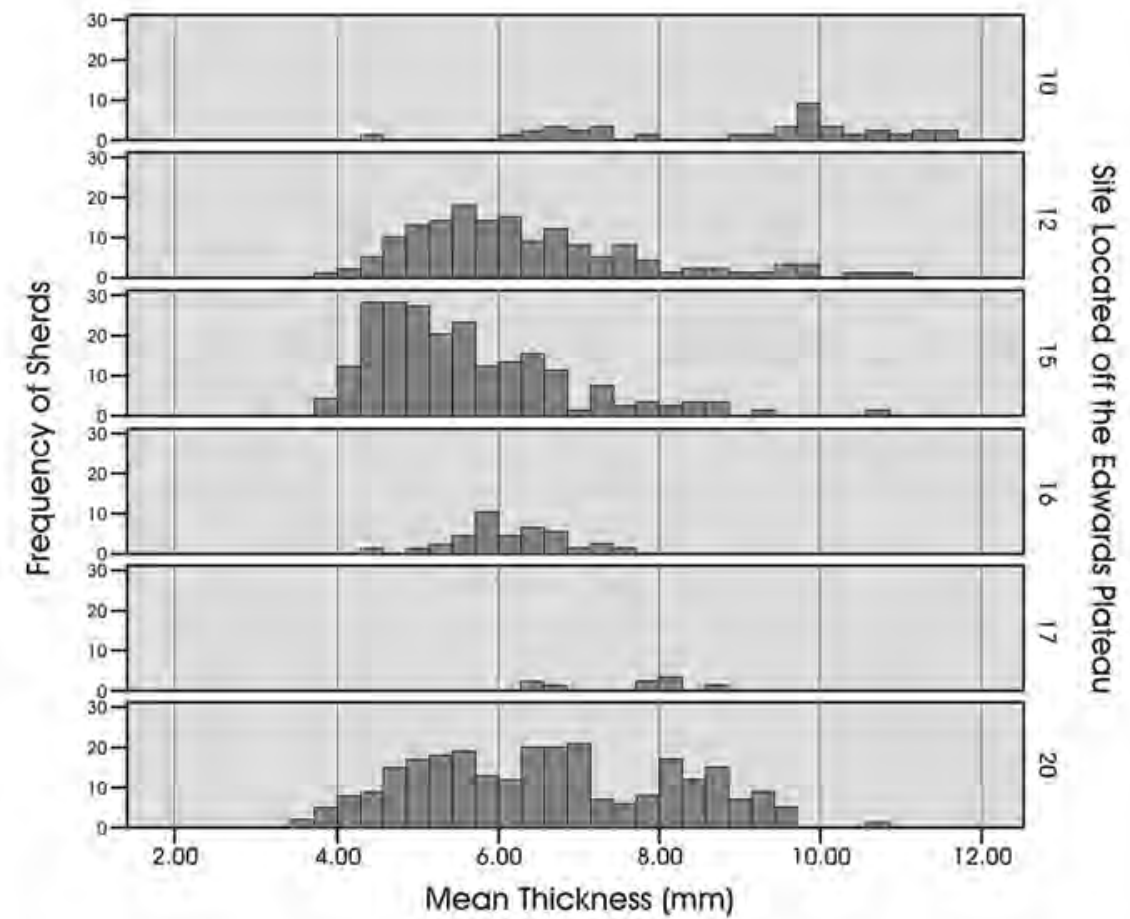

Figure 15-5. The mean thickness of Toyah interval sherds from sites located off the Edwards Plateau. 
information on temper ideally should have been collected for each of 300 points to enable a calculation of temper per area. However, the area across which temper information was gathered is unknown and inconsistent from slide to slide. We rely then on a smaller sample size of point counts $(n=126)$ taken during temper measurements from the photomicrographs. The data from petrographic analysis is used here to examine temper size and density first with the point counting data, then with the temper measurement data.

There were no statistically significant temper groups borne out of the petrographic data point counting data. Caddo sherds contained little to no bone temper while Toyah sherds contained little to no grog temper (Figure 15-6). Even at the site level, there are no apparent groupings. The only site showing any clustered pattern was $41 \mathrm{KM} 69$, which has similar intrasite ratios of bone to sand temper (Figure 15-7), more so than collections from other sites.

An examination of temper analysis from the measurement data of 126 grid points shows some different trends. Some temper types that were not encountered on the variable point counting grid, did show up on the measurement grid because the two grids did no align and likely covered different portions of the slide (see Appendix F for details). Table 15-2 shows the density of temper sorted by site from lowest to highest density. At the site level, Caddo sherds showed the lowest number of hits (out of 126 grid points) while the Toyah sites in general had a higher density of temper. Sherds with the highest density came from sites off the Edwards Plateau. 41KM69 sherds contained the lowest temper density of any other Toyah site.

At the group level (Caddo vs. Toyah), there was no apparent temper size difference between the two groups; both have an average temper size of $.29 \mathrm{~mm}$ (all sherds combined per group). Looking at density with this data, the average number of "hits" on the photomicrograph grid for Toyah sherds in general was still higher (28.017 hits per 126 grid points) than the average for Caddo sherds (20.8529 hits per 126 grid points).

\section{INAA and SEM-EDS Contribution}

At the time of data recovery, INAA submission of ceramics was not part of the research design and therefore no local clays were sampled for comparison. After final agreement on the research design and after data recovery, TxDOT required INAA of ceramics from 41KM69. Six sherds were sent for this special analysis in accordance with TxDOT protocol and to contribute to other INAA ceramics studies in Texas. The Archaeometry Laboratory at the University of Missouri Research Reactor conducted the analysis and compared the sherds to others in their database. Initial estimates were that the ceramic

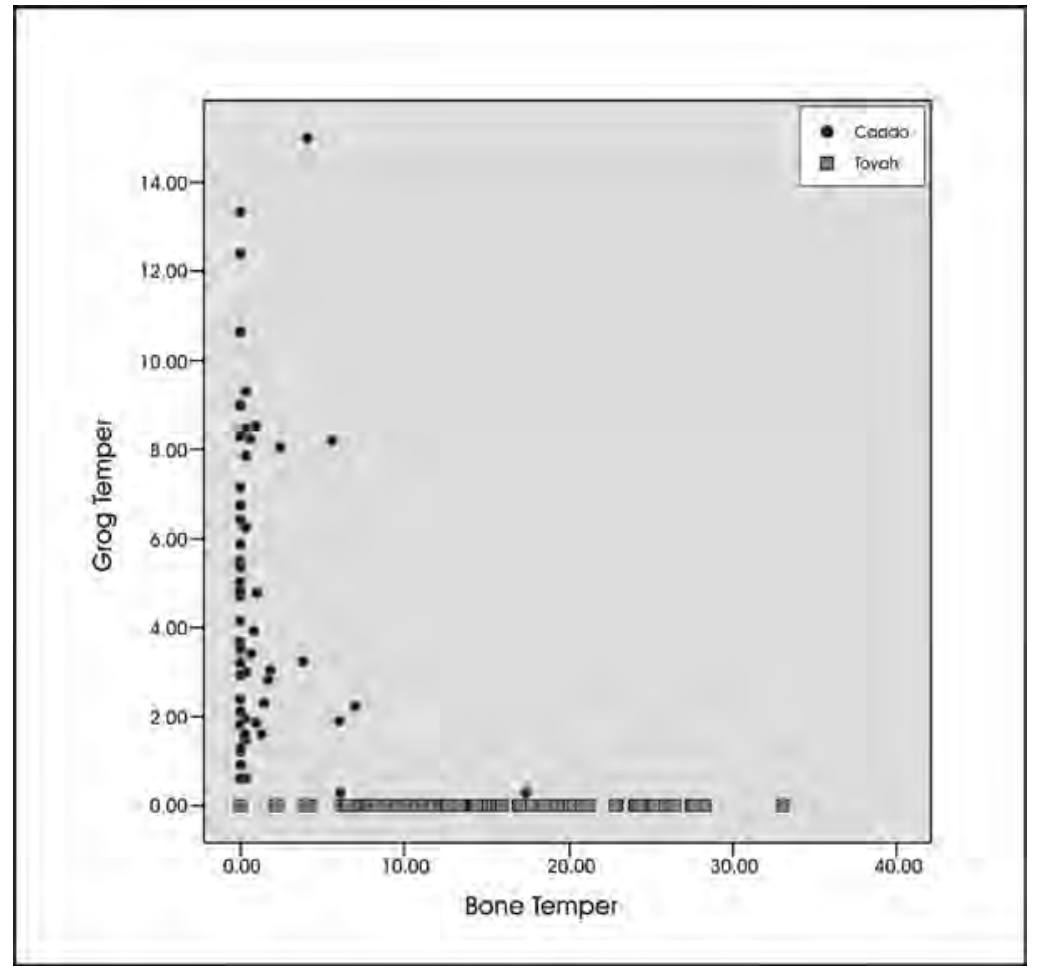

Figure 15-6. Percentages of bone and grog temper within Caddoan and Toyah interval sherds. 


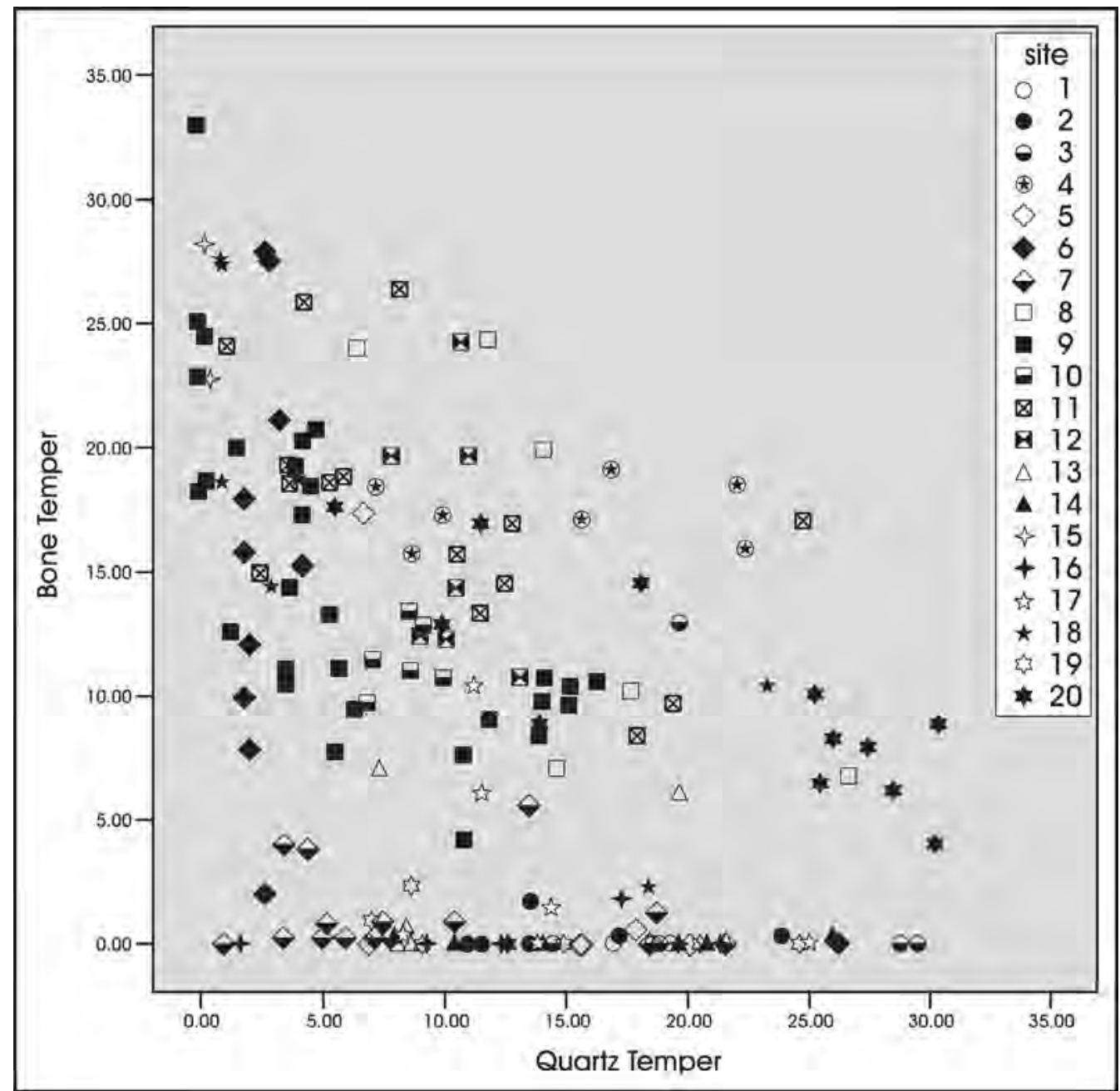

Figure 15-7. Percentages of quartz (sand) and bone temper within Caddoan and Toyah interval sherds $(1-3,5,7,13-14,16-17,19=$ Caddo $)$.

collection included three vessels. Six sherds, two from each vessel, were submitted to MURR. Thin sections of these same sherds submitted for petrographic and SEM-EDS analysis. The INAA analysis report is included in Appendix M.

As anticipated, the samples were very similar to each other and were likely made from the same source clays. Among the six sherds, three potential pairs $(33 \& 36 ; 37 \& 38$, and 34 $\& 35$-MURR sample numbers) were identified possibly representing three vessels, though the authors stress that all six sherds are similar and could be from the same vessel.

Comparison with the MURR database resulted in few matches. The closest matches are from ceramics in found in southeast Central Texas, which are a part of the Central Texas 2 compositional group. The conclusion of the INAA analysis then suggests that the sample shows great internal similar- ity, but is quite different from sherds in the regional database with the closest matches coming from the same region as 41KM69 (see Appendix M).

To supplement the compositional information provided by the INAA study, CAR also submitted thin section of these sherds to the Scanning Electronic Microscope and X-Ray Microanalysis Unit at UTSA (Appendix M). This analysis provided a visual means by which to compare the structure of the ceramic fabric and additional information on paste composition. In terms of visual characteristics (i.e., the structure of the paste, including the shape and frequency of voids), four groupings could be discerned ( $7 \& 11$ [38 \& 34]; $10 \& 12$ [35 $\& 33]$; and $8 \& 9$ [37 \&36] (thin section number followed by MURR sample number) each on their own. Neither of these pairs corresponds to the pairs identified in the INAA analysis. In terms of the coarse elemental analysis provided by SEMEDS, only samples 7 and $9[36 \& 38]$ are alike, while the 
Table 15-2. Leon Plain and Caddo Temper Density

\begin{tabular}{|c|c|c|c|c|}
\hline Site Group & Site & Temper Hits & $\begin{array}{c}\text { Relative Density } \\
\text { (\# of hits out of 126) }\end{array}$ & $\begin{array}{l}\text { Average temper } \\
\text { size }(\mathrm{mm})\end{array}$ \\
\hline Caddo & HP106 & 14.4 & 11.43 & 0.329 \\
\hline Caddo & WD13 & 18.17 & 14.42 & 0.299 \\
\hline Caddo & MX5 & 20 & 15.87 & 0.291 \\
\hline Caddo & RR9 & 20.5 & 16.27 & 0.272 \\
\hline Toyah & KM69 & 21 & 16.67 & 0.296 \\
\hline Caddo & CE19 & 21.5 & 17.06 & 0.264 \\
\hline Caddo & SM9 & 21.83 & 17.33 & 0.298 \\
\hline Toyah & RN169 & 22.67 & 17.99 & 0.336 \\
\hline Caddo & AN1 & 23.3 & 18.49 & 0.262 \\
\hline Caddo & AN8 & 23.5 & 18.65 & 0.368 \\
\hline Toyah & TG346 & 24.5 & 19.44 & 0.272 \\
\hline Toyah & KM16 & 24.63 & 19.55 & 0.272 \\
\hline Caddo & NA27 & 24.8 & 19.68 & 0.232 \\
\hline Toyah & ED28 & 27.2 & 21.59 & 0.301 \\
\hline Caddo & AN19 & 29 & 23.02 & 0.273 \\
\hline Toyah & BX228 & 29.88 & 23.71 & 0.297 \\
\hline Toyah & LK67 & 30.14 & 23.92 & 0.289 \\
\hline Toyah & WN88 & 30.54 & 24.24 & 0.287 \\
\hline Toyah & LK201 & 31.67 & 25.13 & 0.327 \\
\hline Toyah & JW8 & 41.17 & 32.67 & 0.263 \\
\hline
\end{tabular}

other four are different from each other in small ways. Overall, then, while the INAA work has identified three subgroups within this small and relatively similar sample, these three groups were not clearly reflected by the SEM-EDS analysis.

\section{Conclusion}

With thickness, temper type, temper size, and concentration recorded we can then make statements about the level of mobility at each of the sampled sites. We expected to see hunter-gathering societies adopt ceramics when high-ranking dietary resources were absent or scarce and the addition of new dietary elements or greater quantities of foods requiring cooking was incorporated into the subsistence strategy. As the availability of the food supply changed, we would expect to see changes in mobility and ceramic technology. We proposed that an examination of sherd thickness, temper type and temper size will promote archeological study of ceramics in Texas beyond the cultural-historical perspective. Our attempt was to use ceramic technologies to predict mobility patterns based on ceramic assemblages from known sedentary and mobile groups. The two elements of ceramic technology we explored were temper (size and density) and sherd thickness. We assumed mobile groups would be more concerned with the mechanical strength of their ceramic vessels and therefore expected sherds from Toyah interval sites to be thicker and have relatively coarser grained temper than the sherds from the Caddo sites. Conversely, we expected Caddo groups to be more concerned with thermal strength, which would be expressed in thinner sherd size and finer grained temper.

The results of the sherd thickness study did not support our expectations. Sherds from the Toyah interval sites were thinner. Caddo sherds were noticeable thicker and more durable than the Toyah sherds, though the Toyah sherds are older than the Caddo sherds. The study then does seem to support the general knowledge of thickness promoting mechanical strength, but may not be a good predictor of mobility under the parameters used in this study. 
The temper study was largely inconclusive or did not meet expectations due to the sample size problems with point counting. No temper size density was noted between the two groups either at the site level or the group level but the Toyah interval sherds did have a higher temper density, particularly those sites off the Edwards Plateau.

Turning specifically to sherds from 41KM69, CAR submitted six sherds for INAA to the MURR laboratory. Their findings did not identify any vessel groups but did conclude either that they were from the same vessel or that the vessels they represent came from the same source clays. No clays were available for comparison. When compared to other groups in the MURR database, the 41KM69 sherds most closely resemble other sherds from southeast Central Texas. The MURR lab concluded that the 41KM69 sherds have great internal similarity but do not resemble most sherds in the regional database. Furthermore, the only site showing any statistically significant grouping based on temper from the petrographic analysis was 41KM69.

The same sherds selected for Petrographic, as well as INAA study were submitted to the Scanning Electronic Microscope and X-Ray Microanalysis Unit at UTSA. These results identified some groupings among the sherds in terms of the structural characteristics of the fabric but these groupings did not correspond to the ones identified by the INAA analysis. In addition, the elemental analysis of the thin sections using the SEM-EDS also did not reveal the same subgroups as in the INAA. 


\title{
Chapter 16: Investigating Changes in Mobility
}

\author{
Steve A. Tomka, Eric Oksanen, and Raymond P. Mauldin
}

Both archeological and paleovegetation data sets reviewed in the previous chapters suggest that bison were declining slowly throughout the Late Archaic and Initial Late Prehistoric, only to experience major year-to-year fluctuations in population and spatial distribution during the Terminal Late Prehistoric Period. The faunal studies of the materials recovered from 41KM69 and the regional scale database partially support our expectations that diet breadth widened through time from the Late Archaic to the Late Prehistoric. These patterns suggest that hunters and gatherers might have begun to broaden their diets to include a larger number of lower ranked animals and plants in response to decreasing bison availability. In addition, the faunal studies suggest that the exploitation of spatially clustered resources may have taken on an increased logistical component during the Terminal Late Prehistoric.

In this chapter, we examine two independent aspects of technology, namely artifact variety and raw material procurement, to determine whether hunter gatherers adjusted their mobility strategies in response to these apparent changes in diet breadth precipitated by fluctuations in bison availability. We suggest that an additional response to lower bison availability and shifts in the distribution of bison on the landscape, could involve changes in mobility strategies. Specifically, during the Terminal Late Prehistoric, a shift in mobility strategies, with an increasing portion of the system involving logistical hunting of bison, might have been initiated. That is, during the Terminal Late Prehistoric, hunter-gatherers could have intensified bison procurement by shifting to a logistically organized mobility system that relied on task groups to target bison when and where it was available.

In addition to an increase in the frequency of logistical components, this change in mobility strategies also could result in an increase in the range (i.e., scale) of annual mobility. Specifically, we would expect that groups following annual foraging systems in the Middle and Terminal Late Archaic, and to a lesser degree in the Initial Late Prehistoric, would have operated in a relatively small area. Conversely, Terminal Late Prehistoric occupations would be part of a larger-scale system, and a logistical form of organization would be increasingly reflected in those systems. Unfortunately, no established methods for differentiating locations dominated by foraging from sites or components dominated by collecting are available, and while some investigations of scale have been undertaken, they are usually tied to the presence of "trade" items (e.g., Hester 1995; Prewitt 1981: 81-82; for several Terminal Archaic sites) that are not common in most assemblages.
Here, we investigate the suggested changes in the organization of mobility between the Middle and Terminal Late Archaic/Initial Late Prehistoric components relative to the Terminal Late Prehistoric components by initially focusing on measures of artifact variety as a method for distinguishing locations used in a residential manner from those used for more task-specific activities. We then further explore the scale of mobility reflected in archaeological components dated to these time periods by focusing on diversity in chert types.

\section{Relationships between Artifact Variety and Mobility}

As we suggested previously in our discussion of faunal diversity, residential components should be distinguishable from more limited activity sites by patterns in artifact variety (see Thomas 1983, 1989). Wider varieties of activities are conducted at most collector and forager residential sites relative to special-purpose locations. Even relatively simple, foraging residential sites (e.g., Yellen 1977) show a wide variety of tasks conducted.

Other things being equal, residential sites should have a wider variety of artifact types than special-purpose locations. However, the actual number of artifacts discarded on a site appears to depend on at least two other converging factors: the length of each occupation episode of the site and the length of use-life of tools employed on site (Schiffer 1975; Shott 1989). Specifically, if a residential site is occupied for a relatively short time, any newly made formal tools in use by the occupants may not wear out or fail while at the site and therefore may not be discarded there because the life of the tool exceeded the length of site occupation. However, we would expect to find other tool types dominating the assemblage. These include older tools that had expended their use-life during the occupation along with low manufacture cost tools that were not worth taking to the next site. Such assemblages would exhibit a low diversity of tool forms and an over-representation of low-manufacture costs specimens.

During a lengthy occupation, new and long use-life tools will be more likely to wear out and fail because the length of stay outlasted the life of the tool. These tools would be discarded on site. Therefore, the portion of the assemblage represented by the archeologically recovered sample from long-term occupation sites may contain a more even distribution of short and long-use life tool forms and a greater diversity of tools than short-term occupation sites. 
An additional aspect of the artifact variety issue that is also related to our abilities to differentiate systems organized under a collector versus forager system is the relationship between occupation lengths of residential base camps within the two mobility systems. Within a residential forager system of mobility, length of individual occupation episodes of base camps as well as the number of people present is usually dependent on the diversity and abundance of resources within a day's round trip of the camp. As a result, we can expect a great degree of variability in residence times and group sizes of base camps among foragers, dependent on resource patch productivity in proximity to the camps. Among foragers, therefore, one can expect great variability in tool assemblage richness even within assemblages derived from functionally similar residential base camps. This variability of richness and evenness will be conditioned by the relationship between the length of individual occupation episodes, group size, the use-life of tools employed on site, and their likelihood of entering the archeological record.

Within a collector system, at least in the case of certain resource types, the provisioning of the inhabitants of the residential site is done by task groups. Site residence time and the number of occupants are more directly conditioned by the size of the area accessed by tasks groups. Since task groups can use over-night stays to reach distant resources, it is likely that the region being exploited from a residential base camp by collectors will be larger than that exploited by foragers. For the same reason, it is likely that the occupation of each residential camp will be longer and more similar between different camps occupied during the annual round than among foragers. Because of the greater expected similarity in occupation lengths and group sizes among logistical base camps, while their absolute diversity is expected to be higher than that among foragers, we would also expect less diversity (i.e., richness and evenness) between tool assemblages recovered from residential base camps generated within a collector system. However, because of the use of special activity sites, these relatively homogenous assemblages from base camps would contrast dramatically with the low diversity assemblages derived from special activity sites. Several researchers have demonstrated, however, that sample size has a significant influence on diversity or variety (see Bobrowsky and Ball 1989; Kintigh 1989). Therefore, we cannot simply contrast the number of different artifact types at a series of archeological components without considering the effect of sample size upon the expected patterns.

Figure 16-1 presents these expected relationships, taking into account both sample size and artifact variety. We expect that the number of different artifact types will increase at a faster rate on residential sites as a function of more varied activities, as well as a greater overall length of occupation (above tangential line of graph). Conversely, activities at special-pur-

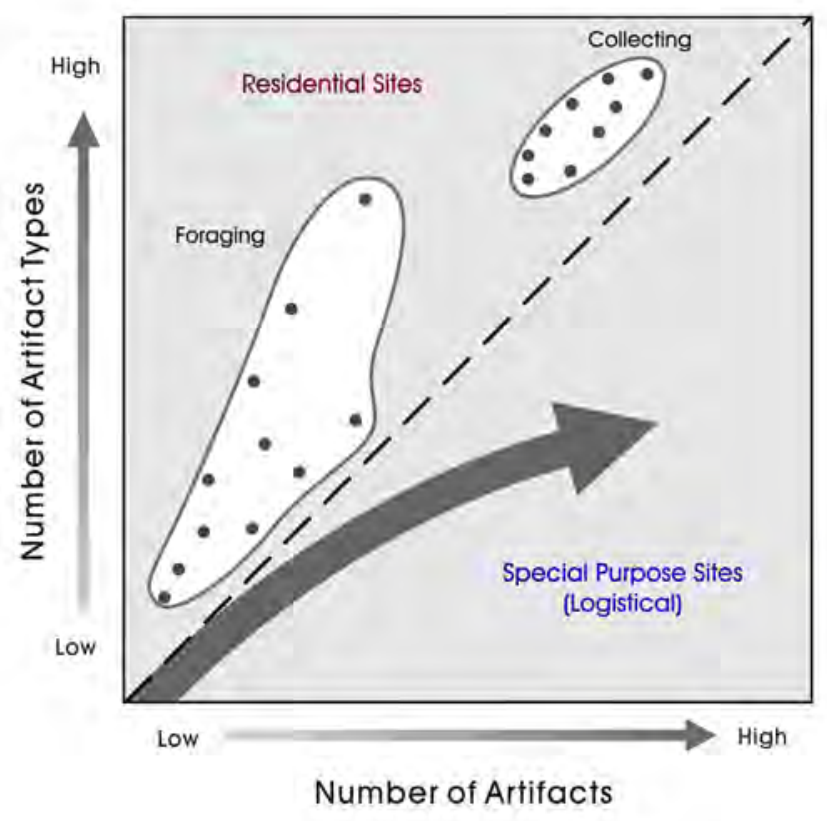

Figure 16-1. Expected relationship between the number of artifact types and sample size for different organizational components. 
pose locations will differentially increase the number of artifacts relative to the number of new artifact types. Conducting the same set of activities will increase the number of items without a concomitant increase in the artifact types. While the interpretations are complicated by the possibility that some special-purpose locations are reoccupied for a different range of activities, unless several such reoccupation episodes are present, we suggest that the overall pattern will remain intact. Due to the shorter and more varied occupation lengths of base camps occupied by foragers relative to collectors, we expect that residential camps generated by foragers would have lower richness and evenness values and a greater diversity in values than residential camps occupied by collectors.

If our general model of the inverse relationship between diet breadth and logistical organization is supported, Middle and Terminal Late Archaic, as well as Initial Late Prehistoric components should differentially fall within the residential side of the Figure 16-1 plot. Terminal Late Prehistoric components should differentially occupy the special-purpose area of the figure. Terminal Late Prehistoric residential components are expected, but the number of special-purpose components dating to the Middle and Terminal Late Archaic periods, and the Initial Late Prehistoric period, should be few since foraging systems should generate few of these site types. In addition, we would expect that Terminal Late Prehistoric, residential components would be characterized by consistently high samples and artifact richness and evenness (i.e., the upper cluster on Figure 16-1). We expect a great degree of variability in richness and evenness within assemblages from residential components predating the Terminal Late Prehistoric period. Few if any of these components should approach the richness and evenness of assemblages derived from Terminal Late Prehistoric residential components.

To explore the proposed relationship between artifact variety (i.e., richness and evenness) and different levels of activity, we collected data on the number of different types of tools and other items present at 19 dated components, as well as information on the sample size.

We defined tool types as broadly as possible in order to reflect a variety of behaviors at a location. We identified 16 artifact categories (Table 16-1) that were present within the selected archeological components.

Table 16-2 shows the frequency of the artifact types within the 19 archaeological components selected for analysis. Fig-

Table 16-1. Artifact Types Proposed for Use in Sample Size and Type Comparisons

\begin{tabular}{|c|c|}
\hline Artifact Type & Definitions/Notes on Type \\
\hline $\begin{array}{l}\text { Single-use Utilized } \\
\text { Flake }\end{array}$ & Utilized flake with evidence of only one type of use (e.g., scraping) on one or more edges. \\
\hline $\begin{array}{l}\text { Multiple-use Utilized } \\
\text { Flake }\end{array}$ & Utilized flake with evidence of more than one type of use (e.g., chopping and scraping) on one or more edges. \\
\hline $\begin{array}{l}\text { Biface with Hafting } \\
\text { Element }\end{array}$ & $\begin{array}{l}\text { Includes formal knives but not projectile points, preforms, or drills. May include adzes and "gouges," depending } \\
\text { on how extensive the item is retouched. }\end{array}$ \\
\hline $\begin{array}{l}\text { Uniface with Hafting } \\
\text { Element }\end{array}$ & Will include most formal scrapers. If hafting element is not clear, classify as Other Uniface. \\
\hline $\begin{array}{l}\text { Marginally Retouched } \\
\text { Item }\end{array}$ & May include some scrapers, as well as items characterized as choppers and "core" tools. \\
\hline Drills/Perforators & Usually bifacially worked. \\
\hline $\begin{array}{l}\text { Projectile Points and } \\
\text { Preforms }\end{array}$ & Does not include items characterized as blanks. \\
\hline Hammerstones & Evidence of hammering. If grinding is also present, count as ground stone rather than hammerstone. \\
\hline Manos & Must have evidence of grinding and a convex surface. \\
\hline Metates & Must have evidence of grinding and a concave surface. \\
\hline Pestles & Evidence of hammering or grinding present on one or both ends of cylindrical-shaped stone. \\
\hline Cores & Cobble or nodule with three of more flake scars present. \\
\hline Tested Cobbles & Cobble or nodule with less than three flake scars present. \\
\hline Other Ground Stone & Will probably be dominated by fragments, as well as multi-use ground stone tools. \\
\hline Other Unifaces & Unifaces without any clear hafting element present. \\
\hline Other Bifaces & Bifaces without any clear hafting element present. \\
\hline Other Items & Items not covered by the above, such as worked shell. Does not count ceramics. \\
\hline
\end{tabular}


ure 16-2 plots the number of tool types (x-axis) against sample size per component ( $y$-axis) to account for any trends simply explained by the nature of the sample. There is a relatively strong linear relationship $\left(\mathrm{R}^{2}=0.575\right)$ between sample size and the number of tool types identified in the components indicating that the number of tool types is strongly dependent on sample size. However, only five of the components fall within the 95 percent confidence interval. Seven components have tool type counts higher than the 95 percent interval and the tool type counts for six other components fall slightly below this line.

Four of the six components that fall above the 95 percent confidence line are Terminal Late Prehistoric in age. This pattern meets with our expectation outlined above. Of the remaining three components, two are Initial Late Prehistoric and only one is a Middle Late Archaic component. We suspect that the high number of tool types at these two sites may be due to resource patch productivity in the vicinity of the site and concomitant increase in site occupation span and number of occupants. Six components fall below the 95 percent confidence line in Figure 16-2. Two of these are Terminal Late Prehistoric components from 41ED28 and 41KM69, respectively. They may represent special purpose sites with a limited suite of activities performed. The other four components may result from very short-term foraging occupations where few tools were discarded during the use of the site.

Table 16-2. Tool Types within the Components of the Regional Comparative Database

\begin{tabular}{|c|c|c|c|c|c|c|c|c|c|c|c|c|c|c|c|c|c|c|c|c|c|c|}
\hline \multirow[b]{2}{*}{ 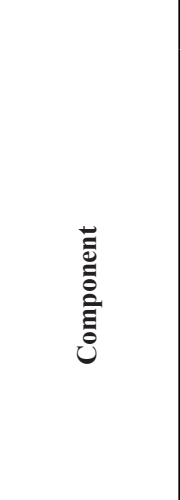 } & \multirow[b]{2}{*}{ 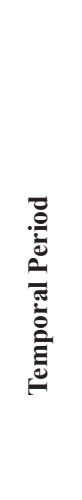 } & \multicolumn{4}{|c|}{ Flake Tool Analysis } & \multicolumn{15}{|c|}{ Tool Categories } & \multicolumn{2}{|c|}{ Totals } \\
\hline & & 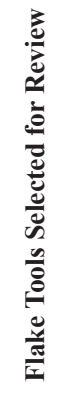 & 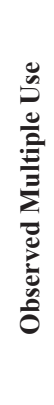 & 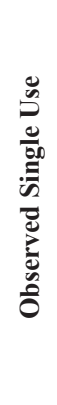 & 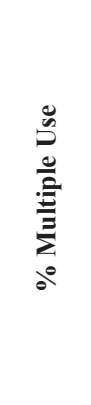 & 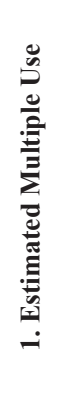 & 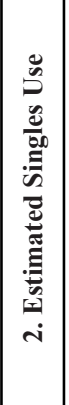 & 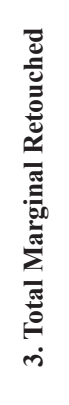 & 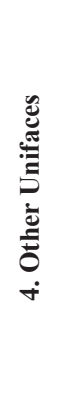 & 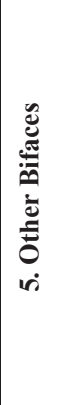 & 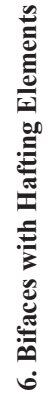 & 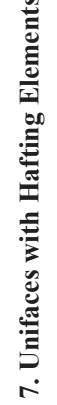 & 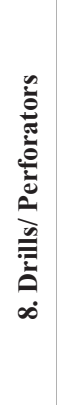 & 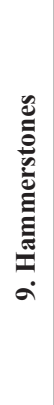 & 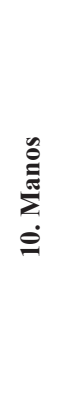 & 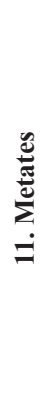 & 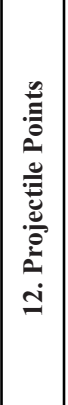 & 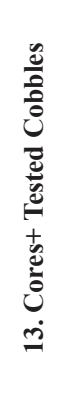 & 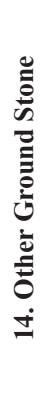 & 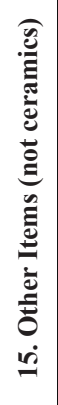 & 苞 & है \\
\hline 41BN33 & ILP & 12 & 0 & 12 & $0.0 \%$ & 0 & 12 & 9 & 1 & 13 & 3 & 0 & 1 & 2 & 0 & 1 & 20 & 20 & 0 & 0 & 82 & 10 \\
\hline 41BN33 & TLA & 5 & 1 & 4 & $20.0 \%$ & 1 & 4 & 3 & 0 & 1 & 1 & 0 & 0 & 0 & 0 & 0 & 3 & 5 & 0 & 0 & 18 & 7 \\
\hline $41 \mathrm{BN} 33$ & TLP & 20 & 2 & 18 & $10.0 \%$ & 2 & 18 & 17 & 1 & 12 & 1 & 1 & 1 & 0 & 0 & 0 & 22 & 13 & 0 & 0 & 88 & 10 \\
\hline 41BX300 & TLA & 1 & 0 & 1 & $0.0 \%$ & 0 & 8 & 0 & 0 & 5 & 0 & 0 & 0 & 0 & 0 & 0 & 3 & 1 & 0 & 0 & 17 & 4 \\
\hline 41ED28 & TLP & 39 & 0 & 39 & $0.0 \%$ & 0 & 39 & 61 & 1 & 61 & 5 & 1 & 5 & 0 & 0 & 0 & 27 & 37 & 0 & 0 & 237 & 9 \\
\hline 41JW8 & TLP & 47 & 15 & 32 & $31.9 \%$ & 23 & 49 & 115 & 64 & 196 & 12 & 4 & 1 & 7 & 5 & 20 & 125 & 35 & 6 & 41 & 703 & 15 \\
\hline 41KM69 & ILP & 1 & 0 & 1 & $0.0 \%$ & 0 & 1 & 23 & 10 & 77 & 11 & 2 & 0 & 0 & 0 & 0 & 5 & 30 & 0 & 0 & 159 & 8 \\
\hline 41KM69 & MLA & 3 & 1 & 2 & $33.3 \%$ & 1 & 2 & 9 & 0 & 24 & 2 & 0 & 0 & 0 & 0 & 0 & 9 & 3 & 0 & 0 & 50 & 7 \\
\hline 41KM69 & TLA & 1 & 0 & 1 & $0.0 \%$ & 1 & 0 & 12 & 11 & 41 & 1 & 0 & 1 & 0 & 0 & 0 & 24 & 9 & 0 & 0 & 100 & 8 \\
\hline 41KM69 & TLP & 1 & 1 & 0 & $100.0 \%$ & 0 & 1 & 6 & 11 & 9 & 0 & 18 & 0 & 0 & 0 & 0 & 3 & 7 & 0 & 0 & 55 & 7 \\
\hline 41LK201 & TLP & 9 & 4 & 5 & $44.4 \%$ & 4 & 5 & 33 & 11 & 85 & 10 & 4 & 3 & 0 & 12 & 3 & 55 & 50 & 6 & 21 & 302 & 14 \\
\hline 41LK67 & TLP & 11 & 6 & 5 & $54.5 \%$ & 6 & 5 & 9 & 3 & 7 & 1 & 0 & 0 & 3 & 0 & 0 & 4 & 18 & 0 & 1 & 57 & 10 \\
\hline $41 \mathrm{MC} 296$ & ILP & 7 & 1 & 6 & $14.3 \%$ & 1 & 6 & 3 & 0 & 13 & 1 & 0 & 0 & 0 & 11 & 16 & 0 & 10 & 1 & 7 & 69 & 10 \\
\hline $41 \mathrm{MC} 296$ & MLA & 6 & 3 & 3 & $50.0 \%$ & 4 & 4 & 5 & 1 & 6 & 0 & 0 & 0 & 0 & 11 & 16 & 1 & 20 & 4 & 0 & 72 & 10 \\
\hline $41 \mathrm{MC} 296$ & TLP & 4 & 2 & 2 & $50.0 \%$ & 2 & 2 & 19 & 11 & 27 & 2 & 0 & 0 & 0 & 8 & 17 & 34 & 21 & 0 & 2 & 145 & 11 \\
\hline 41MM340 & MLA & 50 & 15 & 35 & $30.0 \%$ & 28 & 66 & 29 & 8 & 52 & 0 & 0 & 0 & 4 & 0 & 1 & 34 & 36 & 0 & 0 & 258 & 9 \\
\hline 41MM341-au1 & ILP & 50 & 16 & 34 & $32.0 \%$ & 47 & 101 & 73 & 16 & 98 & 8 & 0 & 2 & 11 & 0 & 4 & 33 & 90 & 0 & 18 & 501 & 12 \\
\hline 41MM341-au2 & ILP & 50 & 14 & 36 & $28.0 \%$ & 30 & 77 & 43 & 4 & 65 & 5 & 0 & 0 & 6 & 0 & 3 & 19 & 60 & 0 & 10 & 322 & 11 \\
\hline $41 \mathrm{MV} 120$ & MLA & 1 & 0 & 1 & $0.0 \%$ & 0 & 1 & 2 & 1 & 3 & 1 & 0 & 0 & 0 & 1 & 0 & 1 & 1 & 0 & 0 & 11 & 8 \\
\hline \multicolumn{2}{|l|}{ Totals } & 317 & 81 & 236 & $25.6 \%$ & 150 & 401 & 471 & 154 & 795 & 64 & 30 & 14 & 33 & 48 & 81 & 422 & 466 & 17 & 100 & 3,246 & \\
\hline
\end{tabular}




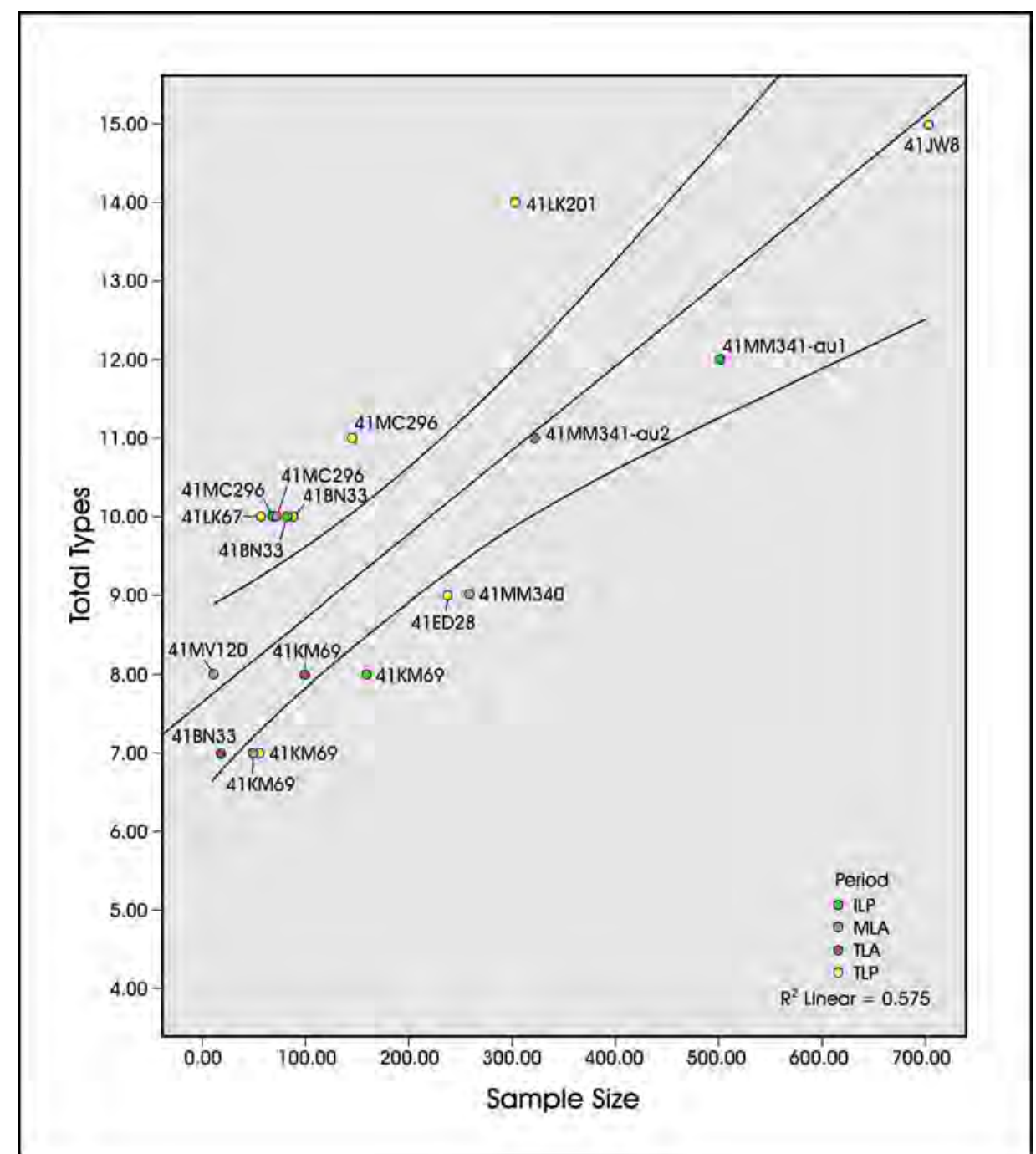

Figure 16-2. Plot of tool types against sample size among the comparative site components in the study area.

\section{Investigating the Scale of Mobility}

We argued that when diet breadth is expanding, especially during the Terminal Late Prehistoric, the scale of mobility should be increased as a function of increased search time, and increased reliance on logistical procurement, associated with high-ranked prey. In contrast, if earlier mobility systems differentially used a foraging strategy, these earlier periods should have lower overall mobility. While the number of residential moves may increase in a foraging system relative to a logistical organized system, the scale covered by the entire mobility system should be drastically reduced with a foraging organization (see Kelly 1995).

We suggest that as the scale of the mobility increases, there should be concomitant increases in the range of tool stone encountered and used in tool production. A corollary of this expectation is that the greater the scale of mobility the more likely that some of the tool stone present on site arrived there from nonlocal resources in the form of staged, finished, tools or well-worn tools and represents the debris from staged manufacture, tool rejuvenation, and reworking. Several studies (e.g., Amick 1994) have shown that debitage and tools can be used to track mobility. While these studies often involve the matching of specific raw materials with known source locations, the relationship demonstrated by these earlier studies is applicable even if the specific tool stone source areas are not known ${ }^{\text {(note 1) }}$. Figure 16-3 presents the proposed relationship between the number of raw material types present and mobility. The upper right quadrant of the graph should be dominated by logistically organized residential components. Whether the acquisition of tool stone is embedded in other activities, or is a task-specific activity, these logistical residential components should reflect the range of raw materials present in the system. Regardless of the activities, task-specific, special- 


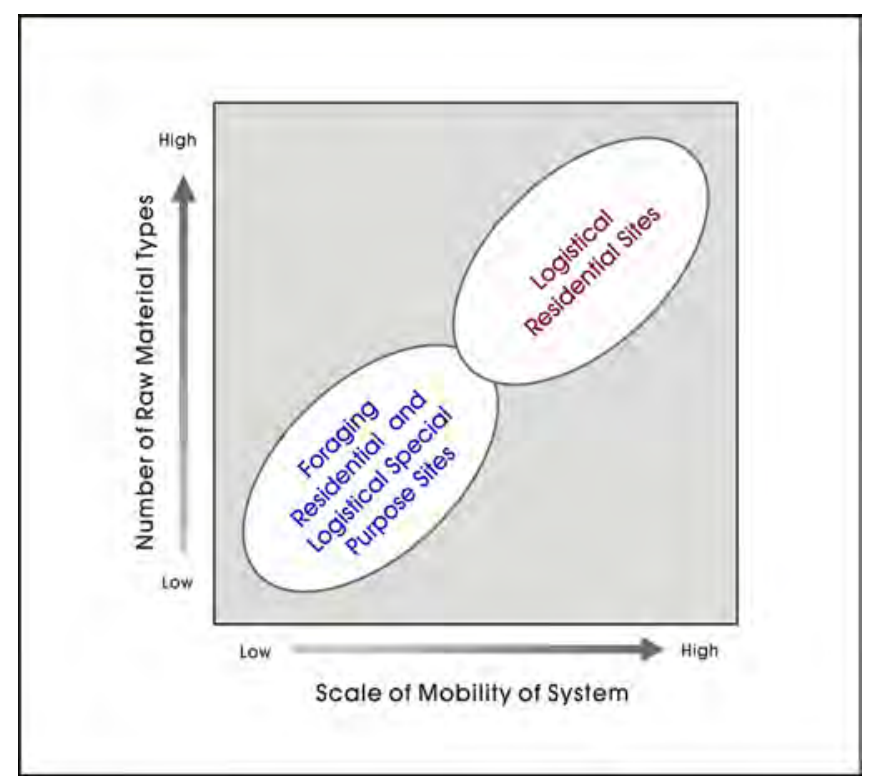

Figure 16-3. Anticipated relationship between scale and number of raw material types.

purpose locations should have a smaller range of raw materials present. Similarly, foraging components should also encounter a smaller range of raw materials simply as a function of the more limited scale of mobility. For instance, forager groups centered on the exploitation of the Hill Country region of the Edwards Plateau will have access to good quality cherts characterized by tan, brown and gray color ranges. These resources would include both primary sources, as well as a variety of secondary sources available in river gravel deposits. Foraging groups off the plateau in South Texas would have a more limited selection, with tool stone primarily limited to river gravel deposits and some lower quality raw materials blanketing high spots across the landscape.

To address the issue of scale of mobility, we collected data on raw material color categories from 17 archeological components ranging from middle Late Archaic to Terminal Late Prehistoric in age. A sample of approximately 1000 pieces of unmodified lithic debitage (i.e., lots totaling approximately 1000 specimens) was selected from each component. During the preliminary analysis of the debitage, all heated and heat spalled specimens were culled as were all patinated specimens for which original color could not be assessed. These processing steps left us with a collection of between 300-400 pieces of debitage that could be classified into color groups. The color categories defined for each site only applied to that specific site and were not intended to match across sites. Once each color group was finalized, the debitage from each group was screened through $1 / 4$-inch, $1 / 2$-inch and 1-inch and 2-inch screens and each size class was divided into corticated and decorticate subgroups. The number of color categories identified in the comparative assemblages and the sample sizes from which they derive are listed in Table 16-3.

Table 16-3. Number of Stone Tool Color Categories by Component, Regional Database

\begin{tabular}{|c|c|c|c|}
\hline Component & Period & Color & Sample Size \\
\hline $41 \mathrm{BN} 33$ & ILP & 46 & 1,342 \\
\hline $41 \mathrm{BN} 33$ & TLA & 14 & 290 \\
\hline $41 \mathrm{BN} 33$ & TLP & 45 & 2,374 \\
\hline 41BX300 & TLA & 17 & 176 \\
\hline 41ED28 & TLP & 27 & 336 \\
\hline 41ED28 & TLA & 18 & 357 \\
\hline 41ED28 & MLA & 17 & 418 \\
\hline 41JW8 & TLP & 31 & 296 \\
\hline 41KM69 & ILP & 233 & 2,180 \\
\hline 41KM69 & MLA & 144 & 1,182 \\
\hline 41KM69 & TLA & 192 & 898 \\
\hline 41KM69 & TLP & 124 & 742 \\
\hline 41LK67 & TLP & 52 & 515 \\
\hline 41MM340 & MLA & 18 & 352 \\
\hline $41 \mathrm{MM} 340$ & ILA & 18 & 397 \\
\hline 41MM341 & ILP & 22 & 795 \\
\hline 41MV120 & MLA & 28 & 494 \\
\hline 41MV120 & TLA & 32 & 376 \\
\hline
\end{tabular}


All tools from the respective archeological components were also categorized into the color groups defined from the debitage. Colors that had no matches in the debitage were assigned a new color number.

Figure 16-4 shows the plot of color categories identified in the regional comparative debitage database against the respective sample sizes. It is evident that only one debitage assemblage, 41LK67, falls above the 95 percent confidence interval on the plot. While this assemblage is Terminal Late Prehistoric in age, the other three contemporaneous assemblages do not plot above the confidence interval clearly contrary to our expectations. In contrast, neither of the three components that plot below the 95 percent confidence level are Terminal Late Prehistoric in age. This supports our contention that scales of mobility may have been more reduced prior to the intensification of bison procurement during the Terminal Late Prehistoric.
The differentiation of color categories for the 41KM69 assemblage proceeded slightly differently due to the much larger sample of debitage investigated and the availability of locally collected comparative raw materials. Approximately 10,000 pieces of lithic debitage were selected for the color analysis from 41KM69. As in the case of the other assemblages, heated, heat-treated and patinated pieces were pulled from the collection. The remaining specimens were then screened through $1 / 8$ inch mesh to exclude from the analysis debitage that was smaller than this maximum size. This was done to standardize the materials that would be compared to the regional comparative assemblages since none of them included debitage smaller than that recovered in $1 / 4$-inch screens. At the completion of this stage, we were left with roughly 5500 pieces of lithic debitage from four components identified at the site. Using a splitter approach, the initial separation of the 41KM69 debitage collection resulted in the differentiation of 296 color groups that cross-cut proveniences and

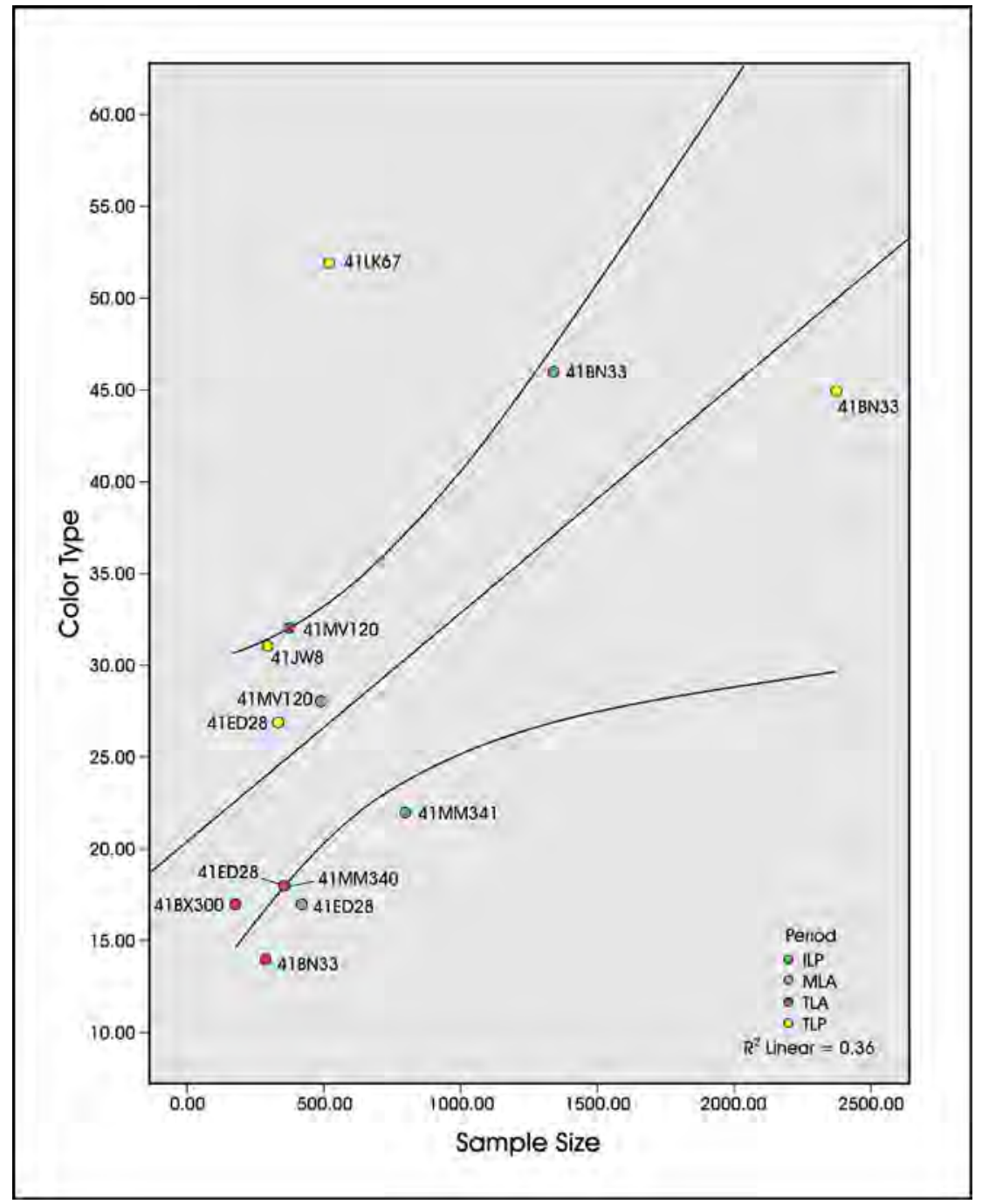

Figure 16-4. Plot of color types against sample size among the comparative site components in the study area. 
components across the site. Following an exhaustive examination of the variability within locally obtained comparative chert collection, the 296 color groups were combined into a total of 248 more inclusive color groups.

Because of the dramatically higher number of color categories defined within the 41KM69 debitage assemblage, we did not include these components into the plot shown in Figure 16-5. Rather, we calculated the adjusted standardized residuals for color categories present within the four components of the site. Figure 16-5 shows that the number of color categories is over-represented given sample size, in the Terminal Late Archaic and Terminal Late Prehistoric assemblages. Any values that exceed $+/-1.96$ are statistically valid at the .05 level of significance. The Late Archaic pattern is unexpected while the TLP pattern fits with our expectations of greater scales of mobility during the later part of the Late Prehistoric.

If our assumptions about the relationship between scale of mobility and numbers of chert types is accurate, we can also expect that as the at least some of the chert color categories isolated during the color analyses will be represented entirely by decorticate specimens. That is, if some of the many chert types were acquired off-site during long-distance forays, it is likely that they will have produced only decorticate debitage once the artifacts made of them arrived on site. Therefore, we would expect that there would be a strong relationship between the total number of chert colors within a collection and the number of chert color groups consisting entirely of decorticate debitage.

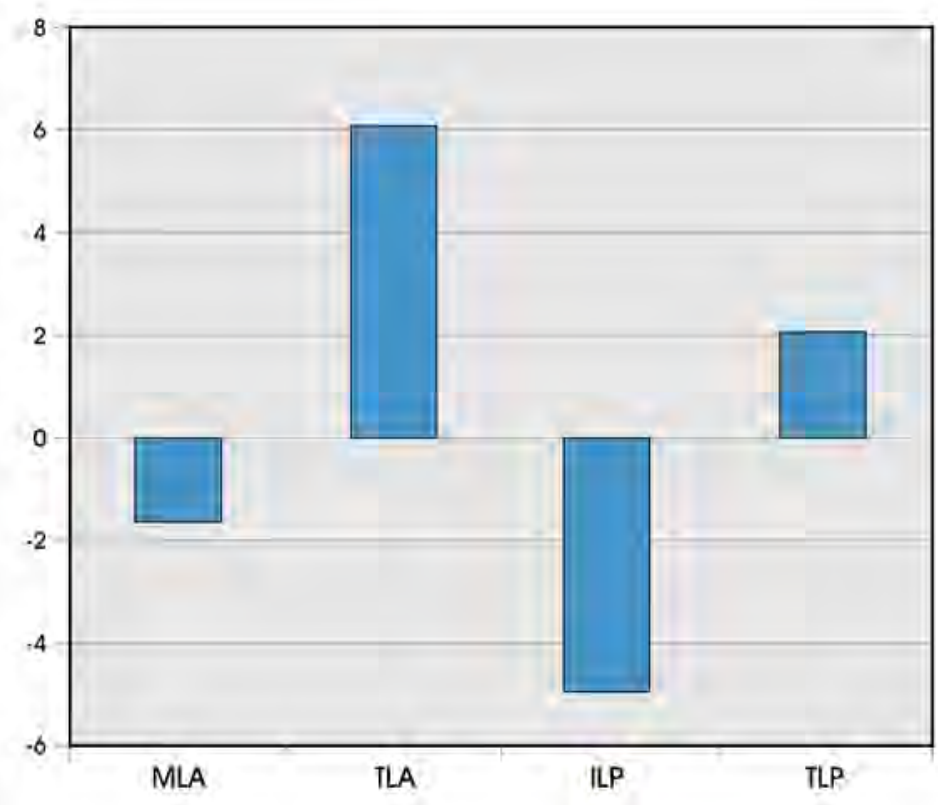

Figure 16-5. Adjusted standardized residuals showing over- and underrepresented total color counts by time period.
Table 16-4 presents the breakdown of total chert colors and numbers of colors consisting entirely of decorticate debitage within each comparative database assemblage.

Figure 16-6 shows the relationship between these two analytical categories. It is evident that there is a strong linear relationship between the total number of chert color categories identified in a component and the number of color categories that consist of entirely decorticate debitage. The pattern overall suggests that the assumption that as the scale of mobility increases so does the proportion of debitage that is derived from off-site localities.

As before, given the highly detailed color classifications carried out for the 41KM69 assemblage we did not include the data into the regional comparison plot. Rather, we investigated the patterning using adjusted standardized residuals. No statistically significant patterns were noted in the residual analysis.

\section{Results of the Instrumental Neutron Activation Analysis}

A sample of 29 chert flakes was submitted to the Archaeometry Laboratory at the University of Missouri Research Reactor (MURR) for analysis. The samples consisted of five specimens removed from chert nodules found in the gravel bars adjacent the site. The remaining 24 specimens were archaeological debitage representing eight color categories identified during the color/ texture sorting of the debitage from 41KM69. Three specimens representing each of the eight color categories were submitted. Table 16-5 lists the samples and their temporal affiliations. The table also lists the percentage of decorticate debitage found within the color category. It is evident that in the case of some color categories, more than half of the debitage is corticated (i.e., 38 percent decorticate; Color 76), while in the case of others (Color 92) only a small proportion consists of corticated debitage.

Unfortunately, since the samples were submitted before all of the color categorizations were completed, none of the color groups represent categories that consisted only of decorticate debitage. There are no fewer than 50 color categories $(20$ percent) that consist entirely of decorticate debitage. The majority of these 50 color groups consist of fewer than five flakes each. 
Table 16-4. Number of Tool Stone Color Categories and Decorticate Colors by Component, Regional Database

\begin{tabular}{|c|c|c|c|}
\hline Component & Period & Number of Color Categories & Decorticate Colors \\
\hline $41 \mathrm{BN} 33$ & ILP & 46 & 24 \\
\hline $41 \mathrm{BN} 33$ & TLA & 14 & 6 \\
\hline $41 \mathrm{BN} 33$ & TLP & 45 & 27 \\
\hline $41 \mathrm{BX} 300$ & TLA & 17 & 17 \\
\hline $41 \mathrm{ED} 28$ & TLP & 27 & 3 \\
\hline 41ED28 & TLA & 18 & 8 \\
\hline $41 \mathrm{ED} 28$ & MLA & 17 & 5 \\
\hline $41 \mathrm{JW} 8$ & TLP & 31 & 9 \\
\hline $41 \mathrm{LK} 67$ & TLP & 52 & 18 \\
\hline $41 \mathrm{MM} 340$ & MLA & 18 & 13 \\
\hline $41 \mathrm{MM} 341$ & ILP & 22 & 8 \\
\hline $41 \mathrm{MV} 120$ & MLA & 28 & 13 \\
\hline $41 \mathrm{MV} 120$ & TLA & 32 & 16 \\
\hline
\end{tabular}

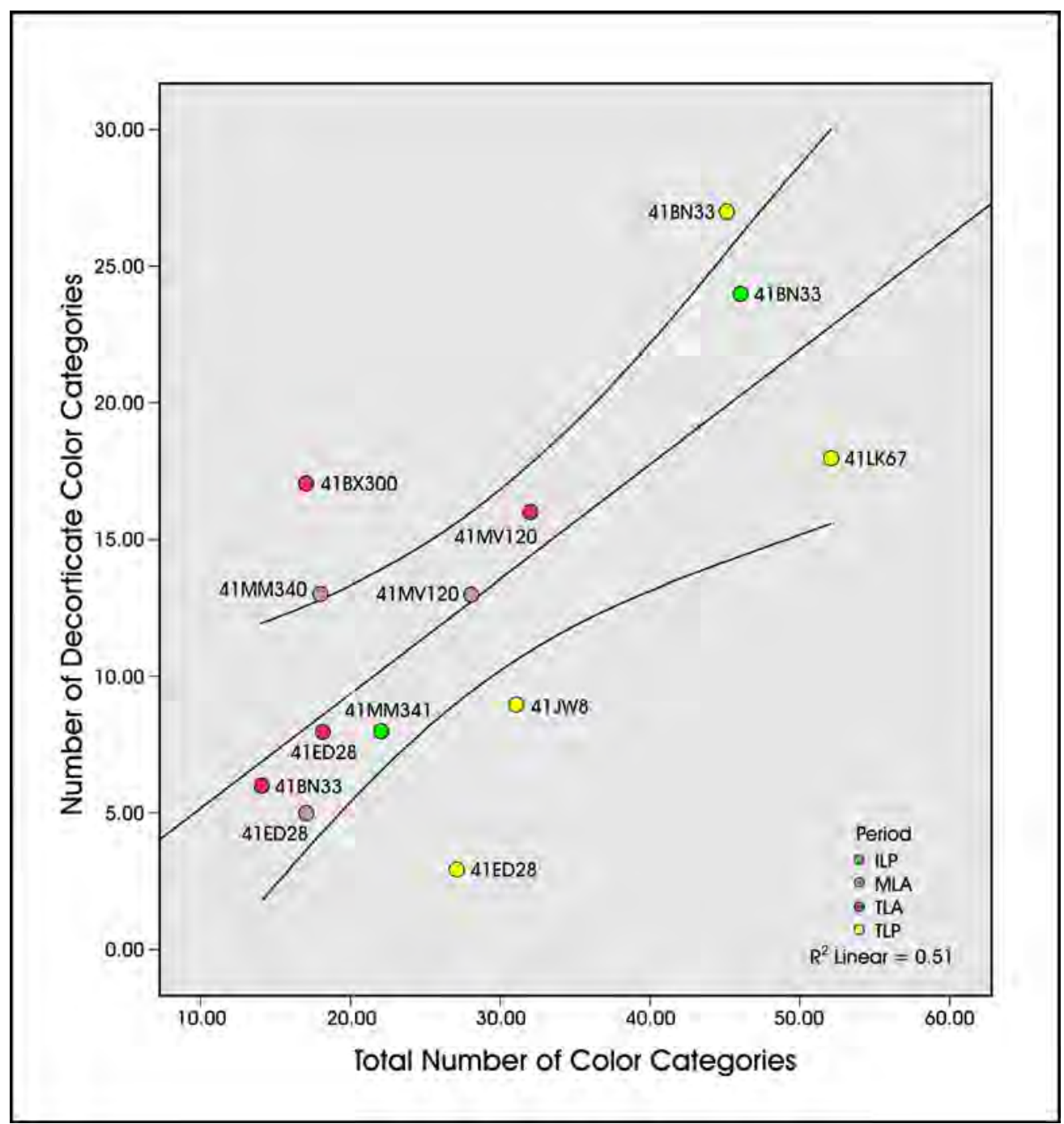

Figure 16-6. Plot of the number of chert color categories against the number of categories represented entirely by decorticate debitage, regional comparative database. 
The INAA finds that some of the color groups are definitively of local origin, that is, they match the comparative chert specimens collected from the vicinity of the site. Other samples appear to have chemical signatures similar to Edwards Plateau cherts and at least two samples appear to be similar to Callahan Divide cherts in chemical signature. Interestingly, the three samples that consists of principally decorticate debitage have chemical signatures that do not match the signatures of any other cherts hitherto analyzed from Texas by the MURR staff.

The results show that in general, the submission of locally collected cherts as controls for provenience is useful and necessary when conducting INAA of chert samples. The MURR analysis suggests that a subgroup of Junction chert may be defined within the broader Edwards Group due to the tight chemical clustering of the cherts submitted from the vicinity of the site. The results also suggest that the proportion of cortex on debitage collections may not necessarily be a good indicator of local nonlocal origin, although insufficient numbers of color categories with high proportions of decorticate debitage were submitted for analysis to definitively answer this question. Finally, the analysis also shows that during the Terminal Late Prehistoric, mobility patterns may have extended outside of the borders of what is currently Texas as indicated by the presence of cherts that do not match any previously defined classes in the State. Such cherts could have been brought into the region as curated tools manufactured outside of the state.

Table 16-5. Debitage Samples Submitted to MURR for INAA

\begin{tabular}{|c|c|c|c|c|}
\hline Time Period & Final Color & Per. Decorticate & CAR Assessment & MURR Assessment \\
\hline N/A & N/A & N/A & Local Gravel Sample & N/A \\
\hline N/A & N/A & N/A & Local Gravel Sample & N/A \\
\hline N/A & N/A & N/A & Local Gravel Sample & N/A \\
\hline $\mathrm{N} / \mathrm{A}$ & N/A & N/A & Local Gravel Sample & $\mathrm{N} / \mathrm{A}$ \\
\hline $\mathrm{N} / \mathrm{A}$ & N/A & $\mathrm{N} / \mathrm{A}$ & Local Gravel Sample & $\mathrm{N} / \mathrm{A}$ \\
\hline ILP & 258 & 44 & Poss. local & Poss. Local or Nonlocal \\
\hline TLA & 258 & 44 & Poss. local & Poss. Local or Nonlocal \\
\hline ILP & 258 & 44 & Poss. local & likely Edwards Group chert \\
\hline MLA & 76 & 38 & Poss. local & Local \\
\hline ILP & 76 & 38 & Poss. local & likely Edwards Group chert \\
\hline ILP & 76 & 38 & Poss. local & Local \\
\hline ILP & 43 & 64 & poss. Nonlocal & Local \\
\hline ILP & 43 & 64 & poss. Nonlocal & Local \\
\hline ILP & 43 & 64 & poss. Nonlocal & Local \\
\hline ILP & 28 & 61 & poss. Nonlocal & Poss. Nonlocal \\
\hline ILP & 28 & 61 & poss. Nonlocal & Local \\
\hline ILP & 28 & 61 & poss. Nonlocal & likely Edwards Group chert \\
\hline TLP & 63 & 61 & Poss. local & Local \\
\hline TLA & 63 & 61 & Poss. local & Poss. Local or Nonlocal \\
\hline MLA & 63 & 61 & Poss. local & Poss. Local or Nonlocal \\
\hline TLP & 293 & 86 & Poss. Nonlocal & Nonlocal \\
\hline TLP & 293 & 86 & Poss. Nonlocal & Nonlocal \\
\hline TLP & 293 & 86 & Poss. Nonlocal & Nonlocal \\
\hline MLA & 102 & 55 & Poss. Nonlocal & Local \\
\hline MLA & 102 & 55 & Poss. Nonlocal & Poss. Nonlocal \\
\hline ILP & 92 & 85 & Poss. Nonlocal & Local \\
\hline TLA & 92 & 85 & Poss. Nonlocal & Poss. Local or Nonlocal \\
\hline
\end{tabular}




\section{Chapter 17: Conclusion}

\section{Steve A. Tomka and Jennifer L. Thompson}

In 2004, the TxDOT contracted with the Center for Archaeological Research to conduct National Register of Historic Places eligibility testing at 41KM69 in Junction, Kimble County, Texas. The significance testing was begun under Texas Antiquities Permit Number 3350 and continued to the data recovery phase in 2005 under Texas Antiquities Permit Number 3584 with Raymond Mauldin serving as Principal Investigator on both permits. The work was begun under Work Authorization No. 57315SA002 and Contract No.573XX5A002 and completed under Work Authorization No. 7902SA001 Contract No. 579XXSA001.

During testing 120 auger tests, six backhoe trenches, eight $50-\mathrm{x}-50-\mathrm{cm}$ units and five $1-\mathrm{x}-1-\mathrm{m}$ units were excavated across the western portion of the site within the planned TxDOT right-of-way. This effort confirmed intact Late Archaic and Late Prehistoric Austin and Toyah interval components as well as a disturbed twentieth century component. The prehistoric deposits included four burned rock features including a large burned rock midden, 3,000 chipped stone artifacts, 10 temporally diagnostic projectile points, unifacial tools typical of Toyah end-scrapers and native ceramics, also commonly found on Toyah occupations. A small quantity of bone was collected including one bison tibia fragment. The historic component was confined to the upper level of the site from the surface to approximately $20 \mathrm{cmbs}$. The Kimble Courts resort camp once stood in the area, though the buildings were moved to city of Junction.

Data recovery excavations targeted the prehistoric components after the historic levels were removed by backhoe. Four large blocks were excavated in areas of high artifact density. Approximately $130 \mathrm{~m}^{3}$ and 40,000 artifacts were recovered from these blocks including 350 stone tools and 114 earthenware sherds. Projectile point types found are Castroville, Pedernales, Montell, Ellis, Frio, Ensor, Fairland, Edwards, and Perdiz. Seventy-three prehistoric thermal rock features and soil stains were also recorded. We also collected bone, shell, feature burned rock, and soil samples.

Following hand excavations, the project area was monitored during Gradall stripping of the remaining deposits. Fifty-seven auger tests were also excavated after a shift in the project ROW. Artifact density was sparse in the shifted ROW and most artifacts came from disturbed upper level deposits.

The analysis of the materials subsequent to the field investigations showed that site 41KM69 is a multi-component site with significant Late Archaic, Late Prehistoric Austin interval, and Late Prehistoric Toyah interval components. The excavated portion of the site contained 47 burned rock features including one large burned rock midden. The site also yielded over 40,000 chipped stone artifacts from all components and a discrete group of plain, bone-tempered earthenware ceramics similar to those typically found in Toyah components. Several radiocarbon samples were submitted, with the oldest from a hearth feature dating to the middle of the Late Archaic period $(2550 \pm 50$ B.P.). The most recent sample dated the upper level ceramic assemblage, targeted during data recovery excavations, to the very Late Prehistoric or Protohistoric Period. The site contains a twentieth century historic component as well, but it was not targeted during excavation. In this chapter, we provide a summary of the results of the analyses conducted on materials recovered from the site.

The research design developed following the data recovery investigations at 41KM69 identified several research domains around which to organize the research and for which the testing and data recovery efforts retrieved relevant data types. The research design had a heavy theoretical focus on cultural and evolutionary ecology and the research domains targeted several topics common to such approaches including the reconstruction of paleoclimatic conditions, variability in subsistence strategies during the site's occupation span, assessment of technological organization as seen in both ceramic and lithic artifact assemblages, and the investigation of changes in hunter-gatherer mobility. While a plethora of post-processual theoretical approaches have emerged in the last decade of American archeology, the authors of this report felt that the data types obtained from the site are well suited to a detailed investigation of hunter-gatherer adaptations to the changing conditions of the Late Archaic and Late Prehistoric periods because their relationships to human behavior has been well established through middle range research over the past few decades. The authors felt that while research on issues of cultural contact, regional interaction spheres, and identity, some of the themes common in post-processual archeology, are well worth pursuing, the linkages between data and behavior have not yet been sufficiently developed to allow systematic research.

One example of this difficulty is exemplified by the assessment of the Terminal Late Prehistoric component present in the lower terrace at 41KM69. The excavations and subsequent analysis identified elements of material culture that typically would be identified as belonging to the Toyah in- 
terval. However, these materials had a somewhat unusual vertical distribution. The deeper manifestation present in the Bk horizon contains lithic artifacts (points, scrapers) that are commonly assigned to the Toyah interval but lacks ceramics. The upper one is a very late Terminal Late Prehistoric assemblage of ceramics and unifacial scrapers. In addition, the radiocarbon dating of associated materials also highlighted some disagreements in the "absolute" dating of the age of the materials and features present on the lower terrace of the site. The normative rather static assumption of collections of material culture is that Toyah Phase or Interval consists of Perdiz arrow points, tear-drop shaped end scrapers, and bone tempered ceramics, typically referred to as Leon Plain wares dating between A.D. 1250-1650. The archeological manifestation of these materials at 41KM69 is interesting and brings into view the difficulties of assigning normative labels to assemblages of artifacts without recognizing that simplistic labels are just that, too simplistic to be of great practical value. That is, the whole suite of cultural materials that define the Toyah is not present within a single depositional zone (points are not co-occurring with ceramics and scrapers). Does this make the materials be something other than affiliated with the Toyah interval? If distinct material elements of the Toyah material culture can still be assumed to represent Toyah "people" does the presence of Perdiz points associated with sandtempered pottery on the coast, represent Toyah "people?" Does the fact that the youngest of the dates on materials associated with features that are in turn rich in tear-dropped end scrapers make the Toyah interval extend into the historic or proto-historic period? Even overlooking the fact that the Toyah interval is a collection of material culture that contemporary archeologists have compiled and as such may have no relationship whatsoever to a prehistoric cultural entity, the overall difficulty is that the linkages between material culture and the ideational concepts implied by terms such as Toyah people have not been established. In contrast, however, some of the relationships between material culture and human behavior (i.e., manufacture costs of tools and their relationship to discard behavior) have been well documented and form only one element of a broad intersecting approach to measuring and tracking changes in human adaptation to changing external conditions.

The theoretical approach of our research began with a novel reinterpretation of the concept that bison availability was at its peak during the Terminal Late Prehistoric Period. Instead, we used a series of data to suggest that bison availability may have been highly variable both in space and time during the period. This volatility may have lead to an increase in unpredictability in terms of the availability of this highly ranked resource. We proposed that in reaction to these conditions, hunter-gatherers began to intensify bison procurement leading to the higher archeological visibility of bison remains and the specialized lithic technology seen during the time period.
The actual analysis of the materials recovered from the site began with the need to determining the paleoclimatic conditions present at the time of site occupation and how they may have conditioned both the resource available, as well as their abundance and structure. Therefore, we proposed to investigate a number of data types recovered from 41KM69 to reconstruct paleoclimatic conditions at the time of site occupation.

Unfortunately, the analysis of pollen and phytolith samples proved of little value do to the degradation of assemblages. The general conclusion from attempts at pollen/phytolith analysis from several open-air sites is that preservation conditions are simply not good for the recovery of non-degraded assemblages. The analysis of the ratios of stable carbon isotopes showed that while $\mathrm{C}_{3}$ plants (e.g., trees) were always present within the site-proximate vegetation community, they became more dominant over time. In this respect, the local climatic conditions appeared to parallel regional trends identified in other parts of the state.

We would expect that as paleoclimatic conditions changed, the types and structure of the resources exploited by prehistoric hunter-gatherers also changed. Several approaches were employed to define trends in prehistoric subsistence at the site. The taxa richness analysis of the materials obtained suggests that during the Austin interval the site inhabitants were practicing a rather broad diet under a residential foraging organization. In contrast, during the Toyah interval (Terminal Late Prehistoric), groups narrowed their diet breadth apparently in response to a greater focus on bison exploitation under a logistically organized land-use strategy. This sitespecific pattern is in general agreement with the regional pattern of narrowing diet breadth exhibited during the Terminal Late Prehistoric compared to the Initial Late Prehistoric. The analysis of bone fragmentation indicates that at the site level, the greatest degree of fragmentation occurs in the Terminal Late Prehistoric bone assemblage but unlike expectations, the least amount occurs in the Terminal Late Archaic not the Middle Late Archaic, as predicted in our research design. The high degree of fragmentation in the Terminal Late Prehistoric assemblage supports our contention that hunter-gatherers were intensifying the exploitation of bison during the period. At the regional level, fragmentation ratios for the Initial Late Prehistoric Period decrease compared to the earlier analytical periods before increasing during the Terminal Late Prehistoric. This trend contradicts our expectations and it may potentially be related to the impact of a new weapons technology on hunting success rates and yield. We argued in the research design that the adoption of the bow and arrow technology may have been precipitated by the increased reliance on hunting smaller and faster prey species such as antelope and deer during the early portion of the Late Prehistoric Period. Faster 
prey would require faster projectiles at the expense of penetration and the bow and arrow would have been superior to the atlatl propelled dart in speed although not penetration.

The role of plant resources in prehistoric diet is more difficult to gauge due to the lack of preservation. Therefore, to asses such aspects of prehistoric subsistence, proxy measures need to be developed. Using the number and types of thermal features as proxy measures for plant use, the data from 41KM69 indicates that both the number of burned-rock and non-rock features increases through time as does the size of burned rock features. This suggests increasing use of plants in the diet of hunter-gatherers from the Middle Late Archaic through the Terminal Late Prehistoric.

The shifts in resources and subsistence would have been accompanied by corresponding changes in technological organization that is, the composition tool assemblages, patterns of raw material procurement, tool rejuvenation and discard, and the manufacture of costly versus expedient tool forms. The analysis of technological organization as reflected by the manufacture costs of stone tools showed that the Terminal Late Prehistoric has the highest percentage of expensive tools, while the greatest use of expedient tools happens during the Middle Late Archaic Period. The regional database also shows that specialized tools are more common during the Terminal Late Prehistoric than any other time period in our sample. Since projectile points and bifacial knives are present during earlier periods as well, the trend in expensive tools seems to be primarily conditioned by the large number of end scrapers that appear during the Terminal Late Prehistoric Period. This time period is also the only one in which the lithic artifact assemblage appears to be the result of gearing up as suggested by the predominance of use-broken specimens over manufacture-failed pieces. The regional database shows no patterning in gearing-up.

The investigation of changes in weapons technology focused on the analysis of projectile point samples from central, south and east Texas, areas of assumed bison availability (central) and scarcity, respectively. One attribute examined was projectile point neck width. It was used as a measure or proxy for foreshaft/shaft thickness and the overall weight of the projectile. The data showed that projectile point neck widths were consistently greater in regions commonly populated by bison prior to the appearance of the bow and arrow. On the other hand, dart point neck widths were consistently narrower in regions where bison was not common. A similar trend was documented in projectile point weight. Prior to the appearance of the bow and arrow, projectile point weights were consistently higher in primary bison habitats compared to regions with secondary or inferior bison habitats. The patterns suggest that the general characteristics of the hunting weaponry, particularly, the weight of the darts, was manipulated to allow increased hunting success when procuring large-bodied prey species such as bison compared to the smaller and speedier antelope and deer. In contrast, the adoption of the bow and arrow may have also been an adaptation to increase hunting success of small, faster animals like deer and antelope.

The investigation of changes in ceramic technology in response to distinct mobility strategies focused on two attributes: the proportion of temper present in the vessel fabric and the thickness of the vessel walls. While we anticipated that the wall thickness of ceramics produced by semi-sedentary populations would be less than those produced by mobile groups, the data did not bear out this expectation. Quite to the contrary, Caddo sherds tended to the thicker than Toyah sherds. The later also tend to have more size variability than Caddo sherds. In terms of temper densities, Toyah sherds tended to have higher densities of temper compared to Caddo samples, however, there was no difference in mean temper size between the two groups. The INAA analysis identified three sub-groups of sherds within the assemblage although the samples were relatively homogenous internally. The samples most resembled other sherds from southeast Central Texas. The variability in the small sherd sample from the site also was supported by the SEM-EDS analysis results which showed differences in the mineralogy of the fabric of the six samples studied.

The investigation of the 41KM69 debitage assemblage revealed that the bulk of the debitage derives from locally reduced nodules and tools manufactured on site. However, the tedious sort of samples of unmodified lithic debitage samples into color and texture categories identified a number of groups that appeared not to represent local-origin materials. These groups consisted primarily of decorticate specimens and tended to be smaller than $30 \mathrm{~mm}$ in maximum dimension. They contrasted with other debitage groups that were composed of a range of debitage sizes and moderate to large proportions of corticated specimens. The latter groups were assumed to represent locally obtained raw materials. The comparison of raw material collections made in the vicinity of the site with the various chert color/texture groupings appeared to support in part the assignments of origin. However, the samples of chert submitted from some of these color/texture groups for INAA analysis combined with locally collected raw materials showed that in general, the samples are adequate to define a circum-Junction subgroup within the Edward Plateau cherts. While most of the cherts matched the general Central Texas/Edwards Plateau chert group, some samples had no matches anywhere within the existing INAA 
comparative database. This finding suggests that the range of mobility of some of the groups inhabiting the site may have taken them entirely outside of the sampling universe of the Edwards cherts or that previously un-sampled varieties of chert still remain within the Edward plateau region.

We developed a research design that was largely based on proxy data in an effort to examine certain predictions about prehistoric hunter-gatherers on the Edwards Plateau. Though the results of some of the research domains did not support our predictions, we find the approach sound in its methodologies and interesting in its perspective. It is our hope that the predictions that do not bear out supporting results prompt further critical speculation and new avenues of research that may help explain human behavior as it is recorded in the archeological record. 


\section{Notes to Text:}

\section{Chapter 2: Environmental Setting}

1.) A TXDOT reviewer has questioned various aspects of this paleoclimate reconstruction, as well as the subsequent uses of these data, primarily in Chapters 9 and 11. They suggest that environmental conditions stabilized, becoming essentially modern, at the beginning of the Late Archaic. They suggest that many of the patterns that we see and interpret as supporting our position simply reflect the "settling in" of "people, animals, and plants" to the "stable post-Pleistocene environmental setting." The shifts we see are, it their view, caused by people "simply perfecting broad spectrum foraging to environments that has stabilized for a long enough period...." They further state that the use of proxy bog pollen data in not applicable because these data are located at a "significant distance" from 41KM69. They suggest that the distance, combined with the environmental settings (bog pollen data and riparian setting of 41KM69) renders our findings "ambiguous, and rather meaningless." They state that "a paleoclimate reconstruction based on pollen and phytolith proxy data gathered from four sites located on or in rivers and bogs following the stabilization of the post-Pleistocene environment and compared at this scale should suggest little change, other than a growing dominance of trees through time."

The reconstruction presented in this Chapter, as well as the material discussed in Chapter 11, does not use phytolith data. The only use of phytolith data mentioned is related to the submission of a small number of samples from 41KM69 to assess the potential for recovery. No phytoliths were recovered, and no additional samples were analyzed. Similarly, the initial pollen samples from the site showed low recovery, and no additional pollen samples were submitted from 41KM69. Our paleoclimate reconstruction does use pollen from bog sites, primarily located in Lee County, as one of a number of different data types (stable isotopes from soils at 41KM69, stable isotopes from the nearby site of Hall's Cave, stable isotope data from the Medina River area, tree-ring data sets from throughout the region) in an effort to reconstruct the paleoclimate. While this is clearly a question of scale, note that with the possible exception of the stable isotopes on soils from 41KM69, none of these data sets seem to reflect the Late Archaic stabilization of the environment suggested by the TxDOT reviewer. It seems unlikely, then, that the "settling in" to a "stable" environment is a likely "explanation" for the patterns that we see in several data sets.

\section{Chapter 8: Theoretical Overview}

1.) There are schools of thought within archeology, as well as archeologists, which focus on social factors as providing explanations for archeological patterns. For example, Arnn (2005) has suggested that issues of chronology, subsistence, and technology were essentially understood in Texas and that it was time to move on to more substantive issues focused on determining "social identity" and defining "social boundaries" using a more "holistic" methodology. We obviously disagree with most aspects of that position. We do not think that issues of chronology, subsistence, and technology are well understood, nor do we think that a focus on social identities and boundaries is a productive research strategy to pursue in terms of developing useful explanations for changes in the archeological record.

2.) Prey models are probably the simplest suite of foraging models. Several other varieties of models are available. These including patch choice models (Charnov 1976), central-place foraging models (Jones and Madsen 1989), models that focus on risk (see Stephens and Krebs 1986), models that use other currency, including information (see O'Connell and Hawkes 1981), macro-nutritional considerations (Hill 1988), and mating and reproductive success (Hill and Hawkes 1983). While these models are often more realistic in their assumptions regarding human foragers, they are, in most cases, significantly more complicated then prey models, and frequently require assessment of conditions that are well beyond currently available archeological methodology. Note also that we acknowledge that human behavior is complex. We use these cost/benefit models to frame possible explanations for that complex behavior. Models are, by design, simplifications of a complex reality that allow researchers to isolate a small number of variables that may prove critical, and develop expectations as to how those variables should behave under different conditions. Any results that do not fit those expectations (and most will not) serve to inform the development of new research endeavors.

3.) In the Figure 8-1 plot, the large animal class is composed of mule deer, mountain sheep, and antelope, while the small and medium size class is composed of jackrabbit, cottontail, squirrel, and gopher. Both the large, as well as the medium/small animal groups come from studies done in the Great Basin of the United States. The large animals range in weight from about 
$84 \mathrm{~kg}$ down to just under $50 \mathrm{~kg}$ while the medium $/ \mathrm{small}$ animals start at about $3 \mathrm{~kg}$. We are not suggesting that the return rates of these particular animals or the return rates of other plants and animals found in the Great Basin and Australia used in Figure 8-1 are directly applicable to Central and South Texas. We are suggesting that the concept demonstrated in the Figure 8-1 plot that post-encounter return rates generally are a function of differences in body weights in animals and seed size in plants is applicable to Central and South Texas.

4.) We are not suggesting that seasonal shifts in mule deer return rates in a highly seasonal setting such as Colorado are directly analogous to seasonal return rate shifts in white-tailed deer in Central and South Texas. The Anderson et al. (1972) study that forms the basis of Figure 8-3 provides an example of a general phenomenon, especially in large ungulates, in which nutritional quality shifts by season and shifts in dramatically different ways for males and females (see also Speth 1983; Speth and Speilman 1983). Though we are not aware of any Central or South Texas data on seasonal fluctuations in kcal in bison, white-tailed deer, and antelope, we would expect that seasonal shifts would have occurred in these species in Central and South Texas, though the differences would not be as dramatic as those shown in Figure 8-3 given differences in seasonality.

5.) In prey models, shifts in the density of a resource (e.g., mesquite) will have no impact on the use of that resource unless the resource is the highest ranked. This is because the focus is on the post-encounter decisions. In the case of encountering mesquite, for example, the question centers on whether foragers should quit searching and collect/process mesquite, or continue searching for a higher ranked resource. The density of the higher ranked resource is the determining element.

6) The observation that high-return resources are likely to be the focus of most logistical acquisition, as well as the observation that, in general, animals are higher ranked in term of return rates than plants, suggests that under most circumstances, animals are likely to be the focus of logistically organized task groups. While this suggestion is clearly complicated by seasonal changes in return rates as well as the probability that some plant foods can be stored, we think that this generalization regarding logistical mobility and animals is likely to be true in most situations. Consider, for example, nut resources. Hall (1998) has suggested that mast crops in Texas, such as pecan, are abundant in certain area, predictable in space, and while there is year to year variability in production, nut resources are highly nutritious, with over 70 percent of nutmeat being composed of fats. Yet, from an optimal foraging position, the abundance and nutritional requirements are only relevant in terms of the post-encounter return rates relative to the post-encounter return rates of other potential and actual dietary items. This can be seen by considering the use of mongongo nuts among the !Kung. Lee (1979) demonstrates mongongo nuts are generally predictable in location, have low year to year variation in production, and are a good source of protein ( 28 percent by weight) and energy (ca. 654 calories per 100 grams). However, Hawkes and O'Connell $(1981 ; 1985)$ demonstrate that when we consider the post-encounter return rates (profitability) of mongongo nuts, they provide return rates comparable to other plant resources, and well below the returns associated with many tropical and sub-tropical animals. This is because of the significant amount of time (i.e., energy) required to crack and pound the nuts into a usable form. The return rates on nut resources in Texas are unknown. It is likely that pecans, hickory nuts, acorns, and walnuts all have high processing requirements (see also Simms 1985a; 1985b), though research on the overall profitability of these resources is needed.

7.) The archeological record is not generated at a temporal scale that is analogous to the ethnographic time frame (see Binford 1992; Dunnell 1992; Ebert 1992), the context where most human foraging cost/benefit models have been developed and used. In an archeological setting, we lack quantitative data on what resources were available at various points in time, let alone detailed data on seasonal, yearly, or long-term fluctuations in the quality and density of those resources.

\section{Chapter 9: Modeling Adaptations in the Late Archaic and Late Prehistoric Periods}

1.) We recognize that diet expansion or contraction is a complex issue. As we have outlined in Figures 8-5 and 8-6 in the previous Chapter, shifts in diet may be only one of several alternatives open to human foragers. In a given situation, other issues may prove to be critical. For example, the acquisition of several bison, especially by small groups, would require a series of decisions regarding both transport issues and processing/storage decisions that might significantly increase handling costs. These decisions may, depending on specific circumstances, result in the abandonment of usable product, and thus a lowering of caloric benefits if we measure those benefits only by body size. Actual return rates will reflect calories consumed relative to the overall effort involved in the acquisition of those calories. Other considerations, such as risk on injury or death, will also play into decisions. As we noted previously (see \# 2, Chapter 8), models are, by their very nature, a simplification of reality designed to isolate a small number of critical variables. 
2.) Dillehay's original work compiled data from many different sources, possibly including communications with individual excavators or reviews of the faunal assemblages. When we reviewed the publications cited as sources for bison presence/ absence, in several cases the cited work did not contain any discussion of faunal remains. In others, the publications failed to mention bison as present though they were counted as present in the 1974 article. While bison may well have been present in such situations, we could not confirm that presence based on the source cited. In addition, in one instance in our sample, Dillehay reports the same site as having bison present and absent during the same period.

3.) Throughout this discussion, we assume a relationship between forage availability and quality and bison density. Of course, other factors (e.g., water availability, levels of predation, snow depth, tolerance to extreme heat and cold) all interact with food quality and availability to produce actual densities (see Emerson 1990; Knapp 1990). In addition, bison group size appears to fluctuate seasonally, with larger groups present during the rut in the fall (see Meagher 1978).

4.) We are not suggesting that Kansas is equivalent to Central and South Texas or that this specific equation is applicable to Central and South Texas. Similar relationships between grass productivity and rainfall have been demonstrated from around the world, as grasslands tend to be water limited (see Solh 2005). We are suggesting that years with high rainfall at locations in Central and South Texas will produce high production, and that years with low rainfall will result in lower production. The specific equation may not apply, but the relationship is applicable.

5.) Several authors suggest that bison populations began a rapid expansion in the 17th and 18th centuries in response to declining Native American populations (see discussion in Mann 2005). This reduction in hunting pressure occurred at roughly the same time where climate was becoming more mesic. The high densities of bison noted in early chronicles of the Great Plains may not have been characteristic of the region during the prehistoric era.

6.) A TxDOT reviewer correctly notes that some of these fluctuations in the observed bison herd sizes may be related to seasonal patterns of breeding and calving. Note also that we do not mean to imply that these responses were related to reproduction. Rather, we are suggesting that the responses are behavioral. Long term changes in the overall sizes of bison population should track long-term shifts in several variables, including forage availability. Short term variability in forage production should result in behavioral responses, such as smaller or larger herd sizes, and higher or lower mobility.

7.) A TxDOT reviewer suggests that "the probability of a forager group encountering bison would increase as the bison become more mobile and split into smaller groups." Initially, this may well have been the case. However, we suggest subsequently that shrinking grasslands would have resulted in both reduced overall bison populations and a more clustered spatial distribution of bison. The latter would have been a function of the increasingly patchy grassland distributions.

8.) Clearly, additional component data will change the relative frequencies. The 182 components investigated within Central and South Texas represented an extensive, though not exhaustive, search of data recovery and testing excavations. Patterns for periods with small sample sizes, such as the Initial Late Prehistoric and the Initial Late Archaic, could be significantly altered by additional components. However, while this research is ongoing, additions to the component data are unlikely to have a significant impact on the two major conclusions derived from the Appendix A data set. These are 1) the presence of bison throughout the sequence and 2) the high proportion of components within the Terminal Late Prehistoric (Toyah) that have bison present.

9.) The suggestion that bison were declining in numbers during much of the Late Prehistoric period, especially during the Terminal Late Prehistoric, is contrary to aspects of most other models of this period in Texas. This period is often seen as one focused on bison, with an increasing bison density, especially relative to the Initial Late Prehistoric, commonly assumed (e.g., Ahr 1998; Collins 1995; Creel 1990, 1991; Dickens and Wiederhold 2003; Dillehay 1974; Huebner 1991; Johnson 1994; Prewitt 1981; Ricklis and Collins 1994; Tomka 2001). We are not disputing the observation that bison were an important resource during the Terminal Late Prehistoric, nor are we disputing the observations that bison remains were common on Toyah interval components or that many of the technological changes associated with Toyah assemblages probably reflect a focus on bison. We are questioning, however, the assumption that bison were increasing in density during this time across Central and South Texas.

10.) Several researchers have suggested that plant and animal diversity are related to the frequency and intensity of environmental stress (Fulbright 1996; Tilman 1982, 1988, 1994). Regions with intermediate intensity of stress and a moderate frequency of stress probably have the highest diversity of species. This is because under these conditions, wide ranges of successional states, 
and consequently a wide range of habitats, are present at any given time. With low levels of disturbance and a low frequency of disturbance, regions move towards a late successional, or climax stage in which only a few species dominate. Conversely, with extremely high levels and/or frequencies of disturbance, the successional clock is constantly being reset. Under these conditions, diversity of habitats, and diversity of species, should be limited. In the Texas data, we have demonstrated that plant and animal food diversity is inversely correlated with measures of primary productivity provided by Owen and Schmidly (1986). As primary productivity within Texas is highly correlated with rainfall (Owen and Schmidly 1986), the relationships between diversity and productivity may be primarily related to variability in rainfall.

Our suggestion that high diversity, low primary productivity settings like the Trans-Pecos potentially result in a more stable, resilient hunter-gatherer adaptation when compared to low diversity, high primary productivity settings is based primarily on two presuppositions. First, we assume that different species of plants and animals are adapted to different niches, and have different tolerances for environmental stress. A given environmental perturbation, regardless of its severity, will differentially affect species. An environment with a high diversity of plants and animals is more likely to have some species whose tolerances are not exceeded by a given perturbation. Even in extreme situations, we suggest that some species will be available for exploitation by hunters and gatherers. Secondly, areas like the Pineywoods region of Texas are a relatively late successional stage. Plants under these conditions frequently follow what Grime $(1977,1979)$ has characterized as a "competitive" evolutionary strategy in which plants primary compete with other plants for critical resources such as light, nutrients, water, and space. Under such conditions, plants use energy primarily for maintenance and growth in trunks and stems in an attempt to maximize access to these critical resources. In most cases, little energy is invested in reproductive tissues such as seeds and fruits, and frequently the seeds and fruits contain compounds that are toxic, at least with respect to humans. Much of the annual net above ground primary productivity in late successional settings is simply not usable by humans. At the other extreme within the state, plants within the Trans-Pecos area tend to follow a disturbance or "ruderal" strategy (Grime 1977; 1979). Ruderal plants have been selected for rapid growth, and invest a large proportion of their energy into reproductive tissues, especially seeds. Ruderal plants often produce large quantities of seeds, which are designed for easy dispersion (Grime 1977; Noy-Meir 1973). As such, while the overall above ground annual net primary productivity in areas like the Trans-Pecos is low, much of that new growth is invested in reproductive tissues that are used by humans, as well as other animals.

11) We realize that a given decision to adopt, or not adopt, a given technology may involve the interaction of a variety of motives (e.g., risk minimization; desire for prestige; fashion; cultural tradition.). As we suggested previously, our use of the cost/ benefit framework, and the assumption that hunters and gatherers are attempting to maximize their average return rate in making these decisions, is certainly a simplification of reality. The simplification allows researchers to isolate a small number of variables that may prove critical, and develop expectations as to how those variables should behave under different conditions. In addition, we suggest that factors such as cultural traditions, or lack of such a tradition, are elements that require an explanation, and are unlikely to be useful as explanatory variables.

12.) We are not suggesting that the Nunamiut case is directly applicable to Central and South Texas. The specific characteristics and migration patterns of caribou are not analogous to bison, and Alaska is, obviously, a different climate regime than Central and South Texas. Rather, we are using this example to make a general point regarding hunter-gatherer response.

\section{Chapter 12: Changes in Diet Breadth and Configuration}

1.) Our distinction between a residential site, also referred to as a residential base camp, and a logistical site, will be based on logical relationships between activity variety, artifact variety, and sample size. The measure is not focused exclusively on faunal material. The faunal comparisons are simply the first of several sample size, variety comparisons. Thomas $(1983,1986)$ has eloquently expressed the notion that there should be relationships between variety and sample size that track residential and logistical components. Tomka (1994) has ethnoarchaeological data that support the underlying relationships between activity variety, artifact assemblage variety, and sample size. Mauldin (1996) has used these artifact variety and sample size relationships on assemblages in far west Texas. Here, and in a subsequent section of this research design, we are proposing to use these measures to identify residential and special purpose components in the archeological record. This is a first step in identifying logistical and residential sites.

A TxDOT reviewer has suggested that our measures for identifying residential and logistical sites are inadequate. They propose that residential sites can be identified "almost entirely on the basis of the presence of mussel shell." This is related to the idea that "mussels have the types of things, nutritionally speaking, that pregnant and nursing mothers as well as senior citizens need 
to produce viable off-spring and survive." They further suggest that "mothers and pregnant women as well at the elderly occupied residential sites and these types of people have very specific nutritional needs - real people with real dietary concerns." While it may be the case that the some nutritional components of mussels are essential for mothers, pregnant women, growing children, and the elderly, this position represents a misunderstanding of what we mean by the residential / logistical distinction (see Binford 1980, 1983, 2001; Thomas 1983). Our distinction is based on the organization of mobility and labor, not on who lives at a location. Depending on the nature of the activities, pregnant women, mothers, kids, and the elderly can certainly occupy logistical sites at various points. Burned rock middens may, in fact, represent an activity that was performed in a logistical manner. Among the Western Apache, for example, Buskirk (1986:169-174) notes that groups of "five to eight women" would frequently leave "their local groups for a few days for the express purpose of preparing mescal."

2.) At a TxDOT reviewer correctly notes, the patterns in Figure 12-3 and by extension 12-4 are also influenced by taphonomic processes. Faunal remains are much more common on more recent sites.

3.) Interpreting fragmentation data is complicated both by taphonomic processes as well as cultural factors. A TxDOT reviewer noted that bison bone is probably more productive for grease processing than other, smaller bones and the bison bone, being more robust, is likely to be more resistant to weathering.

4.) A TxDOT reviewer has questioned this notion. "Why would the exploitation of lower ranked resources through a logistical strategy not be common ...?" They suggest that plant resources "were used to a greater or lesser extent year round." Furthermore, they point out that "70-80 percent of the diet was likely not meat." We agree that most of the diet was probably plant related and that plants were probably used throughout the year. There is, however, no necessary relationship between the frequency of plant use or the quantity of plant use and whether or not they would be pursued with a logistical strategy. In general, logistical strategies are designed to process resources in excess of need for transport back to a residential location. Highly profitable resources are more likely to be targeted in these situations, most obviously because of both the need to generate a surplus of energy relative to the costs and costs associated with transportation of that surplus from the location of acquisition back to the residential site.

\section{Chapter 13: Assessing Technological Organization and Change}

1.) It is certainly possible to create scenarios that this measure of time investment does not take into account. For example, one of the reviewers of an earlier draft of this research design suggested that our analysis would not adequately measure situations in which a tool user spend a long amount of time selecting an unretouched flake from a pile of debitage to obtain a flake tool that meet exacting specifications for desirable tool characteristics. We agree that is this particular instance, the time invested in what would become a utilized flake would probably be greater than that invested in most cases where a flake was modified by retouch. However, the time invested would have to be significant indeed for this particular flake to exceed that associated with the production of a biface with a hafting element and the associated wooden or bone tool to which the item would be attached.

2.) We are not suggesting that the decline in the availability of bison is the only factor involved in these technological changes. From our perspective, the decision to adopt a new technology, or modify and old technology, is productively seen as involving trade-offs between a variety of cost/benefit alternatives. Shifts in prey density and prey type are certainly one of the elements that should impact those decisions, though it is certainly not the only element.

\section{Chapter 16: Investigating Changes in Mobility}

1.) For the purposes of this discussion, locally available raw materials refer to tool stone that is available within the boundaries of a site or its immediate vicinity so that the costs of transporting the material to the site is minimal. In addition, the terms tool stone, parent material, and/or raw material are used interchangeably in their broadest sense to denote pebbles in their natural state, as well as cores, preforms, and other artifacts from which flakes are being removed. 



\section{References Cited:}

Ahr, S.W.

1998 Ramifications of Late Holocene Hide-Processing Geographies along the Lower Medina River, Texas. Unpublished Master's thesis, Department of Anthropology, Texas A\&M University, College Station.

Aitken, M.J.

1985 Thermoluminescence Dating. Academic Press, London.

1989 Luminescence Dating - a Guide for Non-Specialists. Archaeometry 31:147-159.

Alley, W.M.

1984 The Palmer Drought Severity Index - Limitations and Assumptions. Journal of Climate and Applied Meteorology 23(7):1100-1109.

Anderson, A.E., D.E. Medin, and D.C. Bowden 1972 Indices of Carcass Fat in a Colorado Mule Deer Population. Journal of Wildlife Management 36(2):579-594.

Arnn, J.W.

2005 Chronology, Technology and Subsistence: Is That All There Is? Council of Texas Archeologists Newsletter 29(2):17-28.

2007 Transformation and Persistence of Indigenous Cultural Identity during the Early Colonial and Late Prehistoric Periods in Texas. Ph.D. dissertation, University of Kentucky, Lexington, Kentucky.

Arnold, D.E.

1985 Ceramic Theory and Cultural Process. Cambridge University Press, Cambridge.

Bamforth, D.B.

1988 Ecology and Human Organization on the Great Plains. Interdisciplinary Contributions to Archaeology. Plenum Press, New York.

Bamforth, D.B., and P. Bleed

1997 Technology, Flaked Stone Technology, and Risk. In Rediscovering Darwin: Evolutionary Theory in Archaeological Explanation, edited by C.M. Barton and G.A. Clark, pp. 109-140. Archaeological Papers of the American Anthropological Association No. 7, Arlington, Virgina.

Barnes, P.W.

1983 Geological Atlas of Texas: Llano Sheet. Bureau of Economic Geology, The University of Texas at Austin.

Barnett, S.M.

1999 Date List 6: Luminescence Dates for Late Bronze Age and Iron Age Pottery Assemblages in Eastern and Northern Britain. Ancient TL 17(1):23-40.

Barnett, W.K., and J.W. Hoopes

1995 The Emergence of Pottery: Technology and Innovation in Ancient Societies. Smithsonian Institution Press, Washington, D.C.

Bettinger, R.L.

1982 Explanatory/Predictive Models of Hunter-Gatherer Adaptation. In Advances in Archaeological Method and Theory: Selections from Students, 4 vols., edited by M.B. Schiffer, pp. 157-223. Academic Press, New York. 
Binford, L.R.

1977 Forty-seven Trips: A Case Study in the Character of Archaeological Formations Process. In Stone Tools as Cultural Markers, edited by R.V.S. Wright, pp. 24-36. Australian Institute of Aboriginal Studies, Canberra, Australia.

1978 Nunamiut Ethnoarchaeology. Studies in Archeology. Academic Press, New York.

1979 Organization and Formation Processes - Looking at Curated Technologies. Journal of Anthropological Research 35(3):255-273.

1980 Willow Smoke and Dogs Tails - Hunter-Gatherer Settlement Systems and Archaeological Site Formation. American Antiquity 45(1):4-20.

1983 The Archaeology of Place. In Working at Archaeology, edited by L. Binford, pp. 357-378. Academic Press, New York.

1992 Seeing the Present and Interpreting the Past--and Keeping Things Straight. In Space, Time, and Archaeological Landscapes, edited by J. Rossignol and L. Wandsnider, pp. 43-59. Plenum Press, New York.

Black, C.C.

1973 Photosynthetic Carbon Fixation in Relation to $\mathrm{Net}_{2} \mathrm{CO}_{2}$ Uptake. Annual Review of Plant Physiology 24:253-286.

Black, S.L.

1997 The Honey Creek Site, 41MS32. In Hot Rock Cooking on the Greater Edwards Plateau: Four Burned Rock Midden Sites in West Central Texas, edited by S.L. Black, L.W. Ellis, D.G. Creel, and G.T. Goode, pp. 99-168. Studies in Archeology 22. Texas Archeological Research Laboratory, The University of Texas at Austin.

2003 Research Module 2: Studying the Hearths of the Greater Edwards Plateau. In Pavo Real (41BX52): A Paleoindian and Archaic Camp and Workshop on the Balcones Escarpment, South-Central Texas, edited by M.B. Collins, D.B. Hudler, and S.L. Black, pp. 375-405. Studies in Archeology, No. 41, Texas Archeological Research Laboratory, The University of Texas at Austin. Archeological Studies Program,Report No. 50, Environmental Affairs Division, Texas Department of Transportation, Austin.

Black, S.L., and D. Creel

1997 The Central Texas Burned Rock Midden Reconsidered. In Hot Rock Cooking on the Greater Edwards Plateau: Four Burned Rock Middens in West Central Texas, edited by S.L. Black, L.W. Ellis, D.G. Creel, and G.T. Goode, pp. 296305. Studies in Archeology 22. Texas Archeological Research Laboratory, The University of Texas at Austin.

Black, S.L., L.W. Ellis, D.G. Creel, and G.T. Goode 1997 Hot Rock Cooking on the Greater Edwards Plateau: Four Burned Rock Midden Sites in West Central Texas. Studies in Archaeology, No. 22. 2 vols. Texas Archaeological Research Laboratory, The University of Texas at Austin.

Blair, W.F.

1950 The Biotic Provinces of Texas. Texas Journal of Science 2(1):93-117.

Bleed, P. 1986 The Optimal-Design of Hunting Weapons - Maintainability or Reliability. American Antiquity 51(4):737-747.

Blum, E.L., United States Soil Conservation Service, and Texas Agricultural Experiment Station. 1982 Soil Survey of Kimble County, Texas. The Service, Washington, D.C.

Bousman, C.B. 1998 Paleoenvironmental Change in Central Texas: The Palynological evidence. Plains Anthropologist 43(164):201-219.

Braun, D.

1983 Pots as Tools. In Archaeological Hammers and Theories, edited by A. Keene and J. Moore, pp. 107-134. Academic, New York. 
Bronitsky, G., and R. Hamer

1986 Experiments in Ceramic Technology: The Effects of Various Tempering Materials on Impact and Thermal Shock Resistance. American Antiquity 51(1):89-101.

Brown, D.A.

1993 Early-19th-Century Grasslands of the Midcontinent Plains. Annals of the Association of American Geographers 83(4):589-612.

Bryant,V.M., Jr., and R.G. Holloway

1983 The Role of Palynology in Archaeology. In Advances in Archaeological Method and Theory, Vol.6, edited by M.B. Schiffer, pp. 191-224. Academic Press, Waltham, Massachusetts.

Burger, O., M.J. Hamilton, and R. Walker

2005 The Prey as Patch Model: Optimal Handling of Resources with Diminishing Returns. Journal of Archaeological Science 32:1147-1158.

Cabeza de Vaca, A.N.

1555 La relacion y comentarios del gouernador Aluar nunez cabeca de vaca de lo acaescido en las dos jornadas que hizo a las Indias. Electronic document. Scanned copy with English translation by M.A. Favata and J.B. Fernandez, http://www.library.txstate.edu/swwc/cdv/index.html, accessed September, 22010.

Cable, D.R.

1975 Influence of Precipitation on Perennial Grass Production in Semidesert Southwest. Ecology 56(4):981-986.

Callahan, E.

1979 The Basics of Biface Knapping in the Eastern Fluted Point Tradition: A Manual for Flintknappers and Lithic Analysts. Archaeology of Eastern North America 7:1-180.

Camper, H.A.

1991 Pollen analysis of Patschke Bog. Unpublished Master's thesis, Department of Botany, Texas A\&M University, College Station. Data archived at the World Data Center System, http://www.ncdc.noaa.gov/paleo/datalist.html, accessed January 2006. North American Pollen Database, made available by the NOAA Paleoclimatology Program, National Climatic Data Center (NCDC), Boulder. Contributor of data to site is V. M. Bryant, Jr.

Cane, S.

1987 Australian Aboriginal Subsistence in the Western Desert. Human Ecology 15(4):391-434.

Caswell, H., F. Reed, Stephenson, S.N., and P.A. Werner

1973 Photosynthetic Pathways and Selective Herbivory - Hypothesis. American Naturalist 107(956):465-480.

Charnov, E.L.

1976 Optimal Foraging, the Marginal Value Theorem. Theoretical Population Biology 9(2):129-136.

Charnov, E.L., G.H. Orians, and K. Hyatt

1976 Ecological Implications of Resource Depression. American Naturalist 110(972):247-259.

Chisholm, B., J. Driver, S. Dube, and H.P. Schwarz

1986 Assessment of Prehistoric Bison Foraging and Movement Patterns Via Stable-Carbon Isotopic Analysis. Plains Anthropologist 31(113):193-205.

Collins, M.B.

1995 Forty Years of Archeology in Texas. Bulletin of the Texas Archeological Society 66:361-400.

2004 Archeology in Central Texas. In The Prehistory of Texas, edited by T.K. Perttula, pp. 205-265. Texas A\&M University Press, College Station. 
Condamin, J.F., F. Formenti, M.O. Metais, M. Michel, and O. Blond 1976 Application of Gas Chromatography to the Tracing of Oil in Ancient Amphorae. Archaeometry 18(2):195-201.

Cook, E.R. and P.J. Krusic

2004 The North American Drought Atlas. Lamont-Doherty Earth Observatory and the National Science Foundation. Electronic document, http://iridl.ldeo.columbia.edu/SOURCES/.LDEO/.TRL/.NADA2004/.pdsi-atlas.html, accessed April 10, 2010.

Cook, E.R., D.M. Meko, D.W. Stahle, and M.K. Cleveland 1999 Drought Reconstructions for the Continental United States. Journal of Climate 12(4):1145-1162.

Cooke, M.J.

2005 Soil Formation and Erosion in Central Texas: Insights from Relict Soils and Cave Deposits. Unpublished Ph.D. dissertation, University of Texas at Austin.

Coppedge, B.R., D.M. Leslie and J.H. Shaw 1998 Botanical Composition of Bison Diets on Tallgrass Prairie in Oklahoma. Journal of Range Management 51(4):379-382.

Coppock, D.L., J.K. Detling, J.E. Ellis, and M.I. Dyer

1983a Plant-Herbivore Interactions in a North-American Mixed-Grass Prairie .1. Effects of Black-Tailed Prairie Dogs on Intraseasonal above-Ground Plant Biomass and Nutrient Dynamics and Plant-Species Diversity. Oecologia 56(1):1-9.

Coppock, D.L., J.E. Ellis, J.K. Detling, and M.I. Dyer 1983b Plant-Herbivore Interactions in a North-American Mixed-Grass Prairie .2. Responses of Bison to Modification of Vegetation by Prairie Dogs. Oecologia 56(1):10-15.

Crabtree, D.E.

1972 An Introduction to Flintworking. In Occasional Papers of the Idaho State Museum, No. 28. Idaho State University, Pocatello.

Creel, D.

1990 Excavations at 41TG91, Tom Green County, 1978. Publications in Archeology, No. 38. Texas State Department of Highways and Public Transportation, Austin.

1991 Bison Hides in Late Prehistoric Exchange in the Southern Plains. America Antiquity 56(1):40-49.

Creel, D., and G.T. Goode

1997 The Heard Schoolhouse Site. In Hot Rock Cooking on the Greater Edwards Plateau: Four Burned Rock Midden Site in West Central Texas, edited by S.L. Black, L.W. Ellis, D.G. Creel, and G.T. Goode. Studies in Archeology 22. Texas Archeological Research Laboratory, The University of Texas at Austin.

Crown, P.L., and W.H. Wills

1995 The Origins of Southwestern Ceramic Containers: Women's Time Allocation and Economic Intensification. Journal of Anthropological Archaeology 51(2):173-186.

Davis, W.B., and D.J. Schmidly

1997 The Mammals of Texas Online Edition. Texas Tech University and Texas Parks and Wildlife Department, Nongame and Urban Program, Austin. Electronic database, http://www.nsrl.ttu.edu/tmot1/Default.htm, accessed January 2006.

Dean, J.S.

1988 Dendrochronology and Paleoenvironmental Reconstruction on the Colorado Plateaus In The Anasazi in a Changing Environment, edited by G.J. Gumerman, pp. 119-167. Cambridge University Press, New York. 
Dering, J.P.

2003 Botanical Perspectives on Land use in the Cross Timbers and Prairies. In Archaeological Testing to Determine the National Register Status of 18 Prehistoric Sites on Camp Bowie, Brown County, Texas, edited by R.P. Mauldin, D.L. Nickels, and C.J. Broehm, pp. 58-79. Archaeological Survey Report No. 334. Vol. 2. Center for Archaeological Research, The University of Texas at San Antonio.

2008 Late Prehistoric Subsistence Economy on the Edwards Plateau. Plains Anthropologist 53(205):59-77.

Dickens, W.A., and J.E. Wiederhold

2003 Some Notes on Bison, the Texas Post Oak Savanna, and the Late Prehistoric Period of Texas. Bulletin of the Texas Archaeological Society 74:31-54.

Dillehay, T.D.

1974 Late Quaternary Bison Population Changes on the Southern Plains. Plains Anthropologist 19:180-196.

Doughty, R.W.

1983 Wildlife and Man in Texas. Texas A\&M University Press, College Station.

Duncan, D.E.

1997 Hernando de Soto: A Savage Quest in the Americas. Oklahoma pbk. ed. University of Oklahoma Press, Norman.

Dunnell, R.C.

1992 The Notion of Site. In Space, Time, and Archaeological Landscapes, edited by J. Rossignol and L. Wandsnider, pp. 21-41. Plenum Press, New York.

Dykeman, D.D., R.H. Towner, and J.K. Feathers

2002 Correspondence in Tree Ring and Thermoluminenscence Dating: A Protohistoric Navajo Pilot Study. American Antiquity 67(1):145-164.

Ebert, J.I.

1992 Distributional Archaeology. University of New Mexico Press, Albuquerque.

Eerkin, J.W.

2003 Residential Pottery Use in the Western Great Basin. Current Anthropology 44(5):728-738.

Eerkin, J.W., H. Neff, and M. Glascock

2002 Ceramic Production Among Small Scale and Mobile Hunter Gatherers: A Case Study from the Southwest Great Basin. Journal of Anthropological Archaeology 21(2):200-229.

Ehleringer, J.R.

1978 Implications of Quantum Yield Differences on Distributions of $C_{3}$ and $C_{4}$ Grasses. Oecologia 31(3):255-267.

Ellis, L.W.

1997 Hot Rock Technology. In Hot Rock Cooking on the Greater Edwards Plateau: Four Burned Rock Midden Sites in West Central Texas, edited by S.L. Black, L.W. Ellis, D.G. Creel, and G.T. Goode, pp. 43-81. Studies in Archeology 22, Texas Archeological Research Laboratory, The University of Texas at Austin and Archeological Studies Program Report No. 2, Environmental Affairs Division, Texas Department of Transportation, Austin.

Ellis, L.W., G.L. Ellis, and C.D. Frederick

1995 Implications of Environmental Diversity in the Central Texas Archeological Region. Bulletin of the Texas Archeological Society 66:401-426.

Emerson, A.M.

1990 Implications of Variability in the Economic Anatomy of Bison bison. Unpublished Ph.D. dissertation, Washington State University, Pullman. University Microfilms, Ann Arbor. 
Emlen, J.M.

1966 The Role of Time and Energy in Food Preference. American Naturalist 100:611-617.

Epp, H.T.

1988 Way of the Migrant Herds - Dual Dispersion Strategy among Bison. Plains Anthropologist 33(121):309-320.

Epstein, H.E., W.K. Lauenroth, I.C. Burke, and D.P. Coffin

1997 Productivity Patterns of $\mathrm{C}_{3}$ and $\mathrm{C}_{4}$ Functional Types in the US Great Plains. Ecology 78(3):722-731.

Everitt, B.S.

1977 The Analysis of Contingency Tables. Chaptman and Hall, London.

Feathers, J.K.

1997 The Application of Luminescence Dating in American Archaeology. Journal of Archaeological Method and Theory 4:1-66.

Feathers, J.K., and D. Rhode

1998 Luminescence Dating of Protohistoric Pottery from the Great Basin. Geoarchaeology 13(3):287-308.

Folmer, H.

1940 De Bellisle on the Texas Coast. Southwestern Historical Quarterly 44:204-231.

Fritz, H.C.

1976 Tree-Rings and Climate. Academic Press, New York.

1991 Reconstructing Large-scale Climatic Patterns from Tree-Ring Data. The University of Arizona, Tucson.

Fulbright, T.E.

1996 Viewpoint: A theoretical Basis for Planning Woody Plant Control to Maintain Species Diversity. Journal of Range Management 49(6):554-559.

Gamble, C.

1986 The Palaeolithic Settlement of Europe. Cambridge World Archaeology. Cambridge University Press, Cambridge.

Gordon, B.H.C.

1979 Of Men and Herds in Canadian Plains Prehistory. Canadian Museum of Civilization Mercury Series.

Archaeological Survey of Canada Paper 84, Ottawa.

Gould, F.W., G.O. Hoffman, and C.A. Rechenthin

1960 Vegetation Areas of Texas. Texas Agricultural Experimental Station Leaflet No. 492. Texas A\&M University, College Station.

Grime, J.P.

1977 Evidence for the Existence of Three Primary Strategies in Plants and its Relevance to Ecological and Evolutionary Theory. American Naturalist 111:1169-1194.

1979 Plant Strategies and Vegetation Processes. John Wiley and Sons, New York.

Haberman, S.J.

1973 The Analysis of Residuals in Cross-classified Tables. Biometrics 29:205-220.

Hall, G.D.

1985 Comparative Ecologies: The Texas Chaparral Versus the Australian Outback. La Tierra 12(3):6-19.

1998 Prehistoric Human Food Resources Patches on the Texas Coastal Plain. Bulletin of the Texas Archaeological Society 69:1-10. 
Hammond, G.P., and A. Rey

1940 Narratives of the Coronado Expedition, 1540-1542. The University of New Mexico Press, Albuquerque.

Hart, R.H., O.M. Abdalla, D.H. Clark, M.B. Marshall, M.H. Hamid, J.A. Hager, and J.W. Waggoner 1983 Quality of Forage and Cattle Diets on the Wyoming High-Plains. Journal of Range Management 36(1):46-51.

Hatch, S.L., K.N. Gandhi, and L.E. Brown

1990 Checklist of the Vascular Plants of Texas. MP-1655. Texas Agricultural Experiment Station. Texas A\&M University, College Station.

Hawkes, K., and J.F. O'Connell

1981 Affluent Hunters? Some Comments in Light of the Alyawara Case. American Anthropologist 83:622-626.

1985 Optimal Foraging Models and the Case of the !Kung. American Anthropologist 87:401-405.

Henderson, J.

2001 Excavations at the Rainey site (41BN33): A Late Prehistoric Sinkhole Site in Bandera County, Texas. Archeological Studies Program Report 5. Texas Department of Transportation, Environmental Affairs Division, Austin.

Hester, T.R. 1980 Digging into South Texas Prehistory: A Guide for Amateur Archaeologists. Corona Publishing, San Antonio.

1995 The Prehistory of South Texas. Bulletin of the Texas Archeological Society 66:427-459.

Hill, K.

1988 Macronutrient Modifications of Optimal Foraging Theory: An Approach Using Indifference Curves Applied to Some Modern Foragers. Human Ecology 16:157-197.

Hill, K., and K. Hawkes

1983 Neotropical Hunting among the Ache of Eastern Paraguay. In Adaptive Responses of Native Amazonians, edited by R.B. Hames and W.T. Vickers, pp. 139-188. Academic Press, New York.

Huebner, J.A.

1991 Late Prehistoric Bison Populations in Central and Southern Texas. Plains Anthropologist 36(137):343-358.

Jelks, E.B.

1962 The Kyle Site: A Stratified Central Texas Aspect Site in Hill Country, Texas. Archeology Series 5. Department of Anthropology, The University of Texas at Austin.

Jochim, M.

1975 Hunter-gatherer Subsistence and Settlement: A Predictive Model. Academic Press, New York.

Johnson, J.K.

1979 Archaic Biface Manufacture: Production Failures, a Chronicle of the Misbegotten. Lithic Technology 8(2):25-35.

1981 Further Additional Biface Production Failures. Lithic Technology 10(20):26-28.

Johnson, L., Jr.

1994 The Life and Times of Toyah-Culture Folk: The Buckhollow Encampment, Site 41KM16, Kimble County, Texas.

Office of the State Archeologist Report 38. Texas Department of Transportation and Texas Historical Commission, Austin.

Johnson, L., Jr., and G.T. Goode

1994 A New Try at Dating and Characterizing Holocene Climates, as well as Archaeological Periods, on the Eastern Edwards Plateau. Bulletin of the Texas Archaeological Society 65:1-51. 
Jones, K.T., and D.B. Madsen

1989 Calculating the Cost of Resource Transportation - a Great-Basin Example. Current Anthropology 30(4):529-534.

Karl, T.R.

1986 The Sensitivity of the Palmer Drought Severity Index and Palmer Z-Index to Their Calibration Coefficients

Including Potential Evapotranspiration. Journal of Climate and Applied Meteorology 25(1):77-86.

Kelly, R.L.

1995 The Foraging Spectrum: Diversity in Hunter-gatherer Lifeways. Smithsonian Institution Press, Washington.

Kirch, P.

1982 The Archaeological Study of Adaptation: Theoretical and Methodological Issues. In Advances in Archaeological Method and Theory: Selections from Students, Vols. 1-4, edited by M.B. Schiffer, pp. 101-156. Academic Press, New York.

Kirchner, H.P.

1979 Strengthening of Ceramics: Treatments, Tests, and Design Applications. Marcel Dekker, New York.

Knapp, A.K., J.M. Blair, J.M. Briggs, S.L. Collins, D.C. Hartnett, L.C. Johnson, and E.G. Towne 1999 The Keystone Role of Bison in North American Tallgrass Prairie. Bioscience 49(1):39-50.

Knapp, A.K., J.M. Briggs, J.M. Blair, and C.L. Turner

1998 Patterns and Controls of Aboveground Net Primary Production in Tallgrass Prairie. In Grassland Dynamics: LongTerm Ecological Research in Tallgrass Prairie, edited by A.K. Knapp, J.M. Briggs, D.C. Hartnett, and S.L. Collins, pp. 193-221. Oxford University Press, New York.

Knapp, A.K., J.M. Briggs, and J.K. Koelliker

2001 Frequency and Extent of Water Limitation to Primary Production in a Mesic Temperate Grassland. Ecosystems 4(1):19-28.

Kojo, Y.

1991 The Reliability of TL Dating: A Pilot Experiment. Geoarchaeology 6:367-374.

Lauenroth, W.K., M.P. Burke, and M.P. Gutmann

1999 The Structural Function of Ecosystems in the Central North American Grassland Region. Great Plains Research 9:223-259.

Lee, R.B.

1979 The !Kung San: Men Women, and Work in a Foraging Society. Cambridge University Press, Cambridge.

Loy, T.

1994 Residue Analysis of Artifacts and Burned Rock from the Mustang Branch and Barton Sites (41HY209 and 41HY202). In Archaic and Late Prehistoric Human Ecology in the Middle Onion Creek Valley, Hays County, Texas, Vol. 2 Topical Studies, edited by R.A. Ricklis and M.B. Collins, pp. 607-627. Studies in Archeology 19. Texas Archeological Research Laboratory, The University of Texas at Austin.

MacArthur, R.H., and E.R. Pianka 1966 On Optimal Use of a Patchy Environment. American Naturalist 100(916):603-609.

Malainey, M.E.

2000 Analysis of Fatty Acid Compositions of Burned Rock Residues from Site 41ZP364, Zapata County, Texas. Appendix

K. In Data Recovery at 41ZP364: An Upland Campsite at Falcon Reservoir, Zapata County, Texas, edited by J.M. Quigg and C. Cordova, pp. 331-345. Technical Report No. 22317. TRC Mariah Associates Inc., Austin. 
Malof, A.F.

2001 Feast or Famine: The Dietary Role of Rabdotus Species Snails in Prehistoric Central Texas. Master's thesis, Department of Anthropology, The University of Texas at San Antonio.

Mann, C.

2005 1491. Vintage Books, Random House, New York.

Marchbanks, M.L

1989 Lipid Analysis in Archaeology: An Initial Study of Ceramics and Subsistence at the George C. Davis Site. Unpublished Master's thesis, The University of Texas at Austin.

Marks, S.A.

1976 Large Mammals and a Brave People: Subsistence Hunters in Zambia. University of Washington Press, Seattle.

Mauldin, R., R.D. Greaves, J.L. Thompson, C.M. Munoz, L. Kemp, B.A. Meissner, B.K. Moses, and S.A. Tomka 2010 Archeological Testing and Data Recovery at 41ZV202, Zavala County, Texas. Archaeological Survey Report No. 409. Center for Archaeological Research, The University of Texas at San Antonio and Archeological Studies Program Report No. 121. Environmental Affairs Division, Texas Department of Transportation, Austin.

Mauldin, R., and L. Kemp

2005 An Initial Summary of Bison Presence/Absence Associated with Data Recovery at 41ZV202. Report on file, Center for Archaeological Research, The University of Texas at San Antonio.

Mauldin, R., D.L. Nickels, and C.J. Broehm

1998 Archaeological Testing to Determine the National Register Eligibility Status of 18 Prehistoric Sites on Camp Bowie, Brown County, Texas. Archaeological Survey Report No. 334. Center for Archaeological Research, The University of Texas at San Antonio.

Mauldin, R.P.

1996 Exploring Patterns in Late Archaic and Early Ceramic Residential Occupation in the Northern Chihuahuan Desert. In Early Formative Adaptations in the Southern Southwest, edited by B.J. Roth. Monographs in World Archaeology No. 25. Prehistory Press, Madison, Wisconsin.

Mauldin, R.P., D.L. Nickels, C.J. Broehm, and C.B. Bousman

2003 Archaeological Testing to Determine the National Register Eligibility Status of 18 Prehistoric Sites on Camp Bowie, Brown County, Texas. Archaeological Survey Report No. 334, Vol. 1. Center for Archaeological Research, The University of Texas at San Antonio.

McDonald, J.N.

1981 North American Bison: Their Classification and Evolution. University of California Press, Berkeley.

Meagher, M.M.

1978 Bison. In Big Game of North America, Ecology, and Management, edited by J.L. Schmidt and D.L. Gilbert, pp. 123134. Stackpole Books, Mechanicsburg, Pennsylvania.

Metcalfe, D., and K.R. Barlow

1992 A Model for Exploring the Optimal Trade-Off between Field Processing and Transport. American Anthropologist 94(2):340-356.

Moerman, D.

2005 North American Ethnobotany: A Database of Foods, Drugs, Dyes, and Fibers of Batuve American Peoples, Derived from Plants. Dearborn College of Arts and Sciences, University of Michigan. Electronic database, http://herb. umd.umich.edu, accessed January 2006. 
Morgan, R.G.

1980 Bison Movement Patterns on the Canadian Plains: An Ecological Analysis. Plains Anthropologist 25(88):143-60.

Morin, E.

2007 Fat Composition and Nunamiut Decision-Making: A new look at the marrow and bone grease indices. Journal of Archaeological Science 34:69-82.

Muto, G.R.

1971 A Technological Analysis of the Early Stages in the Manufacture of Lithic Artifacts. Unpublished Master's thesis, Idaho State University, Pocatello.

National Integrated Drought Information System (NIDIS)

2009 US Drought Monitor. Electronic document, http://www.drought.gov/portal/server.pt/community/drought_gov/202, accessed October 2009.

National Weather Service

2007a Climate Records for Austin. Electronic document, http:/www.srh.noaa.gov/ewx/html/cli/cli/aus/aclidata.htm, accessed April 2007.

2007b Historical Monthly and Annual Rainfall Data for Abilene and San Angelo. Electronic document, http://www.srh. noaa.gov/sjt/html/climate/climo/html, accessed April 2007.

2007c North Central Texas Climatology. Electronic document, http:/www.srh.noaa.gov.fwd/ntexclima.html, accessed April 2007.

Netting, R.M.

1986 Cultural Ecology. 2nd ed. Waveland Press, Prospect Heights, Illinois.

Newcomb, W.W., Jr.

1961 The Indians of Texas from Prehsitoric to Modern Times. University of Texas Press, Austin.

Nickels, D.L., and R.P. Mauldin

2001 The Project Environment. In An Archaeological Survey of Twin Buttes Reservoir, Tom Green County, Texas, Vol. 1, edited by R.P. Mauldin and D.L. Nickels. Archaeological Survey Report, No. 300. Center for Archaeological Research, The University of Texas at San Antonio.

Nippert, J.B., A.K. Knapp, and J.M. Briggs

2006 Intra-annual Rainfall Variability and Grassland Productivity: Can the Past Predict the Future? Plant Ecology 184(1):65-74.

Nordt, L.C., T.W. Boutton, J.S. Jacob, and R.D. Mandel

2002 C-4 Plant Productivity and Climate- $\mathrm{CO}_{2}$ Variations in South-Central Texas during the Late Quaternary. Quaternary Research 58(2):182-188.

Noy-Meir, I.

1973 Desert Ecosystems: Environment and Producers. Annual Review of Ecology and Systematics 4:25-51.

O’Connell, J.F., and K. Hawkes

1981 Alyawara Plant Use and Optimal Foraging Theory. In Hunter-Gatherer Foraging Strategies: Ethnographic and Archaeological Analyses, edited by B. Winterhalder and E.A. Smith, pp. 13-35. University of Chicago Press, Chicago.

Odum, E.P.

1971 Fundamentals of Ecology. 3rd ed. Saunders, Philadelphia, Pennsylvania.

Owen, J.G.

1988 On Productivity as a Predictor of Rodent and Carnivore Diversity. Ecology 69(4):1161-1165. 
1990 An Analysis of the Spatial Structure of Mammalian Distribution Patterns in Texas. Ecology 71(5):1823-1832.

Owen, J.G., and D.J. Schmidly

1986 Environmental Variables of Biological Importance in Texas. Texas Journal of Science 38:99-117.

Palmer, W.C.

1965 Meteorological Drought. US Weather Bureau, Research Paper No. 45, Washington, D.C.

Parkman, F.

1883 La Salle and the Discovery of the West. 12th ed. The Parkman Anthology Vol. 3. Little Brown, and Company, Morristown, New Jersey.

Paruelo, J.M., and W.K. Lauenroth

1996 Relative Abundance of Plant Functional Types in Grasslands and Shrublands of North America. Ecological Applications 6(4):1212-1224.

Pearsall, D.M.

2000 Paleoethnobotany. A Handbook of Procedures. 2nd ed. Academic Press, San Diego.

Peden, D.G.

1976 Botanical Composition of Bison Diets on Shortgrass Plains. American Midland Naturalist 96(1):225-229.

Peden, D.G., G.M. Vandyne, R.W. Rice, and R.M. Hansen

1974 Trophic Ecology of Bison-Bison L on Shortgrass Plains. Journal of Applied Ecology 11(2):489-497.

Pieper, R.D., and C.H. Herbel

1982 Herbage Dynamics and Primary Productivity of a Desert Grassland Ecosystem. U.S. Department of Agriculture and the Agricultural Experiment Station, New Mexico Sate University, Las Cruces, Bulletin 695.

Prewitt, E.R.

1981 Cultural Chronology in Central Texas. Bulletin of the Texas Archaeological Society 52:65-89.

Quigg, J.M.

1997a Bison Processing at the Rush Site, 41TG346, and Evidence for Pemmican Production in the Southern Plains. In Southern Plains Bison Procurement and Utilization from Paleoindian to Historic, edited by L.C. Bement, pp. 145161. Plains Anthropologist 42(159), Memoir 29.

1997b The Sanders Site (41HF128): A Single Event Late Archaic Camp/Bison Processing Site, Hansford County, Texas. TRC Mariah Associates, Austin, Texas.

Quigg, J.M., J.D. Owens, P.M. Matchen, G.D. Smith, R.A. Ricklis, M.C. Cody, and C.D. Frederick 2008 The Varga Site: A Multicomponent, Stratified Campsite in the Canyonlands of Edwards County. Technical Report No. 35319.2 vols. TRC Environmental, Austin, Texas.

Quigg, J.M., and J. Peck

1995 The Rush Site (41TG346): A Stratified Late Prehistoric Locale in Tom Green County, Texas. Technical Report, No. 816C. TRC Mariah Associates, Austin.

Quigg, J.M., S. Prichard, and G. Smith

2002 The Boiler Site (41WB557): Utilization of an Upland Setting Over the Last 4200 Years, Webb County, Texas.

Technical Report No. 27277, TRC Mariah Associates. Archeological Studies Program, Report No. 45,

Environmental Affairs Division, Texas Department of Transportation, Austin. 
Rauzi, F., and A.K. Dobrenz

1970 Seasonal Variation of Chlorophyll in Western Wheatgrass and Blue Grama. Journal of Range Management 23(5):372-373.

Rice, $\mathrm{P}$.

1987 Pottery Analysis: A Sourcebook. The University of Chicago Press, Chicago.

Ricklis, R.A.

1994a Occupations in the Project Area during the Austin Interval, or Early Part of the Late Prehistoric Period. In Archaic and Late Prehistoric Human Ecology in the Middle Onion Creek Valley, Hays County, Texas, edited by R.A. Ricklis and M.B. Collins. Studies in Archeology 19. Texas Archeological Research Laboratory, The University of Texas at Austin.

1994b Toyah Components: Evidence for Occupations in the Project Area during the Latter Part of the Late Prehistoric Period. In Archaic and Late Prehistoric Human Ecology in the Middle Onion Creek Valley, Hays County, Texas, edited by R.A. Ricklis and M. Collins, pp. 207-316. Studies in Archeology 19. Vol. 1. Texas Archeological Research Laboratory, The University of Texas at Austin.

1996 The Karankawa Indians of Texas: An Ecological Study of Cultural Tradition and Change. 1st ed. Texas Archaeology and Ethnohistory Series. University of Texas Press, Austin.

Ricklis, R.A., and M.B. Collins

1994a Archaic and Late Prehistoric Human Ecology in the Middle Onion Creek Valley, Hays County, Texas. Studies in Archeology 19. 2 vols. Texas Archeological Research Laboratory, The University of Texas at Austin.

1994b Introduction. In Archaic and Late Prehistoric Human Ecology in the Middle Onion Creek Valley, Hays County, Texas, edited by R.A. Ricklis and M.B. Collins. Studies in Archeology 19. Vol. 1. Texas Archeological Research Lab, The University of Texas at Austin.

Roberts, R.G.

1997 Luminescence Dating in Archaeology: From Origins to Optical. Radiation Measurements 27(5):819-892.

Roe, F.G.

1951 The North American Buffalo: A Critical Study of the Species in its Wild State. University of Toronto Press, Toronto.

Rosenzweig, M.L.

1968 Net Primary Productivity of Terrestrial Communities: Prediction from Climatological Data. American Naturalist 102(923):67-74.

Sala, O.E., and W.K. Lauenroth 1982 Small Rainfall Events - an Ecological Role in Semi-Arid Regions. Oecologia 53(3):301-304.

Sassaman, K.E.

1993 Early Pottery in the Southeast. University of Alabama Press, Birmingham.

Shaffer, B.S

2006 Appendix E. Analysis of the Vertebrate Remains from 41MM341. In Data Recovery Excavations at the J.B. White Site (41MM341), Milan County, Texas, edited by E.F. Gadus, R.C. Fields, and K.W. Kibler, pp. 238-259. Reports of Investigation No. 145. Prewitt and Associates, Austin, Texas.

Sih, A., and K.A. Milton 1985 Optimal Diet Theory: Should the !Kung Eat Mongongos? American Anthropologist 87(2):395-401.

Simms, S.R.

1985a Acquisition Cost and Nutritional Data on Great Basin Resources. Journal of California and Great Basin Anthropology 7(1):117-126. 
1985b Pine Nut Use in Three Great Basin Cases: Data, Theory, and a Fragmentary Material Record. Journal of California and Great Basin Anthropology 7(2):166-175.

1987 Behavioral Ecology and Hunter-gatherer Foraging: an Example from the Great Basin. British Archaeological Reports International Series 381. B.A.R., Oxford, England.

Simms, S.R., J.R. Bright, and A. Ugan

1997 Plain Ware Ceramics and Residential Mobility: A Case Study from the Great Basin. Journal of Archaeological Science 24:779-792.

Sims, P.L., and J.S. Singh

1978a Structure and Function of 10 Western North-American Grasslands 2. Intra-Seasonal Dynamics in Primary Producer Compartments. Journal of Ecology 66(2):547-572.

1978b Structure and Function of 10 Western North-American Grasslands 3. Net Primary Production, Turnover and Efficiencies of Energy Capture and Water-Use. Journal of Ecology 66(2):573-597.

Skibo, J.M.

1992 Pottery Function: A Use Alteration Perspective. Plenum Press, New York.

Smith, B.

1986 The Archaeology of the Southeastern United States: From a Dalton to de Soto, 10,500 to 500 BP. Advances in World Archaeology 5:1-92.

Solh, M.

2005 Grasslands of the World. FAO, Rome.

Southern Regional Climate Center (SRCC)

2009 Climate Atlas. Electronic document, http://www.srcc.lsu.edu/southernClimate/atlas/climograph?id=417945, accessed October 2009.

Speth, J.D.

1983 Bison Kills and Bone Counts: Decision Making by Ancient Hunters. Prehistoric Archeology and Ecology. University of Chicago Press, Chicago.

Speth, J.D., and K.A. Spielmann

1983 Energy-Source, Protein-Metabolism, and Hunter Gatherer Subsistence Strategies. Journal of Anthropological Archaeology 2(1):1-31.

Stephens, D.W., and J.R. Krebs 1986 Foraging Theory. Monographs in Behavior and Ecology. Princeton University Press, Princeton, New Jersey.

Sutton, M.Q., and E.N. Anderson 2004 Introduction to Cultural Ecology. AltaMira Press, Walnut Creek, California.

Teeri, J.A., and L.G. Stowe 1976 Climatic Patterns and Distribution of $\mathrm{C}_{4}$ Grasses in North-America. Oecologia 23(1):1-12.

Texas Parks and Wildlife Department

2007 Birds of the South Llano River State Park and Walter Buck Wildlife Management Area: A Field Checklist.

2009 Great Texas Wildlife Trails: Heart of Texas West Wildlife Trail. Electronic document, http://www.tpwd.state.tx.us/ huntwild/wild/wildlife_trails/heart/hot_west/llano, accessed December 2009. 
Thomas, D.H.

1983 The Archaeology of Monitor Valley: 2. Gatecliff Shelter. Anthropological Papers Vol. 59, Pt. 1. American Museum of Natural History, New York.

1989 Diversity in Hunter-Gatherer Cultural Geography. In Quantifying Diversity in Archaeology, edited by R.D. Leonard and G.T. Jones, pp. 85-91. Cambridge University Press, Cambridge.

Thompson, J.L.

2006 Interim Report: Data Recovery at 41KM69, Flatrock Road Site in Junction, Kimble County, Texas. Report on file, Center for Archaeological Research, The University of Texas at San Antonio and TxDOT Environmental Affairs, Austin.

Thompson, J.L., R. Mauldin, and S.A. Tomka

2007 A Research Design for the Analysis of Data Recovered at 41KM69, Kimble County, Texas. Center for Archaeological Research, The University of Texas at San Antonio.

Thompson, J.L., S.A. Tomka, and R.P. Mauldin

2004 A Scope of Work for Data Recovery Excavations at 41KM69, Kimble County, Texas. Submitted to the Department of Transportation, Environmental Affairs Division. Report on file, Center for Archaeological Research, The University of Texas at San Antonio.

Tilman, D.

1982 Resource Competition and Community Structure. Princeton University Press, Princeton.

1988 Plant Strategies and the Dynamics of Structure of Plant Communities. Princeton University Press, Princeton.

1994 Competition and Biodiversity in Spatially Structured Habitats. Ecology 75(1):2-16.

Tite, M.S., V. Kilikogliu, and G. Vekinis

2001 Strength Toughness and Thermal Shock Resistance of Ancient Ceramics and Their Influence on Technological Choice. Archaeometry 43(3):301-324.

Tomka, S.A.

1986 Biface Manufacture Failures. Manuscript on file, Texas Archeological Research Laboratory, The University of Texas at Austin.

1994 Quinua and Camelids on the Bolivian Altiplano: An Ethnoarchaeological Approach to Agro-Pastoral Subsistence Production with an Emphasis on Agro-Pastoral Transhumance. Ph.D dissertation, Department of Anthropology, The University of Texas at Austin.

2001 The Effect of Precessing Requirements on Reduction Strategies and Tool Form: A New Perspective. In Lithic Debitage Context, Form and Meaning, edited by W. Andrefsky, pp. 207-223. The University of Utah Press, Salt Lake City.

Tomka, S.A., R. Mauldin, and R.D. Greaves

2004a Late Prehistoric and Late Archaic Subsistence Practices: A Comparative Analysis. In Millican Bench (41TV163): A Multicomponent Site in Travis County, Texas. Archaeological Survey Report No. 351. Center for Archaeological Research, The University of Texas at San Antonio and the Archeological Studies Program, Report No. 66 Environmental Affairs Division, Texas Department of Transportation, Austin.

2004b Research Design for Analysis of Testing and Data Recovery Materials from 41ZV202, Zavala County, Texas. Report on file, Center for Archaeological Research, The University of Texas at San Antonio.

2004cLate Prehistoric and Late Archaic Subsistence Practices: A Comparative Analysis. In Millican Bench (41TV163): A Multicomponent Site in Travis County, Texas. Archaeological Survey Report No. 351. Center for Archaeological Research, The University of Texas at San Antonio and the Archeological Studies Program, Report No. 66 Environmental Affairs Division, Texas Department of Transportation, Austin. 
Torrence, R.

1983 Time Budgeting and Hunter-Gathering Technology. In Hunter-Gatherer Economy in Prehistory: A European Perspective, edited by G. Bailey, pp. 11-22. Cambridge University Press, New York.

1989 Tools as Optimal Solutions. In Time, Energy, and Stone Tools, edited by R. Torrence. Cambridge University Press, New York.

Treece, A.C., C. Lintz, W.N. Trierweiler, J.M. Quigg, and K.A. Miller

1993a Cultural Resources Investigations in the O.H. Ivie Reservoir, Concho, Coleman, and Runnels Counties, Texas. Vol. III Data Recovery from Non-Ceramic Sites. Technical Report 346-III. Mariah Associates, Austin, Texas.

1993b Cultural Resources Investigations in the O.H. Ivie Reservoir, Concho, Coleman, and Runnels Counties, Texas. Vol. IV Data Recovery from Ceramic Sites. Technical Report 346-IV, Austin, Texas Mariah Associates.

Tringham, R., G. Cooper, G. Odell, R. Voytek, and A. Whitman

1974 Experimentation in the Formation of Edge Damage: A New Approach to Lithic Analysis. Journal of Field Archaeology 1:171-196.

Turner, E.S., and T.R. Hester 1999 A Field Guide to Stone Artifacts of Texas Indians. 3rd ed. Gulf Publishing, Houston.

United States Department of Agriculture

2009 Web Soil Survey. Electronic document, http://websoilsurvey.nrcs.usda.gov/app/WebSoilSurvey.aspx, accessed October 2009.

Wade, M.d.F

1998 The Native Americans of the Texas Edwards Plateau and Related Areas, 1582-1799. Unpublished Ph.D. dissertation, The University of Texas at Austin.

2003 The Native Americans of the Texas Edwards Plateau, 1582-1799. 1st ed. Texas Archaeology and Ethnohistory Series. University of Texas Press, Austin.

Wandsnider, L.

1997 The Roasted and the Boiled: Food Composition and Heat Treatment with Special Emphasis on Pit-hearth Cooking. Journal of Anthropological Archaeology 16(1):1-48.

Weather Source 2007a Station Junction Kimble County Airport. Electronic document, http://www.weathersource.com, accessed April 2007. 2007b Station: Junction 4 Ssw. Electronic document, http://www.weathersource.com, accessed April 2007.

Weir, F.A.

1976 The Central Texas Archaic. Unpublished Ph.D. dissertation, Department of Anthropology, Washington State University, Pullman.

Weniger, D.

1984 The Explorers’ Texas. Eakin Press, Austin, Texas.

Weston, J.D., R.D. Greaves, R. Mauldin, and S.A. Tomka

2004 Significance Testing at 41KM69, Flatrock Road Site in Junction, Kimble County, Texas. Manuscript on file, Center for Archaeological Research, The University of Texas at San Antonio.

Winberg, L.A.

1997 Annual Fruit Production of Pricklypear (Opunita engelmanni) and Mesquite (Prosopis glandulosa) in Southern Texas. Texas Journal of Science 49(1):65-72. 


\section{Winship, G.P.}

1904 The Journey of Coronado, 1540-1542. Fulcrum, Golden, Colorado.

Winterhalder, B.

1981 Optimal Foraging Strategies and Hunter-Gatherer Research in Anthropology: Theory and Models. In Hunter Gatherer Foraging Strategies: Ethnographic and Archaeological Analyses, edited by B. Winterhalder and E.A. Smith, pp. 13-35. The University of Chicago Press, Chicago.

Young, G.A., and M. Hoffman

1999 The Expedition of Hernando de Soto West of the Mississippi, 1541-1543. In Proceedings of the de Soto Symposia, 1988 and 1990. University of Arkansas Press, Fayetteville. 
Appendix A:

Geomorphological Descriptions of Backhoe Trenches at 41 KM69 and Soil Susceptibility Graphs and Raw Data

Russell Greaves 



\title{
Appendix A: \\ Geomorphological Descriptions of Backhoe Trenches at $41 \mathrm{KM} 69$ and Soil Susceptibility Graphs and Raw Data
}

\author{
Russell Greaves
}

This report describes the stratigraphic integrity and age of archeological deposits at 41KM69 as first reported in the Significance Testing Interim Report by Weston et al. in 2004. To make this assessment, CAR exposed over $114 \mathrm{~m}$ in six backhoe trenches (BHTs 4-9) at the site (see Figure A-1). These exposed long profiles, provided a geomorphic context for the cultural materials and located some burned rock features. CAR continued numbering BHTs 4-9 sequential to the backhoe trenches previously dug by TxDOT (BHTs1-3). Magnetic susceptibility samples (MSS) were collected from five of the backhoe trench profiles, including the burned rock midden exposed in BHT 5. The results of this analysis are provided following the geomorphology description of this appendix (Figure A-8 through A-13; Table A-4).

\section{BHT 4}

The southernmost trench excavated on 41KM69 (Figures A-1, A-2), BHT 4, was situated on the upper terrace. The location was selected to excavate through the eastern margin of the burned rock midden, Feature 1. BHT 4 was $27.31 \mathrm{~m}$ long and was oriented to grid north. Because of trees and topography, this trench curved slightly westward. The maximum depth of excavation was $168 \mathrm{~cm}$, but most of the trench was $150 \mathrm{~cm}$ deep.

Soils in BHT 4 exhibited three recent epipedons overlying an AB-Bk-Ck-Ab-2Ck sequence (Figure A-2, Table A-1). Recent historic disturbances extend to the base of the A2 horizon. Minimally, the Oa and A1 soils have developed since the events responsible for these disturbances. Feature 1 may be associated with the sediments now forming the AB soil or the Bk1 unit.

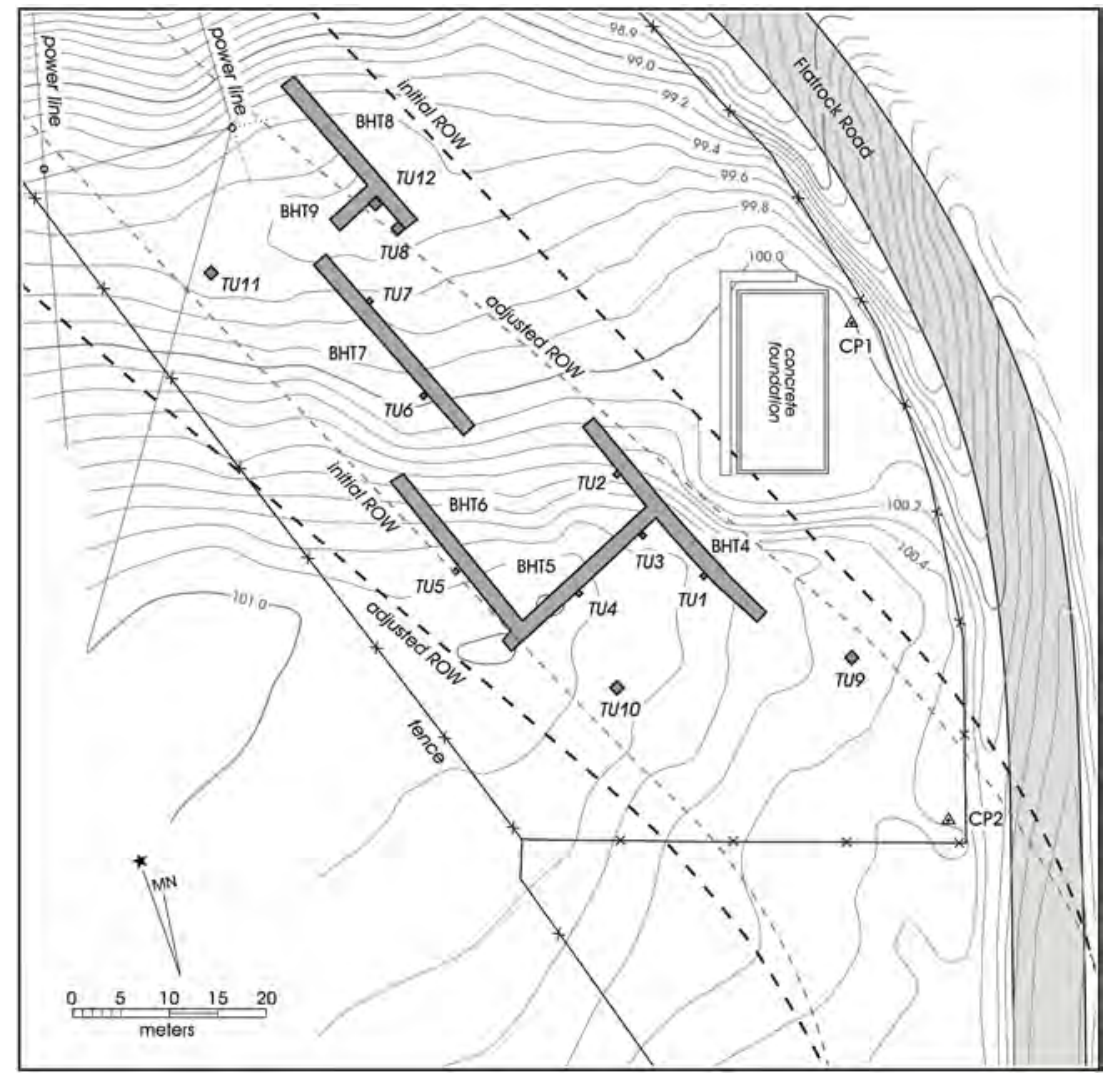

Figure A-1. Site map showing locations of CAR backhoe trenches and test units relative to terraces. 


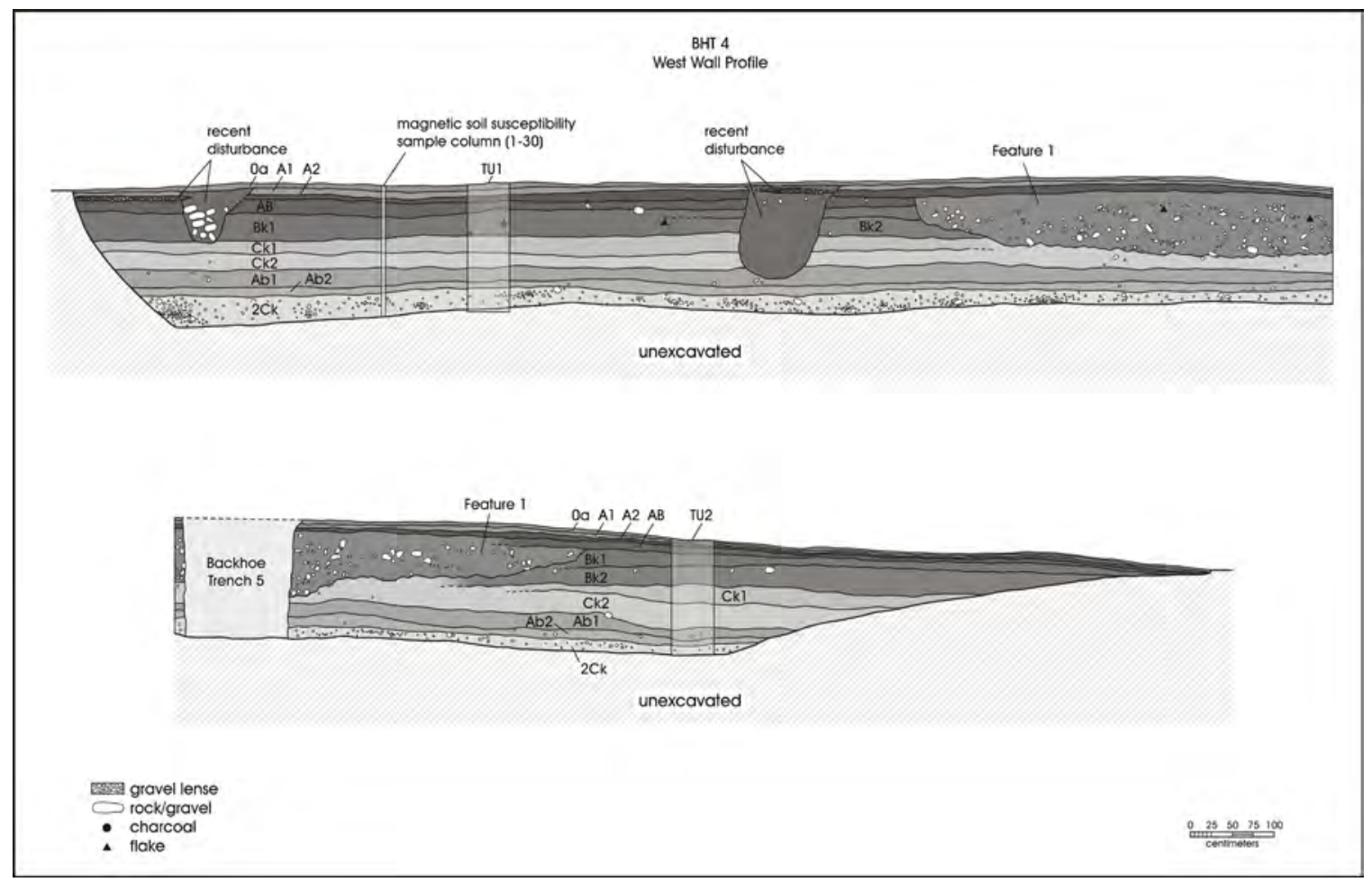

Figure A-2. West wall profile of Backhoe Trench 4. Note Feature 1 and Test Units 1 and 2.

Underlying the Bk2 soil, two $\mathrm{C}$ horizon sediments sit above a buried soil (Ab1 and Ab2). This paleosol rests conformably on top of higher-energy $2 \mathrm{Ck}$ deposits that contain significantly more gravels than any other sediment exposed in the profile.

There is excavation disturbance of the sediments east of the location of BHT 4 associated with the hotel foundations (see Figure A-1). That disturbance appears to be related to construction and possibly demolition of the hotel structure. Undisturbed midden deposits were visible in both walls of the backhoe trench. Minor recent disturbances were seen in the western wall of BHT 4, though these recent excavations have not affected the integrity of Feature 1. One historic pit was located 1.28-2.15 m north of the southern end of the trench (Figure A-2). The majority of the pit was $47 \mathrm{~cm}$ wide and it was $70 \mathrm{~cm}$ deep. Many large pieces of river-rolled limestone were found within the loose fill of this pit at the time of the backhoe excavation. No historic artifacts were encountered in association with this recent feature.

South of this pit was a deposit of small gravels near the ground surface. This may be an accidental or intentional gravel layer associated with this historic pit. A second recent pit was identified between 7.92 and $9.17 \mathrm{~m}$ north of the southern end of BHT 4 (Figure A-2). This pit was $94 \mathrm{~cm}$ wide and $116 \mathrm{~cm}$ deep. The fill was loose sediment with few rocks. A single stump or post was found within this pit at the time of the backhoe excavation. Although its orientation is difficult to determine because of the backhoe excavation, it appears to have been lying horizontally at the time of discovery. This log appears to have been included as backfill and was not in position representing an in situ post. A thin layer of fine gravels was present in the uppermost fill of this pit. No historic artifacts were associated with this pit. Neither of these pits has disturbed the burned rock midden deposits.

Feature 1 was exposed in BHT 4 from approximately 10.00-19.90 m north of the southern end of the trench. The feature was readily apparent as significantly darker sediments associated with large amounts of fire-cracked rock. Feature 1 obscured definition of the $\mathrm{AB}$ soil in the portion of this profile below the midden. The feature may be associated with the Bk soils (Bk1 and Bk2).

Two flakes were recovered from within the Feature 1 exposure in BHT 4 (Figure A-2). Fire-cracked rocks outside of Feature 1 were exposed only in low densities, primarily within the Bk soils roughly $3 \mathrm{~m}$ south of the margin of Feature 1 and $2.15 \mathrm{~m}$ north of the edge of the midden. Significant amounts of bioturbation were associated with the lower boundary of Feature 1 within the 
Table A-1. BHT 4 Soil Descriptions

\begin{tabular}{|c|c|c|c|c|c|c|c|c|c|c|c|}
\hline Horizon & Texture & Consistence & $\begin{array}{l}\text { Clay } \\
\text { films }\end{array}$ & $\begin{array}{c}\text { Grain } \\
\text { Coatings }\end{array}$ & Structure & Roots & Pores & $\mathrm{CaCO}_{3}$ & Boundary & $\begin{array}{c}\text { Color (Wet/ } \\
\text { Dry) }\end{array}$ & Comments \\
\hline $\mathrm{Oa}$ & $\begin{array}{l}\text { fine, well } \\
\text { sorted silt } \\
\text { loam }\end{array}$ & $\begin{array}{c}\mathrm{W}=\text { non-sticky; } \\
\text { non-plastic } \\
\mathrm{D}=\text { loose-soft }\end{array}$ & 0 & organics & $\begin{array}{c}\text { weak; single } \\
\text { grain-fine; } \\
\text { subangular } \\
\text { blocky }\end{array}$ & $\begin{array}{l}\text { abundant; } \\
\text { fine-coarse }\end{array}$ & 0 & slight & $\begin{array}{l}\text { abrupt; } \\
\text { smooth }\end{array}$ & $\begin{array}{l}\mathrm{W}=10 \mathrm{YR} 2 / 2 \\
\mathrm{D}=10 \mathrm{YR} 3 / 2\end{array}$ & \\
\hline $\mathrm{A} 1$ & $\begin{array}{l}\text { fine, well } \\
\text { sorted silt } \\
\text { loam }\end{array}$ & $\begin{array}{c}\mathrm{W}=\text { non-sticky; } \\
\text { non-plastic } \\
\mathrm{D}=\text { loose-soft }\end{array}$ & 0 & organics & $\begin{array}{c}\text { weak; single } \\
\text { grain-fine; } \\
\text { subangular } \\
\text { blocky }\end{array}$ & $\begin{array}{l}\text { abundant; } \\
\text { fine-coarse }\end{array}$ & 0 & slight & $\begin{array}{l}\text { abrupt; } \\
\text { smooth }\end{array}$ & $\begin{array}{l}\mathrm{W}=10 \mathrm{YR} 2 / 2 \\
\mathrm{D}=10 \mathrm{YR} 3 / 2\end{array}$ & \\
\hline $\mathrm{A} 2$ & $\begin{array}{l}\text { fine, well } \\
\text { sorted silt } \\
\text { loam }\end{array}$ & $\begin{array}{c}\mathrm{W}=\text { slightly } \\
\text { sticky; slightly } \\
\text { plastic } \mathrm{D}=\text { soft }\end{array}$ & 0 & silt & $\begin{array}{c}\text { weak; fine; } \\
\text { subangular } \\
\text { blocky }\end{array}$ & $\begin{array}{l}\text { abundant; } \\
\text { fine-coarse }\end{array}$ & 0 & slight & \begin{tabular}{|c|} 
abrupt; \\
smooth-wavy
\end{tabular} & $\begin{array}{l}\mathrm{W}=10 \mathrm{YR} 2 / 2 ; \\
\mathrm{D}=10 \mathrm{YR} 3 / 2\end{array}$ & $\begin{array}{c}\text { base of root } \\
\text { zone }\end{array}$ \\
\hline $\mathrm{AB}$ & $\begin{array}{l}\text { fine, well } \\
\text { sorted silt } \\
\text { loam }\end{array}$ & $\begin{array}{c}\mathrm{W}=\text { slightly } \\
\text { sticky; slightly } \\
\text { plastic } \mathrm{D}=\text { soft-sl } \\
\text { hard }\end{array}$ & 0 & $\begin{array}{c}\text { common } \\
\text { silt bridges }\end{array}$ & $\begin{array}{c}\text { moderate; } \\
\text { fine-coarse; } \\
\text { subangular } \\
\text { blocky }\end{array}$ & $\begin{array}{l}\text { few; fine- } \\
\text { coarse }\end{array}$ & few; fine & slight & $\begin{array}{c}\text { clear; } \\
\text { smooth-wavy }\end{array}$ & $\begin{array}{l}\mathrm{W}=10 \text { YR } 3 / 1 \\
\mathrm{D}=10 \mathrm{YR} 3 / 2\end{array}$ & $\begin{array}{c}\text { some insect// } \\
\text { annelid } \\
\text { activity }\end{array}$ \\
\hline Bk1 & $\begin{array}{l}\text { fine, well } \\
\text { sorted silt } \\
\text { loam }\end{array}$ & $\begin{array}{c}\mathrm{W}=\text { slightly } \\
\text { sticky; slightly } \\
\text { plastic } \mathrm{D}=\text { soft }\end{array}$ & 0 & $\begin{array}{c}\text { common } \\
\text { silt bridges }\end{array}$ & $\begin{array}{c}\text { moderate; } \\
\text { med-coarse; } \\
\text { subangular } \\
\text { blocky }\end{array}$ & $\begin{array}{l}\text { few; fine- } \\
\text { coarse }\end{array}$ & few; fine & violent & $\begin{array}{l}\text { diffuse; } \\
\text { wavy }\end{array}$ & $\begin{array}{l}\mathrm{W}=10 \mathrm{YR} 3 / 1 ; \\
\mathrm{D}=10 \mathrm{YR} \text { 4/2 }\end{array}$ & $\begin{array}{c}\text { less } \\
\text { invertebrate } \\
\text { bioturbation } \\
\text { than } \mathrm{AB} ; \\
\text { common } \\
\text { thin } \\
\text { dispersed } \\
\mathrm{CaCO}_{3}\end{array}$ \\
\hline $\mathrm{Bk} 2$ & $\begin{array}{l}\text { fine, well } \\
\text { sorted silt } \\
\text { loam }\end{array}$ & $\begin{array}{c}\mathrm{W}=\text { slightly } \\
\text { sticky; slightly } \\
\text { plastic } \mathrm{D}=\text { soft }\end{array}$ & 0 & $\begin{array}{c}\text { common } \\
\text { silt bridges }\end{array}$ & $\begin{array}{c}\text { moderate; } \\
\text { med-coarse; } \\
\text { subangular } \\
\text { blocky }\end{array}$ & $\begin{array}{l}\text { few; fine- } \\
\text { coarse }\end{array}$ & few; fine & violent & $\begin{array}{c}\text { diffuse; } \\
\text { wavy }\end{array}$ & $\begin{array}{l}\mathrm{W}=10 \mathrm{YR} 3 / 1 ; \\
\mathrm{D}=10 \mathrm{YR} 4 / 2\end{array}$ & $\begin{array}{l}\text { common } \\
\text { diffuse } \\
\mathrm{CaCO}_{3}\end{array}$ \\
\hline Ck1 & $\begin{array}{c}\text { fine, well } \\
\text { sorted sandy } \\
\text { loam }\end{array}$ & $\begin{array}{c}\mathrm{W}=\text { slightly } \\
\text { sticky; slightly } \\
\text { plastic } \mathrm{D}=\text { soft }\end{array}$ & 0 & silt & $\begin{array}{c}\text { weak; } \\
\text { fine-med; } \\
\text { subangular } \\
\text { blocky }\end{array}$ & $\begin{array}{l}\mathrm{v} \text { few; } \\
\text { coarse }\end{array}$ & 0 & violent & $\begin{array}{l}\text { diffuse; } \\
\text { wavy }\end{array}$ & $\begin{array}{l}\mathrm{W}=10 \text { YR } 5 / 3 \\
\mathrm{D}=10 \mathrm{YR} 5 / 3\end{array}$ & $\begin{array}{c}\text { common } \\
\text { fine } \mathrm{CaCO}_{3} \\
\text { filaments }\end{array}$ \\
\hline Ck2 & $\begin{array}{c}\text { fine, well } \\
\text { sorted sandy } \\
\text { loam }\end{array}$ & $\begin{array}{c}\mathrm{W}=\text { slightly } \\
\text { sticky; slightly } \\
\text { plastic } \mathrm{D}=\text { soft-sl } \\
\text { hard }\end{array}$ & 0 & silt & $\begin{array}{c}\text { weak; fine; } \\
\text { subangular } \\
\text { blocky }\end{array}$ & $\begin{array}{l}\mathrm{v} \text { few; } \\
\text { coarse }\end{array}$ & 0 & violent & clear; wavy & $\begin{array}{l}\mathrm{W}=10 \mathrm{YR} 4 / 2 \\
\mathrm{D}=10 \mathrm{YR} 5 / 3\end{array}$ & $\begin{array}{c}\text { common } \\
\text { fine } \mathrm{CaCO}_{3} \\
\text { filaments }\end{array}$ \\
\hline Ab1 & $\begin{array}{c}\text { fine, mod } \\
\text { well sorted } \\
\text { silt loam }\end{array}$ & $\begin{array}{c}\mathrm{W}=\text { slightly } \\
\text { sticky; slightly } \\
\text { plastic } \mathrm{D}=\mathrm{s} 1 \text { hard }\end{array}$ & 0 & silt & $\begin{array}{c}\text { weak- } \\
\text { moderate; } \\
\text { fine-med; } \\
\text { subangular } \\
\text { blocky }\end{array}$ & $\begin{array}{l}\mathrm{v} \text { few; } \\
\text { coarse }\end{array}$ & $\begin{array}{c}\text { common; } \\
\text { fine }\end{array}$ & $\begin{array}{l}\text { slight- } \\
\text { violent }\end{array}$ & clear; wavy & $\begin{array}{l}\mathrm{W}=10 \mathrm{YR} 3 / 2 \\
\mathrm{D}=10 \mathrm{YR} 4 / 2\end{array}$ & $\begin{array}{c}\text { uncommon } \\
\text { diffuse } \\
\mathrm{CaCO}_{3}\end{array}$ \\
\hline $\mathrm{Ab} 2$ & $\begin{array}{l}\text { fine, mod- } \\
\text { poorly } \\
\text { sorted silt } \\
\text { loam }\end{array}$ & $\begin{array}{c}\mathrm{W}=\text { slightly } \\
\text { sticky; slightly } \\
\text { plastic } \mathrm{D}=\text { soft }\end{array}$ & 0 & silt & $\begin{array}{c}\text { weak- } \\
\text { moderate; } \\
\text { fine; } \\
\text { subangular } \\
\text { blocky }\end{array}$ & $\begin{array}{l}\mathrm{v} \text { few; } \\
\text { coarse }\end{array}$ & $\begin{array}{l}\text { many; } \\
\text { fine }\end{array}$ & $\begin{array}{l}\text { slight- } \\
\text { violent }\end{array}$ & $\begin{array}{l}\text { abrupt; } \\
\text { wavy }\end{array}$ & $\begin{array}{l}\mathrm{W}=10 \mathrm{YR} 4 / 2 \\
\mathrm{D}=10 \mathrm{YR} 4 / 2\end{array}$ & \\
\hline $2 \mathrm{Ck}$ & \begin{tabular}{|c|} 
coarse, \\
poorly \\
sorted sandy \\
loam
\end{tabular} & $\begin{array}{c}\mathrm{W}=\text { non-sticky; } \\
\text { non-plastic } \\
\mathrm{D}=\text { loose-soft }\end{array}$ & 0 & silt & $\begin{array}{c}\text { weak; single } \\
\text { grain-fine; } \\
\text { subangular } \\
\text { blocky }\end{array}$ & $\begin{array}{l}\mathrm{v} \text { few; } \\
\text { coarse }\end{array}$ & 0 & slight & unknown & $\begin{array}{l}\mathrm{W}=10 \mathrm{YR} 4 / 3 \\
\mathrm{D}=10 \mathrm{YR} 5 / 3\end{array}$ & $\begin{array}{l}\text { abundant } \\
\text { gravels; } 6 \\
\text { cm or less }\end{array}$ \\
\hline
\end{tabular}


Ck soils. This was the only soil within the site that showed much burrowing activity. Krotovina were relatively large $(\geq 10 \mathrm{~cm})$ and indicate disturbance of some portions of the burned rock midden. Bioturbation was most visible in the Ck horizons because of the contrasts between the unmodified sediment and the dark fill of Feature 1.

Artifacts collected from the profile include flakes from the western wall, found in the Bk soils, and two lithics collected from the fill of Feature 1. The elevation of the flakes in the midden was approximately the same as those from the Bk soils. A charcoal sample from the west wall also was recovered from the base of the Bk horizon. From the eastern wall, one flake was collected from the $\mathrm{Ck} 1$ sediment, two lithics came from the Ab2 soil, and two flakes came from the Bk horizons. One piece of bone was mapped at the boundary between the $2 \mathrm{Ck}$ and $\mathrm{Ab} 2$ horizons. One charcoal sample was collected from the boundary between the $\mathrm{Ab} 1$ and $\mathrm{Ck} 2$ horizons and the other was found in the fill of Feature 1.

\section{BHT 5}

This trench was excavated perpendicular to BHT 4 to further expose Feature 1 (see Figure A-1) and provide additional profile information. BHT 5 was entirely within the upper terrace unit. The trench was $20.43 \mathrm{~m}$ long (Figure A-3). The deepest portion of the trench was $156 \mathrm{cmbs}$, but most of it was roughly $150 \mathrm{~cm}$ deep. The soils in BHT 5 were identical to those recorded and described for BHT 4.

Below the very recent $\mathrm{Oa}$ and $\mathrm{A} 1$ epipedons, an $\mathrm{AB}-\mathrm{Bk}-\mathrm{Ck}-\mathrm{Ab}-2 \mathrm{Ck}$ sequence was apparent in the western $11.5 \mathrm{~m}$ of the south wall profile. The recent anthropogenic gravel deposit has removed the A2 and portions of the AB soils in the western half of BHT 5. The gravel deposit, roughly 6 to $20 \mathrm{~cm}$ in thickness, was present in a portion of both trench walls. The lower boundary of this gravel is an abrupt erosional unconformity. Pieces of concrete, glass, and punch-top beverage cans were recovered from this deposit in the controlled excavation of TU 4 (Figures A-1, A-3). Other historic debris was seen in the profile exposure of these gravels in BHT 6. The eastern end of this gravel deposit is associated with a recent pit, identified from 10.58-11.18 m west of the eastern end of the trench. The widest upper portion of the pit was $56 \mathrm{~cm}$ and it narrowed to $26 \mathrm{~cm}$ wide at its base. This pit was $61 \mathrm{~cm}$ deep. A comparable pit was also visible in the north wall profile. That pit was approximately $110 \mathrm{~cm}$ east of the pit in the south wall profile. From the excavation exposure it is unclear if this represents a trench or two separate historic pit features. The pit visible in the northern wall was also associated with the easternmost expression of the anthropic gravel deposit. Except for these pits associated with the gravel deposits, there was no evidence of intrusive historic disturbances of the underlying soils and sediments. Neither the gravel deposit nor the intrusive pits have affected the integrity of Feature 1 or the natural stratigraphy of the majority of this profile.

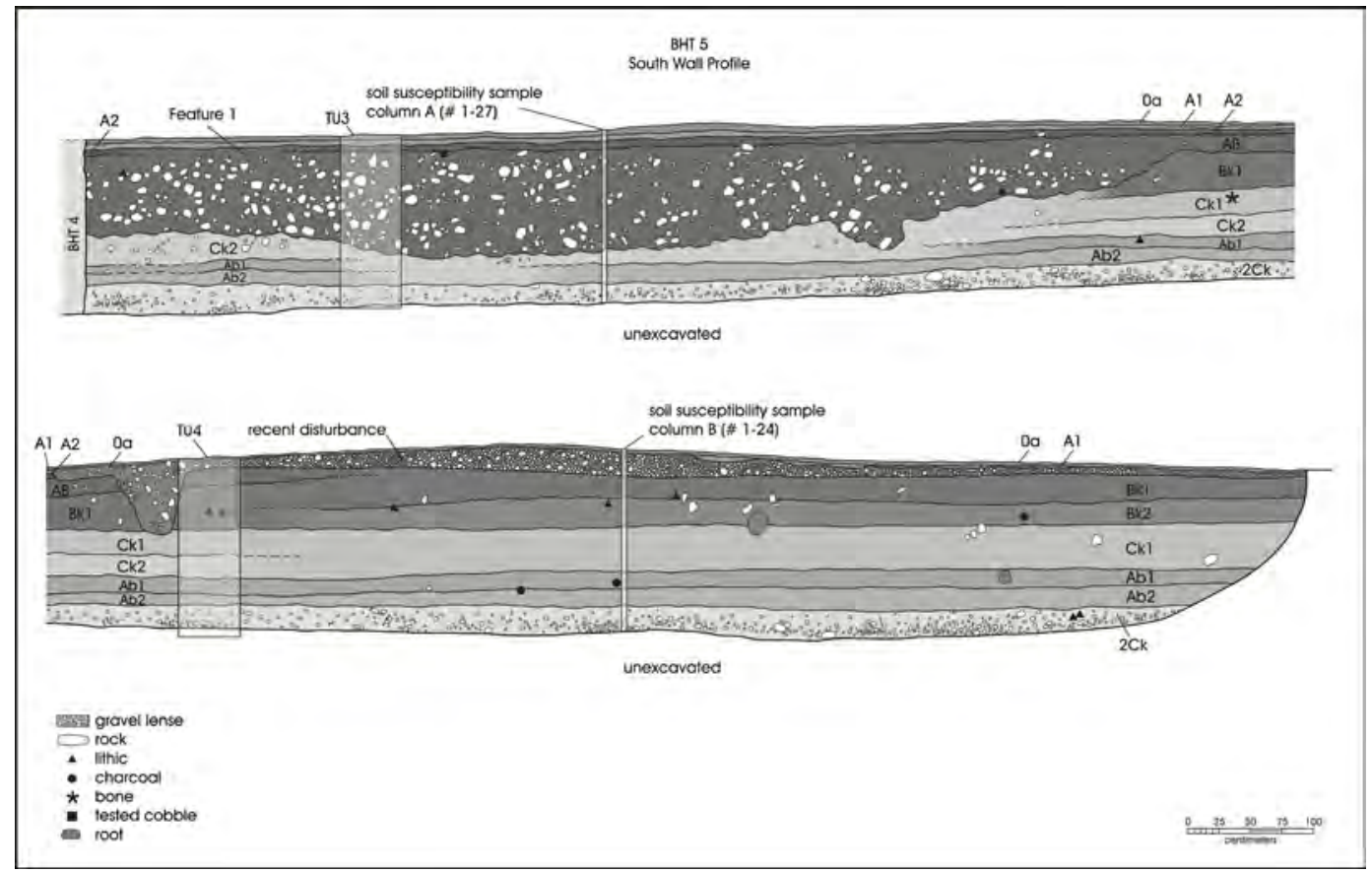

Figure A-3. South wall profile of Backhoe Trench 5. Note Feature 1 and Test Units 3 and 4. 
Feature 1 was exposed from the eastern end of the trench to approximately $9 \mathrm{~m}$ west of the intersection of BHTs 4 and 5 . The definition of this feature was clear. BHT 5 exposed portions of the midden with significantly greater amounts of fire-cracked rock than seen in the BHT 4 profiles. Negligible amounts of fire-cracked rock were visible west of the margin of Feature 1. In general, definable patterns in the distribution of fire-cracked rock were not apparent in the profile. At the western margin there was a single concentration of fire-cracked rock close to the base of Feature 1. That also was visible in the north wall. The northern wall of BHT 5 showed apparent linear associations of fire-cracked rock that may suggest definable episodes of excavation of this feature. Although the lower boundary was significantly bioturbated, a single lower extension of the feature fill did not resemble krotovina disturbances and may relate to feature use. Between 6.20-6.76 m west of the eastern end of the trench (Figure A-3), a portion of the fill with several large fire-cracked rocks extends 20-26 cm into the Ck sediment. The shape of this disturbance was unlike the other krotovina. It was contiguous with the main body of the feature fill and there were no textural or content differences between this extension of the fill and the main cultural deposit. All of the other infilled burrows lacked any large pieces of fire-cracked rock. This disturbance contained several pieces of fire-cracked rock in excess of $10 \mathrm{~cm}$ in size. A similar possible pit was visible in approximately the same location on the northern profile wall.

Prehistoric artifacts recovered from the profiles of BHT 5 include several lithics, bone, and charcoal. The majority of the lithics were recovered in association with the Bk horizons. A single piece of recent plastic was found at the boundary between the Bk1 and Bk2 horizons. Two pieces of fire-cracked rock were adjacent to this plastic and situated below the thickest part of the recent gravels. While this demonstrates translocation of small, recent material to a depth of $40 \mathrm{cmbs}$, there is no evidence for significant historic disturbances of the archeological deposits.

\section{BHT 6}

This trench was excavated perpendicular to BHT 5 and represents an overlapping view of the upper terrace on the western side of the project area. With BHTs 4 and 5, BHT 6 forms a detailed set of profiles of the area of the site where the Feature 1 midden is located (Figure A-1). BHT 6 was $19.48 \mathrm{~m}$ long. This trench was maximally $1.9 \mathrm{~m}$ deep, but most of the trench was excavated to $1.6-1.8 \mathrm{~m}$ below the current ground surface. This trench was excavated more deeply than the target elevation primarily due to the looser gravels (2Ck sediments) encountered in the base of the trench.

The western wall of BHT 6 was profiled (Figure A-4). A soil description of this profile was not performed, as soils were nearly identical to those in BHT 4 (see Figure A-2 and Table A-1) and BHT 5 (Figure A-3). There was minimal bioturbation of the deposits. There were two primary differences between BHT 6 and the other two contiguous backhoe trenches. First, the lower

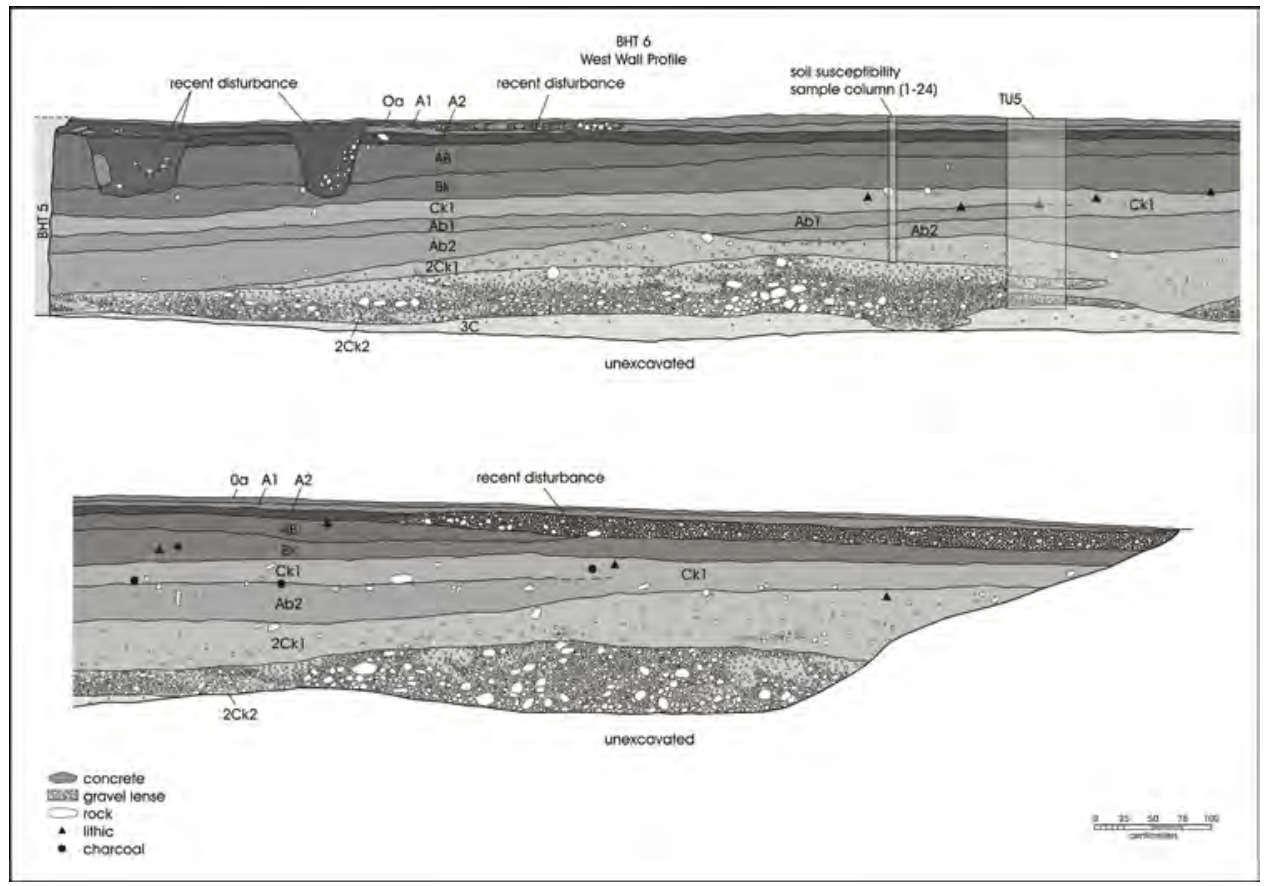

Figure A-4. West wall profile of Backhoe Trench 6. Note Test Unit 5. 
2Ck units contained significantly greater amounts of gravel than those exposed in BHTs 4 and 5 and second, the paleosols (Ab1 and Ab2) were not present throughout the entirely of the exposed profile. The exposure of the gravel deposit was partially due to the deeper excavation in portions of BHT 6 . The density of gravels at the southern end of BHT 6 was comparable to that visible in BHT 5. The density increased dramatically toward the northern end of the trench. There was both a higher density and greater size to gravels in the $2 \mathrm{Ck} 2$ horizon than seen in the other two backhoe trenches on the UPPER TERRACE surface. The gravels disappeared as thin lenses at approximately $9 \mathrm{~m}$ north of the southern end of BHT 6 demonstrating that this is near the margin of the paleo-channel meander. From approximately $9.5 \mathrm{~m}$ north of the southern end of the trench, the density and thickness of the $2 \mathrm{Ck} 2$ unit increased. This portion of the sediment is entirely clast supported. The underlying low-energy $3 \mathrm{C}$ sediments were not visible in the northern end of this trench.

The paleosols ( $\mathrm{Ab} 1$ and $\mathrm{Ab} 2)$ were not consistently expressed across the entire profile. Between roughly 4.4-5.6 m north of the southern end of BHT 6, the buried A horizon was obscured by a higher position of the $2 \mathrm{Ck} 1$ sediment. The distinction of the $\mathrm{Ab}$ unit was not apparent from $14.4 \mathrm{~m}$ north of the southern origin of the trench to the northern end of BHT 6 that was deeply enough excavated to expose the potential presence of this soil. The lack of a visual or textural indication of this soil may suggest a time transgressive difference in the surface stability between the southern and northern ends of the trench. The increase in gravels in the northern portion of the trench and its proximity with the subtle surface elevation differences between the upper terrace and the lower terraces surfaces suggest that past floodplain formation and stream migration probably moved from the south to the north of this landform.

There was evidence of significant historic disturbances of portions of the upper soils in BHT 6. This consisted of two recent pits evident in the southern end of the trench in the west wall profile. The most southern of these pits (see Figure A-4) contained loose fill and one large $(>20 \mathrm{~cm})$ piece of concrete. This pit extended from $28-116 \mathrm{~cm}$ north of the southern end of BHT 6 . Two pieces of concrete were associated with the southern margin of this excavation in BHT 6 from $6-15 \mathrm{~cm}$ below the current ground surface. The pit was $66 \mathrm{~cm}$ deep. There also was reddish sand present over the top of this pit that appeared to come from recent construction events. There were several large rocks visible in the eastern trench wall at the same depth as this pit and several pieces of brick and bottle glass were present near the ground surface above these rocks in the eastern wall. A second pit was visible in the western wall from 1.98-2.72 m north of the southern end of BHT 6. This pit extended to $67 \mathrm{~cm}$ below ground surface. The upper portions of these two pits were associated with the A1 or A2 soils. Only the Oa horizon clearly postdates these disturbances. A small amount of recent paving gravel and a cluster of concrete fragments was present just north of this pit from approximately $2.8-4.71 \mathrm{~m}$ north of the southern end of the trench. A shallow pit also was present in the eastern wall approximately $7 \mathrm{~m}$ north of the southern end of BHT 6 . All of the recent disturbances are discrete events that have not affected soils beyond their limits. The majority of the soils and sediments show no compromise of their integrity.

Artifacts recovered from the profile include several lithics, two pieces of bone, and several charcoal samples. Most of the flakes were recovered from the $\mathrm{Ck} 1$ sediment. Although recent artifacts were noted in both walls at the southern end of the trench (bottle glass, bricks, fragments of concrete), none were collected.

\section{BHT 7}

This trench was excavated at the southern margin of the lower terrace surface (Figure A-1). BHT 7 was $23.43 \mathrm{~m}$ long and had a maximum depth of $187 \mathrm{~cm}$. Most of the trench was 160-175 cm deep. A narrow pit was excavated into the floor of BHT 7 to expose the location of gravel deposits that could be compared with those visible in BHTs 8 and 9. This exposed a small portion 15.5-15.85 m north of the south end of BHT 8. Soils were analogous to those described on upper terrace (BHTs 4-6), but there were slight differences. A profile was drawn of the western wall (Figure A-5) of this trench and a complete soil description was performed (Table A-2).

There was less historic disturbance in BHT 7 than in the trenches on the upper terrace surface. A thin $(\leq 8 \mathrm{~cm})$ layer of recent gravels, identical to those seen in BHTs 5 and 6 , was present between $4.12-6.30 \mathrm{~m}$ north of the southern end of BHT 7. A recent excavation was evident between 1.2-1.88 m north of the southern end of the trench. This pit was $70 \mathrm{~cm}$ north-south and $45 \mathrm{~cm}$ below the modern ground surface in the western wall profile. Unlike the pits in BHTs 4-5, this was a carefully excavated pit with a flat bottom and straight walls. Although no test excavations were recorded to have been performed at this site, this pit is unlike the other historic pit disturbances at 41KM69 and resembles a shallow archeological test unit. 


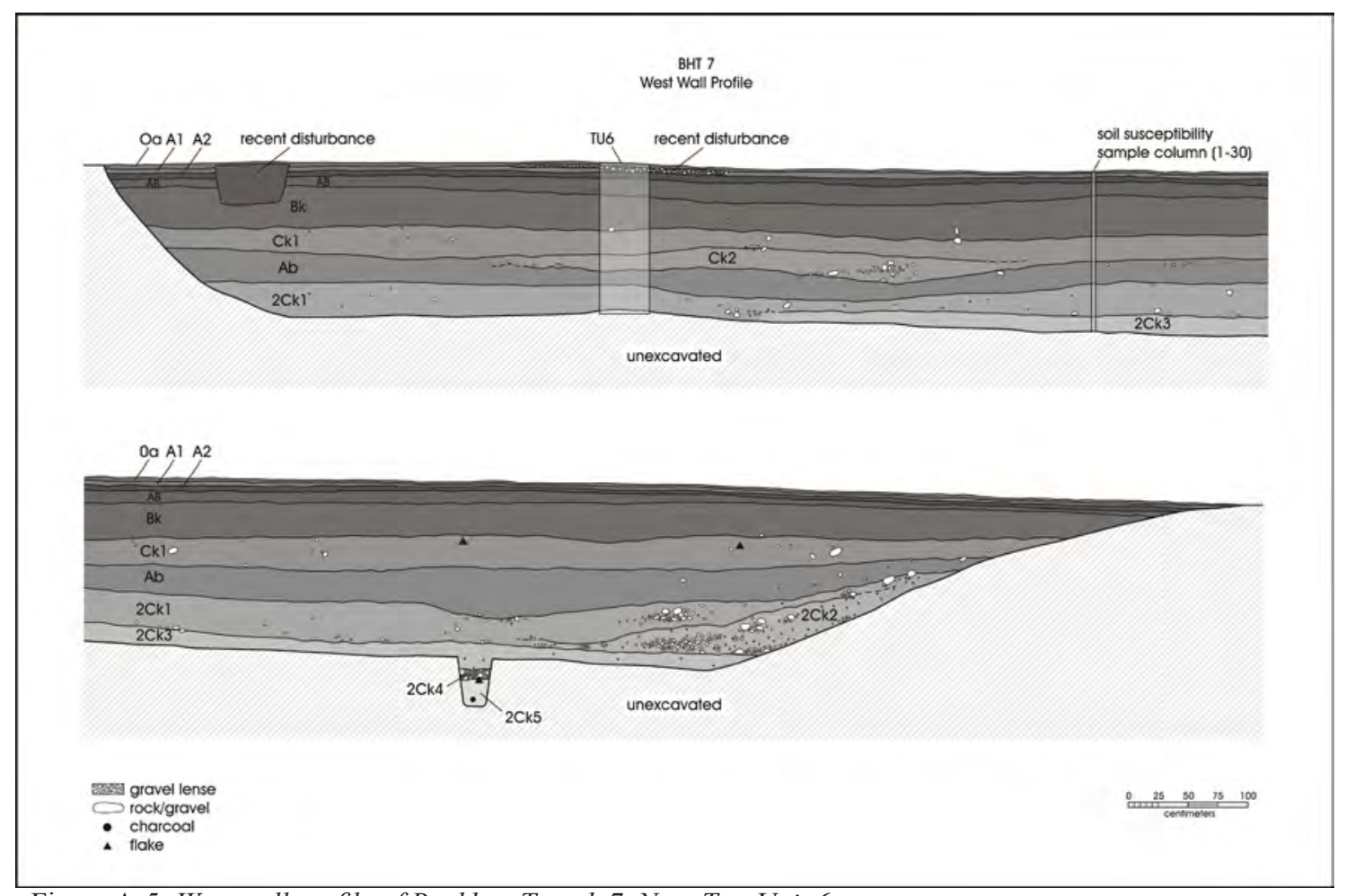

Figure A-5. West wall profile of Backhoe Trench 7. Note Test Unit 6.

Only three flakes and one piece of charcoal were recovered from the west wall profile. Ten flakes were collected from the east wall, with most material associated with the $\mathrm{Ck}$ sediments and $2 \mathrm{Ck}$ horizons. In comparison with BHTs 4-6, lithics in BHT 7 appeared to be in deeper stratigraphic positions and were not associated with the analogous soil units seen in those other trenches. If the archeological materials in BHT 7 are approximately contemporaneous with those in BHTs 4 and 5 (no dates are currently available for BHT 7) then the lower terrace surface may exhibit more deeply buried artifacts of similar ages to those in the upper terrace deposits. The soil morphology, geomorphic position, and artifact associations all suggest that the solum in BHT 7 may be younger than similar soils in BHTs 4-6.

Soils in BHT 7 were similar to those exposed in BHTs 4, 5, and 6. Although the setting of BHT 7 was the slightly lower, lower terrace surface, the profile was unlike that of the adjacent BHTs 8 and 9 that were on the lower terrace unit. The lack of thick clast-rich $2 \mathrm{Ck}$ sediments indicates that this location was peripheral to a channel exposed in BHTs 8 and 9. The deposits in BHT 7 are floodplain sediments that have not been eroded by channel meanders and are analogous to those in the slightly higher setting. Soil formation is not as robust in BHT 7 as in the profiles on the upper terrace. The differences between BHT 7 and the BHTs 4-6 soils indicates a time-transgressive effect of analogous deposits being subjected to a shorter period of pedogenesis.

\section{BHT 8}

Backhoe Trench 8 was situated east of the northern end of BHT 7 on the lower terrace (Figure A-1). This trench was excavated $18.45 \mathrm{~m}$ long and was maximally $193 \mathrm{~cm}$ deep. The lowermost 70-100 cm represents very dense clast supported gravel deposits. These were the thickest gravels exposed in the backhoe trenching of 41KM69. They were associated with the thinnest overlying sediments uncovered on the site. The solum and underlying fine $\mathrm{C}$ sediments in BHT 8 were only $60-80 \mathrm{~cm}$ thick. Soils in the other trenches above the gravel horizons varied between 120 and $>280 \mathrm{~cm}$. The western wall of BHT 8 was profiled (Figure A-6) and a complete description of the soils and sediments was recorded (Table A-3).

Soils in BHT 8 appeared to be much younger than those in BHTs 4-7. Several characteristics of the profile in BHT 8 contrast with the older deposits described for BHTs 4 and 7 (see Tables A-1 and A-2). The soils and C sediments in BHT 8 were thinner accumulations above the gravel, there was a lower amount of pedogenic clay accumulation in the A horizons (Table 
Table A-2. BHT 7 West Wall Profile Descriptions

\begin{tabular}{|c|c|c|c|c|c|c|c|c|c|c|c|c|c|}
\hline 咅 & 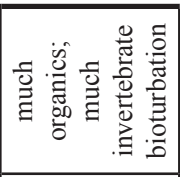 & 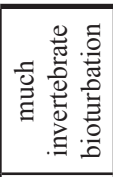 & 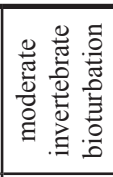 & 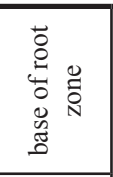 & 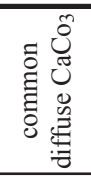 & 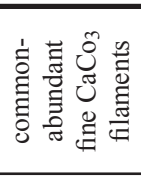 & 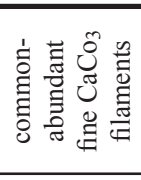 & 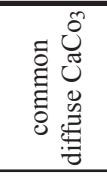 & 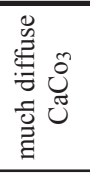 & 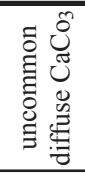 & 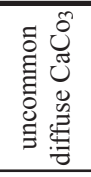 & 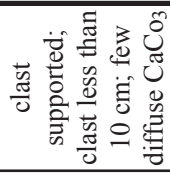 & 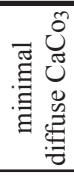 \\
\hline$\frac{\grave{0}}{\dot{\theta}}$ & 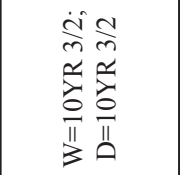 & 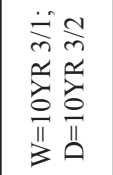 & 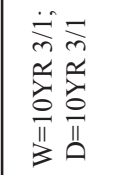 & 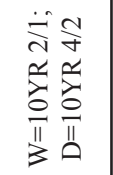 & 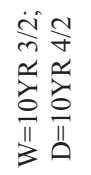 & 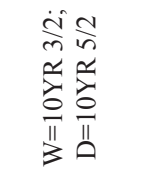 & 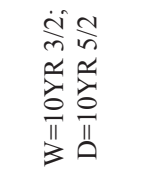 & 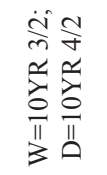 & 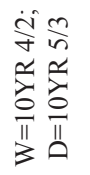 & 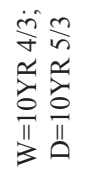 & 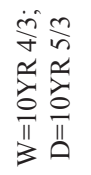 & 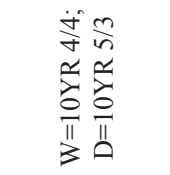 & 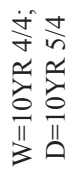 \\
\hline 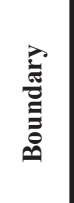 & 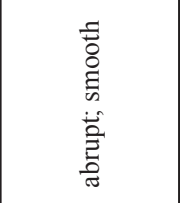 & 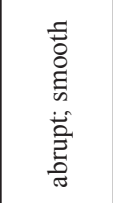 & 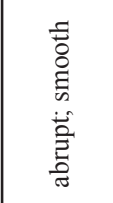 & 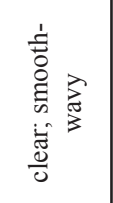 & 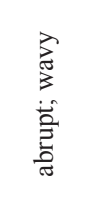 & 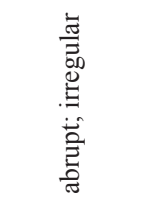 & 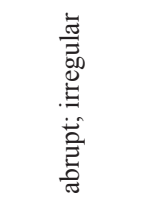 & 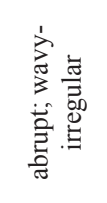 & 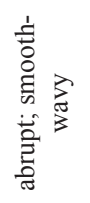 & 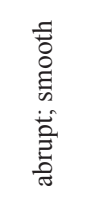 & 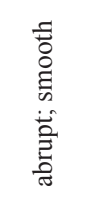 & 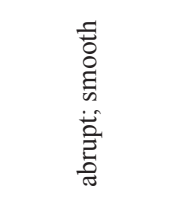 & $\begin{array}{l}\frac{E}{3} \\
\text { 竘 } \\
\Xi\end{array}$ \\
\hline in & $\begin{array}{l}\frac{\pi}{\pi} \\
\frac{\pi}{0} \\
0 \\
\vdots\end{array}$ & 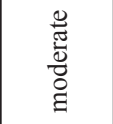 & 营 & 苟 & $\begin{array}{l}\frac{\overrightarrow{0}}{600} \\
\frac{\vec{n}}{n}\end{array}$ & $\begin{array}{l}\frac{\pi}{\pi ँ} \\
\frac{\pi}{0} \\
\vdots \\
\Xi\end{array}$ & $\frac{\overrightarrow{0}}{\frac{0}{0}}$ & $\frac{\overrightarrow{0}}{\frac{0}{0}}$ & $\frac{\overrightarrow{0}}{\frac{0}{0}}$ & $\begin{array}{l}\frac{\pi}{\pi ँ} \\
\frac{\pi}{0} \\
\vdots \\
\Xi\end{array}$ & $\begin{array}{l}\frac{\overrightarrow{5}}{500} \\
\frac{30}{n}\end{array}$ & 劳 & $\begin{array}{l}\frac{\overrightarrow{5}}{50} \\
\frac{30}{n}\end{array}$ \\
\hline$\stackrel{\mathscr{c}}{0}$ & 0 & 0 & 0 & 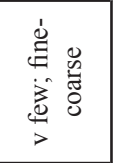 & 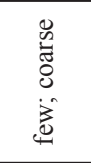 & 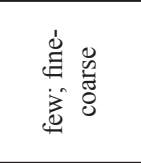 & 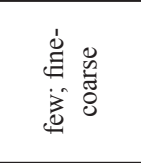 & 0 & 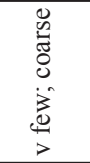 & 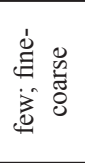 & 0 & 0 & 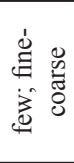 \\
\hline$\stackrel{\check{0}}{\mathscr{0}}$ & 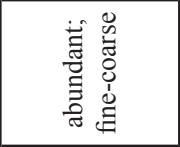 & 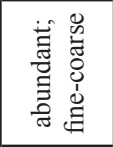 & 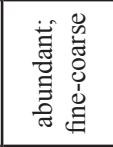 & 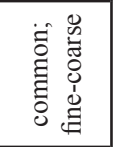 & 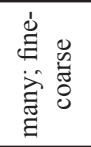 & 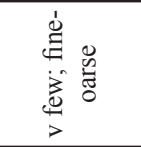 & 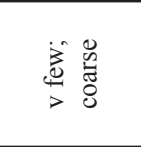 & 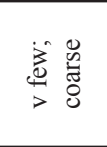 & 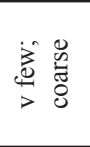 & 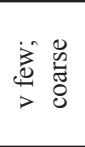 & 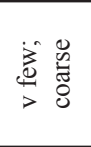 & 0 & 0 \\
\hline 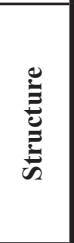 & 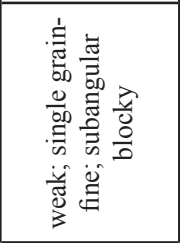 & 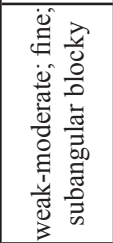 & 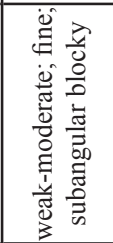 & 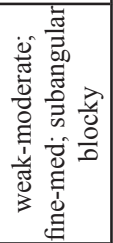 & 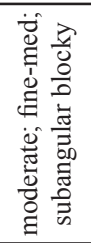 & 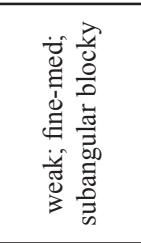 & 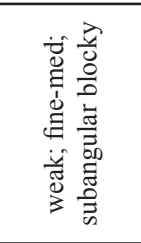 & 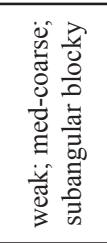 & 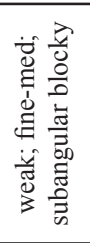 & 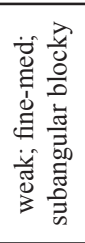 & 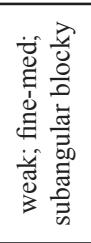 & 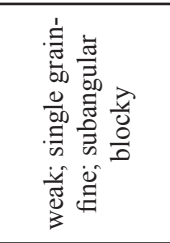 & 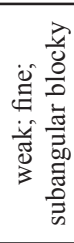 \\
\hline 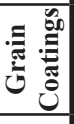 & $\frac{\vec{n}}{\omega}$ & 常 & 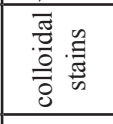 & 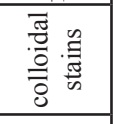 & 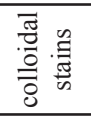 & 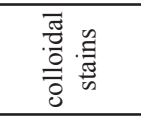 & $\begin{array}{l}\bar{\pi} \\
\frac{\pi}{0} \\
0 \\
0 \\
0\end{array}$ & 营 & 击 & 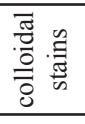 & 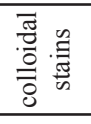 & 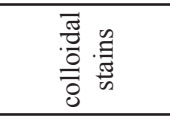 & 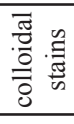 \\
\hline 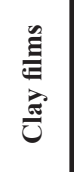 & 0 & 0 & 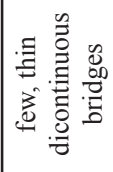 & 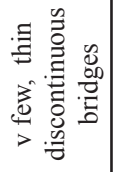 & 0 & 0 & 0 & 0 & 0 & 0 & 0 & 0 & 0 \\
\hline 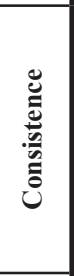 & 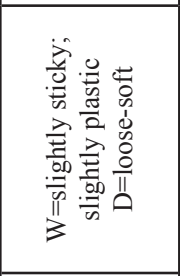 & 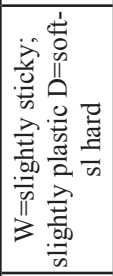 & 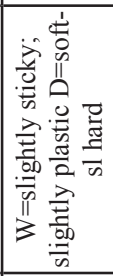 & 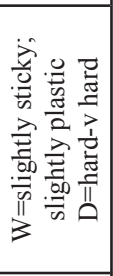 & 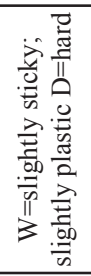 & 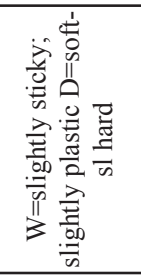 & 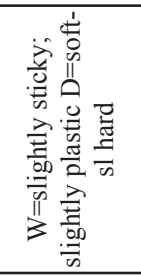 & 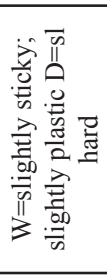 & 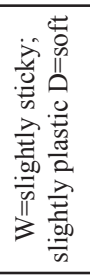 & 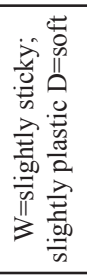 & 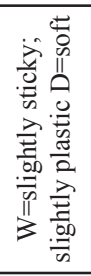 & 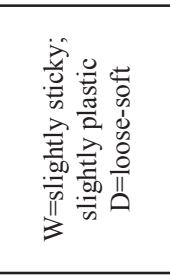 & 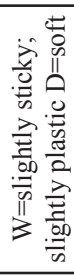 \\
\hline 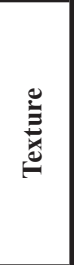 & 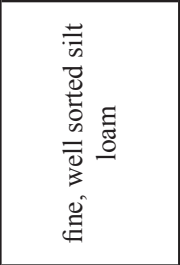 & 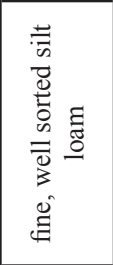 & 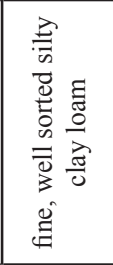 & 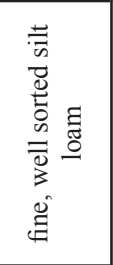 & 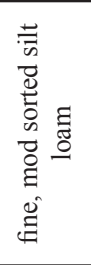 & 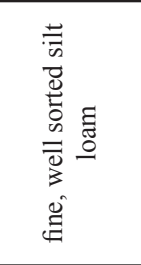 & 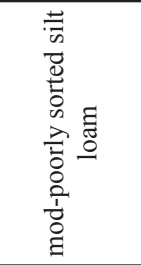 & 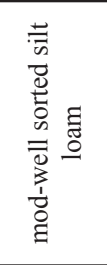 & 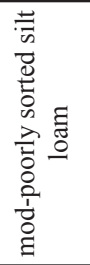 & 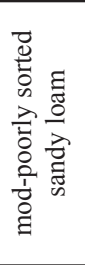 & 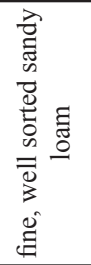 & 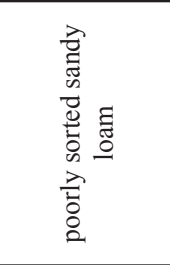 & 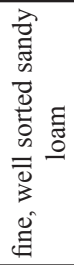 \\
\hline 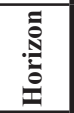 & రే & $\overline{4}$ & Z & $\stackrel{m}{4}$ & $\frac{y}{m}$ & $\frac{\bar{v}}{0}$ & $\frac{\partial}{0}$ & \& & 离 & 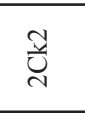 & $\frac{\tilde{N}}{\text { D }}$ & 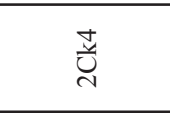 & $\frac{n}{0}$ \\
\hline
\end{tabular}


A-3), smaller ped size (demonstrating finer structure), and greater amounts of carbonate in the upper portion of the solum that have not yet been translocated down the profile. The most distinctive difference between BHT 8 and the previously described trenches were the thick gravels in the lower half of the profile exposure. There was $70 \mathrm{~cm}$ to $>100 \mathrm{~cm}$ of clast supported, poorly sorted alluvial gravels visible in all of BHT 8 . The thinner soils overlying these high-energy deposits indicate that the active stream channel of the South Llano was situated much higher and farther west than its current position.

Two prehistoric features were encountered in profiling of BHT 8. Both were situated at the base of the Bk1 horizon (Figure A-6). Feature 2 was a basin-shaped hearth exposed at the most southern end of BHT 8. It was clearly visible in the western wall and a portion of the hearth also was apparent in the southern end of the trench. At the same level as Feature 2, a second accumulation of fire-cracked rock was identified $2.85 \mathrm{~m}$ north of that hearth and designated Feature 3 (3.92-4.66 m north of the southern end of BHT 8). No charcoal was apparent in association with the fire-cracked rock in this feature. Several tools were recovered from the trench profiles in the vicinity of these two features. During profiling, one scraper was recovered from the western wall $73 \mathrm{~cm}$ south of the southern margin of Feature 3. This tool was $20 \mathrm{cmbs}$, which was the uppermost elevation of the top of the rocks in Feature 3. A second scraper was recovered during examination of the eastern wall of BHT 8 directly opposite Feature 2 at $28 \mathrm{cmbs}$. This scraper was morphologically identical to that recovered from the western wall.

At the northern end of BHT 8, an isolated erosional unconformity was present that may represent a prehistoric pit or natural feature. Between 15.96-17.64 m there was a conical anomaly in the base of the Bk2 horizon with associated fine gravels at the margins (Figure A-6). This pit extended from 16.24-17.04 $\mathrm{m}$ and reaches a depth of $32 \mathrm{~cm}$ into the Ck horizon. There were abundant fine gravels $(\leq 1 \mathrm{~cm})$ at the southern and northern margins of this pit. There were fewer on the southern margin extending $6 \mathrm{~cm}$ below the top of the $\mathrm{Ck}$ sediment. A greater extent of these fine clasts was associated with the northern margin of this feature and they were present to a depth of $13 \mathrm{~cm}$ below the upper boundary of the Ck unit. The sediment filling this pit was identical to the Bk2 horizon. No archeological artifacts were associated with this erosional anomaly. There were no indications of disturbance of the Bk2 or any overlying soils. It did not appear to be a recent excavation. It is uncertain whether this may be a cultural feature or a natural erosional event such as a rill.

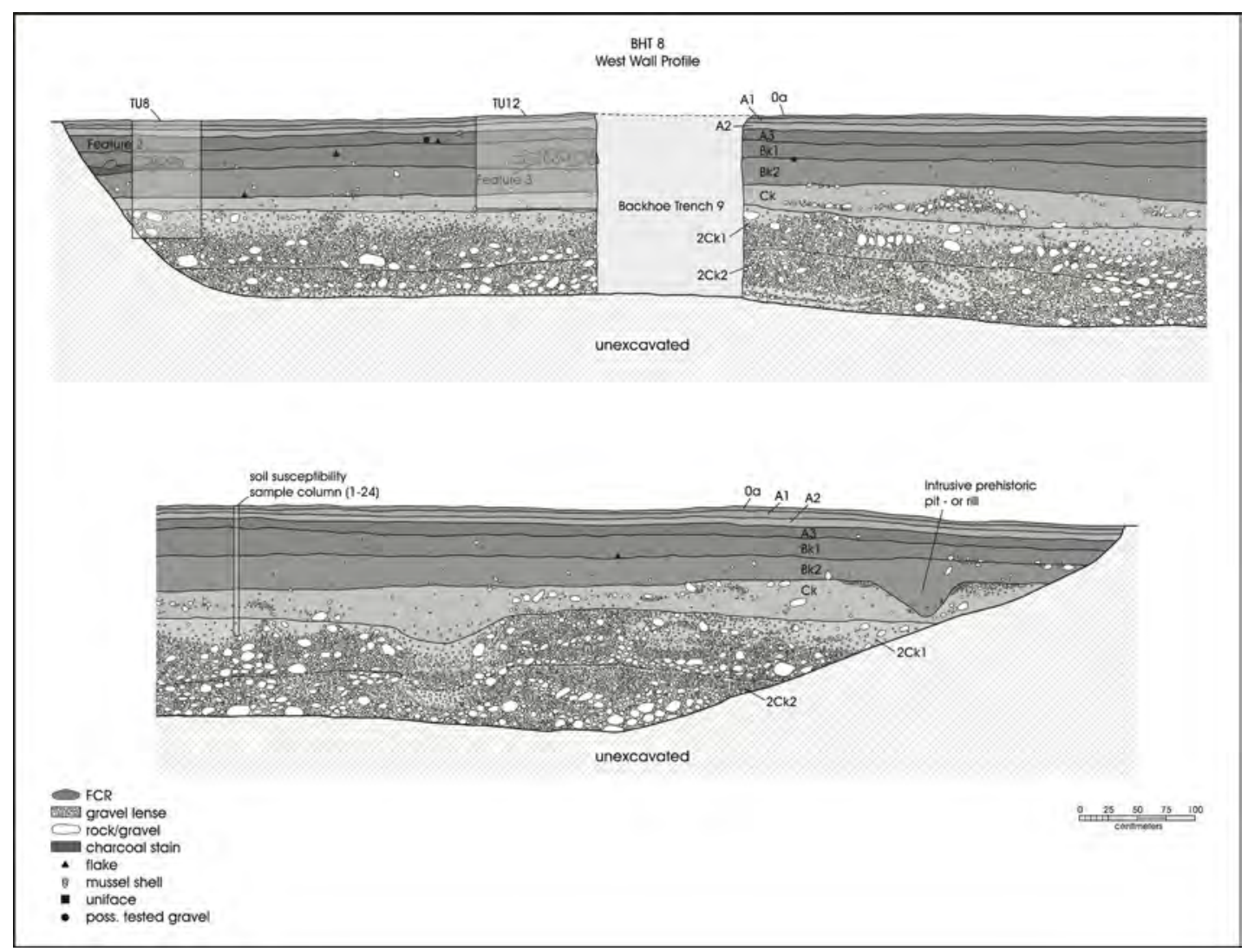

Figure A-6. West wall profile of Backhoe Trench 8. Note Features 2 and 3 and Test Units 8 and 12. 
There was evidence of a possible earlier rill feature within the $2 \mathrm{Ck} 1$ and $2 \mathrm{Ck} 2$ horizons in the western wall of the BHT 8 profile. Between approximately 12-13.2 m north of the southern end of BHT 8 there were basin-shaped areas of the gravel deposits (Figure A-6) that suggest the presence of a small surface drainage. Within both the 2Ck2 and 2Ck1, these were apparent as features that lack larger clasts and represent two fining-upward sequences. There also was a noticeable interruption in the deposit of larger clasts in the overlying $\mathrm{Ck}$ horizon above these natural drainage features. This may indicate the persistence of this rill during localized deposition of gravels on the north and south sides of this small surface drainage. All of these features indicate a series of slightly lower-energy deposits associated with the main channel as exposed in BHT 8.

\section{BHT 9}

This trench was excavated perpendicular to BHT 8 (Figure A-1) in order to determine how the dense 2Ck gravel deposits visible in BHT 8 are related to the lack of high-energy deposits exposed in the northern end of BHT 7. This trench was excavated between 4.66-5.94 m north of the southern end of BHT 8. BHT 9 was $5.64 \mathrm{~m}$ long and was maximally $158 \mathrm{~cm}$ deep. The southern wall of this trench was profiled (Figure A-7). No description of the soils was performed because they were identical to those described for BHT 8 (Table A-3). The only difference from BHT 8 was the disappearance of the 2Ck2 horizon and decrease in gravel density in the $2 \mathrm{Ck} 1$ unit of the western portion of the BHT 9 profile.

A portion of Feature 3 was also encountered in this trench. As noted in the description of Features 2 and 3 in the BHT 8 profile, Feature 3 was situated at the base of the Bk1 horizon (see Figure A-6, A-7). The Oa, A1 and A2 horizons are probably very recent. A3 represents a slightly older soil developed above the Bk1 and Bk2. The solum in BHT 9 was only $60-70 \mathrm{~cm}$ thick. Underneath the Bk2, the sequence of Ck, 2Ck1, and 2Ck2 horizons were nearly identical to the exposure in BHT 8. West of the easternmost $1.5 \mathrm{~m}$ of this trench there was a dramatic decrease in gravel density and the $2 \mathrm{Ck} 2$ horizon could not be distinguished. A gradual decrease in clast density approximately $1.6 \mathrm{~m}$ west of the eastern end of BHT 9 indicates that the channel did not migrate farther westward. It appears that this channel may have been contemporaneous with some of the archeological occupations and was certainly more recent than the portion of the archeological deposits associated with the upper terrace surface. There was no erosional unconformity apparent between BHTs 8, 9, and 7. BHT 9 demonstrates that the lower-energy sediments in BHT 7 may be associated with this channel representing slackwater floodplain deposits from that stream position. This further indicates that Features 2 and 3 may be more recent archeological remains than much of the archeology on the lower terrace surface away from this eastern side of 41KM69, and are younger than materials on the upper terrace floodplain.

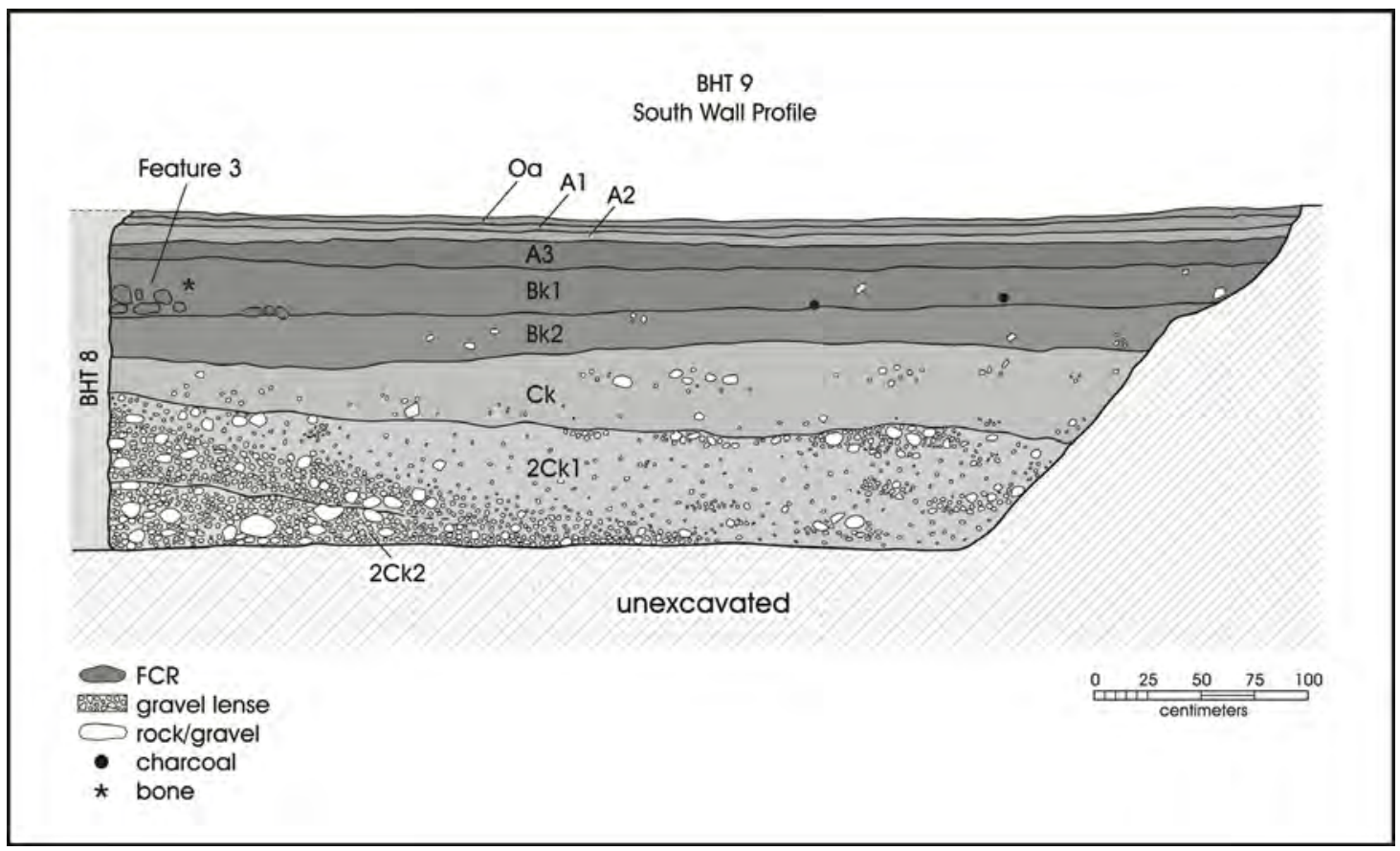

Figure A-7. South wall profile of Backhoe Trench 9. Note Feature 3. 
Table A-3. BHT 8 West Wall Profile Description

\begin{tabular}{|c|c|c|c|c|c|c|c|c|c|}
\hline 这 & 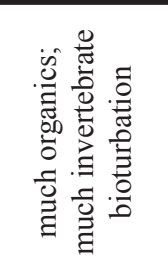 & & & $\begin{array}{l}0 \\
0 \\
N \\
0 \\
0 \\
0 \\
0 \\
0 \\
0 \\
0 \\
0\end{array}$ & & 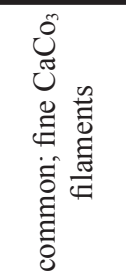 & 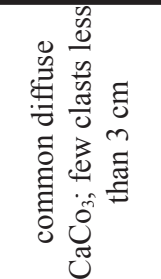 & 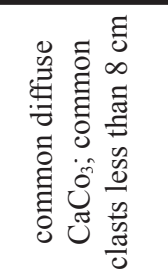 & 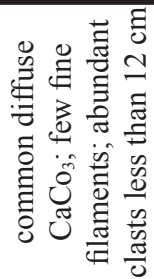 \\
\hline$\frac{\dot{\theta}}{\dot{0}}$ & 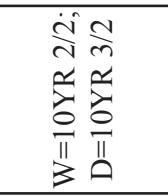 & 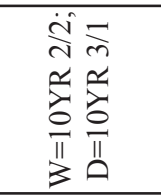 & 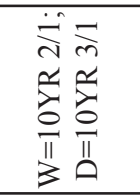 & 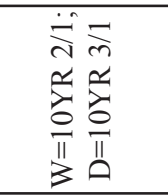 & 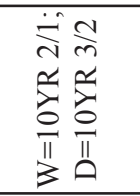 & 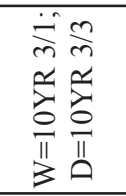 & 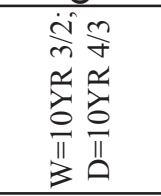 & 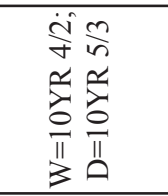 & 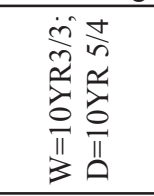 \\
\hline 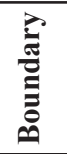 & 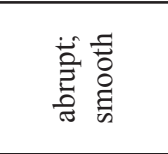 & 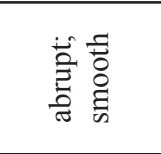 & 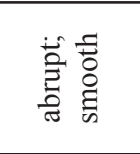 & 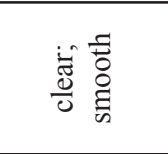 & 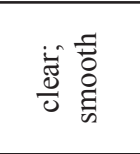 & 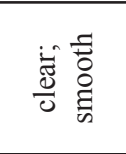 & 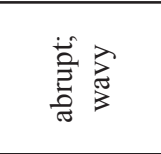 & 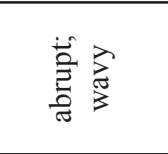 & 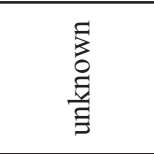 \\
\hline$e_{\tilde{U}}^{\tilde{e}}$ & 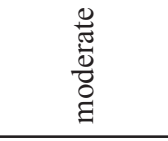 & 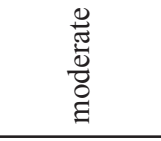 & 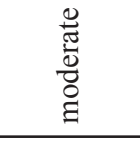 & $\frac{\overrightarrow{0}}{\frac{0}{0}}$ & $\frac{\overrightarrow{0}}{\frac{0}{0}}$ & $\frac{\overrightarrow{0}}{\frac{\overrightarrow{0}}{0}}$ & $\frac{\overrightarrow{0}}{\frac{0}{0}}$ & $\frac{\overrightarrow{0}}{\frac{0}{0}}$ & $\frac{\overrightarrow{0}}{\frac{\overrightarrow{0}}{0}}$ \\
\hline 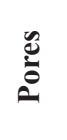 & 0 & 0 & 0 & 0 & 0 & $\begin{array}{l}\stackrel{g}{\Xi} \\
\stackrel{3}{0}\end{array}$ & 0 & 0 & 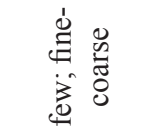 \\
\hline $\begin{array}{l}\tilde{\theta} \\
\stackrel{0}{*}\end{array}$ & 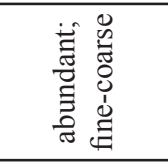 & 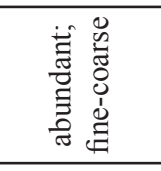 & 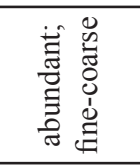 & 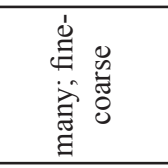 & 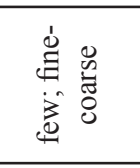 & 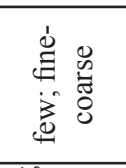 & 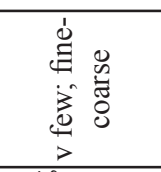 & 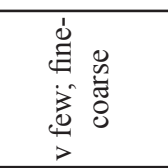 & 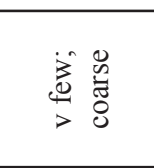 \\
\hline 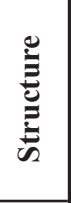 & 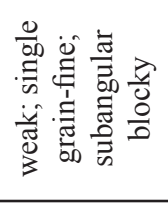 & 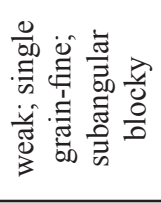 & 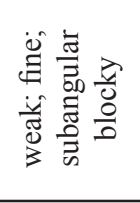 & 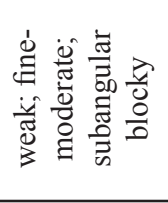 & 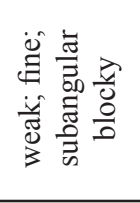 & 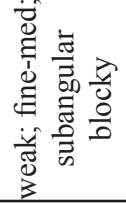 & 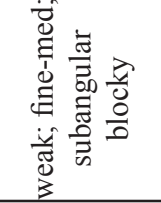 & 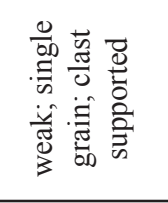 & 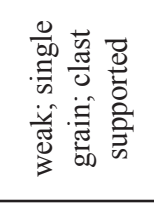 \\
\hline 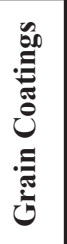 & 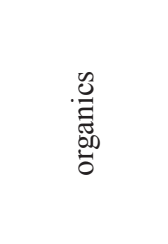 & 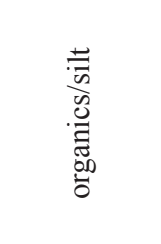 & 营 & 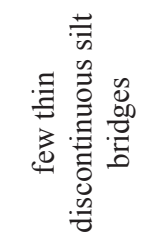 & 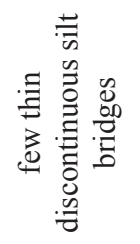 & 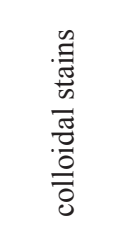 & 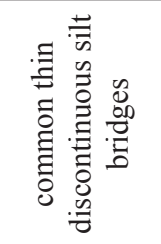 & 节 & 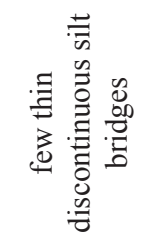 \\
\hline 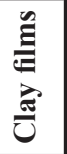 & 0 & 0 & 0 & 0 & 0 & 0 & 0 & 0 & 0 \\
\hline 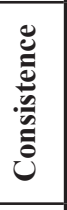 & 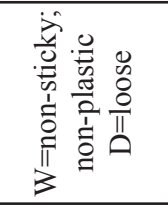 & 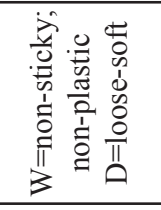 & 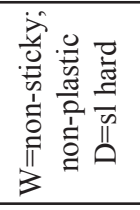 & 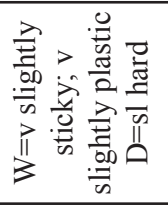 & 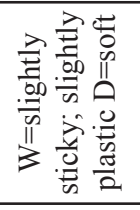 & 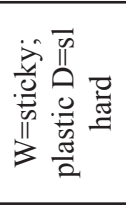 & 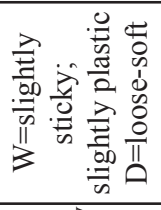 & 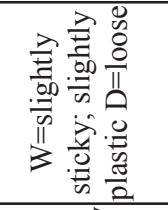 & 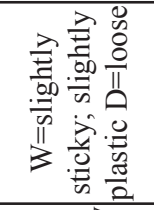 \\
\hline 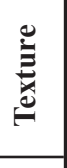 & 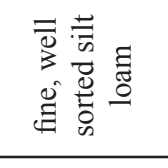 & 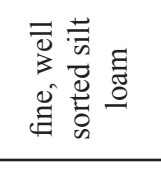 & 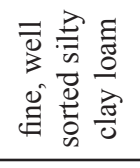 & 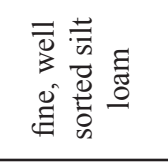 & 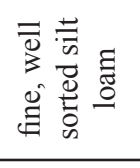 & 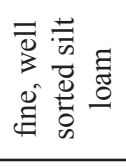 & 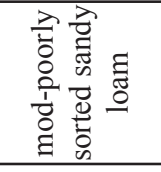 & 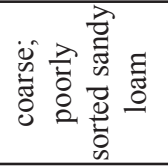 & 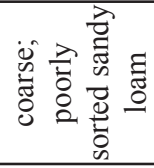 \\
\hline & రొ & Z & Z & 2 & $\frac{\bar{m}}{m}$ & $\frac{\ddot{m}}{m}$ & $\ddot{U}$ & $\underset{\text { D্ }}{\vec{U}}$ & 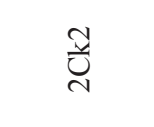 \\
\hline
\end{tabular}




\section{Summary of Geomorphic Observations}

Two general geomorphic areas are represented on 41KM69. Two terraces with only approximately $1 \mathrm{~m}$ elevational differences are present in the area where artifacts and features have been recovered (Figure A-1). The older upper terrace was sampled by BHTs 4-6 and contains artifacts associated with the Bk horizons, two paleosols (Ab1 and Ab2) and some of the C horizon sediments of these profiles. Artifacts were present throughout these profiles. The burned rock midden, Feature 1, is likely associated with the Bk1 horizon. BHTs 7-9 were excavated on the slightly lower terrace to the north. Soils on the southern portion of this terrace, as exposed in BHT 7, are analogous to those formed on upper terrace. The lower position of this surface and association with channel deposits exposed in BHTs 8 and 9, which are overlain by very recent soils, indicate that similar pedogenesis is time transgressive across lower terrace and upper terrace. Artifacts from BHT 7 may be primarily associated with more deeply buried past land surfaces. Because the lower northern terrace is more recent, it is likely that artifacts of comparable age to the materials in the Bk soils of BHTs 4-6 are more deeply buried in the lower terrace unit.

The sediments and soils containing archeological deposits at 41KM69 are fine, well-sorted silt loam deposits with significant integrity. The higher energy deposits seen in BHTs 6, 8, and 9 do not show any disturbances of the artifact bearing deposits exposed in the profiles. Bioturbation was observed only at the base of Feature 1. Despite the bioturbation obscuring definition of the paleosols ( $\mathrm{Ab} 1$ and $\mathrm{Ab} 2)$ in that location, the lower boundary of the midden was distinctive. Recent activity possibly associated with construction and abandonment of the Kimble Courts Hotel has not affected the archeological deposits examined in any significant way. The excellent preservation seen in Feature 2 (artifact associations, dense charcoal, thermally modified soil at the base) also indicates that postdepositional events have had minimal effects on much of the archeological spatial integrity at this site. The fine sediments and lack of erosional features indicate a low probability for significant alluvial movement of artifacts. Geoarcheological investigations indicate that the archeological deposits at 41KM69 probably represent multiple occupations. However, the floodplain context suggests that there is likely good separation between some of these potential occupational events.

\section{Soil Susceptibility Graphs and Raw Data Raymond P. Mauldin}

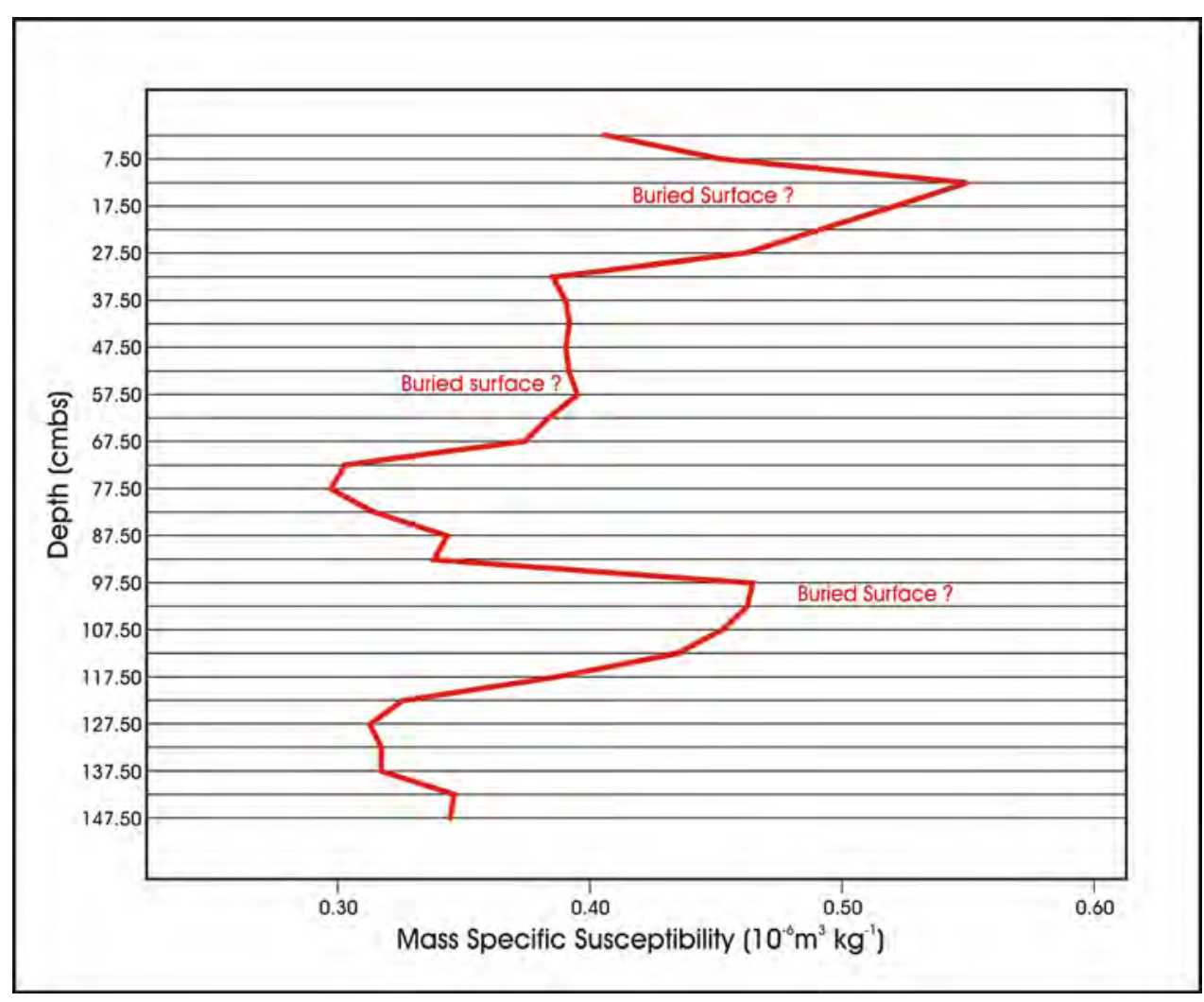

Figure A-8. Soil susceptibility graph showing possible surfaces in BHT 4, west wall profile. 


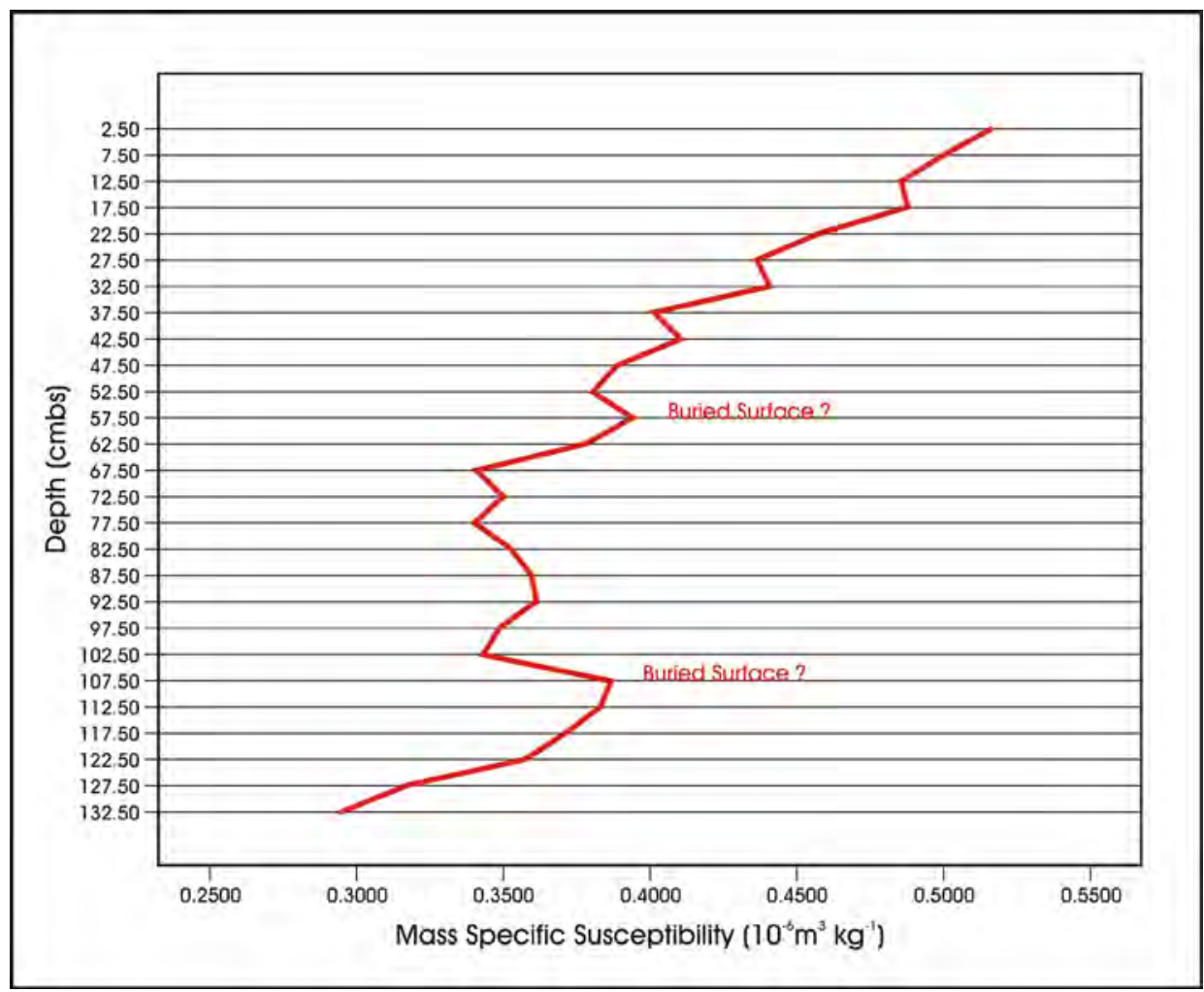

Figure A-9. Soil susceptibility graph showing possible surfaces in BHT 5, south wall profile, $4.27 \mathrm{~m}$ west of east end.

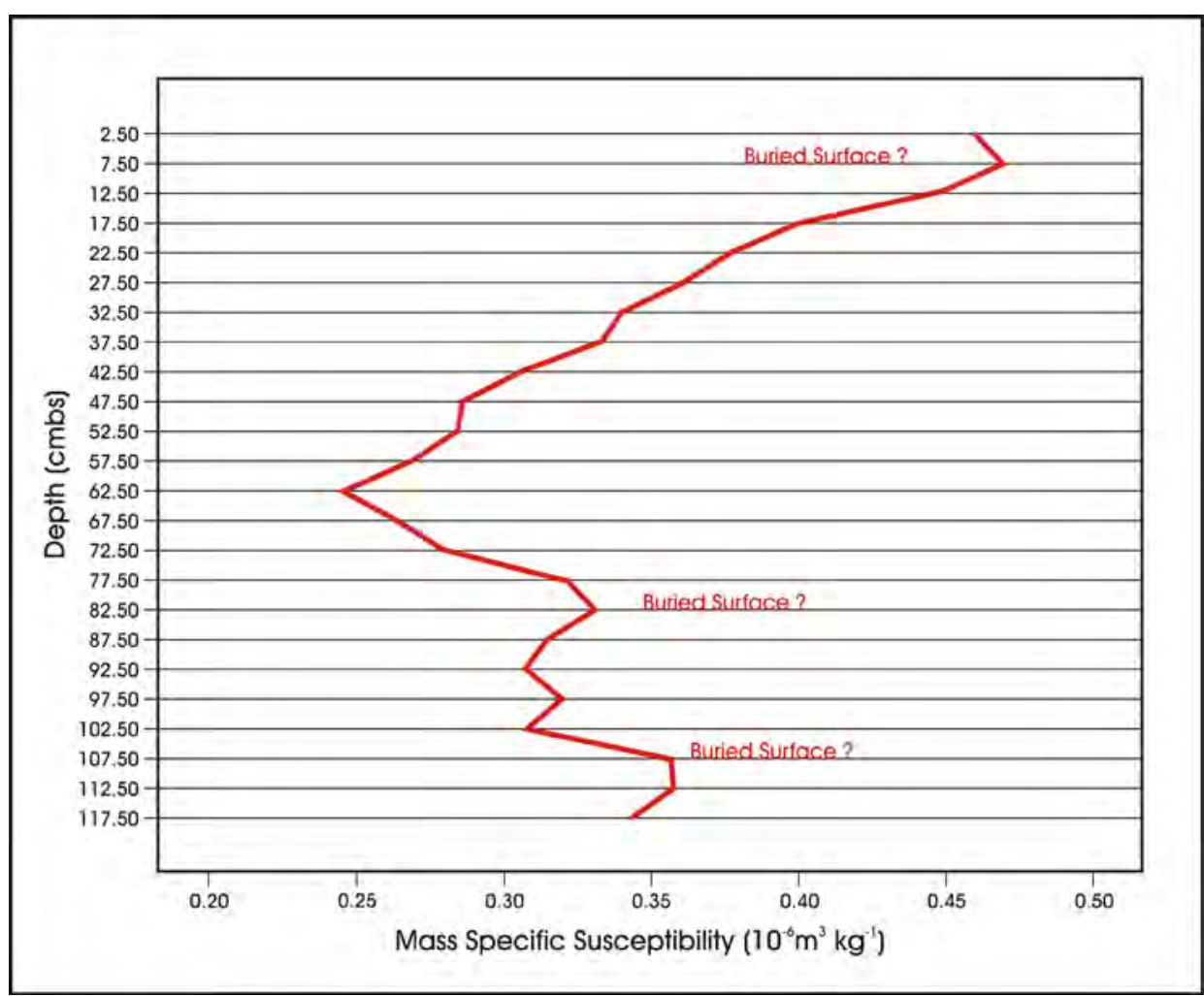

Figure A-10. Soil susceptibility graph showing possible surfaces in BHT 5, south wall profile, $14.78 \mathrm{~m}$ west of east end. 


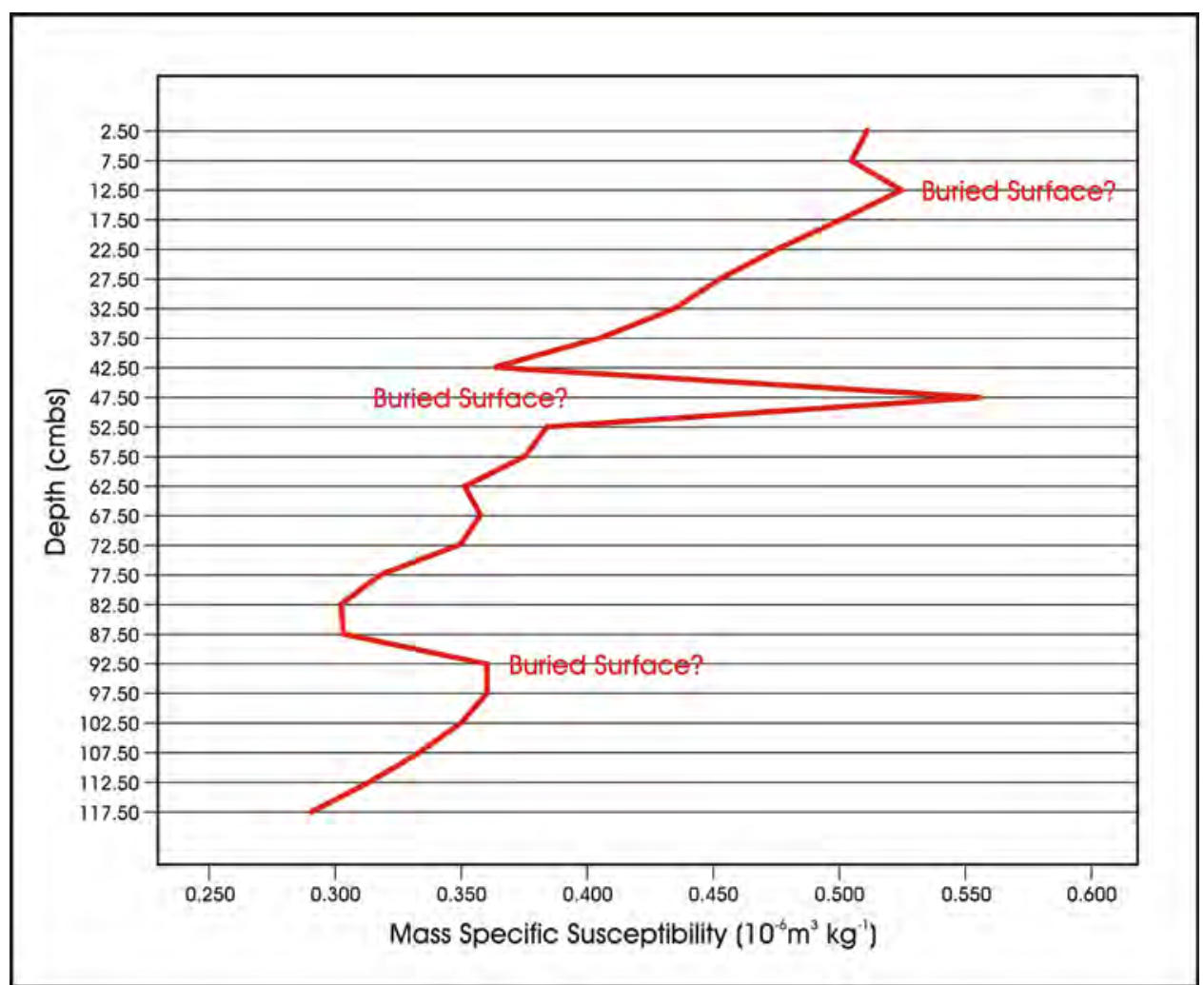

Figure A-11. Soil susceptibility graph showing three possible surfaces in BHT 6, $7 \mathrm{~m}$ from south end.

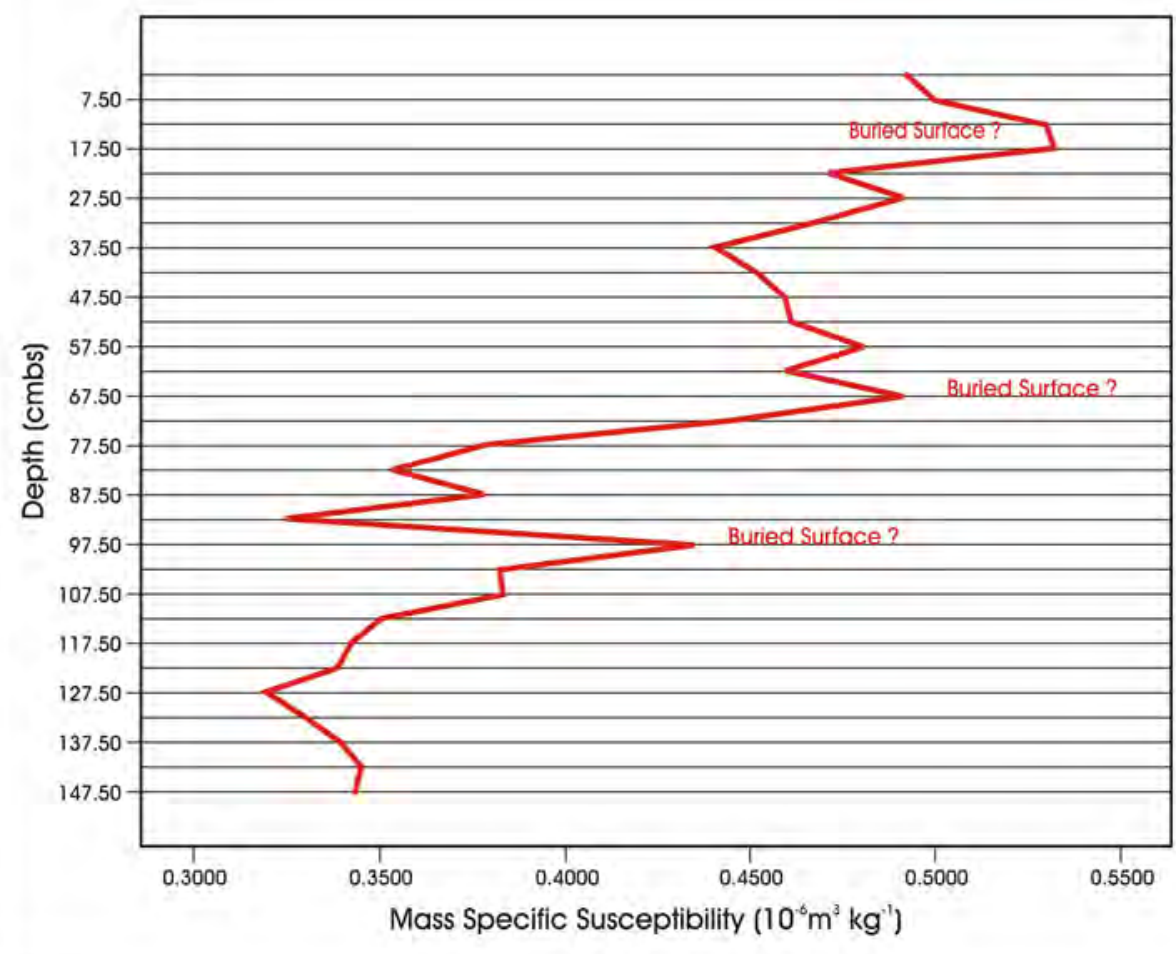

Figure A-12. Soil susceptibility graph showing possible surfaces in BHT 7, west wall profile, $10 \mathrm{~m}$ from south end. 


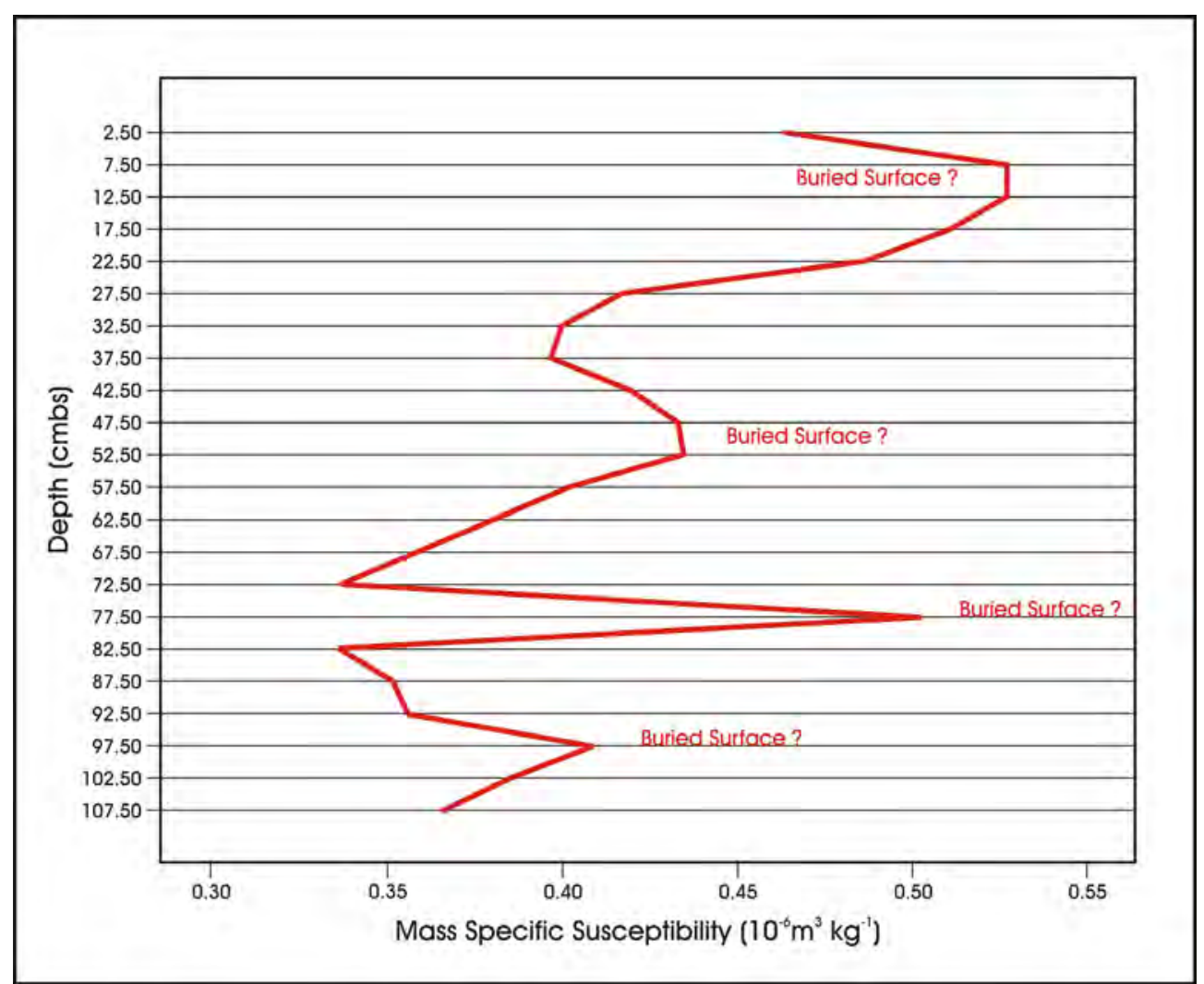

Figure A-13. Soil susceptibility graph showing possible surfaces in BHT 8, 4.7 m from BHT 9/8 intersection.

Table A-4. Magnetic Soil Susceptibility Raw Data

\begin{tabular}{|c|c|c|c|c|c|}
\hline Location & Sample \# & Sample wt. w/o Cube & K (reading) & Mass Specific & Depth \\
\hline BHT $67 \mathrm{~m}$ from south end & 24 & 10.1 & 51.7 & 0.512 & 2.5 \\
\hline BHT $67 \mathrm{~m}$ from south end & 23 & 9.8 & 49.5 & 0.505 & 7.5 \\
\hline BHT $67 \mathrm{~m}$ from south end & 22 & 7.2 & 37.9 & 0.526 & 12.5 \\
\hline BHT $67 \mathrm{~m}$ from south end & 21 & 6.8 & 34.1 & 0.501 & 17.5 \\
\hline BHT $67 \mathrm{~m}$ from south end & 20 & 3.6 & 17.1 & 0.475 & 22.5 \\
\hline BHT $67 \mathrm{~m}$ from south end & 19 & 7.5 & 34 & 0.453 & 27.5 \\
\hline BHT $67 \mathrm{~m}$ from south end & 18 & 8.7 & 37.9 & 0.436 & 32.5 \\
\hline BHT $67 \mathrm{~m}$ from south end & 17 & 4.2 & 17 & 0.405 & 37.5 \\
\hline BHT $67 \mathrm{~m}$ from south end & 16 & 3 & 10.9 & 0.363 & 42.5 \\
\hline BHT $67 \mathrm{~m}$ from south end & 15 & 3.3 & 18.4 & 0.558 & 47.5 \\
\hline BHT $67 \mathrm{~m}$ from south end & 14 & 5 & 19.2 & 0.384 & 52.5 \\
\hline BHT $67 \mathrm{~m}$ from south end & 13 & 5.8 & 21.8 & 0.376 & 57.5 \\
\hline BHT $67 \mathrm{~m}$ from south end & 12 & 4.1 & 14.4 & 0.351 & 62.5 \\
\hline BHT $67 \mathrm{~m}$ from south end & 11 & 8.1 & 29 & 0.358 & 67.5 \\
\hline BHT $67 \mathrm{~m}$ from south end & 10 & 8.4 & 29.4 & 0.35 & 72.5 \\
\hline BHT $67 \mathrm{~m}$ from south end & 9 & 6 & 19.1 & 0.318 & 77.5 \\
\hline BHT $67 \mathrm{~m}$ from south end & 8 & 4.5 & 13.6 & 0.302 & 82.5 \\
\hline BHT $67 \mathrm{~m}$ from south end & 7 & 3 & 9.1 & 0.303 & 87.5 \\
\hline BHT $67 \mathrm{~m}$ from south end & 6 & 5.3 & 19.1 & 0.360 & 92.5 \\
\hline BHT $67 \mathrm{~m}$ from south end & 5 & 6.8 & 24.5 & 0.360 & 97.5 \\
\hline
\end{tabular}


Table A-4. Magnetic Soil Susceptibility Raw Data continued...

\begin{tabular}{|c|c|c|c|c|c|}
\hline Location & Sample \# & Sample wt. w/o Cube & K (reading) & Mass Specific & Depth \\
\hline BHT $67 \mathrm{~m}$ from south end & 4 & 3.2 & 11.2 & 0.35 & 102.5 \\
\hline BHT $67 \mathrm{~m}$ from south end & 3 & 6 & 20 & 0.333 & 107.5 \\
\hline BHT $67 \mathrm{~m}$ from south end & 2 & 5.7 & 17.9 & 0.314 & 112.5 \\
\hline BHT $67 \mathrm{~m}$ from south end & 1 & 6.4 & 18.6 & 0.291 & 117.5 \\
\hline BHT 5 S. wall Profile, $4.27 \mathrm{~m}$ west of east end & 27 & 8.9 & 46 & 0.517 & 2.5 \\
\hline BHT 5 S. wall Profile, $4.27 \mathrm{~m}$ west of east end & 26 & 9.7 & 48.5 & 0.5 & 7.5 \\
\hline BHT 5 S. wall Profile, $4.27 \mathrm{~m}$ west of east end & 25 & 10.4 & 50.5 & 0.486 & 12.5 \\
\hline BHT 5 S. wall Profile, $4.27 \mathrm{~m}$ west of east end & 24 & 6.7 & 32.7 & 0.488 & 17.5 \\
\hline BHT 5 S. wall Profile, $4.27 \mathrm{~m}$ west of east end & 23 & 10.2 & 46.6 & 0.457 & 22.5 \\
\hline BHT 5 S. wall Profile, $4.27 \mathrm{~m}$ west of east end & 22 & 10.5 & 45.8 & 0.436 & 27.5 \\
\hline BHT 5 S. wall Profile, $4.27 \mathrm{~m}$ west of east end & 21 & 9.7 & 42.8 & 0.441 & 32.5 \\
\hline BHT 5 S. wall Profile, $4.27 \mathrm{~m}$ west of east end & 20 & 9.7 & 38.9 & 0.401 & 37.5 \\
\hline BHT 5 S. wall Profile, $4.27 \mathrm{~m}$ west of east end & 19 & 9.4 & 38.6 & 0.411 & 42.5 \\
\hline BHT 5 S. wall Profile, $4.27 \mathrm{~m}$ west of east end & 18 & 9.9 & 38.5 & 0.389 & 47.5 \\
\hline BHT 5 S. wall Profile, $4.27 \mathrm{~m}$ west of east end & 17 & 9.5 & 36.1 & 0.38 & 52.5 \\
\hline BHT 5 S. wall Profile, $4.27 \mathrm{~m}$ west of east end & 16 & 9.4 & 37.1 & 0.395 & 57.5 \\
\hline BHT 5 S. wall Profile, $4.27 \mathrm{~m}$ west of east end & 15 & 9.5 & 36 & 0.379 & 62.5 \\
\hline BHT 5 S. wall Profile, $4.27 \mathrm{~m}$ west of east end & 14 & 10 & 34 & 0.34 & 67.5 \\
\hline BHT 5 S. wall Profile, $4.27 \mathrm{~m}$ west of east end & 13 & 8.6 & 30.1 & 0.35 & 72.5 \\
\hline BHT 5 S. wall Profile, $4.27 \mathrm{~m}$ west of east end & 12 & 6.8 & 23.1 & 0.340 & 77.5 \\
\hline BHT 5 S. wall Profile, $4.27 \mathrm{~m}$ west of east end & 11 & 9.3 & 32.8 & 0.353 & 82.5 \\
\hline BHT 5 S. wall Profile, $4.27 \mathrm{~m}$ west of east end & 10 & 7.9 & 28.4 & 0.359 & 87.5 \\
\hline BHT 5 S. wall Profile, $4.27 \mathrm{~m}$ west of east end & 9 & 10 & 36.1 & 0.361 & 92.5 \\
\hline BHT 5 S. wall Profile, $4.27 \mathrm{~m}$ west of east end & 8 & 8.3 & 28.9 & 0.348 & 97.5 \\
\hline BHT 5 S. wall Profile, $4.27 \mathrm{~m}$ west of east end & 7 & 10.1 & 34.6 & 0.343 & 102.5 \\
\hline BHT 5 S. wall Profile, $4.27 \mathrm{~m}$ west of east end & 6 & 10.1 & 39.1 & 0.387 & 107.5 \\
\hline BHT 5 S. wall Profile, $4.27 \mathrm{~m}$ west of east end & 5 & 9.3 & 35.6 & 0.383 & 112.5 \\
\hline BHT 5 S. wall Profile, $4.27 \mathrm{~m}$ west of east end & 4 & 8 & 29.6 & 0.37 & 117.5 \\
\hline BHT 5 S. wall Profile, $4.27 \mathrm{~m}$ west of east end & 3 & 7.6 & 27.1 & 0.357 & 122.5 \\
\hline BHT 5 S. wall Profile, $4.27 \mathrm{~m}$ west of east end & 2 & 6.8 & 21.5 & 0.316 & 127.5 \\
\hline BHT 5 S. wall Profile, $4.27 \mathrm{~m}$ west of east end & 1 & 11.4 & 33.5 & 0.294 & 132.5 \\
\hline BHT $710 \mathrm{~m}$ from south end of west wall & 1 & 5.3 & 18.2 & 0.343 & 147.5 \\
\hline BHT 7 10m from south end of west wall & 2 & 6.4 & 22.1 & 0.345 & 142.5 \\
\hline BHT 7 10m from south end of west wall & 3 & 3.8 & 12.9 & 0.339 & 137.5 \\
\hline BHT $710 \mathrm{~m}$ from south end of west wall & 4 & 3 & 9.9 & 0.33 & 132.5 \\
\hline BHT 7 10m from south end of west wall & 5 & 3.7 & 11.8 & 0.319 & 127.5 \\
\hline BHT $710 \mathrm{~m}$ from south end of west wall & 6 & 2.6 & 8.8 & 0.338 & 122.5 \\
\hline BHT 7 10m from south end of west wall & 7 & 4.7 & 16.1 & 0.343 & 117.5 \\
\hline BHT 7 10m from south end of west wall & 8 & 3.4 & 11.9 & 0.35 & 112.5 \\
\hline BHT $710 \mathrm{~m}$ from south end of west wall & 9 & 3.6 & 13.8 & 0.383 & 107.5 \\
\hline BHT 7 10m from south end of west wall & 10 & 3.9 & 14.9 & 0.382 & 102.5 \\
\hline BHT $710 \mathrm{~m}$ from south end of west wall & 11 & 6.4 & 27.9 & 0.436 & 97.5 \\
\hline BHT $710 \mathrm{~m}$ from south end of west wall & 12 & 3.8 & 12.3 & 0.324 & 92.5 \\
\hline
\end{tabular}


Table A-4. Magnetic Soil Susceptibility Raw Data continued...

\begin{tabular}{|c|c|c|c|c|c|}
\hline Location & Sample \# & Sample wt. w/o Cube & K (reading) & Mass Specific & Depth \\
\hline BHT $710 \mathrm{~m}$ from south end of west wall & 13 & 4.9 & 18.6 & 0.380 & 87.5 \\
\hline BHT $710 \mathrm{~m}$ from south end of west wall & 14 & 6.8 & 24 & 0.353 & 82.5 \\
\hline BHT $710 \mathrm{~m}$ from south end of west wall & 15 & 4.9 & 18.6 & 0.380 & 77.5 \\
\hline BHT $710 \mathrm{~m}$ from south end of west wall & 16 & 3.3 & 14.7 & 0.445 & 72.5 \\
\hline BHT $710 \mathrm{~m}$ from south end of west wall & 17 & 7.9 & 38.9 & 0.492 & 67.5 \\
\hline BHT $710 \mathrm{~m}$ from south end of west wall & 18 & 4.9 & 22.5 & 0.459 & 62.5 \\
\hline BHT $710 \mathrm{~m}$ from south end of west wall & 19 & 4.3 & 20.7 & 0.481 & 57.5 \\
\hline BHT $710 \mathrm{~m}$ from south end of west wall & 20 & 3.6 & 16.6 & 0.461 & 52.5 \\
\hline BHT $710 \mathrm{~m}$ from south end of west wall & 21 & 6.7 & 30.8 & 0.460 & 47.5 \\
\hline BHT $710 \mathrm{~m}$ from south end of west wall & 22 & 4.8 & 21.7 & 0.452 & 42.5 \\
\hline BHT $710 \mathrm{~m}$ from south end of west wall & 23 & 4.7 & 20.7 & 0.440 & 37.5 \\
\hline BHT $710 \mathrm{~m}$ from south end of west wall & 24 & 5.3 & 24.8 & 0.468 & 32.5 \\
\hline BHT $710 \mathrm{~m}$ from south end of west wall & 25 & 5.3 & 26.1 & 0.492 & 27.5 \\
\hline BHT $710 \mathrm{~m}$ from south end of west wall & 26 & 2.7 & 12.7 & 0.470 & 22.5 \\
\hline BHT $710 \mathrm{~m}$ from south end of west wall & 27 & 8.9 & 47.4 & 0.533 & 17.5 \\
\hline BHT $710 \mathrm{~m}$ from south end of west wall & 28 & 6 & 31.8 & 0.53 & 12.5 \\
\hline BHT $710 \mathrm{~m}$ from south end of west wall & 29 & 4.9 & 24.5 & 0.5 & 7.5 \\
\hline BHT $710 \mathrm{~m}$ from south end of west wall & 30 & 6.5 & 32 & 0.492 & 2.5 \\
\hline BHT 5 S. Wall Profile, $14.78 \mathrm{~m}$ west of east end & 1 & 9.7 & 33.3 & 0.343 & 117.5 \\
\hline BHT 5 S. Wall Profile, $14.78 \mathrm{~m}$ west of east end & 2 & 9.2 & 32.9 & 0.358 & 112.5 \\
\hline BHT 5 S. Wall Profile, $14.78 \mathrm{~m}$ west of east end & 3 & 9.6 & 34.3 & 0.357 & 107.5 \\
\hline BHT 5 S. Wall Profile, $14.78 \mathrm{~m}$ west of east end & 4 & 10.3 & 31.6 & 0.307 & 102.5 \\
\hline BHT 5 S. Wall Profile, $14.78 \mathrm{~m}$ west of east end & 5 & 7.8 & 25 & 0.321 & 97.5 \\
\hline BHT 5 S. Wall Profile, $14.78 \mathrm{~m}$ west of east end & 6 & 5.8 & 17.8 & 0.307 & 92.5 \\
\hline BHT 5 S. Wall Profile, $14.78 \mathrm{~m}$ west of east end & 7 & 9.2 & 28.9 & 0.314 & 87.5 \\
\hline BHT 5 S. Wall Profile, $14.78 \mathrm{~m}$ west of east end & 8 & 10.3 & 34.2 & 0.332 & 82.5 \\
\hline BHT 5 S. Wall Profile, $14.78 \mathrm{~m}$ west of east end & 9 & 7 & 22.5 & 0.321 & 77.5 \\
\hline BHT 5 S. Wall Profile, $14.78 \mathrm{~m}$ west of east end & 10 & 8.4 & 23.5 & 0.280 & 72.5 \\
\hline BHT 5 S. Wall Profile, $14.78 \mathrm{~m}$ west of east end & 11 & 10.7 & 28.2 & 0.264 & 67.5 \\
\hline BHT 5 S. Wall Profile, $14.78 \mathrm{~m}$ west of east end & 12 & 10.3 & 25.2 & 0.245 & 62.5 \\
\hline BHT 5 S. Wall Profile, $14.78 \mathrm{~m}$ west of east end & 13 & 10.6 & 28.5 & 0.269 & 57.5 \\
\hline BHT 5 S. Wall Profile, $14.78 \mathrm{~m}$ west of east end & 14 & 10.2 & 29 & 0.284 & 52.5 \\
\hline BHT 5 S. Wall Profile, $14.78 \mathrm{~m}$ west of east end & 15 & 10.2 & 29.2 & 0.286 & 47.5 \\
\hline BHT 5 S. Wall Profile, $14.78 \mathrm{~m}$ west of east end & 16 & 11.2 & 34.3 & 0.306 & 42.5 \\
\hline BHT 5 S. Wall Profile, $14.78 \mathrm{~m}$ west of east end & 17 & 11.1 & 37 & 0.333 & 37.5 \\
\hline BHT 5 S. Wall Profile, $14.78 \mathrm{~m}$ west of east end & 18 & 10.7 & 36.4 & 0.340 & 32.5 \\
\hline BHT 5 S. Wall Profile, $14.78 \mathrm{~m}$ west of east end & 19 & 10.8 & 39 & 0.361 & 27.5 \\
\hline BHT 5 S. Wall Profile, $14.78 \mathrm{~m}$ west of east end & 20 & 11.1 & 41.8 & 0.377 & 22.5 \\
\hline BHT 5 S. Wall Profile, $14.78 \mathrm{~m}$ west of east end & 21 & 10.8 & 43.3 & 0.401 & 17.5 \\
\hline BHT 5 S. Wall Profile, $14.78 \mathrm{~m}$ west of east end & 22 & 10.5 & 47 & 0.448 & 12.5 \\
\hline BHT 5 S. Wall Profile, $14.78 \mathrm{~m}$ west of east end & 23 & 10.8 & 50.8 & 0.470 & 7.5 \\
\hline BHT 5 S. Wall Profile, $14.78 \mathrm{~m}$ west of east end & 24 & 11.4 & 52.5 & 0.461 & 2.5 \\
\hline BHT $84.7 \mathrm{~m}$ from BHT $9 / 8$ intersection & 1 & 5.5 & 20.1 & 0.365 & 107.5 \\
\hline
\end{tabular}


Table A-4. Magnetic Soil Susceptibility Raw Data continued...

\begin{tabular}{|c|c|c|c|c|c|}
\hline Location & Sample \# & Sample wt. w/o Cube & K (reading) & Mass Specific & Depth \\
\hline BHT 8 4.7m from BHT 9/8 intersection & 2 & 6.2 & 23.9 & 0.385 & 102.5 \\
\hline BHT $84.7 \mathrm{~m}$ from BHT 9/8 intersection & 3 & 7 & 28.6 & 0.409 & 97.5 \\
\hline BHT $84.7 \mathrm{~m}$ from BHT 9/8 intersection & 4 & 2.5 & 8.9 & 0.356 & 92.5 \\
\hline BHT $84.7 \mathrm{~m}$ from BHT 9/8 intersection & 5 & 6.8 & 23.9 & 0.351 & 87.5 \\
\hline BHT 8 4.7m from BHT 9/8 intersection & 6 & 9.3 & 31.3 & 0.337 & 82.5 \\
\hline BHT 8 4.7m from BHT 9/8 intersection & 7 & 6.9 & 34.7 & 0.503 & 77.5 \\
\hline BHT 8 4.7m from BHT 9/8 intersection & 8 & 6.9 & 23.2 & 0.336 & 72.5 \\
\hline BHT $84.7 \mathrm{~m}$ from BHT 9/8 intersection & 9 & 9 & 32.4 & 0.36 & 67.5 \\
\hline BHT 8 4.7m from BHT 9/8 intersection & 10 & 3.4 & 13 & 0.382 & 62.5 \\
\hline BHT $84.7 \mathrm{~m}$ from BHT 9/8 intersection & 11 & 4.2 & 16.9 & 0.402 & 57.5 \\
\hline BHT 8 4.7m from BHT 9/8 intersection & 12 & 4 & 17.4 & 0.435 & 52.5 \\
\hline BHT $84.7 \mathrm{~m}$ from BHT 9/8 intersection & 13 & 5.7 & 24.7 & 0.433 & 47.5 \\
\hline BHT $84.7 \mathrm{~m}$ from BHT 9/8 intersection & 14 & 5.5 & 23.1 & 0.42 & 42.5 \\
\hline BHT $84.7 \mathrm{~m}$ from BHT 9/8 intersection & 15 & 6.4 & 25.4 & 0.397 & 37.5 \\
\hline BHT $84.7 \mathrm{~m}$ from BHT 9/8 intersection & 16 & 5.2 & 20.8 & 0.4 & 32.5 \\
\hline BHT 8 4.7m from BHT 9/8 intersection & 17 & 7.9 & 32.9 & 0.416 & 27.5 \\
\hline BHT $84.7 \mathrm{~m}$ from BHT 9/8 intersection & 18 & 7.7 & 37.5 & 0.487 & 22.5 \\
\hline BHT $84.7 \mathrm{~m}$ from BHT 9/8 intersection & 19 & 6.5 & 33.2 & 0.511 & 17.5 \\
\hline BHT 8 4.7m from BHT 9/8 intersection & 20 & 8.8 & 46.4 & 0.527 & 12.5 \\
\hline BHT $84.7 \mathrm{~m}$ from BHT 9/8 intersection & 21 & 9.1 & 48 & 0.527 & 7.5 \\
\hline BHT 8 4.7m from BHT 9/8 intersection & 22 & 9.2 & 42.6 & 0.463 & 2.5 \\
\hline BHT 4 west wall & 1 & 11.9 & 41 & 0.345 & 147.5 \\
\hline BHT 4 west wall & 2 & 9.6 & 33.3 & 0.347 & 142.5 \\
\hline BHT 4 west wall & 3 & 4 & 12.7 & 0.318 & 137.5 \\
\hline BHT 4 west wall & 4 & 4.5 & 14.3 & 0.318 & 132.5 \\
\hline BHT 4 west wall & 5 & 5.6 & 17.5 & 0.313 & 127.5 \\
\hline BHT 4 west wall & 6 & 10 & 32.5 & 0.325 & 122.5 \\
\hline BHT 4 west wall & 7 & 10.1 & 38.7 & 0.383 & 117.5 \\
\hline BHT 4 west wall & 8 & 7.9 & 34.4 & 0.435 & 112.5 \\
\hline BHT 4 west wall & 9 & 9.4 & 42.5 & 0.452 & 107.5 \\
\hline BHT 4 west wall & 10 & 10.2 & 47.2 & 0.463 & 102.5 \\
\hline BHT 4 west wall & 11 & 7.6 & 35.4 & 0.466 & 97.5 \\
\hline BHT 4 west wall & 12 & 10.4 & 35.2 & 0.338 & 92.5 \\
\hline BHT 4 west wall & 13 & 11.2 & 38.5 & 0.344 & 87.5 \\
\hline BHT 4 west wall & 14 & 10.7 & 33.7 & 0.315 & 82.5 \\
\hline BHT 4 west wall & 15 & 10.5 & 31.2 & 0.297 & 77.5 \\
\hline BHT 4 west wall & 16 & 10.3 & 31.2 & 0.303 & 72.5 \\
\hline BHT 4 west wall & 17 & 9.8 & 36.6 & 0.373 & 67.5 \\
\hline BHT 4 west wall & 18 & 9.3 & 35.7 & 0.384 & 62.5 \\
\hline BHT 4 west wall & 19 & 9.8 & 38.8 & 0.396 & 57.5 \\
\hline BHT 4 west wall & 20 & 10.3 & 40.4 & 0.392 & 52.5 \\
\hline BHT 4 west wall & 21 & 8.7 & 34 & 0.391 & 47.5 \\
\hline BHT 4 west wall & 22 & 9.5 & 37.3 & 0.393 & 42.5 \\
\hline
\end{tabular}


Table A-4. Magnetic Soil Susceptibility Raw Data continued....

\begin{tabular}{|c|c|c|c|c|c|}
\hline Location & Sample \# & Sample wt. w/o Cube & K (reading) & Mass Specific & Depth \\
\hline BHT 4 west wall & 23 & 11.3 & 44.2 & 0.391 & 37.5 \\
\hline BHT 4 west wall & 24 & 10.9 & 42 & 0.385 & 32.5 \\
\hline BHT 4 west wall & 25 & 8.1 & 37.3 & 0.460 & 27.5 \\
\hline BHT 4 west wall & 26 & 5.4 & 26.4 & 0.489 & 22.5 \\
\hline BHT 4 west wall & 27 & 6.3 & 33 & 0.524 & 17.5 \\
\hline BHT 4 west wall & 28 & 2.9 & 16 & 0.552 & 12.5 \\
\hline BHT 4 west wall & 29 & 6.8 & 30.7 & 0.451 & 7.5 \\
\hline BHT 4 west wall & 30 & 1.7 & 6.9 & 0.406 & 2.5 \\
\hline
\end{tabular}



Appendix B:

Vertebrate Faunal Remains at 41KM69

Barbara A. Meissner 



\title{
Appendix B
}

\section{Vertebrate Faunal Remains at 41KM69}

\author{
Barbara A. Meissner
}

A total of 1,651 vertebrate bones, weighing 2,485.98 g, was collected during the excavation. In general, the bone was sparse and highly fragmented, with an average bone weight of only $1.5 \mathrm{~g}$. In addition, bone preservation at the site does not appear to be very good. Many (though not all) bones showed severe damage due to chemical weathering as a result of microorganism activity.

The high rate of fragmentation and other taphonomic factors resulted in only 126 (7.6 percent) bones identified to the Genus taxonomic level (see Table B-1). Only 177 (10.7 percent) could be identified even to the Order taxonomic level. Eleven genera were identified, nine mammals, one bird, the Golden Eagle (Aquila chrysaetos), and one fish, the Channel Catfish (Ictalurus sp.).

Unfortunately, the two most commonly identified species were the Nine-Banded Armadillo (Dasypus novemcinctus) and the Blacktailed Prairie Dog (Cynomys ludivicianus). These two species, which composed 79.4 percent (100/126) of the bone identified to the Genus taxonomic level, are problematic. The armadillo is known to have begun its invasion of Texas in the early nineteenth century, and as late as 1860 , it was only found in the southern-most part of the state, in areas closely adjacent to the Rio Grande (Weniger 1997:128). Thus, the 67 armadillo bones identified in this collection cannot be used in an analysis of prehistoric diet at 41KM69.

The presence of 33 C. ludivicianus bones in the site is unsurprising. Extensive burrowing in Area 3 was revealed during excavations of units west of the burned rock midden. Weighing between 1 and 2 kilograms and living in large colonies (Davis and Schmidly1994:112), there is no question that prairie dogs could constitute a usable, though possibly low-ranked, meat resource. However, while they almost certainly inhabited the site or adjacent areas in the prehistoric past (see Weniger 1997:135), those remains identified at the site are modern as all came from the units containing dens (J. Thompson, personal communication 2007).

\section{Methods}

The bone from 41KM69 was returned to the CAR lab bagged with other ecofacts and artifacts from the same unit and level. The bone was washed in tap water and brushed lightly with soft brushes when needed, to remove dirt from the bone surface. Dirt in the interior of bones, such as the medullary cavity, was removed carefully using bamboo skewers, and occasionally, dental tools. Bone was then allowed to air dry, and was placed in bags by unit and level along with acid free paper tags containing full provenience information.

During analysis, the bone was identified to the most specific taxon possible using the comparative collection at CAR, as well as several reference texts (Balkwill and Cumbaa 1992; Boessneck 1970, Gilbert 1990; Gilbert et al. 1981; Hildebrand 1955, Hillson 1986; Olsen 1960, 1964, 1968; Sobolik and Steele 1996). Taxonomic names used were those defined in the Integrated Taxonomic Information System (ITIS 2007).

Identifications were conservative, i.e., bone that appeared to be bison-sized was not identified as Bison bison unless it could be differentiated from cattle (Bos) and horse (Equus). During the analysis of the bone, certain characteristics were noted when possible. Table B-2 describes these characteristics. When analysis was complete, bone was bagged by taxon and then by provenience. In each bag an acid-free paper tag with provenience information, the taxon, count and weight listed. The data were entered into a site database designed using Microsoft Access ${ }^{\circledR}$ and quality control measures were used to ensure that these data were accurate.

In order to compare differences in animal resource use over time at the site, given that, the highly fragmented bone made identification of genera and species largely impossible, all mammal and bird bone was identified by body size when possible (see Category descriptions in Table B-2). For example, both identified Whitetailed Deer (Odocoileus virginianus), and bone that 
Table B-1. 41KM69 Identified Genera

\begin{tabular}{|c|c|c|c|}
\hline Taxon & Common Name & Ct. & Wgt. (g) \\
\hline Bison bison & American bison & 1 & 62 \\
\hline Odocoileus virginianus & White-tailed deer & 9 & 46.76 \\
\hline Bovinae & Cattle or bison & 5 & 142.05 \\
\hline \multirow[t]{2}{*}{ Artiodactyl } & Deer, sheep, goats & 19 & 46.32 \\
\hline & Total Order Artiodactyla & 34 & 297.13 \\
\hline \multirow[t]{2}{*}{ Procyon lotor } & Raccoon & 5 & 7.46 \\
\hline & Total Order Carnivora & 5 & 7.46 \\
\hline \multirow[t]{2}{*}{ Didelphis virginiana } & Opossum & 1 & 1.26 \\
\hline & Total Order Didelphimorphia & 1 & 1.26 \\
\hline Sylvilagus sp. & Cottontail rabbit & 3 & 1.79 \\
\hline \multirow[t]{2}{*}{ Lepus californicus } & Blacktailed jackrabbit & 1 & 0.7 \\
\hline & Total Order Lagomorpha & 4 & 2.49 \\
\hline Cynomys ludivicianus & Blacktailed prairiedog & 33 & 29.59 \\
\hline Geomys sp. & Pocket gopher & 1 & 0.18 \\
\hline \multirow[t]{2}{*}{ Rodentia } & Rodents & 9 & 0.99 \\
\hline & Total Order Rodentia & 43 & 30.76 \\
\hline \multirow[t]{2}{*}{ Dasypus novemcinctus } & Armadillo & 67 & 36.1 \\
\hline & Total Order Xenarthra & 67 & 36.1 \\
\hline Mammal--V. lg. & Cattle, bison, horse-sized & 451 & $1,676.25$ \\
\hline Mammal--lg. & Deer, sheep-sized & 462 & 312.61 \\
\hline Mammal--med. & Dog-sized & 26 & 7.02 \\
\hline Mammal--sm. & Rabbit-sized & 13 & 1.47 \\
\hline Mammal--Vsm & Rat, mice-sized & 2 & 0.12 \\
\hline \multirow[t]{2}{*}{ Mammal } & Size indeterminate & 426 & 76.86 \\
\hline & Total Mammalia & 1,534 & $2,449.53$ \\
\hline \multirow[t]{2}{*}{ Aquila chrysaetos } & Golden eagle & 1 & 0.75 \\
\hline & Total Order Ciconiiformes & 1 & 0.75 \\
\hline Aves--very large & Turkey, hawk-sized & 2 & 1.34 \\
\hline Aves--large & Chicken-sized & 79 & 15.85 \\
\hline Aves--medium & Pigeon-sized & 2 & 0.21 \\
\hline \multirow[t]{2}{*}{ Aves } & Size indeterminate & 1 & 0.17 \\
\hline & Total Aves & 85 & 18.32 \\
\hline Emydidae & Pond sliders, painted \& box turtles, terrapins & 5 & 10.66 \\
\hline \multirow[t]{2}{*}{ Testudines } & Unidentified Turtles & 12 & 3.42 \\
\hline & Total Order Testudines & 17 & 14.08 \\
\hline \multirow[t]{3}{*}{ Viperidae } & Poisonous snakes & 1 & 0.13 \\
\hline & Total Order Squamata & 1 & 0.13 \\
\hline & Total Reptilia & 18 & 14.21 \\
\hline \multirow[t]{2}{*}{ Ictalurus sp. } & Channel catfish & 4 & 1.87 \\
\hline & Total Order Siluriformes & 4 & 1.87 \\
\hline \multirow[t]{2}{*}{ Actinopterygii } & Unidentified boney fish & 8 & 1.31 \\
\hline & Total Actinopterygii & 12 & 3.18 \\
\hline \multirow[t]{2}{*}{ Vertebrata } & Unidentifed bone & 2 & 0.74 \\
\hline & Overall Total & 1,651 & $2,485.98$ \\
\hline
\end{tabular}


Table B-2. Category Descriptions of Vertebrate Faunal Analysis Used in TablesB-3 and B-4

\begin{tabular}{|c|c|}
\hline Data Collected & Details \\
\hline Provenience & \\
\hline Count & \\
\hline Weight $(\mathrm{g})$ & \\
\hline Taxon & Most specific possible \\
\hline Body Size & $\begin{array}{l}\text { Mammals: } \\
\text { VSm = Mouse to Rat-sized } \\
\text { Sm = Squirrel to Fox-sized } \\
\text { Med = Armadillo to Javelina-sized } \\
\text { Lg = Pronghorn to Whitetailed Deer-sized } \\
\text { VLg = Bison-sized } \\
\text { I = Indeterminate: Body size could not be estimated. } \\
\text { Birds: } \\
\text { VSm = Hummingbird to Sparrow-sized } \\
\text { Sm = Mockingbird to Robin-sized } \\
\text { Med = Pidgeon to Crow-sized } \\
\text { Lg = Duck to Goose-sized } \\
\text { VLg = Turkey, heron, eagle-sized } \\
\text { I = Indeterminate: Body size could not be estimated. }\end{array}$ \\
\hline Element & Only noted for bone identifid to at least the Order taxonomic level \\
\hline Portion & Complete, or specific fragment of element (if noted) \\
\hline $\begin{array}{l}\text { Chemical } \\
\text { Weathering } \\
\text { (The result of } \\
\text { acid etching by } \\
\text { microorganisms) }\end{array}$ & $\begin{array}{l}\mathrm{N}=\text { None observed } \\
\mathrm{S} \text { = Slight: a scatter of round or oval, flat-bottomed pits on bone surface } \\
\mathrm{M}=\text { Moderate: pits are more numerous, somewhat larger, and extend over more of the surface of bone, but some of } \\
\text { the original bone surface remains and overall shape has not been changed. } \\
\mathrm{E}=\text { Extensive: Deep pits cover entire bone surface, eradicating all of original bone surface. Bone has a "chewed" } \\
\text { look and overall shape has been changed. } \\
\mathrm{I}=\text { Indeterminate: degree of weathering could not be determined. }\end{array}$ \\
\hline $\begin{array}{l}\text { Atmospheric } \\
\text { Weathering } \\
\text { (The result of rapid } \\
\text { wetting and drying } \\
\text { and exposure to the } \\
\text { sun while on the } \\
\text { ground surface) }\end{array}$ & $\begin{array}{l}\mathrm{N} \text { = None observed } \\
\mathrm{S} \text { = Slight: a few thin longitudinal cracks } \\
\mathrm{M} \text { = Moderate: longitudinal cracks are longer and deeper and bone surface appears bleached or worn } \\
\mathrm{E} \text { = Extensive: longitudinal cracks extend through entire thickness of cortex, and cross-cracks are present. Surface } \\
\text { is very rough, and appears bleached or worn, and in some cases has exfoliated } \\
\mathrm{I} \text { = Indeterminate: degree of weathering could not be determined. }\end{array}$ \\
\hline Burned? & Yes or No \\
\hline Complete? & Yes or No \\
\hline Fractures & $\begin{array}{l}\mathrm{N} \text { = None observed (bone is complete) } \\
\text { Green = Fractured while bone was fresh--presumably the result of human action. } \\
\text { Dry = Fractured after bone has dried and all easily decomposed organic residue is gone--presumably the result } \\
\text { of trampling, weight of overlying sediment and/or pressure from shrinking and swelling of clay sediment, or } \\
\text { disturbance after burial, including the excavation and screening process. } \\
\mathrm{I} \text { = Indeterminate: kind of break could not be determined. }\end{array}$ \\
\hline Butcher Marks? & Yes or No \\
\hline Notes & Description of butcher marks, evidence of immaturity, or anything else of interest \\
\hline
\end{tabular}


could only be identified as Large Mammal, were grouped together. When these data are grouped by the estimated Time Period of each level in the site, it will be possible to note changes.

The other data collected will also be integrated into the analysis. When the project is complete, the faunal material will be curated at CAR. Tables 7 and 8 at the end of this document list the complete data sets collected from the vertebrate fauna recovered during the significance testing and data recovery phases respectively at 41KM69.

\section{Faunal and Feature Distribution at 41KM69}

Few faunal remains were found in direct relationship to thermal features at 41KM69. Only those features that were excavated with the same methodology as the faunal sample, i.e. in systematic block excavations, are included here. This removes features recorded during Gradall monitoring from the discussion. Though they can be incorporated into a broader discussion, because no bone was found while excavating these features, they are excluded.

Faunal remains from both Significance Testing and Data Recovery were analyzed (Tables B-3 and B-4), however, only a portion of the Significance Testing data was compatible with the subsequent excavations. Some test units, auger tests, and backhoe trenches that contained bone were not incorporated into the discussion or the tables in these chapters when the provenience could not be assigned to an analytical unit (Table B-3). Data Recovery units found to have levels in disturbed contexts were also removed from the faunal discussion (Table B-4). The Data Recovery sample includes 1496 bone fragments and the Significance Testing sample includes 51 fragments that are within the analytical units the Terminal Late Prehistoric, Initial Late Prehistoric, Terminal Late Archaic, and Middle Late Archaic.

\section{Terminal Late Prehistoric (Areas 1 and 2)}

The Terminal Late Prehistoric occupation of 41KM69 was only evident on the lower terrace in Areas 1 and 2. These Areas contained a collection of artifacts that included plain, bone-tempered ceramics, unifaces typically found in Toyah interval components, bison bone, and Perdiz projectile points. The relationship of these artifacts to the site and their temporal places is discussed in Chapter 10. For this discussion, the faunal collection from the upper levels of Area 1 and 2 is assigned to the Terminal Late Prehistoric. The bone counts peak in Levels 4 and 5 in these blocks in the same stratum as hearth Features 2 and 3 in Area 2. Most fragments removed from these levels were placed in the Large to Very Large size categories. Ninety-six percent of all bone fragments in Area 1 and seventy-six percent of fragments in Area 2 were from Levels 4 and 5, where most sherds were found in Area 1 and 18 unifaces were recovered in Area 2. These are slightly higher $(\sim 10 \mathrm{~cm})$ than Features 2 and 3 (and 3B). Bone excavated as part of Feature 2 during Significance Testing includes nine large to very large mammal bones, a bison tibia, two turtle carapace fragments, and one rodent fragment. Feature 3 test excavations only uncovered turtle carapace fragments. No additional bones were recovered from Feature 3 during data recovery. Body size in these Areas was recorded for 736 fragments. Almost this entire faunal sample was within the Large and Very Large size category.

\section{Initial Late Prehistoric (Areas 3 and 4)}

The Initial Late Prehistoric was only evident on the Upper Terrace in Areas 3 and 4. Three features, (53, 54, and 39) besides the burned rock midden (Feature 1), were recorded in Area 3 and no animal remains were excavated from those feature proveniences. Only 28 fragments within the units of Feature 1 were identified. Unfortunately, Features 53 and 54 were discovered while excavating soil samples and recording profiles in the southern wall of Block 3 and were not excavated in a manner consistent with the other block-excavated features. However, all three features were thermal features. The vertical distribution of bone fragments in Area 3 rises to 307 fragments in Levels 8 to 10 before tapering in Level 11.

Features uncovered in Area 4 include 5, 44, 45, 46, 47, and occurred between 70 and $100 \mathrm{cmbd}$. Features 44 and 46 were in Level 8 and Features 5, 45, and 47 were in Level 10. The faunal assemblage from this block is small with only 50 fragments, all occurring between 70 and $150 \mathrm{cmbd}$. Forty-six percent (23) of these fragments fell within the Initial Late Prehistoric levels, though none was excavated in direct association with the features. Initial Late Prehistoric faunal assemblage includes bony fish and large mammals. 


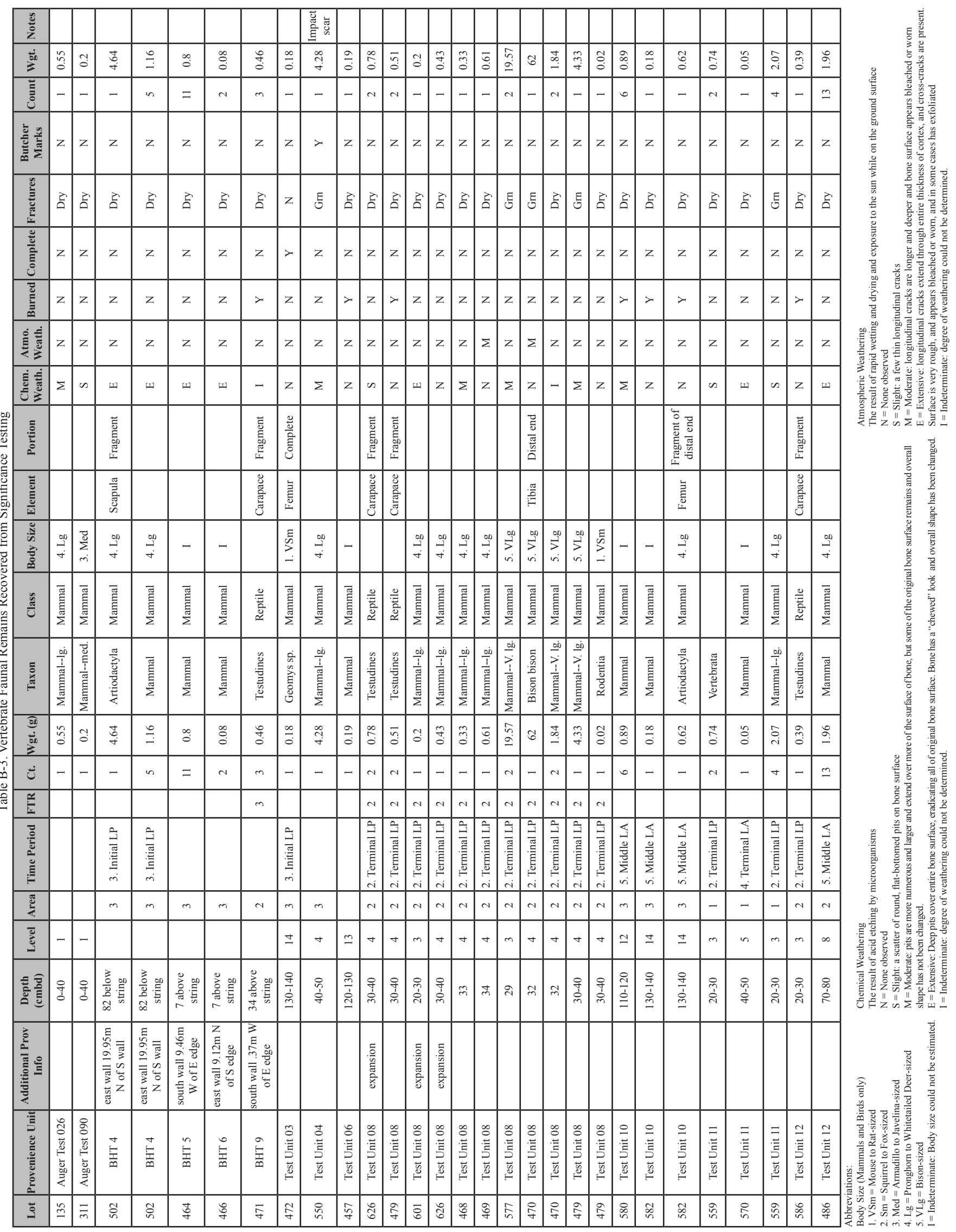




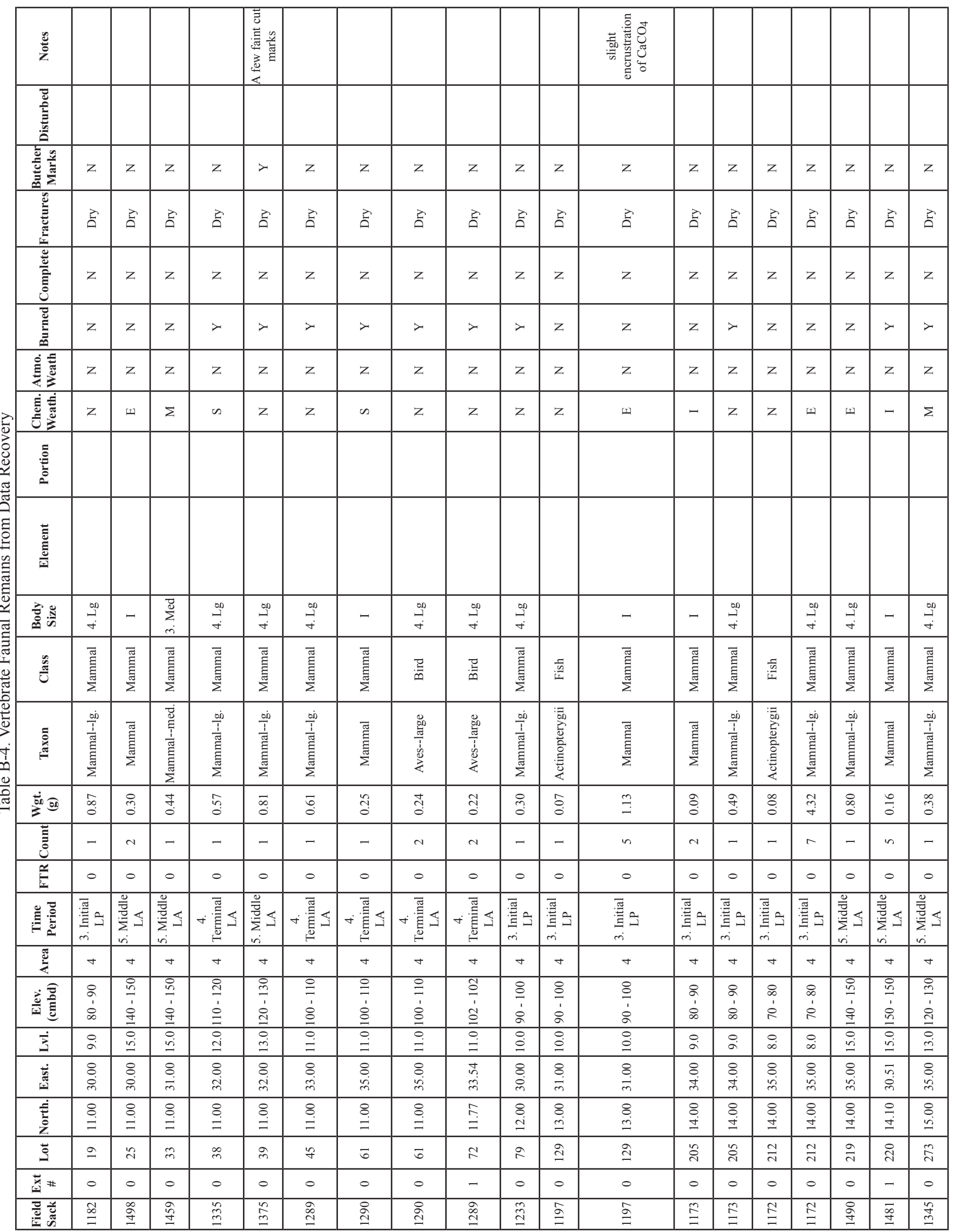




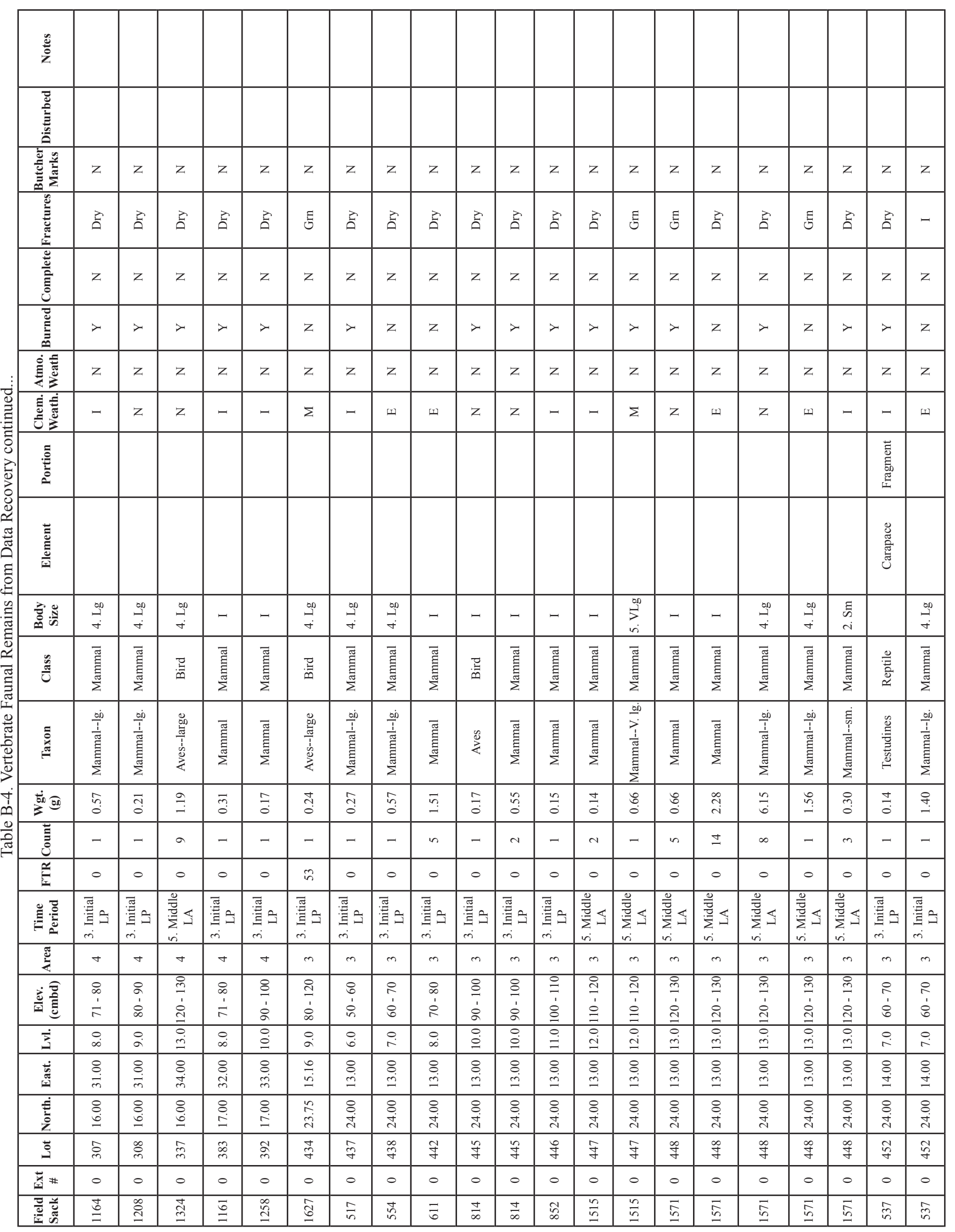




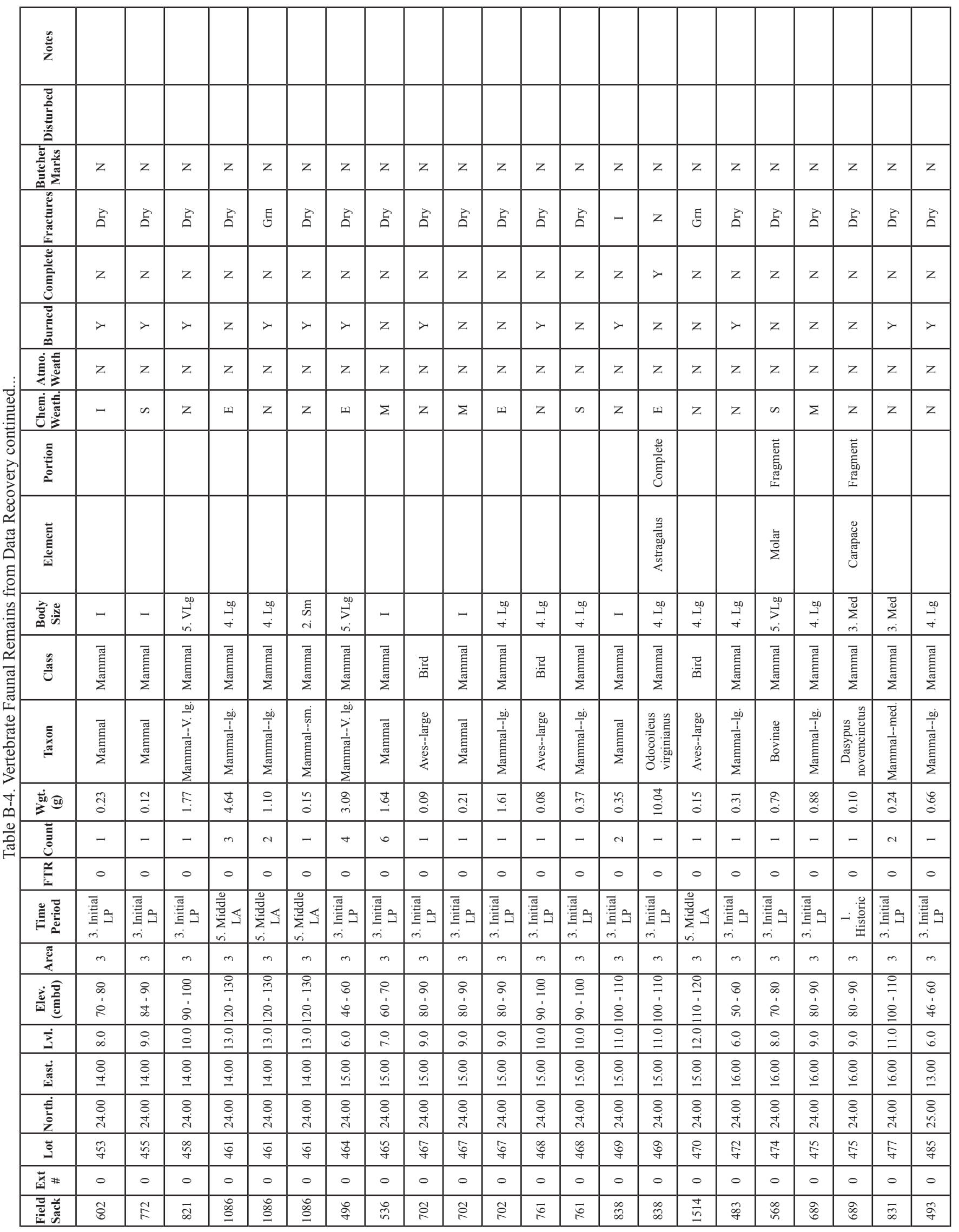




\begin{tabular}{|c|c|c|c|c|c|c|c|c|c|c|c|c|c|c|c|c|c|c|c|}
\hline 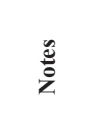 & & & & & $\begin{array}{l}\text { 詰 } \\
\text { 音 }\end{array}$ & $\begin{array}{l}\text { 童 } \\
\text { 音 } \\
\text { 罗 }\end{array}$ & $\begin{array}{l}\text { 竞 } \\
\text { 音 }\end{array}$ & 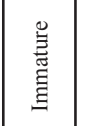 & & 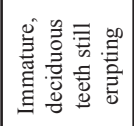 & 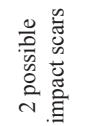 & & & & & & & & \\
\hline 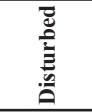 & & & & & & & & & & & & & & & & & & & \\
\hline 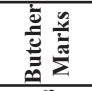 & z & z & z & z & z & z & z & $z$ & z & z & $>$ & z & z & z & z & z & z & z & z \\
\hline 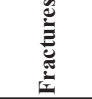 & 疋 & E & 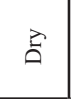 & 咅 & 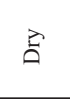 & $\mathrm{z}$ & 咅 & $\vec{\Delta}$ & 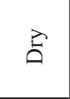 & 空 & $\tau$ & 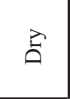 & E & $\vec{a}$ & 点 & E & 点 & E & 忌 \\
\hline 总 & z & z & $\mathrm{z}$ & z & z & $\succ$ & z & $z$ & z & z & z & z & $\mathrm{z}$ & z & z & z & $z$ & z & z \\
\hline 窎 & $\lambda$ & $\lambda$ & z & $>$ & z & z & z & z & z & $>$ & z & z & $\lambda$ & $\lambda$ & $\succ$ & z & $>$ & $>$ & z \\
\hline 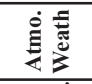 & z & z & $\mathrm{z}$ & z & z & z & z & z & z & z & z & z & z & z & z & z & z & z & z \\
\hline 妾言 & $n$ & $n$ & z & z & z & $n$ & $n$ & z & z & $n$ & 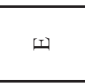 & $\Phi$ & $n$ & z & - & $\Psi$ & - & $n$ & $\omega$ \\
\hline : & & & . & & 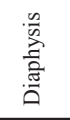 & 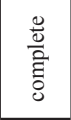 & 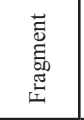 & 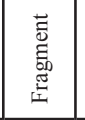 & 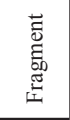 & 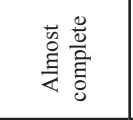 & & & & & & 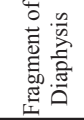 & & & \\
\hline 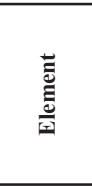 & & & & & 吾 & 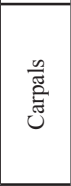 & 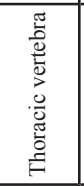 & 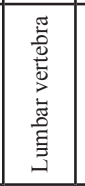 & 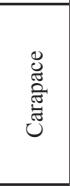 & 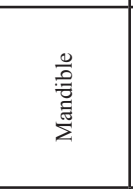 & & & & & & 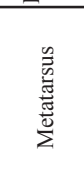 & & & \\
\hline 兘: & - & - & - & - & $\sum_{m}^{\vec{J}}$ & 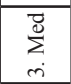 & 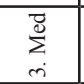 & $\sum_{j}^{\vec{J}}$ & \begin{tabular}{l|}
$\bar{J}$ \\
\\
$m$ \\
$m$
\end{tabular} & 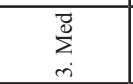 & - & - & $\begin{array}{l}\vec{J} \\
\sum_{m} \\
\dot{m}\end{array}$ & - & $\begin{array}{l}\stackrel{0}{9} \\
+ \\
+\end{array}$ & 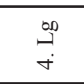 & $\begin{array}{l}\text { on } \\
\stackrel{+}{+}\end{array}$ & $\sum_{M}^{\bar{D}}$ & - \\
\hline $\begin{array}{l}\frac{.}{\tilde{z}} \\
\frac{\pi}{U}\end{array}$ & \begin{tabular}{|l|}
$\bar{\Xi}$ \\
镸 \\
\end{tabular} & $\begin{array}{l}\overline{\bar{m}} \\
\overline{\bar{m}}\end{array}$ & \begin{tabular}{l|}
$\overrightarrow{\widetilde{J}}$ \\
㞗 \\
\end{tabular} & 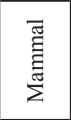 & $\begin{array}{l}\overline{\widetilde{J}} \\
\overline{\tilde{m}}\end{array}$ & \begin{tabular}{|l|}
$\bar{\Xi}$ \\
言 \\
言
\end{tabular} & 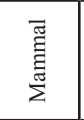 & $\begin{array}{l}\text { 嵒 } \\
\text { 镸 }\end{array}$ & 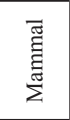 & 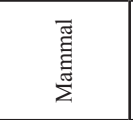 & $\begin{array}{l}\bar{\Xi} \\
\overline{\tilde{E}}\end{array}$ & 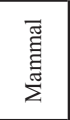 & 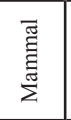 & $\begin{array}{l}\text { 丞 } \\
\text { 镸 }\end{array}$ & $\begin{array}{l}\overline{\text { II }} \\
\text { 镸 }\end{array}$ & 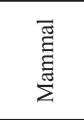 & \begin{tabular}{|l|}
$\overrightarrow{\tilde{J}}$ \\
言 \\
\end{tabular} & $\begin{array}{l}\text { 哾 } \\
\text { 镸 } \\
\end{array}$ & $\begin{array}{l}\bar{\Xi} \\
\overline{\tilde{y}} \\
\bar{\Sigma}\end{array}$ \\
\hline & 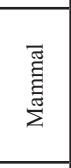 & 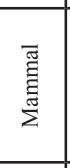 & 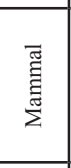 & 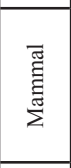 & 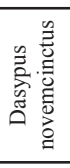 & 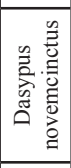 & 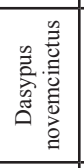 & 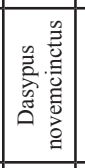 & 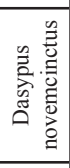 & 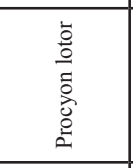 & $\begin{array}{l}\bar{\Xi} \\
\text { 盇 } \\
\text { 之 }\end{array}$ & 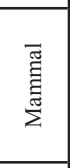 & 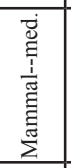 & $\begin{array}{l}\text { 丞 } \\
\text { 善 }\end{array}$ & 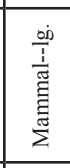 & 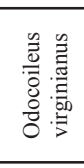 & 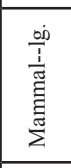 & 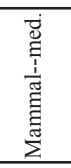 & $\begin{array}{l}\overline{\tilde{I}} \\
\overline{\bar{z}}\end{array}$ \\
\hline 营 & $\stackrel{9}{0}$ & ळे & $\hat{o}$ & $\begin{array}{l}\infty \\
0 \\
0 \\
\end{array}$ & 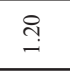 & ñ & $\begin{array}{l}\infty \\
\vdots \\
0 \\
0\end{array}$ & gे & $\stackrel{\overbrace{}}{I}$ & 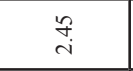 & $\begin{array}{l}\text { d. } \\
+ \\
\end{array}$ & 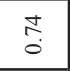 & $\stackrel{n}{3}$ & $\stackrel{m}{0}$ & กิ & के & $\begin{array}{l}5 \\
0 \\
0\end{array}$ & $\stackrel{+}{-}$ & $\stackrel{\infty}{0}$ \\
\hline$\overline{\bar{z}}$ & - & $n$ & + & 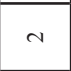 & - & 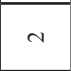 & - & - & $=$ & - & - & $m$ & - & - & - & N & $\sim$ & - & $\mathrm{N}$ \\
\hline $\bar{z}$ & $\circ$ & 0 & 0 & $\circ$ & 0 & $\circ$ & 0 & 0 & 0 & 0 & 0 & $\circ$ & 0 & 0 & 0 & $\circ$ & $\circ$ & 0 & 0 \\
\hline 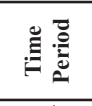 & 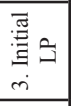 & 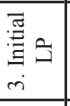 & 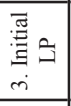 & 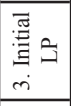 & 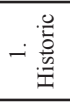 & 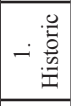 & 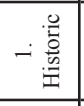 & $-\frac{0}{0}$ & 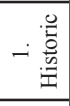 & 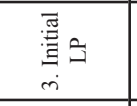 & 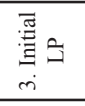 & 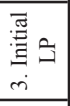 & 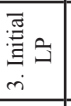 & 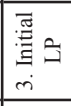 & 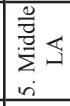 & 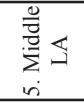 & 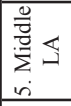 & 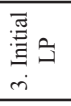 & 覀 \\
\hline 迎 & m & $n$ & m & $n$ & n & $n$ & m & m & m & m & m & m & n & n & $m$ & m & m & m & n \\
\hline 蒿高 & $\begin{array}{l}8 \\
1 \\
1 \\
0\end{array}$ & $\begin{array}{l}0 \\
\infty \\
1 \\
1\end{array}$ & $\begin{array}{l}+ \\
\\
1 \\
1 \\
\infty\end{array}$ & \begin{tabular}{l|}
+ \\
0 \\
1 \\
$\infty$ \\
$\infty$
\end{tabular} & $\begin{array}{l}+ \\
0 \\
1 \\
1 \\
\infty\end{array}$ & \begin{tabular}{l|}
+ \\
\\
1 \\
$\infty$ \\
$\infty$
\end{tabular} & $\begin{array}{l} \\
0 \\
0 \\
0 \\
\infty\end{array}$ & $\begin{array}{l} \\
0 \\
0 \\
0 \\
\infty\end{array}$ & \begin{tabular}{l|}
+ \\
0 \\
1 \\
$\infty$ \\
$\infty$
\end{tabular} & $\begin{array}{l} \\
0 \\
0 \\
0\end{array}$ & 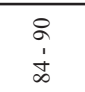 & \begin{tabular}{l}
\multirow{2}{o}{} \\
$\vdots$ \\
2 \\
2
\end{tabular} & $\begin{array}{l}n \\
\stackrel{2}{a} \\
\vdots \\
\alpha\end{array}$ & $\begin{array}{l}\stackrel{8}{7} \\
1 \\
\stackrel{1}{g}\end{array}$ & 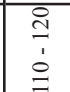 & $\begin{array}{l}\stackrel{9}{\unlhd} \\
\vdots \\
ٍ\end{array}$ & 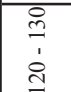 & $\begin{array}{l}8 \\
8 \\
6 \\
5\end{array}$ & $\begin{array}{l}8 \\
\vdots \\
b\end{array}$ \\
\hline$\dot{\Xi}$ & $\stackrel{8}{\circ}$ & $\stackrel{\circ}{\infty}$ & $\stackrel{8}{\circ}$ & $\stackrel{\circ}{\circ}$ & $\stackrel{8}{\circ}$ & $\stackrel{\circ}{\circ}$ & $\stackrel{8}{\circ}$ & $\stackrel{\circ}{\circ}$ & $\stackrel{\circ}{\circ}$ & $\stackrel{\circ}{\circ}$ & $\stackrel{\circ}{\circ}$ & $\stackrel{\circ}{\circ}$ & $\stackrel{\circ}{\circ}$ & $\stackrel{-}{\circ}$ & ì & $\stackrel{-}{\mathrm{i}}$ & \begin{tabular}{|l} 
\\
\end{tabular} & 8 & $\stackrel{\circ}{i}$ \\
\hline 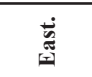 & $\begin{array}{l} \\
\stackrel{8}{7}\end{array}$ & $\begin{array}{l}8 \\
\stackrel{9}{9}\end{array}$ & $\begin{array}{l}8 \\
\stackrel{\leftrightarrow}{-}\end{array}$ & $\begin{array}{l} \\
\\
\stackrel{9}{7}\end{array}$ & $\begin{array}{l}8 \\
\stackrel{\leftrightarrow}{~}\end{array}$ & $\begin{array}{l}8 \\
\\
\stackrel{9}{7}\end{array}$ & $\begin{array}{l}8 \\
\stackrel{\leftrightarrow}{9}\end{array}$ & $\begin{array}{l}8 \\
\stackrel{\leftrightarrow}{9}\end{array}$ & 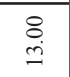 & $\begin{array}{l}8 \\
\stackrel{\leftrightarrow}{9}\end{array}$ & $\begin{array}{l}8 \\
\stackrel{9}{7}\end{array}$ & $\begin{array}{l}8 \\
\stackrel{\leftrightarrow}{\longrightarrow}\end{array}$ & $\begin{array}{l} \\
\end{array}$ & $\begin{array}{l}8 \\
\stackrel{j}{-}\end{array}$ & $\begin{array}{l}8 \\
\stackrel{9}{9}\end{array}$ & $\stackrel{8}{8}$ & $\begin{array}{l}8 \\
\\
\end{array}$ & $\begin{array}{l}8 \\
\dot{ \pm}\end{array}$ & $\begin{array}{l}8 \\
\dot{I}\end{array}$ \\
\hline है & $\begin{array}{l}8 \\
4 \\
4 \\
\end{array}$ & $\begin{array}{l}8 \\
\text { in } \\
4\end{array}$ & $\begin{array}{l}8 \\
\text { iे } \\
4\end{array}$ & $\begin{array}{l}8 \\
\text { id } \\
4 \\
\end{array}$ & $\begin{array}{l}8 \\
\text { i } \\
\text { in }\end{array}$ & $\begin{array}{l}8 \\
\text { a } \\
\text { in } \\
\end{array}$ & $\begin{array}{l}8 \\
\ddot{i} \\
\text { in }\end{array}$ & $\begin{array}{l}8 \\
\text { in } \\
\end{array}$ & \begin{tabular}{l}
8 \\
$\dot{4}$ \\
\cline { 1 - 1 } \\
\end{tabular} & $\begin{array}{l}8 \\
\text { ì } \\
\end{array}$ & $\begin{array}{l}8 \\
4 \\
4 \\
\end{array}$ & $\begin{array}{l}8 \\
\dot{4} \\
\dot{4} \\
\end{array}$ & $\begin{array}{l}8 \\
\dot{1} \\
4\end{array}$ & $\begin{array}{l}8 \\
\text { id } \\
\text { in } \\
\end{array}$ & $\begin{array}{l}8 \\
\text { in } \\
\text { in }\end{array}$ & $\begin{array}{l}8 \\
\dot{4} \\
4\end{array}$ & $\begin{array}{l}8 \\
4 \\
4 \\
\end{array}$ & $\begin{array}{l}8 \\
1 \\
4 \\
\end{array}$ & 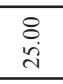 \\
\hline$\ddot{9}$ & 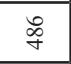 & 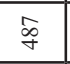 & $\begin{array}{ll}g \\
g\end{array}$ & \begin{tabular}{ll|}
$g$ \\
\end{tabular} & $\begin{array}{l}g \\
g\end{array}$ & $\begin{array}{l}g \\
g\end{array}$ & $\begin{array}{l}g \\
\dot{q}\end{array}$ & $\begin{array}{l}g \\
\dot{g}\end{array}$ & $\begin{array}{l}g \\
g\end{array}$ & $\begin{array}{l}g \\
\dot{g}\end{array}$ & \begin{tabular}{l} 
के \\
\multirow{\alpha}{*}{}
\end{tabular} & $\overrightarrow{\bar{g}}$ & $\overline{\vec{g}}$ & $\bar{g}$ & $\begin{array}{l}+g \\
\text { g }\end{array}$ & \begin{tabular}{ll}
\multicolumn{2}{|c|}{} \\
\end{tabular} & $\begin{array}{ll}a \\
g \\
g\end{array}$ & $\begin{array}{l} \\
q\end{array}$ & $\bar{g}$ \\
\hline 蓄\# & 0 & 0 & 0 & 0 & 0 & 0 & 0 & 0 & 0 & 0 & 0 & 0 & 0 & 0 & 0 & 0 & 0 & 0 & 0 \\
\hline 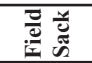 & $\vec{n}$ & $\frac{0}{6}$ & $\tilde{\infty}$ & $\bar{\infty}$ & స్ & $\bar{\infty}$ & $\bar{\infty}$ & $\bar{\infty}$ & 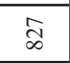 & స్ & $\stackrel{\infty}{\infty}$ & $\underset{\infty}{+}$ & $\underset{\infty}{\Delta}$ & 正 & iे & సิ & 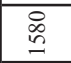 & $\begin{array}{c}\infty \\
\stackrel{\infty}{\alpha}\end{array}$ & तี \\
\hline
\end{tabular}




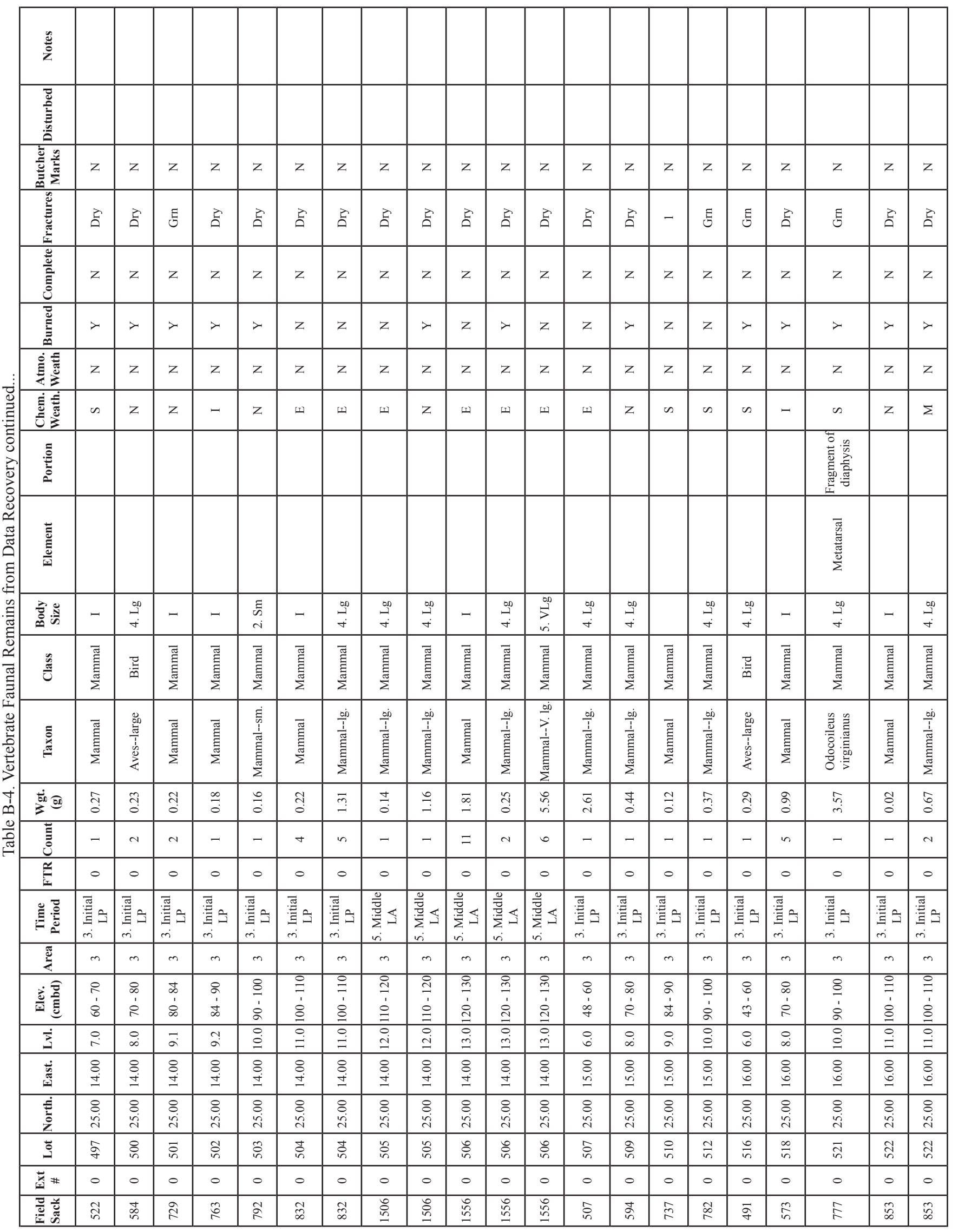




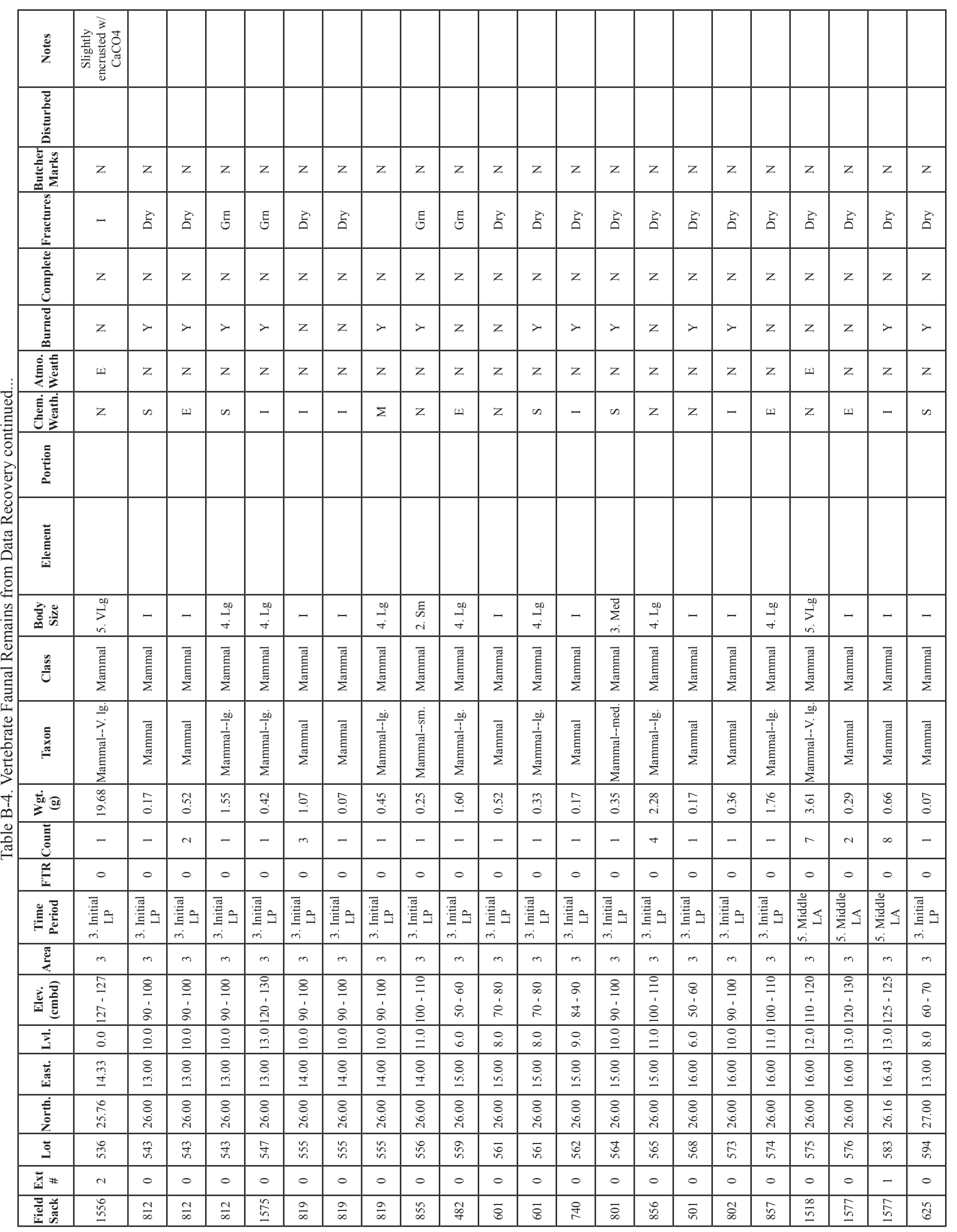




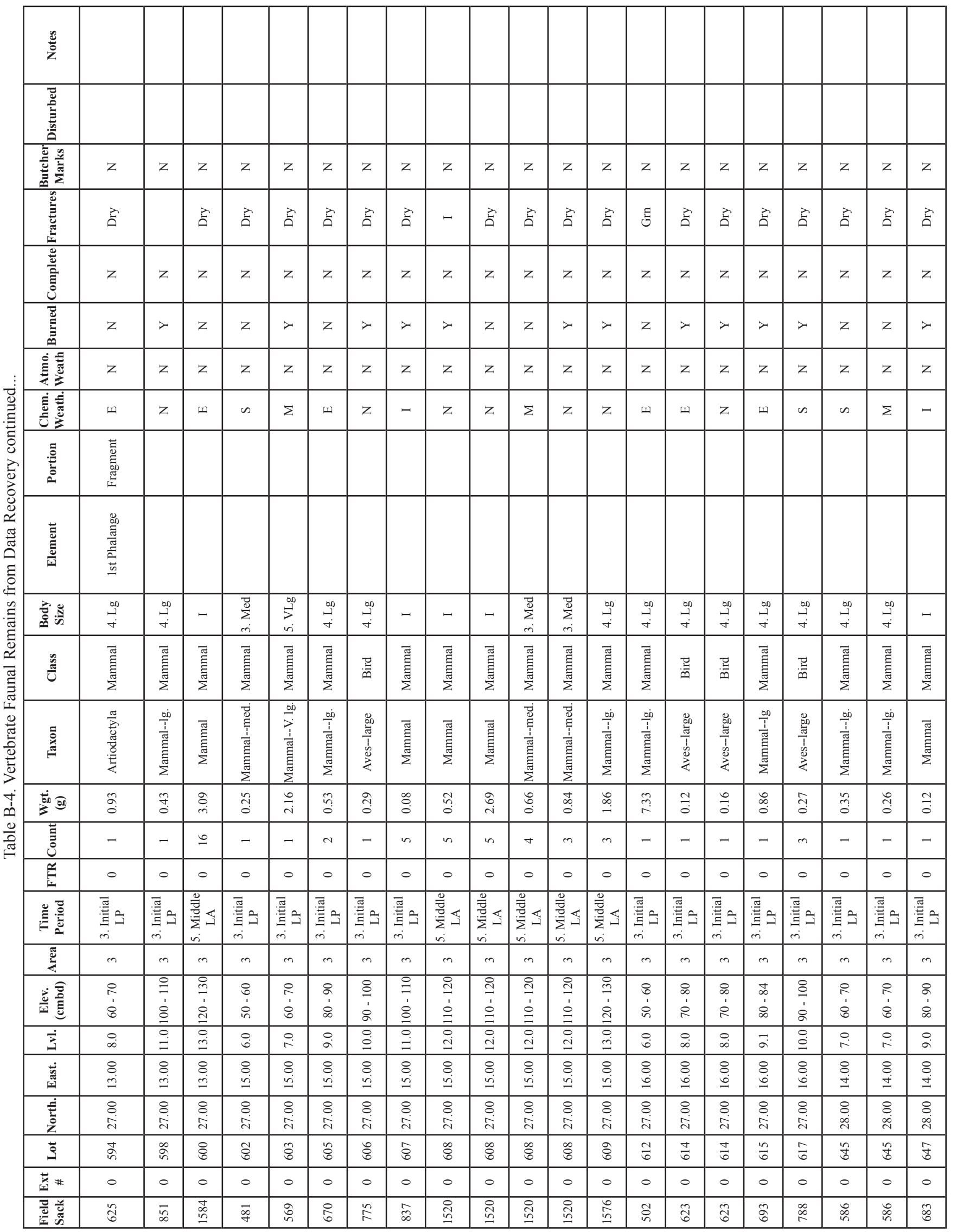




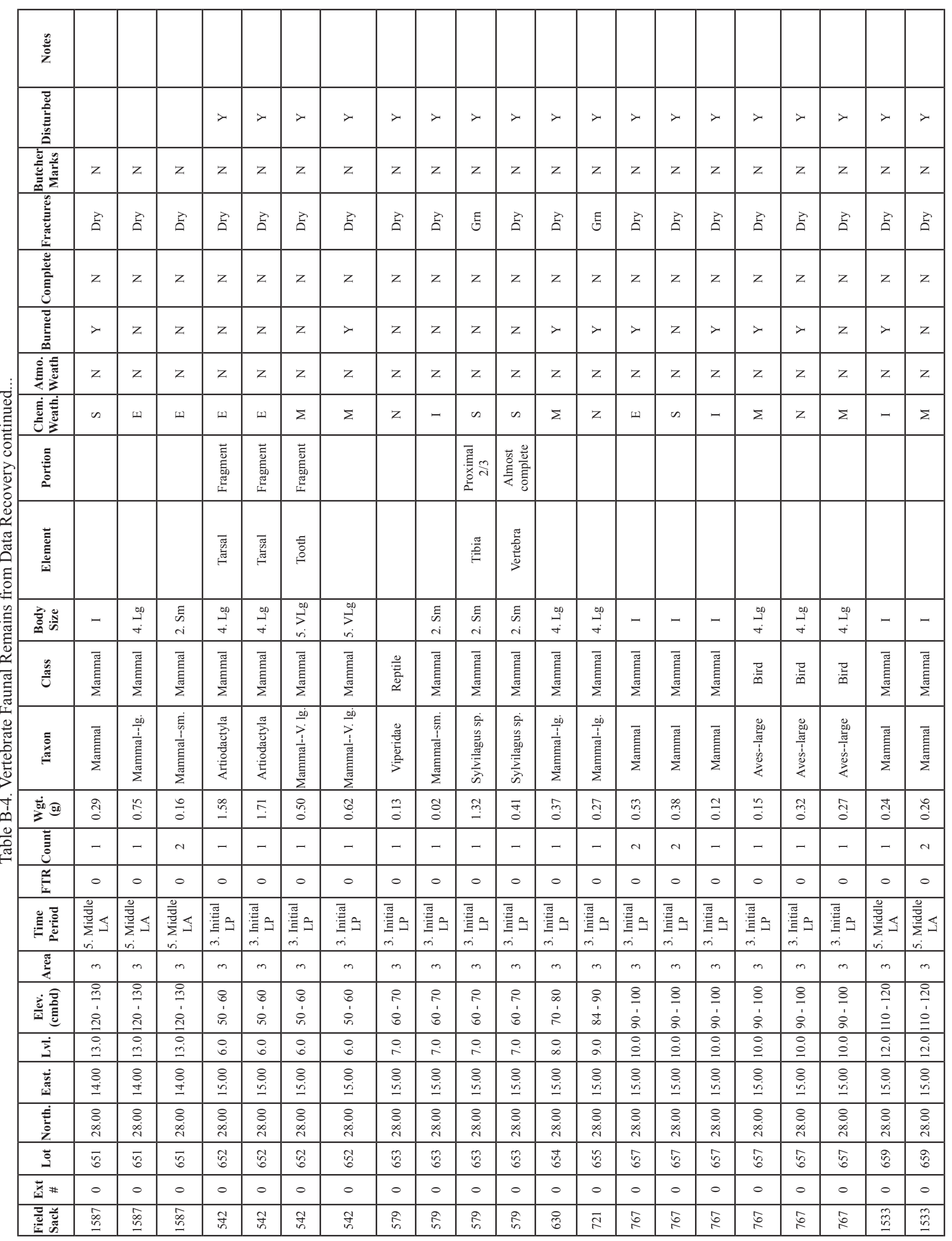




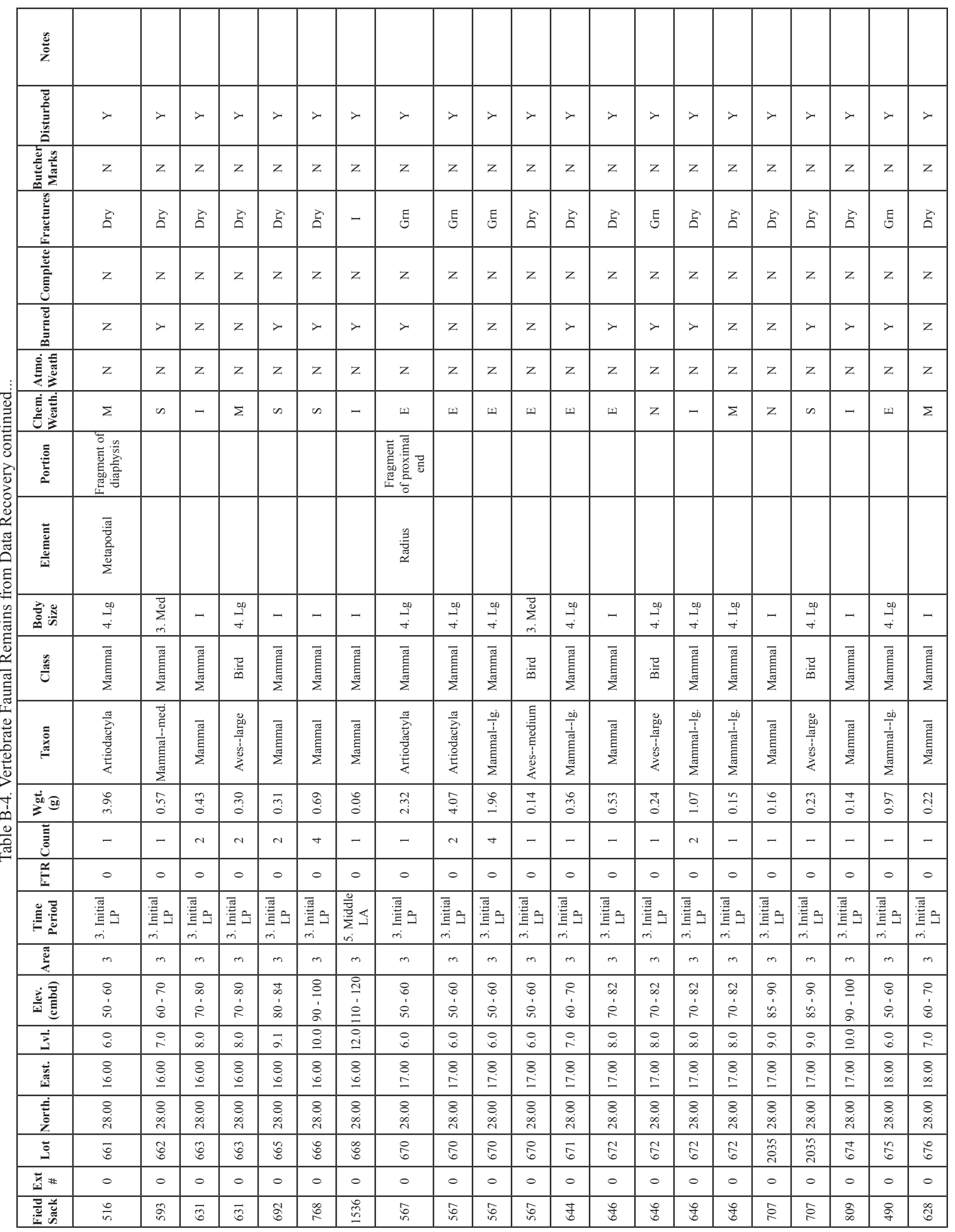




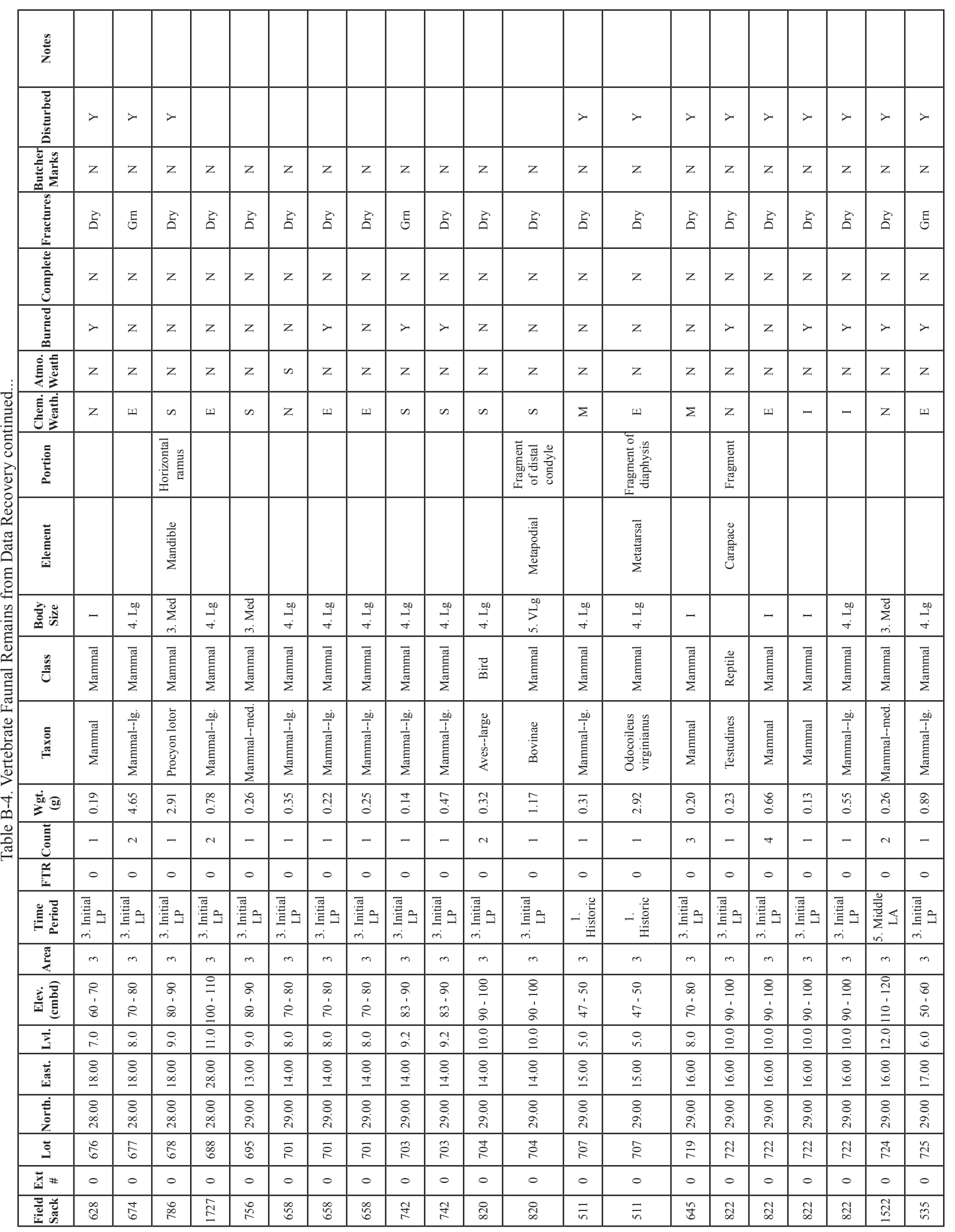




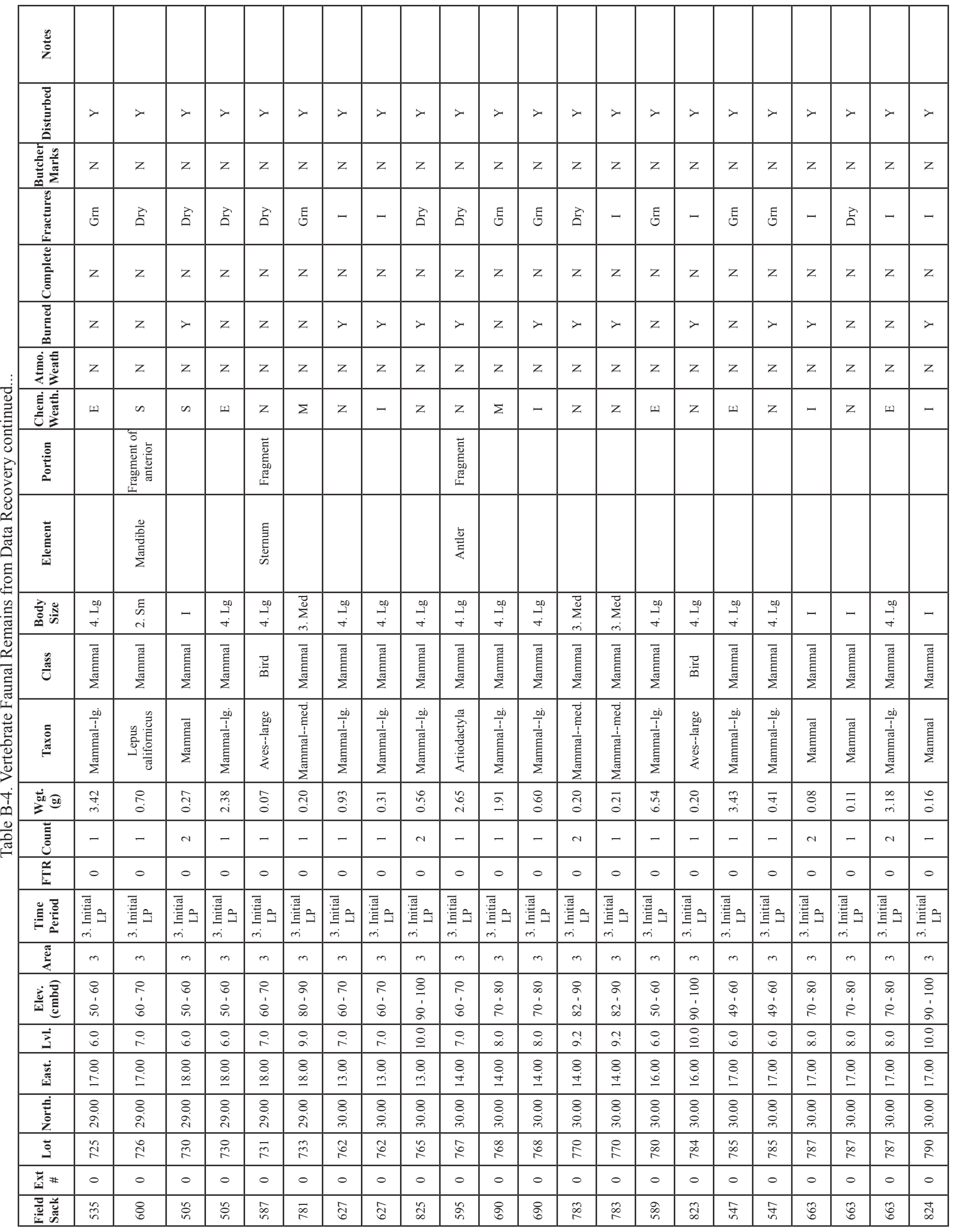




\begin{tabular}{|c|c|c|c|c|c|c|c|c|c|c|c|c|c|c|c|c|c|c|c|c|c|}
\hline 荾 & & & & $\begin{array}{l}\text { 彭 } \\
\text { 兽 }\end{array}$ & $\begin{array}{l}\text { 音 } \\
\text { 音 }\end{array}$ & 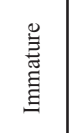 & & & & & & & & & 害高 & & $\begin{array}{l}\text { 竞 } \\
\text { 音 }\end{array}$ & 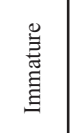 & 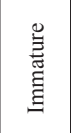 & & \\
\hline 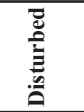 & $\lambda$ & $>$ & $>$ & $>$ & $>$ & $\lambda$ & & & & $>$ & $>$ & $\lambda$ & $>$ & $\lambda$ & $>$ & $>$ & $>$ & $\lambda$ & $>$ & $>$ & $\lambda$ \\
\hline 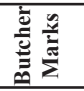 & z & z & z & z & z & z & z & z & z & z & z & z & z & $\mathrm{z}$ & z & z & z & z & z & z & z \\
\hline 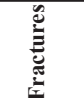 & E & 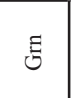 & - & 要 & $\vec{D}$ & $\vec{a}$ & $\Xi$ & $\vec{A}$ & E & E & 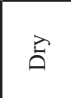 & $\vec{D}$ & - & E & 票 & $\vec{D}$ & 空 & z & z & 点 & 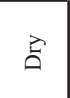 \\
\hline 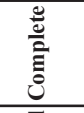 & z & z & z & z & z & z & z & z & z & z & z & $z$ & z & z & z & z & z & $\succ$ & $>$ & z & z \\
\hline 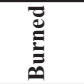 & z & $z$ & z & z & z & z & z & z & z & z & $>$ & $z$ & z & $\succ$ & z & z & z & z & z & $z$ & z \\
\hline 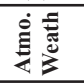 & z & z & z & z & z & $\mathrm{z}$ & z & z & z & z & z & z & z & $\mathrm{z}$ & z & $z$ & z & z & z & z & z \\
\hline 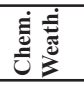 & 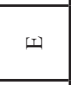 & $\omega$ & $\omega$ & $n$ & is & in & $\Sigma$ & $\Sigma$ & n & $\omega$ & in & $\Sigma$ & - & $\Sigma$ & z & - & $n$ & $n$ & n & z & $n$ \\
\hline & & & & 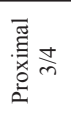 & 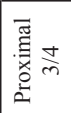 & 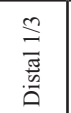 & & & & & & & & & 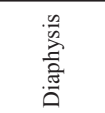 & & 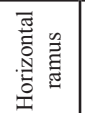 & 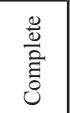 & 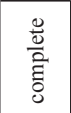 & & 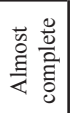 \\
\hline 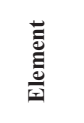 & & & & $\stackrel{\Xi}{5}$ & 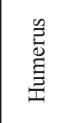 & 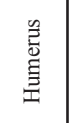 & & & & & & & & & 害 & & 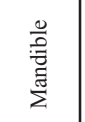 & 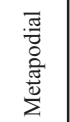 & 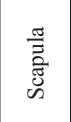 & & $\frac{g}{5}$ \\
\hline 密: 芯 & $\begin{array}{l}\stackrel{\infty}{+} \\
+ \\
+\end{array}$ & 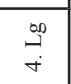 & - & $\sum_{\dot{m}}^{\vec{D}}$ & $\begin{array}{l}\vec{D} \\
\sum_{m}^{\bar{g}} \\
m\end{array}$ & $\sum_{m}^{\bar{J}}$ & 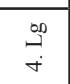 & $\begin{array}{l}\stackrel{\Delta 0}{\rightarrow} \\
+\end{array}$ & $\begin{array}{l}\stackrel{00}{\stackrel{9}{+}} \\
+\end{array}$ & 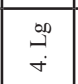 & $\begin{array}{l}\stackrel{\circ}{\circ} \\
\stackrel{+}{+}\end{array}$ & $\begin{array}{l}\stackrel{+0}{+} \\
\stackrel{+}{+}\end{array}$ & - & \begin{tabular}{l|}
00 \\
$\stackrel{\infty}{5}$ \\
$\dot{n}$
\end{tabular} & $\sum_{j}^{\vec{J}}$ & $\sum_{m}^{\vec{E}}$ & $\sum_{j}^{\vec{J}}$ & $\begin{array}{l}\vec{J} \\
\sum_{m}\end{array}$ & \begin{tabular}{|l|}
$\vec{J}$ \\
$\sum_{m}$
\end{tabular} & - & 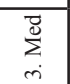 \\
\hline 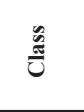 & $\begin{array}{l}\overline{\bar{g}} \\
\overline{\tilde{I}} \\
\bar{\Sigma}\end{array}$ & 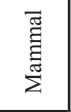 & $\begin{array}{l}\overline{\text { चू }} \\
\text { 㸒 }\end{array}$ & $\begin{array}{l}\overline{\bar{g}} \\
\overline{\tilde{I}} \\
\bar{\Sigma}\end{array}$ & 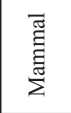 & 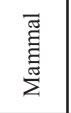 & 范 & 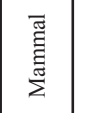 & 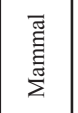 & 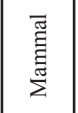 & 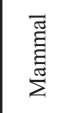 & 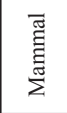 & 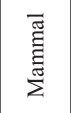 & 莡 & 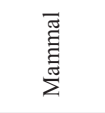 & 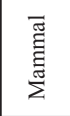 & 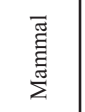 & 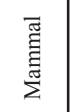 & \begin{tabular}{|l|}
$\overrightarrow{\tilde{\sharp}}$ \\
㷼 \\
\end{tabular} & 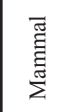 & $\begin{array}{l}\overline{\text { ज्ञ }} \\
\text { 㷼 } \\
\end{array}$ \\
\hline 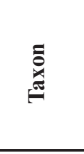 & 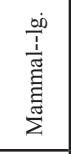 & 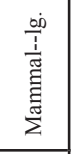 & 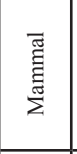 & 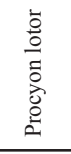 & 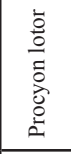 & 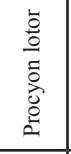 & 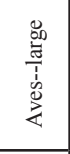 & 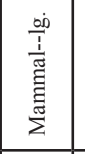 & 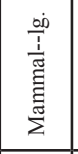 & 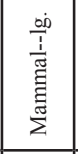 & 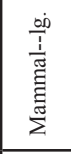 & 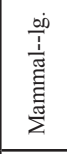 & 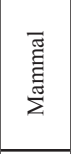 & 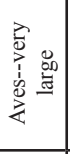 & 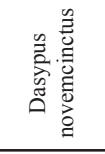 & 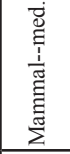 & 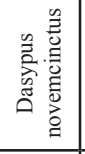 & 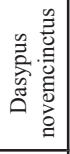 & 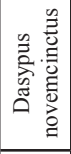 & 沯 & 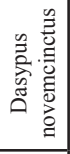 \\
\hline 㻤可 & $\ddot{n}$ & $\underset{\infty}{R}$ & 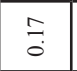 & 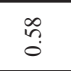 & 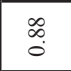 & 苛 & o. & $\bar{a}$ & $\stackrel{8}{8}$ & $\begin{array}{l}\overrightarrow{\sigma_{0}} \\
\dot{n}\end{array}$ & 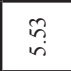 & 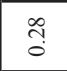 & $\begin{array}{l} \\
0 \\
0 \\
0\end{array}$ & $\stackrel{\cong}{=}$ & gे & $\begin{array}{l} \\
\end{array}$ & ?ִ & กิ่ & $\begin{array}{l}f \\
0 \\
0\end{array}$ & กิ่ & $\begin{array}{l}\infty \\
\infty \\
\infty \\
\infty\end{array}$ \\
\hline$\overline{\bar{z}}$ & - & - & - & - & - & - & - & - & $\sim$ & m & in & - & - & - & - & - & - & - & - & $\sim$ & - \\
\hline$\stackrel{F}{E}$ & 0 & 0 & 0 & 0 & 0 & 0 & 0 & 0 & 0 & o & o & 0 & 0 & 0 & 0 & 0 & 0 & 0 & 0 & 0 & 0 \\
\hline 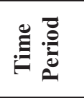 & 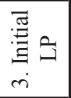 & 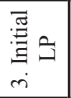 & 恶 & 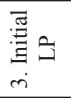 & 覀 & 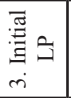 & $-\frac{0}{\frac{0}{\frac{m}{m}}}$ & $-\frac{0}{\frac{0}{0}}$ & 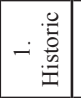 & 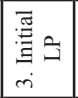 & 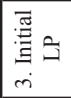 & 蒠 & 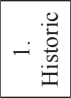 & 焉 & 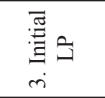 & 奠 & $-\frac{.0}{\frac{0}{0}}$ & $-\frac{0}{\frac{0}{\frac{m}{2}}}$ & $-\frac{0}{\frac{0}{0}}$ & 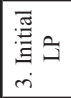 & $-\frac{0}{\frac{0}{\frac{m}{2}}}$ \\
\hline$\frac{\pi}{4}$ & $m$ & $m$ & m & m & $n$ & n & $m$ & $m$ & $m$ & m & $m$ & $m$ & $m$ & $n$ & $m$ & $n$ & $m$ & m & $m$ & $m$ & $m$ \\
\hline 离言 & $\begin{array}{l}8 \\
1 \\
1\end{array}$ & $\begin{array}{l}8 \\
1 \\
1 \\
8\end{array}$ & $\begin{array}{l}0 \\
0 \\
1 \\
1\end{array}$ & $\begin{array}{l}2 \\
8 \\
1 \\
0\end{array}$ & $\begin{array}{l}8 \\
\vdots \\
\vdots \\
\infty\end{array}$ & $\begin{array}{l} \\
8 \\
1 \\
0\end{array}$ & $\begin{array}{l} \\
0 \\
1 \\
q\end{array}$ & $\begin{array}{l}0 \\
i n \\
\vdots \\
q\end{array}$ & \begin{tabular}{l}
\multicolumn{1}{c}{} \\
$\dot{n}$ \\
1
\end{tabular} & $\begin{array}{l}0 \\
\\
1 \\
\vdots \\
1\end{array}$ & $\begin{array}{l}\infty \\
\infty \\
1 \\
2\end{array}$ & $\begin{array}{l}8 \\
1 \\
1 \\
8\end{array}$ & $\begin{array}{l}8 \\
? \\
1 \\
8\end{array}$ & $\begin{array}{l}8 \\
8 \\
1 \\
\infty\end{array}$ & $\begin{array}{l}8 \\
1 \\
1\end{array}$ & $\begin{array}{l}8 \\
1 \\
i\end{array}$ & $\begin{array}{l}8 \\
1 \\
1\end{array}$ & $\begin{array}{l}8 \\
1 \\
\vdots \\
8\end{array}$ & $\begin{array}{l}8 \\
? \\
1 \\
8\end{array}$ & $\begin{array}{l}8 \\
\vdots \\
0 \\
\infty\end{array}$ & $\begin{array}{l}2 \\
8 \\
1 \\
0\end{array}$ \\
\hline$\dot{\vec{J}}$ & 8 & $\stackrel{i}{i}$ & $\stackrel{\infty}{\infty}$ & $\stackrel{8}{\circ}$ & 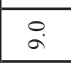 & $\therefore$ & ir & ir & ir & $\dot{\infty}$ & 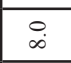 & $\stackrel{8}{0}$ & $\stackrel{9}{\circ}$ & ลב & 8 & 8 & $\stackrel{i}{i}$ & $\stackrel{i}{i}$ & $\stackrel{9}{i}$ & $\stackrel{8}{\circ}$ & $\stackrel{8}{\circ}$ \\
\hline 㟶 & $\begin{array}{l}8 \\
\infty \\
\infty\end{array}$ & $\begin{array}{l}8 \\
\infty \\
\infty\end{array}$ & $\begin{array}{l}8 \\
\infty \\
\infty\end{array}$ & $\begin{array}{l}8 \\
\infty \\
\infty\end{array}$ & $\begin{array}{l}8 \\
\infty \\
\infty \\
-1\end{array}$ & $\begin{array}{l}8 \\
\infty \\
\infty\end{array}$ & \begin{tabular}{|l|}
8 \\
$\dot{8}$ \\
$\dot{d}$
\end{tabular} & $\begin{array}{l}8 \\
\\
d \\
0\end{array}$ & $\begin{array}{l}8 \\
8 \\
d \\
4\end{array}$ & 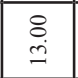 & $\begin{array}{l}8 \\
\\
9 \\
7\end{array}$ & $\begin{array}{l}8 \\
\dot{9}\end{array}$ & $\begin{array}{l}8 \\
\\
\end{array}$ & $\begin{array}{l}8 \\
\dot{I}\end{array}$ & $\begin{array}{l}8 \\
\dot{8} \\
1\end{array}$ & $\begin{array}{l}8 \\
8 \\
1 \\
7\end{array}$ & $\begin{array}{l}8 \\
\dot{8}\end{array}$ & $\begin{array}{l}8 \\
8 \\
10\end{array}$ & $\begin{array}{l}8 \\
8 \\
9 \\
\end{array}$ & $\begin{array}{l}8 \\
8 \\
19\end{array}$ & $\begin{array}{l}8 \\
8 \\
10\end{array}$ \\
\hline 䇏 & $\begin{array}{l} \\
8 \\
0 \\
\end{array}$ & $\begin{array}{l}8 \\
8 \\
\end{array}$ & $\begin{array}{l}8 \\
\\
\end{array}$ & $\begin{array}{l}8 \\
8 \\
\end{array}$ & $\begin{array}{l} \\
\\
0 \\
\end{array}$ & $\begin{array}{l}8 \\
0 \\
\end{array}$ & $\begin{array}{l}8 \\
8 \\
0 \\
\end{array}$ & $\begin{array}{l} \\
\\
\end{array}$ & $\begin{array}{l}8 \\
\\
\end{array}$ & $\frac{8}{\dot{m}}$ & $\begin{array}{l} \\
\dot{m} \\
\end{array}$ & $\begin{array}{l}\dot{8} \\
\dot{m}\end{array}$ & $\begin{array}{l}\stackrel{8}{ } \\
\dot{m} \\
\end{array}$ & $\frac{8}{i}$ & $\frac{8}{9}$ & $\begin{array}{l} \\
\dot{m}\end{array}$ & $\frac{8}{i}$ & $\frac{8}{\dot{m}}$ & $\begin{array}{l}8 \\
\\
\end{array}$ & $\begin{array}{l} \\
\dot{m} \\
\end{array}$ & $\begin{array}{c} \\
\dot{m} \\
\end{array}$ \\
\hline ఏ & $\bar{\AA}$ & న & 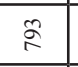 & 㕝 & 齐 & वू & $\stackrel{5}{2}$ & a & a & $\frac{1}{\infty}$ & $\frac{2}{\infty}$ & $\frac{0}{\infty}$ & $\bar{\infty}$ & $\frac{a}{\infty}$ & $\bar{\infty}$ & $\widetilde{\infty}$ & $\check{\infty}_{\infty}$ & $\widehat{్}$ & 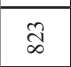 & $\underset{\infty}{11}$ & స్రి \\
\hline 离\# & 0 & 0 & 0 & 0 & 0 & 0 & 0 & 0 & 0 & 0 & 0 & 0 & 0 & 0 & 0 & 0 & 0 & 0 & 0 & 0 & 0 \\
\hline 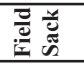 & $\vec{n}$ & $\overrightarrow{\mathrm{\sigma}}$ & fo & 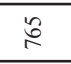 & 8 & $\stackrel{3}{2}$ & $\begin{array}{l}\mathscr{\infty} \\
\stackrel{\infty}{n} \\
n\end{array}$ & 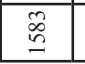 & 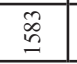 & $\begin{array}{l}\infty \\
0 \\
6\end{array}$ & 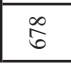 & $\begin{array}{l}\infty \\
i \\
i n\end{array}$ & 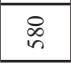 & a & 号 & 8 & $\hat{\tilde{b}}$ & $\hat{\sigma}$ & $\hat{\sigma}$ & $\stackrel{\infty}{\stackrel{\infty}{2}}$ & $\stackrel{\infty}{\stackrel{2}{R}}$ \\
\hline
\end{tabular}




\begin{tabular}{|c|c|c|c|c|c|c|c|c|c|c|c|c|c|c|c|c|c|c|c|}
\hline : & & & & & & & & & & & & & & 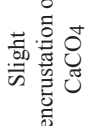 & & & & 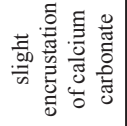 & \\
\hline 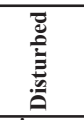 & $>$ & $\succ$ & $\succ$ & $>$ & $\succ$ & $\succ$ & $\succ$ & $>$ & $>$ & $>$ & $\lambda$ & $\succ$ & $\lambda$ & $>$ & $\succ$ & $>$ & 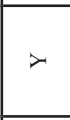 & $\lambda$ & $\succ$ \\
\hline 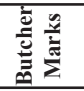 & z & z & z & $z$ & $z$ & z & z & z & z & z & $z$ & $z$ & $z$ & z & z & z & $\mathrm{z}$ & z & $z$ \\
\hline 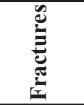 & D & 点 & $\vec{D}$ & $\vec{\Delta}$ & $\vec{\Delta}$ & $\vec{\Delta}$ & $\vec{\Delta}$ & $\vec{\Delta}$ & $\vec{\theta}$ & $\vec{D}$ & $\vec{\Delta}$ & $\vec{\Delta}$ & $z$ & 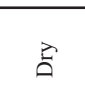 & $\vec{D}$ & z & $\mathrm{z}$ & 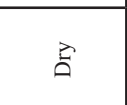 & $\vec{\Delta}$ \\
\hline 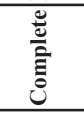 & z & z & z & z & $z$ & z & z & z & z & z & $\mathrm{z}$ & $z$ & $\lambda$ & z & z & $>$ & $\succ$ & z & z \\
\hline 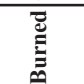 & z & z & z & z & z & z & z & z & z & z & $z$ & $\mathrm{z}$ & $z$ & z & $\succ$ & z & z & z & z \\
\hline 寅焉 & z & z & z & z & $z$ & z & z & z & z & z & $z$ & z & z & z & z & z & z & z & $z$ \\
\hline 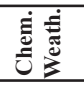 & z & z & is & z & z & z & z & z & z & $\Sigma$ & z & $\mathrm{z}$ & $z$ & $\Sigma$ & n & z & $\mathrm{z}$ & 山 & - \\
\hline & 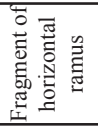 & 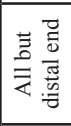 & 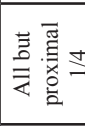 & 音 & $\frac{n}{\bar{z}}$ & 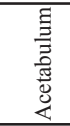 & 音 & 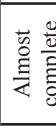 & 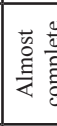 & 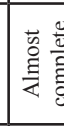 & 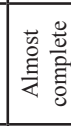 & & \begin{tabular}{|l|}
$\frac{2}{0}$ \\
$\frac{0}{2}$ \\
हैं \\
\end{tabular} & & 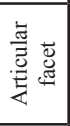 & \begin{tabular}{|l|}
$\frac{2}{0}$ \\
$\frac{0}{2}$ \\
0 \\
0 \\
\end{tabular} & 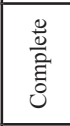 & & \\
\hline 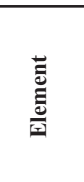 & 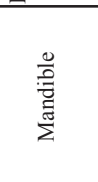 & 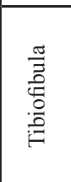 & 吉 & 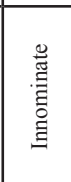 & 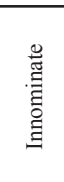 & 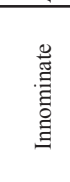 & $\begin{array}{l}\text { 苋 } \\
\text { 产 } \\
\text { 兽 }\end{array}$ & 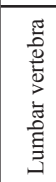 & 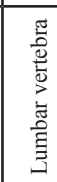 & 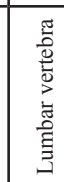 & 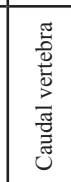 & & 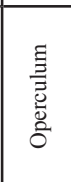 & & 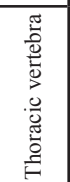 & 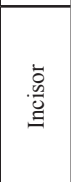 & 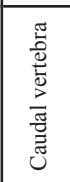 & & \\
\hline 密 & $\sum_{m}^{\vec{J}}$ & $\begin{array}{l}\overrightarrow{\vec{J}} \\
\sum_{\dot{m}}\end{array}$ & $\sum_{m}^{\vec{g}}$ & $\sum_{j}^{\vec{J}}$ & $\sum_{i}^{\vec{D}}$ & $\sum_{j}^{\vec{J}}$ & $\sum_{m}^{\bar{J}}$ & $\sum_{i}^{\vec{D}}$ & $\sum_{i}^{\vec{J}}$ & $\sum_{m}^{\bar{g}}$ & $\sum_{j}^{\bar{J}}$ & 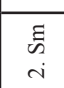 & & - & $\begin{array}{l}{ }_{0} \\
\stackrel{9}{+} \\
\dot{+}\end{array}$ & \begin{tabular}{|l|}
\multirow{n}{*}{} \\
i \\
\end{tabular} & $\begin{array}{l}E \\
\text { E } \\
i\end{array}$ & $\sum_{i}^{\infty 0}$ & - \\
\hline 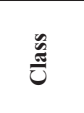 & 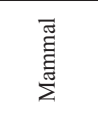 & 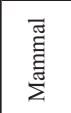 & $\begin{array}{l}\text { 喽 } \\
\text { 言 }\end{array}$ & 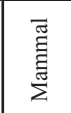 & $\begin{array}{l}\text { 嵒 } \\
\text { 善 }\end{array}$ & 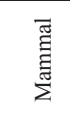 & $\begin{array}{l}\overline{\widetilde{g}} \\
\text { 㷼 } \\
\end{array}$ & 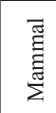 & 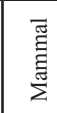 & $\begin{array}{l}\text { 丞 } \\
\text { 善 }\end{array}$ & $\begin{array}{l}\bar{\Xi} \\
\overline{\tilde{I}} \\
\overline{\mathrm{I}}\end{array}$ & $\begin{array}{l}\bar{\Xi} \\
\text { 善 }\end{array}$ & 咅 & 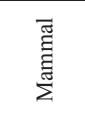 & $\begin{array}{l}\overline{\text { ज्ञ }} \\
\text { 㷼 } \\
\end{array}$ & \begin{tabular}{|l}
$\bar{\Xi}$ \\
$\overline{\tilde{m}}$ \\
$\bar{\Sigma}$
\end{tabular} & 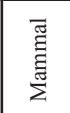 & $\begin{array}{l}\bar{\Xi} \\
\overline{\tilde{I}} \\
\bar{\Sigma}\end{array}$ & \begin{tabular}{|l|}
$\bar{\Xi}$ \\
舀 \\
\end{tabular} \\
\hline 言 & 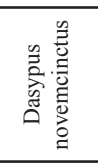 & 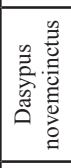 & 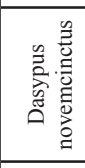 & 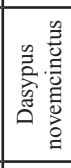 & 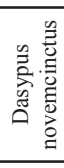 & 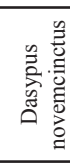 & 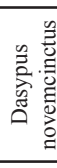 & 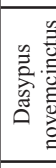 & 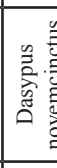 & 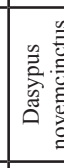 & 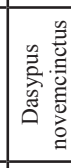 & 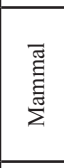 & 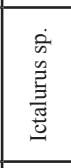 & $\begin{array}{l}\bar{\Xi} \\
\overline{\tilde{I}}\end{array}$ & 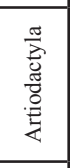 & 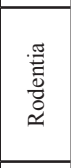 & 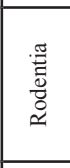 & 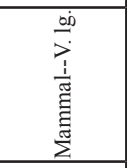 & 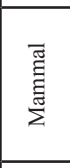 \\
\hline 茄 & oे & $\begin{array}{l}8 \\
\text { in }\end{array}$ & $\tilde{o}_{\infty}$ & $\underset{i}{\stackrel{J}{J}}$ & $\stackrel{m}{g}$ & $\underline{n}$ & $\stackrel{\infty}{\infty}$ & $\stackrel{1}{\square}$ & $\stackrel{8}{\circ}$ & 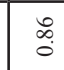 & S. & $\stackrel{n}{\circ}$ & $\begin{array}{l}+\infty \\
0 \\
0\end{array}$ & $\stackrel{0}{\circ}$ & 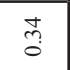 & $\stackrel{ \pm}{0}$ & $\stackrel{m}{0}$ & $\begin{array}{l}\vec{g} \\
\dot{+}\end{array}$ & $\stackrel{8}{\circ}$ \\
\hline$\overline{\bar{E}}$ & - & - & - & - & - & - & - & - & - & - & - & $n$ & - & - & - & - & - & 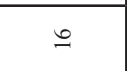 & - \\
\hline 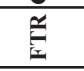 & 0 & $\circ$ & $\circ$ & 0 & 0 & 0 & 0 & 0 & 0 & 0 & 0 & 0 & 0 & 0 & 0 & 0 & 0 & 0 & 0 \\
\hline 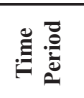 & 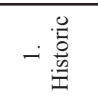 & 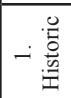 & 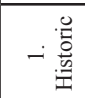 & 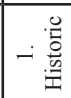 & 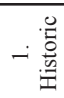 & - & 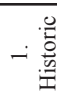 & -0 & -8 & -8 & $-\frac{3}{\frac{9}{n}}$ & 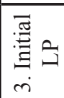 & 焉 & 焉国 & 要专 & 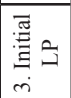 & 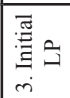 & 焉a & 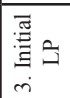 \\
\hline$\frac{\pi}{4}$ & $m$ & $m$ & $m$ & $m$ & $m$ & $m$ & $m$ & $m$ & $m$ & $m$ & $m$ & $m$ & $m$ & $m$ & $m$ & $m$ & $m$ & $m$ & $m$ \\
\hline 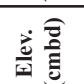 & $\begin{array}{l}8 \\
1 \\
0 \\
0\end{array}$ & $\begin{array}{l}8 \\
0 \\
1 \\
0\end{array}$ & $\begin{array}{l}0 \\
0 \\
0 \\
0\end{array}$ & $\begin{array}{l}8 \\
0 \\
1 \\
2\end{array}$ & $\begin{array}{l} \\
\\
1 \\
0\end{array}$ & $\begin{array}{l}8 \\
\infty \\
1 \\
1\end{array}$ & $\begin{array}{l}8 \\
1 \\
1 \\
2\end{array}$ & $\begin{array}{l}0 \\
0 \\
1 \\
1\end{array}$ & $\begin{array}{l}0 \\
0 \\
1 \\
1\end{array}$ & $\begin{array}{l}8 \\
\infty \\
1 \\
1\end{array}$ & $\begin{array}{l}8 \\
\infty \\
1 \\
1\end{array}$ & $\begin{array}{l}8 \\
\infty \\
1 \\
1\end{array}$ & $\begin{array}{l}n \\
\infty \\
1 \\
0\end{array}$ & $\frac{8}{1}$ & $\frac{8}{1}$ & $\begin{array}{l} \\
\\
1 \\
\end{array}$ & $\frac{8}{1}$ & $\frac{8}{1}$ & $\begin{array}{l}8 \\
0 \\
1 \\
0\end{array}$ \\
\hline$\dot{3}$ & $\stackrel{\circ}{\circ}$ & $\infty_{\infty}^{\infty}$ & ${ }_{\infty}^{\circ}$ & $\stackrel{\infty}{\infty}$ & $\stackrel{0}{\infty}$ & $\stackrel{\infty}{\infty}$ & $\stackrel{\circ}{\infty}$ & $\infty_{\infty}^{\infty}$ & ${ }_{\infty}^{\infty}$ & $\infty_{\infty}$ & $\stackrel{0}{\infty}$ & ${ }_{\infty}^{\circ}$ & $\stackrel{\circ}{\circ}$ & $\stackrel{\circ}{\stackrel{0}{0}}$ & $\stackrel{\circ}{\circ}$ & \begin{tabular}{|l} 
\\
\end{tabular} & $\stackrel{\circ}{\stackrel{0}{0}}$ & $\stackrel{8}{\dot{0}}$ & ${ }_{\infty}$ \\
\hline 离 & $\begin{array}{l}8 \\
6 \\
10\end{array}$ & $\begin{array}{l}8 \\
8 \\
\end{array}$ & : & $\begin{array}{l}8 \\
\\
\end{array}$ & $\begin{array}{l}8 \\
\\
\end{array}$ & $\begin{array}{l}8 \\
0 \\
6\end{array}$ & 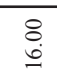 & $\begin{array}{l}8 \\
8 \\
-1\end{array}$ & 8 & $\begin{array}{l}8 \\
8 \\
0\end{array}$ & $\begin{array}{l}8 \\
\\
0\end{array}$ & $\underset{8}{8}$ & 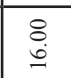 & $\begin{array}{l}8 \\
\\
\end{array}$ & $\begin{array}{l}8 \\
\end{array}$ & $\begin{array}{l}8 \\
\\
0\end{array}$ & $\begin{array}{l}8 \\
\\
\end{array}$ & $\begin{array}{l}8 \\
\\
\end{array}$ & \begin{tabular}{|l|}
8 \\
\end{tabular} \\
\hline 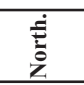 & $\underset{\dot{m}}{\stackrel{8}{ }}$ & $\underset{i}{\stackrel{8}{m}}$ & $\frac{8}{\dot{m}}$ & $\underset{\mathrm{m}}{\mathrm{m}}$ & $\underset{\mathrm{m}}{\mathrm{m}}$ & $\frac{8}{m}$ & $\frac{8}{m}$ & $\frac{8}{m}$ & $\stackrel{8}{\dot{m}}$ & $\stackrel{8}{m}$ & $\underset{i}{\mathrm{~m}}$ & $\underset{i}{i}$ & $\underset{j}{\stackrel{i}{m}}$ & $\underset{m}{\stackrel{8}{m}}$ & $\frac{8}{i}$ & $\underset{\mathrm{i}}{\mathrm{m}}$ & $\stackrel{8}{i}$ & $\frac{8}{m}$ & \begin{tabular}{|l|}
8 \\
\\
\end{tabular} \\
\hline 高 & రి & $\infty_{\infty}^{\infty}$ & $\ddot{\infty}$ & $\hat{\infty}$ & $\hat{\infty}$ & $\tilde{\infty}_{\infty}$ & $\hat{\infty}$ & $\infty_{\infty}$ & $\infty$ & $\infty_{\infty}^{\infty}$ & $\bar{\infty}$ & $\hat{\infty}$ & $\begin{array}{l} \\
\infty\end{array}$ & $\begin{array}{l}0 \\
\infty\end{array}$ & $\infty_{\infty}^{\infty}$ & \begin{tabular}{|l|} 
\\
$\infty$
\end{tabular} & $\underset{\infty}{\infty}$ & $\begin{array}{l}0 \\
\infty\end{array}$ & के \\
\hline 蓄 & 0 & 0 & 0 & 0 & 0 & 0 & 0 & 0 & 0 & 0 & 0 & 0 & $\circ$ & 0 & 0 & 0 & 0 & 0 & 0 \\
\hline 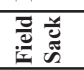 & $\stackrel{\infty}{\stackrel{2}{R}}$ & E & E & हิ & $E$ & 5 & है & 5 & है & E & है & 5 & $\stackrel{\infty}{\sim}$ & $\begin{array}{l}\infty \\
\infty \\
\infty\end{array}$ & $\underset{\infty}{\infty}$ & $\begin{array}{l}\infty \\
\infty\end{array}$ & \begin{tabular}{l} 
\\
\multirow{\infty}{\infty}{}
\end{tabular} & $\begin{array}{l}\substack{\infty \\
\infty \\
\infty} \\
\end{array}$ & 总 \\
\hline
\end{tabular}




\begin{tabular}{|c|c|c|c|c|c|c|c|c|c|c|c|c|c|c|c|c|c|c|c|c|c|c|}
\hline$\frac{\mathscr{o}}{8}$ & $\begin{array}{l}\text { 竎 } \\
\text { 音 }\end{array}$ & & 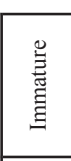 & & & 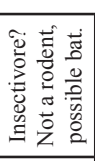 & $\begin{array}{l}\text { 号 } \\
\text { 䔍 } \\
\text { 具 }\end{array}$ & \begin{tabular}{|l}
0 \\
言 \\
音 \\
罗
\end{tabular} & 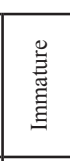 & $\begin{array}{l}\text { 竧 } \\
\text { 兽 }\end{array}$ & $\begin{array}{l}\text { 竧 } \\
\text { 兽 }\end{array}$ & & & & & & 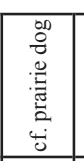 & & & & & \\
\hline 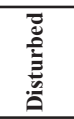 & $>$ & $\lambda$ & $\lambda$ & $>$ & $>$ & $>$ & $\lambda$ & $>$ & $>$ & $\lambda$ & $>$ & $\lambda$ & $>$ & $\succ$ & & & & & & & $>$ & $>$ \\
\hline 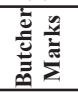 & z & z & z & z & z & z & z & z & z & z & z & z & z & z & z & z & z & z & $z$ & z & $z$ & z \\
\hline 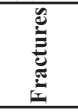 & $\vec{\Delta}$ & 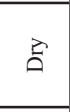 & z & $\vec{\Delta}$ & z & $\vec{\Delta}$ & $\vec{D}$ & $\vec{\Delta}$ & $\vec{\Delta}$ & $\vec{\Delta}$ & $\vec{\Delta}$ & $\vec{\Delta}$ & $\vec{\Delta}$ & 至 & $\tau$ & $\vec{\Delta}$ & E & $\vec{a}$ & 㤩 & $\vec{\Delta}$ & $\vec{a}$ & 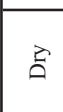 \\
\hline 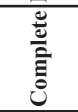 & z & z & $>$ & z & $\succ$ & z & z & z & $\lambda$ & z & $z$ & z & z & z & z & z & z & z & $\mathrm{z}$ & $z$ & $z$ & z \\
\hline 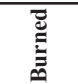 & z & z & $z$ & $\gamma$ & z & $\lambda$ & z & z & $\mathrm{z}$ & z & z & z & $z$ & z & $\succ$ & z & z & z & z & $\lambda$ & z & z \\
\hline 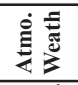 & z & z & z & z & z & z & z & z & z & z & z & z & $\mathrm{z}$ & z & z & z & z & z & z & z & z & z \\
\hline 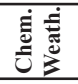 & in & z & in & is & $n$ & w & w & in & is & n & in & in & $n$ & z & z & z & z & z & $\omega$ & - & in & - \\
\hline 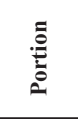 & 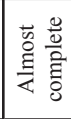 & 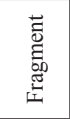 & 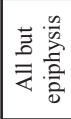 & & 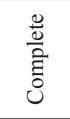 & 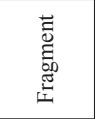 & 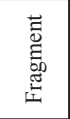 & 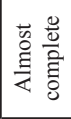 & 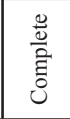 & 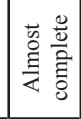 & 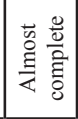 & 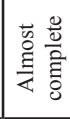 & 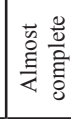 & & & 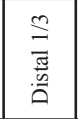 & 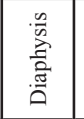 & 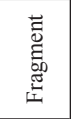 & & & 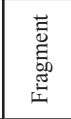 & \\
\hline 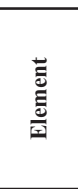 & 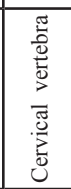 & 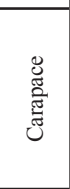 & $\begin{array}{l}\text { 禀 } \\
\text { 空 }\end{array}$ & & 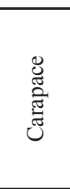 & $\begin{array}{l}\text { 咅 } \\
\text { 恶 }\end{array}$ & $\begin{array}{l}\text { 号 } \\
\text { 总 } \\
\text { 竞 }\end{array}$ & 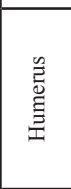 & 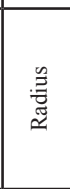 & $\stackrel{g}{5}$ & 㶻 & 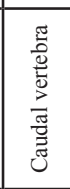 & 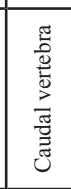 & & & $\begin{array}{l}\text { 苞 } \\
\text { 竞 }\end{array}$ & 尊 & 竡 & & & 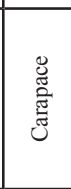 & \\
\hline 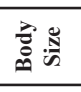 & $\begin{array}{l}0 \\
\stackrel{+}{+} \\
\dot{+}\end{array}$ & \begin{tabular}{|l|}
$\vec{J}$ \\
\\
\end{tabular} & $\begin{array}{l}\vec{J} \\
\sum_{n}^{\vec{J}} \\
\end{array}$ & \begin{tabular}{l}
\multirow{6}{*}{} \\
$\stackrel{+}{+}$ \\
\end{tabular} & $\sum_{i}^{\vec{J}}$ & $\begin{array}{l}=5 \\
\text { 吾. }\end{array}$ & $\begin{array}{l} \\
\stackrel{5}{5} \\
- \\
\end{array}$ & $\begin{array}{l} \\
\text { n } \\
\text { i } \\
\end{array}$ & \begin{tabular}{|l|} 
\\
\\
i \\
\end{tabular} & $\begin{array}{l} \\
\text { ज } \\
\text { i } \\
\end{array}$ & $\begin{array}{l}\text { E } \\
\text { i } \\
\text { in } \\
\end{array}$ & $\begin{array}{l}\text { I } \\
\text { in } \\
\text { i }\end{array}$ & $\begin{array}{l}\text { E } \\
\text { in } \\
\text { i }\end{array}$ & $\begin{array}{l}\text { I } \\
\text { i } \\
\text { i }\end{array}$ & - & $\begin{array}{l}\text { E } \\
\text { in } \\
\text { i }\end{array}$ & \begin{tabular}{|l} 
\\
n \\
$i$ \\
\end{tabular} & $\begin{array}{l} \\
\text { I } \\
\mathrm{i} \\
\end{array}$ & \begin{tabular}{l}
\multirow{3}{*}{} \\
$\stackrel{+}{+}$ \\
\end{tabular} & \begin{tabular}{l}
\multirow{3}{*}{} \\
$\stackrel{+}{+}$ \\
\end{tabular} & & - \\
\hline 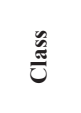 & 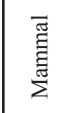 & 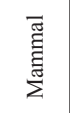 & 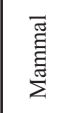 & 㺃 & 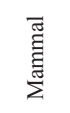 & 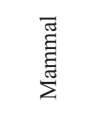 & $\begin{array}{l}\overline{\bar{J}} \\
\overline{\tilde{I}} \\
\overline{\mathrm{I}}\end{array}$ & 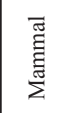 & 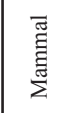 & $\begin{array}{l}\bar{\Xi} \\
\overline{\tilde{I}} \\
\sum\end{array}$ & 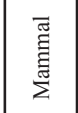 & 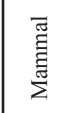 & $\begin{array}{l}\bar{\Xi} \\
\overline{\tilde{E}} \\
\bar{\Sigma}\end{array}$ & 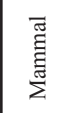 & 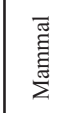 & 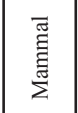 & \begin{tabular}{|l}
$\bar{g}$ \\
爵
\end{tabular} & 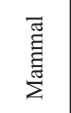 & 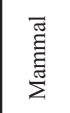 & 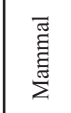 & 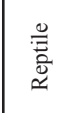 & 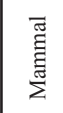 \\
\hline 言 & 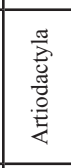 & 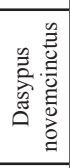 & 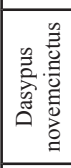 & 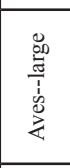 & 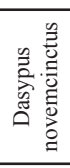 & 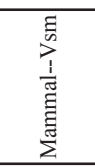 & 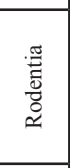 & 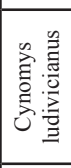 & 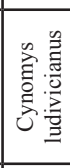 & 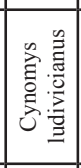 & 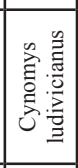 & 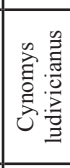 & 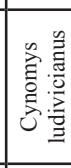 & 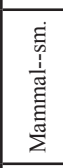 & 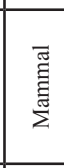 & 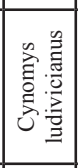 & 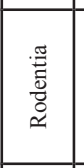 & 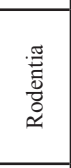 & 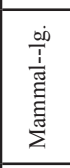 & 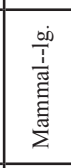 & 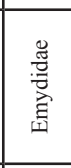 & 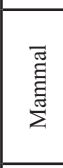 \\
\hline 茄 ख & $\begin{array}{l}\stackrel{2}{2} \\
i\end{array}$ & ণิ & $\begin{array}{l}\text { Fे } \\
\text { if }\end{array}$ & $\stackrel{9}{\circ}$ & $\stackrel{\text { t. }}{-}$ & $\frac{7}{0}$ & $\stackrel{0}{\circ}$ & $\stackrel{\sqrt{m}}{\rightarrow}$ & ff & $\begin{array}{l}\infty \\
0 \\
0\end{array}$ & $\stackrel{?}{?}$ & $\overline{\check{o}}$ & f? & f. & तิ & ֻั & ֻั & $\stackrel{8}{0}$ & $\begin{array}{l}n \\
0 \\
0\end{array}$ & I̊. & $\stackrel{M}{=}$ & $\stackrel{0}{\circ}$ \\
\hline$\overline{\bar{u}}$ & - & a & - & - & $\stackrel{i}{ }$ & 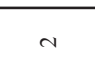 & - & - & - & - & - & - & $m$ & $\tau$ & N & - & - & - & - & r & d & - \\
\hline 益 & $\circ$ & $\circ$ & $\circ$ & $\circ$ & $\circ$ & o & $\circ$ & $\circ$ & $\circ$ & $\circ$ & $\circ$ & $\circ$ & $\circ$ & $\circ$ & $\circ$ & $\circ$ & $\circ$ & $\circ$ & $\circ$ & $\circ$ & $\circ$ & $\circ$ \\
\hline 茵总 & 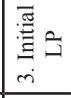 & 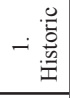 & $-\frac{0}{0.0}$ & 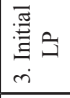 & 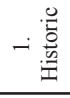 & 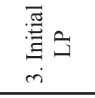 & 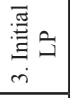 & 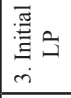 & $\begin{array}{l}\text { 焉 } \\
\text { 品 } \\
\end{array}$ & 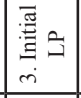 & \begin{tabular}{|l} 
\\
焉 \\
in \\
\end{tabular} & 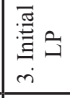 & 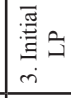 & 焉 & $-\frac{0}{0.0}$ & 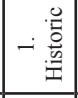 & $-\frac{0}{\frac{0}{0}}$ & 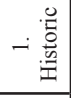 & 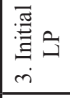 & 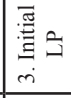 & 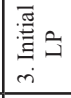 & 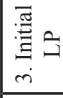 \\
\hline 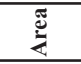 & $m$ & $m$ & $m$ & $m$ & $m$ & $m$ & $m$ & m & m & $m$ & $m$ & $m$ & $m$ & $m$ & $m$ & $m$ & $m$ & $m$ & $m$ & $m$ & m & $m$ \\
\hline 㝘高 & $\begin{array}{l}0 \\
\& \\
\vdots \\
i\end{array}$ & \begin{tabular}{|l|} 
\\
0 \\
0 \\
0
\end{tabular} & $\begin{array}{l} \\
8 \\
\dot{\infty} \\
\end{array}$ & $\begin{array}{l}8 \\
\frac{1}{1} \\
\vdots\end{array}$ & $\begin{array}{l}8 \\
0 \\
1 \\
2\end{array}$ & $\begin{array}{l}0 \\
\infty \\
1 \\
1\end{array}$ & $\begin{array}{l}8 \\
\& \\
\stackrel{1}{R}\end{array}$ & $\begin{array}{l}8 \\
\frac{1}{1} \\
\vdots\end{array}$ & $\begin{array}{l}8 \\
\frac{1}{1} \\
\vdots\end{array}$ & $\begin{array}{l}8 \\
\frac{8}{1} \\
\vdots\end{array}$ & $\begin{array}{l}8 \\
\frac{8}{1} \\
\vdots\end{array}$ & $\begin{array}{l}\frac{8}{1} \\
\vdots \\
\vdots\end{array}$ & $\begin{array}{l}8 \\
\frac{8}{1} \\
\vdots\end{array}$ & $\begin{array}{l}\frac{8}{9} \\
1 \\
2\end{array}$ & $\begin{array}{l}\text { n } \\
\vdots \\
\vdots\end{array}$ & $\begin{array}{l}0 \\
n \\
o \\
\sigma\end{array}$ & $\begin{array}{l}8 \\
b \\
b \\
a\end{array}$ & $\begin{array}{l}0 \\
\vdots \\
\vdots \\
\vdots\end{array}$ & $\begin{array}{l}8 \\
\dot{1} \\
\dot{n}\end{array}$ & $\begin{array}{l}0 \\
0 \\
1 \\
1\end{array}$ & $\begin{array}{l}\infty \\
\infty \\
\infty \\
\infty \\
n\end{array}$ & 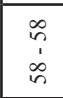 \\
\hline$\dot{\overrightarrow{3}}$ & $\stackrel{0}{\circ}$ & $\stackrel{\circ}{\circ}$ & $\stackrel{\circ}{\circ}$ & $\stackrel{\circ}{\doteq}$ & ${ }_{\infty}^{\circ}$ & $\stackrel{\infty}{\infty}$ & $\stackrel{\circ}{\infty}$ & $\stackrel{\circ}{\circ}$ & $\stackrel{\circ}{\circ}$ & $\stackrel{\circ}{\stackrel{\circ}{S}}$ & $\stackrel{\circ}{\stackrel{\Xi}{S}}$ & $\stackrel{\circ}{\stackrel{9}{9}}$ & $\stackrel{\circ}{\stackrel{9}{9}}$ & $\stackrel{\circ}{\stackrel{\circ}{\leftrightarrows}}$ & $\dot{i n}$ & ir & ir & ir & $\dot{8}$ & $\dot{\infty}$ & 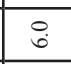 & $\stackrel{8}{\circ}$ \\
\hline 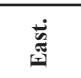 & $\begin{array}{l}8 \\
\\
=\end{array}$ & 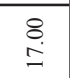 & 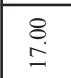 & $\begin{array}{l}\stackrel{8}{8} \\
=\end{array}$ & $\begin{array}{l}8 \\
\infty \\
\infty\end{array}$ & $\underset{\infty}{\stackrel{\infty}{\infty}}$ & $\begin{array}{l}\stackrel{8}{0} \\
\stackrel{\infty}{\sim}\end{array}$ & $\begin{array}{l}\stackrel{8}{8} \\
\stackrel{\infty}{-1}\end{array}$ & $\begin{array}{l}\stackrel{8}{\infty} \\
\stackrel{\infty}{\infty}\end{array}$ & $\begin{array}{l}\stackrel{8}{\infty} \\
\stackrel{\infty}{\longrightarrow}\end{array}$ & $\begin{array}{l}\stackrel{8}{\infty} \\
\stackrel{\infty}{a}\end{array}$ & $\begin{array}{l}\stackrel{8}{\infty} \\
\stackrel{\infty}{\infty}\end{array}$ & $\begin{array}{l}\stackrel{8}{\circ} \\
\stackrel{\infty}{\infty}\end{array}$ & $\begin{array}{l}8 \\
\stackrel{8}{\infty}\end{array}$ & 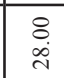 & 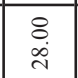 & \begin{tabular}{|l|l}
8 \\
$\infty$ \\
$\infty$
\end{tabular} & 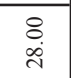 & 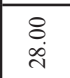 & 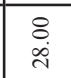 & $\begin{array}{l}\hat{n} \\
\stackrel{n}{=}\end{array}$ & $\begin{array}{l}\tilde{n} \\
\end{array}$ \\
\hline 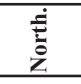 & $\begin{array}{l}8 \\
\dot{m}\end{array}$ & $\begin{array}{l} \\
\\
\end{array}$ & $\begin{array}{l} \\
\\
\dot{m}\end{array}$ & $\begin{array}{l} \\
\dot{m} \\
\end{array}$ & $\begin{array}{l}8 \\
\dot{m}\end{array}$ & $\begin{array}{l}8 \\
\\
\end{array}$ & $\begin{array}{l} \\
\dot{m} \\
\end{array}$ & $\begin{array}{l}8 \\
\dot{m} \\
\end{array}$ & 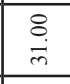 & $\frac{8}{m}$ & $\begin{array}{l}8 \\
\\
\end{array}$ & $\begin{array}{l}8 \\
\dot{m} \\
\end{array}$ & $\begin{array}{l}8 \\
\\
\end{array}$ & $\frac{8}{m}$ & $\begin{array}{l}8 \\
\dot{m} \\
\end{array}$ & $\frac{8}{9}$ & \begin{tabular}{|c|}
8 \\
\\
\end{tabular} & $\begin{array}{l} \\
\\
\end{array}$ & \begin{tabular}{|l|}
8 \\
\end{tabular} & $\begin{array}{l}8 \\
\dot{m} \\
\end{array}$ & \begin{tabular}{|c|}
$\vec{m}$ \\
\end{tabular} & $\vec{~}$ \\
\hline 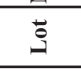 & ळे & ळे & $\begin{array}{l}9 \\
\infty \\
\infty\end{array}$ & $\underset{\infty}{\nexists}$ & $\begin{array}{l} \pm \\
\infty\end{array}$ & $\underset{\infty}{ \pm}$ & $\underset{\infty}{*}$ & $\begin{array}{l}q \\
\infty \\
\infty\end{array}$ & $\begin{array}{l}\text { in } \\
\infty \\
\infty\end{array}$ & $\begin{array}{l}10 \\
\infty \\
\infty\end{array}$ & $\begin{array}{l}\text { 呆 } \\
\infty\end{array}$ & $\begin{array}{l}1 \\
1 \\
\infty \\
\infty\end{array}$ & $\begin{array}{l}1 \\
\infty \\
\infty\end{array}$ & $\begin{array}{l}q \\
\infty \\
\infty\end{array}$ & $\begin{array}{l}\substack{\infty \\
\infty \\
\infty} \\
\end{array}$ & $\begin{array}{l}\substack{\infty \\
\infty \\
\infty} \\
\end{array}$ & \begin{tabular}{|c}
$\infty$ \\
$\infty$ \\
$\infty$
\end{tabular} & 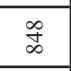 & 高 & $\overrightarrow{\tilde{\sigma}}$ & 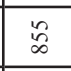 & $\begin{array}{l}n \\
\infty \\
\infty\end{array}$ \\
\hline 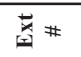 & 0 & 0 & 0 & 0 & 0 & 0 & 0 & 0 & 0 & 0 & 0 & 0 & 0 & 0 & 0 & 0 & 0 & 0 & 0 & 0 & 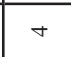 & t \\
\hline 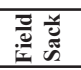 & 。े & 。े & $\vec{\kappa}$ & $\begin{array}{l} \\
\infty\end{array}$ & : & 5 & 5 & $\frac{\Gamma}{\infty}$ & $\stackrel{\bar{\infty}}{\infty}$ & $\frac{\Omega}{\infty}$ & $\stackrel{\Gamma}{\infty}$ & $\stackrel{\bar{\sigma}}{\infty}$ & $\bar{a}$ & $\bar{\infty}$ & $\begin{array}{l}\stackrel{\mathscr{D}}{\stackrel{\rightarrow}{n}} \\
\end{array}$ & $\begin{array}{l}\text { 离 } \\
\stackrel{-}{h}\end{array}$ & $\begin{array}{l}\text { 离 } \\
\stackrel{-}{n}\end{array}$ & 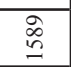 & 灾 & 浐 & in & 品 \\
\hline
\end{tabular}









\begin{tabular}{|c|c|c|c|c|c|c|c|c|c|c|c|c|c|c|c|c|c|c|c|c|}
\hline 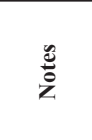 & 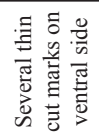 & & & & & & & & & & & & & & & & & & & \\
\hline 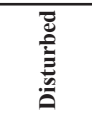 & $>$ & $>$ & $>$ & $\succ$ & $>$ & $\succ$ & 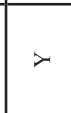 & $\lambda$ & $>$ & $>$ & $\succ$ & $>$ & $\succ$ & $>$ & $>$ & $>$ & $\succ$ & $\succ$ & $\succ$ & $>$ \\
\hline 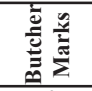 & z & z & z & z & z & $z$ & $z$ & $z$ & z & z & z & z & z & z & z & z & z & z & z & z \\
\hline 竎 & E & z & $z$ & $z$ & z & z & $z$ & z & z & z & z & z & z & z & z & z & z & z & z & z \\
\hline 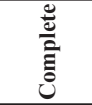 & z & $>$ & $>$ & $>$ & $\succ$ & $\succ$ & $\succ$ & $\succ$ & $>$ & $\succ$ & $>$ & $>$ & $>$ & $\lambda$ & $\lambda$ & $>$ & $\succ$ & $>$ & $>$ & $>$ \\
\hline 离 & z & z & z & z & z & $z$ & $z$ & $\mathrm{z}$ & z & z & z & z & z & z & z & z & z & z & z & z \\
\hline 安言 & z & z & z & z & z & $z$ & $z$ & $\mathrm{z}$ & z & z & z & z & z & z & z & z & z & z & z & z \\
\hline 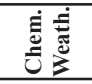 & $n$ & z & z & z & z & z & z & z & z & z & z & z & z & z & z & z & z & z & z & z \\
\hline 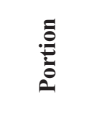 & 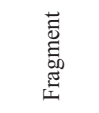 & 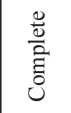 & 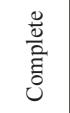 & 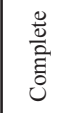 & 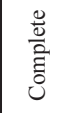 & $\begin{array}{l}\frac{0}{0} \\
\frac{0}{\tilde{0}} \\
\frac{0}{0}\end{array}$ & 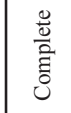 & 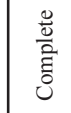 & 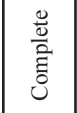 & 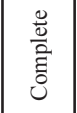 & $\begin{array}{l}\frac{0}{0} \\
\frac{0}{0.0} \\
\text { हैं }\end{array}$ & 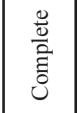 & 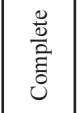 & 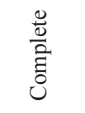 & $\begin{array}{l}\frac{0}{0} \\
\frac{0}{\tilde{0}} \\
\frac{0}{0}\end{array}$ & 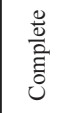 & 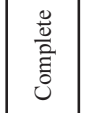 & $\begin{array}{l}\frac{0}{0} \\
\frac{0}{2} \\
\frac{\tilde{g}}{0}\end{array}$ & 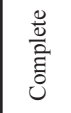 & 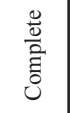 \\
\hline 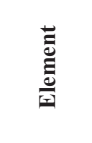 & 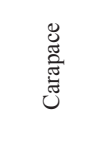 & 竜 & $\stackrel{\stackrel{g}{E}}{\stackrel{E}{4}}$ & 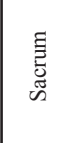 & 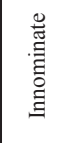 & $\begin{array}{l}\text { 苛 } \\
\text { 音 } \\
\text { 息 }\end{array}$ & 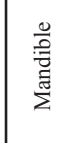 & $\begin{array}{l}\text { 号 } \\
\text { 音 } \\
\text { 密 }\end{array}$ & 言 & $\begin{array}{c}\text { 言 } \\
\text { 竧 }\end{array}$ & 酸 & 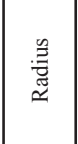 & $\stackrel{\frac{g}{3}}{\frac{\partial}{5}}$ & 를 & 를 & 르 & 름 & 름 & $\overrightarrow{\vec{a}}$ & 気 \\
\hline 迫 & & $\begin{array}{l} \\
\text { 竞 } \\
\text { i } \\
\end{array}$ & $\begin{array}{l} \\
\text { 足 } \\
\text { i } \\
\end{array}$ & $\begin{array}{l} \\
\text { D } \\
\text { i } \\
\end{array}$ & $\begin{array}{l} \\
\text { 竞 } \\
\text { i }\end{array}$ & $\begin{array}{l}\text { E } \\
\text { i } \\
\text { i }\end{array}$ & $\begin{array}{l}\text { I } \\
\text { i } \\
\end{array}$ & $\begin{array}{l}\text { E } \\
\text { in } \\
\text { in }\end{array}$ & $\begin{array}{l}= \\
\text { D } \\
\text { i } \\
\end{array}$ & \begin{tabular}{l|}
$E$ \\
in \\
in \\
\end{tabular} & $\begin{array}{l} \\
\text { D } \\
\text { i }\end{array}$ & \begin{tabular}{l|} 
\\
$n$ \\
$i$ \\
\end{tabular} & $\begin{array}{l}\text { E } \\
\text { i } \\
\end{array}$ & $\begin{array}{l}\text { I } \\
\text { i } \\
\end{array}$ & $\begin{array}{l} \\
\text { H } \\
\text { i }\end{array}$ & $\begin{array}{l} \\
\text { 竞 } \\
\text { i } \\
\end{array}$ & $\begin{array}{l}\text { E } \\
\text { i } \\
\end{array}$ & $\begin{array}{l}\tilde{E} \\
\mathrm{i} \\
\mathrm{i}\end{array}$ & $\begin{array}{l}\text { 员 } \\
\text { i } \\
\end{array}$ & $\begin{array}{l}\text { 足 } \\
\text { i } \\
\end{array}$ \\
\hline 㞭 & 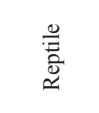 & 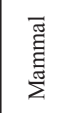 & 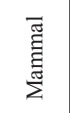 & 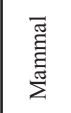 & 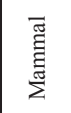 & $\begin{array}{l}\text { 㶵 } \\
\text { 䔍 }\end{array}$ & 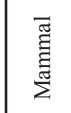 & $\begin{array}{l}\bar{\Xi} \\
\tilde{\tilde{E}}\end{array}$ & $\begin{array}{l}\text { 憩 } \\
\text { 言 }\end{array}$ & 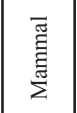 & 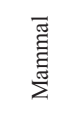 & 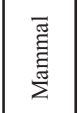 & 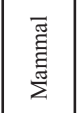 & 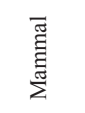 & 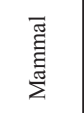 & 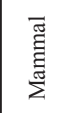 & 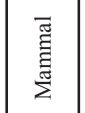 & 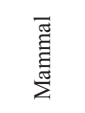 & 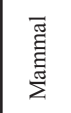 & 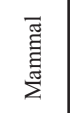 \\
\hline 言 & 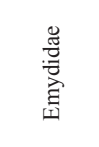 & 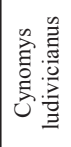 & 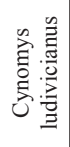 & 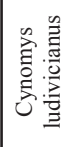 & 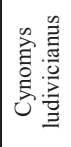 & 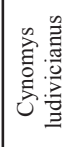 & 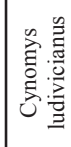 & 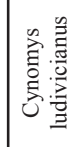 & 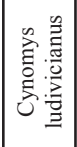 & 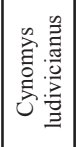 & 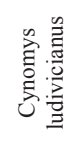 & 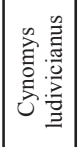 & 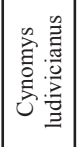 & 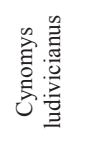 & 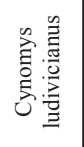 & 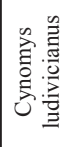 & 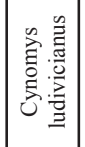 & 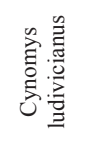 & 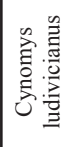 & 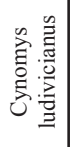 \\
\hline 茄 & aे & 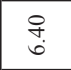 & â & $\begin{array}{l}\stackrel{a}{a} \\
\dot{0}\end{array}$ & ঙิগ & $\stackrel{ \pm}{I}$ & $\stackrel{\Re}{-}$ & $\stackrel{\widetilde{m}}{-}$ & ț & $\stackrel{n}{6}$ & $\stackrel{m}{\stackrel{m}{*}}$ & f. & : & $\because$ & $\begin{array}{l}0 \\
0 \\
0\end{array}$ & $\stackrel{ \pm}{\circ}$ & $\frac{n}{0}$ & $?$ & $\stackrel{ \pm}{0}$ & $\stackrel{0}{0}$ \\
\hline$\overline{\bar{z}}$ & - & - & - & - & - & - & - & - & - & - & - & - & - & - & - & - & - & - & - & - \\
\hline$\stackrel{F}{E}$ & $\circ$ & $\circ$ & $\circ$ & $\circ$ & $\circ$ & $\circ$ & $\circ$ & $\circ$ & $\circ$ & 0 & $\circ$ & $\circ$ & $\circ$ & $\circ$ & $\circ$ & $\circ$ & $\circ$ & $\circ$ & $\circ$ & $\circ$ \\
\hline 高 & 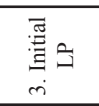 & 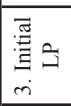 & 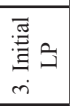 & 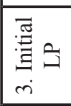 & 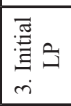 & 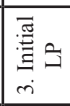 & 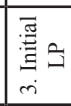 & 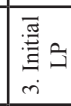 & \begin{tabular}{|l|} 
焉 \\
m \\
i \\
\end{tabular} & \begin{tabular}{|l|} 
焉 \\
m \\
m \\
\end{tabular} & 焉 & 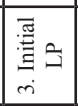 & 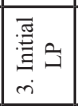 & 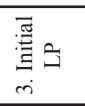 & 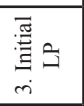 & 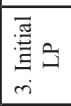 & 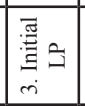 & 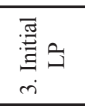 & 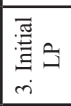 & 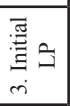 \\
\hline 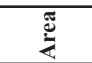 & m & $m$ & $m$ & $n$ & $m$ & $m$ & $m$ & $m$ & $m$ & $m$ & $m$ & m & m & $m$ & m & $m$ & m & m & $m$ & $m$ \\
\hline 童高 & $\begin{array}{l}\infty \\
1 \\
1\end{array}$ & $\begin{array}{l}\infty \\
\infty \\
1 \\
2\end{array}$ & $\begin{array}{l}0 \\
0 \\
1 \\
2\end{array}$ & $\begin{array}{l}0 \\
0 \\
1 \\
2\end{array}$ & $\begin{array}{l}\infty \\
\infty \\
1 \\
2\end{array}$ & $\begin{array}{l}8 \\
0 \\
1 \\
2\end{array}$ & $\begin{array}{l}0 \\
0 \\
1 \\
2\end{array}$ & $\begin{array}{l}0 \\
\infty \\
1 \\
2\end{array}$ & $\begin{array}{l}0 \\
0 \\
1 \\
\vdots\end{array}$ & $\begin{array}{l}0 \\
0 \\
1 \\
\vdots\end{array}$ & $\begin{array}{l}\infty \\
1 \\
1\end{array}$ & $\begin{array}{l}0 \\
\infty \\
1 \\
1\end{array}$ & $\begin{array}{l}0 \\
\vdots \\
\vdots \\
i\end{array}$ & $\begin{array}{l}0 \\
0 \\
1 \\
i\end{array}$ & $\begin{array}{l}\infty \\
0 \\
1 \\
2\end{array}$ & $\begin{array}{l}\infty \\
0 \\
1 \\
2\end{array}$ & $\begin{array}{l}0 \\
\dot{0} \\
\vdots \\
i\end{array}$ & $\begin{array}{l}0 \\
0 \\
i \\
i\end{array}$ & $\begin{array}{l}\infty \\
\infty \\
1 \\
2\end{array}$ & $\begin{array}{l}0 \\
\infty \\
1 \\
1\end{array}$ \\
\hline$\dot{\vec{j}}$ & ${ }_{\infty}^{\circ}$ & ${ }_{\infty}^{\circ}$ & $\begin{array}{l}0 \\
\infty\end{array}$ & $\begin{array}{l}0 \\
\infty\end{array}$ & $\begin{array}{l} \\
\infty\end{array}$ & $\stackrel{\circ}{\circ}$ & $\stackrel{\circ}{\infty}$ & $\stackrel{0}{\infty}$ & ${ }_{\infty}^{\circ}$ & ${ }_{\dot{\infty}}$ & $\dot{D}_{\infty}$ & ${ }_{\infty}^{\circ}$ & ${ }_{\infty}^{\circ}$ & ${ }_{\infty}^{\circ}$ & ${ }_{\infty}$ & $\begin{array}{l}0 \\
\infty\end{array}$ & $P_{\infty}$ & ${ }_{\infty}^{0}$ & $\begin{array}{l}0 \\
\infty\end{array}$ & ${ }_{\infty}^{\circ}$ \\
\hline 㟶 & $\begin{array}{l}8 \\
\\
\end{array}$ & $\begin{array}{l}\stackrel{8}{8} \\
=\end{array}$ & $\begin{array}{l}8 \\
\\
\end{array}$ & $\begin{array}{l}8 \\
\\
1\end{array}$ & $\begin{array}{l}\stackrel{8}{8} \\
=\end{array}$ & $\begin{array}{l}8 \\
\\
=\end{array}$ & $\begin{array}{l}8 \\
\end{array}$ & $\begin{array}{l}8 \\
\end{array}$ & $\stackrel{8}{8}$ & $\begin{array}{l}8 \\
\\
\end{array}$ & $\begin{array}{l}8 \\
\\
\end{array}$ & $\stackrel{8}{\stackrel{8}{I}}$ & $\begin{array}{l}8 \\
\\
\end{array}$ & $\begin{array}{l}8 \\
\end{array}$ & $\stackrel{8}{8}$ & \begin{tabular}{|l|}
$\stackrel{8}{9}$ \\
\end{tabular} & $\begin{array}{l}8 \\
\\
\end{array}$ & $\begin{array}{l}8 \\
\\
\end{array}$ & $\begin{array}{l}\stackrel{8}{8} \\
=\end{array}$ & $\begin{array}{l}8 \\
\stackrel{5}{I}\end{array}$ \\
\hline 意 & $\begin{array}{l}8 \\
\dot{m} \\
\dot{m}\end{array}$ & \begin{tabular}{|l|}
8 \\
$j$ \\
\end{tabular} & $\begin{array}{l}8 \\
\dot{1} \\
\dot{m}\end{array}$ & $\begin{array}{l}8 \\
\dot{j} \\
\end{array}$ & $\begin{array}{l}8 \\
\dot{m} \\
\dot{m}\end{array}$ & $\begin{array}{l}8 \\
\dot{m} \\
\end{array}$ & $\begin{array}{l}8 \\
\dot{m} \\
\end{array}$ & $\begin{array}{l}8 \\
\dot{m} \\
\end{array}$ & 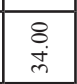 & 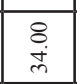 & $\begin{array}{l}8 \\
\dot{1} \\
\dot{m}\end{array}$ & 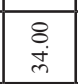 & $\begin{array}{l}8 \\
\dot{j} \\
\dot{m}\end{array}$ & $\begin{array}{l} \\
\\
\dot{m}\end{array}$ & $\begin{array}{l}8 \\
\\
j \\
j\end{array}$ & \begin{tabular}{|l|}
8 \\
\\
\\
\end{tabular} & $\begin{array}{l}g \\
\dot{f} \\
\end{array}$ & $\begin{array}{l}g \\
\dot{f} \\
\end{array}$ & $\begin{array}{l}8 \\
\dot{f} \\
\end{array}$ & $\begin{array}{l}8 \\
\\
\dot{m}\end{array}$ \\
\hline $\bar{\Xi}$ & ¿ & ঃั & ¿ & ঃั & ঃั & ঃু & ঃั & \&ু & ஃ & ঃু & : & \&ু & ¿ू & ঃু & ஃ & ঃั & ڤু & ஃু & ঃั & \& \\
\hline 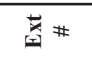 & 0 & 0 & 0 & 0 & 0 & 0 & 0 & 0 & 0 & 0 & 0 & 0 & 0 & 0 & 0 & 0 & 0 & 0 & 0 & 0 \\
\hline 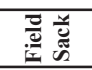 & 守 & ? & 过 & i & ? & 앙 & 导 & 商 & 秥 & 过 & 앙 & 秥 & 过 & 过 & 웅 & 奀 & 过 & 品 & 过 & 웅 \\
\hline
\end{tabular}




\begin{tabular}{|c|c|c|c|c|c|c|c|c|c|c|c|c|c|c|c|c|c|c|c|c|c|}
\hline 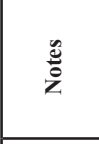 & 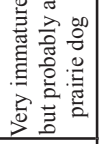 & 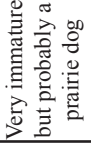 & & & & & & 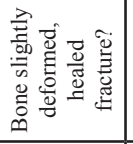 & & & & & & & & 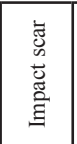 & & & & & \\
\hline 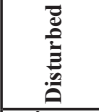 & $>$ & $>$ & $\succ$ & $>$ & $\lambda$ & & & & $\succ$ & $\succ$ & $>$ & & $>$ & & & & & & & & \\
\hline 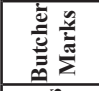 & z & z & z & z & z & z & z & z & z & z & z & z & z & z & z & $>$ & z & z & z & z & z \\
\hline 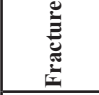 & z & z & छ & z & 咅 & E & $\vec{a}$ & ह & 离 & 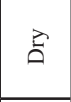 & z & 코 & 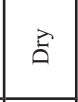 & 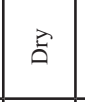 & z & E & 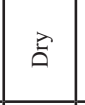 & $\vec{\Delta}$ & 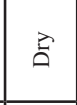 & 吾 & 코 \\
\hline 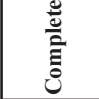 & z & z & z & z & z & z & z & z & $z$ & z & $>$ & z & z & z & $>$ & z & z & z & z & z & z \\
\hline 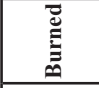 & z & z & $z$ & $>$ & $\succ$ & z & z & z & $\lambda$ & $>$ & z & z & $>$ & z & z & z & z & z & z & z & z \\
\hline 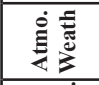 & z & z & z & z & z & z & z & z & z & z & z & z & z & z & z & z & z & z & z & z & z \\
\hline 醇 & z & z & 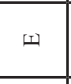 & z & - & z & z & z & $n$ & z & $n$ & z & $\infty$ & z & z & $n$ & 피 & $\omega$ & $\omega$ & $\Sigma$ & 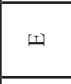 \\
\hline & 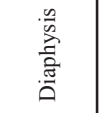 & 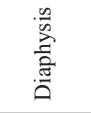 & & 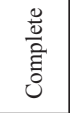 & & & & 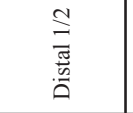 & & & $\begin{array}{l}\frac{0}{0} \\
\frac{\tilde{0}}{\bar{\Xi}} \\
\frac{0}{0}\end{array}$ & & & & 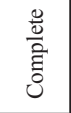 & & & & & & \\
\hline 离 & 竭 & 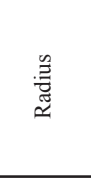 & & 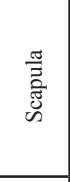 & & & & 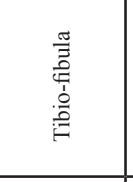 & & & 䓌 & & & & 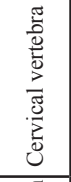 & & & & & & \\
\hline 密苋 & $\begin{array}{l} \\
\\
i \\
i \\
\end{array}$ & $\begin{array}{l} \\
\text { in } \\
i \\
\end{array}$ & \begin{tabular}{l}
\multirow{2}{*}{} \\
$\stackrel{8}{+}$ \\
\end{tabular} & \begin{tabular}{l|l} 
\\
0 \\
$i$ \\
$i$
\end{tabular} & - & - & - & $\begin{array}{l} \\
\\
i \\
i\end{array}$ & - & 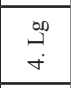 & $\begin{array}{l}\text { I } \\
\text { i } \\
\text { in }\end{array}$ & - & $\begin{array}{l} \\
\\
+ \\
+\end{array}$ & 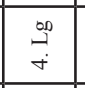 & $\begin{array}{l}=5 \\
\text { 量 } \\
- \\
\end{array}$ & 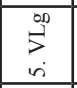 & $\begin{array}{l}0 \\
\stackrel{50}{+} \\
+\end{array}$ & - & 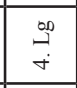 & 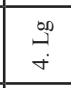 & 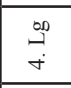 \\
\hline 参 & $\begin{array}{l}\bar{\Xi} \\
\text { 竧 } \\
\text { ¿ }\end{array}$ & 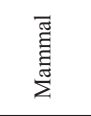 & 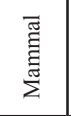 & 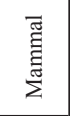 & $\begin{array}{l}\overline{\tilde{J}} \\
\overline{\bar{E}}\end{array}$ & 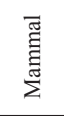 & 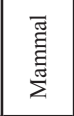 & 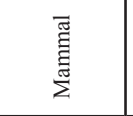 & 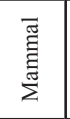 & 丞 & 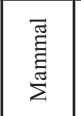 & 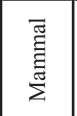 & 丞 & 褐 & \begin{tabular}{|l|}
$\bar{\Xi}$ \\
言 \\
喜
\end{tabular} & 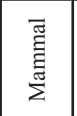 & 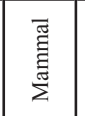 & $\begin{array}{l}\text { 完 } \\
\text { 㷼 }\end{array}$ & 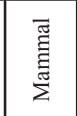 & 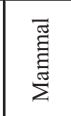 & 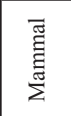 \\
\hline 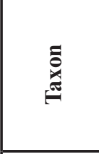 & 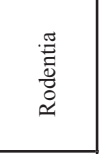 & 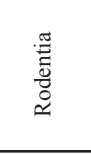 & 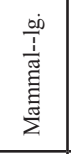 & 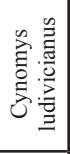 & $\begin{array}{l}\overline{\widetilde{J}} \\
\overline{\tilde{E}} \\
\overline{\tilde{E}}\end{array}$ & $\begin{array}{l}\overline{\underline{u}} \\
\overline{\bar{z}}\end{array}$ & 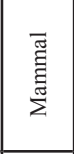 & 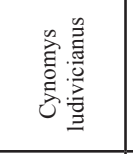 & 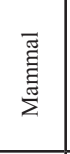 & 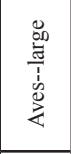 & 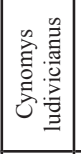 & 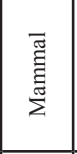 & 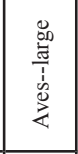 & 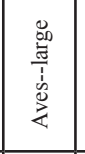 & 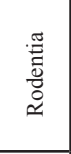 & 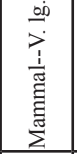 & 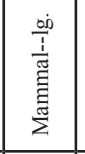 & $\begin{array}{l}\text { 慇 } \\
\text { 㷼 }\end{array}$ & 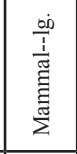 & 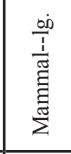 & 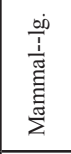 \\
\hline 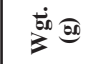 & $\stackrel{m}{0}$ & $\stackrel{\infty}{0}$ & $\stackrel{m}{i}$ & to & $\stackrel{\text { on }}{0}$ & $\frac{9}{0}$ & ֻٓ & $\stackrel{9}{\rightarrow}$ & తి & $\stackrel{ \pm}{ \pm}$ & $\stackrel{?}{-}$ & ֻิ & $\begin{array}{l}\text { fo } \\
\text { - }\end{array}$ & $\stackrel{\infty}{0}$ & $\overline{\overline{0}}$ & : & $\stackrel{\circ}{\text { aे }}$ & $\begin{array}{l}\text { בิ } \\
\text { : }\end{array}$ & సે & $\stackrel{\infty}{\stackrel{\infty}{n}}$ & $\stackrel{\text { and }}{a}$ \\
\hline 竞 & - & - & - & - & - & - & - & - & - & $\sim$ & - & - & 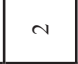 & 4 & - & - & $=$ & 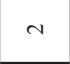 & $m$ & $\sigma$ & - \\
\hline 兽 & 0 & $\circ$ & $\circ$ & 0 & 0 & - & - & - & 0 & $\circ$ & 0 & - & 0 & - & - & - & 0 & - & - & - & - \\
\hline 䓊总 & 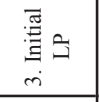 & 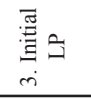 & 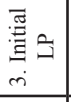 & 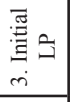 & 嘿 & 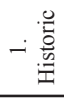 & $-\frac{0}{0}$ & 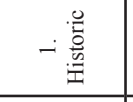 & 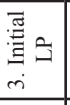 & 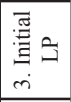 & 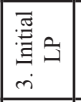 & 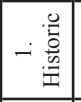 & \begin{tabular}{|l|l|} 
焉 \\
m \\
\end{tabular} & 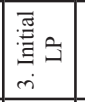 & 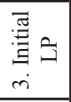 & 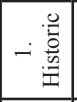 & 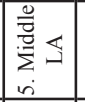 & 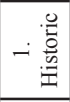 & 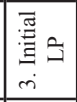 & 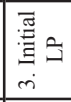 & 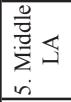 \\
\hline 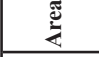 & $n$ & m & n & $n$ & $n$ & $n$ & $m$ & $n$ & $n$ & $n$ & m & $n$ & $n$ & $n$ & $n$ & $n$ & $n$ & $m$ & $m$ & $n$ & $n$ \\
\hline 童高 & $\begin{array}{l}2 \\
8 \\
0 \\
\infty\end{array}$ & $\begin{array}{l}8 \\
\vdots \\
\infty\end{array}$ & $\begin{array}{l}R \\
1 \\
b\end{array}$ & $\begin{array}{l}8 \\
1 \\
1 \\
0\end{array}$ & $\begin{array}{l}8 \\
\frac{1}{1} \\
\vdots \\
8\end{array}$ & $\begin{array}{l}\text { ôn } \\
\text { 山ें }\end{array}$ & $\begin{array}{l}q \\
+ \\
0 \\
0 \\
m\end{array}$ & $\begin{array}{l}n \\
b \\
\vdots \\
a\end{array}$ & \begin{tabular}{l}
$\infty$ \\
\multirow{2}{\alpha}{} \\
$\dot{1}$
\end{tabular} & $\begin{array}{l}8 \\
1 \\
8 \\
0\end{array}$ & $\begin{array}{l}8 \\
8 \\
1 \\
\infty\end{array}$ & $\begin{array}{l}\text { o } \\
\text { d } \\
\text { d }\end{array}$ & 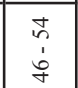 & $\begin{array}{l}8 \\
1 \\
1 \\
8\end{array}$ & $\begin{array}{l}8 \\
1 \\
1 \\
0\end{array}$ & 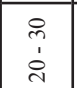 & 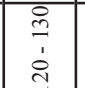 & $\begin{array}{l}0 \\
\text { n } \\
1 \\
a\end{array}$ & $\begin{array}{l}8 \\
1 \\
1 \\
n\end{array}$ & $\begin{array}{l}8 \\
\vdots \\
\vdots \\
\infty\end{array}$ & 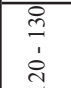 \\
\hline$\dot{\overrightarrow{3}}$ & $\stackrel{8}{\circ}$ & $\stackrel{8}{\circ}$ & $\rightleftarrows$ & $\vec{\pi}$ & $\stackrel{\circ}{\circ}$ & $\stackrel{\mathrm{c}}{\mathrm{i}}$ & $\begin{array}{l} \\
\end{array}$ & is & $\overrightarrow{\underline{\Xi}}$ & $\stackrel{8}{\circ}$ & $\stackrel{8}{\circ}$ & $\stackrel{\circ}{+}$ & $\overrightarrow{6}$ & $\stackrel{8}{i}$ & $\stackrel{9}{\circ}$ & $\stackrel{i}{i}$ & ì & is & 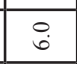 & $\stackrel{\circ}{\circ}$ & iे \\
\hline $\begin{array}{l}\dot{\vec{m}} \\
\text { 垔 }\end{array}$ & $\begin{array}{l}8 \\
\end{array}$ & $\stackrel{8}{\stackrel{8}{\leftrightarrows}}$ & $\begin{array}{l} \\
\stackrel{8}{-} \\
\end{array}$ & $\begin{array}{l}8 \\
\infty \\
\\
\end{array}$ & $\begin{array}{l} \\
\dot{\infty} \\
\\
\end{array}$ & $\begin{array}{l}8 \\
\stackrel{0}{0} \\
\end{array}$ & $\begin{array}{l}8 \\
\infty \\
\infty \\
\end{array}$ & $\begin{array}{l}8 \\
\dot{\infty} \\
\dot{4} \\
\end{array}$ & $\stackrel{8}{\stackrel{8}{\leftrightarrows}}$ & $\begin{array}{l} \\
\\
\infty \\
\end{array}$ & $\begin{array}{l} \\
\stackrel{8}{\infty} \\
\end{array}$ & 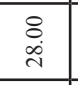 & $\begin{array}{l}8 \\
\\
\end{array}$ & 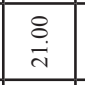 & $\begin{array}{l}8 \\
\overrightarrow{4} \\
\end{array}$ & \begin{tabular}{l|}
8 \\
i \\
\end{tabular} & $\begin{array}{l}8 \\
\ddot{\lambda} \\
\end{array}$ & $\begin{array}{l}8 \\
\dot{4} \\
\end{array}$ & $\begin{array}{l}8 \\
\dot{4} \\
\end{array}$ & $\begin{array}{l}8 \\
\dot{4} \\
\end{array}$ & $\begin{array}{l}8 \\
\dot{1} \\
\end{array}$ \\
\hline 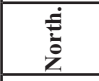 & $\begin{array}{l}8 \\
\dot{m} \\
\end{array}$ & $\begin{array}{l}8 \\
\dot{m} \\
\end{array}$ & $\begin{array}{l}8 \\
\dot{0} \\
\end{array}$ & $\begin{array}{l}8 \\
\dot{m} \\
\end{array}$ & $\begin{array}{l}8 \\
\dot{1} \\
\end{array}$ & $\begin{array}{l}8 \\
\\
\dot{m} \\
\end{array}$ & 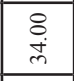 & 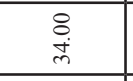 & $\begin{array}{l}8 \\
\text { in } \\
\text { ch }\end{array}$ & \begin{tabular}{|c|}
8 \\
$\dot{c}$ \\
$n$
\end{tabular} & $\begin{array}{l}8 \\
\dot{m} \\
m\end{array}$ & $\begin{array}{l}8 \\
8 \\
m \\
m\end{array}$ & \begin{tabular}{|l|}
8 \\
\\
$i$ \\
$m$
\end{tabular} & $\begin{array}{l}8 \\
\\
0\end{array}$ & $\begin{array}{l}8 \\
0 \\
i \\
\end{array}$ & $\begin{array}{l}8 \\
0 \\
i \\
\end{array}$ & $\begin{array}{l}8 \\
\\
\text { c. }\end{array}$ & \begin{tabular}{|l|}
8 \\
0 \\
\end{tabular} & $\begin{array}{l}8 \\
\\
i \\
\end{array}$ & $\begin{array}{l}8 \\
\\
i \\
\end{array}$ & $\begin{array}{l}8 \\
0 \\
i \\
\end{array}$ \\
\hline$\stackrel{\circ}{9}$ & 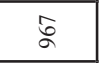 & 5 & $\vec{a}$ & $\overrightarrow{5}$ & 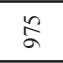 & 芩 & 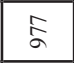 & $\begin{array}{l}\infty \\
\vdots \\
\vdots\end{array}$ & 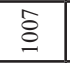 & $\stackrel{\circ}{\Xi}$ & $\stackrel{ \pm}{\Xi}$ & $\stackrel{\infty}{\Xi}$ & \begin{tabular}{|l|l}
\multirow{0}{*}{} \\
.
\end{tabular} & 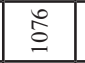 & $\begin{array}{ll}0 \\
\vdots \\
\end{array}$ & 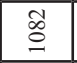 & $\stackrel{\widetilde{\Omega}}{\leftrightarrows}$ & $\stackrel{\circ}{=}$ & $\begin{array}{l}\stackrel{\circ}{\leftrightarrows} \\
\end{array}$ & $\stackrel{g}{g}$ & $\stackrel{m}{\Xi}$ \\
\hline $\begin{array}{l}\bar{y}^{*} \\
\end{array}$ & 0 & 0 & 0 & 0 & 0 & 0 & 0 & 0 & 0 & 0 & 0 & 0 & 0 & 0 & 0 & 0 & 0 & 0 & 0 & 0 & 0 \\
\hline 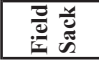 & 莺 & t & 5. & in & $\stackrel{\infty}{\circ}$ & 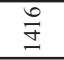 & $\begin{array}{l}\tilde{I} \\
\mathcal{I}\end{array}$ & 导 & $\stackrel{\infty}{\infty}$ & $\begin{array}{l}\infty \\
\infty \\
\infty \\
n\end{array}$ & 咅 & I & 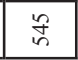 & $\stackrel{\overleftarrow{b}}{+}$ & 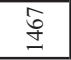 & 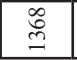 & $\begin{array}{l}\infty \\
\infty \\
\end{array}$ & I্ & 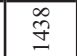 & 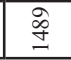 & $\begin{array}{l}\tilde{n}^{\infty} \\
\end{array}$ \\
\hline
\end{tabular}




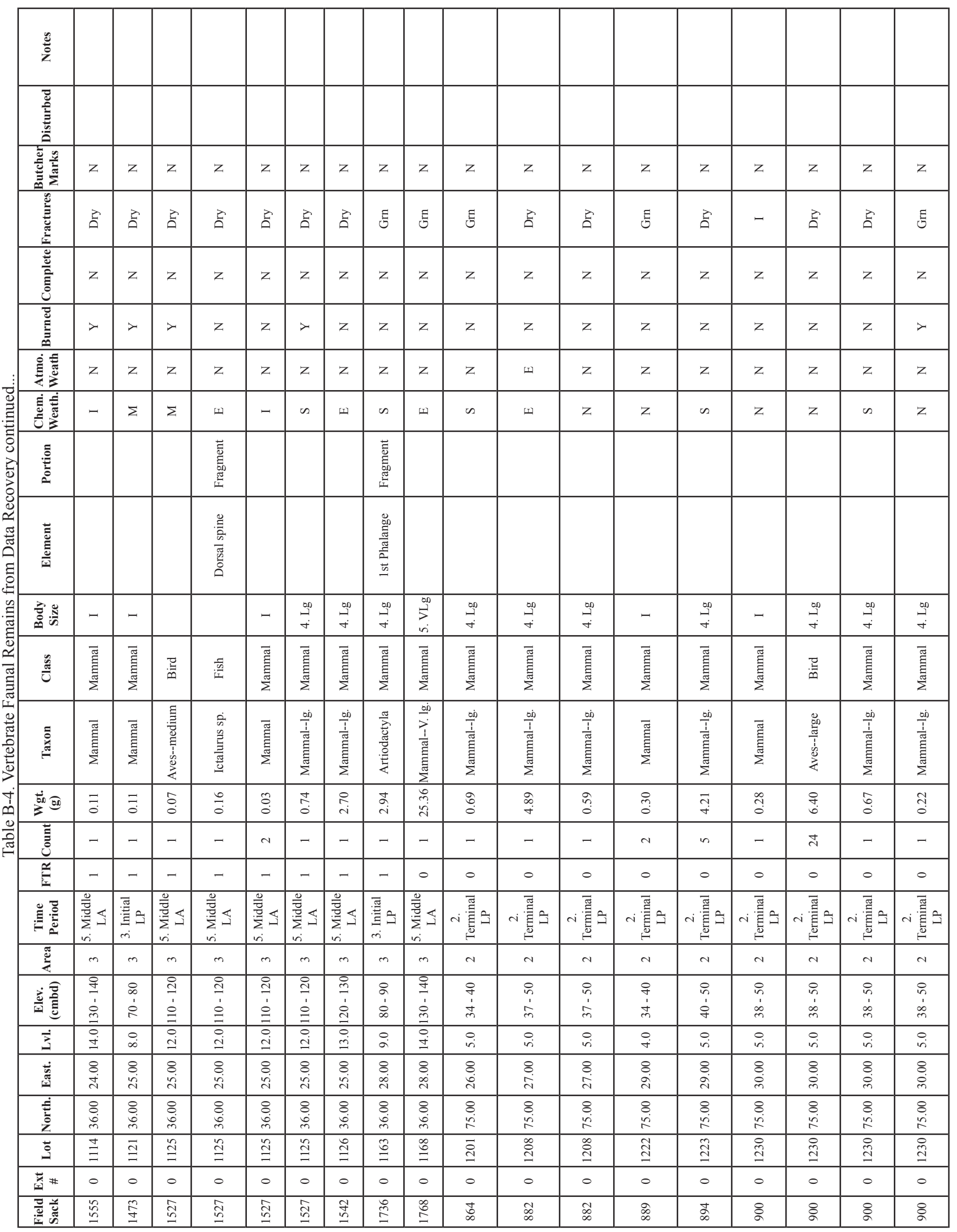




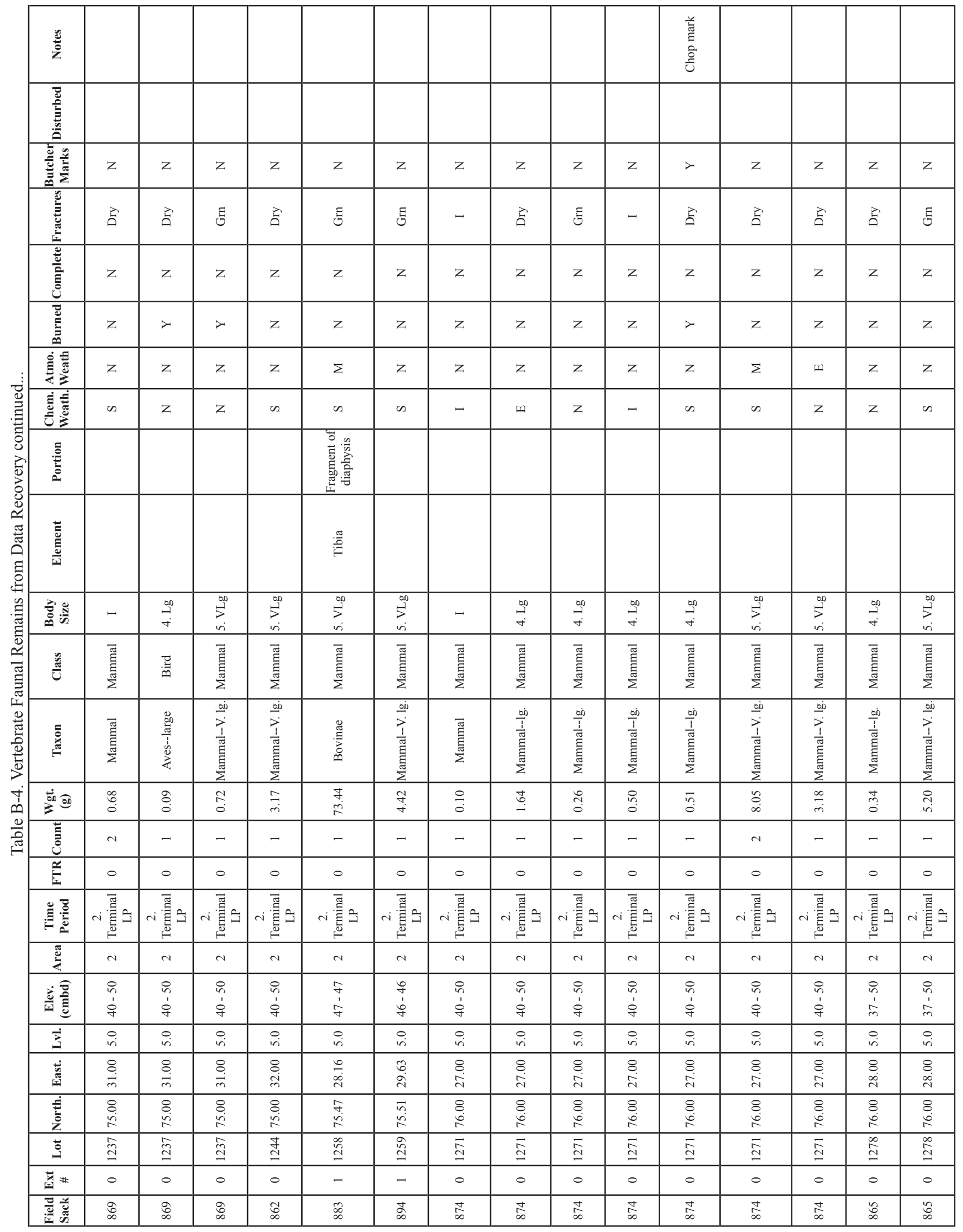




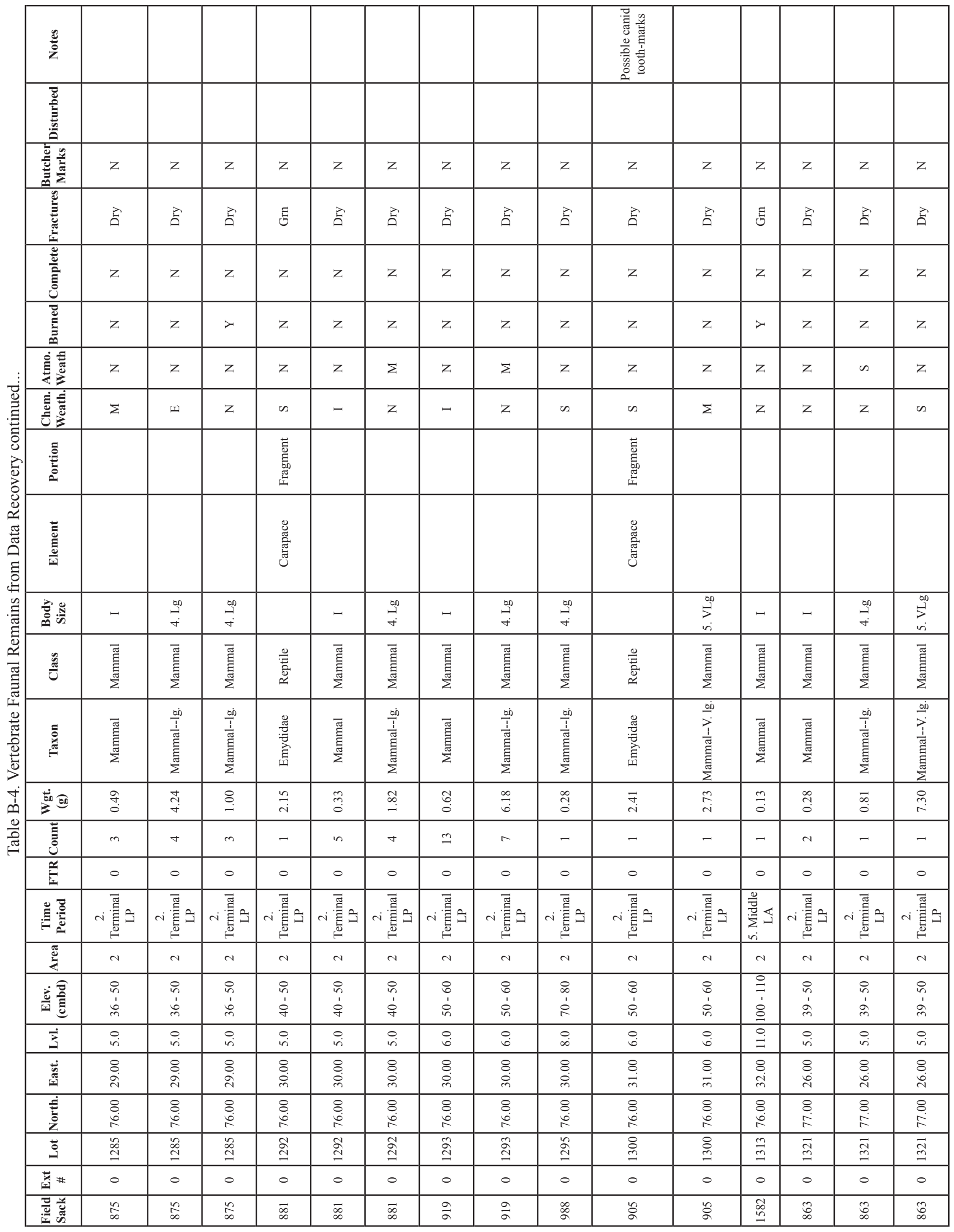




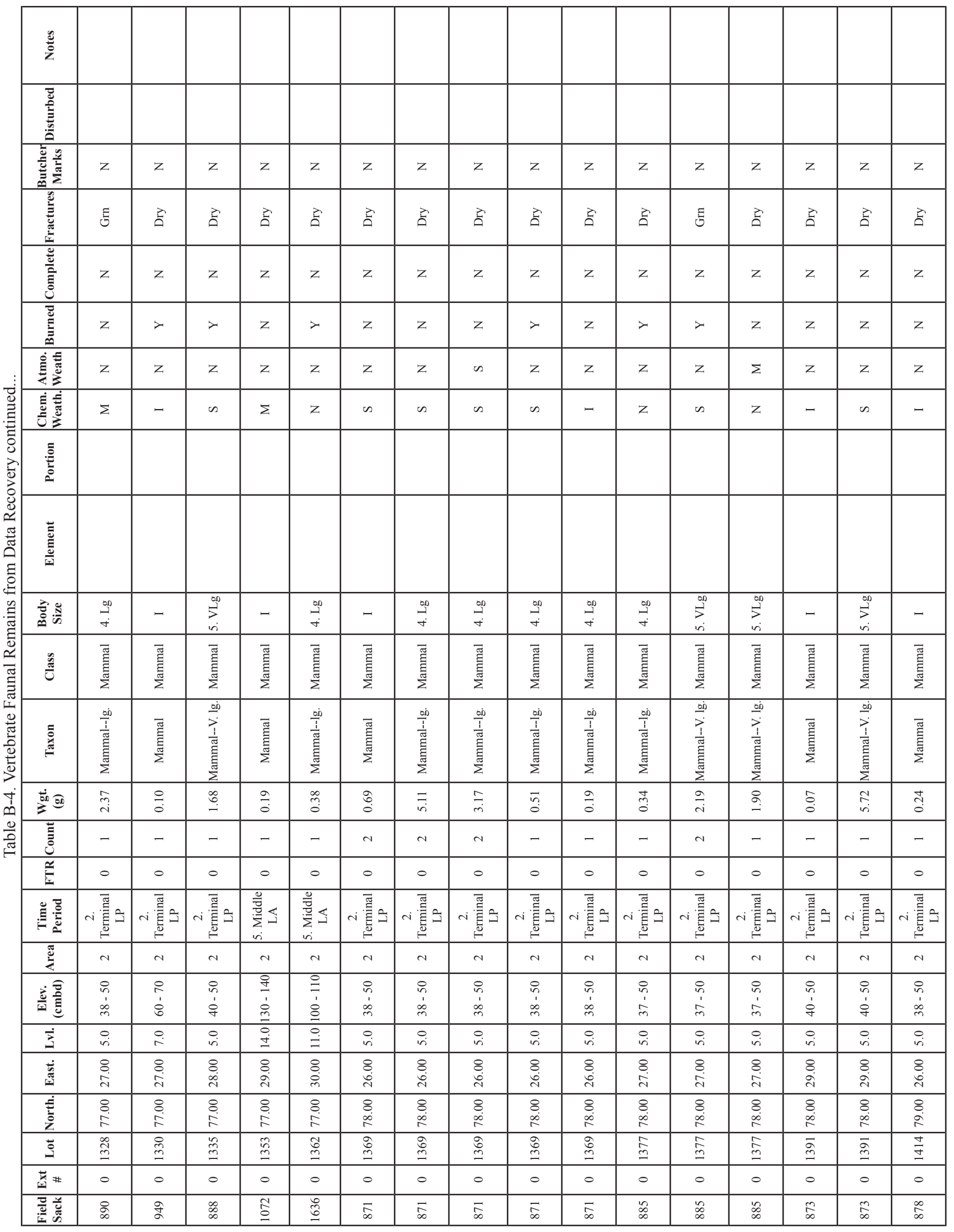




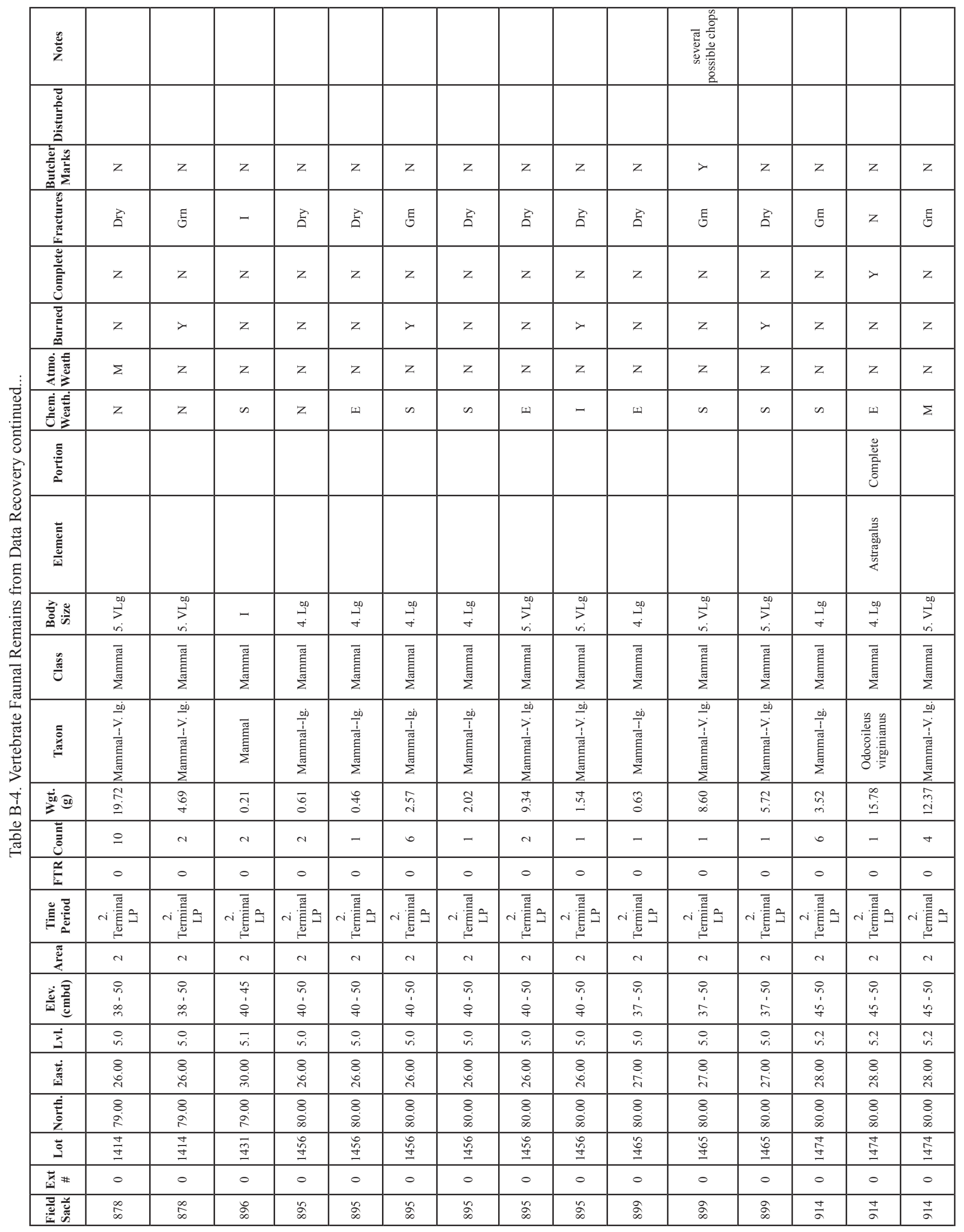




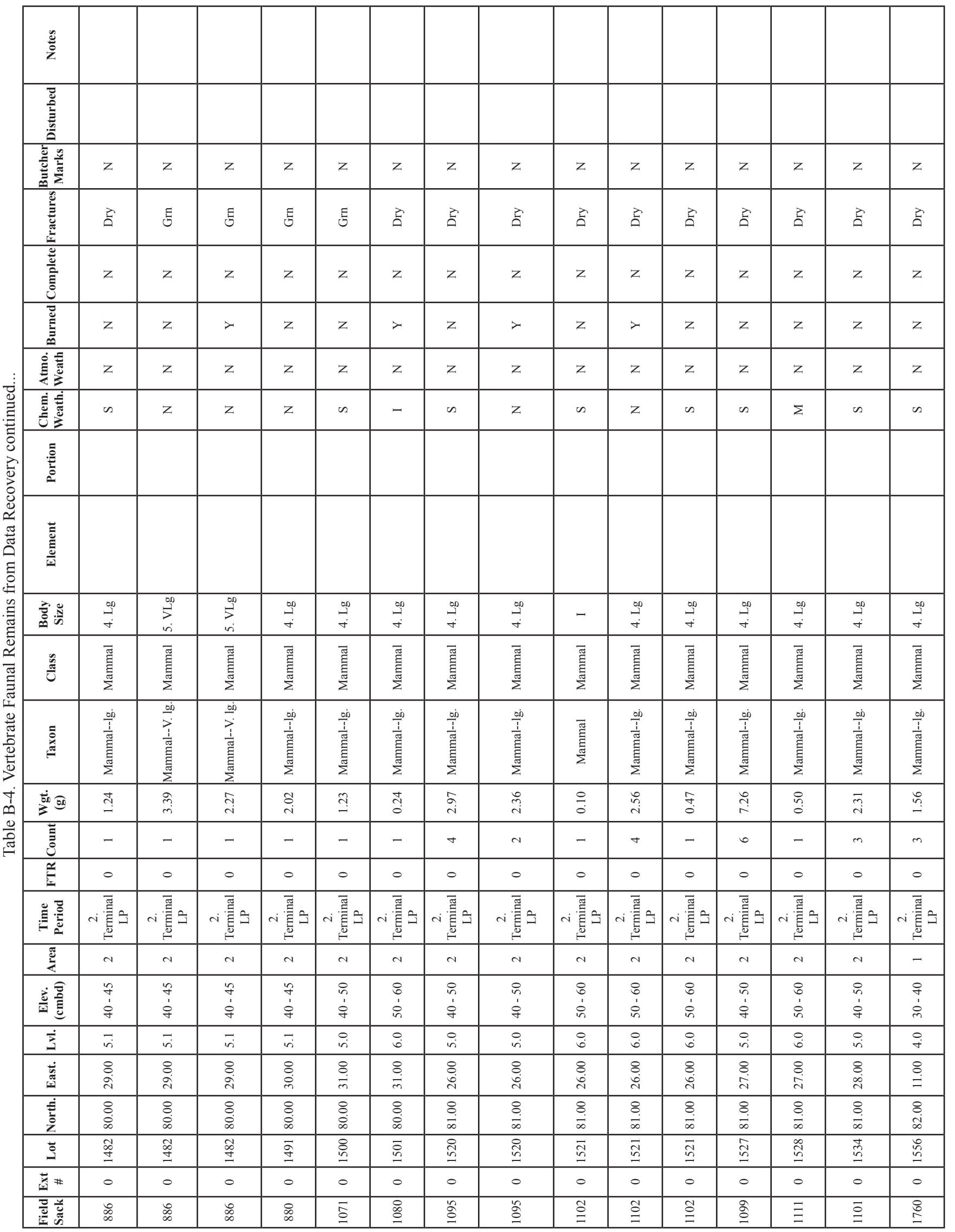




\begin{tabular}{|c|c|c|c|c|c|c|c|c|c|c|c|c|c|c|c|}
\hline : & & & & & & & & & & & & & & 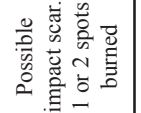 & \\
\hline 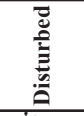 & & & & & & & & & & & & & & & \\
\hline 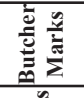 & z & z & z & z & z & z & z & z & z & z & z & z & z & $>$ & z \\
\hline 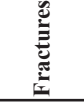 & - & E & - & $\vec{\Delta}$ & E & $\vec{a}$ & - & - & 空 & $\overrightarrow{8}$ & E & 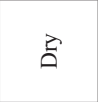 & E & E & - \\
\hline 苋 & z & z & z & $\mathrm{z}$ & z & z & z & z & z & z & z & z & z & z & z \\
\hline 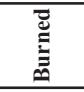 & z & z & $\lambda$ & $\mathrm{z}$ & z & z & z & $>$ & z & z & z & z & z & $\succ$ & z \\
\hline 㝘焉 & z & z & z & $z$ & z & z & z & z & z & z & z & z & z & $n$ & z \\
\hline 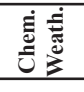 & - & $n$ & $\Sigma$ & $\Sigma$ & z & z & - & - & $n$ & n & n & - & z & $\Sigma$ & $n$ \\
\hline 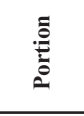 & & & & & & & & & & & & & & & \\
\hline 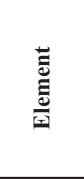 & & & & & & & & & & & & & & & \\
\hline 递芯 & - & $\begin{array}{l}\sum_{0}^{\infty 0} \\
i\end{array}$ & $\stackrel{\substack{f \\
+}}{+}$ & $\begin{array}{l}\stackrel{\infty}{9} \\
+ \\
+\end{array}$ & $\begin{array}{l}00 \\
\stackrel{50}{5} \\
\text { in }\end{array}$ & - & - & - & $\begin{array}{l}+00 \\
\stackrel{+}{+} \\
+\end{array}$ & $\begin{array}{l}\stackrel{50}{+} \\
\dot{n}\end{array}$ & 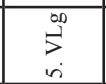 & - & 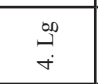 & $\begin{array}{l}{ }^{\infty} \\
\stackrel{5}{1} \\
i\end{array}$ & $\begin{array}{l}\text { on } \\
\stackrel{+}{+}\end{array}$ \\
\hline 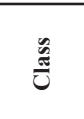 & $\begin{array}{l}\overline{\tilde{I}} \\
\text { 言 }\end{array}$ & $\begin{array}{l}\text { 嵒 } \\
\text { 产 }\end{array}$ & $\begin{array}{l}\text { 辴 } \\
\text { 产 }\end{array}$ & 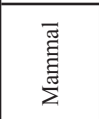 & 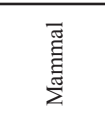 & $\begin{array}{l}\text { 氶 } \\
\text { 镸 }\end{array}$ & 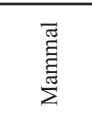 & 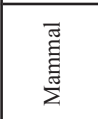 & 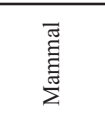 & 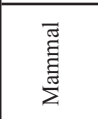 & 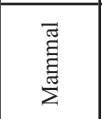 & 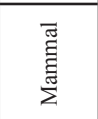 & $\begin{array}{l}\text { 氶 } \\
\text { 镸 }\end{array}$ & $\begin{array}{l}\text { 㧛 } \\
\text { 镸 }\end{array}$ & 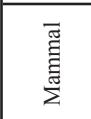 \\
\hline 言 & 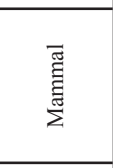 & 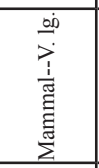 & 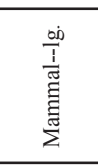 & 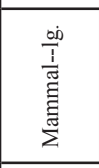 & 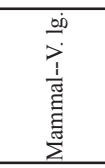 & 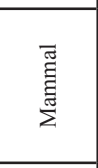 & 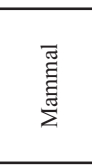 & $\begin{array}{l}\overline{\text { II }} \\
\text { 言 }\end{array}$ & 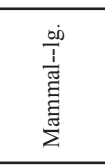 & 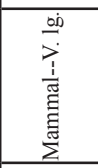 & 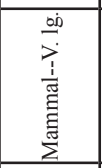 & 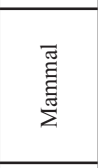 & 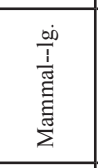 & 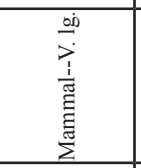 & 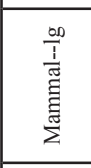 \\
\hline$\dot{s}^{+\infty}$ & के. & $\begin{array}{l}\text { के } \\
\text { ¿ें }\end{array}$ & $\bar{\sigma}$ & : & in & $\stackrel{9}{0}$ & $\stackrel{\Xi}{ت}$ & $\stackrel{0}{\circ}$ & $\stackrel{i}{-}$ & $\begin{array}{l}\Delta \\
\infty \\
\infty\end{array}$ & $\stackrel{\substack{n \\
i}}{i}$ & ণิ่ & ڤై & సै. & 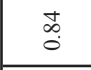 \\
\hline $\bar{E}$ & a & - & a & - & a & a & $m$ & - & a & + & - & - & - & - & a \\
\hline$\stackrel{\widetilde{F}}{\mathrm{~F}}$ & 0 & 0 & 0 & 0 & 0 & 0 & 0 & 0 & 0 & 0 & 0 & 0 & 0 & 0 & $\circ$ \\
\hline 气 & 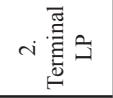 & $\mathrm{Ni}$ & 小蛋 & $\mathrm{i}$ & 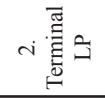 & i & 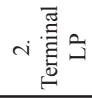 & 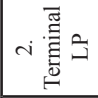 & 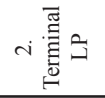 & i & $\mathrm{N}$ 要 & i & $\mathrm{N}$ i & 小襡 & $\therefore$ 票 \\
\hline 比 & - & - & - & - & - & - & - & - & - & - & - & - & - & - & - \\
\hline 产 & 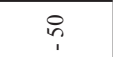 & in & q & q & q & 8 & q & q & q & q & q & in & $\frac{9}{9}$ & q & in \\
\hline 齿 & á & 字 & 官 & 㝏 & ஓं & 官 & $\stackrel{\infty}{i}$ & $\stackrel{\infty}{i}$ & $\stackrel{\infty}{i}$ & $\stackrel{1}{i}$ & $\stackrel{1}{1}$ & ’́ & ஓं & 㝏 & 字 \\
\hline$\dot{\vec{j}}$ & ir & ir & $\stackrel{+}{+}$ & $\stackrel{\circ}{+}$ & $\stackrel{\circ}{\circ}$ & 8 & $\stackrel{+}{+}$ & $\stackrel{\circ}{\dot{+}}$ & $\stackrel{\circ}{+}$ & $\stackrel{\circ}{\dot{+}}$ & $\stackrel{+}{\dot{+}}$ & ir & $\stackrel{\circ}{\dot{+}}$ & $\stackrel{P}{+}$ & ir \\
\hline $\begin{array}{l}\dot{\vec{\Delta}} \\
\text { 离 } \\
\end{array}$ & $\stackrel{\odot}{\rightleftarrows}$ & 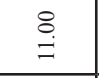 & 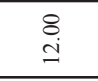 & 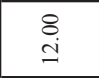 & 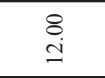 & 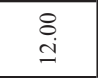 & $\begin{array}{l}\stackrel{8}{\mathrm{e}} \\
\mathrm{j}\end{array}$ & 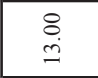 & 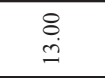 & $\underset{\leftrightarrow}{\stackrel{8}{9}}$ & $\stackrel{8}{\stackrel{8}{9}}$ & $\begin{array}{l}8 \\
\\
9\end{array}$ & $\begin{array}{l}8 \\
\dot{I}\end{array}$ & $\begin{array}{l}8 \\
\dot{+}\end{array}$ & $\begin{array}{l}8 \\
15\end{array}$ \\
\hline 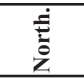 & 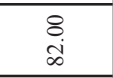 & 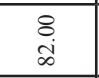 & $\begin{array}{l}\underset{8}{8} \\
\infty \\
\infty\end{array}$ & $\begin{array}{l}\underset{8}{8} \\
\infty \\
\infty\end{array}$ & 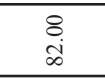 & $\begin{array}{l}\underset{\mathbb{i}}{8} \\
\infty \\
\infty\end{array}$ & 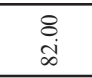 & $\begin{array}{l}\underset{8}{8} \\
\infty \\
\infty\end{array}$ & $\begin{array}{l}\underset{8}{i} \\
\infty \\
\infty\end{array}$ & $\begin{array}{l}\underset{8}{8} \\
\infty \\
\infty\end{array}$ & 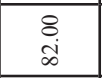 & $\begin{array}{c}\underset{i}{i} \\
\infty \\
\infty\end{array}$ & 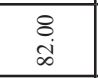 & 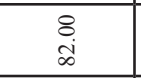 & $\begin{array}{l}\underset{8}{8} \\
\infty \\
\infty\end{array}$ \\
\hline 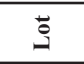 & $\stackrel{n}{n}$ & $\stackrel{n}{n}$ & $\begin{array}{l}\overrightarrow{0} \\
\stackrel{n}{n}\end{array}$ & $\begin{array}{l}\overrightarrow{0} \\
:\end{array}$ & $\begin{array}{l}\vec{b} \\
\text { n. }\end{array}$ & 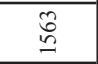 & 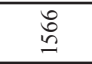 & 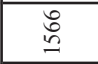 & 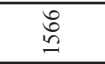 & 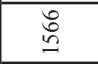 & 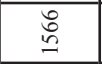 & 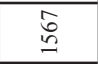 & $\bar{n}$ & $\bar{n}$ & 点 \\
\hline 蓄\# & 0 & 0 & 0 & 0 & 0 & 0 & 0 & 0 & 0 & 0 & 0 & 0 & 0 & $\circ$ & 0 \\
\hline 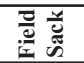 & $\begin{array}{l}\bar{\infty} \\
\stackrel{\Xi}{\Xi}\end{array}$ & $\overrightarrow{\underline{\infty}}$ & $\begin{array}{l}0 \\
\Xi\end{array}$ & $\begin{array}{l}0 \\
\vdots \\
\Xi\end{array}$ & $\begin{array}{l}0 \\
\stackrel{1}{\Xi}\end{array}$ & $\underset{\underline{\infty}}{\underline{\infty}}$ & 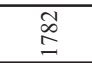 & $\begin{array}{l}\tilde{\infty} \\
\stackrel{\Sigma}{\triangle}\end{array}$ & $\begin{array}{l}\tilde{\infty} \\
\stackrel{\Sigma}{\Xi}\end{array}$ & $\begin{array}{l}\widetilde{D} \\
\stackrel{\infty}{\Xi}\end{array}$ & $\begin{array}{l}\tilde{\infty} \\
\stackrel{\infty}{\leftrightharpoons}\end{array}$ & $\begin{array}{l} \\
\searrow\end{array}$ & $\begin{array}{l}\mathscr{\infty} \\
\stackrel{\mathscr{D}}{\subseteq}\end{array}$ & $\stackrel{\mathscr{\infty}}{\stackrel{\infty}{\triangle}}$ & $\vec{\Phi}$ \\
\hline
\end{tabular}




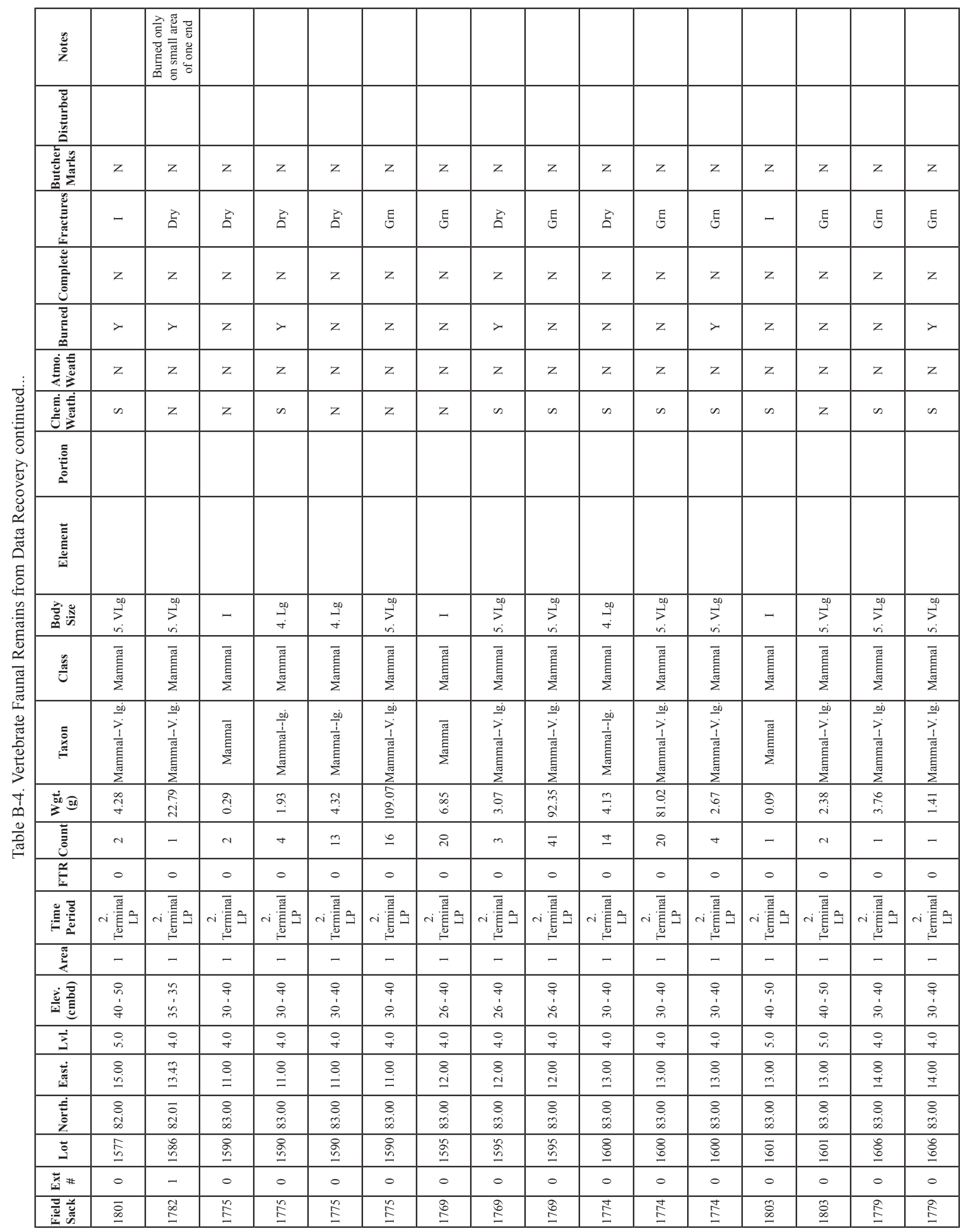




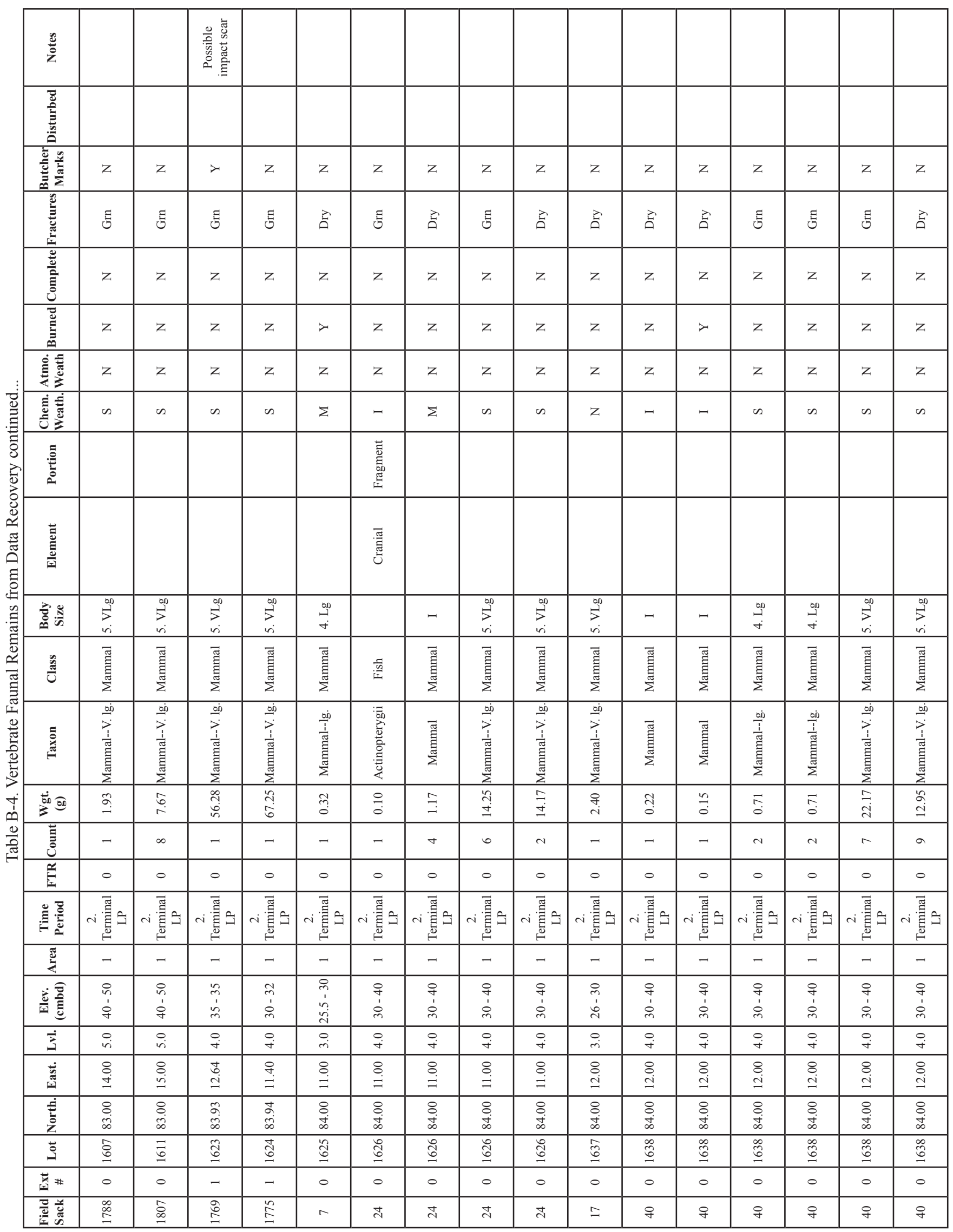




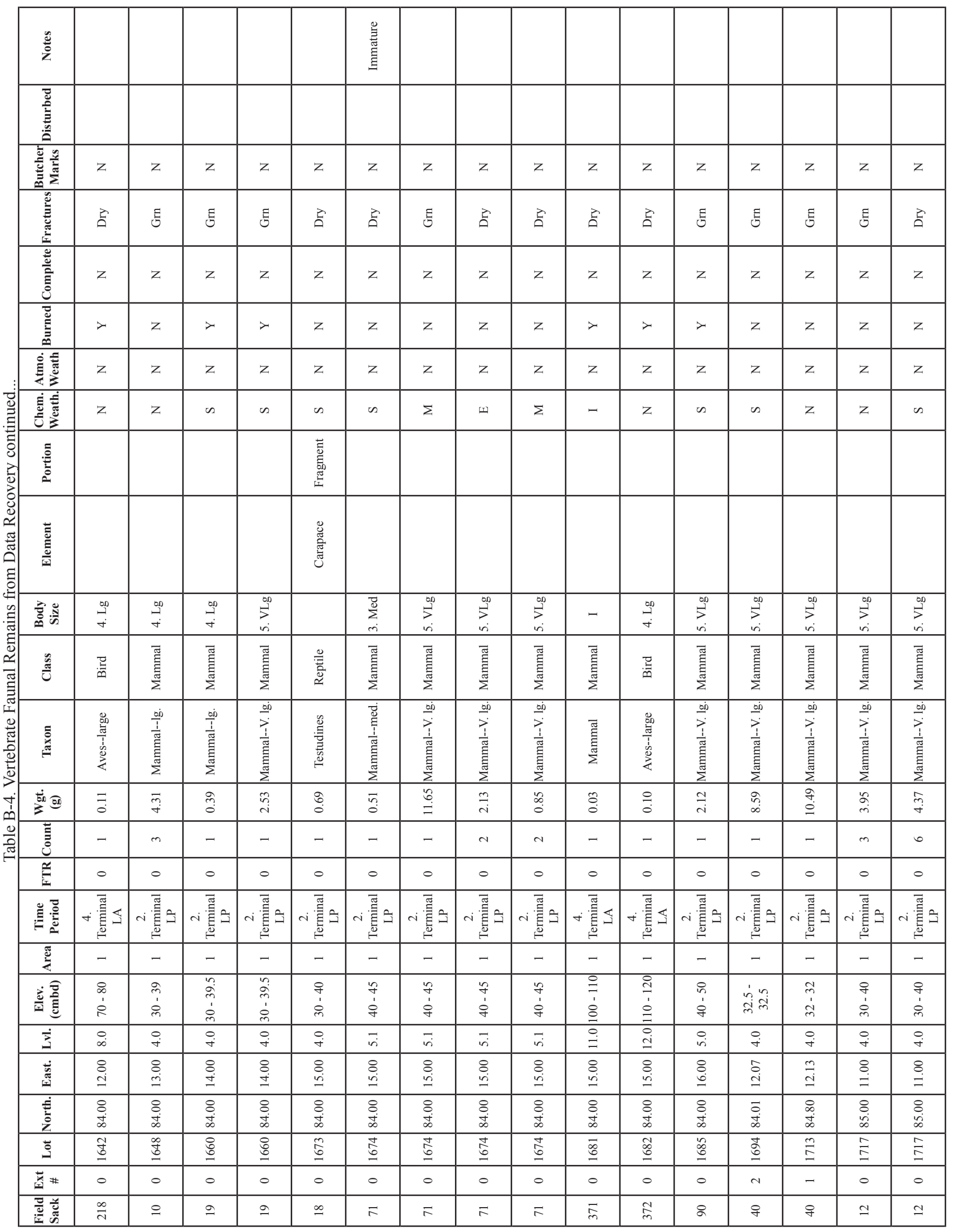




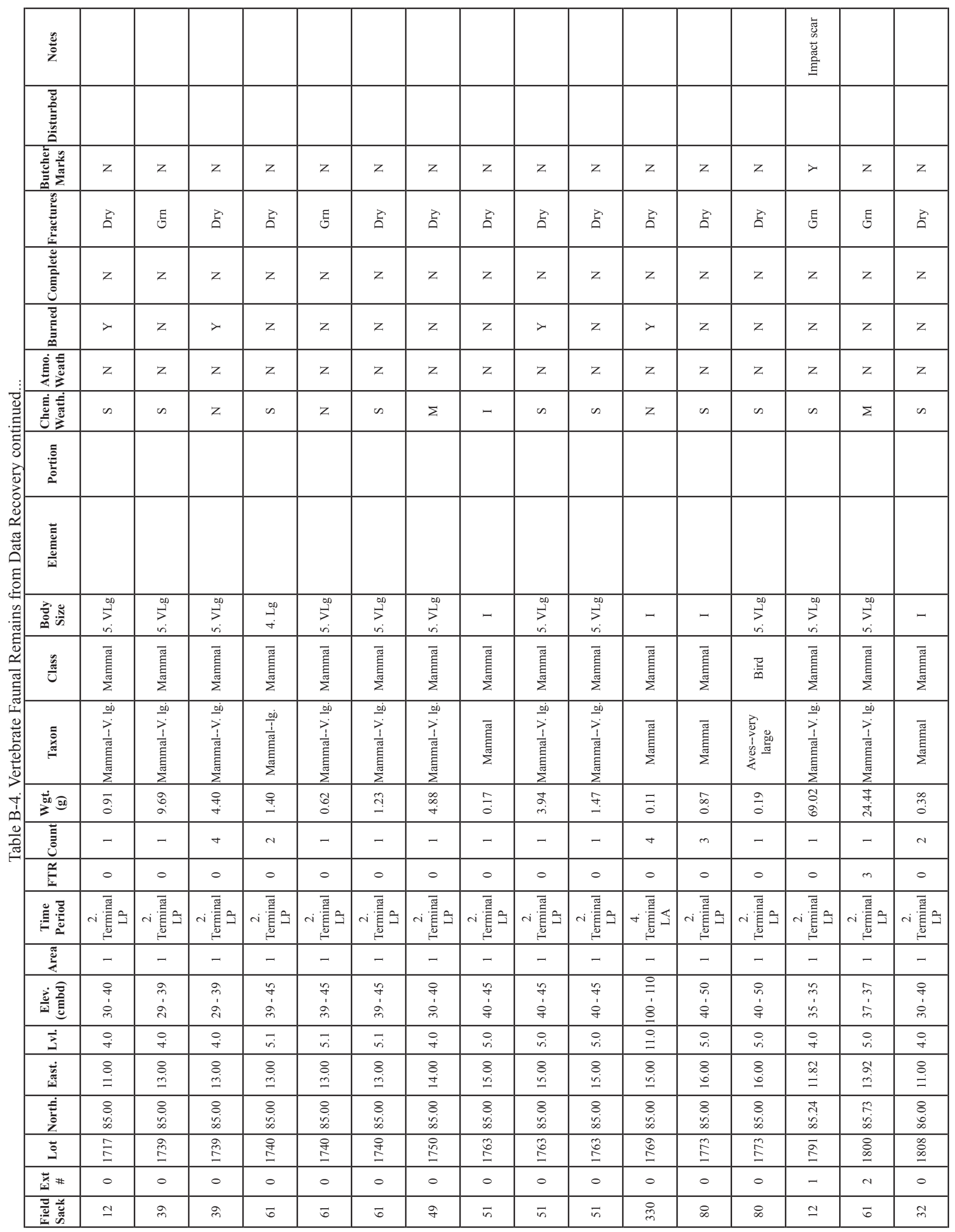




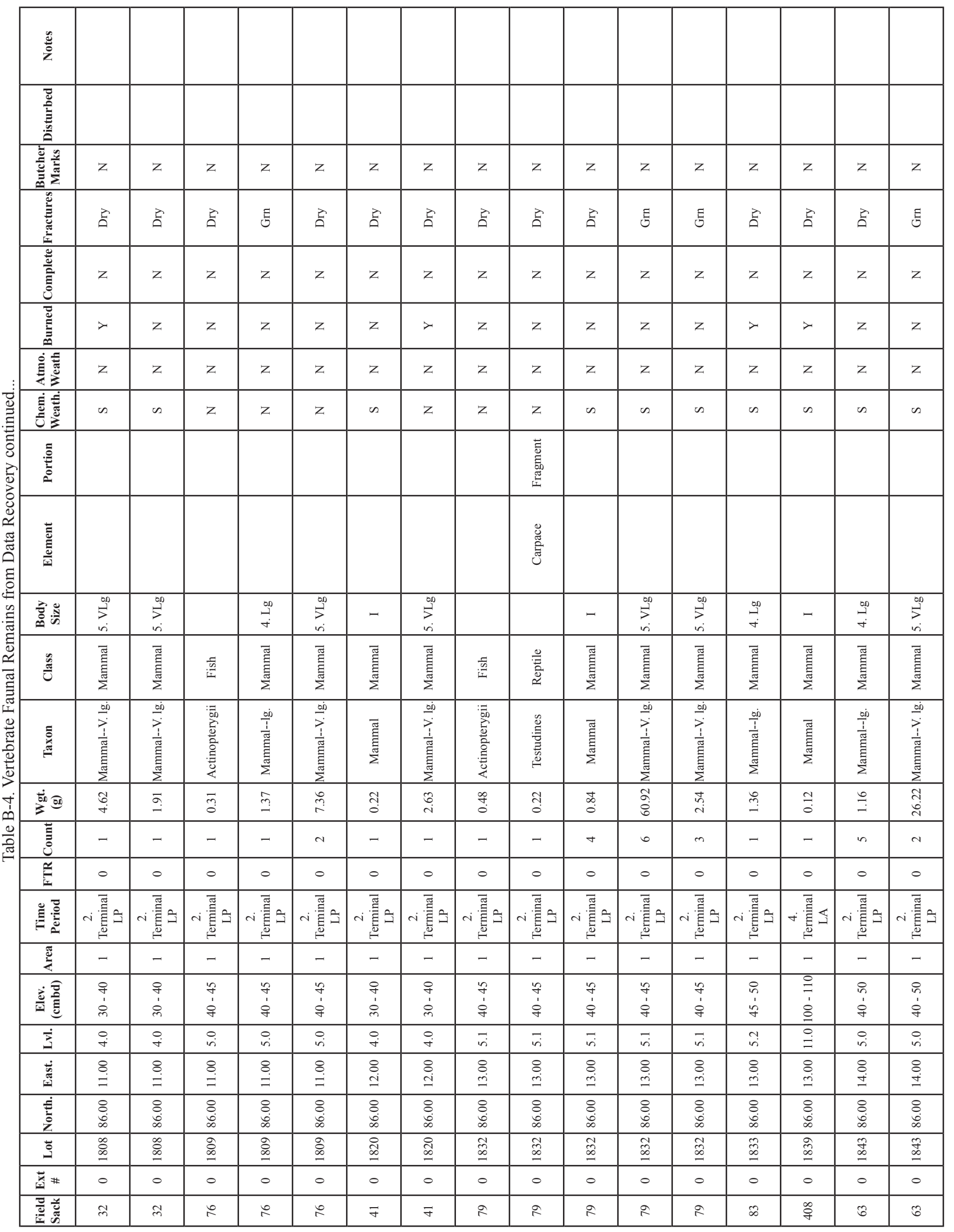




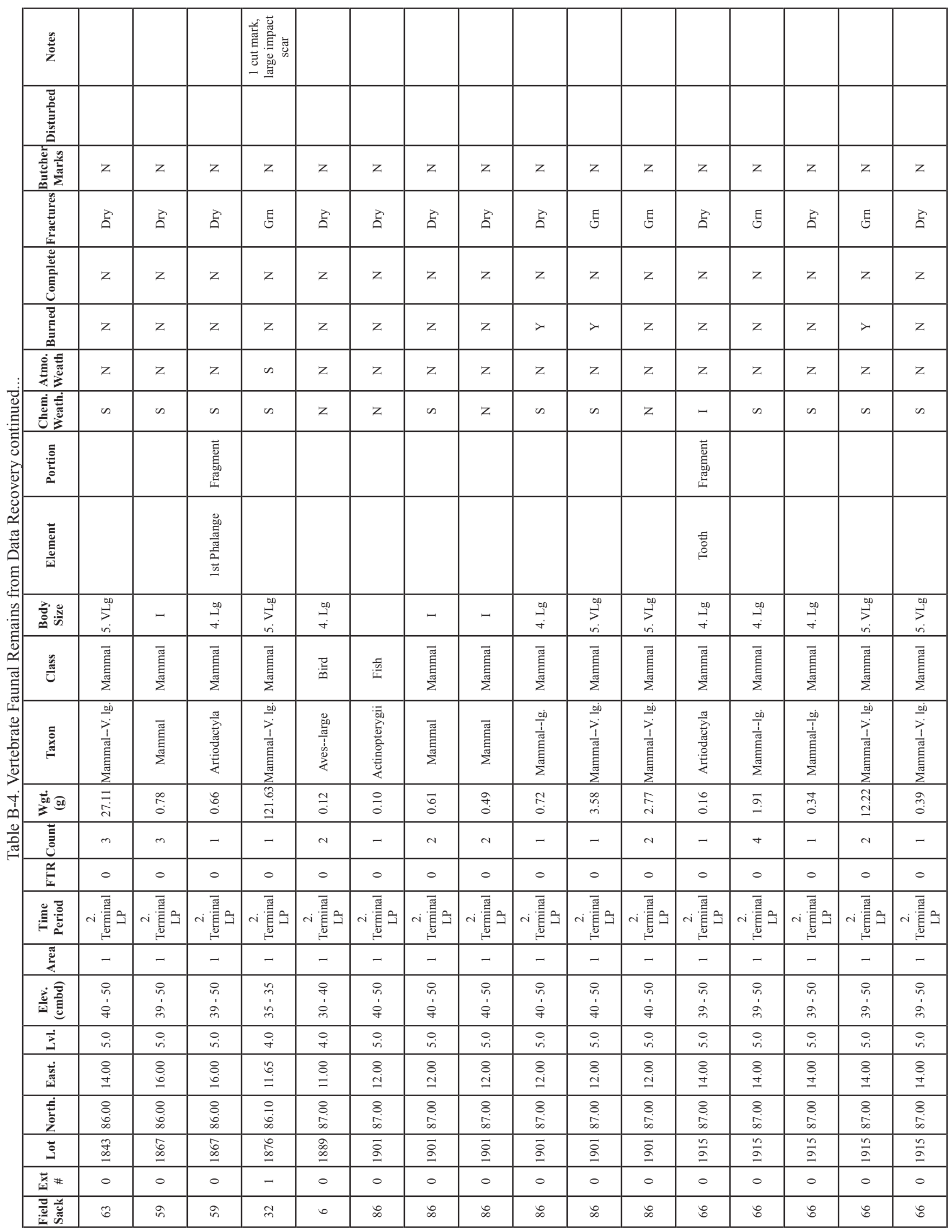




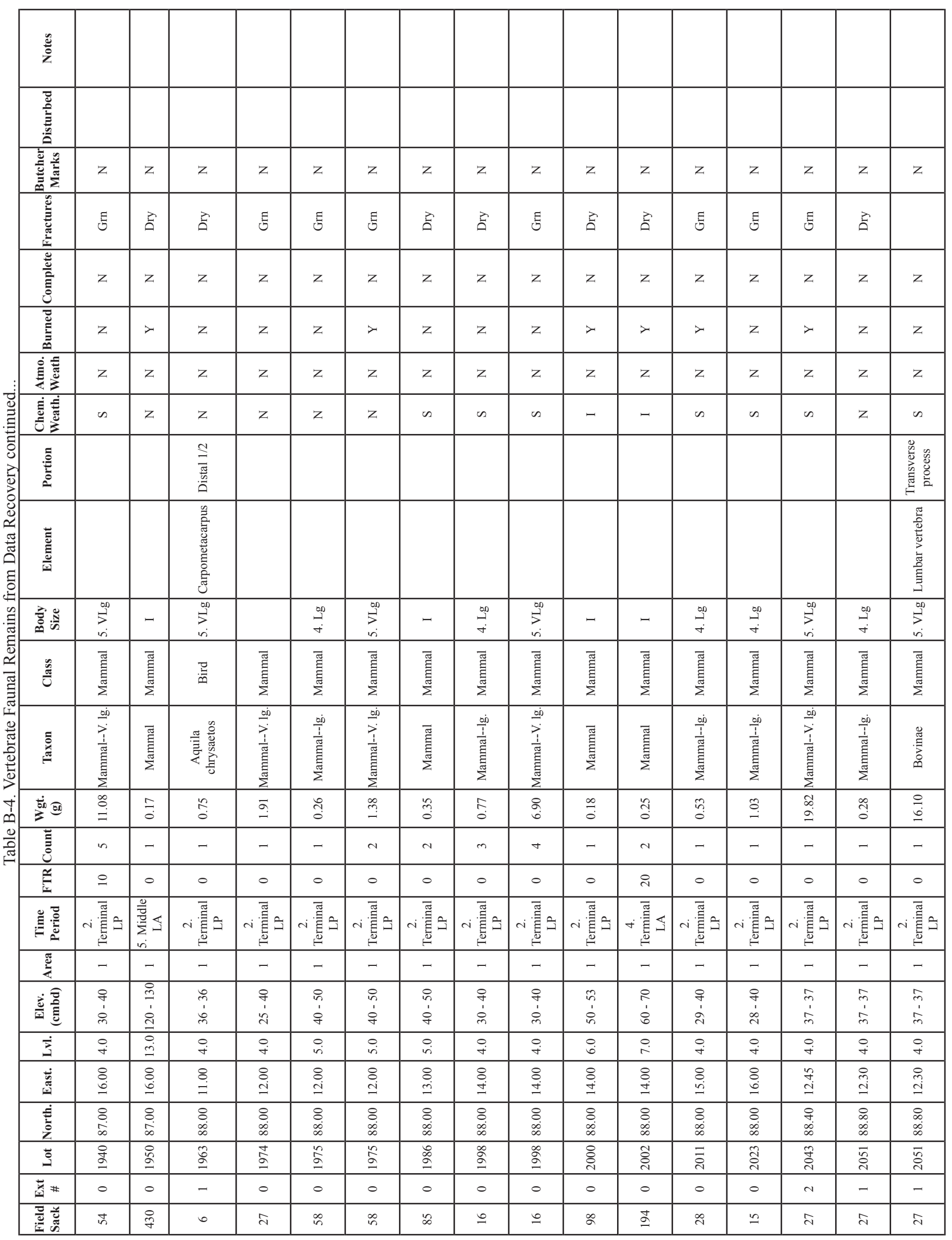




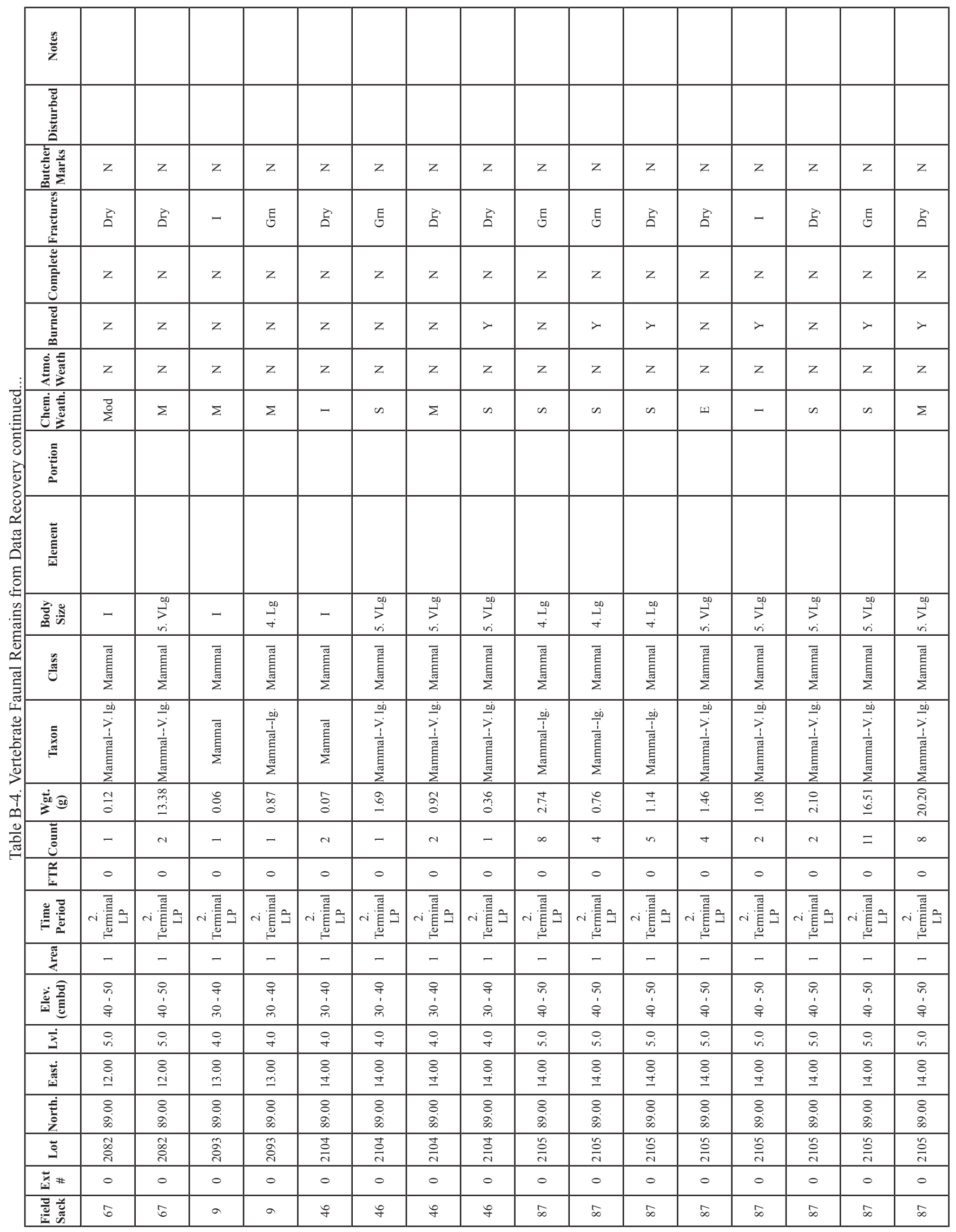




\begin{tabular}{|c|c|c|c|c|c|c|c|c|c|c|c|c|c|c|c|c|}
\hline 造 & 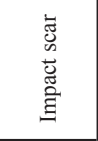 & & & & & & & & 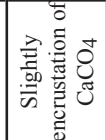 & 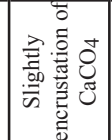 & & & & & & \\
\hline 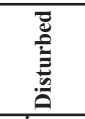 & & & & & & & & & & & & & & & & \\
\hline 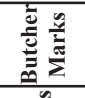 & $\lambda$ & $z$ & z & z & z & z & z & z & z & z & z & z & z & z & z & z \\
\hline 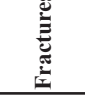 & ह & $\vec{\Delta}$ & 空 & $\vec{\Delta}$ & 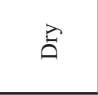 & $\vec{a}$ & E & E & 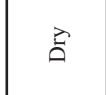 & 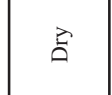 & 至 & $\overrightarrow{0}$ & 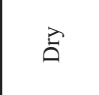 & 空 & 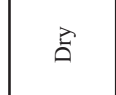 & 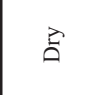 \\
\hline 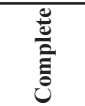 & $\mathrm{z}$ & $\mathrm{z}$ & z & z & z & $z$ & z & z & z & z & z & z & z & z & z & z \\
\hline 焉 & z & $\succ$ & $\succ$ & z & z & $z$ & $\succ$ & z & z & z & z & $>$ & z & z & z & z \\
\hline 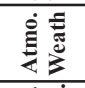 & z & $\mathrm{z}$ & z & z & z & z & $z$ & z & z & z & z & z & z & z & z & $\mathrm{z}$ \\
\hline 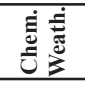 & $\infty$ & $n$ & z & $\Sigma$ & $n$ & $n$ & z & z & 피 & $n$ & 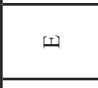 & $n$ & 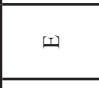 & $\Sigma$ & $\Sigma$ & $\Sigma$ \\
\hline & & & & & & & & & & & & & & & & \\
\hline 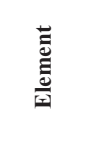 & & & & & & & & & & & & & & & & \\
\hline 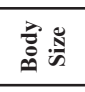 & $\begin{array}{l}0 \\
\qquad \\
i n \\
\end{array}$ & - & $\begin{array}{l} \\
\text { I } \\
\text { i } \\
\end{array}$ & $\begin{array}{l}\text { so } \\
\stackrel{5}{n} \\
i\end{array}$ & 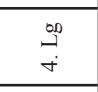 & $\begin{array}{l}0 \\
\stackrel{+}{+0} \\
\dot{+} \\
\end{array}$ & 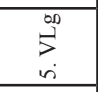 & $\begin{array}{l}0 \\
\stackrel{\infty}{\infty} \\
i\end{array}$ & $\begin{array}{l}0 \\
\stackrel{\infty}{\infty} \\
i \\
\end{array}$ & $\begin{array}{l}0 \\
\stackrel{\infty}{\infty} \\
i \\
\end{array}$ & - & - & - & - & $\begin{array}{l}\stackrel{00}{9} \\
\stackrel{+}{+} \\
\end{array}$ & $\begin{array}{l}0 \\
\stackrel{\infty}{\infty} \\
i n \\
\end{array}$ \\
\hline 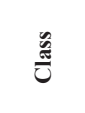 & $\begin{array}{l}\text { 吾 } \\
\text { 言 }\end{array}$ & $\begin{array}{l}\bar{\Xi} \\
\bar{\Xi} \\
\text { 吾 }\end{array}$ & $\begin{array}{l}\bar{\Xi} \\
\overline{\bar{E}} \\
\bar{\Sigma}\end{array}$ & 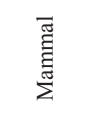 & 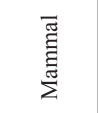 & 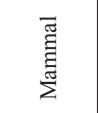 & $\begin{array}{l}\bar{\Xi} \\
\bar{E} \\
\text { हूँ }\end{array}$ & $\begin{array}{l}\bar{\Xi} \\
\text { 镸 } \\
\text { 之on }\end{array}$ & 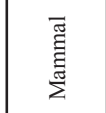 & 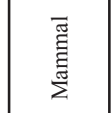 & $\begin{array}{l}\text { 嵒 } \\
\text { 燕 }\end{array}$ & 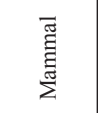 & $\begin{array}{l}\bar{\Xi} \\
\tilde{\tilde{E}}\end{array}$ & 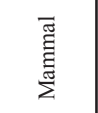 & 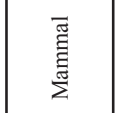 & 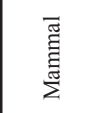 \\
\hline 言 & 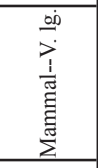 & $\begin{array}{l}\text { 䒜 } \\
\text { 镸 }\end{array}$ & 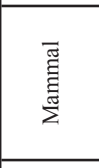 & 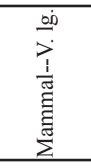 & 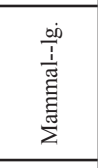 & 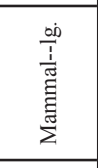 & 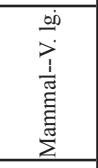 & 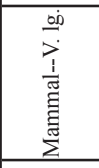 & 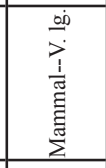 & 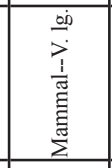 & 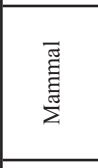 & 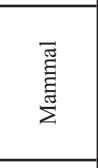 & $\begin{array}{l}\text { 監 } \\
\text { 吾 }\end{array}$ & 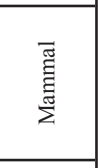 & 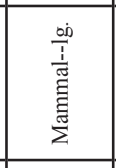 & 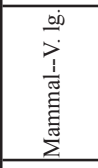 \\
\hline 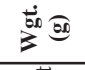 & $\begin{array}{l}8 \\
\infty \\
\infty \\
i\end{array}$ & $\stackrel{\infty}{0}$ & $\stackrel{0}{0}$ & $\Xi$ & हे & $\stackrel{n}{i}$ & $\begin{array}{c}\infty \\
\infty \\
\infty \\
\infty\end{array}$ & $\begin{array}{l}\text { वे } \\
\text { wे } \\
\end{array}$ & $\begin{array}{l}0 \\
\text { in } \\
\end{array}$ & ले & $\Xi$ & ปั & $\stackrel{\infty}{\leftarrow}$ & $\vec{\Delta}$ & $\vec{y}$ & $\underset{+}{\stackrel{\leftrightarrow}{+}}$ \\
\hline $\overrightarrow{\bar{z}}$ & - & - & - & - & N & $r$ & in & $=$ & 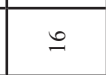 & $\infty$ & $\simeq$ & N & r & 4 & N & m \\
\hline 总 & $\circ$ & $\circ$ & $\circ$ & $\circ$ & $\circ$ & $\circ$ & $\circ$ & $\circ$ & $\circ$ & $\circ$ & $\circ$ & $\circ$ & $\circ$ & $\circ$ & $\circ$ & $\circ$ \\
\hline 兽: & $\mathrm{i}$ & 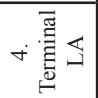 & 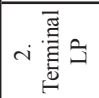 & 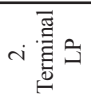 & $\mathrm{i}$ & 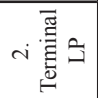 & 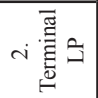 & 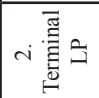 & i & 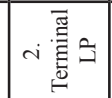 & 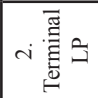 & 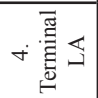 & 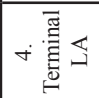 & i & 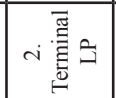 & i \\
\hline 岛 & - & - & - & - & - & - & - & - & - & - & - & - & - & - & - & - \\
\hline 層言 & $\begin{array}{l}\neq \\
\text { J } \\
\vdots\end{array}$ & $\begin{array}{l}\stackrel{9}{7} \\
\stackrel{1}{o}\end{array}$ & 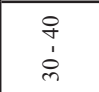 & $\begin{array}{l}\text { o } \\
\text { d } \\
\vdots \\
\text { d }\end{array}$ & $\begin{array}{l}0 \\
i \\
\vdots \\
\vdots\end{array}$ & $\begin{array}{l}0 \\
\vdots \\
5 \\
a\end{array}$ & $\begin{array}{l}0 \\
\dot{m} \\
\dot{q}\end{array}$ & $\begin{array}{l}0 \\
b \\
\vdots \\
\vdots\end{array}$ & $\begin{array}{l}0 \\
b \\
\vdots \\
\vdots\end{array}$ & $\begin{array}{l}0 \\
\vdots \\
5 \\
\vdots\end{array}$ & $\begin{array}{l}\hat{n} \\
\vdots \\
n\end{array}$ & $\begin{array}{l}8 \\
1 \\
\vdots\end{array}$ & $\begin{array}{l}\stackrel{8}{\circ} \\
\vdots \\
\stackrel{1}{0}\end{array}$ & $\begin{array}{l}\text { o } \\
\text { q } \\
0 \\
\text { d }\end{array}$ & $\begin{array}{l}\text { qu } \\
\text { o } \\
\text { o }\end{array}$ & $\begin{array}{l}\text { p } \\
\text { q } \\
\text { d }\end{array}$ \\
\hline$\dot{\vec{B}}$ & in & $\stackrel{\circ}{\exists}$ & $\stackrel{\circ}{\dot{+}}$ & $\stackrel{P}{\dot{+}}$ & $\dot{i n}$ & $\dot{i n}$ & $\dot{i n}$ & $\dot{i n}$ & ir & $\dot{i n}$ & $\vec{b}$ & $\stackrel{\circ}{\dot{\Xi}}$ & $\stackrel{\circ}{\dot{I}}$ & $\stackrel{\circ}{\dot{+}}$ & $\stackrel{+}{\dot{+}}$ & $\stackrel{+}{\dot{+}}$ \\
\hline 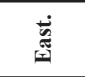 & $\begin{array}{l} \\
\dot{I}\end{array}$ & $\begin{array}{l} \\
\dot{I}\end{array}$ & $\begin{array}{l}8 \\
\qquad \\
1\end{array}$ & $\begin{array}{l}8 \\
\qquad \\
17\end{array}$ & $\begin{array}{l}8 \\
\qquad \\
11\end{array}$ & $\begin{array}{l}8 \\
\qquad \\
11\end{array}$ & $\begin{array}{l}8 \\
\dot{8} \\
2\end{array}$ & $\begin{array}{l}8 \\
6 \\
17\end{array}$ & $\begin{array}{l}8 \\
8 \\
17\end{array}$ & $\begin{array}{l}8 \\
\qquad \\
1\end{array}$ & $\begin{array}{l}8 \\
\qquad \\
11\end{array}$ & $\begin{array}{l}8 \\
\\
1 \\
1\end{array}$ & $\begin{array}{l}8 \\
\\
1 \\
1\end{array}$ & $\begin{array}{l}8 \\
\stackrel{8}{6}\end{array}$ & \begin{tabular}{l}
8 \\
\multirow{6}{*}{}
\end{tabular} & \begin{tabular}{l}
8 \\
\multirow{6}{*}{}
\end{tabular} \\
\hline 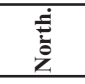 & $\begin{array}{l}8 \\
\vdots \\
\infty\end{array}$ & $\begin{array}{l}8 \\
\vdots \\
\infty\end{array}$ & $\begin{array}{l}8 \\
\dot{\infty} \\
\infty\end{array}$ & $\begin{array}{l}8 \\
\vdots \\
\infty\end{array}$ & $\begin{array}{l} \\
\\
\infty \\
\end{array}$ & $\begin{array}{l} \\
\\
\infty \\
\end{array}$ & $\begin{array}{l}8 \\
\vdots \\
\infty\end{array}$ & $\begin{array}{l} \\
\\
\infty \\
\end{array}$ & $\begin{array}{l}8 \\
\dot{\infty} \\
\infty\end{array}$ & $\begin{array}{l}8 \\
\vdots \\
\infty\end{array}$ & $\begin{array}{l}8 \\
\vdots \\
\infty\end{array}$ & $\begin{array}{l} \\
\\
\infty \\
\end{array}$ & $\begin{array}{l}8 \\
\vdots \\
\infty\end{array}$ & $\begin{array}{l}8 \\
\dot{\infty} \\
\infty\end{array}$ & $\begin{array}{l}8 \\
\vdots \\
\infty\end{array}$ & $\begin{array}{l}8 \\
\vdots \\
\infty\end{array}$ \\
\hline 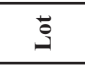 & $\frac{\circ}{d}$ & $\stackrel{m}{\sim}$ & $\overline{\bar{N}}$ & $\overline{\bar{\lambda}}$ & $\stackrel{\infty}{\vec{N}}$ & $\stackrel{\infty}{\vec{N}}$ & $\stackrel{\infty}{\underset{\sim}{\sim}}$ & $\stackrel{\infty}{\vec{N}}$ & $\stackrel{\infty}{\stackrel{\infty}{二}}$ & $\stackrel{\infty}{\stackrel{\infty}{二}}$ & $\stackrel{\vec{\lambda}}{\stackrel{\vartheta}{*}}$ & $\frac{\pi}{\pi}$ & 尝 & 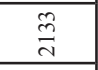 & $\stackrel{m}{\vec{n}}$ & $\frac{m}{\vec{n}}$ \\
\hline 蓄\# & - & 0 & 0 & 0 & 0 & 0 & 0 & 0 & 0 & 0 & 0 & 0 & 0 & 0 & 0 & 0 \\
\hline 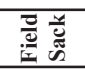 & $\infty$ & $\stackrel{n}{n}$ & $\infty$ & $\infty$ & $\infty$ & $\infty$ & $\infty$ & $\infty$ & $\infty$ & $\infty$ & $\stackrel{ \pm}{\Xi}$ & స్ల & : & i & i & i \\
\hline
\end{tabular}




\begin{tabular}{|c|c|c|c|c|c|c|c|c|c|c|c|c|c|c|c|c|}
\hline 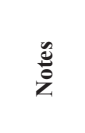 & & & & & & & & & & & & 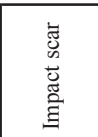 & & & & \\
\hline 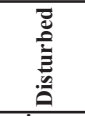 & & & & & & & & & & & & & & & & \\
\hline 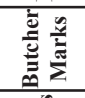 & z & z & z & z & z & z & z & z & z & z & z & z & z & z & $\mathrm{z}$ & z \\
\hline 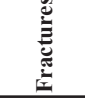 & 㤩 & $\overrightarrow{8}$ & $\vec{\theta}$ & $\vec{\Omega}$ & E & $\overrightarrow{8}$ & 蛋 & 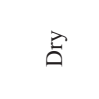 & E & $\vec{A}$ & E & $E$ & 票 & $\overrightarrow{0}$ & $\vec{A}$ & 点 \\
\hline 产 & z & $z$ & $\mathrm{z}$ & z & z & z & z & z & z & z & z & z & z & z & $\mathrm{z}$ & z \\
\hline 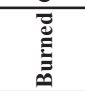 & $>$ & z & $>$ & $\lambda$ & z & z & z & $>$ & $\lambda$ & $>$ & z & z & z & $\succ$ & $\lambda$ & $\lambda$ \\
\hline 㝘吾 & z & z & z & z & z & z & z & z & z & z & z & $z$ & z & $z$ & z & $z$ \\
\hline 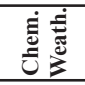 & in & - & - & $n$ & $\infty$ & $n$ & $n$ & in & $n$ & - & $\infty$ & $n$ & - & $n$ & $\Sigma$ & $n$ \\
\hline : & & & & & & & 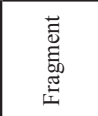 & & & & & & & & & 氶 \\
\hline & & & & & & & 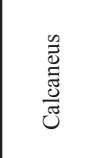 & & & & & & & & & $\begin{array}{l}\text { 号 } \\
\text { 章 } \\
\text { 竞 }\end{array}$ \\
\hline 递苋 & 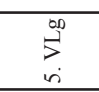 & - & - & $\begin{array}{l}\stackrel{0}{9} \\
+ \\
+\end{array}$ & 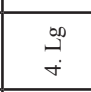 & $\begin{array}{l}\stackrel{s 0}{\stackrel{5}{*}} \\
+ \\
\end{array}$ & 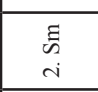 & 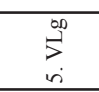 & $\begin{array}{l}\sum^{\infty} \\
i \\
i\end{array}$ & 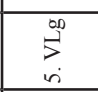 & $\begin{array}{l}0 \\
5^{50} \\
\text { in }\end{array}$ & $\begin{array}{l}\sum_{0}^{\infty} \\
i \\
i\end{array}$ & $\begin{array}{l}0 \\
\stackrel{\infty}{+} \\
+ \\
+\end{array}$ & - & - & $\begin{array}{l}{ }_{30}^{80} \\
\stackrel{5}{5} \\
i\end{array}$ \\
\hline 总 & 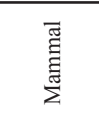 & 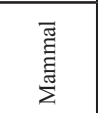 & 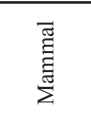 & $\begin{array}{l}\overline{\text { J }} \\
\overline{\tilde{I}}\end{array}$ & 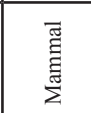 & 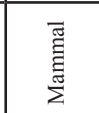 & 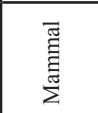 & 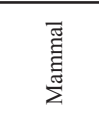 & 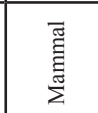 & $\begin{array}{l}\overline{\text { J }} \\
\text { 㷼 } \\
\end{array}$ & 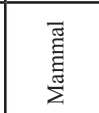 & 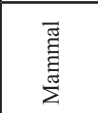 & 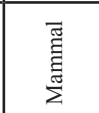 & 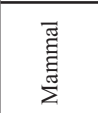 & 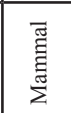 & 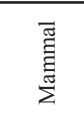 \\
\hline 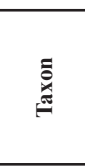 & 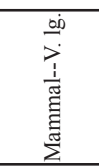 & $\begin{array}{l}\bar{\Xi} \\
\text { 镸 } \\
\text { 之. }\end{array}$ & 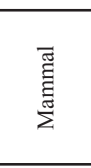 & 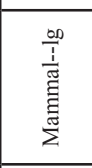 & 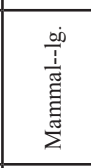 & 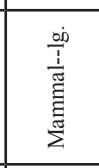 & 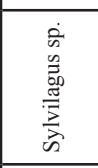 & 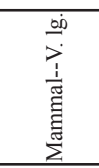 & 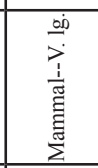 & 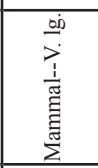 & 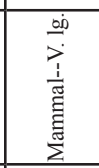 & 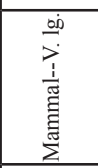 & 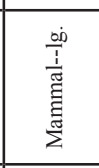 & $\begin{array}{l}\bar{\Xi} \\
\text { 䍃 }\end{array}$ & 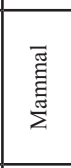 & 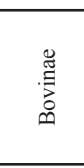 \\
\hline 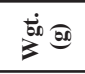 & $\begin{array}{l}\hat{R} \\
\text { in }\end{array}$ & f. & $\begin{array}{l}0 \\
\\
0\end{array}$ & $\stackrel{9}{9}$ & $\begin{array}{l}\hat{2} \\
\hat{0} \\
\end{array}$ & 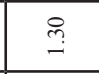 & $\begin{array}{l}0 \\
\\
0\end{array}$ & $\begin{array}{c}n \\
\infty \\
\infty\end{array}$ & fี & $\frac{0}{i}$ & $\stackrel{5}{=}$ & तิ & శึ & 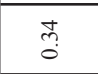 & $\frac{9}{0}$ & $\begin{array}{l}n \\
i n \\
i n\end{array}$ \\
\hline$\overline{\bar{z}}$ & $N$ & + & + & + & $m$ & $m$ & - & ナ & r & m & $m$ & - & - & r & - & - \\
\hline 密 & 0 & 0 & $\circ$ & 0 & 0 & $\circ$ & 0 & o & 0 & 0 & 。 & 0 & 0 & 0 & 0 & 0 \\
\hline 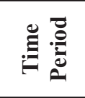 & 小駦 & 小产 & 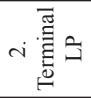 & N㩊 & 醇 & 跑 & i. & 小番 & 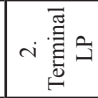 & 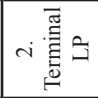 & S & N. & N & 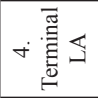 & 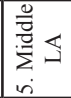 & 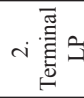 \\
\hline 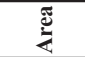 & - & - & - & - & - & - & - & - & - & - & - & - & - & - & - & - \\
\hline 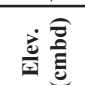 & $\begin{array}{l}q \\
\dot{1} \\
\dot{0}\end{array}$ & $\begin{array}{l}\text { in } \\
\text { in }\end{array}$ & $\begin{array}{l}0 \\
\vdots \\
5 \\
q\end{array}$ & $\begin{array}{l}0 \\
b \\
\vdots \\
q\end{array}$ & $\begin{array}{l}0 \\
\vdots \\
\vdots \\
q\end{array}$ & $\begin{array}{l}0 \\
n \\
1 \\
q\end{array}$ & $\begin{array}{l}n \\
\text { in } \\
1\end{array}$ & $\begin{array}{l}\text { in } \\
1 \\
\dot{q}\end{array}$ & $\begin{array}{l}0 \\
b \\
\vdots \\
q\end{array}$ & $\begin{array}{l}0 \\
\vdots \\
5 \\
q\end{array}$ & $\begin{array}{l}8 \\
1 \\
1 \\
j\end{array}$ & $\begin{array}{l}8 \\
i \\
1 \\
q\end{array}$ & ñ & $\begin{array}{l}2 \\
\dot{1} \\
\infty \\
\infty\end{array}$ & $\begin{array}{l}0 \\
\stackrel{0}{1} \\
\vdots \\
\grave{d}\end{array}$ & $\begin{array}{l}\vec{F} \\
\dot{I} \\
\bar{F}\end{array}$ \\
\hline$\dot{\vec{J}}$ & $\stackrel{8}{+}$ & is & is & is & is & is & i & is & is & is & ir & is & 7 & ปุ & \begin{tabular}{|c|}
- \\
\\
\end{tabular} & $\stackrel{\circ}{+}$ \\
\hline 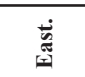 & 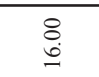 & ن. & 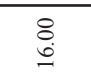 & 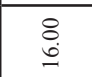 & ن. & 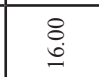 & $\begin{array}{l}8 \\
\\
\end{array}$ & \begin{tabular}{l}
8 \\
\multirow{6}{*}{}
\end{tabular} & $\begin{array}{l}8 \\
\\
0\end{array}$ & $\begin{array}{l}8 \\
\\
0\end{array}$ & $\begin{array}{l}8 \\
\\
0\end{array}$ & \begin{tabular}{l}
8 \\
\multirow{6}{*}{}
\end{tabular} & \begin{tabular}{l}
8 \\
\multirow{6}{*}{}
\end{tabular} & \begin{tabular}{l}
8 \\
\multirow{6}{*}{}
\end{tabular} & $\begin{array}{l}8 \\
\\
\end{array}$ & $\begin{array}{l}\widetilde{T} \\
\underline{\Omega}\end{array}$ \\
\hline 萻 & $\begin{array}{l}8 \\
\dot{0} \\
\infty\end{array}$ & $\begin{array}{l}8 \\
\vdots \\
\infty\end{array}$ & $\begin{array}{l}8 \\
\dot{0} \\
\infty\end{array}$ & $\begin{array}{l}8 \\
\dot{\infty} \\
\dot{\infty}\end{array}$ & $\begin{array}{l}8 \\
\infty \\
\infty\end{array}$ & $\begin{array}{l}8 \\
0 \\
\infty\end{array}$ & $\begin{array}{l}8 \\
0 \\
\infty\end{array}$ & $\begin{array}{l}8 \\
\stackrel{0}{\infty} \\
\infty\end{array}$ & $\begin{array}{l}8 \\
\infty \\
\infty\end{array}$ & $\begin{array}{l}8 \\
\dot{0} \\
\infty\end{array}$ & $\begin{array}{l}8 \\
\substack{0 \\
\infty}\end{array}$ & $\begin{array}{l}8 \\
\dot{0} \\
\infty\end{array}$ & $\begin{array}{l}8 \\
\dot{0} \\
\infty\end{array}$ & $\begin{array}{l}8 \\
\infty \\
\infty\end{array}$ & \begin{tabular}{|l|} 
\\
\\
0 \\
$\infty$
\end{tabular} & 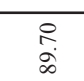 \\
\hline$\vec{a}$ & $\stackrel{\rho}{\sim}$ & 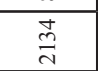 & $\frac{\vec{m}}{\mathrm{~d}}$ & $\begin{array}{l}\mathrm{d} \\
\stackrel{\mathrm{m}}{\mathrm{N}}\end{array}$ & $\begin{array}{l}\frac{d}{d} \\
\frac{d}{d}\end{array}$ & $\frac{d}{d}$ & $\frac{d}{d}$ & $\begin{array}{l}\mathrm{d} \\
\stackrel{\mathrm{N}}{\mathrm{N}}\end{array}$ & $\vec{d}$ & $\frac{\vec{d}}{\mathrm{~d}}$ & $\frac{\vec{d}}{\mathrm{~d}}$ & $\frac{d}{d}$ & $\frac{n}{n}$ & $\frac{9}{4}$ & $\frac{d}{d}$ & $\begin{array}{l}\frac{n}{n} \\
\stackrel{n}{N}\end{array}$ \\
\hline$\overline{x_{i}} \#$ & 0 & 0 & 0 & 0 & 0 & 0 & 0 & 0 & 0 & 0 & 0 & 0 & 0 & 0 & 0 & $N$ \\
\hline 竜前 & i & 8 & 8 & 8 & 8 & 8 & 8 & 8 & 8 & 8 & 8 & 8 & $\stackrel{\infty}{=}$ & 8 & के & i \\
\hline
\end{tabular}




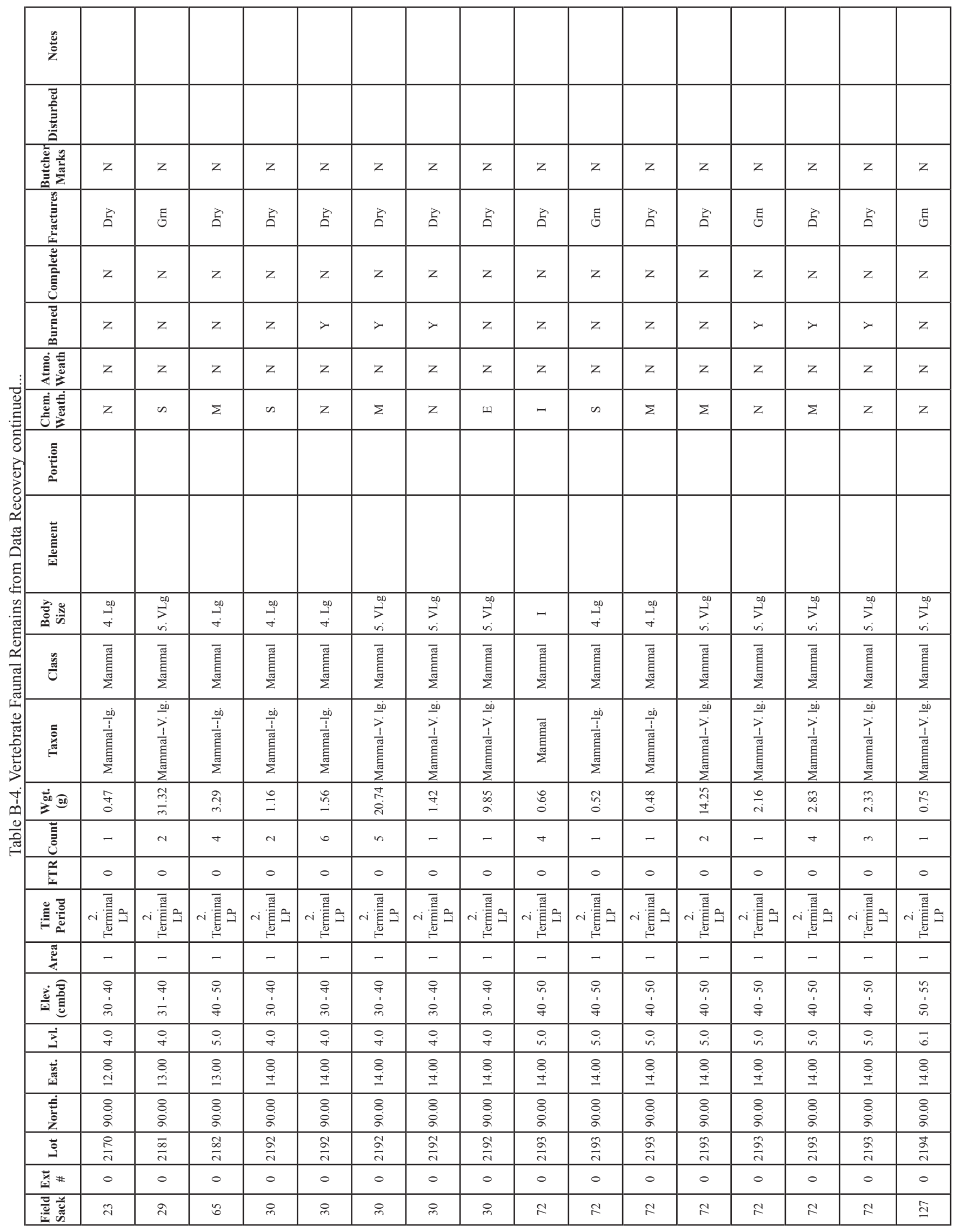




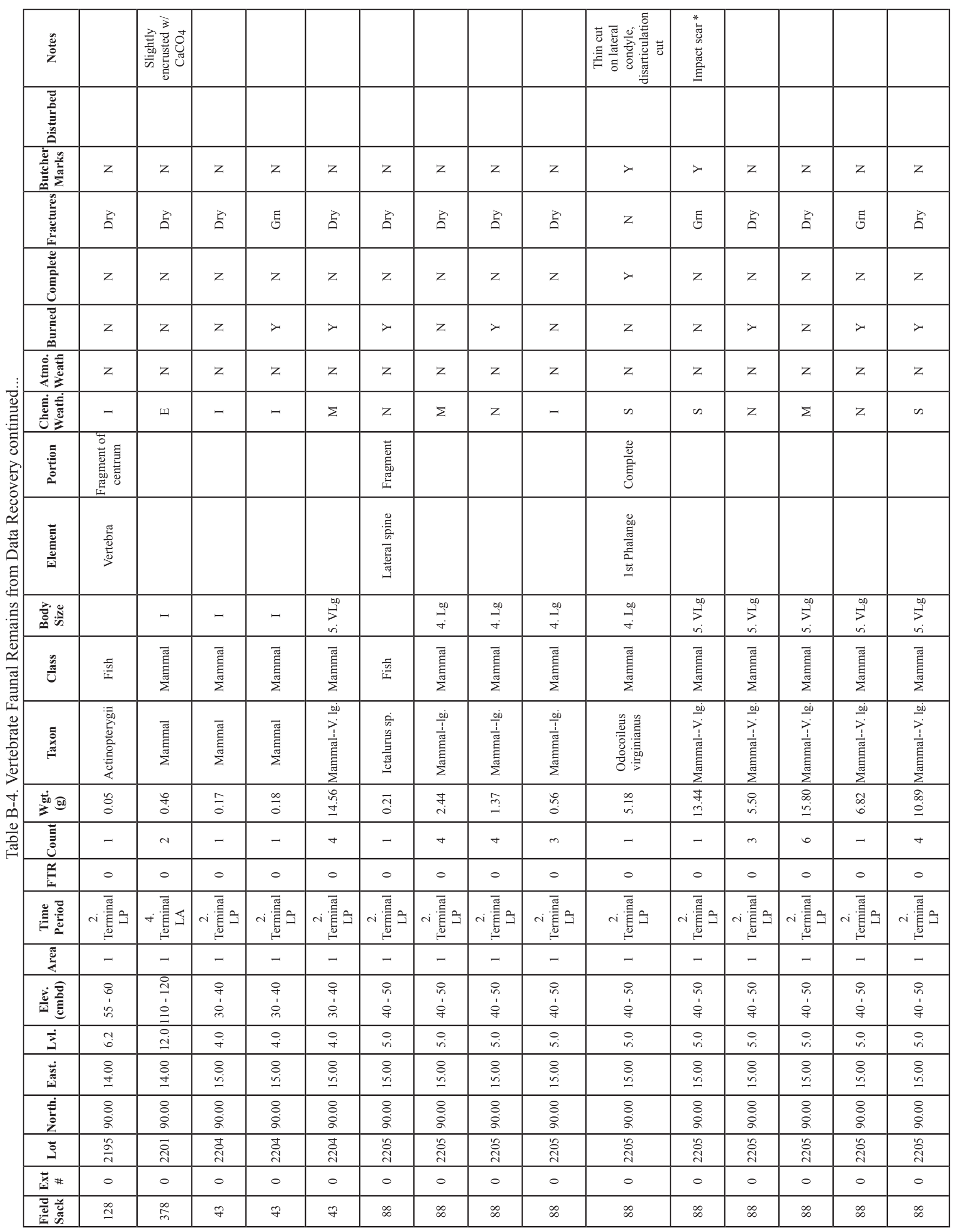




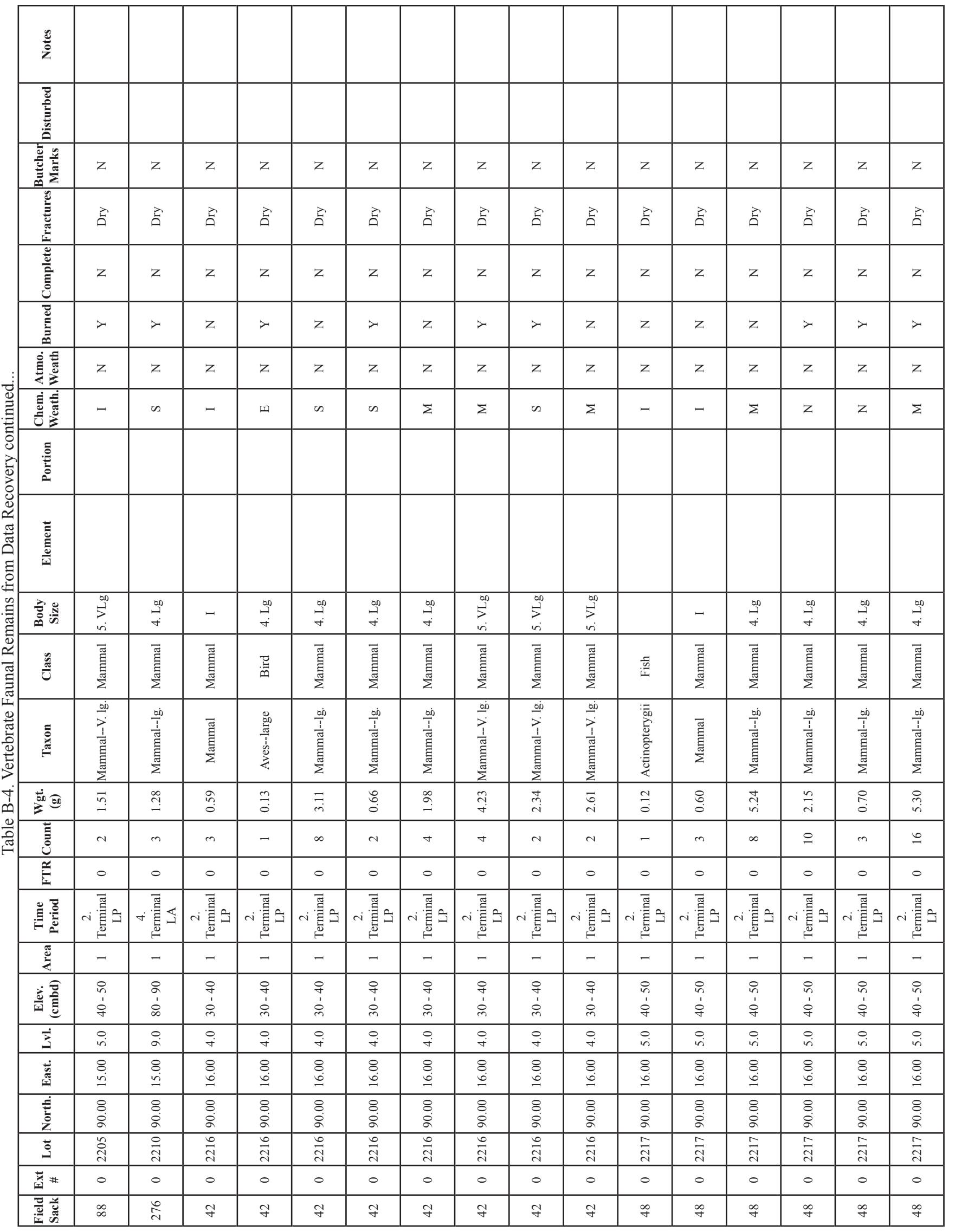




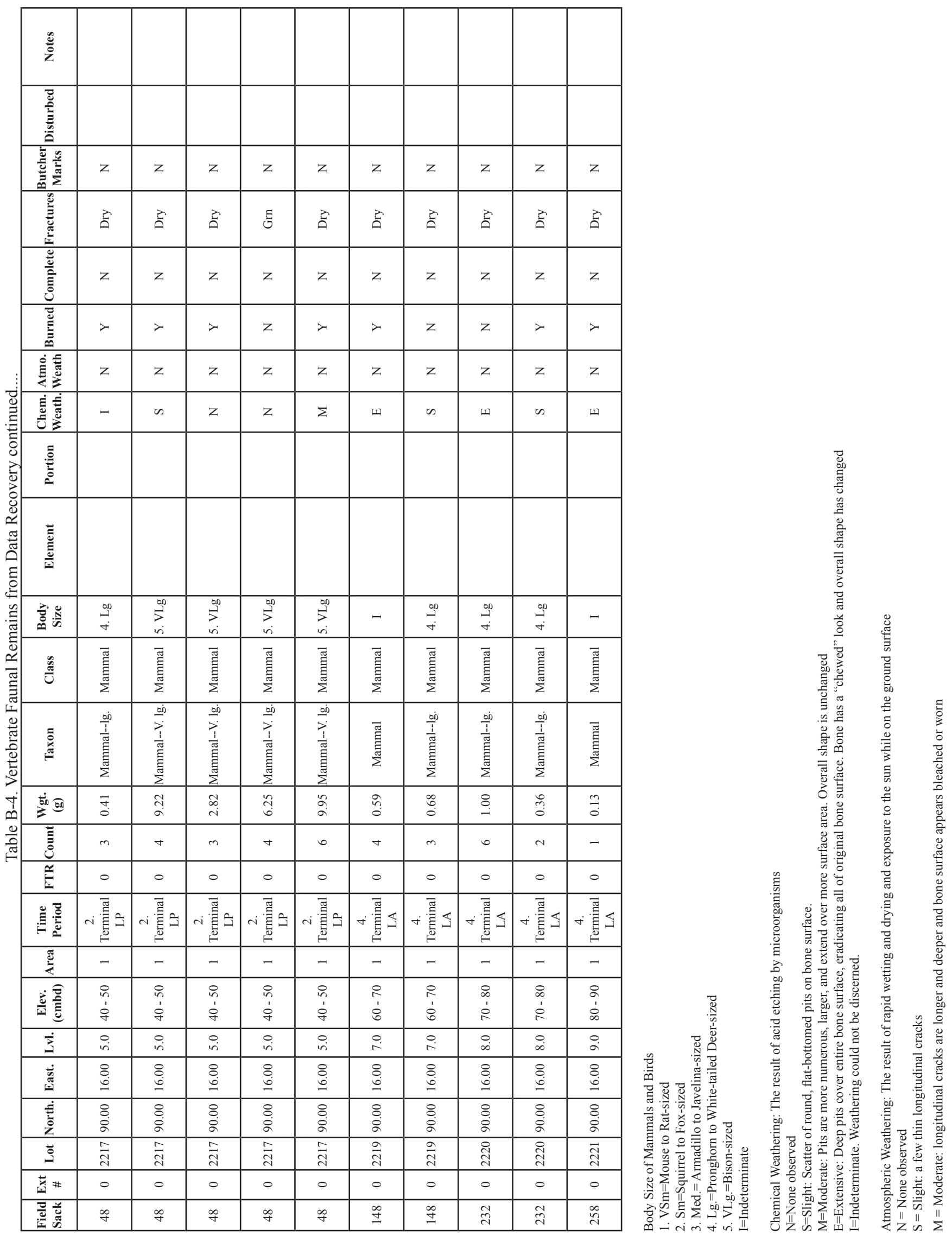


Body size of bone fragments in the Initial Late Prehistoric fall mostly within the Large category and were found in Area 3. All 27 Very Large specimens came from Area 3, most (18) from Level 10 just above the level of Feature 39 and where 10 biface tools were also recovered.

\section{Terminal Late Archaic (Areas 1 and 4)}

The Terminal Late Archaic component was present in Areas 1, 2 and 4, though associated features were only recorded in Areas 2 and 4. Large bird and mammal bones were recorded in Areas 1 and 4. No faunal remains were discovered in this component in Area 2. Bones from large mammal and Aves species were identified in Area 4 during the Terminal Late Archaic where two features were excavated (48 and 49). No bone was associated with the excavation of these small thermal features. Bone counts drop in the Terminal Late Archaic component to only 52. Of these, 22 were from Large mammals, mostly within the upper levels of the component in Area 1.

\section{Middle Late Archaic (Areas 1-4)}

The Middle Late Archaic component contained vertebrate remains in all four Areas. In Area 1, features 35, 36 and 99 were excavated between 105 and $130 \mathrm{cmbd}$. Two mammal bone fragments of undetermined size also came from this elevation. Area 2 contained a cluster of thermal features $(42,43,55$, and 56) between 96 and $110 \mathrm{cmbd}$. Two small mammal bone fragments occurred in this level outside the features. Additional bone was found $20 \mathrm{~cm}$ deeper. Area 3 units not associated with the burned rock midden contained 142 small to very large mammal and bird bone fragments. All of the Very Large and most of the Large Middle Late Archaic bone fragments came from Area 3. Only one species was identified, Odocoileus virginianus. Eight fish, mammal, and bird bone fragments were also identified at the base or below the burned rock midden Feature 1 in Area 3 . These were recovered between 110 and $130 \mathrm{cmbd}$. The deepest part of the midden began to disappear at this depth in units from which bone was recovered. Area 4 contained only 20 fragments, nine from a large bird. The remaining eleven were from large animals and found in Level 13 the same level as Feature 50, though none of the fragments was found within its boundaries.

\section{Body Size}

The majority of the faunal fragments placed in size categories came from Data Recovery excavations. Table B-5 shows combined data from significance testing $(n=36)$ and data recovery $(n=1095)$ by time period and area. By far the biggest faunal assemblages are from Large and Very Large Mammals. These both peak in the Terminal Late Prehistoric and drop precipitously in the Initial Late Prehistoric. The Very Large category drops out completely during the Terminal Late Archaic, while Large category counts continue to drop before rising slightly during the Middle Late Archaic. Very Large counts return in the Middle Late Archaic.

Table B-5. Body Size Through Time per Excavation Area

\begin{tabular}{|c|c|c|c|c|c|c|c|}
\hline Terminal LP & 1 & & 2 & 1 & 203 & 370 & 576 \\
\hline & 2 & 1 & & & 115 & 44 & 159 \\
\hline Terminal LP Total & & 1 & 2 & 1 & 318 & 414 & 736 \\
\hline \multirow[t]{2}{*}{ Initial LP } & 3 & 5 & 49 & 24 & 155 & 28 & 261 \\
\hline & 4 & & & & 12 & & 12 \\
\hline Initial LP Total & & 5 & 49 & 24 & 167 & 28 & 273 \\
\hline \multirow[t]{2}{*}{ Terminal LA } & 1 & & & & 16 & & 16 \\
\hline & 4 & & & & 6 & & 6 \\
\hline Terminal LA Total & & & & & 22 & & 22 \\
\hline \multirow[t]{3}{*}{ Middle LA } & 2 & & & & 14 & & 14 \\
\hline & 3 & & 6 & 9 & 43 & 15 & 73 \\
\hline & 4 & & & 1 & 12 & & 13 \\
\hline Middle LA Total & & & 6 & 10 & 69 & 15 & 100 \\
\hline Grand Total & & 6 & 57 & 35 & 576 & 457 & 1,131 \\
\hline
\end{tabular}




\section{Summary}

Faunal counts are highest during the Terminal Late Prehistoric and drop through the Initial Late Archaic before climbing again in the Middle Late Archaic. Specimens that cannot be placed within size categories follow the same pattern. The overall vertical distribution of artifacts does not follow this pattern. Stone artifact counts are lowest in the Terminal Late Prehistoric and highest in the Initial Late Prehistoric. The Terminal Late Prehistoric assemblage in Area 1 contains the most faunal remains, much of which comes from Large and Very Large mammals. Area 2 also contains a high number of Terminal Late Prehistoric faunal remains, all within these categories for a total of 723 sized specimens. The faunal assemblage and its relationship to other Toyah Phase artifacts and features is of particular interest. The Area 2 thermal features correlate with the high bone counts in the Terminal Late Prehistoric. Area 3 also shows a rise in bone counts during the Initial Late Prehistoric when the burned rock midden was in use. Though Area 4 had several features dating to Initial Late Prehistoric and both Late Archaic components, little bone was recovered from this block. 


\section{References Cited:}

Balkwill, D. M. and S. L. Cumbaa

1992 A Guide to the Identification of Postcranial Bones of Bos taurus and Bison bison. Canadian Museum of Nature, Ottawa.

Boessneck, J.

1970 Osteological Differences Between Sheep (Ovis aries Linné) and Goats (Capra hircus Linné). In Science in Archaeology, edited by D. Brothwell and E. Higgs, pp. 331-358. Praeger, New York.

Davis, W. B., and D. J. Schmidly

1994 The Mammals of Texas. Texas Parks and Wildlife, Austin.

Gilbert, B. M.

1990 Mammalian Osteology. Missouri Archaeological Society, Columbia.

Gilbert, B. M., L. D. Martin, and H. G. Savage

1981 Avian Osteology. Published by B. Miles Gilbert, Laramie, Wyoming.

Hildebrand, M.

1955 Skeletal Differences Between Deer, Sheep, and Goats. California Fish and Game 41:327-346.

Hillson, S.

1986 Teeth. Cambridge University Press, Cambridge.

ITIS

2007 Integrated Taxonomic Information System. Electronic document, http:/www.itis.gov/index.html, accessed October 18, 2007.

Olsen, Stanley J.

1960 Post-Cranial Skeletal Characters of Bison and Bos. Peabody Museum, Cambridge.

1964 Mammal Remains from Archaeological Sites Part I; Southeastern and Southwestern United States. Peabody Museum, Cambridge.

1968 Fish, Amphibian, and Reptile Remains from Archaeological Sites Part I: Southeastern and Southwestern United States. Peabody Museum, Cambridge.

Sobolik, K. D. and D. G. Steele

1996 A Turtle Atlas to Facilitate Archaeological Identifications. Mammoth Site of Hot Springs, South Dakota, Inc., Rapid City, South Dakota.

Weniger, D.

1997 The Explorers' Texas: The Animals They Found. Eakin Press, Austin. 
Appendix C:

Feature Descriptions from 41KM69

Jennifer L. Thompson 



\section{Appendix C}

This appendix consists of two main segments. The first provides descriptions for the features identified at 41KM69. The second segment consists of three tables C-1 through C-3, each providing quantifiable data on the 41KM69 burned rock features, the features used for typology development (see Chapter 12), and feature data from the broader study area, respectively.

\section{Feature Descriptions from 41KM69 \\ Jennifer L. Thompson}

Ninety-four features were documented and excavated at 41KM69. Their distribution is shown in Figure C-1. Twenty of these were ruled out because they were not cultural in origin. This appendix describes seventy-two prehistoric features and two historic features.

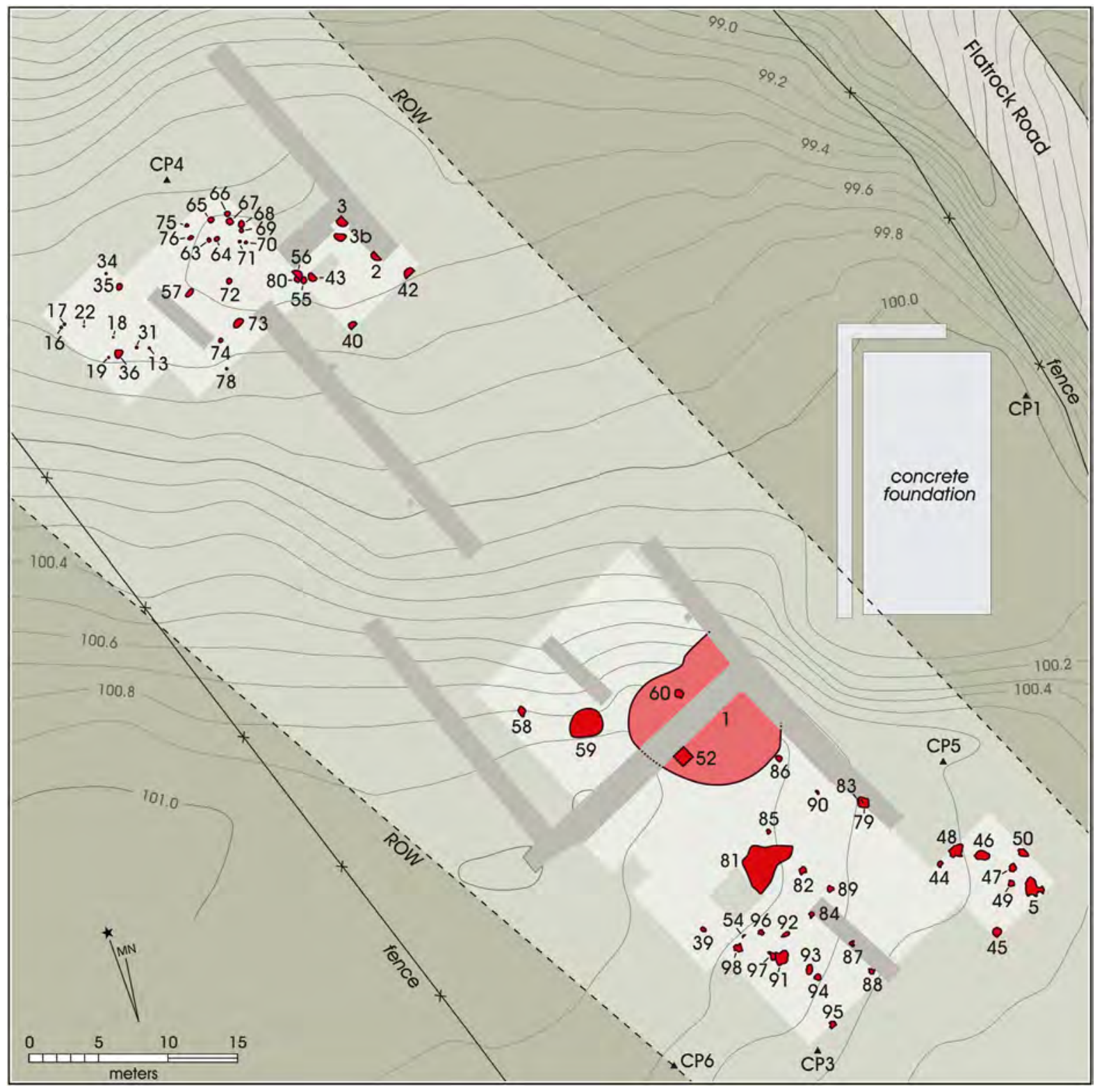

Figure C-1. Map of all features recorded at 41 KM69. 


\section{Feature 1, Burned Rock Midden, Area 3}

This midden was identified during the Phase II testing project in 2004. Weston et al. (2004) estimated the boundaries of the distribution of burned rock recovered in auger tests. Backhoe Trenches 4 and 5 run perpendicular to each other intersecting the midden from the north and the east (Figure C-2). Dimensions estimated from these first excavations show the feature measured approximately $11 \mathrm{~m} \mathrm{E-W}, 9 \mathrm{~m} \mathrm{~N}-\mathrm{S}$ and was one meter thick. Two test units (Test Units 2 and 3) were excavated into the midden adjacent to the trenches. Excavators recovered few artifacts from the test units. The geomorphologist retrieved two samples of charred material from the backhoe trenches (see Figures A-2 and A-3).

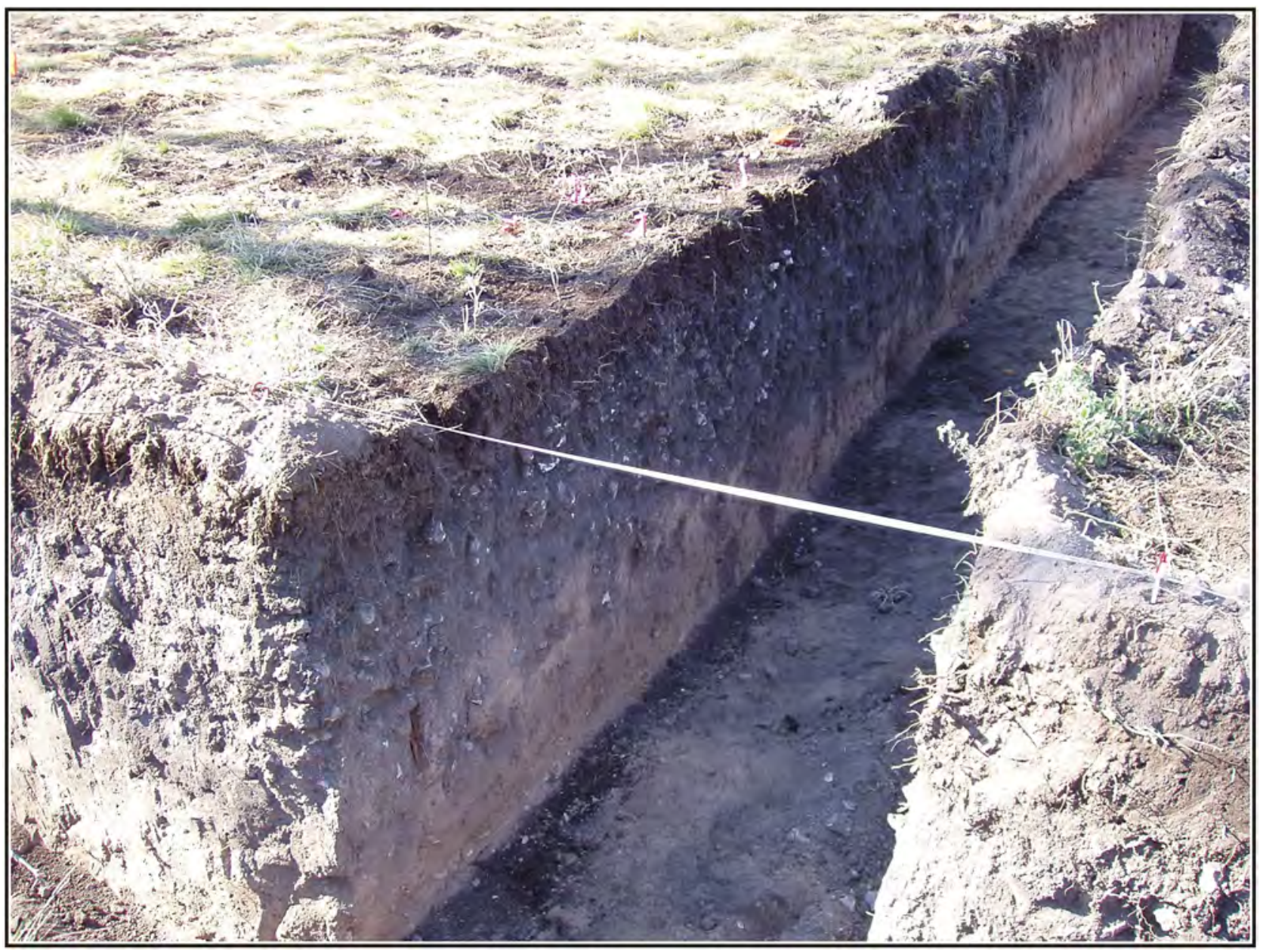

Figure C-2. Feature 1 in south wall of BHT 5 (from Weston et al. 2004).

During data recovery, 17 units were hand excavated adjacent to the two perpendicular backhoe trenches; thirteen of these contained midden fill. The southern-most unit along the north-south trench placed within the boundaries of the midden fill was unit N32 E28 (see Figure 5-7). The midden deposits here were only $40 \mathrm{~cm}$ thick from 50 to $90 \mathrm{cmbd}$. The western-most units along the east-west trench placed within the boundaries of the midden fill was unit N36 E20. Here, the deposit was only $20 \mathrm{~cm}$ thick, from 40 to $60 \mathrm{cmbd}$ (Figure C-3).

From these extreme ends of the feature, the deposit dived to $110 \mathrm{cmbd}$ at its lowest point in unit N36 E26 where the Ck deposit began to mottle the feature fill in Level 11. In this unit, the midden was $80 \mathrm{~cm}$ thick (Figure 4-5, 4-6). Figure C-4 shows the western and center of the excavations in the midden.

After the hand excavation and backhoe trenches were backfilled, a Gradall scraped back the burned rock midden and surrounding areas in 10-cm levels. This procedure allowed us to document the boundaries of the entire burned rock midden and look for any internal features. 


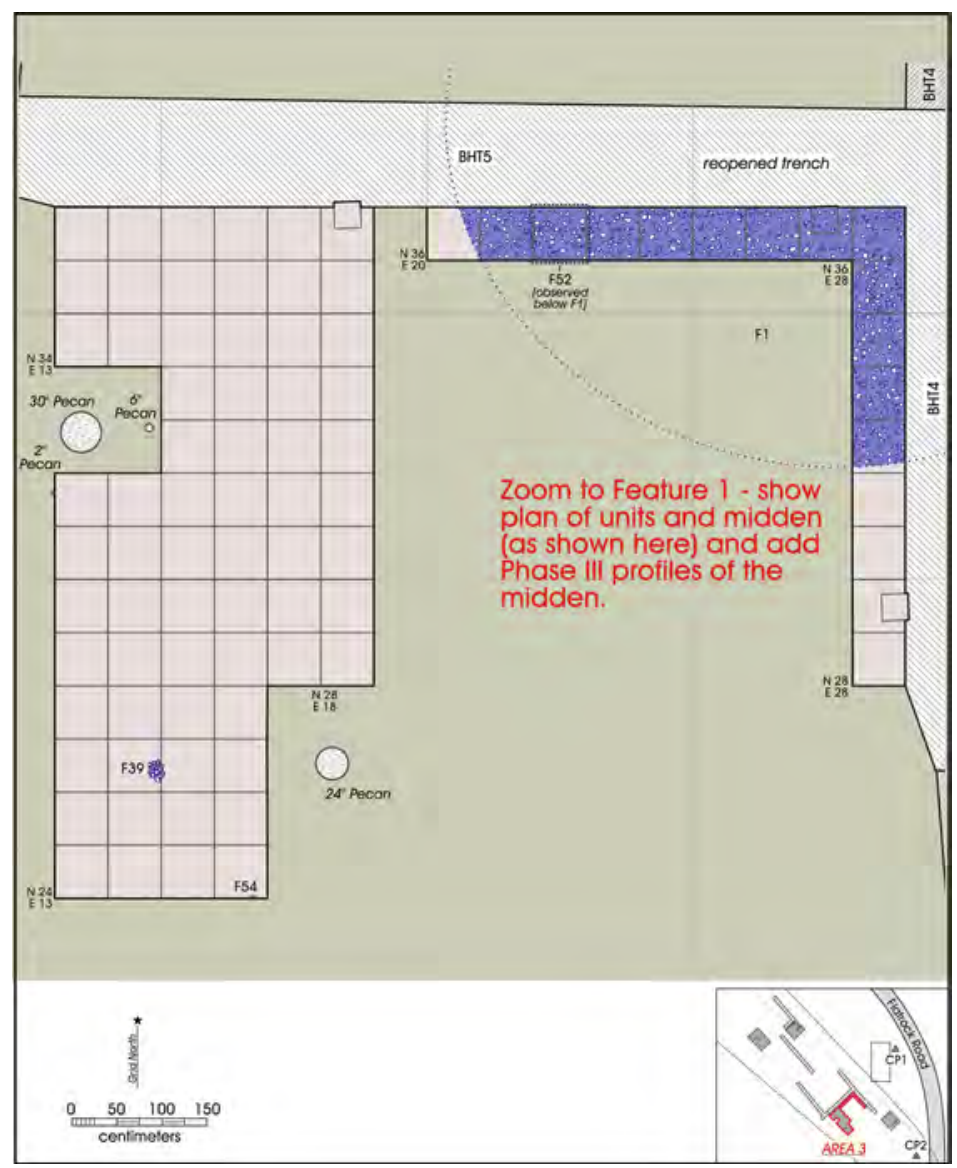

Figure C-3. Dimensions of Feature 1 as documented during data recovery excavations.

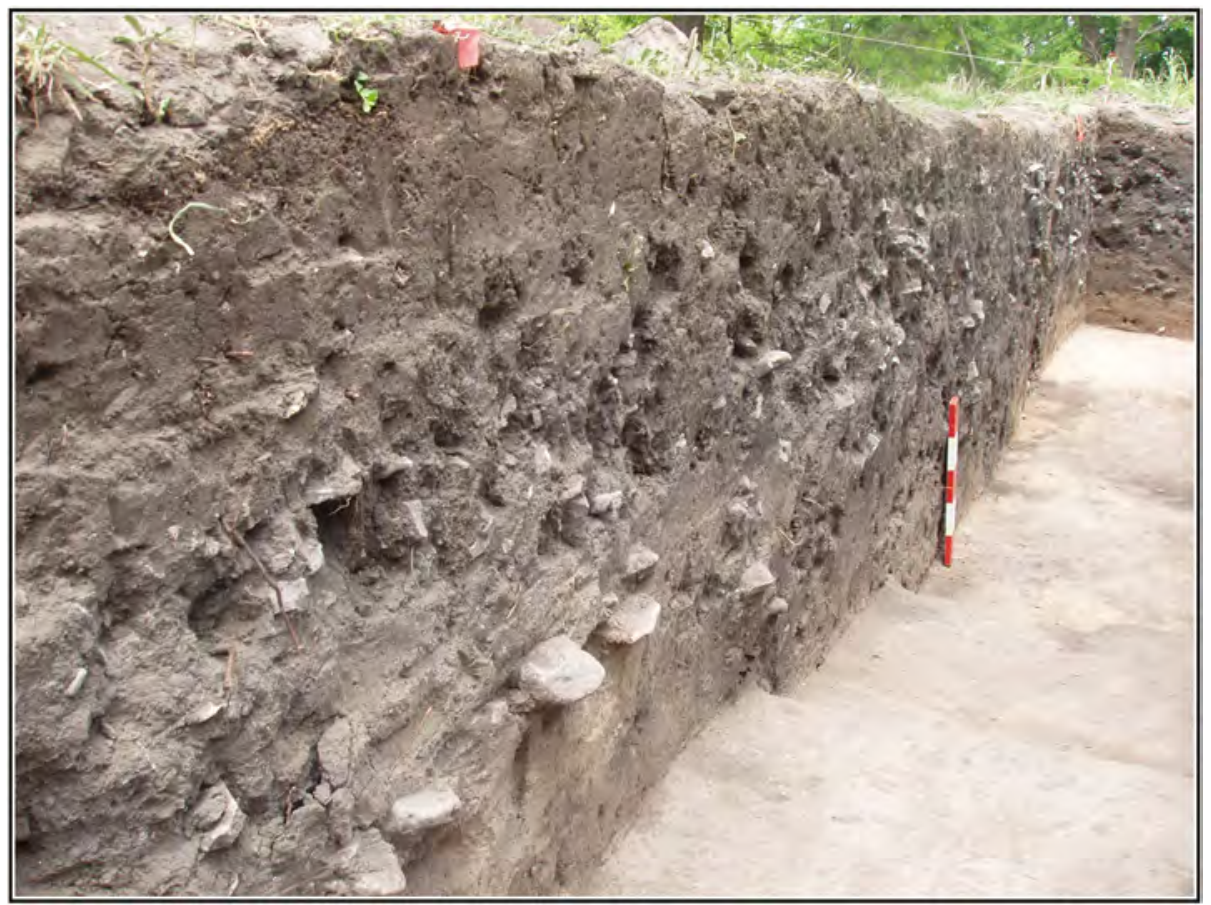

Figure C-4. The northern profile photograph of Feature 1 shows a sharp contrast between the midden fill and burned rock over the Ck horizon. 
Feature 1 contained artifacts from every category except Native ceramics. Included were bone, shell, thousands of pieces of debitage, tools, cores, and historic artifacts. Less than 50 stone tools were recovered from the burned rock midden. The projectile point forms recovered from the midden include Edwards, Fairland, and Frio along with other untypable arrow and dart points. They were all found between Levels 4 and 14. Other stone tools within the midden were typical of the rest of the site and include bifaces, edge-modified flakes and a uniface.

\section{Feature 2, Hearth, Area 2}

Provenience: Test Unit 8 (N77 E30); Elevation: 48-70 cmbd; Dimensions: unknown

This feature was uncovered in Test Unit 8 at the southern end of Backhoe Trench 8 during testing (see Figure 6-13). The trench removed half the feature; but the test unit, expanded from a $50-\mathrm{x}-50-\mathrm{cm}$ to a $1-\mathrm{x}-1-\mathrm{m}$ unit, captured the remaining portions (Figures C-5 and C-6).

Radiocarbon samples were submitted from Feature 2 (see Table 10-1). Sample 1 from the bottom of the hearth dated to $120 \pm$ 40 B.P. (UGA \#13508). This sample was too recent to calibrate. Two additional samples were dated from slightly higher than the first. Sample 2 (UGA\#13590) returned a corrected date of $480 \pm 40$ B.P. (A.D. 1390-1490). This dates the feature to the late Late Prehistoric subperiod or the Toyah Phase. A third sample (UGA \#13591) produced another historic date, A.D. 1640-1960. Because no historic artifacts were found and a bison tibia (Figure C-7) with associated chipped stone artifacts was found near the feature, initial assumptions were that Feature 2 was a Late Prehistoric Toyah interval feature. Data recovery excavation in Area 2 found no other evidence of Feature 2, though we did find the boundaries of Test Unit 8, which correspond to unit N77 E30 in Area 2 (see Figure 6-13).

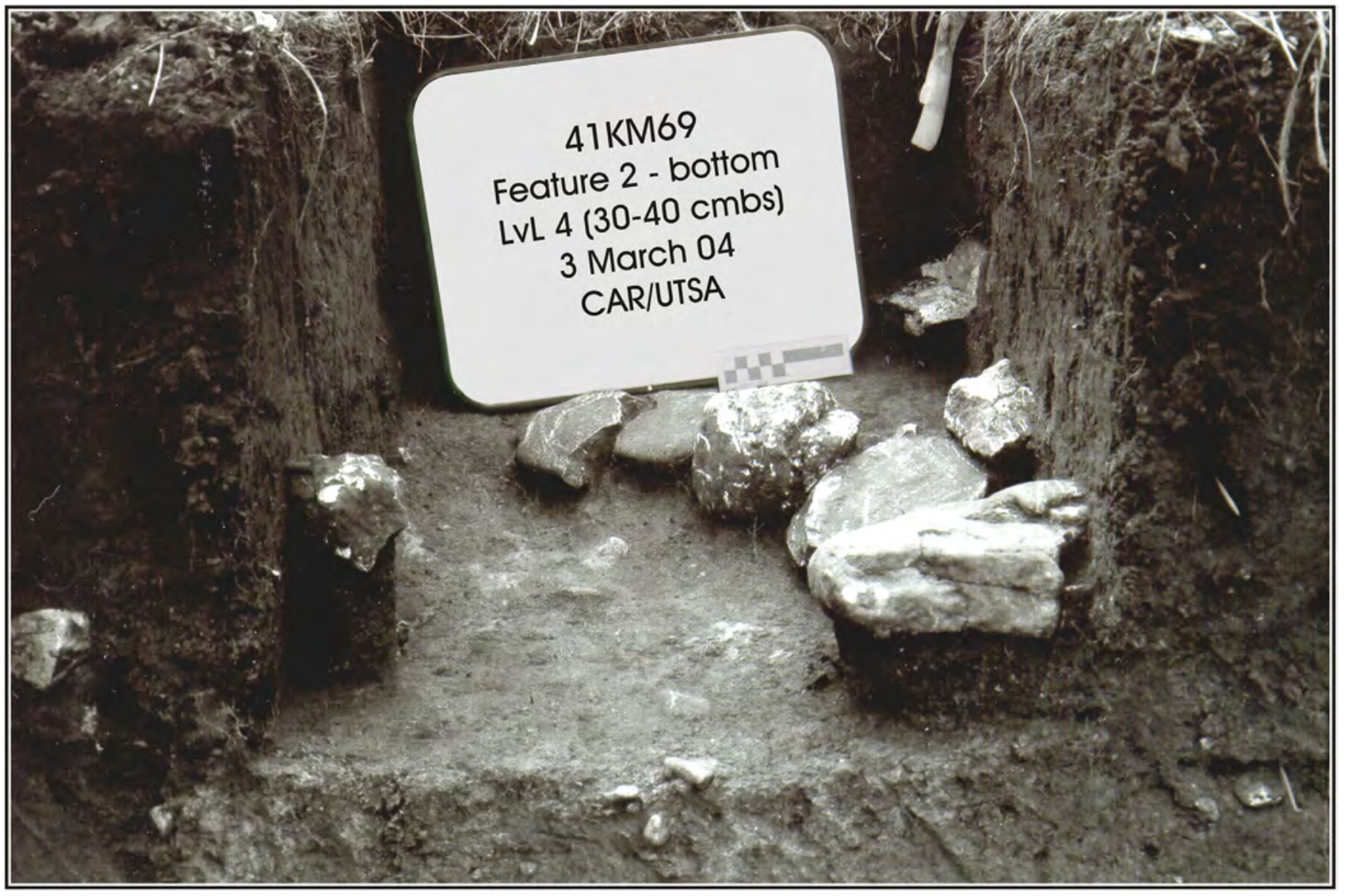

Figure C-5. Feature 2, hearth feature in Test Unit 8 (from Weston et al. 2004). 


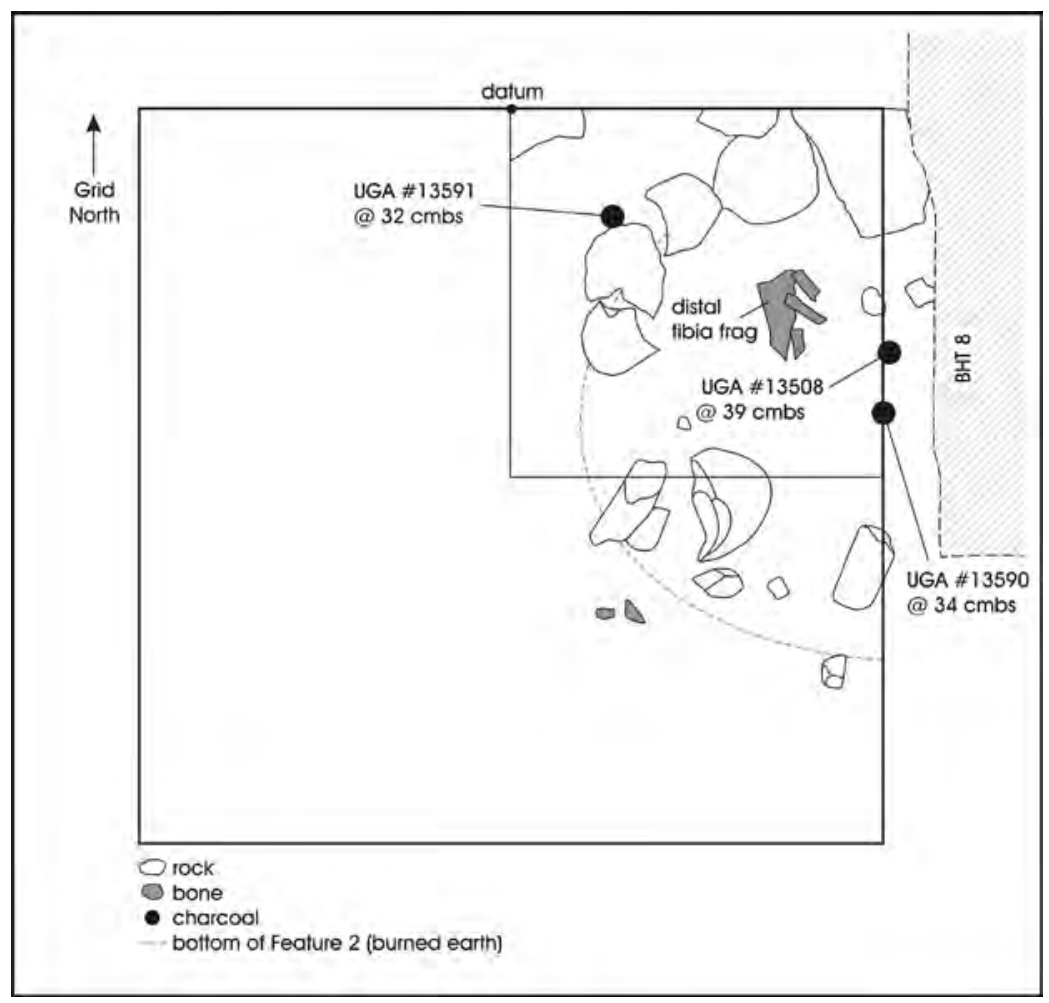

Figure C-6. Plan view of Feature 2 in Test Unit 8 (from Weston et al. 2004).

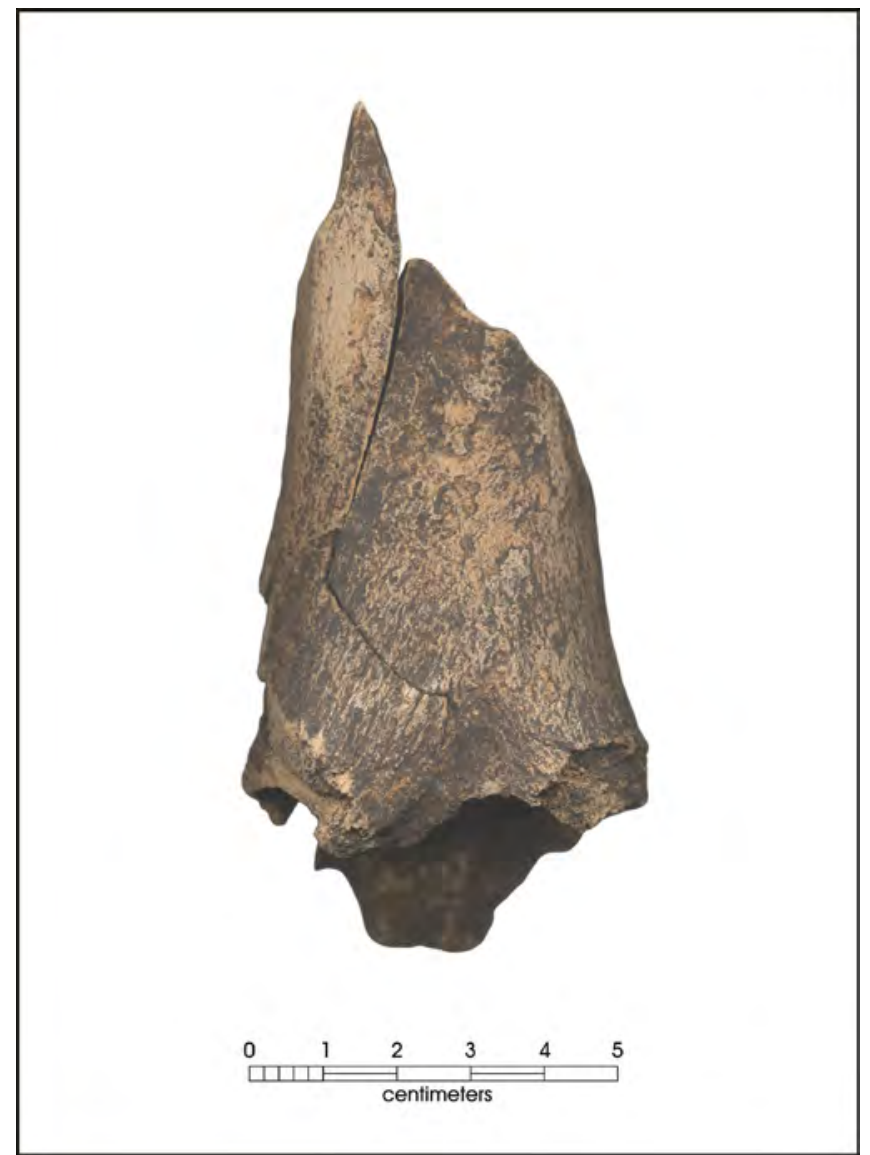

Figure C-7. Bone fragments recovered from Feature 2 (from Weston et al. 2004). 
Features 3 and 3B, Burned Rock Clusters, Area 2

Feature 3 Provenience: Test Unit 12 (N80 E30); Elevation: 62-66 cmbd

Dimensions: unknown

Feature 3B Provenience: N80.33 E30.20; Elevation 58-71 cmbd

Dimensions: $67-x-57 \mathrm{~cm}$

Feature 3 was uncovered in Area 2 in the northeast quadrant of Test Unit 12 (see Figure 6-13; Figures C-8 and C-9). Backhoe Trenches 8 and 9 encountered this feature at $60-66 \mathrm{cmbd}$. Notes from the testing indicate that excavators left some FCR in place in the western wall of Test Unit 12 and speculate that this may be a different feature approximately $50 \mathrm{~cm}$ away from Feature 3. Data recovery excavation in units N80 E29-30 explored the area adjacent to Test Unit 12. An additional scattering of burned rock noted as Feature 3B was uncovered in units N80 E29-30 at $58 \mathrm{cmbd}$, which corresponds to the depths of Features 2 and 3 , likely placing it in the Late Prehistoric, Toyah interval.

\section{Feature 5, Burned Rock Cluster, Area 4}

Provenience: N12 E34; Elevation: 85 cmbd; Dimensions: unknown

Feature 5 showed up in auger test data before it was exposed in Test Unit 9 (N12 E34) (see Figure 6-15, Figure C-10). Early predictions suggested that this was the edge of a burned rock cluster. Excavations in Area 4 in units N11 E33 and N11 E34, one meter south of Test Unit 9, and N11 E35 uncovered more burned and fire-cracked rock scattered $1.5 \mathrm{~m}$ from east to west and 1.0 meter south into the wall of Area 4 at approximately $85 \mathrm{cmbd}$. We retrieved one ${ }^{14} \mathrm{C}$ sample from the cluster and several lithic artifacts.

\section{Feature 10, Burned Rock Cluster, Area 1}

Provenience: N87.50 E15.80; Elevation: $28 \mathrm{cmbd}$; Dimensions: $87-x-69 \mathrm{~cm}$

Feature 10 was located in Area 1 in units N87 E15-16 (see Figure 6-12). It lay at a shallow elevation (28 cmbd) directly below large gravels possibly associated with a road. The feature is disturbed with historic artifacts like concrete and glass but also contains prehistoric artifacts such as debitage. Some of the debitage appears cemented into the concrete. No charcoal samples were observed but soil samples were taken from between the rocks. All the rocks were collected and returned to the CAR lab.

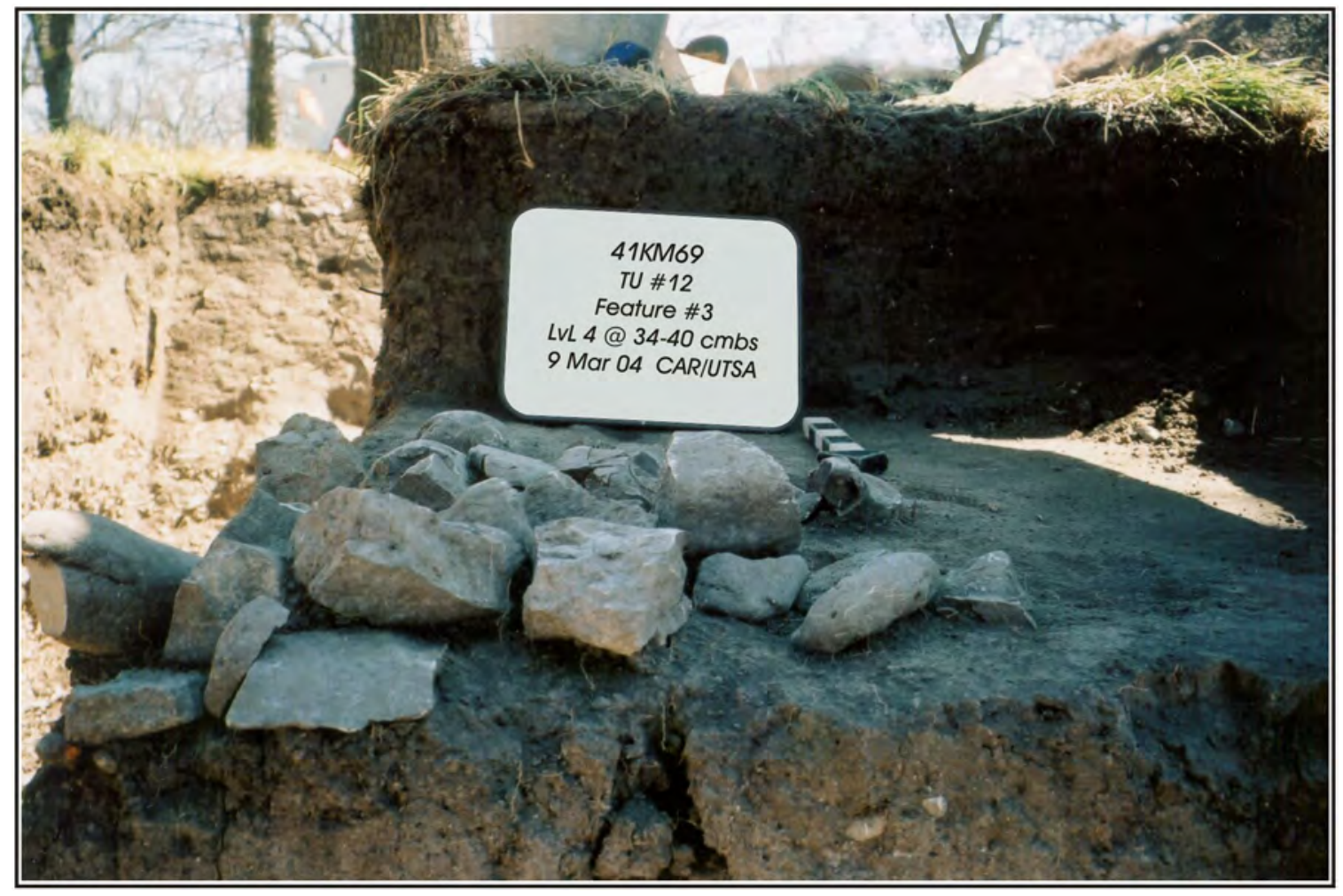

Figure C-8. Feature 3, burned rock cluster in Test Unit 12 (from Weston et al. 2004). 


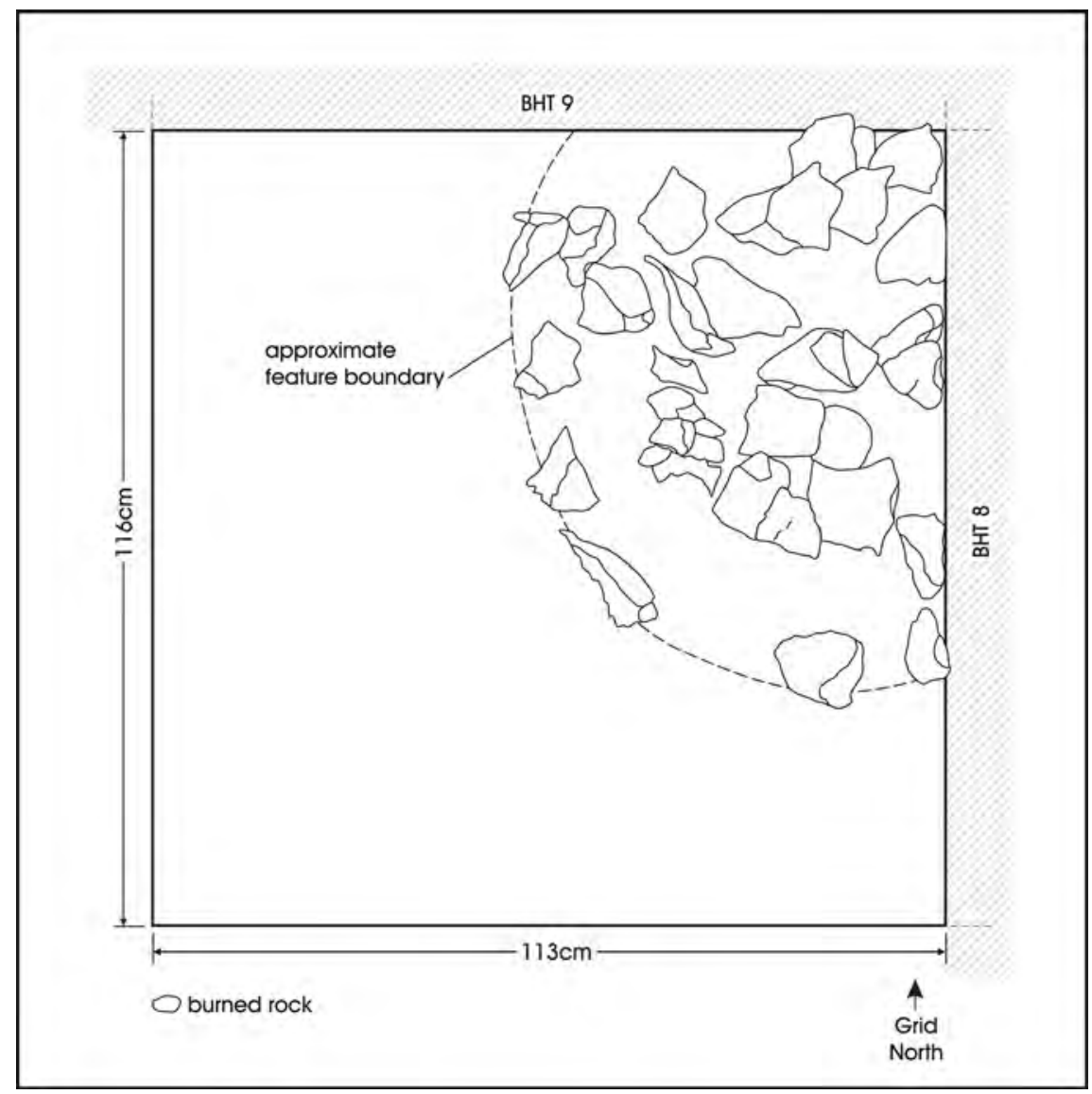

Figure C-9. Plan view of Feature in TU12, 30-35 cmbs (from Weston et al. 2004).

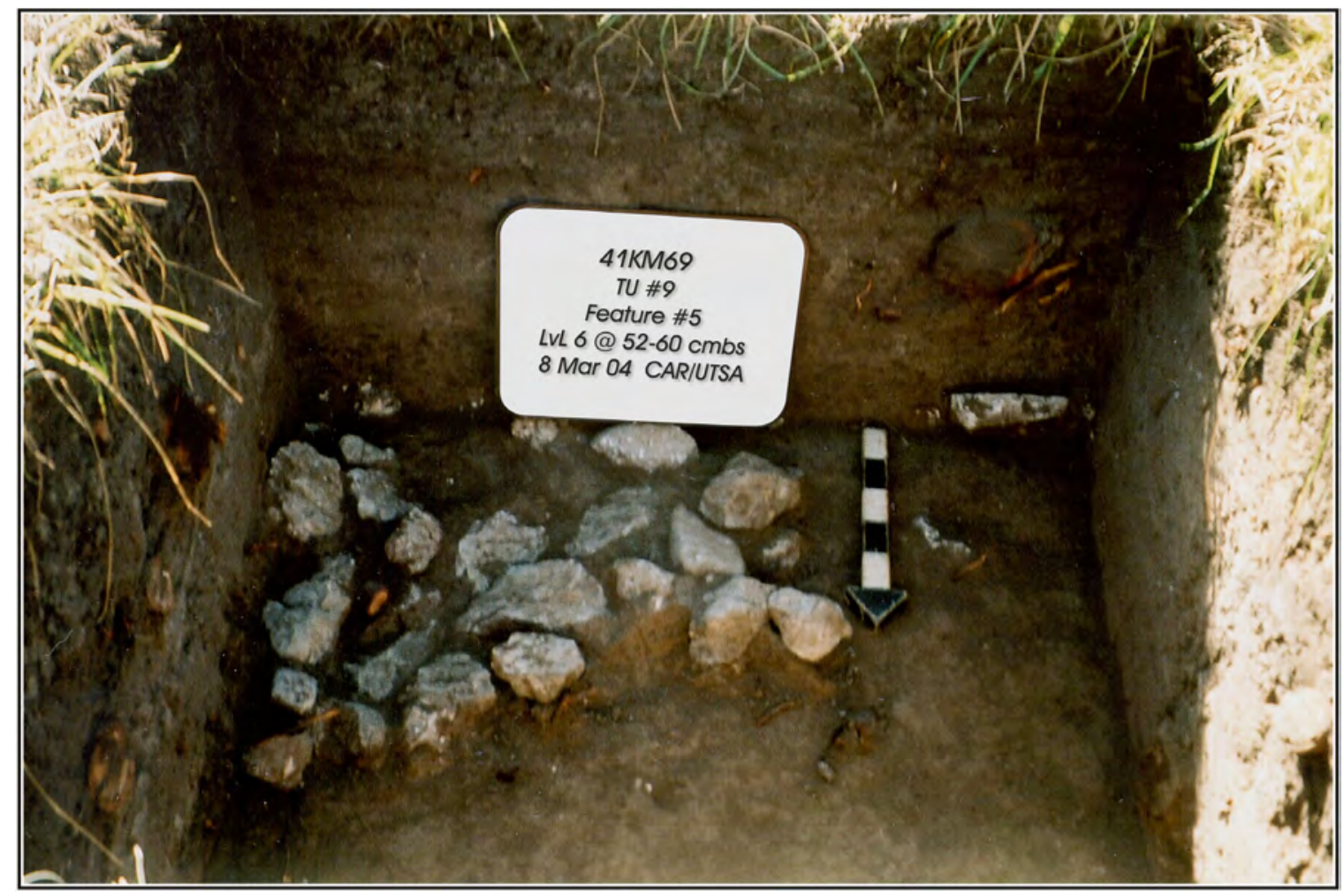

Figure C-10. Feature 5, burned rock cluster in TU 9 (from Weston et al. 2004). 


\section{Feature 35, Rock lined Hearth, Area 1}

Provenience: N88.80 E16.40; Elevation: 140 cmbd; Dimensions: $55-x-50 \mathrm{~cm}$

This hearth lay in the Ck horizon in Area 1 from 129-140 cmbd (see Figure 6-12). It is ovoid and basin shaped, lined with rock (Figures C-11 and C-12). Extremely heavy gravels underlie this feature, which indicate this may have been a gravel bar while occupied. The feature fill contained some small pieces of debitage. Soil samples were taken from above and below the slab lining and one sample of carbon was collected and sent for radiometric dating. This returned a date of $2550 \pm 50$ B.P. (UGA \#15179, Delta 13 corrected; Table 7-3), placing it in the middle of the Late Archaic. This feature could represent the oldest documented occupation of the site. It was the only feature found at this depth in Area 1; however, another rock cluster, Feature 36, was discovered slightly higher and 4.5 m southwest of Feature 35 (see Figure 6-12). Features 42, 43, 55, and 56 also lie at the surface of the $\mathrm{Ck}$ horizon in Area 2 and likely date to the same time but may indicate a different visit to the site.

\section{Feature 36, Burned Rock Cluster, Area 1}

Provenience: N85.40 E13.00; Elevation: $105 \mathrm{cmbd}$; Dimensions: 40-x-60 cm

Also at the $\mathrm{Ck}$ horizon level in Area 1 (see Figure 6-12), Feature 36 was a burned rock cluster first noted at $105 \mathrm{cmbd}$. This was a jumble of FCR spanning units N84-85 E13 in upper levels. Only in Level 11 did the FCR begin to cluster densely enough to warrant a feature number.

\section{Feature 39, Burned Rock Cluster, Area 3}

Provenience: N26.40 E14.90; Elevation: 90 cmbd; Dimensions: $41-x-37 \mathrm{~cm}$

This burned rock cluster was uncovered between units N26 E14 and E15 in Area 3 (see Figure 6-14). FCR was present across the entire block. In Feature 39, the rocks were placed in a 41-x-37 cm circular pattern at 84-90 cmbd. As with the other rock features, Feature 39 exhibited no burned earth or discolored fill, though a soil sample was collected from between the rocks, which were also collected. No artifacts were collected or noticed in the fill.

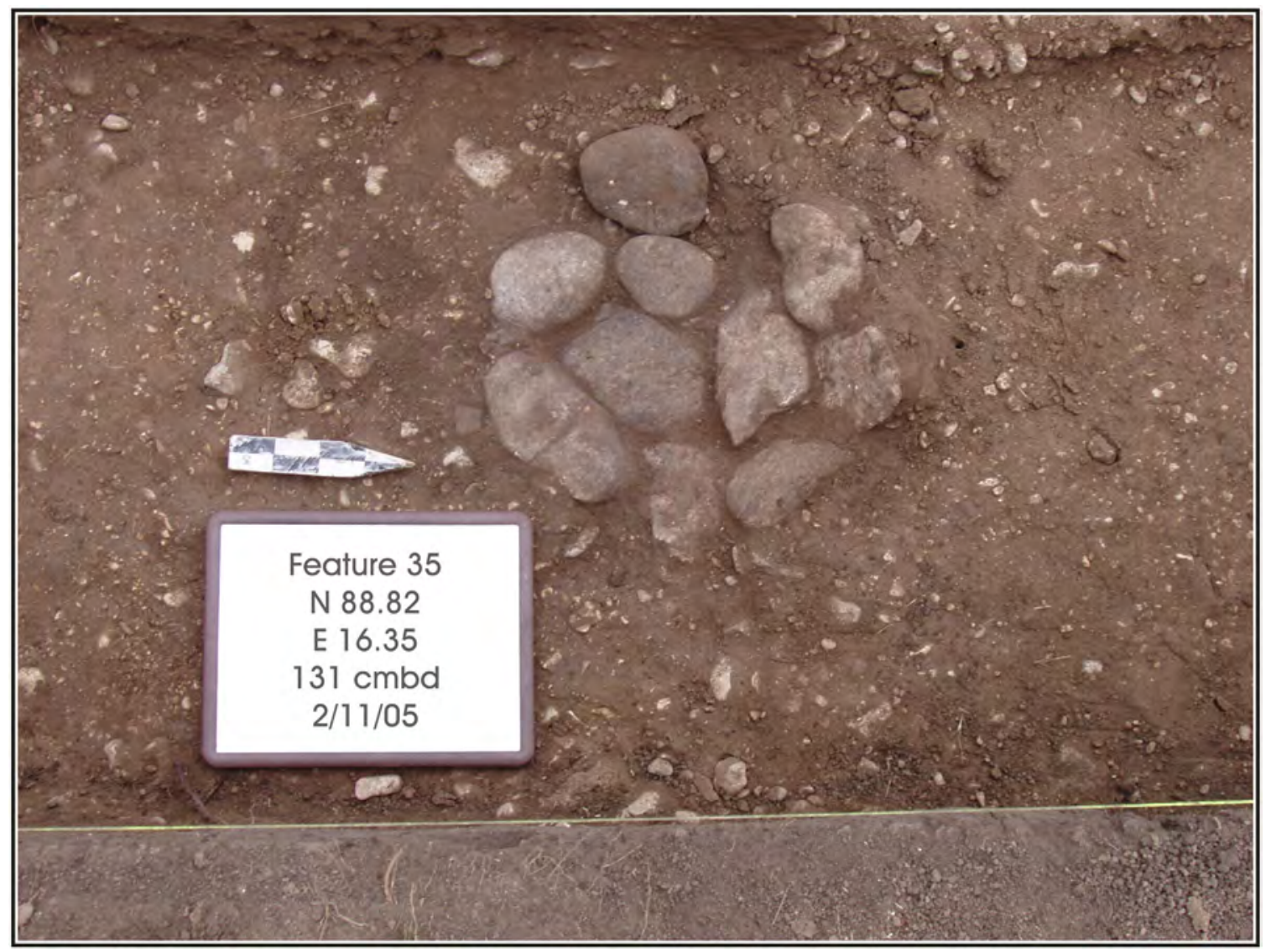

Figure C-11. Feature 35 was discovered in heavy gravels in Area 1. 

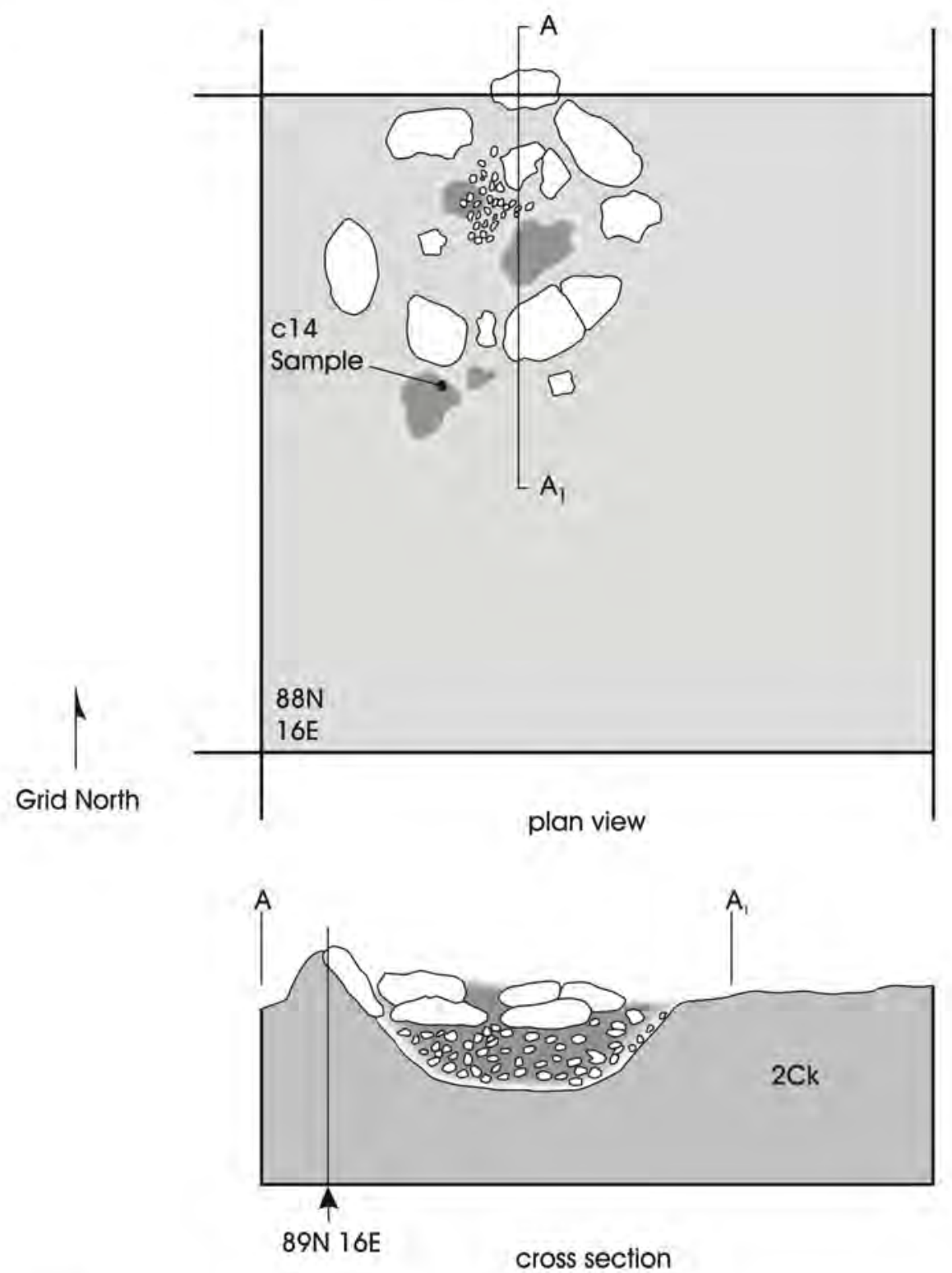

\section{$\therefore 800$ gravels \\ rock \\ staining}

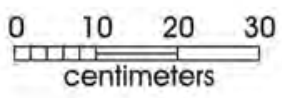

Figure C-12. Plan view of Feature 35 shows the locations of the ${ }^{14} \mathrm{C}$ samples submitted for dating.

The cross section shows the soils stain beneath the level of the rock basin.

\section{Feature 40, Burned Rock Cluster, Area 2}

Provenience: N75.16 E26.53; Elevation: $82 \mathrm{cmbd}$; Dimensions: 44-x-50 cm

Feature 40 is a small cluster of burned rock recovered from Area 2 (see Figure 6-13). It was approximately $6.0 \mathrm{~m}$ west of Feature 42 in unit N75 E26 at $75 \mathrm{cmbd}$ in the Bk horizon. Feature 40 exhibited no discernible differences between the fill and the surrounding matrix, but we collected a soil sample. Lithic artifacts were also observed in the feature. The feature was circular with a slight basin shape to it. The extreme southern edge of the feature was left in the unexcavated south wall of the unit. 


\section{Feature 41, Soil Stain, Area 2}

Provenience: N77.52 E27.18; Elevation: $80 \mathrm{cmbd}$; Dimensions: $28-x-30 \mathrm{~cm}$

Feature 41 is a small circular stain identified in Area 2 (Figure 6-13). It was approximately $1.5 \mathrm{~m}$ northeast of Feature 40 in the $\mathrm{Ck} 1$ horizon. Feature 41 fill was darker than the surrounding matrix and contained charcoal. No artifacts were found within the fill. In profile, the feature had a clear basin shape with steep walls.

\section{Feature 42, Hearth, Area 2}

Provenience: N75.00 E32.00; Elevation: $110 \mathrm{cmbd}$; Dimensions: $75-x-50 \mathrm{~cm}$

In Area 2, Feature 42 lay approximately $6.0 \mathrm{~m}$ east of Feature 40 and less than 2 meters south of Feature 2 (see Figure 6-13). It was uncovered at $96-110 \mathrm{cmbd}$. The exact dimensions are unknown because the rocks go into the southern wall of the unit, but the measurable dimensions are $75 \mathrm{~cm}$ east-west, and $50 \mathrm{~cm}$ north-south into the wall of Area 2 (Figure C-13). The feature sits at the surface of the $\mathrm{Ck}$ horizon. The fill seems to have the same properties as the surrounding matrix. There is no obvious pit. We collected soil samples above and between the rocks. We plotted one piece of debitage within the feature but observed no bone or charcoal. The main body of the feature straddles units N75 E31-32. FCR is scattered across the block at this level (see Figure 6-13).

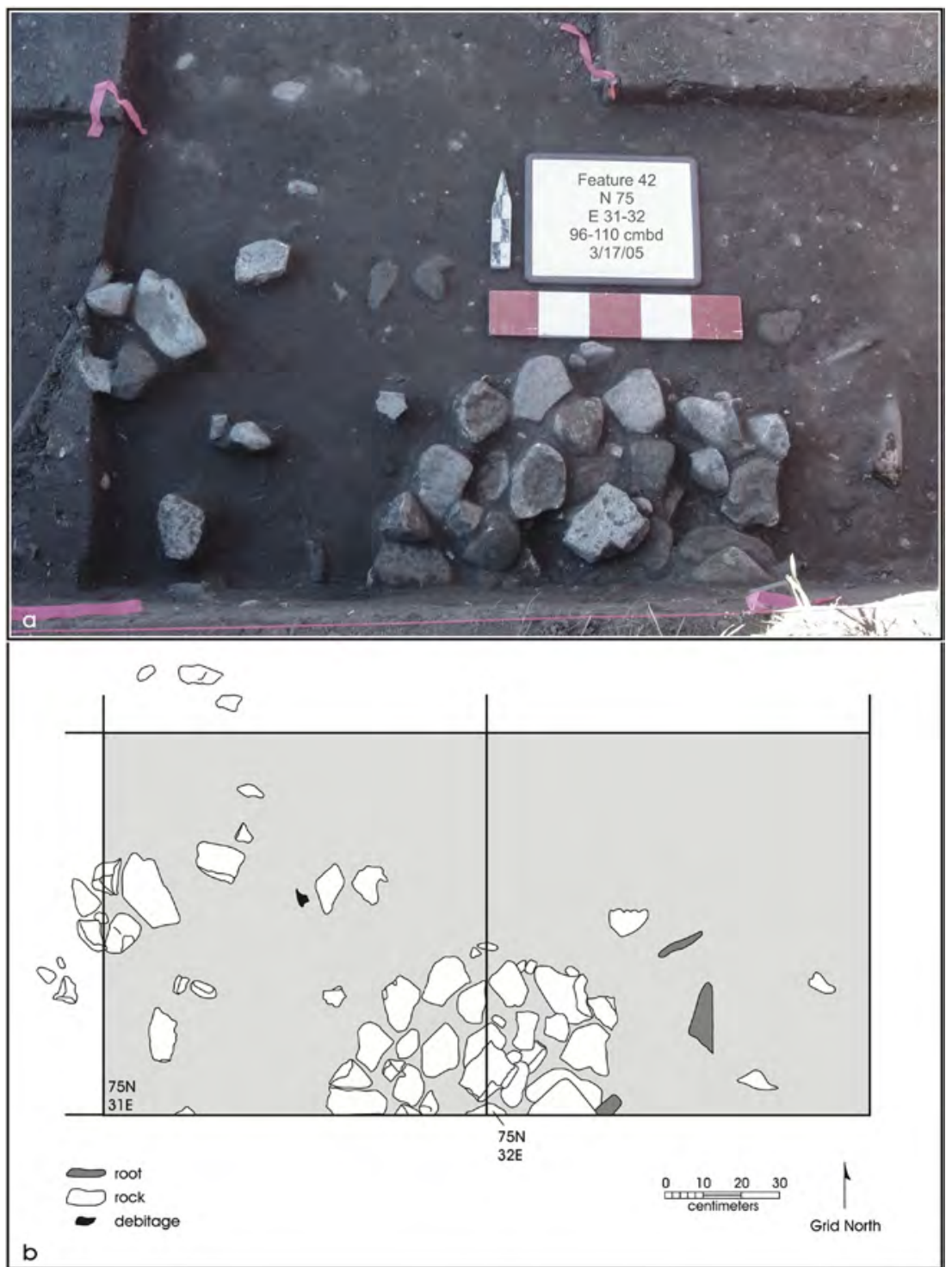

Figure C-13. Feature 42 is a large, Late Archaic hearth feature in Area 2. a) photo; b) plan view drawing. 


\section{Feature 43, Burned Rock Cluster, Area 2}

Provenience: N79.75 E26.75; Elevation: $101 \mathrm{cmbd}$; Dimensions: 49-x-35 cm

This is a burned rock scatter found in Area 2 above the Ck horizon (see Figure 6-13). Other fire-altered rocks may be present within the unexcavated N79 E27 unit. In proximity to Feature 43, (within $1 \mathrm{~m}$ ), other heated rocks were documented as Features 55 and 56. Though Feature 43 is slightly higher than the other two, first observed at $98 \mathrm{cmbd}$, it is likely part of the same feature or a product of the same activity. Across Area 2, within this general level we recovered lithic debitage.

\section{Feature 44, Burned Rock Cluster, Area 4}

Provenience: N17.75 E30.75; Elevation: 80 cmbd; Dimensions: unknown

We recorded Feature 44 in Area 4 approximately 1.0 m west of Feature 48 and 5.0 m northwest of Feature 5 (see Figure 6-15). This feature formed a semi-circular pattern in the floor of Level $8(80 \mathrm{cmbd})$. We collected no soil sample from this feature and no ${ }^{14} \mathrm{C}$ sample was available.

\section{Feature 45, Hearth, Area 4}

Provenience: N11.30 E30.50; Elevation: 90-98 cmbd; Dimensions: $58-x-72 \mathrm{~cm}$

Feature 45 was a large circular hearth with a slight basin shape. The southern half of the feature has a lower elevation than the northern half. This lay approximately $4.0 \mathrm{~m}$ west of Feature 5 at approximately the same level as Features 5 and 47 (see Figure 6-15). Feature 45 is a single, circular layer of rock with a depressed center and southern end (Figures C-14 and C-15). Soil from $4.0 \mathrm{~cm}$ above the rock to $1.0 \mathrm{~cm}$ below the rock appeared discolored and contained charcoal flecking. Mussel shell fragments interspersed in the units around the feature were absent from the feature itself. Snails, mostly Helecina sp. were also found in proximity to this hearth. Roots were present above and through the feature.

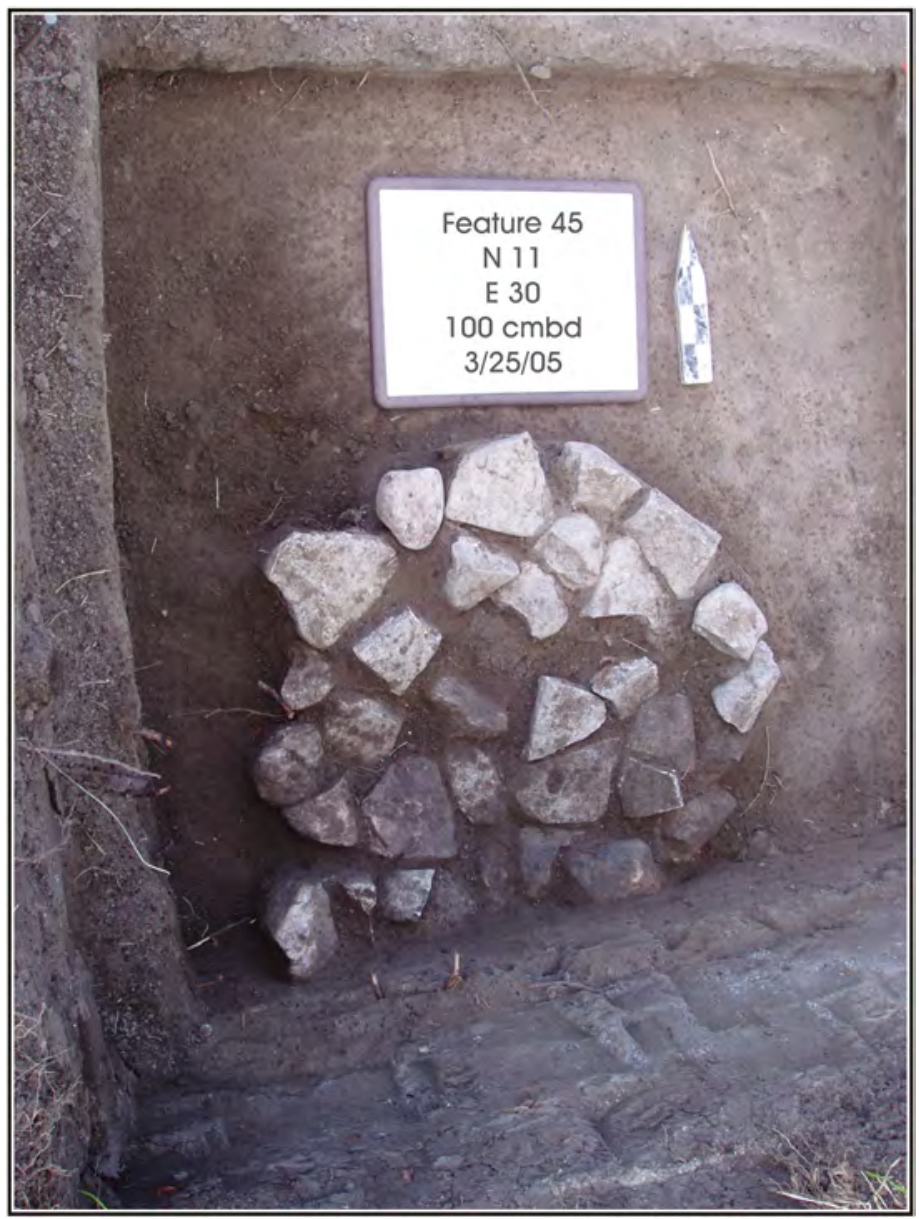

Figure C-14. Feature 45 is a large basin-shaped hearth excavated in Area 4. 


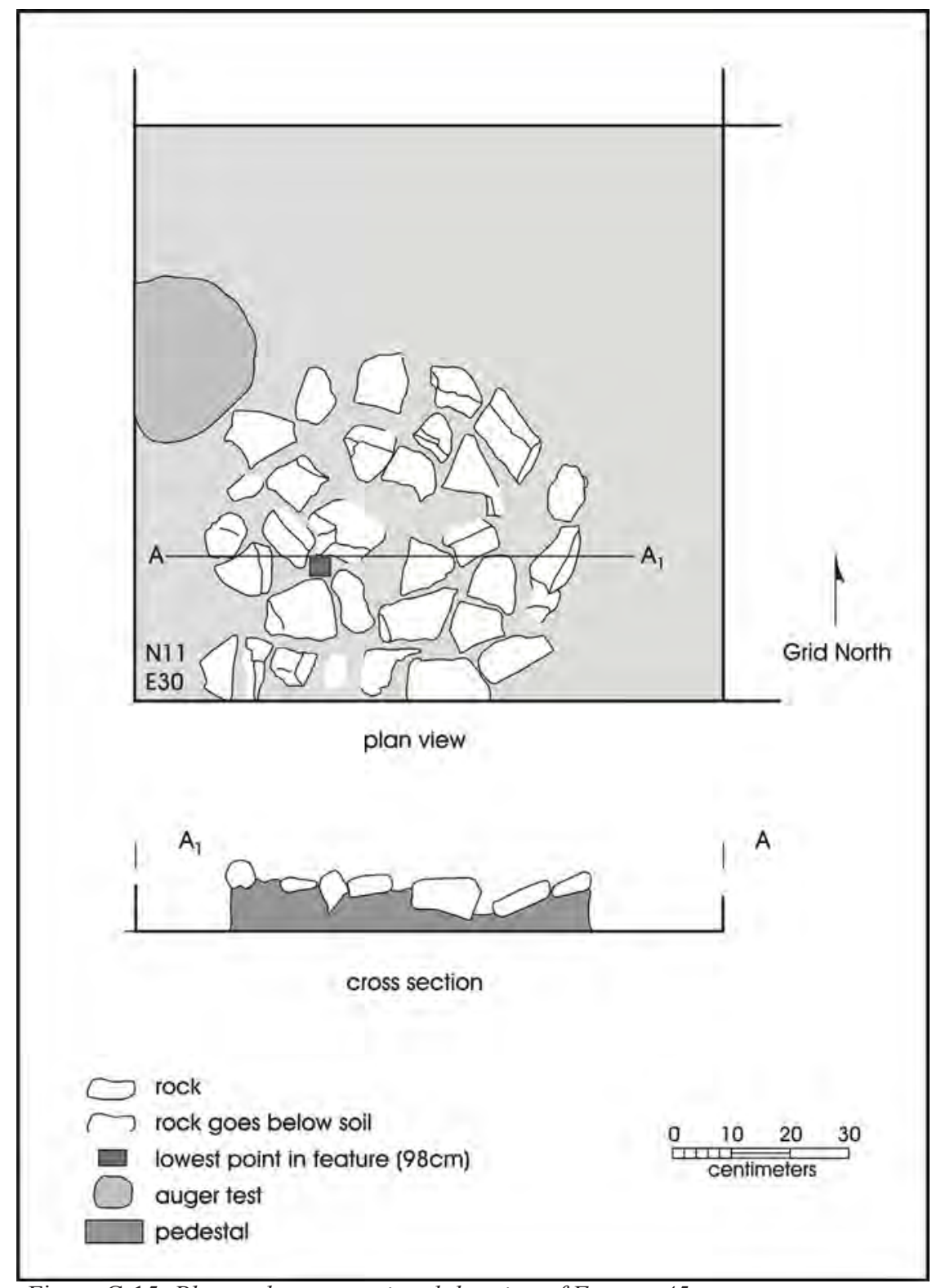

Figure C-15. Plan and cross-sectional drawing of Feature 45.

Feature 46, Burned Rock Cluster with dense charcoal deposits, Area 4

Provenience: N16.10 E33.35; Elevation: 71-80 cmbd; Dimensions: $95-x-55 \mathrm{~cm}$

In Area 4, Feature 46 was an irregular scatter of FCR with a high amount of charcoal but no discolored or burned soil (see Figure 6-15). There was no organized arrangement of rock. We collected soil samples and charcoal samples. The depth of this feature corresponds with Feature 44, approximately $2.0 \mathrm{~m}$ to the northwest. The excellent preservation of charred material in this feature is unusual for this site and therefore may indicate a more recent origin.

\section{Feature 47, Hearth, Area 4}

Provenience: N13.90 E34.50; Elevation: 84-94 cmbd; Dimensions: $55-x-60 \mathrm{~cm}$

Feature 47 in Area 4 sat at the same level as Feature 5 and $1.0 \mathrm{~m}$ to the north (see Figure 6-15). It was also at the same approximate level as Feature 45, which is approximately $5.0 \mathrm{~m}$ to the southwest of Feature 47 . Feature 47 had no fill distinguishable from the surrounding matrix. The burned and cracked rocks were set in a circular form, with those on the eastern side set vertically or angled in the ground (Figure C-16). The feature was not lined, but did have fire-cracked rock throughout. The center of the feature was slightly lower than the outer edges, forming a very shallow basin (Figure C-17). 


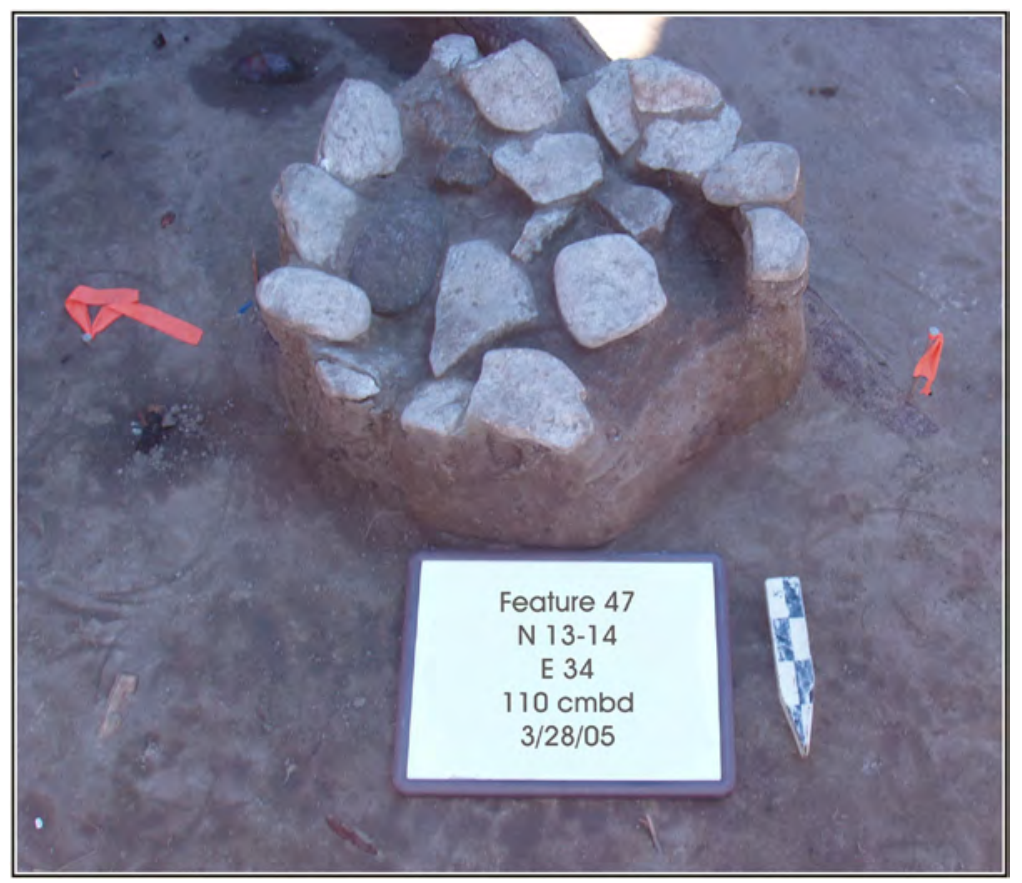

Figure C-16. Feature 47 is a small hearth with vertically set stones.

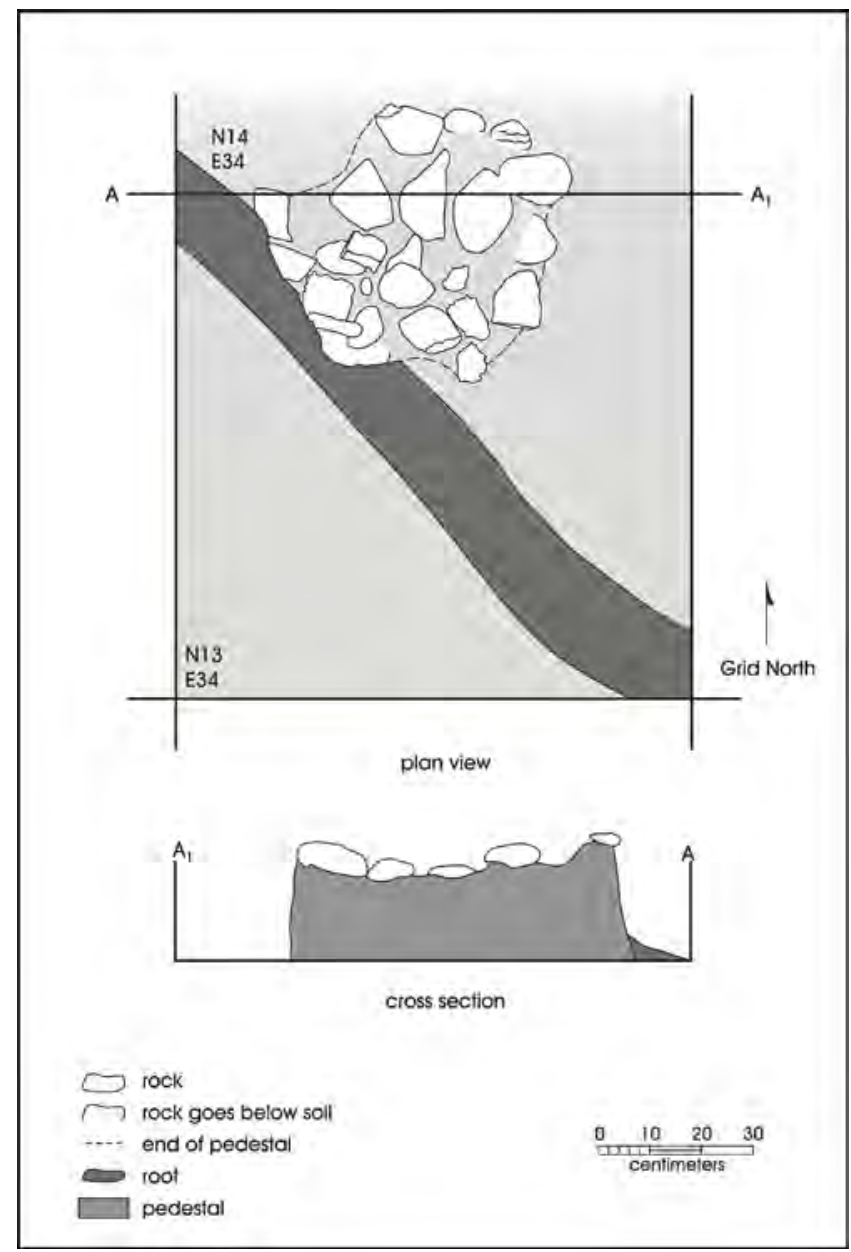

Figure C-17. Feature 47 illustrated in plan view and cross section showing the basin shape. 


\section{Feature 48, Burned Rock Cluster, Area 4}

Provenience: N17.63 E32.36; Elevation: $92-110 \mathrm{cmbd}$; Dimensions: 125-x-93 cm

Feature 48 was comprised of a wide scatter of burned and fire-cracked rock forming an ovoid shape (Figure C-18). This burned rock cluster was found at approximately the same level, but slightly lower than, Features 45 and 47, on the northern edge of Area 4 (see Figure 6-15). Portions of the feature entered the wall of the block and were not available for measurement. Carbon flecking and debitage were more prevalent within the feature boundaries than in the larger unit. The feature fill exhibited no other color or textural differences. The only difference seemed to be the differential artifact densities. Artifacts taken from the feature include burned bone and debitage, shell, non-burned bone, carbon, land snails and fire-cracked rock. Root disturbance within this feature was high. The burned rocks extended an unknown distance to the north. Soil samples were taken from the feature fill between the rocks. No carbon samples were collected for dating.

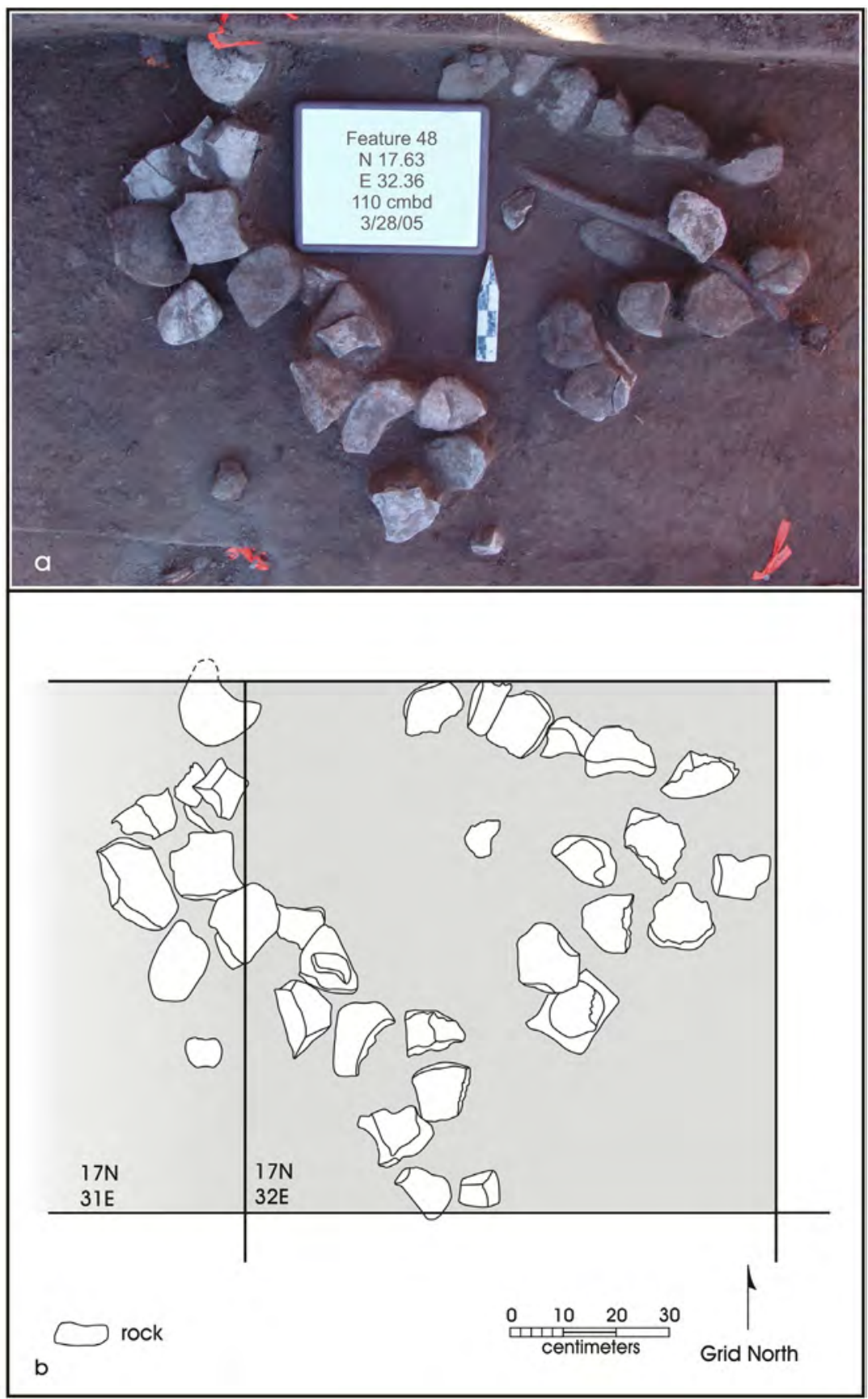

Figure C-18. Feature 48 is a large burned rock cluster in Area 4. a) photo; b) plan view drawing. 


\section{Feature 49, Hearth, Area 4}

Provenience: N12.15 E33.60; Elevation: 99-111 cmbd; Dimensions: 42-x-41 cm

Feature 49 was in Area 4 at a somewhat lower elevation than Features 5, 45, and 47, though it was in horizontal proximity to Feature 47 and Feature 5 (see Figure 6-15). This hearth feature was also a round formation of fire-cracked and burned rock (Figure C-19). A ${ }^{14} \mathrm{C}$ sample came from the southern half of the feature with small flecks present in the soil samples. Within the general level, we collected two bifaces from the matrix. Roots seemed to have disturbed this feature, though it retains a circular shape. It is not basin shaped. Feature 49 has rocks that sit at various elevations as seen in the northern profile drawing (Figure C-20).

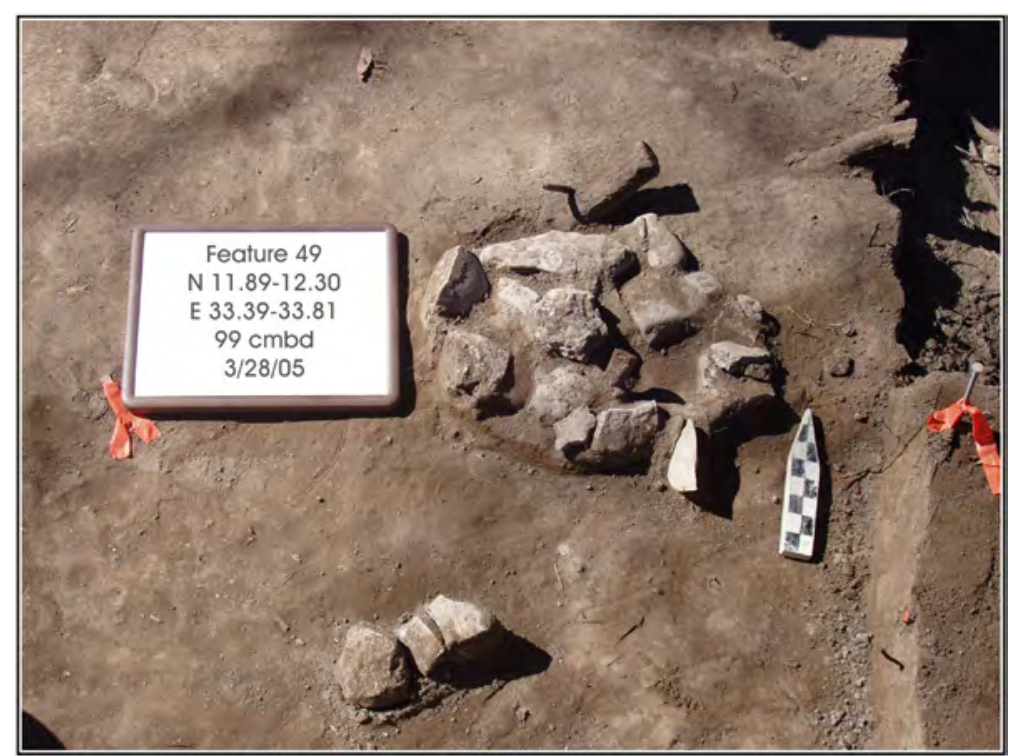

Figure C-19. Feature 49 is a round hearth located near Features 5 and 47.

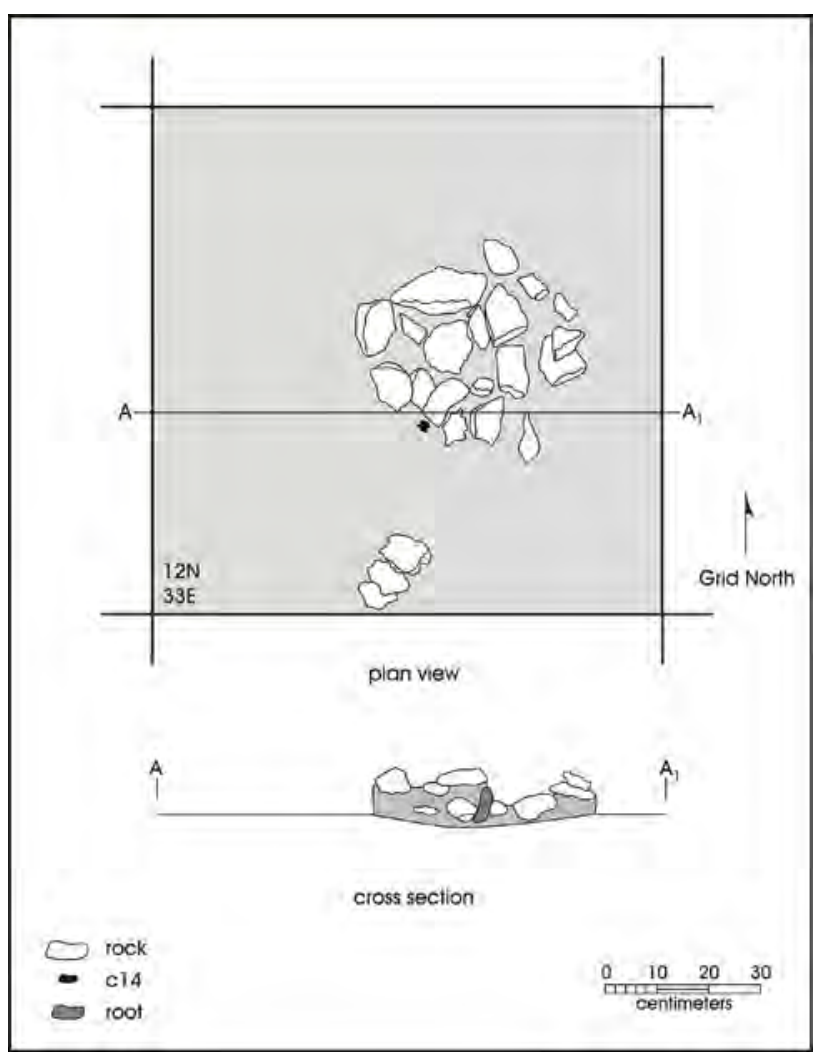

Figure C-20. Feature 49 shown in plan view and cross section. 


\section{Feature 50, Burned Rock Cluster, Area 4}

Provenience: N14.16 E35.80; Elevation: 139-147 cmbd; Dimensions: 60-x-42 cm

Feature 50 was approximately $5.0 \mathrm{~m}$ east of a lithic concentration (Feature 51) in Area 4 (Figure 6-15). It is less than a meter east of Feature 47. The feature is a concentration of burned rock and rock cracked in place. There was some charcoal in the surrounding matrix but none was collected for dating. The rock appears to be disturbed by roots but essentially in place. Soil samples were collected from between the rocks.

\section{Feature 51, Lithic Concentration, Area 4}

Provenience N14.46 E30.99; Elevation: 140-143 cmbd; Dimensions: 25-x-29 cm

Feature 51 was a concentration of debitage within the $\mathrm{Ck}$ horizon of Area 4. The debitage appears smaller than $.64 \mathrm{~cm}(0.25$ in.) so would have slipped through the screen. The fill was bagged along with all the debitage in the soil sample. We observed no differentiation or pit feature in the profile. The rest of the units at this level were largely devoid of artifacts. Feature 51 is at the same elevation as Feature 50 and is $5.0 \mathrm{~m}$ to the west (see Figure 6-15).

\section{Feature 52, Internal Hearth within Feature 1, Area 3}

Provenience: N36.50 E22.50; Elevation: $85 \mathrm{cmbd}$, Dimensions: 100-x-[unknown] cm

Feature 52 is a possible hearth comprised of approximately 30 pieces of burned rock situated beneath Feature 1 (Figure 6-14) on the $\mathrm{Ck}$ horizon, at $85-90 \mathrm{cmbd}$ (Figure C-21). No pit or basin shape was visible in cross-section. The cluster is $1.0 \mathrm{~m}$ east to west but runs into unexcavated unit walls to the north and south so the exact dimensions are unknown. Fill from the interior of the feature is mixed with $\mathrm{Ck}$ soils and Feature 1 fill. Fill specific to Feature 52 was unidentifiable. Soil samples came from between the rock at the southern edge of the unit and charcoal within the fill was collected for dating.

\section{Feature 53, Hearth, Area 3}

Provenience: N23.75 E15.16; Elevation: 111 cmbd; Dimensions: 97-x-40 cm

Feature 53 lay in the southern wall of Area 3. We exposed burned rocks during soil profiling. The feature was oval and basin shaped. From the fill, we collected bone and charcoal. The very southern edge of the feature lies in the southern block wall so exact dimensions could not be measured.

\section{Feature 54, Burned Rock Cluster, Area 3}

Provenience: N23.37 E 16.72; Elevation: 88-105 cmbd; Dimensions: 14-x-23 cm

This small scatter of burned rock (6 pieces) was discovered during the collection of paleo-ethnobotany samples from the Bk2 horizon in soil column E (see Figure 6-14). These samples were excavated from the floor of the excavation up, so the base of the feature was discovered first. Areas to the east and west were exposed to locate the horizontal extent of the feature in the profile wall. The soil sample from this feature because soil was incorporated into the botanical soil samples for flotation.

\section{Feature 55, Burned Rock Cluster, Area 2}

Provenience: N79.92 E26.29; Elevation: $110 \mathrm{cmbd}$; Dimensions: 53-x-24 cm

This was a burned rock scatter found in Area 2 above the $\mathrm{Ck}$ horizon (Figure 6-13). Five pieces of burned and cracked rock formed an ovoid pattern. Within $.50 \mathrm{~m}$ proximity to the Feature other heated rocks were documented as Features 43 and 56. Though Feature 43 is slightly higher than the other two, first observed at $98 \mathrm{cmbd}$, it is likely part of the same feature or a product of the same activity.

\section{Feature 56, Hearth, Area 2}

Provenience: N80.53 E26.18; Elevation: $110 \mathrm{cmbd}$; Dimensions: 100-x-90 cm

This was a concentration of burned rock in Area 2 associated with Features 43 and 55 (Figure 6-13). It is likely all these are from the same activity, though we documented them separately. Feature 56 is the largest of the three with a circular pattern of rocks concentrated along and running into the western wall of Area 2. Burned rock is scattered across the unit. We collected both soil and charcoal samples from Feature 56. 

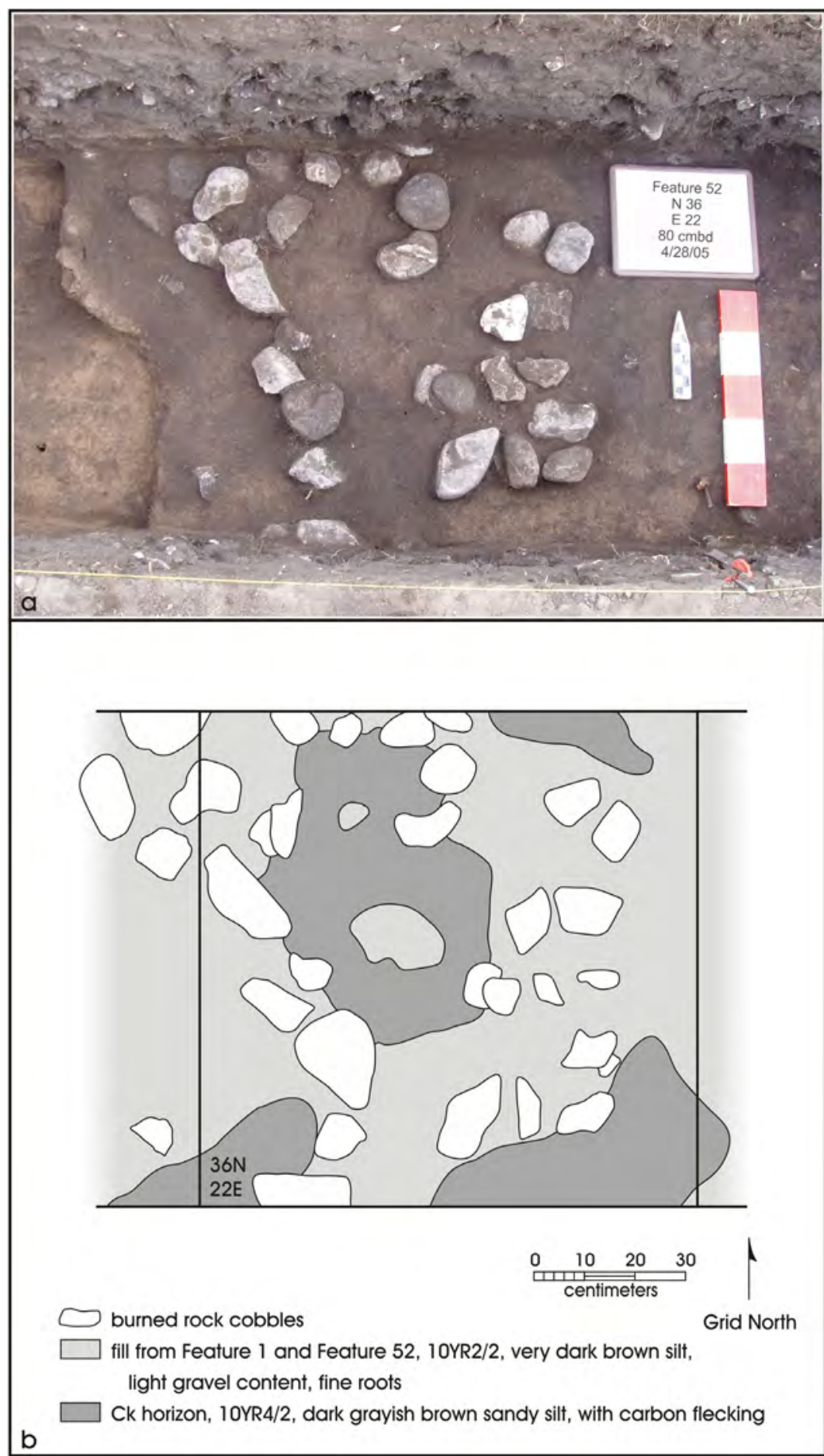

Figure C-21. Feature 52 lay at the base of Feature 1 on the Ck horizon.

a) photo; b) plan view drawing.

\section{Feature 99, Hearth, Area 1}

Provenience: N85.15 E12.75; Elevation: $110 \mathrm{cmbd}$; Dimensions: 25-x-30 cm

This hearth feature in Area 1 is possibly associated with Feature 36 which was recorded in the adjacent unit N85 E13, though approximately $10 \mathrm{~cm}$ higher (Figure 6-12). The feature was characterized by burned rock in stained soil with medium to high amounts of debitage found within the general level. 


\section{Features 13, 16-19, 22, 31 and 34, Possible Post Molds, Area 1}

The possible post molds recorded in Area 1 were all uncovered within the same soil horizon (Bk) between 60 and $73 \mathrm{cmbd}$ (Figure 6-12). We initially recorded twenty-four stains, but as many of them continued below the level of excavation at approximately $150 \mathrm{cmbd}$, we determined they were root molds (Figure C-22). For some others, however, we were able to find a termination level within the parameters of our excavation. Features 13, 16-19, 22, 31 and 34 all meet size and shape requirements typical of a feature left by a post (Figure C-23). Together, they do not form any obvious patterns. Excavators bisected all these features, usually on a north-south axis with the western profile drawn and photographed. All were symmetrical, straight-sided and tapered to a rounded base. They were all at least $8-10 \mathrm{~cm}$ in diameter and no more than $60-75 \mathrm{~cm}$ long.

Fill for each feature usually lacked artifacts and charcoal, though it was very organic and loosely compacted. Fill was difficult to remove from the cross-section because of its tendency to crumble. Also common were small voids where no fill was present at all until excavation collapsed the fill.

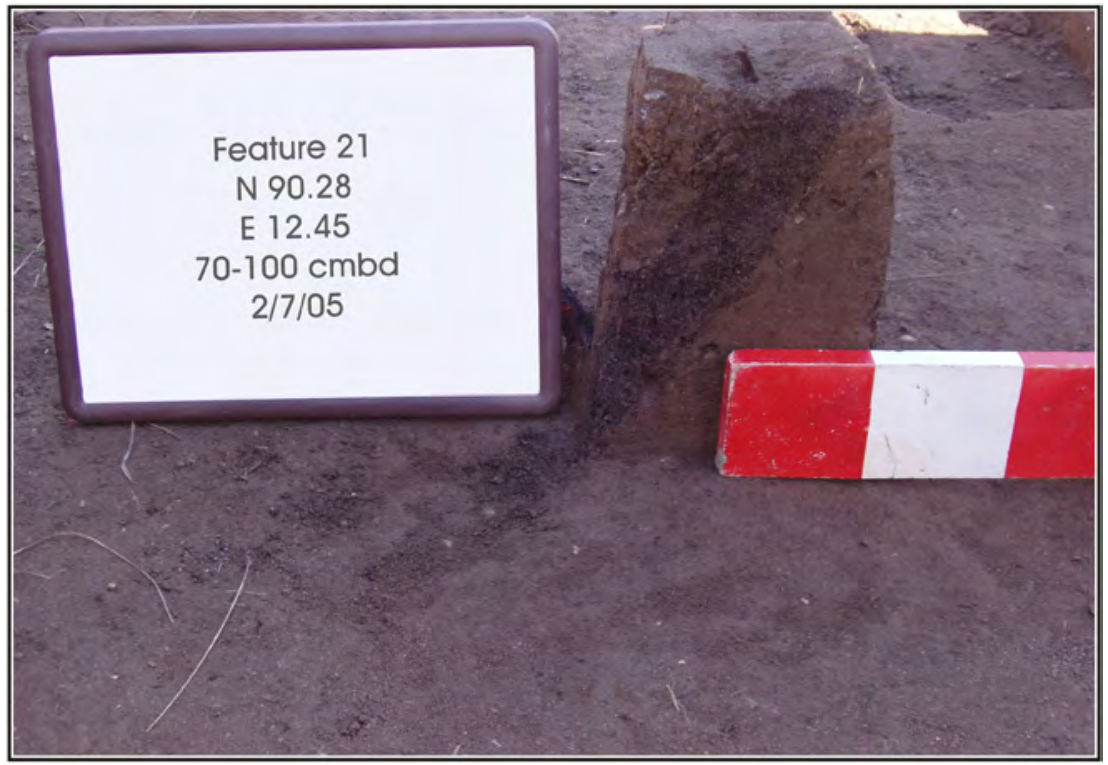

Figure C-22. Feature 21 represents one of the many root molds excavated at $41 K M 69$

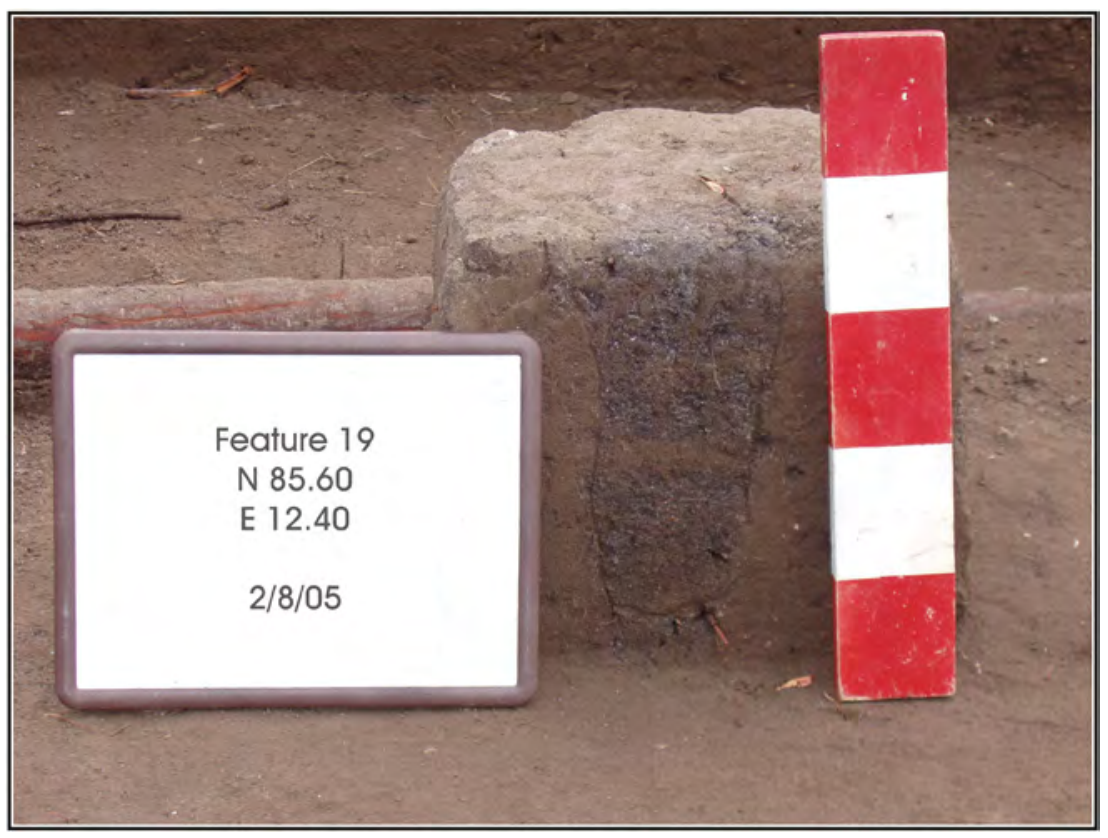

Figure C-23. Feature 19 represents a typical post mold in Area 1 at 41 KM69. 


\section{Graded Features}

\section{Feature 57, Burned Rock Cluster, Graded Area}

Provenience: N84.80 E20.00; Elevation: 99.735 amsl; Dimensions: 50-x-30 cm

Gradall scraping between Areas 1 and 2 uncovered Feature 57. The heavy machinery disturbed much of the feature, but a few of the rocks were salvaged and recorded. Soil samples were taken though no artifacts were noticed in the fill.

\section{Feature 58, Hearth, Graded Area}

Provenience: N46.50 E16.60; Elevation: 99.38 amsl; Dimensions: $50-x-45 \mathrm{~cm}$

The hearth dimensions were taken across the visible rocks after excavation by Gradall. The feature exhibited no depth beyond the layer of rock. A uniface, biface, and debitage were recorded in association with this feature. These were collected along with a soil sample.

\section{Feature 59, Fire-cracked Rock Scatter, Graded Area}

Provenience: N42.50 E19.00; Elevation: 100.457 amsl; Dimensions: 250-x-200 cm

Feature 59 was not hand excavated because it was not a uniform or purposeful gathering of FCR and burned rock. It was an area of scattered burned rock that may represent a by-product of Feature 1, the burned rock midden. The area of the scatter was approximately $2.5-\mathrm{x}-2.00 \mathrm{~m}$ across and only $10 \mathrm{~cm}$ deep. It was first recognized at $100.457 \mathrm{amsl}$.

\section{Feature 79, Burned Rock Cluster, Graded Area}

Provenience: N24.80 E30.00; Elevation: 99.126 amsl; Dimensions: $75-x-80 \mathrm{~cm}$

This is a loosely associated grouping of 10-20 burned and fire-cracked rocks on the upper terrace of the Graded Area. No pit was observed in profile and no artifacts noted in the fill. One soil sample was collected during excavation.

\section{Feature 80, Burned Rock Cluster, Graded Area}

Provenience: N80.05 E26.40; Elevation: 98.847 amsl; Dimensions: $54-x-32 \mathrm{~cm}$

The upper portion of this feature was impacted by the Gradall bucket but the lower level rocks remained in place for documentation and excavation. Five limestone cobbles arranged in a oval pattern were mapped. No artifacts were observed in the fill.

\section{Feature 81, Fire-cracked Rock Scatter, Graded Area}

Provenience: N E; Elevation: 98.847 amsl; Dimensions: $300-x-400 \mathrm{~cm}$

Another burned rock scatter was observed during monitoring of the scraping of the upper terrace. This feature, like Feature 59 , was not excavated by hand but mapped with a total station. The burned rock is likely refuse from hearths nearby. The rock continued for a depth of approximately $20 \mathrm{~cm}$ before disappearing.

\section{Feature 82, Hearth, Graded Area}

Provenience: N24.20 E23.15; Elevation: 100.469 amsl; Dimensions: 180-x-18 cm

This small collection of burned and cracked rock retained somewhat of a basin shape with rock throughout the fill. No artifacts were observed, but some of the fill was collected.

\section{Feature 83, Hearth, Graded Area}

Provenience: N25.00 E29.95; Elevation: 100.201 amsl; Dimensions: 40-x-30 cm

This small rock feature measured approximately $40-\mathrm{x}-30 \mathrm{~cm}$ with little depth. Excavation of this feature did not go beyond 10 $\mathrm{cm}$. No artifacts were recorded. 


\section{Feature 84, Burned Rock Cluster, Graded Area}

Provenience: N21.50 E21.65; Elevation: 100.101 amsl; Dimensions: $36-x-32 \mathrm{~cm}$

This feature was approximately $36-\mathrm{x}-32 \mathrm{~cm}$ in diameter with a slight basin shape. The feature contained heated rock throughout the 10 -cm thick excavation. No artifacts were recorded but a soil sample was collected.

\section{Feature 85, Burned Rock Cluster, Graded Area}

Provenience: N28.00 E24.50; Elevation: 100.268 amsl; Dimensions: $25-x-30 \mathrm{~cm}$

Upper portions of the feature contained only three intact burned rocks. Within the fill, we observed more burned rock.

\section{Feature 86, Hearth, Graded Area}

Provenience: N31.30 E27.80; Elevation: 100.312 amsl; Dimensions: $50-x-45 \mathrm{~cm}$

FCR was present in the $1.0 \mathrm{~m}^{2}$ area surrounding this feature, which was determined to possibly be discarded rock from this feature. The upper portion of the feature was hit with the Gradall. Therefore we did not record it as an intact feature. However, the rock did retain a small, circular pattern approximately $50 \mathrm{~cm}$ in diameter.

\section{Feature 87, Burned Rock Cluster, Graded Area}

Provenience: N18.00 E22.20; Elevation: 100.014 amsl; Dimensions: $36-x-34 \mathrm{~cm}$

Burned rock in this feature only amounted to seven rocks in a triangular pattern. We recovered no associated artifacts in the matrix surrounding the feature or within the feature fill.

\section{Feature 88, Hearth, Graded Area}

Provenience: N15.50 E21.95; Elevation: 99.781 amsl; Dimensions: 60-x-35 cm

Feature 88 was also impacted by the Gradall but the shape remained intact as a small circular, rock-lined hearth. No artifacts were recovered near this feature.

Feature 89, Hearth, Graded Area

Provenience: N21.99 E23.95; Elevation: 99.393 amsl; Dimensions: 40-x-50 cm

This feature lay in the heavy gravels of the $\mathrm{Ck}$ horizon on the upper, $\mathrm{T}_{4}$ terrace. A small dark stain was sampled outside the larger cobbles of the feature. This was taken separately from the feature fill within the boundaries of the burned rock.

Feature 90, Soil Stain, Graded Area

Provenience: N27.75 E28.00; Elevation: 99.22 amsl; Dimensions: $35-x-35 \mathrm{~cm}$

This entire stain of charred material was collected at approximately $140 \mathrm{cmbs}$. No unit was excavated around this feature; therefore, we collected no artifacts.

\section{Feature 91, Burned Rock Cluster, Graded Area}

Provenience: N20.60 E18.00; Elevation: 100.549 amsl; Dimensions: $88-x-80 \mathrm{~cm}$

This is a burned rock cluster within the Bk horizon on the upper terrace. Artifacts were noted in proximity to and within the unit. Rocks are present to $17 \mathrm{cmbd}$ at the lowest point, which is in the southern half of the feature. 


\section{Feature 92, Hearth, Graded Area}

Provenience: N21.80 E19.30; Elevation: 100.138 amsl; Dimensions: 20-x-30 cm

This feature represents one of the few remaining features that showed soil discoloration below the level of the burned rock. Though the upper portion of the rock was hit with the Gradall, several pieces of debitage, shell and FCR were recovered from the fill below the rock.

\section{Feature 93, Hearth, Graded Area}

Provenience: N18.75 E18.90; Elevation: 100.186 amsl; Dimensions: $70-x-70 \mathrm{~cm}$

This circular feature contained numerous small rocks within the upper $10 \mathrm{~cm}$ of the feature. We recovered some debitage from the unit surrounding the feature.

\section{Feature 94, Hearth, Graded Area}

Provenience: N17.98 E18.95; Elevation: 100.05 amsl; Dimensions: $45-x-35 \mathrm{~cm}$

Feature 94 contained approximately ten burned rocks in a roughly circular shape above a dark soil stain reaching $10 \mathrm{~cm}$ below the rock. No artifacts were observed in the surrounding matrix.

\section{Feature 95, Hearth, Graded Area}

Provenience: N14.75 E17.25; Elevation: 100.024 amsl; Dimensions: $50-x-55 \mathrm{~cm}$

Some artifacts were observed on the periphery of this unit with a layer of burned rock below. A dark soil stain below the burned rock formed a basin shape reaching approximately $15 \mathrm{~cm}$ below the level of the rock.

\section{Feature 96, Burned Rock Cluster, Graded Area}

Provenience: N23.05 E18.00; Elevation: 99.993 amsl; Dimensions: 40-x-40 cm

This small, burned rock cluster includes eight cobbles with some debitage present. The soil beneath the rock is loose and may represent the $\mathrm{Bk}$ to $\mathrm{Ck}$ transition on the upper terrace.

Feature 97, Hearth, Graded Area

Provenience: N21.40 E17.65; Elevation: 99.838 amsl; Dimensions: $75-x-50 \mathrm{~cm}$

This is a small circular rock feature with some debitage nearby.

\section{Feature 98, Burned Rock Cluster, Graded Area}

Provenience: N23.30 E16.20; Elevation: 99.735 amsl; Dimensions: $60-x-60 \mathrm{~cm}$

This burned rock cluster extended down approximately $20 \mathrm{~cm}$ below the surface of the rock. No artifacts were collected from the feature fill.

\section{Features 63 through 76 and 78, Circular Stains, Graded Area}

This grouping of circular stains was recognized during monitoring of the Gradall scraping of the central area of the site. The majority of these circular stains were identified at an average depth of 99.09 amsl and terminated at the Ck level of heavy gravels. The average dimensions of the features were $28.5-\mathrm{x}-30.85-\mathrm{x}-17.7 \mathrm{~cm}$. The maximum horizontal dimensions were from Feature 67 at $43-\mathrm{x}-50 \mathrm{~cm}$. The maximum height was $35 \mathrm{~cm}$ recorded for Feature 78 . Feature 78 also was the smallest in horizontal dimensions at $11-\mathrm{x}-12 \mathrm{~cm}$. 


\section{Historic Features}

\section{Feature 4, Gravel Deposit}

Feature 4 was recognized in all excavation blocks at the site and recorded in the field profile drawings (Figure C-24). Earlier interpretations suggested that it is a gravel driveway associated with the Kimble Courts resort (Weston et al. 2004). We do know that the Kimble Courts housing units did not sit within the current ROW but to the northwest. Local informants remember dirt roads crosscutting the hill in the 1940s, before the construction of Texas Tech University and Flat Rock Road, after the removal of the Kimble Courts. At that time, those dirt roads were popular hangouts for teenagers. Historic artifacts found in association with the gravel deposit could derive from a mixture of early resort activities and from loitering Junction youth.

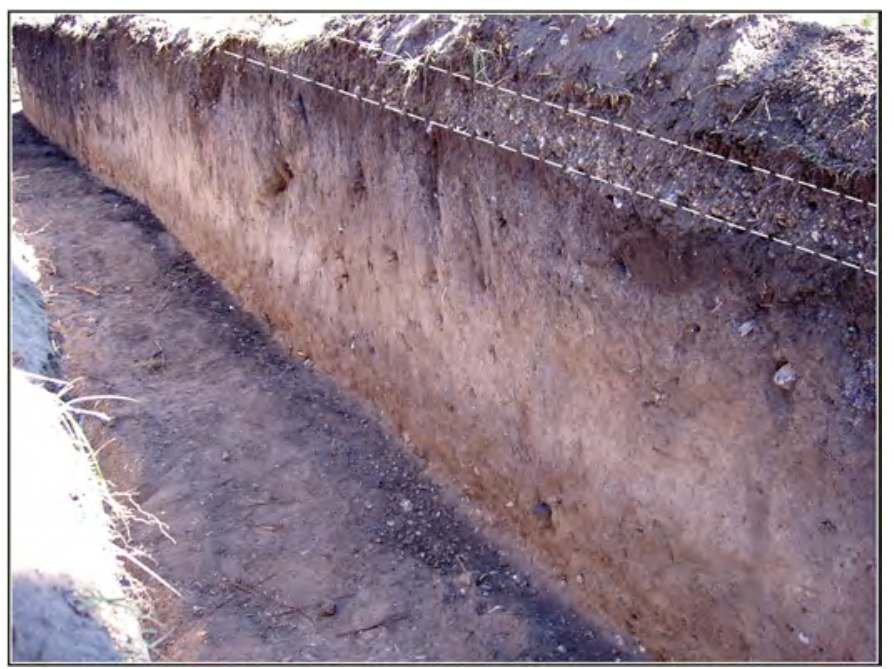

Figure C-24. Feature 4, gravel driveway in south wall of BHT 5 (from Weston et al. 2004).

\section{Feature 6, Kimble Courts Hotel Foundation}

Feature 6 is a concrete slab pad described as the original foundation of the main Kimble Courts structure (Weston et al. 2004; Figure C-25). However, informant interviews now lead us to believe the contrary. Neither the Kimble Courts housing units nor the main office sat within the current ROW where the slab is located. They were located closer to the river to the northwest of the project area. During data recovery work, we were able to photograph some of the original Kimble Court buildings within the Junction city limits. The main office is now a private residence (Figure C-26). The guest houses were single story apartments which were in dilapidated condition but still standing behind an abandoned motel complex of the same name in the Spring of 2005 (Figure C-27). All the guest houses have since been torn down.

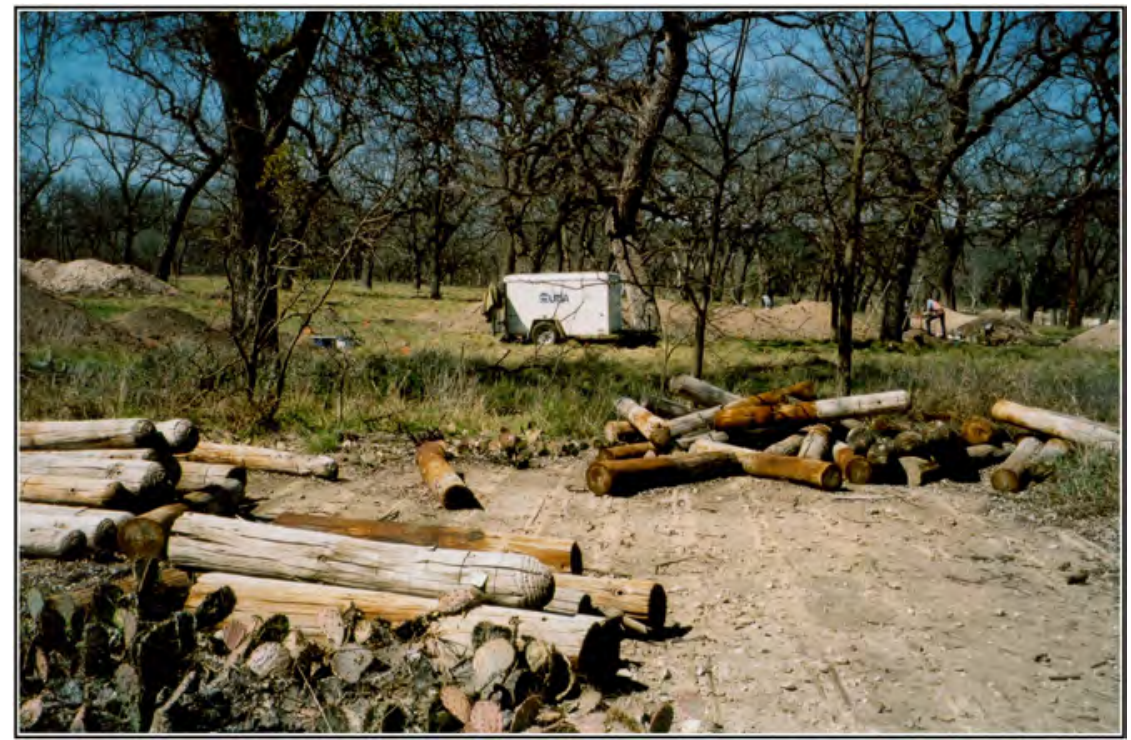

Figure C-25. Feature 6, historic slab foundation (from Weston et al. 2004). 


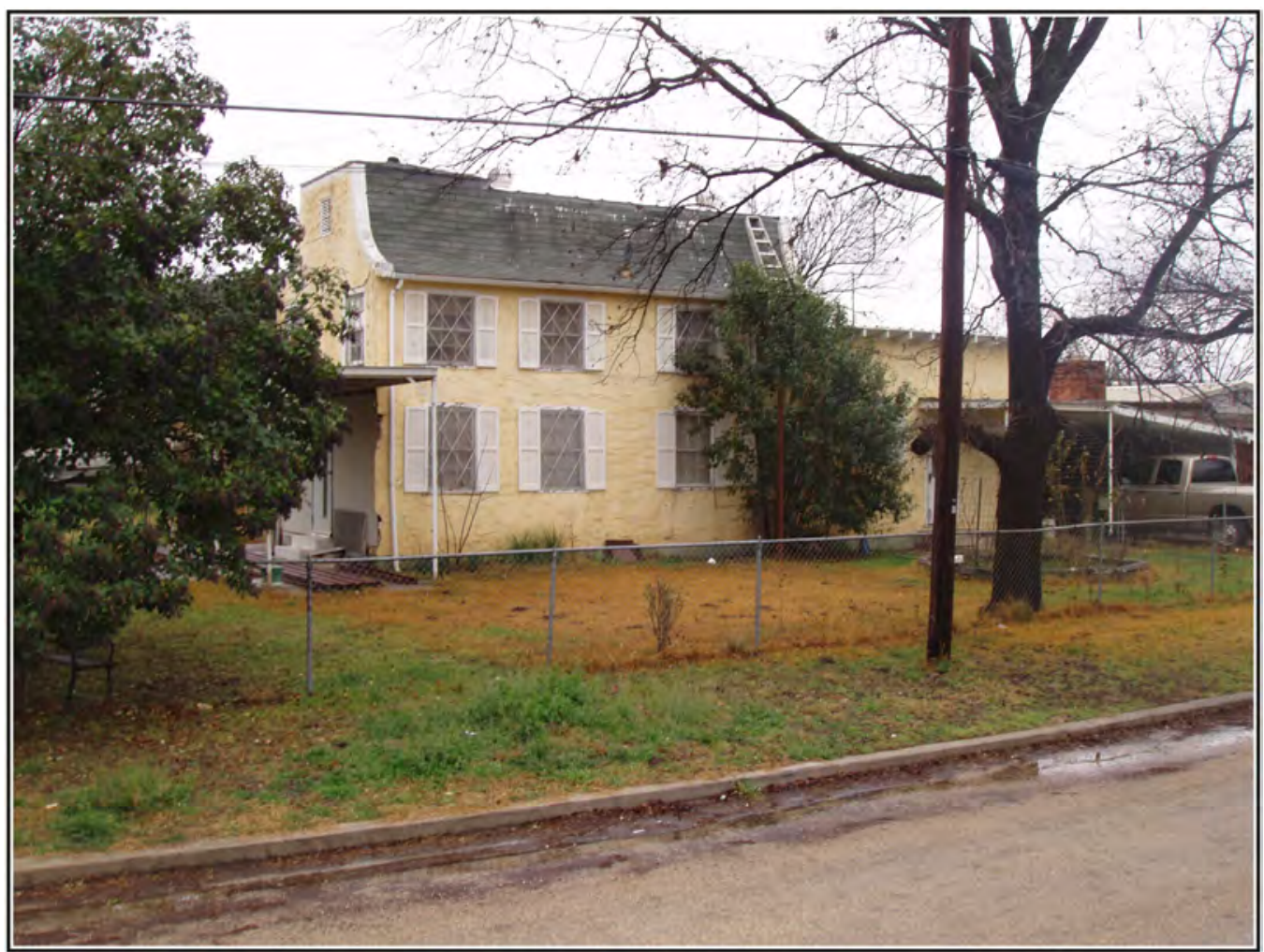

Figure C-26. The two-story main office of the historic Kimble Courts is now a private residence in Junction, Texas.

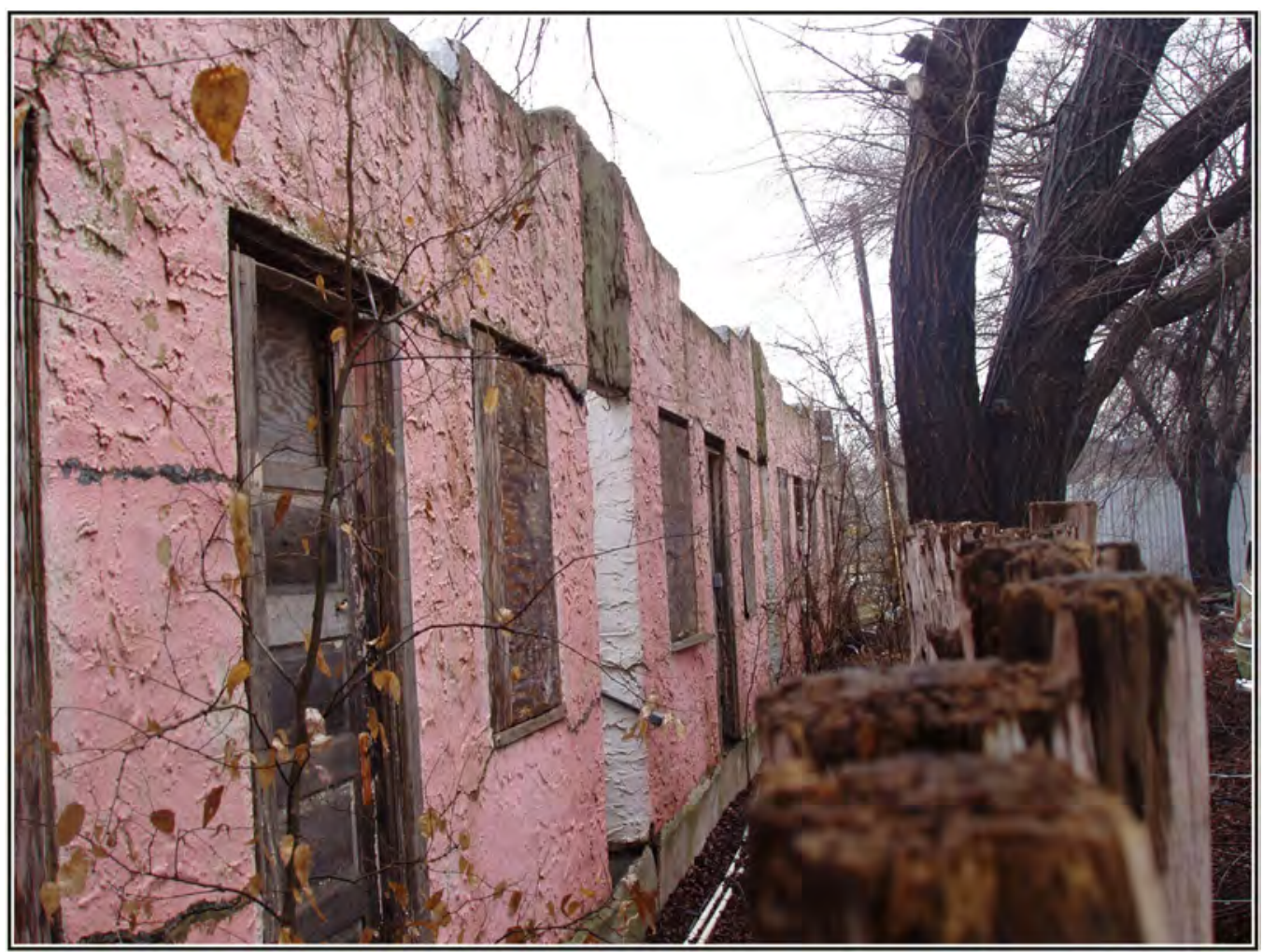

Figure C-27. The single story guest houses of the historic Kimble Courts have been demolished but are illustrated here in Spring 2005 in Junction, Texas, after they were moved in 1935 from the banks of the South Llano River. 
Table C-1. Burned Rock Features from 41KM69

\begin{tabular}{|c|c|c|c|c|c|c|c|c|c|c|c|}
\hline Feature \# & Excavation Area & Length $(\mathrm{m})$ & Width (m) & Thickness (m) & Area m² & Plan & Profile & Time Period & Type & $\begin{array}{c}\text { Number of } \\
\text { Rrocks }\end{array}$ & Weight (g) \\
\hline 1 & Area 3 & 11 & 11 & 0.8 & & circle & & ILP & burned rock midden & & \\
\hline 2 & Area 2 & 1.5 & & & & & basin & TLP & hearth & 122 & 23181.4 \\
\hline 3 & Area 2 & 0.67 & 0.57 & 0.13 & 0.30 & circle & basin & TLP & burned rock cluster & 130 & 35322.7 \\
\hline 5 & Area 4 & 0.6 & 0.6 & 0 & 0.28 & circle & & ILP & burned rock cluster & 126 & 28896.4 \\
\hline 10 & Area 1 & 0.87 & 0.69 & 0 & 0.47 & irregular & flat & TLP & burned rock cluster & 91 & 36596.6 \\
\hline 35 & Area 1 & 0.55 & 0.5 & 0.11 & 0.22 & oval & basin & MLA & hearth & 42 & 11877.2 \\
\hline 36 & Area 1 & 0.4 & 0.6 & 0 & 0.19 & irregular & flat & MLA & burned rock cluster & 78 & 17023.2 \\
\hline 39 & Area 3 & 0.41 & 0.37 & 0.06 & 0.12 & circle & flat & ILP & burned rock cluster & 21 & 5484.6 \\
\hline 40 & Area 2 & 0.44 & 0.5 & 0.07 & 0.17 & circle & basin & TLA & burned rock cluster & 22 & 7882.7 \\
\hline 42 & Area 2 & 0.75 & 0.5 & 0.14 & 0.29 & & & MLA & hearth & 42 & 17600.3 \\
\hline 43 & Area 2 & 0.49 & 0.35 & 0.03 & 0.13 & & & MLA & burned rock cluster & 7 & 4934.8 \\
\hline 44 & Area 4 & 0 & 0 & 0.8 & 0.00 & semi-circle & & ILP & burned rock cluster & 10 & 2921.4 \\
\hline 45 & Area 4 & 0.58 & 0.72 & 0.08 & 0.33 & circle & basin & ILP & hearth & 39 & 16637.2 \\
\hline 46 & Area 4 & 0.95 & 0.55 & 0.09 & 0.41 & irregular & & ILP & burned rock cluster & 27 & 7474.1 \\
\hline 47 & Area 4 & 0.55 & 0.6 & 0.1 & 0.26 & circle & basin & ILP & hearth & 29 & 9392.6 \\
\hline 48 & Area 4 & 1.25 & 0.93 & 0.18 & 0.91 & oval & & TLA & burned rock cluster & 55 & 18971 \\
\hline 49 & Area 4 & 0.42 & 0.41 & 0.12 & 0.14 & circle & flat & TLA & hearth & 29 & 11709.7 \\
\hline 50 & Area 4 & 0.6 & 0.42 & 0.08 & 0.20 & oval & & MLA & burned rock cluster & 30 & 6548.7 \\
\hline 52 & Area 3 & 1 & 0 & 0.05 & 0.00 & & flat & ILP & internal hearth & 46 & 25605.1 \\
\hline 53 & Area 3 & 0.97 & 0.4 & 0.21 & 0.30 & oval & basin & ILP & hearth & 33 & 13277.6 \\
\hline 54 & Area 3 & 0.14 & 0.23 & 0.17 & 0.03 & & & ILP & burned rock cluster & 8 & 1105 \\
\hline 55 & Area 2 & 0.53 & 0.24 & 1.1 & 0.10 & & & MLA & burned rock cluster & & \\
\hline 56 & Area 2 & 0 & 0.9 & 0.09 & 0.00 & circle & & MLA & hearth & 51 & 14648.7 \\
\hline 57 & Lower Terrace & 0.5 & 0.3 & 0.001 & 0.12 & & & TLP & burned rock cluster & 12 & 2684 \\
\hline 58 & Lower Terrace & 0.5 & 0.45 & 0.001 & 0.18 & circle & flat & TLP & hearth & 18 & 1432.9 \\
\hline 59 & Upper Terrace & 2.5 & 2 & 0.001 & 3.93 & & & TLP & burned rock scatter & & \\
\hline 79 & Upper Terrace & 0.75 & 0.8 & 0 & 0.47 & circle & flat & TLP & burned rock cluster & 105 & 7149.7 \\
\hline 80 & Lower Terrace & 0.54 & 0.32 & 0.001 & 0.14 & oval & & MLA & burned rock cluster & 10 & 2901.7 \\
\hline 81 & Upper Terrace & 3 & 4 & 0.988 & 9.42 & & flat & ILP & burned rock scatter & & \\
\hline 82 & Upper Terrace & 0.18 & 0.18 & 0.001 & 0.03 & circular & basin & TLP & hearth & 33 & 5916 \\
\hline 83 & Upper Terrace & 0.4 & 0.3 & 0.001 & 0.09 & oval & flat & ILP & hearth & 19 & 2561.3 \\
\hline 84 & Upper Terrace & 0.36 & 0.32 & 0.001 & 0.09 & irregular & basin & ILP & burned rock cluster & 17 & 4851.9 \\
\hline 85 & Upper Terrace & 0.25 & 0.3 & 0.001 & 0.06 & oval & basin & ILP & burned rock cluster & 11 & 2375.8 \\
\hline 86 & Upper Terrace & 0.5 & 0.45 & 0.002 & 0.18 & oval & basin & ILP & hearth & 35 & 7798.5 \\
\hline 87 & Upper Terrace & 0.36 & 0.34 & 0.000 & 0.10 & irregular & flat & TLA & burned rock cluster & 6 & 1135.2 \\
\hline 88 & Upper Terrace & 0.6 & 0.35 & 0.001 & 0.16 & oval & basin & MLA & hearth & 9 & 2979.5 \\
\hline 89 & Upper Terrace & 0.4 & 0.5 & 0 & 0.16 & oval & flat & MLA & hearth & 16 & 4127.8 \\
\hline 91 & Upper Terrace & 0.88 & 0.8 & 0.002 & 0.55 & irregular & flat & TLP & burned rock cluster & 72 & 11807 \\
\hline 92 & Upper Terrace & 0.2 & 0.3 & 0.2 & 0.05 & oval & irregular & TLP & hearth & 24 & 5218 \\
\hline 93 & Upper Terrace & 0.7 & 0.7 & 0.001 & 0.38 & circle & basin & ILP & hearth & 27 & 9511.5 \\
\hline 94 & Upper Terrace & 0.45 & 0.35 & 0.002 & 0.12 & oval & basin & TLA & hearth & 15 & 6164.9 \\
\hline 95 & Upper Terrace & 0.5 & 0.55 & 0.001 & 0.22 & oval & basin & TLA & hearth & 34 & 11797.8 \\
\hline 96 & Upper Terrace & 0.4 & 0.4 & 0.002 & 0.13 & circle & irregular & TLA & burned rock cluster & 11 & 3433.1 \\
\hline 97 & Upper Terrace & 0.75 & 0.5 & 0.002 & 0.29 & oval & irregular & MLA & hearth & 24 & 2339 \\
\hline 98 & Upper Terrace & 0.6 & 0.6 & 0.002 & 0.28 & circle & basin & MLA & burned rock cluster & 38 & 11630.2 \\
\hline 99 & Area 1 & 0.3 & 0.3 & 0.2 & 0.07 & circle & flat & MLA & hearth & 26 & 4345.1 \\
\hline
\end{tabular}




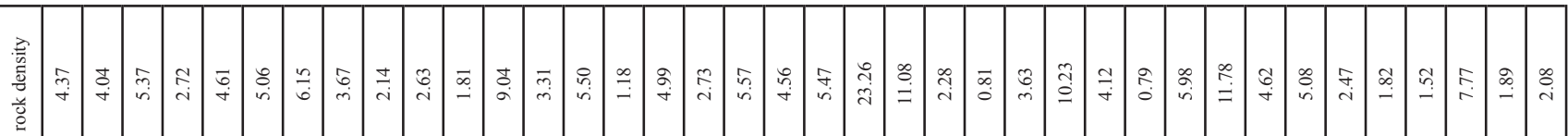

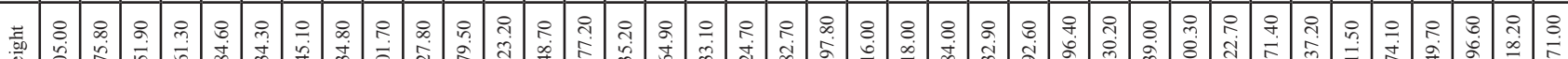

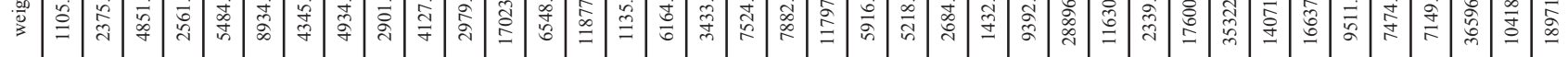

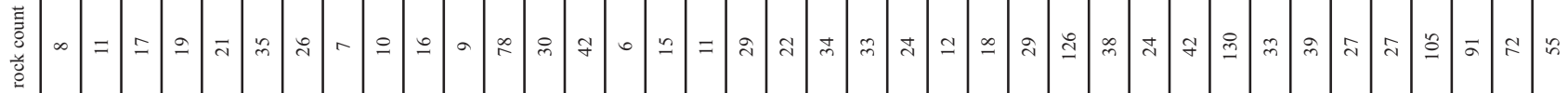

\begin{tabular}{|c|c|c|c|c|c|c|c|c|c|c|c|c|c|c|c|c|c|c|c|c|c|c|c|c|c|c|c|c|c|c|c|c|c|c|}
\hline 今ે & 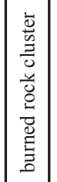 & 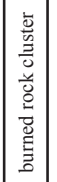 & & 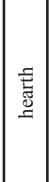 & 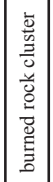 & 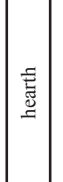 & . & 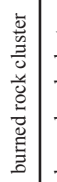 & 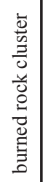 & & 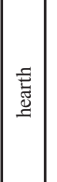 & 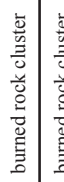 & 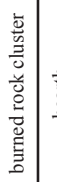 & & & 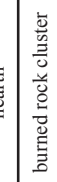 & $\begin{array}{l}\overline{\underline{\underline{E}}} \\
\underline{\underline{\underline{D}}}\end{array}$ & 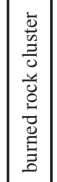 & 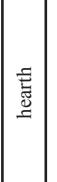 & & & 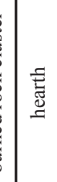 & 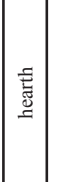 & 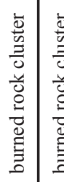 & & & 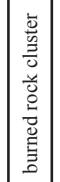 & & & 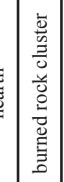 & 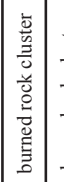 & & & \\
\hline 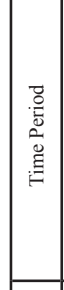 & 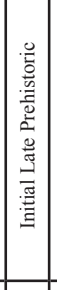 & 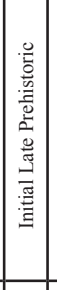 & 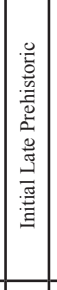 & 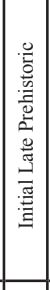 & 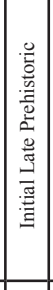 & 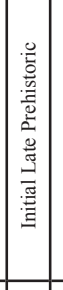 & 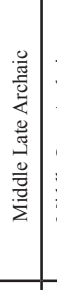 & 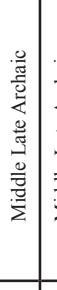 & 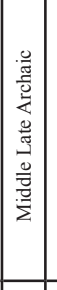 & 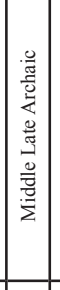 & 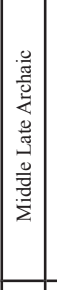 & 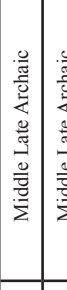 & 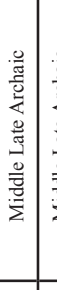 & 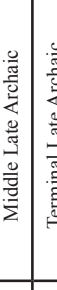 & 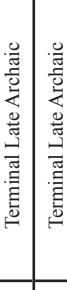 & 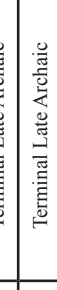 & 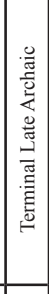 & 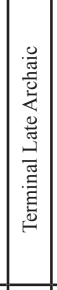 & 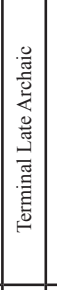 & 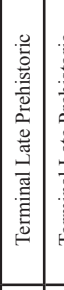 & 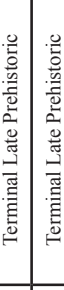 & 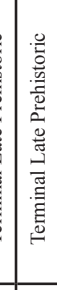 & 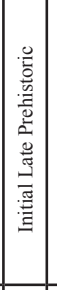 & & 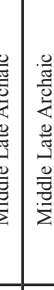 & 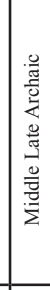 & 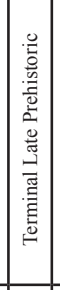 & 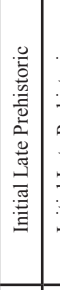 & & 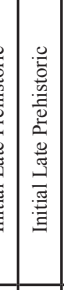 & 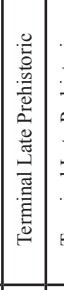 & 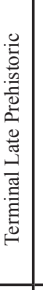 & & \\
\hline $\begin{array}{l}\stackrel{0}{0} \\
\stackrel{0}{2} \\
\end{array}$ & & 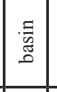 & 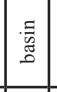 & 芩 & $\Xi$ & 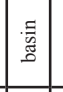 & 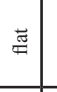 & & & 亲 & 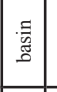 & 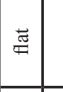 & & 压 & $\begin{array}{l}\varpi \\
\varpi\end{array}$ & 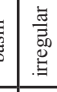 & $\overrightarrow{\tilde{m}}$ & 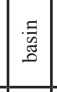 & 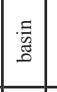 & 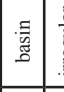 & & 芭 & 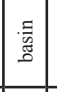 & & 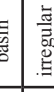 & & 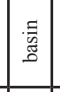 & 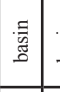 & 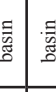 & & 亲 & ङ & छ্ & \\
\hline$\frac{\mathrm{g}}{2}$ & & 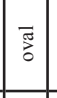 & 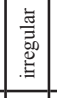 & $\overrightarrow{\mathrm{g}}$ & יב: & $\overline{\frac{5}{\partial}}$ & $\frac{0}{0}$ & & \begin{tabular}{|l|} 
\\
\end{tabular} & $\mid$\begin{tabular}{|l} 
\\
\end{tabular} & $|\overline{\mathrm{g}}|$ & 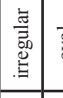 & 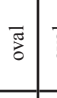 & $\overline{\frac{\mathrm{T}}{\mathrm{s}}}$ & 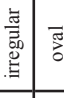 & $\frac{0}{3}$ & 足 & $\mid \frac{0}{\frac{0}{2}}$ & 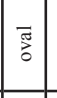 & 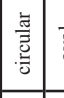 & 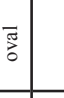 & $\frac{0}{\stackrel{0}{0}}$ & $\mid \frac{0}{\frac{0}{2}}$ & : & 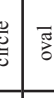 & & 竞 & $\bar{g}$ & 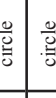 & 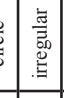 & $\frac{0}{\frac{0}{2}}$ & 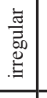 & & \\
\hline : & 言 & 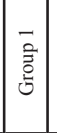 & $\mid$\begin{tabular}{|c|} 
\\
$\overline{\bar{g}}$ \\
$\dot{0}$
\end{tabular} & 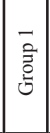 & 言 & 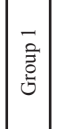 & 言 & 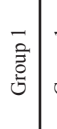 & 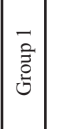 & 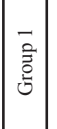 & 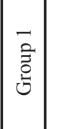 & 言 & 言 & $\overrightarrow{\bar{z}}$ & 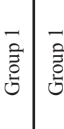 & $\begin{array}{ll}\overrightarrow{3} \\
\vec{z}\end{array}$ & 言 & 言 & \begin{tabular}{|l} 
言 \\
总
\end{tabular} & 言 & 言 & $\overrightarrow{\bar{z}}$ & 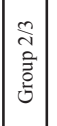 & 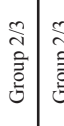 & 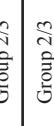 & 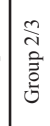 & 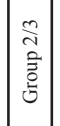 & 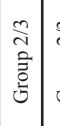 & & 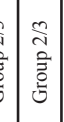 & 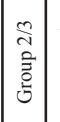 & 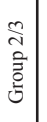 & & 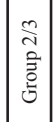 \\
\hline 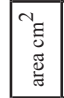 & 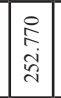 & \begin{tabular}{|c|c|}
$\circ$ \\
0 \\
$\infty$ \\
$n$ \\
$n$
\end{tabular} & 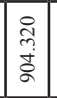 & $\begin{array}{l} \\
0 \\
g \\
g\end{array}$ & \begin{tabular}{|c|}
0 \\
0 \\
0 \\
0 \\
$=$
\end{tabular} & 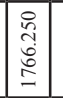 & \begin{tabular}{l|}
8 \\
0 \\
0 \\
0 \\
0
\end{tabular} & 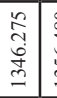 & \begin{tabular}{|l|l}
0 \\
0 \\
0 \\
0 \\
$m$
\end{tabular} & 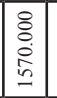 & \begin{tabular}{|l|l|}
0 \\
0 \\
0 \\
0 \\
0 \\
\end{tabular} & \begin{tabular}{l|l} 
\\
0 \\
0 \\
0 \\
0 \\
$\infty$
\end{tabular} & 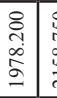 & 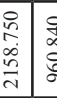 & 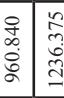 & 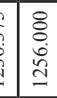 & \begin{tabular}{|l}
0 \\
$\vdots$ \\
$\vdots$ \\
0 \\
\end{tabular} & \begin{tabular}{|c|} 
\\
$\vdots$ \\
\\
$\vdots$
\end{tabular} & \begin{tabular}{|l|}
0 \\
$\infty$ \\
$\infty$ \\
\\
\end{tabular} & 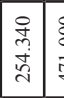 & 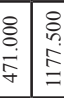 & 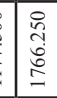 & 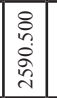 & & 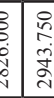 & & \begin{tabular}{|l|} 
\\
2 \\
2 \\
$a$ \\
$a$ \\
\end{tabular} & \begin{tabular}{|l|l}
0 \\
0 \\
0 \\
0 \\
0 \\
0
\end{tabular} & & 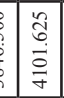 & \begin{tabular}{|l|l|}
0 \\
0 \\
\\
\\
\end{tabular} & 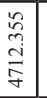 & & \\
\hline 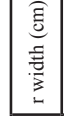 & $\stackrel{n}{=}$ & $\simeq 1$ & $\simeq$ & $\simeq$ & $\stackrel{\infty}{\infty}$ & הู่ & $\cong$ & $\stackrel{n}{=}$ & $\simeq$ & $\approx$ & $\mid \stackrel{?}{=}$ & $\stackrel{\infty}{\infty}$ & $\bar{\lambda}$ & $\approx=$ & $=?$ & is & ñ & $\approx$ & $\stackrel{n}{n}_{\substack{n \\
i}}$ & $a$ & $\therefore \because$ & בై & in & $\stackrel{\infty}{\infty}=$ & $\Rightarrow$ & ה & $\begin{array}{l}n \\
\substack{\infty \\
\sim}\end{array}$ & i & $m$ & $\mid \begin{array}{ll}n \\
n \\
n\end{array}$ & q & 售 & 8 & \\
\hline 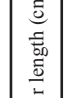 & 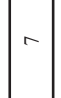 & $\stackrel{\sim}{\beth}$ & 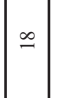 & i & 管 & $\pi$ & $\cong$ & $\begin{array}{ll}n \\
⿱ 亠 䒑 \\
d\end{array}$ & ते & 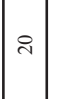 & i & त & ৪): & $\begin{array}{c}n \\
\\
\end{array}$ & $\simeq \mid \begin{array}{c}n \\
\end{array}$ & i & $\vec{\sim}$ & $\pi$ & $\approx$ & $a$ & 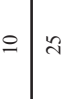 & $a$ & $\frac{n}{2}$ & 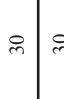 & $n$ & $\mid \begin{array}{l}n \\
n \\
m\end{array}$ & $\mid \begin{array}{l}n \\
m \\
m\end{array}$ & $\mid$ & ते & $\mid \begin{array}{l}n \\
z \\
r\end{array}$ & 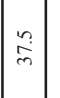 & $\tilde{q}$ & 斗 & a \\
\hline 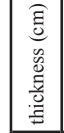 & $=$ & $\mid$\begin{tabular}{c}
$\infty$ \\
\hdashline \\
0
\end{tabular} & \begin{tabular}{|l|} 
\\
0 \\
0 \\
0
\end{tabular} & 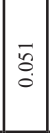 & 6 & त్ & ¿ & $m$ & $\left|\begin{array}{l}0 \\
0 \\
0 \\
0\end{array}\right|$ & \begin{tabular}{|l|} 
\\
8 \\
0
\end{tabular} & 离 & 0 & $\infty$ & $=\Rightarrow$ & 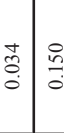 & ఫ્తి & $\simeq$ & $\therefore$ & $\frac{\rho_{0}}{\frac{9}{0}}$ & $\frac{\pi}{0}$ & 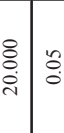 & 蓉 & 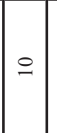 & - 0 & דִ & \pm & 9 & $\vec{\sim}$ & $\infty \frac{8}{0}$ & $\circ$ & \begin{tabular}{|l|} 
\\
0 \\
0
\end{tabular} & 。 & 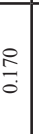 & 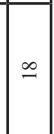 \\
\hline 产 & $\tilde{\imath}$ & 이 & $\approx$ & 只 & $\approx$ & ' 子 & 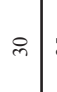 & $\approx$ & $\approx$ & in & $\approx$ & 81 & \begin{tabular}{l|l}
7 & 5
\end{tabular} & $8=$ & \begin{tabular}{l|l}
$m$ & $m$
\end{tabular} & $\begin{array}{l}8 \\
\end{array}$ & F & in & in & $\cong$ & i & if & 8 & 80 & 5 & in & $i n$ & \begin{tabular}{l|l}
$o$ & $:$
\end{tabular} & i 18 & in & 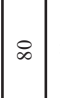 & 81 & $\infty$ & $\%$ \\
\hline 吾 & \pm & $\because 1$ & $\mid$ & q & $F$ & in & i & of & in & o & 8 & q & 84 & $\therefore$ & $\begin{array}{lll}0 & f\end{array}$ & q & f & $\neq$ & in & $\stackrel{(\infty)}{ }$ & तो in & in & in & 80 & 8 & 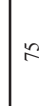 & 5 & 5 & $\infty:$ & $\because 2$ & $\therefore$ & $\infty$ & $\infty$ & 3 \\
\hline $\begin{array}{l}\text { 畄 } \\
\end{array}$ & $\begin{array}{l}\stackrel{1}{0} \\
\stackrel{6}{6}\end{array}$ & \begin{tabular}{|l|} 
\\
$\dot{d}$ \\
\end{tabular} & \begin{tabular}{|c|} 
\\
$\dot{\mathrm{i}}$ \\
\end{tabular} & \begin{tabular}{|l}
0 \\
2 \\
2 \\
\end{tabular} & $\dot{ \pm}$ & 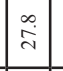 & $\stackrel{9}{9}$ & $\begin{array}{l}n \\
\dot{i} \\
\dot{c}\end{array}$ & \begin{tabular}{|l|l|}
\multirow{2}{*}{} \\
|
\end{tabular} & 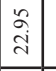 & 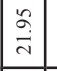 & $=$ & 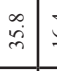 & $\stackrel{+}{ \pm}=2$ & 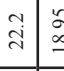 & $\simeq$ & 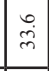 & \begin{tabular}{|l|} 
\\
$\hat{j}$ \\
$\hat{i}$
\end{tabular} & 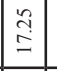 & 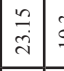 & $\cong \therefore$ & $\stackrel{\leftrightarrow}{\dot{\leftrightarrow}}$ & \begin{tabular}{|l|} 
\\
$f$ \\
$f$ \\
$m$
\end{tabular} & \pm & 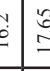 & $\approx$ & \begin{tabular}{|c|} 
g \\
\end{tabular} & \begin{tabular}{|l}
$\stackrel{0}{0}$ \\
$\stackrel{\underline{m}}{2}$
\end{tabular} & $\stackrel{\infty}{\infty}=\infty$ & {$\left[\begin{array}{l}\tilde{m} \\
\tilde{m} \\
\tilde{m}\end{array}\right.$} & i & $\begin{array}{l}\infty \\
\\
\end{array}$ & $\simeq$ & \begin{tabular}{|l}
0 \\
$\tilde{n}$ \\
$\tilde{m}$
\end{tabular} \\
\hline 竞 & సె & $\stackrel{\infty}{\sim}$ & $\mid \begin{array}{l}\mid n \\
\stackrel{n}{i}\end{array}$ & $\approx$ & 节 & $\frac{m}{m}$ & $\begin{array}{l}n \\
\infty \\
\infty \\
\infty\end{array}$ & $\begin{array}{ll}n \\
\vdots \\
2\end{array}$ & $\mid$ & 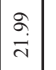 & 奋 & $\begin{array}{ll}+ \\
\infty \\
\infty\end{array}$ & \begin{tabular}{l|l} 
\\
\pm \\
$\dot{ \pm}$
\end{tabular} & \begin{tabular}{l|l}
$\infty$ & $\infty$ \\
$\infty$ & \multicolumn{1}{|c|}{}
\end{tabular} & 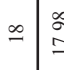 & 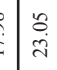 & $\begin{array}{l}n \\
\stackrel{n}{\mathrm{I}}\end{array}$ & $\mid \begin{array}{c}0 \\
\dot{5} \\
x\end{array}$ & $\mid \begin{array}{l}n \\
\dot{I} \\
q\end{array}$ & $\begin{array}{ll}I \\
d\end{array}$ & 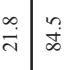 & 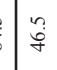 & $\begin{array}{l}\stackrel{\dot{\rho}}{\ominus} \\
\end{array}$ & $\simeq \approx$ & $\vec{c}$ & $\therefore$ & 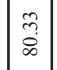 & 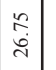 & $=\left[\begin{array}{l}2 \\
2 \\
0\end{array}\right.$ & $\overrightarrow{0}$ & $\begin{array}{l}\infty \\
\dot{\tau} \\
\end{array}$ & $\frac{n}{\infty}$ & & $=$ \\
\hline 总 & it & & 芯 & $\approx$ & 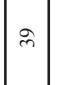 & $\infty$ & 2 & F & $\infty$ & $\infty$ & \begin{tabular}{|l|}
$\infty$ \\
$\infty$
\end{tabular} & in & in & $\approx 2$ & \begin{tabular}{l|l}
$\infty$ \\
\end{tabular} & $\%$ & f & F & 2 & $\infty$ & s. & $\infty$ & F & in $\alpha$ & $: 5$ & F & $m$ & in & $8 \%$ & 8 & $\therefore$ & 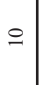 & $\vec{a}$ & $\stackrel{\infty}{q}$ \\
\hline
\end{tabular}




\begin{tabular}{|c|c|c|c|c|c|c|c|c|c|c|c|c|c|c|c|c|c|c|c|c|c|c|c|c|c|c|c|c|c|}
\hline 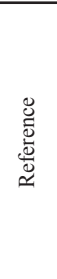 & 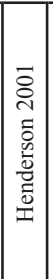 & 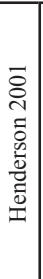 & 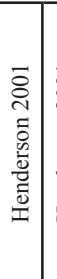 & 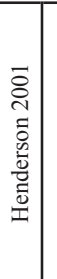 & 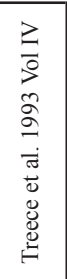 & 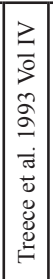 & 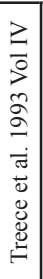 & 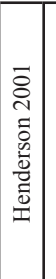 & 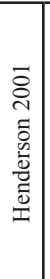 & 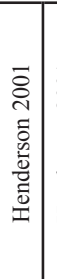 & 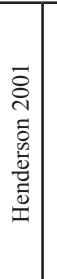 & 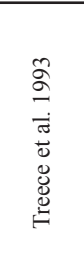 & 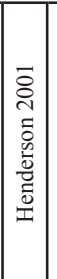 & 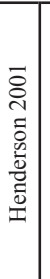 & 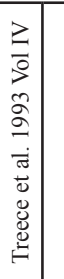 & 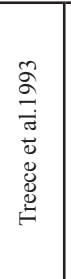 & 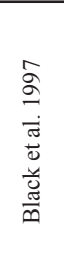 & 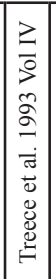 & 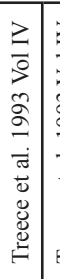 & 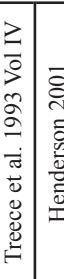 & 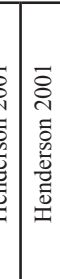 & 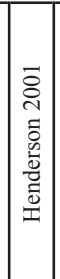 & 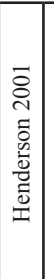 & 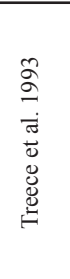 & 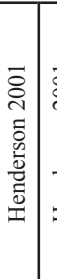 & & 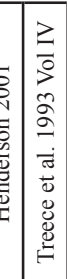 & 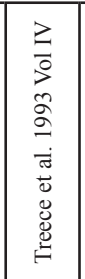 & $\begin{array}{l}\overrightarrow{0} \\
\stackrel{0}{0} \\
\overline{0} \\
\overline{0} \\
\overline{0} \\
\overline{0}\end{array}$ \\
\hline 号 & & & & & & & & & & & & 崩̊ & & & & & $\frac{1}{0}$ & & & & & & & & & & & 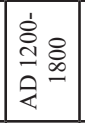 & \\
\hline 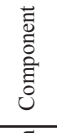 & $\mid \hat{\vec{H}}$ & $\stackrel{\vec{\xi}}{\vec{\theta}}$ & $\overrightarrow{\vec{H}}$ & $\overrightarrow{\vec{\xi}}$ & $\overrightarrow{\vec{H}}$ & $\mid \overrightarrow{\vec{\theta}}$ & $\overrightarrow{\vec{H}}$ & $\overrightarrow{\vec{\theta}}$ & $\overrightarrow{\vec{\theta}}$ & 当 & $\overrightarrow{\vec{H}}$ & $\overrightarrow{\vec{\xi}}$ & 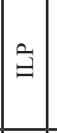 & $\stackrel{\vec{\beta}}{\vec{\beta}}$ & $\overrightarrow{\vec{F}}$ & 当 & $\stackrel{\vec{\jmath}}{\mathrm{g}}$ & $\hat{\vec{F}}$ & $\overrightarrow{\vec{\theta}}$ & $\hat{\vec{H}}$ & $\overrightarrow{\vec{\theta}}$ & 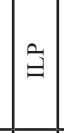 & $\overrightarrow{\vec{G}}$ & $\hat{\vec{H}}$ & $\hat{\vec{H}}$ & $\hat{\vec{\theta}}$ & $\overrightarrow{\vec{\theta}}$ & & $\vec{g}$ \\
\hline 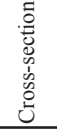 & & & & 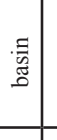 & $\begin{array}{l}\text { 袁 } \\
\text { 告 }\end{array}$ & & & & & & ๘ & 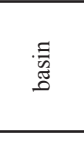 & \begin{tabular}{|l} 
言 \\
s.
\end{tabular} & & 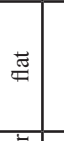 & 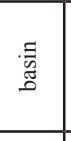 & & & & 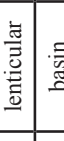 & 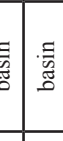 & 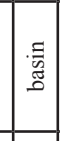 & & 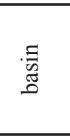 & $\begin{array}{l}\text { 袁 } \\
\text { 势 }\end{array}$ & & $\stackrel{\Xi}{\sharp}$ & 䓌 & \\
\hline 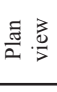 & $\mid \begin{array}{l}\bar{\pi} \\
\mathrm{g}\end{array}$ & 㞼 & & $\begin{array}{l}\frac{0}{0} \\
\frac{3}{3} \\
0\end{array}$ & 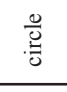 & 舘 & 丞 & & \begin{tabular}{|l|}
$\overline{7}$ \\
ठ
\end{tabular} & & एँ & $\begin{array}{l}0 \\
\\
0 \\
0\end{array}$ & \begin{tabular}{|l}
$\bar{J}$ \\
吾
\end{tabular} & & 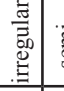 & 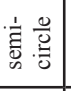 & $\begin{array}{l}\bar{\sigma} \\
\text { ठ }\end{array}$ & 莺 & & 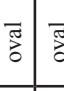 & $\begin{array}{l}5 \\
\end{array}$ & 吾 & & & 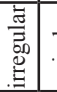 & "艹 & 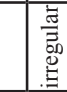 & 㐘 & 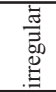 \\
\hline 产 & 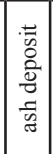 & 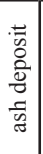 & 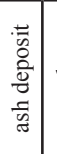 & $\overline{\mathrm{g}}$ & 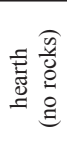 & 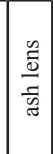 & $\begin{array}{c}\frac{n}{0} \\
\frac{\overrightarrow{0}}{\vec{n}} \\
\frac{1}{n}\end{array}$ & 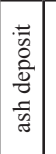 & 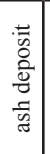 & 善 & 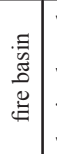 & 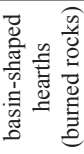 & 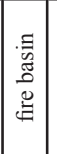 & षิ & 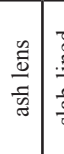 & 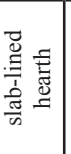 & " & \begin{tabular}{|c|}
$\frac{n}{0}$ \\
$\frac{0}{\bar{v}}$ \\
$\frac{\vec{y}}{\tilde{c}}$ \\
\end{tabular} & 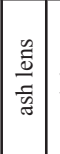 & 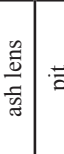 & 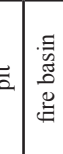 & 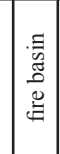 & 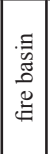 & 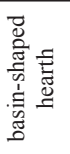 & 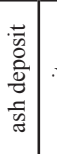 & & 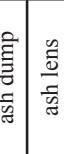 & 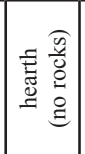 & 言 \\
\hline
\end{tabular}

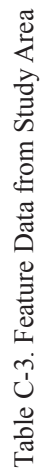

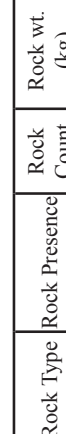

产产重

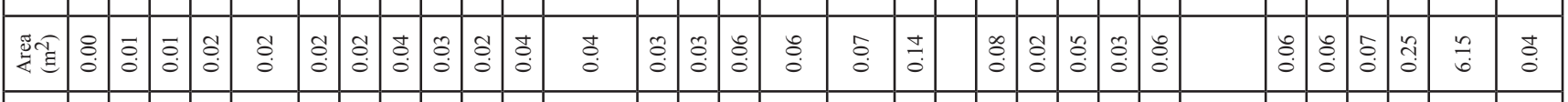

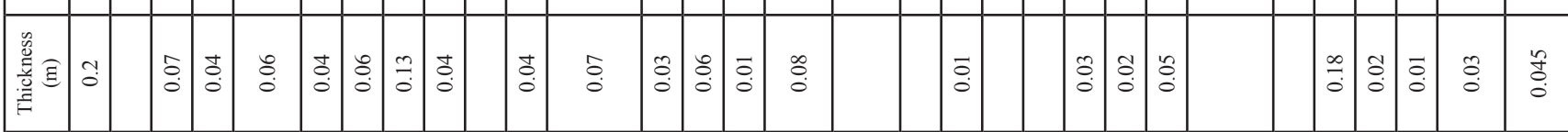

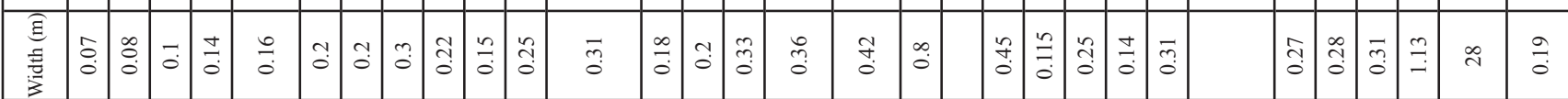

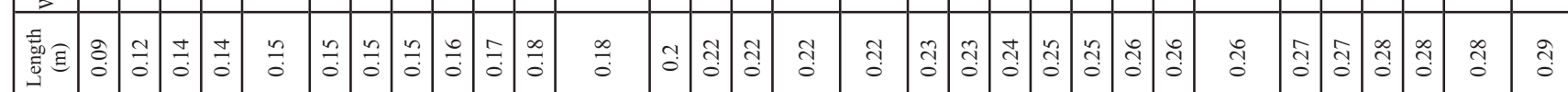

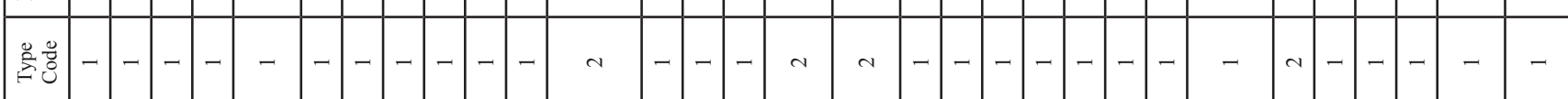

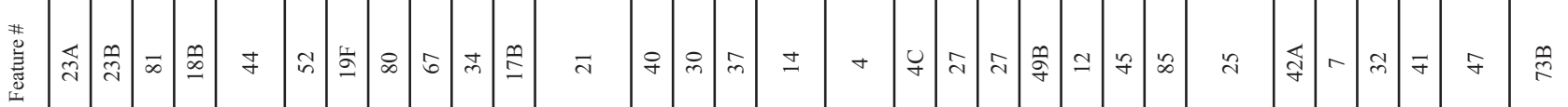

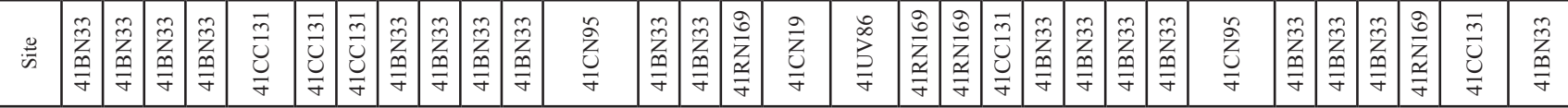




\begin{tabular}{|c|c|c|c|c|c|c|c|c|c|c|c|c|c|c|c|c|c|c|c|c|c|c|c|c|c|c|c|}
\hline 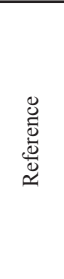 & 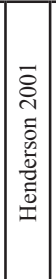 & 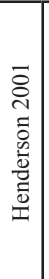 & 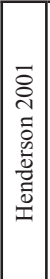 & 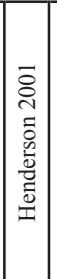 & 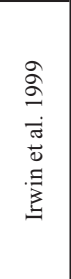 & 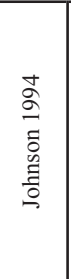 & 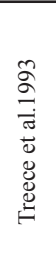 & 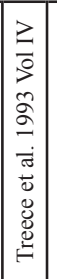 & 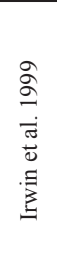 & 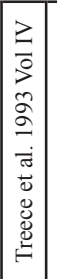 & 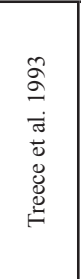 & 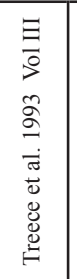 & 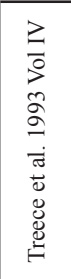 & 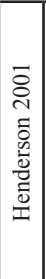 & 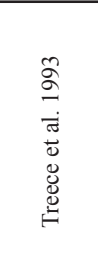 & 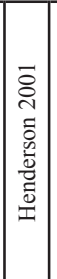 & 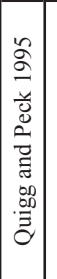 & 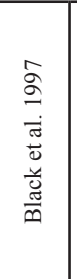 & 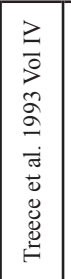 & 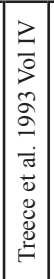 & 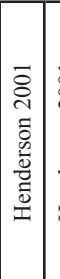 & 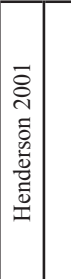 & 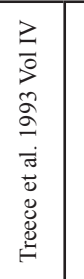 & 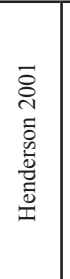 & 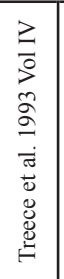 & 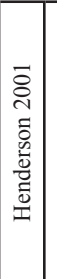 & 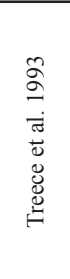 \\
\hline 总 & & & & & 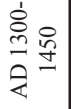 & & & & & & & & & & & & & & & & & & & & & & \\
\hline 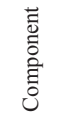 & 学 & 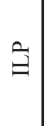 & $\stackrel{\Xi}{\exists}$ & 息 & $\overrightarrow{\vec{\xi}}$ & $\overrightarrow{\vec{\xi}}$ & $\stackrel{\vec{g}}{\vec{\theta}}$ & $\overrightarrow{\vec{F}}$ & $\overrightarrow{\vec{g}}$ & $\overrightarrow{\vec{H}}$ & $\overrightarrow{\vec{H}}$ & $\stackrel{\overleftarrow{\Sigma}}{\vec{\Sigma}}$ & $\overrightarrow{\vec{F}}$ & $\overrightarrow{\vec{F}}$ & $\overrightarrow{\vec{H}}$ & $\stackrel{a}{\exists}$ & $\overrightarrow{\vec{\forall}}$ & $\hat{\vec{F}}$ & $\overrightarrow{\vec{\exists}}$ & $\mid \vec{\exists}$ & $\overrightarrow{\vec{\xi}}$ & $\overrightarrow{\vec{F}}$ & $\overrightarrow{\vec{F}}$ & $\overrightarrow{\vec{F}}$ & $\overrightarrow{\vec{H}}$ & $\overrightarrow{\vec{\xi}}$ & $\overrightarrow{\vec{F}}$ \\
\hline 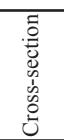 & 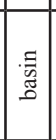 & & 离 & & & & 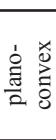 & & & & 寻 & 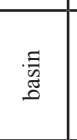 & 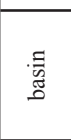 & & 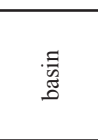 & 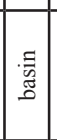 & 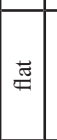 & 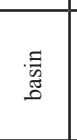 & $\underset{\varpi}{\leftrightarrows}$ & $\underset{\Xi}{\leftrightarrows}$ & 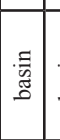 & 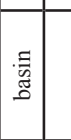 & 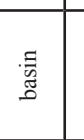 & & 氶 & 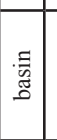 & 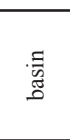 \\
\hline 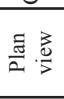 & \begin{tabular}{|l|}
$\overline{\mathrm{g}}$ \\
\end{tabular} & 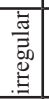 & 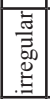 & 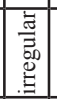 & & 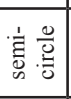 & 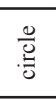 & & & $\begin{array}{l}\mathrm{g} \\
\mathrm{\sigma}\end{array}$ & 喽 & 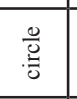 & 㗁 & \begin{tabular}{|l|}
$\pi$ \\
5
\end{tabular} & 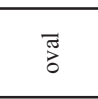 & $\begin{array}{l}\mathrm{g} \\
\mathrm{\sigma}\end{array}$ & 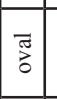 & & 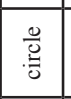 & $\begin{array}{l}\mathrm{J} \\
\mathrm{\sigma}\end{array}$ & & & $\overline{\mathrm{g}}$ & 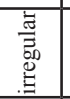 & $\bar{\sigma}$ & \begin{tabular}{l|l} 
\\
g
\end{tabular} & $\begin{array}{l}\frac{0}{0} \\
\frac{0}{y}\end{array}$ \\
\hline 总 & 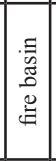 & $\begin{array}{l}\text { 害 } \\
\text { ज्ञ } \\
\overline{\mathrm{v}} \\
\mathrm{v}\end{array}$ & 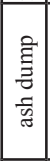 & 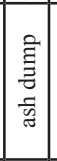 & 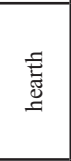 & $\begin{array}{l}\bar{E} \\
\underline{E} \\
\underline{E}\end{array}$ & 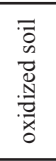 & 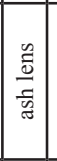 & 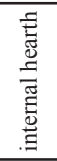 & 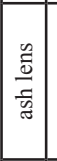 & 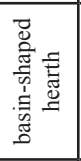 & 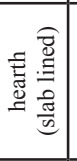 & 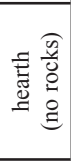 & 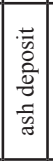 & 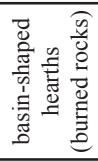 & 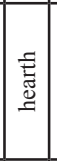 & 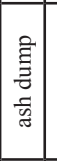 & 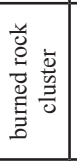 & 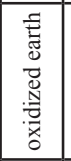 & 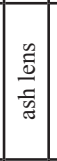 & 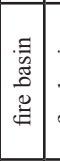 & 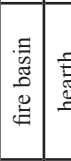 & 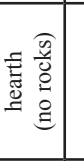 & 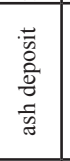 & 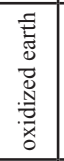 & 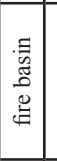 & 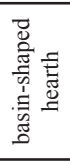 \\
\hline 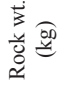 & & & & & & & & & & & & $\cong$ & & & & & & & & & & & & & & & \\
\hline 总 & & & & & & & & & & & & f & & & 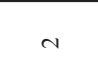 & & & & & & & & - & & & & $N$ \\
\hline 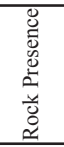 & 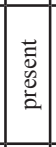 & 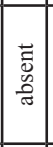 & 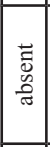 & 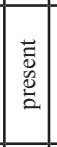 & $\begin{array}{l}\overrightarrow{\tilde{z}_{0}} \\
\underline{0} \\
\underline{2}\end{array}$ & 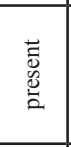 & 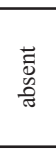 & 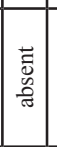 & 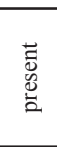 & 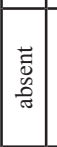 & 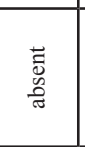 & 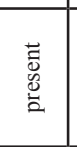 & 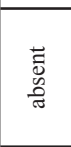 & 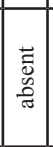 & 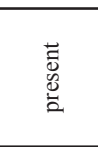 & 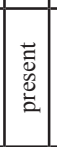 & 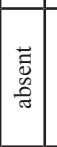 & 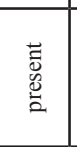 & 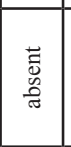 & 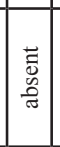 & 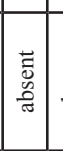 & 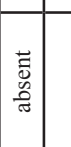 & 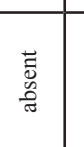 & $\begin{array}{l}\text { 言 } \\
\text { 嵩 }\end{array}$ & 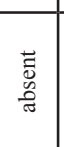 & 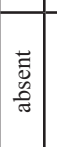 & 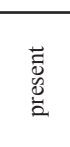 \\
\hline 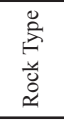 & & & & & & & & & & & & & & & & & & & & & & & & & & & \\
\hline 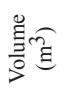 & $\stackrel{8}{\circ}$ & : & $\because$ & 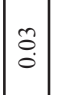 & o. & $\stackrel{n}{0}$ & $\stackrel{n}{0}$ & $\mid \begin{array}{l}0 \\
0 \\
0\end{array}$ & $\stackrel{\leftrightarrow}{0}$ & $\begin{array}{l}0 \\
0 \\
0\end{array}$ & ठे. & $\stackrel{8}{\circ}$ & : & $\mid \begin{array}{l}0 \\
0 \\
0\end{array}$ & 营 & oे & $\begin{array}{l}0 \\
0 \\
0\end{array}$ & $\stackrel{0}{\circ}$ & \begin{tabular}{l|}
0 \\
0 \\
0
\end{tabular} & 官 & \begin{tabular}{|l|} 
\\
0 \\
0
\end{tabular} & \begin{tabular}{|l|} 
\\
0 \\
0 \\
\end{tabular} & $\overline{0}$ & $\stackrel{t}{\circ}$ & $\stackrel{8}{\circ}$ & $\stackrel{\circ}{\circ}$ & $\stackrel{\circ}{\circ}$ \\
\hline 芻哥 & \begin{tabular}{l|}
$\infty$ \\
0 \\
0
\end{tabular} & $\begin{array}{l}0 \\
0 \\
0\end{array}$ & $\stackrel{n}{0}$ & $\begin{array}{l}0 \\
0 \\
0\end{array}$ & ó. & $\hat{o}$ & $\stackrel{a}{0}$ & $\mid \begin{array}{l}0 \\
0 \\
0\end{array}$ & $\stackrel{5}{0}$ & $\mid \begin{array}{l}0 \\
0 \\
0 \\
0\end{array}$ & $\stackrel{7}{0}$ & $\stackrel{\infty}{0}$ & $\stackrel{\circ}{\circ}$ & $\stackrel{8}{\circ}$ & $\stackrel{0}{0}$ & $\because$ & $\mid \begin{array}{l}0 \\
0 \\
0\end{array}$ & $\stackrel{\circ}{\circ}$ & $\because$ & $\because$ & $=$ & $\mid \begin{array}{l}n \\
: \\
0 \\
0\end{array}$ & $\stackrel{ \pm}{0}$ & $\stackrel{\circ}{\circ}$ & $\stackrel{5}{0}$ & $\begin{array}{l}\infty \\
\stackrel{0}{0} \\
0\end{array}$ & $\stackrel{m}{0}$ \\
\hline 总 & : & 告 & $\begin{array}{c}\tilde{O} \\
\stackrel{0}{0}\end{array}$ & 官 & ชี & & $\stackrel{\Omega}{0}$ & & $\overrightarrow{0}$ & $\mid \begin{array}{l}\stackrel{0}{\circ} \\
\stackrel{\circ}{*}\end{array}$ & $\stackrel{0}{0}$ & $\frac{7}{0}$ & $\begin{array}{l}n \\
\stackrel{0}{0} \\
0\end{array}$ & $\overrightarrow{\widehat{\lambda}}$ & $\stackrel{\circ}{\circ}$ & $\mid \stackrel{0}{\circ}$ & o. & ภี & 䓵 & \begin{tabular}{c}
0 \\
\hdashline
\end{tabular} & & & $\stackrel{5}{0}$ & तె & $\stackrel{\Omega}{0}$ & $\stackrel{\leftrightarrow}{\circ}$ & $\overline{\overline{0}}$ \\
\hline 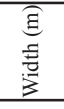 & $\tilde{c}$ & $\tilde{m}$ & $\mid \begin{array}{c}\infty \\
\stackrel{0}{0}\end{array}$ & 7 & 3 & 3 & $\stackrel{3}{0}$ & 3 & ?3 & $\mid \begin{array}{l}0 \\
0 \\
0 \\
0\end{array}$ & $\hat{n}$ & $\overrightarrow{3}$ & $\stackrel{t}{0}$ & $\begin{array}{c}\text { ît } \\
\text { S }\end{array}$ & สี & 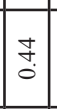 & స్ & ֶֻ. & $\mid \begin{array}{c}n \\
\tilde{o} \\
0\end{array}$ & 品 & : & $\stackrel{\infty}{\stackrel{0}{0}}$ & g. & $\stackrel{\stackrel{\circ}{0}}{\circ}$ & స్ & 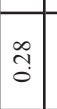 & 声 \\
\hline 䓌 & خृ & ণิ & خิ & $\stackrel{3}{0}$ & 3 & 3 & 3 & $\stackrel{3}{0}$ & ?3. & 3 & 3 & $\overrightarrow{3}$ & $\vec{m}$ & $\tilde{\jmath}$ & d. & 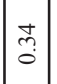 & $\mid \begin{array}{c}n \\
\tilde{o} \\
0\end{array}$ & $\stackrel{n}{n}$ & $\mid \begin{array}{c}n \\
\tilde{o} \\
0\end{array}$ & $\tilde{c}$ & $\mid$\begin{tabular}{l|} 
\\
0 \\
0
\end{tabular} & के. & $\hat{\tilde{0}}$ & $\hat{3}$ & $\stackrel{\infty}{\infty}$ & $\begin{array}{l}\infty \\
\vdots \\
0 \\
0\end{array}$ & $\stackrel{\infty}{\substack{0 \\
0}}$ \\
\hline 总: 웅 & $\mathrm{N}$ & - & - & N & $\mathrm{N}$ & $\sim$ & - & - & $\sim$ & -1 & - & $\mathrm{N}$ & - & -1 & $\sim$ & $\sim$ & - & $d$ & - & - & - & - & - & - & - & - & N \\
\hline 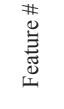 & \pm & i & \& & 怘 & $\mathrm{N}$ & 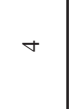 & $\simeq$ & 望 & $\unlhd$ & 3 & $\hat{\lambda}$ & $=$ & $\approx$ & 8 & $\stackrel{\circ}{-1}$ & $1 \approx$ & $\cong$ & in & $\stackrel{n}{n}$ & 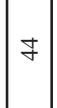 & $\underset{\sim}{\infty}$ & $\mid \begin{array}{c}\infty \\
\underset{\sim}{\infty} \\
\sim\end{array}$ & $\overrightarrow{0}$ & $\therefore$ & in & $=$ & $=$ \\
\hline 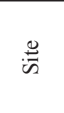 & 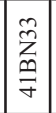 & \begin{tabular}{|l|}
$\stackrel{m}{z}$ \\
$\stackrel{m}{q}$ \\
\end{tabular} & \begin{tabular}{l|}
$\stackrel{m}{z}$ \\
$\stackrel{m}{\sigma}$ \\
\end{tabular} & 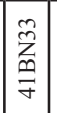 & $\underset{\vec{y}}{\grave{a}}$ & 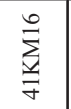 & $\underset{\vec{F}}{\vec{Z}}$ & 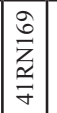 & $\underset{\grave{y}}{\hat{y}}$ & \begin{tabular}{|l|}
$\vec{n}$ \\
$\bar{U}$ \\
$\bar{\sigma}$ \\
\end{tabular} & $\sum_{\bar{z}}^{n}$ & $\stackrel{\Re}{\dddot{z}}$ & $\begin{array}{l}\vec{m} \\
\vec{U} \\
\vec{\sigma}\end{array}$ & $\hat{m}$ & $\frac{\stackrel{n}{a}}{\sum_{\sigma}^{n}}$ & \begin{tabular}{|l|}
$\stackrel{m}{z}$ \\
$\vec{\sigma}$ \\
\end{tabular} & 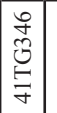 & $\underset{\xi}{\grave{y}}$ & \begin{tabular}{|l|}
$\vec{m}$ \\
$\vec{U}$ \\
$\bar{v}$ \\
$\vec{\sigma}$
\end{tabular} & 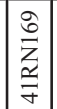 & 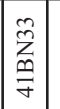 & \begin{tabular}{|l|}
$\tilde{z}$ \\
$\tilde{g}$ \\
\end{tabular} & $\begin{array}{l}\overrightarrow{\vec{n}} \\
\vec{U} \\
\vec{\gamma}\end{array}$ & $\begin{array}{l}\stackrel{m}{\tilde{m}} \\
\stackrel{m}{\sigma}\end{array}$ & $\begin{array}{l}\overrightarrow{\vec{m}} \\
\vec{U} \\
\vec{F}\end{array}$ & 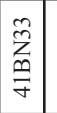 & $\begin{array}{l}\stackrel{n}{Z} \\
\frac{a}{\sigma}\end{array}$ \\
\hline
\end{tabular}




\begin{tabular}{|c|c|c|c|c|c|c|c|c|c|c|c|c|c|c|c|c|c|c|c|c|c|c|}
\hline 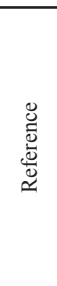 & 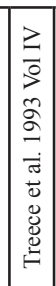 & 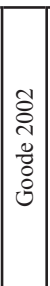 & 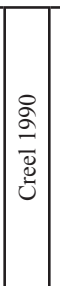 & 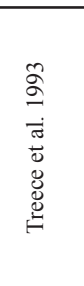 & 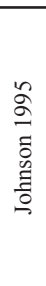 & 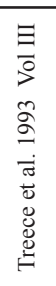 & 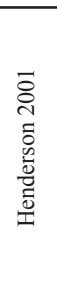 & 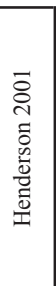 & 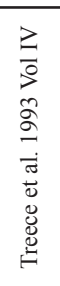 & 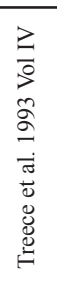 & 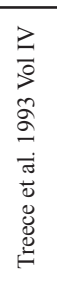 & 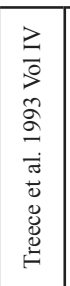 & 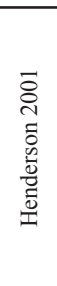 & 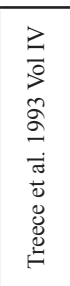 & 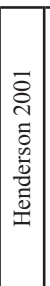 & 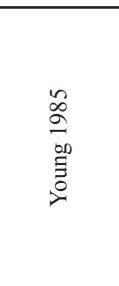 & 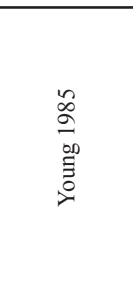 & 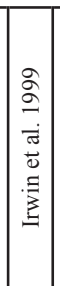 & 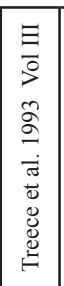 & 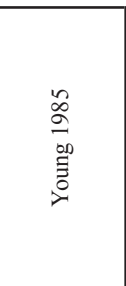 & 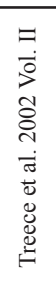 & 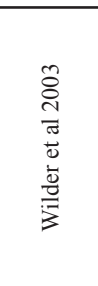 \\
\hline$\stackrel{\varrho}{\tilde{\Xi}}$ & & & & 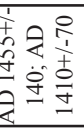 & & & & & & & & & & & & 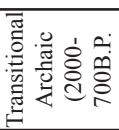 & 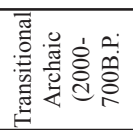 & & & 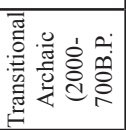 & & 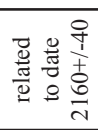 \\
\hline 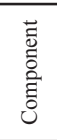 & $\overrightarrow{\vec{F}}$ & 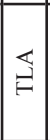 & $\overrightarrow{\vec{F}}$ & $\overrightarrow{\vec{\theta}}$ & $\overleftrightarrow{\Sigma}$ & $\underset{\Sigma}{\overleftrightarrow{\Sigma}}$ & $\stackrel{\vec{\theta}}{ }$ & 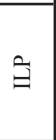 & $\overrightarrow{\vec{F}}$ & $\overrightarrow{\vec{F}}$ & $\overrightarrow{\vec{\theta}}$ & $\vec{\xi}$ & $\hat{\vec{\theta}}$ & $\overrightarrow{\vec{\xi}}$ & $\vec{\exists}$ & $\overleftrightarrow{\lessgtr}$ & $\overleftrightarrow{\sharp}$ & $\mid \begin{array}{l}\overleftrightarrow{\xi} \\
\end{array}$ & $\overleftrightarrow{\Xi}$ & $\overleftrightarrow{\Xi}$ & $\overrightarrow{\vec{F}}$ & $\overleftrightarrow{\Sigma}$ \\
\hline 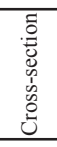 & $\underset{\mathbb{E}}{\mathbb{\Xi}}$ & 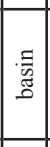 & $\underset{\mathrm{J}}{\mathrm{t}}$ & $\begin{array}{l}\text { 袁 } \\
\text { 昜 }\end{array}$ & 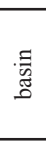 & & 槖 & $\begin{array}{l}\text { 表 } \\
\text { 焉 }\end{array}$ & 氶 & 壱 & $\underset{\varpi ّ}{\mathbb{J}}$ & 志 & $\begin{array}{l}\text { 专 } \\
\text { g }\end{array}$ & 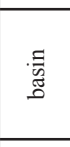 & & 壳 & 壱 & & \begin{tabular}{|l|}
\multirow{\pi}{*}{} \\
\end{tabular} & $\underset{\varpi}{\mathbb{\sharp}}$ & & 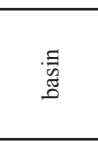 \\
\hline 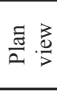 & \begin{tabular}{|l|}
$\frac{0}{0}$ \\
$\frac{0}{0}$ \\
\end{tabular} & \begin{tabular}{|l|}
$\frac{0}{0}$ \\
$\frac{0}{0}$ \\
\end{tabular} & 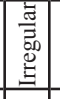 & 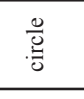 & $\begin{array}{l}0 \\
\end{array}$ & $\begin{array}{l} \\
\\
\end{array}$ & 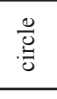 & 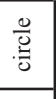 & $\begin{array}{l}\frac{\pi}{0} \\
\frac{0}{0}\end{array}$ & & & & $\begin{array}{l} \\
\frac{0}{0} \\
\frac{1}{0}\end{array}$ & $\overline{\widetilde{J}}$ & \begin{tabular}{|l|}
$\frac{0}{0}$ \\
$\frac{0}{0}$ \\
\end{tabular} & 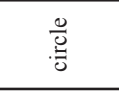 & 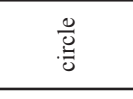 & \begin{tabular}{|l|}
$\frac{0}{0}$ \\
$\frac{0}{0}$ \\
\end{tabular} & 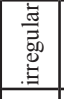 & 票 & & \\
\hline 产 & 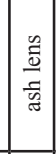 & 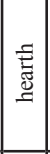 & 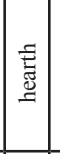 & 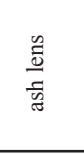 & 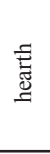 & 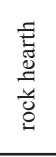 & $\begin{array}{l}\text { 䓌 } \\
\text { 品 }\end{array}$ & $\begin{array}{l}\text { 馬 } \\
\stackrel{\vec{E}}{g}\end{array}$ & 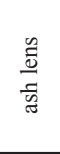 & 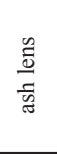 & 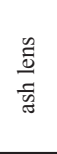 & $\mid \frac{0}{0}$ & 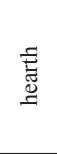 & 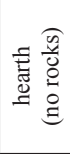 & 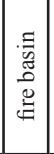 & $\begin{array}{l}\text { 䔍 } \\
\text { 吾 }\end{array}$ & 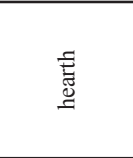 & 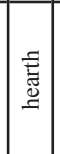 & 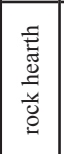 & $\begin{array}{l}\text { 志 } \\
\text { 䔍 }\end{array}$ & 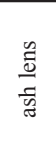 & $\begin{array}{l}\text { 志 } \\
\text { 䔍 }\end{array}$ \\
\hline 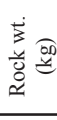 & & & & & & $\stackrel{n}{q}$ & & & & & & & & & & & & & & & & \\
\hline $\begin{array}{l}\text { 范 } \\
\approx \\
\end{array}$ & & & & & & & & & & & & & & - & & $\stackrel{\infty}{-}$ & $m$ & & & $\underline{0}$ & & \\
\hline 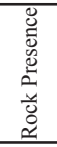 & 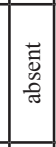 & 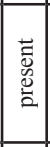 & 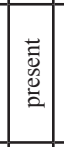 & 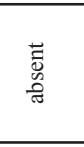 & 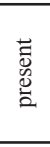 & 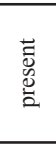 & 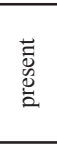 & 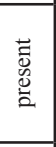 & 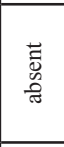 & 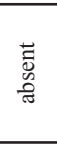 & 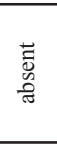 & 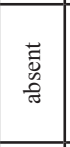 & 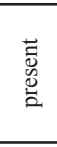 & $\begin{array}{l}\text { 芯 } \\
\text { 芫 }\end{array}$ & 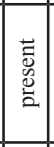 & $\begin{array}{l}\text { 蒿 } \\
\text { 总 }\end{array}$ & 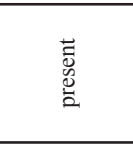 & 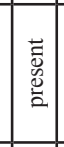 & 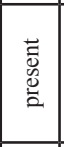 & 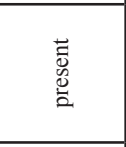 & 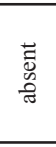 & 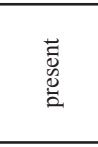 \\
\hline 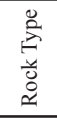 & & 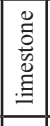 & 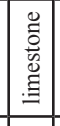 & & & & & & & & & & & & & 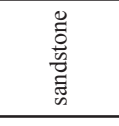 & 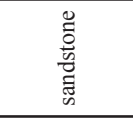 & & & 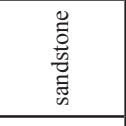 & & \\
\hline 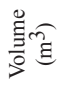 & $\stackrel{0}{0}$ & $\stackrel{g}{\circ}$ & $\mid \begin{array}{l}0 \\
\vdots \\
0\end{array}$ & $\stackrel{\infty}{0}$ & : & $\stackrel{8}{\circ}$ & $\stackrel{8}{\circ}$ & $\stackrel{8}{0}$ & o. & $\stackrel{\circ}{\circ}$ & $\stackrel{8}{\circ}$ & oे & : & $\bar{F}$ & $\because$ & $\stackrel{7}{0}$ & $\stackrel{7}{0}$ & $\stackrel{7}{0}$ & $\because$ & $\stackrel{ \pm}{0}$ & & $\stackrel{0}{0}$ \\
\hline 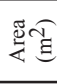 & $\stackrel{m}{0}$ & $\because$ & \begin{tabular}{|l|} 
\\
\\
0 \\
\end{tabular} & $\overline{0}$ & $\stackrel{m}{0}$ & $\stackrel{m}{0}$ & $\stackrel{m}{0}$ & $\stackrel{m}{0}$ & $\stackrel{m}{0}$ & $\stackrel{m}{0}$ & $\stackrel{m}{0}$ & $\begin{array}{l}m \\
0 \\
0\end{array}$ & $\stackrel{m}{0}$ & $\stackrel{ \pm}{0}$ & $\begin{array}{ll} \\
0 \\
0\end{array}$ & $\stackrel{0}{0}$ & $\stackrel{0}{\circ}$ & $\stackrel{0}{0}$ & \begin{tabular}{|l|}
0 \\
\end{tabular} & $\stackrel{9}{\circ}$ & & $\overline{0}$ \\
\hline 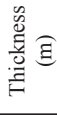 & 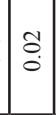 & & 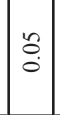 & & & $\stackrel{n}{\circ}$ & $\begin{array}{l}n \\
0 \\
0\end{array}$ & รี & 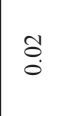 & 荅 & $\overrightarrow{0}$ & $\overrightarrow{0}$. & $\stackrel{0}{0}$ & 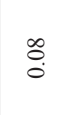 & 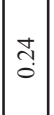 & $\overrightarrow{0}$ & $\overrightarrow{0}$ & & o. & $\overrightarrow{0}$ & & $\overrightarrow{0}$ \\
\hline 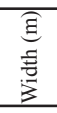 & 苛 & $\begin{array}{c}\hat{\sigma} \\
\tilde{\sigma} \\
0\end{array}$ & $\mid \begin{array}{c}\mathfrak{c} \\
0 \\
0\end{array}$ & $\stackrel{t}{m}$ & $\stackrel{t}{0}$ & $\stackrel{t}{0}$ & $\stackrel{t}{\circ}$ & $\stackrel{ \pm}{0}$ & t. & $\stackrel{t}{0}$ & $\stackrel{+}{0}$ & $\stackrel{t}{0}$ & $\stackrel{t}{0}$ & 犕 & 勇 & $n$ & $\because$ & $\because$ & $n$ & $\stackrel{0}{\circ}$ & & 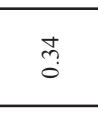 \\
\hline 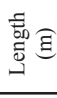 & $\begin{array}{l}\infty \\
\vdots \\
0 \\
0\end{array}$ & $\begin{array}{c}\hat{0} \\
0 \\
0 \\
\end{array}$ & $\because$ & $\stackrel{t}{0}$ & $\stackrel{t}{0}$ & $\stackrel{t}{0}$ & $\stackrel{t}{0}$ & $\stackrel{t}{0}$ & t. & $\stackrel{t}{0}$ & $\stackrel{t}{0}$ & $\stackrel{t}{0}$ & $\stackrel{t}{0}$ & $\stackrel{t}{0}$ & $\stackrel{+}{0}$ & $\stackrel{t}{0}$ & $\stackrel{t}{0}$ & $\stackrel{t}{0}$ & $\because$ & $\stackrel{t}{0}$ & $\stackrel{t}{0}$ & $\begin{array}{l}7 \\
0\end{array}$ \\
\hline 密 웡 & - & $\sim$ & $\mathrm{N}$ & - & $\sim$ & $\sim$ & $\sim$ & $\sim$ & - & - & - & - & $N$ & - & $\sim \mid$ & N & $\sim$ & $\sim$ & $\sim$ & $N$ & - & $N$ \\
\hline 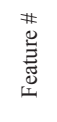 & $\dot{A}$ & 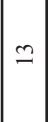 & \pm & $=$ & - & 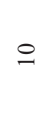 & $\stackrel{\infty}{\infty}$ & के & $g$ & 8 & 3 & t & $\approx$ & $\underset{N}{ \pm}$ & - & t & in & 0 & $\simeq$ & $r$ & $n$ & 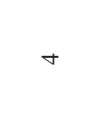 \\
\hline 善 & \begin{tabular}{|l|}
$\frac{8}{Z}$ \\
$z$ \\
$\frac{z}{7}$ \\
\end{tabular} & $\begin{array}{l} \\
0 \\
3 \\
7 \\
7\end{array}$ & \begin{tabular}{|l|}
$\overrightarrow{0}$ \\
$\overrightarrow{7}$ \\
$\overrightarrow{7}$ \\
\end{tabular} & 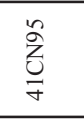 & 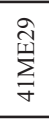 & $\sum_{\frac{\pi}{\sigma}}^{m}$ & $\stackrel{\tilde{z}}{\stackrel{m}{\sigma}}$ & $\begin{array}{c}\tilde{z}_{\tilde{m}} \\
\vec{\sigma}\end{array}$ & 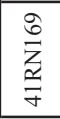 & 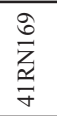 & 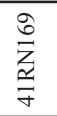 & 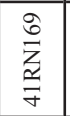 & 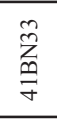 & $\begin{array}{l}\vec{n} \\
\vec{U} \\
\vec{\sigma}\end{array}$ & \begin{tabular}{|l}
$\tilde{\tilde{z}}$ \\
$\stackrel{\tilde{z}}{\sigma}$ \\
\end{tabular} & $\begin{array}{l}\stackrel{0}{\Rightarrow} \\
\frac{7}{7}\end{array}$ & $\frac{\mathscr{0}}{\frac{7}{7}}$ & 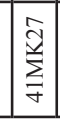 & \begin{tabular}{|l|}
\multirow{2}{*}{} \\
\end{tabular} & $\begin{array}{l}\text { D. } \\
\stackrel{8}{F}\end{array}$ & 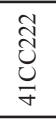 & 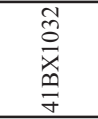 \\
\hline
\end{tabular}




\begin{tabular}{|c|c|c|c|c|c|c|c|c|c|c|c|c|c|c|c|c|c|c|c|c|c|c|c|c|c|c|}
\hline 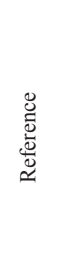 & 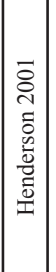 & 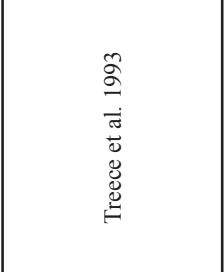 & 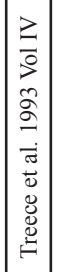 & 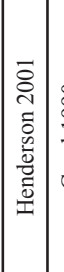 & 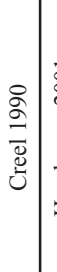 & & 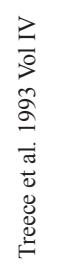 & 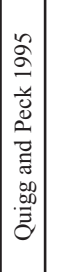 & 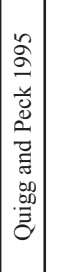 & 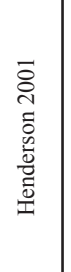 & 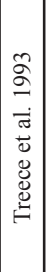 & & 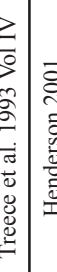 & 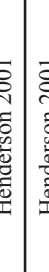 & 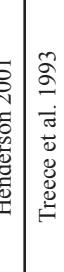 & 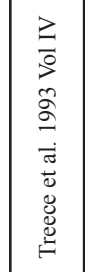 & 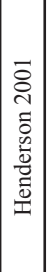 & & 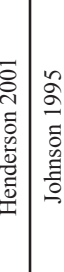 & 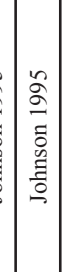 & 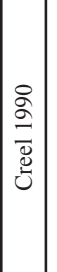 & 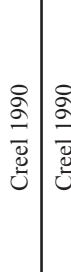 & 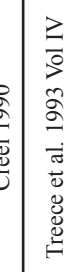 & 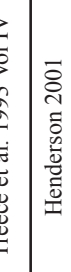 & 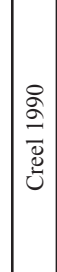 & 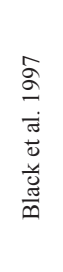 \\
\hline$\frac{9}{\tilde{y}}$ & & 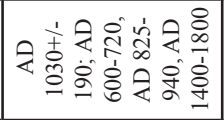 & & & & & 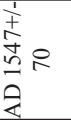 & & & & & & & & & & & & & & & & & & & $\begin{array}{l}0 \\
\text { o. } \\
+1\end{array}$ \\
\hline $\begin{array}{l}\text { 言 } \\
\text { 言 } \\
\text { 言 } \\
0\end{array}$ & 肖 & $\overrightarrow{\vec{\theta}}$ & $\overrightarrow{\vec{H}}$ & $\vec{\exists}$ & $\overrightarrow{\vec{\theta}}$ & $\overrightarrow{\vec{\xi}}$ & $\vec{\xi}$ & $\overrightarrow{\vec{\theta}}$ & $\overrightarrow{\vec{\theta}}$ & $\overleftrightarrow{\sharp}$ & $\vec{\xi}$ & $\overrightarrow{\vec{F}}$ & $\vec{E}$ & $\exists$ & $\vec{\theta}$ & $\overrightarrow{\vec{H}}$ & $\overrightarrow{\vec{\theta}}$ & $\hat{\exists}$ & $\overrightarrow{\vec{t}}$ & $\overleftrightarrow{\Sigma}$ & $\overrightarrow{\vec{\theta}}$ & $\stackrel{\Xi}{\Sigma}$ & $\overrightarrow{\vec{t}}$ & $\vec{\Xi}$ & $\hat{\vec{\theta}}$ & $\vec{\exists}$ \\
\hline 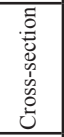 & 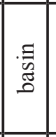 & 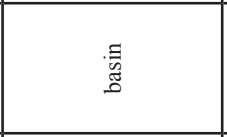 & 穿 & 壱 & & & 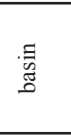 & 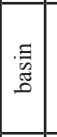 & 壳 & $\underset{\mathbb{F}}{\mathbb{G}}$ & & & 范 & \pm & 密 & $\begin{array}{l}\text { 量 } \\
\text { 品 }\end{array}$ & 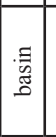 & & 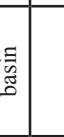 & & & & ङ & 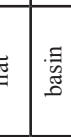 & $\begin{array}{l}\text { 袁 } \\
\text { 尊 }\end{array}$ & 逽 \\
\hline 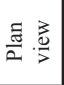 & 吾 & 足 & 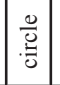 & \begin{tabular}{|l|l|}
$\frac{0}{0}$ \\
$\frac{3}{0}$ \\
\end{tabular} & & : & $\begin{array}{l}0 \\
\frac{0}{0} \\
\frac{0}{0}\end{array}$ & \begin{tabular}{|l|}
$\frac{0}{0}$ \\
$\frac{0}{0}$ \\
\end{tabular} & 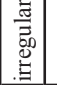 & 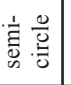 & 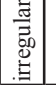 & & $\begin{array}{l}\frac{5}{5} \\
\frac{5}{5}\end{array}$ & 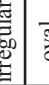 & 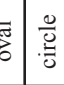 & 足 & 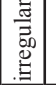 & 递 & 몸 & 焉 & & 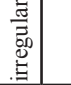 & $\overline{\mathrm{J}}$ & \begin{tabular}{l|l}
5 \\
5
\end{tabular} & & 䓅 \\
\hline 离 & 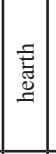 & 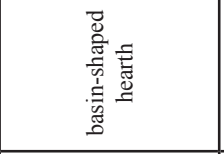 & 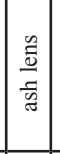 & 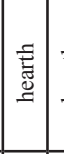 & 鴶 & 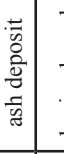 & 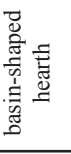 & 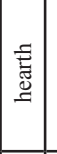 & 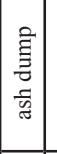 & $\begin{array}{l}\text { 害 } \\
\text { 吾 } \\
\frac{\vec{g}}{\mathrm{~g}}\end{array}$ & $\mid \frac{5}{\frac{b}{0}}$ & 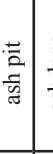 & 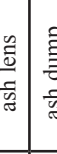 & & 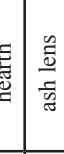 & 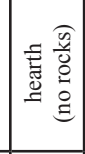 & 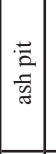 & 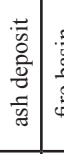 & 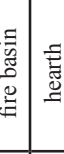 & 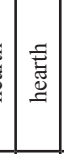 & & 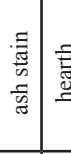 & 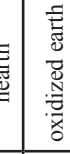 & 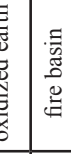 & 馬 & 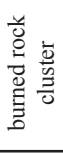 \\
\hline 表 & & & & & & & & & & & & & & & & $\stackrel{n}{\stackrel{c}{c}}$ & & & & & & & & & & \\
\hline 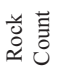 & & & & & & & & & & & & & & & & & & & & & & & & & & \\
\hline 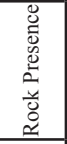 & 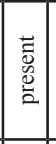 & 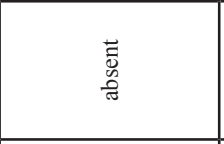 & 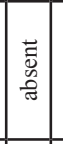 & 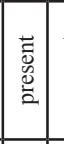 & 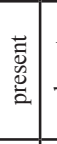 & 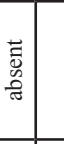 & $\begin{array}{l}\text { 蒿 } \\
\text { 号 }\end{array}$ & 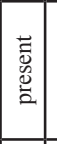 & 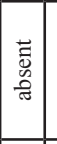 & 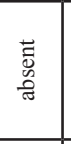 & \begin{tabular}{|c|} 
\\
$\vec{v}$ \\
o. \\
$\vec{\sigma}$
\end{tabular} & 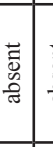 & 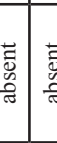 & 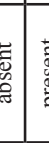 & 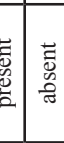 & 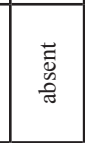 & 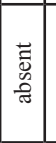 & 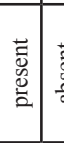 & & 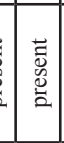 & 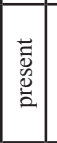 & 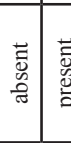 & 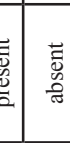 & 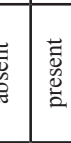 & 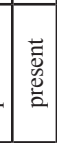 & $\begin{array}{l}\text { 节 } \\
\text { 递 }\end{array}$ \\
\hline 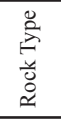 & & & & & 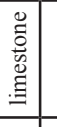 & & & & & & & & & & & & & & & & 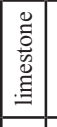 & & & & 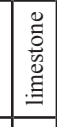 & \\
\hline 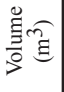 & ठे & $\stackrel{\circ}{\circ}$ & $\stackrel{0}{\circ}$ & $\because$ & $\begin{array}{l}\overline{0} \\
0\end{array}$ & $\begin{array}{l}7 \\
0 \\
0\end{array}$ & $\stackrel{7}{0}$ & $\stackrel{2}{\circ}$ & $\stackrel{0}{0}$ & $\stackrel{\leftrightarrow}{0}$ & $\begin{array}{l}\infty \\
0 \\
0\end{array}$ & $\begin{array}{c}7 \\
0\end{array}$ & $\begin{array}{l}\frac{1}{0} \\
\end{array}$ & $=$ & $\div \div$ & $\frac{7}{0}$ & $\stackrel{?}{0}$ & $\stackrel{0}{\circ}$ & $\begin{array}{l}\overrightarrow{0} \\
\end{array}$ & $\begin{array}{l}0 \\
0 \\
0 \\
0\end{array}$ & $\begin{array}{l} \\
\\
\end{array}$ & \begin{tabular}{l|l}
$\vdots$ \\
$\vdots$ \\
0
\end{tabular} & $\stackrel{\circ}{\circ}$ & 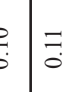 & $\because$ & t. \\
\hline 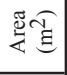 & $\because$ & $\stackrel{t}{\circ}$ & $\stackrel{ \pm}{\circ}$ & $=$ & $\stackrel{ \pm}{0}$ & 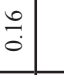 & $\stackrel{0}{\circ}$ & $\stackrel{\circ}{0}$ & जે & $\stackrel{\circ}{\circ}$ & $\begin{array}{l}7 \\
0\end{array}$ & $\overrightarrow{0}$ & \pm & 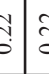 & $\begin{array}{lll}0 & ? \\
0\end{array}$ & $\frac{n}{0}$ & $\stackrel{0}{0}$ & 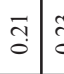 & तु & $\mid$\begin{tabular}{l}
0 \\
\hdashline \\
0
\end{tabular} & $\mid \begin{array}{l}\infty \\
\stackrel{0}{0} \\
0\end{array}$ & $\because \frac{7}{\circ}$ & $\stackrel{5}{\circ}$ & $\frac{1}{0}$ & $\because$ & $\dot{b}$ \\
\hline 鄫 & $\stackrel{0}{\circ}$ & o. & $\mid \begin{array}{l}\overrightarrow{0} \\
\dot{0}\end{array}$ & $\stackrel{ \pm}{\stackrel{ \pm}{0}}$ & & $\begin{array}{l}0 \\
0 \\
0\end{array}$ & $\stackrel{m}{0}$ & \begin{tabular}{|l|} 
\\
$\dot{0}$ \\
$\dot{0}$
\end{tabular} & Oे & $\stackrel{\circ}{\circ}$ & $\begin{array}{l}0 \\
0 \\
0\end{array}$ & & : & 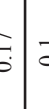 & \begin{tabular}{l|l}
0 \\
\end{tabular} & $\overline{0}$ & 㞷 & ธี & : & & $=$ & \begin{tabular}{l|l}
$\stackrel{n}{0}$ & \multicolumn{2}{c}{} \\
0
\end{tabular} & & 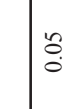 & & \\
\hline 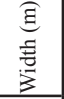 & $\mid \hat{3}$ & fै & $\begin{array}{l}f \\
\text { f }\end{array}$ & $\begin{array}{l}\text { gे } \\
\text { gे }\end{array}$ & $\stackrel{t}{\circ}$ & $\begin{array}{l}\text { fo } \\
\text { of } \\
0\end{array}$ & for & $\mid \begin{array}{l}n \\
\vdots \\
0 \\
0\end{array}$ & $\stackrel{0}{\circ}$ & $\stackrel{5}{0}$ & $\vec{m}$ & $\begin{array}{l}0 \\
0 \\
0\end{array}$ & है & 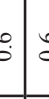 & 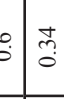 & $\begin{array}{l}\xi \\
0\end{array}$ & 吕 & $\tilde{n}$ & 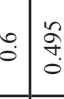 & $\stackrel{2}{0}$ & 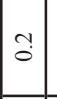 & 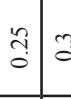 & 3 & $\hat{s}$ & $\stackrel{t}{\circ}$ & t. \\
\hline 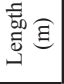 & f. & ริ. & f. & $\begin{array}{l}f \\
0\end{array}$ & $\stackrel{f}{\circ}$ & $\begin{array}{l}\text { fo } \\
0 \\
0 \\
0\end{array}$ & 僁 & \begin{tabular}{l|} 
\\
fo \\
0 \\
0
\end{tabular} & if & $\stackrel{?}{\stackrel{0}{0}}$ & 官. & fo. & $\begin{array}{lll}f & \text { f } \\
0 & \end{array}$ & f. & 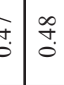 & $\stackrel{\infty}{\stackrel{0}{0}}$ & $\stackrel{\infty}{\stackrel{\infty}{0}}$ & 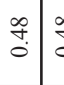 & 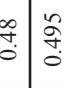 & $\because$ & $\because$ & $\begin{array}{lll}n & n \\
0 & 2\end{array}$ & 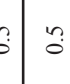 & 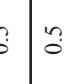 & $\because$ & n. \\
\hline 옹 웅 & $\sim$ & - & - & $\sim$ & $\mathrm{N}$ & - & - & $\sim$ & - & - & - & - & -1 & -1 & $\checkmark-$ & - & - & $\sim$ & $-\Delta$ & $\sim$ & $\sim$ & $-\sigma$ & - & 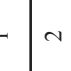 & $\mathrm{N}$ & v \\
\hline 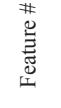 & 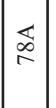 & $a$ & $\begin{array}{l}\infty \\
\infty\end{array}$ & $\vec{\gamma}$ & $\simeq$ & 8 & $\stackrel{m}{2}$ & r & $=1$ & 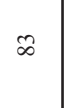 & i & $=$ & $\therefore$ & $\vec{\infty}$ & $0 \pi$ & 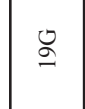 & in & $\mathcal{S}$ & ते $m$ & 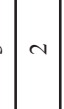 & $\simeq$ & $==$ & $=\stackrel{\infty}{n}$ & $\therefore=$ & in & $\hat{\imath}$ \\
\hline 善 & 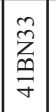 & 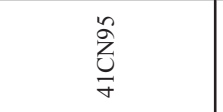 & 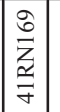 & \begin{tabular}{|c|c|}
$\tilde{z}$ \\
$\tilde{m}$ \\
$\bar{\sigma}$
\end{tabular} & $\begin{array}{l}\overrightarrow{\mathrm{g}} \\
\overrightarrow{\mathrm{\sigma}}\end{array}$ & $\underset{m}{m}$ & $\begin{array}{l}\vec{m} \\
\vec{U} \\
\vec{\sigma}\end{array}$ & 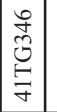 & 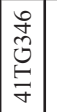 & $\stackrel{m}{\tilde{m}}$ & 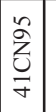 & $\frac{5}{7}$ & 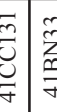 & & $\begin{array}{l}n \\
z \\
z \\
z\end{array}$ & $\begin{array}{l}\vec{m} \\
\vec{U} \\
\vec{J}\end{array}$ & 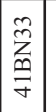 & 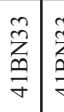 & 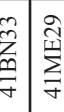 & 館 & $\mid \begin{array}{l}\overrightarrow{0} \\
\vec{b} \\
\vec{\sigma}\end{array}$ & 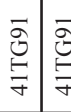 & $\begin{array}{l}\vec{b} \\
\vec{y} \\
\vec{y} \\
\vec{j} \\
\end{array}$ & 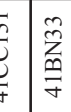 & \begin{tabular}{|l}
$\vec{S}$ \\
$\vec{G}$ \\
$\overrightarrow{7}$
\end{tabular} & $\sum^{n}$ \\
\hline
\end{tabular}




\begin{tabular}{|c|c|c|c|c|c|c|c|c|c|c|c|c|c|c|c|c|c|c|c|c|c|c|c|c|}
\hline 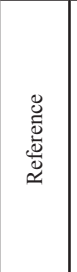 & 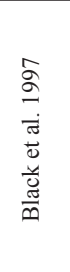 & 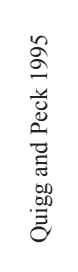 & 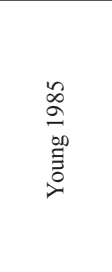 & 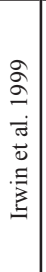 & 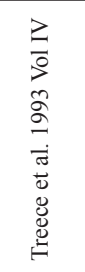 & 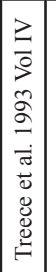 & 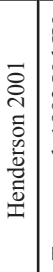 & 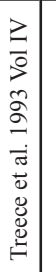 & $\begin{array}{l}\stackrel{8}{\circ} \\
\frac{\bar{q}}{8} \\
\text { Uे }\end{array}$ & 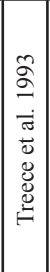 & 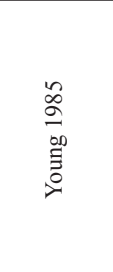 & 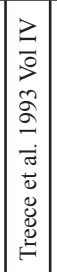 & 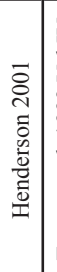 & 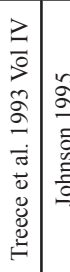 & 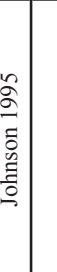 & 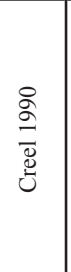 & 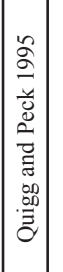 & 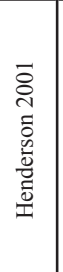 & 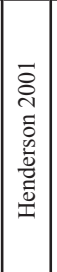 & 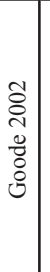 & 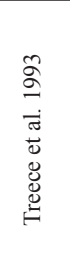 & 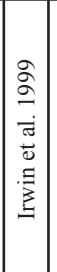 & 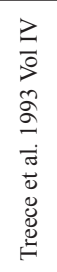 & 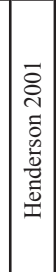 \\
\hline 总 & 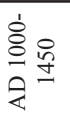 & & 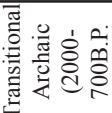 & & 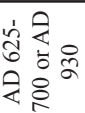 & & & & & & 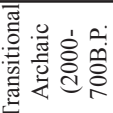 & & & & & & & & & & & & 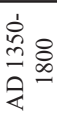 & \\
\hline $\begin{array}{l}\text { 言 } \\
\text { 言 } \\
\text { 言 }\end{array}$ & $\begin{array}{l}\stackrel{\overrightarrow{\vec{H}}}{\overrightarrow{!}} \\
\dot{G}\end{array}$ & $\overrightarrow{\vec{H}}$ & $\overleftrightarrow{\leftrightarrows}$ & 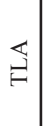 & $\overrightarrow{\vec{H}}$ & $\overrightarrow{\vec{H}}$ & $\overleftrightarrow{\sharp}$ & $\overrightarrow{\vec{H}}$ & $\overrightarrow{\vec{H}}$ & $\overrightarrow{\vec{H}}$ & $\overleftrightarrow{\sharp}$ & $\vec{\xi}$ & 当 & $\overrightarrow{\vec{H}}$ & 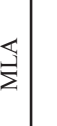 & 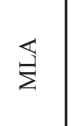 & 宵 & 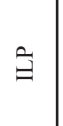 & 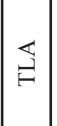 & 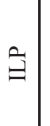 & $\overrightarrow{\vec{H}}$ & 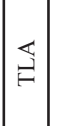 & $\overrightarrow{\vec{H}}$ & $\mid \overrightarrow{\vec{H}}$ \\
\hline 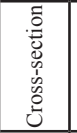 & $\begin{array}{l}\text { 点 } \\
\text { 出 }\end{array}$ & & 槖 & & & 离 & 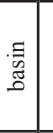 & & 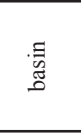 & 壱 & 黑 & 离 & 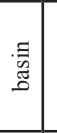 & & & & 亲 & 壱 & 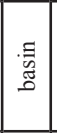 & & $\begin{array}{l}\text {. } \\
\text { 荡 }\end{array}$ & & 毒 & \\
\hline 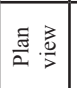 & $\begin{array}{l}\frac{0}{0} \\
\frac{0}{0}\end{array}$ & & 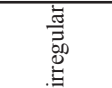 & 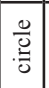 & $\begin{array}{l}\frac{0}{0} \\
: \frac{0}{0} \\
0\end{array}$ & & 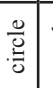 & 急 & 営 & 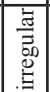 & 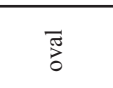 & $\begin{array}{l}\bar{g} \\
\bar{\partial}\end{array}$ & 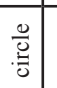 & & 粟 & & 氶 & $\begin{array}{l}\frac{0}{0} \\
\stackrel{0}{0} \\
\end{array}$ & 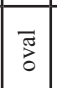 & & $\overline{\mathrm{g}}$ & 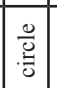 & $\frac{0}{\frac{0}{0}}$ & \\
\hline 兽 & 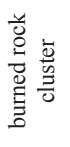 & 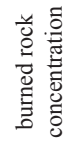 & 焉 & 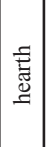 & $\frac{\frac{a}{0}}{\frac{\vec{v}}{\bar{g}}}$ & 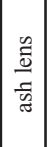 & 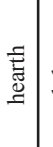 & 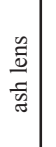 & 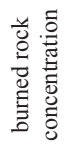 & 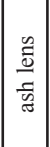 & 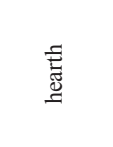 & 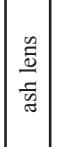 & 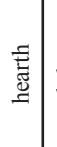 & 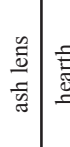 & E్ & 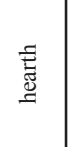 & 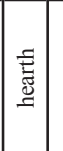 & 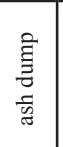 & 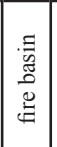 & $\begin{array}{l}\text { 志 } \\
\stackrel{\mathbb{E}}{=}\end{array}$ & 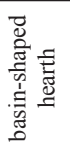 & 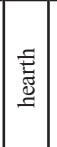 & 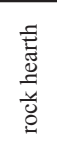 & 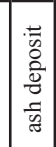 \\
\hline 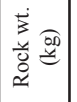 & & & & & & & & & & & & & & & & & 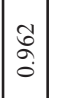 & & & & & & & \\
\hline \begin{tabular}{ll}
$\stackrel{0}{0}$ \\
$\approx$ \\
\hdashline
\end{tabular} & & $\vec{n}$ & $\stackrel{0}{\circ}$ & & & & & & & & $\stackrel{i}{i}$ & & & & & & $\alpha$ & & & & & & & \\
\hline 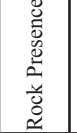 & $\begin{array}{l}\text { 蒿 } \\
\text { 苟 }\end{array}$ & 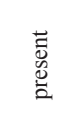 & 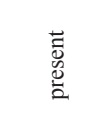 & 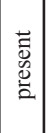 & 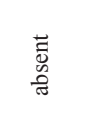 & 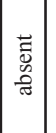 & 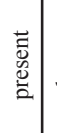 & 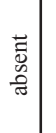 & 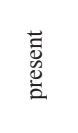 & 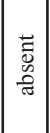 & 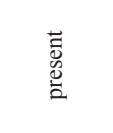 & 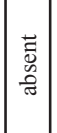 & 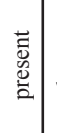 & 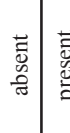 & 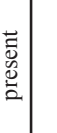 & 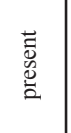 & 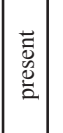 & 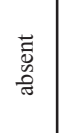 & 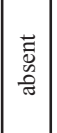 & 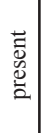 & 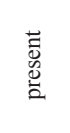 & 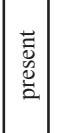 & 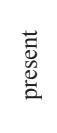 & 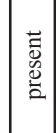 \\
\hline 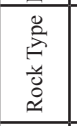 & 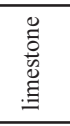 & 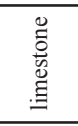 & 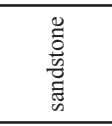 & & & & & & 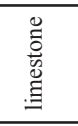 & & 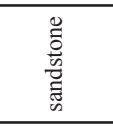 & & & & 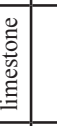 & & & & & 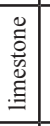 & & & 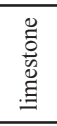 & \\
\hline 厗色 & $\stackrel{n}{0}$ & $\stackrel{n}{0}$ & $\stackrel{n}{0}$ & $\stackrel{2}{\circ}$ & $\stackrel{n}{0}$ & $\stackrel{2}{0}$ & $\stackrel{2}{0}$ & $\stackrel{\infty}{\circ}$ & $\overline{\vec{\sigma}}$ & 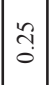 & तે & Oे & $\because$ & $\because$ & $\stackrel{7}{\circ}$ & $\stackrel{ \pm}{\circ}$ & $\frac{n}{0}$ & $\stackrel{n}{0}$ & ס & ป̊. & $\stackrel{m}{0}$ & $\stackrel{\infty}{\stackrel{0}{0}}$ & $\stackrel{\infty}{\circ}$ & $\overrightarrow{\widehat{c}}$ \\
\hline 苞焉 & ָัతి & ণัণ & ঙ্ণি & ঙ̣̊ & ঙั: & ¿̊. & : & $\stackrel{t}{\stackrel{\Delta}{0}}$ & $\tilde{a}$ & 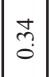 & के & $\because$ & $\begin{array}{l}0 \\
\circ \\
0\end{array}$ & $\stackrel{\circ}{\circ}$ & $\stackrel{0}{\circ}$ & $\stackrel{\circ}{0}$ & 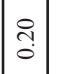 & ఫิ & 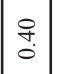 & $\tilde{3}$ & $\stackrel{5}{0}$ & 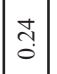 & $\stackrel{\text { đ̃ }}{0}$ & $\begin{array}{l}\infty \\
\stackrel{1}{0} \\
\stackrel{0}{0}\end{array}$ \\
\hline 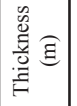 & & & $=$ & & & $\stackrel{\rho}{0}$ & & $\stackrel{\overbrace{}}{\circ}$ & & $\mid \begin{array}{l}0 \\
0 \\
0 \\
0\end{array}$ & $\overrightarrow{0}$ & $\mid \begin{array}{c}\tilde{O} \\
\stackrel{0}{0}\end{array}$ & $\begin{array}{l}\text { ta } \\
0 \\
0\end{array}$ & & & $\stackrel{\infty}{0}$ & & $\stackrel{\infty}{\stackrel{0}{0}}$ & $\mid \begin{array}{c}0 \\
0 \\
0\end{array}$ & & & & & $\begin{array}{l}0 \\
\text { oे } \\
0\end{array}$ \\
\hline 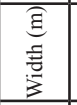 & 3 & 3 & $n$ & $\begin{array}{l}n \\
0\end{array}$ & 3 & \begin{tabular}{|l|}
$n$ \\
0
\end{tabular} & 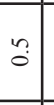 & $\stackrel{0}{\circ}$ & $\hat{o}$ & \begin{tabular}{|c|c}
0 \\
$\infty$ \\
0
\end{tabular} & - & $\vec{m}$ & $\dot{0}$ & \begin{tabular}{l|l}
$\vec{f}$ \\
$\dot{0}$
\end{tabular} & 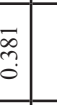 & fof & f & $\stackrel{\infty}{\stackrel{\infty}{0}}$ & 台 & 尺̂. & $\stackrel{0}{0}$ & $\mid \begin{array}{l}n \\
n \\
o \\
0\end{array}$ & in & 苨 \\
\hline 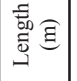 & $n$ & 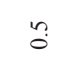 & $n$ & $\mid \begin{array}{l}n \\
0\end{array}$ & $n$ & $n$ & $\begin{array}{ll}n \\
\vdots\end{array}$ & $n$ & ? & $\begin{array}{l}n \\
0\end{array}$ & $?$ & $\vec{n}$ & $\vec{n}$ & $\bar{n}: \bar{n}$ & ? & n̂? & $\hat{n}$ & 萑 & 苟 & $\begin{array}{l}\text { fै } \\
\text { wे }\end{array}$ & n. & : & in & in \\
\hline 总总 & N & $\sim$ & 4 & $\sim \mid$ & - & -1 & $\sim$ & - & $m$ & -1 & m & - & $\curvearrowright$ & $-\tau$ & $\sim$ & N & N & - & - & m & 4 & $m$ & $m$ & $m$ \\
\hline 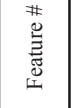 & - & $\sigma$ & $\infty$ & $\infty$ & q & in & in & $\therefore$ & - & $\exists$ & 0 & q & 8 & \begin{tabular}{l|l} 
& +
\end{tabular} & † & $\stackrel{\infty}{-}$ & $\infty$ & 8 & 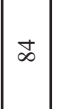 & $\stackrel{m}{2}$ & i & $a$ & 产 & $\mathcal{N}$ \\
\hline$\stackrel{\frac{g}{\hbar}}{2}$ & \begin{tabular}{l}
$\infty$ \\
3 \\
\multirow{\sigma}{*}{}
\end{tabular} & 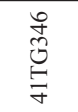 & $\frac{⿱ 丷}{\Rightarrow}$ & $\sum_{\bar{\gamma}}^{\grave{a}}$ & $\begin{array}{l}\vec{n} \\
\overrightarrow{0} \\
\vec{\sigma}\end{array}$ & 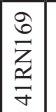 & 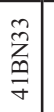 & $\begin{array}{l}\overrightarrow{\vec{n}} \\
\vec{u} \\
\vec{\sigma}\end{array}$ & $\begin{array}{l}\overrightarrow{\hat{O}} \\
\vec{F}\end{array}$ & $\mid \begin{array}{l}0 \\
z \\
z \\
z \\
F\end{array}$ & $\frac{8}{\Rightarrow}$ & \begin{tabular}{|l|}
$\vec{b}$ \\
$\frac{z}{z}$ \\
$\frac{\sigma}{\gamma}$
\end{tabular} & 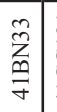 & 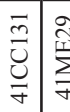 & 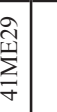 & $\begin{array}{l}\overrightarrow{\hat{O}} \\
\vec{y}\end{array}$ & 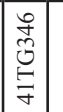 & 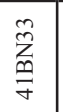 & \begin{tabular}{|l|}
$\tilde{z}$ \\
$\stackrel{m}{\sigma}$ \\
\end{tabular} & $\begin{array}{l} \\
0 \\
3 \\
7\end{array}$ & \begin{tabular}{l}
\multirow{2}{n}{} \\
$\bar{z}$ \\
$z$
\end{tabular} & 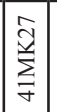 & $\begin{array}{l}\overrightarrow{\bar{n}} \\
\vec{U} \\
\vec{\sigma}\end{array}$ & $\begin{array}{l}\tilde{z} \\
\underline{m} \\
\bar{z}\end{array}$ \\
\hline
\end{tabular}




\begin{tabular}{|c|c|c|c|c|c|c|c|c|c|c|c|c|c|c|c|c|c|c|c|c|c|c|c|c|c|c|}
\hline 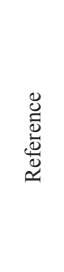 & 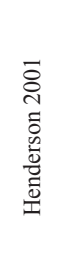 & 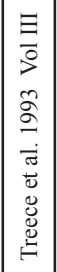 & 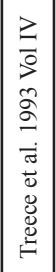 & 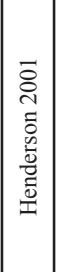 & 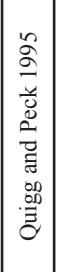 & 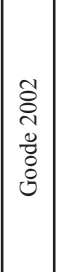 & 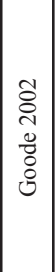 & 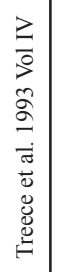 & 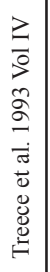 & 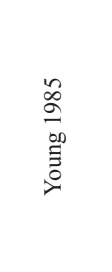 & 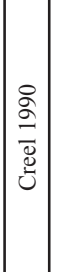 & 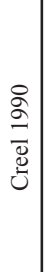 & 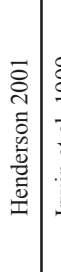 & 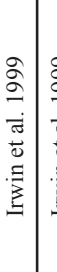 & 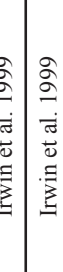 & 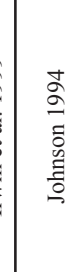 & 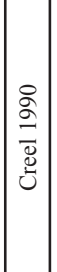 & 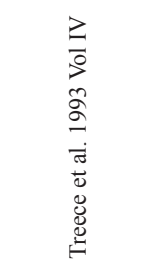 & 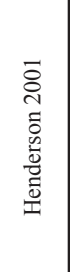 & 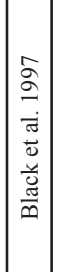 & 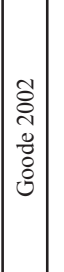 & 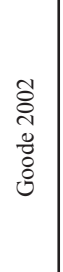 & 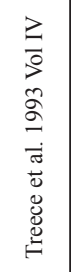 & 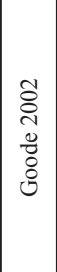 & 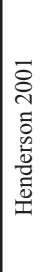 & 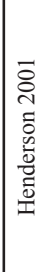 \\
\hline$\frac{\mathscr{y}}{\tilde{J}}$ & 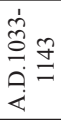 & & & & & & & & & 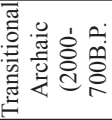 & & & & & & & & 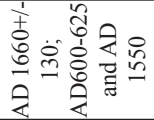 & & \begin{tabular}{|l|} 
\\
0 \\
1 \\
0 \\
0 \\
0 \\
\end{tabular} & & & $\begin{array}{l}\dot{1} \\
\infty \\
\infty \\
\gtrless^{\circ}\end{array}$ & & & \\
\hline $\begin{array}{l}\text { 志 } \\
\text { 言 } \\
\text { 言 } \\
\text { o }\end{array}$ & 㝠 & $\overleftrightarrow{\Sigma}$ & $\overrightarrow{\vec{F}}$ & $\vec{H}$ & $\overrightarrow{\vec{H}}$ & 当 & 当 & $\overrightarrow{\vec{F}}$ & $\overrightarrow{\mid \vec{F}}$ & 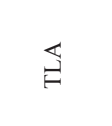 & $\vec{\exists}$ & $\vec{\exists}$ & $\overrightarrow{\vec{H}}$ & $\overleftrightarrow{\xi}$ & 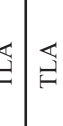 & $\overrightarrow{\vec{F}}$ & 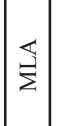 & $\overrightarrow{\vec{F}}$ & 当 & $\vec{\exists}$ & $\stackrel{a}{\exists}$ & $\overleftrightarrow{\xi}$ & $\overrightarrow{\vec{H}}$ & 肖 & $\stackrel{\rho}{\Leftrightarrow}$ & $\vec{\exists}$ \\
\hline 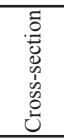 & & 离 & 売 & 离 & 离 & 离 & 忢 & $\underset{\mathbb{\sigma}}{\mathbb{\Xi}}$ & 胥 & 㧜 & & & & 丞 & & $\begin{array}{l}\text { 䔍 } \\
\text { 告 }\end{array}$ & & 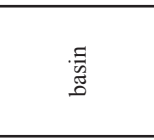 & 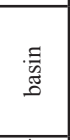 & & 氶 & $\begin{array}{l}\text { 点 } \\
\text { 超 }\end{array}$ & & 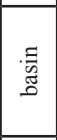 & & 壱 \\
\hline 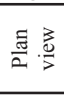 & 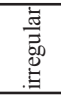 & 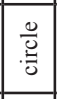 & & 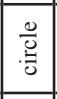 & 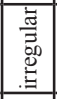 & 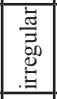 & \begin{tabular}{|l|} 
\\
\\
\end{tabular} & 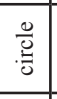 & $\overline{\mathrm{g}}$ & 曾 & 要 & $\overline{\mathrm{g}}$ & & . & \begin{tabular}{l|l} 
\\
\end{tabular} & $\frac{0}{\frac{\pi}{0}}$ & \begin{tabular}{|c|} 
\\
\\
$\overline{0}$ \\
\end{tabular} & $\frac{0}{0}$ & 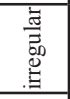 & \begin{tabular}{|l|}
$\bar{\Xi}$ \\
$\mathrm{z}$
\end{tabular} & 氶 & $\begin{array}{l}\frac{0}{0} \\
\frac{0}{0}\end{array}$ & $\begin{array}{l}\frac{0}{0} \\
: 0\end{array}$ & 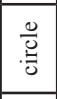 & 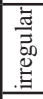 & 竘 \\
\hline 总 & 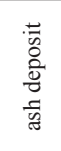 & 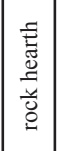 & 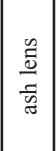 & 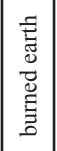 & 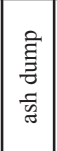 & 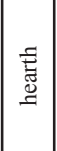 & 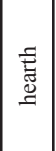 & 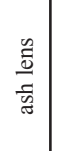 & $\frac{\frac{n}{0}}{\frac{\overrightarrow{0}}{\bar{v}}}$ & 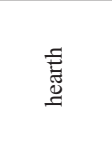 & 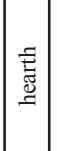 & 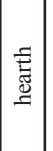 & 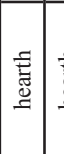 & 䔍 & 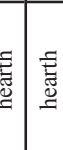 & 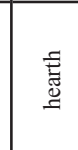 & 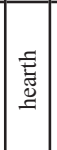 & 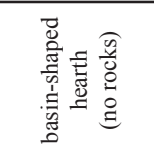 & 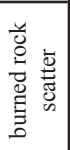 & $=$ & \begin{tabular}{|l} 
\\
志 \\
吾
\end{tabular} & $\begin{array}{l}\text { 志 } \\
\text { 䔍 }\end{array}$ & $\frac{\frac{n}{\overline{0}}}{\frac{\vec{v}}{\bar{v}}}$ & 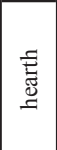 & 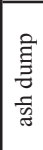 & 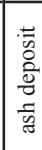 \\
\hline 章 & & $\stackrel{+}{\dot{m}}$ & & & & & & & & & & & & & & & & & & & & & & & & \\
\hline 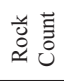 & & $\infty$ & & in & 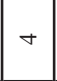 & & & & & $\vec{N}$ & & & & & & & & & & & & & & & & \\
\hline 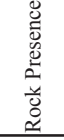 & $\begin{array}{l}\text { 节 } \\
\text { 商 }\end{array}$ & 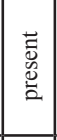 & 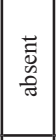 & 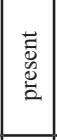 & 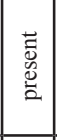 & 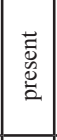 & 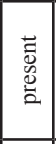 & 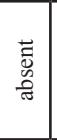 & $\begin{array}{l}\overrightarrow{\tilde{J}_{0}} \\
\text { 岕 }\end{array}$ & 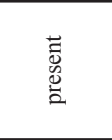 & 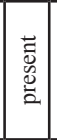 & 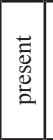 & 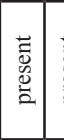 & 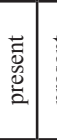 & 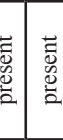 & 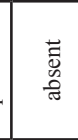 & 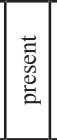 & $\begin{array}{l}\text { 蒿 } \\
\text { 崖 }\end{array}$ & 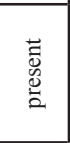 & 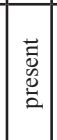 & 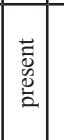 & 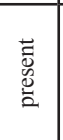 & 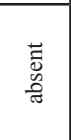 & 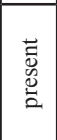 & 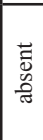 & \begin{tabular}{|l}
$\mid \overrightarrow{\tilde{J}}$ \\
ते \\
ते
\end{tabular} \\
\hline 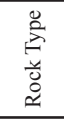 & & & & & & 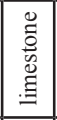 & 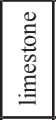 & & & 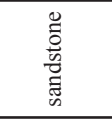 & 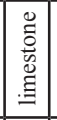 & 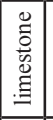 & & & & & 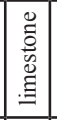 & 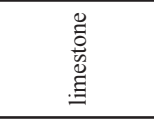 & & 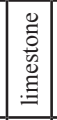 & 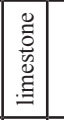 & 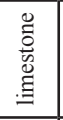 & & 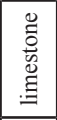 & & \\
\hline 兽㐿 & $\stackrel{\text { ֻे }}{\text { ஸे }}$ & $\frac{\infty}{0}$ & $\frac{\infty}{0}$ & $\stackrel{2}{0}$ & $\overrightarrow{\tilde{O}}$ & $\stackrel{0}{\circ}$ & ণֶ̃ & $\stackrel{m}{0}$ & $\stackrel{\infty}{\stackrel{ }{0}}$ & $\stackrel{ \pm}{0}$ & 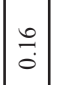 & $\frac{\infty}{0}$ & $\stackrel{0}{2}$ & 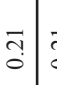 & \begin{tabular}{c|c}
$\overrightarrow{0}$ \\
\end{tabular} & $\overline{\grave{o}}$ & $\overrightarrow{\tilde{S}}$ & $\overline{\check{c}}$ & $\vec{\jmath}$ & $\mid \begin{array}{c}m \\
0 \\
0\end{array}$ & $\stackrel{0}{0}$ & $\stackrel{\infty}{0}$ & $\stackrel{\infty}{0}$ & 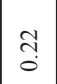 & $\stackrel{9}{0}$ & $\stackrel{n}{0}$ \\
\hline 苞可 & $\hat{n}$ & 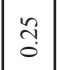 & 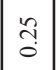 & \begin{tabular}{l}
0 \\
\multirow{2}{0}{} \\
0
\end{tabular} & ते & $\overrightarrow{\tilde{y}}$ & $\overrightarrow{\tilde{s}}$ & $\stackrel{7}{0}$ & $\hat{n}$ & $\stackrel{े}{0}$ & $\overline{\hat{y}}$ & İ & 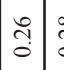 & 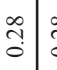 & 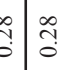 & 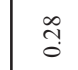 & 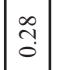 & $\stackrel{\infty}{\sim}$ & $\stackrel{\infty}{\dddot{1}}$ & $\begin{array}{l}f \\
\dot{f} \\
0\end{array}$ & శี & กุ & İ & خे & $\frac{\infty}{0}$ & तิ \\
\hline 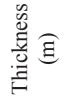 & $=$ & $\begin{array}{l} \pm \\
0 \\
0\end{array}$ & $\begin{array}{l}\tilde{O} \\
\dot{0}\end{array}$ & & $\mid \begin{array}{l}0 \\
0 \\
0\end{array}$ & & & $\stackrel{\overbrace{}}{\circ}$ & $\begin{array}{l}0 \\
\\
\end{array}$ & $\overrightarrow{0}$ & $\stackrel{\leftrightarrow}{\circ}$ & & $\stackrel{7}{0}$ & & & & & $\frac{a}{0}$ & $\frac{\text { qo }}{0}$ & $\stackrel{n}{0}$ & & & 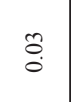 & & & $\begin{array}{l}\stackrel{n}{0} \\
0 \\
0\end{array}$ \\
\hline $\begin{array}{l}\text { 镸 } \\
\text { 吾 } \\
\end{array}$ & 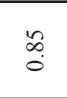 & $\mid \begin{array}{l}0 \\
\vdots \\
0\end{array}$ & $\begin{array}{l}0 \\
: \\
0 \\
0\end{array}$ & $\begin{array}{l}n \\
\hat{n}\end{array}$ & $\begin{array}{l}0 \\
0 \\
0\end{array}$ & 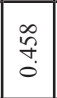 & $\mid \begin{array}{l}\overrightarrow{5} \\
0 \\
0\end{array}$ & $\hat{\tilde{o}}$ & $\begin{array}{c}\vec{\infty} \\
\stackrel{\infty}{0}\end{array}$ & t. & 告 & $\because$ & {$\left[\begin{array}{ll}n \\
n \\
0\end{array}\right.$} & $\stackrel{\circ}{\circ}$ & $\begin{array}{c}0 \\
\end{array}$ & $\stackrel{\circ}{\circ}$ & $\stackrel{\circ}{\circ}$ & $\stackrel{\circ}{\circ}$ & $\stackrel{0}{\circ}$ & - & 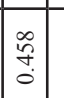 & 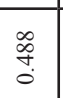 & $\because$ & 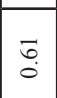 & 角 & के \\
\hline 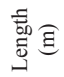 & $\hat{n}$ & $\mid \begin{array}{l}0 \\
: \\
0\end{array}$ & $\begin{array}{l}0 \\
: \\
0 \\
0\end{array}$ & $\begin{array}{l}n \\
0 \\
0\end{array}$ & $\begin{array}{l}n \\
\tilde{o}\end{array}$ & $\mid \begin{array}{c}0 \\
0 \\
0 \\
0\end{array}$ & $\mid \begin{array}{l}0 \\
0 \\
0 \\
0\end{array}$ & $\begin{array}{l}\infty \\
n \\
0 \\
0\end{array}$ & $\begin{array}{l}\infty \\
\vdots \\
0 \\
0\end{array}$ & $\stackrel{\circ}{\circ}$ & $\stackrel{0}{\circ}$ & $\stackrel{\circ}{\circ}$ & 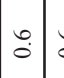 & $\stackrel{\circ}{\circ}$ & $\stackrel{\circ}{\circ}: \stackrel{\circ}{\circ}$ & $\stackrel{\circ}{\circ}$ & $\stackrel{\circ}{\circ}$ & $\stackrel{\circ}{\circ}$ & : & $\mid \begin{array}{l}0 \\
0\end{array}$ & 茴 & $\stackrel{\vec{b}}{\circ}$ & $\overrightarrow{0}$ & $\begin{array}{l}\overrightarrow{0} \\
0\end{array}$ & : & : \\
\hline 올 & - & $n$ & - & $m$ & $m$ & 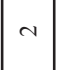 & n & - & -1 & 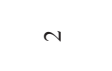 & $\sim$ & $m$ & $m$ & $m$. & $m m$ & - & m & $m$ & $m$ & $\nabla$ & $\sim$ & $m$ & - & $n$ & - & - \\
\hline 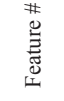 & t & $r$ & $\stackrel{0}{n}$ & $\stackrel{i}{\sim}$ & $=$ & $\approx$ & $\begin{array}{l}4 \\
\text { J }\end{array}$ & $\approx$ & $\vec{m}$ & $\stackrel{\circ}{\circ}$ & $\infty$ & 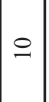 & 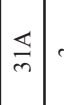 & $m$ & $+r$ & $=$ & 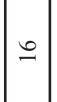 & $\stackrel{\infty}{\sim}$ & $m$ & $\circ$ & $\stackrel{\infty}{\sim}$ & 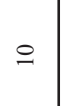 & li & $=$ & in & $\underset{\Xi}{\Xi}$ \\
\hline$\stackrel{\mathscr{D}}{\tilde{w}}$ & $\sum_{\tilde{m}}^{m}$ & 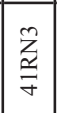 & \begin{tabular}{|l|} 
o \\
$z$ \\
$\frac{a}{y}$ \\
\end{tabular} & \begin{tabular}{|l|}
$\stackrel{m}{z}$ \\
$\stackrel{m}{\sigma}$ \\
\end{tabular} & 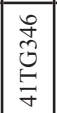 & \begin{tabular}{|l|}
8 \\
\\
\\
7
\end{tabular} & \begin{tabular}{|l|}
0 \\
3 \\
\end{tabular} & \begin{tabular}{|l|}
$\stackrel{g}{o}$ \\
$\vec{z}$ \\
$\frac{a}{\gamma}$
\end{tabular} & 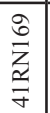 & $\begin{array}{l}\frac{8}{b} \\
\frac{\partial}{7}\end{array}$ & $\mid$\begin{tabular}{|l}
$\overrightarrow{0}$ \\
$\vec{\sigma}$ \\
$\vec{\gamma}$
\end{tabular} & \begin{tabular}{|l}
$\overrightarrow{\hat{O}}$ \\
$\overrightarrow{\mathrm{y}}$
\end{tabular} & 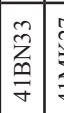 & $\sum_{\bar{y}}^{\bar{y}}$ & $\vec{y}$ & 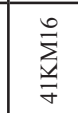 & \begin{tabular}{|l|}
$\vec{O}$ \\
$\stackrel{\theta}{F}$ \\
\end{tabular} & $\begin{array}{l}\overrightarrow{\vec{m}} \\
\vec{U} \\
\vec{\sigma}\end{array}$ & $\begin{array}{c}\tilde{\hat{z}} \\
\bar{z}\end{array}$ & \begin{tabular}{|l|} 
\\
$\infty$ \\
3 \\
\\
7
\end{tabular} & $\begin{array}{l}0 \\
0 \\
3 \\
7\end{array}$ & $\stackrel{8}{7}^{8}$ & 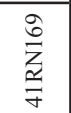 & \begin{tabular}{|l|}
8 \\
\\
\\
7 \\
\end{tabular} & $\begin{array}{l}m \\
m_{m} \\
\xi\end{array}$ & $\tilde{n}_{\tilde{m}}$ \\
\hline
\end{tabular}




\begin{tabular}{|c|c|c|c|c|c|c|c|c|c|c|c|c|c|c|c|c|c|c|c|c|c|c|c|c|c|c|c|}
\hline 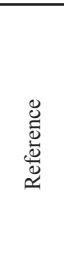 & 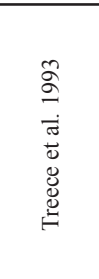 & 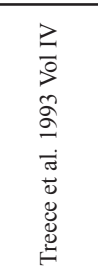 & 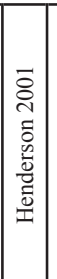 & 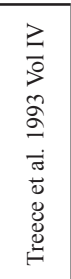 & 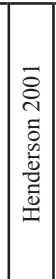 & 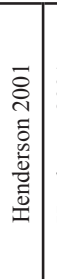 & 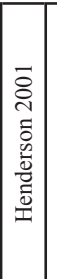 & 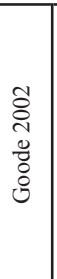 & 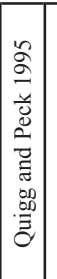 & 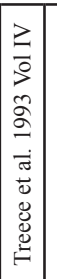 & 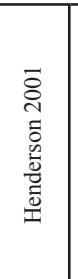 & 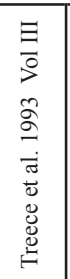 & 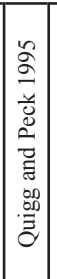 & 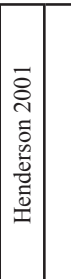 & 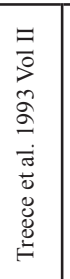 & 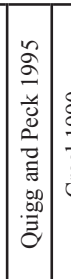 & 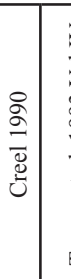 & 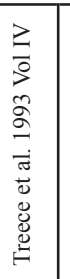 & 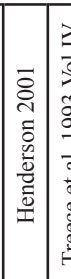 & 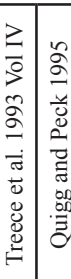 & 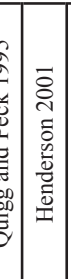 & 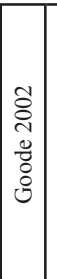 & 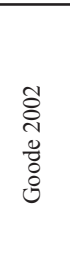 & 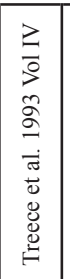 & 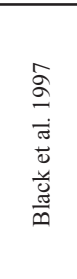 & 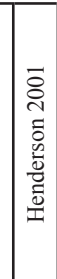 & 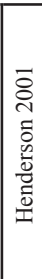 \\
\hline 迆 & $\begin{array}{l}30 \\
8 \\
0\end{array}$ & 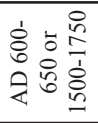 & & & & & & & & & & 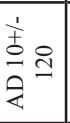 & & & & & & 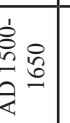 & & & & & & & 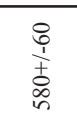 & & \\
\hline $\begin{array}{l}\text { 言 } \\
\text { 言 } \\
\text { 言 } \\
\text { ठ }\end{array}$ & $\overrightarrow{\vec{F}}$ & $\overrightarrow{\vec{\xi}}$ & $\stackrel{\leftrightarrow}{\theta}$ & 岂 & $\hat{\exists}$ & $\overrightarrow{\vec{\xi}}$ & $\vec{\exists}$ & $\overleftrightarrow{\Sigma}$ & $\overrightarrow{\vec{\xi}}$ & $\overrightarrow{\vec{\theta}}$ & 荨 & $\overleftrightarrow{\Sigma}$ & $\mid \vec{\exists}$ & $\hat{\vec{H}}$ & $\overrightarrow{\vec{\xi}}$ & $\vec{\exists}$ & $\overrightarrow{\vec{H}}$ & $\overrightarrow{\vec{H}}$ & $\hat{\vec{\theta}} \mid \hat{\bar{\theta}}$ & 䒠 & $\vec{\theta}$ & $\overleftrightarrow{\exists}$ & $\overleftrightarrow{\rightleftarrows}$ & $\overrightarrow{\vec{F}}$ & $\overrightarrow{\vec{H}}$ & $\stackrel{a}{\exists}$ & $\overrightarrow{\vec{F}}$ \\
\hline 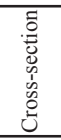 & 言 & & 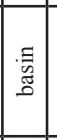 & $\begin{array}{l}\text { 毒 } \\
\text { 焉 }\end{array}$ & $\stackrel{\mathbb{\Xi}}{\sharp}$ & 离 & 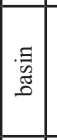 & & 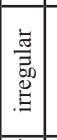 & 氶 & & 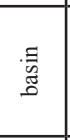 & ङ & 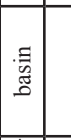 & & 离 & 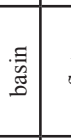 & $\underset{\mathbb{E}}{\mathbb{E}}$ & 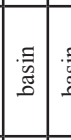 & 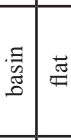 & 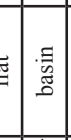 & & & $\underset{\mathbb{\sharp}}{\mathbb{t}}$ & & $\begin{array}{l}\text { 雲 } \\
\end{array}$ & 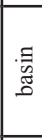 \\
\hline 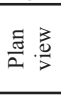 & 㗁 & 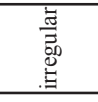 & 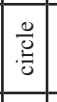 & $\begin{array}{l}\frac{0}{0} \\
\stackrel{0}{0} \\
\end{array}$ & $\overrightarrow{|c|}$ & & 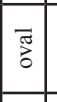 & & 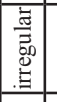 & \begin{tabular}{|l|l|} 
嵒 \\
\end{tabular} & & $\begin{array}{l}\frac{0}{\bar{U}} \\
\frac{\bar{y}}{0}\end{array}$ & $\begin{array}{l}\mathrm{J} \\
\end{array}$ & 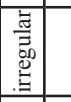 & & \begin{tabular}{|l|} 
\\
\\
$\frac{\pi}{2}$ \\
\end{tabular} & & $\begin{array}{l}\frac{0}{0} \\
\\
\\
\end{array}$ & \begin{tabular}{|c|c}
0 \\
$\frac{\pi}{0}$ \\
$\frac{3}{0}$
\end{tabular} & 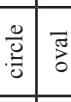 & 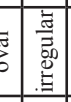 & & 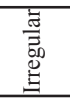 & \begin{tabular}{|l|} 
\\
\\
\\
\end{tabular} & 递 & $\begin{array}{l}5 \\
\end{array}$ & $\mid \frac{0}{0}$ \\
\hline 总 & 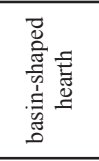 & 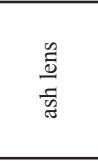 & 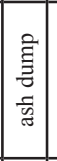 & 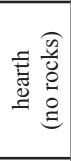 & 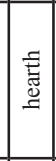 & & 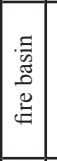 & 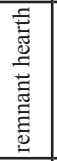 & 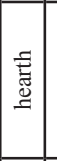 & 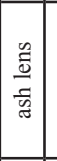 & 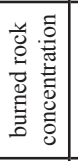 & 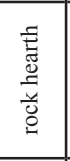 & 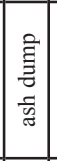 & 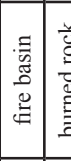 & 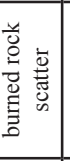 & 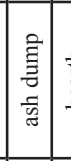 & 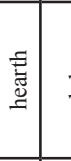 & $\frac{\tilde{a}}{\frac{\tilde{\Xi}}{\tilde{J}}}$ & 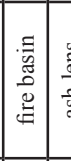 & 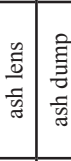 & 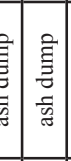 & 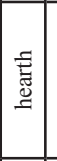 & 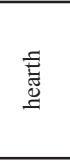 & 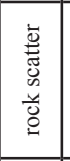 & 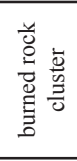 & $\begin{array}{l}\text { 褰 } \\
\text { 章 }\end{array}$ & 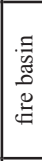 \\
\hline 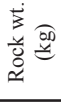 & & & & & & & & & & & & $\stackrel{n}{ \pm}$ & & & & & & & & & & & & & & & \\
\hline 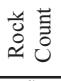 & & 0 & & & & & & & \% & & & & & in & $\underline{\square}$ & & & & & & & & & & & & \\
\hline 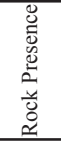 & $\begin{array}{l}\text { 䓂 } \\
\text { 㟧 }\end{array}$ & $\begin{array}{l}\text { 䓂 } \\
\text { 总. }\end{array}$ & 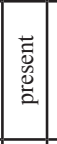 & 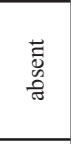 & 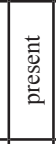 & 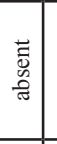 & 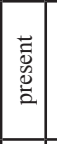 & 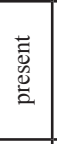 & 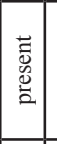 & 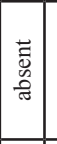 & 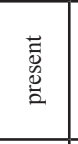 & 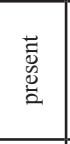 & 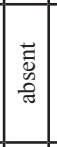 & 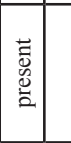 & 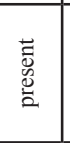 & \begin{tabular}{l|l}
$\overrightarrow{\mathrm{v}}$ & \\
$\mathrm{v}$ \\
$\mathrm{v}$ \\
$\mathrm{v}$
\end{tabular} & 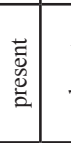 & $\begin{array}{l}\text { 节 } \\
\text { 迥 }\end{array}$ & 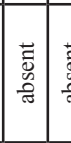 & 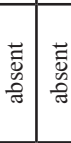 & 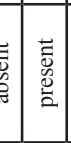 & 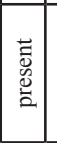 & 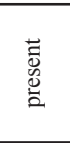 & 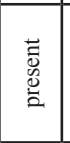 & 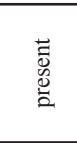 & 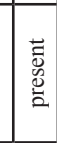 & 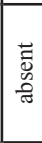 \\
\hline 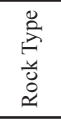 & & & & & & & & 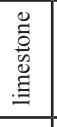 & & & & & & & 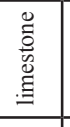 & & 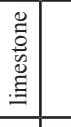 & & & & & 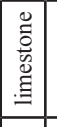 & 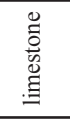 & & 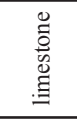 & & \\
\hline 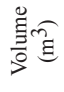 & $\stackrel{े}{0}$ & $\overrightarrow{0}$ & $\mid$\begin{tabular}{l}
\multirow{2}{*}{} \\
\hdashline \\
0
\end{tabular} & đa & $\hat{m}$ & $\stackrel{\circ}{\circ}$ & $\begin{array}{l}0 \\
0\end{array}$ & वे & â & $\begin{array}{l}0 \\
q \\
0\end{array}$ & స్రి & $\frac{7}{0}$ & $\overrightarrow{\widehat{S}}$ & 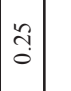 & 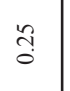 & సે & के. & ત્રે & $\begin{array}{l}f \\
0\end{array}$ & 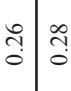 & 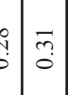 & $\stackrel{\infty}{\circ}$ & ָับ & ڤై & ત્રે & $\begin{array}{c}0 \\
\vdots \\
0 \\
0\end{array}$ & 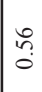 \\
\hline 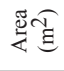 & ర్తి & ֻั & $\hat{\overbrace{}}$ & 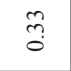 & 㠻 & $\stackrel{m}{\circ}$ & ภึ & d. & 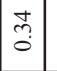 & 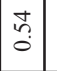 & $\stackrel{n}{0}$ & $\stackrel{0}{0}$ & ָ̃ & ల్రి & $\stackrel{\overbrace{}}{0}$ & \begin{tabular}{|c|c} 
& $\infty$ \\
\hdashline & 5 \\
0 & 5
\end{tabular} & $\tilde{3}$ & ț. & 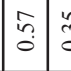 & 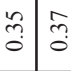 & 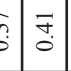 & 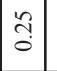 & $\stackrel{n}{0}$ & 导 & ले & 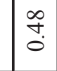 & $\stackrel{2}{\stackrel{2}{o}}$ \\
\hline 噌 & : & $\stackrel{5}{0}$ & 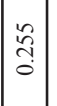 & 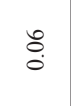 & $\begin{array}{c}7 \\
0 \\
0\end{array}$ & & $\begin{array}{l}7 \\
0\end{array}$ & & 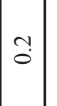 & 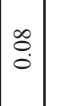 & $\stackrel{\infty}{0}$ & ก̃ & $\overrightarrow{0}$ & {$\left[\begin{array}{l}2 \\
0 \\
0\end{array}\right.$} & $\overrightarrow{0}$ & & & $\stackrel{8}{\circ}$ & $\begin{array}{lll}2 & 2 \\
0 & 2\end{array}$ & $\stackrel{7}{0}$ & $\begin{array}{l}0 \\
0 \\
0\end{array}$ & & & & & ্ֻণ & $\stackrel{8}{\circ}$ \\
\hline 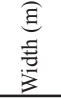 & $\stackrel{n}{o}$ & $n$ & $\mid \begin{array}{l}: \\
0 \\
0\end{array}$ & $\begin{array}{l}n \\
0 \\
0\end{array}$ & 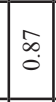 & $\mid$\begin{tabular}{l}
$n$ \\
\multirow{2}{*}{} \\
0 \\
0
\end{tabular} & $\begin{array}{l}7 \\
0 \\
0\end{array}$ & $\begin{array}{l}\vec{f} \\
\stackrel{0}{0}\end{array}$ & \begin{tabular}{|l|}
0 \\
0 \\
0
\end{tabular} & $\vec{\sigma}$ & t: & 3 & 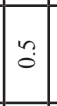 & $\stackrel{\circ}{\circ}$ & $\stackrel{\circ}{\circ}$ & $\hat{\circ}$ & $\stackrel{n}{o}$ & $\vec{\circ}$ & $\stackrel{\delta}{-}$ & 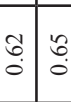 & $\begin{array}{l}6 \\
\dot{0}\end{array}$ & $\mid \begin{array}{l}\overrightarrow{7} \\
\text { वे }\end{array}$ & $\vec{\Xi}$ & $\stackrel{n}{n}$ & : & $\stackrel{\infty}{\infty}$ & $\stackrel{\text { ๙n }}{\rightarrow}$ \\
\hline 孠 & $\stackrel{n}{0}$ & 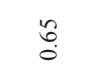 & $\mid \begin{array}{l}0 \\
\stackrel{0}{0}\end{array}$ & $\begin{array}{l}n \\
0 \\
0\end{array}$ & $\begin{array}{l}0 \\
0 \\
0\end{array}$ & $\begin{array}{l}\tilde{0} \\
\stackrel{\circ}{\circ}\end{array}$ & $\mid \begin{array}{l}0 \\
\stackrel{0}{0}\end{array}$ & $\begin{array}{l}\overrightarrow{6} \\
0 \\
0\end{array}$ & \begin{tabular}{|l|} 
\\
$\stackrel{\infty}{\circ}$ \\
$\stackrel{0}{0}$
\end{tabular} & : & oे & $\hat{o}$ & $\hat{0}$ & $\ddot{o}$ & 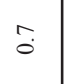 & $\ddot{\circ}$ & $\hat{\circ}$ & ㄹ. & $\vec{r}$ & \begin{tabular}{l|l}
$\stackrel{N}{0}$ & \multirow{0}{0}{} \\
\end{tabular} & $\begin{array}{l}c \\
\vdots \\
\vdots\end{array}$ & $\mid \begin{array}{c}\tilde{ల} \\
\stackrel{0}{0}\end{array}$ & $\stackrel{\tilde{c}}{\stackrel{0}{0}}$ & $\stackrel{n}{\stackrel{2}{0}}$ & $\stackrel{0}{\stackrel{0}{0}}$ & $\begin{array}{l}\stackrel{0}{0} \\
:\end{array}$ & $\stackrel{0}{\circ}$ \\
\hline 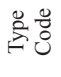 & - & N & m & - & + & - & $n$ & $m$ & $m$ & - & $m$ & $\sim$ & - & $m$ & m & - & + & - & - & -- & $-A$ & $m$ & $m$ & t & m & $\sim$ & - \\
\hline 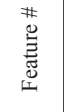 & $\simeq$ & $\bar{F}$ & $m$ & 苚 & 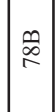 & $\stackrel{\infty}{\sim}$ & A & $\infty$ & \pm & 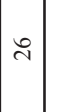 & $\stackrel{\infty}{+}$ & $a$ & $\infty$ & $\therefore$ & $\varangle$ & a & $a$ & d & \pm & $\stackrel{\infty}{\infty}=0$ & $=\infty$ & $a$ & 0 & 氐 & in & 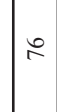 & $\cong$ \\
\hline$\stackrel{g}{\tilde{n}}$ & $\overbrace{\tilde{\sigma}}^{\stackrel{n}{z}}$ & $\begin{array}{l}\vec{n} \\
\vec{U} \\
\vec{\sigma}\end{array}$ & 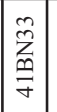 & $\begin{array}{l}\vec{m} \\
\vec{U} \\
\vec{f}\end{array}$ & 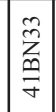 & 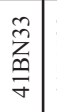 & 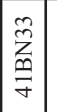 & 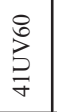 & 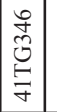 & 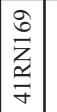 & $\underset{\tilde{z}}{\tilde{\xi}}$ & $\begin{array}{l}\sum_{\dddot{z}} \\
\stackrel{z}{\sigma}\end{array}$ & \begin{tabular}{|l|}
0 \\
0 \\
0 \\
$G$ \\
$\sigma$ \\
\end{tabular} & \begin{tabular}{|l|l|}
$\tilde{z}$ & \\
$\ddot{q}$ & \\
$\tilde{\sigma}$ &
\end{tabular} & $\begin{array}{l}\stackrel{a}{o} \\
z \\
g \\
\sigma\end{array}$ & 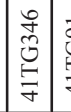 & \begin{tabular}{l|l}
$\overrightarrow{\mathrm{g}}$ & \\
$\overrightarrow{\mathrm{\sigma}}$ &
\end{tabular} & 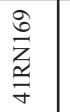 & 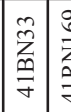 & 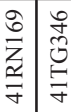 & 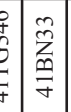 & \begin{tabular}{|l|}
8 \\
0 \\
3 \\
7 \\
\end{tabular} & $\begin{array}{l}8 \\
3 \\
7 \\
7\end{array}$ & \begin{tabular}{|l|}
$\vec{m}$ \\
$\vec{U}$ \\
$\vec{\sigma}$
\end{tabular} & $\begin{array}{l}\infty \\
j_{F}^{\infty} \\
\exists\end{array}$ & $\begin{array}{l}\stackrel{m}{Z} \\
\ddot{z}\end{array}$ & $\stackrel{\tilde{z}}{\tilde{m}}$ \\
\hline
\end{tabular}




\begin{tabular}{|c|c|c|c|c|c|c|c|c|c|c|c|c|c|c|c|c|c|c|c|c|c|c|c|c|}
\hline 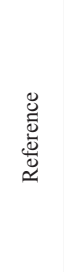 & 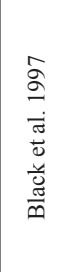 & 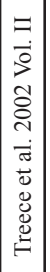 & 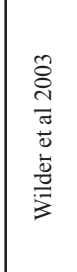 & 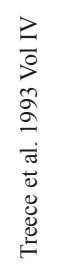 & 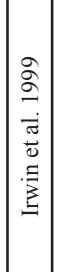 & 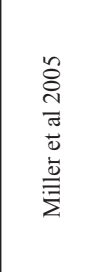 & 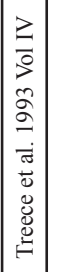 & 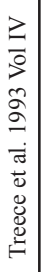 & 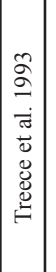 & 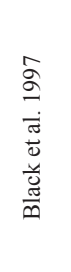 & 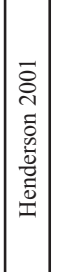 & 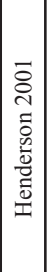 & 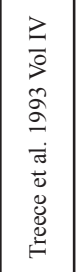 & 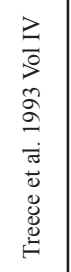 & 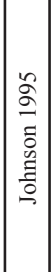 & 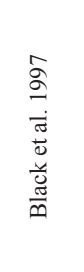 & 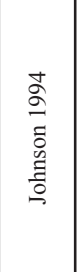 & 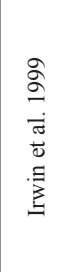 & 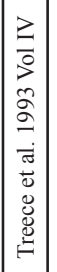 & 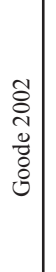 & 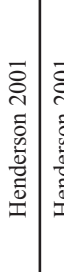 & 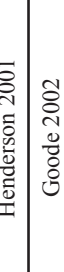 & 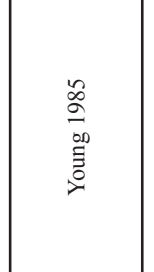 & 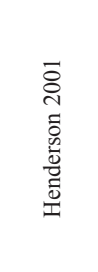 \\
\hline$\stackrel{\circ}{\tilde{\Xi}}$ & & & 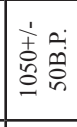 & & & 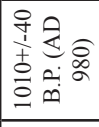 & & & & $\begin{array}{l}8 \\
1 \\
1 \\
\vdots \\
0 \\
\\
\end{array}$ & & & 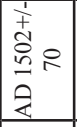 & & & & & 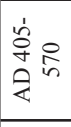 & & & & & 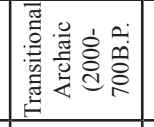 & \\
\hline 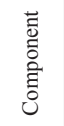 & 当 & $\overrightarrow{\vec{\exists}}$ & 岁 & $\overrightarrow{\vec{\theta}}$ & $\overleftrightarrow{\sharp}$ & 肖 & $\overrightarrow{\vec{\theta}}$ & 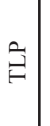 & $\overrightarrow{\vec{G}}$ & 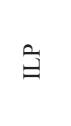 & 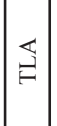 & $\stackrel{\stackrel{G}{\exists}}{ }$ & $\hat{\vec{\xi}}$ & $\hat{\vec{\exists}}$ & $\overleftrightarrow{\Sigma}$ & $\hat{\exists}$ & 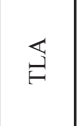 & 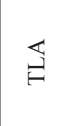 & $\overrightarrow{\breve{F}}$ & 当 & $\stackrel{\vec{\exists}}{=}$ & 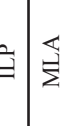 & $\overleftrightarrow{\Xi}$ & $\overrightarrow{\vec{H}}$ \\
\hline 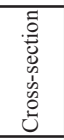 & & & & $\begin{array}{l}\text { 袁 } \\
\text { 哥 }\end{array}$ & & $\underset{\mathbb{F}}{\mathbb{t}}$ & $\mid \frac{\vec{\varpi}}{\varpi}$ & 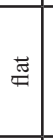 & & 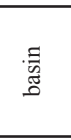 & 壱 & 离 & 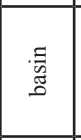 & $\underset{\mathbb{G}}{\mathbb{E}}$ & & 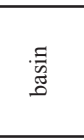 & & & $\stackrel{\Xi}{\varpi}$ & 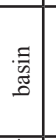 & 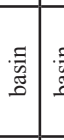 & 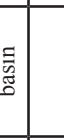 & 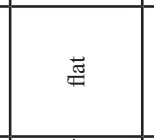 & \\
\hline 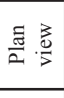 & $\overline{\mathrm{g}}$ & & 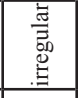 & $\begin{array}{l} \\
\\
\end{array}$ & \begin{tabular}{|l|}
$\frac{0}{0}$ \\
$\frac{0}{0}$ \\
\end{tabular} & 氶 & & $\overline{\mathrm{J}}$ & 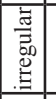 & $\begin{array}{l}\frac{0}{0} \\
\frac{0}{0}\end{array}$ & 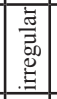 & 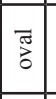 & 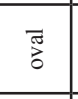 & 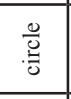 & & 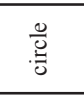 & & & 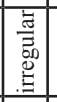 & 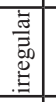 & $\frac{0}{0}$ & हु & 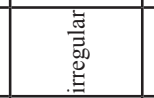 & \\
\hline 总 & 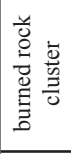 & 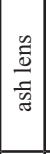 & 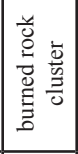 & 存 & 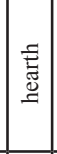 & 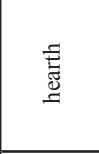 & 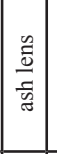 & 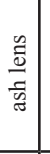 & 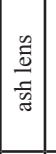 & 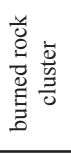 & 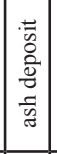 & 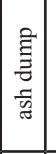 & 志 & 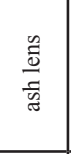 & 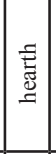 & 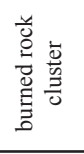 & 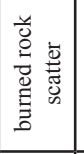 & 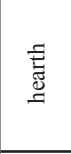 & 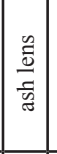 & 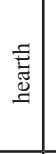 & 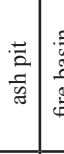 & 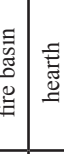 & 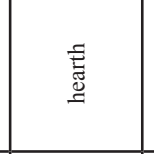 & 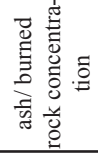 \\
\hline 岁 & & & $I$ & & & & & & & & & & & & & & & & & & & & & \\
\hline 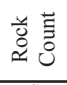 & & & ה & & & $\bar{\infty}$ & & & & m & & & in & & & in & & & & & & & & \\
\hline 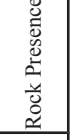 & 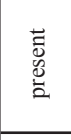 & 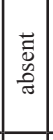 & 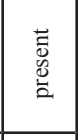 & $\begin{array}{l}\overrightarrow{\tilde{D}^{\circ}} \\
\text { 总 }\end{array}$ & 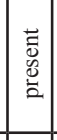 & $\begin{array}{l}\text { 䓌 } \\
\text { 总. }\end{array}$ & 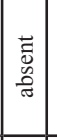 & 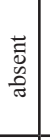 & 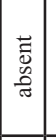 & 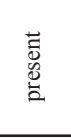 & 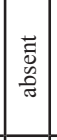 & 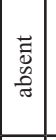 & 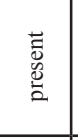 & 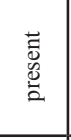 & 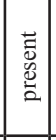 & 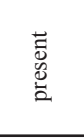 & 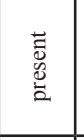 & 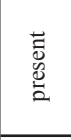 & 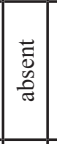 & 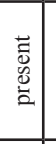 & 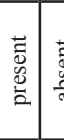 & 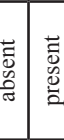 & 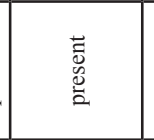 & 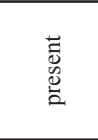 \\
\hline 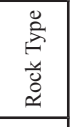 & 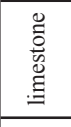 & & & & & & & & & & & & 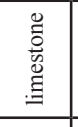 & 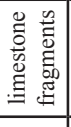 & & 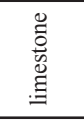 & 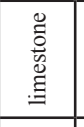 & & & 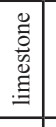 & & 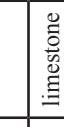 & 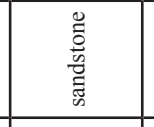 & \\
\hline 产色 & సે & $\stackrel{9}{0}$ & సี & $\hat{3}$ & $\mid \begin{array}{c}\infty \\
0 \\
0\end{array}$ & fี & & 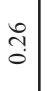 & $\begin{array}{c}m \\
0 \\
0\end{array}$ & ח̂n. & $\stackrel{\tilde{m}}{0}$ & \begin{tabular}{|l|}
0 \\
0 \\
0
\end{tabular} & $\vec{n}$ & $\begin{array}{l}0 \\
0 \\
0\end{array}$ & 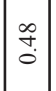 & 赵 & $\stackrel{\infty}{\substack{0 \\
0}}$ & $\begin{array}{l}\infty \\
: \\
0\end{array}$ & $\mid \begin{array}{c}\infty \\
0 \\
0 \\
0\end{array}$ & $\stackrel{m}{0}$ & $\begin{array}{lll} \\
0\end{array}$ & $\begin{array}{c}0 \\
0 \\
0\end{array}$ & $\stackrel{7}{0}$ & ma \\
\hline 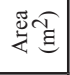 & fै & 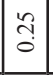 & లై & $\stackrel{7}{\circ}$ & $\mid \begin{array}{c}0 \\
\vdots \\
0 \\
\end{array}$ & in & & 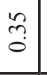 & \begin{tabular}{l}
$f$ \\
\multirow{0}{*}{} \\
\end{tabular} & $\stackrel{f}{\circ}$ & 守 & $\begin{array}{l}\infty \\
\stackrel{\infty}{0} \\
\stackrel{0}{*}\end{array}$ & $\stackrel{\infty}{0}$ & $\vec{b}$ & $\begin{array}{l}0 \\
0 \\
0\end{array}$ & t. & t. & $\stackrel{\infty}{\stackrel{0}{0}}$ & \begin{tabular}{l}
$\infty$ \\
$\stackrel{0}{\circ}$ \\
\hdashline
\end{tabular} & $\begin{array}{l}7 \\
0\end{array}$ & bे & $\begin{array}{lll}\infty \\
0\end{array}$ & $\stackrel{0}{\circ}$ & fo \\
\hline 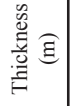 & & $\mid \begin{array}{l}0 \\
0 \\
0\end{array}$ & $\stackrel{7}{\circ}$ & $\frac{7}{0}$ & & m. & $\mid \begin{array}{l}0 \\
0 \\
0\end{array}$ & $\stackrel{\tilde{O}}{\circ}$ & & & $\mid \begin{array}{l}\mid \\
\stackrel{0}{0} \\
\stackrel{0}{|c|}\end{array}$ & $\stackrel{\circ}{\circ}$ & $\stackrel{\overrightarrow{0}}{0}$ & $\stackrel{\text { ô }}{0}$ & & & & & $\mid \begin{array}{l}n \\
0 \\
0 \\
0\end{array}$ & & \begin{tabular}{l|l}
$\because$ & 0 \\
0 &
\end{tabular} & 5 & $\overrightarrow{0}$ & \\
\hline \begin{tabular}{|l|} 
吾 \\
吾 \\
3 \\
\end{tabular} & : & $\stackrel{\square}{0}$ & f. & ó & $\mid \begin{array}{l}\infty \\
0 \\
0\end{array}$ & oे & & $\begin{array}{l}\tilde{n} \\
\tilde{o}\end{array}$ & $\hat{0}$ & $\hat{\circ}$ & $\begin{array}{l}\tilde{n} \\
0\end{array}$ & 弪 & - & $\begin{array}{l}\infty \\
\infty \\
0\end{array}$ & $\dot{0}$ & $\dot{o}$ & $\dot{\partial}$ & $\exists$ & $\exists$ & $\overrightarrow{0}$ & 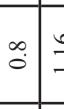 & 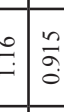 & ฮี & $\stackrel{\circ}{\circ}$ \\
\hline 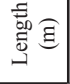 & $\stackrel{\infty}{\stackrel{\infty}{0}}$ & $\mid \begin{array}{l}\infty \\
0 \\
0\end{array}$ & $\stackrel{\infty}{0}$ & $\stackrel{\infty}{\circ}$ & $\stackrel{\infty}{\circ}$ & $\stackrel{\infty}{0}$ & $\mid$\begin{tabular}{c}
0 \\
0 \\
0 \\
\hdashline
\end{tabular} & $\begin{array}{l}\mid \begin{array}{l}+ \\
0 \\
0 \\
0\end{array} \\
\end{array}$ & $\left|\begin{array}{l}0 \\
0 \\
0 \\
0\end{array}\right|$ & $\begin{array}{l}\infty \\
\infty \\
\infty \\
\infty\end{array}$ & $\mid$\begin{tabular}{l|}
$\infty$ \\
$\infty$ \\
0 \\
0
\end{tabular} & $\left|\begin{array}{l}0 \\
0 \\
0 \\
0\end{array}\right|$ & $\begin{array}{l}\stackrel{0}{\infty} \\
\stackrel{0}{0}\end{array}$ & $\dot{o}$ & $\dot{o}$ & ò & $\dot{\circ}$ & ò & $\stackrel{\partial}{0}$ & $\begin{array}{l}\frac{n}{a} \\
\vdots \\
0\end{array}$ & 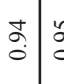 & \begin{tabular}{lll}
0 \\
\hdashline \\
$\vdots$
\end{tabular} & - & - \\
\hline 总总 & + & -1 & m & - & + & ナ & -1 & -1 & - & + & - & -1 & t & $\sim$ & $\odot$ & $\sigma$ & t & $\nabla$ & - & + & † & -1 & $\sim$ & + \\
\hline 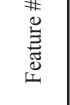 & $\sim$ & -1 & - & लि & in & - & in & $\approx$ & $\vec{m}$ & 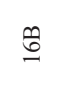 & $\tilde{n}$ & in & $\lesssim$ & $\approx$ & in & 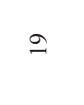 & ส & 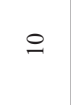 & 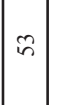 & in & in : & $\hat{i})$ & m & $\infty$ \\
\hline 总 & $\sum_{\substack{\infty \\
\vdots}}^{\infty}$ & $\mid \begin{array}{l}\tilde{z} \\
\tilde{Z} \\
\frac{Z}{\gamma}\end{array}$ & 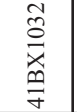 & $\begin{array}{l}\bar{m} \\
\bar{U} \\
\vec{\sigma}\end{array}$ & 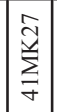 & $\begin{array}{l}\infty \\
\vdots \\
\vdots \\
\vdots\end{array}$ & 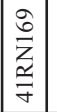 & 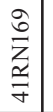 & 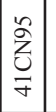 & $\sum_{F}^{\infty}$ & 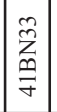 & 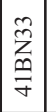 & $\begin{array}{l}\vec{n} \\
\vec{U} \\
\vec{F}\end{array}$ & 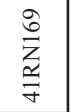 & 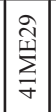 & $\sum_{\xi}^{N}$ & $\begin{array}{l}0 \\
\stackrel{2}{7} \\
\underline{z}\end{array}$ & $\sum_{\exists}^{\bar{y}}$ & \begin{tabular}{|l|} 
\\
$z$ \\
$z$ \\
$\frac{z}{\sigma}$
\end{tabular} & \begin{tabular}{l|} 
\\
8 \\
$\vdots$ \\
$\ddots$ \\
\end{tabular} & 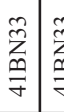 & 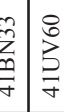 & $\begin{array}{l}\text { D̊ } \\
\stackrel{7}{7}\end{array}$ & $\stackrel{\tilde{z}}{\ddot{\theta}}$ \\
\hline
\end{tabular}




\begin{tabular}{|c|c|c|c|c|c|c|c|c|c|c|c|c|c|c|c|c|c|c|c|c|c|c|c|}
\hline 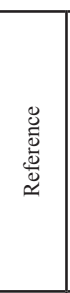 & 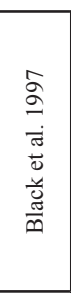 & 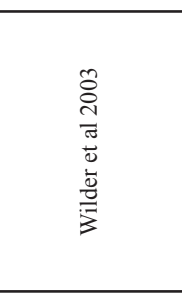 & 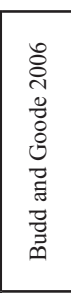 & 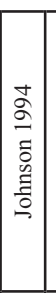 & 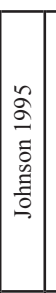 & 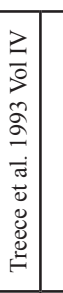 & 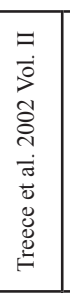 & 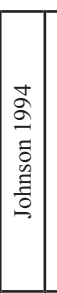 & 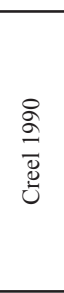 & 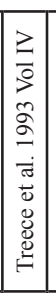 & 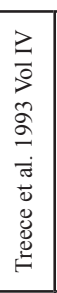 & 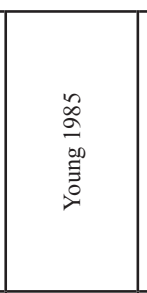 & 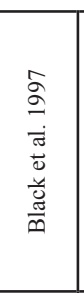 & 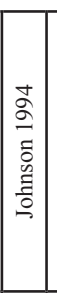 & 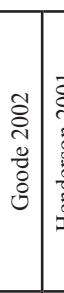 & 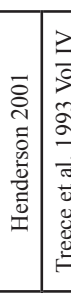 & 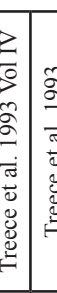 & 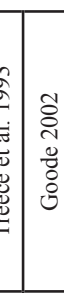 & 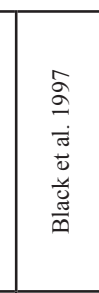 & 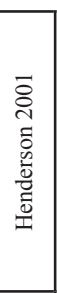 & 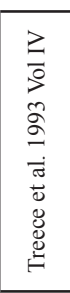 & 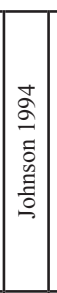 & 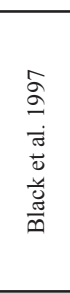 \\
\hline 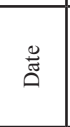 & & 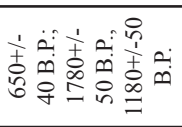 & 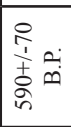 & & & & 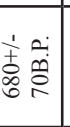 & & & & & 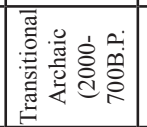 & 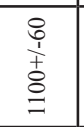 & & & & & & 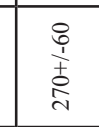 & & & & \\
\hline 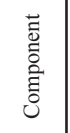 & $\overrightarrow{\vec{H}}$ & 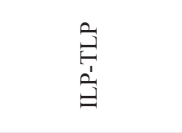 & $\overrightarrow{\vec{H}}$ & $\overrightarrow{\vec{\theta}}$ & $\overleftrightarrow{\Sigma}$ & 宵 & $\overrightarrow{\vec{F}}$ & $\overrightarrow{\vec{\theta}}$ & $\overrightarrow{\vec{\xi}}$ & $\overrightarrow{\vec{F}}$ & $\overrightarrow{\vec{\beta}}$ & 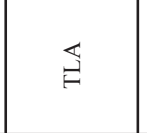 & $\hat{\exists}$ & $\overrightarrow{\vec{\xi}}$ & $\stackrel{\Xi}{\Xi}$ & 岁㿠 & $\bar{\xi} \mid \hat{F}$ & $\vec{y}$ & $\overrightarrow{\vec{F}}$ & $\overrightarrow{\vec{F}}$ & 㞩 & $\mid \vec{\exists}$ & 当 \\
\hline 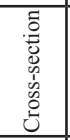 & 艼 & 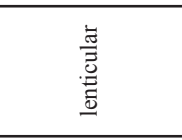 & & 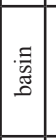 & 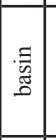 & 壱 & & 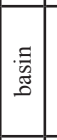 & 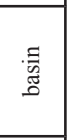 & & 导 & $\begin{array}{l}\text { 量 } \\
\text { 足 }\end{array}$ & 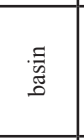 & & 売 & & 菏 & 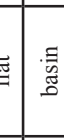 & 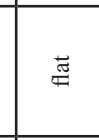 & 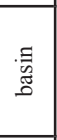 & 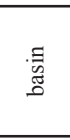 & 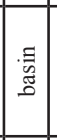 & 志 \\
\hline$\frac{\vec{z}}{a} \cdot \frac{z}{\frac{z}{z}}$ & 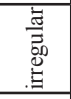 & $\begin{array}{l}0 \\
\\
\\
\\
\end{array}$ & $\begin{array}{l}\frac{0}{0} \\
\\
\end{array}$ & \begin{tabular}{|l|l|}
$\frac{0}{2}$ \\
$\frac{0}{0}$ \\
\end{tabular} & & 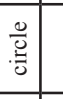 & & \begin{tabular}{|l|l|}
$\frac{0}{2}$ \\
$\frac{0}{0}$ \\
\end{tabular} & . & 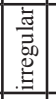 & 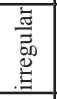 & 品 & $\frac{0}{0}$ & & 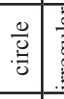 & 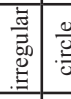 & 资 & 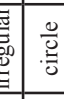 & $\overline{\mathrm{g}}$ & $\overline{\mathrm{J}}$ & $\overline{\mathrm{J}}$ & 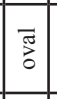 & $\begin{array}{l}\frac{0}{0} \\
\stackrel{0}{0}\end{array}$ \\
\hline 总 & 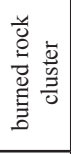 & 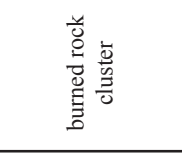 & 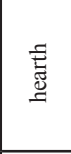 & 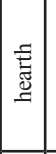 & 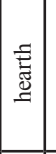 & 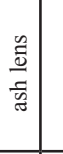 & 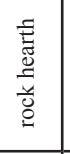 & \begin{tabular}{|l|} 
\\
\\
焉 \\
\end{tabular} & 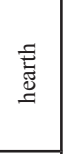 & 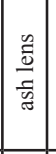 & 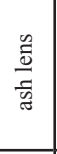 & 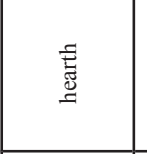 & 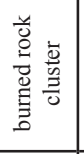 & 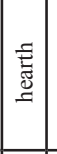 & 氠 & 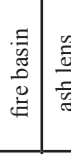 & $\begin{array}{l}\frac{n}{0} \\
\frac{0}{5} \\
\frac{5}{5} \\
\end{array}$ & \begin{tabular}{c|c} 
: \\
:
\end{tabular} & 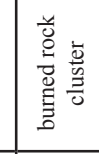 & $\begin{array}{l}\frac{\overrightarrow{2}}{\mathrm{a}} \\
\frac{\vec{v}}{\bar{v}}\end{array}$ & 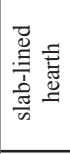 & 胥 & 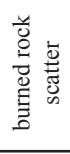 \\
\hline 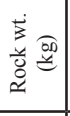 & & ले & & & & & $\approx$ & & & & & & & & & & & & & & in & & \\
\hline 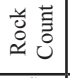 & $\infty$ & in & & & & & $\approx$ & & & & & & $\stackrel{\beth}{\beth}$ & & & & & & 8 & & & & \\
\hline 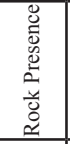 & 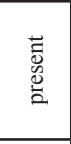 & $\begin{array}{l}\text { 节 } \\
\text { 递 }\end{array}$ & 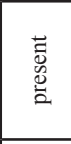 & 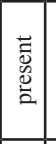 & 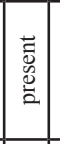 & 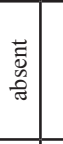 & 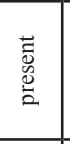 & 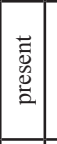 & 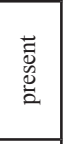 & 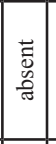 & $\begin{array}{l}\vec{z} \\
\text { 离 } \\
\text { d. }\end{array}$ & 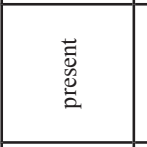 & 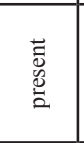 & 莺 & 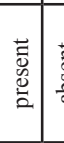 & 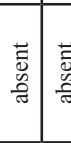 & 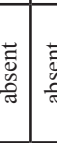 & 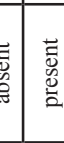 & $\begin{array}{l}\text { 志 } \\
\text { 总 }\end{array}$ & $\begin{array}{l}\overrightarrow{\tilde{J}_{0}} \\
\text { ond }\end{array}$ & $\begin{array}{l}\text { 节 } \\
\text { 总. }\end{array}$ & 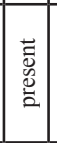 & 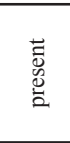 \\
\hline 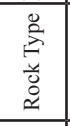 & 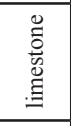 & & 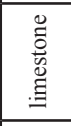 & & & & 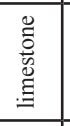 & 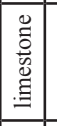 & 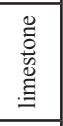 & & & 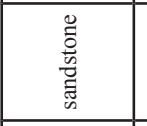 & & 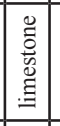 & 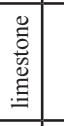 & & & 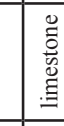 & 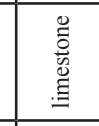 & & & 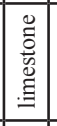 & 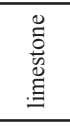 \\
\hline 厗扈 & f & $\begin{array}{l}n \\
: \\
0\end{array}$ & है & bे & ڤે & ñ. & $\stackrel{\infty}{\rightrightarrows}$ & \begin{tabular}{|l|}
$\overrightarrow{0}$ \\
$\dot{0}$
\end{tabular} & $\stackrel{\substack{\infty \\
\infty \\
0}}{0}$ & \begin{tabular}{l}
$\stackrel{0}{0}$ \\
$\vdots$ \\
\hdashline
\end{tabular} & \begin{tabular}{l}
$\stackrel{\infty}{0}$ \\
\hdashline
\end{tabular} & î & $\stackrel{\infty}{\circ}$ & $\stackrel{\bullet}{-}$ & 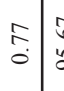 & 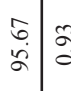 & $\stackrel{0}{0}$ & 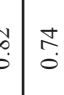 & $\overrightarrow{\underline{0}}$ & $\begin{array}{l} \pm \\
\stackrel{n}{0} \\
0\end{array}$ & 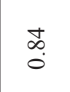 & oे & बे \\
\hline 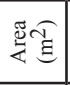 & $\begin{array}{l}\tilde{b} \\
0\end{array}$ & $\begin{array}{l}5 \\
0 \\
\end{array}$ & શે & $\begin{array}{l}\hat{\imath} \\
\stackrel{0}{0}\end{array}$ & \begin{tabular}{|l|}
$\hat{\imath}$ \\
$\stackrel{0}{0}$
\end{tabular} & ڤે & $\stackrel{n}{n}$ & \begin{tabular}{|l|} 
\\
$o$ \\
$o$ \\
$o$
\end{tabular} & $\exists$ & $\stackrel{\overrightarrow{0}}{-}$ & $\stackrel{8}{\circ}$ & $\begin{array}{l}t \\
\text { o. }\end{array}$ & $\stackrel{t}{\stackrel{t}{.}}$ & $\underset{+}{\stackrel{F}{-}}$ & 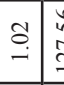 & 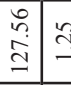 & $\stackrel{\overbrace{}}{\rightarrow}$ & $\begin{array}{ll}: \\
: & \stackrel{\infty}{\circ} \\
\end{array}$ & f. & $\begin{array}{l}\overrightarrow{1} \\
0 \\
\end{array}$ & $\stackrel{\overbrace{}}{ت}$ & 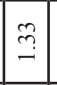 & $\stackrel{m}{\rightarrow}$ \\
\hline 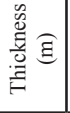 & & $\stackrel{7}{0}$ & กี & & & $\stackrel{\Omega}{\delta}$ & กั & & ชี & \begin{tabular}{|l|}
$\overrightarrow{0}$ \\
$\dot{0}$
\end{tabular} & $\stackrel{\widetilde{L}}{0}$ & $\overrightarrow{0}$ & & & & & 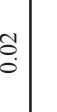 & & & $\bar{Z}$ & $\stackrel{\text { กิ }}{0}$ & & \\
\hline $\begin{array}{l}\text { ह } \\
\text { 咅 } \\
\dot{3} \\
\end{array}$ & $\stackrel{\infty}{0}$ & 然 & - & -1 & -1 & - & $\sim$ & $\exists$ & 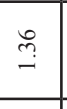 & $\stackrel{\sim}{=}$ & - & - & $\Xi$ & $\because$ & 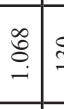 & 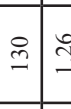 & đ: & $=\begin{array}{l}= \\
= \\
\vdots \\
0\end{array}$ & $\stackrel{t}{0}$ & $\hat{o}$ & $\exists$ & $\stackrel{?}{-}$ & $\stackrel{m}{?}$ \\
\hline 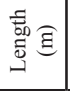 & - & - & - & -1 & -1 & - & - & $\exists$ & $\Xi$ & $\cong$ & $\stackrel{?}{ت}$ & $\stackrel{\Upsilon}{\Im}$ & $\stackrel{9}{\exists}$ & 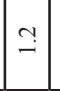 & $\stackrel{\mathbb{Z}}{-}$ & 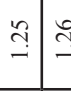 & đ̊ & 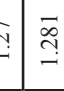 & $\stackrel{m}{=}$ & $\stackrel{?}{-}$ & $\stackrel{m}{-}$ & $\because$ & $\stackrel{m}{-}$ \\
\hline 总: : & t & t & $\nabla$ & $\nabla$ & $\nabla$ & - & $\nabla$ & + & ナ & -1 & - & t & $\sigma$ & $\nabla$ & + & -- & - & $-\sigma$ & 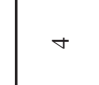 & - & $\nabla$ & $\nabla$ & $\nabla$ \\
\hline $\begin{array}{l}\text { \# } \\
\text { 总 } \\
\text { 总 } \\
\text { L }\end{array}$ & $\infty$ & $m$ & - & $\circ$ & 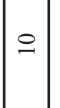 & $\vec{n}$ & $\sim$ & \pm & 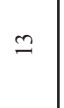 & in & $\widetilde{\sigma}$ & $\sim$ & 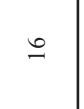 & $\sim$ & $+\mid \delta$ & तi & in $:$ & s. & in & $a$ & J & $m$ & $a$ \\
\hline 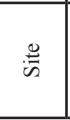 & $\sum_{\forall}^{N}$ & 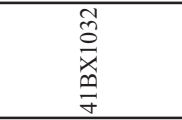 & 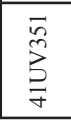 & 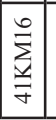 & 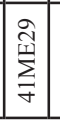 & $\begin{array}{l}o \\
z \\
z \\
z\end{array}$ & $\begin{array}{l}\text { त̃ } \\
\frac{0}{\gamma} \\
\end{array}$ & 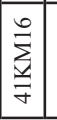 & $\begin{array}{l}\overrightarrow{\mathrm{O}} \\
\stackrel{F}{F}\end{array}$ & \begin{tabular}{|l}
$\vec{m}$ \\
$\vec{U}$ \\
$\vec{y}$ \\
\end{tabular} & 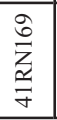 & 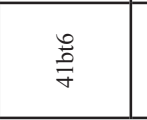 & $\sum_{\forall}^{\infty}$ & 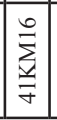 & 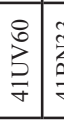 & 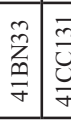 & 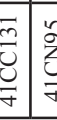 & \begin{tabular}{ll}
8 \\
\hdashline \\
\end{tabular} & 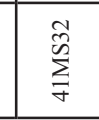 & $\underset{\tilde{z}}{\stackrel{m}{\sigma}}$ & $\begin{array}{l}\overrightarrow{\vec{n}} \\
\vec{u} \\
\vec{\sigma} \\
\vec{y}\end{array}$ & \begin{tabular}{|l|}
\multirow{2}{*}{} \\
$\stackrel{2}{7}$ \\
$\vdots$ \\
\end{tabular} & 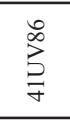 \\
\hline
\end{tabular}




\begin{tabular}{|c|c|c|c|c|c|c|c|c|c|c|c|c|c|c|c|c|c|c|c|c|c|c|c|c|}
\hline 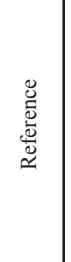 & 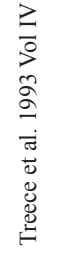 & 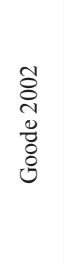 & 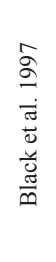 & 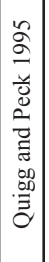 & 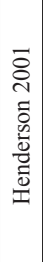 & 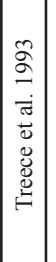 & 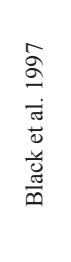 & 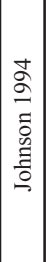 & 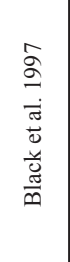 & 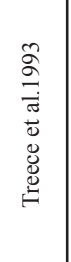 & 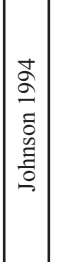 & 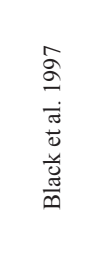 & 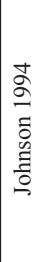 & 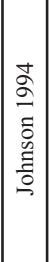 & 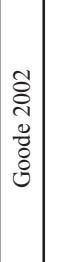 & 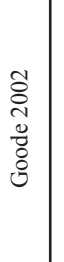 & 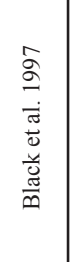 & 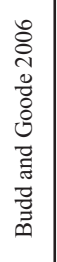 & 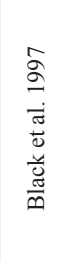 & 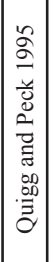 & 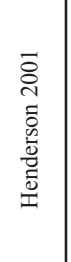 & $\begin{array}{l}\infty \\
\stackrel{\infty}{0} \\
\stackrel{0}{00} \\
\overline{0} \\
0\end{array}$ & 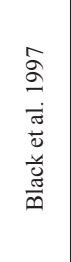 & 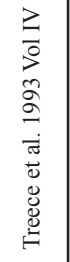 \\
\hline Ðّ & 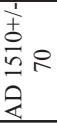 & & 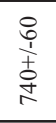 & & & & 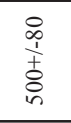 & & 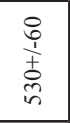 & 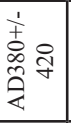 & & 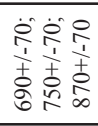 & & & & & 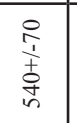 & & & & & 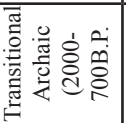 & 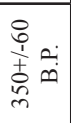 & \\
\hline 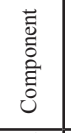 & $\overrightarrow{\vec{F}}$ & $\overleftrightarrow{\exists}$ & $\overrightarrow{\vec{H}}$ & $\overrightarrow{\vec{F}}$ & $\$$ & $\mid \overrightarrow{\vec{F}}$ & $\overrightarrow{\vec{H}}$ & $\mid \overrightarrow{\vec{H}}$ & $\overrightarrow{\vec{H}}$ & 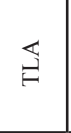 & $\mid \overrightarrow{\vec{H}}$ & $\overrightarrow{\vec{H}}$ & $\overrightarrow{\vec{\xi}}$ & $\overrightarrow{\vec{\theta}}$ & 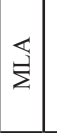 & 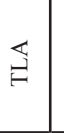 & $\overrightarrow{\vec{F}}$ & $\stackrel{\vec{g}}{ }$ & $\overrightarrow{\vec{F}}$ & $\mid \overrightarrow{\vec{H}}$ & $\overrightarrow{\mathrm{g}}$ & 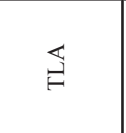 & $\overrightarrow{\vec{H}}$ & $\overrightarrow{\vec{H}}$ \\
\hline 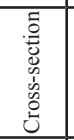 & $\begin{array}{l}\text { 点 } \\
\text { 品 }\end{array}$ & 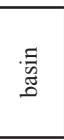 & 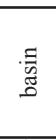 & & $\begin{array}{l}\text { 足 } \\
\text { 忽 }\end{array}$ & 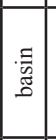 & 槖 & & 志 & $\underset{\varpi}{\tilde{\Psi}}$ & 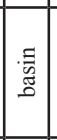 & 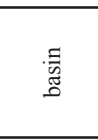 & 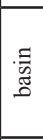 & & & 羔 & 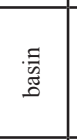 & & 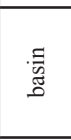 & & 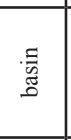 & $\stackrel{\vec{\Xi}}{\sharp}$ & 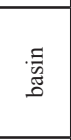 & 䔍 \\
\hline$\frac{g}{2} \cdot \frac{3}{2}$ & 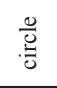 & $\overline{\mathrm{J}}$ & 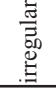 & 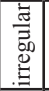 & 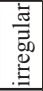 & \begin{tabular}{|l|}
$\mathrm{J}$ \\
\end{tabular} & 㱒 & & $\frac{0}{\frac{0}{0}}$ & 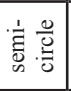 & 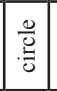 & & $\mid \frac{0}{0}$ & & $\begin{array}{l}\text { 苞 } \\
:\end{array}$ & & 舘 & 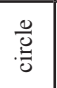 & 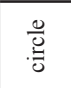 & 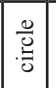 & & 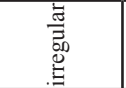 & $\overline{\mathrm{J}}$ & $\bar{~}$ \\
\hline 总 & 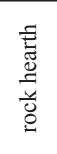 & $\begin{array}{l}\text { 焉 } \\
\underline{\underline{D}}\end{array}$ & 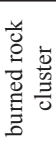 & 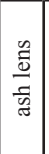 & $\begin{array}{l}\text { 志 } \\
\text { s. } \\
0 \\
0 \\
=\end{array}$ & 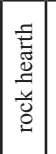 & 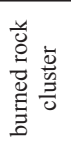 & 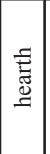 & 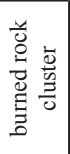 & 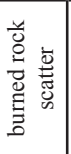 & 胥 & 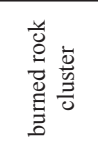 & 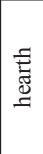 & 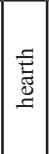 & 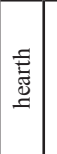 & 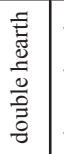 & 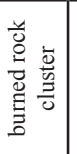 & $\begin{array}{l}\text { 志 } \\
\stackrel{\mathbb{E}}{\Phi}\end{array}$ & 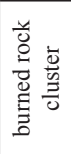 & 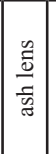 & 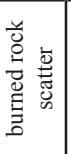 & 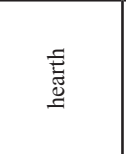 & 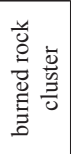 & 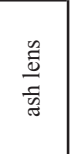 \\
\hline 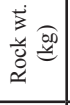 & $\frac{n}{\infty}$ & & & & & & & & & & & & & & & & & & & & & & & \\
\hline 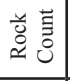 & & & in & & & & $\stackrel{n}{n}$ & & $\stackrel{8}{\circ}$ & & & & & & & & 孛 & & ণ্ণ & & & & 索 & \\
\hline 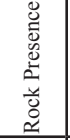 & $\begin{array}{l}\text { 言 } \\
\text { 产 }\end{array}$ & 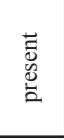 & 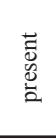 & 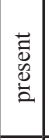 & $\begin{array}{l}\overrightarrow{\bar{v}} \\
\text { o. } \\
\vec{\sigma}\end{array}$ & 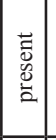 & 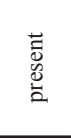 & 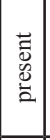 & 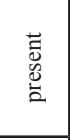 & 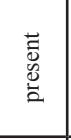 & 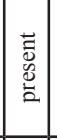 & 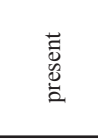 & 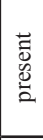 & 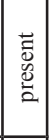 & 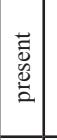 & 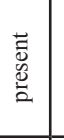 & 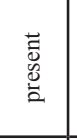 & $\begin{array}{l}\overrightarrow{\tilde{E}^{\circ}} \\
\stackrel{0}{2}\end{array}$ & 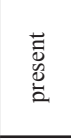 & 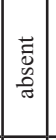 & 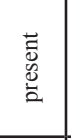 & $\begin{array}{l}\text { 蒿 } \\
\text { 总 }\end{array}$ & 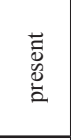 & 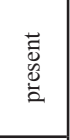 \\
\hline 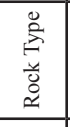 & & 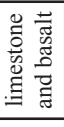 & & & & 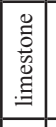 & 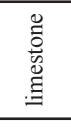 & 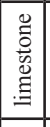 & 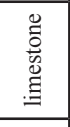 & & 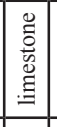 & 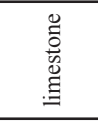 & & & 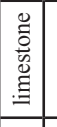 & 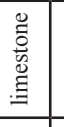 & 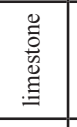 & 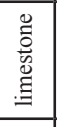 & & & & 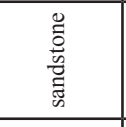 & & 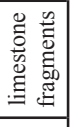 \\
\hline 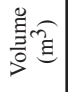 & gे & $\stackrel{\circ}{\circ}$ & $\stackrel{\text { fa }}{0}$ & $\mid$\begin{tabular}{l} 
\pm \\
\multirow{2}{*}{} \\
0
\end{tabular} & $\begin{array}{c}0 \\
y \\
y\end{array}$ & $\mid \begin{array}{l}\vec{\sigma} \\
\dot{O}\end{array}$ & & $\stackrel{2}{=}$ & $\stackrel{\Upsilon ્}{\dddot{I}}$ & $\stackrel{ \pm}{\stackrel{I}{I}}$ & 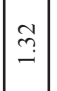 & $\stackrel{\overbrace{}}{2}$ & $\stackrel{\overbrace{}}{g}$ & $\stackrel{ }{-}$ & 古 & के & $\stackrel{\sqrt[m]{g}}{9}$ & $\underset{\exists}{J}$ & $\stackrel{n}{\stackrel{n}{\rightarrow}}$ & $\stackrel{\infty}{\stackrel{\infty}{二}}$ & $\stackrel{\beta}{-}$ & $\stackrel{\leftrightarrow}{\longrightarrow}$ & $\stackrel{?}{\stackrel{9}{-}}$ & : \\
\hline 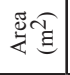 & $\stackrel{m}{\rightarrow}$ & $\stackrel{\text { ণิ }}{-}$ & $\stackrel{\circ}{\circ}$ & बे & ठे. & $\vec{I}$ & $\stackrel{\overbrace{}}{\rightarrow}$ & 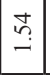 & 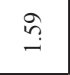 & $\stackrel{n}{-}$ & $\stackrel{i}{i}$ & $\stackrel{F}{=}$ & $\stackrel{\text { F }}{-}$ & $\mid \begin{array}{l}0 \\
\stackrel{\overbrace{}}{i}\end{array}$ & 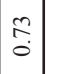 & $\vec{m}$ & $\stackrel{\infty}{\stackrel{\infty}{-}}$ & $\stackrel{\sim}{-}$ & $\underset{\mathrm{N}}{\mathrm{i}}$ & $\mid \begin{array}{l}\infty \\
\stackrel{i}{i}\end{array}$ & $\stackrel{\infty}{i}$ & $\stackrel{F}{ت}$ & i & $\stackrel{\text { Z }}{\text { i }}$ \\
\hline 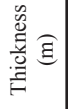 & $\stackrel{\text { âd }}{0}$ & & & $\begin{array}{l}: \\
\stackrel{\circ}{\circ}\end{array}$ & $\mid \begin{array}{l} \pm \\
\stackrel{\Delta}{0} \\
0\end{array}$ & 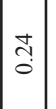 & & & & $\frac{ \pm}{0}$ & & & & & & & & & & $\begin{array}{c}0 \\
\stackrel{0}{0}\end{array}$ & กี & $=$ & & :े \\
\hline \begin{tabular}{|l|} 
ही \\
吾 \\
严 \\
\end{tabular} & $\stackrel{m}{?}$ & I & $\stackrel{\circ}{\circ}$ & $\stackrel{\circ}{0}$ & $\dot{\partial}$ & $\exists$ & $\stackrel{\Im}{\Im}$ & $\stackrel{\sim}{-}$ & 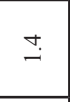 & $\stackrel{+}{-}$ & $\because$ & $\because$ & $\because$ & $\mathrm{N}$ & $\begin{array}{l}\overrightarrow{0} \\
:\end{array}$ & 足 & 尔 & $\stackrel{ \pm}{-}$ & 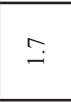 & $=$ & $\stackrel{n}{n}$ & - & $\stackrel{0}{-}$ & $\because$ \\
\hline 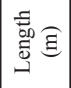 & $\stackrel{m}{-}$ & $\stackrel{\text { f }}{\longrightarrow}$ & $\stackrel{ \pm}{-}$ & $\stackrel{\Xi}{-}$ & $\stackrel{+}{-}$ & $\stackrel{\Delta}{-}$ & $\stackrel{ナ}{-}$ & $\stackrel{\sim}{-}$ & 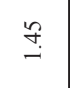 & $\because$ & $\because$ & $\stackrel{n}{n}$ & $\because$ & $\because$ & $\begin{array}{l}\stackrel{n}{2} \\
\stackrel{n}{-}\end{array}$ & $\stackrel{\overbrace{}}{\approx}$ & $\stackrel{\circ}{-}$ & $\stackrel{n}{\stackrel{n}{=}}$ & $\stackrel{n}{\stackrel{c}{g}}$ & $\stackrel{\infty}{\stackrel{\infty}{\sim}}$ & $\stackrel{શ}{i}$ & $\stackrel{\infty}{-}$ & $\stackrel{\infty}{-}$ & $\stackrel{9}{-}$ \\
\hline 送 & 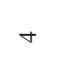 & 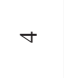 & 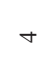 & + & - & 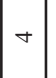 & $\nabla$ & + & 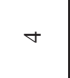 & + & 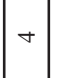 & $\sigma$ & $\nabla$ & + & 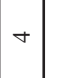 & + & ナ & $\sigma$ & 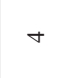 & - & 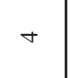 & + & $\sigma$ & $N$ \\
\hline 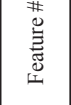 & $\stackrel{2}{2}$ & $n$ & $\vec{\sim}$ & 0 & $i$ & ন & $\stackrel{\infty}{.}$ & in & $\cong$ & ปั & - & - & 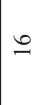 & 0 & $\approx$ & $=$ & নి & $\sim$ & $r$ & $\simeq$ & F & $a$ & $\pi$ & ते \\
\hline 前 & $\begin{array}{l}\overrightarrow{3} \\
\overrightarrow{0} \\
\vec{\sigma}\end{array}$ & $\begin{array}{l}8 \\
3 \\
\end{array}$ & $\sum_{\forall}^{N}$ & \begin{tabular}{|l|}
$f$ \\
0 \\
0 \\
$G$ \\
$\forall$ \\
\end{tabular} & 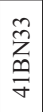 & \begin{tabular}{|l|}
\multirow{2}{*}{} \\
$\bar{z}$ \\
$\sigma$ \\
\end{tabular} & $\sum_{\exists}^{N}$ & 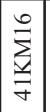 & $\sum_{\exists}^{\tilde{N}}$ & $\underset{\vec{F}}{\stackrel{\vec{Z}}{\sigma}}$ & \begin{tabular}{|l|}
\multirow{2}{*}{} \\
$\stackrel{2}{*}$ \\
\hdashline
\end{tabular} & $\underset{\forall}{\stackrel{y}{F}}$ & $\begin{array}{l}0 \\
\\
y \\
y\end{array}$ & 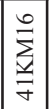 & \begin{tabular}{l|} 
\\
0 \\
3 \\
7 \\
7
\end{tabular} & $\sum_{7}^{8}$ & $\sum_{F}^{N}$ & 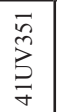 & $\sum_{\xi}^{N}$ & \begin{tabular}{|l|}
0 \\
0 \\
0 \\
$G$ \\
$\forall$ \\
\end{tabular} & $\underset{\tilde{z}}{\stackrel{M}{\sigma}}$ & $\begin{array}{l}\frac{8}{0} \\
\overrightarrow{7}\end{array}$ & $\sum_{\forall}^{N}$ & 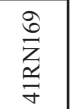 \\
\hline
\end{tabular}




\begin{tabular}{|c|c|c|c|c|c|c|c|c|c|c|c|c|c|c|c|c|c|c|c|}
\hline 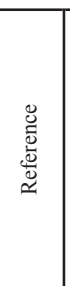 & 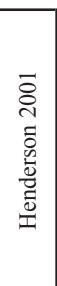 & 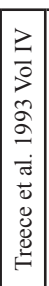 & 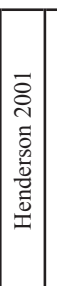 & 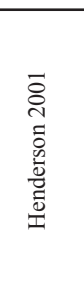 & 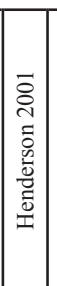 & 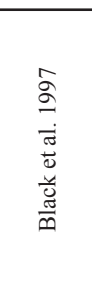 & 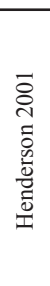 & 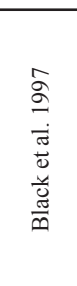 & 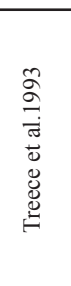 & 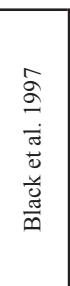 & 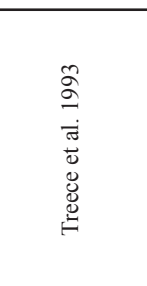 & 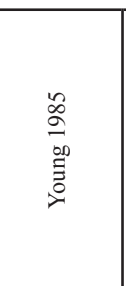 & 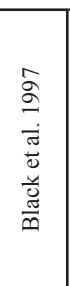 & 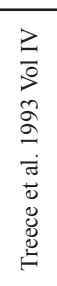 & 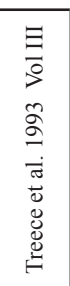 & $\begin{array}{l}\hat{\sigma} \\
\bar{\sigma} \\
\bar{\sigma} \\
\overline{0} \\
\overline{0} \\
\frac{\tilde{0}}{\oplus}\end{array}$ & 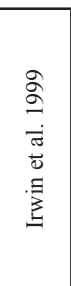 & 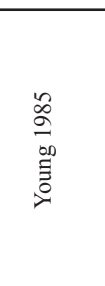 & 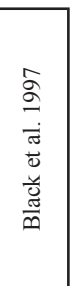 \\
\hline$\stackrel{\mathscr{\Xi}}{\Xi}$ & & & & & & 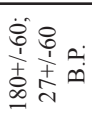 & & 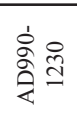 & & & 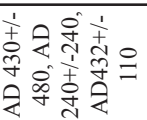 & 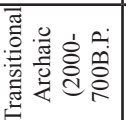 & 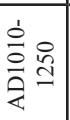 & & 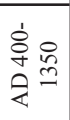 & 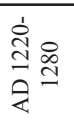 & & 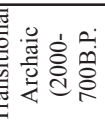 & 客 \\
\hline 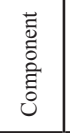 & $\overleftrightarrow{\xi}$ & $\stackrel{\vec{G}}{\vec{\theta}}$ & $\overrightarrow{\vec{\theta}}$ & 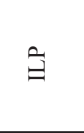 & $\stackrel{\vec{G}}{\mid}$ & $\overrightarrow{\vec{H}}$ & 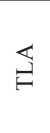 & 当 & $\stackrel{\vec{g}}{\vec{\theta}}$ & 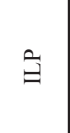 & 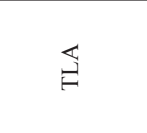 & 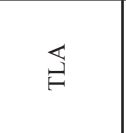 & $\stackrel{\tilde{g}}{\exists}$ & $\stackrel{\vec{\beta}}{\vec{\beta}}$ & 育 & $\begin{array}{l}\overrightarrow{\vec{H}} \\
\dot{\vec{\theta}}\end{array}$ & 当 & $\overleftrightarrow{\Leftrightarrow}$ & $\begin{array}{l}\overrightarrow{\vec{H}} \\
\dot{\Xi} \\
\dot{G}\end{array}$ \\
\hline 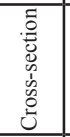 & $\begin{array}{l}\text { 毒 } \\
\text { 吾 }\end{array}$ & & 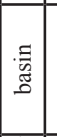 & & & $\begin{array}{l}\text { 袁 } \\
\text { 焉 }\end{array}$ & 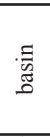 & & $\underset{\mathbb{G}}{\mathbb{E}}$ & & & 异 & & $\underset{\mathbb{\Psi}}{\breve{\Psi}}$ & 黑 & & & $\stackrel{\square}{\sharp}$ & \\
\hline$\frac{\Xi}{\frac{E}{2}} \cdot \frac{3}{\frac{7}{7}}$ & 敔 & \begin{tabular}{|l|}
$\frac{0}{0}$ \\
0 \\
0 \\
\end{tabular} & 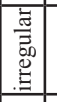 & 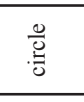 & & 㗁 & 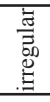 & & 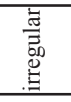 & & & $\overline{\mathrm{g}}$ & 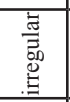 & 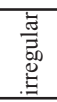 & & $\frac{0}{0}$ & & $\begin{array}{l}\stackrel{\vec{J}}{\Xi} \\
\end{array}$ & 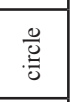 \\
\hline 总 & $\begin{array}{l}\text { 童 } \\
\text { 吾 } \\
\text { 恋 }\end{array}$ & 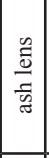 & 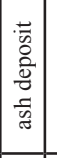 & 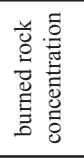 & 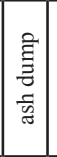 & 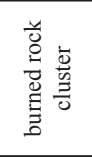 & 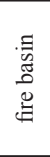 & 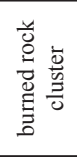 & 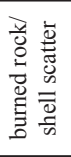 & 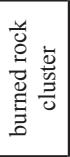 & 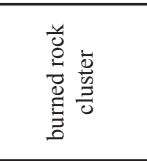 & 咭 & 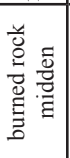 & 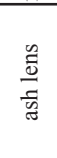 & 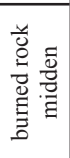 & 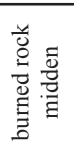 & 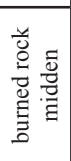 & 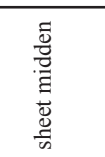 & 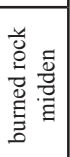 \\
\hline 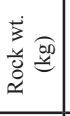 & & & & & & & & & & & & & & & 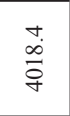 & & & & \\
\hline 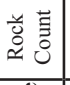 & & & & & & 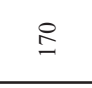 & & & & & & $=$ & & & & & & & \\
\hline 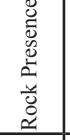 & 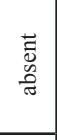 & 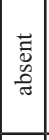 & 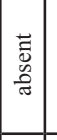 & 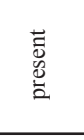 & 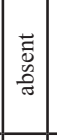 & $\begin{array}{l}\text { 离 } \\
\text { 总 }\end{array}$ & 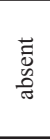 & $\begin{array}{l}\overrightarrow{\tilde{E}^{\circ}} \\
\stackrel{0}{2}\end{array}$ & 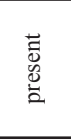 & 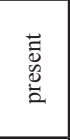 & 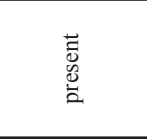 & 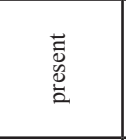 & 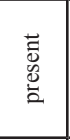 & 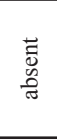 & 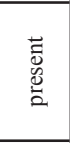 & $\begin{array}{l}\text { 蒿 } \\
\stackrel{0}{2}\end{array}$ & $\begin{array}{l}\overrightarrow{\tilde{E}^{\circ}} \\
\underline{\omega_{2}}\end{array}$ & $\begin{array}{l}\overrightarrow{\tilde{E}^{\circ}} \\
\stackrel{0}{2}\end{array}$ & 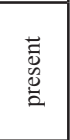 \\
\hline 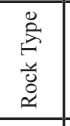 & & & & & & 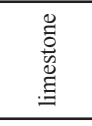 & & 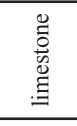 & 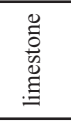 & 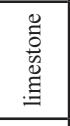 & & 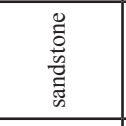 & & & & 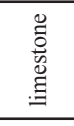 & 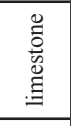 & 营 & \\
\hline 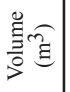 & $\stackrel{\infty}{=}$ & 号 & $\stackrel{\infty}{\stackrel{\infty}{-}}$ & $\stackrel{\vartheta}{I}$ & $\stackrel{2}{-1}$ & $\underset{\mathrm{i}}{\tilde{i}}$ & $\stackrel{\infty}{\circ}$ & aे & $\begin{array}{l}\stackrel{\circ}{\circ} \underset{+}{+} \\
\end{array}$ & iृ & $\stackrel{\Omega}{=}$ & $\stackrel{\infty}{\infty} \stackrel{\infty}{\circ}$ & $\begin{array}{l}n \\
\text { in } \\
\text { ij }\end{array}$ & 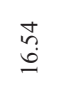 & $\begin{array}{l}\infty \\
\stackrel{\infty}{ \pm} \\
\dot{J}\end{array}$ & 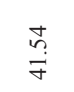 & $\begin{array}{l}\underset{y}{\gamma} \\
\tilde{\gamma}\end{array}$ & $\begin{array}{l}\text { カે } \\
\text { הે }\end{array}$ & 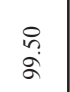 \\
\hline 苞奇 & $\stackrel{n}{n}$ & $\stackrel{\Delta}{\dot{m}}$ & \begin{tabular}{|l|}
$f$ \\
-
\end{tabular} & ते & \begin{tabular}{|l|}
\multirow{2}{*}{} \\
$\stackrel{2}{*}$ \\
\end{tabular} & 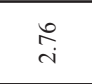 & $\vec{m}$ & i্ & 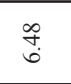 & $\stackrel{5}{r}$ & $\begin{array}{l}8 \\
\qquad \\
6 \\
6\end{array}$ & $\stackrel{\infty}{=}$ & 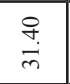 & 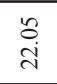 & $\begin{array}{l}\text { गु } \\
\text { in } \\
\text { in }\end{array}$ & 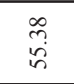 & $\begin{array}{l}\stackrel{p}{1} \\
\text { in }\end{array}$ & 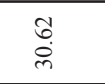 & $\begin{array}{l}\tilde{6} \\
\mathbb{2} \\
\widetilde{\Omega}\end{array}$ \\
\hline 总 & $\stackrel{\infty}{0}$ & $\stackrel{\overbrace{}}{0}$ & $\stackrel{ \pm}{0}$ & $\stackrel{ \pm}{0}$ & $\mid \begin{array}{l}\infty \\
0 \\
0\end{array}$ & & $\stackrel{5}{0}$ & $\overrightarrow{0}$ & $\stackrel{n}{0}$ & & รี & $\overrightarrow{0}$ & รี & & - & $\stackrel{n}{o}$ & $n$ & $\stackrel{n}{0}$ & \\
\hline $\begin{array}{l}\text { 吾 } \\
\text { 吾 } \\
\text { 妾 }\end{array}$ & - & $\sim$ & $\mid \begin{array}{c}1 \\
\infty \\
0 \\
0\end{array}$ & $\stackrel{\text { fq }}{\mathrm{f}}$ & $\underset{\leftarrow}{-}$ & $\stackrel{\circ}{\longrightarrow}$ & 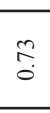 & તે & $\stackrel{n}{i}$ & $m$ & $\stackrel{n}{+}$ & 3 & $\infty$ & ? & $\infty$ & 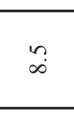 & $\dddot{n}$ & m & 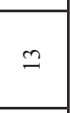 \\
\hline$\stackrel{\overrightarrow{5}}{\overrightarrow{5}} \widehat{\Xi}$ & $\sim$ & 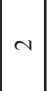 & $\vec{i}$ & $\vec{i}$ & $\vec{i}$ & הี & $\stackrel{\infty}{\underset{N}{N}}$ & m & $m$ & $m$ & ?ֶ & in & in & min & $\infty$ & $m_{\infty}^{m}$ & $\stackrel{\infty}{a}$ & 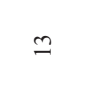 & 2 \\
\hline 总 : & - & -1 & - & + & -1 & t & - & + & + & + & + & + & in & - & in & in & in & + & 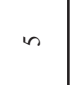 \\
\hline 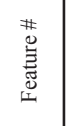 & $\vec{n}$ & $\circ$ & 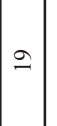 & 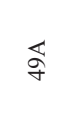 & 8 & $m$ & $\approx$ & 0 & 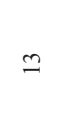 & $m$ & $\stackrel{\circ}{\circ}$ & $=$ & $\begin{array}{l}u \\
\frac{\bar{v}}{0} \\
\frac{0}{\Sigma}\end{array}$ & 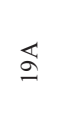 & $\mathrm{N}$ & 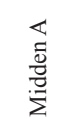 & - & - & $\frac{\vec{v}}{\bar{v}}$ \\
\hline$\stackrel{\mathscr{H}}{\ddot{n}}$ & 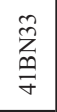 & $\mid \begin{array}{l}\vec{m} \\
\tilde{U} \\
\vec{\gamma}\end{array}$ & $\begin{array}{c}\tilde{z} \\
\tilde{m} \\
\sigma\end{array}$ & $\underset{\tilde{z}}{\tilde{y}}$ & $\begin{array}{c}\tilde{z} \\
\dot{m} \\
\vec{\sigma}\end{array}$ & $\sum_{\forall}^{\tilde{W}}$ & 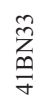 & $\begin{array}{l}\infty \\
\stackrel{\infty}{b} \\
\xi\end{array}$ & $\underset{\vec{z}}{\stackrel{\vec{Z}}{F}}$ & \begin{tabular}{l}
$\infty$ \\
$\vdots$ \\
\multirow{\sigma}{\infty}{} \\
\end{tabular} & $\frac{\dddot{n}}{\mathfrak{z}_{\sigma}}$ & $\begin{array}{l}\frac{0}{\partial} \\
\frac{\partial}{F}\end{array}$ & $\sum_{\xi}^{\grave{\xi}}$ & $\begin{array}{l}\vec{j} \\
\overrightarrow{0} \\
\vec{\sigma}\end{array}$ & 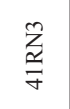 & $\sum_{\exists}^{\grave{g}}$ & $\underset{\Xi}{\bar{y}}$ & $\begin{array}{l}\frac{0}{7} \\
\frac{7}{7}\end{array}$ & $\tilde{\tilde{n}}$ \\
\hline
\end{tabular}




\begin{tabular}{|c|c|c|c|c|c|c|c|}
\hline 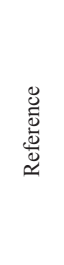 & 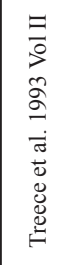 & 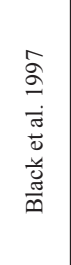 & 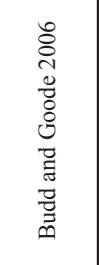 & 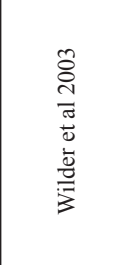 & 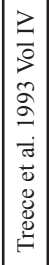 & 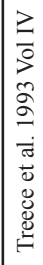 & 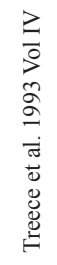 \\
\hline 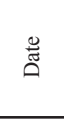 & 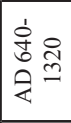 & 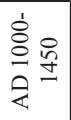 & 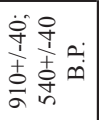 & 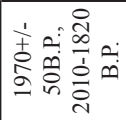 & & & 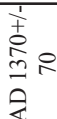 \\
\hline 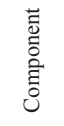 & 实 & $\begin{array}{l}\overrightarrow{\vec{H}} \\
\dot{\vec{g}} \\
\vec{\exists}\end{array}$ & 状 & $\overleftrightarrow{\Sigma}$ & $\overrightarrow{\vec{F}}$ & $\overrightarrow{\vec{F}}$ & $\hat{\vec{H}}$ \\
\hline 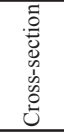 & $\begin{array}{l}\text { 吕 } \\
\text { 咭 }\end{array}$ & & & & & & \\
\hline 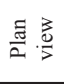 & 恖 & & वू & & & & \\
\hline 总 & 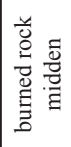 & 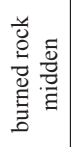 & 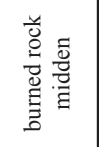 & 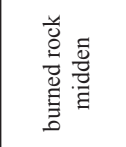 & 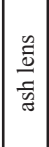 & 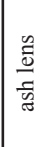 & $\frac{\stackrel{n}{\frac{D}{0}}}{\frac{\bar{v}}{\tilde{g}}}$ \\
\hline 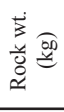 & 高 & & & & & & \\
\hline 总 言 & & & & & & & \\
\hline 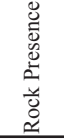 & 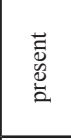 & 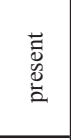 & 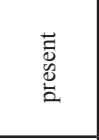 & 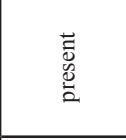 & 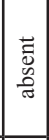 & 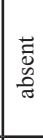 & 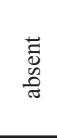 \\
\hline 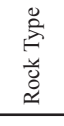 & 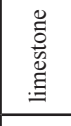 & 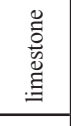 & & & & & \\
\hline 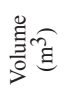 & 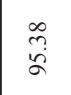 & $\begin{array}{l}8 \\
\dot{q}\end{array}$ & 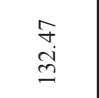 & $\begin{array}{l}\text { Iิ } \\
\text { f̀ }\end{array}$ & & & \\
\hline 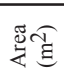 & 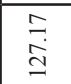 & $\begin{array}{l}\infty \\
0 \\
\dot{0} \\
-1 \\
\end{array}$ & 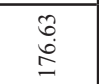 & 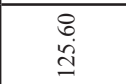 & & & \\
\hline 总 & م̂ & in & & ชี & & & \\
\hline 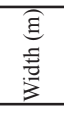 & $\simeq$ & $\cong$ & $\simeq$ & $\infty$ & & & \\
\hline 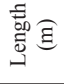 & $\stackrel{n}{m}$ & \pm & $\cong$ & तิ & & & \\
\hline 胥善 & in & in & in & in & - & - & - \\
\hline 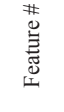 & - & 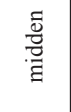 & 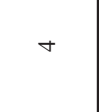 & - & in & in & $\stackrel{\mathscr{P}}{q}$ \\
\hline$\stackrel{\mathscr{V}}{\mathrm{n}}$ & 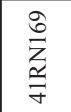 & $\begin{array}{l}\infty \\
\vdots \\
\vdots \\
\exists\end{array}$ & 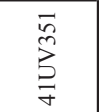 & $\begin{array}{l}\overline{\bar{N}} \\
\underset{\partial}{\sigma}\end{array}$ & 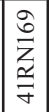 & $\begin{array}{l}\text { ò } \\
z \bar{z} \\
\frac{g}{\gamma}\end{array}$ & $\begin{array}{l}\text { ô } \\
\bar{Z} \\
\frac{g}{\gamma}\end{array}$ \\
\hline
\end{tabular}



Appendix D:

Analysis of the Fatty Acid Composition of Archeological Burned Rock from Site 41KM69 and Experimental Samples

\author{
M. E. Malainey
}





\title{
Appendix D
}

\section{Analysis of the Fatty Acid Compositions of Archeological Burned Rock from Site 41KM69 and Experimental Samples}

\author{
M. E. Malainey, Ph.D. \\ 11 Mager Drive West \\ Winnipeg, $M B$ \\ Canada R2MOR9
}

\section{Introduction}

Six archaeological burned rocks were submitted for analysis (Table D-1); subsamples were taken from these large archaeological rocks. Exterior surfaces were ground off to remove any contaminants and samples were crushed. Absorbed lipid residues were extracted with organic solvents. Fatty acid components of the lipid extracts were analyzed using gas chromatography. Residues were identified using criteria developed from the decomposition patterns of experimental residues. The first section of this report outlines the development of the identification criteria. Following this, analytical procedures and results are presented.

Table D-1. List of Archeological Samples

\begin{tabular}{|c|c|c|c|c|}
\hline Lab No. & Sample \# & Field Specimen \# & Feature \# & Sample Size (g) \\
\hline 7UT 43 & 6 & $444-2$ & 35 & 28.807 \\
\hline 7UT 44 & 7 & $1077-3$ & 42 & 28.31 \\
\hline 7UT 45 & 8 & $1183-1$ & 45 & 33.352 \\
\hline 7UT 46 & 9 & 1301 & 47 & 33.333 \\
\hline 7UT 47 & 10 & 1284 & 49 & 31.83 \\
\hline 7UT 48 & 11 & 1945 & 82 & 28.039 \\
\hline
\end{tabular}

\section{Fatty Acids and Development of the Identification Criteria}

\section{Introduction and Previous Research}

Fatty acids are the major constituents of fats and oils (lipids) and occur in nature as triglycerides, consisting of three fatty acids

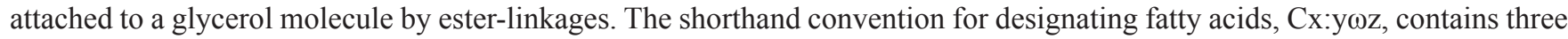
components. The "Cx" refers to a fatty acid with a carbon chain length of $\mathrm{x}$ number of atoms. The "y" represents the number of double bonds or points of unsaturation, and the " $\omega z$ " indicates the location of the most distal double bond on the carbon chain, i.e. closest to the methyl end. Thus, the fatty acid expressed as C18:1 19 , refers to a mono-unsaturated isomer with a chain length of 18 carbon atoms with a single double bond located nine carbons from the methyl end of the chain. Similarly, the shorthand designation, C16:0, refers to a saturated fatty acid with a chain length of 16 carbons.

Their insolubility in water and relative abundance compared to other classes of lipids, such as sterols and waxes, make fatty acids suitable for residue analysis. Since employed by Condamin et al. (1976), gas chromatography has been used extensively to analyze the fatty acid component of absorbed archaeological residues. The composition of uncooked plants and animals provides important baseline information, but it is not possible to directly compare modern uncooked plants and animals with highly degraded archaeological residues. Unsaturated fatty acids, which are found widely in fish and plants, decompose more readily than saturated fatty acids, sterols or waxes. In the course of decomposition, simple addition reactions might occur at 
points of unsaturation (Solomons 1980) or peroxidation might lead to the formation of a variety of volatile and non-volatile products which continue to degrade (Frankel 1991). Peroxidation occurs most readily in fatty acids with more than one point of unsaturation.

Attempts have been made to identify archaeological residues using criteria that discriminate uncooked foods (Marchbanks 1989; Skibo 1992; Loy 1994). Marchbanks' (1989) percent of saturated fatty acids (\%S) criteria has been applied to residues from a variety of materials including pottery, stone tools and burned rocks (Marchbanks 1989; Marchbanks and Quigg 1990; Collins et al. 1990). Skibo (1992:89) could not apply the \%S technique and instead used two ratios of fatty acids, C18:0/C16:0 and $\mathrm{C} 18: 1 / \mathrm{C} 16: 0$. He (1992) reported that it was possible to link the uncooked foods with residues extracted from modern cooking pots actively used to prepare one type of food; however, the ratios could not identify food mixtures. The utility of these ratios did not extend to residues extracted from archaeological potsherds because the ratios of the major fatty acids in the residue changed with decomposition (Skibo 1992:97). Loy (1994) proposed the use of a Saturation Index (SI), determined by the ratio: $\mathrm{SI}=1-[(\mathrm{C} 18: 1+\mathrm{C} 18: 2) / \mathrm{C} 12: 0+\mathrm{C} 14: 0+\mathrm{C} 16: 0+\mathrm{C} 18: 0)]$. He (1994) admitted, however, that poorly understood decompositional changes to the original suite of fatty acids make it difficult to develop criteria for distinguishing animal and plant fatty acid profiles in archaeological residues.

The major drawback of the distinguishing ratios proposed by Marchbanks (1989), Skibo (1992) and Loy (1994) is they have never been empirically tested. The proposed ratios are based on criteria that discriminate food classes on the basis of their original fatty acid composition. The resistance of these criteria to the effects of decompositional changes has not been demonstrated. Rather, Skibo (1992) found his fatty acid ratio criteria could not be used to identify highly decomposed archaeological samples.

In order to identify a fatty acid ratio unaffected by degradation processes, Patrick et al. (1985) simulated the long-term decomposition of one sample and monitored the resulting changes. An experimental cooking residue of seal was prepared and degraded in order to identify a stable fatty acid ratio. Patrick et al. (1985) found that the ratio of two C18:1 isomers, oleic and vaccenic, did not change with decomposition; this fatty acid ratio was then used to identify an archaeological vessel residue as seal. While the fatty acid composition of uncooked foods must be known, Patrick et al. (1985) showed that the effects of cooking and decomposition over long periods of time on the fatty acids must also be understood.

\section{Development of the Identification Criteria}

As the first stage in developing the identification criteria used herein, the fatty acid compositions of more than 130 uncooked Native food plants and animals from Western Canada were determined using gas chromatography (Malainey 1997; Malainey et al. 1999a). When the fatty acid compositions of modern food plants and animals were subject to cluster and principal component analyses, the resultant groupings generally corresponded to divisions that exist in nature (Table D-2). Clear differences in the fatty acid composition of large mammal fat, large herbivore meat, fish, plant roots, greens and berries/seeds/nuts were detected, but the fatty acid composition of meat from medium-sized mammals resembles berries/seeds/nuts.

Samples in cluster A, the large mammal and fish cluster had elevated levels of C16:0 and C18:1 (Table D-2). Divisions within this cluster stemmed from the very high level of C18:1 isomers in fat, high levels of C18:0 in bison and deer meat and high levels of very long chain unsaturated fatty acids (VLCU) in fish. Differences in the fatty acid composition of plant roots, greens and berries/seeds/nuts reflect the amounts of $\mathrm{C} 18: 2$ and $\mathrm{C} 18: 3 \omega 3$ present. The berry, seed, nut and small mammal meat samples appearing in cluster B have very high levels of C18:2, ranging from 35\% to $64 \%$ (Table D-2). Samples in subclusters V, VI and VII have levels of C18:1 isomers from $29 \%$ to $51 \%$, as well. Plant roots, plant greens and some berries appear in cluster C. All cluster C samples have moderately high levels of C18:2; except for the berries in subcluster XII, levels of C16:0 are also elevated. Higher levels of C18:3 13 and/or very long chain saturated fatty acids (VLCS) are also common except in the roots which form subcluster XV.

Secondly, the effects of cooking and degradation over time on fatty acid compositions were examined. Originally, 19 modern residues of plants and animals from the plains, parkland and forests of Western Canada were prepared by cooking samples of meats, fish and plants, alone or combined, in replica vessels over an open fire (Malainey 1997; Malainey et al. 1999b). After four days at room temperature, the vessels were broken and a set of sherds analysed to determine changes after a short term of decomposition. A second set of sherds remained at room temperature for 80 days, then placed in an oven at $75^{\circ} \mathrm{C}$ for a period of 30 days in order to simulate the processes of long term decomposition. The relative percentages were calculated on the basis of the ten fatty acids $(\mathrm{C} 12: 0, \mathrm{C} 14: 0, \mathrm{C} 15: 0, \mathrm{C} 16: 0, \mathrm{C} 16: 1, \mathrm{C} 17: 0, \mathrm{C} 18: 0, \mathrm{C} 18: 1 \mathrm{w} 9, \mathrm{C} 18: 1 \mathrm{w} 11$, and $\mathrm{C} 18: 2)$ that regularly appeared 
Table D-2. Summary of Average Fatty Acids Compositions of Modern Food Groups Generated by Hierarchical Cluster Analysis

\begin{tabular}{|c|c|c|c|c|c|c|c|c|c|c|c|c|c|c|c|}
\hline Cluster & \multicolumn{4}{|c|}{$\mathbf{A}$} & \multicolumn{6}{|c|}{ B } & \multicolumn{5}{|c|}{ C } \\
\hline Subcluster & I & II & III & IV & V & VI & VII & VIII & IX & $\mathbf{X}$ & XI & XII & XIII & XIV & XV \\
\hline 芯 & 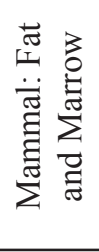 & 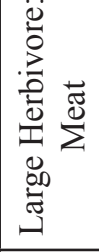 & 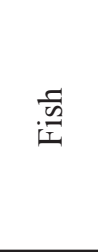 & 㺼 & 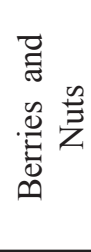 & 总 & 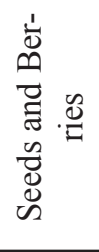 & $\begin{array}{l}n \\
0 \\
0\end{array}$ & $\begin{array}{l}\vec{n} \\
\mathbb{U} \\
\tilde{n}\end{array}$ & $\stackrel{\vec{D}}{\stackrel{凶}{\Sigma}}$ & 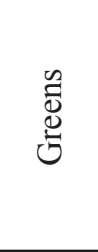 & $\begin{array}{l}\mathscr{Q} \\
\stackrel{\vec{E}}{0} \\
\tilde{D}\end{array}$ & 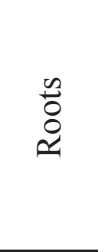 & 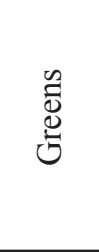 & 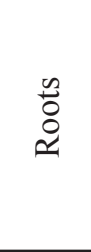 \\
\hline C16:0 & 19.9 & 19.39 & 16.07 & 14.1 & 3.75 & 12.06 & 7.48 & 19.98 & 7.52 & 10.33 & 18.71 & 3.47 & 22.68 & 24.19 & 18.71 \\
\hline C18:0 & 7.06 & 20.35 & 3.87 & 2.78 & 1.47 & 2.36 & 2.58 & 2.59 & 3.55 & 2.43 & 2.48 & 1.34 & 3.15 & 3.66 & 5.94 \\
\hline C18:1 & 56.77 & 35.79 & 18.28 & 31.96 & 51.14 & 35.29 & 29.12 & 6.55 & 10.02 & 15.62 & 5.03 & 14.95 & 12.12 & 4.05 & 3.34 \\
\hline C18:2 & 7.01 & 8.93 & 2.91 & 4.04 & 41.44 & 35.83 & 54.69 & 48.74 & 64.14 & 39.24 & 18.82 & 29.08 & 26.24 & 16.15 & 15.61 \\
\hline C18:3 & 0.68 & 2.61 & 4.39 & 3.83 & 1.05 & 3.66 & 1.51 & 7.24 & 5.49 & 19.77 & 35.08 & 39.75 & 9.64 & 17.88 & 3.42 \\
\hline VLCS & 0.16 & 0.32 & 0.23 & 0.15 & 0.76 & 4.46 & 2.98 & 8.5 & 5.19 & 3.73 & 6.77 & 9.1 & 15.32 & 18.68 & 43.36 \\
\hline VLCU & 0.77 & 4.29 & 39.92 & 24.11 & 0.25 & 2.7 & 1 & 2.23 & 0.99 & 2.65 & 1.13 & 0.95 & 2.06 & 0.72 & 1.1 \\
\hline
\end{tabular}

VLCS - Very Long Chain (C20, C22, and C24) Saturated Fatty Acids

VLCU - Very Long Chain (C20, C22, and C24) Unsaturated Fatty Acids

in Precontact Period vessel residues from Western Canada. Observed changes in fatty acid composition of the experimental cooking residues enabled the development of a method for identifying the archaeological residues (Table D-3).

It was determined that levels of medium chain fatty acids (C12:0, $\mathrm{C} 14: 0$ and $\mathrm{C} 15: 0), \mathrm{C} 18: 0$ and $\mathrm{C} 18: 1$ isomers in the sample could be used to distinguish degraded experimental cooking residues (Malainey 1997; Malainey et al. 1999b). These fatty acids are suitable for the identification criteria because saturated fatty acids are stable and the mono-unsaturated fatty acid degrades very slowly, as compared to polyunsaturated fatty acids (deMan 1992). Higher levels of medium chain fatty acids, combined with low levels of C18:0 and C18:1 isomers, were detected in the decomposed experimental residues of plants, such as roots, greens and most berries. High levels of C18:0 indicated the presence of large herbivores. Moderate levels of C18:1 isomers, with low levels of C18:0, indicated the presence of either fish or foods similar in composition to corn. High levels of C18:1 isomers with low levels of C18:0, were found in residues of beaver or foods of similar fatty acid composition. The criteria for identifying six types of residues were established experimentally; the seventh type, plant with large herbivore, was inferred (Table D-3). These criteria were applied to residues extracted from more than 200 pottery cooking vessels from 18 Western Canadian sites (Malainey 1997; Malainey et al. 1999c; 2001b). The identifications were found to be consistent with the evidence from faunal and tool assemblages for each site.

Work has continued to understand the decomposition patterns of various foods and food combinations (Malainey et al. 2000a, 2000b, 2000c, 2001a; Quigg et al. 2001). The collection of modern foods has expanded to include plants from the Southern Plains. The fatty acid compositions of mesquite beans (Prosopis glandulosa), Texas ebony seeds (Pithecellobium ebano Berlandier), tasajillo berry (Opuntia leptocaulis), prickly pear fruit and pads (Opuntia engelmannii), Spanish dagger pods (Yucca treculeana), cooked sotol (Dasylirion wheeler), agave (Agave lechuguilla), cholla (Opuntia imbricata), piñon (Pinus edulis) and Texas mountain laurel (or mescal) seed (Sophora secundiflora) have been determined. Experimental residues of many of these plants, alone or in combination with deer meat, have been prepared by boiling foods in clay cylinders or using sandstone for either stone boiling (Quigg et al. 2000) or as a griddle. In order to accelerate the processes of oxidative degradation that naturally occur at a slow rate with the passage of time, the rock or clay tile containing the experimental residue was placed in an oven at $75^{\circ} \mathrm{C}$. After either 30 or 68 days, residues were extracted and analysed using gas chromatography.

The results of these decomposition studies enabled refinement of the identification criteria. 
Table D-3. Criteria for the Identification of Archaeological Residues

Based on the Decomposition Patterns of Experimental Cooking

Residues Prepared in Pottery Vessel

\begin{tabular}{|c|c|c|c|}
\hline Identification & \multirow{2}{*}{ Medium Chain } & C18:0 & \multirow{2}{*}{ C18:1 isomers } \\
\hline Large herbivore & $£ 15 \%$ & ${ }^{3} 27.5 \%$ & $£ 15 \%$ \\
\hline Large herbivore with plant & low & ${ }^{3} 25 \%$ & $15 \% £ X £ 25 \%$ \\
\hline OR Bone marrow & & ${ }^{3} 25 \%$ & no data \\
\cline { 1 - 3 } Plant with large herbivore & ${ }^{3} 15 \%$ & Low & ${ }^{3} 25 \%$ \\
\hline Beaver & low & $£ 25 \%$ & $15 \% £ X £ 27.5 \%$ \\
\hline Fish or Corn & low & $£ 25 \%$ & $15 \% £ X £ 27.5 \%$ \\
\hline Fish or Corn with Plant & ${ }^{3} 15 \%$ & $£ 27.5 \%$ & $£ 15 \%$ \\
\hline Plant (except corn) & ${ }^{3} 10 \%$ & & \\
\hline
\end{tabular}

\section{Methodology}

Descriptions of the samples are presented in Table D-1. Exterior surfaces were ground off using a Dremel ${ }^{\circledR}$ tool fitted with a silicon carbide bit. Immediately thereafter, the sample was crushed with a hammer mortar and pestle and the powder transferred to an Erlenmeyer flask. Lipids were extracted using a variation of the method developed by Folch et al. (1957). The powdered sample was mixed with a 2:1 mixture, by volume, of chloroform and methanol ( 2 X $25 \mathrm{~mL})$ using ultrasonication ( 2 X $10 \mathrm{~min})$. Solids were removed by filtering the solvent mixture into a separatory funnel. The lipid/solvent filtrate was washed with 13 $\mathrm{mL}$ of ultrapure water. Once separation into two phases was complete, the lower chloroform-lipid phase was transferred to a round-bottomed flask and the chloroform removed by rotary evaporation. Any remaining water was removed by evaporation with benzene $(1.5 \mathrm{~mL}) ; 1.5 \mathrm{~mL}$ of chloroform-methanol $(2: 1, \mathrm{v} / \mathrm{v})$ was used to transfer the dry total lipid extract to a screw-top glass vial with a Teflon ${ }^{\circledR}$-lined cap. The sample was flushed with nitrogen and stored in a $-20^{\circ} \mathrm{C}$ freezer.

A $400 \mu \mathrm{L}$ sample of the total lipid extract solution was placed in a screw-top test tube and dried in a heating block under nitrogen. Fatty acid methyl esters (FAMES) were prepared by treating the dry lipid with $5 \mathrm{~mL}$ of $0.5 \mathrm{~N}$ anhydrous hydrochloric acid in methanol $\left(68^{\circ} \mathrm{C} ; 60 \mathrm{~min}\right)$. Fatty acids that occur in the sample as di- or triglycerides are detached from the glycerol molecule and converted to methyl esters. After cooling to room temperature, $3.4 \mathrm{~mL}$ of ultrapure water was added. FAMES were recovered with petroleum ether $(2.5 \mathrm{~mL})$ and transferred to a vial. The solvent was removed by heat under a gentle stream of nitrogen; the FAMES were dissolved in $75 \mu \mathrm{L}$ of iso-octane then transferred to a $\mathrm{GC}$ vial with a conical glass insert.

Solvents and chemicals were checked for purity by running a sample blank. The entire lipid extraction and methyl esterification process was performed and FAMES were dissolved in $75 \mu \mathrm{L}$ of iso-octane. Traces of contamination were subtracted from sample chromatograms. The relative percentage composition was calculated by dividing the integrated peak area of each fatty acid by the total area of fatty acids present in the sample.

The step in the extraction procedure where the chloroform, methanol and lipid mixture is washed with water is standard procedure for the extraction of lipids from modern samples. Following Evershed et al. (1990), who reported that this step was unnecessary for the analysis of archaeological residues, previously the solvent-lipid mixture was not washed. This step was adopted to remove impurities so that clearer chromatograms could be obtained in the region where very long chain fatty acids (C20:0, C20:1, C22:0, and C24:0) occur. It was anticipated that the detection and accurate assessment of these fatty acids could be instrumental in separating residues of animal origin from those of plant (Malainey et al. 2000a, 2000b, 2000c, 2001a).

In order to identify the residue, the relative percentage composition was determined first with respect to all fatty acids present in the sample (including very long chain fatty acids) (see Table D-4) and secondly with respect to the ten fatty acids utilized in the development of the identification criteria (C12:0, C14:0, C15:0, C16:0, C16:1, C17:0, C18:0, C18:1w9, C18:1w11, and C18:2) (not shown). The second step is necessary for the application of the identification criteria presented in Table D-3. 
Table D-4. Fatty Acid Composition and Identification of Archaeological Residues*

\begin{tabular}{|c|c|c|c|c|c|c|c|c|}
\hline \multirow{2}{*}{ Fatty acid } & \multicolumn{2}{|c|}{ 7UT 43} & \multicolumn{2}{|c|}{ 7UT 45} & \multicolumn{2}{|c|}{ 7UT 47} & \multicolumn{2}{|c|}{ 7UT 48} \\
\hline & Area & Rel\% & Area & Rel\% & Area & Rel\% & Area & Rel\% \\
\hline C12:0 & 613 & 0.12 & 11283 & 2.21 & 63 & 0.02 & 85 & 0.01 \\
\hline C14:0 & 3972 & 0.76 & 48689 & 9.54 & 7821 & 2.27 & 5412 & 0.45 \\
\hline C14:1 & 0 & 0 & 5321 & 1.04 & 0 & 0 & 0 & 0 \\
\hline C15:0 & 13952 & 2.68 & 174106 & 34.11 & 167066 & 48.46 & 21426 & 1.78 \\
\hline C16:0 & 106483 & 20.42 & 98264 & 19.25 & 80842 & 23.45 & 190333 & 15.84 \\
\hline C16:1 & 21138 & 4.05 & 19768 & 3.87 & 9303 & 2.7 & 2580 & 0.21 \\
\hline $\mathrm{C} 17: 0$ & 1504 & 0.29 & 3361 & 0.66 & 1786 & 0.52 & 3133 & 0.26 \\
\hline $\mathrm{C} 17: 1$ & 0 & 0 & 0 & 0 & 0 & 0 & 0 & 0 \\
\hline C18:0 & 20152 & 3.86 & 31413 & 6.15 & 25859 & 7.5 & 907293 & 75.52 \\
\hline $\mathrm{C} 18: 1 \mathrm{~s}$ & 293270 & 56.23 & 86786 & 17 & 38429 & 11.15 & 47517 & 3.96 \\
\hline C18:2 & 37260 & 7.14 & 7015 & 1.37 & 0 & 0 & 6000 & 0.5 \\
\hline C18:3w3 & 2741 & 0.53 & 0 & 0 & 0 & 0 & 0 & 0 \\
\hline C20:0 & 6383 & 1.22 & 4491 & 0.88 & 5368 & 1.56 & 7752 & 0.65 \\
\hline C20:1 & 9834 & 1.89 & 14758 & 2.89 & 4457 & 1.29 & 8192 & 0.68 \\
\hline C24:0 & 4212 & 0.81 & 5236 & 1.03 & 3721 & 1.08 & 1697 & 0.14 \\
\hline Total & 521514 & 100 & 510491 & 100 & 344716 & 100 & 1201420 & 100 \\
\hline Identification & \multicolumn{2}{|c|}{$\begin{array}{l}\text { Very high fat content } \\
\text { (nuts/seeds) }\end{array}$} & \multicolumn{2}{|c|}{$\begin{array}{l}\text { Medium fat content } \\
\text { combined with low fat } \\
\text { content }\end{array}$} & \multicolumn{2}{|c|}{ Low fat content plant } & \multicolumn{2}{|c|}{ Large Herbivore } \\
\hline
\end{tabular}

* insufficient lipids present in samples 7UT44 and 7UT46 to attempt identification

It must be understood that the identifications given do not necessarily mean that those particular foods were actually prepared because different foods of similar fatty acid composition and lipid content would produce similar residues. It is possible only to say that the material of origin for the residue was similar in composition to the food(s) indicated.

\section{Gas Chromatography Analysis Parameters}

The GC analysis was performed on a Varian 3800 gas chromatograph fitted with a flame ionization detector connected to a personal computer. Samples were separated using a DB-23 fused silica capillary column (30 m X 0.25 mm I.D.; J\&W Scientific; Folsom, CA). An autosampler injected a $3 \mu \mathrm{L}$ sample using a split/splitless injection system. Hydrogen was used as the carrier gas with a column flow of $1.0 \mathrm{~mL} / \mathrm{min}$. Column temperature was held at $80^{\circ} \mathrm{C}$ for 1 minute then increased to $140^{\circ} \mathrm{C}$ at a rate of $20^{\circ} \mathrm{C}$ per minute. It was then programmed from 140 to $230^{\circ} \mathrm{C}$ at $4{ }^{\circ} \mathrm{C}$ per minute. The upper temperature was held for 17 minutes. Chromatogram peaks were integrated using Varian MS Workstation ${ }^{\circledR}$ software and identified through comparisons with external qualitative standards (NuCheck Prep; Elysian, MN).

\section{Results of Archaeological Data Analysis}

The fatty acid compositions of residues with sufficient lipids for analysis are presented in Table D-4. The term, Area, represents the area under the chromatographic peak of a given fatty acid, as calculated by the Varian MS Workstation ${ }^{\circledR}$ software minus the solvent blank. The term, Rel\%, represents the relative percentage of the fatty acid with respect to the total fatty acids in the sample. Hydroxide or peroxide degradation products interfered with the integration of the $\mathrm{C} 22: 0$ and $\mathrm{C} 22: 1$ peaks; these fatty acids were excluded from the analysis. Insufficient lipids were present in two archaeological residues, 7 UT 44 and 7UT 46, to attempt their identification; the amounts in residue 7 UT 47 were low. 
The level of C18:1 isomers in one residue, $7 \mathrm{UT} 43,56.23 \%$, is very high. Similar levels are observed in the decomposed residues of very high fat content seeds or nuts, such as piñon. Rendered fats of certain mammals (other than large herbivores) exhibit similarly very high levels of C18:1 isomers, but only when fresh. This residue also has an elevated level of C18:2 and a low level of C18:0, suggesting it is from plant material.

Two residues, 7UT 45 and 7UT 47, are characterized by every high levels of medium chain fatty acids. The sum of C12:0, $\mathrm{C} 14: 0$ and $\mathrm{C} 15: 0$ in these residues are $45.85 \%$ and $50.75 \%$, respectively, which is rather unusual. Levels of C18:1 isomers in the residues differ somewhat. The level of C18:1 isomers in 7 UT 47 suggest the residue represents low fat content plant. Certain types of plant roots, greens and fruits or berries produced similar residues. The level of C18:1 isomers in residue 7 UT 45 is consistent with a medium fat content food. Given the high level of medium chain fatty acids, residue 7UT 45 seems to represent a combination of a medium fat content food and low fat content plant. Research has shown that the decomposed cooking residues from a variety of plant and animal foods are of medium fat content, including freshwater fish, fat depleted elk, Rabdotus snails and terrapin, corn, mesquite beans and cholla (Malainey 2007; Table D-3).

One residue, 7UT 48, has an extremely high level of C18:0, over 75\%. Values over 61\% were found in Late Precontact period pottery residues from bison kill sites in Saskatchewan and Alberta; the higher level of C18:0 may mean residue 7UT 48 is more highly decomposed. The C18:0 fatty acid is often associated with the preparation of large herbivore products. Large herbivore residues result from the preparation of bison, deer, moose, fat elk meat or other bovines or cervids; but javelina meat and tropical oil seeds also produce residues high in C18:0 and must be considered as potential sources where available. 


\section{References Cited:}

Collins M. B., B. Ellis, and C. Dodt-Ellis

1990 Excavations at the Camp Pearl Wheat Site (41KR243): An Early Archaic Campsite on Town Creek, Kerr County, Texas. Studies in Archaeology 6. Texas Archaeological Research Laboratory, The University of Texas at Austin.

Condamin, J., F. Formenti, M. O. Metais, M. Michel, and P. Blond 1976 The Application of Gas Chromatography to the Tracing of Oil in Ancient Amphorae. Archaeometry 18(2):195-201.

deMan, J. M.

1992 Chemical and Physical Properties of Fatty Acids. In Fatty Acids in Foods and their Health Implications, edited by C. K. Chow, pp. 17-39. Marcel Dekker, New York.

Evershed, R. P., C. Heron, and L. J. Goad 1990 Analysis of Organic Residues of Archaeological Origin by High Temperature Gas Chromatography and Gas Chromatography-Mass Spectroscopy. Analyst 115:1339-1342.

Folch, J., M. Lees, and G. H. Sloane-Stanley 1957 A Simple Method for the Isolation and Purification of Lipid Extracts from Brain Tissue. Journal of Biological Chemistry 191:833.

Frankel, E. N.

1991 Recent Advances in Lipid Oxidation. Journal of the Science of Food and Agriculture 54:465-511.

Loy, T.

1994 Residue Analysis of Artifacts and Burned Rock from the Mustang Branch and Barton Sites (41HY209 and 41HY202). In Archaic and Late Prehistoric Human Ecology in the Middle Onion Creek Valley, Hays County, Texas, Vol. 2: Topical Studies, by R. A. Ricklis and M. B. Collins, pp. 607- 627. Studies in Archeology 19, Texas Archaeological Research Laboratory, The University of Texas at Austin.

Malainey, M. E.

1997 The Reconstruction and Testing of Subsistence and Settlement Strategies for the Plains, Parkland and Southern boreal forest. Unpublished Ph.D. thesis, University of Manitoba.

2007 Chapter 7: Fatty Acid Analysis of Archaeological Residues: Procedures and Possibilities,In Theory and Practice of Archaeological Residue Analysis, edited by H. Barnard and J. Eerkens, BAR International Series of Archaeopress, Oxford.

Malainey, M. E., K. L. Malisza, R. Przybylski, and G. Monks

2001a The Key to Identifying Archaeological Fatty Acid Residues. Paper presented at the 34th Annual Meeting of the Canadian Archaeological Association, Banff, Alberta, May 2001.

Malainey, M. E., R. Przybylski, and B. L. Sherriff

1999a The Fatty Acid Composition of Native Food Plants and Animals of Western Canada. Journal of Archaeological Science 26:83-94.

1999b The Effects of Thermal and Oxidative Decomposition on the Fatty Acid Composition of Food Plants and Animals of Western Canada: Implications for the Identification of archaeological vessel residues. Journal of Archaeological Science 26:95-103.

1999c Identifying the Former Contents of Late Precontact Period Pottery Vessels from Western Canada Using Gas Chromatography. Journal of Archaeological Science 26(4): 425-438. 
2001b One Person's Food: How and Why Fish Avoidance May Affect the Settlement and Subsistence Patterns of HunterGatherers. American Antiquity 66(1): 141-161.

Malainey, M. E., R. Przybylski, and G. Monks

2000a The identification of archaeological residues using gas chromatography and applications to archaeological problems in Canada, United States and Africa. Paper presented at The 11th Annual Workshops in Archaeometry, State University of New York at Buffalo, February 2000.

$2000 \mathrm{~b}$ Refining and testing the criteria for identifying archaeological lipid residues using gas chromatography. Paper presented at the 33rd Annual Meeting of the Canadian Archaeological Association, Ottawa, May 2000.

2000c Developing a General Method for Identifying Archaeological Lipid Residues on the Basis of Fatty Acid Composition. Paper presented at the Joint Midwest Archaeological \& Plains Anthropological Conference, Minneapolis, Minnesota, November 2000.

Marchbanks, M. L.

1989 Lipid Analysis in Archaeology: An Initial Study of Ceramics and Subsistence at the George C. Davis Site. Unpublished M.A. thesis, The University of Texas at Austin.

Marchbanks, M. L., and J. M. Quigg

1990 Appendix G: Organic Residue and Phytolith Analysis. In Phase II Investigations at Prehistoric and Rock Art Sites, Justiceburg Reservoir, Garza and Kent Counties, Texas, Volume II, by D. K. Boyd, J. T. Abbott, W. A.Bryan, C. M. Garvey, S. A. Tomka and R. C. Fields. pp. 496-519. Reports of Investigations No. 71. Prewitt and Associates, Inc, Austin.

Patrick, M., A. J. de Konig, and A. B. Smith

1985 Gas Liquid Chromatographic Analysis of Fatty Acids in Food Residues from Ceramics Found in the Southwestern Cape, South Africa. Archaeometry 27(2): 231-236.

Quigg, J. M., C. Lintz, S. Smith, and S. Wilcox

2000 The Lino Site: A Stratified Late Archaic Campsite in a Terrace of the San Idelfonzo Creek, Webb County, Southern Texas. Technical Report No. 23765, TRC Mariah Associates Inc., Austin. Texas Department of Transportation, Environmental Affairs Division, Archaeological Studies Program Report 20, Austin.

Quigg, J. M., M. E. Malainey, R. Przybylski, and G. Monks

2001 No Bones about It: Using Lipid Analysis of Burned Rock and Groundstone Residues to Examine Late Archaic Subsistence Practices in South Texas. Plains Anthropologist 46(177): 283-303.

Skibo, J. M.

1992 Pottery Function: A Use-Alteration Perspective. Plenum Press, New York.

Solomons, T. W. G.

1980 Organic Chemistry. John Wiley \& Sons, Toronto. 
Appendix E:

Analysis of Plant Remains at 41KM69 and 41 KM69

Flotation Inventory

\author{
J. Philip Dering
}





\title{
Appendix E
}

\section{Analysis of Plant Remains at 41KM69 and 41 KM69 Flotation Inventory}

\author{
J. Philip Dering \\ Shumla Archeobotanical Services
}

The purpose of this analysis is to identify and describe the botanical remains in samples recovered from data recovery excavations at 41KM69, a multi-component campsite on the South Llano River. Sixty-five flotation samples totaling 143.9 liters were floated by personnel at Center for Archeological Research, The University of Texas at San Antonio. The light fractions were submitted to Shumla Archeobotanical Services for analysis.

\section{Methods}

The analysis followed standard archeobotanical laboratory procedures for flotation samples. Flotation is a method of recovering organic remains from archeological sediment samples by using water to separate heavy or soluble inorganic particles from plant parts and small animal bone. The material floating to the surface is called the light fraction, and this is caught on a fine mesh screen or strainer. The material that sinks to the bottom is the heavy fraction, and it is also caught on a series of screens. Most of the soil including clay and silt is suspended in water, passes through the screens, and is either recycled or discarded.

At the most open sites, only carbonized plant remains are considered to be a potential part of the archeological record. In some rare cases, certain durable and easily identifiable wood types such as juniper may survive in a partially carbonized state, but only at younger sites, particularly in the case of historic sites. Uncarbonized seeds and fruits are considered to be of recent origin.

The light fractions of each flotation sample were passed through a nested set of screens of 4-mm, 2-mm, 1-mm, and 0.450-mm mesh and examined for charred material that is separated for identification. Carbonized wood from the $4 \mathrm{~mm}$ and $2 \mathrm{~mm}$ screens (smaller pieces are seldom identifiable) is separated in a 25-piece grab sample and identified. In cases where the charred wood is abundant (more than 25 fragments), instead of counting each fragment the volume of the wood charcoal is recorded. The charred material caught on all the smaller sieve levels $(1 \mathrm{~mm}$ and $0.450 \mathrm{~mm})$ and the bottom pan is scanned for floral parts, fruits, seeds, and other potentially edible or useful plant parts such as yucca fibers. All of the potentially edible plant parts are counted and examined for identification.

Identification of wood is accomplished by snapping a fragment across the transverse and radial planes, examining the fragments at 8 to 45 magnifications with a binocular dissecting microscope, and comparing the material to samples in the archeobotanical herbarium. Seeds and fruit fragments are identified using reference specimens in the Shumla Archeobotanical Services laboratory. Counts and weights from each sample are presented in tabular format. These data reflect the potential for the site to provide some preliminary information on local vegetation and land use.

Disturbance Indicators. Sample content may be affected by various biological disturbance factors, including insect or small mammal activity, and plant root growth. In an effort to assess this impact, the quantity of root fragments, insect parts, termite pellets, gastropods, mammal remains (including fecal pellets), and modern uncharred seeds are estimated for each flotation sample. These amounts are reported on a scale of 1-5 (+), 6-25 (++), 26-50 (+++), and over $50(++++)$.

\section{Results}

Table E-1 presents a summary of the samples, including number, provenience, disturbance indicators, and weight of plant materials recovered from the flotation samples. Carbonized plant remains were identified from 31 of the 63 samples. The analysis noted a total of $6.9 \mathrm{~g}$ of carbonized plant material, including wood, fiber fragments, seeds, and nut fragments. The severely degraded condition of the charred plant remains 1 suggests that the material has been subjected to repeated wet-dry cycles; many of the flotation samples contain dark, sooty material that is made up of tiny fragments of charcoal. 
Table E-1. Flotation Sample Summary

\begin{tabular}{|c|c|c|c|c|c|c|c|c|c|c|}
\hline $\begin{array}{l}\# \\
0 \\
0\end{array}$ & 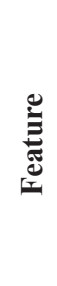 & 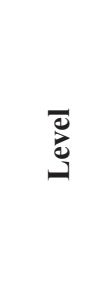 & 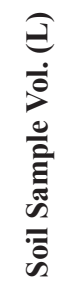 & 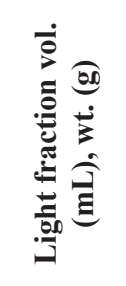 & 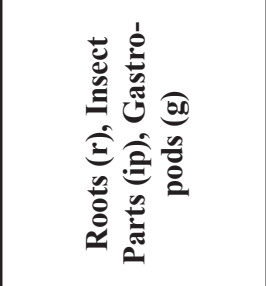 & 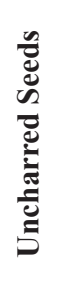 & 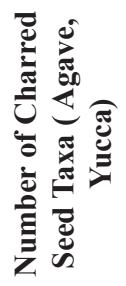 & 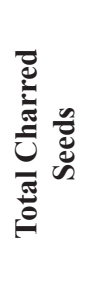 & 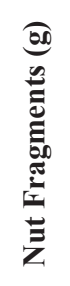 & 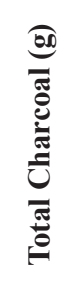 \\
\hline 1820 & 1 & 8 & 9.7 & $34 ; 12.3$ & $\mathrm{r}+++, \mathrm{g}+++$, ip ++ & 1 & 2 & 1 & 0.1 & 0.3 \\
\hline 1824 & 1 & 5 & 6.5 & $17 ; 5.7$ & $\mathrm{r}+++, \mathrm{g}+++$, ip ++ & 1 & 2 & 1 & 0.2 & 0.4 \\
\hline 1045 & 2 & 5 & 1.1 & $26 ; 4.3$ & $\mathrm{r}+++, \mathrm{g}+$ & 0 & 0 & 0 & 0 & 0.1 \\
\hline 1825 & 2 & 7 & 6.4 & $17 ; 4.1$ & $\mathrm{r}+++, \mathrm{g}++$ & 1 & 0 & 0 & 0.2 & 0.3 \\
\hline 151 & 13 & 6 & 1.5 & $5 ; 0.1$ & $\mathrm{r}+++; \mathrm{g}+$ & 1 & 0 & 0 & 0 & $<0.1$ \\
\hline 163 & 16 & 7 & 3 & $34 ; 7.4$ & $\mathrm{r}+++, \mathrm{g}++, \mathrm{ip}++$ & 1 & 2 & 2 & 0.1 & 0.3 \\
\hline 164 & 17 & 7 & 3.3 & $37 ; 12.7$ & $\mathrm{r}+++; \mathrm{g}+++$ & 2 & 1 & 1 & 0.3 & 0.5 \\
\hline 184 & 18 & 7 & 3.2 & $27 ; 4.9$ & $\mathrm{r}+++; \mathrm{g}+++$ & 2 & 0 & 0 & 0 & 0.4 \\
\hline 185 & 19 & 7 & 1.6 & $12 ; .4$ & $\mathrm{r}+++$ & 0 & 0 & 0 & 0 & $<<.1$ \\
\hline 185 & 19 & 7 & 1.5 & $17 ; 3.1$ & $\mathrm{r}+++; \mathrm{g}+++$ & 1 & 0 & 0 & 0 & 0.1 \\
\hline 393 & 22 & 7 & 1 & $7 ; 1.2$ & $\mathrm{r}+++; \mathrm{g}++$ & 0 & 0 & 0 & 0 & 0 \\
\hline 225 & 31 & 8 & 1.5 & $12 ; 3.7$ & $\mathrm{r}+++; \mathrm{g}+++$ & 1 & 0 & 0 & 0 & 0.1 \\
\hline 470 & 34 & 8 & 2.6 & $32 ; 11.2$ & $\mathrm{R}+++, \mathrm{g}+++$ & 2 & 0 & 0 & 0 & 0.0 \\
\hline 444 & 35 & 13 & 1.1 & $9 ; 1.2$ & $\mathrm{r}+++$ & 0 & 0 & 0 & 0 & 0 \\
\hline 471 & 36 & 10 & 2.6 & $5 ; 0.3$ & $\mathrm{r}+++; \mathrm{g}++$ & 0 & 0 & 0 & 0 & 0.4 \\
\hline 757 & 39 & 9 & 4.8 & $11 ; 6.1$ & $\mathrm{r}+++; \mathrm{g}++;$ ip + & 0 & 0 & 0 & 0.2 & 0.2 \\
\hline 998 & 40 & 7,8 & 0.8 & $3 ; 0.2$ & $\mathrm{r}+++$ & 0 & 0 & 0 & 0 & $<0.1$ \\
\hline 1062 & 41 & & 3 & $27 ; 6.9$ & $\mathrm{r}+++; \mathrm{g}++;$ ip + & 2 & 0 & 0 & 0 & 0.4 \\
\hline 1077 & 42 & & 3.3 & $22 ; 7.7$ & $\mathrm{r}++++; \mathrm{g}++$ & 0 & 0 & 0 & 0 & 0 \\
\hline 1078 & 43 & 11 & 3.5 & $5 ; 0.2$ & $\mathrm{r}+++$ & 0 & 0 & 0 & 0 & 0.1 \\
\hline 1183 & 45 & 10 & 3.5 & $20 ; 4.1$ & $\mathrm{r}+++, \mathrm{g}++$, ip ++ & 2 & 0 & 0 & 0 & 0.1 \\
\hline 1238 & 46 & Fill & 1.3 & $4 ; 0.1$ & $\mathrm{r}+++$ & 0 & 0 & 0 & 0 & $<.1$ \\
\hline 1238 & 46 & Fill & 1.5 & $22 ; 4.9$ & $\mathrm{r}+++; \mathrm{g}+$ & 2 & 0 & 0 & 0 & 0 \\
\hline 1301 & 47 & & 2.6 & $12 ; 3.5$ & $\mathrm{r}+++$; $\mathrm{g}++;$ ip + & 1 & 0 & 0 & 0 & 0.1 \\
\hline 1279 & 48 & 10 & 1.6 & $6 ; 2.0$ & $\mathrm{r}+++$ & 0 & 0 & 0 & 0 & 0 \\
\hline 1284 & 49 & 11-Oct & 3.4 & $24 ; 5.9$ & $\mathrm{r}+++; \mathrm{g}+++$ & 0 & 0 & 0 & 0 & 0 \\
\hline 1505 & 50 & 14 & 3.9 & $27 ; 2.6$ & $\mathrm{r}+++$ & 4 & 0 & 0 & 0 & 0.1 \\
\hline 1511 & 52 & 8 & 3.7 & $22 ; 6.4$ & $\mathrm{r}+++; \mathrm{g}++$ & 1 & 0 & 0 & 0 & 0.2 \\
\hline 1627 & 53 & 11 & 1.4 & $12 ; 0.7$ & $\mathrm{r}+++; \mathrm{g}+++$ & 2 & 0 & 0 & 0 & 0.1 \\
\hline 1681 & 56 & 11 & 1.8 & $3 ; 0.1$ & $\mathrm{r}+++$ & 0 & 0 & 0 & 0 & $<0.1$ \\
\hline 1870 & 57 & 1 & $? ?$ & $22 ; 5.4$ & $\mathrm{r}+++; \mathrm{g}+++$ & 3 & 0 & 0 & 0 & 0.3 \\
\hline 1873 & 58 & 2 & 1.4 & $10 ; .8$ & $\mathrm{r}+++$; $\mathrm{g}++$ & 0 & 0 & 0 & 0 & 0 \\
\hline 1906 & 63 & 1 & 1.7 & $8 ; .3$ & $\mathrm{r}+++$ & 0 & 0 & 0 & 0 & 0 \\
\hline 1909 & 64 & 1 & 1.4 & $7 ; 0.3$ & $\mathrm{r}+++$ & 0 & 0 & 0 & 0 & $<.1$ \\
\hline 1905 & 65 & 1 & 2 & $5 ; 0.1$ & $\mathrm{r}+++$ & 0 & 0 & 0 & 0 & 0 \\
\hline 1902 & 66 & 1 & 1.6 & $4 ; 0.3$ & $\mathrm{r}+++$ & 0 & 0 & 0 & 0 & 0 \\
\hline 1920 & 67 & 1 & 1.6 & $17 ; 0.7$ & $\mathrm{r}+++$ & 0 & 0 & 0 & 0 & 0 \\
\hline 1921 & 68 & 1 & 1.4 & $8 ; 0.2$ & $\mathrm{r}+++$ & 0 & 0 & 0 & 0 & 0 \\
\hline
\end{tabular}


Table E-1. Flotatation Sample Summary continued....

\begin{tabular}{|c|c|c|c|c|c|c|c|c|c|c|}
\hline $\begin{array}{l}\# \\
\text { \# } \\
\text { 足 }\end{array}$ & 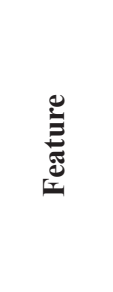 & d্త & 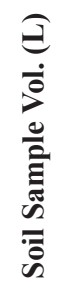 & 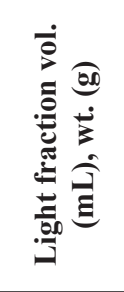 & 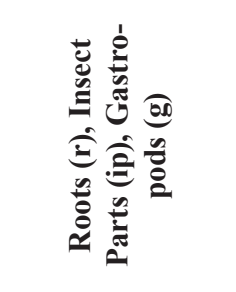 & 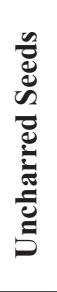 & 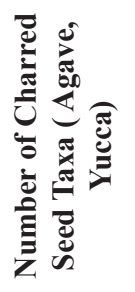 & 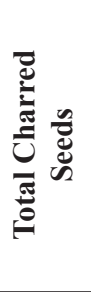 & 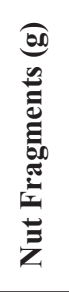 & 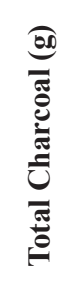 \\
\hline 1924 & 69 & 1 & 1 & $4 ; 0.1$ & $\mathrm{r}+++$ & 0 & 0 & 0 & 0 & 0 \\
\hline 1912 & 70 & 1 & 1.6 & $20 ; 0.9$ & $\mathrm{r}+++$ & 0 & 0 & 0 & 0 & 0 \\
\hline 1917 & 71 & 1 & 1.5 & $35 ; 12.4$ & $\mathrm{r}+++$, silt & 0 & 0 & 0 & 0 & 0 \\
\hline 1891 & 73 & 1 & 1.7 & $12 ; 0.8$ & $\mathrm{r}+++; \mathrm{g}++$ & 2 & 0 & 0 & 0 & 0 \\
\hline 1900 & 75 & 1 & 1.7 & $5 ; 0.2$ & $\mathrm{r}+++$ & 0 & 0 & 0 & 0 & 0 \\
\hline 1897 & 76 & 1 & 1.2 & $6 ; 0.4$ & $\mathrm{r}+++$ & 0 & 0 & 0 & 0 & 0 \\
\hline 1933 & 78 & 1 & 1.7 & $42 ; 8.9$ & $\mathrm{r}+++, \mathrm{g}++$, ip + & 0 & 2 & 8 & 0.3 & 1.1 \\
\hline 1930 & 79 & 1 & 1.8 & $11 ; 0.7$ & $\mathrm{r}+++$ & 0 & 0 & 0 & 0 & $<0.1$ \\
\hline 1938 & 80 & 1 & 1.6 & $5 ; .3$ & $\mathrm{r}+++$ & 0 & 0 & 0 & 0 & 0 \\
\hline 1945 & 82 & 1 & 1.6 & $23 ; 8.3$ & $\mathrm{r}+++$ & 0 & 0 & 0 & 0 & 0.2 \\
\hline 1948 & 83 & 1 & 1.7 & $12 ; .7$ & $\mathrm{r}+++; \mathrm{g}+$ & 0 & 0 & 0 & 0 & $<0.1$ \\
\hline 1951 & 84 & 1 & 1.4 & $18 ; 3.2$ & $\mathrm{r}+++; \mathrm{g}++$ & 0 & 1 & 2 & 0.1 & 0.2 \\
\hline 1953 & 85 & 1 & 1.9 & $7 ; .3$ & $\mathrm{r}+++; \mathrm{g}+$ & 0 & 0 & 0 & 0 & 0.1 \\
\hline 1958 & 86 & 1 & 2 & $18 ; 2.7$ & $\mathrm{r}+++$ & 0 & 0 & 0 & 0 & 0 \\
\hline 1964 & 88 & 1 & 2.7 & $22 ; 2.3$ & $\mathrm{r}+++, \mathrm{g}+$ & 2 & 0 & 0 & 0 & 0 \\
\hline 1966 & 89 & 1 & 0.3 & $1 ;<.1$ & $\mathrm{r}+$ & 0 & 0 & 0 & 0 & 0 \\
\hline 1967 & 89 & 1 & 2.9 & $3 ; 0.2$ & $\mathrm{r}+++$ & 0 & 0 & 0 & 0 & 0 \\
\hline 1974 & 91 & 1 & 2.3 & $12 ; 3.1$ & $\mathrm{r}+++, \mathrm{g}+$ & 0 & 0 & 0 & 0 & 0 \\
\hline 1977 & 92 & 1 & 2.1 & $10 ; 0.3$ & $\mathrm{r}+++, \mathrm{g}++$ & 0 & 0 & 0 & 0 & 0 \\
\hline 1985 & 94 & 1 & 1.6 & $12 ; 2.6$ & $\mathrm{r}+++, \mathrm{g}+$ & 0 & 0 & 0 & 0 & $<0.1$ \\
\hline 1987 & 95 & 1 & 2.3 & $<1 ;<.1$ & -- & 0 & 0 & 0 & 0 & 0 \\
\hline 1991 & 96 & 1 & 2.1 & $19 ; 2.1$ & $\mathrm{r}+++$ & 0 & 0 & 0 & 0 & 0 \\
\hline 1995 & 97 & 1 & 2 & $6 ; 0.7$ & $\mathrm{r}+++$ & 0 & 0 & 0 & 0 & 0 \\
\hline 1279 & $12 ; 1.3$ & Fill & 1.9 & $12 ; 1.3$ & $\mathrm{r}+++$ & 0 & 0 & 0 & 0 & 0.3 \\
\hline 958 & $3 \mathrm{~B}$ & $58-71$ & 3.5 & $34 ; 5.7$ & $\mathrm{r}+++; \mathrm{g}+++$ & 0 & 0 & 0 & 0 & 0.1 \\
\hline
\end{tabular}

Disturbance indicators were abundant. Roots and gastropod shells constituted the majority of the disturbance indicators. A few samples contained insect fragments. Uncarbonized seeds included Chenopodium album, sunflower achenes, and a few unidentified fragments of grass seeds.

\section{Taxa Identified in the Samples}

The identified taxa are presented by feature number and field sample number in Table E-2. Despite the small quantity of charred material, a remarkable plant assemblage was identified in the samples. Plant remains include pecan nut fragments, acorn fragments, wintergrass/needlegrass seed, wild cherry, and very long and slender fibers with imbedded calcium oxalate crystals that appear to be the remains of yucca leaves. These fibers contain styloid (rod-shaped) or raphide (needle-shaped) calcium oxalate crystals, typical of yucca, agave, or sotol. The wintergrass seeds (actually a caryopsis) are long and slender, measuring about 4-to 5-mm. They are remarkably well-preserved considering the condition of most of the wood charcoal in the samples. Likewise the Agavaceae fibers occurred in great abundance in one sample (from Feature 78) and in lesser quantities in two other samples. Wood charcoal taxa include hackberry, Rose family (cf. Prunus sp.), hickory family, oak, and woody legume (cf. mesquite). By far oak was the most abundant of the wood types identified in the samples. Hickory-type, most likely pecan, was also fairly abundant. 
Table E-2. Plant Materials Identified in Flotation Samples from 41KM69

\begin{tabular}{|c|c|c|c|c|c|c|c|c|}
\hline Feature & FS\# & Level & Taxon & Common & Part & Count & Vol (ml) & Wt (g) \\
\hline 1 & 1820 & 8 & Quercus sp. & Oak & Wood & 12 & -- & 0.2 \\
\hline 1 & 1820 & 8 & Carya sp. & Walnut Family/ pecan & Wood & 7 & & 0.1 \\
\hline 1 & 1820 & 8 & Fabaceae & Woody legume & Wood & 3 & & $<0.1$ \\
\hline 1 & 1824 & 5 & Quercus sp. & Oak & Wood & 7 & & 0.1 \\
\hline 1 & 1824 & 5 & Carya illinoiensis & Pecan & Nut & 4 & & 0.1 \\
\hline 1 & 1824 & 5 & Ulmus sp. & Elm & Wood & 4 & & 0.1 \\
\hline 1 & 1824 & 5 & Fabaceae & Woody legume & Wood & 3 & & 0.1 \\
\hline 2 & 1045 & 5 & Quercus sp. & Oak & Acorn & 2 & & $<0.1$ \\
\hline 2 & 1045 & 5 & Quercus sp. & Oak & Wood & 3 & & 0.1 \\
\hline 2 & 1825 & 7 & Quercus sp. & Oak & Wood & 12 & & 0.2 \\
\hline 2 & 1825 & 7 & Carya illinoiensis & Pecan & Nut & 6 & & 0.1 \\
\hline 2 & 1825 & 7 & Carya sp. & Walnut Family/ pecan & Wood & 8 & & 0.1 \\
\hline 2 & 1825 & 7 & Rosaceae & Rose/Cherry Family & Wood & 3 & & 0.1 \\
\hline 13 & 151 & 6 & Indeterminate & NA & Wood & 12 & & $<0.1$ \\
\hline 16 & 163 & 7 & Quercus sp. & Oak & Wood & 9 & & 0.2 \\
\hline 16 & 163 & 7 & Quercus sp. & Oak & Acorn & 3 & & $<0.1$ \\
\hline 16 & 163 & 7 & Carya sp. & Pecan & Nut & 4 & & 0.1 \\
\hline 16 & 163 & 7 & Fabaceae & Woody legume & Wood & 7 & & 0.1 \\
\hline 16 & 163 & 7 & Quercus sp. & Oak & Wood & 12 & & 0.1 \\
\hline 17 & 164 & 7 & Celtis sp. & Hackberry & Wood & 4 & & 0.1 \\
\hline 17 & 164 & 7 & Quercus sp. & Oak & Wood & 7 & & 0.2 \\
\hline 17 & 164 & 7 & Carya illinoiensis & Pecan & Nut & 6 & & 0.1 \\
\hline 17 & 164 & 7 & Agavaceae & cf. Yucca sp & Fiber & 7 & & $<0.1$ \\
\hline 17 & 164 & 7 & Rosaceae & Rose/Cherry Family & Wood & 4 & & 0.1 \\
\hline 18 & 184 & 7 & Quercus sp. & Oak & Wood & 12 & & 0.2 \\
\hline 18 & 184 & 7 & Celtis sp. & Hackberry & Wood & 8 & & 0.1 \\
\hline 18 & 184 & 7 & Nassella sp. & Wintergrass, speargrass & Seed & 2 & & -- \\
\hline 18 & 184 & 7 & Rosaceae & Rose/Cherry Family & Wood & 5 & & 0.1 \\
\hline 19 & 185 & 7 & Quercus sp. & Oak & Wood & 9 & & 0.1 \\
\hline 19 & 185 & 7 & Indeterminate & NA & Wood & 8 & & $<0.1$ \\
\hline 31 & 225 & 8 & Quercus sp. & Oak & Wood & 12 & & 0.1 \\
\hline 34 & 470 & 8 & & & & & & \\
\hline 36 & 471 & 10 & Quercus sp. & Oak & Wood & 14 & & 0.2 \\
\hline 36 & 471 & 10 & Rosaceae & Rose/Cherry Family & Wood & 4 & & $<0.1$ \\
\hline 36 & 471 & 10 & Carya sp. & Pecan & Nut & 3 & & 0.1 \\
\hline 36 & 471 & 10 & Celtis sp. & Hackberry & Wood & 9 & & 0.1 \\
\hline 39 & 757 & 9 & Quercus sp. & Oak & Wood & 14 & & 0.2 \\
\hline 40 & 998 & 7,8 & Indeterminate & NA & Wood & 7 & & $<0.1$ \\
\hline 41 & 1062 & & Quercus sp. & Oak & Wood & 13 & & 0.2 \\
\hline 41 & 1062 & & Carya sp. & Walnut Family/ pecan & Wood & 8 & & 0.1 \\
\hline 41 & 1062 & & Carya illinoiensis & Pecan & Nut & 4 & & 0.1 \\
\hline 43 & 1078 & 11 & Quercus sp. & Oak & Wood & 5 & & 0.1 \\
\hline 45 & 1183 & 10 & Quercus sp. & Oak & Wood & 9 & & 0.1 \\
\hline 46 & 1238 & Fill & Indeterminate & NA & Wood & 7 & & $<0.1$ \\
\hline 47 & 1301 & & Quercus sp. & Oak & Wood & 4 & & 0.1 \\
\hline
\end{tabular}


Table E-2. Plant Materials Identified in Flotation Samples from 41KM69 continued....

\begin{tabular}{|c|c|c|c|c|c|c|c|c|}
\hline Feature & FS\# & Level & Taxon & Common & Part & Count & Vol (ml) & Wt (g) \\
\hline 47 & 1301 & & Quercus sp. & Oak & Acorn & 2 & & $<0.1$ \\
\hline 50 & 1505 & 14 & Celtis sp. & Hackberry & Wood & 12 & & 0.1 \\
\hline 52 & 1511 & 8 & Quercus sp. & Oak & Wood & 5 & & 0.1 \\
\hline 52 & 1511 & 8 & Agavaceae & cf. Yucca sp & Fiber & 9 & & $<0.1$ \\
\hline 52 & 1511 & 8 & Celtis sp. & Hackberry & Wood & 4 & & 0.1 \\
\hline 53 & 1627 & 11 & Quercus sp. & Oak & Wood & 7 & & 0.1 \\
\hline 53 & 1627 & 11 & Carya illinoiensis & Pecan & Nut & 3 & & $<0.1$ \\
\hline 56 & 1681 & 11 & Indeterminate & NA & Wood & 13 & & $<0.1$ \\
\hline 57 & 1870 & 1 & Quercus sp. & Oak & Wood & 8 & & 0.1 \\
\hline 57 & 1870 & 1 & Carya sp. & Walnut Family/ pecan & Wood & 4 & & 0.1 \\
\hline 57 & 1870 & 1 & Nassella sp. & Wintergrass, speargrass & Seed & 2 & & - \\
\hline 64 & 1909 & 1 & Indeterminate & NA & Wood & 13 & & $<0.1$ \\
\hline 78 & 1933 & 1 & Nassella sp. & Wintergrass, speargrass & Seed & 6 & & -- \\
\hline 78 & 1933 & 1 & Carya illinoiensis & Pecan & Nut & 9 & & 0.2 \\
\hline 78 & 1933 & 1 & Agavaceae & cf. Yucca sp & Fiber & $25+$ & 4 & 0.5 \\
\hline 78 & 1933 & 1 & Quercus sp. & Oak & Wood & $25+$ & 2 & 0.3 \\
\hline 78 & 1933 & 1 & Indeterminate & NA & Wood & 7 & & 0.1 \\
\hline 79 & 1930 & 1 & Indeterminate & NA & Wood & 5 & & $<0.1$ \\
\hline 82 & 1945 & 1 & Quercus sp. & Oak & Wood & 4 & & 0.1 \\
\hline 82 & 1945 & 1 & Rosaceae & Rose/Cherry Family & Wood & 3 & & $<0.1$ \\
\hline 82 & 1945 & 1 & Carya illinoiensis & Pecan & Nut & 7 & & 0.1 \\
\hline 83 & 1948 & 1 & Carya illinoiensis & Pecan & Nut & 9 & & 0.1 \\
\hline 83 & 1948 & 1 & Carya sp. & Walnut Family/ pecan & Wood & 5 & & 0.1 \\
\hline 84 & 1951 & 1 & Quercus sp. & Oak & Wood & 12 & & 0.1 \\
\hline 84 & 1951 & 1 & Indeterminate & NA & Wood & 4 & & $<0.1$ \\
\hline 84 & 1951 & 1 & Celtis sp. & Hackberry & Wood & 10 & & 0.1 \\
\hline 85 & 1953 & 1 & Rosaceae & Rose/Cherry Family & Wood & 4 & & 0.1 \\
\hline 94 & 1985 & 1 & Indeterminate & NA & Wood & 13 & & $<0.1$ \\
\hline $12 ; 1.3$ & 1279 & Fill & Quercus sp. & Oak & Acorn & 5 & & $<0.1$ \\
\hline $12 ; 1.3$ & 1279 & Fill & Quercus sp. & Oak & Wood & 7 & & 0.1 \\
\hline $12 ; 1.3$ & 1279 & Fill & Indeterminate & NA & Wood & 14 & & 0.1 \\
\hline $3 \mathrm{~B}$ & 958 & $58-71$ & Quercus sp. & Oak & Wood & 7 & & 0.1 \\
\hline
\end{tabular}

\section{Wood Types}

As noted in Table E-3, oak is the most common wood type recovered from the samples. The assemblage strongly reflects a riverine vegetation, with pecan, hackberry, cherry-type, and oak. Notably lacking is juniper, a very common upland tree or shrub. However, this may be due to the location of the site within the South Llano River valley. The presence of woody legume is notable, for it may signal the presence of mesquite in the region. However, there was not enough material to identify the charcoal beyond the woody legume type.

\section{Nut Fragments}

Pecan nut fragments were recovered from 10 samples, including Features 1, 2, 16, 17, 36, 41, 53, 78, 82, and 83. Unlike hickory nuts, which often constitute the most abundant plant material recovered from sites in the eastern half of Texas, pecan is seldom identified from archaeological sites. This is likely due to the fact that pecan shell is thin and delicate compared to hickory nut 
Table E-3. Wood Types from 41KM69

\begin{tabular}{|c|c|c|c|}
\hline Taxon & Common & Samples Present & Weight (g) \\
\hline Carya sp. & Walnut Family/ pecan & 5 & 0.5 \\
\hline Celtis sp. & Hackberry & 6 & 0.7 \\
\hline Fabaceae & Woody legume & 3 & 0.2 \\
\hline Quercus sp. & Oak & 24 & 3.4 \\
\hline Rosaceae & Rose/Cherry Family & 6 & 0.4 \\
\hline Ulmus sp. & Elm & 1 & 0.1 \\
\hline
\end{tabular}

shell, and to the fact that pecans were not processed for oil, reducing the chances for pecan fragments to become charred. Even so, given the seasonal importance of pecan to the Native American diet, it is surprising that the material from 41KM69 is one of the few reports of pecan from archeological sites in Texas (Hall 2000). In addition to the pecan nuts, acorn fragments were recovered from Features 2, 16, 47, and 12. This constitutes a rare find of acorn remains from a site on the Edwards Plateau, despite the fact that the region is an oak-savannah.

\section{Texas Wintergrass}

Seeds of Nassella sp. (formerly Stipa sp.) were noted from three samples recovered from Features 18, 57, and 78. Grass seeds are not often recovered from sites in Texas, and wintergrass (or needlegrass) has been reported from only one other site in Texas - Hinds Cave.

\section{Agavaceae - cf. Yucca}

Long, straight fibers of material closely resembling yucca were noted in three samples, Yucca was noted in abundance from Feature 78, and in lesser quantity from Feature 17 and 52. To find these fibers in such great quantity is unusual, and the fact that they contain abundant raphide/styloid calcium oxalate crystals suggests strongly that they represent the remains of either yucca or sotol.

\section{Discussion: Ethnobotanical Review}

Three of the resources identified from 41KM69 merit discussion and review because of the unusual nature of their occurrence. These are the wintergrass/needlegrass seeds, the cf. yucca fibers, and the pecan nut fragments. Each of these constitute potentially important plants that are underreported, or have never been reported from open archaeological sites in Texas.

\section{Wintergrass/needlegrass}

Wintergrass is reported from one other site in the southern plains periphery - Hinds Cave. Because it was recovered from a Late/Transitional Archaic midden deposit in a dry rockshelter, it was possible to identify the well-preserved floret and seed to species, Nassella leucotricha, or Texas wintergrass. The material from 41KM69 consists of several charred seeds (caryopsis), an unusual find, but not sufficiently complete to identify beyond the genus level. Although there are no recorded uses for Nassella, Texas wintergrass was once placed in a genus (Stipa) that has since been separated into many genera. These plants are, from an applied view, essentially identical in form; that is, they have a long, slender, oversized seed, tipped with a sharp point and possessing a long, trailing awn. The Hopi used the closely related New Mexico needlegrass as a ceremonial necklace (Colton 1974). In a more mundane application, closely related species were used for food by the Kawaiisu (Zigmond 1981), and given the context of the charred seeds at 41KM69, this is the likely application. In preparation for grinding, grass seeds were often parched to remove the membranes surrounding them, greatly increasing the possibility of charring.

\section{Yucca}

The identity of the fibers recovered from 41KM69 cannot be absolutely ascertained, but given the dense concentration and thin, calcium oxalate impregnated nature of the fibers, they are likely yucca. Although sotol is a possible identification, the material is somewhat thinner and there is a lot more of it than one would find in a group of sotol leaves. The most likely species of yucca 
in the region is a thin-leaved, dry-fruited Yucca constricta. This yucca was most likely utilized for its strong fibers, and not for food. At any rate, the straight fibers in the samples came from leaves and not from the central stem (where food is stored).

Yucca leaves posses fibers well suited for weaving and making rope or cordage, and the tissues of the plant contain saponins, which can be utilized for detergent. Additionally, the flowers and flower stalks are edible. The material at 41KM69 constitutes the most reliable find of tissue containing calcium oxalate-bearing fibers outside of a rockshelter in Texas. There are no archeological findings of yucca seeds from open sites, but in rockshelters with better preservation, however, the findings abound. San Angelo yucca, similar to Buckley yucca, was common in the trash deposits in Baker Cave, on the Devils River (Brown 1991). In all of the rockshelters in the Lower Pecos, where the preservation of plant materials is astonishingly good, both yucca leaves and yucca seeds occur by the thousands (Dering 1979, 1999). Until the discovery at 41KM69, fibers had not been described in open sites.

\section{Acorn}

Acorns are nuts that composed of a hard pericarp fused to a seedcoat that surrounds the food storage organ, two cotyledons. The cotyledons are the edible part of the acorn, but to process food stored in the cotyledons, harvesters have to remove the pericarp, a fairly tedious, labor intensive process. Despite the fact that the Edwards Plateau is an oak-savannah, acorns are seldom reported from archeological sites in the region. This does not mean that acorns were not utilized, but that the archeological evidence is scarce. In sheltered sites with excellent preservation, evidence of acorn utilization abounds, and rockshelter deposits in the Pecos River and Devils River areas contain large quantities of acorn fragments (Dering 1979). Thus, the presence of acorns in the deposits in 41KM69 provides some direct evidence of acorn use on the Edwards Plateau, evidence that was previously only reported from the Honey Creek site in Edwards County (Dering 1997).

Acorn processing was labor-intensive and seldom involved fire, a likely reason for the dearth of finds in archeological sites. In fact, in California, where ethnographic documentation is extensive, archeological evidence is lacking (Jackson 1991). Processing tools were mortars and pestles or manos and metates, carrying baskets, sifting baskets, leaching baskets, and brushes made of yucca fiber or other plants to clean out the mortars. The pericarp must first be removed before the cotyledons can be pounded into meal (Bean and Saubel 1972; Jackson 1991).

\section{Pecan}

Although historical sources note that pecan was collected by Native Americans, archeological investigations have uncovered little direct evidence of its use. Pecan trees grow well in deep soils along streams in east and central Texas, and creek and river terraces of central and southern Texas house thousands of acres of native pecan trees. Historic accounts note that the pecan groves of southern Texas were a focal point of Native American subsistence and a regular stop on the seasonal rounds of these hunters and gatherers.

Archaeological finds of pecan remains are relatively infrequent, and pecan is seldom recovered from archeological sites on the Edwards Plateau, the South Texas Plains, or the Coastal Plains of Texas. Thick lenses of pecan nut fragments are present in Baker Cave, a rockshelter located at the southwestern edge of the Edwards Plateau north of Del Rio. The earlier strata containing pecan remains that are over 5,000 years old. Pecans were recovered from a Late Prehistoric context at the Kyle site in Hill County, central Texas. The Varga site in Edwards County contained pecan nut fragments, also from Late Prehistoric deposits. Pecan has also been found at several Caddo Indian sites in eastern Texas, and from a site on the San Gabriel River (Crane 1982; Dering 1992; 1993; Fritz 1987; Hall 2000; Story 1981).

Europeans were unfamiliar with the pecan, which has no direct counterpart in the Old Word. Thus, the early historic accounts do not name pecan but instead often confuse them with more familiar nuts such as walnut. Also confusing is the fact that other hickories and the black walnut (Juglans nigra), often grow with pecans. Pecan, however, is the only nut-bearing tree that produces a thin-shelled, oblong nut, and Europeans occasionally described this unusually shaped nut.

During the early 16th century, Cabeza de Vaca was the first European to observe Native Americans harvesting pecan nuts: "They grind up some little grains with them [the nuts], two months of the year, without eating anything else, and even this they do not have every year, because one year they bear, and the next they do not. They [the nuts] are the size of those of Galicia and the trees are very large and there is a great number of them." (Krieger 2002:189-190). In his account, Cabeza de Vaca uses the 
Spanish word for walnut (nueces), but the pecan is by far the most abundant nut-bearing tree in the region and the Spanish did not have a word for pecan at that time. He notes that pecan nut production is biennial, an unusual detail for a traveler to emphasize, and a habit distinctly related to pecan. It is true that many nut or fruit-bearing trees have good and bad years of production, and that stands of pecans produce variably from year to year, often alternating between a low-yield harvest and a high-yield harvest. However, this variation in productivity could be altered by disease, insect predation, or natural disasters. At any rate, it had an impact on the people who depended on pecans for a source of fat and calories. Cabeza de Vaca probably encountered his pecan groves located on the lower San Antonio and Guadalupe Rivers near Goliad (Krieger 2002:190; 39).

About 150 years later a member of the Mendoza-Lopez expedition provides another record of pecan use. In February of 1684, the expedition encountered pecans on the Middle Concho River and on the Colorado River just below its confluence with the Concho. The entire party had been living on a meat diet, and they gratefully gathered nuts that were left over from the fall crop, most or all of which had fallen on the ground (Wade 2003:106-113).

In 1709 Espinosa, while journeying between the Medina and San Marcos Rivers, Espinosa recorded the use of pecan:

The nuts are so abundant that throughout the land the natives gather them, using them for food the greater part of the year. For this purpose they make holes in the ground where they bury them in large quantities. Not all the nuts are of the same quality, for there are different sizes and the shells of some are softer than others, but all of them are more tasty and palatable than those of Castile, though they are longer and thinner. The Indians are very skillful in shelling them, taking the kernels out whole. Sometimes they thread them on long strings, but ordinarily they keep a supply in small sacks made of leather for the purpose (Tous 1930:9-11).

Hall (2000) has argued that the large pecan stands were such an important food resource of central and southern Texas that they had an impact on Native American population density, territories, and regional interaction. Noting that groups traveled up to 120 kilometers to harvest pecans, Hall (2000) argues that variation in production, producing very good and/or bad years of a valued source of oil and calories, would have affected inter-group behavior, and that alliances may have been negotiated among groups during periods of plenty. Communication during good times would have facilitated communication during times of stress, and allow groups to avoid areas of poor harvest and to converge on areas with the best harvest. Suggesting that early population aggregation and sedentism during the Archaic may have been facilitated by the food-rich pecan groves, Hall (2000) notes the presence of Archaic cemeteries on the coastal plain.

\section{Summary and Conclusion}

The flotation samples recovered from 41KM69 were, on the whole, not very productive. Part of the problem may have been the size of the flotation sample, which averaged about 2.3-liters. However, this size of the samples may have been dictated by the size of the features. Nevertheless, 31 of the samples contained charred plant material, and 15 of these samples contained a remarkable plant assemblage.

The material from 41KM69 demonstrates that the occupants of the site utilized the forest mast along the terraces of the North Llano River. It provides the first example of pecan recovered from an open site in the region, confirming the importance of this resource in prehistory. The remains of calcium oxalate-bearing fibers also constitute a rare find, suggesting the use of yucca fibers at the site. Acorn fragments, which previously have been rarely encountered in the deposits of sites on the Edwards Plateau, were present at 41KM69. This also provides some evidence of acorn utilization at the site.

As often is the case at archeological sites, botanical evidence for season of occupation is conflicting. Needlegrass is a springflowering and early-setting seed. However, the archaeobotanical assemblage provides positive evidence, in the presence of forest mast, for a fall season occupation at 41KM69. It is possible that the seeds of the wintergrass/speargrass persisted on the plants until fall, but this is a pretty thin argument. The area was occupied for the purpose of harvesting the riverine forest mast, and it is quite possible that groups visited the area in other seasons on a regular basis. 


\section{References:}

Bean, L.J. and K.S. Saubel

1972 Temalpakh: Cahuilla Indian Knowledge and Usage of Plants. Malki Museum Press. Morongo Indian Reservation, Banning, California.

Brown, K.

1991 Prehistoric Economics at Baker Cave: A Plan for Research. In Papers on Lower Pecos Prehistory, edited by S. Turpin, pp. 87-140. Studies in Archeology 8. Texas Archaeological Laboratory. The University of Texas at Austin.

Colton, H.S.

1974 Hopi History and Ethnobotany. In Hopi Indians, edited by D.A. Horr, pp. 360-382. Garland Press. New York.

Crane, C.J.

1982 Macrobotanical Analysis. In Archaeological Investigations at the San Gabriel Reservoir Districts, Central Texas, Vol. 2, edited by T. R. Hays, pp. 15.5-15.12. Institute of Applied Sciences, North Texas State University, Denton, Texas.

Dering, P.

1977 Baker Cave plant macrofossil report. Unpublished manuscript on file with the Baker Cave Project, Texas Archeological Research Laboratory, University of Texas at Austin.

1979 Pollen and Plant Macrofossil Vegetation Record Recovered from Hinds Cave, Val Verde County, Texas. Unpublished Master's thesis. Texas A\&M University. College Station, Texas.

1997 Macrobotanical Remains. In Hot Rock Cooking on the Greater Edwards Plateau: Four Burned Rock Midden Sites in West Central Texas, by S.L. Black, L.W. Ellis, D.G. Creel, and G.T. Goode, pp. 573-600. Studies in Archeology 22, Texas Archeological Research Laboratory, University of Texas at Austin, and Archeology Studies Program, Report 2, Environmental Affairs Department, Texas Department of Transportation, Austin.

1999 Earth-oven Plant Processing in Archaic Period Economies: An Example from a Semi-Arid Savannah in SouthCentral North America. American Antiquity 64(4):659-674.

Hall, G.D.

2000 Pecan Food Potential in Prehistoric North America. Economic Botany 54 (1):103-112.

Jackson, T.L.

1991 Pounding Acorn: Women's Production as Social and Economic Focus. In Engendering Archaeology: Women and Prehistory, edited by J.M. Gero and M.W. Conkey, pp. 301-325. Blackwell, Oxford, UK and Cambridge, USA.

Jelks, E.B.

1962 The Kyle Site: A Stratified Central Texas Aspect Site in Hill County, Texas. Archaeology Series 5. Department of Anthropology, The University of Texas at Austin.

Krieger, A. 2002 We Came Naked and Barefoot: The Journey of Cabeza de Vaca Across North America. University of Texas Press. Austin.

Tous, G.

1930 The Espinosa-Olivares-Aguirre Expedition. Preliminary Studies of the Texas Catholic Historical Society 1(4):2-24. Austin, Texas.

Zigmond, M.L. 1981 Kawaiisu Ethnobotany. Salt Lake City. University of Utah Press. 


\section{Flotation of Feature Fill from 41KM69}

Sixty-five soil samples from 57 features were floated from 41KM69. Usually, $2.0 \mathrm{~L}$ of soil was collected from a bisected feature if $2.0 \mathrm{~L}$ were available. During flotation, the light fraction was separated from the heavy fraction and sent for botanical analysis. The heavy fraction was sorted and inventoried at CAR. The heavy fraction is sorted by feature number and includes information on provenience, the unique sample number (FS), the volume of fill processed and the presence of various industries that includes hackberry seeds, debitage, charcoal, snail and mussel shell, burned rock, bone, stone tools, and other rock. Because some of the features have multiple proveniences that were processed separately, sixty-five feature proveniences appear in Table E-4. The various types of features described in the Research Design (Thompson et al. 2007:Table 6) are also noted. 


\begin{tabular}{|c|c|c|c|c|c|c|c|c|c|c|c|c|c|c|c|c|c|c|c|c|c|c|c|c|c|c|c|c|c|c|c|c|c|}
\hline : & 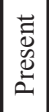 & 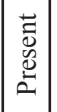 & 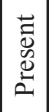 & \begin{tabular}{|l|} 
\\
$\overrightarrow{0}$ \\
0 \\
0 \\
$\vec{u}$
\end{tabular} & 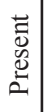 & 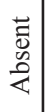 & $\begin{array}{l}\overrightarrow{\vec{u}} \\
\overrightarrow{0} \\
\overrightarrow{4}\end{array}$ & \begin{tabular}{|l|}
$\overrightarrow{\vec{u}}$ \\
0 \\
0 \\
$\vec{\psi}$
\end{tabular} & 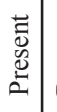 & 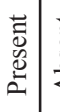 & 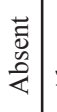 & 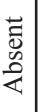 & 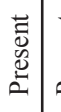 & 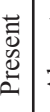 & 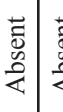 & & 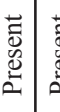 & 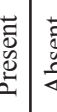 & 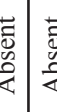 & 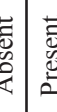 & 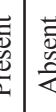 & 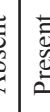 & 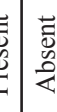 & 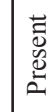 & 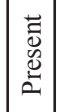 & 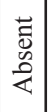 & 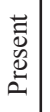 & $\begin{array}{l}\text { 节 } \\
\text { 品 }\end{array}$ & 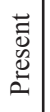 & 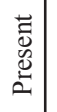 & 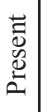 & & 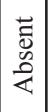 \\
\hline 豙 & 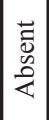 & 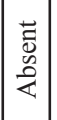 & 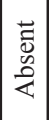 & 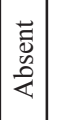 & 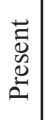 & 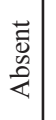 & 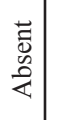 & 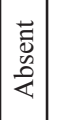 & 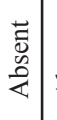 & 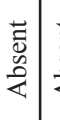 & 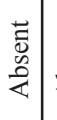 & 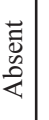 & 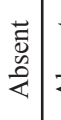 & 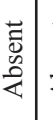 & 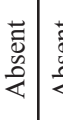 & $\begin{array}{l}\text { 苛 } \\
0 \\
\\
\end{array}$ & 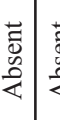 & 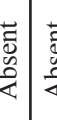 & 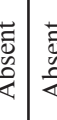 & 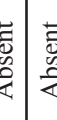 & 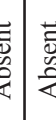 & 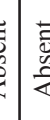 & 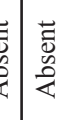 & $\begin{array}{l}\overrightarrow{\tilde{D}^{2}} \\
\text { 足 }\end{array}$ & 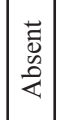 & 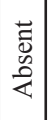 & 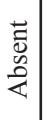 & 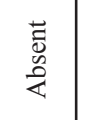 & 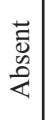 & $\begin{array}{l}\overrightarrow{0} \\
\overrightarrow{0} \\
\stackrel{0}{<}\end{array}$ & $\begin{array}{l}\overrightarrow{0} \\
\overline{0} \\
\frac{0}{4}\end{array}$ & & 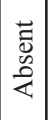 \\
\hline $\mid \begin{array}{l}\overrightarrow{0} \overline{0} \\
\overline{0} \\
\overline{0}\end{array}$ & 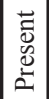 & 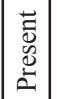 & 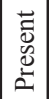 & 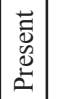 & 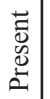 & 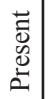 & 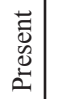 & 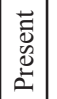 & 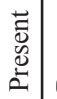 & 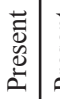 & 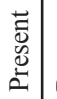 & 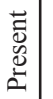 & 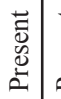 & 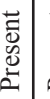 & $\begin{array}{ll}\vec{z} & \\
0 \\
0\end{array}$ & 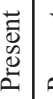 & $\begin{array}{ll} \\
\overline{0} \\
0 \\
0\end{array}$ & 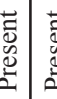 & 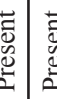 & 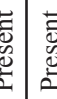 & 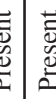 & 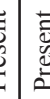 & 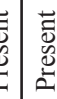 & 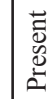 & 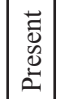 & 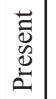 & 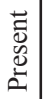 & 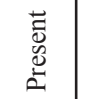 & 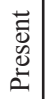 & 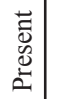 & 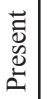 & 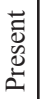 & 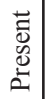 \\
\hline $\begin{array}{l}\overline{\bar{W}} \overline{\bar{\Xi}} \\
\bar{w}\end{array}$ & 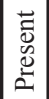 & 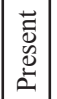 & 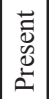 & 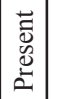 & 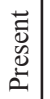 & 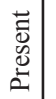 & 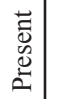 & 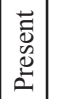 & 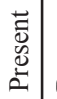 & 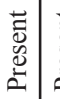 & 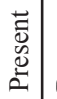 & 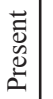 & 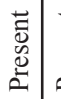 & 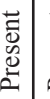 & $\begin{array}{ll}\vec{z} \\
\bar{z} \\
0\end{array}$ & 节 & $\begin{array}{ll} \\
\overline{0} \\
0 \\
0\end{array}$ & 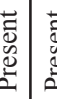 & 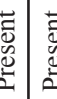 & 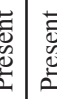 & 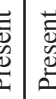 & 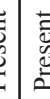 & 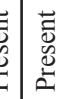 & 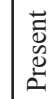 & 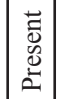 & 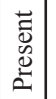 & 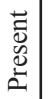 & 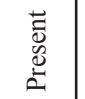 & 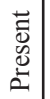 & 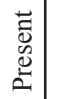 & 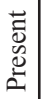 & & 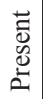 \\
\hline $\begin{array}{l}\overline{\widetilde{J}} \\
\text { [ँّ } \\
\text { Jँ }\end{array}$ & 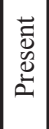 & 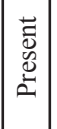 & 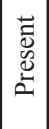 & 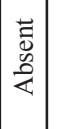 & 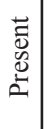 & 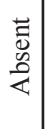 & $\begin{array}{l}\overrightarrow{\vec{D}} \\
\stackrel{0}{0} \\
\stackrel{0}{2}\end{array}$ & \begin{tabular}{|l|}
$\overrightarrow{\vec{u}}$ \\
0 \\
$\stackrel{0}{<}$ \\
$\overrightarrow{0}$
\end{tabular} & 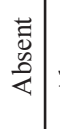 & $\begin{array}{l}\vec{z} \\
\overrightarrow{0} \\
\vec{\psi} \\
\overrightarrow{<}\end{array}$ & 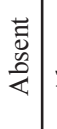 & $\begin{array}{l}\overrightarrow{\vec{D}^{2}} \\
\text { 这 }\end{array}$ & 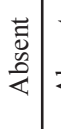 & 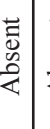 & $\begin{array}{l}\overrightarrow{0} \\
\overrightarrow{0} \\
\vec{\alpha} \\
\overrightarrow{<}\end{array}$ & 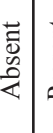 & 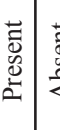 & 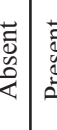 & 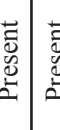 & 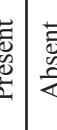 & 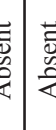 & 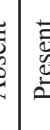 & 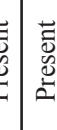 & $\begin{array}{l}\vec{z} \\
\overline{0} \\
\text { 这 }\end{array}$ & 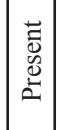 & 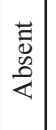 & 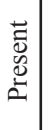 & $\begin{array}{l}\overrightarrow{\tilde{0}} \\
\text { on } \\
\text { }\end{array}$ & 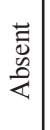 & 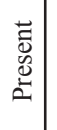 & $\begin{array}{l}\overrightarrow{0} \\
\overline{0} \\
\text { 岸 }\end{array}$ & 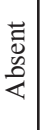 & 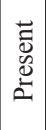 \\
\hline 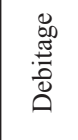 & 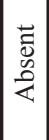 & 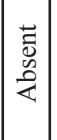 & 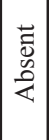 & 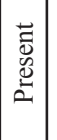 & 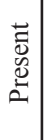 & 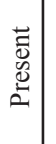 & 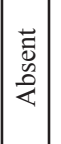 & 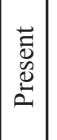 & 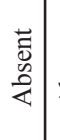 & 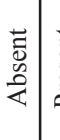 & 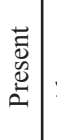 & $\begin{array}{l}\overrightarrow{0} \\
\overline{0} \\
\text { 岸 }\end{array}$ & 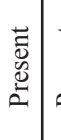 & 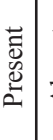 & 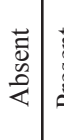 & 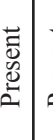 & \begin{tabular}{l|l} 
\\
0 \\
0 \\
0
\end{tabular} & 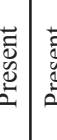 & 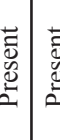 & 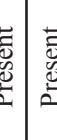 & 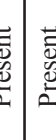 & 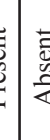 & 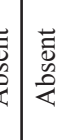 & 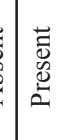 & 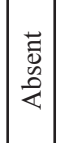 & 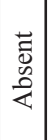 & 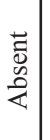 & $\begin{array}{l}\overrightarrow{\tilde{0}} \\
\text { on } \\
\text { }\end{array}$ & 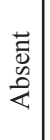 & 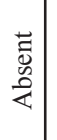 & $\begin{array}{l}\overrightarrow{0} \\
\overline{0} \\
\text { 岸 }\end{array}$ & & 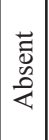 \\
\hline 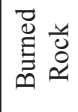 & 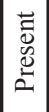 & 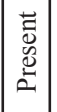 & 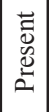 & 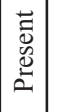 & 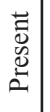 & 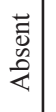 & 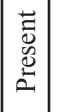 & 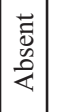 & 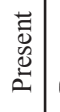 & 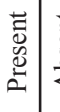 & 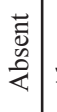 & 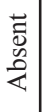 & 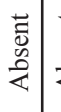 & 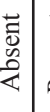 & 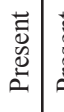 & 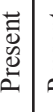 & 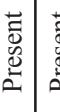 & 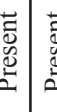 & 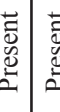 & 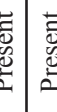 & 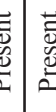 & 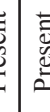 & 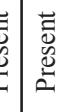 & 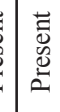 & 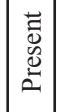 & 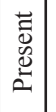 & 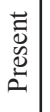 & 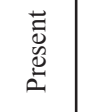 & 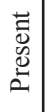 & 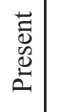 & 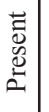 & 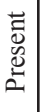 & 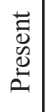 \\
\hline 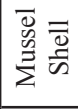 & 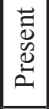 & 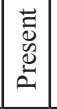 & 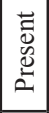 & 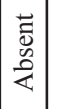 & 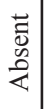 & 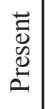 & 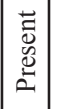 & \begin{tabular}{|l|}
$\vec{z}$ \\
0 \\
0 \\
$\mathbb{\psi}$
\end{tabular} & 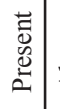 & 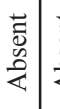 & 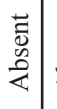 & 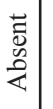 & 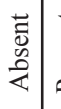 & 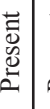 & 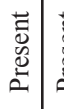 & 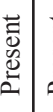 & 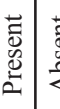 & 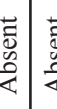 & 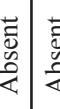 & 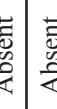 & 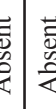 & 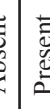 & 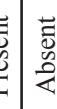 & 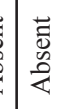 & 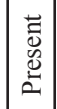 & 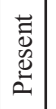 & 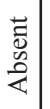 & 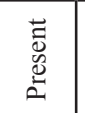 & 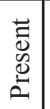 & 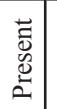 & 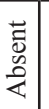 & & 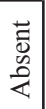 \\
\hline 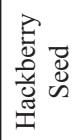 & 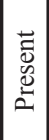 & 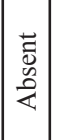 & 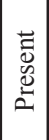 & 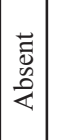 & 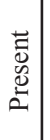 & 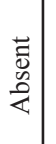 & 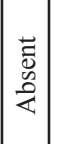 & 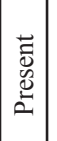 & 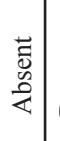 & 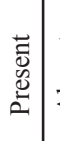 & 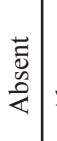 & 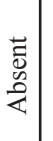 & $\begin{array}{l}\vec{u} \\
\overline{0} \\
\stackrel{0}{<}\end{array}$ & 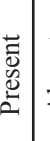 & 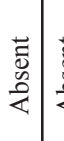 & 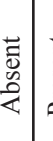 & 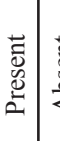 & 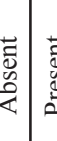 & 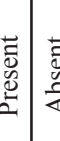 & 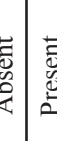 & 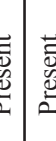 & 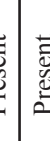 & 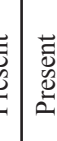 & 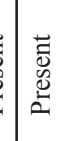 & 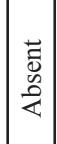 & 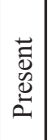 & 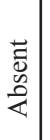 & 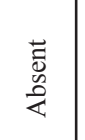 & 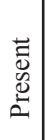 & 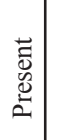 & $\begin{array}{l}\overrightarrow{0} \\
\overline{0} \\
\text { 岸 }\end{array}$ & 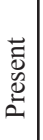 & 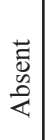 \\
\hline 息兽 & $\begin{array}{l}R \\
a \\
a\end{array}$ & 号 & 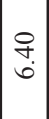 & $\left|\begin{array}{c}8 \\
i\end{array}\right|$ & $\stackrel{\circ}{=}$ & 足 & $\begin{array}{l}8 \\
\dot{m}\end{array} \mid$ & 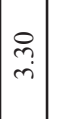 & त्ञ̂ & $\stackrel{\bullet}{\bullet}$ & : & $\underset{-}{\stackrel{8}{-}}$ & $\stackrel{n}{\rightarrow}$ & $\begin{array}{l}: \\
ن \\
i\end{array}$ & $\stackrel{ }{\longrightarrow}$ & $\begin{array}{l}\stackrel{8}{0} \\
i \\
i\end{array}$ & $\begin{array}{l}\stackrel{D}{\infty} \\
+ \\
+\end{array}$ & \begin{tabular}{l}
$\infty$ \\
\hdashline
\end{tabular} & \begin{tabular}{l|l} 
\\
\end{tabular} & $\begin{array}{l}n \\
n \\
n\end{array}$ & $\stackrel{?}{0}$ & $\begin{array}{l}0 \\
i \\
n\end{array}$ & $\stackrel{0}{:}$ & ?ִ & $\begin{array}{l}8 \\
i \\
i\end{array}$ & $\stackrel{\leftrightarrow}{\stackrel{\leftrightarrow}{-}}$ & $\stackrel{-}{-}$ & $\underset{\substack{q \\
m}}{ }$ & 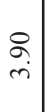 & $\stackrel{R}{i}$ & $\stackrel{?}{\rightarrow}$ & 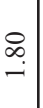 & $\underset{-}{8}$ \\
\hline 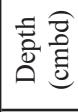 & 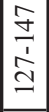 & \begin{tabular}{|c|}
0 \\
0 \\
$\frac{1}{1}$ \\
$\infty$ \\
\end{tabular} & $\mid \begin{array}{l}0 \\
\infty \\
i \\
0\end{array}$ & $\mid$ & \begin{tabular}{l|}
0 \\
0 \\
1 \\
$⿱ 亠 乂$ \\
\end{tabular} & $\begin{array}{l}2 \\
\hat{1} \\
0 \\
0\end{array}$ & 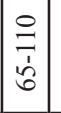 & $\begin{array}{l}2 \\
\hat{i} \\
0\end{array}$ & $\begin{array}{l}\vec{a} \\
\dot{1} \\
\vec{b}\end{array}$ & $\begin{array}{l}\text { âे } \\
\text { ̀े }\end{array}$ & $\begin{array}{l}n \\
\hat{c} \\
\grave{2}\end{array}$ & 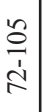 & $\begin{array}{l}0 \\
0 \\
0 \\
⿱ 亠 䒑 \\
2\end{array}$ & $\begin{array}{l}m \\
\frac{0}{2} \\
\frac{1}{2}\end{array}$ & 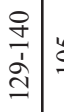 & $\stackrel{2}{\varrho}$ & 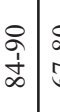 & \begin{tabular}{l|l}
0 \\
0 \\
1 \\
0 \\
0
\end{tabular} & 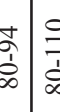 & 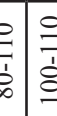 & 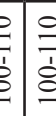 & 定 & 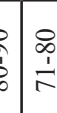 & $\mid \begin{array}{l}\infty \\
\substack{1 \\
i}\end{array}$ & $\mid \begin{array}{c}+ \\
\dot{1} \\
\dot{d} \\
\infty\end{array}$ & 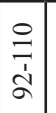 & \begin{tabular}{l|}
$n$ \\
0 \\
$\vdots$ \\
$\vdots$ \\
0
\end{tabular} & $\underset{\Xi}{\Xi}$ & 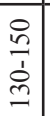 & $\begin{array}{l}\not \\
0 \\
0 \\
\infty \\
1\end{array}$ & \begin{tabular}{l}
$\bar{\Xi}$ \\
$\vdots$ \\
\multirow{2}{*}{}
\end{tabular} & $\begin{array}{l}0 \\
\\
\vdots \\
0\end{array}$ & $\frac{0}{0}$ \\
\hline 总 & $\infty$ & in & - & h & in & 0 & -1 & r & -1 & $r$ & - & $r$ & $\infty$ & $\infty$ & $\cong \mathrm{s}$ & 은 & $a 1 \%$ & $\infty$ & $\frac{0}{\alpha^{\prime}}=\bar{\sigma}$ & $=$ & $E=$ & $\because 0$ & $\underset{\infty}{\vec{\infty}}$ & $\underset{\infty}{\underset{\infty}{\mid}}$ & $a$ & 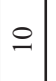 & $=$ & $\begin{array}{l}\bar{\Xi} \\
\stackrel{0}{0}\end{array}$ & \pm & $\infty$ & $=$ & $=$ & - \\
\hline 㺃 & $\begin{array}{l}8 \\
\vdots \\
i \\
i\end{array}$ & $\begin{array}{l}8 \\
\dot{2} \\
i\end{array}$ & $\begin{array}{l}8 \\
0 \\
i \\
7\end{array}$ & $\mid \begin{array}{l}\dot{m} \\
\dot{m}\end{array}$ & $\frac{8}{\dot{m}}$ & $\begin{array}{l}\dot{ \pm} \\
\dot{ \pm} \\
\dot{ \pm}\end{array}$ & $\stackrel{\stackrel{\sim}{J}}{=}$ & $\begin{array}{l}\vec{\sigma} \\
=\end{array}$ & $\begin{array}{c}\stackrel{\Xi}{0} \\
\dot{g}\end{array}$ & $\begin{array}{l}\tilde{\hat{U}} \\
\dot{\Xi}\end{array}$ & $\begin{array}{c}\tilde{\hat{U}} \\
\stackrel{\mathrm{g}}{ }\end{array}$ & 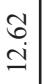 & $\begin{array}{l}8 \\
\dot{ \pm}\end{array}$ & 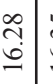 & 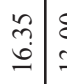 & $\begin{array}{lll}\stackrel{\Delta}{0} & \\
\dot{m} & & \end{array}$ & 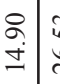 & 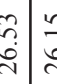 & 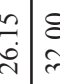 & 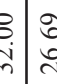 & $\begin{array}{ll}0 \\
0 \\
\dot{0} & \\
i & 0 \\
0\end{array}$ & $\begin{array}{l}0 \\
\dot{b} \\
i\end{array}$ & 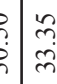 & $\begin{array}{l}n \\
m \\
m \\
m\end{array}$ & $\mid \begin{array}{l}0 \\
i \\
\dot{p} \\
m\end{array}$ & 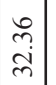 & 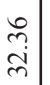 & $\begin{array}{cc}\dot{m} & \vec{\sim} \\
\dot{m} & \vec{m} \\
\dot{m}\end{array}$ & $\begin{array}{l}\triangleright \\
\infty \\
\dot{m}\end{array}$ & $\begin{array}{l}\text { तิ } \\
\text { ה̀ }\end{array}$ & 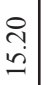 & $\begin{array}{l}8 \\
\stackrel{8}{0} \\
\dot{i}\end{array}$ & $\frac{9}{+}$ \\
\hline 苔 & $\begin{array}{l}0 \\
0 \\
\infty \\
m \\
m\end{array}$ & $\mid \begin{array}{c}0 \\
0 \\
\infty \\
\infty \\
n\end{array}$ & $\begin{array}{l}0 \\
0 \\
\infty \\
m\end{array}$ & \begin{tabular}{|l|} 
\\
0 \\
0 \\
\end{tabular} & $\begin{array}{l}8 \\
\stackrel{1}{1}\end{array}$ & $\begin{array}{l}2 \\
0 \\
\dot{\infty} \\
\infty\end{array}$ & 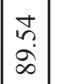 & $\mid \begin{array}{l}\vec{n} \\
\dot{\infty}\end{array}$ & $\begin{array}{l}\tilde{n} \\
\tilde{c} \\
\infty \\
\infty\end{array}$ & $\begin{array}{l}n \\
\dot{0} \\
\infty \\
\infty\end{array}$ & $\begin{array}{l}n \\
\dot{0} \\
\dot{\infty} \\
\infty\end{array}$ & 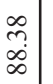 & $\begin{array}{l}8 \\
\dot{+} \\
\dot{\infty}\end{array}$ & $\begin{array}{c}\infty \\
\stackrel{0}{8} \\
\dot{8}\end{array}$ & \begin{tabular}{c|c}
0 \\
$\infty$ \\
$\infty$ \\
$\infty$ \\
$\infty$
\end{tabular} & $\begin{array}{l}0 \\
q \\
\dot{a} \\
\infty \\
\infty\end{array}$ & 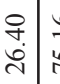 & \begin{tabular}{l|l}
0 & 7 \\
& 7
\end{tabular} & 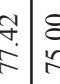 & $\begin{array}{ll}0 \\
0 \\
0\end{array}$ & $\begin{array}{c}c \\
2 \\
2 \\
2\end{array}$ & $\stackrel{m}{=}$ & \begin{tabular}{ll}
$\stackrel{0}{0}$ \\
\hdashline
\end{tabular} & $\stackrel{\circ}{\stackrel{0}{6}}$ & $\begin{array}{l}\stackrel{2}{2} \\
\grave{9}\end{array}$ & $\begin{array}{l}\qquad \\
\stackrel{0}{=}\end{array}$ & $\begin{array}{l}\tilde{b} \\
\stackrel{-}{-}\end{array}$ & 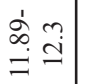 & $\begin{array}{l}\stackrel{0}{1} \\
\dot{ \pm}\end{array}$ & 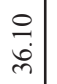 & $\begin{array}{l}\infty \\
\infty \\
\ddot{n} \\
\end{array}$ & 8 & 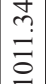 \\
\hline 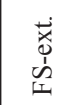 & $\begin{array}{l}\stackrel{\infty}{\infty} \\
\infty\end{array}$ & 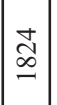 & $\begin{array}{l}\tilde{a} \\
\infty \\
\infty\end{array}$ & \& & $\begin{array}{l}\text { ? } \\
0\end{array}$ & $\sqrt{n}$ & $\underline{0}$ & 志 & 志 & $\begin{array}{l}\overrightarrow{1} \\
\infty \\
\infty\end{array}$ & $\begin{array}{l}1 \\
\dot{\omega} \\
\infty \\
-1\end{array}$ & ڤે & $\stackrel{\sim}{\sim}$ & $\stackrel{?}{\stackrel{P}{f}}$ & 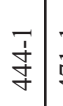 & $\frac{1}{r}$ & $i$ & م. & 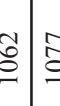 & 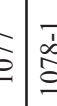 & 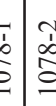 & 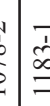 & 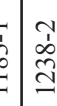 & 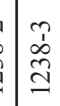 & $\overrightarrow{0}$ & $\stackrel{\vartheta}{\hat{\Xi}}$ & 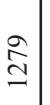 & $\begin{array}{l}\text { İ } \\
\text { D̃ } \\
\text { I }\end{array}$ & $\begin{array}{l}n \\
0 \\
n \\
n\end{array}$ & $\overrightarrow{\bar{n}}$ & \begin{tabular}{l}
\multicolumn{1}{c}{} \\
$\hat{\Lambda}$ \\
$\underline{\sigma}$ \\
\end{tabular} & $\frac{1}{\infty}$ & $\begin{array}{l}\stackrel{P}{\infty} \\
\stackrel{\infty}{-}\end{array}$ \\
\hline 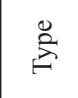 & 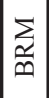 & $\sum_{\frac{m}{m}}$ & $\sum_{\frac{m}{m}}$ & 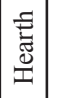 & $\begin{array}{l}\text { 䔍 } \\
\text { 至 }\end{array}$ & $\sum_{\grave{\Omega}}$ & 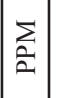 & 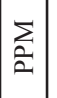 & $\sum_{\grave{\Omega}}$ & 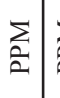 & 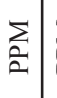 & 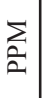 & 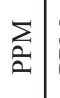 & $\sum_{\substack{2 \\
2}}$ & 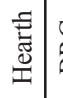 & 1 & 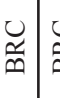 & $\frac{\pi}{0.0}$ & 與 & 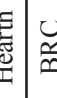 & $\underline{\underline{v}}$ & 僦 & 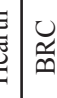 & 童 & 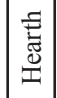 & $\frac{\ddot{n}}{\ddot{m}}$ & $\stackrel{\sim}{m}$ & 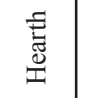 & $\begin{array}{l}0 \\
\frac{\tilde{m}}{m}\end{array}$ & $\ddot{\mathscr{m}}$ & 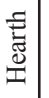 & & $\stackrel{\simeq}{\infty}$ \\
\hline 堐 & -1 & -1 & -1 & $\alpha$ & $\sim$ & 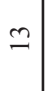 & 0 & $=$ & $\stackrel{\infty}{-}$ & 2 & $\approx$ & $\tilde{N}$ & $\bar{m}$ & 放 & $\approx$ & ల్m & के & $8 \mid 7$ & 78 & $\begin{array}{l}7 \\
7\end{array}$ & $f \mid 7$ & 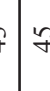 & $\begin{array}{l}f \\
\end{array}$ & 18 & f & $\stackrel{\infty}{+}$ & $\stackrel{\infty}{+}$ & qे & in & $\approx$ & $n$ & in & in \\
\hline
\end{tabular}




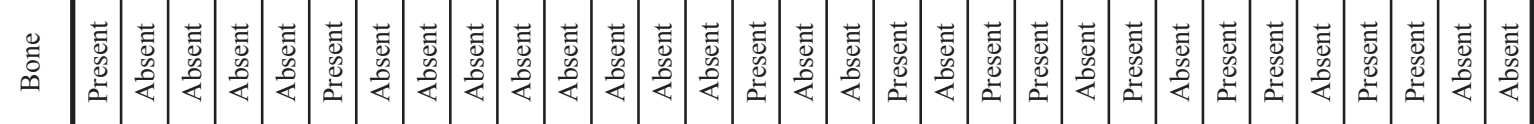

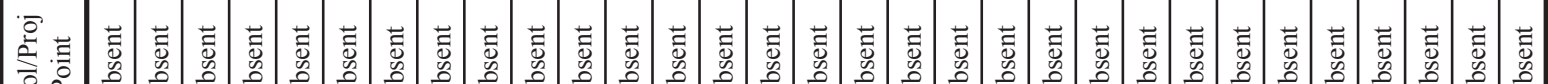

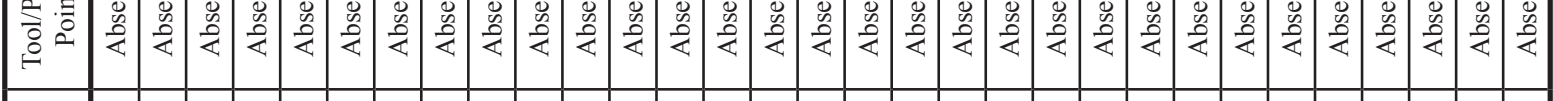

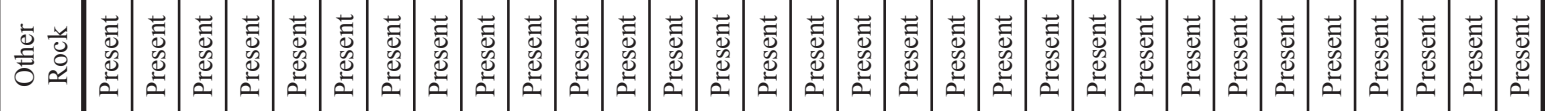

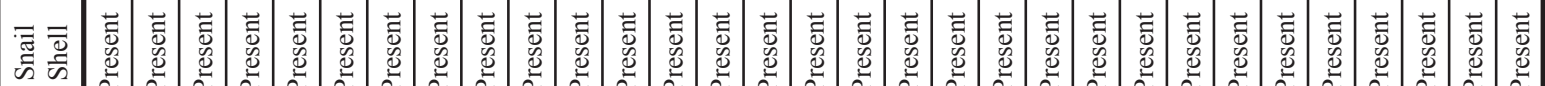

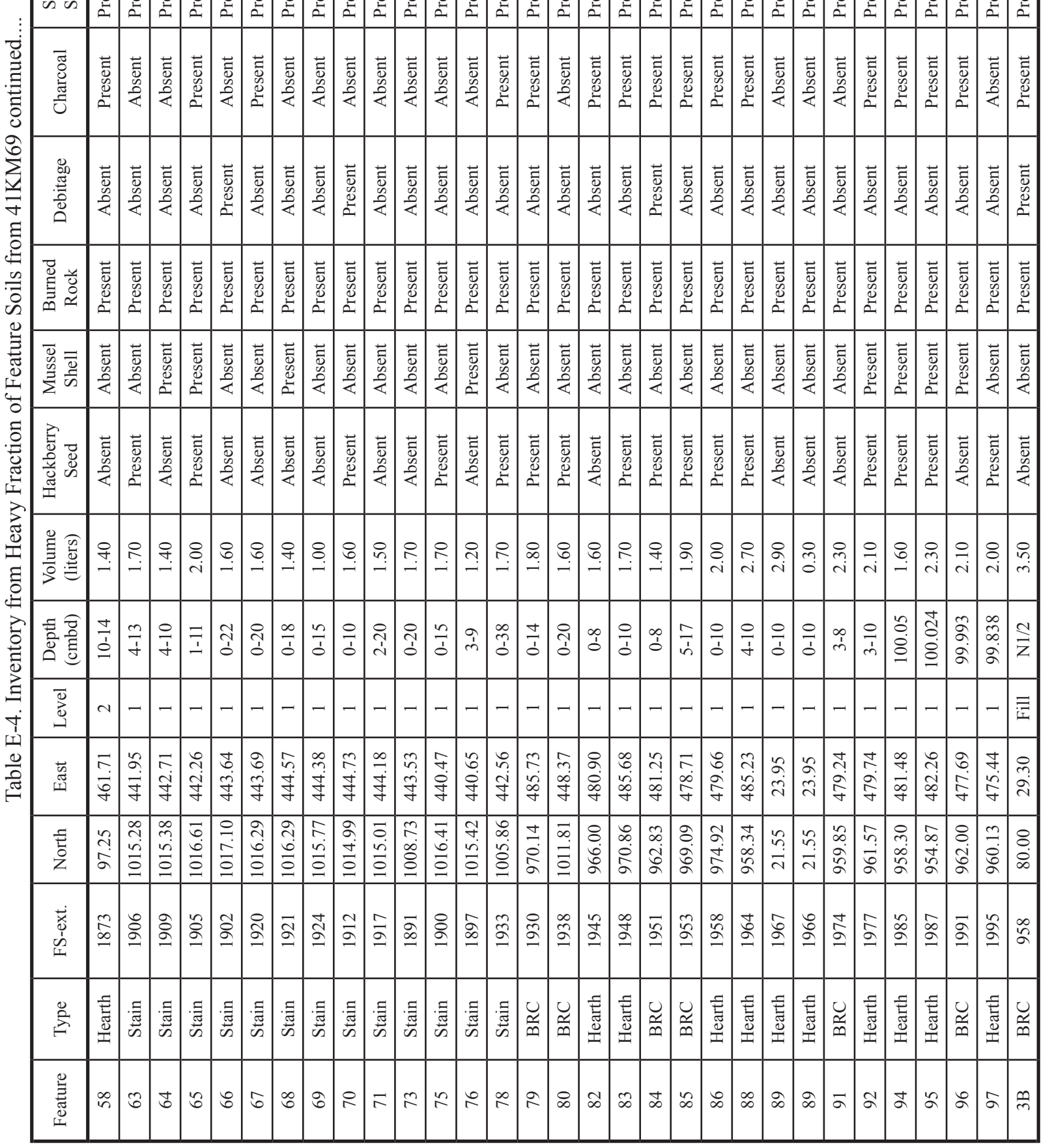


Appendix F:

Petrographic Analysis of Leon Plain and

Caddoan Ceramics

Lori Barkwill-Love 



\section{Appendix F}

\section{Petrographic Analysis of Leon Plain and Caddoan Ceramics}

\section{Lori Barkwill-Love}

Petrographic analysis was completed on 186 thin sections from both Caddoan and Leon Plain ceramics that were collected from a total of 22 sites in Texas. The Caddoan ceramics came from 10 sites and totaled 68 thin sections (Table F-1). The Leon Plain ceramics came from 12 sites and totaled 118 thin sections (Table F-2). However, four thin sections were not completely analyzed due to thin section quality and one thin section was of bone and not pottery. All of the unanalyzed thin sections were in the Leon Plain group. Therefore, only 181 thin sections were completely analyzed. The purpose of this petrographic analysis was to provide information on the temper compositional similarities and differences between Caddoan and Leon Plain ceramics.

Table F-1. Number of Caddoan Thin Sections by Site

\begin{tabular}{|l|c|}
\hline Site & Number of Thin Sections \\
\hline $41 \mathrm{HP} 106$ & 14 \\
\hline $41 \mathrm{SM} 9$ & 6 \\
\hline $41 \mathrm{R} 9$ & 6 \\
\hline $41 \mathrm{NA} 27$ & 6 \\
\hline 41AN1 & 6 \\
\hline 41AN8 & 6 \\
\hline 41AN19 & 6 \\
\hline 41MX5 & 6 \\
\hline $41 \mathrm{CE} 19$ & 6 \\
\hline $41 \mathrm{WD} 13$ & 6 \\
\hline Total & 68 \\
\hline
\end{tabular}

Table F-2. Number of Leon Plain Thin Sections by Site

\begin{tabular}{|c|c|}
\hline Site & Number of Thin Sections \\
\hline 41RN169 & 3 \\
\hline 41TG346 & 8 \\
\hline 41KM16 & 32 \\
\hline 41WN88 & 14 \\
\hline 41JW8 & 6 \\
\hline 41KM69 & 6 \\
\hline 41LK67 & 7 \\
\hline 41LK201 & 15 \\
\hline 41BX228 & 7 \\
\hline 41ED28 & 11 \\
\hline Total & 109 \\
\hline
\end{tabular}




\section{Methods}

A three-step process was used to examine the thin sections. All the analyses were done using a Lecia petrographic microscope with a rotating stage. The first step involved examining the thin section for general characteristics and taking photomicrographs. The general characteristics recorded included paste description, temper and minerals found, bone color, and any additional comments about the thin section. To identify the general characteristics, the thin section was viewed in plane-polarized light (PP) and cross-polarized light (CP). The second step involved point counting. The point counting was done using the GlagolevChayes method. The Glagolev-Chayes method involves using a rotating stage, which allows one to move the thin section at a given interval beneath the crosshair in the ocular and recording each point encountered in the crosshair (Stoltman 2001). A minimum of 300 points was recorded for each thin section using $10 \mathrm{X}$ magnification at $4 \mathrm{~mm}$ intervals. However, four thin sections were too small to obtain 300 points and the point counting ranged from 50 to 205 points for these thin sections. Each nonpaste element was only counted once regardless if it was encountered more than once using the $.4 \mathrm{~mm}$ interval. The third step involved measuring the temper, which included all nonpaste elements. For this step, a .4 mm grid was placed on an image of the thin section using Motic imaging software and a photomicrograph was taken. All nonpaste elements under the crosshair of the grid were measured at the widest part of the object using the Motic measuring tool. After all measurements were record on the photomicrograph, a second photo was taken approximately $4 \mathrm{~mm}$ from the first and the procedures were repeated. Two photographs were taken for each thin section, which produced a total of 126 points.

\section{Descriptions of Individual Thin Sections by Site}

Descriptions of the individual thin sections are listed below. The descriptions include temper group, paste characteristics/color, a list minerals/temper found during point counting or initial characterization of thin section and bone color (if present). The temper groups are defined later in this document. The results from the point counting of each thin section are listed in Table F-3 (Leon Plain) and Table F-4 (Caddo). Also attached are the tables (Table F-5 [Leon Plain] and Table F-6 [Caddo]) for temper measurements. These tables include the mean measurement and the minimum and maximum sizes for bone, quartz, limestone, and grog for each thin section. The number in brackets $[\mathrm{x}]$ next to the ID Number refers to the placement in the point counting and measurement tables.

Although most of the minerals/temper identified are self explanatory, there are some that require further explanation. In both the Leon Plain ceramics and the Caddoan ceramics, clay pellets were found in several of the thin sections. The clay pellets were dark brown, rounded and noticeably distinct from the paste matrix. Often quartz inclusion could be seen in the clay pellets. However, they did not appear to be grog temper. They were possibly the result of the clay not being thoroughly processed or small pieces of dry clay being incorporated into the paste.

Also listed are unknown inclusions and dark opaques. Unknown inclusions were typically orange, red, or brown in color, round or subrounded in shape, translucent in PP, and darker to opaque in CP. Consultation with the geology department at UTSA failed to provide positive identification. It was suggested that these inclusions be further examined with SEM for positive identification. The dark opaques were typically black or brownish-black opaque looking objects in PP and had no change in CP. It is likely that many of the dark opaques found in the thin sections were hematite; however, completely burnt bone is also a possibility. Further petrographic analysis is needed to determine the identification of the dark opaques.

The present of calcification on the bone was noted on several Leon Plain thin section. Calcification appeared as bright white/ pastel spots on the bone in CP. It appears that the bone was being replaced by calcite or some other mineral. In some cases the bone was almost completely replaced. It has been suggest that the formation of the calcification on the bone may be due postdepositional alternations in the bone (Kittleman 1994). Additional analysis, possibly SEM, is needed to determine the mineral makeup of the cement. 


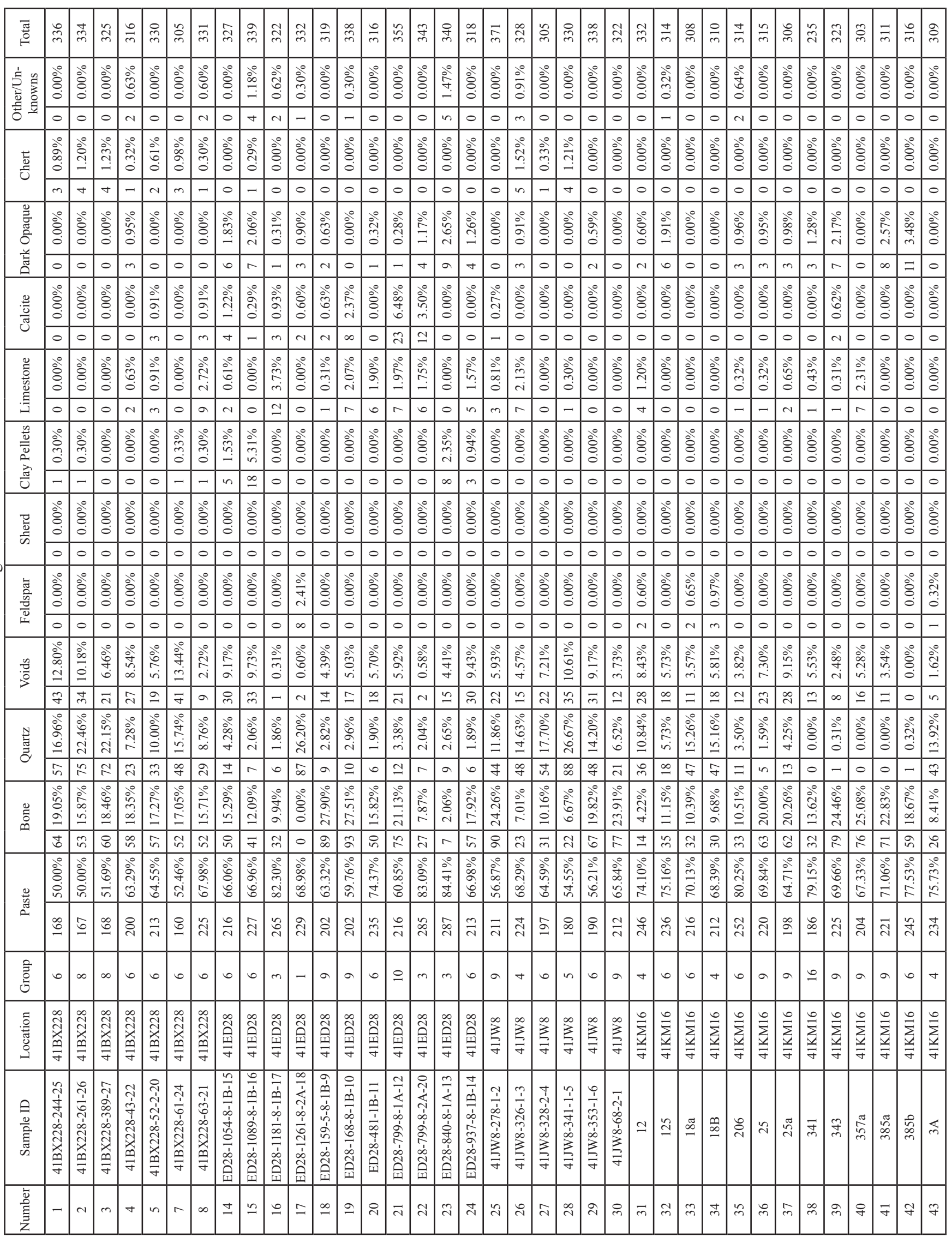




\begin{tabular}{|c|c|c|c|c|c|c|c|c|c|c|c|c|c|c|c|c|c|c|c|c|c|c|c|c|c|c|c|c|c|c|c|c|}
\hline 苋 & $\vec{m}$ & ন্లి & $\frac{\pi}{m}$ & $\frac{m}{m}$ & ì & $m$ & 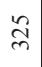 & $\stackrel{0}{0}$ & ర్ల & & $\pi$ & 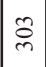 & J & $\frac{n}{m}$ & $\stackrel{\circ}{m}$ & 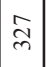 & $\stackrel{m}{m}$ & & & & $\frac{\Delta}{m}$ & $\stackrel{\text { }}{2}$ & & స్ల & ક્లి & $\vec{D}$ & స్ల & 考 & $\frac{b}{m}$ & ले & & \\
\hline \multirow{2}{*}{\begin{tabular}{|l}
5 \\
5 \\
0 \\
0 \\
0 \\
0 \\
0
\end{tabular}} & ఏें & छे & ठे. & $\mid \begin{array}{c}0 \\
\vdots \\
0 \\
0\end{array}$ & . & 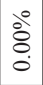 & ठั & 嵩 & हెे & & ठ̊. & 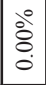 & $\begin{array}{l}\stackrel{0}{0} \\
\text { o. } \\
0\end{array}$ & 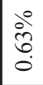 & 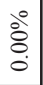 & 寍 & $\begin{array}{l}\text { oे } \\
\text { ळे }\end{array}$ & छे & 亏े & & 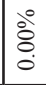 & 它 & छे & 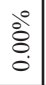 & ठे & ذें & & & $\therefore$ & 8 & & \\
\hline & 0 & 0 & 0 & 0 & 0 & -1 & 0 & 4 & 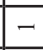 & $\bar{\gamma}$ & 0 & 0 & & $N$ & 0 & in & $m$ & & 0 & 0 & 0 & 0 & 0 & 0 & 0 & 0 & - & - & 0 & 0 & $m$ & \\
\hline \multirow[t]{2}{*}{$\frac{\overline{\mathrm{g}}}{\mathrm{J}}$} & $\begin{array}{l}\text { oें } \\
\text { Oें }\end{array}$ & \begin{tabular}{|l|}
0 \\
oे \\
$\dot{0}$
\end{tabular} & $\begin{array}{l}0 \\
\text { ¿ें } \\
0\end{array}$ & \begin{tabular}{|c|} 
\\
$\vdots$ \\
0 \\
$\dot{0}$
\end{tabular} & 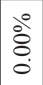 & 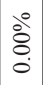 & $\begin{array}{l}0 \\
\dot{0} \\
\dot{0} \\
\dot{0}\end{array}$ & 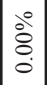 & ذ্े & & ذِّ & 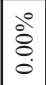 & 8 & 客 & 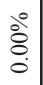 & $\begin{array}{ll}\circ \\
\\
0 \\
0\end{array}$ & 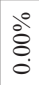 & & ذి & छे & 客 & ठ̊ㅇㅇ & छे & 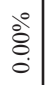 & ঃे & ڤ̀ & & & 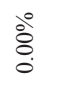 & $0^{\circ}$ & & \\
\hline & 0 & - & 0 & 0 & 0 & 0 & 0 & 0 & 인 & $\circ$ & 0 & 0 & 0 & 0 & 0 & 0 & 0 & 0 & 0 & 0 & 0 & 0 & 0 & 0 & $\circ$ & $N$ & - & $\sigma$ & $\circ$ & - & & \\
\hline \multirow{2}{*}{ 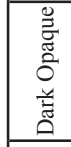 } & 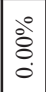 & \begin{tabular}{|c|} 
\\
oे \\
0 \\
\end{tabular} & ذ̊. & $\mid \begin{array}{l}0 \\
\vdots \\
o \\
0\end{array}$ & \begin{tabular}{|l}
$\stackrel{\circ}{\circ}$ \\
$\stackrel{0}{\circ}$
\end{tabular} & $\begin{array}{l}\text { ذें } \\
\stackrel{0}{0}\end{array}$ & \begin{tabular}{|c|}
0 \\
Oें \\
\end{tabular} & $\begin{array}{l}0 \\
\vdots \\
0 \\
0\end{array}$ & ذ্ّ & \& & $\stackrel{\circ}{\circ}$ & \begin{tabular}{|c|c}
0 \\
के \\
0 \\
0
\end{tabular} & 0 & 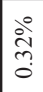 & 客 & \begin{tabular}{|l|l} 
\\
\\
0 \\
0
\end{tabular} & @ें & $\overrightarrow{0}$ & छें & ఫิ & 官 & $\begin{array}{l}0 \\
\text { तें } \\
\text { Oें }\end{array}$ & छे & \begin{tabular}{|c|}
0 \\
$\vdots$ \\
0 \\
0
\end{tabular} & $\begin{array}{l}\circ \\
\stackrel{0}{0} \\
\text {. }\end{array}$ & $\stackrel{\circ}{\doteq}$ & $\stackrel{\circ}{\circ}$ & ఏें & $\dot{\alpha}^{\circ}$ & $\begin{array}{l}\text { ठे } \\
\text { cे }\end{array}$ & & \\
\hline & 0 & $\circ$ & 0 & m & 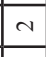 & $m$ & 0 & 0 & 0 & 。 & $m$ & - & - & - & $\circ$ & 0 & $m$ & $\mathrm{~N}$ & 0 & 0 & 0 & $\sim$ & 0 & 0 & $\circ$ & + & $\sim$ & 0 & 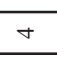 & - & - & \\
\hline & \begin{tabular}{|l} 
\\
\\
0 \\
0
\end{tabular} & \begin{tabular}{|c|} 
\\
$\vdots$ \\
0 \\
0
\end{tabular} & ఏँ & \begin{tabular}{|c|} 
\\
$\vdots$ \\
0 \\
0
\end{tabular} & \begin{tabular}{|l} 
\\
¿ें \\
0
\end{tabular} & 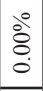 & 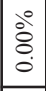 & \begin{tabular}{|l}
0 \\
0 \\
6 \\
0
\end{tabular} & ठ̀ & & ठ̊. & 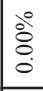 & & \begin{tabular}{|l} 
\\
ò \\
gे \\
\end{tabular} & 㐫 & 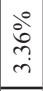 & 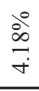 & & 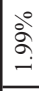 & 0 & 高 & ¿ें & 0 & \begin{tabular}{|c|} 
\\
\\
0 \\
0
\end{tabular} & 0 & $\circ$ & 3 & & ڤें & $\begin{array}{l}\infty \\
0 \\
0 \\
\end{array}$ & & \\
\hline & 0 & 0 & 0 & 0 & 0 & 0 & 0 & - & 0 & 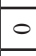 & 0 & 0 & 2 & $\exists$ & $\stackrel{i}{1}$ & $\Xi$ & \pm & $N$ & - & 0 & $\circ$ & 0 & 0 & 0 & 0 & 0 & - & n & $\circ$ & m & in & \\
\hline 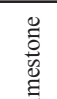 & \begin{tabular}{|l} 
\\
tे \\
0 \\
0
\end{tabular} & \begin{tabular}{|c|} 
\\
Oें \\
0
\end{tabular} & लें & $\begin{array}{l}0 \\
\\
\\
\end{array}$ & 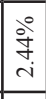 & $\begin{array}{l}\text { :ें } \\
\text { రें } \\
\end{array}$ & 商 & 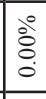 & 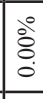 & & $\therefore$ & ذें & & 8 & 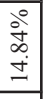 & $\stackrel{\circ}{\circ}$ & $\begin{array}{l}\frac{\circ}{\bar{n}} \\
\dot{n}\end{array}$ & & & & సें & ลेํํ & & \begin{tabular}{|c|} 
\\
\\
0 \\
0
\end{tabular} & 0 & 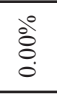 & & & సें & $\begin{array}{l}\text { oें } \\
\text {. }\end{array}$ & & \\
\hline
\end{tabular}

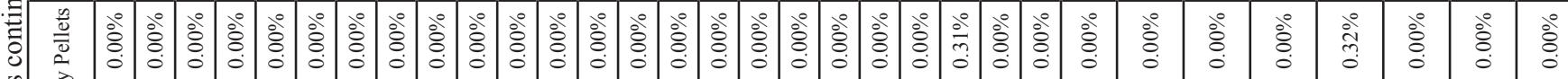

है

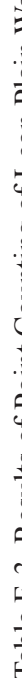

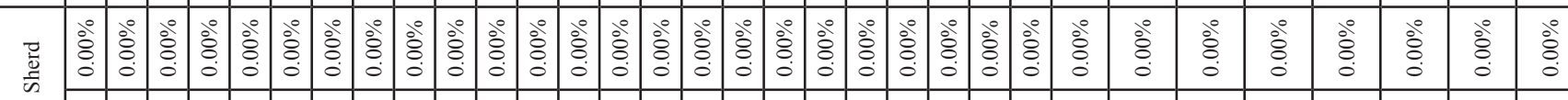

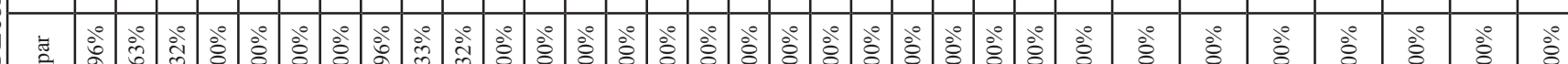

西

\begin{tabular}{|c|c|c|c|c|c|c|c|c|c|c|c|c|c|c|c|c|c|c|c|c|c|c|c|c|c|c|c|c|c|c|c|c|}
\hline : & $\frac{\circ}{\sim}$ & 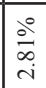 & $\frac{\stackrel{0}{0}}{3}$ & 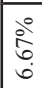 & 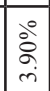 & 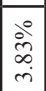 & $\begin{array}{l}\stackrel{\circ}{\circ} \\
\text { ते } \\
\text { ஸे }\end{array}$ & 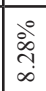 & 客 & 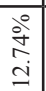 & 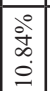 & 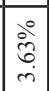 & $\mid \begin{array}{c}\stackrel{0}{0} \\
\hat{n} \\
i n\end{array}$ & 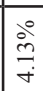 & लें & $\mid \begin{array}{c}\stackrel{0}{0} \\
\stackrel{i}{i}\end{array}$ & $\mid \begin{array}{l}20 \\
\vdots \\
\vdots \\
\dot{n}\end{array}$ & 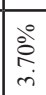 & 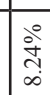 & 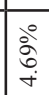 & $\mid \begin{array}{c}\stackrel{0}{2} \\
\stackrel{2}{r}\end{array}$ & & 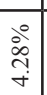 & $\begin{array}{l}\dot{0} \\
\infty \\
\infty \\
i \\
i\end{array}$ & ذి & 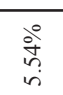 & 离 & $\frac{\stackrel{\partial}{+}}{\infty}$ & 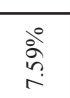 & 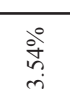 & 递 & $\begin{array}{c}\stackrel{0}{0} \\
\infty_{\infty}^{\circ}\end{array}$ \\
\hline & 9 & $a$ & ¿ & $\bar{\nu}$ & $\infty$ & $\simeq$ & $\simeq$ & \pm & $\because$ & q & $m$ & $=$ & i & 9 & 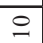 & $a$ & I & $\simeq$ & ì & $\because$ & ণ & $\pi$ & $m$ & 2 & $\overline{\vec{N}}$ & ¿̊ & \pm & $\infty_{\sim}^{\infty}$ & $\stackrel{+}{\mathrm{N}}$ & $\simeq$ & $\stackrel{\infty}{\infty}$ & $\infty$ \\
\hline 苞 & 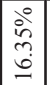 & 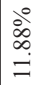 & 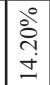 & $\begin{array}{l}\stackrel{\circ}{\circ} \\
\text { iे } \\
\text { bे }\end{array}$ & $\mid$ & 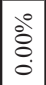 & 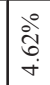 & 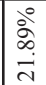 & 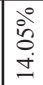 & 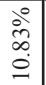 & $\begin{array}{l}0 \\
\text { ì } \\
i n \\
i n\end{array}$ & 递 & 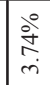 & $\begin{array}{l}0 \\
\text { ò } \\
\text { in }\end{array}$ & 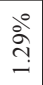 & $\begin{array}{l}\stackrel{0}{\circ} \\
\stackrel{0}{\circ} \\
\dot{m}\end{array}$ & 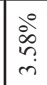 & $\begin{array}{l}\text { 守 } \\
\text { ণ }\end{array}$ & $\begin{array}{l}\stackrel{0}{ } \\
\grave{0} \\
\dot{\sim} \\
\dot{\sim}\end{array}$ & $\begin{array}{l}0 \\
\stackrel{0}{0} \\
0 \\
0 \\
0\end{array}$ & 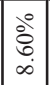 & ثَّ & $\stackrel{\circ}{\vec{\partial}}$ & 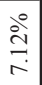 & $\begin{array}{l}\text { 品 } \\
\stackrel{0}{0}\end{array}$ & $\underset{\infty}{\stackrel{\circ}{m}}$ & $\begin{array}{c}\stackrel{0}{ } \\
\text { iे } \\
\stackrel{y}{+}\end{array}$ & 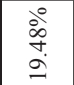 & iे & $\begin{array}{l}\text { 仓ें } \\
\stackrel{0}{\varrho}\end{array}$ & $\begin{array}{l}\stackrel{\circ}{\circ} \\
\stackrel{n}{=}\end{array}$ & 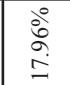 \\
\hline & $\overrightarrow{\mid \vec{n}}$ & $\infty$ & f & i & $m$ & 0 & $\because$ & m & f & 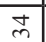 & $\infty$ & 0 & $m$ & $I$ & $\nabla$ & 9 & $\simeq$ & \pm & $I$ & ה & $\bar{\sim}$ & 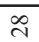 & $\mid$\begin{tabular}{|l|}
$\infty$ \\
$\infty$
\end{tabular} & $\pi$ & $\bar{m}$ & d & $\Xi$ & $\overline{6}$ & $\infty$ & ర) & m & \\
\hline 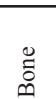 & \begin{tabular}{|c|}
\multirow{2}{0}{} \\
0 \\
0 \\
$\varrho$
\end{tabular} & 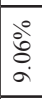 & 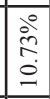 & 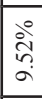 & 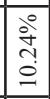 & \begin{tabular}{|l|}
$\stackrel{\circ}{\circ}$ \\
$\infty$ \\
$\infty$ \\
\end{tabular} & \begin{tabular}{|l}
$\stackrel{0}{0}$ \\
$\vdots$ \\
$\dot{0}$ \\
$\dot{\infty}$
\end{tabular} & \begin{tabular}{|l|}
$\stackrel{\circ}{\circ}$ \\
$\stackrel{i}{\circ}$
\end{tabular} & 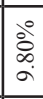 & 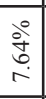 & 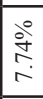 & 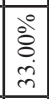 & 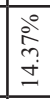 & $\begin{array}{c}\stackrel{\circ}{\circ} \\
\stackrel{3}{2}\end{array}$ & 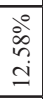 & 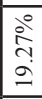 & 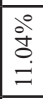 & 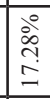 & 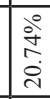 & 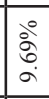 & \begin{tabular}{|c|}
0 \\
0 \\
$\stackrel{0}{3}$ \\
\end{tabular} & $\begin{array}{l}\stackrel{\circ}{\circ} \\
\stackrel{\circ}{\exists}\end{array}$ & \begin{tabular}{|l|}
0 \\
0 \\
0 \\
İ \\
\end{tabular} & 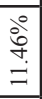 & \begin{tabular}{l|}
\multirow{\circ}{\circ}{} \\
$\stackrel{\circ}{\circ}$
\end{tabular} & 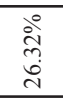 & 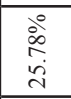 & $\begin{array}{l}\text { के } \\
\text { के }\end{array}$ & 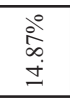 & $\begin{array}{l}\circ \\
\stackrel{\circ}{6} \\
\stackrel{0}{0}\end{array}$ & 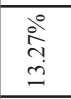 & \\
\hline & $m$ & ì & 崩 & in & $\vec{\sim}$ & in & 8 & $\ddot{m}$ & in & A & $\ddot{n}$ & 8 & in & F & mे & 8 & in & in & $m$ & $\bar{m}$ & F & i & m & $n$ & $m$ & ณू & $\infty$ & $m$ & f & $n$ & ig & \\
\hline & \begin{tabular}{|l|l}
0 \\
$i$ \\
0 \\
0 \\
0
\end{tabular} & 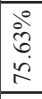 & 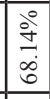 & 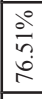 & 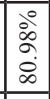 & \begin{tabular}{|l|}
0 \\
0 \\
0 \\
0 \\
0 \\
\end{tabular} & $\begin{array}{l}0 \\
\text { in } \\
\dot{0}\end{array}$ & \begin{tabular}{|l|}
$\circ$ \\
0 \\
$b$ \\
$y$ \\
\end{tabular} & 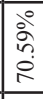 & 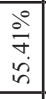 & 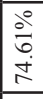 & 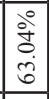 & $\begin{array}{l}\text { हें } \\
\text { है }\end{array}$ & 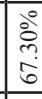 & 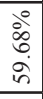 & 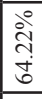 & 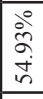 & 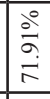 & 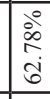 & 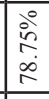 & \begin{tabular}{|c|}
0 \\
0 \\
0 \\
0 \\
0 \\
\end{tabular} & ठे & 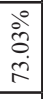 & 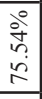 & 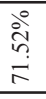 & 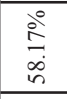 & 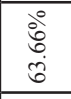 & 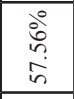 & 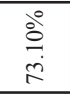 & 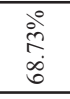 & 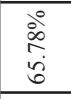 & \\
\hline & $\frac{m}{\vec{N}}$ & בิ & $\frac{0}{N}$ & 省 & $\stackrel{\circ}{\circ}$ & $\hat{\jmath}$ & సి & $\approx$ & $\stackrel{\circ}{\sim}$ & \pm & $\vec{J}$ & $\bar{\beth}$ & సి & $\frac{\pi}{\sim}$ & $\stackrel{\infty}{\rightarrow}$ & $\stackrel{\circ}{\mathrm{N}}$ & $\stackrel{ \pm}{\Phi}$ & $\hat{\imath}$ & $\overrightarrow{\mathcal{N}}$ & సิ సิ & $\overline{\mathbb{N}}$ & స్త్స & สี & $\underset{d}{\mathbb{Z}}$ & $\overrightarrow{\mathcal{\lambda}}$ & $\stackrel{\circ}{\wedge}$ & ڤે & $\stackrel{\infty}{=}$ & $\overline{\widetilde{\jmath}}$ & $\widetilde{\approx}$ & สิ & \\
\hline $\begin{array}{l}\text { है } \\
\text { है }\end{array}$ & 6 & o & 0 & t & $\stackrel{0}{-}$ & 6 & 6 & $\stackrel{0}{2}$ & t & + & t & $a$ & r & r & $n$ & In & $r$ & 0 & $a$ & $\theta$ & 0 & 6 & 6 & 6 & 0 & $a$ & $a$ & ナ & 0 & 0 & 0 & \\
\hline 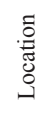 & $\mid$ & $\stackrel{0}{\sum^{2}}$ & 章 & 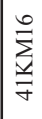 & 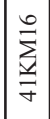 & $\stackrel{0}{\sum}$ & 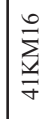 & $\sum_{\vec{z}}$ & $\sum_{\substack{\sigma \\
\sigma}}$ & 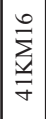 & $\sum_{\substack{b \\
\sigma}}^{\circ}$ & $\begin{array}{l}\sum_{F}^{\circ} \\
\frac{y}{\sigma}\end{array}$ & 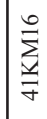 & $\sum_{\frac{3}{F}}$ & 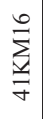 & $\stackrel{0}{2}$ & $\stackrel{0}{\sum}$ & $\underset{y}{\vec{z}}$ & 1 & 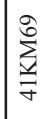 & 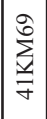 & $\sum_{z}^{\circ}$ & 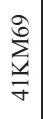 & 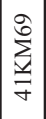 & $\begin{array}{l}\stackrel{a}{0} \\
\frac{b}{\sigma}\end{array}$ & 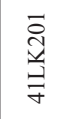 & 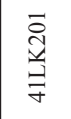 & 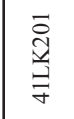 & $\stackrel{\vec{z}}{\vec{F}}$ & 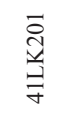 & $\begin{array}{l}\overrightarrow{\bar{\triangle}} \\
\stackrel{\vec{y}}{\exists} \\
\vec{\sigma}\end{array}$ & \\
\hline 产 & m & $\ddot{n}$ & ల్ల & 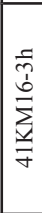 & 离 & $\overrightarrow{\vec{q}}$ & $\Varangle$ & f & 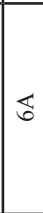 & $\ddot{6}$ & $\infty$ & $\bar{\Sigma}$ & $\bar{\approx}$ & $\approx$ & $\approx$ & $\approx$ & $\approx$ & $\dot{\aleph}$ & $\vec{x}$ & $\begin{array}{l}\infty \\
1 \\
\vdots \\
0 \\
1 \\
0 \\
0 \\
0 \\
0 \\
\vdots\end{array}$ & 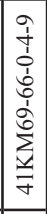 & & 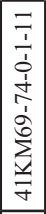 & $\left|\begin{array}{l}0 \\
0 \\
0 \\
\vdots \\
\vdots\end{array}\right|$ & 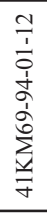 & 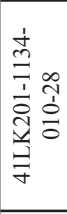 & 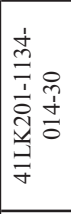 & 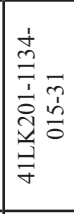 & 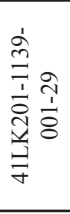 & 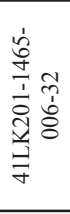 & 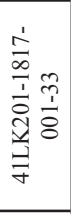 & 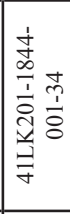 \\
\hline
\end{tabular}

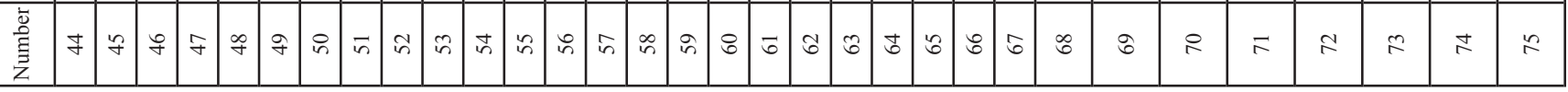




\begin{tabular}{|c|c|c|c|c|c|c|c|c|c|c|c|c|c|c|c|c|c|c|c|c|c|c|c|c|c|c|c|}
\hline 要 & f & $m$ & m & m & $m$ & $\bar{N}$ & लె & $\frac{\infty}{m}$ & $\bar{m}$ & స్లై & f & 品 & $\bar{m}$ & $\vec{m}$ & స్లి & $\frac{\vec{m}}{m}$ & 18 & in & $\stackrel{\circ}{m}$ & $\mid \begin{array}{c}0 \\
\vdots \\
m\end{array}$ & స్ల & $\frac{\infty}{m}$ & $\stackrel{\circ}{m}$ & $\stackrel{g}{a}$ & f & 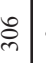 & 0 \\
\hline \multirow{2}{*}{ 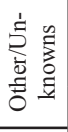 } & $\stackrel{0}{\circ}$ & $\stackrel{\circ}{\circ}$ & 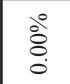 & $\stackrel{8}{\circ}$ & 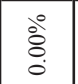 & 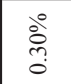 & 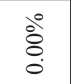 & 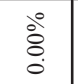 & ?. & 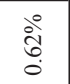 & 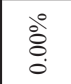 & 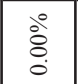 & : & : & $\stackrel{3}{0}$ & & 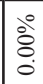 & : & $\mid \begin{array}{c}\mid \\
0 \\
0 \\
0\end{array}$ & & $\mid$ & 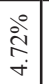 & $\begin{array}{l}0 \\
\text { oे } \\
0 \\
\dot{0}\end{array}$ & 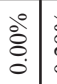 & & 8 & 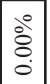 \\
\hline & 0 & 0 & 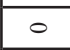 & $\circ$ & 0 & - & 0 & & 7 & 4 & & & & & - & 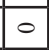 & 0 & 0 & 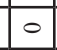 & 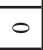 & \begin{tabular}{l|} 
\\
\end{tabular} & $n$ & 0 & 0 & $\exists$ & 0 & 0 \\
\hline \multirow[t]{2}{*}{$\begin{array}{l}\frac{\mathrm{E}}{\mathrm{D}} \\
\mathrm{J}\end{array}$} & $\begin{array}{l}\text { ڤे } \\
\text { aे }\end{array}$ & ठे. & d. & 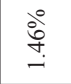 & है & $\begin{array}{l}\square \\
\dot{0}\end{array}$ & $\begin{array}{l}\stackrel{\circ}{\circ} \\
\stackrel{0}{0} \\
\stackrel{0}{\circ}\end{array}$ & 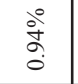 & $\stackrel{0}{\circ}$ & $\begin{array}{l}0 \\
\vdots \\
0\end{array}$ & 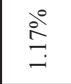 & ஸे & $\stackrel{0}{0}$ & 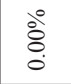 & $\begin{array}{l}\text { dì } \\
\text { à }\end{array}$ & ठ̊̊. & 定 & ذँّ & $\left|\begin{array}{l}0 \\
0 \\
0 \\
0\end{array}\right|$ & ठัें & $\mid \begin{array}{c}0 \\
\vdots \\
0 \\
0\end{array}$ & 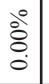 & $\begin{array}{l}0 \\
\text { ठे. } \\
\dot{0}\end{array}$ & ठे. & ठั & 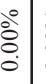 & 客 \\
\hline & $\mathrm{N}$ & 0 & 7 & - & ? & 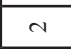 & $N$ & 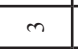 & 0 & - & 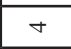 & - & & & $m$ & 0 & 0 & 0 & 0 & 0 & 0 & 0 & 0 & 0 & $\circ$ & 0 & 0 \\
\hline \multirow{2}{*}{ 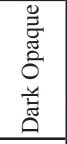 } & 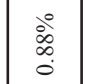 & $\frac{\circ}{\frac{0}{3}}$ & ذ્ণ & ڤัे & $\begin{array}{l}\stackrel{\circ}{\circ} \\
\stackrel{0}{\circ}\end{array}$ & $\begin{array}{l}\stackrel{\circ}{\circ} \\
\stackrel{\circ}{\circ}\end{array}$ & $\begin{array}{l}\stackrel{0}{\circ} \\
\stackrel{0}{\circ}\end{array}$ & ذँّ & ڤัें & 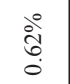 & @̊̊̊̊口: & ذّ̊ & 宫 & छेँ. & @̊̊̊̊口 & $\begin{array}{l}0 \\
\vdots \\
0 \\
0 \\
0\end{array}$ & $\begin{array}{l}0 \\
\text { Sे } \\
\text { oे }\end{array}$ & : & 产 & 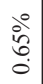 & $\mid \begin{array}{l}0 \\
\vdots \\
0 \\
0 \\
0\end{array}$ & 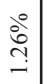 & 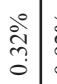 & ڤें & 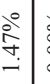 & ¿. & 它 \\
\hline & $m$ & - & \pm & - & $m$ & $\mathrm{~N}$ & 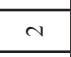 & $\circ$ & $\sim$ & $\mathrm{N}$ & 0 & $\circ$ & $\circ$ & $\circ$ & 0 & 0 & $m$ & 0 & 0 & 4 & 0 & + & -1 & -1 & in & 0 & 0 \\
\hline \multirow{2}{*}{ 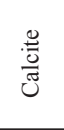 } & 守 & 官 & 㤐 & 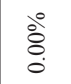 & $\stackrel{8}{\circ}$ & 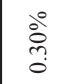 & $\begin{array}{l}\text { oें } \\
\vdots \\
0\end{array}$ & ठें & 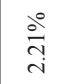 & $\begin{array}{l}0 \\
\dot{0} \\
\vdots \\
0\end{array}$ & @̊․․ & ذ̊. & 客 & @̊̊. & ذ̊ㅇํ & $\begin{array}{l}0 \\
\vdots \\
0 \\
0\end{array}$ & 定 & 客 & 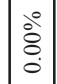 & 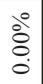 & \begin{tabular}{|l|}
$\stackrel{\circ}{\circ}$ \\
د̀
\end{tabular} & $\frac{\circ}{m}$ & $\begin{array}{l}\text { 今े } \\
\text { ले } \\
0\end{array}$ & $\begin{array}{l}\text { ذें } \\
\vdots \\
0\end{array}$ & \begin{tabular}{l|l}
$\circ$ \\
$\stackrel{0}{0}$ \\
iे
\end{tabular} & 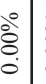 & \begin{tabular}{|l|} 
\\
\\
\\
\\
\end{tabular} \\
\hline & in & in & in & 0 & 0 & - & 0 & 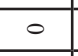 & $r$ & - & - & 0 & 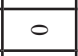 & 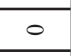 & 음 & 0 & 0 & 0 & 0 & 0 & \begin{tabular}{|l|}
+ \\
\end{tabular} & - & -1 & $\exists$ & 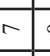 & - & 0 \\
\hline \multirow{2}{*}{ 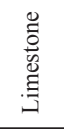 } & ڤे & $\frac{\circ}{3}$ & 今े & 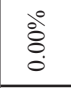 & ڤ̊․ & ठें & $\begin{array}{l}\text { oें } \\
\\
\end{array}$ & ذें & 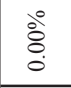 & 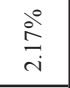 & $\stackrel{8}{\stackrel{8}{\circ}}$ & 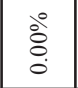 & సें & 产 & $\begin{array}{l}\text { ओे } \\
\text { Oे }\end{array}$ & \begin{tabular}{|c|}
$\frac{\partial}{\vec{n}}$ \\
$\vec{i}$
\end{tabular} & 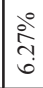 & $\begin{array}{l} \\
\text { ذें } \\
\text { in }\end{array}$ & $\begin{array}{l}\mid 0 \\
\vdots \\
0 \\
\dot{0}\end{array}$ & 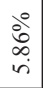 & 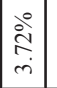 & $\begin{array}{l}0 \\
\stackrel{0}{0} \\
\dot{0}\end{array}$ & $\begin{array}{l}0 \\
\text { ठें } \\
\dot{0}\end{array}$ & $\begin{array}{l}\text { ڤे } \\
\text { ठे }\end{array}$ & ذे & 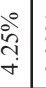 & \begin{tabular}{|c|}
0 \\
$\vdots$ \\
0 \\
0
\end{tabular} \\
\hline & 0 & - & 0 & $\circ$ & 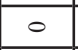 & 0 & $\circ$ & $\circ$ & 0 & $r$ & in & $\circ$ & 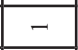 & $m$ & $m$ & $\infty$ & 2 & - & 0 & $\stackrel{\infty}{\longrightarrow}$ & $\simeq$ & $\sim$ & 0 & -1 & 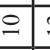 & 2 & 0 \\
\hline \multirow{2}{*}{ 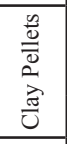 } & 宫 & 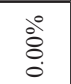 & 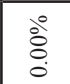 & 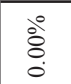 & 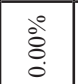 & 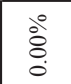 & $\begin{array}{l}\text { oें } \\
\text { oे } \\
0\end{array}$ & ठें & $\begin{array}{l}\text { वें } \\
\text { ते } \\
\text { ?. }\end{array}$ & $\begin{array}{l} \\
\text { oें } \\
0\end{array}$ & $\begin{array}{l}\text { वें } \\
\text { ते }\end{array}$ & 递 & ذें & $\frac{\circ}{\stackrel{0}{m}}$ & 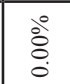 & $\begin{array}{l}0 \\
0 \\
0 \\
0\end{array}$ & : & 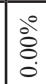 & \begin{tabular}{|c|} 
\\
$\vdots$ \\
$\vdots$ \\
0
\end{tabular} & $\begin{array}{l} \\
\\
0 \\
0\end{array}$ & \begin{tabular}{|c|}
0 \\
$\vdots$ \\
0 \\
0
\end{tabular} & $\begin{array}{l}\mid \\
\vdots \\
0 \\
0\end{array}$ & 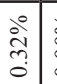 & 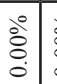 & 高 & ל. & \begin{tabular}{|l|l|} 
\\
\\
0 \\
0
\end{tabular} \\
\hline & $\circ$ & $\circ$ & 0 & 0 & . & $\circ$ & $\circ$ & 0 & - & $\circ$ & - & $\circ$ & - & - & 0 & 0 & 0 & 0 & m & 0 & \begin{tabular}{l|} 
\\
\end{tabular} & 0 & -1 & \begin{tabular}{l|l} 
\\
\end{tabular} & 0 & - & 0 \\
\hline \multirow{2}{*}{$\begin{array}{l}\frac{\bar{v}}{\bar{m}} \\
\end{array}$} & ¿ें & $\stackrel{\circ}{\circ}$ & ¿ें & ठ̊. & छे & ठें & ठ̊̀े & 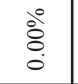 & ठें & ذें & - & 客 & 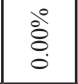 & $\begin{array}{l}\text { ذें } \\
\text {. }\end{array}$ & ¿ें & \begin{tabular}{|c|}
0 \\
0 \\
0 \\
0
\end{tabular} & ¿ें & 客 & $\mid \begin{array}{l}0 \\
0 \\
0\end{array}$ & 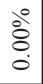 & $\mid$ & $\begin{array}{l}0 \\
\vdots \\
0 \\
\circ\end{array}$ & $\begin{array}{l}0 \\
\text { ठे. } \\
0\end{array}$ & ठ̊. & ठ̊. & 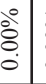 & 它 \\
\hline & $\circ$ & $\circ$ & $\circ$ & - & $\circ$ & $\circ$ & $\circ$ & $\circ$ & $\circ$ & $\circ$ & $\circ$ & $\circ$ & $\circ$ & $\circ$ & $\circ$ & $\circ$ & 0 & ० & 0 & 0 & \begin{tabular}{l|} 
\\
\end{tabular} & 0 & $\circ$ & \begin{tabular}{l|l}
$\circ$ \\
\end{tabular} & $\circ$ & - & ० \\
\hline \multirow{2}{*}{ 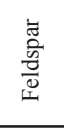 } & 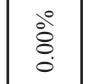 & ठें & ठें & ठें & ठे & $\stackrel{\circ}{\circ}$ & ذें & 宫 & ذें & $\begin{array}{l}0 \\
\text { ठें } \\
0\end{array}$ & ठें & $\stackrel{\square}{\circ}$ & 客 & @ें & ठें & $\mid \begin{array}{l}0 \\
\vdots \\
0 \\
0\end{array}$ & 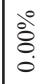 & 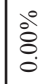 & $\begin{array}{l}0 \\
\vdots \\
\dot{0} \\
\dot{0}\end{array}$ & 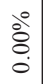 & \begin{tabular}{|c|}
0 \\
$\vdots$ \\
0 \\
0
\end{tabular} & $\begin{array}{l}0 \\
\vdots \\
\vdots \\
0\end{array}$ & $\begin{array}{l}0 \\
\text { ठें } \\
0\end{array}$ & ठัें & ठั & ¿.| & 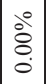 \\
\hline & $\circ$ & $\circ$ & $\circ$ & 0 & 0 & 0 & $\stackrel{\circ}{\circ}$ & 0 & 0 & $\circ$ & 0 & $\circ$ & - & & $\circ$ & 0 & 0 & 0 & 0 & 0 & \begin{tabular}{l|}
0 \\
\end{tabular} & 0 & $\circ$ & $\circ$ & 0 & $\circ$ & $\circ$ \\
\hline \multirow[t]{2}{*}{$\frac{0}{0}$} & $\begin{array}{l}\text { वे } \\
\text { ì } \\
\text { in }\end{array}$ & $\begin{array}{l}\text { ¿ें } \\
\stackrel{2}{\circ}\end{array}$ & $\begin{array}{l}\stackrel{\circ}{\partial} \\
\vec{\forall}\end{array}$ & 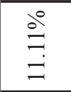 & 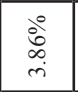 & $\begin{array}{l}\text { वे } \\
\text { oे } \\
\dot{y}\end{array}$ & $\begin{array}{l}\stackrel{\circ}{0} \\
\stackrel{्}{=}\end{array}$ & $\begin{array}{l}\circ \\
\grave{y}\end{array}$ & in & dั่ & $\stackrel{\circ}{\circ}$ & ลे & స్త్రి & o & 守 & $\begin{array}{l}\text { ¿ें } \\
\text { ते } \\
\text { - }\end{array}$ & 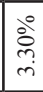 & 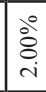 & $\begin{array}{c}0 \\
\text { i⿱ } \\
0 \\
0\end{array}$ & $\begin{array}{l}\frac{\partial}{2} \\
\dot{\vec{\sigma}}\end{array}$ & 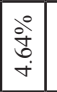 & 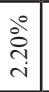 & 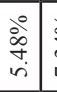 & 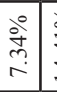 & $\frac{80}{7}$ & 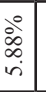 & 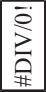 \\
\hline & 9 & $\stackrel{0}{0}$ & \pm & $\stackrel{\infty}{m}$ & $\stackrel{3}{3}$ & $\stackrel{\infty}{\longrightarrow}$ & $\stackrel{\infty}{m}$ & 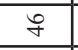 & 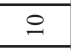 & 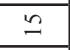 & $\pi$ & - & $\overline{3}$ & & $\Gamma$ & i & 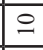 & $=$ & त) & $\cong$ & $\because$ & $r$ & $\Xi$ & $\infty$ & 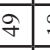 & $\stackrel{\infty}{\infty}$ & \\
\hline \multirow{2}{*}{ 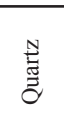 } & 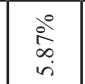 & 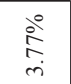 & $\begin{array}{l}\text { के } \\
\text { के }\end{array}$ & $\begin{array}{l}\text { ¿े } \\
\infty \\
\dot{y}\end{array}$ & $\stackrel{\text { ๖े }}{\Rightarrow}$ & 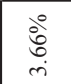 & 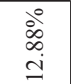 & $\stackrel{d}{d}$ & ठे & है & ळे & iे & 离 & $\therefore$ & ओं & $\frac{\stackrel{0}{0}}{\mathrm{~m}}$ & $\begin{array}{c}\stackrel{0}{0} \\
\text { ले } \\
\text { o. }\end{array}$ & $\begin{array}{l}\text { @ें } \\
\text { ì }\end{array}$ & \begin{tabular}{|c|}
0 \\
0 \\
0 \\
0
\end{tabular} & $\begin{array}{l} \\
\stackrel{0}{0} \\
0 \\
0\end{array}$ & \begin{tabular}{|c|}
0 \\
$\hat{\sigma}$ \\
0 \\
0
\end{tabular} & 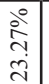 & $\begin{array}{l}0 \\
\vdots \\
\vdots \\
\vdots \\
0\end{array}$ & 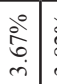 & 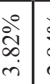 & 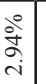 & 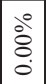 \\
\hline & 8 & 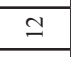 & $\infty$ & $\infty$ & $\vec{\nabla}$ & S & $\widetilde{N}$ & 8 & $\Omega$ & 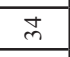 & 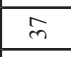 & $\bar{d}$ & $n$ & f & ते & - & - & - & in & $m$ & \begin{tabular}{|l|} 
\\
\end{tabular} & I & $m$ & +5 & $\stackrel{9}{9}$ & a & 0 \\
\hline \multirow[t]{2}{*}{ 号 } & 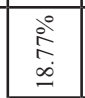 & 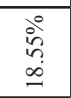 & 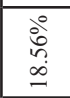 & 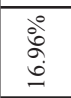 & के & $\stackrel{\circ}{\stackrel{\circ}{\Omega}}$ & 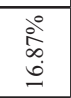 & วิे & ठें & ذें & & ఫे & ठํํㅇ & & 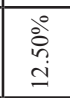 & 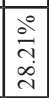 & \begin{tabular}{|l}
\multirow{2}{\circ}{} \\
$\hat{i}$ \\
ì
\end{tabular} & 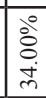 & \begin{tabular}{|l}
\multirow{3}{*}{} \\
ते
\end{tabular} & 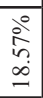 & 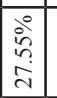 & $\begin{array}{l}0 \\
0 \\
0 \\
0 \\
0\end{array}$ & 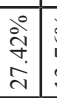 & 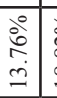 & 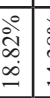 & 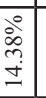 & $\begin{array}{l} \\
\\
\vdots\end{array}$ \\
\hline & t & in & $\widehat{\sigma}$ & $\stackrel{\infty}{i}$ & - & 8 & $n$ & 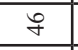 & g & 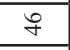 & 2 & & $\overline{6}$ & & & 8 & 8 & $\Xi$ & -1 & in & $\infty$ & $m$ & 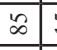 & $\because$ & $\begin{array}{ll}0 \\
\end{array}$ & 寸 & \\
\hline \multirow[t]{2}{*}{$\frac{0}{5}$} & $\begin{array}{l}0 \\
0 \\
0 \\
0 \\
0\end{array}$ & 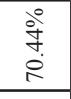 & 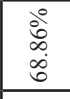 & $\begin{array}{l}\text { dे̀ } \\
\text { ì } \\
\text { z̧ }\end{array}$ & 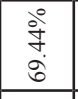 & ळे & $\dot{0}^{\circ}$ & iे & $\stackrel{\circ}{\circ}$ & $\stackrel{\circ}{\infty}$ & 8 & 3ั & ذें & & & 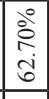 & 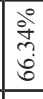 & 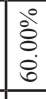 & \begin{tabular}{|c|}
0 \\
$\vdots$ \\
0 \\
$\dot{0}$ \\
\end{tabular} & 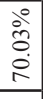 & \begin{tabular}{|c|}
2 \\
2 \\
$\vdots$ \\
0 \\
\end{tabular} & $\begin{array}{l}0 \\
\text { dे } \\
\vdots \\
\text { in } \\
\end{array}$ & $\begin{array}{l}0 \\
\dot{0} \\
\dot{3}\end{array}$ & $\begin{array}{l}0 \\
0 \\
0 \\
3 \\
3\end{array}$ & $n$ & $\begin{array}{l}\text { 离 } \\
\text { an } \\
\end{array}$ & \begin{tabular}{|l} 
\\
\\
0 \\
\end{tabular} \\
\hline & 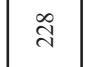 & $\stackrel{ \pm}{\mathbb{N}}$ & ণ্ণ & $i n$ & $\stackrel{\sim}{\sim}$ & तે & $\stackrel{\infty}{\infty}$ & $\stackrel{\infty}{\sim}$ & & & $\stackrel{\infty}{-}$ & $\stackrel{\infty}{\sim}$ & $\stackrel{\infty}{\sim}$ & $\hat{\sim}$ & & 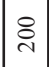 & ¿े & i & $\vec{\sim}$ & $\stackrel{\curvearrowleft}{\sim}$ & $\stackrel{\sim}{.}$ & $\stackrel{\mathscr{\infty}}{\rightarrow}$ & ڤิ & 8 & $\bar{\Xi}$ & तี & - \\
\hline 产 & 0 & 6 & 6 & $\infty$ & (1) & 6 & 6 & 6 & 6 & 6 & & 6 & 6 & 6 & 6 & $a$ & $\stackrel{\circ}{\circ}$ & $\stackrel{0}{\circ}$ & in & $r$ & $a$ & $\infty$ & $a$ & $\stackrel{?}{\simeq}$ & r & 0 & $\underline{-1}$ \\
\hline 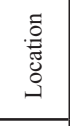 & $\begin{array}{l}\overrightarrow{\mathbb{Z}} \\
\stackrel{3}{J}\end{array}$ & $\begin{array}{l}\overline{\bar{y}} \\
\vec{\exists}\end{array}$ & $\begin{array}{l}\overrightarrow{\widetilde{a}} \\
\vec{z}\end{array}$ & 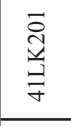 & $\bar{\vdots}$ & $\Im$ & $\overline{\check{y}}$ & $\Xi$ & 3 & $\stackrel{5}{2}$ & 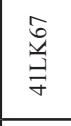 & $\underline{a}$ & $\tilde{g}$ & 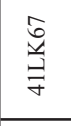 & $\begin{array}{l}\stackrel{\widehat{a}}{\ddot{\exists}} \\
\vec{\exists}\end{array}$ & 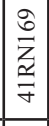 & 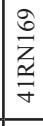 & 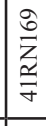 & 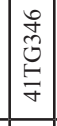 & 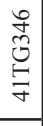 & 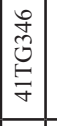 & $\begin{array}{l}\mathcal{B} \\
⿱ 乛 \\
\forall \\
\end{array}$ & $\begin{array}{l}5 \\
\vec{F} \\
\vec{F}\end{array}$ & 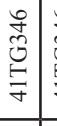 & & & $\begin{array}{l}\infty \\
\infty \\
z \\
z \\
z\end{array}$ \\
\hline 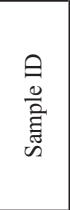 & 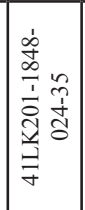 & 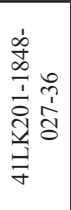 & 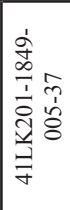 & 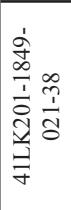 & 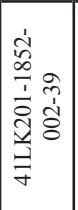 & 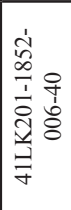 & 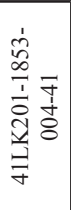 & 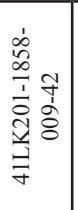 & 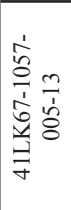 & 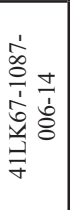 & 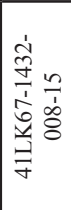 & 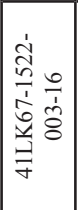 & 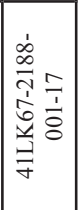 & 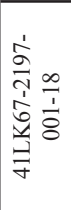 & 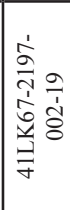 & 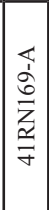 & 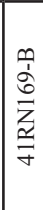 & 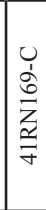 & 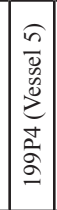 & 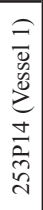 & 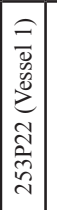 & 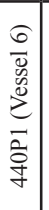 & 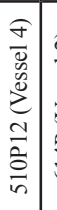 & 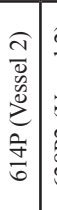 & 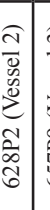 & 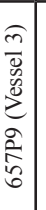 & 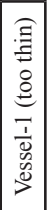 \\
\hline 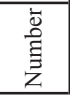 & $\stackrel{?}{?}$ & 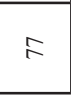 & ก & 尺े & $\triangleright$ & $\bar{\infty}$ & $\infty$ & $\infty$ & $\underset{\infty}{ \pm}$ & $\infty$ & $\infty$ & $\infty$ & $\infty$ & ळ) & 8 & む & 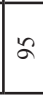 & 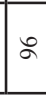 & $\hat{\sigma}$ & ळ & 2 & 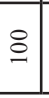 & 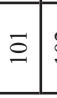 & $\stackrel{\widetilde{\sigma}}{-}$ & & $\stackrel{0}{0}$ & $\stackrel{n}{=}$ \\
\hline
\end{tabular}




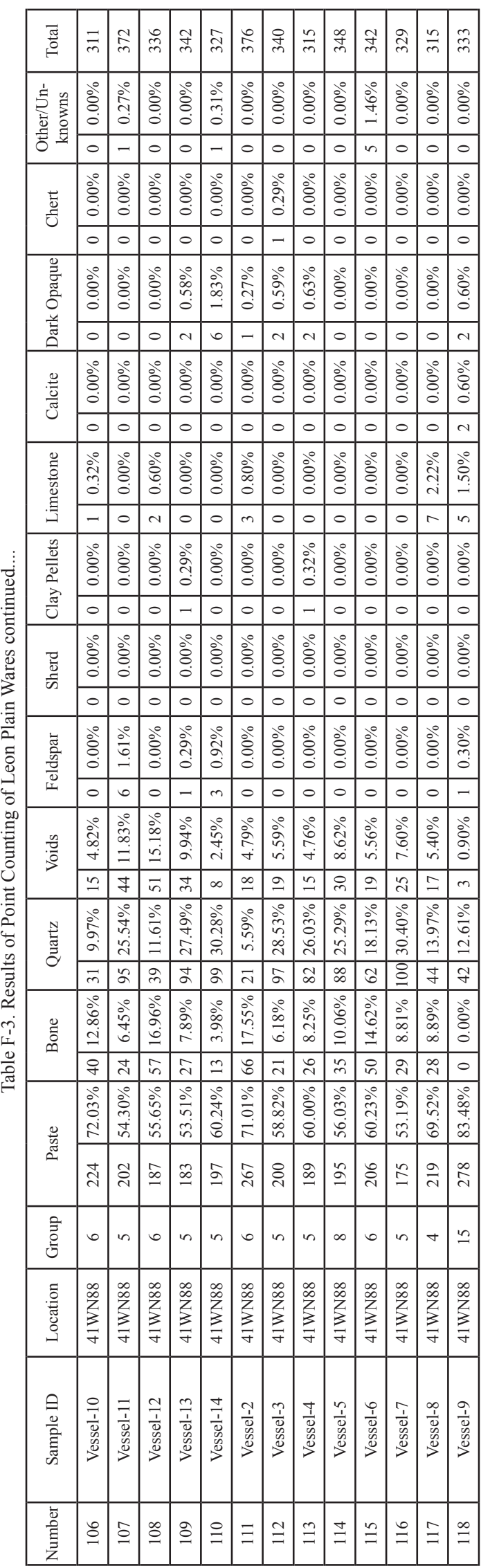




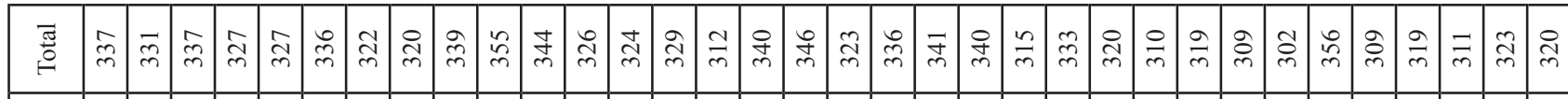

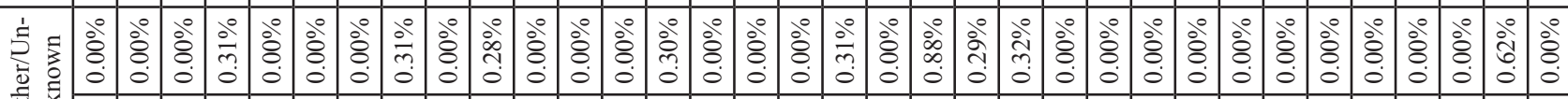
ప̃

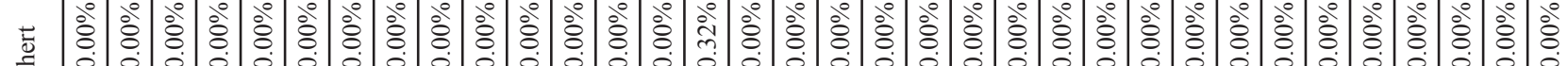

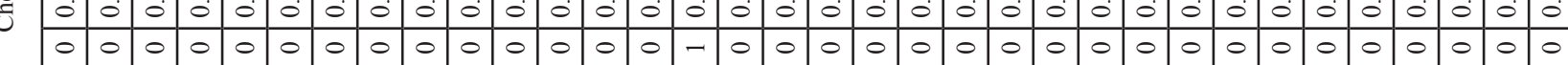

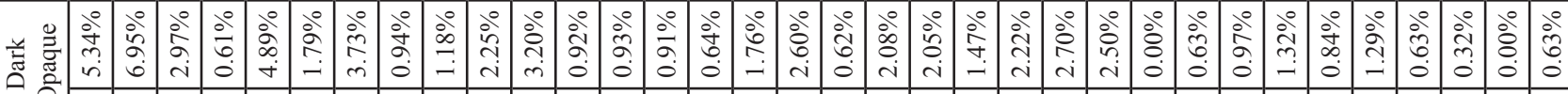

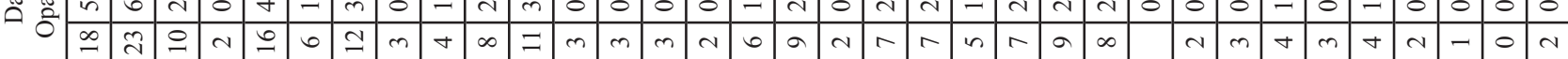
. 岂

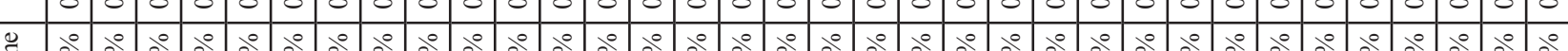

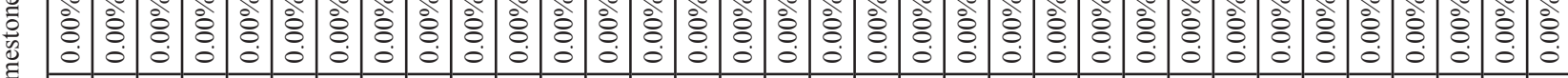

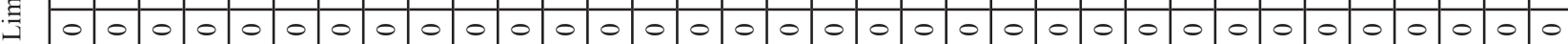

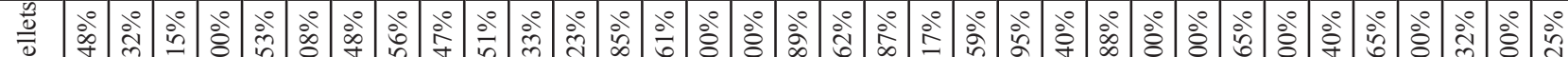

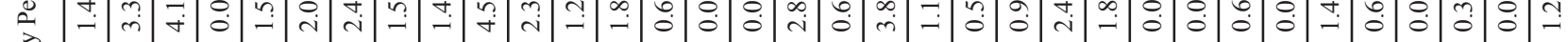

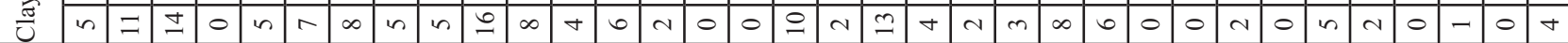

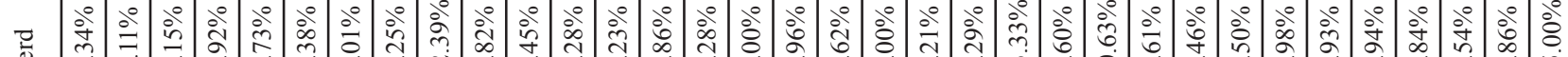

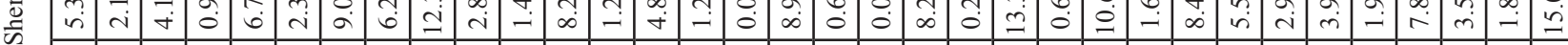

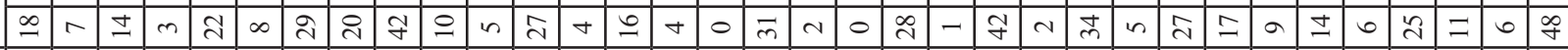

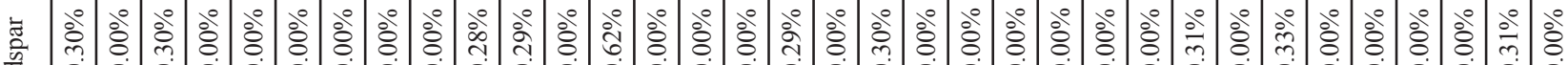

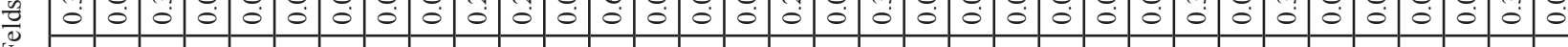
L

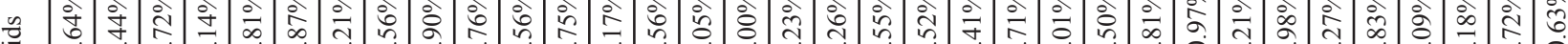

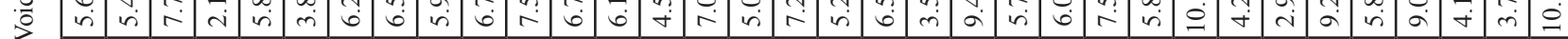

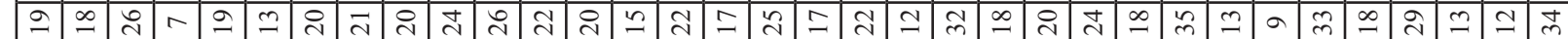

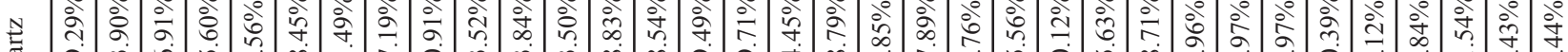

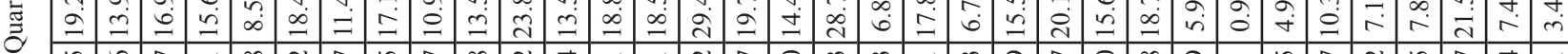

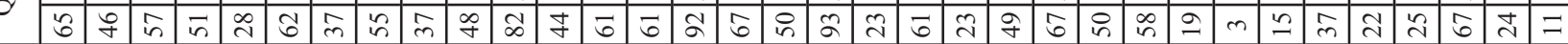

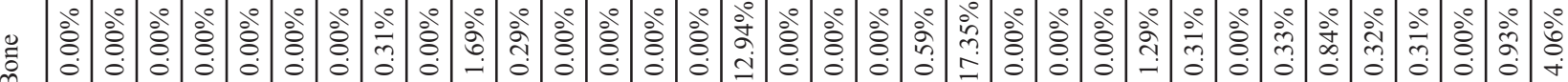

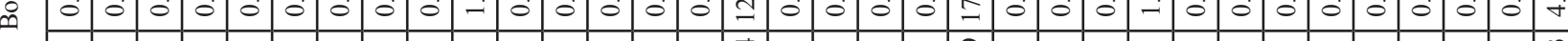

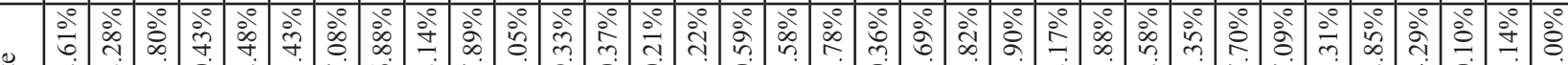

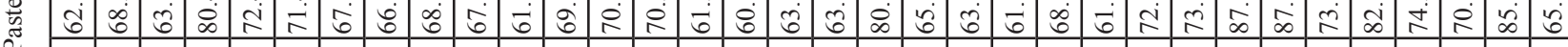

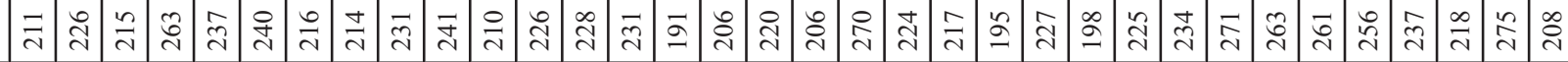

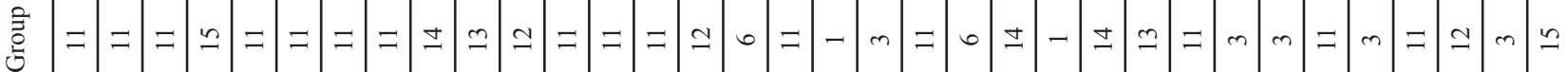

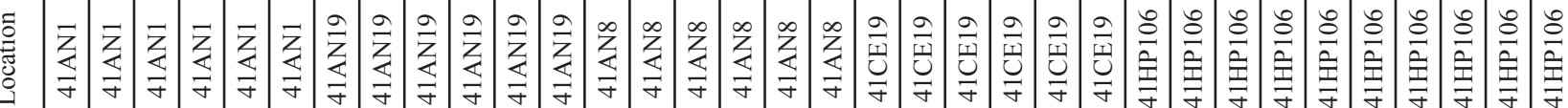

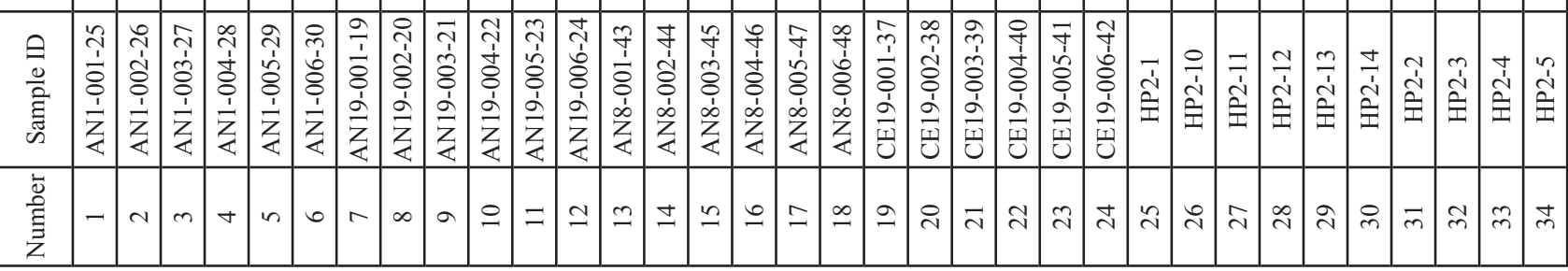




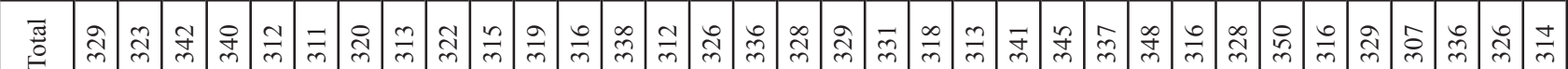

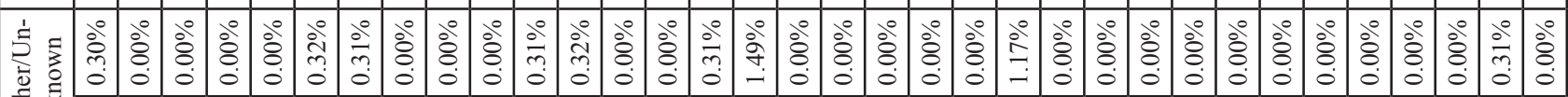
0 芯 \begin{tabular}{|lllllllllllllllllllllllllllllllllll}
\hline & 0 & 0 & 0 & 0 & 0 & 0 & 0 & 0 & 0 & 0 & 0 & 0 & 0 & 0 & 0 & 0 & 0 & 0 & 0 & 0 & 0 & 0 & - & 0 & 0 & 0 & 0 & 0 & 0 & 0 & - & 0 & 0 & 0 \\
\hline
\end{tabular}

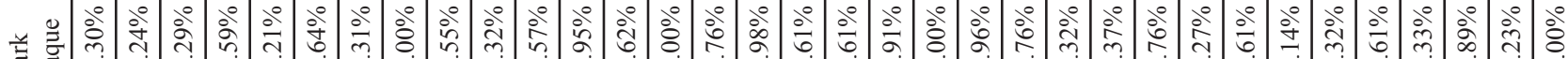

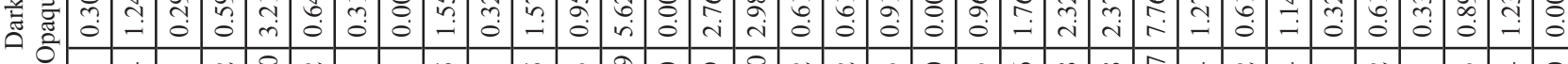

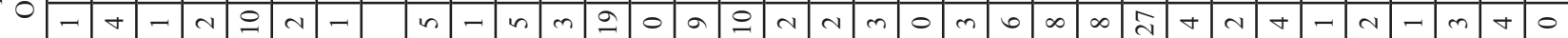

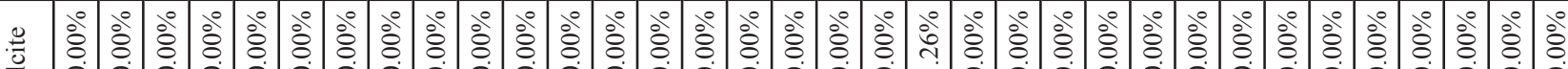
Uు 亏 ठें 苛

J

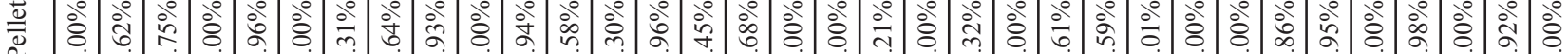

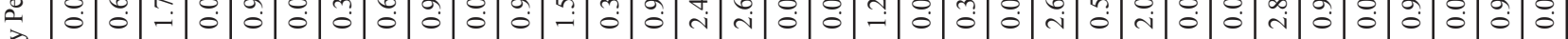

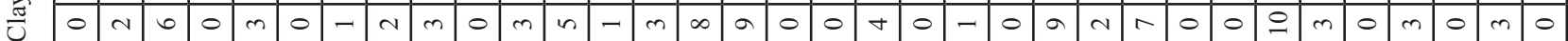

च

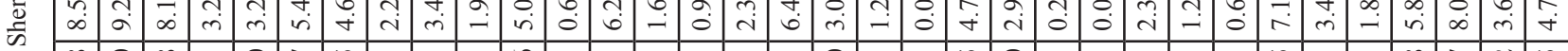

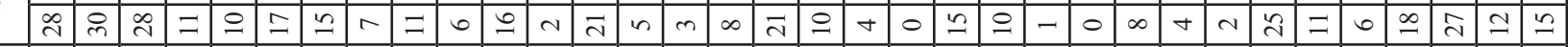

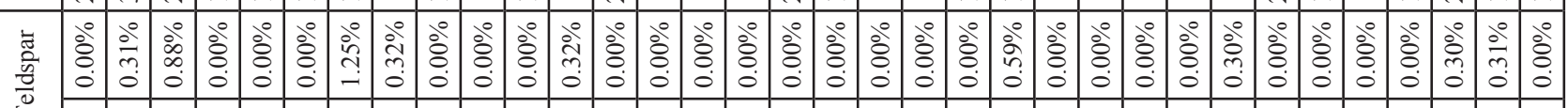
至 0 -

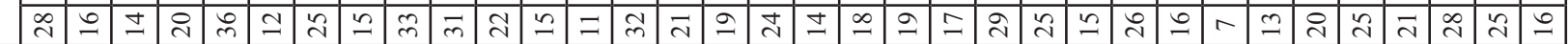

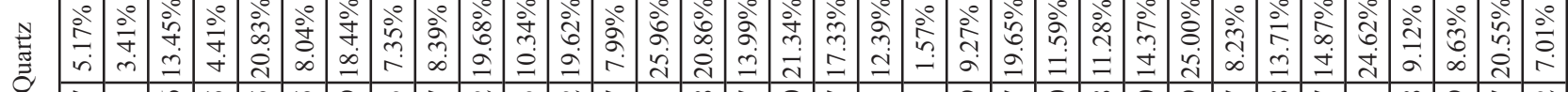

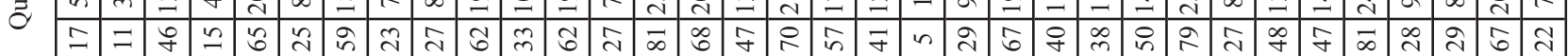

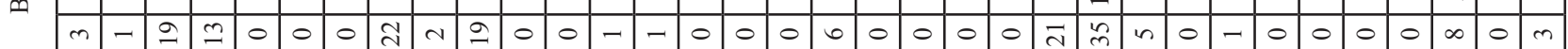

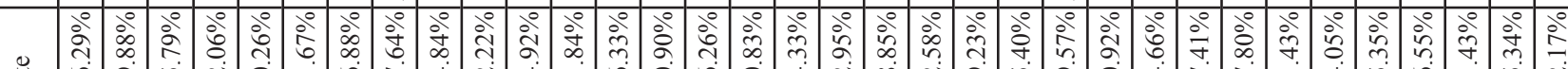

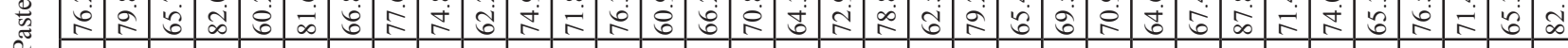

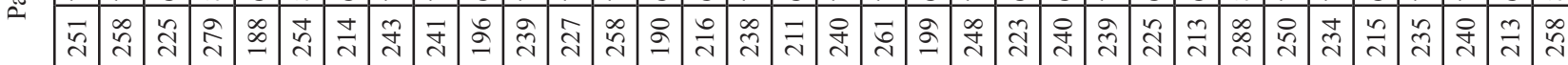

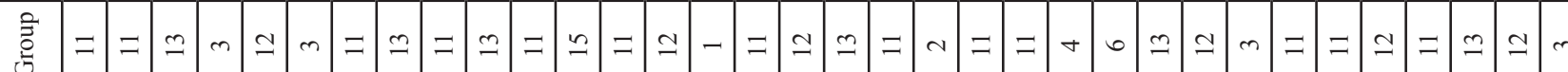

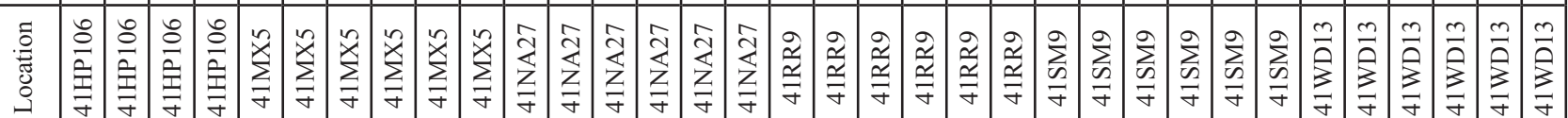

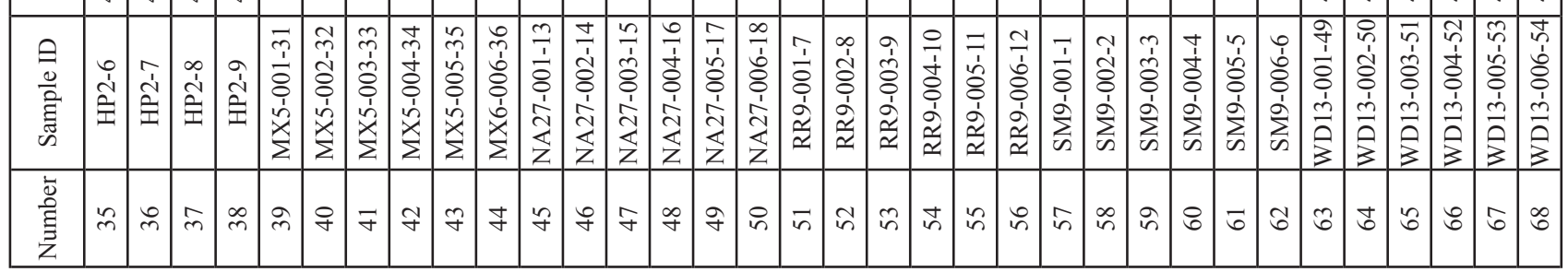




\begin{tabular}{|c|c|c|c|c|c|c|c|c|c|c|c|c|c|c|c|c|c|c|c|c|c|c|c|c|c|c|c|c|c|c|c|}
\hline 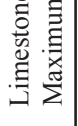 & & & & 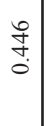 & $\mid$\begin{tabular}{l}
$\infty$ \\
\multirow{3}{0}{} \\
0 \\
0
\end{tabular} & & $\mid \begin{array}{c}1 \\
0 \\
\infty \\
0 \\
0\end{array}$ & & & 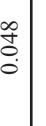 & & 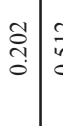 & & 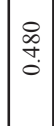 & $\mid \begin{array}{c}0 \\
0 \\
0 \\
0\end{array}$ & & & $\begin{array}{l}y \\
y \\
0 \\
0\end{array}$ & & & 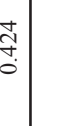 & & & & & $\mid \begin{array}{c}0 \\
\hat{\imath} \\
0 \\
0\end{array}$ & $\begin{array}{l}0 \\
\vdots \\
0 \\
0\end{array}$ & 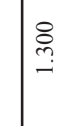 & & & \\
\hline 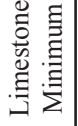 & & & & \begin{tabular}{l}
0 \\
\multirow{1}{*}{} \\
0
\end{tabular} & 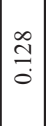 & & $\mid \begin{array}{c}\stackrel{\sim}{0} \\
\stackrel{0}{0}\end{array}$ & & & 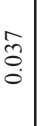 & & \begin{tabular}{l|l}
$\vec{\vdots}$ & \\
0 &
\end{tabular} & & $\mid \begin{array}{l}0 \\
0 \\
0 \\
0\end{array}$ & $\mid \begin{array}{l}0 \\
0 \\
0 \\
0 \\
0\end{array}$ & & & $\begin{array}{l}\text { yे } \\
\text { s. } \\
0\end{array}$ & & & & & & & & $\left(\begin{array}{l}0 \\
\stackrel{0}{\circ}\end{array}\right.$ & $\begin{array}{l}0 \\
: \\
0 \\
0\end{array}$ & 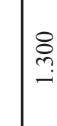 & & & \\
\hline 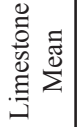 & & & & $\begin{array}{l}0 \\
+ \\
0 \\
0\end{array}$ & $\left|\begin{array}{c}\infty \\
\stackrel{2}{0} \\
0 \\
0\end{array}\right|$ & & $\mid \begin{array}{l}\overrightarrow{0} \\
\dot{a} \\
0\end{array}$ & & & $\begin{array}{l}\text { ț } \\
0 \\
0\end{array}$ & & \begin{tabular}{c}
$\tilde{Z}$ \\
\hdashline
\end{tabular} & గ్రి & 竎 & $\mid$\begin{tabular}{|c|}
0 \\
0 \\
0 \\
0 \\
0
\end{tabular} & & & $\begin{array}{l}\text { ỹ } \\
\text { w. } \\
0\end{array}$ & & & & & & & & $\mid \begin{array}{l}1 \\
0 \\
0 \\
0 \\
0\end{array}$ & $\begin{array}{l}0 \\
\vdots \\
0 \\
0\end{array}$ & 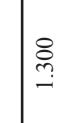 & & & \\
\hline 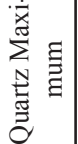 & $\begin{array}{l}\text { ले } \\
\text { है }\end{array}$ & 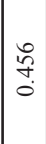 & 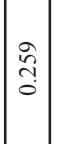 & $\begin{array}{l}5 \\
0 \\
0\end{array}$ & $\mid$\begin{tabular}{|c|}
0 \\
0 \\
0 \\
0 \\
0
\end{tabular} & 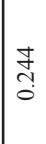 & \begin{tabular}{|l}
0 \\
\hdashline \\
0
\end{tabular} & $\mid \begin{array}{l}\infty \\
\infty \\
0 \\
0 \\
0\end{array}$ & $\begin{array}{l}\overrightarrow{0} \\
\dot{0}\end{array}$ & : & $\begin{array}{c}\vec{a} \\
\stackrel{\sigma}{0}\end{array}$ & \begin{tabular}{l|l}
0 \\
$\vdots$ \\
0
\end{tabular} & $\begin{array}{l}: \\
: \\
0 \\
0\end{array}$ & $\mid \begin{array}{c}\infty \\
0 \\
0 \\
0\end{array}$ & $\mid \begin{array}{l}f \\
o \\
0 \\
0\end{array}$ & 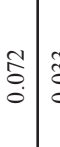 & 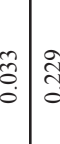 & 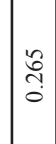 & 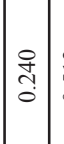 & 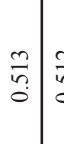 & \begin{tabular}{l|l}
7 \\
$\vdots$ \\
0 & 0 \\
0
\end{tabular} & 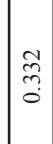 & $\frac{1}{9}$ & \begin{tabular}{c|c} 
& \multicolumn{1}{c}{} \\
\\
0
\end{tabular} & 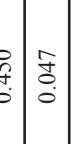 & & $\begin{array}{l}\infty \\
\substack{0 \\
0 \\
0}\end{array}$ & & $\mid \begin{array}{l}0 \\
0 \\
0 \\
0 \\
0\end{array}$ & 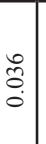 & \\
\hline 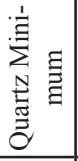 & ते & Fे & $\mid \begin{array}{l}0 \\
\vdots \\
0 \\
0\end{array}$ & $\mid \begin{array}{l}0 \\
0 \\
0 \\
0\end{array}$ & $\mid \begin{array}{l}0 \\
\vdots \\
0 \\
0\end{array}$ & ¿̊. & \begin{tabular}{|l|}
0 \\
0 \\
0
\end{tabular} & \begin{tabular}{|l|}
0 \\
0 \\
0
\end{tabular} & 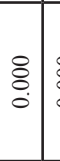 & : & $\begin{array}{l}n \\
\vdots \\
0 \\
0\end{array}$ & ¿̊. & 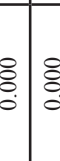 & $\mid \begin{array}{l}0 \\
\vdots \\
0\end{array}$ & $\mid$ & \begin{tabular}{l|l} 
\pm \\
$\vdots$ \\
$\dot{0}$
\end{tabular} & : & 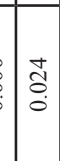 & $\mid \begin{array}{l}n \\
\vdots \\
0 \\
0\end{array}$ & \begin{tabular}{l|l}
$\overrightarrow{\mathrm{d}}$ \\
$\mathrm{O}$
\end{tabular} & \begin{tabular}{l|l}
$\stackrel{0}{0}$ \\
\\
\end{tabular} & $\mid \begin{array}{l}\tilde{\delta} \\
\dot{0} \\
0\end{array}$ & $\frac{1}{9}$ & $\begin{array}{c}\text { ¿ेి } \\
0\end{array}$ & $\begin{array}{l}0 \\
\vdots \\
\vdots \\
\dot{0}\end{array}$ & & \begin{tabular}{l}
0 \\
\multirow{0}{0}{} \\
0 \\
0
\end{tabular} & do & $\begin{array}{l}0 \\
\stackrel{0}{0} \\
0 \\
0\end{array}$ & $\begin{array}{l}0 \\
\vdots \\
0 \\
0\end{array}$ & \\
\hline 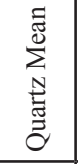 & $\frac{\mathrm{S}}{0}$ & : & $\cong$ & శ్ & \begin{tabular}{|c|}
0 \\
0 \\
0 \\
0
\end{tabular} & 竞 & $\mid \begin{array}{l}0 \\
0 \\
0 \\
0\end{array}$ & $\mid \begin{array}{l}\tilde{c} \\
\tilde{o} \\
\dot{0}\end{array}$ & $\vec{\sigma}$ & \begin{tabular}{l|l}
0 & \\
0 \\
0 \\
0
\end{tabular} & $\begin{array}{l}\overrightarrow{\overrightarrow{0}} \\
\overrightarrow{0}\end{array}$ & ¿े| & $\begin{array}{l}\text { ô. } \\
\end{array}$ & $\left|\begin{array}{l}\infty \\
\vdots \\
0 \\
0\end{array}\right|$ & $\mid$ & 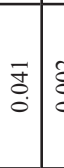 & \begin{tabular}{l|l}
$\delta_{0}^{0}$ \\
0 \\
0
\end{tabular} & $\frac{9}{9}$ & $\mid \begin{array}{l}0 \\
0 \\
0\end{array}$ & $\begin{array}{l}0 \\
\stackrel{0}{0} \\
0\end{array}$ & \begin{tabular}{l|l}
$\stackrel{2}{0}$ \\
\\
\end{tabular} & $\frac{n}{2}$ & $\frac{1}{9}$ & $\begin{array}{ll}\stackrel{0}{a} \\
0 \\
0\end{array}$ & 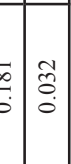 & & $\begin{array}{l}\infty \\
0 \\
0 \\
0 \\
0\end{array}$ & $\hat{\tilde{\delta}}$ & $\mid \begin{array}{l}0 \\
\vdots \\
0 \\
0 \\
0\end{array}$ & $\begin{array}{c}\bar{a} \\
\vdots \\
0\end{array}$ & \\
\hline 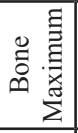 & $\stackrel{n}{\stackrel{n}{a}}$ & $\mid \begin{array}{c}0 \\
\vdots \\
0 \\
0\end{array}$ & $\stackrel{\substack{n \\
\hdashline}}{=}$ & $\mid \begin{array}{c}1 \\
0 \\
0 \\
0 \\
0\end{array}$ & 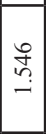 & 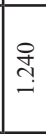 & $\stackrel{\vec{m}}{=}$ & $\begin{array}{l}\stackrel{0}{0} \\
\stackrel{6}{-}\end{array}$ & $\mid$\begin{tabular}{c|}
$\vec{t}$ \\
$\stackrel{0}{0}$ \\
-
\end{tabular} & 告 & 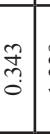 & సે & 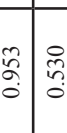 & $\stackrel{\hat{a}}{\stackrel{2}{\rightarrow}}$ & $\mid \begin{array}{l}n \\
0 \\
2 \\
0\end{array}$ & 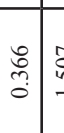 & 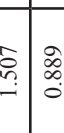 & $\begin{array}{l}0 \\
0 \\
0 \\
0 \\
0\end{array}$ & 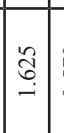 & 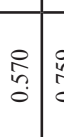 & 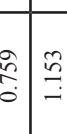 & ơ & 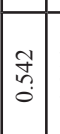 & 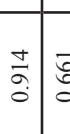 & 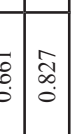 & \begin{tabular}{l|} 
\\
\\
Oे \\
0
\end{tabular} & 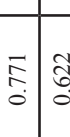 & 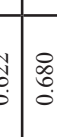 & $\stackrel{\stackrel{m}{\rightleftharpoons}}{=}$ & 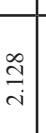 & $\underset{ت}{ت}$ \\
\hline 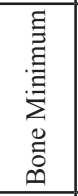 & $\begin{array}{l}\tilde{o} \\
\stackrel{0}{0}\end{array}$ & $\left|\begin{array}{l}1 \\
0 \\
0 \\
0\end{array}\right|$ & $\frac{\tilde{I}}{0}$ & 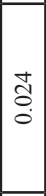 & $\mid \begin{array}{l}n \\
\hat{o} \\
0 \\
0\end{array}$ & $\overrightarrow{\mid}$ & $\left|\begin{array}{|c}n \\
\hdashline \\
0 \\
0\end{array}\right|$ & $\mid \begin{array}{l}0 \\
\stackrel{0}{0} \\
0\end{array}$ & $\mid \begin{array}{c}0 \\
\stackrel{\infty}{0} \\
\end{array}$ & 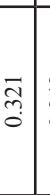 & 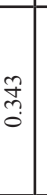 & \begin{tabular}{l|l}
$:$ & \\
$:$ & \\
$:$ &
\end{tabular} & 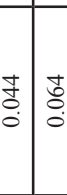 & $\left|\begin{array}{l}\infty \\
\vdots \\
0 \\
0\end{array}\right|$ & $\mid$\begin{tabular}{|c}
0 \\
$\hat{y}$ \\
0
\end{tabular} & 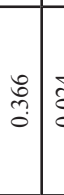 & 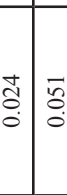 & $\mid \begin{array}{l}\hat{\tilde{o}} \\
\dot{0}\end{array}$ & $\mid \begin{array}{l}0 \\
\tilde{B} \\
0 \\
0\end{array}$ & $\begin{array}{l}0 \\
0 \\
0 \\
0 \\
0\end{array}$ & \begin{tabular}{c|c} 
¿े \\
¿े
\end{tabular} & $\stackrel{m}{\rightrightarrows}$ & $\stackrel{2}{\stackrel{2}{0}}$ & \begin{tabular}{l|l}
0 & \multicolumn{1}{c}{} \\
0 & 0 \\
0 & 0
\end{tabular} & $\begin{array}{ll}f \\
\vdots \\
\vdots\end{array}$ & $\begin{array}{l}\tilde{0} \\
0 \\
0 \\
0\end{array}$ & \begin{tabular}{l|l}
$\vec{b}$ & $\bar{z}$ \\
$\dot{0}$ & 0
\end{tabular} & 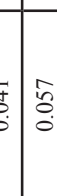 & \begin{tabular}{|l}
$\vec{r}$ \\
0 \\
0
\end{tabular} & $\begin{array}{c}\stackrel{d}{o} \\
\text { d. }\end{array}$ & 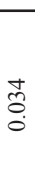 \\
\hline $\begin{array}{l}\sum_{0}^{5} \\
\sum_{0}^{0} \\
0 \\
0 \\
0\end{array}$ & $\begin{array}{l}\text { 孛 } \\
\text { o }\end{array}$ & 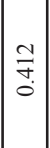 & $\mid \begin{array}{l}\hat{\vartheta} \\
\hat{f} \\
0\end{array}$ & 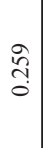 & $\mid \begin{array}{l}0 \\
0 \\
o \\
0 \\
0\end{array}$ & $\begin{array}{l}\text { f } \\
\text { fo }\end{array}$ & $\mid \begin{array}{l}1 \\
0 \\
0 \\
0\end{array}$ & $\begin{array}{l}\bar{\xi} \\
0\end{array}$ & $\mid \begin{array}{l}0 \\
0 \\
0 \\
0 \\
0\end{array}$ & 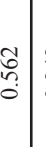 & \begin{tabular}{l}
0 \\
\multirow{2}{*}{} \\
$\vdots$ \\
0
\end{tabular} & 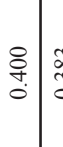 & 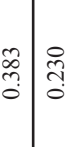 & $\mid \begin{array}{l}m \\
0 \\
0 \\
0\end{array}$ & 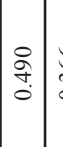 & 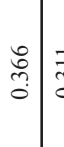 & 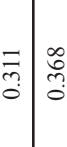 & $\begin{array}{l}\tilde{y} \\
\tilde{0}\end{array}$ & 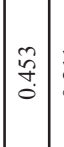 & 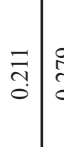 & 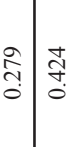 & 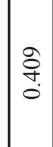 & ๙ิ & 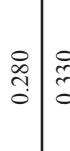 & 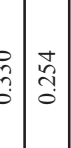 & 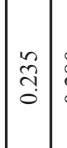 & 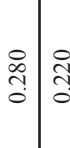 & 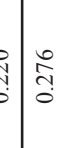 & $\begin{array}{l}0 \\
\check{0} \\
0\end{array}$ & 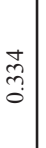 & 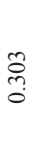 \\
\hline 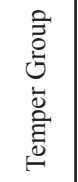 & 0 & $\infty$ & $\infty$ & 0 & 0 & 0 & 0 & 0 & 0 & $m$ & -1 & $\sigma \mid 0$ & \begin{tabular}{l|l}
$\sigma$ & 0
\end{tabular} & $\circ$ & $m$ & $m$ & \begin{tabular}{l|l}
0 & $\sigma$
\end{tabular} & $\sigma$ & 6 & in & \begin{tabular}{l|l}
$\circ$ & $\sigma$
\end{tabular} & $\nabla$ & 0 & \begin{tabular}{l|l}
0 & म
\end{tabular} & +0 & a & $\circ 0$ & $=a$ & $a$ & $\sigma$ & 6 \\
\hline 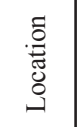 & $\begin{array}{l}\infty \\
\stackrel{\tilde{x}}{x} \\
\stackrel{\leftrightarrow}{\sigma}\end{array}$ & 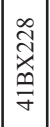 & 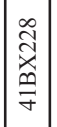 & 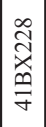 & 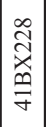 & 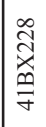 & 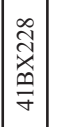 & 空 & 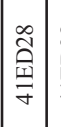 & 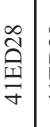 & 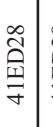 & 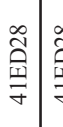 & 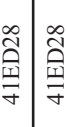 & 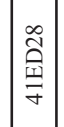 & 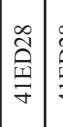 & 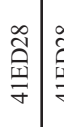 & 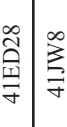 & $\stackrel{\infty}{\stackrel{\infty}{z}}$ & \begin{tabular}{|l|l}
$\infty$ \\
\multirow{2}{*}{} \\
$\vec{\sigma}$
\end{tabular} & $\sum_{\vec{\sigma}}^{\infty}$ & 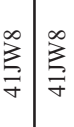 & 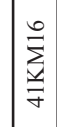 & $\mid$ & 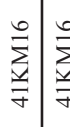 & 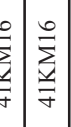 & $\underset{\substack{z \\
F}}{\stackrel{0}{z}}$ & $\stackrel{0}{\sum_{y}}$ & $\frac{0}{\sum_{F}}$ & 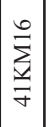 & 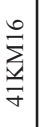 & 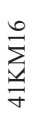 \\
\hline 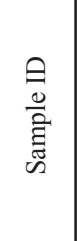 & 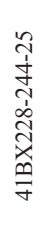 & 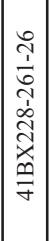 & 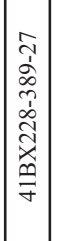 & 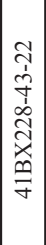 & 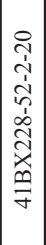 & 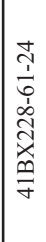 & 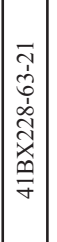 & 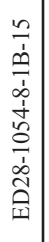 & 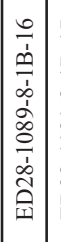 & 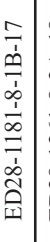 & 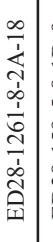 & 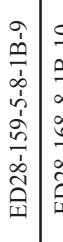 & 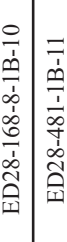 & 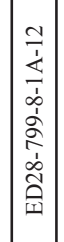 & 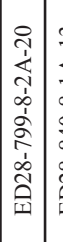 & 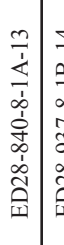 & 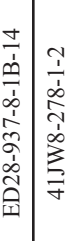 & 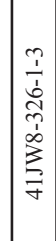 & 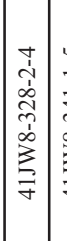 & 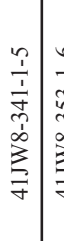 & 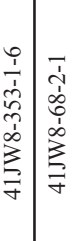 & $\simeq$ & $\cong$ & \begin{tabular}{l|l}
$\stackrel{\infty}{\infty}$ & $\infty$
\end{tabular} & $\begin{array}{lll}\hat{0} \\
0\end{array}$ & $\dddot{\sim}$ & 气̃ & $\begin{array}{l}f \\
f\end{array}$ & 离 & 离 & ڤ్ \\
\hline 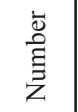 & - & $\sim \mid$ & $m$ & + & in & $r$ & $\infty$ & \pm & $\because$ & $\stackrel{0}{-1}$ & $=$ & $\stackrel{\infty}{-}$ & 2 ¿ & $\vec{\sim}$ & I & $\pi$ & \begin{tabular}{l|l}
$\Delta$ \\
\end{tabular} & 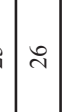 & $\hat{\sim}$ & 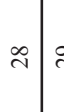 & নী & $\vec{m}$ & $\approx$ & $m$ & $\begin{array}{c}\dot{n} m \\
m\end{array}$ & $\stackrel{0}{0}$ & $\tilde{m} \mid \infty$ & : & $q$ & $F$ & f \\
\hline
\end{tabular}




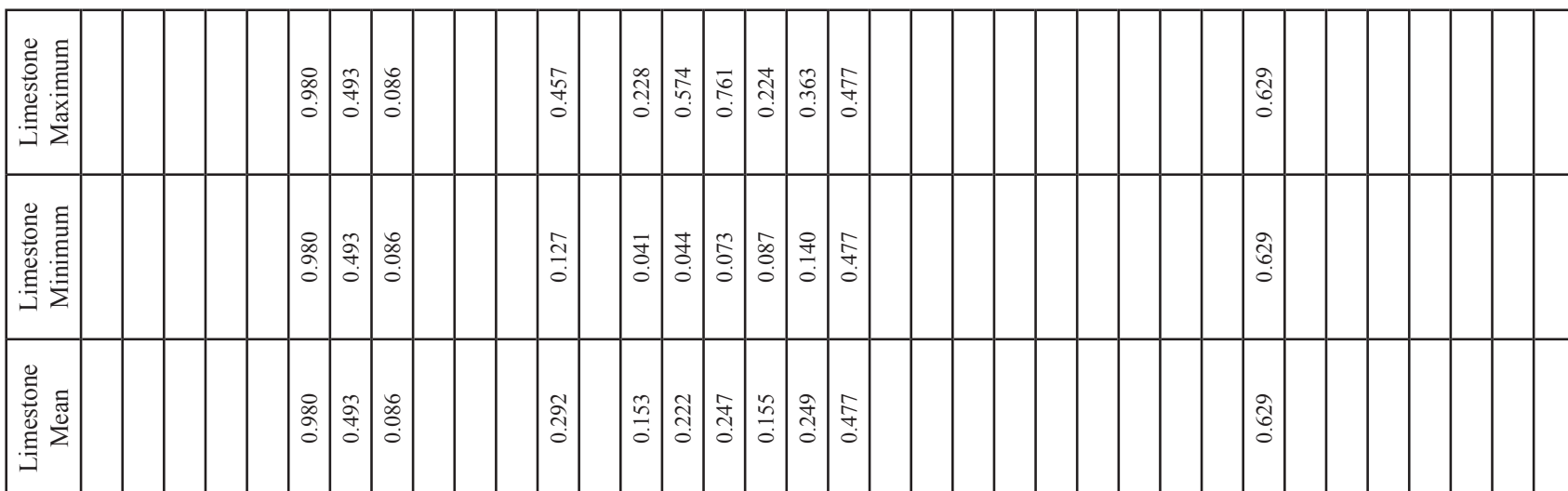

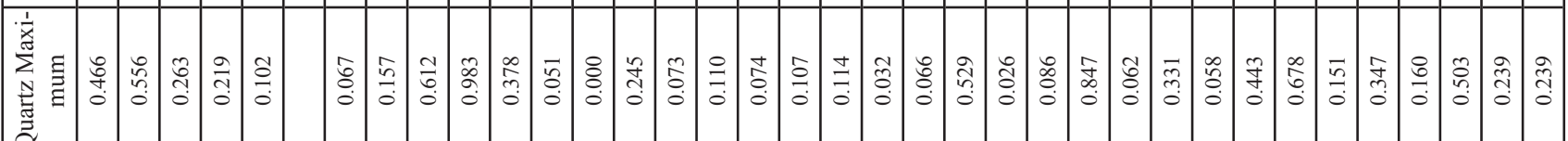

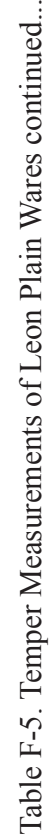

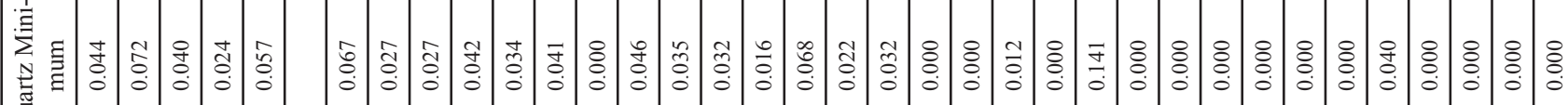
营

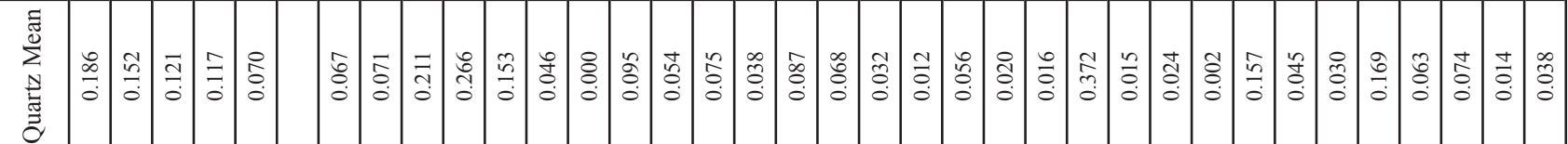

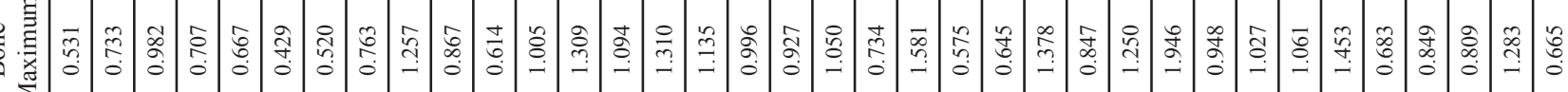

\section{音}

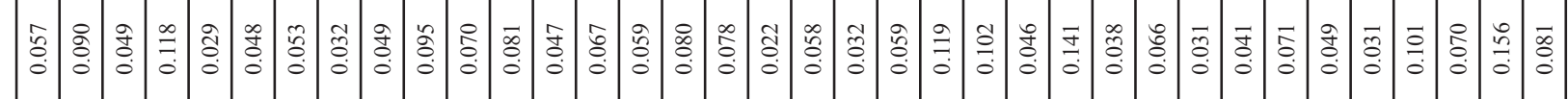
๑े

|

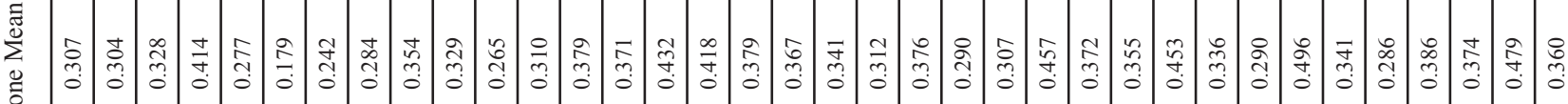
๓

产

离

总

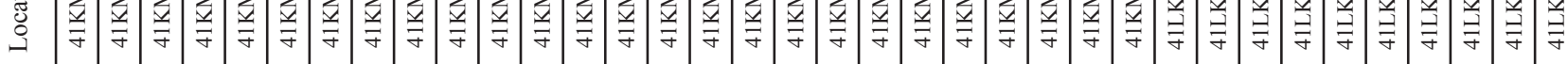

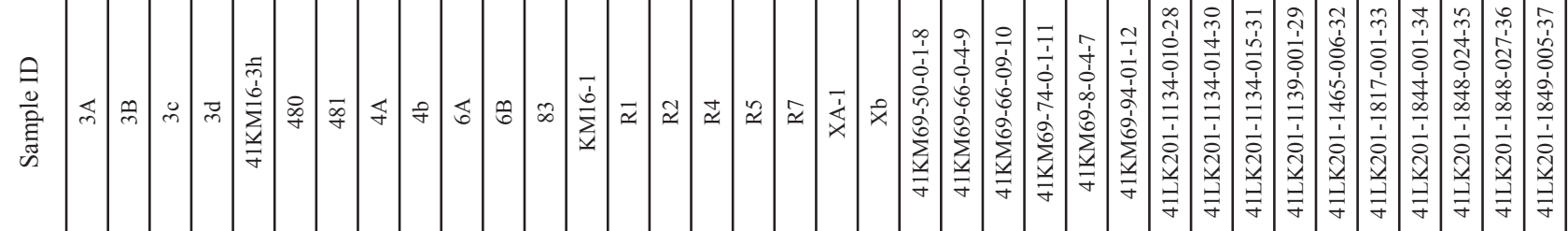

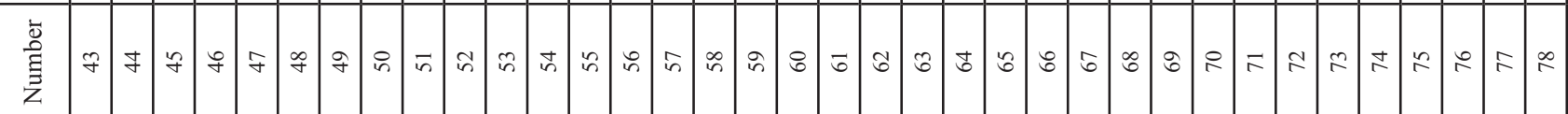




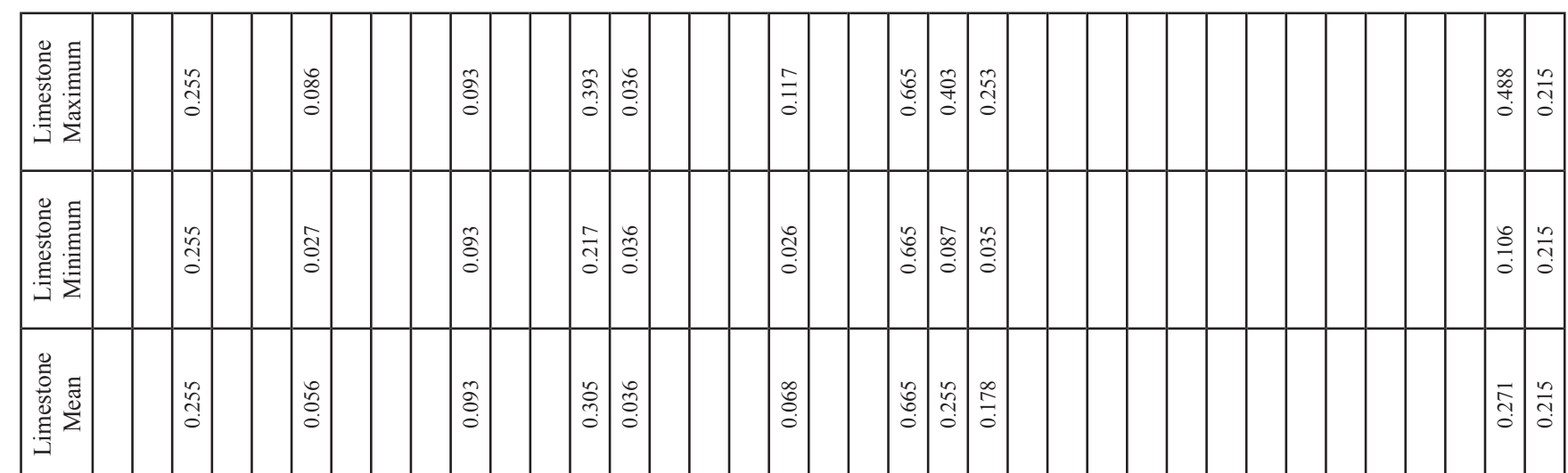

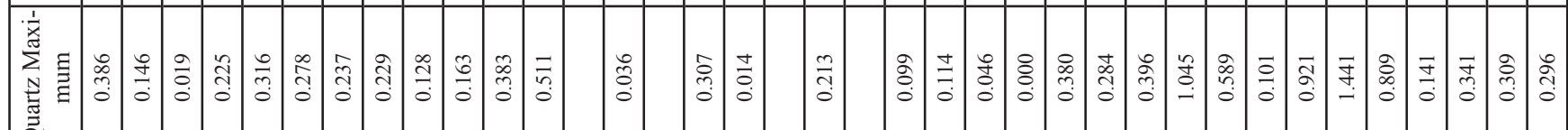

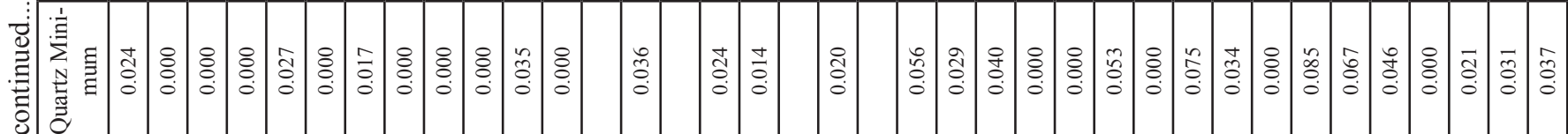

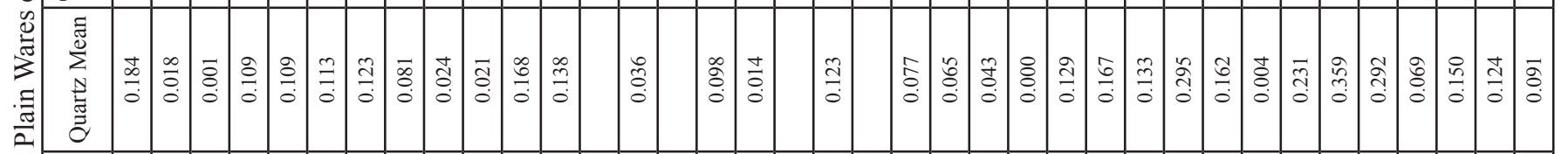

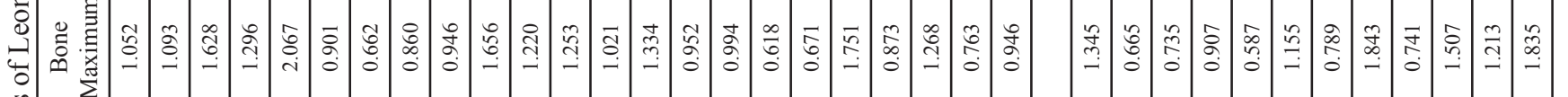

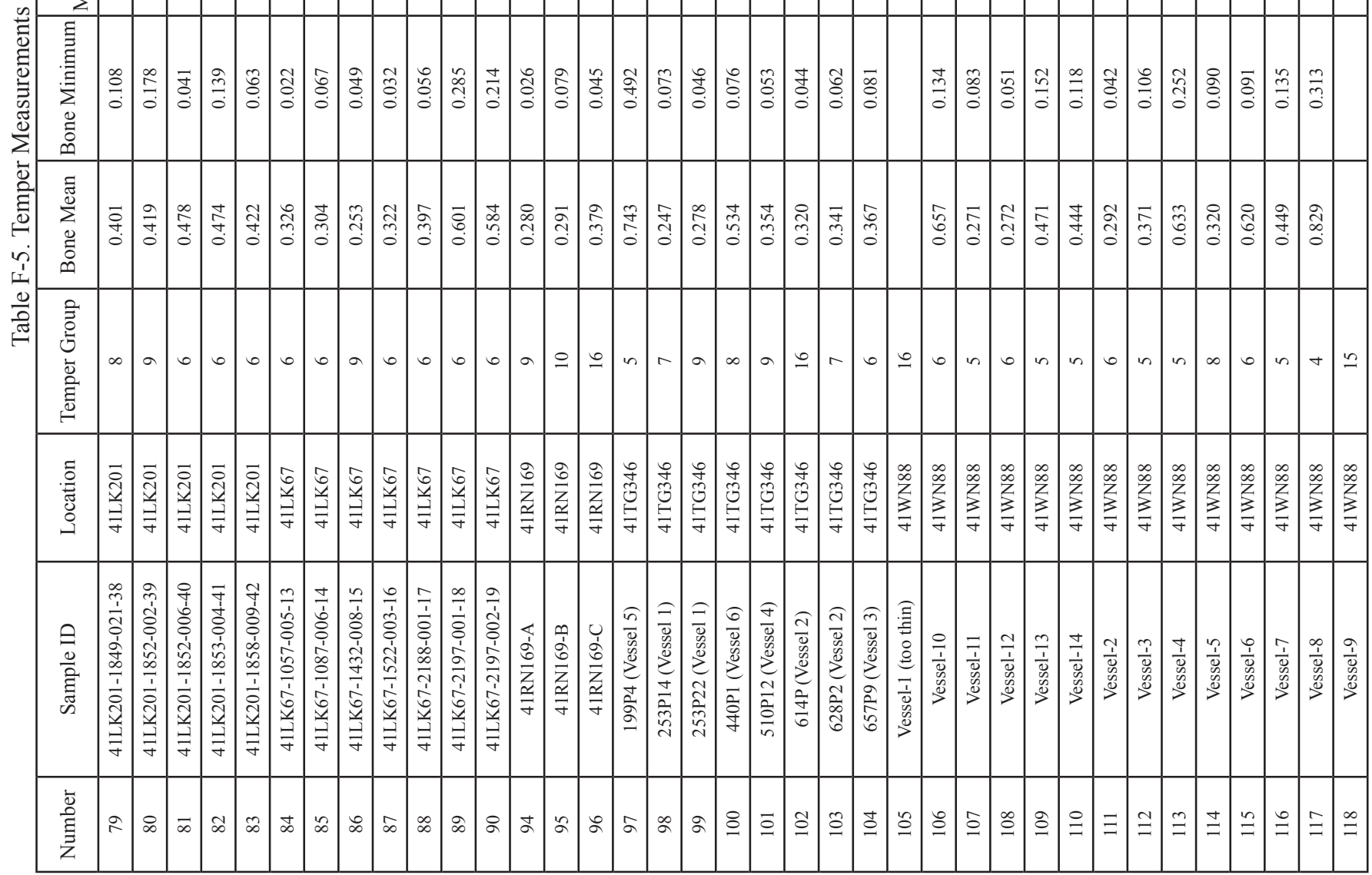




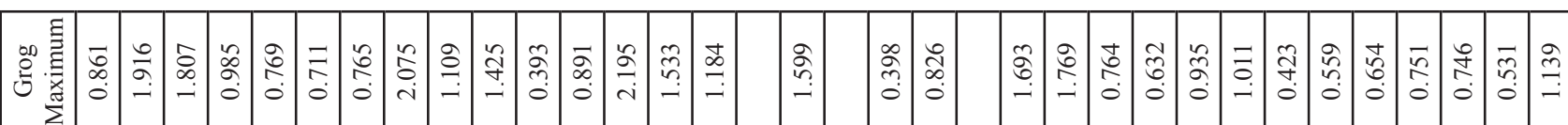

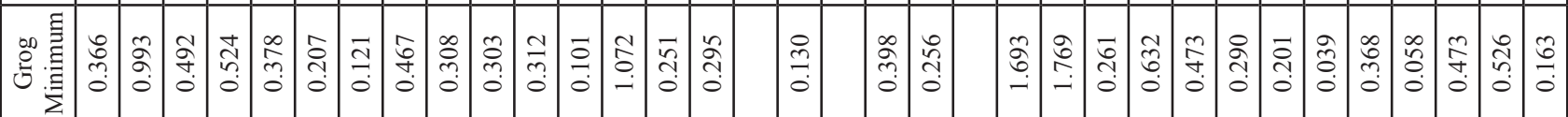

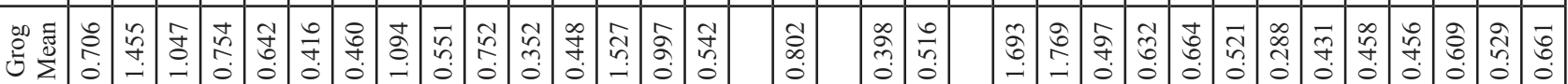

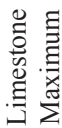

总言

当

$\stackrel{0}{0}$

¿્ప

总

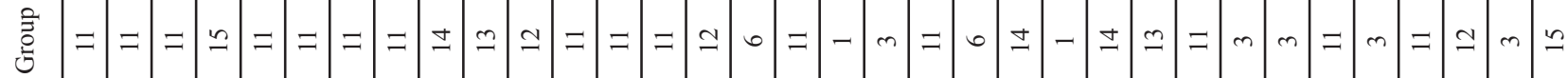

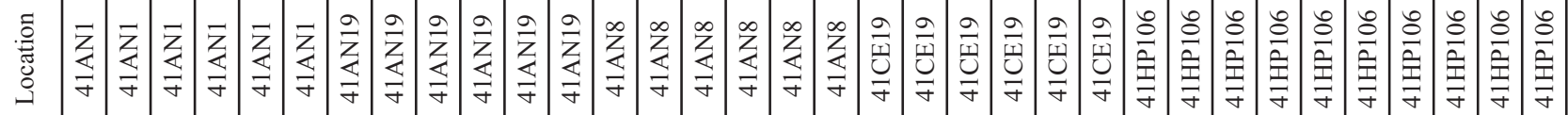
•

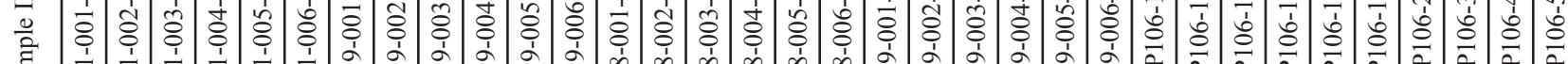

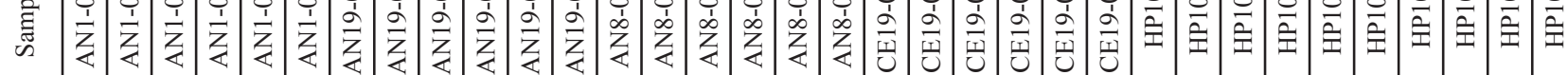

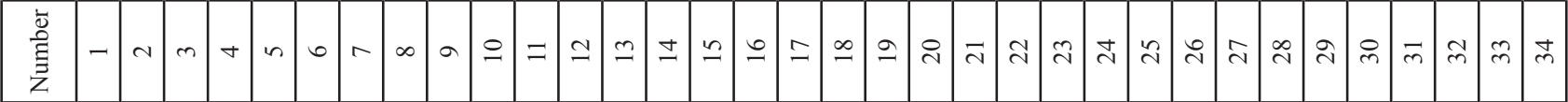




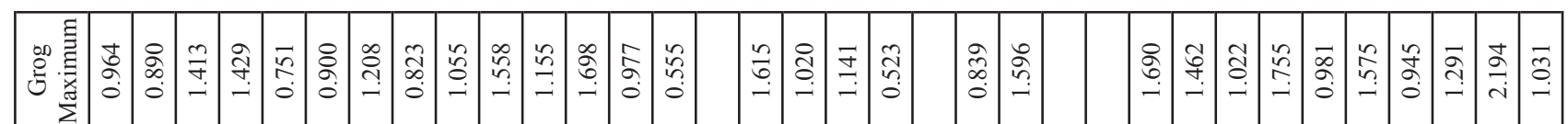

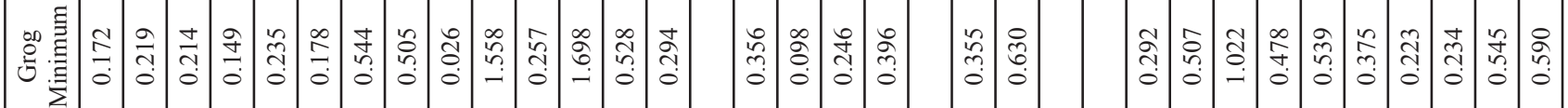

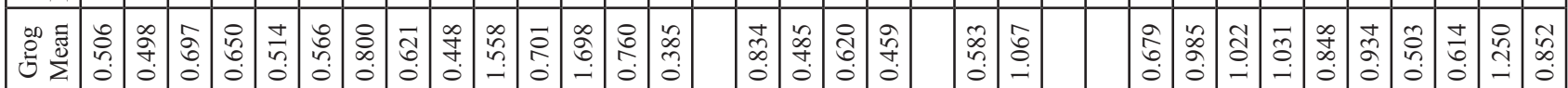

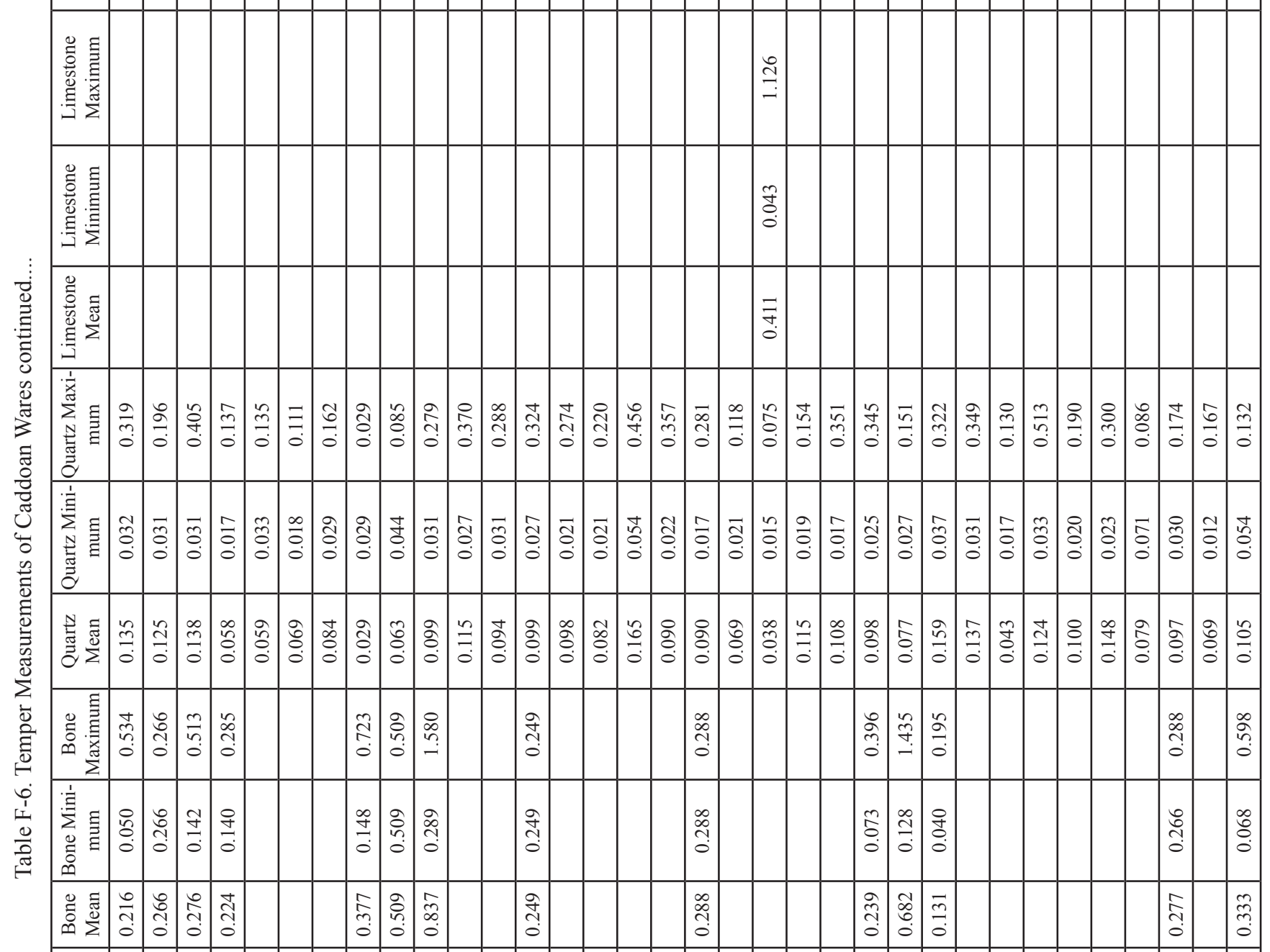

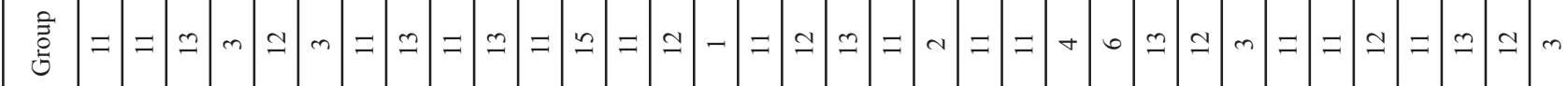

焉

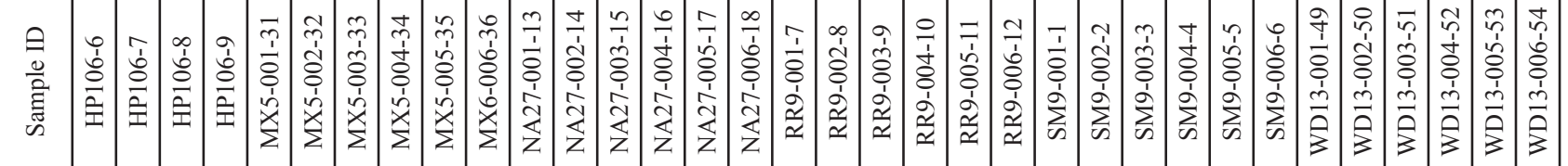

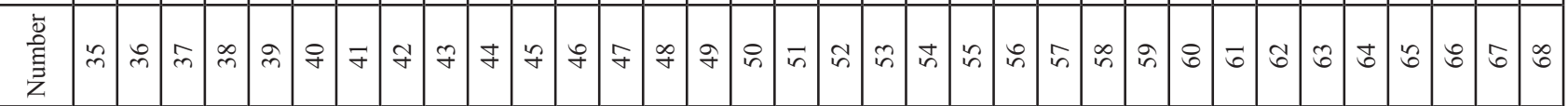




\section{Leon Plain}

Site: 41BX288

ID Number: 41BX288-244-25 [1]

Temper Group: 6

Paste Description: The paste is golden brown along edges with a darker brown center with no color change in CP. Very porous. Minerals/Temper Identified: Quartz, bone, chert (some with iron oxide), feldspar, mica (muscovite), polycrystalline quartz, clay pellets

Bone Color (if present): White, tan

ID Number: 41BX288-261-26 [2]

Temper Group: 8

Paste Description: The half of paste is golden brown and other half is dark brown with a little darker color change in CP.

Minerals/Temper Identified: Quartz, bone, chert (some with iron oxide), feldspar, mica (muscovite), polycrystalline quartz, clay pellets

Bone Color (if present): White, tan, reddish brown

Notes: No calcification was found on the bone.

ID Number: 41BX288-389-27 [3]

Temper Group: 8

Paste Description: The half of paste is golden brown and other half is dark brown. The paste goes darker in CP.

Minerals/Temper Identified: Quartz, bone, chert (some with iron oxide), feldspar, mica (muscovite), polycrystalline quartz, iron oxide, clay pellets, dark opaques

Bone Color (if present): White, tan, brown, black

Notes: No calcification was found on the bone.

ID Number: 41BX288-43-22 [4]

Temper Group: 6

Paste Description: The paste is golden brown with darker color change in CP.

Minerals/Temper Identified: Quartz, bone, chert, mica (muscovite), clay pellets, dark opaques, limestone

Bone Color (if present): White, tan

Notes: Some calcification was found on the bone.

ID Number: 41BX288-52-5-20 [5]

Temper Group: 6

Paste Description: The paste is dark brown with no color change in CP. Reddish-brown paste along edge.

Minerals/Temper Identified: Quartz, bone, chert, polycrystalline quartz, clay pellets, dark opaques, limestone

Bone Color (if present): Brown, black, white, tan

Notes: There was a little calcification found on the bone.

ID Number: 41BX288-58-23 [6]

Temper Group: 16

Paste Description: This was a piece of bone - no pottery.

ID Number: 41BX288-61-24 [7]

Temper Group: 6

Paste Description: The paste is golden brown with no color change in CP. Very porous.

Minerals/Temper Identified: Quartz, bone, chert (some with iron oxide), feldspar, mica, polycrystalline quartz, clay pellets Bone Color (if present): White, tan

Notes: No calcification was found on the bone. 
ID Number: 41BX288-63-21 [8]

Temper Group: 6

Paste Description: The paste is dark brown with no color change in CP. Reddish-brown paste along edge.

Minerals/Temper Identified: Quartz, bone, chert, feldspar, mica (muscovite), polycrystalline quartz, clay pellets, dark opaques, limestone

Bone Color (if present): White, tan, brown, black

Notes: Some calcification was found on the bone.

\section{Site: 41BX5}

ID Number: BX5-13002-B [9]

Temper Group: 6

Paste Description: The paste is brown in color and gets darker in CP.

Minerals/Temper Identified: Quartz, bone, polycrystalline quartz, mica (muscovite), limestone, clay pellets

Bone Color (if present): Pink/peach, brown

Notes: Calcification was found on the bone.

ID Number: BX5-13006-B [10]

Temper Group: 3

Paste Description: The paste is golden brown with spots of greenish-brown and bright orange. The paste is cloudy in CP.

Minerals/Temper Identified: Bone, limestone, quartz, mica (muscovite), polycrystalline quartz, dark opaques

Bone Color (if present): White/tan, pink

Notes: Present

ID Number: BX5-13008-B [11]

Temper Group: 3

Paste Description: The paste is motley brown in color with a cloudy gray appearance in CP.

Minerals/Temper Identified: Bone, quartz, dark opaques

Bone Color (if present): Olive brown, dusty brown

ID Number: BX5-13010-B [12]

Temper Group: 3

Paste Description: The paste is reddish-brown in color with some brown and orange spots. There is no color change in CP.

Minerals/Temper Identified: Quartz, bone, mica (muscovite), dark opaques, calcite

Bone Color (if present): Pink/peach, brown, some dusty-cloudy brown, white

ID Number: BX5-13013-B [13]

Temper Group: 4

Paste Description: The paste is golden brown in color with some darker brown spots. In CP the paste is a bright olive color.

Minerals/Temper Identified: Quartz, bone, clay pellets, mica (muscovite), limestone, dark opaques, feldspar, calcite

Bone Color (if present): Pink/peach, dusty brown

Notes: Some calcification present on the bone.

Site: 41ED28

ID Number: ED28-1054-8-1B [14]

Temper Group: 6

Paste Description: The paste is light golden brown in color and goes olive brown in CP.

Minerals/Temper Identified: Quartz, bone, limestone, mica (muscovite), calcite, clay pellets, polycrystalline quartz, calcite Bone Color (if present): Pink/peach, dusty brown

Notes: Calcification is present on the bone. 
ID Number: ED28-1089-8-1B [15]

Temper Group: 6

Paste Description: The paste is golden brown in color and goes darker in CP.

Minerals/Temper Identified: Quartz, bone, chert, clay pellets, calcite, limestone, unknown bright orange inclusion

Bone Color (if present): Pink, dusty brown

ID Number: ED28-1181-8-1B [16]

Temper Group: 3

Paste Description: The paste is golden brown in color with dark brown spots throughout. The paste gets slightly darker in CP.

Minerals/Temper Identified: Quartz, bone, limestone, limestone fossils, calcite, dark opaques, shell

Bone Color (if present): Pink, white, tan

Notes: Some calcification is present on the bone.

ID Number: ED28-1261-8-2A [17]

Temper Group: 1

Paste Description: The paste is golden brown in color and goes darker in color in CP.

Minerals/Temper Identified: Quartz, feldspar, polycrystalline quartz, rock fragment (feldspar and quartz), mica (muscovite), dark opaques, calcite, unknown bright orange inclusion

Bone Color (if present): Only one piece of bone was found. It was brown in color

ID Number: 41ED28-159-5-8-1B [18]

Temper Group: 9

Paste Description: The paste is a light golden brown color that does not change in CP.

Minerals/Temper Identified: Bone, quartz, limestone, polycrystalline quartz, mica (muscovite), dark opaques, calcite

Bone Color (if present): Pink, white/tan

ID Number: ED28-168-8-1B [19]

Temper Group: 9

Paste Description: The paste is golden brown in color that goes olive golden brown in CP.

Minerals/Temper Identified: Quartz, bone, limestone, polycrystalline quartz, calcite, shell, mica (muscovite), clay pellets

Bone Color (if present): Pink, dusty brown

ID Number: ED28-481-8-1B [20]

Temper Group: 6

Paste Description: The paste is light golden brown in color that gets slightly darker in CP.

Minerals/Temper Identified: Bone, quartz, limestone, limestone fossils, dark opaques

Bone Color (if present): White, pink

Notes: Some calcification present on the bone.

ID Number: ED28-799-8-1A [21]

Temper Group: 10

Paste Description: The paste is brown in color.

Minerals/Temper Identified: Quartz, bone, calcite, limestone, dark opaques

Bone Color (if present): Brown, white, light pink or pinkish brown, dusty brown

Notes: Some calcification present on the bone.

ID Number: ED28-799-8-2A [22]

Temper Group: 3

Paste Description: The paste is golden brown in color with some darker brown spots.

Minerals/Temper Identified: Quartz, bone, limestone, calcite, limestone fossils, clay pellets, dark opaques

Bone Color (if present): White, tan, pink

Notes: Some calcification was present on the bone. 
ID Number: ED28-840-8-1A [23]

Temper Group: 3

Paste Description: The paste is brown in color with lots a small light brown spots. The paste goes almost black in CP.

Minerals/Temper Identified: Quartz, bone, clay pellets, mica, (muscovite), feldspar, polycrystalline quartz, dark opaques, tourmaline

Bone Color (if present): Tan, light brown

ID Number: ED28-937-8-1B [24]

Temper Group: 6

Paste Description: The paste is dark golden brown in color that gets slightly darker in CP.

Minerals/Temper Identified: Quartz, bone, limestone, mica (muscovite), and polycrystalline quartz, feldspar, clay pellets, dark opaques

Bone Color (if present): Pink/peach, dusty brown

\section{Site: 41JW8}

ID Number: 41JW8-278-1-2 [25]

Temper Group: 9

Paste Description: The paste is brown with no color change in CP.

Minerals/Temper Identified: Quartz, polycrystalline quartz, bone, feldspar, calcite, limestone

Bone Color (if present): Brown, white/tan

ID Number: 41JW8-326-1-3 [26]

Temper Group: 4

Paste Description: The paste is dark brown with no color change in CP. Edges are a lighter brown with spots of dark brown. Minerals/Temper Identified: Quartz, bone, feldspar, mica (muscovite), chert (some with iron oxide), limestone, dark opaque, unknown yellowish brown inclusions

Bone Color (if present): Tan, brown, black

ID Number: 41JW8-328-2-4 [27]

Temper Group: 6

Paste Description: The paste is light brown with no color change in CP. There are dark brown spots in the paste. It has a very fine grain texture.

Minerals/Temper Identified: Bone, quartz (some with iron oxide), chert, mica (muscovite), dark opaques

Bone Color (if present): White, tan

ID Number: 41JW8-341-1-5 [28]

Temper Group: 5

Paste Description: The paste is dark brown with no color change in CP. The paste is very porous with a lighter brown paste along one edge.

Minerals/Temper Identified: Quartz, bone, chert (some with iron oxide), mica (muscovite), feldspar, clay pellets, limestone Bone Color (if present): White

ID Number: 41JW8-353-1-6 [29]

Temper Group: 6

Paste Description: The paste is light golden and goes darker in CP.

Minerals/Temper Identified: Quartz, bone, limestone, mica (muscovite), clay pellets, polycrystalline quartz (some with iron oxide), dark opaques

Bone Color (if present): White/tan 
ID Number: 41JW8-68-2-1 [30]

Temper Group: 9

Paste Description: The paste is light brown with little color change in CP. There are spots in the paste that are very fine and do not appear to have many inclusions.

Minerals/Temper Identified: Quartz, polycrystalline quartz, bone, mica (muscovite), clay pellets

Bone Color (if present): Brown, black, white/tan

\section{Site: $41 K M 16$}

ID Number: 12 [31]

Temper Group: 4

Paste Description: The paste is dark brown in color with no change in CP.

Minerals/Temper Identified: Quartz, bone, limestone, feldspar, dark opaques

Bone Color (if present): White/tan

ID Number: 125 [32]

Temper Group: 6

Paste Description: The paste is olive brown with reddish brown along one edge. In CP, the paste appears cloudy.

Minerals/Temper Identified: Quartz, bone, dark opaques

Bone Color (if present): White/tan, brown, dusty brown

ID Number: 18a [33]

Temper Group: 6

Paste Description: The paste is dark brown in color with no change in CP.

Minerals/Temper Identified: Quartz, feldspar, bone

Bone Color (if present): White/tan, olive

Notes: No calcification is present on the bone.

ID Number: 18B [34]

Temper Group: 4

Paste Description: The paste is dark brown in color with no change in CP.

Minerals/Temper Identified: Quartz, bone, feldspar, limestone, polycrystalline quartz

Bone Color (if present): White/tan

Notes: No calcification is present on the bone.

ID Number: 206 [35]

Temper Group: 6

Paste Description: The paste is grayish brown in color. In CP, the paste does not change color but appears cloudy.

Minerals/Temper Identified: Quartz, bone, mica, clay pellets, limestone, unknown light brown inclusion specked with quartz, dark opaques

Bone Color (if present): Brown

Notes: There was a little calcification present on the bone.

ID Number: 25 [36]

Temper Group: 9

Paste Description: The paste is brown in color with no change in CP.

Minerals/Temper Identified: Quartz, bone, limestone, polycrystalline quartz, dark opaques

Bone Color (if present): White/tan, brown, dusty brown

Notes: There was a little calcification present on the bone. 
ID Number: 25a [37]

Temper Group: 9

Paste Description: The paste is golden brown to dark golden brown in color with no change in CP.

Minerals/Temper Identified: Quartz, bone, limestone, clay pellets, polycrystalline quartz, feldspar, dark opaques

Bone Color (if present): White/tan

Notes: The bone is heavily calcified.

ID Number: 341 [38]

Temper Group: 16

Paste Description: The paste is light brown in color. In CP, the paste gets orange streaks.

Minerals/Temper Identified: Quartz, bone, limestone

Bone Color (if present): White/tan

Notes: There is a little calcification present on the bone. The thin section was too small to get 300 points for point counting.

ID Number: 343 [39]

Temper Group: 9

Paste Description: The paste is light brown in color. In CP, the paste does not change color but gets orange streaks.

Minerals/Temper Identified: Quartz, bone, limestone, calcite, dark opaques

Bone Color (if present): White/tan, brown

ID Number: $357 \mathrm{a}$ [40]

Temper Group: 9

Paste Description: The paste is dark brown in color with no change in CP.

Minerals/Temper Identified: Quartz, bone, limestone

Bone Color (if present): White/tan

Notes: The bone is heavily calcified.

ID Number: 385A [41]

Temper Group: 9

Paste Description: The paste is tan in color with gray streaks. In CP, the paste is grayish brown with orange streaks.

Minerals/Temper Identified: Quartz, bone, dark opaques

Bone Color (if present): White/tan, brown

ID Number: $385 b$ [42]

Temper Group: 6

Paste Description: The paste was light tan in color. In CP, the paste is gray with yellow streaks.

Minerals/Temper Identified: Bone, quartz, dark opaques

Bone Color (if present): Brown, white/tan

ID Number: $3 \mathrm{~A}$ [43]

Temper Group: 4

Paste Description: The paste is dark brown in color with no change in CP.

Minerals/Temper Identified: Quartz, bone, feldspar, limestone, unknown red inclusion

Bone Color (if present): White/tan

Notes: There is a little calcification present on the bone.

ID Number: 3B [44]

Temper Group: 6

Paste Description: The paste is dark reddish brown in color with no change in CP.

Minerals/Temper Identified: Quartz, bone, limestone, feldspar

Bone Color (if present): White/tan, olive

Notes: No calcification was found on the bone. 
ID Number: $3 \mathrm{c}$ [45]

Temper Group: 4

Paste Description: The paste is dark brown in color with no change in CP.

Minerals/Temper Identified: Quartz, bone, feldspar, polycrystalline quartz

Bone Color (if present): White/tan, olive

Notes: No calcification was found on the bone.

ID Number: $3 d$ [46]

Temper Group: 6

Paste Description: The paste is dark brown in color with no change in CP.

Minerals/Temper Identified: Quartz, bone, limestone, feldspar, rock fragments (quartz and feldspar), unknown orange inclusion Bone Color (if present): White/tan, olive

Notes: There was a little calcification present on the bone.

ID Number: KM16-3h [47]

Temper Group: 4

Paste Description: The paste is olive brown in color and appears cloudy in CP.

Minerals/Temper Identified: Quartz, bone, polycrystalline quartz, tourmaline, dark opaques

Bone Color (if present): White/tan, brown

Notes: There is a little calcification present on the bone.

ID Number: 480 [48]

Temper Group: 16

Paste Description: The paste is brown in color and gets orange streaks in CP.

Minerals/Temper Identified: Limestone, bone, quartz, shell, calcite, chert, dark opaques

Bone Color (if present): White/tan

Notes: The thin section was too small/thin to get 300 points for point counting.

ID Number: 481 [49]

Temper Group: 6

Paste Description: The paste is reddish brown in color and does not change in CP.

Minerals/Temper Identified: Quartz, bone, limestone

Bone Color (if present): White/tan, brown

Notes: There was a little calcification present on the bone.

ID Number: 4A [50]

Temper Group: 6

Paste Description: The paste is dark brown in color with no change in CP.

Minerals/Temper Identified: Quartz, bone, limestone, chert, polycrystalline quartz, unknown red inclusion

Bone Color (if present): White/tan

Notes: There is a little calcification present on the bone.

ID Number: $4 b[51]$

Temper Group: 16

Paste Description: The paste is reddish brown in color with no change in CP.

Minerals/Temper Identified: Quartz, bone, feldspar, calcite, mica (muscovite), dark opaques, unknown orange inclusion

Notes: Thin section was too small to get 300 points in point counting.

ID Number: 6A [52]

Temper Group: 4

Paste Description: The paste is dark brown in color with no change in CP.

Minerals/Temper Identified: Quartz, bone, feldspar, tourmaline

Bone Color (if present): White/tan

Notes: There is a little calcification present on the bone. 
ID Number: 6B [53]

Temper Group: 4

Paste Description: The paste is dark brown in color with no change in CP.

Minerals/Temper Identified: Quartz, bone, feldspar, dark opaques

Bone Color (if present): White/tan

ID Number: 83 [54]

Temper Group: 4

Paste Description: The paste is olive gray in color with a lighter olive color along one edge. The paste gets darker and appears cloudy in CP.

Minerals/Temper Identified: Bone, quartz, limestone, dark opaques

Bone Color (if present): White/tan

Notes: There was a little calcification present on the bone.

ID Number: KM16-1 [55]

Temper Group: 9

Paste Description: The paste is tan in color and goes grayish brown with yellow streaks in CP.

Minerals/Temper Identified: Quartz, bone, dark opaques

Bone Color (if present): White/tan

ID Number: R1 [56]

Temper Group: 7

Paste Description: The paste is reddish brown with no change in color in $\mathrm{CP}$.

Minerals/Temper Identified: Quartz, bone, limestone, calcite, rock fragment (quartz and calcite), shell, dark opaques, unknown orange inclusion

Bone Color (if present): White/tan, brown

Notes: No calcification was found on the bone.

ID Number: R2 [57]

Temper Group: 7

Paste Description: The paste is reddish brown in color with no change in CP.

Minerals/Temper Identified: Quartz, bone, calcite, limestone, shell, dark opaques

Bone Color (if present): White/tan, brown, dusty brown

Notes: No calcification was found on the bone.

ID Number: R4 [58]

Temper Group: 7

Paste Description: The paste is brown in color with no change in CP.

Minerals/Temper Identified: Quartz, bone, limestone, calcite, shell, limestone fossils, dark opaques

Bone Color (if present): White/tan, dusty brown

ID Number: R5 [59]

Temper Group: 7

Paste Description: The paste is brown in color with no change in CP.

Minerals/Temper Identified: Quartz, bone, limestone, calcite, shell, feldspar, dark opaques, limestone fossils, polycrystalline quartz, tourmaline, unknown brown inclusion

Bone Color (if present): White/tan, dusty brown

Notes: There was a little calcification present on the bone. 
ID Number: R7 [60]

Temper Group: 7

Paste Description: The paste is olive brown in color with no change in CP.

Minerals/Temper Identified: Bone, limestone, quartz, shell, dark opaques, limestone fossils, calcite, polycrystalline quartz, unknown brown inclusions, mica (muscovite)

Bone Color (if present): White/tan, brown, dusty brown

ID Number: XA-1 [61]

Temper Group: 6

Paste Description: The paste was brown to dark brown in color with no change in CP.

Minerals/Temper Identified: Quartz, limestone, bone, calcite, dark opaques

Bone Color (if present): White/tan, brown

Notes: Brown bone found mostly along one edge. There was a little calcification present on the bone.

ID Number: $\mathrm{Xb}$ [62]

Temper Group: 9

Paste Description: The paste is golden brown in color. In CP, the paste is lighter and birefringent.

Minerals/Temper Identified: Quartz, bone, limestone, calcite, unknown orange inclusions

Bone Color (if present): White/tan

Site: $41 \mathrm{KM} 69$

ID Number: 41KM69-50-0-1-8 [63]

Temper Group: 4

Paste Description: The paste is grayish brown with no color change in $\mathrm{CP}$.

Minerals/Temper Identified: Quartz, bone, mica (muscovite), feldspar, clay pellets

Bone Color (if present): White, tan

Notes: Calcification is present on the bone.

ID Number: 41KM69-66-0-4-9 [64]

Temper Group: 6

Paste Description: The paste is grayish brown with a darker color in CP.

Minerals/Temper Identified: Quartz, bone, feldspar, limestone, dark opaque

Bone Color (if present): White, tan, light brown

Notes: There is a little calcification present on the bone.

ID Number: 41KM69-66-09-10 [65]

Temper Group: 6

Paste Description: The paste is golden brown with a little darker color in CP.

Minerals/Temper Identified: Quartz, bone, mica (muscovite), clay pellet

Bone Color (if present): White, tan

Notes: Calcification is present on the bone.

ID Number: 41KM69-74-0-1-11 [66]

Temper Group: 6

Paste Description: The paste is golden brown in color.

Minerals/Temper Identified: Quartz, bone, limestone

Bone Color (if present): White, tan

Notes: There is a little calcification present on the bone. 
ID Number: 41KM69-8-0-4-7 [67]

Temper Group: 6

Paste Description: The paste is light brown with spots of darker brown paste mixed in. No color change in dark part but light brown paste goes lighter in $\mathrm{CP}$.

Minerals/Temper Identified: Quartz, bone, mica (muscovite), limestone

Bone Color (if present): White, tan, brown

Notes: There is a little calcification present on the bone.

ID Number: 41KM69-94-01-12 [68]

Temper Group: 6

Paste Description: The paste is brown with streaks of darker brown along one edge.

Minerals/Temper Identified: Quartz, bone, clay pellets, limestone

Bone Color (if present): White, tan

Notes: Calcification is present on the bone.

Site: 41LK201

ID Number: 41LK201-1134-010-28 [69]

Temper Group: 9

Paste Description: The paste is brown and slightly lighter along edges with no color change in CP.

Minerals/Temper Identified: Quartz, bone, chert, mica (muscovite), dark opaques,

Bone Color (if present): White, tan, brown, black

Notes: No calcification was found on the bone.

ID Number: 41LK201-1134-014-30 [70]

Temper Group: 9

Paste Description: The paste is brown with lighter brown along the edges.

Minerals/Temper Identified: Quartz, bone, chert, mica (muscovite), limestone

Bone Color (if present): White, tan, brown, black

Notes: No calcification was found on the bone.

ID Number: 41LK201-1134-015-31 [71]

Temper Group: 4

Paste Description: The paste is light, golden brown with no color change in CP.

Minerals/Temper Identified: Quartz, bone, chert, feldspar, mica, polycrystalline quartz, calcite, limestone, unknown grayish-green inclusion

Bone Color (if present): White, tan

Notes: No calcification was found on the bone.

ID Number: 41LK201-1134-001-29 [72]

Temper Group: 6

Paste Description: The paste is golden brown with no color change in CP.

Minerals/Temper Identified: Quartz, bone, mica (muscovite), clay pellets, limestone, dark opaques, polycrystalline quartz

Bone Color (if present): White, tan, black, brown

Notes: Some calcification is present on the bone.

ID Number: 41LK201-1465-006-32 [73]

Temper Group: 3

Paste Description: The paste is golden brown along edges with a dark brown center with no color change in CP.

Minerals/Temper Identified: Quartz, bone, chert, mica (muscovite), polycrystalline quartz, clay pellets, calcite, feldspar

Bone Color (if present): White, tan, brown, black

Notes: No calcification was found on the bone. 
ID Number: 41LK201-1817-001-33 [74]

\section{Temper Group: 6}

Paste Description: The paste is golden brown with no color change in CP.

Minerals/Temper Identified: Quartz, bone, chert (some with iron oxide), feldspar, polycrystalline quartz, clay pellets

Bone Color (if present): White, tan

Notes: No calcification was found on the bone.

ID Number: 41LK201-1844-001-34 [75]

Temper Group: 4

Paste Description: The paste is dark brown with no color change in CP. Very porous.

Minerals/Temper Identified: Quartz, bone, polycrystalline quartz, mica (muscovite), calcite, dark opaques, feldspar, calcite Bone Color (if present): White, tan

Notes: Heavy calcification was found on the bone.

ID Number: 41LK201-1848-024-35 [76]

Temper Group: 6

Paste Description: The paste is dark golden brown with no color change in CP.

Minerals/Temper Identified: Quartz, bone, chert (some with iron oxide), mica (muscovite), feldspar, polycrystalline quartz, calcite Bone Color (if present): Brown, black, tan

ID Number: 41LK201-1848-027-36 [77]

Temper Group: 6

Paste Description: The paste is dark golden brown and lighter along one edge. Porous

Minerals/Temper Identified: Quartz, bone, feldspar, polycrystalline quartz, clay pellets, calcite, limestone, dark opaques, rock fragment (quartz and calcite)

Bone Color (if present): White, tan

ID Number: 41LK201-1849-005-37 [78]

Temper group: 6

Paste Description: The paste is dark golden brown in color. Spots in the paste are void of any inclusions.

Minerals/Temper Identified: Quartz, bone, chert, mica (muscovite), polycrystalline quartz, calcite, dark opaques

Bone Color (if present): White, tan, black, brown

ID Number: 41LK201-1849-021-38 [79]

Temper Group: 8

Paste Description: The paste is brown with dark brown along one edge. Very porous.

Minerals/Temper Identified: Quartz, bone, chert (some with iron oxide), mica (muscovite), dark opaques

Bone Color (if present): White, tan, brown

ID Number: 41LK201-1852-002-39 [80]

Temper Group: 9

Paste Description: The paste is golden brown with brighter color change in CP.

Minerals/Temper Identified: Quartz, bone, chert (some with iron oxide), mica (muscovite), iron oxide

Bone Color (if present): White, tan, brown, black

ID Number: 41LK201-1852-006-40 [81]

Temper Group: 6

Paste Description: The paste is golden brown with no color change in $\mathrm{CP}$.

Minerals/Temper Identified: Quartz, bone, chert, mica (muscovite), calcite, limestone

Bone Color (if present): White, tan, brown, black 
ID Number: 41LK201-1853-004-41 [82]

Temper Group: 6

Paste Description: The paste is very dark brown with reddish brown paste along one edge.

Minerals/Temper Identified: Quartz, bone, chert (some with iron oxide), feldspar, mica (muscovite), dark opaques

Bone Color (if present): White, tan

ID Number: 41LK201-1853-009-42 [83]

Temper Group: 6

Paste Description: The paste is very dark brown. Very porous.

Minerals/Temper Identified: Quartz, bone, chert, dark opaques, polycrystalline quartz

Bone Color (if present): White, tan

Site: 41LK67

ID Number: 41LK67-1087-005-13 [84]

Temper Group: 6

Paste Description: The paste is brown with some darker brown streaks.

Minerals/Temper Identified: Quartz (some with iron oxide), bone, mica (muscovite), chert, feldspar, polycrystalline quartz, clay pellets, calcite, rock fragments (quartz and calcite), shell

Bone Color (if present): Brown, black, white, tan

ID Number: 41LK67-1087-006-14 [85]

Temper Group: 6

Paste Description: The paste is golden brown with no color change in CP.

Minerals/Temper Identified: Quartz, bone, mica (muscovite), clay pellets, feldspar, polycrystalline quartz, calcite, limestone, rock fragment (calcite and quartz)

Bone Color (if present): White, tan, brown, black

Notes: Some calcification present on bone.

ID Number: 41LK67-1432-008-15 [86]

Temper Group: 9

Paste Description: The paste is dark golden brown with no color change but yellow streaks in CP. Very porous.

Minerals/Temper Identified: Quartz, bone, chert, feldspar, polycrystalline quartz, mica (muscovite), clay pellets, limestone Bone Color (if present): White, tan, some brown, black fragment

ID Number: 41LK67-1522-003-16 [87]

Temper Group: 6

Paste Description: The paste is almost black to grayish black with brown along one edge.

Minerals/Temper Identified: Quartz (some with iron oxide), bone, feldspar, mica, polycrystalline quartz, chert

Bone Color (if present): White, tan

Notes: Heavy calcification found on the bone.

ID Number: 41LK67-2188-001-17 [88]

Temper Group: 6

Paste Description: The paste is dark brown with no color change in CP.

Minerals/Temper Identified: Quartz, bone, mica (muscovite), polycrystalline quartz, limestone

Bone Color (if present): White, tan

Notes: Heavy calcification found on the bone. 
ID Number: 41LK67-2197-001-18 [89]

Temper Group: 6

Paste Description: The paste is reddish brown with spots of light golden paste.

Minerals/Temper Identified: Quartz (some with iron oxide), bone, chert, mica (muscovite), polycrystalline quartz, clay pellets, limestone

Bone Color (if present): White, tan, brown

Notes: No calcification found on the bone.

ID Number: 41LK67-2197-002-19 [90]

Temper Group: 6

Paste Description: The paste is brown with no color change in CP. Dark brownish-black paste on one edge.

Minerals/Temper Identified: Quartz (some with iron oxide), bone, chert, feldspar, mica (muscovite), clay pellets, limestone Bone Color (if present): Brown, white, tan

Notes: There was a little calcification found on one bone fragment.

Site: 41RE1

ID Number: RE1-1872-32B [91]

Temper Group: 1

Paste Description: The paste is dark brown in color with no change in CP.

Minerals/Temper Identified: Quartz, feldspar, polycrystalline quartz, chert, rock fragment (quartz, polycrystalline quartz, mica), mica (muscovite)

Bone Color (if present): None

ID Number: RE1-1872-66 [92]

Temper Group: 1

Paste Description: The paste is dark to golden brown in color with no color changes in CP.

Minerals/Temper Identified: Quartz, feldspar, polycrystalline quartz, rock fragment (quartz and feldspar), chert, mica (muscovite), clay pellets

Bone Color (if present): None

ID Number: RE1-1872-B [93]

Temper Group: 2

Paste Description: The paste is light to dark golden brown, gets darker in CP.

Minerals/Temper Identified: Quartz, limestone, calcite, polycrystalline quartz, mica (muscovite), dark opaques

Bone Color (if present): None

\section{Site: 41RN169}

ID Number: 41RN169-A [94]

Temper Group: 9

Paste Description: The paste is brown in color and goes slightly darker in CP.

Minerals/Temper Identified: Quartz, limestone, bone, calcite, unknown reddish-orange inclusion

Bone Color (if present): White/tan

Notes: Some calcification present on bone.

ID Number: 41RN169-B [95]

Temper Group: 10

Paste Description: The paste is light brown in color with no color change in CP.

Minerals/Temper Identified: Quartz, bone, limestone, dark opaques

Bone Color (if present): White/tan, brown, black

Notes: Some calcification present on bone. 
ID Number: 41RN169-C [96]

Temper Group: 16

Paste Description: The paste is golden brown in color with no change in CP.

Minerals/Temper Identified: Quartz, bone, limestone, polycrystalline quartz, feldspar

Bone Color (if present): White/tan, brown, black

Notes: Some calcification present; Most of the thin section was too thin for point counting.

Site: 41TG346

ID Number: 199P4 (Vessel 5) [97]

Temper Group: 5

Paste Description: The paste is light brown in color and changes to a grayish brown in CP. A dark brown paste is found along one edge.

Minerals/Temper Identified: Quartz, polycrystalline quartz, mica (muscovite), bone, clay pellets, dark opaques

Bone Color (if present): White/tan, brown

ID Number: 253P14 (Vessel 1) [98]

Temper Group: 7

Paste Description: The paste is brown in color with no change in CP. Along one edge the paste is a reddish brown color.

Minerals/Temper Identified: Quartz, bone, polycrystalline quartz, limestone, dark opaques

Bone Color (if present): White/tan

ID Number: 253P22 (Vessel 1) [99]

Temper Group: 9

Paste Description: The paste is brown in color with no change in CP.

Minerals/Temper Identified: Quartz, bone, limestone, calcite, dark opaques

Bone Color (if present): White/tan

Notes: Heavily calcified; There was a possible shell piece. Some of the calcite might be complete bone calcification.

ID Number: 440P1 (Vessel 6) [100]

Temper Group: 8

Paste Description: The paste is brown in color with no change in CP.

Minerals/Temper Identified: Quartz, bone, mica (muscovite), calcite, polycrystalline quartz, limestone, rock fragment (quartz and calcite), dark opaques, feldspar (plagioclase)

Bone Color (if present): Brown, black, white/tan

ID Number: 510P12 (Vessel 4) [101]

Temper Group: 9

Paste Description: The paste is light brown in color with no change in CP. There were some reddish brown spots in paste.

Minerals/Temper Identified: Quartz, bone, limestone, calcite, clay pellets, dark opaques

Bone Color (if present): White/tan

Notes: Some calcification present on bone.

ID Number: 614P (Vessel 2) [102]

Temper Group: 16

Paste Description: The paste is reddish brown in color with no change in $\mathrm{CP}$.

Minerals/Temper Identified: Quartz, bone, limestone, calcite, polycrystalline quartz, dark opaques

Bone Color (if present): White/tan

Notes: Some calcification present on the bone. Most of the thin section was too thin for point counting. 
ID Number: 628P2 (Vessel 2) [103]

Temper Group: 7

Paste Description: The paste is golden brown in color and goes darker in CP.

Minerals/Temper Identified: Quartz, bone, calcite, limestone, dark opaques, limestone fossils

Bone Color (if present): White/tan, light olive

ID Number: 657P9 (Vessel 3) [104]

Temper Group: 6

Paste Description: The paste is dark brown in color with no change in CP.

Minerals/Temper Identified: Quartz, limestone, bone, dark opaques

Bone Color (if present): White/tan, brown

Notes: Brown bone is found along one edge.

\section{Site: $41 \mathrm{WN88}$}

ID Number: Vessel 1 [105]

Temper Group: 16

Paste Description: The paste is light brown in color.

Notes: The thin section was too thin to analyze.

ID Number: Vessel 10 [106]

Temper Group: 6

Paste Description: The paste is light brown in color and goes slightly darker in CP.

Minerals/Temper Identified: Quartz, polycrystalline quartz, bone, feldspar, mica (muscovite), limestone

Bone Color (if present): Tan, brown

ID Number: Vessel 11 [107]

Temper Group: 5

Paste Description: The paste is very dark brown in color with spots of light brown. There is no color change in CP.

Minerals/Temper Identified: Quartz, polycrystalline quartz, feldspar, bone, chert, unknown olive colored inclusion

Bone Color (if present): Dusty brown

ID Number: Vessel 12 [108]

Temper Group: 6

Paste Description: The paste is very dark brown in color and does not change in CP.

Minerals/Temper Identified: Quartz, bone, limestone, feldspar, polycrystalline quartz

Bone Color (if present): Tan, dusty brown

Notes: Some calcification present on bone.

ID Number: Vessel 13 [109]

Temper Group: 5

Paste Description: The paste is golden brown in color. In CP the paste turns a grayish brown with bright orange streaks.

Minerals/Temper Identified: Quartz, bone, polycrystalline quartz, clay pellets, feldspar, dark opaques

Bone Color (if present): Tan, dusty brown

ID Number: Vessel 14 [110]

Temper Group: 5

Paste Description: The paste is golden brown in color. In $\mathrm{CP}$ the paste turns grayish brown with bright orange streaks.

Minerals/Temper Identified: Quart, feldspar, polycrystalline quartz, bone, dark opaques

Bone Color (if present): Tan, brown 
ID Number: Vessel 2 [111]

Temper Group: 6

Paste Description: The paste is brown to dark brown in color that does not change in CP.

Minerals/Temper Identified: Quartz, polycrystalline quartz, bone, limestone, chert, dark opaques

Bone Color (if present): Tan, brown

ID Number: Vessel 3 [112]

Temper Group: 5

Paste Description: The paste is golden brown in color and goes darker with orange streaks in CP.

Minerals/Temper Identified: Quartz, polycrystalline quartz, bone, feldspar, chert, dark opaques

Bone Color (if present): Tan, dusty brown

ID Number: Vessel 4 [113]

Temper Group: 5

Paste Description: The paste is reddish brown in color with no change in $\mathrm{CP}$.

Minerals/Temper Identified: Quartz, polycrystalline quartz, bone, feldspar, dark opaques, clay pellet

Bone Color (if present): Tan, dusty brown

ID Number: Vessel 5 [114]

Temper Group: 8

Paste Description: The paste is golden brown in color and goes darker brown in CP with some orange streaks.

Minerals/Temper Identified: Quartz, polycrystalline quartz, bone, feldspar, dark opaques

Bone Color (if present): Tan, dusty brown

ID Number: Vessel 6 [115]

Temper Group: 6

Paste Description: The paste is a dark reddish brown color and does not change in CP.

Minerals/Temper Identified: Quartz, polycrystalline quartz, bone, brown tourmaline, dark opaques

Bone Color (if present): Tan, brown, black

ID Number: Vessel 7 [116]

Temper Group: 5

Paste Description: The paste is dark brown in color with no change in CP.

Minerals/Temper Identified: Quartz, polycrystalline quartz, bone, feldspar

Bone Color (if present): Tan, brown

ID Number: Vessel 8 [117]

Temper Group: 4

Paste Description: The paste is light brown in color with no change in CP.

Minerals/Temper Identified: Quartz, polycrystalline quartz, bone, limestone, feldspar, tourmaline, shell, unknown orange inclusion Bone Color (if present): Tan, brown, dusty brown

ID Number: Vessel 9 [118]

Temper Group: 15

Paste Description: The paste is light brown in color with no change in CP.

Minerals/Temper Identified: Quartz, polycrystalline quartz, limestone, feldspar, calcite, dark opaques, tourmaline Bone Color (if present): None 


\section{Caddo Ceramics}

\section{Site: 41AN1}

ID Number: AN1-001-25 [1]

Temper Group: 11

Paste Description: The paste is tan in color and goes gray in color with orange streaks in CP.

Minerals/Temper Identified: Quartz, grog, polycrystalline quartz, feldspar, mica (muscovite), dark opaques

ID Number: AN1-002-26 [2]

Temper Group: 11

Paste Description: The paste is golden brown along both edges and brown in the center. The paste gets darker in $\mathrm{CP}$ with orange streaks.

Minerals/Temper Identified: Quartz, grog, clay pellets, mica (muscovite), polycrystalline quartz, feldspar, dark opaques, unknown orange inclusion

ID Number: AN1-003-27 [3]

Temper Group: 11

Paste Description: The paste is tan to light olive brown in color and goes a darker olive brown in $\mathrm{CP}$ with orange streaks along one edge.

Minerals/Temper Identified: Quartz, grog, clay pellets, polycrystalline quartz, feldspar, mica (muscovite), dark opaques

ID Number: AN1-004-28 [4]

Temper Group: 15

Paste Description: The paste is brown to dark brown with one edge a light tan. In CP, the light tan paste goes gray with orange streaks, while there is no change in color for the brown paste.

Minerals/Temper Identified: Quartz, mica (muscovite), feldspar, polycrystalline quartz, clay pellets, grog, dark opaques

ID Number: AN1-005-29 [5]

Temper Group: 11

Paste Description: The paste is tan with golden brown along one edge (possible slip). In CP, the tan paste goes gray with yellow streaks, while the golden brown paste does not change color but has orange streaks.

Minerals/Temper Identified: Quartz, grog, clay pellets, polycrystalline quartz, feldspar, mica (muscovite), dark opaques, unknown orange inclusion

ID Number: AN1-006-30 [6]

Temper Group: 11

Paste Description: The paste is light golden brown to tan in color and goes gray with yellow streaks in CP.

Minerals/Temper Identified: Quartz, grog, clay pellets, mica (muscovite), polycrystalline quartz, chert, feldspar, tourmaline, dark opaques, bone, unknown orange inclusion

Bone Color (if present): White

Notes: Only one bone fragment found.

Site: 41AN19

ID Number: AN19-001-19 [7]

Temper Group: 11

Paste Description: The paste is golden in color along both edges and olive brown in color in the center (dark core). In CP there is no color change, but along the edges there are orange streaks.

Minerals/Temper Identified: Quartz, grog, polycrystalline quartz, clay pellets, feldspar, chert, dark opaques 
ID Number: AN19-002-20 [8]

Temper Group: 11

Paste Description: The paste is golden brown in color along one edge (possible slip) and olive brown in color elsewhere. In $\mathrm{CP}$, there is no change in paste color, but see bright orange streaks.

Minerals/Temper Identified: Quartz, mica (muscovite), polycrystalline quartz, grog, feldspar, clay pellets, dark opaques, unknown brown inclusion

ID Number: AN19-003-21 [9]

Temper Group: 14

Paste Description: The paste is golden brown in color with orange streaks in CP.

Minerals/Temper Identified: Quartz, grog, mica (muscovite), polycrystalline quartz, clay pellets, dark opaques

ID Number: AN19-004-22 [10]

Temper Group: 13

Paste Description: The paste is light tan in color with yellow streaks in CP.

Minerals/Temper Identified: Quartz, grog, clay pellets, feldspar, polycrystalline quartz, chert, bone, mica (muscovite), tourmaline, unknown orange inclusion

Bone Color (if present): White, dark brown

ID Number: AN19-005-23 [11]

Temper Group: 12

Paste Description: The paste is reddish brown along both edges and olive brown in the center. The paste gets darker in color in CP.

Minerals/Temper Identified: Quartz, bone, grog, chert, polycrystalline quartz, clay pellets, feldspar, dark opaques, mica (muscovite)

Bone Color (if present): White, brown

ID Number: AN19-006-24 [12]

Temper Group: 11

Paste Description: The paste is olive brown in color with one edge a reddish brown (possible slip). The paste gets darker in $\mathrm{CP}$ with bright orange streaks.

Minerals/Temper Identified: Quartz, grog, clay pellets, mica (muscovite), polycrystalline quartz, feldspar, dark opaques

\section{Site: 41AN8}

ID Number: AN8-001-43 [13]

Temper Group: 11

Paste Description: The paste is dark brown to olive brown in color and gets very dark in CP.

Minerals/Temper Identified: Quartz, grog, clay pellets, mica (muscovite), feldspar, chert, polycrystalline quartz (some with iron oxide), dark opaques

Bone Color (if present): White/tan

ID Number: AN8-002-44 [14]

Temper Group: 11

Paste Description: The paste is dark golden brown in color and gets darker in CP.

Minerals/Temper Identified: Quartz, feldspar, polycrystalline quartz, grog, mica (muscovite), chert (some with iron oxide), dark opaques

Notes: Unknown white inclusion may be small bone fragment

ID Number: AN8-003-45 [15]

Temper Group: 12

Paste Description: The paste is golden brown to dark brown in color.

Minerals/Temper Identified: Quartz, grog, feldspar, mica (muscovite), chert, polycrystalline quartz, tourmaline, dark opaques, unknown bright orange inclusion 
ID Number: AN8-004-46 [16]

Temper Group: 6

Paste Description: The paste is golden brown with no change in color in CP.

Minerals/Temper Identified: Quartz, bone, polycrystalline quartz, mica (muscovite), feldspar, dark opaques

Bone Color (if present): White, tan, brown, black

ID Number: AN8-005-47 [17]

Temper Group: 11

Paste Description: The paste is dark olive brown in color and gets darker and has a cloudy appearance in CP.

Minerals/Temper Identified: Quartz, grog, feldspar, clay pellets, mica (muscovite), polycrystalline quartz, bone, dark opaques

Bone Color (if present):Brown

ID Number: AN8-006-48 [18]

Temper Group: 1

Paste Description: The paste is reddish brown to dark golden brown in color and gets darker in CP.

Minerals/Temper Identified: Quartz, clay pellets, chert, grog, feldspar, mica (muscovite), dark opaques

Notes: Unknown white inclusion may be small bone fragment

\section{Site: $41 \mathrm{CE} 19$}

ID Number: CE19-001-37 [19]

Temper Group: 3

Paste Description: The paste is golden brown in color with darker brown spots. There are orange streaks in CP.

Minerals/Temper Identified: Quartz, clay pellets, grog, polycrystalline quartz, mica (muscovite), feldspar, dark opaques

ID Number: CE19-002-38 [20]

Temper Group: 11

Paste Description: The paste is golden brown in color with no change in CP.

Minerals/Temper Identified: Quartz, bone, grog, mica (muscovite), polycrystalline quartz, feldspar, dark opaques, unknown reddish orange inclusions,

Bone Color (if present): White, tan

ID Number: CE19-003-39 [21]

Temper Group: 6

Paste Description: The paste is brown in color with no change in CP.

Minerals/Temper Identified: Quartz, bone, mica (muscovite), feldspar, dark opaques, clay pellets

Bone Color (if present): White, tan, dark brown, black

ID Number: CE19-004-40 [22]

Temper Group: 14

Paste Description: The paste is golden brown with no change in CP.

Minerals/Temper Identified: Quartz, grog, feldspar, mica (muscovite), bone, dark opaques, polycrystalline quartz, clay pellets Bone Color (if present): Olive/tan

ID Number: CE19-005-41 [23]

Temper Group: 1

Paste Description: The paste is golden brown and gets slightly darker in CP.

Minerals/Temper Identified: Quartz, mica (muscovite), grog, polycrystalline quartz, chert, feldspar, dark opaques, clay pellets 
ID Number: CE19-006-42 [24]

Temper Group: 14

Paste Description: The paste is golden brown in color.

Minerals/Temper Identified: Quartz, grog, clay pellets, mica (muscovite), polycrystalline quartz, feldspar, dark opaques, bone Bone Color (if present): Brown

Notes: Only one small bone fragment found.

Site: 41FW2

ID Number: FW2-1 [25]

Temper Group: 13

Paste Description: The paste is brown in color. In CP, there is no color change in paste, but gets orange streaks.

Minerals/Temper Identified: Quartz, bone, mica (muscovite), grog, feldspar, polycrystalline quartz, dark opaques

Bone Color (if present): Tan, brown

ID Number: FW2-10 [26]

Temper Group: 11

Paste Description: The paste is brown in color. In CP, the paste is grayish brown with yellow streaks.

Minerals/Temper Identified: Quartz, grog, clay pellets, bone, dark opaques, feldspar

Bone Color (if present): Tan

ID Number: FW2-11 [27]

Temper Group: 3

Paste Description: The paste is reddish brown along both edges with a brown core. In CP, the core is grayish brown with yellow streaks, while the edges are lighter. There are few inclusions found in the paste

Minerals/Temper Identified: Quartz, grog, bone, mica (muscovite), clay pellets, dark opaques

Bone Color (if present): Tan

ID Number: FW2-12 [28]

Temper Group: 3

Paste Description: The paste is dark brown in color and goes reddish brown in color in CP.

Minerals/Temper Identified: Quartz, mica (muscovite), chert, grog, bone, clay pellets, feldspar, dark opaques

Bone Color (if present): Tan

ID Number: FW2-13 [29]

Temper Group: 11

Paste Description: The paste is light brown along both edges with a brown core. In CP, the core does not change, but the edges go a grayish brown with orange streaks.

Minerals/Temper Identified: Quartz, bone, grog, clay pellets, dark opaques

Bone Color (if present): Tan, brown

ID Number: FW2-14 [30]

Temper Group: 3

Paste Description: The paste is brown in color and goes grayish brown with orange streaks in CP.

Minerals/Temper Identified: Quartz, mica (muscovite), clay pellets, feldspar, bone, grog, polycrystalline quartz, dark opaques Bone Color (if present): Tan

ID Number: FW2-2 [31]

Temper Group: 11

Paste Description: The paste is brown in color with no color change in CP, but gets orange streaks.

Minerals/Temper Identified: Quartz, grog, bone, mica (muscovite), dark opaques, polycrystalline quartz

Bone Color (if present): Tan, brown 
ID Number: FW2-3 [32]

Temper Group: 12

Paste Description: The paste is golden brown along both edges with a dark brown core. In CP, the core does not change, but get orange streaks along the edges.

Minerals/Temper Identified: Quartz, bone, grog, feldspar, mica (muscovite), polycrystalline quartz, tourmaline, dark opaques Bone Color (if present): Brown

ID Number: FW2-4 [33]

Temper Group: 3

Paste Description: The paste is golden brown to brown in color. There are spots in the paste with no inclusions. In CP, the paste does not change color but gets orange streaks.

Minerals/Temper Identified: Quartz, feldspar, grog, bone, dark opaques, unknown grainy tan inclusions

Bone Color (if present): Dusty brown

ID Number: FW2-5 [34]

Temper Group: 15

Paste Description: The paste is brown in color and goes a grayish brown with orange streaks in CP.

Minerals/Temper Identified: Quartz, bone, grog, mica (muscovite), clay pellets, dark opaques

Bone Color (if present): White/tan, brown

ID Number: FW2-6 [35]

Temper Group: 11

Paste Description: The paste is light brown along both edges with a dark brown core. In CP, the core does not change, but get orange streaks along the edges

Minerals/Temper Identified: Quartz, bone, grog, mica (muscovite), dark opaques, unknown orange inclusion

Bone Color (if present): White/tan, brown

ID Number: FW2-7 [36]

Temper Group: 11

Paste Description: The paste is light brown and goes a grayish brown with orange streaks in CP.

Minerals/Temper Identified: Quartz, grog, feldspar, polycrystalline quartz, clay pellets, bone, mica (muscovite), dark opaques Bone Color (if present): Tan

ID Number: FW2-8 [37]

Temper Group: 13

Paste Description: The paste is light to dark brown in color. In CP, the paste is a golden brown with orange streaks along one edge. Minerals/Temper Identified: Quartz, polycrystalline quartz, feldspar, bone, mica (muscovite), grog, clay pellets, tourmaline, dark opaques

Bone Color (if present): White/tan, dusty brown

ID Number: FW2-9 [38]

Temper Group: 3

Paste Description: The paste is light brown in color. In CP, the paste is grayish brown with yellow streaks.

Minerals/Temper Identified: Quartz, grog, mica (muscovite), bone, clay pellets, feldspar, unknown reddish orange inclusion Bone Color (if present):Tan, dusty brown

\section{Site: $41 \mathrm{MX5}$}

ID Number: MX5-001-31 [39]

Temper Group: 12

Paste Description: The paste has a tan core with reddish brown edges. In CP, the core is gray with yellow streaks, while the edges have more orange streaks.

Minerals/Temper Identified: Quartz, clay pellets, grog, feldspar, polycrystalline quartz, dark opaques, mica (muscovite) 
ID Number: MX5-002-32 [40]

Temper Group: 3

Paste Description: The paste is dark brown with tan along one edge (possible slip). There is no change in CP for the dark brown paste, but the tan paste goes gray with yellow streaks.

Minerals/Temper Identified: Quartz, feldspar, mica (muscovite), polycrystalline quartz, grog, bone, unknown bright orange inclusion Bone Color (if present): Tan

ID Number: MX5-003-33 [41]

Temper Group: 11

Paste Description: The paste is brown in color with one edge a golden brown (possible slip). In CP there is no color change for the golden brown paste but it has several orange steaks. The brown paste color gets darker and cloudy in CP.

Minerals/Temper Identified: Quartz, feldspar, tourmaline, grog, mica (muscovite), polycrystalline quartz, clay pellets, chert (some with iron oxide), dark opaques, bone

Bone Color (if present): White, tan

Notes: Bone is very rare.

ID Number: MX5-004-34 [42]

Temper Group: 13

Paste Description: The paste is golden to tan in color and goes grayish brown in CP with yellow streaks.

Minerals/Temper Identified: Quartz, bone, clay pellets, grog, mica (muscovite), feldspar, dark opaques

Bone Color (if present): White, tan

ID Number: MX5-005-35 [43]

Temper Group: 11

Paste Description: The paste is dark golden brown to dark brown in color. In CP, the dark golden paste becomes golden color with orange streaks, while the dark brown paste gets darker.

Minerals/Temper Identified: Quartz, bone, clay pellets, mica (muscovite), polycrystalline quartz, feldspar, grog, dark opaques Bone Color (if present): Brown, tan

ID Number: MX5-006-36 [44]

Temper Group: 13

Paste Description: The paste is golden brown in color and gets lighter in CP.

Minerals/Temper Identified: Quartz, bone, grog, polycrystalline quartz, clay pellets, tourmaline, mica (muscovite), feldspar, dark opaques

Bone Color (if present): White, tan

Site: 41NA27

ID Number: NA27-001-13 [45]

Temper Group: 11

Paste Description: The paste is amber colored and has a slightly cloudy appearance with some orange streaks in CP.

Minerals/Temper Identified: Quartz, mica (muscovite), grog, clay pellets, polycrystalline quartz, bone, unknown reddish brown inclusion

Bone Color (if present): Only one bone fragment found - color not recorded

ID Number: NA27-002-14 [46]

Temper Group: 15

Paste Description: The paste is golden brown in color along one edge with the rest a dark brown color. There is no change in paste color in CP. (Possible slip)

Minerals/Temper Identified: Quartz, feldspar, polycrystalline quartz, clay pellets, mica (muscovite), grog, chert (some with iron oxide), bone, dark opaques

Bone Color (if present): Light brown 
ID Number: NA27-003-15 [47]

Temper Group: 11

Paste Description: The paste is dark golden brown in color with no change in CP.

Minerals/Temper Identified: Quartz, grog, mica (muscovite), clay pellets, bone, dark opaques

Bone Color (if present): White

ID Number: NA27-004-16 [48]

Temper Group: 12

Paste Description: The paste is olive brown in color and very porous. The paste goes a dark olive gray in CP.

Minerals/Temper Identified: Quartz, bone, clay pellets, polycrystalline quartz, grog, mica (muscovite), feldspar

Bone Color (if present): Dusty brown, white

ID Number: NA-005-17 [49]

Temper Group: 1

Paste Description: The paste is olive brown in color and goes darker in CP.

Minerals/Temper Identified: Quartz, clay pellets, polycrystalline quartz, mica (muscovite), feldspar, dark opaques

ID Number: NA27-006-18 [50]

Temper Group: 11

Paste Description: The paste color is dark amber to dark brown in color with no color change in $\mathrm{CP}$.

Minerals/Temper Identified: Quartz, grog, clay pellets, feldspar, mica (muscovite), unknown bright yellow inclusion, unknown orange inclusion

Site: 41RR9

ID Number: RR9-001-7 [51]

Temper Group: 12

Paste Description: The paste is brown in color and gets darker in CP.

Minerals/Temper Identified: Quartz, polycrystalline quartz, grog, feldspar, brown tourmaline, mica (muscovite), tourmaline, dark opaques

ID Number: RR9-002-8 [52]

Temper Group: 13

Paste Description: The paste is dark golden along both edges with a brown core. In CP, the paste goes slightly darker.

Minerals/Temper Identified: Quartz, bone, grog, mica (muscovite), clay pellets, tourmaline, dark opaques

Bone Color (if present): White/tan, brown

ID Number: RR9-003-9 [53]

Temper Group: 11

Paste Description: The paste tan in color and goes gray with yellow streaks in CP.

Minerals/Temper Identified: Quartz, polycrystalline quartz, grog, clay pellets, brown tourmaline, mica (muscovite), dark opaques, feldspar

ID Number: RR9-004-10 [54]

Temper Group: 2

Paste Description: The paste is reddish brown to golden in color and does not change in CP.

Minerals/Temper Identified: Quartz, limestone, calcite, mica (muscovite), limestone fossils, shell, dark opaques

ID Number: RR9-005-11 [55]

Temper Group: 11

Paste Description: The paste is reddish brown along both edges with a dark golden brown core. In CP, the core does not change in color, but the edges get lighter.

Minerals/Temper Identified: Quartz, polycrystalline quartz, feldspar, grog, bone, dark opaques, tourmaline, clay pellets Bone Color (if present): White/tan 
ID Number: RR9-006-12 [56]

Temper Group: 11

Paste Description: The paste is golden brown to brown in color. In CP, the paste is brown with orange streaks.

Minerals/Temper Identified: Quartz, feldspar, grog, polycrystalline quartz, bone, chert, mica (muscovite), unknown orange inclusion Bone Color (if present): Tan

\section{Site: 41SM9}

ID Number: SM9-001-1 [57]

Temper Group: 4

Paste Description: The paste is dark reddish brown along one edge and the rest is dark brown in color. There is no color change in CP. Minerals/Temper Identified: Quartz, bone, clay pellets, grog, mica (muscovite), dark opaques, chert, polycrystalline quartz Bone Color (if present): White/tan, brown

ID Number: SM9-002-2 [58]

Temper Group: 6

Paste Description: The paste is dark brown with no color change in CP.

Minerals/Temper Identified: Quartz, bone, mica (muscovite), polycrystalline quartz, clay pellets, dark opaques Bone Color (if present): White/tan, brown

ID Number: SM9-003-3 [59]

Temper Group: 13

Paste Description: The paste dark golden brown in color and goes brown with orange streaks in CP.

Minerals/Temper Identified: Quartz, bone, clay pellets, chert, mica (muscovite), grog, polycrystalline quartz, tourmaline, brown tourmaline, dark opaques

Bone Color (if present): White/tan, olive, brown

ID Number: SM9-004-4 [60]

Temper Group: 12

Paste Description: The paste is dark brown on one side and golden brown on the other. In CP, the dark brown paste does not change color, but the golden brown paste goes grayish brown with orange streaks.

Minerals/Temper Identified: Quartz, polycrystalline quartz, mica (muscovite), grog, feldspar, chert, brown tourmaline, tourmaline, dark opaques

ID Number: SM9-005-5 [61]

Temper Group: 3

Paste Description: The paste is golden brown in color. In CP, the paste goes grayish brown with orange streaks.

Minerals/Temper Identified: Quartz, polycrystalline quartz, mica (muscovite), clay pellets, grog, dark opaques, feldspar

Bone Color (if present): Tan, olive

ID Number: SM9-006-6 [62]

Temper Group: 11

Paste Description: The paste is golden brown in color. In CP, the paste does not change color but gets orange streaks.

Minerals/Temper Identified: Quartz, polycrystalline quartz, mica (muscovite), clay pellets, grog, dark opaques

Notes: Bone was found in the grog temper.

\section{Site: 41WD13}

ID Number: WD13-001-49 [63]

Temper Group: 11

Paste Description: The paste is light to dark tan (dark core) and goes olive brown in CP.

Minerals/Temper Identified: Quartz, grog, bone, feldspar, polycrystalline quartz, mica (muscovite), clay pellets, dark opaques Bone Color (if present): Dusty brown 
ID Number: WD13-002-50 [64]

Temper Group: 12

Paste Description: The paste is light tan in color and goes gray with yellow streaks in CP.

Minerals/Temper Identified: Quartz, grog, mica (muscovite), chert, polycrystalline quartz, feldspar, clay pellets, dark opaque

ID Number: WD13-003-51 [65]

Temper Group: 11

Paste Description: The paste is light tan in color and goes olive brown with yellow streaks in CP.

Minerals/Temper Identified: Quartz, grog, polycrystalline quartz, mica (muscovite), clay pellets, feldspar, chert, dark opaques

ID Number: WD13-004-52 [66]

Temper Group: 13

Paste Description: The paste is light tan in color with dark brown along one edge. The paste goes grayish olive in color with yellow streaks in CP.

Minerals/Temper Identified: Quartz, bone, grog, mica (muscovite), feldspar, clay pellets, dark opaques

Bone Color (if present): White, tan, light olive

ID Number: WD13-005-53 [67]

Temper Group: 12

Paste Description: The paste is light tan to olive brown in color. In CP, the paste goes olive gray with some cloudy orange spots. Minerals/Temper Identified: Quartz, grog, feldspar, mica (muscovite), chert, clay pellets, dark opaques, unknown reddishbrown inclusions

ID Number: WD13-006-54 [68]

Temper Group: 3

Paste Description: The paste is golden tan to dark brown in color. In CP, there is no color change in paste but get orange streaks. Minerals/Temper Identified: Quartz, bone, grog, polycrystalline quartz, mica (muscovite), chert, feldspar, dark opaques

Bone Color (if present): White, tan, brown

\section{Temper Groups}

For the purpose of this study, temper was limited to bone, quartz, limestone/calcite, and grog. Based on the point counting percentages, 16 temper groups were identified based on a combination of temper and paste. Temper inclusions less than 1 percent were considered as none present. It should be noted that the temper groups were based solely on the point counting percentages. There are some cases in which the pointing counting did not encounter a particular mineral/temper, but the mineral/temper was encountered during the measurements. Therefore, on the measurements table, a temper group such as Group 1 (Sand Tempered) may show a bone measurement.

\section{Group 1 - Sand Tempered}

Group 1 consists of thin sections with no bone, grog, or limestone and a heavy amount of quartz (over 20 percent).

\section{Leon Plain}

Sample ID

ED28-1261-8-2A-18

RE1-1872-66-1

RE1-1872-32B-3

\section{Caddo}

Sample ID

AN8-006-48

CE19-005-41

NA27-005-17
Location

41ED28

41RE1

41RE1 


\section{Group 2 - Limestone Tempered}

Group 2 consists of thin sections with no bone or grog temper, a light amount of quartz (less than 10 percent) and moderate to heavy amount of limestone/calcite (greater than 10 percent).

\section{Leon Plain}

Sample ID

RE1-1872-B-2

Location

41RE1

\section{Caddo}

Sample ID

Location

RR9-004-10

41RR9

\section{Group 3 - Lightly Tempered}

Group 3 consists of thin sections in which the paste matrix exceeded 80 percent and all other inclusions were less than 10 percent.

$\begin{array}{ll}\begin{array}{l}\text { Leon Plain } \\ \text { Sample ID }\end{array} & \begin{array}{l}\text { Location } \\ \text { BX5-13008-B-6 }\end{array} \\ \text { B1BX5 } \\ \text { BX5-13010-B-7 } & \text { 41BX5 } \\ \text { BX5-13006-B-5 } & \text { 41BX5 } \\ \text { ED28-840-8-1A-13 } & \text { 41ED28 } \\ \text { ED28-799-8-2A-20 } & \text { 41ED28 } \\ \text { ED28-1181-8-1B-17 } & \text { 41ED28 } \\ & \\ \text { Caddo } & \\ \text { Sample ID } & \text { Location } \\ \text { CE19-001-37 } & \text { 41CE19 } \\ \text { FW2-4 } & \text { 41FW2 } \\ \text { FW2-14 } & \text { 41FW2 } \\ \text { FW2-12 } & \text { 41FW2 } \\ \text { FW2-9 } & \text { 41FW2 } \\ \text { FW2-11 } & \text { 41FW2 } \\ \text { MX5-002-32 } & \text { 41MX5 } \\ \text { SM9-005-5 } & \text { 41SM9 } \\ \text { WD13-006-54 } & \text { 41WD13 }\end{array}$

Group 4 - Lightly Bone Tempered, Lightly Sandy Paste

Group 4 consists of thin sections with a light amount of bone (1to 10 percent) and quartz (less than 20 percent), no grog temper, and less than 5 percent limestone/calcite.

\section{Leon Plain}

Sample ID

BX5-13013-B-8

41JW8-326-1-3

83

41KM16-3h

12

$6 \mathrm{~B}$

$3 \mathrm{~A}$
Location

41BX5

41JW8

41KM16

41KM16

41KM16

41KM16

41KM16 


$\begin{array}{ll}3 \mathrm{c} & \text { 41KM16 } \\ \text { 18B } & \text { 41KM16 } \\ \text { 6A } & \text { 41KM16 } \\ \text { 41KM69-50-0-1-8 } & \text { 41KM69 } \\ \text { 41LK201-1844-001-34 } & \text { 41LK201 } \\ \text { 41LK201-1134-015-31 } & \text { 41LK201 }\end{array}$

Vessel-8 $41 \mathrm{WN} 88$

\section{Caddo}

$\begin{array}{ll}\text { Sample ID } & \text { Location } \\ \text { SM9-001-1 } & \text { 41SM9 }\end{array}$

\section{Group 5 - Lightly Bone Tempered, Sandy Paste}

Group 5 consists of thins sections with a light amount of bone (1to 10 percent) and heavy amount of quartz (greater than 20 percent). There is no grog temper and less than 5 percent limestone/calcite in this group.

\section{Leon Plain}

$\begin{array}{ll}\text { Sample ID } & \text { Location } \\ \text { 41JW8-341-1-5 } & \text { 41JW8 } \\ \text { 199P4 (Vessel 5) } & 41 \text { TG346 } \\ \text { Vessel-14 } & 41 \mathrm{WN88} \\ \text { Vessel-3 } & 41 \mathrm{WN} 88 \\ \text { Vessel-11 } & 41 \mathrm{WN} 88 \\ \text { Vessel-13 } & 41 \mathrm{WN} 88 \\ \text { Vessel-4 } & 41 \mathrm{WN} 88 \\ \text { Vessel-7 } & 41 \mathrm{WN} 88\end{array}$

\section{Group 6 - Moderately Bone Tempered, Lightly Sandy Paste}

Group 6 consists of thin sections with a moderate amount of bone (10 to 20 percent) and little quartz (less than 20 percent). There is no grog temper in this group and limestone/calcite is less than 5 percent.

$\begin{array}{ll}\text { Leon Plain } & \\ \text { Sample ID } & \text { Location } \\ \text { 41BX288-63-21 } & \text { 41BX288 } \\ \text { 41BX288-52-2-20 } & \text { 41BX288 } \\ \text { 41BX288-43-22 } & \text { 41BX288 } \\ \text { 41BX288-61-24 } & \text { 41BX288 } \\ \text { 41BX288-244-25 } & \text { 41BX288 } \\ \text { BX5-13002-B-4 } & \text { 41BX5 } \\ \text { ED28-1089-8-1B-16 } & \text { 41ED28 } \\ \text { ED28-1054-8-1B-15 } & \text { 41ED28 } \\ \text { ED28-481-1B-11 } & \text { 41ED28 } \\ \text { ED28-937-8-1B-14 } & \text { 41ED28 } \\ \text { 41JW8-328-2-4 } & \text { 41JW8 } \\ \text { 41JW8-353-1-6 } & \text { 41JW8 } \\ \text { 206 } & \text { 41KM16 } \\ \text { 125 } & \text { 41KM16 } \\ \text { XA-1 } & \text { 41KM16 } \\ \text { 481 } & \text { 41KM16 } \\ \text { 4A } & \text { 41KM16 }\end{array}$




\begin{tabular}{|c|c|}
\hline $5 b$ & M16 \\
\hline $18 \mathrm{a}$ & M16 \\
\hline $3 \mathrm{~B}$ & M16 \\
\hline $3 d$ & KM16 \\
\hline 41KM69-66-09-10 & 41KM69 \\
\hline 1KM69-8-0-4-7 & 41KM69 \\
\hline 41KM69-74-0-1-11 & 41KM69 \\
\hline 1KM69-66-0-4-9 & 1KM69 \\
\hline 41KM69-94-01-12 & 41KM69 \\
\hline 41LK201-1139-001-29 & 41LK201 \\
\hline $201-1848-027-36$ & K201 \\
\hline 41LK201-1849-005-37 & LK201 \\
\hline 41LK201-1848-024-35 & K201 \\
\hline $01-1852-006-40$ & K201 \\
\hline $41 \mathrm{LK}$ & LK201 \\
\hline 41LK201-1858-009-42 & ILK201 \\
\hline 41LK201-1465-006-32 & 41LK201 \\
\hline 41LK201-1853-004-41 & 41LK201 \\
\hline 41LK67-2197-002-19 & 41LK67 \\
\hline 41LK67-2188-001-17 & 41LK67 \\
\hline 41LK67-2197-001-18 & 41LK67 \\
\hline 41LK67-1057-005-13 & 41LK67 \\
\hline 41LK67-1087-006-14 & 41LK67 \\
\hline 41LK67-1522-003-16 & 41LK67 \\
\hline 657P9 (Vessel 3) & $41 \mathrm{TG} 346$ \\
\hline Vessel-10 & $41 \mathrm{WN} 88$ \\
\hline Vessel-2 & $41 \mathrm{WN} 88$ \\
\hline Vessel-6 & $41 \mathrm{WN} 88$ \\
\hline Vessel-12 & $41 \mathrm{WN}$ \\
\hline
\end{tabular}

Caddo

Sample ID

Location

AN8-004-46

$41 \mathrm{AN} 8$

CE19-003-39

41CE19

SM9-002-2

41SM9

\section{Group 7 - Moderately Bone Tempered, Limestone Paste}

Group 7 consists of thin sections with a moderate amount of bone (10 to 20 percent) and no grog temper. The paste is lightly sandy (less than 20 percent quartz) and the limestone is over 5 percent.

$\begin{array}{ll}\text { Leon Plain } & \\ \text { Sample ID } & \text { Location } \\ \text { R2 } & 41 \text { KM16 } \\ \text { R1 } & 41 \text { KM16 } \\ \text { R5 } & 41 \text { KM16 } \\ \text { R7 } & 41 \text { KM16 } \\ \text { R4 } & 41 \text { KM16 } \\ \text { 253P14 (Vessel 1) } & 41 \mathrm{TG} 346 \\ \text { 628P2 (Vessel 2) } & 41 \mathrm{TG} 346\end{array}$




\section{Group 8 - Moderately Bone Tempered, Sandy Paste}

Group 8 consists of thin sections with a moderate amount of bone (10 to 20 percent), less than 5 percent limestone and no grog temper. The paste is very sandy with greater than 20 percent quartz.

$\begin{array}{ll}\text { Leon Plain } & \\ \text { Sample ID } & \text { Location } \\ \text { 41BX288-261-26 } & \text { 41BX288 } \\ \text { 41BX288-389-24 } & \text { 41BX288 } \\ \text { 41LK201-1849-021-38 } & \text { 41LK201 } \\ \text { 440P1 (Vessel 6) } & \text { 41TG346 } \\ \text { Vessel-5 } & \text { 41WN88 }\end{array}$

\section{Group 9 - Heavily Bone Tempered, Lightly Sandy Paste}

Group 9 consists of thin sections with an abundant amount of bone (greater than 20 percent), less than 5 percent limestone and no grog temper. The paste is lightly sandy with less than 20 percent quartz.

\begin{tabular}{|c|c|}
\hline Leon Plain & \\
\hline Sample ID & Location \\
\hline ED28-168-8-1B-10 & 41ED28 \\
\hline ED28-159-5-8-1B-9 & 41ED28 \\
\hline 41JW8-68-2-1 & $41 \mathrm{JW} 8$ \\
\hline 41JW8-278-1-2 & $41 \mathrm{JW} 8$ \\
\hline 25 & 41KM16 \\
\hline $25 \mathrm{a}$ & $41 \mathrm{KM} 16$ \\
\hline $\mathrm{Xb}$ & $41 \mathrm{KM} 16$ \\
\hline $385 \mathrm{a}$ & $41 \mathrm{KM} 16$ \\
\hline 343 & $41 \mathrm{KM} 16$ \\
\hline $357 \mathrm{a}$ & $41 \mathrm{KM} 16$ \\
\hline KM16-1 & 41KM16 \\
\hline 41LK67-1432-008-15 & 41LK67 \\
\hline 41LK201-1852-002-39 & 41LK201 \\
\hline 41LK201-1134-014-30 & 41LK201 \\
\hline 41LK201-1134-010-28 & 41LK201 \\
\hline 41RN169-A & 41RN169 \\
\hline 510P12 (Vessel 4) & 41TG346 \\
\hline 253P22 (Vessel 1) & 41TG346 \\
\hline
\end{tabular}

\section{Group 10 - Heavily Bone Tempered, Limestone Paste}

Group 10 consists of thin sections with an abundant amount of bone (greater than 20 percent), less than 20 percent quartz, no grog temper, and greater than 5 percent limestone/calcite.

\section{Leon Plain}

Sample ID

ED28-799-8-1A-12

41RN169-B 41RN169 
Group 11 - Lightly Grog Tempered, Lightly Sandy Paste

Group 11 consists of thin sections with less than 10 percent grog temper present, less than 20 percent quartz, and no bone or limestone/calcite.

\begin{tabular}{|c|c|}
\hline \multicolumn{2}{|l|}{ Caddo } \\
\hline Sample ID & Location \\
\hline AN1-002-26 & 41AN1 \\
\hline AN1-006-30 & 41AN1 \\
\hline AN1-003-27 & 41AN1 \\
\hline AN1-001-25 & 41AN1 \\
\hline AN1-005-29 & 41AN1 \\
\hline AN19-002-20 & 41AN19 \\
\hline AN19-006-24 & 41AN19 \\
\hline AN19-001-19 & 41AN19 \\
\hline AN8-001-43 & 41AN8 \\
\hline AN8-002-44 & 41AN8 \\
\hline AN8-005-47 & 41AN8 \\
\hline CE19-002-38 & 41CE19 \\
\hline FW2-13 & 41FW2 \\
\hline FW2-2 & 41FW2 \\
\hline FW2-10 & 41FW2 \\
\hline FW2-6 & 41FW2 \\
\hline FW2-7 & 41FW2 \\
\hline MX5-003-33 & $41 \mathrm{MX} 5$ \\
\hline MX5-005-35 & $41 \mathrm{MX5}$ \\
\hline NA27-006-18 & 41NA27 \\
\hline NA27-001-13 & 41NA27 \\
\hline NA27-003-15 & 41NA27 \\
\hline RR9-003-9 & 41RR9 \\
\hline RR9-006-12 & 41RR9 \\
\hline RR9-005-11 & 41RR9 \\
\hline SM9-006-6 & 41SM9 \\
\hline WD13-001-49 & 41WD13 \\
\hline WD13-003-51 & 41WD13 \\
\hline
\end{tabular}

\section{Group 12 - Lightly Grog Tempered, Sandy Paste}

Group 12 consists of thin sections with less than 10 percent grog temper, no bone or limestone, and greater than 20 percent quartz.

$\begin{array}{ll}\text { Caddo } & \\ \text { Sample ID } & \text { Location } \\ \text { AN19-005-23 } & \text { 41AN19 } \\ \text { AN8-003-45 } & \text { 41AN8 } \\ \text { FW2-3 } & \text { 41FW2 } \\ \text { MX5-001-31 } & \text { 41MX5 } \\ \text { NA27-004-16 } & \text { 41NA27 } \\ \text { RR9-001-7 } & \text { 41RR9 } \\ \text { SM9-004-4 } & \text { 41SM9 } \\ \text { WD13-002-50 } & \text { 41WD13 } \\ \text { WD13-005-53 } & \text { 41WD13 }\end{array}$


Group 13 - Lightly Bone and Grog Tempered, Lightly Sandy Paste

Group 13 consists of thin sections with less than 10 percent bone and grog temper, less than 20 percent quartz, and no limestone.

\section{Caddo}

Sample ID

AN19-004-22

FW2-1

FW2-8

MX6-006-36

MX5-004-34

RR9-002-8

SM9-003-3

WD13-004-52
Location
41AN19
41FW2
$41 \mathrm{FW} 2$
$41 \mathrm{MX} 5$
$41 \mathrm{MX} 5$
41RR9
41SM9
41WD13

\section{Group 14 - Moderately Grog Tempered, Lightly Sandy Paste}

Group 14 consists of thin sections with greater than 10 percent grog temper, less than 20 percent quartz, and no bone or limestone.

\section{Caddo}

$\begin{array}{ll}\text { Sample ID } & \text { Location } \\ \text { AN19-003-21 } & \text { 41AN19 } \\ \text { CE19-006-42 } & \text { 41CE19 } \\ \text { CE19-004-40 } & \text { 41CE19 }\end{array}$

\section{Group 15 - Indeterminate}

Group 15 consists of thin sections that did not fit any of the above categories.

\section{Leon Plain}

Sample ID

Vessel-9

\section{Location}

$41 \mathrm{WN} 88$

Note: This thin section had over 80 percent paste, no bone, and over 10 percent quartz.

\section{Caddo}

$\begin{array}{ll}\text { Sample ID } & \text { Location } \\ \text { AN1-004-28 } & \text { 41AN1 } \\ \text { FW2-5 } & \text { 41FW2 } \\ \text { NA27-002-14 } & \text { 41NA27 }\end{array}$

Note: AN1-004-28 had over 80 percent paste, no bone, and over 10 percent quartz. FW2-4 had less than 10 percent bone and quartz and over 10 percent grog temper. NA27-002-14 had less than 20 percent quartz and no bone or grog temper.

\section{Group 16 - Not Grouped}

Group 16 consists of thin sections that did not get point counted due to a problem with the slide or were too small to get 300 points.

\section{Leon Plain}

Sample ID

41BX288-58-23 (not pottery)

480

$4 \mathrm{~b}$

341

41RN169-C

614P (Vessel 2)
Location

41BX288

41KM16

41KM16

41KM16

41RN169

$41 \mathrm{TG} 346$ 


\section{Summary}

A total of 185 thin sections were analyzed from 10 Caddoan sites and 12 Toyah sites and divided into 14 temper groups based on percentages of temper and paste derived from point counting. In addition, there were two other groups, indeterminate (thin sections that did not fit into one of the 14 temper groups) and not grouped (thin sections that could not be point counted), which are not included in the discussion below. The purpose of this petrographic study was to compare Caddoan ceramics to Toyah (Leon Plain) ceramics. The study found that there was considerable temper variability within both of these ceramic types (Table F-7).

Table F-7. Distribution of Temper Groups by Type

\begin{tabular}{|c|c|c|c|c|}
\hline Temper Group & \multicolumn{2}{|c|}{ Caddo } & \multicolumn{2}{c|}{ Leon Plain } \\
\hline $\mathbf{1}$ & 3 & $4.41 \%$ & 3 & $2.54 \%$ \\
\hline $\mathbf{2}$ & 1 & $1.47 \%$ & 1 & $0.85 \%$ \\
\hline $\mathbf{3}$ & 9 & $13.24 \%$ & 6 & $5.08 \%$ \\
\hline $\mathbf{4}$ & 1 & $1.47 \%$ & 8 & $11.86 \%$ \\
\hline $\mathbf{5}$ & 0 & $0.00 \%$ & 46 & $6.78 \%$ \\
\hline $\mathbf{6}$ & 3 & $4.41 \%$ & 7 & $38.98 \%$ \\
\hline $\mathbf{7}$ & 0 & $0.00 \%$ & 5 & $5.93 \%$ \\
\hline $\mathbf{8}$ & 0 & $0.00 \%$ & 18 & $4.24 \%$ \\
\hline $\mathbf{9}$ & 0 & $0.00 \%$ & 2 & $15.25 \%$ \\
\hline $\mathbf{1 0}$ & 0 & $0.00 \%$ & 0 & $1.69 \%$ \\
\hline $\mathbf{1 1}$ & 28 & $41.18 \%$ & 0 & $0.00 \%$ \\
\hline $\mathbf{1 2}$ & 9 & $13.24 \%$ & 0 & $0.00 \%$ \\
\hline $\mathbf{1 3}$ & 8 & $11.76 \%$ & 0 & $0.00 \%$ \\
\hline $\mathbf{1 4}$ & 3 & $4.41 \%$ & 1 & $0.00 \%$ \\
\hline $\mathbf{1 5}$ & 3 & $4.41 \%$ & 7 & $0.85 \%$ \\
\hline $\mathbf{1 6}$ & 0 & $0.00 \%$ & 118 & $5.93 \%$ \\
\hline Total & $\mathbf{6 8}$ & & & \\
\hline & & & & \\
\hline
\end{tabular}

Ten temper groups were determined from the 118 thin sections of the Leon Plain ceramics and nine temper groups were determined from the 68 Caddoan ceramics. The most common temper group for Leon Plain ceramics was Group 6 (Moderately Bone Tempered, Unsandy Paste). Group 6 accounts for 38.98 percent of the Leon Plain ceramics. This temper group could be found at all Toyah sites except 41RE1 and 41RN169 (Table F-8). The most common temper group for Caddoan ceramics was Group 11 (Lightly Grog Tempered, Unsandy Paste). Group 11 accounts for 41.18 percent of the Caddoan ceramics. This temper group could be found at all 10 Caddoan sites (Table F-9).

Table F-8. Distribution of Temper Groups for Toyah Sites

\begin{tabular}{|c|c|c|c|c|c|c|c|c|c|c|c|c|}
\hline $\begin{array}{l}\text { Temper } \\
\text { Group }\end{array}$ & 41BX228 & 41BX5 & 41ED28 & 41JW8 & $41 \mathrm{KM} 16$ & $41 \mathrm{KM} 69$ & 41LK201 & 41LK67 & 41RE1 & 41RN169 & 41 TG346 & $41 \mathrm{WN} 88$ \\
\hline 1 & 0 & 0 & 1 & 0 & 0 & 0 & 0 & 0 & 2 & 0 & 0 & 0 \\
\hline 2 & 0 & 0 & 0 & 0 & 0 & 0 & 0 & 0 & 1 & 0 & 0 & 0 \\
\hline 3 & 0 & 3 & 3 & 0 & 0 & 0 & 0 & 0 & 0 & 0 & 0 & 0 \\
\hline 4 & 0 & 1 & 0 & 1 & 8 & 1 & 2 & 0 & 0 & 0 & 0 & 1 \\
\hline 5 & 0 & 0 & 0 & 1 & 0 & 0 & 0 & 0 & 0 & 0 & 1 & 6 \\
\hline 6 & 5 & 1 & 4 & 2 & 9 & 5 & 9 & 6 & 0 & 0 & 1 & 4 \\
\hline 7 & 0 & 0 & 0 & 0 & 5 & 0 & 0 & 0 & 0 & 1 & 2 & 0 \\
\hline 8 & 2 & 0 & 0 & 0 & 0 & 0 & 1 & 0 & 0 & 1 & 1 & 1 \\
\hline 9 & 0 & 0 & 2 & 2 & 7 & 0 & 3 & 1 & 0 & 0 & 2 & 0 \\
\hline 10 & 0 & 0 & 1 & 0 & 0 & 0 & 0 & 0 & 0 & 0 & 0 & 0 \\
\hline
\end{tabular}


Table F-8. Distribution of Temper Groups for Toyah Sites continued....

\begin{tabular}{|c|c|c|c|c|c|c|c|c|c|c|c|c|}
\hline $\begin{array}{c}\text { Temper } \\
\text { Group }\end{array}$ & 41BX228 & 41BX5 & 41ED28 & 41JW8 & 41KM16 & 41KM69 & 41LK201 & 41LK67 & 41RE1 & 41RN169 & 41TG346 & 41WN88 \\
\hline 11 & 0 & 0 & 0 & 0 & 0 & 0 & 0 & 0 & 0 & 0 & 0 & 0 \\
\hline 12 & 0 & 0 & 0 & 0 & 0 & 0 & 0 & 0 & 0 & 0 & 0 & 0 \\
\hline 13 & 0 & 0 & 0 & 0 & 0 & 0 & 0 & 0 & 0 & 0 & 0 & 0 \\
\hline 14 & 0 & 0 & 0 & 0 & 0 & 0 & 0 & 0 & 0 & 0 & 0 & 0 \\
\hline 15 & 0 & 0 & 0 & 0 & 0 & 0 & 0 & 0 & 0 & 0 & 0 & 1 \\
\hline 16 & 1 & 0 & 0 & 0 & 3 & 0 & 0 & 0 & 0 & 1 & 1 & 1 \\
\hline
\end{tabular}

Table F-9. Distribution of Temper Groups for Caddoan Sites

\begin{tabular}{|c|c|c|c|c|c|c|c|c|c|c|}
\hline $\begin{array}{l}\text { Temper } \\
\text { Group }\end{array}$ & 41AN1 & 41AN19 & 41AN8 & 41CE19 & 41FW2 & $41 \mathrm{MX5}$ & 41NA27 & 41RR9 & 41SM9 & 41 WD13 \\
\hline 1 & 0 & 0 & 1 & 1 & 0 & 0 & 1 & 0 & 0 & 0 \\
\hline 2 & 0 & 0 & 0 & 0 & 0 & 0 & 0 & 1 & 0 & 0 \\
\hline 3 & 0 & 0 & 0 & 1 & 5 & 1 & 0 & 0 & 1 & 1 \\
\hline 4 & 0 & 0 & 0 & 0 & 0 & 0 & 0 & 0 & 1 & 0 \\
\hline 5 & 0 & 0 & 0 & 0 & 0 & 0 & 0 & 0 & 0 & 0 \\
\hline 6 & 0 & 0 & 1 & 1 & 0 & 0 & 0 & 0 & 1 & 0 \\
\hline 7 & 0 & 0 & 0 & 0 & 0 & 0 & 0 & 0 & 0 & 0 \\
\hline 8 & 0 & 0 & 0 & 0 & 0 & 0 & 0 & 0 & 0 & 0 \\
\hline 9 & 0 & 0 & 0 & 0 & 0 & 0 & 0 & 0 & 0 & 0 \\
\hline 10 & 0 & 0 & 0 & 0 & 0 & 0 & 0 & 0 & 0 & 0 \\
\hline 11 & 5 & 3 & 3 & 1 & 5 & 2 & 3 & 3 & 1 & 2 \\
\hline 12 & 0 & 1 & 1 & 0 & 1 & 1 & 1 & 1 & 1 & 2 \\
\hline 13 & 0 & 1 & 0 & 0 & 2 & 2 & 0 & 1 & 1 & 1 \\
\hline 14 & 0 & 1 & 0 & 2 & 0 & 0 & 0 & 0 & 0 & 0 \\
\hline 15 & 1 & 0 & 0 & 0 & 1 & 0 & 1 & 0 & 0 & 0 \\
\hline 16 & 0 & 0 & 0 & 0 & 0 & 0 & 0 & 0 & 0 & 0 \\
\hline
\end{tabular}

The Leon Plain ceramics were mostly bone tempered with 96.39 percent of the Leon Plain thin sections containing greater than 1 percent bone. The Caddoan ceramics were mostly grog tempered with 85.29 percent of the thin section containing greater than 1 percent grog temper. Five of the bone temper groups (Group 5 - Lightly Bone Tempered, Sandy Paste; Group 7 - Moderately Bone Tempered, Limestone Paste; Group 8 - Moderately Bone Tempered, Sandy Paste; Group 9 - Heavily Bone Tempered, Lightly Sandy Paste; and Group 10 - Heavily Bone Tempered, Limestone Paste) were only found with the Leon Plain ceramics. Four of the temper groups (Group 11 - Lightly Grog Tempered, Lightly Sandy Paste; Group 12 - Lightly Grog Tempered, Sandy Paste; Group 13 - Lightly Bone and Grog Tempered, Lightly Sandy Paste; and Group 14 - Moderately Grog Tempered, Lightly Sandy Paste) were only found with the Caddoan ceramics. However five temper groups (Group 1 - Sand Tempered; Group 2 - Limestone Tempered; Group 3 - Lightly Tempered; Group 4 - Lightly Bone Tempered, Lightly Sandy Paste; and Group 6 - Moderately Bone Tempered, Lightly Sandy Paste) were found with both the Leon Plain and Caddoan ceramics.

In Tables F-10 and F-11 the average of the means for each temper type for each temper group is listed. From these tables it appears that the grog temper used in the Caddoan ceramics is on average larger than the bone temper used in the Leon Plain ceramics. Additional research is needed to determine if the size difference is due to the functional properties of the temper used. It is also interesting to note that the mean bone size in Group 6 for Caddoan ceramics is almost twice as the bone in the Leon Plain ceramics. 
Table F-10. Mean of Temper (in $\mathrm{mm}$ ) by Temper Group for Leon Plain Ceramics

\begin{tabular}{|c|c|c|c|}
\hline Temper Group & Bone Mean & Quartz Mean & Limestone Mean \\
\hline 1 & 0.343 & 0.198 & \\
\hline 2 & & 0.005 & 0.442 \\
\hline 3 & 0.416 & 0.014 & 0.202 \\
\hline 4 & 0.366 & 0.124 & 0.433 \\
\hline 5 & 0.449 & 0.202 & 0.257 \\
\hline 6 & 0.378 & 0.078 & 0.214 \\
\hline 7 & 0.365 & 0.061 & 0.449 \\
\hline 8 & 0.429 & 0.176 & 0.138 \\
\hline 9 & 0.340 & 0.026 & 0.215 \\
\hline 10 & 0.347 & 0.022 & 0.822 \\
\hline 15 & & 0.091 & \\
\hline 16 & 0.242 & 0.072 & \\
\hline
\end{tabular}

Table F-11. Mean of Temper (in mm) by Temper Groups for Caddoan Ceramics

\begin{tabular}{|c|c|c|c|c|}
\hline Temper Group & Bone Mean & Quartz Mean & Limestone Mean & Grog Mean \\
\hline 1 & & 0.098 & & 1.769 \\
\hline 2 & & 0.038 & 0.411 & \\
\hline 3 & 0.262 & 0.126 & & 0.587 \\
\hline 4 & 0.239 & 0.098 & & \\
\hline 6 & 0.732 & 0.063 & & 0.739 \\
\hline 11 & 0.399 & 0.105 & & 0.673 \\
\hline 12 & & 0.100 & & 0.772 \\
\hline 13 & 0.371 & 0.107 & & 0.913 \\
\hline 14 & & 0.150 & & 1.038 \\
\hline 15 & 0.210 & 0.066 & & \\
\hline
\end{tabular}

Although there is a difference in the temper used in Leon Plain ceramics and Caddoan ceramics in most cases, there is some overlap between the two ceramics. Additional research is suggested to see if there are any additional similarities in the ceramics. 


\section{References:}

\section{Stoltman, J.B.}

2001 The Role of Petrography in the Study of Archaeological Ceramics. In Earth Sciences and Archaeology, edited by P.Goldbert, V.T. Holliday, and C.R. Ferring, pp. 297-326. Kluwer Academic/Plenum Publishers, New York. 
Appendix G:

Absolute Dating of 41KM69 Ceramics, Luminescence

Dating of Ceramics from West-Central Texas, and Radiocarbon Analysis Report

James Feathers and Alexander Cherkinsky 



\section{Appendix G}

\section{Absolute Dating of 41KM69 Cermaics, Luminescence Dating of Ceramics from West-Central Texas, and Radiocarbon Analysis Report}

\section{James Feathers}

Six ceramic sherds from site 41KM69 in west-central Texas were submitted for luminescence analysis by the Center for Archaeological Research at the University of Texas at San Antonio. Each sherd had been divided in half prior to submission. The other half was submitted to the University of Georgia Center for Applied Isotope Studies for ${ }^{14} \mathrm{C}$ radiocarbon AMS analyses. The radiocarbon analysis was performed on soot scraped from the sherd surface. Table G-1 gives the UW laboratory numbers, the sherd identification, burial depth, and uncalibrated ${ }^{14} \mathrm{C}$ ages (with one sigma error) for those sherds on which a date could be obtained.

Table G-1. Uncalibrated ${ }^{14} \mathrm{C}$ Ages (with one sigma error) for Those Sherds on Which a Date Could Be Obtained

\begin{tabular}{|c|c|c|c|}
\hline UW lab \# & Specimen \# & Burial depth $(\mathbf{c m})$ & ${ }^{14}$ C age (years B.P.) \\
\hline UW2006 & $66-0-2 B$ & $39-50$ & $900 \pm 40$ \\
\hline UW2007 & $86-0-2 B$ & $40-50$ & $830 \pm 30$ \\
\hline UW2008 & $86-0-3 B$ & $40-50$ & \\
\hline UW2009 & $52-1-3 B$ & 40 & $790 \pm 30$ \\
\hline UW2010 & $52-1-2 B$ & 40 & $1020 \pm 25$ \\
\hline UW2011 & $66-0-11 B$ & $39-50$ & \\
\hline
\end{tabular}

Luminescence laboratory procedures are given in the Appendix 1. Dose rate data are given in Table G-2. These include relevant concentrations, a comparison of beta dose rates determined in two ways, and the total dose rate for each sample. Also included are concentrations for three associated sediment samples. The radioactivity of the latter did not vary significantly, except for an unusually high Th concentration for sediment $\mathrm{C}$. Because this seemed anomalous, the external dose rate was taken from an average of only sediments A and B. The beta dose rate for the sherds was calculated from flame photometry and alpha counting, assuming secular equilibrium, and also measured directly by beta counting. Only UW2009 showed a significant difference (but not at 2-sigma). For this sample, the beta counting results were used for the total dose rate, while for the other samples the more precise alpha counting/flame photometry results were used. Moisture contents were taken as $50 \pm 30$ percent of the saturated value for the sherds, and $6 \pm 3$ percent for the sediments.

Table G-2. Dose Rate Data for Samples on Which Date Could Be Obtained

\begin{tabular}{|c|c|c|c|c|c|c|}
\hline \multirow{2}{*}{ Sample } & \multirow{2}{*}{${ }^{238} \mathbf{U}(\mathbf{p p m})$} & \multirow{2}{*}{${ }^{232} \mathrm{Th}(\mathrm{ppm})$} & \multirow{2}{*}{$\% \mathbf{K}$} & \multicolumn{2}{|c|}{ Beta dose rate (Gy/ka) } & \multirow{2}{*}{$\begin{array}{c}\begin{array}{c}\text { Total dose } \\
\text { rate }\end{array} \\
\text { (Gy/ka) }\end{array}$} \\
\hline & & & & B-counting & $\begin{array}{c}\alpha \text {-counting/flame } \\
\text { photometry }\end{array}$ & \\
\hline UW2006 & $2.77 \pm 0.17$ & $4.43 \pm 0.72$ & $2.41 \pm 0.07$ & $2.30 \pm 0.22$ & $2.46 \pm 0.07$ & $3.57 \pm 0.17$ \\
\hline UW2007 & $2.43 \pm 0.15$ & $2.69 \pm 0.67$ & $2.34 \pm 0.08$ & $2.37 \pm 0.21$ & $2.31 \pm 0.07$ & $3.40 \pm 0.15$ \\
\hline UW2008 & $2.87 \pm 0.17$ & $2.66 \pm 0.68$ & $2.30 \pm 0.07$ & $2.25 \pm 0.18$ & $2.33 \pm 0.06$ & $3.36 \pm 0.17$ \\
\hline UW2009 & $3.00 \pm 0.20$ & $6.80 \pm 1.09$ & $2.42 \pm 0.07$ & $2.28 \pm 0.20$ & $2.56 \pm 0.07$ & $3.70 \pm 0.24$ \\
\hline UW2010 & $2.73 \pm 0.18$ & $4.76 \pm 0.89$ & $2.39 \pm 0.08$ & $2.25 \pm 0.21$ & $2.44 \pm 0.08$ & $3.57 \pm 0.17$ \\
\hline UW2011 & $3.30 \pm 0.21$ & $6.31 \pm 0.98$ & $2.32 \pm 0.07$ & $2.27 \pm 0.19$ & $2.52 \pm 0.07$ & $3.69 \pm 0.17$ \\
\hline Sediment A & $1.77 \pm 0.14$ & $5.24 \pm 0.92$ & $0.58 \pm 0.04$ & & & \\
\hline Sediment B & $2.69 \pm 0.17$ & $5.11 \pm 0.79$ & $0.67 \pm 0.02$ & & & \\
\hline Sediment C & $2.29 \pm 0.41$ & $41.76 \pm 3.16$ & $0.64 \pm 0.05$ & & & \\
\hline
\end{tabular}


(Equivalent dose was determined by thermoluminescence (TL), infrared stimulated luminescence (IRSL), and optically stimulated luminescence (OSL), as described in the Appendix 1. The natural TL signal was very weak in these sherds, and while there was a measurable signal with dose, this induced signal was not strong either. On three of the samples an equivalent dose could not be derived, because the value obtained was zero or negative, a statistical artifact of poor signal to noise ratio, although anomalous fading could play a role as well. Anomalous fading was detected on UW2006 and UW2008, but not UW2010. Fading rates (in percent loss per decade where a decade is a factor of 10) were $6.0 \pm 0.9$ for UW2006 and $22 \pm 2$ for UW2007. In the latter case a fading correction produced an infinite age.

A measurable IRSL signal was only obtained on four of the six sherds. In all cases the signal was 5 to 10 times weaker than that for OSL. This suggests that feldspar in these samples does not contribute much to the OSL signal, the latter therefore not likely to suffer significant anomalous fading. The strength of the OSL signal, on the other hand, was satisfactory for all samples and this signal was therefore the one predominately used for dating. An equipment problem, however, caused the loss of some of the aliquots used for OSL for UW2008 and UW2009, resulting in only one aliquot available for measurement. Results for these two samples are not as reliable as the others, although their ages are in the same range.

Table G-3 gives the equivalent dose data. Also listed are b-values, which are the slope ratios of additive dose curves using beta and alpha irradiation. These are used to account for the lower efficiency in producing luminescence by alpha irradiation. The derived b-values are typical.

Table G-3. Equivalent Dose Data for Samples on Which Date Could Be Obtained

\begin{tabular}{|c|c|c|c|c|c|c|}
\hline \multirow{2}{*}{ Sample } & \multicolumn{3}{|c|}{ Equivalent Dose (Gy) } & \multicolumn{3}{c|}{ b-value $\left(G y \mu \mathbf{m}^{2}\right)$} \\
\cline { 2 - 7 } & TL & IRSL & OSL & TL & IRSL & OSL \\
\hline UW2006 & $1.36 \pm 0.22$ & $2.49 \pm 0.44$ & $2.52 \pm 0.09$ & $2.64 \pm 0.27$ & $2.04 \pm 0.30$ & $0.77 \pm 0.06$ \\
\hline UW2007 & & $2.02 \pm 0.29$ & $1.15 \pm 0.09$ & & $2.08 \pm 0.20$ & $0.83 \pm 0.06$ \\
\hline UW2008 & $0.85 \pm 0.30$ & & $1.74 \pm 0.09$ & $2.05 \pm 0.36$ & & $0.73 \pm 0.04$ \\
\hline UW2009 & & $5.96 \pm 1.26$ & $1.17 \pm 0.19$ & & $1.31 \pm 0.49$ & $0.98 \pm 0.07$ \\
\hline UW2010 & $1.98 \pm 0.79$ & & $0.94 \pm 0.16$ & $5.94 \pm 1.66$ & & $0.80 \pm 0.04$ \\
\hline UW2011 & & $2.11 \pm 1.07$ & $2.17 \pm 0.08$ & & $0.93 \pm 0.30$ & $0.68 \pm 0.02$ \\
\hline
\end{tabular}

Ages are given in Table G-4. In all cases, OSL is the basis for the age, although in the case of UW2010 the TL age was in agreement and in the case of UW2011 the IRSL age was in agreement. Fading apparently was not a problem in either sample. Fading of the TL signal was detected in UW2006 and UW2008, but only in UW2006 was correction possible and the corrected age was still younger than that of OSL.

The OSL ages are systematically younger than those derived from soot by radiocarbon. The OSL ages reflect when the sample was last heated. The radiocarbon ages reflect the removal of the carbon from the carbon cycle. The two events could be different and that would explain the age differences. The soot could be from old wood, for example.

Table G-4. Ages Obtained on Ceramic Samples

\begin{tabular}{|c|c|c|c|c|c|}
\hline Sample & Age (ka) & \% error & Age (years AD) & $\begin{array}{c}\text { Basis for } \\
\text { age }\end{array}$ & $\begin{array}{c}\text { Calibrated }{ }^{14} \mathbf{C} \\
\text { (years AD) }\end{array}$ \\
\hline UW2006 & $0.70 \pm 0.05$ & 6.8 & $1300 \pm 50$ & OSL & $1045-1206$ \\
\hline UW2007 & $0.34 \pm 0.03$ & 9.4 & $1670 \pm 30$ & OSL & $1186-1254$ \\
\hline UW2008 & $0.52 \pm 0.04$ & 7.8 & $1490 \pm 40$ & OSL & \\
\hline UW2009 & $0.31 \pm 0.06$ & 18 & $1690 \pm 60$ & OSL & $1224-1263$ \\
\hline UW2010 & $0.27 \pm 0.04$ & 16.5 & $1740 \pm 40$ & OSL/TL & $994-1023$ \\
\hline UW2011 & $0.59 \pm 0.04$ & 6.8 & $1420 \pm 40$ & OSL/IRSL & \\
\hline
\end{tabular}




\section{Appendix 1}

\section{Procedures for Thermoluminescence Analysis of Pottery}

\section{Sample preparation -- fine grain}

The sherd is broken to expose a fresh profile. Material is drilled from the center of the cross-section, more than $2 \mathrm{~mm}$ from either surface, using a tungsten carbide drill tip. The material retrieved is ground gently by a corundum mortar and pestle, treated with $\mathrm{HCl}$, and then settled in acetone for 2 and 20 minutes to separate the 1-8 $\mu \mathrm{m}$ fraction. This is settled onto a maximum of 72 stainless steel discs.

\section{Glow-outs}

Thermoluminescence is measured by a Daybreak reader using a 9635Q photomultiplier with a Corning 7-59 blue filter, in $\mathrm{N}_{2}$ atmosphere at $1{ }^{\circ} \mathrm{C} / \mathrm{s}$ to $450^{\circ} \mathrm{C}$. A preheat of $240^{\circ} \mathrm{C}$ with no hold time precedes each measurement. Artificial irradiation is given with a ${ }^{241} \mathrm{Am}$ alpha source and a ${ }^{90} \mathrm{Sr}$ beta source, the latter calibrated against a ${ }^{137} \mathrm{Cs}$ gamma source. Discs are stored at room temperature for at least one week after irradiation before glow out. Data are processed by Daybreak TLApplic software.

\section{Fading test}

Several discs are used to test for anomalous fading. The natural luminescence is first measured by heating to $450^{\circ} \mathrm{C}$. The discs are then given an equal alpha irradiation and stored at room temperature for varied times: 10 min., 2 hours, 1 day, 1 week, and 8 weeks. The irradiations are staggered in time so that all of the second glows are performed on the same day. The second glows are normalized by the natural signal and then compared to determine any loss of signal with time (on a log scale). If the sample shows fading and the signal versus time values can be reasonably fit to a logarithmic function, an attempt is made to correct the age following procedures recommended by Huntley and Lamothe (2001). The fading rate is calculated as the g-value, which is given in percent per decade, where decade represents a power of 10.

\section{Equivalent dose}

The equivalent dose is determined by a combination additive dose and regeneration (Aitken 1985). Additive dose involves administering incremental doses to natural material. A growth curve plotting dose against luminescence can be extrapolated to the dose axis to estimate an equivalent dose, but for pottery this estimate is usually inaccurate because of errors in extrapolation due to nonlinearity. Regeneration involves zeroing natural material by heating to $450^{\circ} \mathrm{C}$ and then rebuilding a growth curve with incremental doses. The problem here is sensitivity change caused by the heating. By constructing both curves, the regeneration curve can be used to define the extrapolated area and can be corrected for sensitivity change by comparing it with the additive dose curve. This works where the shapes of the curves differ only in scale (i.e., the sensitivity change is independent of dose). The curves are combined using the "Australian slide" method in a program developed by David Huntley of Simon Fraser University (Prescott et al. 1993). The equivalent dose is taken as the horizontal distance between the two curves after a scale adjustment for sensitivity change. Where the growth curves are not linear, they are fit to quadratic functions. Dose increments (usually five) are determined so that the maximum additive dose results in a signal about three times that of the natural and the maximum regeneration dose about five times the natural. If the regeneration curve has a significant negative intercept, which is not expected given current understanding, the additive dose intercept is taken as the best, if not fully reliable approximation.

A plateau region is determined by calculating the equivalent dose at temperature increments between $240^{\circ}$ and $450^{\circ} \mathrm{C}$ and determining over which temperature range the values do not differ significantly. This plateau region is compared with a similar one constructed for the b-value (alpha efficiency), and the overlap defines the integrated range for final analysis.

\section{Alpha effectiveness}

Alpha efficiency is determined by comparing additive dose curves using alpha and beta irradiations. The slide program is also used in this regard, taking the scale factor (which is the ratio of the two slopes) as the b-value (Aitken 1985). 


\section{Radioactivity}

Radioactivity is measured by alpha counting in conjunction with atomic emission for $40 \mathrm{~K}$. Samples for alpha counting are crushed in a mill to flour consistency, packed into plexiglass containers with $\mathrm{ZnS}$ :Ag screens, and sealed for one month before counting. The pairs technique is used to separate the $U$ and Th decay series. For atomic emission measurements, samples are dissolved in HF and other acids and analyzed by a Jenway flame photometer. K concentrations for each sample are determined by bracketing between standards of known concentration. Conversion to ${ }^{40} \mathrm{~K}$ is by natural atomic abundance. Radioactivity is also measured, as a check, by beta counting, using a Risø low level beta GM multicounter system. About $0.5 \mathrm{~g}$ of crushed sample is placed on each of four plastic sample holders. All are counted for 24 hours. The average is converted to dose rate following Bøtter-Jensen and Mejdahl (1988) and compared with the beta dose rate calculated from the alpha counting and flame photometer results.

Both the sherd and an associated soil sample are measured for radioactivity. Additional soil samples are analyzed where the environment is complex, and gamma contributions determined by gradients (after Aitken 1985: appendix H). Cosmic radiation is determined after Prescott and Hutton (1988). Radioactivity concentrations are translated into dose rates following Adamiec and Aitken (1998).

\section{Moisture Contents}

Water absorption values for the sherds are determined by comparing the saturated and dried weights. For temperate climates, moisture in the pottery is taken to be $80 \pm 20$ percent of total absorption, unless otherwise indicated by the archaeologist. Again for temperate climates, soil moisture contents are taken from typical moisture retention quantities for different textured soils (Brady 1974: 196), unless otherwise measured. For drier climates, moisture values are determined in consultation with the archaeologist.

\section{Procedures for Optically Stimulated or Infrared Stimulated Luminescence of Fine-grained Pottery}

Optically stimulated luminescence (OSL) and infrared stimulated luminescence (IRSL) on fine-grain (1-8 $\mu \mathrm{m})$ pottery samples are carried out on single aliquots following procedures adapted from Banerjee et al. (2001) and Roberts and Wintle (2001. Equivalent dose is determined by the single-aliquot regenerative dose (SAR) method (Murray and Wintle 2000).

The SAR method measures the natural signal and the signal from a series of regeneration doses on a single aliquot. The method uses a small test dose to monitor and correct for sensitivity changes brought about by preheating, irradiation or light stimulation. SAR consists of the following steps: 1) preheat, 2) measurement of natural signal (OSL or IRSL), L(1), 3) test dose, 4) cut heat, 5) measurement of test dose signal, $\mathrm{T}(1), 6)$ regeneration dose, 7) preheat, 8) measurement of signal from regeneration, $\mathrm{L}(2)$, 9) test dose, 10) cut heat, 11) measurement of test dose signal, T(2), 12) repeat of steps 6 through 11 for various regeneration doses. A growth curve is constructed from the L(i)/T(i) ratios and the equivalent dose is found by interpolation of L(1)/T(1). Usually a zero regeneration dose and a repeated regeneration dose are employed to insure the procedure is working properly. For fine-grained ceramics, a preheat of $240^{\circ} \mathrm{C}$ for $10 \mathrm{~s}$, a test dose of $3.1 \mathrm{~Gy}$, and a cut heat of $200^{\circ} \mathrm{C}$ are currently being used, although these parameters may be modified from sample to sample.

The luminescence, L(i) and T(i), is measured on a Risø TL-DA-15 automated reader by a succession of two stimulations: first $100 \mathrm{~s}$ at $60^{\circ} \mathrm{C}$ of IRSL ( $880 \mathrm{~nm}$ diodes), and then $100 \mathrm{~s}$ at $125^{\circ} \mathrm{C}$ of OSL (470nm diodes). Detection is through $7.5 \mathrm{~mm}$ of Hoya U340 (ultra-violet) filters. The two stimulations are used to construct IRSL and OSL growth curves, so that two estimations of equivalent dose are available. Anomalous fading usually involves feldspars and only feldspars are sensitive to IRSL stimulation. The rationale for the IRSL stimulation is to remove most of the feldspar signal, so that the subsequent OSL (post IR blue) signal is free from anomalous fading. However, feldspar is also sensitive to blue light (470nm), and it is possible that IRSL does not remove all the feldspar signal. Some preliminary tests in our laboratory have suggested that the OSL signal does not suffer from fading, but this may be sample specific. The procedure is still undergoing study.

A dose recovery test is performed by first zeroing the sample by exposure to light and then administering a known dose. The SAR protocol is then applied to see if the known dose can be obtained. 
The laboratory is currently investigating using pulsed OSL to measure equivalent dose on ceramics. In pulsed mode, the stimulating light is turned off and on in a series of pulses with the luminescence only measured during the off-time. Because the time between stimulation and emission is much longer for quartz than feldspar, an appropriate pulse width can be chosen to

eliminate any feldspar signal. Previous work has suggested that a $10 \mu \mathrm{s}$ on-time and $240 \mu \mathrm{s}$ off-time for each pulse, and also using an initial infrared exposure (as in double SAR), will minimize the feldspar signal during the off-time, so that the signal stems mainly from quartz. Pulsed OSL is measured on a Risø DA-20 using similar parameters as in the double SAR. Detection is for $100 \mathrm{~s}$ total (both on- and off-time) which includes 400,000 pulses for a total on-time of 4 seconds. This procedure is currently undergoing study because it is not certain 4 seconds is sufficient exposure to deplete the signal.

Alpha efficiency will surely differ among IRSL, OSL and TL on fine-grained materials. It does differ between coarse-grained feldspar and quartz (Aitken 1985). Research is currently underway in the laboratory to determine how much b-value varies according to stimulation method. Results from several samples from different geographic locations show that OSL b-value is less variable and centers around 0.5. IRSL $b$-value is more variable and is higher than that for OSL. TL $b$-value tends to fall between the OSL and IRSL values. We currently are measuring the b-value for IRSL and OSL by giving an alpha dose to aliquots whose luminescence have been drained by exposure to light. An equivalent dose is determined by SAR using beta irradiation, and the beta/alpha equivalent dose ratio is taken as the b-value.

\section{Age and error terms}

The age and error for both OSL and TL are calculated by a laboratory constructed spreadsheet, based on Aitken (1985). All error terms are reported at 1-sigma. 


\section{References:}

Adamiec, G., and Aitken, M. J.

1998 Dose Rate Conversion Factors: Update. Ancient TL 16:37-50.

Aitken, M. J.

1985 Thermoluminescence Dating. Academic Press, London.

Banerjee, D., Murray, A. S., Bøtter-Jensen, L., and Lang, A.

2001 Equivalent Dose Estimation Using a Single Aliquot of Polymineral Fine Grains. Radiation Measurements 33:73-93.

Bøtter-Jensen, L, and Mejdahl, V.

1988 Assessment of Beta Dose-rate Using a GM Multi-counter System. Nuclear Tracks and Radiation Measurements 14:187-191.

Brady, N. C.

1974 The Nature and Properties of Soils. Macmillan, New York.

Huntley, D. J., and Lamothe, M.

2001 Ubiquity of Anomalous Fading in K-feldspars, and Measurement and Correction for It in Optical Dating. Canadian Journal of Earth Sciences 38:1093-1106.

Murray, A. S., and Wintle, A. G.

2000 Luminescence Dating of Quartz Using an Improved Single-aliquot Regenerative-dose Protocol. Radiation Measurements 32:57-73.

Prescott, J. R., Huntley, D. J., and Hutton, J. T.

1993 Estimation of Equivalent Dose in Thermoluminescence Dating - the Australian Slide Method. Ancient TL 11:1-5.

Prescott, J. R., and Hutton, J. T.

1988 Cosmic Ray and Gamma Ray Dose Dosimetry for TL and ESR. Nuclear Tracks and Radiation Measurements $14: 223-235$.

Roberts, H. M., and Wintle, A. G.

2001 Equivalent Dose Determinations for Polymineralic Fine-grains Using the SAR Protocol: Application to a Holocene Sequence of the Chinese Loess Plateau. Quaternary Science Reviews 20:859-863.

For a general review of luminescence dating by the director of this laboratory, see:

Feathers, J. K.

2003 Use of Luminescence Dating in Archaeology. Measurement Science and Technology 14:1493-1509 


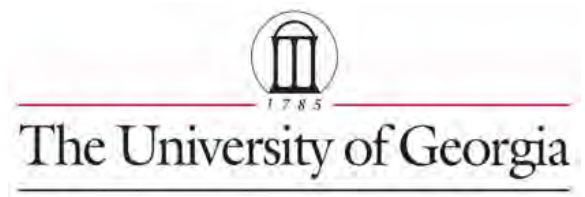

Center for Applied Isotope Studies

\section{RADIOCARBON ANALYSIS REPORT}

May 8, 2009

Dr. Jim Abbott

Environmental Affairs Division

Texas Dept. of Transportation

125 E. $11^{\text {th }} \mathrm{St}$

Austin, TX 78701

Dear Dr. Abbott

Enclosed please find the results of ${ }^{14} \mathrm{C}$ Radiocarbon AMS analyses and Stable Isotope Ratio $\delta^{13} \mathrm{C}$ analyses for the samples received by our laboratory on April 10, 2009

\begin{tabular}{|c|c|c|c|c|c|}
\hline UGAMS\# & Sample ID & Material & $\delta^{13} \mathbf{C}, \%$ o & ${ }^{14} \mathbf{C}$ age, years BP & $\mathbf{\pm}$ \\
\hline 4352 & 41KM69-52-1-2A & Ceramic sherd & -22.0 & 1020 & 25 \\
\hline 4353 & 41KM69-52-1-3A & Ceramic sherd & -21.1 & 790 & 30 \\
\hline 4354 & $41 \mathrm{KM} 69-66-0-11 \mathrm{~A}$ & Ceramic sherd & -23.3 & $\mathrm{n} / \mathrm{a}$ & \\
\hline 4355 & 41KM69-86-0-2A & Ceramic sherd & -21.9 & 830 & 30 \\
\hline 4356 & 41KM69-86-0-3A & Ceramic sherd & -25.4 & $\mathrm{n} / \mathrm{a}$ & \\
\hline 4357 & 41KM69-66-0-2A & Ceramic sherd & -21.3 & 900 & 40 \\
\hline
\end{tabular}

$\mathrm{n} / \mathrm{a}$ - insufficient sample for dating

The pottery sherd was carefully cleaned with organic solvents. The soot from the pottery was scratched and treated with $5 \% \mathrm{HCl}$ at the temperature $80^{\circ} \mathrm{C}$ for 1 hour, then it were washed and with deionized water on the fiberglass filter and rinsed with diluted $\mathrm{NaOH}$ to remove possible contamination by humic acids. After that the sample was treated with diluted HCL again, washed with deionized water and dried at $60^{\circ} \mathrm{C}$. The cleaned sample was combusted at $900^{\circ} \mathrm{C}$ in evacuated/sealed quartz ampoule in the present $\mathrm{CuO}$.

The resulting carbon dioxide was cryogenically purified from the other reaction products and catalytically converted to graphite using the method of Vogel et al. (1984) Nuclear Instruments and Methods in Physics Research B5, 289-293. Graphite ${ }^{14} \mathrm{C} /{ }^{13} \mathrm{C}$ ratios were measured using the CAIS $0.5 \mathrm{MeV}$ accelerator mass spectrometer. The sample ratios were compared to the ratio measured from the Oxalic Acid I (NBS SRM 4990). The sample ${ }^{13} \mathrm{C} /{ }^{12} \mathrm{C}$ ratios were measured separately using a stable isotope ratio mass spectrometer and expressed as $\delta^{13} \mathrm{C}$ with respect to $\mathrm{PDB}$, with an error of less than $0.1 \%$. 
The quoted uncalibrated dates have been given in radiocarbon years before 1950 (years $\mathrm{BP})$, using the ${ }^{14} \mathrm{C}$ half-life of 5568 years. The error is quoted as one standard deviation and reflects both statistical and experimental errors. The date has been corrected for isotope fractionation.

If the dates are to be published, please quote the UGAMS numbers, as it identifies our laboratory as having produced the dates.

If we can be of further assistance, or you wish to discuss these results, please do not hesitate to contact me.

Sincerely,

Dr.Alexander Cherkinsky 


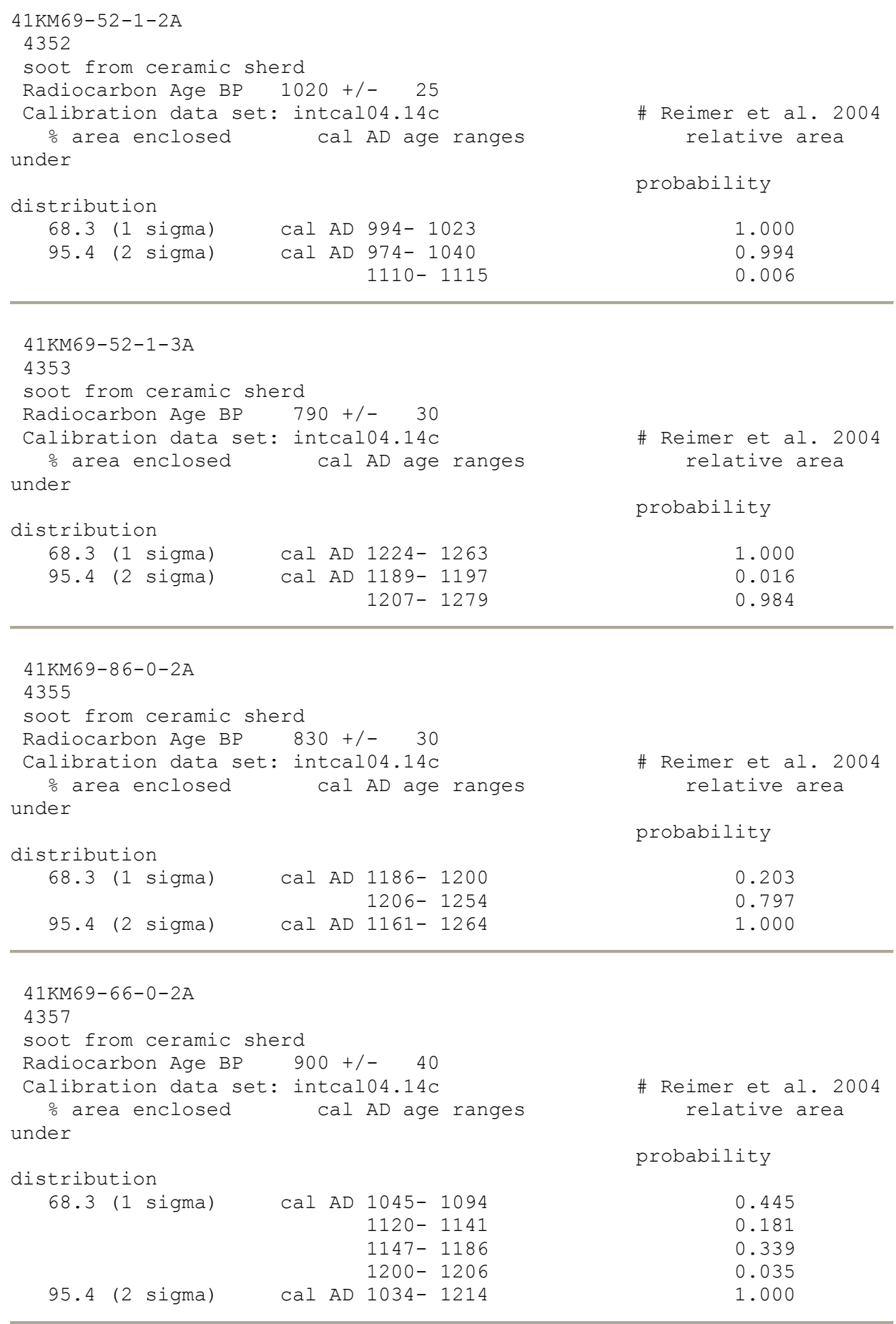


References for calibration datasets:

PJ Reimer, MGL Baillie, E Bard, A Bayliss, JW Beck, C Bertrand, PG Blackwell,

CE Buck, G Burr, KB Cutler, PE Damon, RL Edwards, RG Fairbanks, M Friedrich,

TP Guilderson, KA Hughen, B Kromer, FG McCormac, S Manning, C Bronk Ramsey,

RW Reimer, S Remmele, JR Southon, M Stuiver, S Talamo, FW Taylor,

J van der Plicht, and CE Weyhenmeyer (2004), Radiocarbon 46:10291058 .

Comments:

* This standard deviation (error) includes a lab error multiplier.

$\star \star 1$ sigma $=$ square root of (

$\star \star 2$ sigma $=2 \times$ square root of (sample std. dev.^2 + curve std. dev.^2)

where $\wedge 2$ = quantity squared.

[ ] = calibrated range impinges on end of calibration data set

0 * represents a "negative" age $\mathrm{BP}$

1955* or 1960* denote influence of nuclear testing C-14

NOTE: Cal ages and ranges are rounded to the nearest year which may be too precise in many instances. Users are advised to round results to the nearest 10 yr for samples with standard deviation in the radiocarbon age greater than 50 yr. 


\section{Appendix H:}

Stable Isotope Analyses of Soil Samples: $\delta^{13} \mathrm{C}$ of Soil Organic Matter, $\delta^{13} \mathrm{C}$ and $\delta^{18} \mathrm{O}$ of Soil Carbonate

Debajyoti Paul and Grzegorz Skrzypek 



\title{
Appendix H
}

\section{Stable Isotope Analyses of Soil Samples: $\delta^{13} \mathrm{C}$ of Soil Organic Matter, $\delta^{13} \mathrm{C}$ and $\delta^{18} \mathrm{O}$ of Soil Carbonate}

\author{
Debajyoti Paul and Grzegorz Skrzypek \\ Department of Earth and Environmental Science \\ University of Texas at San Antonio
}

\section{Introduction}

Consistent with the research design for the analysis of excavated material from 41KM69 (Thompson et al. 2007), a series of sediment samples, collected from a profile on the site and spanning depths from the surface down to $115 \mathrm{cmbs}$, were analyzed for shifts in stable isotopes that may be indicative of local vegetation shifts. The analysis was conducted at the Laboratory for Stable Isotope Geochemistry in the Department of Earth and Environmental Science at the University of Texas at San Antonio. Two samples (FS 1889, 1890) were collected from the upper portion of the profile, and organic matter in these samples should reflect modern vegetation on the site. Eleven samples were collected from between 60 and $115 \mathrm{cmbs}$, at $5 \mathrm{~cm}$ intervals. A buried paleosol is present at the site, starting at approximately $120 \mathrm{cmbs}$. The paleosol has been radiocarbon dated to $2340-2120$ B.P. (Thompson et al. 2007: 67) based on a sample extracted from near the base of Backhoe Trench 5 in the west-central part of the site. Of the eleven samples, the upper seven were extracted from above the paleosol in the sampling locality. Sample 8 is described as representing a transition zone at the top of the paleosol and the three deepest samples are derived from within the paleosol. The column samples were extracted from a profile located between Area 3 and Backhoe Trench 5 and were pulled during the gradall stripping of the unexcavated portions of the site. The location of the two samples obtained from near the surface was just south of Area 4, at the southeastern end of the site.

We had originally planned to use additional samples collected for pollen analysis to fill the gap between $60 \mathrm{cmbs}$ and $10 \mathrm{cmbs}$, as well as depths below $115 \mathrm{cmbs}$. However, these samples were treated in the field with alcohol to retard mold growth that can destroy pollen grains. The addition of alcohol could potentially result in ambiguous isotopic results, and these samples were not processed. Nevertheless, the samples that were processed provide information on shifts in the vegetation community on site over the last 2000 years. Based on regional data (see Thompson et al. 2007), we would expect that if local conditions follow the regional trends, then an increase in the contribution of $\mathrm{C}_{3}$ plants should be present over this 2000 year time frame.

\section{Analytical Procedure}

All carbon $\left(\delta^{13} \mathrm{C}\right)$ and oxygen $\left(\delta^{18} \mathrm{O}\right)$ isotopic composition of samples in this report are presented in the standard $\delta$-notation in the VPDB (Vienna PeeDee Belemnite) scale. The $\delta$ value is defined as the relative difference, in parts per thousand (\%o), between the isotope ratio of the sample and international standards (established by International Atomic Energy Authority, IAEA, Vienna). For example, $\delta^{13} \mathrm{C}$ is defined as:

$$
\delta^{13} C_{V P D B}(\text { sample })=\left(\frac{\left({ }^{13} C / / 12 C\right)_{\text {sample }}}{\left({ }^{13} C /{ }^{12} C\right)_{\text {standard }, V P D B}}-1\right) \times 10^{3} \%
$$


The organic matter from soil and inorganic soil-carbonate were analyzed for carbon and oxygen isotopic compositions by following the procedures described below. All analyses were performed using the continuous-flow isotope ratio mass spectrometry (CF-IRMS) facility at UTSA.

\section{GasBench II (GB)/IRMS Technique $-\delta^{13} \mathrm{C}$ and $\delta^{18} \mathrm{O}$ of Inorganic Soil-Carbonate Samples}

For soil carbonate analyses, organic matter present in soil samples were removed following the procedure described by Grosman and $\mathrm{Ku}$ (1986). Soil samples were treated with $5 \%$ sodium hypochlorite, followed by washing several times with DI water. Samples were dried, finely powdered, weighed $(\sim 200-400 \mu \mathrm{g})$ into $10 \mathrm{~mL}$ glass vials sealed with butyl rubber septa and loaded into the Gasbench (GB) II sample preparation device. After flushing the vials for 700 seconds with high purity He (in order to remove air from vials), samples were reacted with about $0.2 \mathrm{~mL}$ of $100 \%$ ortho-phosphoric acid at $72^{\circ} \mathrm{C}\left(1 \mathrm{hr}\right.$.). The sample $\mathrm{CO}_{2}$ gas produced from carbonate-acid reaction gas passes through a GasBench system (Gas Chromatograph, an Active Open-Split, and finally through a capillary) into the ionization chamber of the IRMS. During each analysis, reference $\mathrm{CO}_{2}$ gas is injected three times followed by 10 injections of sample gas. The raw $\delta^{13} \mathrm{C}$ of ten individual sample peaks are calculated with respect to the $\delta$-value of the second reference gas injection, and the average and standard deviation (internal error) of these 10 measurements are reported. Details of this procedure are reported by Paul and Skrzypek (2006).

\section{Elemental Analyzer (EA)/IRMS Technique $-\delta^{13} \mathrm{C}$ of Organic Matter}

Prior to isotope analyses using the Elemental Analyzer (EA) sample preparation device, soil samples where treated using $4 \% \mathrm{HCl}$ to remove the inorganic carbonates, and then washed multiple times in DI water to remove the chloride ions (Boutton 1991). In the EA/IRMS technique, the sample is instantaneously melted and cracked by thermal treatment, oxidized (in the presence of $\left.\mathrm{O}_{2}\right)$, and converted into homogenous combustion gases $\left(\mathrm{CO}_{2}, \mathrm{~N}_{2}\right.$, and $\left.\mathrm{H}_{2} \mathrm{O}\right)$ in amounts stoichiometrically equivalent to its elemental components in the sample (Pella 1990). In this study we used a CHNS Elemental Analyzer, which is coupled to the DeltaPlus XP IRMS via the Universal Elemental Analyzer Interface (Finnigan ConFlo III) for online carbon and nitrogen isotope ratio analyses. The EA analytical circuit comprises of a combustion reactor $\left(\mathrm{Cr}_{2} \mathrm{O}_{3}\right.$ catalyst $+\mathrm{Co}_{3} \mathrm{O}_{4} \operatorname{coated}$ with silver), a reduction reactor (copper reduced wire) and a GC column.

About 1000-2000 $\mu \mathrm{g}$ of soil samples were weighed into tin ( $\mathrm{Sn}$ ) capsules and placed in the Zero Blank Autosampler, followed by purging with helium for $5 \mathrm{~min}$. The $\mathrm{Sn}$ capsules were dropped into the combustion reactor (maintained at $1020^{\circ} \mathrm{C}$ ) about 1-2 seconds after the arrival of oxygen to ensure that enough oxygen is available for complete combustion. The oxidation of tin (exothermic reaction) accelerates the breakdown and combustion of sample by increasing the reaction temperature from $1020^{\circ} \mathrm{C}$ to $1700-1800^{\circ} \mathrm{C}$; as a result a mixture of combustion gases $\left(\mathrm{CO}_{2}, \mathrm{~N}_{2}\right.$, and $\left.\mathrm{H}_{2} \mathrm{O}\right)$ is produced. The gas mixture (in a stream of $\mathrm{He}$ ) then passes through the reduction reactor (maintained at $650{ }^{\circ} \mathrm{C}$ ), where copper wires scavenge any excess oxygen not used during combustion. A water removal trap filled with anhydrous magnesium perchlorate $\left[\mathrm{Mg}\left(\mathrm{ClO}_{4}\right)_{2}\right]$ removes $\mathrm{H}_{2} \mathrm{O}$ present in the mixture. Finally, the mixture passes through the $3 \mathrm{~m}$ long GC column (maintained at $55^{\circ} \mathrm{C}$ ), where $\mathrm{CO}_{2}$ is separated from other gases and carried to the Conflo III interface. Skrzypek and Paul (2007) give details of this procedure.

\section{Normalization of Raw Isotope data using international standards}

Using a "multiple-point" normalization technique (Paul et al. 2007, Coplen et al., 2006), where the linear relationship between the measured and true isotopic composition of two or more international reference standards were used to convert the measured $\delta$-value of samples to true $\delta$-value in the isotope reference scale. For normalization, the following IAEA reference standards were used specific to the isotope of interest: IAEA600, NBS22 and USGS24 for $\delta^{13} \mathrm{C}$ of organic matter and NBS19, NBS18 and LSVEC for $\delta^{13} \mathrm{C}$ and $\delta^{18} \mathrm{O}$ of carbonates. During each set of unknown sample analyses international references standards are analyzed several times along with an interlaboratory calibration standard (for quality control). Based on the long term measurements of international reference standards and internal calibration standards, we assign external precision ( $1 \sigma$ standard deviation) of $0.10 \%$ for $\delta^{13} \mathrm{C}$ for EA analyses, and $0.10 \%$ for $\delta^{13} \mathrm{C}$ and $\delta^{18} \mathrm{O}$ of carbonates. 


\section{Results and Discussion}

The stable isotopic composition of total inorganic carbon $\left(\delta^{13} \mathrm{C}\right)$ in the soil profile varies in the range from -2.15 to $-4.63 \%$ (mean $-3.66 \%$ ). The stable isotopic composition of oxygen $\left(\delta^{18} \mathrm{O}\right)$ varies in much more narrow range than $\delta^{13} \mathrm{C}$, from -3.22 to $-3.92 \% 0(-3.63 \%)$. These values represent the total inorganic carbon that was deposited in soil profile from two major sources: erosion and deposition of carbonates rock, which are common in the surrounding area, and direct precipitation in the soil (so called carbonate paleosoils). In the first case, the isotopic composition simply reflects the isotopic composition of eroded rock material. In the second case, the isotopic composition can be used as a possible carbonate paleothermometer, because the isotopic fractionation during the precipitation depends on the temperature of solution which is related to air temperature. To distinguish which type of carbonate materials is represented in this particular soil profile, additional mineralogical studies are required. A weak correlation $\left(\mathrm{R}^{2}=0.42\right)$ between $\mathrm{CaCO}_{3}$ concentration and $\delta^{13} \mathrm{C}$ (inorganic) in the profile is also observed (the maxima and minima are in general coherent). The correlation between the concentration and the isotopic composition may suggest two common mechanisms: mixing of materials from two sources (with two difference isotopic composition) or fractionation during decomposition/dissolutions.

The stable isotopic composition of the total soil organic carbon varies in the relatively wide range, from -25.61 to $-22.83 \%$ o (mean $-23.59 \%$, Table H-1). Two modern samples from the upper part of profile (depth 3.5 and $7.5 \mathrm{~cm}$ ) have significantly more negative value than the older samples (-25.61 and $-24.70 \%$ ). The carbon isotopic composition of soil depends on several factors, the most important of which are 1) the original isotopic composition of plant material, 2) the type and degree of decomposition of organic matter in soil and 3) contamination of soil by other non-in situ carbon (human pollution, long-distance transport etc.). Assuming that the study area is unpolluted and the decomposition of the organic matter is similar in the profile and very high (which the extremely low organic nitrogen confirms, with contents below the analytical detections level), the $\delta^{13} \mathrm{C}$ variation may have resulted from vegetation changes, or changes in the general environmental parameters (e.g., temperature, humidity etc.).

Table H-1. The Carbon and Oxygen Stable Isotopic Composition of Total Soil Carbonates and the Carbon Stable Isotopic Composition of Total Organic Matter

\begin{tabular}{|c|c|c|c|c|c|}
\hline \multirow{2}{*}{ Depth [cm] } & \multirow{2}{*}{ Name } & \multicolumn{3}{|c|}{ Soil CaCO } & Soil organic matter \\
\cline { 3 - 6 } & & $\mathbf{d}^{\mathbf{1 3}} \mathbf{C}[\% \mathbf{\% P D B}]$ & $\mathbf{d}^{\mathbf{1 8}} \mathbf{O}$ [\%o VPDB] & CaCO $_{\mathbf{3}}$ \% & $\mathbf{d}^{\mathbf{1 3}}$ C [\%o VPDB] \\
\hline 3.5 & FS1889 & -4.46 & -3.55 & 40 & -25.61 \\
\hline 7.5 & FS1890 & -4.63 & -3.89 & 46 & -24.7 \\
\hline 62.5 & FS1878 & -2.15 & -3.74 & 53 & -23.57 \\
\hline 67.5 & FS1879 & -2.91 & -3.44 & 58 & -23.08 \\
\hline 72.5 & FS1880 & -3.09 & -3.92 & 49 & -23.68 \\
\hline 77.5 & FS1881 & -4.24 & -3.52 & 42 & -23.47 \\
\hline 82.5 & FS1882 & -3.56 & -3.66 & 50 & -23.24 \\
\hline 87.5 & FS1883 & -3.84 & -3.65 & 40 & -23.82 \\
\hline 92.5 & FS1884 & -4.13 & -3.53 & 40 & -23.4 \\
\hline 97.5 & FS1885 & -4.05 & -3.79 & 46 & -23.24 \\
\hline 102.5 & FS1886 & -3.92 & -3.52 & 53 & -23.13 \\
\hline 107.5 & FS1887 & -3.86 & -3.73 & 55 & -22.95 \\
\hline 112.5 & FS1888 & -2.78 & -3.22 & 53 & -22.83 \\
\hline & aver & $\mathbf{- 3 . 6 6}$ & $\mathbf{- 3 . 6 3}$ & $\mathbf{4 8}$ & $\mathbf{- 2 3 . 5 9}$ \\
\hline & stdev & $\mathbf{0 . 7 3}$ & $\mathbf{0 . 1 9}$ & $\mathbf{6}$ & $\mathbf{0 . 7 7}$ \\
\hline & min & $\mathbf{- 4 . 6 3}$ & $\mathbf{- 3 . 9 2}$ & $\mathbf{4 0}$ & $\mathbf{- 2 5 . 6 1}$ \\
\hline & max & $\mathbf{- 2 . 1 5}$ & $\mathbf{- 3 . 2 2}$ & $\mathbf{5 8}$ & $\mathbf{- 2 2 . 8 3}$ \\
\hline
\end{tabular}

Depth - represents the depth of the middle of samples horizon, an average of $5 \mathrm{~cm}$ thick samples 
The carbon isotopic composition of plant tissue depends in a very limited range on the $\delta^{13} \mathrm{C}$ value of assimilated atmospheric $\mathrm{CO}_{2}$ (which is usually -6 to $-8 \%$ ). The most important is the effect of atmospheric $\mathrm{CO}_{2}$ - plant tissue isotope fractionation (e.g., O'Leary et al., 1986; Farquhar et al., 1989). Plant growth results in an $18-27 \%\left(\mathrm{C}_{3}\right.$ plants $)$ and $4-6 \% 0\left(\mathrm{C}_{4} \text { plants }\right)^{12} \mathrm{C}$-enrichment in the plant tissue with respect to atmospheric $\mathrm{CO}_{2}\left(\mathrm{O}^{\prime}\right.$ Leary, 1986; Lajtha and Marshal, 1994). Therefore, the $\delta^{13} \mathrm{C}$ of $\mathrm{C}_{4}$ and $\mathrm{C}_{3}$ plants are significantly different, with $C_{4}$ plants ranging from -9 to $-17 \%$ (mean $-13 \%$ ) and $C_{3}$ plants producing isotopic values of between -20 to $-35 \%$ (mean $-27 \%$ ). One more category of plant with specific photosynthesis pathways (CAM) is common in the southern states, and especially in south Texas. Plants using the CAM or Calvin and Hatch-Slack pathways produce ranges between the $\mathrm{C}_{4}$ and $\mathrm{C}_{3}$ signatures. For example, cacti use both pathways (Calvin and Hatch-Slack), to give a range of $\delta^{13} \mathrm{C}$ between -15 and $-30 \%$.

The $\delta^{13} \mathrm{C}$ value of soil organic matter from the analyzed samples at $41 \mathrm{KM} 69$ varies in the range characteristic for $\mathrm{C}_{3}$ plants, and a negative trend is observed with depth in the profile (Figure $\mathrm{H}-1$ ). The $\delta^{13} \mathrm{C}$ values progressively increase with depth and reach a maximum $(-22.83 \%)$ at the bottom of profile $(112.5 \mathrm{~cm})$. This relation is relatively strong, with an $\mathrm{R}_{2}$ of 0.83 . Such a trend can be caused by an increase of $\mathrm{C}_{3} / \mathrm{C}_{4}$ plants ratio in this area. Overall, the values are consistent with $\mathrm{C}_{3}$ plants dominating the local landscape, with increased contributions of $\mathrm{C}_{3}$ plants, or a shift in the types of $\mathrm{C}_{3}$ plants, near the surface.

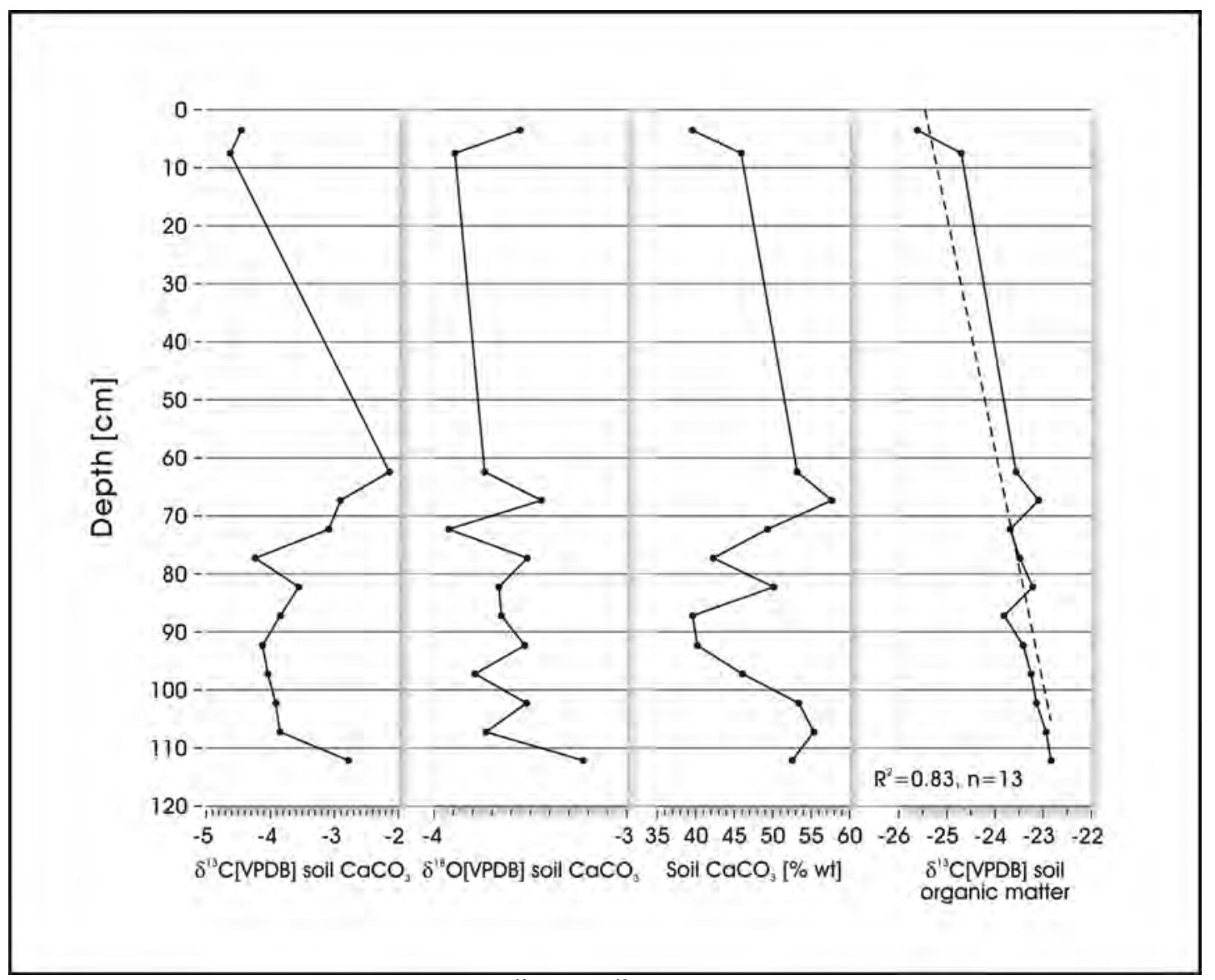

Figure $\mathrm{H}-1$. The stable isotope composition $\delta^{13} \mathrm{C}$ and $\delta^{18} \mathrm{O}$ and concentration of $\mathrm{CaCO}(\%$ wt) and carbon isotope composition of total organic matter $\delta^{13} \mathrm{C}$. 


\section{References Cited:}

Boutton TW,

1991 Stable isotope ratios of natural materials: I sample preparation and mass spectrometric analysis. In: Coleman DC, Fry B (eds) Carbon Isotope Techniques: 155-171.

Coplen, T.B., Brand W.A., Gehre, M., Groning, M., Meijer, H.A.J., Toman, B., Verkouteren, R.M., 2006 New Guidelines for $\delta^{13}$ Cmeasurements. Analytical Chemistry 78: 2439-2441.

Farquhar, G.D., Ehleringer, J.R., Hubic, K.T.

1989 Carbon isotope discrimination and photosynthesis. Annual Review of Plant Physiology and Plant Molecular Biology 40: 503-537.

Grosman EL, Ku T,

1986 Oxygen and carbon isotope fractionation in biogenic aragonite: Temperature effects. Chemical Geology 59: 59-74

Lajtha, K., Marshal, J.D.

1994 Sources of variation in the stable isotopic composition of plants. In: Lajtha, K., Michener, R.H. (Eds.), Stable Isotopes in Ecology and Environmental Sciences. Blackwell Scientific Publication, Oxford, pp. 1-21.

O'Leary, M.H., Treichel, I., Rooney, M.

1986 Short-term measurement of carbon isotope fractionation in plants. Plant Physiology 80: 578-582.

Paul, D., and Skrzypek, G., 2006 Rapid Commun. Mass Spectrom 20:1

Paul D., Skrzypek G.

2007 Assessment of Carbonate-Phosphoric Acid Analytical Technique Performed using GasBench II In Continuous Flow Isotope Ratio Mass Spectrometry, International Journal of Mass Spectrometry 262: 180-186

Paul D., Skrzypek G., Forizs I,

2007 Normalization of measured stable isotope composition to isotope reference scale -a review, Rapid Commun. Mass Spectrom 21: 3006-3014.

Pella, E. 1990 Am. Lab. 22:116

Skrzypek G., Kałużny A., Wojtuń B, Jędrysek M.O.

2007 The carbon stable isotopic composition of mosses - the record of temperature variations Organic Geochemistry (in press DOI: 10.1016/j.orggeochem.2007.05.002)

Thompson, J., R. Mauldin, and S. Tomka

2007 A Research Design for the Analysis of Data Recovered at 41KM69, Kimble County, Texas. Report of file at the Center for Archaeological Research, University of Texas at San Antonio, San Antonio, Texas. 



\section{Appendix I:}

Pollen and Phytolith Extraction from

Archeological Sediments in Area 1 of Site 41KM69,

Kimble County, Texas

Vaughn M. Bryant 



\title{
Appendix I
}

\section{Pollen and Phytolith Extraction from Archeological Sediments in Area 1 of Site 41 KM69, Kimble County, Texas}

\author{
Vaughn M. Bryant \\ (vbryant@neo.tamu.edu) \\ Palynology Laboratory \\ Texas A\&M University \\ College Station, Texas 77843-4352
}

August 2005

\section{Sample Data Base}

The current study focuses on four pollen and phytolith samples from one column in Area I of an archaeological site located in Kimble County, Texas. The pollen samples examined in this study are listed in Table I-1.

Table I-1. Soil Samples Collected from Site 41KM69 for Pollen and Phytolith Studies

\begin{tabular}{|c|c|c|c|}
\hline Sample Number & Sample Provenience & \multicolumn{2}{|c|}{ Weight of Sample Processed } \\
\hline & & Pollen (grams) & Phytolith (grams) \\
\hline 1 & FS-1845: two vials of soil & 20 & 15 \\
\hline 2 & FS-1837: two vials of soil & 20 & 15 \\
\hline 3 & FS-1835: two vials of soil & 20 & 15 \\
\hline 4 & FS-1833: two vials of soil & 20 & 15 \\
\hline
\end{tabular}

\section{Pollen and Phytolith Extraction}

There are a number of articles, chapters, and even books on methods that one can use to successfully extract fossil pollen from various types of sediments (Hunt, 1985; Riding and Kyffin-Hughes, 2004), including some articles that focus specifically on techniques used for archaeological sediments (Bryant, 1988; Bryant and Holloway, 1983; Coil et al., 2003).

Pollen extraction is a critical part of any project because the use of certain acids and methods can lead to the loss of fossil pollen, while other methods may not remove enough of the detritus to permit accurate identification of the fossil pollen in the remaining residue. For these reasons, it is essential that reports, such as this, include the precise methods used during the extraction procedure so that the reader can be assured that pollen recovery was maximized and that fossil pollen was not inadvertently destroyed or lost during processing.

Facilities: All work for this project was conducted using sterile, surgical gloves in the sealed Texas A\&M Palynology Laboratory under a fume hood. In addition, glycerin-coated slides are left exposed in various locations within the lab and they are checked weekly for any signs of outside pollen contamination. None were noted during processing or after this project was completed. Thus, I am certain that none of the pollen I found came from contamination in our facility.

Pollen Extraction Procedures: The extraction procedure I used for these samples consisted of the following steps.

1. From each sample, I removed 20 grams of soil and placed it into a $600 \mathrm{ml}$ plastic beaker. Next, I added $50 \mathrm{ml}$ of concentrated hydrochloric acid ( $\mathrm{HCl})$, to dissolve calcium carbonates in the soil, and two Lycopodium tablets each of which contained 13,500 
tracer spores. I used two tablets because the vast majority of pollen samples I have examined from the arid regions of Texas and the American Southwest suggest that pollen counts rarely exceed 54,000 pollen grains per gram of soil. Thus the ratio of tracer spores to fossil pollen in each gram of soil is rarely greater than a ratio of 1:2.

The use of tracer spores in pollen samples has been extensively studied by Louis Maher (1981) and others. He noted that the number of tracer spores added to samples should be in a ratio of between 1:1 and 1:2 (tracer spores vs. fossil pollen) to achieve statistically accurate calculations of fossil pollen concentrations per gram or milliliter of sediment. I use Lycopodium spores as a tracer in most sediment from sites in the temperate and arid regions of the United States because it is extremely rare to find naturally occurring Lycopodium plants growing in these regions. Therefore, the only potential source of these spores in the samples I examined is most probably the tablets that were added.

2. After all reaction with the $\mathrm{HCl}$ had stopped, I filled the beaker with distilled water and allowed the beaker to stand for four hours. After that, the liquid portion was carefully poured off. Pollen will remain suspended in water for various periods of time, but after four hours fossil pollen will settle to the bottom of a container and thus the liquid portion can be poured off without loss of fossil pollen (Lentfer et al., 2003). The remaining sediment in the beaker was spun down using $50 \mathrm{ml}$ centrifuge tubes (CT) in a centrifuge and the liquid was then poured off. This process was repeated twice.

3. I then added $15 \mathrm{ml}$ of concentrated hydrofluoric acid (HF) (56\%) to the sediment in the CT, stirred the sample, and let it sit overnight in the fume hood. I might caution others that this is very dangerous and that the HF must be added very slowly at the rate of only 1-2 $\mathrm{ml}$ at a time. The sample must then be thoroughly stirred and allowed to sit for one minute before adding more HF. Some sediment, especially those containing fine-grained clays and mica, will react violently to the HF once the sediment reaches a high temperature caused by the rapid dissolving of some of the fine-grained silicates. After HF is added, it will slowly heat the sediment as it begins to react with the silicates. If one adds too much HF at first, once it heats to a certain temperature, the HF will "explode" out of the top of the CT and hot HF will cover everything in the fume hood. This will not only "ruin" the original sample, but can contaminate other samples under the fume hood and will deposit the HF on all the counter surfaces, which must then be neutralized with sodium bicarbonate $\left(\mathrm{NaHCO}_{3}\right)$. Worst of all, if the processor is standing in front of the fume hood when this occurs; he will also be peppered with HF, which can cause permanent injury and even death to the individual.

The HF process removes most of the fine-grained silicates from the sample and does not damage the pollen. The next day I filled the CT with distilled water, spun it down, rinsed it twice with distilled water, and then filled the CT with concentrated $\mathrm{HCl}$. This $\mathrm{HCl}$ step is necessary to ensure removal of fluorosilicates in the sample, which often form as a result of the HF treatment. After two or three $\mathrm{HCl}$ rinses, the samples were rinsed again in distilled water twice.

4. Next I transferred the material in each sample to a $15 \mathrm{ml} \mathrm{CT}$ and then added $10 \mathrm{ml}$ of $5 \%$ potassium hydroxide $(\mathrm{KOH})$ and heated them for 10 minutes at $180^{\circ} \mathrm{F}$. This was followed by two washes in distilled water.

5. Next, I added $10 \mathrm{ml}$ of concentrated $\mathrm{HCl}$ and heated each sample for one minute. I then spun down the sample, poured out the liquid and again rinsed the sample twice in distilled water. This $\mathrm{HCl}$ step is essential to remove any remaining humic acids and dissolved compounds that might be present in each sample after the $\mathrm{KOH}$ treatment, but are not removed during repeated water washings.

6. Each sample was then rinsed in glacial acetic acid, centrifuged, and then the glacial acetic acid was carefully poured off.

7. Next, I added $10 \mathrm{ml}$ of a mixture of 1 part sulfuric acid to 9 parts acetic anhydride. This is known as the acetolysis process (Erdtman, 1960). After heating each sample in a heating block at $180^{\circ} \mathrm{F}$ for 10 minutes, I centrifuged the solution and then poured off the liquid.

8. I then rinsed each sample in glacial acetic acid and after centrifuging, I poured off the glacial acetic acid.

9. Next, the samples were rinsed twice in distilled water.

10. The next step was to fill each CT one-half full of zinc bromide $\left(\mathrm{ZnBr}_{2}\right)$, which has a specific gravity of 2.0. That solution was thoroughly mixed with a wooden stick in the sample for 60 seconds as it was being spun on a vortex stirrer to ensure 
complete mixing of all solid material in the CT. I then let the samples sit for 5 minutes. After that I spun the samples at 500 RPMs for 5 minutes. When that was completed, I very carefully used a pipette to remove the upper part of the $\mathrm{ZnBr}_{2}$, which contained all of the pollen and tracer spores. I then checked the material that was at the bottom of each CT to ensure that no pollen was lost. None was lost. The $\mathrm{ZnBr}_{2}$ solution containing the pollen was placed into a $100 \mathrm{ml}$ beaker and $80 \mathrm{ml}$ of $95 \%$ ethanol $(\mathrm{ETOH})$ was added to reduce the specific gravity and permit the pollen to sink during centrifuging (Jones and Bryant, 2001). All of the solution in each sample was carefully spun down in $12 \mathrm{ml} \mathrm{CT}$ during 8 separate centrifuging processes.

11. The final step consisted of rinsing the residue in each sample twice in ETOH, adding five drops of safranin-0 stain, then rinsing each $\mathrm{CT}$ once again in $\mathrm{ETOH}$ and centrifuging the $\mathrm{CT}$. The remaining liquid was carefully poured off and the residue at the bottom of the CT was then poured into a one dram vial. Five drops of glycerin was added to each sample and the samples were placed on a warming plate to enable the remaining ETOH to evaporate overnight.

Phytolith Extraction Procedures: The phytolith extraction procedure I used for these samples consisted of the following steps.

1. From each sample, I removed 15 grams of soil and placed it into a $600 \mathrm{ml}$ plastic beaker. Next, I added $50 \mathrm{ml}$ of concentrated hydrochloric acid $(\mathrm{HCl})$, to dissolve calcium carbonates in the soil.

2. After all reaction with the $\mathrm{HCl}$ had stopped; I filled the beaker with distilled water and allowed the beaker to stand for one hour. After that, the liquid portion was carefully poured off. Phytoliths have a specific gravity greater than 1.0 and thus tend to sink fairly quickly in a solution of water. This process was repeated twice to remove excess clay particles.

3. Next, I added concentrated Hydrogen Peroxide (34\%) to the beakers and let them sit overnight under the fume hood. Hydrogen Peroxide is a strong oxidant that will oxidize most organic compounds fairly quickly.

4. The residue in the beakers were added to $50 \mathrm{ml}$ centrifuge tubes and spun down and the residue in the tubes was then washed twice in distilled water.

5. The next step was to fill each CT one-half full of zinc bromide $\left(\mathrm{ZnBr}_{2}\right)$, which has a specific gravity of 2.34 (Piperno, 1988). That solution was thoroughly mixed with a wooden stick in the sample for 60 seconds as it was being spun on a vortex stirrer to ensure complete mixing of all solid material in the CT. I then let the samples sit for 5 minutes. After that I spun the samples at 500 RPMs for 5 minutes.

6. When this was completed, I very carefully used a pipette to remove the upper part of the $\mathrm{ZnBr}_{2}$, which contained all of the phytoliths. I then checked the material that was at the bottom of each CT to ensure that it contained mostly sand and other debris, but that there were no phytoliths lost. No phytoliths that I could recognize were lost. The $\mathrm{ZnBr}_{2}$ solution containing the phytoliths was placed into a $100 \mathrm{ml}$ beaker and $80 \mathrm{ml}$ of $95 \%$ ethanol (ETOH) was added to reduce the specific gravity and permit the phytoliths to sink during centrifuging. All of the solution in each sample was carefully spun down in $15 \mathrm{ml} \mathrm{CT}$ during 8 separate centrifuging processes.

7. The remaining residue was then placed into one-dram glass vials in water. Slides were then prepared from these residue samples.

\section{Pollen and Phytolith Identification and Analysis}

When the remaining ETOH had evaporated in each of the processed pollen samples, I carefully stirred the residue in each vial and then added additional glycerin to the samples because the remaining residue was still too thick to apply to microscope slides. The objective is to thin the remaining residue enough so that when it is placed on a slide, all of the materials will remain in a single plane thereby not obscuring pollen grains that might be either above or below other objects. I then prepared a series of individual slides for each sample using the technique explained in the paper by Jones and Bryant (1998). Failure to prepare slides carefully and properly can result in skewed data results during the examination and counting of fossil pollen, as noted in experiments conducted by Brooks and Thomas (1967). 
Pollen examination was performed using a NIKON OPTIPHOT binocular microscope at magnifications ranging from 400x1000x. Appropriate photographs of pollen and phytoliths in the samples were taken with an attached Nikon 950 COOLPIX camera. Identifications of pollen and spore types are checked against reference materials on file in the Texas A\&M Palynology Laboratory. These modern pollen reference materials include the Texas A\&M Modern Pollen Reference Collection, the Mobil Oil Modern Pollen Reference Collection, the Meredith Lieux Modern Pollen Reference Collection, and the AMOCO Modern Pollen Reference Collection.

Fossil Pollen: I scanned the prepared microscope slides from each of the four samples and found that overall the fossil pollen preservation was very poor and that there was a low concentration of fossil pollen in the each of the samples. Some of the examples of degraded pollen are shown in Figure I-1.

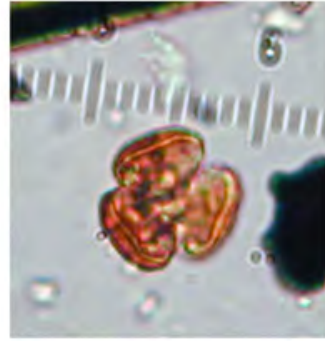

a) Artemisia

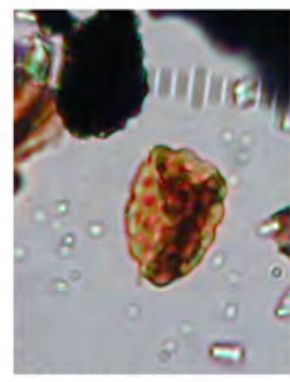

d) Cheno-Am

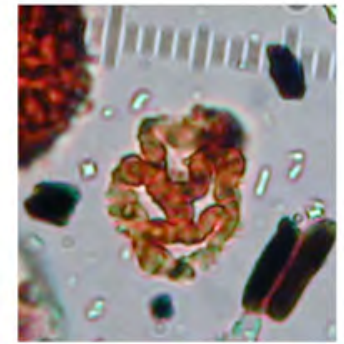

b) Dandelion type

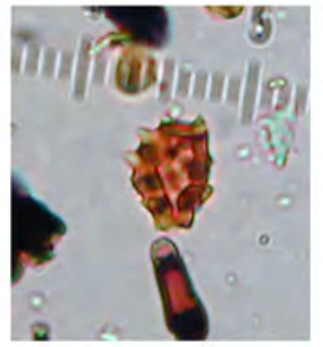

c) Asteraceae HS

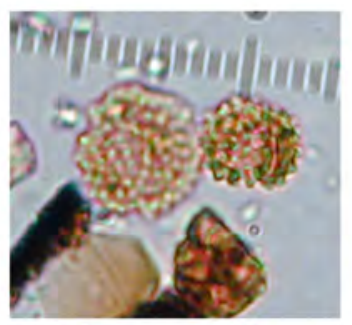

e) Asteraceae LS

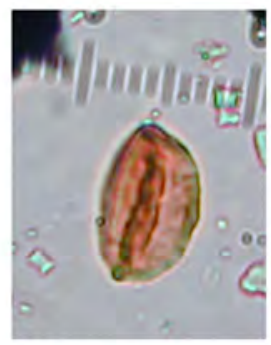

f) Unknown

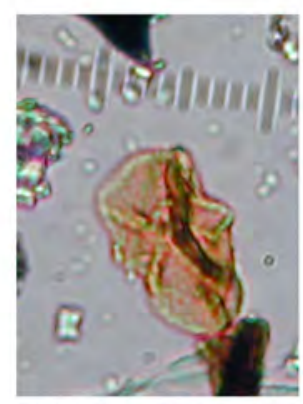

g) Unknown

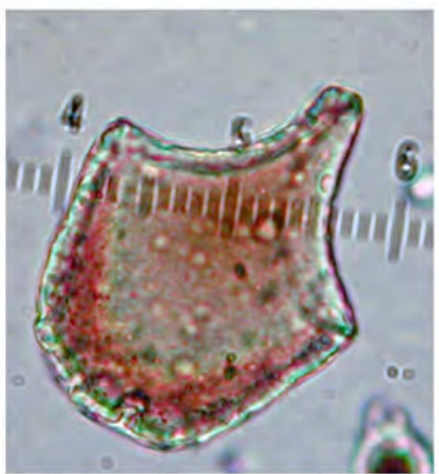

h) Phytolith

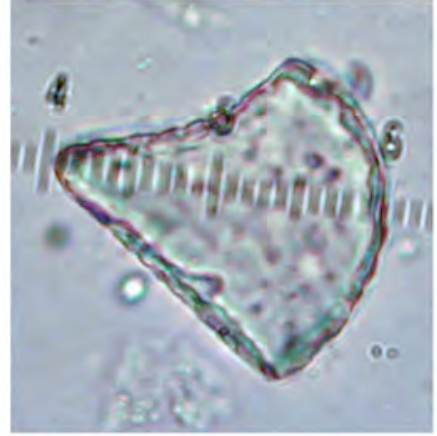

i) Phytolith

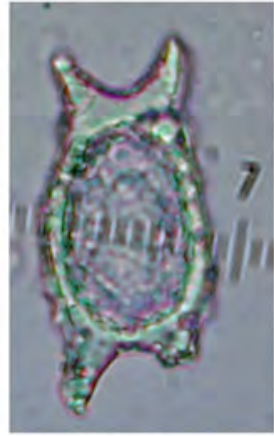

j) Phytolith

Figure I-1. Pollen and Phytoliths a) Artemisia, b) Dandelion type, c) Asteraceae HS, d) Cheno-Am, e) Asteraceae LS, f) Unknown, g) Unknown, h) Phytolith, i) Phytolith, and j) Phytolith. 
The dominant types of pollen grains that could still be recognized in these four samples included mostly types of composites, pollen from a few different grass species, and pollen in the group called Cheno-Am. These pollen types are the most common types that tend to be found in highly degraded archaeological samples (Bryant and Hall, 1993).

During analyses of samples from Texas and the arid regions of the American Southwest, most palynologists divide fossil pollen in the Asteraceae (composite) plant family into a few specific categories. Overall, the composite family contains more than 1,500 genera and more than 22,000 species that grow in almost every known habit (Mabberley, 1997). Asteraceae fossil pollen can be divided into certain categories. One primary group, which is insect-pollinated, is called the "high-spine (HS)" group because their pollen grains have a surface morphology consisting of long spines greater than 2.5 microns in length (Martin, 1963). Three other major pollen groups within the composite family include: 1) the ragweed group, which consists of windpollinated types and are called "low-spine (LS)" types); 2) another group is insect-pollinated and has pollen grains that have a fenestrate morphology and belong in the tribe Lactuceae (dandelion types); and 3) the Artemisia or wormwood group. A few of the other pollen types produced by plant genera within the composites are very distinctive and can often be identified and listed separately by a specific genus. Several of these include Centaurea (star thistle), Cirsium (thistle), and Mutisia (mutisia). For most of the 1,500 genera of composites the pollen morphology is not distinctive enough to warrant separation into specific genera without extensive keys produced at the scanning electron (SEM) or transmission electron microscope (TEM) levels.

Fossil Phytoliths: I do not profess to know the many types of phytoliths that exist. However, I have examined photographs of phytoliths in published reports and books and thus know what some of the more prominent types look like (Piperno, 1984; 1988). Overall, the phytolith preservation appeared to be minimal with many types showing what appeared to be evidence of erosion, perhaps from exposure to weak acids in the ground water. Some of the phytolith types are shown in Figures I-1 and I-2.

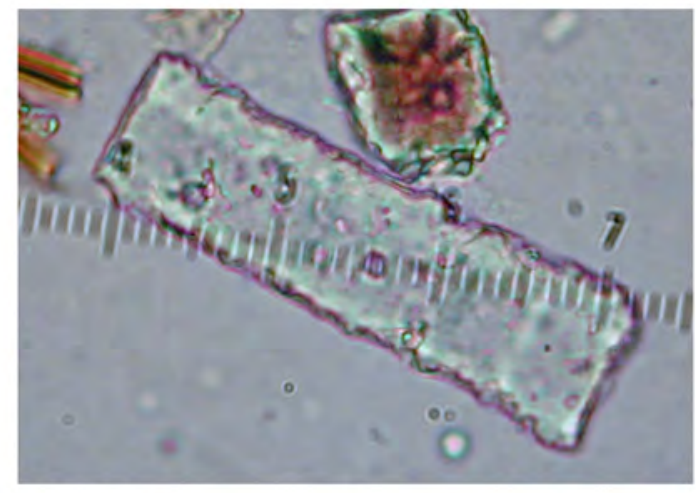

a) Phytolith

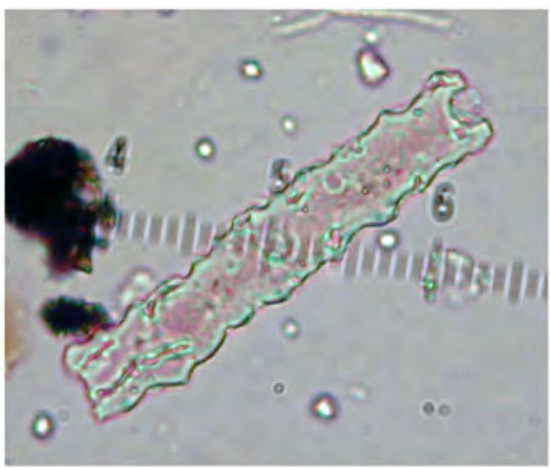

c) Phytolith

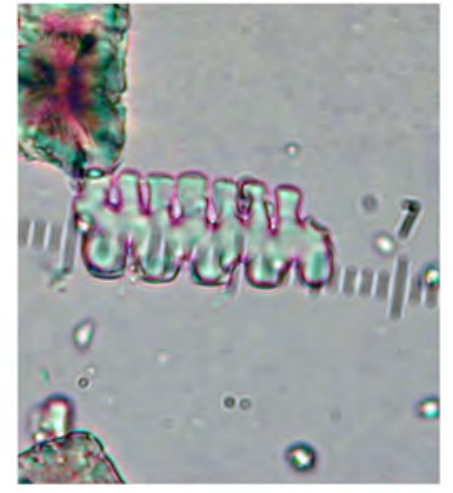

b) Phytolith

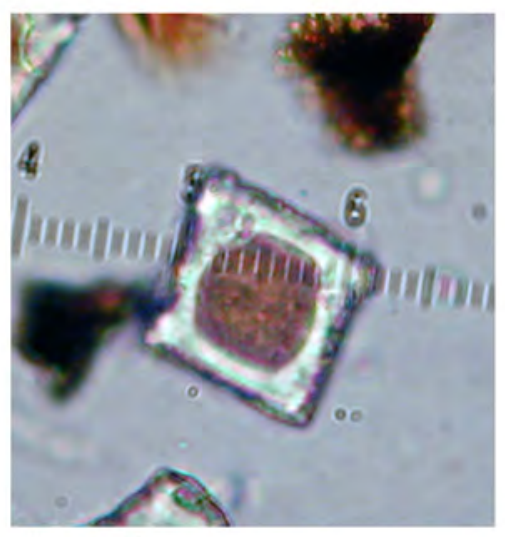

d) Phytolith

Figure I-2. Phytoliths: a) Phytolith, b) Phytolith, c) Phytolith, and d) Phytolith. 


\section{Discussion}

Pollen analyses form the data base for many types of interpretations ranging from sequential changes in past environments to information about the lifestyles and diets of prehistoric human populations. In each of these studies, the eventual interpretation of pollen data must account for all factors that may have influenced the composition of the original pollen rain, and later for the factors that may have affected and altered the composition of the buried pollen assemblage.

During the last 50 years, palynologists have learned that there are many complex factors that determine the original composition of the pollen rain in a region. These include factors such as: 1) types of pollination; 2) differences in pollen production; 3) differential dispersion patterns; and 4) the size, weight, and aerodynamic ability of pollen types to remain airborne. In addition, for some locations, pollen deposition will also be influenced by the activities of animals, birds, or humans using the site area. Once deposited, other factors influence the eventual loss or recovery of specific pollen types. These factors include: 1) pollen recycling and/or mixture due to wind, water, human, or animal interference; 2) the chemical composition of a pollen grain's wall (exine); 3) the morphological shape and surface ornamentation type of each pollen type; and 4) the susceptibility of each pollen type to various types of degradation processes including those from mechanical, chemical, or biological agents (Bryant et al., 1994; Bryant and Hall, 1993; Campbell and Campbell, 1994; Holloway, 1989; King et al., 1975; O’Rourke, 1990).

As noted by Jackson and Lyford (1999) and others, there are substantial differences among plant taxa in terms of their pollen production, methods of dispersal, and in the ability of their pollen grains to remain aloft and travel various distances from their dispersal source. These differences create an uneven distributional relationship between the amount of pollen that will fall to the ground (pollen rain) and the actual vegetational coverage of each plant taxon. Adding to this problem is the knowledge that a large number of plants produce small amounts of pollen that rarely is cast adrift into the atmosphere because the plants rely on insect or animal pollinators. These pollen types are seldom found in the normal pollen rain of a region even though the plants that produce them compose a major portion of the vegetational coverage. Finally, animals and humans gathering plants for food or for other purposes can artificially introduce additional amounts and types of pollen into the pollen spectrum of a region.

Once deposited, pollen is subjected to a host of potential factors that will determine whether or not the grains will remain preserved over time and, because not all pollen types are created equal, some types will succumb to destruction much more rapidly than will other more durable types.

One of the first agents that can affect pollen grains is mechanical degradation. After pollen is released from its source, it can become abraded or broken during the transportation phase before it falls to the ground and becomes part of the pollen rain. These alterations can result from impact or from changes in climatic conditions. Studies by Duhoux (1982), for example, have shown that changes in the level of atmospheric moisture can result in high numbers of exine ruptures in closely related, thinwalled pollen taxa such as Juniperus, and Thuja. Later, after being deposited, many of the thin-walled pollen types, as well as other pollen types, can become further abraded by various types of animal disturbances, and frequently by the cultural practices of humans that might include activities such as burning, land surface modifications, construction activities, and agricultural practices. Mechanical abrasion of pollen can also occur from various other causes in the natural environment including impact against objects, exposure to water, recycling and wind erosion, changes in temperature, changes in atmospheric or soil moisture levels, volcanic eruptions, and soil movement.

The morphological structure and ornamentation of pollen walls seem to be important factors in determining their potential susceptibility to mechanical degradation. For example, protruding structures on certain pollen grains, like the bladders of many conifer species or the spines of some composites and mallows, have a tendency to break or erode through a variety of mechanical processes. In some cases, the actual appearance of a pollen grain may become so altered after the loss of an appended structure, or structures, that accurate identification is no longer possible. In addition, structural alteration by mechanical processes can also cause severe exine weakening, thereby hastening the eventual destruction of the entire grain through other processes. An analogy would be the difference between a whole egg and one that has a hair-line crack. The whole egg is much stronger and durable than the one with even a tiny crack!

Soil chemistry, acting on the natural chemical composition of a pollen grain's exine, is another factor that often plays an important role in determining pollen preservation. Although the exine is composed mostly of cellulose and various types of proteins, 
there are interlocking strands of a highly durable material called sporopollenin. Studies by chemists and palynologists including Brooks and Shaw (1968), Shaw (1971), Rowley and Prijanto (1977), and Rowley et al. (1990) have discovered that differences in the amount of sporopollenin and differences in its specific molecular structure within the exine of a pollen grain will make specific pollen types either more, or less, resistant to various types of chemical deterioration.

One of the primary indications of potential pollen preservation in sediments can be gained by determining the soil $\mathrm{pH}$. By itself, $\mathrm{pH}$ is not entirely responsible for pollen destruction, but it is an important factor. As early as the 1950s, Dimbleby (1957) searched for causes of pollen deterioration in various types of soils. His experiments and research were the first to chart differences in pollen preservation caused by soil chemistry. His research revealed that most soils with an acidic $\mathrm{pH}$ seem to provide ideal deposits for pollen preservation. However, he noted that once soil $\mathrm{pH}$ levels reach the weakly acidic level of 6.0, significant pollen destruction can begin to occur. Dimbleby even cautioned that attempts to recover fossil pollen from soils with a $\mathrm{pH}$ greater that 6.0 would most probably result in failure. Since Dimbleby's original study, other studies by palynologists including Bryant et al. (1994), Hall (1981), and Martin (1963) have demonstrated that fossil pollen can be recovered from slightly acidic and even alkaline soils with a $\mathrm{pH}$ as high as 8.9. Nevertheless, as noted in the study by Bryant and Hall (1993), in most cases the recovered fossil pollen from such sediments is often in a poor state of preservation, is highly deteriorated, and frequently presents evidence of differential preservation (i.e., many of the fragile pollen types have disappeared leaving behind only the most durable pollen types).

Related to Dimbleby's (1957) initial study on soil pH is Tschudy's (1969) later research on the effects of Eh (oxidation potential) on the preservation potential of pollen in various types of sediments. Tschudy noted that Eh seems to be a better indicator than $\mathrm{pH}$ of the potential preservation or destruction of pollen. Sediments with a low Eh (from -1 to 0) reflect a reducing, anaerobic type of condition where carbon dioxide and hydrogen sulfide are often present and result from the by-products of microbe respiration. This combination decreases the levels of oxygen and also lowers $\mathrm{pH}$ values. Thus, the creation of a negative Eh value results in the formation of a strongly reducing environment (Tschudy 1969). Because a reducing environment retards oxygen retention, which will oxidize organic compounds, and presents a less favorable habitat for certain types of bacteria and fungi which feed on pollen, a low soil or sediment Eh becomes ideal for pollen preservation. One of the common types of sediments with a low Eh potential is the acidic peat bog, which is among the best locations to recover fossil pollen. Likewise, as the Eh potential of sediments rises from 0 to +1 , it indicates oxidizing conditions which speed the destruction of pollen in two ways: first, by direct oxidation, when pollen grains come in contact with free oxygen, and second, when pollen comes in contact with oxygenated water from the surface that percolates into sub-surface levels. This second type of oxidation is often more prevalent, especially in well-drained soils containing an ample sand content. The oxygenation of sub-surface soil levels also provides an ideal habitat for certain species of pollen-eating bacteria and fungi.

Not all pollen types are created equally. The chemical composition of the pollen walls of some plant species is not nearly as durable as it is in other types. In addition, the structural morphology of the pollen wall plays an important role in determining whether or not a specific type of pollen grain will remain preserved in various types of sediments. In a 20 -year study beginning in 1964 and ending in 1984, Havinga $(1964,1984)$ reported that the relationship between the structure and percentage of sporopollenin in the wall composition of pollen grains seems to affect their susceptibility to eventual destruction by oxidation. He found, for example, that pollen grains having high percentages of sporopollenin in their walls tended to remain preserved longer, even in soils with high $\mathrm{pH}$ and Eh values, than did pollen grains with walls composed mostly of cellulose and proteins.

Subsequent to Havinga's initial study, Rowley et al. (1990) conducted detailed SEM and TEM studies of the various pollen types used by Havinga during his 20 -year study. The study by Rowley and his colleagues provides a detailed explanation and ample illustrations of the destructive processes that affect pollen in various types of soil conditions.

Biological agents, including certain species of fungi and bacteria, can cause damage to pollen grains that will speed their eventual destruction. Studies by Holloway (1989) noted that some types of Phycomycete fungi will seek out and feed on the nutrient materials in the cytoplasm of recently-deposited pollen grains. His experimental studies show that the filamentous threads of fungi, called hyphae, will often enter a pollen grain through one of the grain's natural aperture openings. Nevertheless, at other times the fungal hyphae seem to have the ability to dissolve areas of the pollen wall in order to enter the grain. Both types of fungi attack and weaken the wall structure of pollen, and speed the grain's eventual destruction by other forms of chemical and mechanical degradation. 
Some years earlier, Goldstein (1960) conducted experiments with various species of Phycomycete fungi and found they were a causative factor in the destruction of pollen. His original study revealed that certain species of Phycomycetes seem to be selective in their preference for pollen types. One group of Phycomycetes, for example, seemed to prefer to infect certain types of conifer pollen, even when other pollen types were available. Unlike Holloway's later study in 1989, Goldstein did not focus on how fungi actually damaged pollen grains. Instead, Goldstein was primarily concerned with the percentage of pollen that would be infected and which pollen taxa seemed to be the most susceptible to fungi infection.

Elsik (1966) was the first to note that bacterial degradation of pollen grains occurs. He found that certain bacteria, especially certain species of Actinomycetes, will degrade pollen walls and seem to do so in a specific pattern. He found that although much of the bacterial infection of pollen seems to occur when the pollen contains cytoplasm, in some cases this type of bacterial destruction continues long after the pollen grains have lost their cytoplasm and have become part of the sedimentary record.

Finally, one of the most destructive forces on pollen in sediments seems to come from repeated cycles of wetting and drying (Campbell and Campbell, 1994). The walls of many pollen grains are fairly elastic, which enable them to expand and contract, depending upon the changing levels of atmospheric humidity (without rupturing) between the time they are released from the anther and the time they either reach their intended destination, or fall to the surface as part of the pollen rain. For those pollen grains that fall to the surface, their natural tendency to expand and contract, depending upon the different levels of available moisture, eventually weakens the grain over time and causes it to rupture or crack. Once weakened, pollen grains are much more susceptible to other processes of mechanical destruction. As Campbell and Campbell (1994) and Holloway (1989) have demonstrated in experimental studies, even one sequence of wetting and drying after pollen is deposited in soils can result in significant overall loss in terms of the total pollen concentration values per gram of soil. As the wetting and drying sequences continue, more pollen destruction occurs until at some point all pollen becomes destroyed.

Primarily due to the unfavourable soil and climatic conditions, the pollen study from site 41KM69 does not provide us with sufficient fossil pollen to form any types of meaningful conclusions about either the paleoenvironment or significant cultural traits. Instead, these samples provide an excellent example of the many problems that confront archaeologists attempting to conduct fossil pollen studies from certain types of sites in the arid regions of Texas.

For over half a century, palynologists have been searching for answers as to why pollen remains perfectly preserved in some types of sediments and why fossil pollen in other sediments are either completely destroyed or selectively destroyed. Earlier I alluded to some of the studies that have already been done in an attempt to answer these questions. Nevertheless, our knowledge of pollen wall morphology, internal structure, and its chemical composition is still being debated. Also, we still do not yet fully understand all of the elements that determine pollen destruction or preservation in different types of environmental settings.

I believe that one of the more important factors determining pollen preservation or destruction in the soils from the site in this study is the frequency of soil saturation and subsequent drying. Various forms of pollen destruction and deterioration seem to be linked to phenomena associated with the evaporative process of changing a liquid into a gas. Experiments conducted by Burstyn and Bartlett (1975) showed that significant pressure is exerted on the curved surface of an organic-walled, hollow sphere (i.e., pollen grains) at the instant when water is transformed, by evaporation, from a liquid to a gas. This pressure phenomenon would be especially critical for water-filled, tiny, spherical structures such as pollen grains. As such, these forces could cause major structural damage to the thin, outer walls of pollen grains. Each time the soil hydration-dehydration process occurs from normal conditions, such as moisture from rain, followed by drying from wind and heat, pollen in the soil would be subjected to two potentially destructive processes. First, the expansion-contraction process caused by being dry and then wet, and second by the pressure phenomenon described by Burstyn and Bartlett (1975) in their study. The more frequently this cycle occurs in a soil, the greater the potential for fossil pollen to become distorted, crumpled, or destroyed (Campbell and Campbell, 1994). The final destruction of the fossil pollen in soils often begins first by the development of stress areas and hairline cracks in the outer wall, and second by the crumbling of the pollen wall into fragments through additional mechanical processes.

In later studies that tested the Burstyn and Bartlett phenomenon on specific types of pollen, first Holloway $(1981,1989)$ and later Campbell and Campbell (1994) conducted controlled cycles of hydration-dehydration on soils containing pollen grains. Both authors noted that after only one hydration-dehydration cycle there were already significant changes and noticeable amounts of exine deterioration in some of the pollen types testing. In the Holloway experiment, he showed that $76 \%$ of the fresh pollen tested and $86 \%$ of the fossilized pollen tested already contained some degree of exine alteration and deterioration at the end of 
only 25 cycles of wetting and drying. Holloway's experiments also provided a clue about how differential pollen preservation can occur as a result of the hydration-dehydration process. Of the 14 pollen taxa he tested, those showing the greatest degree of alteration and destruction at the end of the 25 hydration-dehydration cycles were: pecan (Carya), juniper (Juniperus), aspen and cottonwood (Populus), Douglas Fir (Pseudotsuga), willow (Salix), cattail (Typha), and maize (Zea mays). For many of these seven pollen types the 25 hydration-dehydration cycles were so destructive that a number of the individual pollen grains could no longer be identified with certainty because of deterioration in the form of breakage, corrosion of surface areas, severe folding, warping, and/or degradation of the surface ornamentation. Some of the other types included in the Holloway experiment, such as the pollen of the low-spine composite (Iva) and the pollen of amaranths (Amaranthus), showed only minor degradation and those pollen types were still easily recognizable.

Hall (1981) pointed out from his studies of archaeological sites that fossil pollen assemblages in sites containing certain types of soil conditions become progressively altered and suffer more intensely from deterioration as the soil depth and time of exposure increases. He found that the percentage of degraded and indeterminate pollen increases as the depth of the deposits increase in sites with unfavorable conditions. Furthermore, as Hall's study demonstrates, the presence of low diversity of pollen types combined with high percentages of indeterminate pollen grains indicate significant losses of pollen by various types of deterioration. In most cases these pollen losses will be differentially distributed among the various fossil pollen taxa that were originally deposited. As noted in a later study by Bryant and Hall (1993), with increased amounts of destruction of fossil pollen in soils, the original, highly diverse pollen record becomes reduced down to only a few remaining pollen types. These last, remaining pollen types are generally represented by genera that produce pollen grains that are highly resistant to various agents of destruction, or are pollen types that have unique morphological features that enable them to be recognized even though they become severely degraded. As they note (Bryant and Hall, 1993), for many U.S. regions of the arid and semi-arid Southwest and West including west Texas, these last remaining identifiable pollen types most frequently include: 1) pine pollen, 2) grass pollen, 3) pollen produced by various species of composites [including Artemisia], 4) Ephedra, and 5) pollen grains in the group called Cheno-Ams. As already noted earlier, what minor amounts of fossil pollen that could be identified in these four soil samples come mostly from these main pollen types and include very few other pollen taxa.

Previous studies (Bryant et al., 1994; Bryant and Hall, 1993; Hall, 1981, 1985) have also found that in most soils demonstrating severe examples of fossil pollen destruction, the total number of pollen grains remaining in each soil unit of weight (g) or volume (ml) usually decreases as the soil depth increases. Thus, the total pollen concentration values per gram of soil are usually the highest at the surface and continue to decrease as depth increases until total fossil pollen destruction occurs.

In conclusion, the fossil pollen record from the four samples at this site does not provide any significant information that could be used for either environmental or cultural interpretations. 


\section{References Cited:}

Brooks, D. and Thomas, K. W.

1967 The distribution of pollen grains on microscope slides. Part I: the non-randomness of the distribution. Pollen et Spores 9 (3):621-629.

Brooks, J. and Shaw, G.

1968 Chemical structure of the exine of pollen walls and a new function for carotenoids in nature. Nature 219:523-524.

Bryant, V.M.

1988 Preservation of biological remains from archaeological sites. In: Interdisciplinary Workshop on the Physical-

Chemical-Biological Processes Affecting Archaeological Sites (C. Mathewson, Ed.). U.S. Army Corp of Engineers Waterways Experiment Station, Vicksburg, pp. 85-115.

Bryant, V. M. and S. Hall

1993 Archaeological palynology in the USA: a critique. American Antiquity (58 (2):277-286.

Bryant, V.M., and R.G. Holloway

1983 The role of palynology in archaeology. In: Advances in Archaeological Method and Theory 6 (M. Schiffer, Ed.).

Academic Press, New York, pp. 191-224.

Bryant, V. M., R. Holloway, J. Jones, and D. Carlson

1994 Pollen preservation in alkaline soils of the American Southwest. In: Sedimentation of Organic Particles (A.

Traverse, Ed.). Cambridge University Press, London. pp. 47-58.

Burstyn, H.P. and A.A. Bartlett

1975 Critical point drying: application of the physics of the PVT surface to electron microscopy. American Journal of Physics 43:414-419.

Campbell, I. D. and C. Campbell

1994 Pollen preservation: experimental wet-dry cycles in saline and desalinated sediments. Palynology 18:5-10.

Coil, J., M. A. Korstanje, S. Archer, and C. A. Hastorf

2003 Laboratory goals and considerations for multiple microfossil extraction in archaeology. Journal of Archaeological Science 30:991-1008.

Dimbleby, G.W.

1957 Pollen analysis of terrestrial soils. New Phytologist 56:12-28.

Duhoux. E.

1982 Mechanism of exine rupture in hydrated taxoid type of pollen. Grana 21:1-7.

Elsik, W. K.

1966 Biologic degradation of fossil pollen grains and spores. Micropaleontology 12:515-518.

Erdtman, G.

1960 The acetolysis method: a revised description. Svensk Botanisk Tidskrift 54:561-564.

Goldstein, S.

1960 Destruction of pollen by Phycomycetes. Ecology 41:543-545. 
Hall, S.A.

1981 Deteriorated pollen grains and the interpretation of Quaternary pollen diagrams. Review of Paleobotany and Palynology 32:193-206.

1985 Quaternary pollen analysis and vegetational history of the Southwest. In: Pollen Records of Late-Quaternary North American Sediments, (V.M. Bryant, Jr. and R.G. Holloway, Eds.). American Association of Stratigraphic Palynologists Foundation, Dallas, pp. 95-125.

Havinga, A.J.

1964 Investigations into the differential corrosion susceptibility of pollen and spores. Pollen et Spores 6:621-635.

1984 A 20-year experimental investigation into the differential corrosion susceptibility of pollen and spores in various soil types. Pollen et Spores 26:541-558.

Holloway, R.G.

1981 Preservation and experimental diagenesis of the pollen exine. Ph.D. Dissertation, Texas A\&M University (Botany), College Station, Texas, $317 \mathrm{p}$.

1989 Experimental mechanical pollen degradation and its application to Quaternary age deposits. Texas Journal of Science 41:131-145.

Hunt, C. O.

1985 Recent advances in pollen preparation techniques: a brief review. British Archaeological Review International Series (Archaeological Series) 266:181-187

Jackson, S. T. and M. E. Lyford

1999 Pollen dispersal models in Quaternary plant ecology: assumptions, parameters, and prescriptions. The Botanical Review 65 (1): 39-75.

Jones, G. and V. Bryant

1998 Are all counts created equal? In: American Association of Stratigraphic Palynologists Foundation Contribution Series No.33: New Developments in Palynomorph Sampling, Extraction, and Analysis, (Bryant, V.M. and Wrenn, J. H., Eds.), American Association of Stratigraphic Palynologists Foundation Contribution, Dallas, Texas. pp. 115-120.

2001 Alcohol dilution of honey: In: Proceedings of the IX International Palynological Congress, Houston, Texas, U.S.A., 1996, (Goodman, D.K., and Clarke, R.T., Eds.). American Association of Stratigraphic Palynologists Foundation, Dallas, Texas. pp. 483-488.

King, J., W.E. Klippel, and R. Duffield

1975 Pollen Preservation and Archaeology in Eastern North America. American Antiquity 40 (2):180-190.

Lentfer, C. J., M. M. Cotter, and W. E. Boyd

2003 Particle settling times for gravity sedimentation and centrifugation: a practical guide for palynologists. Journal of Archaeological Science 30:149-168.

Mabberley, D. J.

1997 The Plant-Book. Cambridge Press, Cambridge, United Kingdom.

Mack, R. N.

1971 Pollen size variation in some western North American pines as related to fossil pollen identification. Northwest Science 95 (2):390-397.

Maher, L. J. Jr.

1981 Statistics for microfossil concentration measurements employing samples spiked with marker grains. Review of Palaeobotany and Palynology 32:153-191. 
Martin, P. S.

1963 The Last 10,000 Years: A Fossil Pollen Record of the American Southwest. University of Arizona Press, Tucson.

O'Rourke, M.K.

1990 Pollen reentrainment: contributions to the pollen rain in an arid environment. Grana 29:147-152.

Piperno, Dolores R.

1984 A Comparison and Differentiation of Phytoliths from Maize and Wild Grasses: Use of Morphological Criteria. American Antiquity 49 (2):361-383.

1988 Phytolith Analysis: An Archaeological and Geological Perspective. Academic Press, Inc., New York.

Riding, J. B. and J. E. Kyffin-Hughes

2004 A review of the laboratory preparation of palynomorphs with a description of an effective non-acid technique. Revista Brasileria de Paleontologia 7 (1):13-44.

Rowley, J.R. and B. Prijanto

1977 Selective destruction of the exine of pollen grains. Geophytology 7:1-23.

Rowley, J.R., J.S. Rowley and J. Skvarla

1990 Corroded exines from Havinga's leaf mold experiment. Palynology 14:53-80.

Shaw, G.

1971 The chemistry of sporopollenin. In: Sporopollenin. (J.Brooks, P.Grant, M.Muir, P. van Gijzel, and G. Shaw, Eds.). Academic Press, New York, pp. 305-350.

Traverse, A.

1988 Paleopalynology. Unwin Hyman Pub., Boston.

Tschudy, R.H.

1969 Relationship of palynomorphs to sedimentation. In: Aspects of Palynology. (R. Tschudy and R. Scott, Eds.). Wiley \& Sons, New York, pp. 79-96. 
Appendix J:

Bison Presence/Absence Data from Central and South Texas and Supporting Documentation 

Table J-1. Data Table (from Mauldin and Kemp 2005)

\begin{tabular}{|c|c|c|c|c|c|c|c|c|c|c|c|c|}
\hline Site \# & Status & TRINOMIAL & Zone & $\begin{array}{c}\text { UTM } \\
\text { NORTH }\end{array}$ & UTM EAST & Period & Bison +/- & Assn. & $\begin{array}{l}\text { Prim. } \\
\text { table }\end{array}$ & $\begin{array}{l}\text { Sec. } \\
\text { Table }\end{array}$ & $\begin{array}{l}\text { Tert. } \\
\text { Table }\end{array}$ & NOTES \\
\hline 1 & 1 & 41BL104 & 14 & 3429465 & 628733 & $\begin{array}{c}\text { Terminal Late } \\
\text { Prehistoric }\end{array}$ & 1 & 5 & 2 & & & \\
\hline 1 & 1 & 41BL104 & 14 & 3429465 & 628733 & $\begin{array}{c}\text { Terminal Late } \\
\text { Archaic }\end{array}$ & 1 & 5 & 2 & & & \\
\hline 1 & 1 & 41BL104 & 14 & 3429465 & 628733 & $\begin{array}{l}\text { Middle Late } \\
\text { Archaic }\end{array}$ & 1 & 5 & 2 & & & \\
\hline 1 & 1 & 41BL104 & 14 & 3429465 & 628733 & $\begin{array}{c}\text { Initial Late } \\
\text { Archaic }\end{array}$ & 1 & 5 & 2 & & & \\
\hline 2 & 1 & 41BL85 & 14 & 3426436 & 625411 & $\begin{array}{c}\text { Initial Late } \\
\text { Archaic }\end{array}$ & 1 & 2 & 2 & & & $\begin{array}{l}\text { no numbers refer } \\
\text { enced in report- } \\
\text { direct date on } \\
\text { bison bone }\end{array}$ \\
\hline 3 & 1 & $41 \mathrm{BN} 33$ & 14 & 3292586 & 450958 & $\begin{array}{c}\text { Terminal Late } \\
\text { Prehistoric }\end{array}$ & 1 & 5 & 1 & 3 & & \\
\hline 3 & 1 & $41 \mathrm{BN} 33$ & 14 & 3292586 & 450958 & $\begin{array}{l}\text { Initial Late } \\
\text { Prehistoric }\end{array}$ & 1 & 5 & 1 & 3 & & \\
\hline 4 & 1 & 41BR420 & 14 & 3501960 & 505652 & $\begin{array}{l}\text { Initial Late } \\
\text { Prehistoric }\end{array}$ & 1 & 5 & 1 & & & \\
\hline 4 & 1 & 41BR420 & 14 & 3501960 & 505652 & $\begin{array}{c}\text { Terminal Late } \\
\text { Archaic }\end{array}$ & 0 & 0 & 1 & & & \\
\hline 5 & 1 & $41 \mathrm{CC} 131$ & 14 & 3490251 & 431122 & $\begin{array}{c}\text { Terminal Late } \\
\text { Prehistoric }\end{array}$ & 1 & 4 & 1 & 3 & & $\begin{array}{c}83 \text { Bos/bison- } \\
\text { problem with } \\
\text { counts- could be } \\
3240\end{array}$ \\
\hline 6 & 1 & $41 \mathrm{CC} 222$ & 14 & 3486443 & 425864 & $\begin{array}{c}\text { Terminal Late } \\
\text { Prehistoric }\end{array}$ & 1 & 7 & 3 & & & $\begin{array}{l}\text { bison noted as } \\
\text { present, but } \\
\text { distribuiton relies } \\
\text { on "bison sized" } \\
\text { data }\end{array}$ \\
\hline 6 & 1 & $41 \mathrm{CC} 222$ & 14 & 3486443 & 425864 & $\begin{array}{c}\text { Initial Late } \\
\text { Archaic }\end{array}$ & 1 & 7 & 3 & & & $\begin{array}{l}\text { bison noted as } \\
\text { present, but } \\
\text { distribuiton relies } \\
\text { on "bison sized" } \\
\text { data }\end{array}$ \\
\hline 7 & 1 & 41CK30 & 14 & 3531862 & 351061 & $\begin{array}{c}\text { Terminal Late } \\
\text { Prehistoric }\end{array}$ & 1 & 7 & 2 & & & see notes page \\
\hline 8 & 1 & 41CK76 & 14 & 3542343 & 338080 & $\begin{array}{c}\text { Terminal Late } \\
\text { Prehistoric }\end{array}$ & 1 & 7 & 2 & & & \\
\hline 9 & 1 & 41CK79 & 14 & 3543051 & 339793 & $\begin{array}{c}\text { Terminal Late } \\
\text { Prehistoric }\end{array}$ & 1 & 7 & 2 & & & $\begin{array}{c}\text { no prov. on bison } \\
\text { Note also earlier } \\
\text { point types pres- } \\
\text { ent in small } \\
\text { quantities }\end{array}$ \\
\hline
\end{tabular}


Table J-1. Data Table (from Mauldin and Kemp 2005) continued...

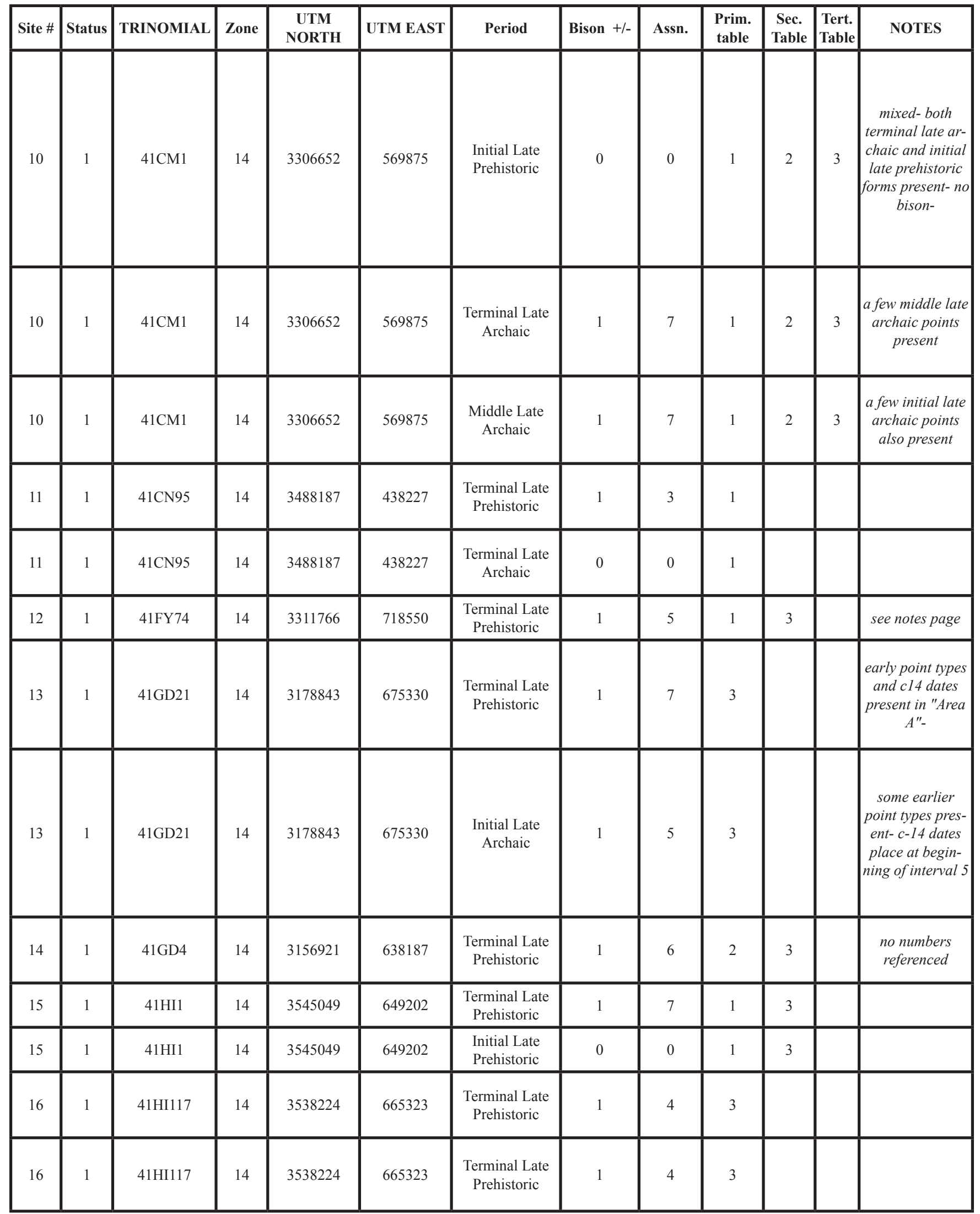


Table J-1. Data Table (from Mauldin and Kemp 2005) continued...

\begin{tabular}{|c|c|c|c|c|c|c|c|c|c|c|c|c|}
\hline Site \# & Status & TRINOMIAL & Zone & $\begin{array}{c}\text { UTM } \\
\text { NORTH }\end{array}$ & UTM EAST & Period & Bison $+/-$ & Assn. & $\begin{array}{c}\text { Prim. } \\
\text { table }\end{array}$ & $\begin{array}{l}\text { Sec. } \\
\text { Table }\end{array}$ & $\begin{array}{l}\text { Tert. } \\
\text { Table }\end{array}$ & NOTES \\
\hline 16 & 1 & 41HI117 & 14 & 3538224 & 665323 & $\begin{array}{c}\text { Middle Late } \\
\text { Archaic }\end{array}$ & 1 & 4 & 3 & & & \\
\hline 16 & 1 & 41HI117 & 14 & 3538224 & 665323 & $\begin{array}{c}\text { Initial Late } \\
\text { Archaic }\end{array}$ & 1 & 4 & 3 & & & \\
\hline 17 & 1 & $41 \mathrm{HI} 54$ & 14 & 3545016 & 648379 & $\begin{array}{c}\text { Terminal Late } \\
\text { Prehistoric }\end{array}$ & 0 & 0 & 1 & & & $\begin{array}{c}\text { also known as } \\
41-26 D 7-12\end{array}$ \\
\hline 17 & 1 & $41 \mathrm{HI} 54$ & 14 & 3545016 & 648379 & $\begin{array}{l}\text { Initial Late } \\
\text { Prehistoric }\end{array}$ & 0 & 0 & 1 & & & $\begin{array}{c}\text { also known as } \\
41-26 D 7-12\end{array}$ \\
\hline 18 & 1 & $41 \mathrm{HI} 55$ & 14 & 3551894 & 648648 & $\begin{array}{c}\text { Terminal Late } \\
\text { Prehistoric }\end{array}$ & 0 & 0 & 1 & & & $\begin{array}{c}\text { also known as } \\
41-26 D 7-20\end{array}$ \\
\hline 18 & 1 & $41 \mathrm{HI} 55$ & 14 & 3551894 & 648648 & $\begin{array}{l}\text { Initial Late } \\
\text { Prehistoric }\end{array}$ & 0 & 0 & 1 & & & $\begin{array}{c}\text { also known as } \\
41-26 D 7-20\end{array}$ \\
\hline 18 & 1 & $41 \mathrm{HI} 55$ & 14 & 3551894 & 648648 & $\begin{array}{c}\text { Terminal Late } \\
\text { Archaic }\end{array}$ & 0 & 0 & 1 & & & $\begin{array}{c}\text { also known as } \\
41-26 D 7-20\end{array}$ \\
\hline 18 & 1 & $41 \mathrm{HI} 55$ & 14 & 3551894 & 648648 & $\begin{array}{c}\text { Middle Late } \\
\text { Archaic }\end{array}$ & 0 & 0 & 1 & & & $\begin{array}{c}\text { also known as } \\
41-26 D 7-20\end{array}$ \\
\hline 19 & 1 & 41HY202A & 14 & 3325779 & 608634 & $\begin{array}{c}\text { Terminal Late } \\
\text { Prehistoric }\end{array}$ & 1 & 4 & 1 & & & \\
\hline 19 & 1 & 41HY202B & 14 & 3325779 & 608634 & $\begin{array}{l}\text { Middle Late } \\
\text { Archaic }\end{array}$ & 1 & 2 & 1 & & & 73 bison sized \\
\hline 20 & 1 & 41HY209T & 14 & 3325516 & 608701 & $\begin{array}{c}\text { Terminal Late } \\
\text { Prehistoric }\end{array}$ & 1 & 4 & 1 & 3 & & \\
\hline 20 & 1 & 41HY209T & 14 & 3325516 & 608701 & $\begin{array}{l}\text { Initial Late } \\
\text { Prehistoric }\end{array}$ & 1 & 4 & 1 & 3 & & \\
\hline 20 & 1 & 41HY209T & 14 & 3325516 & 608701 & $\begin{array}{c}\text { Terminal Late } \\
\text { Archaic }\end{array}$ & 0 & 0 & 1 & 3 & & \\
\hline 21 & 1 & 41JW8 & 14 & 3084421 & 586734 & $\begin{array}{c}\text { Terminal Late } \\
\text { Prehistoric }\end{array}$ & 1 & 4 & 1 & 3 & & \\
\hline 22 & 1 & 41KM16 & 14 & 3373877 & 404905 & $\begin{array}{c}\text { Terminal Late } \\
\text { Prehistoric }\end{array}$ & 1 & 5 & 1 & & & \\
\hline 23 & 1 & 41KM69 & 14 & 3371778 & 425448 & $\begin{array}{c}\text { Terminal Late } \\
\text { Prehistoric }\end{array}$ & 1 & 4 & 1 & & & \\
\hline 23 & 1 & 41KM69 & 14 & 3371778 & 425448 & $\begin{array}{l}\text { Initial Late } \\
\text { Prehistoric }\end{array}$ & 0 & 0 & 1 & & & \\
\hline 23 & 1 & 41KM69 & 14 & 3371778 & 425448 & $\begin{array}{c}\text { Terminal Late } \\
\text { Archaic }\end{array}$ & 0 & 0 & 1 & & & \\
\hline 24 & 1 & 41LK201 & 14 & 3150890 & 571262 & $\begin{array}{c}\text { Terminal Late } \\
\text { Prehistoric }\end{array}$ & 1 & 4 & 1 & 3 & & \\
\hline 24 & 1 & 41LK201 & 14 & 3150890 & 571262 & $\begin{array}{c}\text { Initial Late } \\
\text { Archaic }\end{array}$ & 1 & 5 & 1 & 3 & & \\
\hline
\end{tabular}


Table J-1. Data Table (from Mauldin and Kemp 2005) continued...

\begin{tabular}{|c|c|c|c|c|c|c|c|c|c|c|c|c|}
\hline Site \# & Status & TRINOMIAL & Zone & $\begin{array}{c}\text { UTM } \\
\text { NORTH }\end{array}$ & UTM EAST & Period & Bison $+/-$ & Assn. & $\begin{array}{c}\text { Prim. } \\
\text { table }\end{array}$ & $\begin{array}{l}\text { Sec. } \\
\text { Table }\end{array}$ & $\begin{array}{l}\text { Tert. } \\
\text { Table }\end{array}$ & NOTES \\
\hline 25 & 1 & 41LK67 & 14 & 3151982 & 573651 & $\begin{array}{c}\text { Terminal Late } \\
\text { Prehistoric }\end{array}$ & 0 & 0 & 3 & & & $\begin{array}{c}\text { huebner cists as } \\
\text { bison present-re- } \\
\text { port says no. }\end{array}$ \\
\hline 25 & 1 & 41LK67 & 14 & 3151982 & 573651 & $\begin{array}{c}\text { Middle Late } \\
\text { Archaic }\end{array}$ & 0 & 0 & 3 & & & $\begin{array}{l}\text { huebner cists as } \\
\text { bison present- re- } \\
\text { port says no. }\end{array}$ \\
\hline 25 & 1 & 41LK67 & 14 & 3151982 & 573651 & $\begin{array}{l}\text { Initial Late } \\
\text { Archaic }\end{array}$ & 0 & 0 & 3 & & & $\begin{array}{c}\text { huebner cists as } \\
\text { bison present-re- } \\
\text { port says no. }\end{array}$ \\
\hline 26 & 1 & $41 \mathrm{MC} 222$ & 14 & 3149796 & 549928 & $\begin{array}{l}\text { Terminal Late } \\
\text { Prehistoric }\end{array}$ & 1 & 5 & 1 & 3 & & \\
\hline 27 & 1 & $41 \mathrm{MC} 296$ & 14 & 3157200 & 557574 & $\begin{array}{c}\text { Terminal Late } \\
\text { Prehistoric }\end{array}$ & 1 & 5 & 1 & & & \\
\hline 28 & 1 & 41MC55 & 14 & 3150235 & 560077 & $\begin{array}{c}\text { Terminal Late } \\
\text { Prehistoric }\end{array}$ & 1 & 4 & 3 & & & $\begin{array}{c}\text { no numbers } \\
\text { referenced }\end{array}$ \\
\hline 29 & 1 & 41ML35 & 14 & 3499164 & 660415 & $\begin{array}{c}\text { Terminal Late } \\
\text { Prehistoric }\end{array}$ & 0 & 0 & 1 & 2 & & \\
\hline 29 & 1 & 41ML35 & 14 & 3499164 & 660415 & $\begin{array}{l}\text { Initial Late } \\
\text { Prehistoric }\end{array}$ & 0 & 0 & 1 & 2 & & \\
\hline 29 & 1 & 41ML35 & 14 & 3499164 & 660415 & $\begin{array}{c}\text { Terminal Late } \\
\text { Archaic }\end{array}$ & 0 & 0 & 1 & 2 & & \\
\hline 29 & 1 & 41ML37 & 14 & 3498822 & 660233 & $\begin{array}{c}\text { Terminal Late } \\
\text { Archaic }\end{array}$ & 0 & 0 & 1 & 2 & & \\
\hline 30 & 1 & 41ML39 & 14 & 3504225 & 674337 & $\begin{array}{c}\text { Terminal Late } \\
\text { Prehistoric }\end{array}$ & 0 & 0 & 3 & & & $\begin{array}{l}\text { Huebner cites } \\
\text { bison/ no bison } \\
\text { is cited in this } \\
\text { report }\end{array}$ \\
\hline 31 & 1 & 41MM340 & 14 & 3413675 & 695700 & $\begin{array}{c}\text { Terminal Late } \\
\text { Archaic }\end{array}$ & 0 & 0 & 1 & & & $\begin{array}{l}\text { bison sized } \\
\text { present }\end{array}$ \\
\hline 31 & 1 & $41 \mathrm{MM} 340$ & 14 & 3413675 & 695700 & $\begin{array}{l}\text { Middle Late } \\
\text { Archaic }\end{array}$ & 1 & 4 & 1 & & & $\begin{array}{l}\text { bison sized } \\
\text { present }\end{array}$ \\
\hline 31 & 1 & $41 \mathrm{MM} 340$ & 14 & 3413675 & 695700 & $\begin{array}{c}\text { Initial Late } \\
\text { Archaic }\end{array}$ & 0 & 0 & 1 & & & $\begin{array}{l}\text { bison sized } \\
\text { present }\end{array}$ \\
\hline 32 & 1 & 41NU221 & 14 & 3081992 & 641504 & $\begin{array}{c}\text { Terminal Late } \\
\text { Prehistoric }\end{array}$ & 1 & 4 & 3 & & & \\
\hline 33 & 1 & 41NU37 & 14 & 3058078 & 657646 & $\begin{array}{c}\text { Terminal Late } \\
\text { Prehistoric }\end{array}$ & 1 & 7 & 3 & & & \\
\hline
\end{tabular}


Table J-1. Data Table (from Mauldin and Kemp 2005) continued...

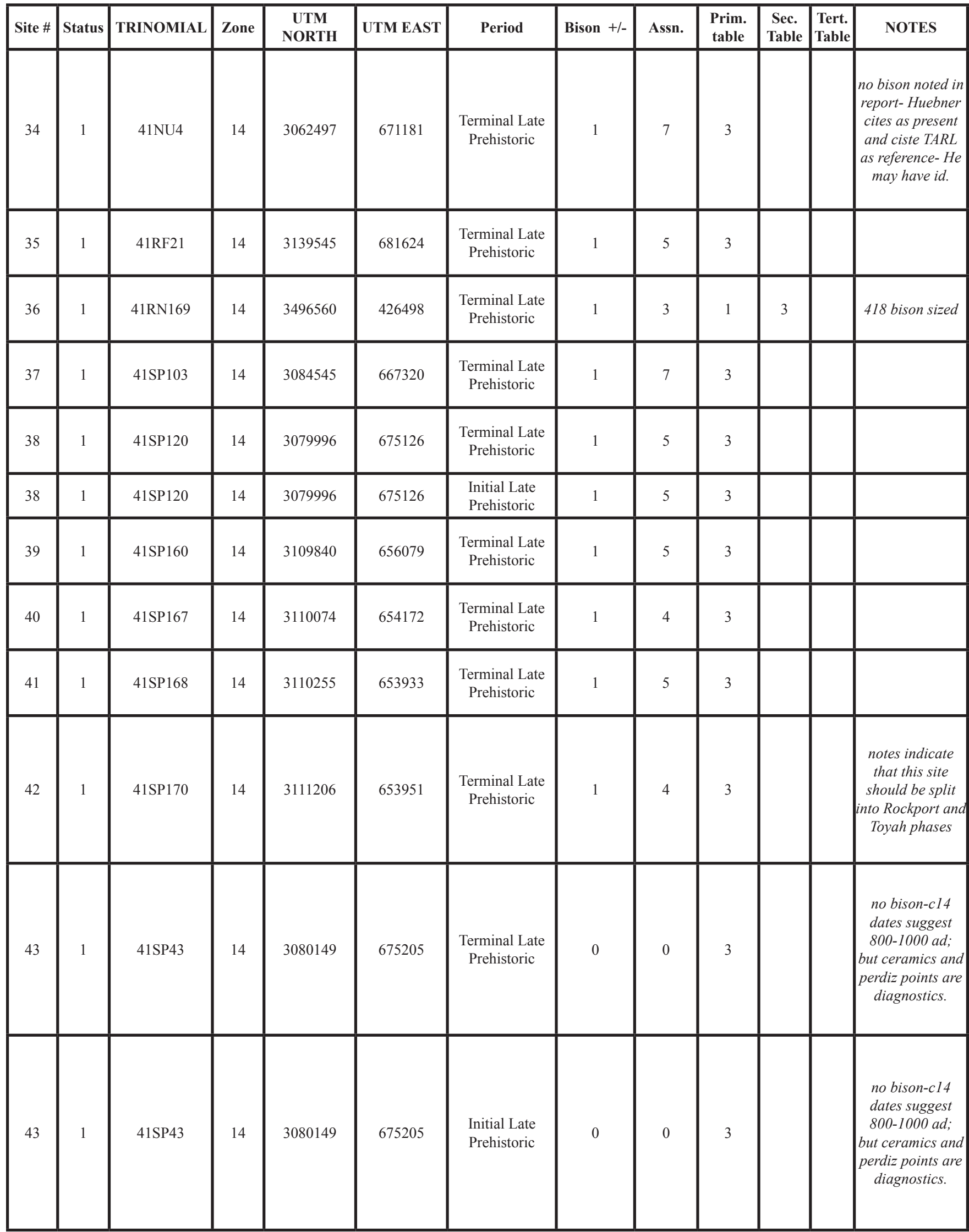


Table J-1. Data Table (from Mauldin and Kemp 2005) continued...

\begin{tabular}{|c|c|c|c|c|c|c|c|c|c|c|c|c|}
\hline Site \# & Status & TRINOMIAL & Zone & $\begin{array}{c}\text { UTM } \\
\text { NORTH }\end{array}$ & UTM EAST & Period & Bison +/- & Assn. & $\begin{array}{l}\text { Prim. } \\
\text { table }\end{array}$ & $\begin{array}{l}\text { Sec. } \\
\text { Table }\end{array}$ & $\begin{array}{c}\text { Tert. } \\
\text { Table }\end{array}$ & NOTES \\
\hline 44 & 1 & $41 \mathrm{SS} 20$ & 14 & 3460042 & 505409 & $\begin{array}{l}\text { Terminal Late } \\
\text { Prehistoric }\end{array}$ & 1 & 4 & 1 & 3 & & $\begin{array}{l}\text { no numbers } \\
\text { referenced }\end{array}$ \\
\hline 45 & 1 & $41 \mathrm{TG} 346$ & 14 & 3491316 & 350739 & $\begin{array}{c}\text { Terminal Late } \\
\text { Prehistoric }\end{array}$ & 1 & 2 & 1 & & & 9911 bison sized \\
\hline 46 & 1 & 41TG91 & 14 & 3465679 & 358860 & $\begin{array}{c}\text { Terminal Late } \\
\text { Prehistoric }\end{array}$ & 1 & 4 & 1 & 3 & & $\begin{array}{c}880 \text { bison sized, } 1 \\
\text { buffalo? }\end{array}$ \\
\hline 46 & 1 & 41TG91 & 14 & 3465679 & 358860 & $\begin{array}{l}\text { Middle Late } \\
\text { Archaic }\end{array}$ & 0 & 0 & 1 & 3 & & \\
\hline 47 & 1 & 41TV42 & 14 & 3339751 & 622926 & $\begin{array}{l}\text { Terminal Late } \\
\text { Prehistoric }\end{array}$ & 1 & 7 & 1 & 2 & 3 & some mixing \\
\hline 47 & 1 & $41 \mathrm{TV} 42$ & 14 & 3339751 & 622926 & $\begin{array}{l}\text { Initial Late } \\
\text { Prehistoric }\end{array}$ & 0 & 0 & 1 & 2 & 3 & some mixing \\
\hline 47 & 1 & $41 \mathrm{TV} 42$ & 14 & 3339751 & 622926 & $\begin{array}{c}\text { Terminal Late } \\
\text { Archaic }\end{array}$ & 1 & 7 & 1 & 2 & 3 & some mixing \\
\hline 48 & 1 & $41 \mathrm{TV} 441$ & 14 & 3340492 & 633431 & $\begin{array}{l}\text { Terminal Late } \\
\text { Prehistoric }\end{array}$ & 1 & 5 & 1 & & & $\begin{array}{c}\text { block } 1 \text { data only- } \\
\text { block } 2 \text { contains } \\
\text { scallorn, perdizr, } \\
\text { and Ensor along } \\
\text { with bison. }\end{array}$ \\
\hline 49 & 1 & 41VT66 & 14 & 3178412 & 679239 & $\begin{array}{l}\text { Terminal Late } \\
\text { Prehistoric }\end{array}$ & 1 & 4 & 3 & & & $\begin{array}{c}\text { approximate } \\
\text { number of NISP }\end{array}$ \\
\hline 50 & 1 & 41VV161 & 14 & 3292812 & 266695 & $\begin{array}{c}\text { Terminal Late } \\
\text { Archaic }\end{array}$ & 0 & 0 & 2 & & & \\
\hline 50 & 1 & 41VV161 & 14 & 3292812 & 266695 & $\begin{array}{l}\text { Middle Late } \\
\text { Archaic }\end{array}$ & 0 & 0 & 2 & & & \\
\hline 51 & 1 & 41VV162 & 14 & 3291407 & 268535 & $\begin{array}{c}\text { Terminal Late } \\
\text { Archaic }\end{array}$ & 0 & 0 & 2 & & & $\begin{array}{l}\text { other periods } \\
\text { represented by } \\
\text { small quantities } \\
\text { of diagnostics }\end{array}$ \\
\hline 51 & 1 & 41VV162 & 14 & 3291407 & 268535 & $\begin{array}{l}\text { Middle Late } \\
\text { Archaic }\end{array}$ & 0 & 0 & 2 & & & $\begin{array}{l}\text { other periods } \\
\text { represented by } \\
\text { small quantities } \\
\text { of diagnostics }\end{array}$ \\
\hline 51 & 1 & 41VV162 & 14 & 3291407 & 268535 & $\begin{array}{c}\text { Initial Late } \\
\text { Archaic }\end{array}$ & 0 & 0 & 2 & & & $\begin{array}{l}\text { other periods } \\
\text { represented by } \\
\text { small quantities } \\
\text { of diagnostics }\end{array}$ \\
\hline
\end{tabular}


Table J-1. Data Table (from Mauldin and Kemp 2005) continued...

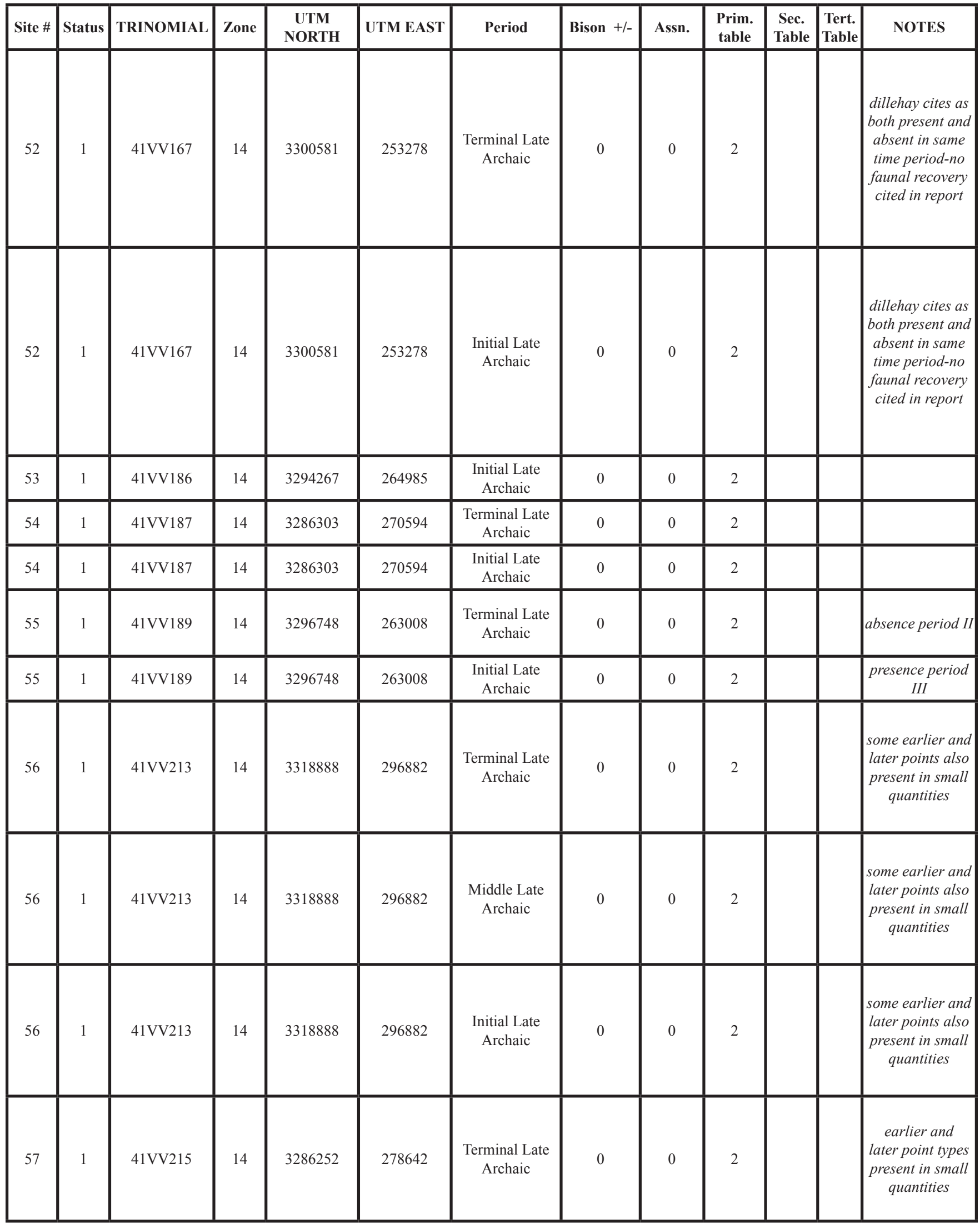


Table J-1. Data Table (from Mauldin and Kemp 2005) continued...

\begin{tabular}{|c|c|c|c|c|c|c|c|c|c|c|c|c|}
\hline Site \# & Status & TRINOMIAL & Zone & $\begin{array}{c}\text { UTM } \\
\text { NORTH }\end{array}$ & UTM EAST & Period & Bison +/- & Assn. & $\begin{array}{l}\text { Prim. } \\
\text { table }\end{array}$ & $\begin{array}{l}\text { Sec. } \\
\text { Table }\end{array}$ & $\begin{array}{l}\text { Tert. } \\
\text { Table }\end{array}$ & NOTES \\
\hline 57 & 1 & 41VV215 & 14 & 3286252 & 278642 & $\begin{array}{l}\text { Middle Late } \\
\text { Archaic }\end{array}$ & 0 & 0 & 2 & & & $\begin{array}{c}\text { earlier and } \\
\text { later point types } \\
\text { present in small } \\
\text { quantities }\end{array}$ \\
\hline 57 & 1 & 41VV215 & 14 & 3286252 & 278642 & $\begin{array}{l}\text { Initial Late } \\
\text { Archaic }\end{array}$ & 0 & 0 & 2 & & & $\begin{array}{c}\text { earlier and } \\
\text { later point types } \\
\text { present in small } \\
\text { quantities }\end{array}$ \\
\hline 58 & 1 & 41VV216 & 14 & 3285164 & 276900 & $\begin{array}{c}\text { Terminal Late } \\
\text { Archaic }\end{array}$ & 0 & 0 & 2 & & & $\begin{array}{l}\text { other periods } \\
\text { represented by } \\
\text { small quantities } \\
\text { of diagnostics }\end{array}$ \\
\hline 58 & 1 & $41 \mathrm{VV} 216$ & 14 & 3285164 & 276900 & $\begin{array}{l}\text { Middle Late } \\
\text { Archaic }\end{array}$ & 0 & 0 & 2 & & & $\begin{array}{l}\text { other periods } \\
\text { represented by } \\
\text { small quantities } \\
\text { of diagnostics }\end{array}$ \\
\hline 59 & 1 & 41VV218 & 14 & 3300917 & 253676 & $\begin{array}{l}\text { Middle Late } \\
\text { Archaic }\end{array}$ & 1 & 4 & 2 & & & bone bed 3 \\
\hline 60 & 1 & 41VV260 & 14 & 3281381 & 290175 & $\begin{array}{c}\text { Terminal Late } \\
\text { Prehistoric }\end{array}$ & 0 & 0 & 2 & & & $\begin{array}{l}\text { earlier point } \\
\text { types present in } \\
\text { small quantities }\end{array}$ \\
\hline 60 & 1 & $41 \mathrm{VV} 260$ & 14 & 3281381 & 290175 & $\begin{array}{c}\text { Terminal Late } \\
\text { Archaic }\end{array}$ & 0 & 0 & 2 & & & $\begin{array}{c}\text { earlier and } \\
\text { later point types } \\
\text { present in small } \\
\text { quantities }\end{array}$ \\
\hline 60 & 1 & $41 \mathrm{VV} 260$ & 14 & 3281381 & 290175 & $\begin{array}{l}\text { Middle Late } \\
\text { Archaic }\end{array}$ & 0 & 0 & 2 & & & $\begin{array}{c}\text { earlier and } \\
\text { later point types } \\
\text { present in small } \\
\text { quantities }\end{array}$ \\
\hline 61 & 1 & $41 \mathrm{VV} 74$ & 14 & 3287421 & 276282 & $\begin{array}{c}\text { Terminal Late } \\
\text { Archaic }\end{array}$ & 0 & 0 & 2 & & & $\begin{array}{l}\text { other periods } \\
\text { represented by } \\
\text { small quantities } \\
\text { of diagnostics }\end{array}$ \\
\hline
\end{tabular}


Table J-1. Data Table (from Mauldin and Kemp 2005) continued...

\begin{tabular}{|c|c|c|c|c|c|c|c|c|c|c|c|c|}
\hline Site \# & Status & TRINOMIAL & Zone & $\begin{array}{c}\text { UTM } \\
\text { NORTH }\end{array}$ & UTM EAST & Period & Bison +/- & Assn. & $\begin{array}{l}\text { Prim. } \\
\text { table }\end{array}$ & $\begin{array}{l}\text { Sec. } \\
\text { Table }\end{array}$ & \begin{tabular}{|l} 
Tert. \\
Table
\end{tabular} & NOTES \\
\hline 61 & 1 & $41 \mathrm{VV} 74$ & 14 & 3287421 & 276282 & $\begin{array}{c}\text { Initial Late } \\
\text { Archaic }\end{array}$ & 0 & 0 & 2 & & & $\begin{array}{l}\text { other periods } \\
\text { represented by } \\
\text { small quantities } \\
\text { of diagnostics }\end{array}$ \\
\hline 62 & 1 & 41VV82 & 14 & 3282994 & 276441 & $\begin{array}{c}\text { Terminal Late } \\
\text { Archaic }\end{array}$ & 0 & 0 & 2 & & & \\
\hline 62 & 1 & 41VV82 & 14 & 3282994 & 276441 & $\begin{array}{l}\text { Middle Late } \\
\text { Archaic }\end{array}$ & 0 & 0 & 2 & & & \\
\hline 62 & 1 & 41VV82 & 14 & 3282994 & 276441 & $\begin{array}{c}\text { Initial Late } \\
\text { Archaic }\end{array}$ & 0 & 0 & 2 & & & \\
\hline 63 & 1 & 41VV87 & 14 & 3283364 & 272439 & $\begin{array}{l}\text { Terminal Late } \\
\text { Prehistoric }\end{array}$ & 1 & 7 & 2 & & & $\begin{array}{l}\text { bison hide-some } \\
\text { earlier point } \\
\text { sytles also pres- } \\
\text { ent. }\end{array}$ \\
\hline 63 & 1 & $41 \mathrm{VV} 87$ & 14 & 3283364 & 272439 & $\begin{array}{c}\text { Terminal Late } \\
\text { Archaic }\end{array}$ & 0 & 0 & 2 & & & \\
\hline 64 & 1 & 41WM118 & 14 & 3393917 & 654674 & $\begin{array}{c}\text { Terminal Late } \\
\text { Prehistoric }\end{array}$ & 1 & 4 & 1 & 3 & & \\
\hline 64 & 1 & 41WM118 & 14 & 3393917 & 654674 & $\begin{array}{c}\text { Terminal Late } \\
\text { Archaic }\end{array}$ & 1 & 6 & 1 & 3 & & \\
\hline 65 & 1 & 41WM130 & 14 & 3394355 & 655590 & $\begin{array}{c}\text { Terminal Late } \\
\text { Prehistoric }\end{array}$ & 1 & 6 & 1 & & & $\begin{array}{c}\text { total } \\
\text { diagnostics }=c a \\
27 ; \text { average } \\
\text { depth } b s=20.43 \\
\mathrm{~cm}-\end{array}$ \\
\hline 65 & 1 & 41WM130 & 14 & 3394355 & 655590 & $\begin{array}{l}\text { Initial Late } \\
\text { Prehistoric }\end{array}$ & 1 & 6 & 1 & & & $\begin{array}{c}\text { total diagnos- } \\
\text { tics }=24 ; \text { average } \\
\text { depth } b s=29.7 \mathrm{~cm}\end{array}$ \\
\hline 65 & 1 & 41WM130 & 14 & 3394355 & 655590 & $\begin{array}{c}\text { Terminal Late } \\
\text { Archaic }\end{array}$ & 1 & 6 & 1 & & & $\begin{array}{c}\text { total diagnos- } \\
\text { tics }=14 ; \text { average } \\
\text { depth } b s=52 \mathrm{~cm}\end{array}$ \\
\hline 66 & 1 & 41WM2 & 14 & 3376572 & 627641 & $\begin{array}{c}\text { Terminal Late } \\
\text { Archaic }\end{array}$ & 1 & 6 & 2 & & & $\begin{array}{l}\text { no numbers } \\
\text { referenced-ear- } \\
\text { lier point forms } \\
\text { also present }\end{array}$ \\
\hline
\end{tabular}


Table J-1. Data Table (from Mauldin and Kemp 2005) continued...

\begin{tabular}{|c|c|c|c|c|c|c|c|c|c|c|c|c|}
\hline Site \# & Status & TRINOMIAL & Zone & $\begin{array}{c}\text { UTM } \\
\text { NORTH }\end{array}$ & UTM EAST & Period & Bison +/- & Assn. & $\begin{array}{c}\text { Prim. } \\
\text { table }\end{array}$ & $\begin{array}{l}\text { Sec. } \\
\text { Table }\end{array}$ & \begin{tabular}{|l|} 
Tert. \\
Table
\end{tabular} & NOTES \\
\hline 66 & 1 & 41WM2 & 14 & 3376572 & 627641 & $\begin{array}{l}\text { Initial Late } \\
\text { Archaic }\end{array}$ & 1 & 6 & 2 & & & $\begin{array}{l}\text { no numbers } \\
\text { referenced-ear- } \\
\text { lier point forms } \\
\text { also present }\end{array}$ \\
\hline 67 & 1 & 41WM230 & 14 & 3392551 & 652579 & $\begin{array}{l}\text { Terminal Late } \\
\text { Prehistoric }\end{array}$ & 0 & 0 & 1 & 3 & & \\
\hline 67 & 1 & $41 \mathrm{WM} 230$ & 14 & 3392551 & 652579 & $\begin{array}{l}\text { Initial Late } \\
\text { Prehistoric }\end{array}$ & 1 & 4 & 1 & 3 & & \\
\hline 67 & 1 & 41WM230 & 14 & 3392551 & 652579 & $\begin{array}{l}\text { Terminal Late } \\
\text { Archaic }\end{array}$ & 0 & 0 & 1 & 3 & & \\
\hline 67 & 1 & 41WM230 & 14 & 3392551 & 652579 & $\begin{array}{l}\text { Middle Late } \\
\text { Archaic }\end{array}$ & 0 & 0 & 1 & 3 & & \\
\hline 68 & 1 & 41WM267 & 14 & 3394784 & 655485 & $\begin{array}{c}\text { Terminal Late } \\
\text { Archaic }\end{array}$ & 0 & 0 & 1 & & & $\begin{array}{l}\text { bison present } \\
\text { from earlier } \\
\text { phases }\end{array}$ \\
\hline 68 & 1 & 41WM267 & 14 & 3394784 & 655485 & $\begin{array}{l}\text { Middle Late } \\
\text { Archaic }\end{array}$ & 0 & 0 & 1 & & & $\begin{array}{l}\text { bison present } \\
\text { from earlier } \\
\text { phases }\end{array}$ \\
\hline 69 & 1 & 41WM437 & 14 & 3389465 & 647306 & $\begin{array}{l}\text { Terminal Late } \\
\text { Prehistoric }\end{array}$ & 1 & 7 & 3 & & & $\begin{array}{l}\text { no numbers } \\
\text { referenced-"lots } \\
\text { of bison"- "single } \\
\text { component } \\
\text { toyah"- no evi- } \\
\text { dence }\end{array}$ \\
\hline 70 & 1 & 41WM56 & 14 & 3395133 & 615468 & $\begin{array}{l}\text { Initial Late } \\
\text { Prehistoric }\end{array}$ & 0 & 0 & 1 & & & $\begin{array}{l}\text { bison present } \\
\text { from earlier } \\
\text { phases }\end{array}$ \\
\hline 70 & 1 & 41WM56 & 14 & 3395133 & 615468 & $\begin{array}{c}\text { Terminal Late } \\
\text { Archaic }\end{array}$ & 0 & 0 & 1 & & & $\begin{array}{l}\text { bison present } \\
\text { from earlier } \\
\text { phases }\end{array}$ \\
\hline 70 & 1 & 41WM56 & 14 & 3395133 & 615468 & $\begin{array}{l}\text { Middle Late } \\
\text { Archaic }\end{array}$ & 0 & 0 & 1 & & & $\begin{array}{l}\text { bison present } \\
\text { from earlier } \\
\text { phases }\end{array}$ \\
\hline 71 & 1 & 41WM815 & 14 & 3372101 & 647800 & $\begin{array}{l}\text { Middle Late } \\
\text { Archaic }\end{array}$ & 0 & 0 & 1 & & & \\
\hline 72 & 1 & 41ZV155 & 14 & 3182663 & 431652 & $\begin{array}{l}\text { Terminal Late } \\
\text { Prehistoric }\end{array}$ & 1 & 6 & 3 & & & \\
\hline 72 & 1 & 41ZV155 & 14 & 3182663 & 431652 & $\begin{array}{l}\text { Initial Late } \\
\text { Prehistoric }\end{array}$ & 1 & 4 & 3 & & & \\
\hline 73 & 1 & 41ZV202 & 14 & 3214135 & 392183 & $\begin{array}{l}\text { Initial Late } \\
\text { Prehistoric }\end{array}$ & 0 & 0 & 1 & & & \\
\hline
\end{tabular}


Table J-1. Data Table (from Mauldin and Kemp 2005) continued...

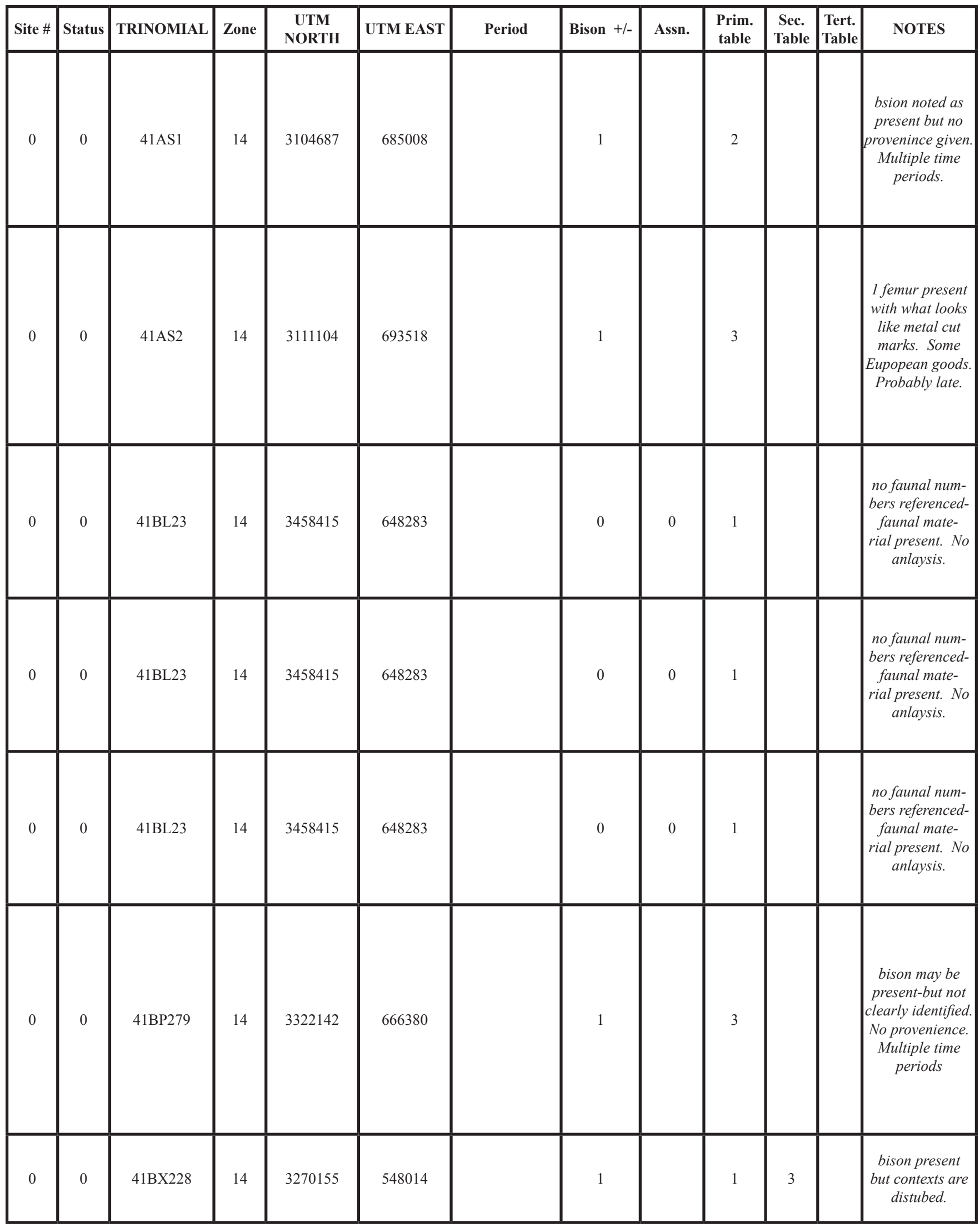


Table J-1. Data Table (from Mauldin and Kemp 2005) continued...

\begin{tabular}{|c|c|c|c|c|c|c|c|c|c|c|c|c|}
\hline Site \# & Status & TRINOMIAL & Zone & $\begin{array}{c}\text { UTM } \\
\text { NORTH }\end{array}$ & UTM EAST & Period & Bison +/- & Assn. & $\begin{array}{l}\text { Prim. } \\
\text { table }\end{array}$ & $\begin{array}{l}\text { Sec. } \\
\text { Table }\end{array}$ & $\begin{array}{l}\text { Tert. } \\
\text { Table }\end{array}$ & NOTES \\
\hline 0 & 0 & $41 \mathrm{CK} 87$ & 14 & 3529515 & 354898 & & 1 & & 2 & & & $\begin{array}{c}\text { bison presnt, but } \\
\text { no provenience } \\
\text { and multiple time } \\
\text { periods }\end{array}$ \\
\hline 0 & 0 & $41 \mathrm{CM} 1$ & 14 & 3306652 & 569875 & & 1 & 7 & 1 & 2 & 3 & $\begin{array}{c}\text { mixed- both } \\
\text { perdiz and scal- } \\
\text { lorn points along } \\
\text { with bison }\end{array}$ \\
\hline 0 & 0 & $41 \mathrm{CM} 2$ & 14 & 3307151 & 572920 & & 1 & & 2 & & & $\begin{array}{c}\text { bison noted as } \\
\text { present- but no } \\
\text { detials given- } \\
\text { multiple point } \\
\text { types present- no } \\
\text { bison prov. }\end{array}$ \\
\hline 0 & 0 & $41 \mathrm{CM} 3$ & 14 & 3308891 & 563643 & & 1 & & 2 & & & $\begin{array}{l}\text { bison noted as } \\
\text { present- but no } \\
\text { detials given- } \\
\text { multiple point } \\
\text { types present- no } \\
\text { bison prov. }\end{array}$ \\
\hline 0 & 0 & 41FY135 & 14 & 3311123 & 727517 & & 1 & & 1 & & & $\begin{array}{c}\text { no cleraly defined } \\
\text { components at } \\
\text { this site }\end{array}$ \\
\hline 0 & 0 & 41FY42 & 14 & 3308775 & 704072 & & 0 & & 1 & & & $\begin{array}{l}\text { site consists } \\
\text { of burials- no } \\
\text { faunal mate- } \\
\text { rial is specifically } \\
\text { referenced. }\end{array}$ \\
\hline 0 & 0 & 41GD30 & 14 & 3185488 & 678357 & & 1 & & 3 & & & $\begin{array}{l}\text { cf. bos/cf. bison } \\
\text { only.- no clear } \\
\text { identification. }\end{array}$ \\
\hline 0 & 0 & 41GL1 & 14 & 3373473 & 489033 & & 1 & & 1 & 2 & & $\begin{array}{l}\text { no faunal proven- } \\
\text { ince-mixed time } \\
\text { periods }\end{array}$ \\
\hline
\end{tabular}


Table J-1. Data Table (from Mauldin and Kemp 2005) continued...

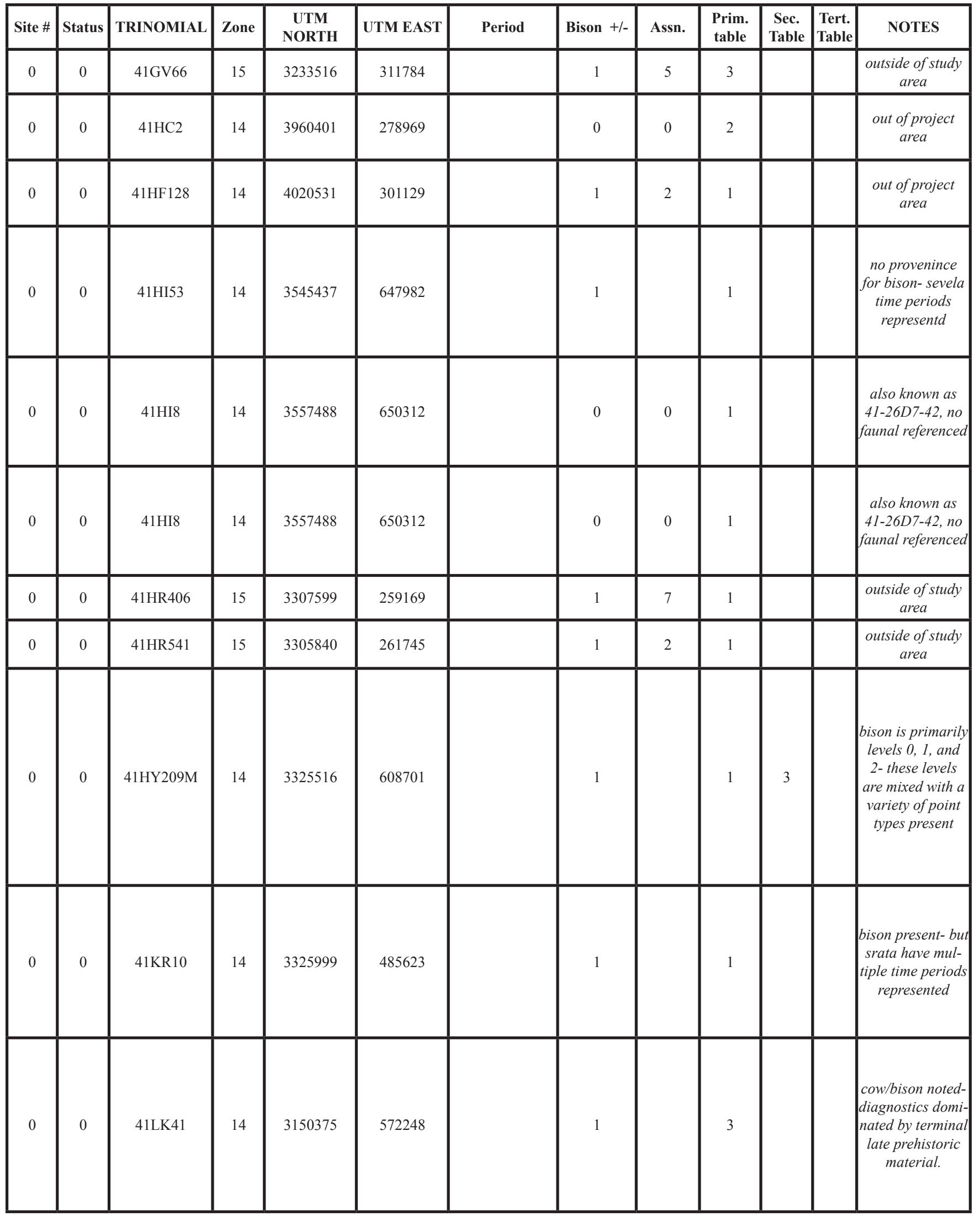


Table J-1. Data Table (from Mauldin and Kemp 2005) continued...

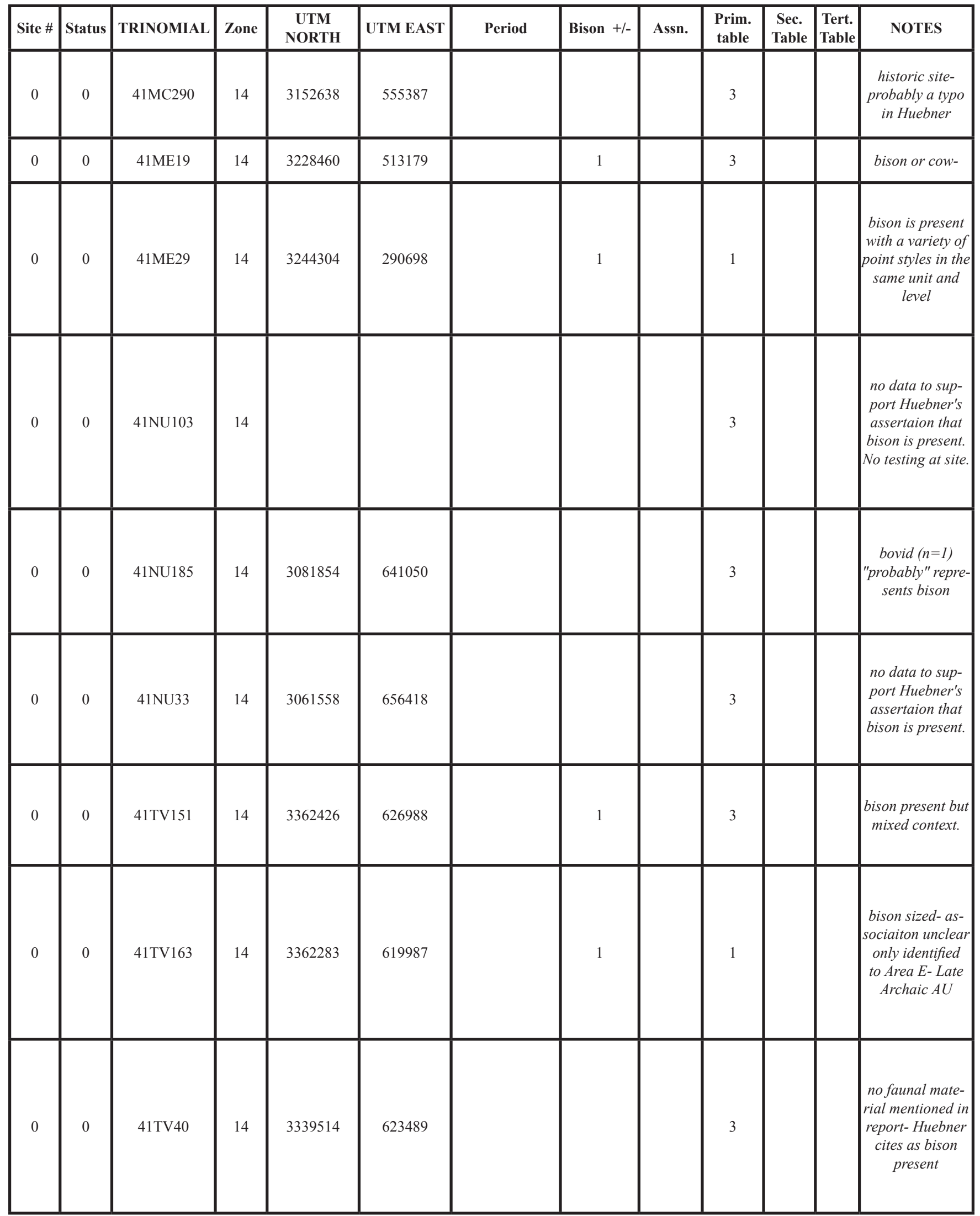


Table J-1. Data Table (from Mauldin and Kemp 2005) continued...

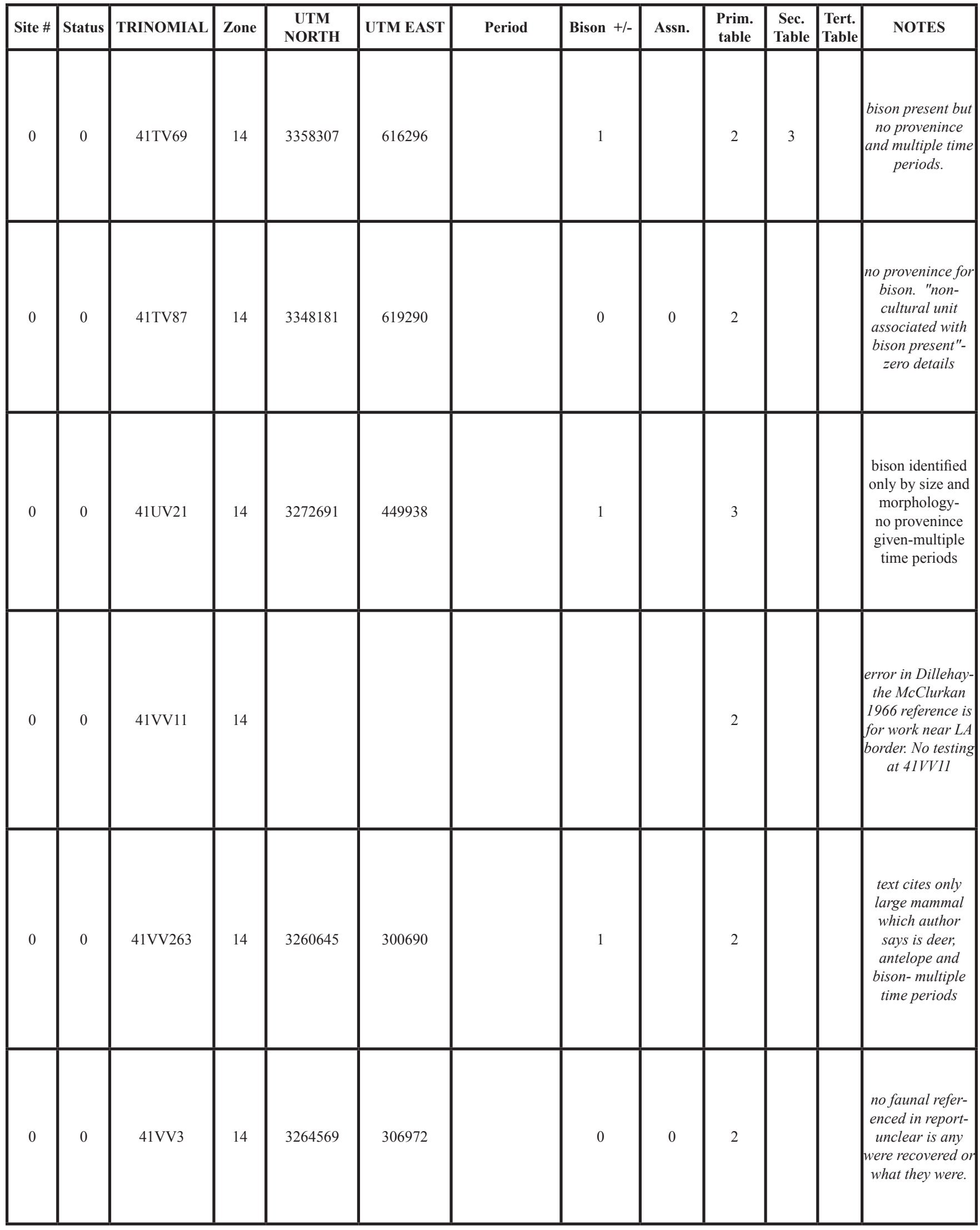


Table J-1. Data Table (from Mauldin and Kemp 2005) continued....

\begin{tabular}{|c|c|c|c|c|c|c|c|c|c|c|c|c|}
\hline Site \# & Status & TRINOMIAL & Zone & $\begin{array}{c}\text { UTM } \\
\text { NORTH }\end{array}$ & UTM EAST & Period & Bison +/- & Assn. & $\begin{array}{c}\text { Prim. } \\
\text { table }\end{array}$ & $\begin{array}{l}\text { Sec. } \\
\text { Table }\end{array}$ & $\begin{array}{l}\text { Tert. } \\
\text { Table }\end{array}$ & NOTES \\
\hline 0 & 0 & $41 \mathrm{VV} 422$ & 14 & 3251790 & 317974 & & 0 & 0 & 2 & & & $\begin{array}{c}\text { bison absent- but } \\
\text { only } 4 \text { projec- } \\
\text { tile points were } \\
\text { present- reflect } \\
\text { at least two time } \\
\text { periods }\end{array}$ \\
\hline 0 & 0 & 41VV99 & 14 & 3288363 & 271432 & & & & 2 & & & $\begin{array}{l}\text { report states fau- } \\
\text { nal collection has } \\
\text { not yet been stud- } \\
\text { ied. -not clear is } \\
\text { bison present or } \\
\quad \text { absent }\end{array}$ \\
\hline 0 & 0 & 41WM133 & 14 & 3392728 & 652565 & & 1 & & 1 & & & $\begin{array}{l}\text { site is too early- } \\
\text { and provenince } \\
\text { data is non- } \\
\text { existent. }\end{array}$ \\
\hline 0 & 0 & 41WM49 & 14 & & & & & & 2 & & & $\begin{array}{l}\text { cf. bison identi- } \\
\text { fied- mutiple time } \\
\text { periods reflected } \\
\text { in types. }\end{array}$ \\
\hline
\end{tabular}

Table J-2. Explanations for Fields in Table J-1

\begin{tabular}{|c|c|c|}
\hline Fields & Explanation & Codes \\
\hline Site \# & Arbitrary number tied to Figure 7 & 1-73 are shown in Figure 7; $0=$ site/component not used in analysis. \\
\hline Status & Status of site or component & $1=$ used, $0=$ not used. \\
\hline TRINOMIAL & trinomial number & \\
\hline Zone & UTM Zone from site atlas & \\
\hline UTM NORTH & Northing UTM from site atlas & \\
\hline UTM EAST & Easting UTM from site atlas & \\
\hline Period & temporal period & $\begin{array}{l}\text { name of temporal period- five possible time periods. See accompanying Table } 4 \text { "tem- } \\
\text { poral association" for details }\end{array}$ \\
\hline Bison $+/-$ & $\begin{array}{l}\text { presence/absence of bison. Note } \\
\text { that cases of Very Large Mam- } \\
\text { mal, Cow/Bison, Probably Bison, } \\
\text { and cf. bison are not included as } \\
\text { present }\end{array}$ & $1=$ present, $0=$ absent. Note that if blank the component should have a " 0 " status. \\
\hline Assos. & $\begin{array}{l}\text { association- an assessment of the } \\
\text { strength of the association between } \\
\text { bison presence and dates. }\end{array}$ & 0 through 7 . See accompanying Table 3-"bison association" for details. \\
\hline Prim. Table & primary source of site & $1=$ CAR research design (Tomka et. al. 2004a); 2= Dillehay (1974); 3=Huebner (1991). \\
\hline Sec. Table & secondary source of site & 2= Dillehay 1974. 3=Huebner 1991 \\
\hline Tert. Table & tertiary source of site & $2=$ Dillehay 1974. 3=Huebner 1991 \\
\hline NOTES & any additional observations & \\
\hline
\end{tabular}


Table J-3. Association of Bison and Diagnostics or Radiocarbon Dates

1. Direct association between radiocarbon dated material and bison. That is, there is at least 1 case where a radiocarbon date comes from the same provenience (level or feature) as bison remains for the site. This would include situations where we have a direct date on bison bone. Also, there are NO other data that indicate earlier or later occupations at the site level.

2. Direct association between radiocarbon dated material and bison. That is, there is at least 1 case where a radiocarbon date comes from the same provenience (level or feature) as bison remains for the site. This would include situations where we have a direct date on bison bone. There are some data that indicate earlier or later occupations at the site level.

3. There is a direct association (same level or feature) of bison with diagnostic artifacts from a single phase or period, and there are no other data indicating earlier or later use of the site.

4. There are no direct associations (same level or feature) between radiocarbon dates or diagnostics and bison that could be clearly documented given available data, but all materials from the site date to a single phase or period. Or there is a direct association (same level or feature) of bison with diagnostic artifacts from a single phase or period, but there are also material that indicate earlier or later use of the site.

5. There are no direct associations (same level or feature) between bison and radiocarbon dates or diagnostic artifacts that could be clearly documented given available data, and while there are indications of earlier or later uses of the site, the majority of dates and/or diagnostics indicate a single period or phase of use.

6. There are no direct associations at a level or feature between diagnostics or dates and bison, and there is no clearly dominant period of use indicated by diagnostics or dates at the site level.

7. There is simply not enough detail reported to make any assessment of association, the original researcher discounts the association, or the secondary researcher presents additional data that appears to contradict the original report.

Note that the code of 0 indicates no bison were present at this component.

Table J-4. Temporal Associations

\begin{tabular}{|c|c|c|c|c|c|}
\hline Name & Start B.P. (cal) & End B.P. (cal) & Start AD/BC & End AD/BC & Some Diagnostics \\
\hline Terminal Prehistoric & 700 & 400 & $1250 \mathrm{AD}$ & $1550 \mathrm{AD}$ & $\begin{array}{c}\text { Perdiz, Ceramics (including Rockport), } \\
\text { Clifton, Livermore }\end{array}$ \\
\hline Initial Late Prehistoric & 1250 & 700 & $700 \mathrm{AD}$ & $1250 \mathrm{AD}$ & Scallorn, Edwards, Alba \\
\hline Terminal Late Archaic & 1600 & 1250 & $350 \mathrm{AD}$ & $700 \mathrm{AD}$ & $\begin{array}{c}\text { Darl, Ensor, Frio, Fairland, Godley, } \\
\text { Figueroa, Ellis, Edgewood, Shulma }\end{array}$ \\
\hline Middle Late Archaic & 2500 & 1600 & $550 \mathrm{BC}$ & $350 \mathrm{AD}$ & $\begin{array}{c}\text { Marcos, Montell, Castroville, Lange, Mar- } \\
\text { shall, Williams }\end{array}$ \\
\hline Initial Late Archaic & 4450 & 2500 & $2500 \mathrm{BC}$ & $550 \mathrm{BC}$ & $\begin{array}{c}\text { Pedernales, Bulverde, Kinney, Langtry, Val } \\
\text { Verde }\end{array}$ \\
\hline
\end{tabular}



Appendix K:

Species and Body Size Data for Texas Mammals* 

Table K-1. Species and Body Size Data for Texas Mammals

\begin{tabular}{|c|c|c|c|}
\hline Animal & Order & weight (kg) & size class \\
\hline Attwater's Pocket Gopher & Rodent & 0.038 & 1 \\
\hline Baird's Pocket Gopher & Rodent & 0.038 & 1 \\
\hline Banner-tailed Kangaroo Rat & Rodent & 0.115 & 1 \\
\hline Black-footed Ferret & carnivore & 0.887 & 1 \\
\hline Botta's Pocket Gopher & rodent & 0.183 & 1 \\
\hline Brush Mouse & rodent & 0.29 & 1 \\
\hline Cactus Mouse & rodent & 0.029 & 1 \\
\hline Common Muskrat & rodent & 0.881 & 1 \\
\hline Cotton Mouse & rodent & 0.043 & 1 \\
\hline Coues' Rice Rat & rodent & 0.06 & 1 \\
\hline Deer Mouse & rodent & 0.024 & 1 \\
\hline Desert Cottontail & Lagomorphs & 0.95 & 1 \\
\hline Desert Pocket Gopher & rodent & 0.206 & 1 \\
\hline Desert Pocket Mouse & rodent & 0.019 & 1 \\
\hline Eastern Flying Squirrel & rodent & 0.054 & 1 \\
\hline Eastern Fox Squirrel & rodent & 0.95 & 1 \\
\hline Eastern Gray Squirrel & rodent & 0.455 & 1 \\
\hline Eastern Harvest Mouse & rodent & 0.013 & 1 \\
\hline Eastern Mole & insectivora & 0.075 & 1 \\
\hline Eastern Spotted Skunk & carnivore & 0.565 & 1 \\
\hline Eastern Woodrat & rodent & 0.275 & 1 \\
\hline Elliot's Short-tailed Shrew & insectivora & 0.014 & 1 \\
\hline Fulvous Harvest Mouse & rodent & 0.018 & 1 \\
\hline Golden Mouse & rodent & 0.02 & 1 \\
\hline Gray-footed Chipmunk & rodent & 0.07 & 1 \\
\hline Gulf Coast Kangaroo Rat & rodent & 0.052 & 1 \\
\hline Hispid Cotton Rat & rodent & 0.115 & 1 \\
\hline Hispid Pocket Mouse & rodent & 0.038 & 1 \\
\hline Hooded Skunk & carnivore & 0.7 & 1 \\
\hline Jones' Pocket Gopher & rodent & 0.038 & 1 \\
\hline Llano Pocket Gopher & rodent & 0.038 & 1 \\
\hline Long-tailed Weasel & carnivore & 0.4 & 1 \\
\hline Marsh Rice Rat & rodent & 0.054 & 1 \\
\hline Mearns' Grasshopper Mouse & rodent & 0.026 & 1 \\
\hline Merriam's Kangaroo Rat & rodent & 0.045 & 1 \\
\hline Merriam's Pocket Mouse & rodent & 0.008 & 1 \\
\hline Mexican Ground Squirrel & rodent & 0.223 & 1 \\
\hline Mexican Spiny Pocket Mouse & rodent & 0.049 & 1 \\
\hline Mexican Vole & rodent & 0.039 & 1 \\
\hline Mexican Woodrat & rodent & 0.163 & 1 \\
\hline Mink & carnivore & 0.782 & 1 \\
\hline Nelson's Pocket Mouse & rodent & 0.016 & 1 \\
\hline Northern Grasshopper Mouse & rodent & 0.037 & 1 \\
\hline
\end{tabular}


Table K-1. Species and Body Size Data for Texas Mammals continued...

\begin{tabular}{|c|c|c|c|}
\hline Animal & Order & weight (kg) & size class \\
\hline Northern Pygmy Mouse & rodent & 0.008 & 1 \\
\hline Northern Rock Mouse & rodent & 0.02 & 1 \\
\hline Ord's Kangaroo Rat & rodent & 0.065 & 1 \\
\hline Piñon Mouse & rodent & 0.02 & 1 \\
\hline Plains Harvest Mouse & rodent & 0.008 & 1 \\
\hline Plains Pocket Gopher & rodent & 0.165 & 1 \\
\hline Plains Pocket Mouse & rodent & 0.011 & 1 \\
\hline Prairie Vole & rodent & 0.04 & 1 \\
\hline Rock Pocket Mouse & rodent & 0.015 & 1 \\
\hline Rock Squirrel & rodent & 0.7 & 1 \\
\hline Silky Pocket Mouse & rodent & 0.007 & 1 \\
\hline Southern Plains Woodrat & rodent & 0.257 & 1 \\
\hline Southern Short-tailed Shrew & insectivora & 0.023 & 1 \\
\hline Spotted Ground Squirrel & rodent & 0.125 & 1 \\
\hline Tawny-bellied Cotton Rat & rodent & 0.21 & 1 \\
\hline Texas Antelope Squirrel & rodent & 0.103 & 1 \\
\hline Texas Kangaroo Rat & rodent & 0.08 & 1 \\
\hline Texas Mouse & rodent & 0.03 & 1 \\
\hline Texas Pocket Gopher & rodent & 0.038 & 1 \\
\hline Thirteen-lined Ground Squirrel & rodent & 0.016 & 1 \\
\hline Western Harvest Mouse & rodent & 0.013 & 1 \\
\hline Western Spotted Skunk & carnivore & 0.466 & 1 \\
\hline White-ankled Mouse & rodent & 0.031 & 1 \\
\hline White-footed Mouse & rodent & 0.025 & 1 \\
\hline White-throated Woodrat & rodent & 0.215 & 1 \\
\hline Woodland Vole & rodent & 0.035 & 1 \\
\hline Yellow-faced Pocket Gopher & rodent & 0.275 & 1 \\
\hline Yellow-nosed Cotton Rat & rodent & 0.065 & 1 \\
\hline American Badger & carnivore & 7 & 2 \\
\hline American Beaver & rodent & 18 & 2 \\
\hline Black-tailed Jackrabbit & Lagomorphs & 2.75 & 2 \\
\hline Black-tailed Prairie Dog & rodent & 1.5 & 2 \\
\hline Bobcat & carnivore & 7 & 2 \\
\hline Collared Peccary & artiodactyls & 19 & 2 \\
\hline Common Gray Fox & carnivore & 4 & 2 \\
\hline Common Hog-nosed Skunk & carnivore & 1.9 & 2 \\
\hline Common Raccoon & carnivore & 8.5 & 2 \\
\hline Coyote & carnivore & 17 & 2 \\
\hline Eastern Cottontail & Lagomorphs & 1.5 & 2 \\
\hline Eastern Hog-nosed Skunk & carnivore & 3.25 & 2 \\
\hline Jaguarundi & carnivore & 6.75 & 2 \\
\hline Ocelot & carnivore & 12.5 & 2 \\
\hline Porcupine & rodent & 8 & 2 \\
\hline
\end{tabular}


Table K-1. Species and Body Size Data for Texas Mammals continued....

\begin{tabular}{|c|c|c|c|}
\hline Animal & Order & weight (kg) & size class \\
\hline Ringtail & carnivore & 1.25 & 2 \\
\hline Striped Skunk & carnivore & 4 & 2 \\
\hline Swamp Rabbit & Lagomorphs & 2.25 & 2 \\
\hline Swift or Kit Fox & carnivore & 1.5 & 2 \\
\hline Virginia Opossum & didelphimorae & 3.15 & 2 \\
\hline White-nosed Coati & carnivore & 4.5 & 2 \\
\hline Black Bear & carnivore & 125 & 3 \\
\hline Mountain Sheep & artiodactyls & 83.75 & 3 \\
\hline Mule Deer & artiodactyls & 79.5 & 3 \\
\hline Pronghorn & artiodactyls & 46.7 & 3 \\
\hline White-tailed Deer & artiodactyls & 50 & 3 \\
\hline Grizzly or Brown Bear & carnivore & 212.5 & 3 \\
\hline Wapiti or Elk & artiodactyls & 275 & 3 \\
\hline Bison & artiodactyls & 600 & 4 \\
\hline
\end{tabular}

*See text for details. Data are primarily from Davis and Schmidly (1997) 

Appendix L:

Ethnobotany Data 

Table L-1. Ethnobotany Data (see text for details)

\begin{tabular}{|c|c|c|c|c|c|c|c|c|c|c|c|c|c|c|c|c|c|c|}
\hline & & & Regi & ions & of $\mathrm{T}$ & Texas & & & & & & & Plant & element & reported & used & & \\
\hline $\begin{array}{l}n \\
0 \\
0 \\
\vdots \\
0 \\
. \\
0\end{array}$ & 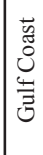 & 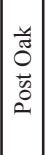 & 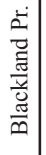 & 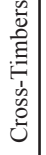 & 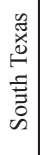 & 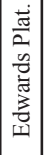 & 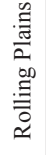 & 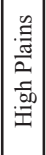 & 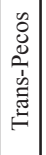 & FAMILY & GENUS & SPECIES & $\begin{array}{c}\text { Greens/ } \\
\text { leaves/ } \\
\text { flowers / } \\
\text { stalk / stem }\end{array}$ & Seeds/ pods & Nuts & $\begin{array}{c}\text { Fruits/ } \\
\text { berries/ } \\
\text { peppers }\end{array}$ & $\begin{array}{c}\text { Tubers/ } \\
\text { hearts / } \\
\text { roots }\end{array}$ & Other \\
\hline 1 & 1 & 1 & 1 & 1 & 1 & 1 & 0 & 0 & 0 & ACERACEAE & Acer & negundo & & & & & & 1 \\
\hline 1 & 1 & 1 & 0 & 0 & 0 & 0 & 0 & 0 & 0 & ACERACEAE & Acer & rubrum & & & & & & 1 \\
\hline 1 & 0 & 0 & 0 & 0 & 0 & 0 & 0 & 0 & 0 & ACERACEAE & Acer & saccharum & & & & & & 1 \\
\hline 1 & 1 & 1 & 1 & 0 & 1 & 1 & 0 & 0 & 1 & AIZOACEAE & Trianthema & portulacastrum & 1 & & & & & \\
\hline 0 & 0 & 0 & 0 & 0 & 0 & 0 & 0 & 1 & 0 & ALISMATACEAE & Sagittaria & cuneata & & & & & 1 & \\
\hline 1 & 1 & 0 & 1 & 0 & 0 & 1 & 1 & 1 & 1 & ALISMATACEAE & Sagittaria & latifolia & & & & & 1 & \\
\hline 0 & 1 & 1 & 1 & 1 & 0 & 1 & 0 & 0 & 1 & AMARANTHACEAE & Amaranthus & acanthochiton & 1 & & & & & \\
\hline 0 & 1 & 1 & 1 & 1 & 1 & 1 & 1 & 1 & 1 & AMARANTHACEAE & Amaranthus & albus & 1 & 1 & & 1 & & \\
\hline 1 & 1 & 0 & 1 & 0 & 1 & 1 & 1 & 1 & 1 & AMARANTHACEAE & Amaranthus & arenicola & 1 & & & & & \\
\hline 0 & 0 & 0 & 0 & 0 & 0 & 0 & 0 & 0 & 1 & AMARANTHACEAE & Amaranthus & fimbriatus & 1 & 1 & & & & \\
\hline 0 & 1 & 1 & 1 & 1 & 1 & 1 & 1 & 1 & 1 & AMARANTHACEAE & Amaranthus & palmeri & 1 & 1 & & & & \\
\hline 0 & 1 & 1 & 1 & 1 & 1 & 1 & 1 & 1 & 1 & AMARANTHACEAE & Amaranthus & retroflexus & 1 & 1 & & & & \\
\hline 0 & 0 & 0 & 0 & 0 & 1 & 1 & 0 & 0 & 0 & AMARYLLIDACEAE & Agave & americana & 1 & & & & 1 & \\
\hline 1 & 1 & 1 & 1 & 1 & 0 & 1 & 1 & 1 & 1 & ANACARDIACEAE & Rhus & aromatica & & & & 1 & & \\
\hline 1 & 1 & 1 & 1 & 0 & 0 & 0 & 0 & 0 & 0 & ANACARDIACEAE & Rhus & copallina & & & & 1 & & \\
\hline 1 & 0 & 1 & 1 & 1 & 0 & 1 & 1 & 0 & 0 & ANACARDIACEAE & Rhus & glabra & 1 & & & 1 & & \\
\hline 1 & 0 & 0 & 0 & 0 & 0 & 0 & 0 & 0 & 0 & ANNONACEAE & Asimina & triloba & & & & 1 & & \\
\hline 0 & 0 & 0 & 1 & 0 & 0 & 1 & 1 & 0 & 1 & APIACEAE & Berula & erecta & 1 & & & & & \\
\hline 0 & 0 & 0 & 0 & 0 & 0 & 0 & 1 & 1 & 0 & APIACEAE & Cymopterus & bulbosus & & & & & 1 & \\
\hline 0 & 0 & 0 & 0 & 0 & 0 & 0 & 1 & 1 & 0 & APIACEAE & Cymopterus & montanus & & 1 & & & 1 & \\
\hline 0 & 0 & 0 & 0 & 0 & 0 & 0 & 0 & 0 & 1 & APIACEAE & Cymopterus & multinervatus & & & & & 1 & \\
\hline 1 & 0 & 1 & 1 & 0 & 0 & 0 & 0 & 0 & 0 & APIACEAE & Oxypolis & rigidior & & & & & 1 & \\
\hline 0 & 0 & 0 & 0 & 0 & 0 & 0 & 0 & 0 & 1 & APIACEAE & Pseudocymopterus & montanus & 1 & & & & 1 & \\
\hline 0 & 0 & 0 & 1 & 1 & 1 & 0 & 0 & 0 & 0 & APIACEAE & Sium & suave & & & & & 1 & \\
\hline 1 & 1 & 1 & 1 & 1 & 0 & 1 & 1 & 0 & 1 & APOCYNACEAE & Apocynum & cannabinum & & 1 & & & & 1 \\
\hline 1 & 1 & 0 & 0 & 0 & 0 & 0 & 0 & 0 & 0 & ARACEAE & Peltandra & virginica & & & & & & 1 \\
\hline 1 & 1 & 1 & 1 & 0 & 0 & 1 & 0 & 0 & 0 & ARECACEAE & Sabal & minor & & & & & 1 & \\
\hline 0 & 0 & 0 & 1 & 1 & 1 & 1 & 1 & 0 & 1 & ASCLEPIADACEAE & Asclepias & incarnata & 1 & & & & & \\
\hline 1 & 1 & 1 & 1 & 1 & 1 & 1 & 0 & 0 & 1 & ASCLEPIADACEAE & Asclepias & verticillata & 1 & & & & & \\
\hline 1 & 1 & 1 & 1 & 1 & 1 & 1 & 1 & 1 & 1 & ASCLEPIADACEAE & Asclepias & viridiflora & & & & & 1 & \\
\hline 0 & 0 & 0 & 0 & 0 & 0 & 0 & 0 & 0 & 1 & ASCLEPIADACEAE & Matelea & producta & & 1 & & & & \\
\hline 0 & 0 & 0 & 0 & 1 & 0 & 0 & 1 & 1 & 1 & ASTERACEAE & Artemisia & campestris & & 1 & & & & \\
\hline 0 & 0 & 0 & 0 & 0 & 0 & 0 & 0 & 1 & 1 & ASTERACEAE & Artemisia & carruthii & & 1 & & & & \\
\hline 0 & 0 & 0 & 0 & 0 & 0 & 1 & 1 & 1 & 1 & ASTERACEAE & Artemisia & dracunculus & 1 & 1 & & & & \\
\hline 1 & 1 & 1 & 1 & 1 & 1 & 1 & 1 & 1 & 1 & ASTERACEAE & Artemisia & ludoviciana & 1 & 1 & & & & \\
\hline 0 & 1 & 0 & 0 & 0 & 1 & 1 & 0 & 0 & 1 & ASTERACEAE & Baccharis & salicifolia & 1 & & & & & \\
\hline 0 & 0 & 0 & 0 & 0 & 0 & 1 & 1 & 1 & 1 & ASTERACEAE & Berlandiera & lyrata & 1 & & & & & \\
\hline 1 & 0 & 1 & 1 & 1 & 0 & 1 & 0 & 0 & 1 & ASTERACEAE & Bidens & laevis & & & & & & 1 \\
\hline 0 & 0 & 0 & 0 & 0 & 0 & 0 & 0 & 1 & 1 & ASTERACEAE & Brickellia & californica & 1 & & & & & \\
\hline 0 & 0 & 0 & 0 & 0 & 0 & 0 & 0 & 0 & 1 & ASTERACEAE & Brickellia & grandiflora & & 1 & & & & \\
\hline 1 & 1 & 1 & 1 & 0 & 1 & 0 & 0 & 0 & 0 & ASTERACEAE & Cirsium & horridulum & & & & & 1 & \\
\hline 0 & 0 & 0 & 0 & 1 & 0 & 1 & 1 & 1 & 1 & ASTERACEAE & Cirsium & ochrocentrum & & & & & 1 & \\
\hline 0 & 0 & 0 & 1 & 1 & 1 & 1 & 1 & 1 & 1 & ASTERACEAE & Cirsium & undulatum & & & & & 1 & \\
\hline 1 & 1 & 1 & 1 & 1 & 1 & 1 & 1 & 1 & 1 & ASTERACEAE & Conyza & canadensis & 1 & & & & & \\
\hline 1 & 1 & 1 & 1 & 1 & 1 & 1 & 1 & 1 & 1 & ASTERACEAE & Coreopsis & tinctoria & 1 & & & & & \\
\hline
\end{tabular}


Table L-1. Ethnobotany Data (see text for details) continued...

\begin{tabular}{|c|c|c|c|c|c|c|c|c|c|c|c|c|c|c|c|c|c|c|}
\hline & & & Regi & ions & of $\mathrm{T}$ & Texa: & & & & & & & Plant & element & reported & used & & \\
\hline 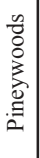 & 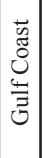 & 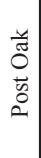 & 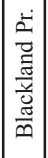 & 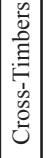 & 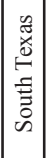 & 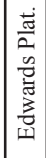 & 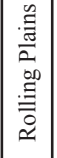 & 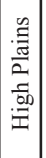 & 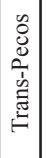 & FAMILY & GENUS & SPECIES & $\begin{array}{c}\text { Greens/ } \\
\text { leaves/ } \\
\text { flowers/ } \\
\text { stalk/stem }\end{array}$ & Seeds/pod & Nuts & $\begin{array}{l}\text { Fruits/ } \\
\text { berries/ } \\
\text { peppers }\end{array}$ & $\begin{array}{c}\text { Tubers/ } \\
\text { hearts/ } \\
\text { roots }\end{array}$ & Other \\
\hline 0 & 0 & 0 & 0 & \begin{tabular}{|l|l|}
0 \\
\end{tabular} & 0 & 0 & 0 & 1 & 0 & ASTERACEAE & Crepis & runcinata & 1 & & & & & \\
\hline 0 & 0 & 0 & 0 & \begin{tabular}{|l|}
0 \\
\end{tabular} & 0 & 0 & 1 & 1 & 1 & ASTERACEAE & Dyssodia & papposa & 1 & 1 & & & & \\
\hline 0 & 0 & 0 & 0 & \begin{tabular}{|l|}
0 \\
\end{tabular} & 0 & 1 & 1 & 1 & 1 & ASTERACEAE & Gaillardia & pinnatifida & & 1 & & & & \\
\hline 1 & 1 & 1 & 1 & 1 & 1 & 1 & 1 & 1 & 1 & ASTERACEAE & Helianthus & annuus & & 1 & & & & \\
\hline 0 & 1 & 1 & 1 & 1 & 0 & 1 & 1 & 1 & 1 & ASTERACEAE & Helianthus & maximiliani & & & & & 1 & \\
\hline 0 & 0 & 0 & 1 & 0 & 0 & 0 & 0 & 0 & 0 & ASTERACEAE & Helianthus & tuberosus & & & & & 1 & \\
\hline 0 & 0 & 0 & 0 & 0 & 0 & 1 & 0 & 0 & 1 & ASTERACEAE & Hymenoclea & monogyra & & 1 & & & & \\
\hline 0 & 0 & 0 & 0 & 0 & 0 & 0 & 0 & 1 & 0 & ASTERACEAE & Hymenopappus & filifolius & 1 & & & & 1 & \\
\hline 1 & 1 & 1 & 1 & 1 & 0 & 1 & 0 & 0 & 0 & ASTERACEAE & Lactuca & canadensis & 1 & & & & & \\
\hline 1 & 1 & 1 & 1 & 1 & 1 & 1 & 1 & 1 & 1 & ASTERACEAE & Lactuca & ludoviciana & 1 & & & & & \\
\hline 0 & 0 & 0 & 0 & 0 & 0 & 0 & 0 & 0 & 1 & ASTERACEAE & Lactuca & tatarica & & & & & & 1 \\
\hline 1 & 0 & 0 & 0 & 0 & 0 & 0 & 1 & 1 & 1 & ASTERACEAE & Liatris & punctata & 1 & & & & 1 & \\
\hline 0 & 0 & 0 & 0 & \begin{tabular}{|l|}
0 \\
\end{tabular} & 0 & 0 & 1 & 1 & 0 & ASTERACEAE & Lygodesmia & juncea & & & & & & 1 \\
\hline 0 & 0 & 0 & 0 & \begin{tabular}{|l|}
0 \\
\end{tabular} & 1 & 1 & 1 & 1 & 1 & ASTERACEAE & Parthenium & incanum & 1 & & & & & \\
\hline 0 & 1 & 0 & 0 & \begin{tabular}{|l|}
0 \\
\end{tabular} & 1 & 1 & 1 & 1 & 1 & ASTERACEAE & Pectis & angustifolia & 1 & & & & & \\
\hline 0 & 0 & 0 & 0 & \begin{tabular}{|l|}
0 \\
\end{tabular} & 0 & 0 & 0 & 0 & 1 & ASTERACEAE & Pectis & papposa & 1 & 1 & & & & \\
\hline 1 & 1 & 1 & 1 & 1 & 0 & 0 & 0 & 0 & 0 & ASTERACEAE & Pyrrhopappus & carolinianus & & & & & 1 & \\
\hline 1 & 1 & 1 & 1 & 1 & 1 & 1 & 1 & 1 & 1 & ASTERACEAE & Ratibida & columnifera & 1 & & & & & \\
\hline 1 & 0 & 0 & 0 & 0 & 0 & 0 & 0 & 0 & 0 & ASTERACEAE & Rudbeckia & laciniata & 1 & & & & & \\
\hline 1 & 1 & 0 & 1 & 1 & 0 & 0 & 0 & 0 & 0 & ASTERACEAE & Silphium & laciniatum & & & & & & 1 \\
\hline 0 & 0 & 0 & 0 & 0 & 0 & 0 & 1 & 1 & 1 & ASTERACEAE & Stephanomeria & pauciflora & & & & & & 1 \\
\hline 1 & 1 & 0 & 1 & 0 & 1 & 1 & 1 & 1 & 1 & ASTERACEAE & Thelesperma & filifolium & 1 & & & & & \\
\hline 0 & 0 & 0 & 0 & 0 & 0 & 1 & 0 & 1 & 1 & ASTERACEAE & Thelesperma & longipes & 1 & & & & & \\
\hline 0 & 0 & 0 & 0 & 1 & 0 & 1 & 1 & 1 & 1 & ASTERACEAE & Thelesperma & megapotamicum & 1 & & & & & \\
\hline 1 & 1 & 1 & 1 & 1 & 1 & 1 & 1 & 1 & 1 & ASTERACEAE & Xanthium & strumarium & & 1 & & & & \\
\hline 0 & 0 & 0 & 0 & 0 & 0 & 0 & 0 & 0 & 1 & BERBERIDACEAE & Mahonia & haematocarpa & & & & 1 & & \\
\hline 0 & 0 & 0 & 0 & 0 & 0 & 0 & 0 & 0 & 1 & BERBERIDACEAE & Mahonia & repens & & & & 1 & & \\
\hline 1 & 1 & 1 & 1 & \begin{tabular}{|l|l|}
0 & \\
\end{tabular} & 0 & 0 & 0 & 0 & 0 & BERBERIDACEAE & Podophyllum & peltatum & & & & 1 & & \\
\hline 0 & 0 & 0 & 0 & 1 & 0 & 1 & 1 & 1 & 1 & BIGNONIACEAE & Chilopsis & linearis & 1 & & & & & \\
\hline 0 & 0 & 0 & 1 & 1 & 0 & 1 & 1 & 1 & 1 & BORAGINACEAE & Heliotropium & convolvulaceum & & 1 & & & & \\
\hline 0 & 1 & 1 & 0 & 1 & 1 & 1 & 1 & 1 & 1 & BORAGINACEAE & Heliotropium & curassavicum & & 1 & & & & \\
\hline 1 & 1 & 1 & 1 & 1 & 1 & 1 & 1 & 1 & 1 & BORAGINACEAE & Lithospermum & incisum & & & & & 1 & \\
\hline 0 & 0 & 0 & 0 & 0 & 0 & 0 & 0 & 0 & 1 & BORAGINACEAE & Lithospermum & multiflorum & & 1 & & & & \\
\hline 1 & 0 & 0 & 0 & 0 & 0 & 0 & 0 & 0 & 0 & BRASSICACEAE & Cardamine & concatenata & & & & & 1 & \\
\hline 0 & 0 & 0 & 0 & 1 & 0 & 0 & 0 & 0 & 1 & BRASSICACEAE & Descurainia & incana & & 1 & & & & \\
\hline 0 & 1 & 1 & 1 & 1 & 1 & 1 & 1 & 1 & 1 & BRASSICACEAE & Descurainia & pinnata & 1 & 1 & & & & \\
\hline 0 & 1 & 0 & 0 & 0 & 1 & 1 & 1 & 0 & 1 & BRASSICACEAE & Lepidium & lasiocarpum & & 1 & & & & \\
\hline 0 & 0 & 0 & 0 & 0 & 0 & 1 & 0 & 1 & 1 & BRASSICACEAE & Lepidium & montanum & & 1 & & & & \\
\hline 0 & 0 & 0 & 0 & 0 & 0 & 0 & 0 & 0 & 1 & BRASSICACEAE & Lepidium & thurberi & & 1 & & & & \\
\hline 1 & 1 & 1 & 1 & 1 & 1 & 1 & 1 & 1 & 1 & BRASSICACEAE & Lepidium & virginicum & 1 & & & & & \\
\hline 0 & 0 & 0 & 0 & 0 & 1 & 0 & 0 & 0 & 1 & BRASSICACEAE & Stanleya & pinnata & 1 & & & & & \\
\hline 0 & 0 & 0 & 0 & 0 & 0 & 1 & 0 & 0 & 1 & BRASSICACEAE & Thelypodium & wrightii & 1 & & & & & \\
\hline 0 & 0 & 0 & 0 & \begin{tabular}{|l|}
0 \\
\end{tabular} & 0 & 0 & 0 & 0 & 1 & BRASSICACEAE & Thlaspi & montanum & & 1 & & & & \\
\hline
\end{tabular}


Table L-1. Ethnobotany Data (see text for details) continued...

\begin{tabular}{|c|c|c|c|c|c|c|c|c|c|c|c|c|c|c|c|c|c|c|}
\hline & & & Regi & ions & of 7 & Texas & & & & & & & Plant & element & reported & used & & \\
\hline 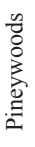 & $\begin{array}{l}\text { 学 } \\
0 \\
0 \\
\text { 生 } \\
0 \\
0\end{array}$ & $\begin{array}{l}\frac{4}{\pi} \\
0 \\
\overrightarrow{0} \\
0 \\
0\end{array}$ & 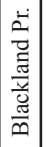 & 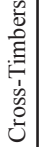 & 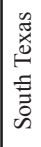 & 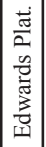 & 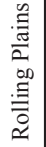 & 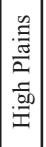 & 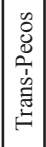 & FAMILY & GENUS & SPECIES & $\begin{array}{c}\text { Greens/ } \\
\text { leaves/ } \\
\text { flowers/ } \\
\text { stalk/stem }\end{array}$ & Seeds/pods & Nuts & $\begin{array}{c}\text { Fruit/ } \\
\text { berries/ } \\
\text { peppers }\end{array}$ & $\begin{array}{c}\text { Tubers/ } \\
\text { hearts/ } \\
\text { pods }\end{array}$ & Other \\
\hline 0 & 1 & 0 & 1 & 0 & 1 & 1 & 0 & 0 & 1 & CACTACEAE & Ferocactus & wislizeni & 1 & 1 & & & & \\
\hline 0 & 0 & \begin{tabular}{|l|l|}
0 \\
\end{tabular} & \begin{tabular}{|l|}
0 \\
\end{tabular} & 0 & 0 & \begin{tabular}{|l|}
0 \\
\end{tabular} & 0 & \begin{tabular}{|l|l|}
0 \\
\end{tabular} & 1 & CACTACEAE & Mammillaria & grahamii & & & & 1 & & \\
\hline 0 & 0 & \begin{tabular}{|l|l|}
0 \\
\end{tabular} & \begin{tabular}{|l|}
0 \\
\end{tabular} & 0 & 0 & \begin{tabular}{|l|}
0 \\
\end{tabular} & 0 & 1 & 1 & CACTACEAE & Mammillaria & wrightii & & & & 1 & & \\
\hline 0 & 0 & 0 & 0 & 0 & 0 & 1 & 0 & 0 & 0 & CACTACEAE & Opuntia & ficus-indica & 1 & & & 1 & & \\
\hline 0 & 0 & 0 & 0 & 0 & 0 & 0 & 1 & 1 & 0 & CACTACEAE & Opuntia & fragilis & 1 & & & 1 & & \\
\hline 1 & 1 & 1 & \begin{tabular}{|l|l|}
1 &
\end{tabular} & 1 & 1 & 1 & 0 & 0 & 0 & CACTACEAE & Opuntia & humifusa & 1 & & & 1 & & \\
\hline 0 & 0 & 0 & 0 & 0 & 0 & 1 & 1 & 1 & 1 & CACTACEAE & Opuntia & imbricata & 1 & & & 1 & & \\
\hline 0 & 1 & 0 & 1 & 1 & 1 & 1 & 1 & 1 & 1 & CACTACEAE & Opuntia & leptocaulis & & & & 1 & & \\
\hline 1 & 1 & \begin{tabular}{|l|l|}
1 & \\
\end{tabular} & \begin{tabular}{|l|l|}
1 & \\
\end{tabular} & 1 & 1 & 1 & 1 & 1 & 1 & CACTACEAE & Opuntia & macrorhiza & & & & 1 & & \\
\hline 0 & 0 & 0 & 0 & 1 & 1 & 1 & 1 & 1 & 1 & САCTACEAE & Opuntia & phaeacantha & 1 & & & 1 & & \\
\hline 0 & 0 & 0 & 0 & 0 & 0 & 1 & 1 & 1 & 1 & CACTACEAE & Opuntia & polyacantha & 1 & & & 1 & & \\
\hline 0 & 0 & 0 & 0 & 0 & 0 & 0 & 0 & 0 & 1 & CAPPARIDACEAE & Cleome & multicaulis & 1 & & & & & \\
\hline 0 & 1 & 0 & 0 & 0 & 0 & 0 & 1 & 0 & 0 & CAPPARIDACEAE & Cleome & serrulata & 1 & 1 & & & & \\
\hline 1 & 1 & 1 & 1 & 1 & 1 & 1 & 1 & 1 & 1 & CAPPARIDACEAE & Polanisia & dodecandra & 1 & & & & & \\
\hline 0 & 0 & 0 & 0 & 0 & 0 & 0 & 0 & 0 & 1 & CAPPARIDACEAE & Wislizenia & refracta & 1 & & & & & \\
\hline 1 & 1 & 1 & 1 & 1 & 1 & 1 & 1 & 1 & 0 & CAPRIFOLIACEAE & Sambucus & canadensis & & & & 1 & & \\
\hline 0 & 0 & 0 & 0 & 0 & 0 & 0 & 0 & 0 & 1 & CAPRIFOLIACEAE & Sambucus & cerulea & & & & 1 & & \\
\hline 0 & 0 & 0 & 0 & 0 & 0 & 0 & 0 & 1 & 0 & CAPRIFOLIACEAE & Symphoricarpos & occidentalis & & & & 1 & & \\
\hline 1 & 1 & 1 & 0 & 0 & 0 & 0 & 0 & 0 & 0 & CAPRIFOLIACEAE & Viburnum & nudum & & & & 1 & & \\
\hline 1 & 0 & 0 & 0 & 0 & 0 & 0 & 0 & 0 & 0 & CAPRIFOLIACEAE & Viburnum & prunifolium & & & & 1 & & \\
\hline 0 & 1 & 0 & 0 & 0 & 1 & 1 & 1 & 1 & 1 & CARYOPHYLLACEAE & Paronychia & jamesii & & & & & & 1 \\
\hline 0 & 0 & 0 & 0 & 0 & 0 & 1 & 0 & 0 & 1 & CELASTRACEAE & Celastrus & scandens & & & & & & 1 \\
\hline 0 & 0 & 0 & 0 & 0 & 0 & 0 & 0 & 0 & 1 & CHENOPODIACEAE & Allenrolfea & occidentalis & & 1 & & & & \\
\hline 0 & 1 & 0 & 0 & 1 & 0 & 1 & 1 & 0 & 1 & CHENOPODIACEAE & Atriplex & argentea & 1 & 1 & & 1 & & \\
\hline 0 & 0 & 0 & 0 & 0 & 1 & 1 & 1 & 1 & 1 & CHENOPODIACEAE & Atriplex & canescens & 1 & 1 & & & & \\
\hline 0 & 0 & 0 & 0 & 0 & 0 & 0 & 1 & 1 & 1 & CHENOPODIACEAE & Atriplex & confertifolia & 1 & 1 & & & & \\
\hline 0 & 0 & 0 & 0 & 0 & 0 & 1 & 1 & 0 & 0 & CHENOPODIACEAE & Atriplex & elegans & 1 & & & & & \\
\hline 0 & 0 & 0 & 0 & 0 & 0 & 0 & 0 & 0 & 1 & CHENOPODIACEAE & Atriplex & obovata & 1 & & & & & \\
\hline 0 & 0 & 0 & 0 & 0 & 0 & 0 & 0 & 0 & 1 & CHENOPODIACEAE & Atriplex & rosea & & 1 & & & & \\
\hline 0 & 0 & 0 & 0 & 0 & 0 & 0 & 0 & 0 & 1 & CHENOPODIACEAE & Atriplex & saccaria & 1 & & & & & \\
\hline 0 & 0 & 0 & 0 & 0 & 0 & 0 & 0 & 0 & 1 & CHENOPODIACEAE & Atriplex & wrightii & 1 & & & & & \\
\hline 0 & 0 & 0 & 1 & 1 & 0 & 0 & 0 & 0 & 0 & CHENOPODIACEAE & Chenopodium & album & 1 & 1 & & & & \\
\hline 0 & 0 & 0 & 1 & 0 & 0 & 1 & 1 & 0 & 1 & CHENOPODIACEAE & Chenopodium & fremontii & 1 & 1 & & & & \\
\hline 0 & 0 & 0 & 0 & 0 & 0 & 0 & 0 & 0 & 1 & CHENOPODIACEAE & Chenopodium & graveolens & & 1 & & & & \\
\hline 0 & 0 & 0 & 0 & 0 & 1 & 1 & 1 & 1 & 1 & CHENOPODIACEAE & Chenopodium & incanum & 1 & 1 & & & & \\
\hline 0 & 1 & 0 & 0 & 1 & 0 & 1 & 1 & 1 & 1 & CHENOPODIACEAE & Chenopodium & leptophyllum & 1 & 1 & & & & \\
\hline 1 & 0 & 1 & 1 & 1 & 0 & 1 & 1 & 1 & 1 & CHENOPODIACEAE & Cycloloma & atriplicifolium & & 1 & & & & \\
\hline 0 & 1 & 0 & 0 & 0 & 0 & 0 & 0 & 0 & 0 & CHENOPODIACEAE & Salicornia & virginica & 1 & & & & & \\
\hline 0 & 0 & 0 & 0 & 0 & 0 & 0 & 0 & 0 & 1 & CHENOPODIACEAE & Sarcobatus & vermiculatus & 1 & & 1 & & & \\
\hline 0 & 1 & 0 & 0 & 0 & 1 & 0 & 0 & 0 & 0 & CHENOPODIACEAE & Suaeda & calceoliformis & & 1 & & & & \\
\hline 0 & 0 & 0 & 0 & 0 & 0 & 0 & 0 & 0 & 1 & CHENOPODIACEAE & Suaeda & moquinii & & 1 & & & & \\
\hline 0 & 0 & 0 & 0 & 0 & 0 & 1 & 1 & 1 & 1 & CHENOPODIACEAE & Suaeda & suffrutescens & & 1 & & & & \\
\hline 1 & 1 & 1 & 1 & 1 & 1 & 1 & 1 & 1 & 1 & COMMELINACEAE & Tradescantia & occidentalis & 1 & & & & & \\
\hline
\end{tabular}


Table L-1. Ethnobotany Data (see text for details) continued...

\begin{tabular}{|c|c|c|c|c|c|c|c|c|c|c|c|c|c|c|c|c|c|c|}
\hline & & & Regi & ions & of $\mathrm{T}$ & Texa & & & & & & & Plant & element & reported & used & & \\
\hline \begin{tabular}{|c|}
0 \\
0 \\
0 \\
$\vdots$ \\
0 \\
. \\
$\vdots$ \\
0
\end{tabular} & 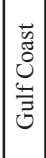 & 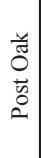 & 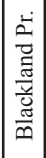 & 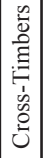 & 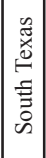 & 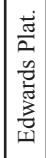 & 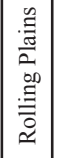 & 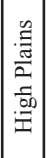 & 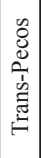 & FAMILY & GENUS & SPECIES & $\begin{array}{c}\text { Greens/ } \\
\text { leaves/ } \\
\text { flowers/ } \\
\text { stalk/stem }\end{array}$ & Seeds/pods & Nuts & $\begin{array}{c}\text { Fruits/ } \\
\text { berries/ } \\
\text { pepper }\end{array}$ & $\begin{array}{c}\text { Tubers/ } \\
\text { hearts/ } \\
\text { roots }\end{array}$ & Other \\
\hline 1 & 0 & 1 & 1 & 1 & 0 & 0 & 0 & 0 & 0 & CONVOLVULACEAE & Ipomoea & batatas & & & & & 1 & \\
\hline 0 & 0 & 0 & 0 & 1 & 0 & 1 & 1 & 1 & 1 & CONVOLVULACEAE & Ipomoea & leptophylla & & & & & 1 & \\
\hline 1 & 0 & 1 & 1 & 1 & 1 & 1 & 0 & 0 & 0 & CONVOLVULACEAE & Ipomoea & pandurata & & & & & 1 & \\
\hline 0 & 0 & 0 & 0 & 0 & 0 & 0 & 0 & 0 & 1 & CUCURBITACEAE & Cucurbita & digitata & & 1 & & & & \\
\hline 0 & 1 & 1 & 1 & 1 & 1 & 1 & 1 & 1 & 1 & CUCURBITACEAE & Cucurbita & foetidissima & & 1 & & 1 & & \\
\hline 0 & 0 & 0 & 0 & 0 & 0 & 1 & 1 & 1 & 1 & CUPRESSACEAE & Juniperus & monosperma & & & & 1 & & \\
\hline 0 & 0 & 0 & 0 & 0 & 0 & 0 & 1 & 1 & 1 & CUPRESSACEAE & Juniperus & scopulorum & & & & 1 & & \\
\hline 1 & 1 & 1 & 1 & 0 & 0 & 1 & 0 & 0 & 0 & CUPRESSACEAE & Juniperus & virginiana & & & & 1 & & \\
\hline 1 & 1 & 1 & 1 & 1 & 0 & 1 & 0 & 0 & 0 & CYPERACEAE & Cyperus & erythrorhizos & & 1 & & & & \\
\hline 1 & 1 & 1 & 1 & 1 & 1 & 1 & 0 & 0 & 1 & CYPERACEAE & Cyperus & esculentus & & & & & 1 & \\
\hline 1 & 1 & 1 & 1 & 1 & 1 & 1 & 1 & 0 & 1 & CYPERACEAE & Cyperus & odoratus & & 1 & & & 1 & \\
\hline 1 & 1 & 1 & 1 & 1 & 1 & 1 & 1 & 0 & 1 & CYPERACEAE & Cyperus & squarrosus & & & & & 1 & \\
\hline 0 & 1 & 1 & 1 & 1 & 1 & 1 & 1 & 1 & 1 & CYPERACEAE & Eleocharis & palustris & & & & & & 1 \\
\hline 0 & 1 & 1 & 1 & 1 & 1 & 1 & 1 & 1 & 1 & EBENACEAE & Diospyros & texana & & & & 1 & & \\
\hline 1 & 1 & 1 & 1 & 1 & 0 & 1 & 1 & 0 & 0 & EBENACEAE & Diospyros & virginiana & & & & 1 & & \\
\hline 0 & 0 & 0 & 0 & 0 & 1 & 1 & 1 & 0 & 1 & EPHEDRACEAE & Ephedra & nevadensis & 1 & & & & & \\
\hline 0 & 0 & 0 & 0 & 0 & 0 & 0 & 1 & 1 & 1 & EPHEDRACEAE & Ephedra & torreyana & 1 & & & & & \\
\hline 0 & 0 & 0 & 0 & 0 & 0 & 0 & 0 & 1 & 0 & EQUISETACEAE & Equisetum & arvense & 1 & & & & & \\
\hline 0 & 1 & 1 & 1 & 1 & 1 & 1 & 1 & 1 & 1 & EQUISETACEAE & Equisetum & hyemale & 1 & & & & & \\
\hline 0 & 1 & 1 & 1 & 1 & 1 & 1 & 1 & 1 & 1 & EQUISETACEAE & Equisetum & laevigatum & 1 & & & & 1 & \\
\hline 0 & 0 & 0 & 0 & 0 & 0 & 0 & 0 & 0 & 1 & ERICACEAE & Arctostaphylos & pungens & & 1 & & 1 & & \\
\hline 0 & 0 & 0 & 0 & 0 & 0 & 0 & 0 & 0 & 1 & ERICACEAE & Pterospora & andromeda & 1 & & & & & \\
\hline 1 & 1 & 1 & 0 & \begin{tabular}{|l|}
0 \\
\end{tabular} & 0 & 0 & 0 & 0 & 0 & ERICACEAE & Vaccinium & corymbosum & & & & 1 & & \\
\hline 0 & 0 & 0 & 0 & 1 & 1 & 1 & 1 & 1 & 1 & EUPHORBIACEAE & Euphorbia & marginata & & & & & & 1 \\
\hline 0 & 1 & 0 & 0 & 1 & 1 & 1 & 1 & 0 & 1 & FABACEAE & Acacia & greggii & & 1 & & & & \\
\hline 1 & 1 & 1 & 1 & 1 & 0 & 0 & 0 & 0 & 0 & FABACEAE & Amphicarpaea & bracteata & 1 & 1 & & 1 & 1 & \\
\hline 1 & 0 & 1 & 0 & 1 & 0 & 1 & 0 & 0 & 0 & FABACEAE & Apios & americana & & 1 & & & 1 & \\
\hline 1 & 1 & 1 & 1 & 0 & 0 & 0 & 0 & 0 & 0 & FABACEAE & Astragalus & canadensis & & & & & 1 & \\
\hline 0 & 1 & 1 & 1 & 1 & 0 & 1 & 0 & 1 & 1 & FABACEAE & Astragalus & crassicarpus & & & & 1 & & \\
\hline 0 & 0 & 0 & 0 & 0 & 1 & 1 & 1 & 1 & 1 & FABACEAE & Caesalpinia & jamesii & & & & & 1 & \\
\hline 1 & 1 & 1 & 1 & 1 & 0 & 1 & 1 & 1 & 1 & FABACEAE & Cercis & canadensis & 1 & 1 & & & & \\
\hline 1 & 1 & 1 & 1 & 1 & 0 & 1 & 1 & 1 & 1 & FABACEAE & Dalea & candida & & & & & 1 & \\
\hline 0 & 1 & 0 & 0 & 1 & 1 & 1 & 1 & 1 & 1 & FABACEAE & Dalea & lanata & & & & & 1 & \\
\hline 0 & 0 & 0 & 0 & 1 & 1 & 1 & 1 & 0 & 1 & FABACEAE & Dalea & lasiathera & & & & & 1 & \\
\hline 0 & 0 & 0 & 1 & 1 & 0 & 0 & 1 & 0 & 1 & FABACEAE & Dalea & purpurea & 1 & & & & 1 & \\
\hline 1 & 1 & 1 & 1 & 1 & 1 & 1 & 0 & 0 & 0 & FABACEAE & Gleditsia & triacanthos & & 1 & & & & \\
\hline 0 & 0 & 0 & 0 & 0 & 0 & 0 & 1 & 1 & 1 & FABACEAE & Glycyrrhiza & lepidota & 1 & & & & 1 & \\
\hline 0 & 0 & 0 & 0 & 0 & 0 & 0 & 0 & 0 & 1 & FABACEAE & Lathyrus & graminifolius & 1 & & & & & \\
\hline 0 & 0 & 0 & 0 & 0 & 0 & 0 & 1 & 0 & 0 & FABACEAE & Lathyrus & polymorphus & & 1 & & & & \\
\hline 1 & 0 & 0 & 0 & 1 & 0 & 0 & 1 & 0 & 0 & FABACEAE & Lespedeza & capitata & 1 & & & & & \\
\hline 0 & 0 & 0 & 1 & 1 & 0 & 1 & 1 & 0 & 0 & FABACEAE & Oxytropis & lambertii & & & & & & 1 \\
\hline 0 & 0 & 0 & 1 & 1 & 0 & 1 & 1 & 1 & 0 & FABACEAE & Pediomelum & hypogaeum & & & & & 1 & \\
\hline 0 & 0 & 0 & 0 & 0 & 0 & 0 & 0 & 0 & 1 & FABACEAE & Phaseolus & acutifolius & & 1 & & & & \\
\hline
\end{tabular}


Table L-1. Ethnobotany Data (see text for details) continued...

\begin{tabular}{|c|c|c|c|c|c|c|c|c|c|c|c|c|c|c|c|c|c|c|}
\hline & & & Regi & ions & of 7 & Texas & & & & & & & Plant & element & reported & used & & \\
\hline & 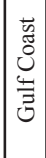 & 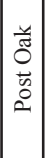 & 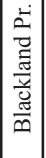 & 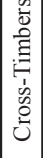 & 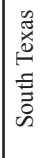 & 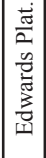 & 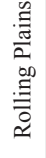 & 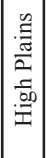 & 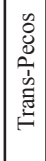 & FAMILY & GENUS & SPECIES & $\begin{array}{c}\text { Greens/ } \\
\text { leaves/ } \\
\text { flowers/ } \\
\text { stalk/stem }\end{array}$ & Seeds/pods & Nuts & $\begin{array}{c}\text { Fruits/ } \\
\text { berries/ } \\
\text { peppers }\end{array}$ & $\begin{array}{c}\text { Tubers/ } \\
\text { hearts/ } \\
\text { roots }\end{array}$ & Other \\
\hline 1 & 1 & 1 & 1 & 1 & 1 & 1 & 1 & 1 & 1 & FABACEAE & Prosopis & glandulosa & & 1 & & & & \\
\hline 0 & 0 & 0 & 0 & 0 & 0 & 1 & 0 & 0 & 1 & FABACEAE & Prosopis & pubescens & & 1 & & & & \\
\hline 0 & 1 & 1 & 1 & 1 & 0 & 1 & 1 & 1 & 1 & FABACEAE & Psoralidium & tenuiflorum & & & & & & 1 \\
\hline 0 & 0 & 0 & 0 & 0 & 0 & 0 & 0 & 0 & 1 & FABACEAE & Robinia & neomexicana & 1 & 1 & & & & \\
\hline 0 & 0 & 0 & 0 & 0 & 0 & 1 & 1 & 1 & 1 & FABACEAE & Sophora & nuttalliana & & & & & 1 & \\
\hline 1 & 1 & 1 & 1 & 1 & 0 & 1 & 0 & 0 & 0 & FABACEAE & Strophostyles & helvula & & & & & 1 & \\
\hline 0 & 0 & 0 & 0 & 0 & 0 & 0 & 0 & 0 & 1 & FABACEAE & Trifolium & willdenovii & 1 & 1 & & & & \\
\hline 0 & 0 & 0 & 0 & 0 & 0 & 0 & 1 & 1 & 1 & FABACEAE & Vicia & americana & 1 & 1 & & & & \\
\hline 1 & 1 & 1 & 0 & 0 & 0 & 0 & 0 & 0 & 0 & FAGACEAE & Fagus & grandifolia & & & 1 & & & \\
\hline 1 & 1 & 1 & 1 & 0 & 0 & 0 & 0 & 0 & 0 & FAGACEAE & Quercus & $a l b a$ & & & 1 & & & \\
\hline 0 & 0 & 0 & 0 & 0 & 0 & 0 & 0 & 0 & 1 & FAGACEAE & Quercus & emoryi & & & 1 & & & \\
\hline 0 & 0 & 0 & 0 & 0 & 0 & 0 & 0 & 0 & 1 & FAGACEAE & Quercus & gambelii & & & 1 & & & \\
\hline 0 & 0 & 0 & 0 & 0 & 0 & 1 & 0 & 0 & 1 & FAGACEAE & Quercus & grisea & & & 1 & & & \\
\hline 1 & 1 & 1 & 1 & 0 & 0 & 1 & 1 & 0 & 0 & FAGACEAE & Quercus & macrocarpa & & & 1 & & & \\
\hline 1 & 1 & 1 & 1 & 0 & 0 & 1 & 1 & 0 & 0 & FAGACEAE & Quercus & marilandica & & & 1 & & & \\
\hline 1 & 1 & 1 & 1 & 0 & 0 & 0 & 0 & 0 & 0 & FAGACEAE & Quercus & nigra & & & 1 & & & \\
\hline 0 & 0 & 0 & 0 & 0 & 0 & 0 & 0 & 0 & 1 & FAGACEAE & Quercus & oblongifolia & & & 1 & & & \\
\hline 0 & 0 & 0 & 0 & 0 & 0 & 1 & 0 & 0 & 1 & FAGACEAE & Quercus & pauciloba & & & 1 & & & \\
\hline 0 & 0 & 0 & 0 & 0 & 0 & 1 & 0 & 0 & 1 & FAGACEAE & Quercus & pungens & & & 1 & & & \\
\hline 1 & 1 & 1 & 1 & 1 & 1 & 1 & 1 & 0 & 0 & FAGACEAE & Quercus & stellata & & & 1 & & & \\
\hline 0 & 0 & 0 & 0 & 0 & 0 & 0 & 0 & 0 & 1 & FAGACEAE & Quercus & turbinella & & & 1 & & & \\
\hline 1 & 0 & 1 & 1 & 0 & 0 & 0 & 0 & 0 & 0 & FAGACEAE & Quercus & velutina & & & 1 & & & \\
\hline 0 & 0 & 0 & 0 & 0 & 0 & 1 & 0 & 0 & 1 & FOUQUIERIACEAE & Fouquieria & splendens & 1 & 1 & & & & \\
\hline 1 & 0 & 1 & 1 & 1 & 0 & 1 & 1 & 1 & 1 & HALORAGACEAE & Myriophyllum & spicatum & & & & & 1 & \\
\hline 1 & 1 & 0 & 0 & 0 & 0 & 1 & 0 & 0 & 0 & HAMAMELIDACEAE & Hamamelis & virginiana & 1 & & & & & \\
\hline 1 & 1 & 1 & 0 & 0 & 0 & 0 & 0 & 0 & 0 & HAMAMELIDACEAE & Liquidambar & styraciflua & & & & & & 1 \\
\hline 1 & 1 & 1 & 1 & 0 & 0 & 0 & 0 & 0 & 0 & JUGLANDACEAE & Carya & cordiformis & & & 1 & & & \\
\hline 1 & 1 & 1 & 1 & 1 & 1 & 1 & 1 & 0 & 1 & JUGLANDACEAE & Carya & illinioensis & & & 1 & & & \\
\hline 1 & 1 & 0 & 0 & 0 & 0 & 0 & 0 & 0 & 0 & JUGLANDACEAE & Carya & ovata & & & 1 & & & \\
\hline 0 & 0 & 0 & 0 & 0 & 0 & 1 & 1 & 1 & 1 & JUGLANDACEAE & Juglans & major & & & 1 & & & \\
\hline 1 & 1 & 1 & 1 & 1 & 0 & 1 & 1 & 0 & 0 & JUGLANDACEAE & Juglans & nigra & & & 1 & & & \\
\hline 0 & 0 & 0 & 0 & 0 & 0 & 0 & 1 & 1 & 1 & JUNCACEAE & Juncus & balticus & & 1 & & & & \\
\hline 1 & 1 & 1 & 1 & 1 & 0 & 1 & 0 & 0 & 0 & JUNCACEAE & Juncus & effusus & 1 & & & & & \\
\hline 0 & 0 & 0 & 0 & 0 & 0 & 0 & 0 & 0 & 1 & LAMIACEAE & Agastache & pallidiflora & 1 & & & & & \\
\hline 0 & 1 & 0 & 1 & 0 & 1 & 1 & 1 & 1 & 1 & LAMIACEAE & Hedeoma & drummondii & 1 & & & & & \\
\hline 0 & 0 & 0 & 0 & 0 & 0 & 0 & 1 & 1 & 0 & LAMIACEAE & Lycopus & asper & & & & & & 1 \\
\hline 0 & 0 & 0 & 0 & 0 & 0 & 1 & 1 & 1 & 1 & LAMIACEAE & Mentha & arvensis & 1 & & & & & \\
\hline 1 & 1 & 1 & 1 & 1 & 1 & 1 & 1 & 1 & 1 & LAMIACEAE & Monarda & citriodora & 1 & & & & & \\
\hline 1 & 1 & 1 & 1 & 1 & 0 & 1 & 0 & 0 & 1 & LAMIACEAE & Monarda & fistulosa & 1 & & & & & \\
\hline 0 & 0 & 0 & 0 & 1 & 1 & 1 & 1 & 1 & 1 & LAMIACEAE & Monarda & pectinata & 1 & & & & & \\
\hline 1 & 1 & 1 & 1 & 0 & 0 & 1 & 0 & 0 & 0 & LAMIACEAE & Prunella & vulgaris & 1 & & & & & \\
\hline 1 & 0 & 0 & 0 & 0 & 0 & 1 & 0 & 0 & 0 & LAURACEAE & Lindera & benzoin & 1 & & & & & \\
\hline 1 & 1 & 1 & 0 & 0 & 0 & 0 & 0 & 0 & 0 & LAURACEAE & Sassafras & albidum & 1 & & & & 1 & \\
\hline
\end{tabular}


Table L-1. Ethnobotany Data (see text for details) continued...

\begin{tabular}{|c|c|c|c|c|c|c|c|c|c|c|c|c|c|c|c|c|c|c|}
\hline & & & Regi & ions & of 7 & Texa & & & & & & & Plant & element & reported & used & & \\
\hline 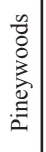 & 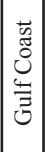 & 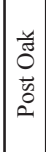 & 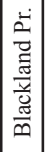 & 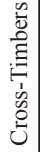 & 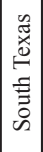 & 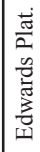 & 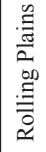 & 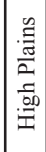 & 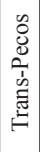 & FAMILY & GENUS & SPECIES & $\begin{array}{c}\text { Greens/ } \\
\text { leaves/ } \\
\text { flowers/ } \\
\text { stalk/stem }\end{array}$ & Seeds/pods & Nuts & $\begin{array}{c}\text { Fruits/ } \\
\text { berries/ } \\
\text { peppers }\end{array}$ & $\begin{array}{c}\text { Tubers/ } \\
\text { hearts/ } \\
\text { roots }\end{array}$ & Other \\
\hline 1 & 1 & 1 & 1 & 1 & 1 & 1 & 1 & 0 & 0 & LILIACEAE & Allium & canadense & 1 & & & & 1 & \\
\hline 0 & 0 & 0 & 0 & 0 & 0 & 1 & 0 & 0 & 1 & LILIACEAE & Allium & сегnиит & 1 & & & & 1 & \\
\hline 1 & 1 & 1 & 1 & 1 & 1 & 1 & 1 & 1 & 1 & LILIACEAE & Allium & drummondii & & & & & 1 & \\
\hline 0 & 0 & 0 & 0 & 0 & 0 & 0 & 0 & 0 & 1 & LILIACEAE & Allium & geyeri & & & & & 1 & \\
\hline 0 & 0 & 0 & 0 & 0 & 0 & 1 & 0 & 0 & 1 & LILIACEAE & Allium & macropetalum & & & & & 1 & \\
\hline 1 & 0 & 1 & 1 & 1 & 0 & 1 & 0 & 0 & 0 & LILIACEAE & Camassia & scilloides & & & & & 1 & \\
\hline 0 & 0 & 0 & 0 & 0 & 0 & 1 & 0 & 0 & 1 & LILIACEAE & Dasylirion & texanum & & & & & 1 & \\
\hline 0 & 0 & 0 & 0 & 0 & 0 & 0 & 0 & 0 & 1 & LILIACEAE & Dasylirion & wheeleri & & & & & 1 & \\
\hline 0 & 0 & 0 & 1 & 1 & 0 & 1 & 0 & 0 & 0 & LILIACEAE & Erythronium & mesochoreum & 1 & & & & & \\
\hline 0 & 0 & 0 & 0 & 0 & 0 & 0 & 0 & 0 & 1 & LILIACEAE & Lilium & philadelphicum & & 1 & & & 1 & \\
\hline 0 & 0 & 0 & 0 & 0 & 0 & 0 & 0 & 0 & 1 & LILIACEAE & Maianthemum & racemosum & 1 & & & 1 & 1 & \\
\hline 0 & 0 & 0 & 0 & 0 & 0 & 0 & 0 & 0 & 1 & LILIACEAE & Nolina & microcarpa & 1 & 1 & & 1 & & \\
\hline 1 & 0 & 1 & 1 & 0 & 0 & 0 & 0 & 0 & 0 & LILIACEAE & Polygonatum & biflorum & 1 & & & & 1 & \\
\hline 1 & 1 & 1 & 1 & 1 & 1 & 1 & 1 & 0 & 0 & LILIACEAE & Smilax & bona-nox & & & & & 1 & \\
\hline 1 & 1 & 1 & 1 & 0 & 1 & 0 & 0 & 0 & 0 & LILIACEAE & Smilax & glauca & & & & & 1 & \\
\hline 1 & 0 & 0 & 0 & 0 & 0 & 0 & 0 & 0 & 0 & LILIACEAE & Smilax & herbacea & & & & 1 & & \\
\hline 1 & 1 & 1 & 0 & 0 & 0 & 0 & 0 & 0 & 0 & LILIACEAE & Smilax & laurifolia & & & & & 1 & \\
\hline 1 & 1 & 1 & 0 & 1 & 0 & 1 & 0 & 0 & 0 & LILIACEAE & Smilax & rotundifolia & & & & & 1 & \\
\hline 1 & 0 & 0 & 0 & 0 & 0 & 0 & 0 & 0 & 0 & LILIACEAE & Uvularia & perfoliata & 1 & & & & & \\
\hline 0 & 0 & 0 & 0 & 0 & 0 & 1 & 0 & 0 & 1 & LILIACEAE & Yисса & baccata & & & & 1 & & \\
\hline 0 & 0 & 0 & 0 & 0 & 0 & 1 & 0 & 0 & 1 & LILIACEAE & Yисcа & elata & 1 & & & & & \\
\hline 0 & 0 & 0 & 0 & 0 & 0 & 0 & 1 & 1 & 0 & LILIACEAE & Yucca & glauca & 1 & & & 1 & & \\
\hline 0 & 0 & 0 & 0 & 0 & 0 & 1 & 0 & 0 & 0 & LILIACEAE & Yисcа & torreyi & & & & 1 & & \\
\hline 0 & 0 & 0 & 0 & 0 & 0 & 1 & 0 & 1 & 1 & LOASACEAE & Mentzelia & albicaulis & & 1 & & & & \\
\hline 0 & 0 & 0 & 0 & 0 & 0 & 0 & 0 & 0 & 1 & LOASACEAE & Mentzelia & multiflora & & 1 & & & & \\
\hline 1 & 1 & 1 & 1 & 1 & 1 & 1 & 1 & 0 & 0 & LYTHRACEAE & Ammannia & coccinea & & 1 & & & 1 & \\
\hline 0 & 0 & 0 & 0 & 1 & 0 & 1 & 1 & 1 & 1 & MALVACEAE & Sphaeralcea & angustifolia & & 1 & & & & \\
\hline 0 & 0 & 0 & 0 & 1 & 0 & 1 & 1 & 1 & 1 & MALVACEAE & Sphaeralcea & coccinea & & & & & 1 & \\
\hline 0 & 0 & 0 & 0 & 0 & 0 & 0 & 1 & 1 & 1 & MARTYNIACEAE & Proboscidea & althaeifolia & & 1 & & 1 & & \\
\hline 1 & 1 & 1 & 1 & 1 & 0 & 1 & 1 & 1 & 1 & MARTYNIACEAE & Proboscidea & louisianica & & 1 & & & & \\
\hline 0 & 0 & 0 & 0 & 0 & 0 & 0 & 0 & 0 & 1 & MARTYNIACEAE & Proboscidea & parviflora & & 1 & & 1 & & \\
\hline 1 & 0 & 1 & 1 & 0 & 0 & 0 & 0 & 0 & 0 & MELASTOMATACEAE & Rhexia & virginica & 1 & & & & & \\
\hline 0 & 0 & 1 & 0 & 1 & 1 & 1 & 1 & 1 & 1 & MORACEAE & Morus & microphylla & & & & 1 & & \\
\hline 1 & 1 & 1 & 1 & 1 & 1 & 1 & 1 & 0 & 0 & MORACEAE & Morus & rubra & & & & 1 & & \\
\hline 0 & 0 & 0 & 0 & 1 & 0 & 1 & 1 & 1 & 1 & NYCTAGINACEAE & Abronia & fragrans & & & & & 1 & \\
\hline 0 & 1 & 1 & 0 & 1 & 1 & 1 & 1 & 1 & 1 & NYCTAGINACEAE & Mirabilis & linearis & & 1 & & 1 & & \\
\hline 0 & 0 & 0 & 0 & 0 & 0 & 1 & 0 & 0 & 1 & NYCTAGINACEAE & Mirabilis & multiflora & & & & & & 1 \\
\hline 0 & 0 & 0 & 0 & 0 & 0 & 0 & 0 & 0 & 1 & NYCTAGINACEAE & Mirabilis & oxybaphoides & 1 & & & & & \\
\hline 1 & 1 & 1 & 1 & 1 & 0 & 1 & 0 & 0 & 0 & NYMPHAEACEAE & Nelumbo & lutea & 1 & 1 & & & 1 & \\
\hline 1 & 1 & 1 & 1 & 0 & 0 & 1 & 0 & 0 & 0 & NYMPHAEACEAE & Nymphaea & odorata & & & & 1 & & \\
\hline 0 & 0 & 0 & 0 & 1 & 0 & 1 & 1 & 1 & 1 & OLEACEAE & Forestiera & pubescens & & & & 1 & & \\
\hline 0 & 0 & 0 & 0 & 0 & 1 & 1 & 1 & 1 & 1 & ONAGRACEAE & Calylophus & lavandulifolius & & 1 & & & & \\
\hline 0 & 0 & 0 & 0 & 0 & 0 & 1 & 1 & 1 & 1 & ONAGRACEAE & Oenothera & albicaulis & & 1 & & 1 & & \\
\hline
\end{tabular}


Table L-1. Ethnobotany Data (see text for details) continued...

\begin{tabular}{|c|c|c|c|c|c|c|c|c|c|c|c|c|c|c|c|c|c|c|}
\hline \multicolumn{10}{|c|}{ Regions of Texas } & \multirow[b]{2}{*}{ FAMILY } & \multirow[b]{2}{*}{ GENUS } & \multirow[b]{2}{*}{ SPECIES } & \multirow{2}{*}{$\begin{array}{c}\text { Plant } \\
\\
\text { Greens/ } \\
\text { leaves/ } \\
\text { flowers/ } \\
\text { stalk/stem }\end{array}$} & \multirow{2}{*}{$\begin{array}{c}\text { element } \\
\text { Seeds/pods }\end{array}$} & \multirow{2}{*}{\begin{tabular}{|c|} 
reported \\
Nuts
\end{tabular}} & \multirow{2}{*}{\begin{tabular}{|c|} 
used \\
\\
Fruits/ \\
berries/ \\
peppers
\end{tabular}} & \multirow[b]{2}{*}{$\begin{array}{c}\text { Tubers/ } \\
\text { hearts/ } \\
\text { roots }\end{array}$} & \multirow[b]{2}{*}{ Other } \\
\hline 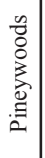 & 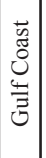 & 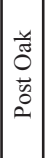 & 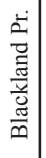 & 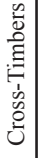 & 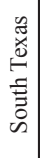 & 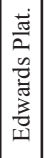 & 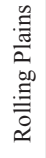 & 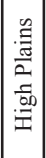 & 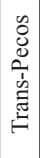 & & & & & & & & & \\
\hline 1 & 0 & 1 & 1 & 0 & 0 & 0 & 0 & 0 & 0 & ONAGRACEAE & Oenothera & biennis & 1 & 1 & & & 1 & \\
\hline 0 & 0 & 1 & 0 & 0 & 0 & 0 & 0 & 0 & 1 & ONAGRACEAE & Oenothera & elata & & & & & & 1 \\
\hline 0 & 1 & 0 & 1 & 1 & 1 & 1 & 1 & 0 & 0 & ONAGRACEAE & Oenothera & triloba & & & & & 1 & \\
\hline 0 & 0 & 0 & 0 & 0 & 0 & 1 & 0 & 0 & 1 & OROBANCHACEAE & Orobanche & cooperi & & & & & 1 & \\
\hline 0 & 0 & 0 & 0 & 1 & 0 & 0 & 1 & 1 & 1 & OROBANCHACEAE & Orobanche & fasciculata & & & & & 1 & \\
\hline 0 & 0 & 0 & 0 & 0 & 0 & 0 & 1 & 1 & 1 & OROBANCHACEAE & Orobanche & ludoviciana & & & & & 1 & \\
\hline 1 & 1 & 1 & 1 & 0 & 0 & 1 & 0 & 0 & 0 & OSMUNDACEAE & Osmunda & cinnamomea & & & & & 1 & \\
\hline 1 & 0 & 0 & 0 & 0 & 0 & 0 & 0 & 0 & 0 & OXALIDACEAE & Oxalis & stricta & 1 & & & & & \\
\hline 1 & 1 & 1 & 1 & 1 & 0 & 1 & 0 & 0 & 0 & OXALIDACEAE & Oxalis & violacea & 1 & & & & 1 & \\
\hline 1 & 1 & 1 & 1 & 1 & 0 & 1 & 0 & 0 & 0 & PASSIFLORACEAE & Passiflora & incarnata & 1 & & & 1 & & \\
\hline 1 & 1 & 1 & 1 & 1 & 1 & 1 & 1 & 0 & 0 & PHYTOLACCACEAE & Phytolacca & americana & 1 & & & 1 & & \\
\hline 0 & 0 & 0 & 0 & 0 & 0 & 1 & 0 & 0 & 1 & PINACEAE & Pinus & edulis & & & 1 & & & 1 \\
\hline 0 & 0 & 0 & 0 & 0 & 0 & 0 & 0 & 0 & 1 & PINACEAE & Pinus & ponderosa & & & 1 & & & 1 \\
\hline 0 & 0 & 0 & 0 & 0 & 0 & 0 & 0 & 0 & 1 & PINACEAE & Pseudotsuga & menziesii & 1 & & & & & 1 \\
\hline 0 & 0 & 0 & 0 & 0 & 0 & 0 & 0 & 0 & 1 & PLANTAGINACEAE & Plantago & ovata & & 1 & & & & \\
\hline 0 & 0 & 1 & 1 & 1 & 1 & 1 & 1 & 1 & 1 & PLANTAGINACEAE & Plantago & patagonica & & 1 & & & & \\
\hline 1 & 0 & 1 & 0 & 0 & 0 & 0 & 0 & 0 & 0 & POACEAE & Agrostis & perennans & & 1 & & & & \\
\hline 1 & 1 & 1 & 1 & 1 & 1 & 1 & 1 & 0 & 0 & POACEAE & Chasmanthium & latifolium & & 1 & & & & \\
\hline 1 & 0 & 0 & 0 & 0 & 0 & 0 & 0 & 0 & 0 & POACEAE & Cinna & arundinacea & & 1 & & & & \\
\hline 1 & 1 & 1 & 1 & 1 & 1 & 1 & 1 & 1 & 1 & POACEAE & Digitaria & cognata & & 1 & & & & \\
\hline 0 & 1 & 0 & 0 & 0 & 0 & 1 & 1 & 1 & 1 & POACEAE & Distichlis & spicata & 1 & & & & & \\
\hline 1 & 1 & 1 & 1 & 1 & 0 & 1 & 1 & 1 & 1 & POACEAE & Elymus & canadensis & & 1 & & & & \\
\hline 0 & 0 & 0 & 0 & 0 & 0 & 1 & 1 & 1 & 1 & POACEAE & Elymus & elymoides & & 1 & & & & \\
\hline 0 & 0 & 0 & 0 & 0 & 0 & 0 & 0 & 0 & 1 & POACEAE & Eragrostis & mexicana & & 1 & & & & \\
\hline 1 & 1 & 1 & 1 & 1 & 1 & 1 & 1 & 1 & 0 & POACEAE & Eragrostis & secundiflora & & 1 & & & & \\
\hline 0 & 0 & 0 & 0 & 0 & 0 & 1 & 1 & 1 & 1 & POACEAE & Hordeum & jubatum & & 1 & & & & \\
\hline 0 & 0 & 0 & 0 & 0 & 0 & 0 & 1 & 0 & 1 & POACEAE & Leymus & triticoides & & 1 & & & & \\
\hline 0 & 0 & 0 & 0 & 0 & 0 & 0 & 0 & 0 & 1 & POACEAE & Melica & bulbosa & & 1 & & & & \\
\hline 0 & 0 & 0 & 0 & 0 & 0 & 1 & 0 & 0 & 1 & POACEAE & Muhlenbergia & rigens & & 1 & & & & \\
\hline 0 & 0 & 0 & 0 & 0 & 0 & 1 & 0 & 0 & 1 & POACEAE & Panicum & bulbosum & & 1 & & & & \\
\hline 1 & 1 & 1 & 1 & 1 & 0 & 1 & 1 & 1 & 1 & POACEAE & Panicum & capillare & & 1 & & & & \\
\hline 0 & 0 & 0 & 0 & 0 & 0 & 1 & 0 & 0 & 1 & POACEAE & Panicum & hirticaule & & 1 & & & & \\
\hline 0 & 1 & 1 & 1 & 1 & 1 & 1 & 1 & 1 & 1 & POACEAE & Panicum & obtusum & & 1 & & & & \\
\hline 1 & 1 & 1 & 1 & 1 & 1 & 1 & 1 & 1 & 1 & POACEAE & Phalaris & caroliniana & & 1 & & & & \\
\hline 1 & 1 & 1 & 1 & 1 & 1 & 1 & 1 & 1 & 1 & POACEAE & Phragmites & australis & & 1 & & & & \\
\hline 0 & 0 & 0 & 0 & 0 & 0 & 0 & 0 & 1 & 0 & POACEAE & Poa & arida & & 1 & & & & \\
\hline 0 & 0 & 0 & 0 & 0 & 0 & 0 & 0 & 0 & 1 & POACEAE & Poa & fendleriana & & 1 & & & & \\
\hline 0 & 1 & 0 & 0 & 0 & 0 & 1 & 1 & 1 & 1 & POACEAE & Sporobolus & airoides & & 1 & & & & \\
\hline 0 & 0 & 0 & 0 & 0 & 0 & 0 & 1 & 1 & 1 & POACEAE & Sporobolus & contractus & & 1 & & & & \\
\hline 0 & 1 & 1 & 1 & 1 & 1 & 1 & 1 & 1 & 1 & POACEAE & Sporobolus & cryptandrus & & 1 & & & & \\
\hline 0 & 0 & 0 & 0 & 0 & 0 & 1 & 0 & 1 & 1 & POACEAE & Sporobolus & flexuosus & & 1 & & & & \\
\hline 0 & 0 & 0 & 0 & 0 & 0 & 1 & 0 & 1 & 1 & POACEAE & Sporobolus & giganteus & & 1 & & & & \\
\hline 0 & 0 & 0 & 0 & 0 & 1 & 1 & 0 & 0 & 1 & POACEAE & Sporobolus & wrightii & & 1 & & & & \\
\hline
\end{tabular}


Table L-1. Ethnobotany Data (see text for details) continued...

\begin{tabular}{|c|c|c|c|c|c|c|c|c|c|c|c|c|c|c|c|c|c|c|}
\hline & & & Regi & ions & of $T$ & exas & & & & & & & Plant & element & reported & used & & \\
\hline 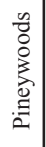 & 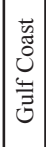 & 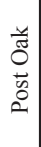 & 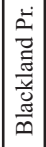 & 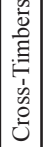 & 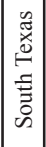 & 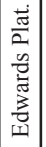 & 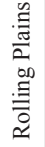 & 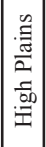 & 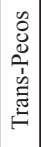 & FAMILY & GENUS & SPECIES & $\begin{array}{c}\text { Greens/ } \\
\text { leaves/ } \\
\text { flowers/ } \\
\text { stalk/stem }\end{array}$ & Seeds/pods & Nuts & $\begin{array}{c}\text { Fruits/ } \\
\text { berries/ } \\
\text { peppers }\end{array}$ & $\begin{array}{c}\text { Tubers/ } \\
\text { hearts/ } \\
\text { roots }\end{array}$ & Other \\
\hline 0 & 1 & 1 & 1 & 1 & 1 & 1 & 1 & 1 & 1 & POACEAE & Tridens & muticus & & 1 & & & & \\
\hline 1 & 1 & 1 & 1 & 1 & 0 & 1 & 1 & 1 & 1 & POACEAE & Vulpia & octoflora & & 1 & & & & \\
\hline 0 & 0 & 0 & 0 & 0 & 0 & 1 & 0 & 0 & 1 & POLEMONIACEAE & Ipomopsis & aggregata & 1 & & & & & \\
\hline 0 & 0 & 0 & 0 & 0 & 0 & 1 & 1 & 1 & 0 & POLYGONACEAE & Eriogonum & alatum & & 1 & & & 1 & \\
\hline 1 & 1 & 1 & 1 & 1 & 0 & 1 & 1 & 1 & 1 & POLYGONACEAE & Eriogonum & longifolium & & & & & 1 & \\
\hline 0 & 0 & 0 & 0 & 0 & 0 & 1 & 0 & 0 & 1 & POLYGONACEAE & Eriogonum & rotundifolium & 1 & & & & & \\
\hline 0 & 0 & 0 & 0 & 0 & 0 & 1 & 1 & 1 & 1 & POLYGONACEAE & Eriogonum & wrightii & & 1 & & & & \\
\hline 0 & 1 & 0 & 1 & 1 & 0 & 1 & 1 & 1 & 1 & POLYGONACEAE & Polygonum & amphibium & 1 & & & & & \\
\hline 1 & 1 & 0 & 0 & \begin{tabular}{|l|}
0 \\
\end{tabular} & 0 & 1 & 0 & 0 & 0 & POLYGONACEAE & Polygonum & hydropiper & 1 & & & & & \\
\hline 0 & 0 & 0 & 0 & 1 & 0 & 1 & 1 & 1 & 1 & POLYGONACEAE & Rumex & hymenosepalus & 1 & 1 & & & 1 & \\
\hline 0 & 0 & 0 & 0 & \begin{tabular}{|l|}
0 \\
\end{tabular} & 0 & 0 & 0 & 1 & 0 & POLYGONACEAE & Rumex & maritimus & & 1 & & & & \\
\hline 0 & 0 & 0 & 0 & 0 & 0 & 0 & 0 & 1 & 0 & POLYGONACEAE & Rumex & obtusifolius & 1 & & & & & \\
\hline 0 & 0 & 0 & 0 & 0 & 0 & 0 & 0 & 0 & 1 & POLYGONACEAE & Rumex & salicifolius & 1 & 1 & & & & \\
\hline 0 & 0 & 0 & 0 & 0 & 0 & 0 & 1 & 0 & 0 & POLYGONACEAE & Rumex & venosus & 1 & & & & & \\
\hline 0 & 0 & 0 & 0 & \begin{tabular}{|l|}
0 \\
\end{tabular} & 0 & 0 & 0 & 0 & 1 & POLYGONACEAE & Rumex & violascens & 1 & & & & & \\
\hline 1 & 1 & 1 & 1 & \begin{tabular}{|l|}
0 \\
\end{tabular} & 0 & 0 & 0 & 0 & 0 & POLYPODIACEAE & Athyrium & filix-femina & 1 & & & & & \\
\hline 0 & 0 & 0 & 0 & \begin{tabular}{|l|}
0 \\
\end{tabular} & 0 & 0 & 0 & 1 & 1 & POLYPODIACEAE & Cheilanthes & fendleri & 1 & & & & & \\
\hline 0 & 0 & 0 & 0 & 0 & 0 & 0 & 0 & 0 & 1 & POLYPODIACEAE & Dryopteris & filix-mas & & & & & 1 & \\
\hline 1 & 1 & 1 & 1 & 0 & 1 & 1 & 0 & 0 & 0 & POLYPODIACEAE & Onoclea & sensibilis & 1 & & & & & \\
\hline 1 & 1 & 0 & 1 & 0 & 0 & 0 & 0 & 0 & 0 & POLYPODIACEAE & Polystichum & acrostichoides & 1 & & & & & \\
\hline 1 & 1 & 1 & 1 & \begin{tabular}{|l|}
0 \\
\end{tabular} & 0 & 0 & 0 & 0 & 1 & POLYPODIACEAE & Pteridium & aquilinum & 1 & & & & 1 & \\
\hline 1 & 1 & 1 & 1 & 1 & 0 & 1 & 1 & 0 & 0 & PORTULACACEAE & Claytonia & virginica & & & & & 1 & \\
\hline 0 & 1 & 1 & 1 & 1 & 1 & 1 & 1 & 0 & 1 & PORTULACACEAE & Portulaca & oleracea & 1 & 1 & & & & \\
\hline 1 & 0 & 0 & 0 & 0 & 0 & 0 & 0 & 0 & 0 & RANUNCULACEAE & Ranunculus & recurvatus & 1 & & & & & \\
\hline 1 & 1 & 1 & 0 & 1 & 0 & 1 & 1 & 0 & 0 & RHAMNACEAE & Ceanothus & americanus & 1 & & & & & \\
\hline 0 & 0 & 0 & 0 & 0 & 0 & 0 & 0 & 0 & 1 & RHAMNACEAE & Ceanothus & fendleri & & & & 1 & & 1 \\
\hline 0 & 0 & 1 & 1 & 1 & 1 & 1 & 1 & 1 & 0 & RHAMNACEAE & Ceanothus & herbaceus & 1 & & & & & \\
\hline 0 & 1 & 1 & 1 & 0 & 1 & 1 & 0 & 0 & 0 & RHAMNACEAE & Condalia & hookeri & & & & 1 & & \\
\hline 1 & 0 & 0 & 1 & 0 & 0 & 0 & 0 & 0 & 0 & ROSACEAE & Amelanchier & arborea & & & & 1 & & \\
\hline 0 & 0 & 0 & 0 & 0 & 0 & 0 & 0 & 0 & 1 & ROSACEAE & Amelanchier & utahensis & & & & 1 & & \\
\hline 1 & 0 & 0 & 0 & \begin{tabular}{|l|}
0 \\
\end{tabular} & 0 & 0 & 0 & 0 & 0 & ROSACEAE & Crataegus & calpodendron & & & & 1 & & \\
\hline 0 & 0 & 0 & 0 & \begin{tabular}{|l|}
0 \\
\end{tabular} & 0 & 0 & 1 & 1 & 0 & ROSACEAE & Crataegus & douglasii & & & & 1 & & \\
\hline 0 & 0 & 0 & 0 & \begin{tabular}{|l|}
0 \\
\end{tabular} & 0 & 0 & 0 & 0 & 1 & ROSACEAE & Fragaria & vesca & 1 & & & 1 & & \\
\hline 1 & 0 & 1 & 1 & \begin{tabular}{|l|}
1 \\
\end{tabular} & 0 & 0 & 0 & 0 & 0 & ROSACEAE & Fragaria & virginiana & & & & 1 & & \\
\hline 0 & 0 & 0 & 0 & \begin{tabular}{|l|}
0 \\
\end{tabular} & 0 & 0 & 0 & 0 & 1 & ROSACEAE & Holodiscus & dumosus & 1 & & & & & \\
\hline 1 & 0 & 0 & 0 & \begin{tabular}{|l|}
0 \\
\end{tabular} & 0 & 0 & 0 & 0 & 0 & ROSACEAE & Malus & angustifolia & & & & 1 & & \\
\hline 0 & 0 & 0 & 0 & \begin{tabular}{|l|}
0 \\
\end{tabular} & 0 & 1 & 0 & 0 & 0 & ROSACEAE & Malus & ioensis & & & & 1 & & \\
\hline 1 & 1 & 1 & 1 & \begin{tabular}{|l|}
1 \\
\end{tabular} & 0 & 1 & 1 & 1 & 0 & ROSACEAE & Prunus & angustifolia & & & & 1 & & \\
\hline 1 & 0 & 1 & 1 & 1 & 0 & 1 & 1 & 1 & 0 & ROSACEAE & Prunus & gracilis & & & & 1 & & \\
\hline 1 & 1 & 1 & 1 & 0 & 1 & 1 & 0 & 0 & 1 & ROSACEAE & Prunus & serotina & & & & 1 & & \\
\hline 0 & 0 & 0 & 0 & \begin{tabular}{|l|}
0 \\
\end{tabular} & 0 & 0 & 1 & 1 & 1 & ROSACEAE & Prunus & virginiana & & & & 1 & & \\
\hline 0 & 0 & 0 & 0 & 1 & 0 & 0 & 1 & 0 & 0 & ROSACEAE & Rosa & arkansana & & & & 1 & 1 & \\
\hline 0 & 0 & 0 & 0 & \begin{tabular}{|l|}
0 \\
\end{tabular} & 0 & 0 & 0 & 0 & 1 & ROSACEAE & Rosa & woodsii & & & & 1 & & \\
\hline
\end{tabular}


Table L-1. Ethnobotany Data (see text for details) continued...

\begin{tabular}{|c|c|c|c|c|c|c|c|c|c|c|c|c|c|c|c|c|c|c|}
\hline \multicolumn{10}{|c|}{ Regions of Texas } & \multirow[b]{2}{*}{ FAMILY } & \multirow[b]{2}{*}{ GENUS } & \multirow[b]{2}{*}{ SPECIES } & \multirow{2}{*}{$\begin{array}{c}\text { Plant } \\
\\
\text { Greens/ } \\
\text { leaves/ } \\
\text { flower/ } \\
\text { stalk/stem }\end{array}$} & \multirow{2}{*}{$\begin{array}{c}\text { element } \\
\text { Seeds/pods }\end{array}$} & \multirow{2}{*}{$\begin{array}{c}\text { reported } \\
\text { Nuts }\end{array}$} & \multirow{2}{*}{\begin{tabular}{|c|} 
used \\
\\
Fruits/ \\
berries/ \\
peppers
\end{tabular}} & \multirow[b]{2}{*}{$\begin{array}{c}\text { Tubers/ } \\
\text { hearts/ } \\
\text { roots }\end{array}$} & \multirow[b]{2}{*}{ Other } \\
\hline 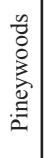 & 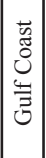 & 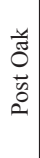 & 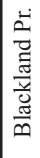 & 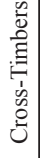 & 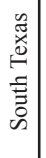 & 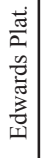 & 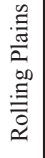 & 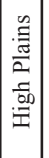 & 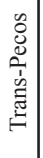 & & & & & & & & & \\
\hline 1 & 0 & 0 & 0 & 1 & 0 & 0 & 0 & 0 & 0 & ROSACEAE & Rubus & flagellaris & & & & 1 & & \\
\hline 1 & 1 & 0 & 1 & 1 & 0 & 1 & 1 & 1 & 1 & RUTACEAE & Ptelea & trifoliata & & & & 1 & & \\
\hline 0 & 0 & 0 & 0 & 0 & 0 & 0 & 0 & 0 & 1 & SALICACEAE & Populus & angustifolia & 1 & & & & & 1 \\
\hline 1 & 1 & 1 & 1 & 1 & 1 & 1 & 1 & 1 & 1 & SALICACEAE & Populus & deltoides & & & & & & 1 \\
\hline 0 & 0 & 0 & 0 & 0 & 0 & 0 & 0 & 0 & 1 & SALICACEAE & Populus & fremontii & 1 & & & & & 1 \\
\hline 0 & 0 & 0 & 0 & 0 & 0 & 0 & 0 & 0 & 1 & SALICACEAE & Populus & tremuloides & & & & & & 1 \\
\hline 1 & 1 & 1 & 1 & 0 & 1 & 1 & 1 & 1 & 1 & SALICACEAE & Salix & exigua & & & & & & 1 \\
\hline 0 & 0 & 0 & 0 & 0 & 0 & 1 & 0 & 0 & 1 & SAURURACEAE & Anemopsis & californica & & 1 & & & & \\
\hline 1 & 1 & 0 & 1 & 0 & 0 & 0 & 0 & 0 & 0 & SAXIFRAGACEAE & Penthorum & sedoides & 1 & & & & & \\
\hline 0 & 0 & 0 & 0 & 0 & 0 & 0 & 0 & 0 & 1 & SAXIFRAGACEAE & Philadelphus & microphyllus & & & & 1 & & \\
\hline 0 & 0 & 0 & 0 & 1 & 0 & 1 & 1 & 1 & 1 & SAXIFRAGACEAE & Ribes & aureum & & & & 1 & & \\
\hline 0 & 0 & 0 & 0 & 0 & 0 & 0 & 0 & 0 & 1 & SAXIFRAGACEAE & Ribes & leptanthum & & & & 1 & & \\
\hline 0 & 0 & 0 & 0 & 0 & 0 & 0 & 0 & 0 & 1 & SAXIFRAGACEAE & Ribes & mescalerium & & & & 1 & & \\
\hline 0 & 0 & 0 & 0 & 1 & 0 & 1 & 0 & 0 & 1 & SCROPHULARIACEAE & Mimulus & glabratus & 1 & & & & & \\
\hline 1 & 0 & 1 & 0 & 0 & 0 & 0 & 0 & 0 & 0 & SCROPHULARIACEAE & Pedicularis & canadensis & 1 & & & & & \\
\hline 0 & 0 & 0 & 0 & 0 & 0 & 0 & 0 & 0 & 1 & SELAGINELLACEAE & Selaginella & densa & & & & 1 & & \\
\hline 0 & 1 & 0 & 1 & 0 & 1 & 1 & 0 & 0 & 0 & SOLANACEAE & Capsicum & аппиит & & & & 1 & & \\
\hline 0 & 0 & 0 & 0 & 0 & 0 & 1 & 0 & 0 & 1 & SOLANACEAE & Lycium & pallidum & & & & 1 & & \\
\hline 0 & 0 & 0 & 0 & 0 & 0 & 1 & 0 & 0 & 1 & SOLANACEAE & Lycium & torreyi & & & & 1 & & \\
\hline 0 & 0 & 0 & 0 & 0 & 1 & 0 & 0 & 0 & 0 & SOLANACEAE & Physalis & acutifolia & & & & 1 & & \\
\hline 0 & 0 & 1 & 0 & 0 & 1 & 1 & 0 & 1 & 1 & SOLANACEAE & Physalis & hederifolia & & & & 1 & & \\
\hline 1 & 1 & 1 & 1 & 1 & 1 & 1 & 0 & 0 & 0 & SOLANACEAE & Physalis & heterophylla & & & & 1 & & \\
\hline 1 & 1 & 1 & 1 & 1 & 1 & 1 & 1 & 1 & 1 & SOLANACEAE & Physalis & longifolia & & & & 1 & & \\
\hline 1 & 1 & 1 & 1 & 0 & 1 & 1 & 0 & 0 & 0 & SOLANACEAE & Physalis & pubescens & & & & 1 & & \\
\hline 0 & 0 & 0 & 0 & 0 & 0 & 0 & 0 & 0 & 1 & SOLANACEAE & Physalis & subulata & & & & 1 & & \\
\hline 1 & 1 & 1 & 1 & 0 & 1 & 1 & 0 & 0 & 0 & SOLANACEAE & Physalis & virginiana & & & & 1 & & \\
\hline 0 & 0 & 0 & 0 & 0 & 0 & 0 & 0 & 0 & 1 & SOLANACEAE & Solanum & douglasii & 1 & & & & & \\
\hline 1 & 1 & 1 & 1 & 1 & 1 & 1 & 1 & 1 & 1 & SOLANACEAE & Solanum & elaeagnifolium & & & & 1 & & \\
\hline 0 & 0 & 0 & 0 & 0 & 0 & 0 & 0 & 0 & 1 & SOLANACEAE & Solanum & fendleri & 1 & & & & 1 & \\
\hline 0 & 0 & 0 & 0 & 0 & 0 & 0 & 0 & 0 & 1 & SOLANACEAE & Solanum & jamesii & 1 & & & & 1 & \\
\hline 0 & 0 & 0 & 0 & 0 & 0 & 0 & 0 & 0 & 1 & SOLANACEAE & Solanum & leptosepalum & & & & 1 & & \\
\hline 0 & 0 & 0 & 0 & 0 & 0 & 1 & 1 & 0 & 1 & SOLANACEAE & Solanum & triflorum & & & & 1 & 1 & \\
\hline 1 & 0 & 0 & 0 & 0 & 0 & 0 & 0 & 0 & 0 & TILIACEAE & Tilia & americana & 1 & & & & & \\
\hline 1 & 0 & 0 & 0 & 0 & 1 & 1 & 0 & 0 & 0 & TYPHACEAE & Typha & angustifolia & 1 & & & & & \\
\hline 1 & 1 & 1 & 1 & 0 & 1 & 1 & 1 & 0 & 1 & TYPHACEAE & Typha & domingensis & 1 & 1 & & & 1 & \\
\hline 1 & 1 & 1 & 1 & 1 & 0 & 1 & 1 & 1 & 1 & TYPHACEAE & Typha & latifolia & 1 & & & & 1 & \\
\hline 1 & 1 & 1 & 1 & 1 & 1 & 1 & 1 & 1 & 1 & ULMACEAE & Celtis & laevigata & & & & 1 & & \\
\hline 0 & 0 & 0 & 0 & 0 & 0 & 0 & 1 & 1 & 0 & ULMACEAE & Celtis & occidentalis & & & & 1 & & \\
\hline 1 & 0 & 1 & 1 & 1 & 1 & 1 & 0 & 0 & 0 & ULMACEAE & Ulmus & rubra & & & & & & 1 \\
\hline 0 & 0 & 0 & 0 & 0 & 0 & 0 & 1 & 0 & 1 & URTICACEAE & Urtica & dioica & 1 & & & & & \\
\hline 0 & 0 & 0 & 0 & 0 & 1 & 1 & 1 & 0 & 1 & VERBENACEAE & Aloysia & wrightii & 1 & & & & & \\
\hline 0 & 0 & 0 & 0 & 0 & 0 & 0 & 0 & 0 & 1 & VISCACEAE & Phoradendron & juniperinum & 1 & & & 1 & & \\
\hline 1 & 1 & 1 & 1 & 0 & 0 & 0 & 0 & 0 & 0 & VITACEAE & Vitis & aestivalis & & & & 1 & & \\
\hline
\end{tabular}


Table L-1. Ethnobotany Data (see text for details) continued....

\begin{tabular}{|c|c|c|c|c|c|c|c|c|c|c|c|c|c|c|c|c|c|c|}
\hline \multicolumn{10}{|c|}{ Regions of Texas } & \multirow[b]{2}{*}{ FAMILY } & \multirow[b]{2}{*}{ GENUS } & \multirow[b]{2}{*}{ SPECIES } & \multirow{2}{*}{$\begin{array}{c}\text { Plant } \\
\\
\text { Greens/ } \\
\text { leaves/ } \\
\text { flowers/ } \\
\text { stalk/stem }\end{array}$} & \multirow{2}{*}{$\begin{array}{c}\text { element } \\
\text { Seeds/pod }\end{array}$} & \multirow{2}{*}{$\begin{array}{c}\text { reported } \\
\text { Nuts }\end{array}$} & \multirow{2}{*}{\begin{tabular}{c|} 
used \\
\\
Fruits/ \\
berries/ \\
peppers
\end{tabular}} & \multirow[b]{2}{*}{$\begin{array}{c}\text { Tubers/ } \\
\text { hearts/ } \\
\text { roots }\end{array}$} & \multirow[b]{2}{*}{ Other } \\
\hline 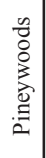 & 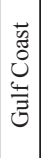 & 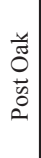 & 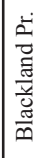 & 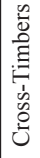 & 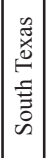 & 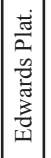 & 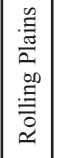 & 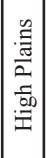 & 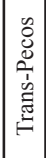 & & & & & & & & & \\
\hline 0 & 0 & 0 & 0 & 0 & 0 & 1 & 0 & 0 & 1 & VITACEAE & Vitis & arizonica & & & & 1 & & \\
\hline 1 & 1 & 1 & 1 & 1 & 0 & 1 & 0 & 0 & 0 & VITACEAE & Vitis & cinerea & & & & 1 & & \\
\hline 0 & 0 & 1 & 1 & 1 & 0 & 1 & 1 & 1 & 1 & VITACEAE & Vitis & riparia & & & & 1 & & \\
\hline 1 & 1 & 1 & 0 & 0 & 0 & 0 & 0 & 0 & 0 & VITACEAE & Vitis & rotundifolia & & & & 1 & & \\
\hline
\end{tabular}


Appendix M:

Instrumental Neutron Activation Analysis of Toyah Phase Ceramics from 41KM69, Kimble County, Texas, and Results of Scanning Electron Microscopy of Sherds from 41KM69, Kimble County, Texas

Jeffrey R. Ferguson and Michael D. Glascock 



\title{
Appendix M
}

\section{Instrumental Neutron Activation Analysis of Toyah Phase Ceramics from 41KM69, Kimble County, Texas, and Results of Scanning Electron Microscopy of Sherds from 41KM69, Kimble County, Texas}

\author{
Jeffrey R. Ferguson and Michael D. Glascock \\ Archaeometry Laboratory \\ Research Reactor Center \\ University of Missouri \\ Columbia, MO 65211
}

January 28,2010

\section{Introduction}

This project involves the analysis of six pottery samples from 41KM69, presumably from a Toyah phase occupation. The primary goal of this research is to examine internal variability and determine the relationship with other samples previously analyzed at MURR. The samples are projected against the entire MURR ceramic database, and more detailed comparisons are made to the Central Texas groups developed by Neff and Glascock (2002). The limited number of samples limits the potential for creating internal groupings. The six samples are remarkably similar in composition, and were likely made from the same suite of raw materials, perhaps even multiple sherds from the same vessel.

\section{Sample Preparation}

Pottery samples were prepared for INAA using procedures standard at MURR. Fragments of about $1 \mathrm{~cm}^{2}$ were removed from each sample and abraded using a silicon carbide burr in order to remove glaze, slip, paint, and adhering soil, thereby reducing the risk of measuring contamination. The samples were washed in deionized water and allowed to dry in the laboratory. Once dry, the individual sherds were ground into powders with an agate mortar and pestle to homogenize the samples. Archival samples were retained from each sherd (when possible) for future research.

Two analytical samples were prepared from each source specimen. Portions of approximately $150 \mathrm{mg}$ of powder were weighed into clean high-density polyethylene vials used for short irradiations at MURR. At the same time, $200 \mathrm{mg}$ of each sample was weighed into clean high-purity quartz vials used for long irradiations. Individual sample weights were recorded to the nearest $0.01 \mathrm{mg}$ using an analytical balance. Both vials were sealed prior to irradiation. Along with the unknown samples, Standards made from National Institute of Standards and Technology (NIST) certified standard reference materials of SRM-1633a (coal fly ash) and SRM-688 (basalt rock) were similarly prepared, as were quality control samples (e.g., standards treated as unknowns) of SRM-278 (obsidian rock) and Ohio Red Clay (a standard developed for in-house applications).

\section{Irradiation and Gamma-Ray Spectroscopy}

Neutron activation analysis of ceramics at MURR, which consists of two irradiations and a total of three gamma counts, constitutes a superset of the procedures used at most other NAA laboratories (Glascock 1992; Neff 1992, 2000). As discussed in detail by Glascock (1992), a short irradiation is carried out through the pneumatic tube irradiation system. Samples in the polyvials are sequentially irradiated, two at a time, for five seconds by a neutron flux of $8 \times 10^{13} \mathrm{n} \mathrm{cm}^{-2} \mathrm{~s}^{-1}$. A 720 -second count yields gamma spectra containing peaks for nine short-lived elements: aluminum ( $\mathrm{Al}$ ), barium (Ba), calcium (Ca), dysprosium (Dy), potassium (K), manganese (Mn), sodium (Na), titanium (Ti), and vanadium (V). The samples encapsulated in quartz vials are subjected to a 24-hour irradiation at a neutron flux of $5 \times 10^{13} \mathrm{n} \mathrm{cm}^{-2} \mathrm{~s}^{-1}$. This long irradiation is analogous to the single irradiation utilized at most other laboratories. After the long irradiation, samples decay for seven days, and then are counted 
for 1,800 seconds (the "middle count") on a high-resolution germanium detector coupled to an automatic sample changer. The middle count yields determinations of seven medium half-life elements, namely arsenic (As), lanthanum (La), lutetium (Lu), neodymium (Nd), samarium (Sm), uranium (U), and ytterbium (Yb). After an additional three- or four-week decay, a final count of 8,500 seconds is carried out on each sample. The latter measurement yields the following 17 long half-life elements: cerium $(\mathrm{Ce})$, cobalt $(\mathrm{Co})$, chromium $(\mathrm{Cr})$, cesium $(\mathrm{Cs})$, europium $(\mathrm{Eu})$, iron $(\mathrm{Fe})$, hafnium $(\mathrm{Hf})$, nickel $(\mathrm{Ni})$, rubidium $(\mathrm{Rb})$, antimony $(\mathrm{Sb})$, scandium $(\mathrm{Sc})$, strontium $(\mathrm{Sr})$, tantalum $(\mathrm{Ta})$, terbium $(\mathrm{Tb})$, thorium $(\mathrm{Th})$, zinc $(\mathrm{Zn})$, and zirconium $(\mathrm{Zr})$.

The element concentration data from the three measurements are tabulated in parts per million using the EXCEL spreadsheet program. Descriptive data for the archaeological samples were appended to the concentration spreadsheet. The data are also stored in a dBASE/FOXPRO database file useful for organizing, sorting, and extracting sample information.

\section{Interpreting Chemical Data}

The analyses at MURR produce concentration values for 33 elements in most samples. Data for Ni in most samples was below detection limits (as is the norm for most New World ceramic analyses) and the element was removed from consideration during the statistical analysis. Because calcium has the potential to affect (dilute) the concentrations of other elements in the analysis, all samples were mathematically corrected to compensate for any possible calcium included effects (the data were examined before and after calcium correction and the results were similar). The same adjustment was made for all comparative datasets. The following mathematical correction was used as it has been proven to be effective in other calcium-rich datasets (Cogswell et al. 1998:64; Steponaitis et al. 1988):

$$
e^{\prime}=\frac{10^{6} e}{10^{6}-2.5 c}
$$

where $e^{\prime}$ is the corrected concentration of a given element in ppm, $e$ is the measured concentration of that element in ppm, and $c$ is the concentration of elemental calcium in ppm. Following the calcium-adjustment, calcium levels were deleted from further analysis. After the calcium correction, statistical analysis was carried out on base-10 logarithms of concentrations on the remaining 31 elements. Use of log concentrations rather than raw data compensates for differences in magnitude between the major elements, such as iron, on one hand and trace elements, such as the rare earth or lanthanide elements (REEs). Transformation to base-10 logarithms also yields a more normal distribution for many trace elements.

The interpretation of compositional data obtained from the analysis of archaeological materials is discussed in detail elsewhere (e.g., Baxter and Buck 2000; Bieber et al. 1976; Bishop and Neff 1989; Glascock 1992; Harbottle 1976; Neff 2000) and will only be summarized here. The main goal of data analysis is to identify distinct homogeneous groups within the analytical database. Based on the provenance postulate of Weigand et al. (1977), different chemical groups may be assumed to represent geographically restricted sources. For lithic materials such as obsidian, basalt, and cryptocrystalline silicates (e.g., chert, flint, or jasper), raw material samples are frequently collected from known outcrops or secondary deposits and the compositional data obtained on the samples is used to define the source localities or boundaries. The locations of sources can also be inferred by comparing unknown specimens (i.e., ceramic artifacts) to knowns (i.e., clay samples) or by indirect methods such as the "criterion of abundance" (Bishop et al. 1992) or by arguments based on geological and sedimentological characteristics (e.g., Steponaitis et al. 1996). The ubiquity of ceramic raw materials usually makes it impossible to sample all potential "sources" intensively enough to create groups of knowns to which unknowns can be compared. Lithic sources tend to be more localized and compositionally homogeneous in the case of obsidian or compositionally heterogeneous as is the case for most cherts.

Compositional groups can be viewed as "centers of mass" in the compositional hyperspace described by the measured elemental data. Groups are characterized by the locations of their centroids and the unique relationships (i.e., correlations) between the elements. Decisions about whether to assign a specimen to a particular compositional group are based on the overall probability that the measured concentrations for the specimen could have been obtained from that group. 
Initial hypotheses about source-related subgroups in the compositional data can be derived from non-compositional information (e.g., archaeological context, decorative attributes, etc.) or from application of various pattern-recognition techniques to the multivariate chemical data. Some of the pattern recognition techniques that have been used to investigate archaeological data sets are cluster analysis (CA), principal components analysis (PCA), and discriminant analysis (DA). Each of the techniques has it own advantages and disadvantages that may depend upon the types and quantity of data available for interpretation.

The variables (measured elements) in archaeological and geological data sets are often correlated and frequently large in number. This makes handling and interpreting patterns within the data difficult. Therefore, it is often useful to transform the original variables into a smaller set of uncorrelated variables in order to make data interpretation easier. Of the above-mentioned pattern recognition techniques, PCA is a technique that transforms from the data from the original correlated variables into uncorrelated variables most easily.

PCA creates a new set of reference axes arranged in decreasing order of variance subsumed. The individual PCs are linear combinations of the original variables. The data can be displayed on combinations of the new axes, just as they can be displayed on the original elemental concentration axes. PCA can be used in a pure pattern-recognition mode, i.e., to search for subgroups in an undifferentiated data set, or in a more evaluative mode, i.e., to assess the coherence of hypothetical groups suggested by other criteria. Generally, compositional differences between specimens can be expected to be larger for specimens in different groups than for specimens in the same group, and this implies that groups should be detectable as distinct areas of high point density on plots of the first few components.

It is well known that PCA of chemical data is scale dependent (Mardia et al. 1979), and analyses tend to be dominated by those elements or isotopes for which the concentrations are relatively large. As a result, standardization methods are common to most statistical packages. A common approach it to transform the data into logarithms (e.g., base 10).

One frequently exploited strength of PCA, discussed by Baxter (1992), Baxter and Buck (2000), and Neff (1994, 2002), is that it can be applied as a simultaneous R- and Q-mode technique, with both variables (elements) and objects (individual analyzed samples) displayed on the same set of principal component reference axes. A plot using the first two principal components as axes is usually the best possible two-dimensional representation of the correlation or variance-covariance structure within the data set. Small angles between the vectors from the origin to variable coordinates indicate strong positive correlation; angles at 90 degrees indicate no correlation; and angles close to 180 degrees indicate strong negative correlation. Likewise, a plot of sample coordinates on these same axes will be the best two-dimensional representation of Euclidean relations among the samples in log-concentration space (if the PCA was based on the variance-covariance matrix) or standardized log-concentration space (if the PCA was based on the correlation matrix). Displaying both objects and variables on the same plot makes it possible to observe the contributions of specific elements to group separation and to the distinctive shapes of the various groups. Such a plot is commonly referred to as a "biplot" in reference to the simultaneous plotting of objects and variables. The variable interrelationships inferred from a biplot can be verified directly by inspecting bivariate elemental concentration plots. [Note that a bivariate plot of elemental concentrations is not a biplot.]

Whether a group can be discriminated easily from other groups can be evaluated visually in two dimensions or statistically in multiple dimensions. A metric known as the Mahalanobis distance (or generalized distance) makes it possible to describe the separation between groups or between individual samples and groups on multiple dimensions. The Mahalanobis distance of a specimen from a group centroid (Bieber et al. 1976, Bishop and Neff 1989) is defined by:

$$
D_{y, X}^{2}=[y-\bar{X}]^{t} I_{x}[y-\bar{X}]
$$


where $\mathrm{y}$ is the $1 \mathrm{x} \mathrm{m}$ array of logged elemental concentrations for the specimen of interest, $X$ is the $\mathrm{n} \mathrm{x}$ data matrix of loggedconcentrations for the group to which the point is being compared with $\bar{X}$ being it $1 \mathrm{x} \mathrm{m}$ centroid, and $I_{x}$ is the inverse of the $\mathrm{m}$ $\mathrm{x} \mathrm{m}$ variance-covariance matrix of group $X$. Because Mahalanobis distance takes into account variances and covariances in the multivariate group it is analogous to expressing distance from a univariate mean in standard deviation units. Like standard deviation units, Mahalanobis distances can be converted into probabilities of group membership for individual specimens. For relatively small sample sizes, it is appropriate to base probabilities on Hotelling's $T^{2}$, which is the multivariate extension of the univariate Student's $t$.

When group sizes are small, Mahalanobis distance-based probabilities can fluctuate dramatically depending upon whether or not each specimen is assumed to be a member of the group to which it is being compared. Harbottle (1976) calls this phenomenon "stretchability" in reference to the tendency of an included specimen to stretch the group in the direction of its own location in elemental concentration space. This problem can be circumvented by cross-validation, that is, by removing each specimen from its presumed group before calculating its own probability of membership (Baxter 1994; Leese and Main 1994). This is a conservative approach to group evaluation that may sometimes exclude true group members.

Small sample and group sizes place further constraints on the use of Mahalanobis distance: with more elements than samples, the group variance-covariance matrix is singular thus rendering calculation of $I_{x}$ (and $D^{2}$ itself) impossible. Therefore, the dimensionality of the groups must somehow be reduced. One approach would be to eliminate elements considered irrelevant or redundant. The problem with this approach is that the investigator's preconceptions about which elements should be discriminate may not be valid. It also squanders the main advantage of multielement analysis, namely the capability to measure a large number of elements. An alternative approach is to calculate Mahalanobis distances with the scores on principal components extracted from the variance-covariance or correlation matrix for the complete data set. This approach entails only the assumption, entirely reasonable in light of the above discussion of PCA, that most group-separating differences should be visible on the first several PCs. Unless a data set is extremely complex, containing numerous distinct groups, using enough components to subsume at least $90 \%$ of the total variance in the data can be generally assumed to yield Mahalanobis distances that approximate Mahalanobis distances in full elemental concentration space.

Lastly, Mahalanobis distance calculations are also quite useful for handling missing data (Sayre 1975). When many specimens are analyzed for a large number of elements, it is almost certain that a few element concentrations will be missed for some of the specimens. This occurs most frequently when the concentration for an element is near the detection limit. Rather than eliminate the specimen or the element from consideration, it is possible to substitute a missing value by replacing it with a value that minimizes the Mahalanobis distance for the specimen from the group centroid. Thus, those few specimens, which are missing a single concentration value, can still be used in group calculations.

\section{Results and Conclusions}

The sample size is too small for statistically valid assessment of internal compositional variation, however we have found pairs of samples that may indicate samples from the same vessels. We have compared the new data to the entire MURR ceramic NAA database as well as reference groups from central Texas. Table M-1 is a list of the current samples along with some descriptive information.

Table M-1. Descriptive Information

\begin{tabular}{|c|c|c|c|c|c|}
\hline ANID & Alt ID & Ware & Ceramic Type & Culture & Period \\
\hline GST033 & $94-0-1$ & bone-tempered plainware & Leon Plain & Toyah & Late Prehistoric possibly later \\
\hline GST034 & $74-0-1$ & bone-tempered plainware & Leon Plain & Toyah & Late Prehistoric possibly later \\
\hline GST035 & $66-0-9$ & bone-tempered plainware & Leon Plain & Toyah & Late Prehistoric possibly later \\
\hline GST036 & $66-0-4$ & bone-tempered plainware & Leon Plain & Toyah & Late Prehistoric possibly later \\
\hline GST037 & $50-0-1$ & bone-tempered plainware & Leon Plain & Toyah & Late Prehistoric possibly later \\
\hline GST038 & $8-0-4$ & bone-tempered plainware & Leon Plain & Toyah & Late Prehistoric possibly later \\
\hline
\end{tabular}




\section{Internal Variability}

The six samples are very uniform in composition. In comparative plots to other Texas reference groups, they form a very tight cluster. These vessels were produced with very similar raw materials, and perhaps some derive from the same vessel. The data roughly form three pairs that may indicate vessel matches. Pair 1 includes samples 033 and 036, pair 2 includes 034 and 035 , and the third pair includes 037 and 038 (see Figure M-1).

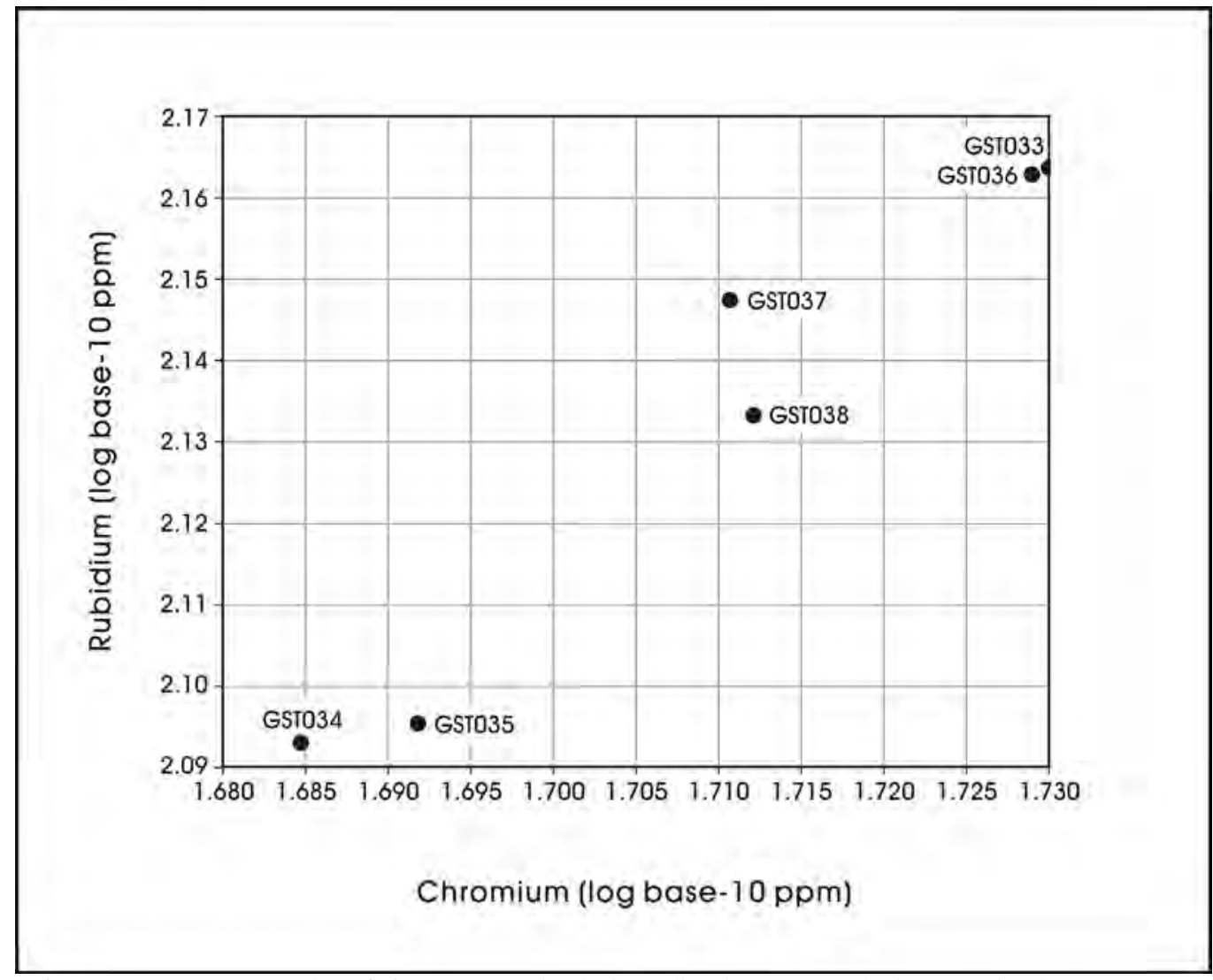

Figure M-1. Bivariate plot of chromium and rubidium (log base-10ppm) showing the three pairs.

\section{Comparison with MURR Database}

The samples were projected against the entire MURR ceramic NAA database containing over 55,000 samples, producing surprisingly few close matches. The only close matches were samples analyzed for Darrell Creel from central Texas. All of the possible matches from the MURR database were assigned by Neff and Glascock (2002) to the central Texas-2 (CT2) compositional group. A more detailed comparison with the central Texas samples follows.

\section{Comparison with Central Texas Compositional Groups}

The central Texas reference groups developed by Neff and Glascock (2002) include six groups, two of which (CT1 and CT2) have 75 or more members. The new samples were compared to the CT groups in bivariate plots, and the only two groups with possible overlap were CT1 and CT2 (see Figure M-2). Table M-2 lists the probabilities of membership in CT1 and CT2. All of the samples have reasonable probabilities of membership in CT2. Neff and Glascock (2002) note that CT2 samples are concentrated in the southeastern portion of central Texas, and this would fit with the location of the current samples. 


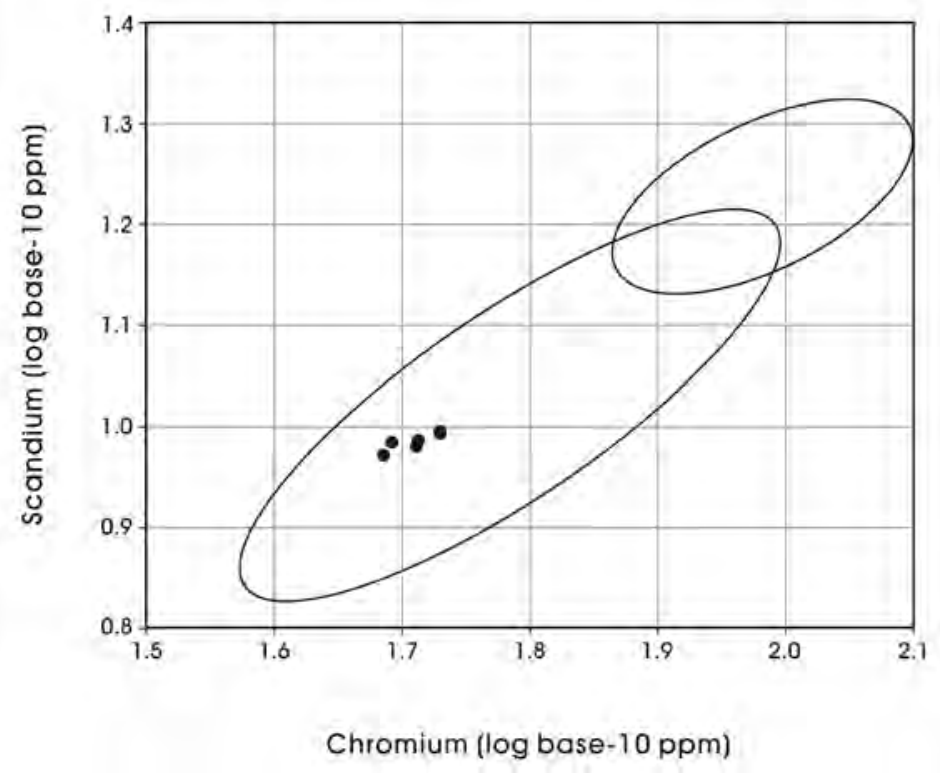

Figure M-2. Bivariate plot of chromium and scandium (log base-10 ppm) showing the samples relative to the CT1 and CT2 reference groups. The new samples are individually plotted. Ellipses represent $90 \%$ confidence intervals for membership in the groups.

Table M-2. Probabilities of Membership in the CT1 and CT2 Groups

Using a Mahalanobis Distance Calculation with All Elements MAHALANOBIS DISTANCE CALCULATION FOR MISCELLANEOUS SPECIMENS

PROJECTED AGAINST TWO OR MORE GROUPS.

Reference groups and numbers of specimens:

1 CT1 75

2 CT2 164

\begin{tabular}{ccccccc}
\multicolumn{7}{c}{ Variables used: } \\
AS & LA & LU & ND & SM & U & YB \\
CE & CO & CR & CS & EU & FE & HF \\
RB & SB & SC & SR & TA & TB & TH \\
ZN & ZR & AL & BA & DY & K & MN \\
& & NA & TI & V & &
\end{tabular}

Probabilities:

$\begin{array}{ccc}\text { ID. NO. } & \text { CT1 } & \text { CT2 } \\ \text { GST033 } & 0.000 & 10.665 \\ \text { GST034 } & 0.000 & 14.123 \\ \text { GST035 } & 0.000 & 7.246 \\ \text { GST036 } & 0.000 & 15.860 \\ \text { GST037 } & 0.000 & 5.768 \\ \text { GST038 } & 0.000 & 15.816\end{array}$


The cover letter accompanying the samples indicates a desire to have the sherds compared to other Leon Plain sherds. The CT2 group is dominated by Leon Plain sherds, but so are all of the other 5 compositional groups from central Texas. We have recently completed a contract project involving 9 Toyah Phase ceramics. Data ownership considerations prohibit a specific presentation of these other Toyah samples, but, in general, the samples were not compositionally similar. The other study revealed a much greater compositional diversity within a similar sample size, further emphasizing the compositional uniformity of this dataset.

\section{Conclusions}

The primary goal of this project is to determine the relationship with other samples previously analyzed at MURR. All of the samples are assigned to the CT2 group that Neff and Glascock (2002) suggested was produced in the southeastern portion of Central Texas. The comparison with other Leon Plain samples is complicated due to the great compositional diversity of samples assigned to this type. The samples analyzed here fall into a compositional group dominated by Leon Plain samples. The limited number of samples in this study restricts the potential for creating statistically meaningful internal groupings, but three pairs of similar samples suggest the possibility of vessel matches. Overall the compositions of the samples are very similar, suggesting very similar raw material use.

\section{Acknowledgments}

We acknowledge Mark Beary and Chris Oswald for their roles in preparing the samples for irradiation. 


\section{References Cited :}

Baxter, Michael J.

1992 Archaeological uses of the biplot - a neglected technique? In Computer Applications and Quantitative Methods in Archaeology, 1991, edited by G. Lock and J. Moffett. BAR International Series S577, 141-148. Tempvs Reparatvm, Archaeological and Historical Associates, Oxford.

1994 Exploratory Multivariate Analysis in Archaeology. Edinburgh University Press, Edinburgh.

Baxter, M.J. and C.E. Buck

2000 Data Handling and Statistical Analysis. In Modern Analytical Methods in Art and Archaeology, edited by E. Ciliberto and G. Spoto, pp. 681-746. John Wiley and Sons, New York.

Bieber, Alan M. Jr., Dorothea W. Brooks, Garman Harbottle, and Edward V. Sayre

1976 Application of multivariate techniques to analytical data on Aegean ceramics. Archaeometry 18:59-74.

Bishop, Ronald L. and Hector Neff

1989 Compositional data analysis in archaeology. In Archaeological Chemistry IV, edited by R. O. Allen, pp. 576-586.

Advances in Chemistry Series 220, American Chemical Society, Washington, D.C.

Bishop, Ronald L., Robert L. Rands, and George R. Holley

1992 Ceramic compositional analysis in archaeological perspective. In Advances in Archaeological Method and Theory, vol. 5, pp. 275-330. Academic Press, New York.

Glascock, Michael D.

1992 Characterization of archaeological ceramics at MURR by neutron activation analysis and multivariate statistics. In Chemical Characterization of Ceramic Pastes in Archaeology, edited by H. Neff, pp. 11-26. Prehistory Press, Madison, WI.

Harbottle, Garman

1976 Activation analysis in archaeology. Radiochemistry 3:33-72. The Chemical Society, London.

Leese, Morven N. and Peter L. Main

1994 The efficient computation of unbiased Mahalanobis distances and their interpretation in archaeometry. Archaeometry 36:307-316.

Lynott, Mark J., Hector Neff, James E. Price, James W. Cogswell, and Michael D. Glascock

2000 Inferences about prehistoric ceramics and people in Southeast Missouri: Results of ceramic compositional analysis. American Antiquity 65(1): 103-126.

Neff, Hector

1992 Introduction. In Chemical Characterization of Ceramic Pastes in Archaeology, edited by H. Neff, pp. 1-10. Prehistory Press, Madison, WI.

1994 RQ-mode principal components analysis of ceramic compositional data. Archaeometry 36:115-130.

2000 Neutron activation analysis for provenance determination in archaeology. In Modern Analytical Methods in Art and Archaeology, edited by E. Ciliberto and G. Spoto, pp. 81-134. John Wiley and Sons, Inc., New York.

2002 Quantitative techniques for analyzing ceramic compositional data. In Ceramic Source Determination in the Greater Southwest, edited by D. M. Glowacki and H. Neff. Monograph 44, Cotsen Institute of Archaeology, UCLA, Los Angeles.

Neff and Glascock

2002 Compositional Variation in Aboriginal Ceramics from Central Texas: Results of Instrumental Neutron Activation Analysis. Report on file at MURR. 
Neff, Hector, Ronald L. Bishop, and Edward V. Sayre

1988 A simulation approach to the problem of tempering in compositional studies of archaeological ceramics. Journal of Archaeological Science 15:159-172.

Sayre, Edward V.

1975 Brookhaven Procedures for Statistical Analyses of Multivariate Archaeometric Data. Brookhaven National Laboratory Report BNL-23128. New York.

Steponaitis, Vincas, M. James Blackman, and Hector Neff

1996 Large-scale compositional patterns in the chemical composition of Mississippian pottery. American Antiquity 61:555-572.

Weigand, Phil C., Garman Harbottle, and Edward V. Sayre

1977 Turquoise sources and source analysis: Mesoamerica and the southwestern U.S.A. In Exchange Systems in Prehistory, edited by T. K. Earle and J. E. Ericson, pp. 15-34. Academic Press, New York. 



\section{Results of Scanning Electron Microscopy of Sherds from 41KM69,} Kimble County, Texas 


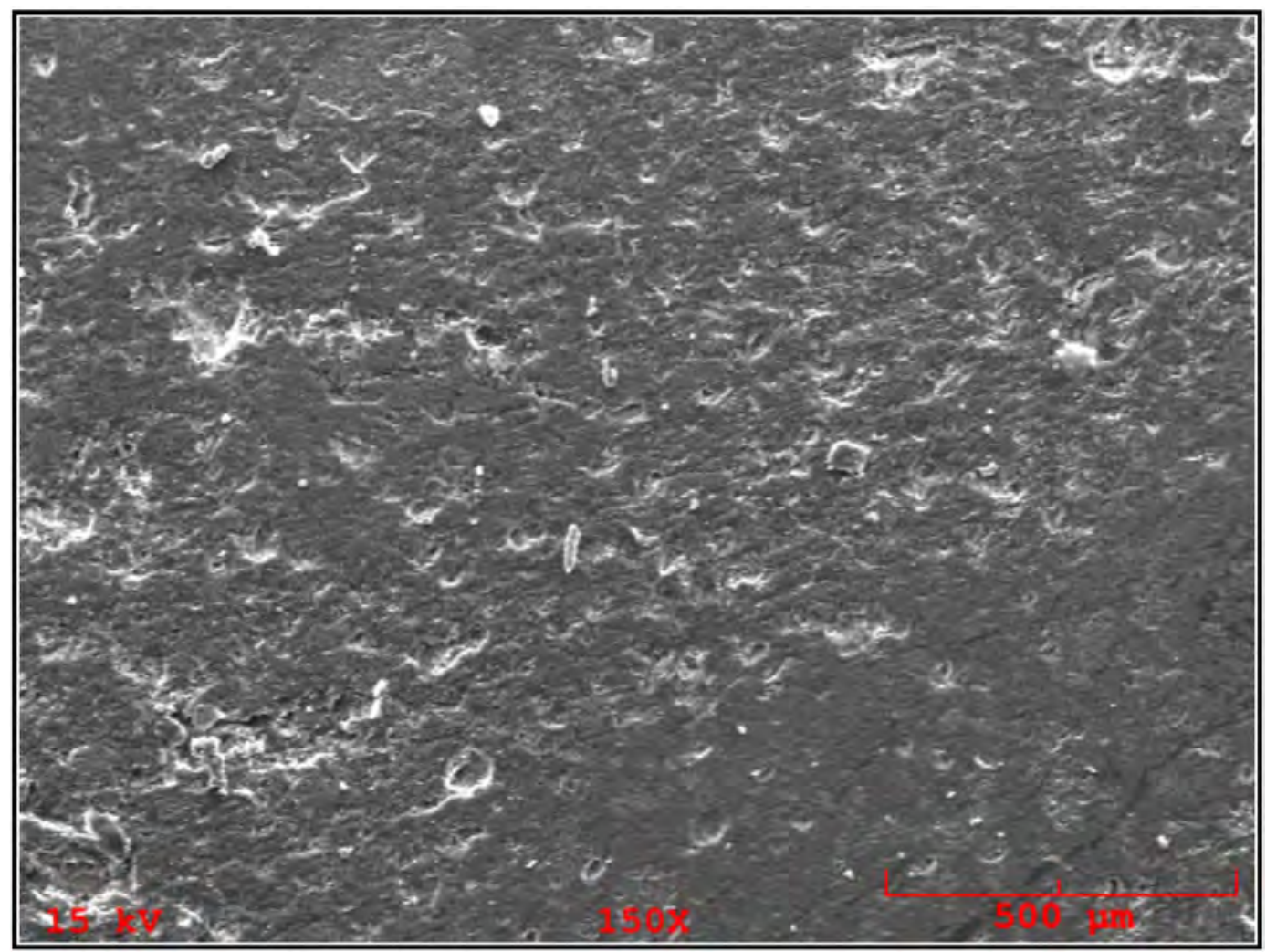

Figure M-3. SEM Micrograph of Sherd Sample 7.

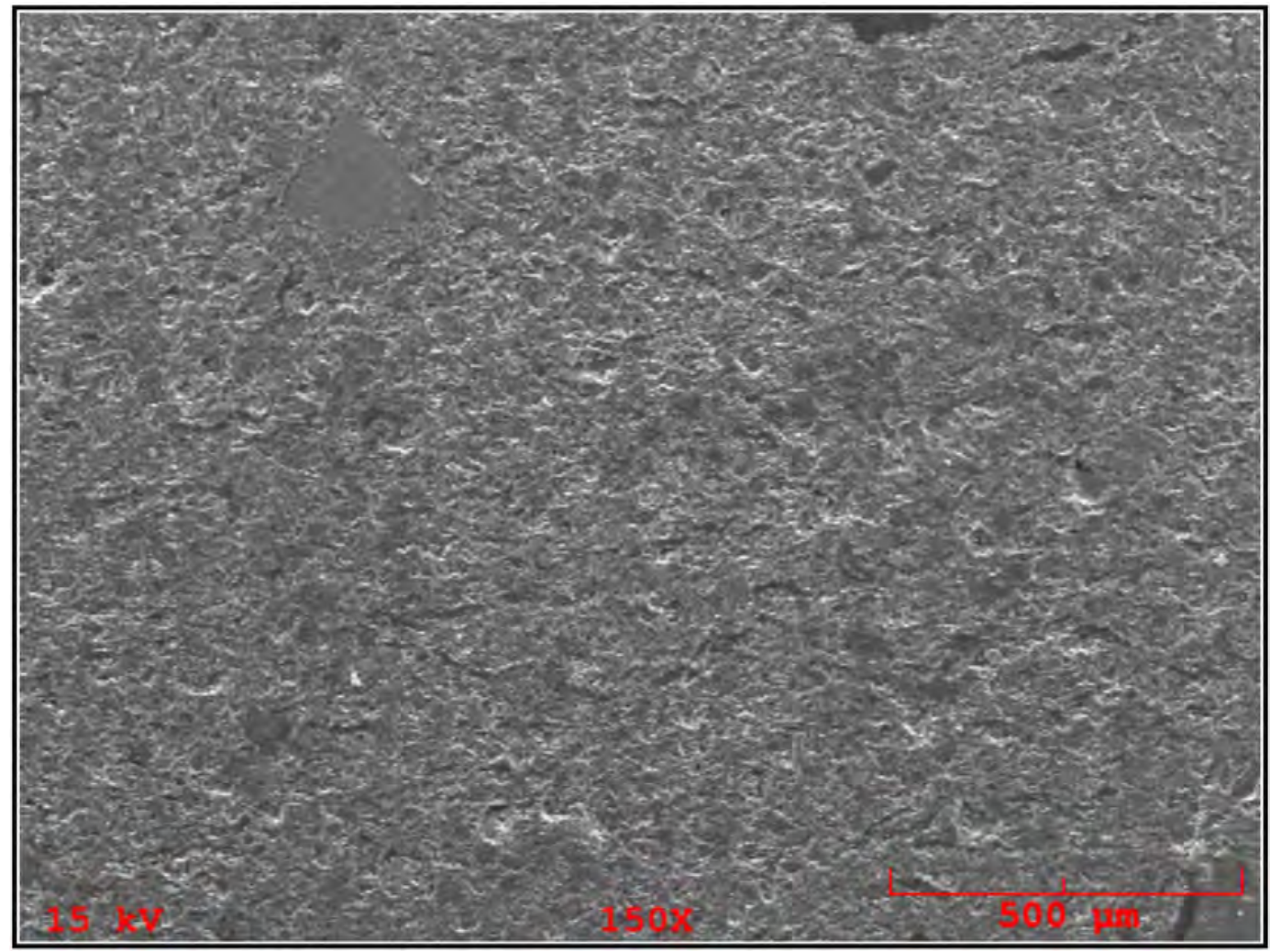

Figure M-4. SEM Micrograph of Sherd Sample 8. 


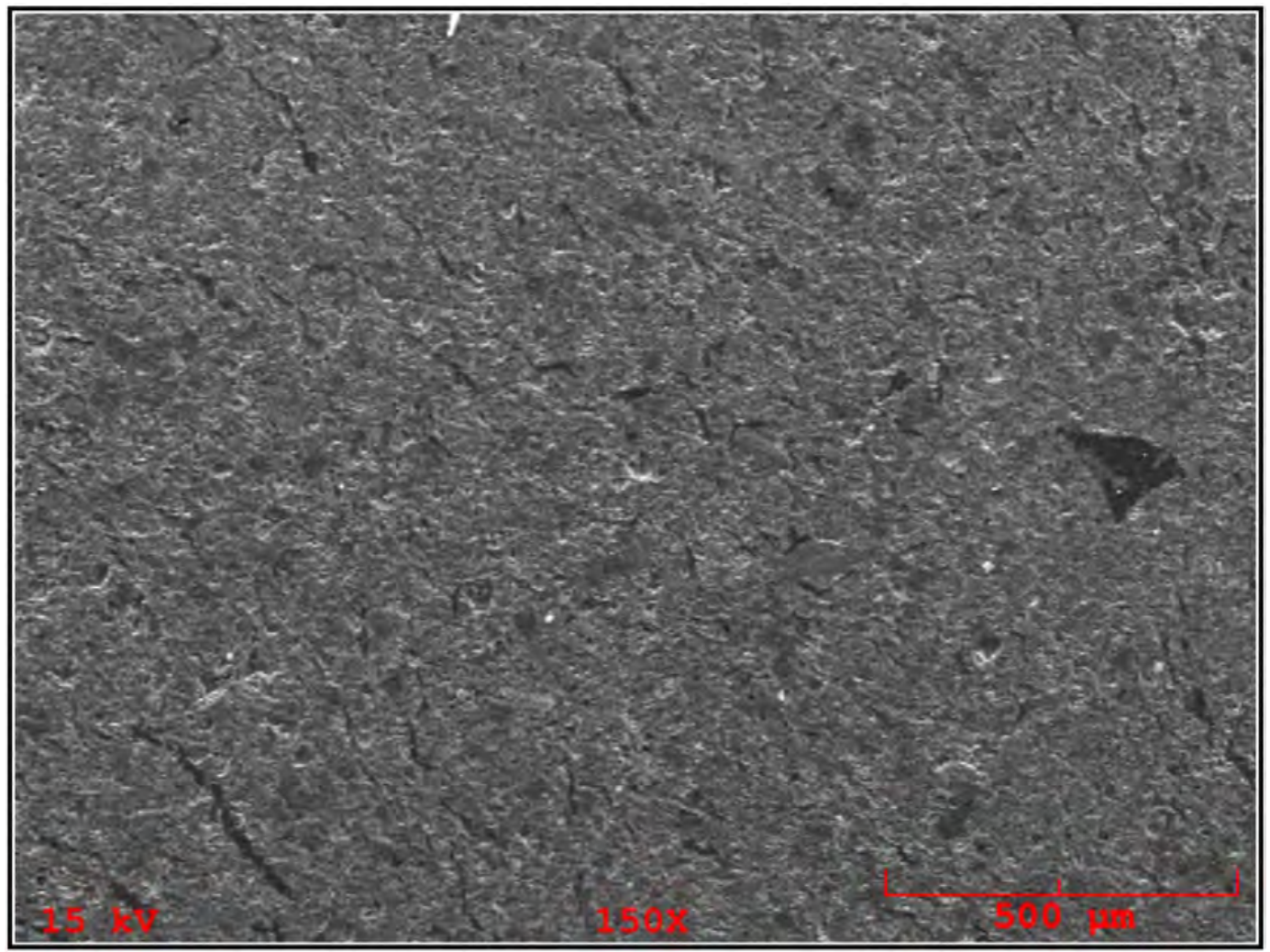

Figure M-5. SEM Micrograph of Sherd Sample 9.

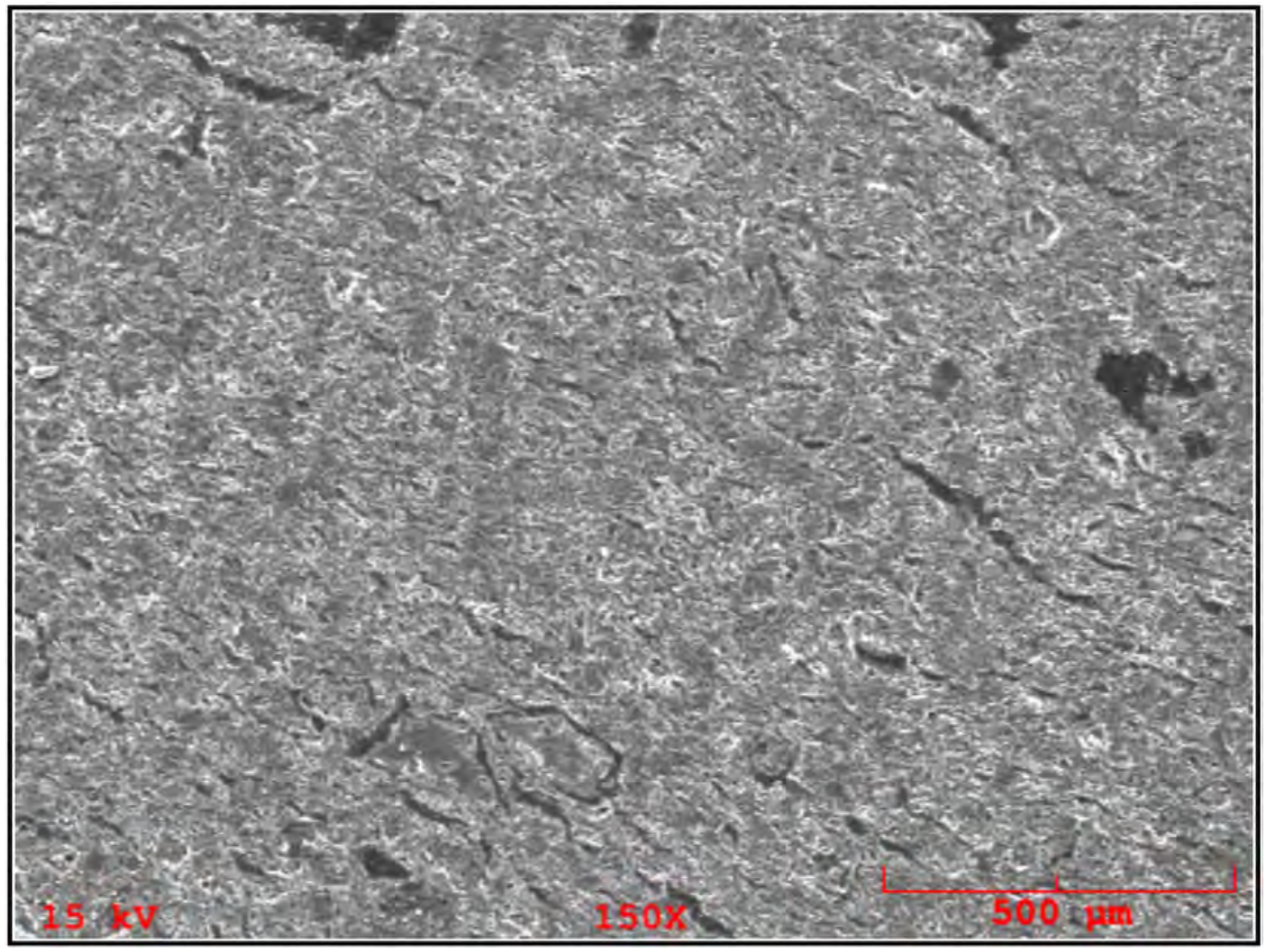

Figure M-6. SEM Micrograph of Sherd Sample 10. 


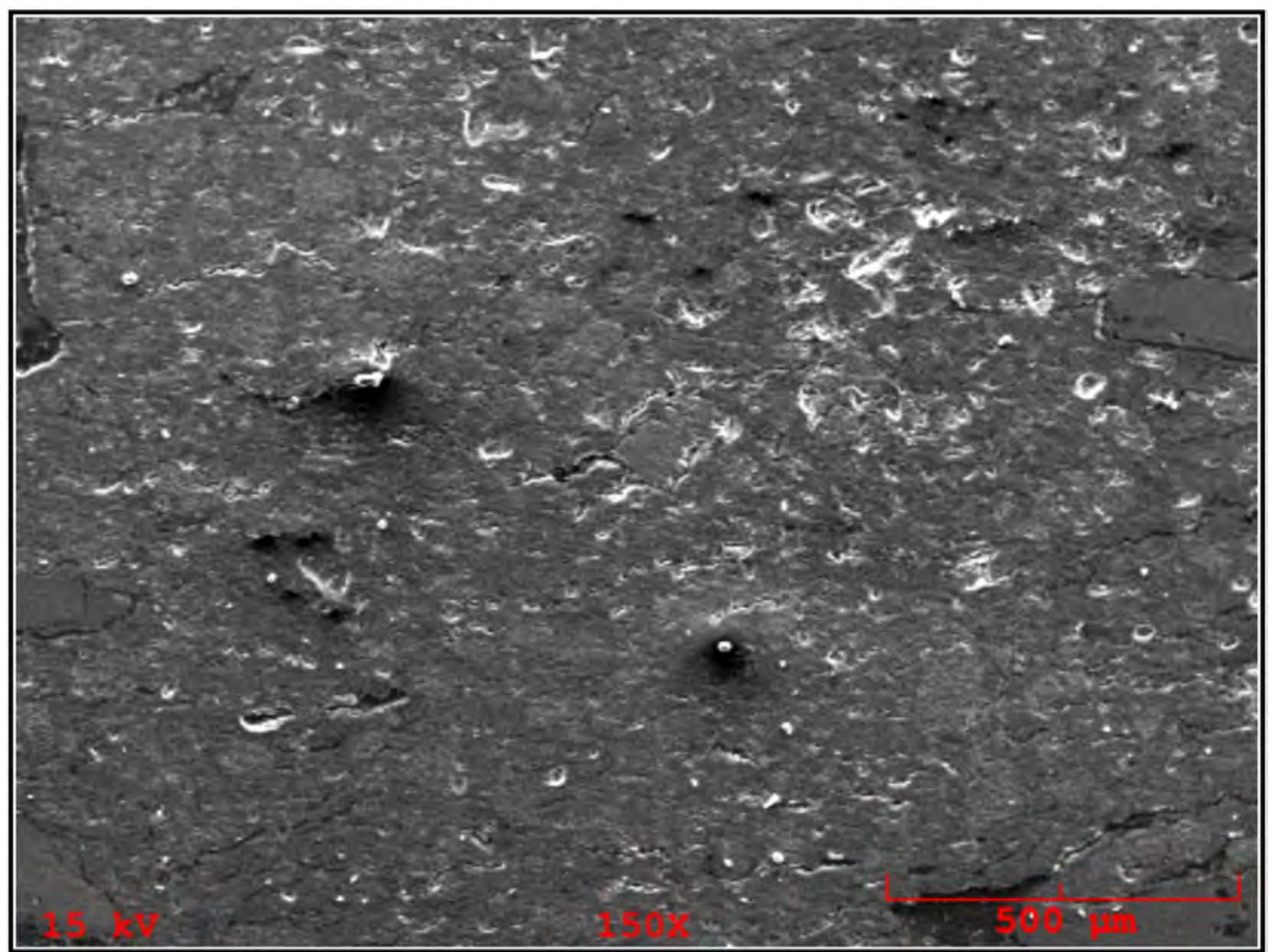

Figure M-7. SEM Micrograph of Sherd Sample 11.

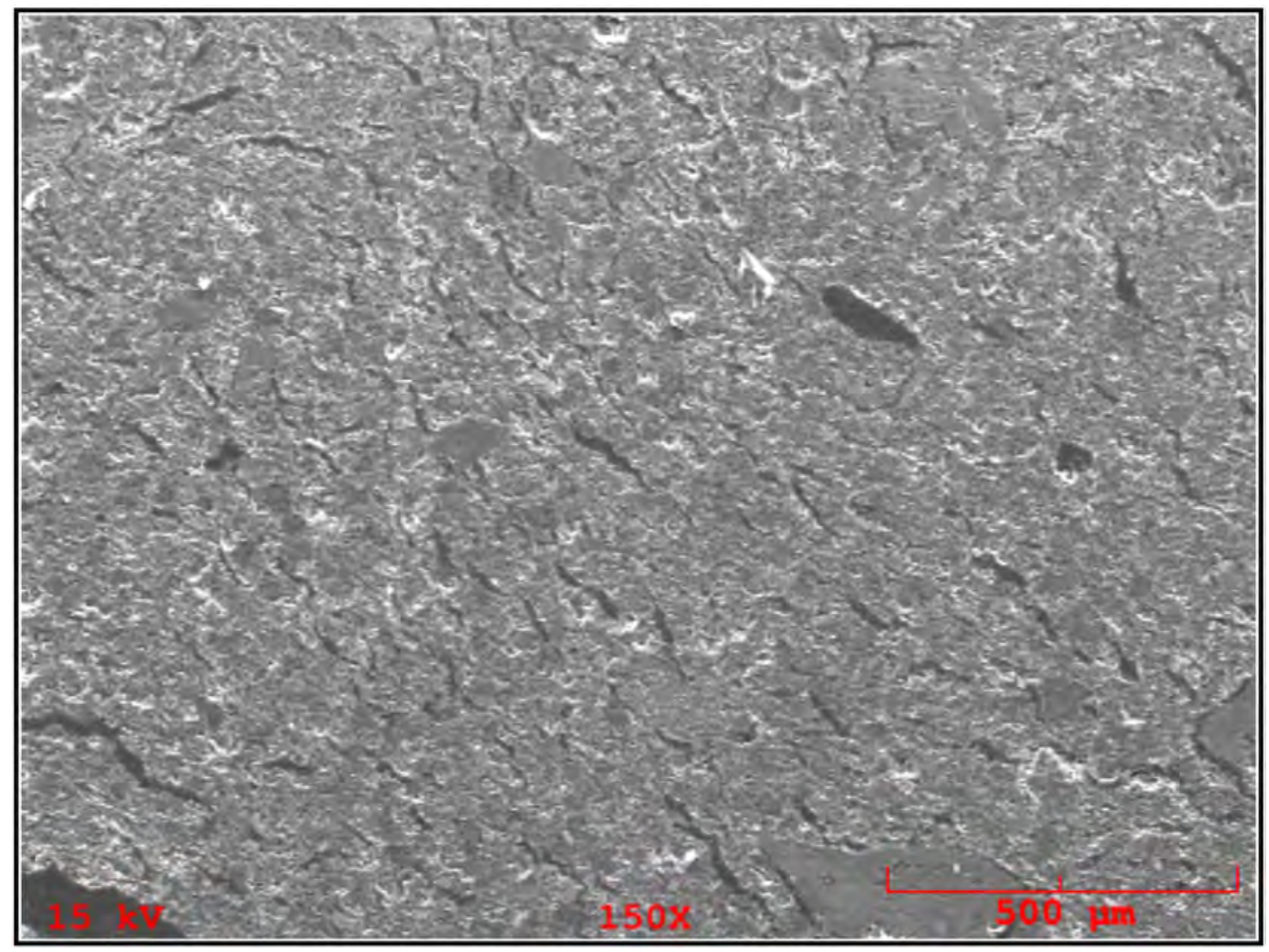

Figure M-8. SEM Micrograph of Sherd Sample 12. 
Table M-3. SEM-EDS Analysis Results of the Six Sherds Shown Above

\begin{tabular}{|c|c|c|c|c|c|c|}
\hline Element & Sherd 12 & Sherd 11 & Sherd 10 & Sherd 9 & Sherd 8 & Sherd 7 \\
\hline $\mathrm{Na}$ & 0 & 0.265 & 0.323 & 0.132 & 0.292 & 0.172 \\
\hline $\mathrm{Mg}$ & 2.812 & 2.278 & 2.692 & 2.642 & 2.815 & 2.437 \\
\hline $\mathrm{Al}$ & 10.253 & 8.805 & 9.69 & 8.221 & 8.851 & 8.388 \\
\hline $\mathrm{Si}$ & 55.91 & 36.531 & 50.328 & 37.58 & 41.83 & 26.995 \\
\hline $\mathrm{P}$ & 2.365 & 4.789 & 2.559 & 0.963 & 1.366 & 1.858 \\
\hline $\mathrm{Cl}$ & 0 & 0.324 & 0.3 & 0.189 & 0.219 & 0.412 \\
\hline K & 4.778 & 4.456 & 4.529 & 3.588 & 4.588 & 2.802 \\
\hline $\mathrm{Ca}$ & 16.731 & 16.548 & 14.189 & 10.702 & 14.677 & 10.974 \\
\hline $\mathrm{Fe}$ & 0 & & 3.056 & 2.523 & & 2.246 \\
\hline $\mathrm{Zr}$ & 6.674 & 7.467 & 6.799 & 5.985 & 3.979 & 9.649 \\
\hline $\mathrm{Ru}$ & 0 & 0 & & & & \\
\hline $\mathrm{Pd}$ & 0 & 0 & 1.448 & 0.9 & 1.046 & 1.058 \\
\hline $\mathrm{Ba}$ & 0 & 0 & 3.07 & 1.401 & & 2.028 \\
\hline In & 0.477 & 0 & 1.015 & 1.393 & & 3.65 \\
\hline $\mathrm{Rb}$ & 0 & 17.457 & & 23.689 & 19.87 & 27.221 \\
\hline $\mathrm{Ra}$ & & 1.079 & & & & \\
\hline $\mathrm{Ti}$ & & & & 0.094 & 0.469 & 0.111 \\
\hline
\end{tabular}



Appendix N:

Analysis of Edwards Formation Chert from the Llano River Gravels and 41KM69

Matthew T. Boulanger and Michael D. Glascock 



\title{
Appendix N
}

\section{Analysis of Edwards Formation Chert from the Llano River Gravels and 41KM69}

\author{
Matthew T. Boulanger and Michael D. Glascock \\ Archaeometry Laboratory, \\ University of Missouri Research Reactor \\ Columbia, MO 65211

\section{Introduction}

A sample of 29 chert specimens from Kimble County, Texas, was submitted for compositional analysis by neutron activation (Figure N-1). Analyses were conducted at the Archaeometry Laboratory at the University of Missouri Research Reactor (MURR). Five specimens analyzed in this study were collected from gravel deposits of the Llano River. The remaining 24 specimens represent artifacts made of presumably locally and non-locally derived cherts obtained from 41KM69 (Table N-1). All specimens were collected and submitted by Steve A. Tomka, Director of the Center for Archaeological Research, University of Texas at San Antonio.

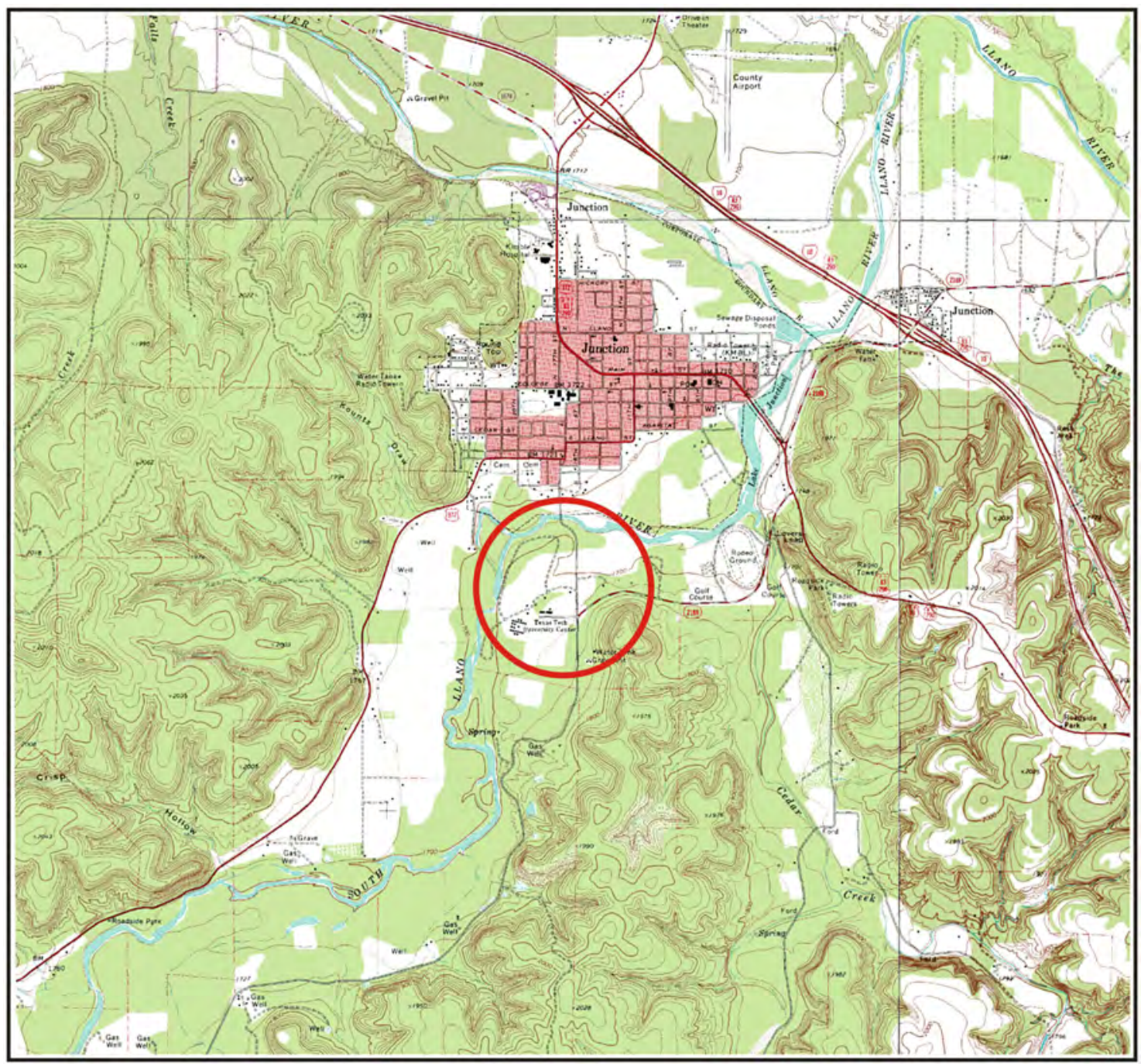

Figure N-1. General Location (red circle) of 41 KM69 and the Collection Site of Gravel Samples from the Llano River in Kimble County, Texas. 
Table N-1. Summary Table of Chert Specimens Submitted for Analysis by Neutron Activation from West-Central Texas

\begin{tabular}{|c|c|}
\hline Provenience & ANID \\
\hline Llano River Gravel & TMK001 \\
\hline \multirow[t]{4}{*}{$\mathrm{n}=5$} & TMK002 \\
\hline & TMK003 \\
\hline & TMK004 \\
\hline & TMK005 \\
\hline 41 KM69 (Possibly Local) & TMK006 \\
\hline \multirow[t]{8}{*}{$\mathrm{n}=9$} & TMK007 \\
\hline & TMK008 \\
\hline & TMK009 \\
\hline & TMK010 \\
\hline & TMK011 \\
\hline & TMK018 \\
\hline & TMK019 \\
\hline & TMK020 \\
\hline 41 KM69 (Possibly Nonlocal) & TMK012 \\
\hline \multirow[t]{14}{*}{$\mathrm{n}=15$} & TMK013 \\
\hline & TMK014 \\
\hline & TMK015 \\
\hline & TMK016 \\
\hline & TMK017 \\
\hline & TMK021 \\
\hline & TMK022 \\
\hline & TMK023 \\
\hline & TMK024 \\
\hline & TMK025 \\
\hline & TMK026 \\
\hline & TMK027 \\
\hline & TMK028 \\
\hline & TMK029 \\
\hline
\end{tabular}

Several researchers have undertaken analyses of chert, here used as a catch-all term for cryptocrystalline silicates such as flint, jasper, agate, etc., from Texas localities (Table N-2). In some instances (e.g., Frederick et al. 1994) studies have resulted in meaningful discrimination among geological sources. Other studies have demonstrated that chemical variation within individual sources is too great to allow confident identification by NAA (e.g., Boulanger and Glascock 2008).

The primary goals of the current study are to determine (1) whether chert samples from 41KM69 and the Llano River can be grouped into compositional groups with geological or archaeological significance, and (2) to assess how the compositions of these samples compare with those data and assign provenance determinations to artifacts if possible.

\section{Sample Preparation}

Upon arrival at MURR, the source samples were washed in deionized water to remove all possible dirt and loose material from their surfaces. Samples for NAA were prepared by placing source specimens between two tool-steel plates and crushing them with a Carver Press. Several small 50-100 mg fragments were obtained from the crushed specimens. Fragments were examined under low-power magnification, and fragments with metallic streaks or crush fractures were eliminated from consideration. Several grams of the remaining fragments were obtained from each sample and temporarily stored in plastic bags. 
Table N-2. Prior Studies of Texas Cherts Conducted by NAA at MURR. Note that Published Reports for Projects by Turnbow (1994) and Hudler (1998) Could Not Be Located at the Time of This Writing

\begin{tabular}{ccccc}
\hline \hline Investigator & Year & Formation or Chert Name & Location & Reference \\
\hline C. Frederick & 1994 & Edwards Grp. & Fort Hood, TX & Frederick et al. (1994) \\
C. Turnbow & 1994 & Edwards Grp., & Segovia Member & Howard County, TX \\
D. Hudler & 1998 & Willis Gravels & De Witt County, TX & -- \\
D. Hudler & 2001 & Leon Creek & Bluff, TX & Glascock (2001) \\
M. Quigg & 2004 & Edwards Grp. & Southwest TX (multiple) & Glascock and Speakman (2004) \\
M. Quigg & 2006 & Glen Rose & Gillespie County, TX & Glascock and Speakman (2006a) \\
M. Quigg & 2006 & Edwards Grp. & Taylor County, TX & Glascock and Speakman (2006b) \\
& & Llano River Gravel & Mason County, TX & Boulanger and Glascock (2007) \\
M. Quigg & 2007 & Gorman Fmt. & Callahan Divide, TX (multiple) & Boulanger and Glascock (2008) \\
& & Marble Falls Fmt. & & Boulanger and Glascock (2009) \\
K. Caffrey & 2008 & Edwards Grp. & Texas Panhandle (multiple) & \\
\hline
\end{tabular}

Two analytical samples were prepared from each source specimen. Portions of approximately $200 \mathrm{mg}$ of rock fragments were weighed into high-density polyethylene vials used for short irradiations at MURR. At the same time, $800 \mathrm{mg}$ aliquots from each sample were weighed into high-purity quartz vials used for long irradiations. Individual sample weights were recorded to the nearest $0.01 \mathrm{mg}$ using an analytical balance. Both vials were sealed prior to irradiation. Along with the unknown samples, standards made from National Institute of Standards and Technology (NIST) certified standard reference materials of SRM1633b (Coal Fly Ash), SRM-278 (Obsidian Rock), and SRM-688 (Basalt Rock) were similarly prepared.

\section{Irradiation and Gamma-Ray Spectroscopy}

Neutron activation analysis of most archaeological samples at MURR, which consists of two irradiations and a total of three gamma counts, constitutes a superset of the procedures used at most other NAA laboratories (Glascock 1992; Glascock and Neff 2003; Neff 2000). As discussed in detail by Glascock (1992), a short irradiation is carried out through the pneumatic tube irradiation system. Samples in the polyvials are sequentially irradiated, two at a time, for five seconds by a neutron flux of 8 $\times 10^{13} \mathrm{n} \mathrm{cm}^{-2} \mathrm{~s}^{-1}$ The 720 -second count yields gamma spectra containing peaks for nine short-lived elements aluminum ( $\left.\mathrm{Al}\right)$, barium $(\mathrm{Ba})$, calcium $(\mathrm{Ca})$, dysprosium $(\mathrm{Dy})$, potassium $(\mathrm{K})$, manganese $(\mathrm{Mn})$, sodium $(\mathrm{Na})$, titanium $(\mathrm{Ti})$, and vanadium $(\mathrm{V})$. The long-irradiation samples are encapsulated in quartz vials and are subjected to a 70-hour irradiation at a neutron flux of 5 $\mathrm{x} 10^{13} \mathrm{n} \mathrm{cm}^{-2} \mathrm{~s}^{-1}$. This long irradiation is analogous to the single irradiation utilized at most other laboratories. After the long irradiation, samples decay for seven days, and then are counted for 1800 seconds (the "middle count") on a high-resolution germanium detector coupled to an automatic sample changer. The middle count yields determinations of seven medium half-life elements, namely arsenic (As), lanthanum (La), lutetium ( $\mathrm{Lu}$ ), neodymium $(\mathrm{Nd})$, samarium $(\mathrm{Sm})$, uranium $(\mathrm{U})$, and ytterbium $(\mathrm{Yb})$. After an additional three- or four-week decay, a final count of 8500 seconds is carried out on each sample. The latter measurement yields the following 17 long half-life elements: cerium $(\mathrm{Ce})$, cobalt $(\mathrm{Co})$, chromium $(\mathrm{Cr})$, cesium $(\mathrm{Cs})$, europium $(\mathrm{Eu})$, iron $(\mathrm{Fe})$, hafnium $(\mathrm{Hf})$, nickel $(\mathrm{Ni})$, rubidium $(\mathrm{Rb})$, antimony $(\mathrm{Sb})$, scandium $(\mathrm{Sc})$, strontium ( $\mathrm{Sr}$ ), tantalum $(\mathrm{Ta})$, terbium $(\mathrm{Tb})$, thorium $(\mathrm{Th})$, zinc $(\mathrm{Zn})$, and zirconium $(\mathrm{Zr})$.

The element concentration data from the three measurements are tabulated in parts per million using Microsoft ${ }^{\circledR}$ Office Excel. Descriptive data for archaeological samples are appended to the concentration spreadsheet. These data are also stored in a dBase/ FoxPro database file useful for organizing, sorting, and extracting sample information. The combined descriptive, contextual, and compositional database for samples analyzed as part of this study is included here as Appendix A. A digital copy of this database is provided with this report. Additional copies of these data are available upon request to the Archaeometry Laboratory. 


\section{Interpreting Chemical Data}

Analyses at MURR described previously produce elemental concentration values for 32 elements in most analyzed samples. However, cryptocrystalline silicates do not always have sufficient quantities of these 32 elements to be detectable using the above procedures, i.e., elemental determinations are "missing" because the abundances of these elements are at or below the detection limits of the technique and/or instrumentation. Compositional data for the newly analyzed specimens and for the extant Texas chert database were divided into subgroups reflecting geological source locations. Each of these subgroups was then assessed for missing values. Any element missing in greater than $50 \%$ of each particular subgroup was eliminated from consideration in the statistical evaluation of these data. This process eliminated the following 12 elements from the database: As, Lu, Nd, Yb, Cs, Ni, Tb, Ca, Dy, K, Ti, and V.

All subgroups were then re-combined, and statistical analyses were subsequently carried out on base-10 logarithms of concentrations on the remaining 20 elements. Use of log concentrations rather than raw data compensates for differences in magnitude between the major elements, such as sodium, and trace elements, such as the rare earth or lanthanide elements (REEs). Transformation to base-10 logarithms also yields a more normal distribution for many trace elements.

The interpretation of compositional data obtained from the analysis of archaeological materials is discussed in detail elsewhere (e.g., Baxter and Buck 2000; Bieber, et al. 1976; Bishop and Neff 1989; Glascock 1992; Harbottle 1976; Neff 2000) and will only be summarized here. The main goal of data analysis is to identify distinct homogeneous groups within the analytical database. Based on the provenance postulate of Weigand et al. (1977), different chemical groups may be assumed to represent geographically restricted sources. For lithic materials such as obsidian, basalt, and cryptocrystalline silicates (e.g., chert, flint, or jasper), raw material samples are frequently collected from known outcrops or secondary deposits and the compositional data obtained on the samples is used to define the source localities or boundaries. The locations of sources can also be inferred by comparing unknown specimens (i.e., ceramic artifacts) to knowns (i.e., clay samples) or by indirect methods such as the "criterion of abundance" (Bishop, et al. 1982) or by arguments based on geological and sedimentological characteristics (e.g., Steponaitis, et al. 1996). The ubiquity of ceramic raw materials usually makes it impossible to sample all potential "sources" intensively enough to create groups of knowns to which unknowns can be compared. Lithic sources tend to be more localized and compositionally homogeneous in the case of obsidian or compositionally heterogeneous as is the case for most cherts.

Compositional groups can be viewed as "centers of mass" in the compositional hyperspace described by the measured elemental data. Groups are characterized by the locations of their centroids and the unique relationships (i.e., correlations) between the elements. Decisions about whether to assign a specimen to a particular compositional group are based on the overall probability that the measured concentrations for the specimen could have been obtained from that group.

Initial hypotheses about source-related subgroups in the compositional data can be derived from non-compositional information (e.g., archaeological context, decorative attributes, etc.) or from application of various pattern-recognition technique to the multivariate chemical data. Some of the pattern recognition techniques that have been used to investigate archaeological data sets are cluster analysis (CA), principal components analysis (PCA), and discriminant analysis (DA). Each of the techniques has it own advantages and disadvantages which may depend upon the types and quantity of data available for interpretation.

The variables (measured elements) in archaeological and geological data sets are often correlated and frequently large in number. This makes handling and interpreting patterns within the data difficult. Therefore, it is often useful to transform the original variables into a smaller set of uncorrelated variables in order to make data interpretation easier. Of the above-mentioned pattern recognition techniques, PCA is a technique that transforms from the data from the original correlated variables into uncorrelated variables most easily.

Principal components analysis creates a new set of reference axes arranged in decreasing order of variance subsumed. The individual PCs are linear combinations of the original variables. The data can be displayed on combinations of the new axes, just as they can be displayed on the original elemental concentration axes. PCA can be used in a pure pattern-recognition mode, i.e., to search for subgroups in an undifferentiated data set, or in a more evaluative mode, i.e., to assess the coherence of hypothetical 
groups suggested by other criteria. Generally, compositional differences between specimens can be expected to be larger for specimens in different groups than for specimens in the same group, and this implies that groups should be detectable as distinct areas of high point density on plots of the first few components.

Principal components analysis of chemical data is scale dependent, and analyses tend to be dominated by those elements or isotopes for which the concentrations are relatively large. As a result, standardization methods are common to most statistical packages. A common approach is to transform the data into logarithms (e.g., base 10). As an initial step in the PCA of most chemical data at MURR, the data are transformed into log concentrations to equalize the differences in variance between the major elements such as Al, $\mathrm{Ca}$ and $\mathrm{Fe}$, on one hand and trace elements, such as the rare-earth elements (REEs), on the other hand. An additional advantage of the transformation is that it appears to produce more nearly normal distributions for the trace elements.

One frequently exploited strength of PCA, discussed by Baxter (1992), Baxter and Buck (2000), and Neff (1994; 2002), is that it can be applied as a simultaneous R- and Q-mode technique, with both variables (elements) and objects (individual analyzed samples) displayed on the same set of principal component reference axes. A plot using the first two principal components as axes is usually the best possible two-dimensional representation of the correlation or variance-covariance structure within the data set. Small angles between the vectors from the origin to variable coordinates indicate strong positive correlation; angles at 90 degrees indicate no correlation; and angles close to 180 degrees indicate strong negative correlation. Likewise, a plot of sample coordinates on these same axes will be the best two-dimensional representation of Euclidean relations among the samples in log-concentration space (if the PCA was based on the variance-covariance matrix) or standardized log-concentration space (if the PCA was based on the correlation matrix). Displaying both objects and variables on the same plot makes it possible to observe the contributions of specific elements to group separation and to the distinctive shapes of the various groups. Such a plot is commonly referred to as a "biplot" in reference to the simultaneous plotting of objects and variables. The variable inter-relationships inferred from a biplot can be verified directly by inspecting bivariate elemental concentration plots.

Whether a group can be discriminated easily from other groups can be evaluated visually in two dimensions or statistically in multiple dimensions. A metric known as the Mahalanobis distance (or generalized distance) makes it possible to describe the separation between groups or between individual samples and groups on multiple dimensions. The Mahalanobis distance of a specimen from a group centroid (Bieber, et al. 1976; Bishop and Neff 1989) is defined by:

$$
D_{y, X}^{2}=[y-\bar{X}]^{t} I_{x}[y-\bar{X}]
$$

where $y$ is the $1 \mathrm{x} \mathrm{m}$ array of logged elemental concentrations for the specimen of interest, $X$ is the $\mathrm{n} \mathrm{x}$ data matrix of logged concentrations for the group to which the point is being compared with $\bar{X}$ being it $1 \mathrm{x} \mathrm{m}$ centroid, and $I_{x}$ is the inverse of the $\mathrm{m}$ $\mathrm{x} \mathrm{m}$ variance-covariance matrix of group $X$. Because Mahalanobis distance takes into account variances and covariances in the multivariate group it is analogous to expressing distance from a univariate mean in standard deviation units. Like standard deviation units, Mahalanobis distances can be converted into probabilities of group membership for individual specimens. For relatively small sample sizes, it is appropriate to base probabilities on Hotelling's $T^{2}$, which is the multivariate extension of the univariate Student's $t$.

When group sizes are small, Mahalanobis distance-based probabilities can fluctuate dramatically depending upon whether or not each specimen is assumed to be a member of the group to which it is being compared. Harbottle (1976) calls this phenomenon "stretchability" in reference to the tendency of an included specimen to stretch the group in the direction of its own location in elemental concentration space. This problem can be circumvented by cross-validation, that is, by removing each specimen from its presumed group before calculating its own probability of membership (Baxter 1994; Leese and Main 1994). This is a conservative approach to group evaluation that may sometimes exclude true group members.

Small sample and group sizes place further constraints on the use of Mahalanobis distance: with more elements than samples, the group variance-covariance matrix is singular thus rendering calculation of $I^{x}$ (and $D^{2}$ itself) impossible. Therefore, the dimensionality of the groups must somehow be reduced. One approach would be to eliminate elements considered irrelevant or redundant. The problem with this approach is that the investigator's preconceptions about which elements should be discriminate may not be valid. It also squanders the main advantage of multielement analysis, namely the capability to measure a large 
number of elements. An alternative approach is to calculate Mahalanobis distances with the scores on principal components extracted from the variance-covariance or correlation matrix for the complete data set. This approach entails only the assumption, entirely reasonable in light of the above discussion of PCA, that most group-separating differences should be visible on the first several PCs. Unless a data set is extremely complex, containing numerous distinct groups, using enough components to subsume at least $90 \%$ of the total variance in the data can be generally assumed to yield Mahalanobis distances that approximate Mahalanobis distances in full elemental concentration space.

Lastly, Mahalanobis distance calculations are also quite useful for handling missing data (Sayre 1975). When many specimens are analyzed for a large number of elements, it is almost certain that a few element concentrations will be missed for some of the specimens. This occurs most frequently when the concentration for an element is near the detection limit. Rather than eliminate the specimen or the element from consideration, it is possible to substitute a missing value by replacing it with a value that minimizes the Mahalanobis distance for the specimen from the group centroid. Thus, those few specimens which are missing a single concentration value can still be used in group calculations.

\section{Results and Discussion}

As stated above, the NAA results were entered into a spreadsheet and combined with the provided descriptive data to create a database for sorting and extraction of quarry subgroups. These data are provided in Appendix A.

An RQ-mode principal components analysis (PCA) with variance-covariance matrix reveals that greater than $90 \%$ of the cumulative variance in the dataset is explained by 8 principal components (Table N-3). The first eigenvector is heavily loaded on

Table N-3. Principal Component Analysis of the Texas Chert Database. The First 8 Principal Components are Shown, Accounting for Greater than $90 \%$ of the Cumulative Variation in the Dataset. Values in Bold Indicate Strong Elemental Loading

\begin{tabular}{|c|c|c|c|c|c|c|c|c|}
\hline & PC1 & PC2 & PC3 & PC4 & PC5 & PC6 & PC7 & PC8 \\
\hline$\%$ Variance & 30.63 & 17.79 & 14.4 & 9.48 & 6.24 & 4.82 & 3.7 & 2.98 \\
\hline Cum. \% Variance & 30.63 & 48.42 & 62.82 & 72.31 & 78.55 & 83.37 & 87.07 & 90.05 \\
\hline Eigenvalues & 0.776 & 0.451 & 0.365 & 0.24 & 0.158 & 0.122 & 0.094 & 0.075 \\
\hline $\mathrm{Ba}$ & -0.014 & 0.541 & -0.124 & 0.44 & 0.006 & -0.024 & -0.52 & 0.218 \\
\hline $\mathrm{U}$ & 0.04 & 0.118 & -0.357 & 0.233 & -0.129 & 0.262 & 0.283 & -0.093 \\
\hline $\mathrm{Al}$ & 0.047 & -0.018 & 0.052 & 0.105 & 0.009 & -0.042 & 0.065 & 0.148 \\
\hline $\mathrm{Na}$ & 0.059 & -0.024 & 0.084 & 0.132 & -0.01 & -0.002 & 0.134 & 0.035 \\
\hline $\mathrm{Sr}$ & 0.075 & 0.486 & 0.335 & 0.218 & 0.334 & -0.295 & 0.173 & -0.5 \\
\hline $\mathrm{Rb}$ & 0.077 & 0.003 & 0.155 & 0.105 & -0.098 & -0.068 & 0.152 & 0.311 \\
\hline $\mathrm{Sm}$ & 0.132 & 0.148 & -0.41 & 0.113 & -0.103 & 0.056 & 0.187 & -0.084 \\
\hline $\mathrm{Sb}$ & 0.148 & 0.313 & -0.018 & -0.311 & -0.483 & -0.164 & 0.318 & -0.149 \\
\hline $\mathrm{Ce}$ & 0.154 & 0.114 & -0.391 & 0.094 & -0.089 & 0.01 & 0.105 & -0.041 \\
\hline $\mathrm{Zn}$ & 0.158 & 0.094 & 0.177 & -0.129 & -0.373 & 0.042 & -0.046 & -0.148 \\
\hline $\mathrm{Cr}$ & 0.173 & -0.214 & 0.149 & 0.091 & -0.015 & 0.142 & -0.155 & -0.218 \\
\hline $\mathrm{Hf}$ & 0.176 & 0.076 & 0.142 & 0.127 & 0.009 & -0.294 & 0.337 & 0.574 \\
\hline $\mathrm{Ta}$ & 0.211 & -0.158 & 0.152 & 0.142 & 0.028 & -0.114 & 0.223 & 0.071 \\
\hline $\mathrm{La}$ & 0.23 & -0.158 & -0.38 & 0.067 & 0.071 & -0.148 & -0.107 & 0.076 \\
\hline $\mathrm{Co}$ & 0.247 & 0.096 & 0.157 & -0.031 & -0.341 & 0.23 & -0.211 & 0.072 \\
\hline $\mathrm{Fe}$ & 0.283 & 0.028 & 0.27 & 0.087 & -0.292 & 0.099 & -0.258 & 0.072 \\
\hline $\mathrm{Eu}$ & 0.346 & -0.059 & -0.217 & -0.336 & 0.068 & -0.615 & -0.326 & -0.05 \\
\hline Th & 0.364 & -0.216 & 0.058 & 0.336 & 0.085 & 0.008 & 0.073 & -0.037 \\
\hline $\mathrm{Sc}$ & 0.393 & -0.251 & -0.011 & 0.213 & 0.053 & 0.095 & -0.003 & -0.286 \\
\hline $\mathrm{Mn}$ & 0.433 & 0.3 & 0.01 & -0.449 & 0.498 & 0.463 & 0.053 & 0.192 \\
\hline
\end{tabular}


$\mathrm{Ba}$, and the second eigenvector is most-heavily loaded on $\mathrm{Ba}, \mathrm{Sr}, \mathrm{Sb}$, and $\mathrm{Mn}$. The third eigenvector shows heavy loading on REEs. Biplots of PC scores show a high degree of overlap between many of the chert sources in the Texas database (Figure N-2 and Figure N-3). However, some distinction can be noted between the Fort Hood sample reported by Frederick et al. (1994) and compositional groups associated with the Edwards Group chert of west-central Texas and the Texas Panhandle. In general, the Edwards group cherts are enriched in $\mathrm{Ba}, \mathrm{Sr}, \mathrm{U}$, and $\mathrm{Sb}$ relative to the Fort Hood specimens. All of the newly analyzed specimens from 41KM69 and the Llano River plot within the 90\% confidence ellipses of the two compositional groups associated with the Edwards Group chert.

Because only slight differences in chemistry exist among specific sources, canonical discriminant analysis (CDA) was conducted to maximize the differences among compositional groups. Scores from the resulting CDA matrix produce clear separation between the Fort Hood compositional groups, the Edwards Group samples from west-central Texas, and the Edwards Group samples from the Callahan Divide (Figure N-4). Projecting the newly analyzed specimens into this CDA demonstrates that they are strongly related to the Edwards Group cherts rather than the Fort Hood sample (Figure N-5). Although the specimens plot close to, and at times within, the $90 \%$ confidence ellipse for the Callahan Divide compositional group, we hesitate to assign this as the provenance of artifacts from 41KM69. This is because at least one of the "source" samples collected from the Llano River also falls within the $90 \%$ confidence ellipse of the Callahan Divide compositional group. A more conservative explanation is that at least some of the gravels of the Llano River are compositionally similar to the previously analyzed specimens from the Callahan Divide.

Results of the first CDA suggest that there is a very low probability that any of the newly analyzed specimens are derived from sources represented in the Fort Hood database. Instead, all of the specimens show strong affinity for Edwards Group cherts collected to the west of Fort Hood. As such, we conducted a second CDA employing only those compositional groups associated with the Edwards Group as well as the newly analyzed sample from the Llano River gravel (Figure N-6). This second CDA, similar to the first, makes the a priori assumption that some chemical differences exist among the compositional groups, and it attempts to maximize these differences. Given that the majority of Llano River gravel samples plotted outside of both Edwards Group compositional groups in the initial CDA, this seems a reasonable assumption. Projecting the artifact samples into a bivariate plot of CDA scores makes it possible to evaluate which compositional group they most resemble.

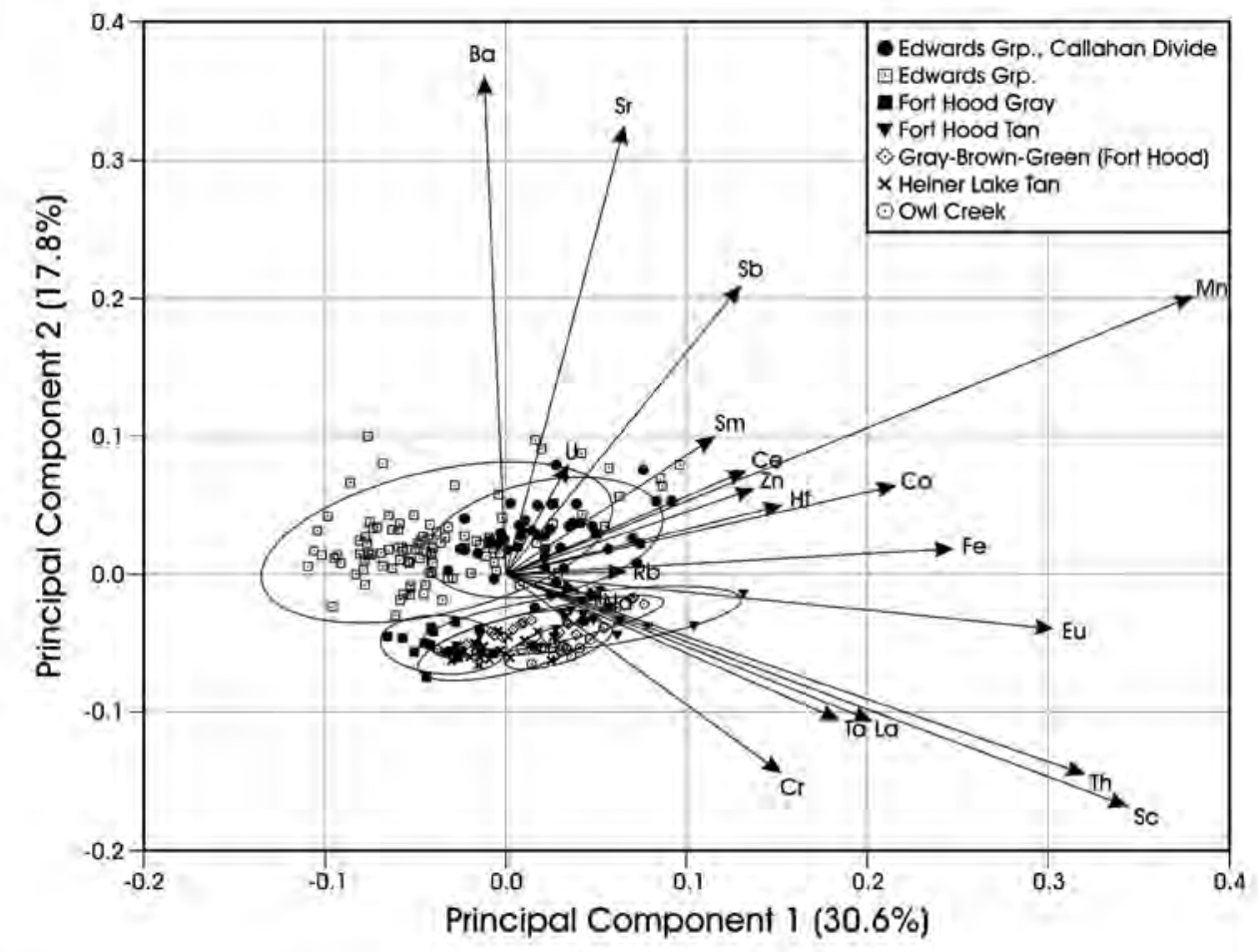

Figure N-2. Biplot of PC scores and elemental vectors for the Texas chert database. Previously defined compositional groups are shown with $90 \%$ confidence ellipses. 


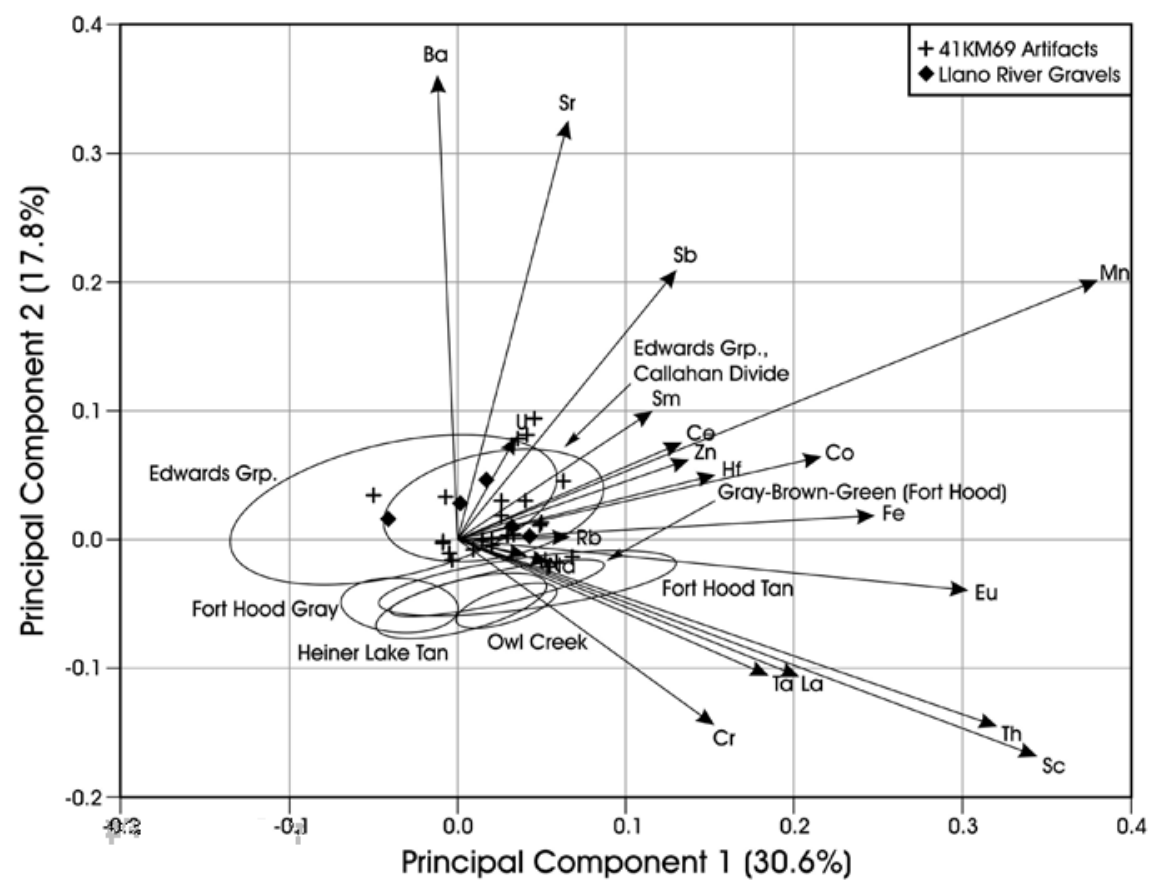

Figure N-3. Biplot of PC scores and elemental vectors for the Texas chert database. Previously defined compositional groups are shown as 90\% confidence ellipses. Newly analyzed specimens from 41 KM69 and the Llano River are shown. Note that the newly analyzed samples cluster within the two compositional groups associated with the Edwards Group cherts.

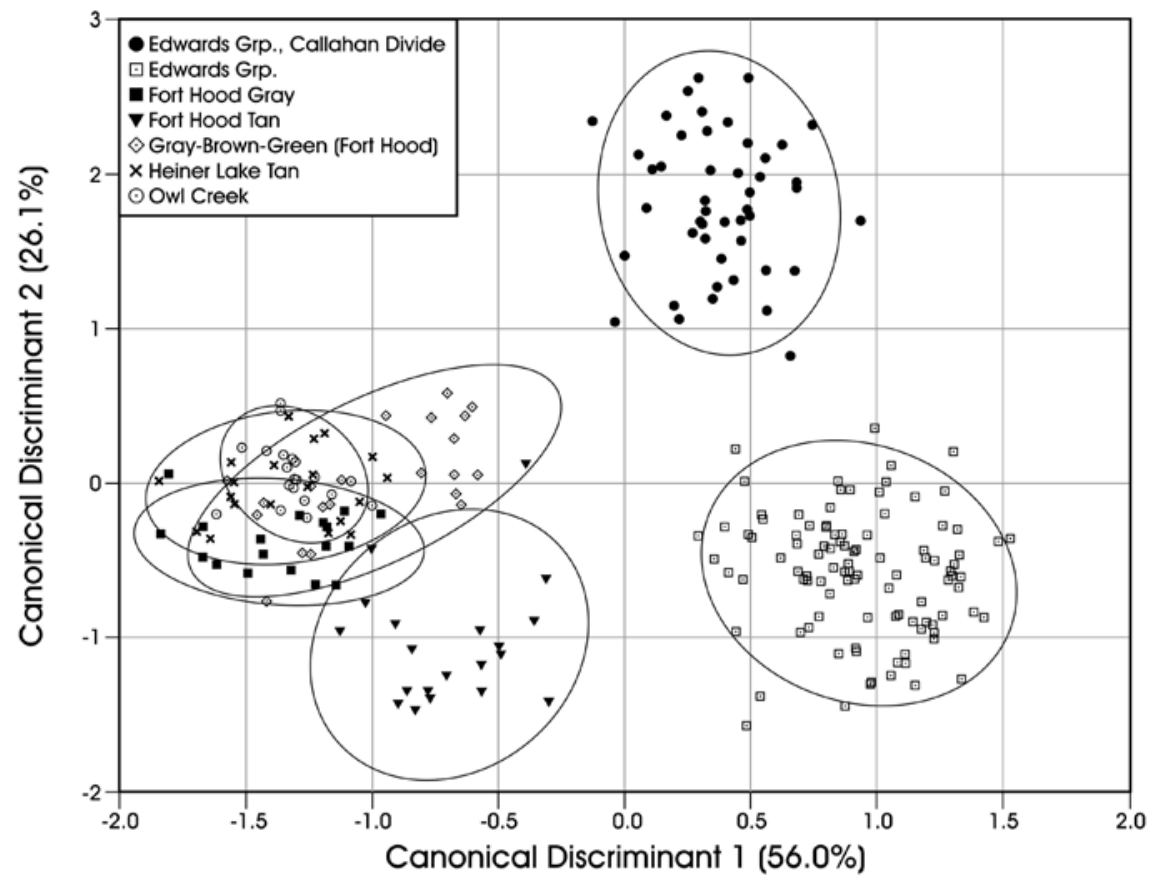

Figure N-4. Bivariate plot of canonical discriminant scores for the Texas chert database. Extant compositional groups are shown with $90 \%$ confidence ellipses. Note clear separation between Fort Hood cherts and Edwards Group cherts. 


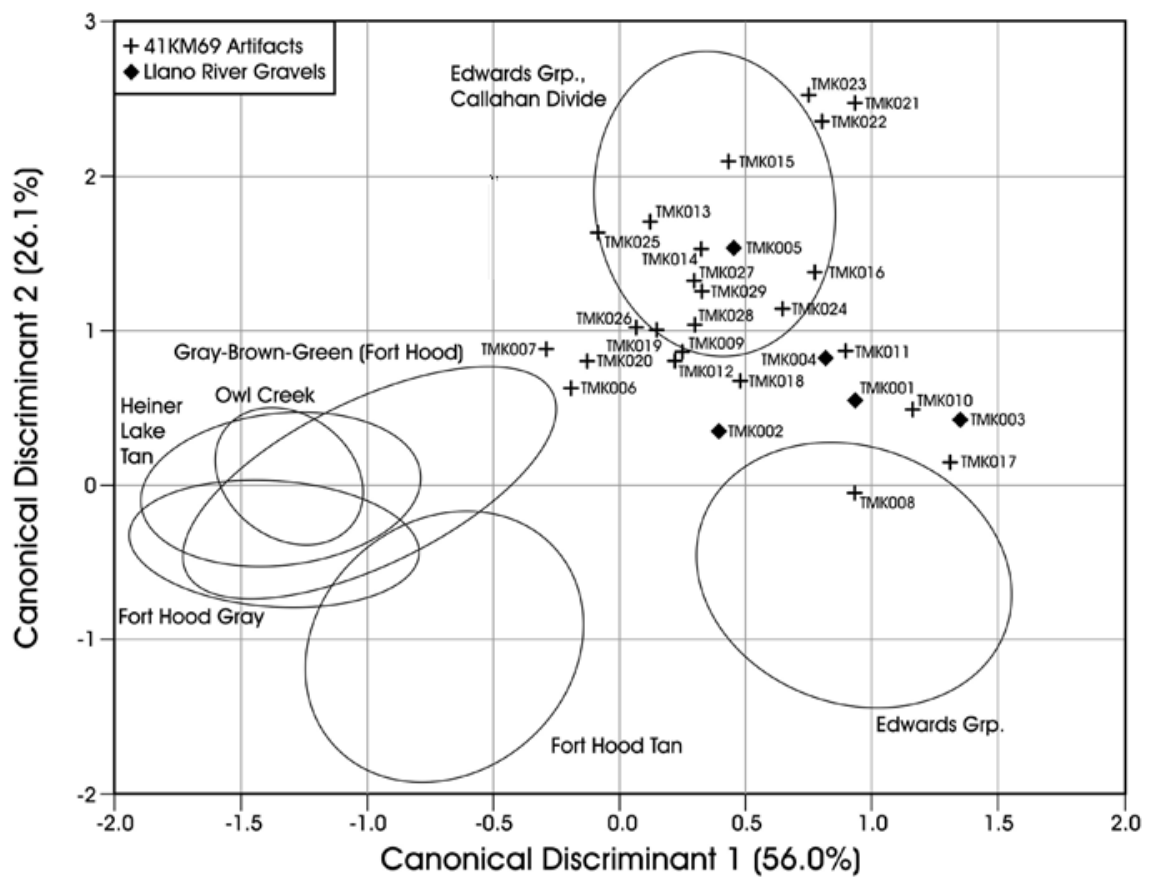

Figure N-5. Bivariate plot of canonical discriminant scores for the Texas chert database showing extant compositional groups as $90 \%$ confidence ellipses. Newly analyzed specimens from 41 KM69 and the Llano River are plotted and labeled with analytical IDs.

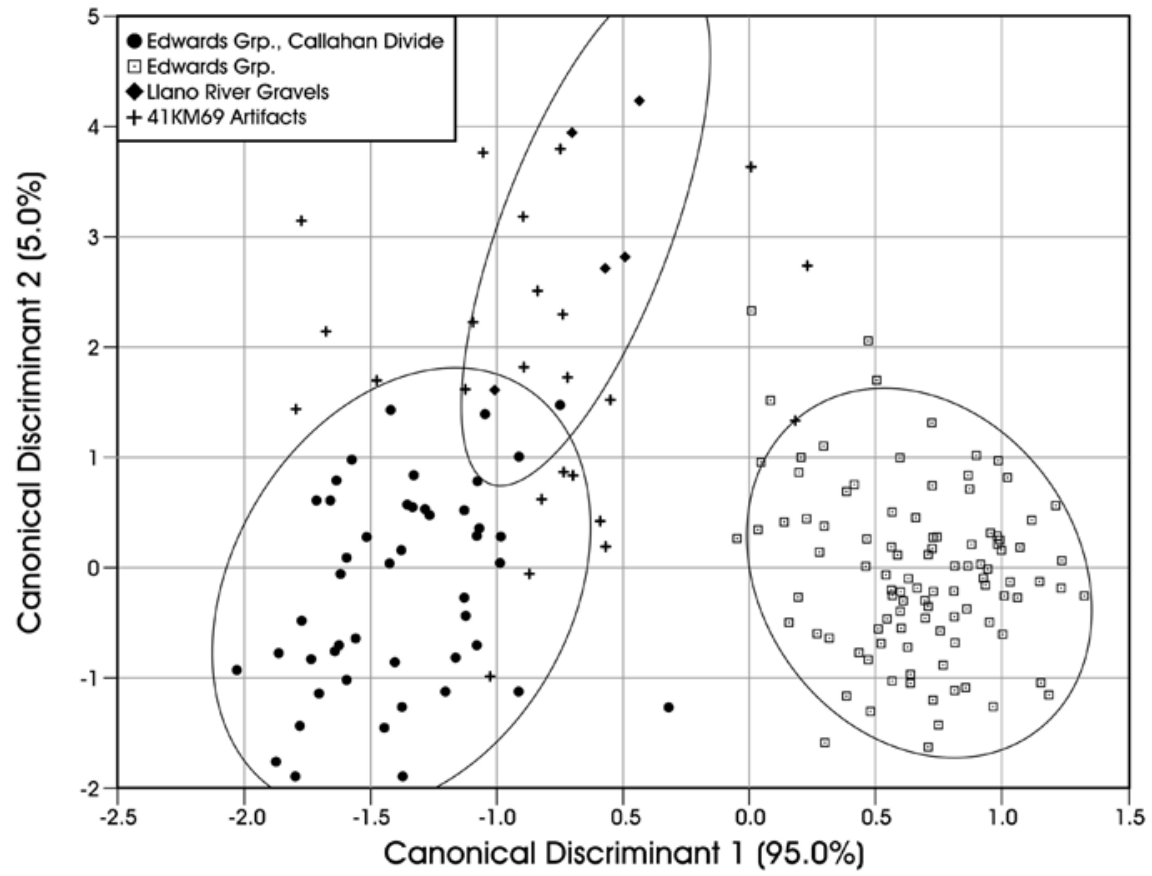

Figure N-6. Bivariate plot of canonical discriminant scores for the Edwards Group chert compositional groups and the Llano River gravels. Compositional groups are shown with 90\% confidence ellipses. Artifacts from 41KM69 are plotted. 
We evaluated the proposed distinctions of local and non-local artifacts by comparing results of all three statistical analyses and arriving at what we believe is a conservative consensus (Table N-4). Importantly, we do not believe it is reasonable to assume that the full compositional variability of the Llano River gravels has been identified with the five source specimens provided. As such, there is some room for subjectivity in these determinations. For example, a cluster of samples in and immediately outside of the Llano River Gravels ellipse contains three specimens believed to be local, and two believed to be nonlocal. On one hand, these specimens could be considered outliers of the Llano River group. On the other hand, they could represent a compositional profile distinct from the Llano River sample. As such, we have opted to consider them as possibly locally or possibly non-locally derived.

Table N-4. Comparison of Determinations of Local Versus Nonlocal Provenance

\begin{tabular}{|c|c|c|}
\hline ANID & Local/Nonlocal (Tomka) & Local/Nonlocal (MURR) \\
\hline TMK006 & Poss. Local & Poss. Local or Nonlocal \\
\hline TMK007 & Poss. Local & Poss. Local or Nonlocal \\
\hline TMK008 & Poss. Local & likely Edwards Group chert \\
\hline TMК009 & Poss. Local & Local \\
\hline TMK010 & Poss. Local & likely Edwards Group chert \\
\hline TMK011 & Poss. Local & Local \\
\hline TMK012 & Poss. Nonlocal & Local \\
\hline TMK013 & Poss. Nonlocal & Local \\
\hline TMK014 & Poss. Nonlocal & Local \\
\hline TMK015 & Poss. Nonlocal & Poss. Nonlocal, Callahan Divide? \\
\hline TMK016 & Poss. Nonlocal & Local \\
\hline TMK017 & Poss. Nonlocal & likely Edwards Group chert \\
\hline TMK018 & Poss. Local & Local \\
\hline TMК019 & Poss. Local & Poss. Local or Nonlocal \\
\hline TMK020 & Poss. Local & Poss. Local or Nonlocal \\
\hline TMK021 & Poss. Nonlocal & Nonlocal \\
\hline TMK022 & Poss. Nonlocal & Nonlocal \\
\hline TMK023 & Poss. Nonlocal & Nonlocal \\
\hline TMK024 & Poss. Nonlocal & Local \\
\hline TMK025 & Poss. Nonlocal & Poss. Nonlocal, Callahan Divide? \\
\hline TMK026 & Poss. Nonlocal & Poss. Local or Nonlocal \\
\hline TMK027 & Poss. Nonlocal & Local \\
\hline TMK028 & Poss. Nonlocal & Poss. Local or Nonlocal \\
\hline TMK029 & Poss. Nonlocal & Local \\
\hline
\end{tabular}

\section{Conclusions}

Analysis of a chert specimens from 41KM69 and a sample from the Llano River gravel suggests that there may be real chemical differences between the Llano River sample and other previously determined compositional groups within the Texas chert database. All of the Llano River specimens and the artifacts from 41KM69 appear to be derived from Edwards Group cherts, as opposed to cherts collected from Fort Hood. Although the Llano River material is chemically similar to chert from the Callahan Divide and other Edwards cherts from west-central Texas, canonical discriminant analysis permits some distinctions to be made among these groups.

Comparison of artifacts to these data has allowed us to distinguish three specimens that appear to be made from Edwards Group chert derived from locations to the east of 41KM69. Two specimens are likely non-local cherts, perhaps derived from 
the Edwards formation north of the project area towards the Callahan Divide. Three specimens are believed to be distinctly non-local, and these do not match any other materials in the Texas chert database. A total of 10 specimens are well within the compositional variability represented by the Llano River gravel sample, and as such, these are likely locally derived (or at least potentially locally derived, considering the secondary nature of the gravel deposits). Provenance assignments for the remaining six samples are somewhat equivocal, and these could potentially be locally or non-locally derived.

\section{Acknowledgements}

Amanda Watkins was responsible for sample preparation, and we gratefully acknowledge her contributions to the completion of this project. Any errors in interpretation and text are the responsibility of the authors. 


\section{References:}

Baxter, M. J.

1992 Archaeological Uses of the Biplot-A Neglected Technique? In Computer Applications and Quantitative Methods in Archaeology, 1991, edited by G. Lock and J. Moffett, pp. 141-148. BAR International Series. vol. S577. Tempvs Reparatvm, Oxford.

1994 Exploratory Multivariate Analysis in Archaeology. Edinburgh University Press, Edinburgh.

Baxter, M. J. and C. E. Buck

2000 Data Handling and Statistical Analysis. In Modern Analytical Methods in Art and Archaeology, edited by E. Ciliberto and G. Spoto, pp. 681-746. John Wiley and Sons, New York.

Bieber, A. M. J., D. W. Brooks, G. Harbottle and E. V. Sayre

1976 Application of Multivariate Techniques to Analytical Data on Aegean Ceramics. Archaeometry 18:59-74.

Bishop, R. L. and H. Neff

1989 Compositional Data Analysis in Archaeology. In Archaeological Chemistry IV, edited by R. O. Allen, pp. $576-586$. Advances in Chemistry. vol. 220. American Chemical Society, Washington, D.C.

Bishop, R. L., R. L. Rands and G. R. Holley

1982 Ceramic Compositional Analysis in Archaeological Perspective. Advances in Archaeological Method and Theory 5:275-330.

Boulanger, M. T. and M. D. Glascock

2007 Neutron Activation Analysis of Chert Artifacts from 41 MS69 and of Geological Chert Samples from the Llano River Gravel, the Gorman Formation, and the Marble Falls Formation. Archaeometry Laboratory, Missouri University Research Reactor. Submitted to Mike Quigg, TRC, Austin, TX.

2008 Neutron Activation Analysis of Geological and Archaeological Chert Source Samples from the Callahan Divide, Jones, Nolan, and Taylor Counties, Texas. Archaeometry Laboratory, Missouri University Research Reactor. Submitted to Karen Caffrey, Department of Anthropology, University of Texas at Austin.

Frederick, C. D., M. D. Glascock, H. Neff and C. M. Stevenson

1994 Evaluation of Chert Patination as a Dating Technique: A Case Study from Fort Hood, Texas. Research Report No. 32, Archaeological Resource Management Series. United States Army, Fort Hood.

Glascock, M. D.

1992 Characterization of Archaeological Ceramics at MURR by Neutron Activation Analysis and Multivariate Statistics. In Chemical Characterization of Ceramic Pastes in Archaeology, edited by H. Neff, pp. 11-26. Prehistory Press, Madison, WI.

2001 Letter report dated May 10, 2001, summarizing INAA of 30 chert samples from Leon Creek, Bluff, Texas. Archaeometry Laboratory, University of Missouri Research Reactor. Submitted to Dale Hudler, Texas Archaeological Research Laboratory.

Glascock, M. D. and H. Neff

2003 Neutron Activation Analysis and Provenance Research in Archaeology. Measurement Science and Technology 14:1516-1526.

Glascock, M. D. and R. J. Speakman

2004 Instrumental Neutron Activation Analysis of Chert from the Varga Site (41ED28) in Southwest Texas. Archaeometry Laboratory, University of Missouri Research Reactor. Submitted to Mike Quigg, TRC Mariah Associates, Inc., Austin, TX. 
2006a Instrumental Neutron Activation Analysis of Natural Chert from Gillespie County in Central Texas -- TRC Project 46843/0020. Archaeometry Laboratory, University of Missouri Research Reactor. Submitted to Mike Quigg, TRC Companies, Inc., Austin, TX.

2006b Instrumental Neutron Activation Analysis of Natural Chert from the Callahan Divide Area of North Central Texas -- TRC Project 49150. Archaeometry Laboratory, University of Missouri Research Reactor. Submitted to Mike Quigg, TRC Companies, Inc., Austin, TX.

Harbottle, G.

1976 Activation Analysis in Archaeology. Radiochemistry 3(1):33-72.

Leese, M. N. and P. L. Main

1994 The Efficient Computation of Unbiased Mahalanobis Distances and their Interpretation in Archaeometry. Archaeometry 36:307-316.

Neff, H.

1994 RQ-mode Principal Component Analysis of Ceramic Compositional Data. Archaeometry 36:115-130.

2000 Neutron Activation Analysis for Provenance Determination in Archaeology. In Modern Analytical Methods in Art and Archaeology, edited by E. Ciliberto and G. Spoto, pp. 81-134. John Wiley and Sons, New York.

2002 Quantitative Techniques for Analyzing Ceramic Compositional Data. In Ceramic Source Determination in the Greater Southwest, edited by D. M. Glowacki and H. Neff. Monograph 44. Cotsen Institute of Archaeology, Los Angeles.

Sayre, E. V.

1975 Brookhaven Procedures for Statistical Analyses of Multivariate Archaeometric Data. Brookhaven National Laboratory Report BNL-23128.

Steponaitis, V., M. J. Blackman and H. Neff

1996 Large-scale Compositional Patterns in the Chemical Composition of Mississippian Pottery. American Antiquity 61(3):555-572.

Weigand, P. C., G. Harbottle and E. V. Sayre

1977 Turquoise Sources and Source Analysis: Mesoamerica and the Southwestern U.S.A. In Exchange Systems in Prehistory, edited by T. K. Earle and J. E. Ericson, pp. 15-34. Academic Press, New York. 

Appendix 0:

Radiocarbon Forms 



\section{(П) \\ The University of Georgia}

Center for Applied Isotope Studies

\section{RADIOCARBON AGE ANALYSIS REPORT}

Dr. James T. Abbott

April 14, 2004

Staff Geoarcheologist

Cultural Resources Management

Texas Department of Transportation

Dewitt C. Greer State Highway BIdg.

125 E. 11th Street

Austin, TX 78701-2483

Dear Dr. Abbotr,

Enclosed please find the results for the Radiocarbon $\left({ }^{4} \mathrm{C}\right)$ analysis including Stable Isotope Ratio analysis $\left(6^{13} \mathrm{C}\right)$ correction for the charcoal samples received by our laboratory on March 26, 2004 for testing.

\begin{tabular}{|c|c|c|c|c|}
\hline \multirow[t]{2}{*}{ UGA\# } & \multirow{2}{*}{$\begin{array}{l}\text { Sarnple } \\
\text { I.D. }\end{array}$} & \multicolumn{2}{|c|}{ Radiocarbon } & \multirow{2}{*}{$\begin{array}{c}\delta^{13} \mathrm{C} \\
\text { (Years } \\
\text { corrected) }\end{array}$} \\
\hline & & $\begin{array}{c}\text { Age } \\
(X B P \pm 10)\end{array}$ & $\begin{array}{l}\delta^{73} \mathrm{C} \text { Corrected } \\
\text { Age (XBP } \pm 1 a)\end{array}$ & \\
\hline 13505 & 41KM69-281: & $1.190=40$ & $1,190 \neq 40$ & $-25.20(-3)$ \\
\hline 13506 & 41KM69-295: & $2,210 \pm 40$ & $2,210 \pm 40$ & $-24.77(+4)$ \\
\hline 13507 & 41KM69-297: & $1,170 \pm 40$ & $1,170 \pm 40$ & $-24.90(+2)$ \\
\hline 13508 & 41KM69-402: & $100 \pm 40$ & $120 \pm 40$ & $-23.58(+23)$ \\
\hline
\end{tabular}

The above charcoal samples were pretreated with acid, alkali and acid to remove potential contaminants from the surface and interior prior to processing for AMS dating. call.

If you have any questions, or need additional information, please do not hesitate to

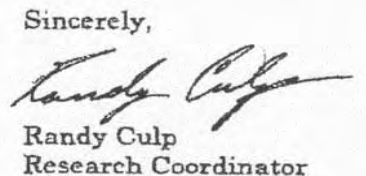

All dales are reported in years before present $(0$ VBP=1950 A D). By internolional convention the haif hife of radiocarbon is leken to be 5568 years. Standardization is with the National Institute of Standards and Technology's Oralic Acid SRM-4990C, which is taken to be 129\% modern (1950). The uncertainty in the reported age is at $a$ one standord deviation con/idence level $\left(68 \%\right.$ probability). Stable carbon isotope ratios ( $\left.\delta^{\prime} \mathrm{C}\right)$ arc given both as per mil $(1 / 00)$ difference from PDE-I standard ratio and as the corrected radiocarbon age, in YBP. The correted age facilitates the comparison. of different mazerials which form in nature with different earbon isotope ratios. To oblairt a corrected date, this correction factor should. be added to the reported afe (YBP).

120 Riverbend Road - Athens, Georgia $30602-4702$

Telephione (706) 542-1395 - Fex (706) 542-6106 * caispuga.edu An Equal Oppornuniry/Afirmative Action listitution 


\section{(III) \\ The University of Georgia}

Center tor Applied Isorope Studies

RADIOCARBON AGE ANALYSIS KEPUKT

Dr. James T. Abbott

May 6, 2004

Staff Geoarcheologist

Cultural Resourceo Management

Texas Department of Transportation

Dewitt C. Greer State Highway Bldg

125 E. 11th. Street

Austin, TX 78701-2483

Dear Dr. Ábbott,

Enclosed please find the resulto for the Radiocarbon $\left({ }^{14} \mathrm{C}\right)$ analysis including Stable Isotope Ratio analysis $\left(\delta^{13} \mathrm{C}\right)$ correction for the charsoal samples received by our laboratory os April 22, 2004 for testing.

\begin{tabular}{|c|c|c|c|c|}
\hline \multirow[t]{2}{*}{ UG.A\# } & \multirow{2}{*}{$\begin{array}{l}\text { Sample } \\
\text { I.D. }\end{array}$} & \multicolumn{2}{|c|}{ Radiocarbon } & \multirow{2}{*}{$\begin{array}{c}\delta^{13} \mathbf{C} \\
\text { (Years } \\
\text { corrected) }\end{array}$} \\
\hline & & $\begin{array}{c}\text { Age } \\
(\text { YRP } \pm 7 \sigma) \\
\end{array}$ & $\begin{array}{l}\delta^{18} \mathrm{C} \text { Corrected } \\
\text { Age (YBP } \pm 1 \sigma) \\
\end{array}$ & \\
\hline 18590 & 41KM69-402-2: & $490 \pm 40$ & $480 \pm 40$ & $-25.76(-12)$ \\
\hline 13591 & 4IKMG9-402-7: & $190 \pm 40$ & $180 \div 40$ & $-25.73(-12)$ \\
\hline
\end{tabular}

The above charcoal samples were pre-treated with acid, alkali and acid to remove potential contaminante from the surface and interior prior to proceseing for AMS dating. cell.

If you have any questions, or need additional information, please do not hepitate to

C.A.I.S. Inv. No. 6312

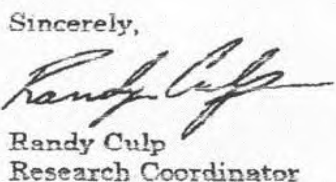

All dares are mported in years before present ( $a$ YRP $=1960$ A.D.). By incernational convention, tho balf life of radiocarbon is taken to be 5568 years. Standardization is with the National Insticute of Standsards snd Technology's Oxalic Acid SRM.4990C, which is cakea to be $129 \%$ madern (1950). The uncextainty in the reported age is at a oze standard deviation confidence level (68\% probability). Stable carbon isotope racias

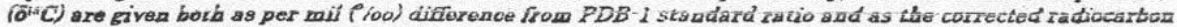
Age, in YQR. The corrected age facilitates the cossparison of difforent ma rerials which form in nature with different carbon isotope rotios. To shtsin a corrected date this correctian factor should be added co the reported age (YBP).

\footnotetext{
120 Ruverbená Rond * Aficns, Gcorgia 30502-1702

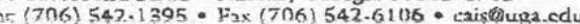

Al Equal Opportunity/Aftirmative Action Insticucion
} 


\section{RADIOCARBON AGE ANALYSIS REPORT}

Dr. James T. Abbott

August 31, 2004

Staff Geoarcheologist

Cultural Resources Management

Texas Department of Transportation

Dewitt C. Greer State Highway Bldg.

125 E. 11th Street

Austin, TX 78701-2483

Dear Dr. Abbott,

Enclosed please find the results for the Radiocarbon $\left({ }^{14} \mathrm{C}\right)$ analysis including Stable Isotope Ratio analysis $\left(\delta^{13} \mathrm{C}\right)$ correction for the charcoal samples received by our laboratory on August 2, 2004.

\begin{tabular}{|c|c|c|c|c|}
\hline \multirow[t]{3}{*}{$\underline{\text { UGA\# }}$} & \multirow{3}{*}{$\begin{array}{c}\text { Sample } \\
\text { I.D. }\end{array}$} & \multicolumn{2}{|c|}{ Radiocarbon } & \multirow{3}{*}{$\begin{array}{c}\delta^{13} \mathrm{C} \\
\text { (Years } \\
\text { corrected) }\end{array}$} \\
\hline & & Age & $\delta^{13} \mathrm{C}$ Corrected & \\
\hline & & $(\mathrm{YBP} \pm 1 \sigma)$ & Age $(\mathrm{YBP} \pm 1 \sigma)$ & \\
\hline 14029 & 41KM69 312: & $2310 \pm 80$ & $2330 \pm 80$ & $-24.07(+15)$ \\
\hline 14030 & 41KM69 321: & $150 \pm 80$ & $120 \pm 80$ & $-27.01(-32)$ \\
\hline 14031 & 41KM69 328: & $1,000 \pm 70$ & $1,020 \pm 70$ & $-24.09(+15)$ \\
\hline 14032 & 41KM69 490-1: & $1,390 \pm 60$ & $1,370 \pm 60$ & $-26.02(-16)$ \\
\hline
\end{tabular}

The above charcoal samples were pre-treated with acid, alkali and acid to remove potential contaminants from the surface and interior prior to processing for AMS dating. call.

If you have any questions, or need additional information, please do not hesitate to

Sincerely,

Randy Culp, Research Coordinator Center for Applied Isotope Studies

C.A.I.S. Inv. No. 6476

All dates are reported in years before present ( $O$ YBP=1950 A.D.). By international convention, the half-life of radiocarbon is taken to be 5568 years. Standardization is with the National Institute of Standards and Technology's Oxalic Acid SRM-4990C, which is taken to be 129\% modern (1950). The uncertainty in the reported age is at a one standard deviation confidence level $\left(68 \%\right.$ probability). Stable carbon isotope ratios $\left(\delta^{13} C\right)$ are given both as per mil $(\% / o$ ) difference from PDB-1 standard ratio and as the corrected radiocarbon age, in YBP. The corrected age facilitates the comparison of different materials which form in nature with different carbon isotope ratios. To obtain a corrected date, this correction factor should be added to the reported age (YBP). 


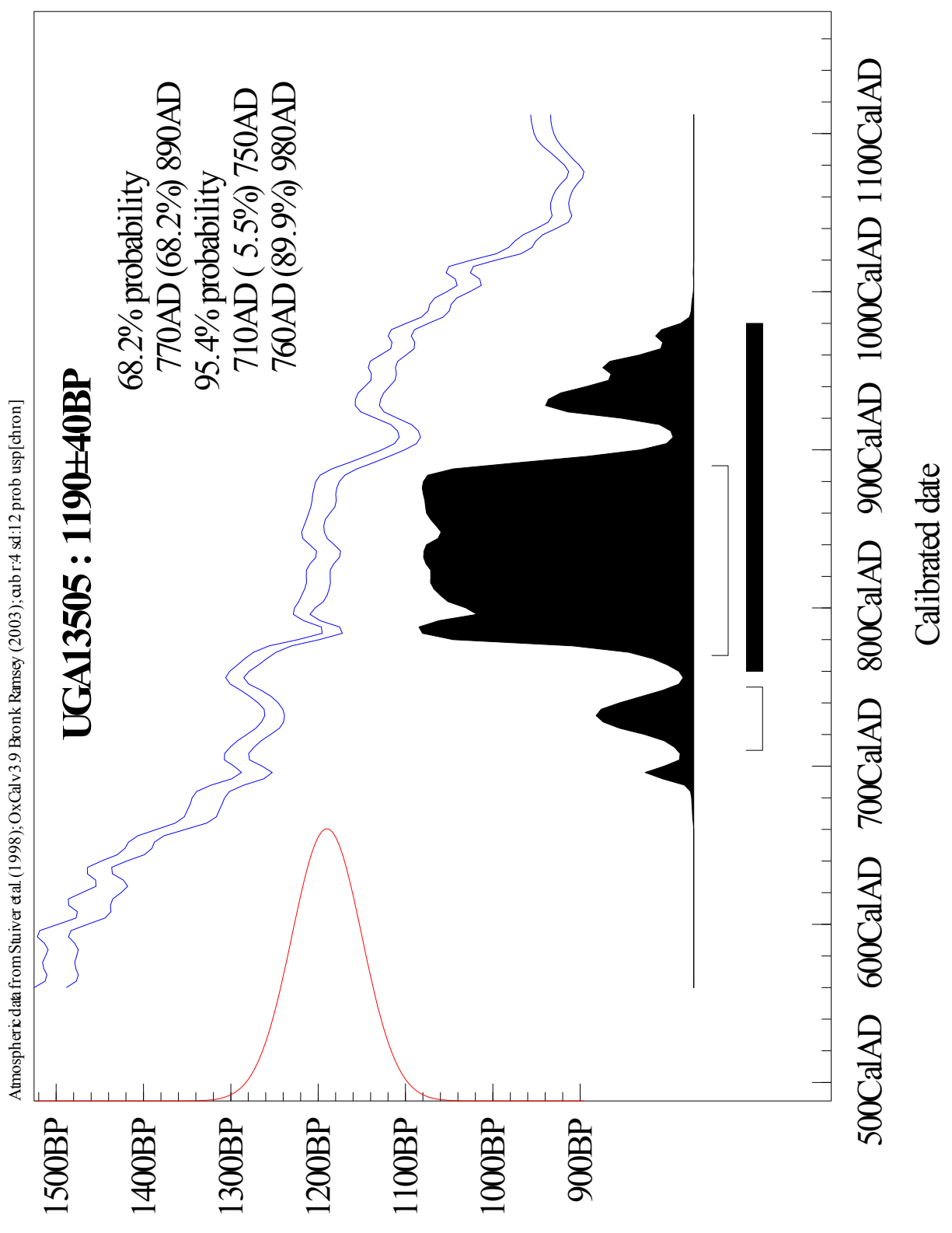




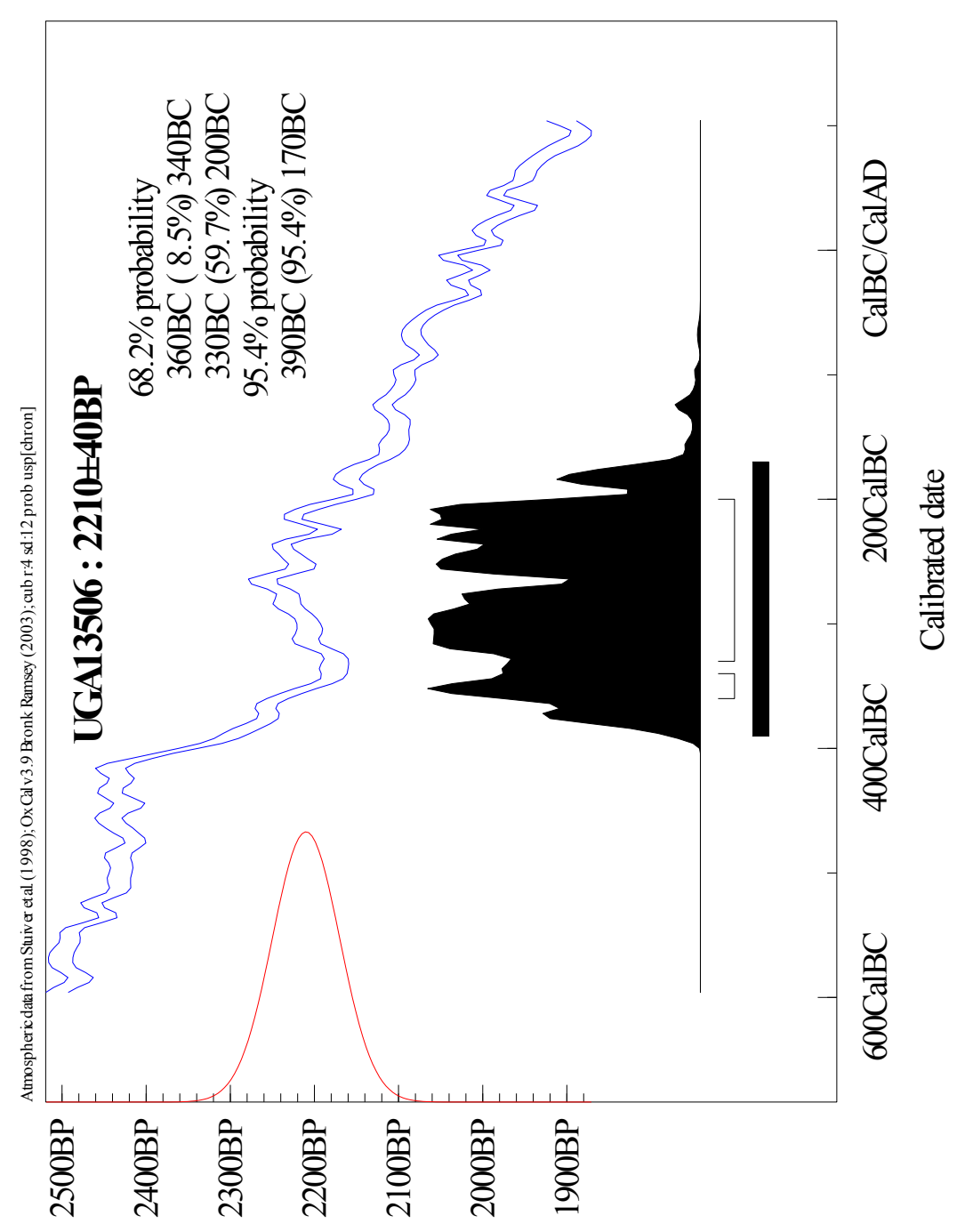




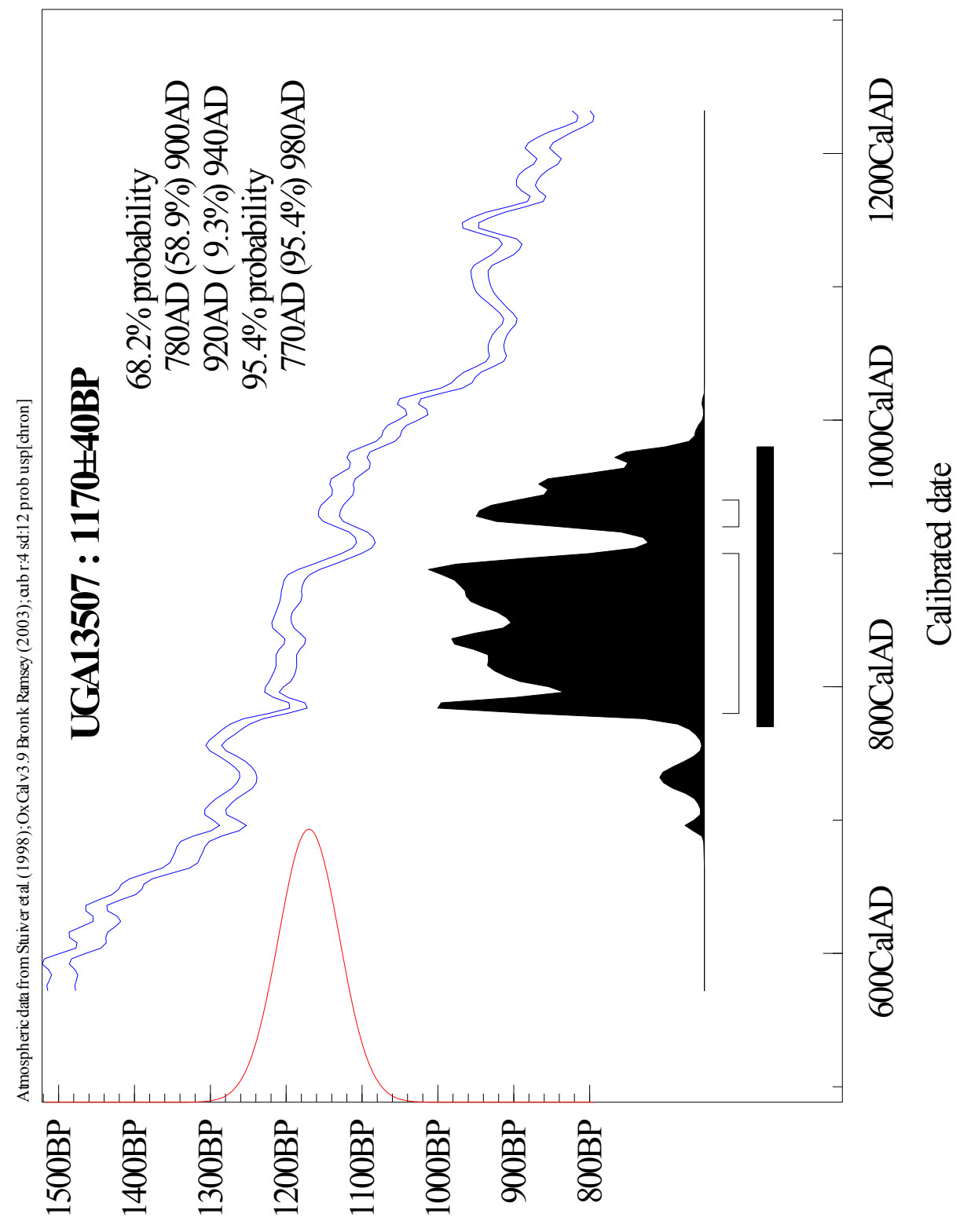




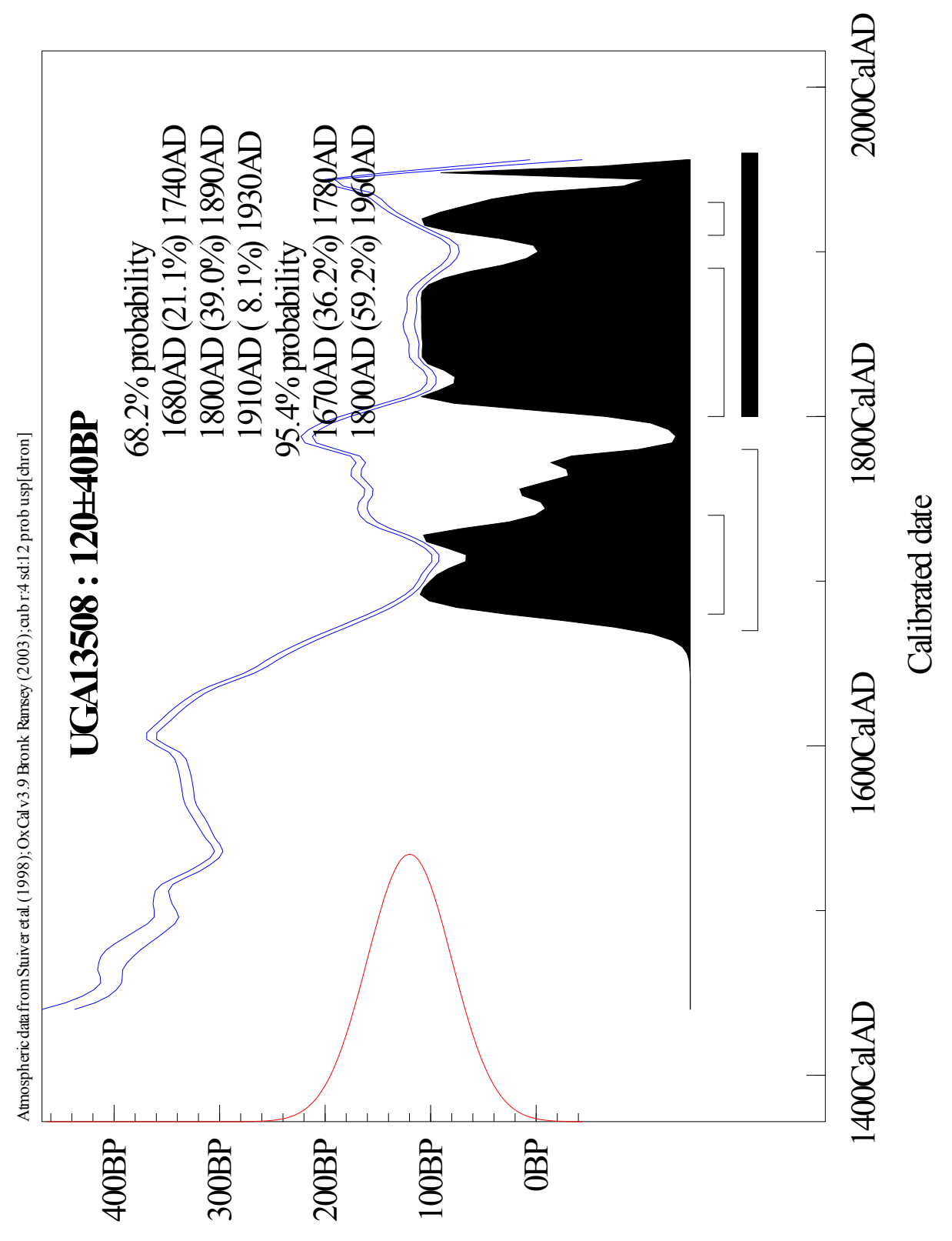




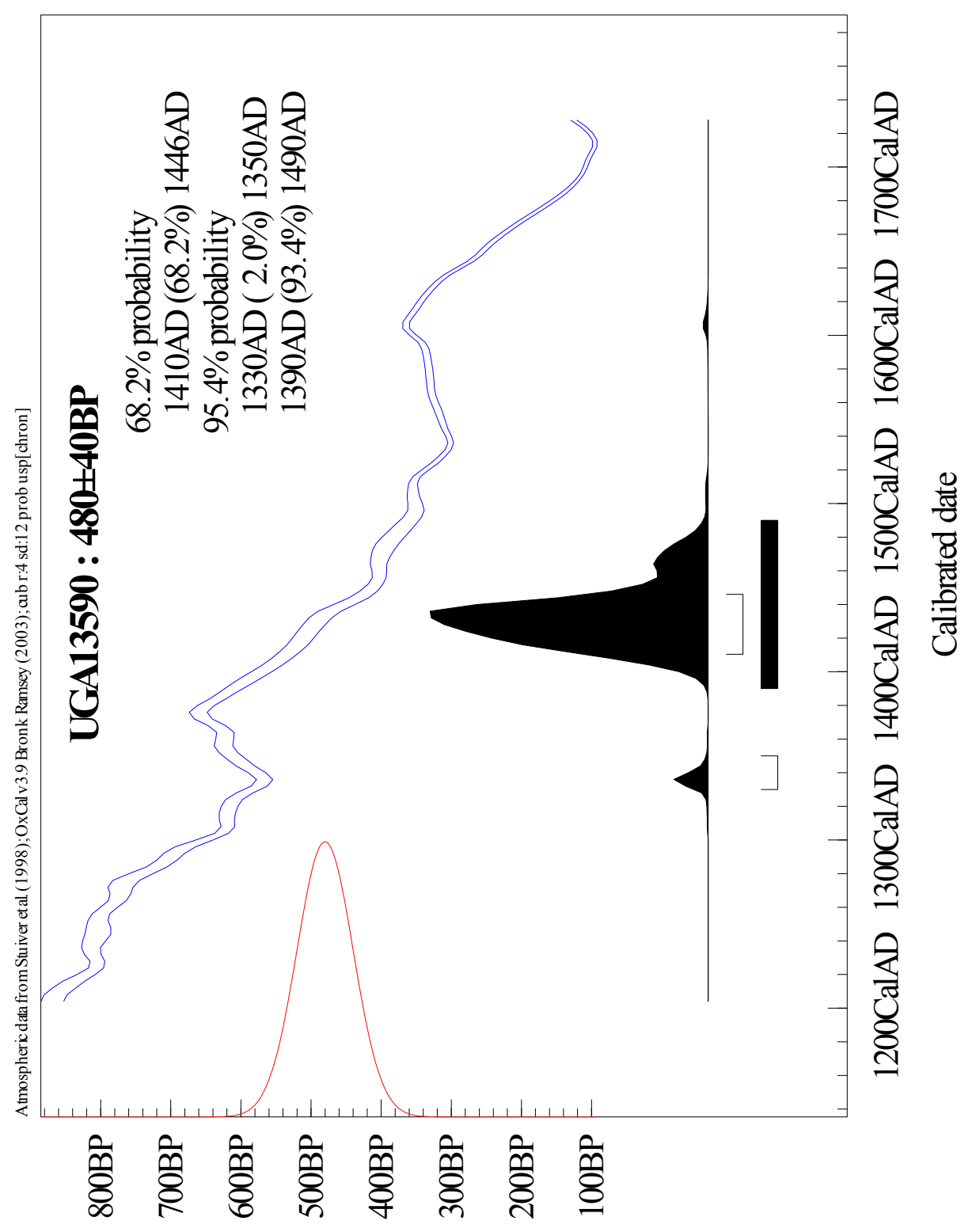




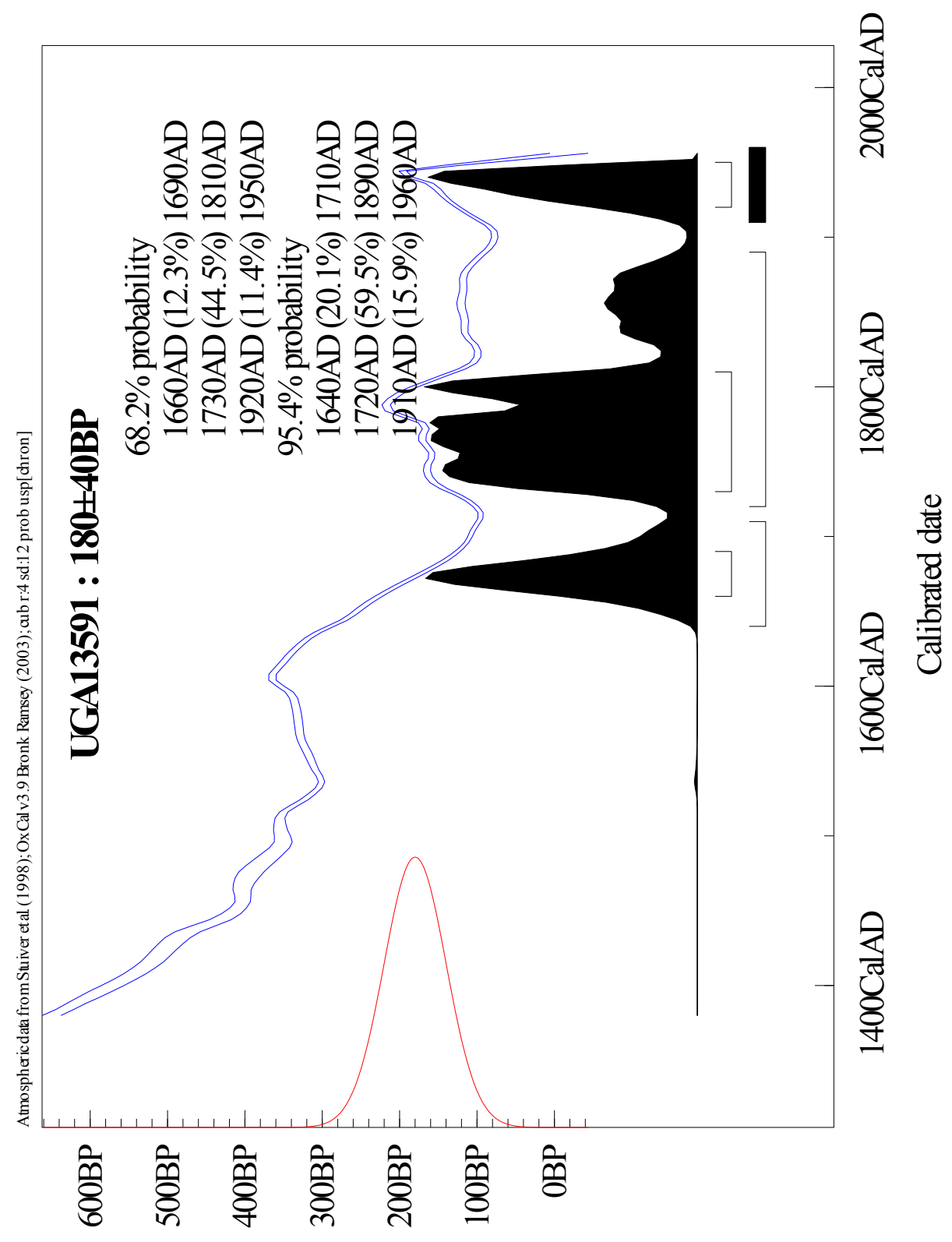

